\title{
Parametric Study of the Potential for BWR ECCS Strainer Blockage Due to LOCA Generated Debris
}

\section{Final Report}

Manuscript Completed: September 1995

Date Published: October 1995

Prepared by

G. Zigler, J. Brideau, D. V. Rao, C. Shaffer, F. Souto, W. Thornas

Science and Engineering Associates, Inc.

SEA Plaza

6100 Uptown Blvd. NE

Albuquerque, NM 87110

A. W. Serkiz, NRC Senior Task Manager

M. L. Marshall, NRC Task Manager

\section{Prepared for}

Division of Safety Issue Resolution

Office of Nuclear Regulatory Research

U.S. Nuclear Regulatory Commission

Washington, DC 20555-0001

NRC Job Code L1854

\section{MASTER}




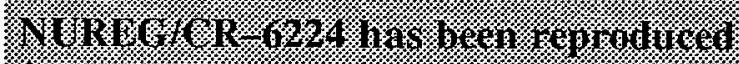

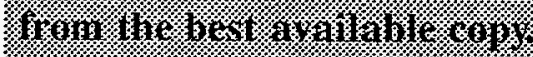

क त y

$4 x$ की 


\begin{abstract}
This report documents a plant-specific study for a BWR/4 with a Mark I containment that evaluated the potential for LOCA generated debris and the probability of losing long term recirculation capability due ECCS pump suction strainer blockage. The major elements of this study were: (1) acquisition of detailed piping layouts and installed insulation details for a reference BWR; (2) analysis of plant specific piping weld failure probabilities to estimate the LOCA frequency; (3) development of an insulation and other debris generation and drywell transport models for the reference BWR; (4) modeling of debris transport in the suppression pool; (5) development of strainer blockage head loss models for estimating loss of NPSH margin; (6) estimation of core damage frequency attributable to loss of ECCS recirculation capability following a LOCA. Elements 2 through 5 were combined into a computer code, BLOCKAGE 2.3.

A point estimate of overall DEGB pipe break frequency (per Rx-year) of 1.59E-04 was calculated for the reference plant, with a corresponding overall ECCS loss of NPSH frequency (per Rx-year) of 1.58E-04. The calculated point estimate of core damage frequency (per Rx-year) due to blockage related accident sequences for the reference BWR ranged from $4.2 \mathrm{E}-06$ to $2.5 \mathrm{E}-05$. The results of this study show that unacceptable strainer blockage and loss of NPSH margin can occur within the first few minutes after ECCS pumps achieve maximum flows when the ECCS strainers are exposed to LOCA generated fibrous debris in the presence of particulates (sludge, paint chips, concrete dust). Generic or unconditional extrapolation of these reference plant calculated results should not be undertaken.
\end{abstract}





\section{DISCLAMMIER}

Portions of this document may be illegible in electronic image products. Images are produced from the best available original document. 


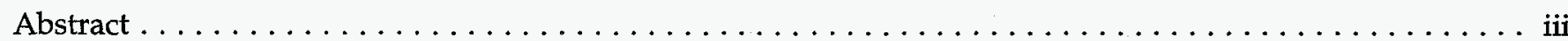

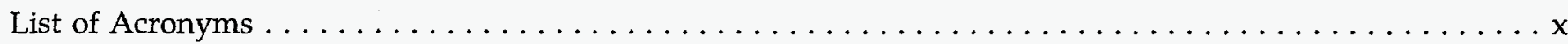

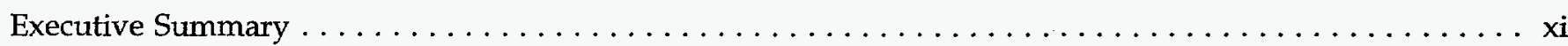

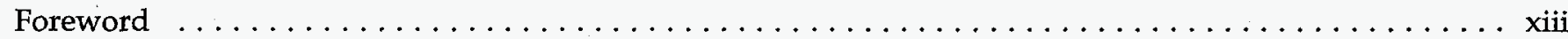

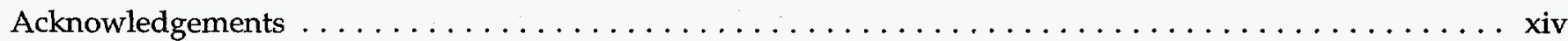

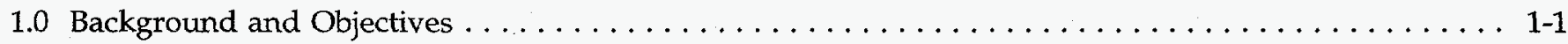

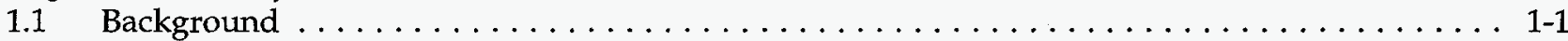

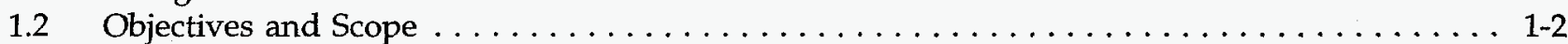

References for Section $1.0 \ldots \ldots \ldots \ldots \ldots \ldots \ldots \ldots \ldots \ldots \ldots \ldots \ldots \ldots \ldots \ldots$

2.0 Methodology for Analysis of Insulation Debris Effects $\ldots \ldots \ldots \ldots \ldots \ldots \ldots \ldots \ldots \ldots \ldots \ldots \ldots$

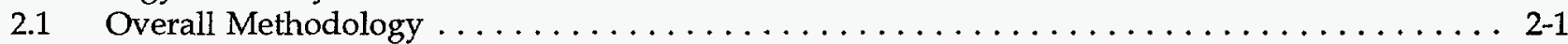

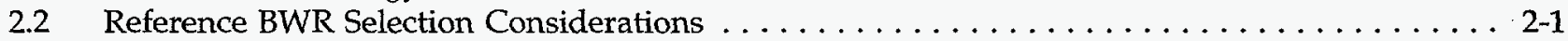

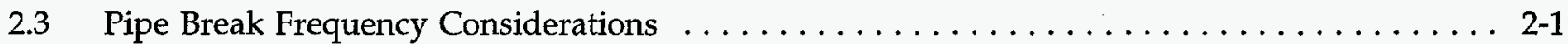

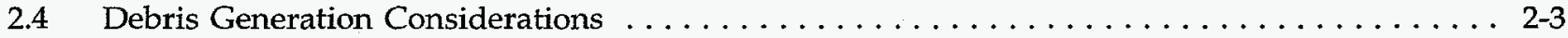

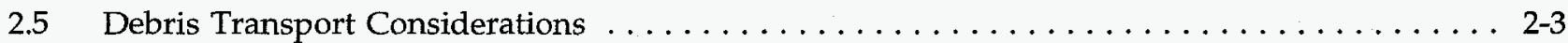

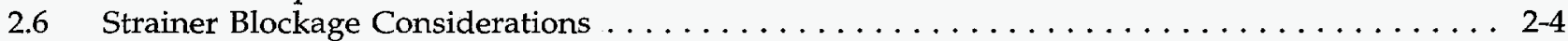

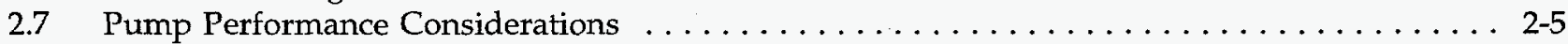

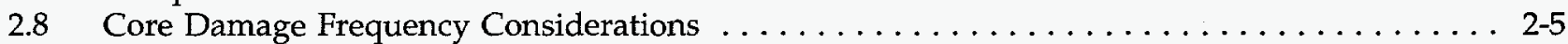

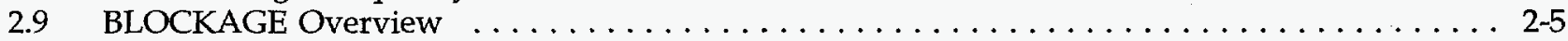

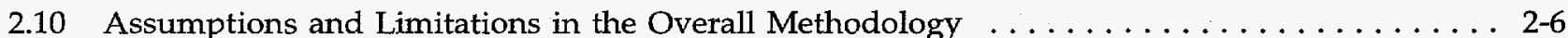

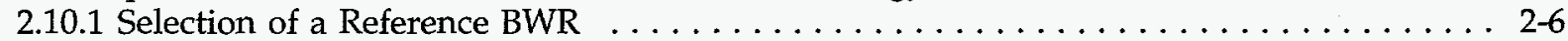

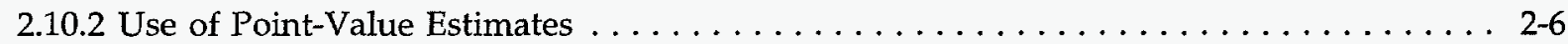

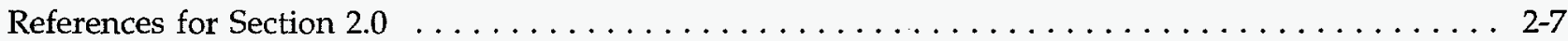

3.0 Debris Generation in the Reference Plant $\ldots \ldots \ldots \ldots \ldots \ldots \ldots \ldots \ldots \ldots \ldots \ldots \ldots \ldots \ldots \ldots$

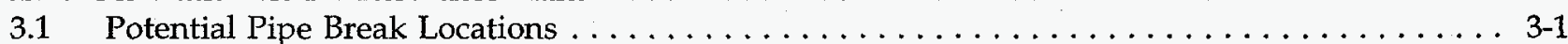

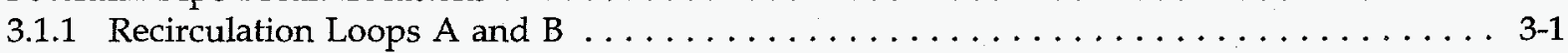

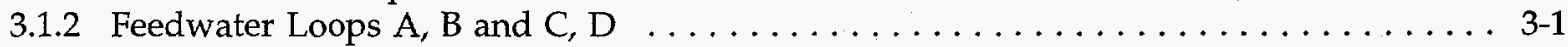

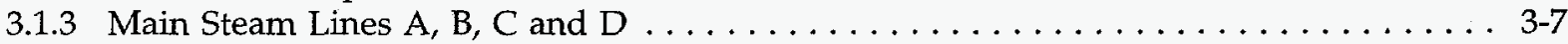

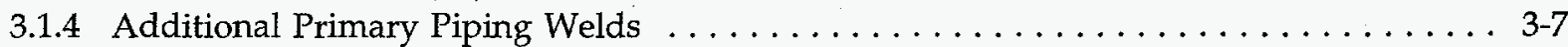

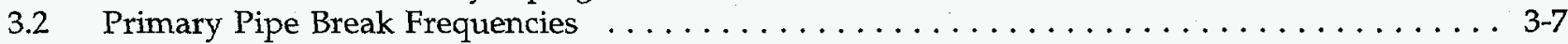

3.2.1 Recommended Weld Break Frequency Data for the Reference Plant . . . . . . . . 3-18

3.2.2 Pipe Break Frequency Estimates for the Reference Plant Piping . . . . . . . . . . 3-18

3.2.3 Comparisons of Recommended Data With Other Data Sources . . . . . . . . . . . . . . 3-19

3.3 Insulation Types, Amount and Location . . . . . . . . . . . . . . . . . . . . . . . . . 3-19

3.4 Break Jet Destruction Model for the Reference Plant $\ldots \ldots \ldots \ldots \ldots \ldots \ldots \ldots \ldots \ldots . \ldots \ldots$

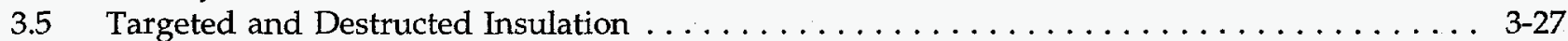

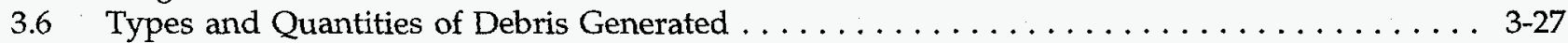

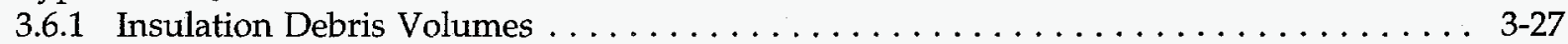

3.6.2 Other Types of Debris Generated by LOCA Jets . . . . . . . . . . . . . . . 3-29

3.7 Assumptions and Limitations in the Debris Generation Models . . . . . . . . . . . . . . . . 3-30

3.7.1 Pipe Break Initiator Assumptions and Limitations $\ldots \ldots \ldots \ldots \ldots \ldots \ldots \ldots \ldots \ldots$

3.7.2 LOCA Debris Types Assumptions and Limitations . . . . . . . . . . . . . . . . . 3-31

3.7.3 Break Jet Zone of Influence Model Assumptions and Limitations . . . . . . . . . . 3-31

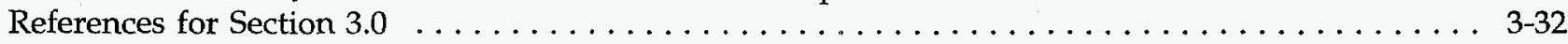


4.0 Drywell Transport in the Reference Plant $\ldots \ldots \ldots \ldots \ldots \ldots \ldots \ldots \ldots \ldots \ldots \ldots \ldots \ldots \ldots \ldots . \ldots 4$

4.1 Drywell Debris Transport Factors for the Reference Plant $\ldots \ldots \ldots \ldots \ldots \ldots \ldots \ldots \ldots \ldots$ 4-1

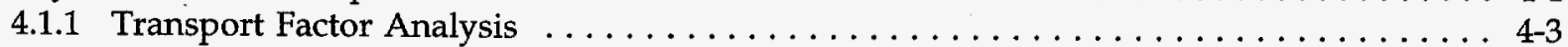

4.1.2 Time Scales for Drywell Transport . . . . . . . . . . . . . . . . . . 4-4

4.2 Quantity and Types of Debris Transported to the Suppression Pool . . . . . . . . . . 4-4

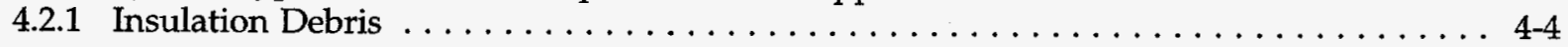

4.2.2 Drywell Particulates . . . . . . . . . . . . . . . . . . . . . . 4-5

4.3 Drywell Transport Assumptions and Limitations $\ldots \ldots \ldots \ldots \ldots \ldots \ldots \ldots \ldots \ldots \ldots$

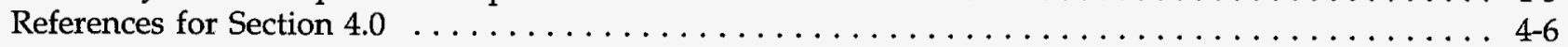

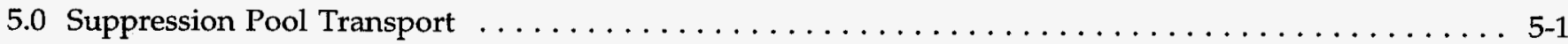

5.1 Volume of Insulation Debris Introduced to the Suppression Pool . . . . . . . . . . . 5-1

5.2 Quantity and Type of Debris Contained in the Reference Plant Suppression Pool . . . . . . . 5-1

5.3 Debris Transport Within the Reference Plant Suppression Pool . . . . . . . . . . . . 5-1

5.3.1 LOCA Induced Hydrodynamic Conditions in the Mark I Containments . . . . . . . 5-2

5.3.2 Reference Plant Suppression Pool Debris Transport Model . . . . . . . . . . . . 5-3

5.3.3 Quantity and Type of Debris Transported to the Strainer $\ldots \ldots \ldots \ldots \ldots \ldots \ldots .4$

5.4 Suppression Pool Transport Assumptions and Limitations $\ldots \ldots \ldots \ldots \ldots \ldots \ldots \ldots .4$

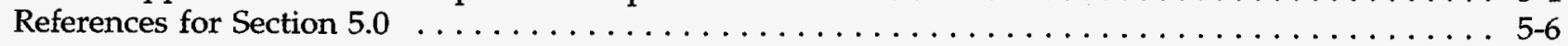

6.0 ECCS Suction Strainer Blockage Analyses $\ldots \ldots \ldots \ldots \ldots \ldots \ldots \ldots \ldots \ldots \ldots \ldots \ldots \ldots \ldots . \ldots \ldots$

6.1 RHR and LPCS Systems Description for the Reference Plant . . . . . . . . . . . . 6 6-1

6.2 Model for Loss of ECCS Pumps for the Reference Plant $\ldots \ldots \ldots \ldots \ldots \ldots \ldots \ldots \ldots$

6.3 Transient Buildup of Debris on the Strainer Model for the Reference Plant $\ldots \ldots \ldots \ldots 6-6$

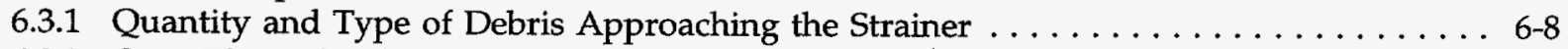

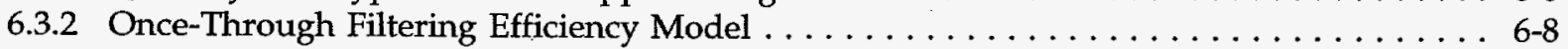

6.3.3 Quantity and Type of Debris Trapped on the Strainer . . . . . . . . . . . . 6-8

6.4 Pressure Drop due to Debris Accumulation . . . . . . . . . . . . . . . . . 6-10

6.4 .1 Head Loss Estimate . . . . . . . . . . . . . . . . . . . . . . . . . 6-10

6.5 ECCS Strainer Blockage Analysis Assumptions and Limitations $\ldots \ldots \ldots \ldots \ldots \ldots \ldots \ldots .6 .11$

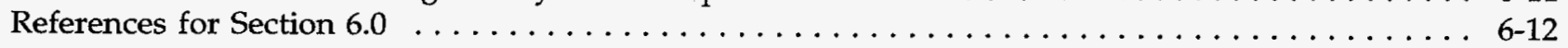

7.0 BWR ECCS Strainer Blockage Analysis Results $\ldots \ldots \ldots \ldots \ldots \ldots \ldots \ldots \ldots \ldots \ldots \ldots \ldots \ldots$

7.1 Estimated Frequency of Loss of ECCS NPSH Margin by System and Pipe Size . . . . . . . 7-1

7.2 Head-Loss and Debris Bed Transient Behavior for the Representative Welds . . . . . . . . . 7 7-4

7.2.1 Time Dependent Debris Transport . . . . . . . . . . . . . . . . . . 7-4

7.2.2 Debris Bed Buildup on the Strainer and Resultant Head Loss . . . . . . . . . . . 7-9

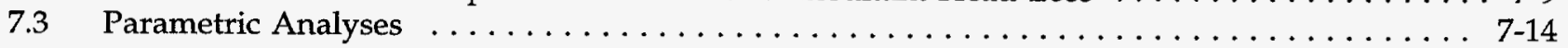

8.0 Core Damage Frequency Estimates $\ldots \ldots \ldots \ldots \ldots \ldots \ldots \ldots \ldots \ldots \ldots \ldots \ldots \ldots \ldots \ldots . \ldots \ldots$

8.1 Important Considerations Related to the Development of Blockage-Related CDF Estimates . . 8-1

8.2 Event Tree Model and CDF Results $\ldots \ldots \ldots \ldots \ldots \ldots \ldots \ldots \ldots \ldots \ldots \ldots \ldots \ldots \ldots \ldots$

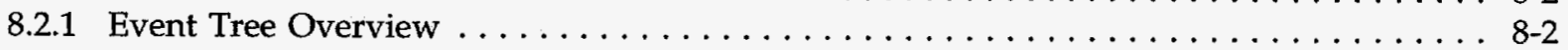

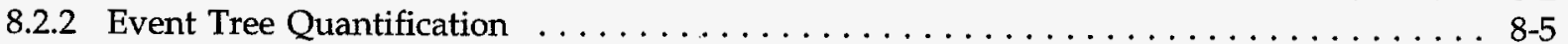

8.2 .3 Accident Sequence Results $\ldots \ldots \ldots \ldots \ldots \ldots \ldots \ldots \ldots \ldots \ldots \ldots \ldots$

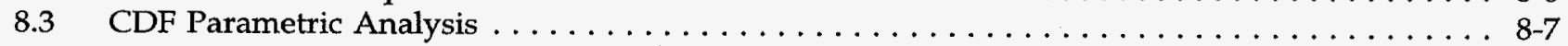

8.3.1 Parametric Analysis for Reference Plant CDF . . . . . . . . . . . . . . 8-8

8.3.2 Extrapolation of the Reference Plant Results to Other BWRs . . . . . . . . . . 8-8

8.4 European Approach for Addressing Potential Accidents Involving ECCS NPSH Loss . . . . 8 8-11

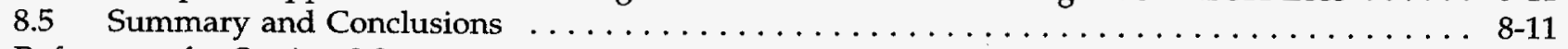

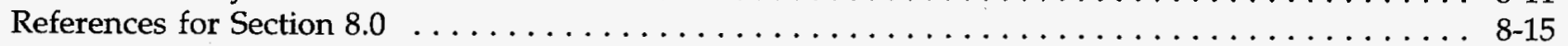


Appendix A: $\quad$ BWR Pipe Weld Break Frequencies

Appendix B: $\quad$ Transient ECCS Strainer Blockage Model

Appendix C: $\quad$ Parametric Analysis

Appendix D: $\quad$ Reference Plant Weld Data Tables

Appendix E: $\quad$ Experimental Investigation of Sedimentation and Head Loss Associated with LOCA Debris

Appendix F: $\quad$ Resolution of Public Comments 
Table No.

Title

Page

3-1 Recommended Weld DEGB Frequency Estimates $\ldots \ldots \ldots \ldots \ldots \ldots \ldots \ldots \ldots \ldots \ldots \ldots \ldots \ldots$

3-2 Weld DEGB Frequency Data for Reference BWR . . . . . . . . . . . . . . . . . . . 3-19

3-3 Pipe Break Frequency Estimates Categorized by System for the Reference BWR Plant . . . . . . 3-20

3-4 Pipe Break Estimates Categorized by Pipe Diameter for the Reference BWR Plant . . . . . . . . . 3-21

3-5 Pipe Break Frequency Estimates Categorized by Pipe Location for the Reference BWR Plant . . . . 3-22

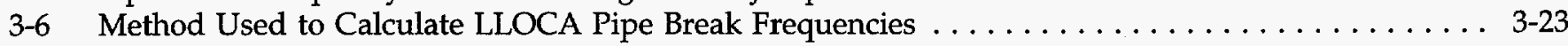

3-7 Comparison of Recommended LLOCA Data with Other BWR 4/Mark I Risk Assessment Data . . . 3-24

3-8 Estimation of Target Lengths for a Key Break Weld ID \#RCA-J006 . . . . . . . . . . . . . . . 3-29

3-9 Volume of Fibrous Debris Generated by Key Breaks . . . . . . . . . . . . . . . . . . . . . 3-30

4-1 Volume of Fibrous Debris Transported to Suppression Pool $\ldots \ldots \ldots \ldots \ldots \ldots \ldots \ldots \ldots \ldots$. . . . . .

5-1 Quantity and Type of Debris Transported to the Strainer for Representative Welds . . . . . . . . . . 5-4

7-1 Reference Plant Data Input to BLOCKAGE for the Base Case (Case A-6) $\ldots \ldots \ldots \ldots \ldots .7-2$

7-2 ECCS Strainer Blockage Estimates by System (Base Case) $\ldots \ldots \ldots \ldots \ldots \ldots \ldots \ldots \ldots \ldots \ldots . \ldots \ldots$

7-3 ECCS Strainer Blockage Estimates by Pipe Diameter (Base Case) $\ldots \ldots \ldots \ldots \ldots \ldots \ldots \ldots \ldots \ldots$

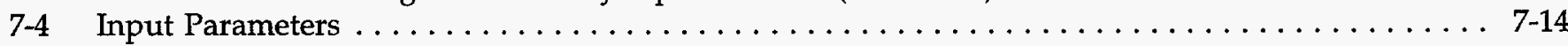

8-1 Estimates of CDF Contributions from ECCS NPSH Loss at BWR 4/Mark I Plants . . . . . . . . . 8-10

8-2 Comparison of Event Tree Break Point Probabilities Used in European and Base Case Event Trees 8-14 


\section{List of Figures}

Figure No.

Title

Page

1-1 BWR Strainer Debris Blockage Considerations $\ldots \ldots \ldots \ldots \ldots \ldots \ldots \ldots \ldots \ldots \ldots \ldots \ldots \ldots \ldots$

2-1 A Pictorial Description of Important Elements of the Methodology Used for Analyzing BWRs . . . . 2-2

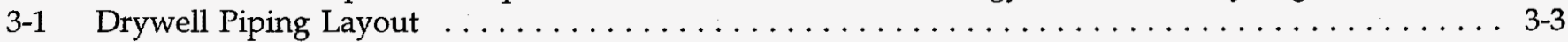

3-2 Isometric Drawing of Recirculation Loop A, Including Manifold \& Risers E, F, G, H . . . . . . . 3-5

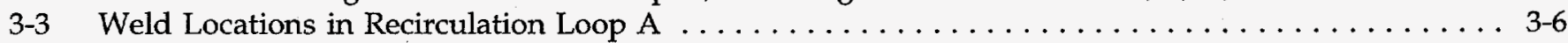

3-4 Isometric Drawing of Welds in Feedwater Loops A \& B . . . . . . . . . . . . . . . 3-8

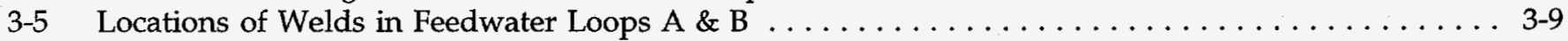

3-6 Isometric Drawing of Welds in Feedwater Loops C \& D . . . . . . . . . . . . . . . . 3-10

3-7 Planview of Main Steam Line Arrangement in Drywell . . . . . . . . . . . . . . . . . . 3-11

3-8 Vertical Cross-Section of Main Steam Line Arrangement in Drywell . . . . . . . . . . . . . . . . 3-12

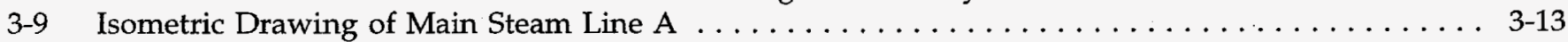

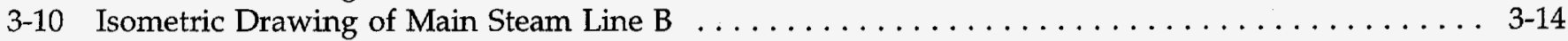

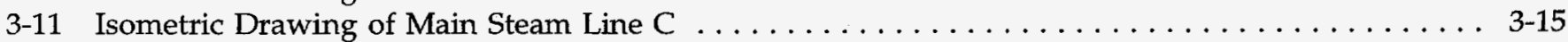

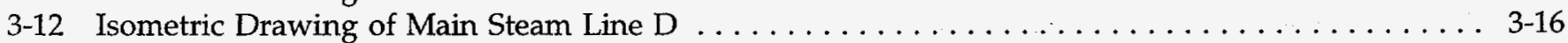

3-13 Weld Locations in Main Steam Line A . . . . . . . . . . . . . . . . . . . . . . . . 3-17

3-14 Installed NUKONTM Insulation Without Steel Jacketing (Top) and With Steel Jacketing (Bottom) .. 3-25

3-15 A Schematic Illustration of the Debris Generation Model $\ldots \ldots \ldots \ldots \ldots \ldots \ldots \ldots \ldots \ldots \ldots . \ldots \ldots$

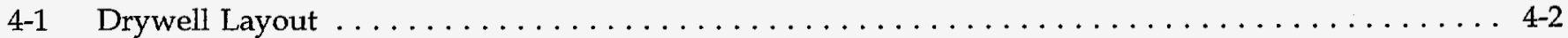

6-1 Planview \& Cross-Section of Strainer . . . . . . . . . . . . . . . . . . . .

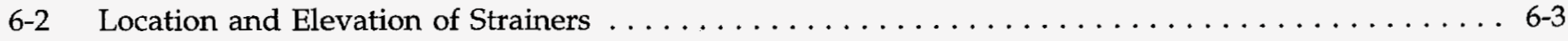

6-3 Low Pressure Core Injection Pump Curves $\ldots \ldots \ldots \ldots \ldots \ldots \ldots \ldots \ldots \ldots \ldots \ldots \ldots \ldots \ldots \ldots$

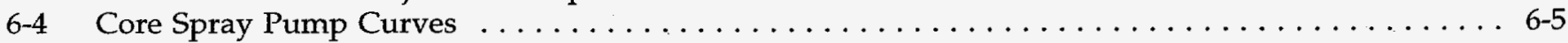

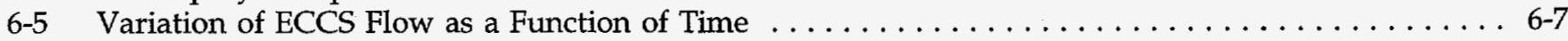

6-6 Filtration Efficiency for Fiber and Sludge Debris Species as a Function of Bed Theoretical Thickness 6-9

7-1 Transient Fibrous Debris Transport in the Suppression Pool for RCA-J006 . . . . . . . . . . . 7-5

7-2 Transient Particulate Debris Transport in the Suppression Pool for RCA-J006 . . . . . . . . . . . 7 7-6

7-3 Transient Fibrous Debris Transport in the Suppression Pool for RCA-J027 . . . . . . . . . . . 7-7

7-4 Transient Particulate Debris Transport in the Suppression Pool for RCA-J027 . . . . . . . . . . . 7-8

7-5 Time-Dependent Buildup of Fibrous Debris Bed on the Strainer Surface for the Representative Welds7-10

7-6 Temporal Variations of Sludge-to-Fiber Mass Ratios on the Debris Bed for the Representative Welds

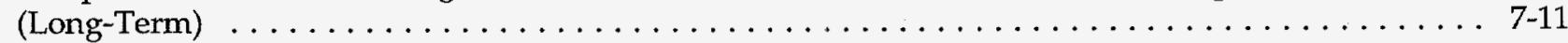

7-7a Variation of Head Loss Across the Debris Bed as a Function of Time for the Representative Welds 7-12

7-7b Variation of Head Loss Across the Debris Bed as a Function of Time for the Representative Welds

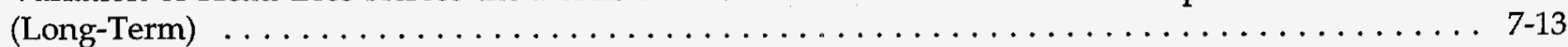

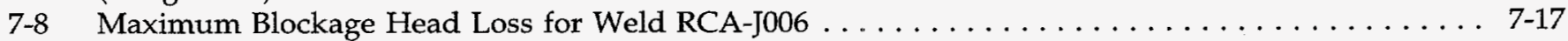

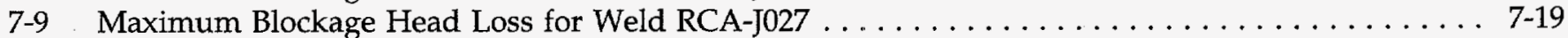

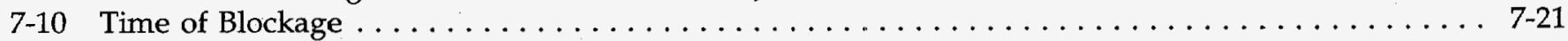

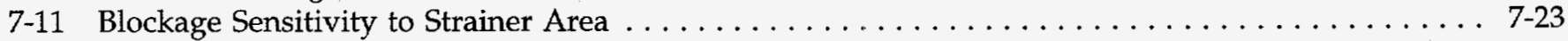

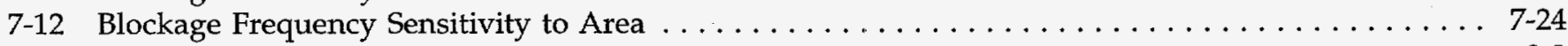

8-1 Simplified Event Tree for LLOCA at the Reference BWR $/ 4 \ldots \ldots \ldots \ldots \ldots \ldots \ldots \ldots \ldots \ldots$

8-2 Simplified Event Tree for LLOCA at the Reference BWR $/ 4 \ldots \ldots \ldots \ldots \ldots \ldots \ldots \ldots . \ldots .9$

8-3 European Approach for Addressing ECCS NPSH Loss (Base Case Data for Alternate Core Cooling Unavailability) . . . . . . . . . . . . . . . . . . . . .

8-4 European Approach for Addressing ECCS NPSH Loss $\ldots \ldots \ldots \ldots \ldots \ldots \ldots \ldots \ldots \ldots \ldots . \ldots \ldots$ 


\begin{tabular}{|c|c|c|c|}
\hline $\mathrm{ABB}$ & ASEA Brown Boveri & $\mathrm{L} / \mathrm{D}$ & Distance from break to target over \\
\hline ADS & Automatic Depressurization System & & diameter of broken pipe \\
\hline ARL & Alden Research Laboratory, Inc. & LCO & Limiting Conditions for Operation \\
\hline \multirow[t]{2}{*}{ ASME } & American Society of Mechanical & LLNL & Lawrence Livermore National Laboratory \\
\hline & Engineers & LLOCA & Large LOCA \\
\hline BPVC & Boiler and Pressure Vessel Code & LOCA & Loss of Coolant Accident \\
\hline BWR & Boiling Water Reactor & LPCI & Low Pressure Coolant Injection \\
\hline BWROG & BWR Owners' Group & LPCS & Low Pressure Core Spray \\
\hline $\mathrm{CDF}$ & Core Damage Frequency & MLOCA & Medium LOCA \\
\hline \multirow[t]{2}{*}{ CEESI } & Colorado Engineering Experiment & MSIP & Mechanical Stress Improvement Process \\
\hline & Station, Inc. & MSL & Main Steam Line \\
\hline CST & Condensate Storage Tank & NPSH & Net Positive Suction Head \\
\hline $\mathrm{D}$ & Diameter of broken pipe & NRC & Nuclear Regulatory Commission \\
\hline DEGB & Double-Ended Guillotine Break & PP\&L & Pennsylvania Power \& Light \\
\hline DGM & Debris Generation Model & P\&ID & Piping and Instrumentation Diagram \\
\hline ECCS & Emergency Core Cooling System & $\mathrm{PCI}$ & Performance Contracting, Inc. \\
\hline EOP & Emergency Operating Procedures & PRA & Probabilistic Risk Assessment \\
\hline FSAR & Final Safety Analysis Report & PWR & Pressurized Water Reactor \\
\hline FSTF & Full Scale Test Facility & RCIC & Reactor Core Isolation Cooling \\
\hline FWHM & Full Width at Half Maximum & RCS & Reactor Coolant System \\
\hline gpm & gallons per minute & RHR & Residual Heat Removal \\
\hline HDR & Heissdampfreaktor & RHRSW & RHR Service Water \\
\hline HPCI & High Pressure Coolant Injection & RMI & Reflective Metallic Insulation \\
\hline HPCS & High Pressure Core Spray & RWCU & Reactor Water Clean-up \\
\hline HWC & Hydrogen Water Chemistry & SEM & Scanning Electron Microscope \\
\hline IGSCC & Intergranular Stress Corrosion Cracking & SI & Stress Improvement \\
\hline IHSI & Induction Heating Stress Improvement & SLOCA & Small LOCA \\
\hline IPE & Individual Plant Examination & SNL & Sandia National Laboratories \\
\hline ISI & In Service Inspection & USI & Unresolved Safety Issue \\
\hline r & ak to & & \\
\hline
\end{tabular}




\section{Executive Summary}

On July 28, 1992, a spurious opening of a safety valve at Barsebäck Unit 2, a Swedish BWR, resulted in clogging of two ECCS pump suction strainers leading to loss of both containment sprays within one hour after the accident. The release of steam dislodged mineral wool insulation, pieces of which were subsequently transported by steam and water into the suppression pool located at the bottom of the containment. Instances of clogging of ECCS pump suction strainers have also occurred at U.S. plants, including two instances that occurred at the Perry Nuclear plant, which is a BWR/ 6 with Mark III containment. The Barsebäck-2 event demonstrated that larger quantities of fibrous debris will reach the strainers than would have been predicted by models and analyses developed for resolution of USI A-43. ${ }^{1,2}$ The instances at Perry suggested that filtering of small particles, e.g., suppression pool sludge, by the fibrous debris bed will result in increased pressure drop across the strainers.

Given these precursor events, NRC staff initiated analyses to estimate potential for loss of NPSH of the ECCS pumps in a BWR due to clogging of suction strainers by a combination of fibrous and particulate debris in essentially the same detail as was done previously for the reference PWR plant used to resolve USI A-43. A BWR/4 with a Mark I containment was selected as the reference plant for this study.

In August 1994 a Draft for Comment of NUREG/CR-6224 was published and this revision to NUREG/CR-6224 reflects the comments received from two foreign regulatory bodies, two American manufactures of insulation and the BWROG. Additionally, the Draft for Comment NUREG/CR6224 identified that there were areas where critical data was lacking. The models in this revision have been significantly changed to reflect the additional data and insights gained in the performance of NRC sponsored head loss and suppression pool experiments in late 1994 and the spring of 1995 and

${ }^{1}$ A. W. Serkiz, “USI A-43 Regulatory Analysis,” US Nuclear Regulatory Commission, NUREG-0869, Rev. 1, October 1985.

${ }^{2}$ A. W. Serkiz, "Containment Emergency Sump Performance," US Nuclear Regulatory Commission, NUREG-0897, Rev. 1, October 1985. from the CSNI/PWG-1 International Task Group for ECCS Recirculation Reliability.

Similar to USI A-43, the present analysis methodology has two components: probabilistic and deterministic. Based on historical evidence and piping failure analyses, this study concluded that pipe breaks in reactor cooling systems would most likely occur at the weld locations, and that weld break frequency is strongly dependent on the type of weld and operating environment. As a result, the number, type and location of each weld in the drywell of the reference plant subjected to high pressure during normal operation were identified. For each weld type, a weld break frequency was obtained based on data extracted from a LLNL BWR pipe break study described in NUREG/CR-4792 taking into consideration the effects of enhanced inspections.

A transient strainer blockage model was developed to estimate the impact of a break for each of the identified welds at the reference plant. Important components of this model included:

1. A reference plant specific LOCA DGM developed to estimate the quantity of insulation debris generated by postulated DEGB at that weld and the size distribution of the debris. A three region spherical DGM was developed to account for the lower operating pressure of BWRs and the congested layout of BWR drywells.

2. A reference plant-specific transient drywell transport model developed to estimate the fraction of the fibrous and particulate debris reaching the suppression pool as a result of transport by blowdown and washdown.

3. A suppression pool model developed to estimate the type and volume of fibrous and particulate debris reaching the strainer as a function of time. The model accounts for (a) resuspension of sludge contained at the bottom of the suppression pool, (b) gravitational sedimentation (or settling) of the particulate and fibrous debris, and (c) continued deposition on the strainer.

4. A head loss model developed to estimate the pressure drop across the strainer due to 
debris bed buildup. This model uses a correlation developed as part of this study for fibrous beds formed of NUKON ${ }^{\mathrm{TM}}$ in the presence of iron oxide particulate.

The key components described above were integrated into a single strainer blockage model which was used to evaluate whether or not a pipe break at each of the welds located in the primary system piping of the reference plant resulted in a head loss larger than the available ECCS NPSH margin. Those welds that resulted in loss of NPSH margin were summed to obtain an estimate of the overall frequency for the loss of NPSH for the reference plant.

The pipe break frequency (per Rx-year) estimates for a DEGB postulated to occur on piping systems analyzed ranged from $3.2 \mathrm{E}-06$ to $1.2 \mathrm{E}-04$ and the overall pipe break frequency was estimated to be of $1.59 \mathrm{E}-04$. The pipe break frequency estimates were dominated by breaks in the recirculation piping which at the reference plant is constructed of Type 304 stainless steel susceptible to IGSCC. Almost all postulated DEGBs resulted in unacceptable strainer blockage leading to the loss of NPSH margin for the ECCS pumps. The estimates of the frequency for loss of NPSH margin attributable to the piping systems studied were essentially the same as the pipe break frequency estimates. The overall loss of NPSH margin frequency (per Rx-year) was estimated to be $1.58 \mathrm{E}-04$. Four representative welds ranging in diameter from 22 " to 1 " were selected to illustrate the temporal behavior of the head loss due to the ECCS strainers blockage by fibrous insulation in the presence of mostly iron oxide particulates. In all cases the NPSH margin was estimated to be lost within a few minutes after full ECCS flow was achieved. An extended parametric analysis was performed to investigate the sensitivity of the temporal head loss estimates to each of 13 key parameters. The estimates for loss of NPSH margin were found to be most sensitive to the strainer surface area, the ECCS flow rate, the filtration efficiency, and the quantity of particulates. Within the variations of the parameters analyzed, the strainer area was found to be the only independent variable which could reduce the head loss below the available NPSH margin; at an approximate 8 fold increase in strainer surface area, loss of NPSH margin was no longer estimated to occur.

To gain additional insights into the potential safety significance of loss of ECCS function due to strainer blockage, $\mathrm{CDF}$ estimates were generated for blockage-related accident sequences for the reference plant. A simplified event tree model, representing the progression and expected outcomes of various possible LOCA sequences, was developed for LLOCA initiators. Estimates for frequency of loss of NPSH were used to obtain the overall CDF. The point estimates for the CDF per Rx-year due to blockage-related LOCA accident sequences for the reference plant ranged from $4.2 \mathrm{E}-06$ to $2.5 \mathrm{E}-05$. 


\section{Foreword}

The initial primary objective of this report was to analyze a reference BWR plant in essentially the same detail as was performed for the reference PWR plant used in the resolution of USI A-43,

"Containment Emergency Sump Performance" (see NUREG-0869, Revision 1). A BWR/4 with a Mark I containment which had been reinsulated with fiberglass insulation was selected as a reference plant to facilitate calculations.

The results of the initial reference plant analysis are reported in NUREG/CR-6224, "Parametric Study of the Potential for BWR ECCS Strainer Blockage Due to LOCA Generated Debris, Draft Report for Comment", which was issued for comment in August 1994. Comments were received, reviewed and responses are discussed in this report.

In addition, the experimental and modelling efforts were significantly expanded and the results were used to revise models and calculations discussed in this report. However, it should be clearly recognized that the variability in BWR containment designs (e.g., Mark I, Mark II and Mark III designs), insulations employed, and other pertinent plant specific design or operational procedures prevent generic or unconditional extrapolation of results discussed in this report without accounting for such differences.

The experimental data and models discussed in this report have also been reviewed in the U.S. by the BWROG strainer blockage working group and members of the Organization for Economic Cooperation and Development/Nuclear Energy Agency (OECD/NEA) sponsored international work group assigned the tasks of ECC water recirculation systems. Although such reviews and feedback have been extremely useful in revising this report, they do not represent endorsement of this report by these bodies.

This report represents the concluding analysis for BWR ECCS strainer blockage due LOCA generated debris as related to the reference plant analyzed. However, results of new and on-going analytical and experimental efforts may significantly impact the results of this study. Finally, this report does not represent NRC policy or requirements which apply to the resolution of this safety issue. 


\section{Acknowledgements}

Numerous individuals and several organizations made significant contributions to this study. This study could not have been completed without the technical and management support from the USNRC. A. Serkiz (RES) provided the historical perspective from USI A-43 and contributed significantly in establishing the technical framework for this study; M. Marshall (RES) was the USNRC Task Manager for this effort and provided critical technical direction, actively participated in all of the experiments, and performed an in-depth review of the technical basis for this study; R. Barrett and R. Elliott (NRR) provided the regulatory perspective and highlighted the effect of particulates on the head loss; and M. Virgilio (NRR) provided a senior regulatory viewpoint on key issues.

From SEA, J. Brideau was my assistant project manager and was responsible for keeping the project on an even keel during my almost continuous travels as well as responsible for the production of NUREG/CR6224; D.V. Rao was my technical director for this project and was responsible for the landmark Appendix B which established the technical foundation for this study; C. Shaffer was responsible for developing the BLOCKAGE 2 family of codes with the results presented in Chapter 7 and the parametric study of Appendix C; W. Thomas developed the probabilistic analysis presented in Sections 3.2, 8 and Appendix A; F. Souto was the lead reviewer of the final report and contributed in the development of the head loss correlation, the sludge characterization efforts, and Appendix E. Also from SEA, F. Sciacca provided critical review of the report and interfaced with SEA's upper management; R. Beaty and L. Comes contributed to the initial debris generation characterization efforts; N. Ruiz and B. Walsh were responsible for the development of BLOCKAGE 1 family of codes which established the link between the USI A-43 efforts and the BLOCKAGE 2 results; S. Ross led the comment resolution effort presented in Appendix F; E. Cramer developed the sludge simulant recipe; B. Zigler drove the mouse performing numerous BLOCKAGE sensitivity analysis; J. Crenshaw was responsible for graphical support; $R$. Flores led the efforts associated with the typing of the earlier versions of the NUREG whilst D. Rettig was responsible for the typing and integration efforts of this final version.

Other organizations whose efforts contributed to this study include Alden Research Laboratory, the University of New Mexico, the CSNI/PWG-1 International Task Group on ECCS Recirculation Reliability, the BWROG ECCS Suction Strainer Committee, and the reference plant. The experimental efforts at the Alden Research Laboratory were led by G. Hecker, who contributed in defining the experiments and performing an independent critical review of the technical basis of this study; M. Padmanabhan, P. Murthy, A. Johnson, and F. Weber were instrumental in developing the head loss and suppression pool experimental apparatus, conducting the tests and analyzing the experimental results. T. Kodas of the University of New Mexico provided the sludge simulant size analysis using the scanning electron microscope. O. Sandervåg (SKI) provided key insights into the Barsebäck-2 event and led the CSNI/PWG-1 International Task Group on ECCS Recirculation Reliability who provided critical reports and data for developing the technical basis of this study; J. Olsén (SKI) and J. Hyvärinen (STUK) were also members of the international task group and provided critical review and constructive comments on the earlier drafts of this report. R. Sagarro led the BWROG ECCS Suction Strainer Committee efforts who were responsible for providing key comments on the conduct of the NRC experimental efforts as well as providing constructive review and comments on earlier drafts of this report. The engineers of the reference plant contributed significantly to this effort by providing detailed drawings, plant layouts, and ECCS performance parameters; answering numerous questions as to details of the plant; and providing review and comments of the earlier versions of this report.

The contributions of the following individuals are also acknowledged: D. Maret of Sequoia Consulting Group for his concise and directly applicable discussions and insights of the complex phenomena associated with this issue; B. Bernahl of Software Edge for developing a user-friendly interface to the BLOCKAGE code; G. Hart and G. Pinsky of PCI for sharing their debris generation and head loss data and providing key insights into the behavior of NUKON ${ }^{\mathrm{TM}}$ material; E. Wolbert of TRANSCO for providing the Thermal Wrap ${ }^{\circledR}$ material for one of the series of head loss experiments; and finally M. Henriksson of Vattenfall for sharing his head loss data and insights into fibrous material behavior. Not specifically acknowledged are the numerous other individuals who willingly contributed background information and shared their insights with us. Your contributions were very much appreciated.

Gilbert Zigler

SEA ECCS Strainer Blockage Project Manager Albuquerque, New Mexico September 1995 


\subsection{Background and Objectives}

\subsection{Background}

In 1979, the NRC established USI A-43, "Containment Emergency Sump Performance," to study safety issues related to the ability of both PWRs and BWRs to recirculate water back to the reactor core following a postulated LOCA. The NRC staff's resolution of USI A-43 regarding the potential loss of post-LOCA recirculation capability due to intake blockage from dislodged insulation debris was transmitted to the industry in Generic Letter 85-22, "Potential for Loss of Post-LOCA Recirculation Capability Due to Insulation Debris Blockage," on December 3, 1985. Although the staff concluded at that time that it was not necessary to impose new requirements on licensees or construction permit holders, the staff did recommend that Regulatory Guide 1.82, Revision 1, "Water Sources for Long-Term Recirculation Cooling Following a Loss-of-Coolant Accident" [Ref. 1.1], be used as a guideline for 10 CFR 50.59 reviews dealing with the changeout and/or modification of thermal insulation installed on reactor coolant system piping and on its components [Ref. 1.2]. NUREG-0897, Revision 1, "Containment Emergency Sump Performance" [Ref. 1.3], contained technical findings related to USI A-43, and was the principal reference for developing the revised regulatory guide. NUREG-0869, Rev. 1, "USI A-43 Regulatory Analysis" [Ref. 1.4] served as the basis for the decision not to impose new requirements.

On July 28, 1992, a spurious opening of a safety valve at Barsebäck-2, a Swedish BWR, resulted in the clogging of two ECCS pump suction strainers [Ref. 1.5]. During the re-start activities, steam was released into the containment from a ruptured disk on a relief valve that had been inadvertently left open. The release of steam dislodged mineral wool insulation, pieces of which were subsequently transported by steam and water into the wetwell located at the bottom of containment. Within one hour, the fibrous debris clogged the ECCS inlet strainers. This type of strainer clogging had been previously considered as a possibility, but it was believed that at least ten hours would have to elapse before clogging would occur. A ten-hour delay in clogging would allow operating personnel time to remove the clogging material by manually reversing flow through the strainers. Such a flow reversal activity would interrupt ECCS flow for
5-10 minutes, but this interruption would be acceptable after ten hours following reactor shutdown because of the large decrease in decay heat levels within this time frame.

The regulatory authorities of Sweden and other northern and central European countries viewed the Barsebäck-2 incident as a precursor to potential loss of ECCS cooling due to LOCA-generated debris and initiated a safety reanalysis effort, coupled with experiments directed at estimating the following: (1) the amount of insulation destroyed by the steam jet created by the pipe break, valve opening, etc.;

(2) the composition of the resulting debris; (3) the amount of debris transported to the suppression pool; (4) the extent of insulation debris buildup on strainers; and (5) the resultant increase in pressure drop across the strainer under the postulated conditions. Results of the European experiments were compared with results obtained for resolution of USI A-43 [Ref. 1.6]. The comparison showed that prior correlations derived for debris head loss, when compared to Swedish experimental data, underestimated pressure losses. The Barsebäck-2 event resulted in a higher amount of insulation debris reaching the intake strainers than would have been predicted by models and data contained in NUREG-0897, Revision 1.

Instances of clogging of ECCS pump strainers have also occurred at U.S. plants, including two instances that occurred at the Perry Nuclear Plant, a BWR 6 [Ref. 1.7]. The first Perry event resulted in deformation of RHR pump suction strainers due to buildup of operational debris. This buildup caused an excessive differential pressure across the strainers. The second Perry event also involved the deposition of debris on the RHR pump suction strainers. The debris consisted of glass fibers that had been inadvertently dropped into the suppression pool from temporary drywell cooling filters; corrosion products and other materials filtered from the pool water by glass fibers adhering to the surface of the strainer also comprised the debris. This phenomenon is referred to as "filtering" and had not been evaluated previously by the staff and industry.

Based on these events, the NRC issued NRC Bulletin 93-02 on May 11, 1993, which requested that both PWR and BWR licensees: (1) identify fibrous air filters and other temporary sources of fibrous 
material in containment not designed to withstand a LOCA, and (2) take prompt action to remove the material and ensure the functional capability of the ECCS.
Although USI A-43 was derived principally from containment emergency sump performance in PWRs, concern about debris blockage also applies to BWRs. The BWR RHR system performs the LPCI function of the ECCS. In addition, BWR designs incorporate a LPCS system as part of the ECCS. The suction strainers in the suppression pool of a BWR RHR system are analogous to the PWR sump debris screen, and both BWRs and PWRs must have adequate recirculation cooling capacity to prevent core melt following a postulated LOCA.

Given the precursor events described above, NRC staff initiated analyses of BWR strainer blockage based on plant surveys; European findings were used to estimate possible shortcomings in existing suction strainer designs in U.S. BWRs. Prior analyses estimating loss of ECCS due to debris blockage [Ref. 1.3, 1.4, 1.8 and 1.9] were based on a detailed piping layout, weld location, and an insulation distribution model for a reference PWR; thus, the NRC decided that a detailed plant-specific study using a BWR 4 with a Mark I containment would be undertaken. This plant-specific study, presented in this report, was initiated in September 1993.

NUREG/CR-6224 was released in August 1994 as a "Draft for Comment." Comments were received from two foreign nuclear regulatory organizations, two American manufacturers of nuclear insulation products, and the BWROG. All comments received were reviewed in detail by both the NRC and SEA, and NUREG/CR-6224 Draft for Comment was revised appropriately. The comments and the associated responses are discussed in Appendix F.

In view of the lack of critical data identified during the preparation of NUREG/CR-6224 Draft for Comment, the NRC sponsored a series of experiments to gain insights into the behavior of debris in the suppression pool and acquire mixed bed head loss data. The results of these NRC experiments were used to revise models and calculation methodologies presented in NUREG/CR6224 Draft for Comment. The new experimental data and the revised models presented in this report have been subjected to review by the CSNI/PWG-1
International Task Group on ECCS Recirculation Reliability. The models in this report, however, do not reflect information made public after April 1995. In particular, this analysis does not take into account insights from the Siemens-Karlstein series of steam blast tests [Ref. 1.10], the recommendations of Draft Regulatory Guide DG-1038 on debris transport in the drywell [Ref. 1.11], or the BWROG position on reduced sludge concentrations [Ref. 1.12].

\subsection{Objectives and Scope}

The primary objective of this report was to analyze a reference BWR plant in essentially the same detail as was done for the reference PWR plant used to resolve USI A-43. Both deterministic and probabilistic analyses were used in the study to evaluate the potential for loss of ECCS NPSH due to strainer blockage. The deterministic analyses focused on determining whether or not a postulated break in the primary system piping of the reference BWR results in ECCS strainer blockage and loss of pump NPSH. Deterministic models were developed to address the LOCA considerations shown in Figure 1-1. The probabilistic analyses focused on evaluating the likelihood of ECCS strainer blockage and blockage-related core damage from LLOCA-initiators. The specific elements of the methodology used in this study are discussed in Section 2.0.

The remainder of the report is organized into the following sections to correspond with Figure 1-1:

2.0 Methodology for Analysis of Insulation Debris Effects

3.0 Debris Generation in the Reference Plant

4.0 Drywell Transport in the Reference Plant

5.0 Suppression Pool Transport

6.0 ECCS Suction Strainer Blockage Analyses

7.0 BWR ECCS Strainer Blockage Analysis Results

8.0 Core Damage Frequency Estimates 
Background
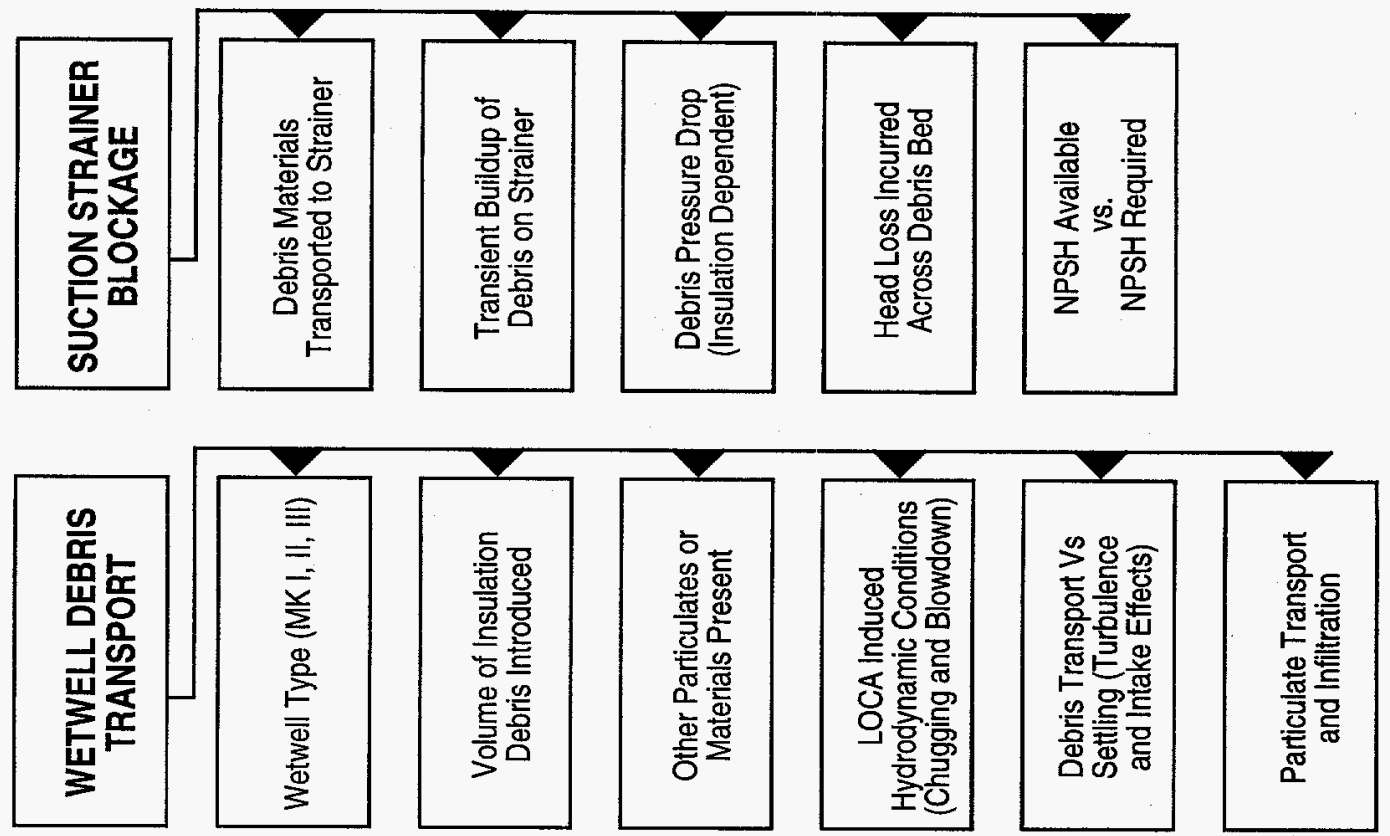

吾

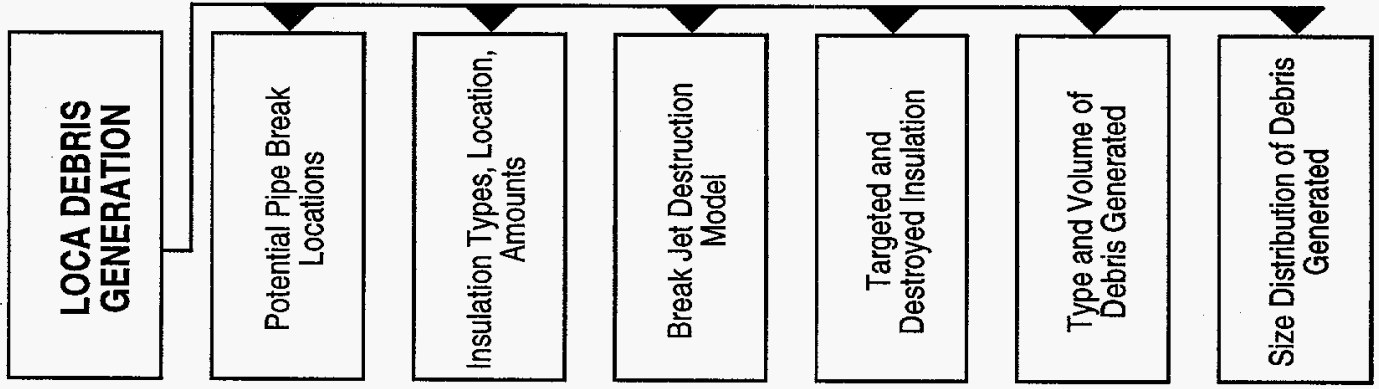




\section{Background}

The following appendices provide further details on model development, weld data, recent NRC experiments, and public comments:

Appendix A - BWR Pipe Weld Break

Frequencies

Appendix B - Transient ECCS Strainer

Blockage Model

Appendix C - Parametric Analysis

Appendix D - Reference Plant Weld Data

Tables

Appendix E - Summary of Results of Head Loss and Suppression Pool Experiments

Appendix F-Resolution of Comments on NUREG/CR 6224 Draft for Comment. 


\section{References for Section 1.0}

1.1 USNRC, "Water Sources for Long-Term Recirculation Cooling Following a Loss-ofCoolant Accident," Regulatory Guide 1.82, Revision 1, November 1985.

1.2 Generic Letter 85-22, "Potential for Loss of Post-LOCA Recirculation Capability Due to Insulation Debris Blockage," December 3, 1985.

1.3 A.W. Serkiz, "Containment Emergency Sump Performance," U.S. Nuclear Regulatory Commission, NUREG-0897, Rev. 1, October 1985.

1.4 A. W. Serkiz, "USI A-43 Regulatory Analysis," U.S. Nuclear Regulatory Commission, NUREG-0869, Rev. 1, October 1985.

1.5 European Nuclear Society Nuclear News Network, "Swedish N-Utilities Explain BWR Emergency Core Cooling Problem," News No. 358/92, September 18, 1992.

1.6 D.N. Brocard, "Buoyancy, Transport, and Head Loss of Fibrous Reactor Insulation," Alden Research Laboratory, Inc., published as Sandia National Laboratories Report No. SAND82-7205, NUREG/CR-2982, Rev. 1, July 1983.

1.7 Perry Nuclear Power Plant, "Excessive Strainer Differential Pressure Across the RHR Suction Strainer Could Have Compromised Long-Term Cooling During Post-LOCA Operation," Licensee Event Report 93-011, Docket 50-440, May 19, 1993.
1.8 J. Wysocki and R. Kolbe, "Methodology for Evaluation of Insulation Debris Effects: Containment Emergency Sump Performance, Unresolved Safety Issue A-43," Burns and Roe, Inc., published as Sandia National Laboratories Report No. SAND82-7067, NUREG/CR-2791, Sept. 1982.

1.9 J. J. Wysocki, "Probabilistic Assessment of Recirculation Sump Blockage Due to Loss of Coolant Accidents: Containment Emergency Sump Performance USI A-43," Vols. 1 and 2, Burns \& Roe, Inc., published as Sandia National Laboratories Report No. SAND83-7116, NUREG/CR-3394, July 1983.

1.10 J. Tryborn, "Metallic Insulation Jet Impact Tests (MIJT)," Vattenfall Energisystem, GEK 77/95, June 1995.

1.11 USNRC, "Water Sources for Long-Term Recirculation Cooling Following a Loss-ofCoolant Accident," Draft Regulatory Guide DG-1038 (Proposed Revision 2 to Regulatory Guide 1.82), July 1995.

1.12. Attachment 1 to Letter, T. Green to O. Sanderväg, "Current BWROG Estimates Regarding Suppression Pool Sludge Accumulation Rates," TAG95-49, August 16, 1995. 



\subsection{Methodology for Analysis of Insulation Debris Effects}

\subsection{Overall Methodology}

The primary objective of this study was to evaluate the potential for BWR ECCS strainer blockage due to LOCA-generated debris. This issue was analyzed for a reference BWR plant selected by the NRC to the same detail as was previously done for a reference PWR plant in resolving USI A-43 [Ref. 2.1, 2.2, 2.3 and 2.4]. Similar to USI A-43, the present analysis methodology had two major components: deterministic analyses and probabilistic analyses. The deterministic analyses focused on determining whether or not a postulated break in the primary system piping results in ECCS strainer blockage and loss of pump NPSH. Important elements of the deterministic analyses are illustrated in Figure 2-1, and can be summarized as follows:

1. Selection of a reference BWR plant for the purpose of identifying potential break locations and the surrounding target pipes that may be affected by the break.

2. Development of a DGM, applicable to the reference BWR, to estimate the volumes and type of insulation debris generated by each postulated break.

3. Development of a drywell transport model, applicable to the reference BWR, to estimate the quantity of the insulation debris and drywell particulates transported to the suppression pool as a function of time.

4. Development of a transient suppression pool model, applicable to the reference BWR, for debris transport to the strainers. This model also addressed transport of suppression pool sludge and drywell particulates to the strainer.

5. Finally, development of a head loss model to predict the pressure drop due to debris accumulation on the surface of the strainer. Included in this model were the effects of sludge and drywell particulates on the pressure drop as a function of time.

The deterministic analyses performed as part of this study assumed loss of ECCS when the head loss due to debris accumulation exceeded the available NPSH margin for the pumps.
The probabilistic aspects of this study focused on evaluating the likelihood of ECCS strainer blockage as well as likelihood of blockage-related core damage from LLOCA-initiators. Essential elements of the probabilistic methods included the following:

1. Estimation of the break frequency for each weld located in the primary system piping. These weld break frequencies were subsequently used to generate pipe break frequencies for each system.

2. Development of a functional event tree that models accident progression for a LLOCA initiator with specific relevance to the ECCS strainer blockage issue. Quantification of the event tree resulted in estimates for the blockage-related CDF due to loss of ECCS following a LLOCA.

Brief descriptions of each individual task performed as part of this analysis are provided below.

\subsection{Reference BWR Selection Considerations}

A General Electric BWR/4 with Mark I containment was selected as the reference BWR for use in this study to estimate pipe break frequencies and the attendant debris generation and transport. The Mark I containment design has a relatively small suppression pool and comparatively larger strainer flow velocities than other BWRs with Mark II and Mark III containments. More than $99 \%$ of the primary piping in the selected BWR is insulated with steel-jacketed fiberglass insulation.

\subsection{Pipe Break Frequency Considerations}

Historical evidence and piping failure analyses suggest pressure boundary failure would most likely occur at weld locations [Ref. 2.5]; hence, weld break location and insulation targeted by the break jet were the primary factors in estimating the debris generation volume. Plant layout reviews identified all welds in the piping that would be subjected to high pressure during normal operation. Based on this analysis, it was concluded that debris generation at the reference BWR would mainly be 
Methodology

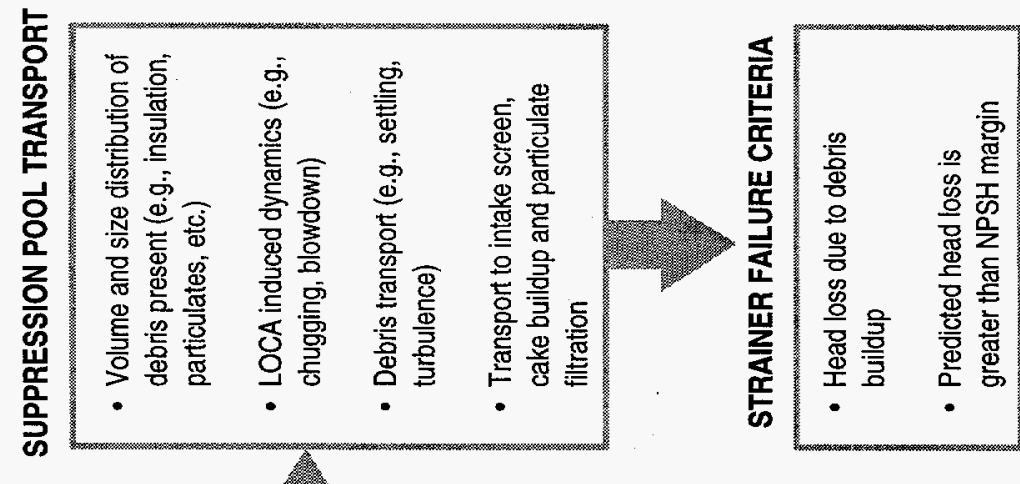

3
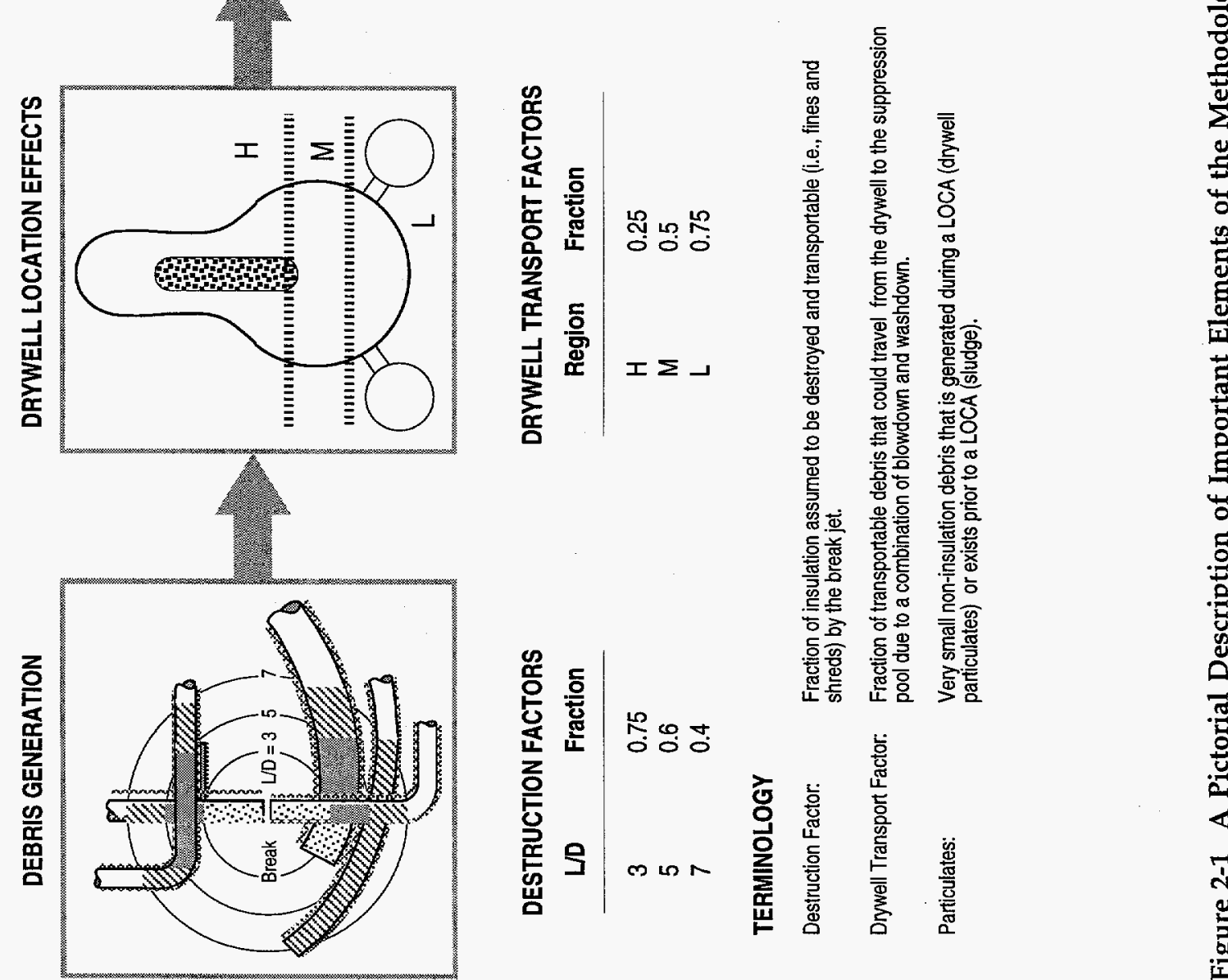
due to breaks postulated in the feedwater piping, in the recirculation system piping, and in MSLs. Section 3.2 describes the methodology used to estimate pipe break frequencies for various BWR system pipes. Appendix A provides details on the derivation of weld break data used to calculate pipe break frequencies.

\subsection{Debris Generation Considerations}

The initial blast wave exiting a DEGB and the ensuing break jet expansion and impingement forces are the dominant contributors to insulation debris generation following a LOCA. Other contributors, such as pipe whip and pipe impact, have been studied and shown to be of secondary importance. Pertinent details are given in NUREG/CR-2791 [Ref. 2.3]. Previous studies, summarized in NUREG-0897, Rev. 1, clearly demonstrated that the volume of debris generated by jet impingement is strongly influenced by the type of insulation and mode of encapsulation (e.g., whether or not it is jacketed). Although the reference plant employs steel-jacketed NUKON ${ }^{\mathrm{TM}}$, and the calculations made use of key insights relevant to this type of insulation, the methodology developed for this study is sufficiently flexible to be extended to other types of insulation.

The three-region, two-phase conical jet expansion model, described in NUREG-0869, Revision 1, Appendix D and NUREG-0897, Revision 1, was revised and used to define a zone of influence over which the insulation would be destroyed and dislodged from the surrounding pipes ${ }^{1}$.

Modifications to the previous DGM addressed the following operating and design features for BWRs:

1. The break jet zone of influence was reduced because BWRs operate at lower pressures than PWRs.

2. BWR drywells are congested in layout, much more so than in typical PWRs, which do not permit free expansion of a break jet into the drywell.

${ }^{1}$ Refer to Section 3.3 .3 and 3.3.4, and Figures 3.26 and 3.27 of NUREG-0897, Revision 1 (Ref. 2.2).
3. The DEGB weld breaks generate simultaneous expansion in opposite directions of break jets.

Based on the foregoing considerations, a spherical zone of model destruction was assumed to extend from the location of the break to a distance of seven times the pipe diameter (i.e., $\mathrm{L} / \mathrm{D}=7$ ), as shown in Figure 2-1.

This debris generation model was used to estimate the quantity of fibrous debris generated by a postulated break. In addition to the fibrous debris, the study included additional sources of debris: containment coatings and concrete dust. Using BWROG estimates [Ref. 2.6], a postulated break inside the drywell was assumed to generate $85 \mathrm{lbm}$ of paint chips. Finally, $156 \mathrm{lbm}(70.8 \mathrm{~kg})$ of additional particulates was assumed to have been generated by LOCA effects on concrete structures, (i.e., concrete dust). Further discussion of debris generation can be found in Appendix B.

\subsection{Debris Transport Considerations}

Debris transport from the drywell to the suppression pool, and subsequently to the strainer, is strongly influenced by factors such as tortuosity of the channels available for transport, flow velocity, and debris size. Debris considered in this study included fibrous and non-fibrous insulation fragments, corrosion products, and unqualified paint chips. At Barsebäck- $2^{2}$, it was reported that about $50 \%$ of the debris generated in the drywell reached the suppression pool. The remaining debris was found to have been retained by the intervening containment structures. In other BWRs, the fraction of transported debris may be lower or higher, depending on the containment type $e^{3}$, the location of the break, and the type and size of the debris produced.

This study postulated that debris transport from the drywell to the suppression pool would occur over

\footnotetext{
${ }^{2}$ The Barsebäck plant is similar to a BWR/4 with a Mark II containment. However, unlike many U.S. Mark II plants, downcomers in Barsebäck are flush with the drywell floor.

${ }^{3} \mathrm{~A}$ review of various containments revealed that this fraction may vary for individual containments due to unique layouts.
} 
two phases: the blowdown phase and the washdown phase. During the blowdown phase debris are carried by the recirculating steam flow and deposited in the suppression pool. Following blowdown, the break flow and the containment sprays, if turned on, will enable time-dependent debris transport of a fraction of the left-over debris to the suppression pool. The complexity of the phenomena involved did not permit arriving at an exact model for debris transport in the drywell within the scope of this study. As a result, this study assigned a transport factor to each of the three elevations in the drywell of the reference plant, as shown in Figure 2-1, to account for blowdown transport.

In addition to debris transported from the drywell, BWR suppression pools are known to contain large quantities of particulate matter commonly referred to as suppression pool sludge [Ref. 2.7]. Estimates of its mass vary from $70 \mathrm{lbm}$ to $5000 \mathrm{lbm}(31.8 \mathrm{~kg}$ to $2,273 \mathrm{~kg}$ ) depending on the plant and suppression pool clean-up procedures. For the reference plant, this study postulated that $850 \mathrm{lbm}(386 \mathrm{~kg})$ of suppression pool sludge, normally contained at the bottom of the pool, would be resuspended during initial blowdown phase and would be available for transport to the strainer, along with the debris added from the drywell.

Debris and particulate transport in the wetwell (or suppression pool) is complicated by a variety of effects, as outlined in Figure 2-1. LOCA-induced effects such as condensation oscillations and chugging will influence debris disintegration and transport to the suction strainer during the early portions of the LOCA. Later in the LOCA sequence, gravitational separation (or settling) would become more important and the transport to suction strainers will be affected by velocities in the vicinity of the strainer itself. These two phenomena are competing effects that need to be modeled.

In the case of a calm suppression pool, the settling velocity and the fluid velocity near the strainer can be estimated, and the quantity and type of debris reaching the strainer can be calculated as a function of time. However, suppression pool dynamics (chugging) immediately following a LOCA are characterized by large scale turbulence and two-phase flow instabilities [Ref. 2.8]. Suspension and further disintegration of the debris, when subjected to these flow instabilities, are complex phenomena and an experimental study was undertaken to provide insights into debris behavior in the suppression pool during and after the high energy phase. A time-dependent suppression pool debris transport model was formulated based on the experimental findings. Further details of the debris transport models are provided in Appendix B.

\subsection{Strainer Blockage Considerations}

Accumulation of debris on the strainer would result in head loss and may lead to loss of NPSH margin. NUREG-0897, Rev. 1 suggested that experimental correlations be used to predict head loss across the strainer as a function of strainer flow velocity and thickness of the debris bed. However, such a simple model may not be able to address various factors that strongly influence head loss characteristics. Those characteristics include:

1. Uniform vs. non-uniform deposition: Non-uniform distribution of debris on the strainer would result in partial blockage of the strainers. Preliminary analyses revealed that the worst-case scenario would be represented by uniform deposition of the debris on the strainer. This worst-case scenario also represented the most credible means of deposition in the initial stages, when strainer blockage would be expected to be dominated by fines.

2. Insulation material type: A survey of U.S. BWRs [Ref. 2.9] revealed that plant insulation consists mostly of low and high density removable fiberglass blankets, reflective metallic insulation (with metal foils), and conventional, permanent mass insulation. Ninety-nine percent of the primary pipes of the reference plant are insulated with steel-jacketed NUKON ${ }^{\mathrm{TM}}$, a low density fiberglass insulation. Experiments reported in NUREG/CR-2982, Rev. 1 [Ref. 2.10] and in NUREG-0897, Rev. 1, supported by recent European data [Ref. 2.11], showed a strong dependence of head loss on the insulation material types. Conclusions derived for steel-jacketed NUKON ${ }^{\mathrm{TM}}$ may not necessarily be representative when compared with metallic (metal reflective), mineral wool, high density fiberglass, or unjacketed NUKON ${ }^{\mathrm{TM}}$ insulation. 
3. Particulate debris: The presence of particulate debris in the suppression pool, during ECCS operation will result in filtration and retention of some of the particulates by the debris bed formed on the strainer. The retention of particulates by the insulation debris bed will result in significantly higher pressure drops than would be expected from the fibrous material alone.

These factors were incorporated into a transient debris build-up and pressure drop model to estimate the severity of debris and particulate blockage. Appendix B presents the details of the strainer blockage models developed for this study.

\subsection{Pump Performance Considerations}

For the reference plant-specific analysis, RHR/CS pump performance under adverse conditions was analyzed as described in Section 3.2 of

NUREG-0897, Rev. 1. ECCS failure was assumed to occur when the head loss due to strainer blockage was estimated to be larger than the available NPSH margin. This present analysis calculated NPSH margin in accordance with Reg. Guide 1.1

[Ref. 2.12], assuming the most severe suppression pool temperature and atmospheric pressure.

\subsection{Core Damage Frequency Considerations}

Blockage-related core damage accidents involve the failure of ECCS pumps due to the loss of NPSH and the subsequent failure to establish alternative means for core cooling. A number of considerations were involved in estimating the contribution of ECCS strainer blockage to $\mathrm{CDF}$, including:

1. LOCA frequency.

2. ECCS strainer blockage probability.

3. Operator recognition of strainer blockage.

4. Availability of back flushing.

5. Alternative means of providing core cooling.

6. Protection of containment integrity.
7. Time available for operators to take mitigating actions.

8. Additional operator recovery actions.

A simplified event tree model, representing the progression and expected outcomes of various possible LOCA sequences, was used to generate the CDF estimates. Section 8.0 focuses on the development of CDF estimates for the reference plant; however, a limited effort was made to extrapolate the results of the $\mathrm{CDF}$ analysis to other types of BWRs.

\subsection{BLOCKAGE Overview}

The USI A-43 study used two main-frame computer codes, PRA and TABLE, to perform loss of NPSH frequency calculations for PWRs [Ref. 2.4]. The exact functions of PRA and TABLE were reproduced by BLOCKAGE 1.0, which is a PC-based software developed as part of this study. The BLOCKAGE 2 series was then developed by modifying BLOCKAGE 1.0 to properly model a BWR. The code calculates debris generation and transport, head loss associated with debris and particulates transported to ECCS pump suction strainers, and impact on NPSH available.

User inputs to BLOCKAGE are:

1. A list of the location and size of welds whose failure can initiate a LOCA.

2. Weld break frequency for each type and size of weld.

3. A list of the number, diameter, and length of target pipes that can be influenced by each potential break location.

4. Type and thickness of insulation on each target pipe.

5. Other parametric input, such as size distribution of the debris, insulation destruction fractions, drywell transport fractions, filtering efficiencies, the amount and type of particulates contained in the suppression pool, settling velocities, and suppression pool/ECCS design information. 
BLOCKAGE then analyzes each weld as a potential break and determines whether or not it results in loss of NPSH margin. Appendix B describes the various equations used by BLOCKAGE to evaluate potential loss of NPSH. After completing the analysis, BLOCKAGE output includes: target volume data; suppression pool and strainer blockage data for each weld; overall plant summary and loss of NPSH frequency reports; and formatted timedependent and plant summary output, which were plotted using commercially available graphics software.

\subsection{Assumptions and Limitations in the Overall Methodology}

In general, the overall methodology used in this study addresses the most significant phenomena involved in the evaluation of potential BWR ECCS strainer blockage due to LOCA generated debris. There are, however, some assumptions and limitations that prevent the unconditional extrapolation of the findings and results derived from this study. The following subsections summarize the assumptions and limitations associated with the selection of a reference plant and the use of point-value estimates for the overall results; the assumptions and limitations specific to the models proposed to simulate ECCS strainer blockage are discussed in the corresponding sections.

\subsubsection{Selection of a Reference BWR}

A BWR/4 Mark I containment nuclear power plant was selected as the reference plant for analysis in this study. In particular, this plant has a relatively small suppression pool and large strainer approach velocities, in comparison to plants with Mark II and Mark III containments, has recirculation pipes made of Type 304 stainless steel, which have been found to be susceptible to IGSCC, a phenomenon that appears to be a dominant mechanism in the postulated breaks, and the vast majority of the primary piping in this reference plant is insulated with fibrous insulation, which results in large amounts of calculated fibrous debris that may be generated during a LOCA. Therefore, these findings and results should not be unconditionally applied to all BWRs.

\subsubsection{Use of Point-Value Estimates}

Results from this study include: estimation of pipe break frequencies, estimation of the amounts of debris generated and transported from the drywell to the suppression pool, estimation of the amounts of debris reaching the strainer, estimation of head loss, and estimation of the corresponding time to lose the ECCS pumps. The results presented are point-value estimates and no uncertainty analyses were performed as part of this study. ${ }^{4}$ As a result, caution must be used in drawing insights related to probabilistic implications of the present study.

\footnotetext{
${ }^{4}$ Note that several sensitivity analyses were conducted to quantify the impacts of varying several key parameters on the results.
} 


\section{References for Section 2.0}

2.1 A. W. Serkiz, "USI A-43 Regulatory Analysis," U.S. Nuclear Regulatory Commission, NUREG-0869, Rev. 1, October 1985.

2.2 A. W. Serkiz, "Containment Emergency Sump Performance," U.S. Nuclear Regulatory Commission, NUREG-0897, Rev. 1, October 1985.

2.3 J. Wysocki and R. Kolbe, "Methodology for Evaluation of Insulation Debris Effects," Burns and Roe, Inc., published as Sandia National Laboratories Report No. SAND82-7067, NUREG/CR-2791, September 1982.

2.4 J. J. Wysocki, "Probabilistic Assessment of Recirculation Sump Blockage Due to Loss of Coolant Accidents: Containment Emergency Sump Performance USI A-43," Vols. 1 and 2, NUREG/CR-3394, July 1983.

2.5 G. S. Holman and C. K. Chou, "Probability of Failure in BWR Reactor Coolant Piping," published as Lawrence Livermore National Laboratory Report UCID-20914,

NUREG/CR-4792, March 1989.

2.6 BWROG, "Interim Report of the BWROG ECCS Suction Strainer Committee," BWROG94157, December 1994.

2.7 Memorandum from M. Marshall to A. Serkiz, Subject: Presentation Slides Used During the May 4, 1994 Meeting, Dated July 20, 1994.
2.8 U.S. NRC, "Safety Evaluation Report: Mark I Containment Long Term Program," NUREG-0661, July 1980.

2.9 Memorandum from M. Marshall to C. Serpan, Subject: Summary of March 30, 1994 Public Meeting Concerning the SEA Study Results Related to the Potential for Loss of LPCI Capability in BWRs Due to LOCA Generated Debris, Dated: April 11, 1994.

2.10 D. N. Brocard, "Buoyancy, Transport, and Head Loss of Fibrous Reactor Insulation," Alden Research Laboratory, published as Sandia National Laboratories report No. SAND82-7205, Rev. 1, NUREG/CR-2982, Rev. 1, July 1983.

2.11 J. Hyvärinen and O. Hongisto, "Metallic Insulation Transport and Strainer Clogging Tests," DLV1-G380-383, Finnish Centre for Radiation and Nuclear Safety (STUK), July 1994.

2.12 U.S. NRC, "Net Positive Suction Head for Emergency Core Cooling and Containment Heat Removal System Pumps," Regulatory Guide 1.1, November 1970. 



\subsection{Debris Generation in the Reference Plant}

The reference plant selected for this study is a BWR/4 with a Mark I containment. Figure 1-1 listed the important considerations for estimation of the quantity and type of debris generated by a postulated break. This chapter provides details on how these debris generation considerations were addressed for the reference plant.

\subsection{Potential Pipe Break Locations}

Based on probability considerations, the weld locations in the primary piping segments that lie in the drywell ${ }^{1}$ were assumed to be potential piping failure points and were analyzed in detail to estimate quantities of LOCA generated debris. Figure 3-1 is a pictorial description of the primary systems layout in the reference plant. A total of 262 circumferential weld locations were identified for pipes equal to or larger than 6 " in diameter. The breaks with diameter $\geq 6$ " are defined as LLOCAs. Another 26 welds were identified for breaks larger than 2 " but smaller than 6". These breaks are classified as MLOCAs. In addition, a total of 57 weld locations were identified for pipes smaller than or equal to $2^{\prime \prime}$ in diameter. These last breaks are classified as small breaks. Both LLOCA and MLOCA would require ECCS flow for short-term and long-term decay heat removal.

Following the small breaks, however, the reactor vessel remains pressurized for a sufficiently long time to provide make-up flow by a combination of HPCI and RCIC. Thus, low pressure core cooling systems are not needed for short-term decay heat removal. However, the RHR systems may be needed for containment pressure and temperature control in the reference plant. As a result, this study analyzed all the breaks starting from a diameter of $1 "$ to $22 "$, although the small break LOCAs were not included in core damage estimates provided in Section 8 .

The assumption was made that any of these circumferential weld locations represented a potential pressure boundary failure (referred to as a break location). The majority of break locations are

\footnotetext{
${ }^{1}$ Breaks outside the drywell can not transport debris to the suppression pool. Therefore, they are excluded from further consideration. Such exclusion is not appropriate for BWRs with Mark III containment.
}

in the recirculation, feedwater and MSLs. The source for the number and location of the welds in each primary pipe was a set of Inservice Inspection, ASME Section XI isometric drawings provided by reference plant personnel. These drawings were cross-referenced with plant-specific P\&IDs and NUKON ${ }^{\mathrm{TM}}$ Blanket Insulation installation drawings to determine weld orientation and location in the drywell. Several tables of data were examined to determine other relevant information such as pipe type and composition, and the type, class, and characteristics of the weld.

\subsubsection{Recirculation Loops A and B}

Recirculation loops A and B are very similar and the discussions presented below are applicable to both loops. Figure 3-2 is an isometric drawing of recirculation loop $A$, reproduced from a set of isometric drawings. Figure $3-3$ is a schematic representation of the circumferential welds in the recirculation loop mapped onto the P\&ID of recirculation loop $A$; however, it may not include some of the T-welds used to connect smaller diameter instrumentation and pressure equalizer penetrations, or 2" $(5 \mathrm{~cm})$ drain or 4 " $(10 \mathrm{~cm})$ bypass lines. The drain line itself is not relevant since manual valve V16-30 (see Figure 3-2) is closed during normal operation. The 4 " $(10 \mathrm{~cm})$ bypass line is used during start up as part of the IHSI program. Motor-operated valve MO-4629 is open during normal operation. Although the bypass loop is not shown in Figure 3-3, all welds in this loop were included in this analysis. The vessel weld RCA-D001 and vessel nozzle weld RCA-F002 were not modeled in this analysis. These welds are a special type and their failure frequency may be substantially different from other welds. A complete listing of the welds in recirculation loops $A$ and $B$ is presented in Table D-1 in Appendix D.

\subsubsection{Feedwater Loops A, B and C, D}

Feedwater enters the drywell through two 16" $(40.6 \mathrm{~cm})$ carbon steel lines at elevation mark $766^{\prime}$. Flow from each $16^{\prime \prime}(40.6 \mathrm{~cm})$ pipe is split into two $10^{\prime \prime}(25.4 \mathrm{~cm})$ lines at elevation mark 783'-3".

Feedwater enters the vessel at an elevation of approximately $811 "-6 "$. Due to minor differences in pipe routing, the feedwater loops differ from each other in number and orientation of welds. 



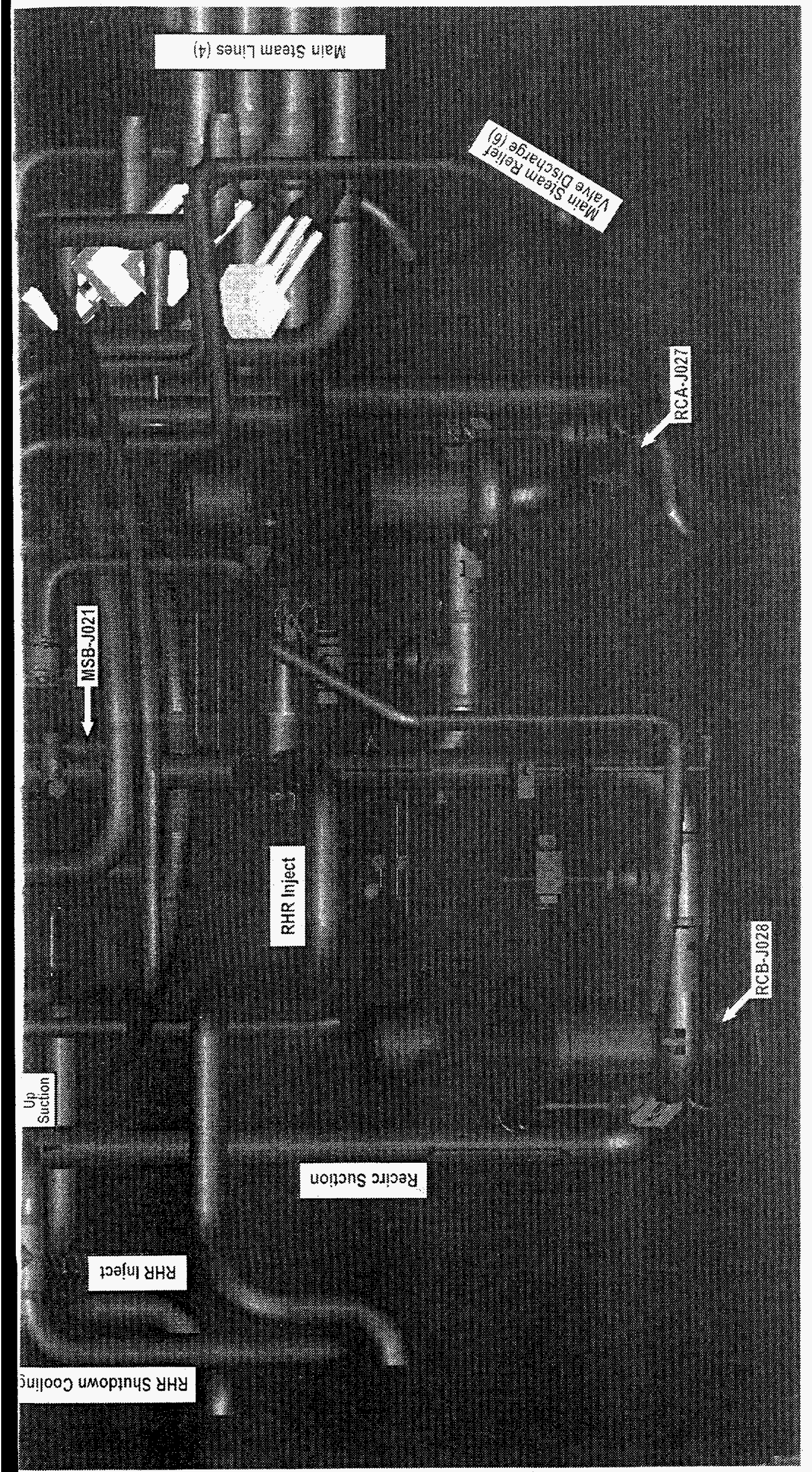





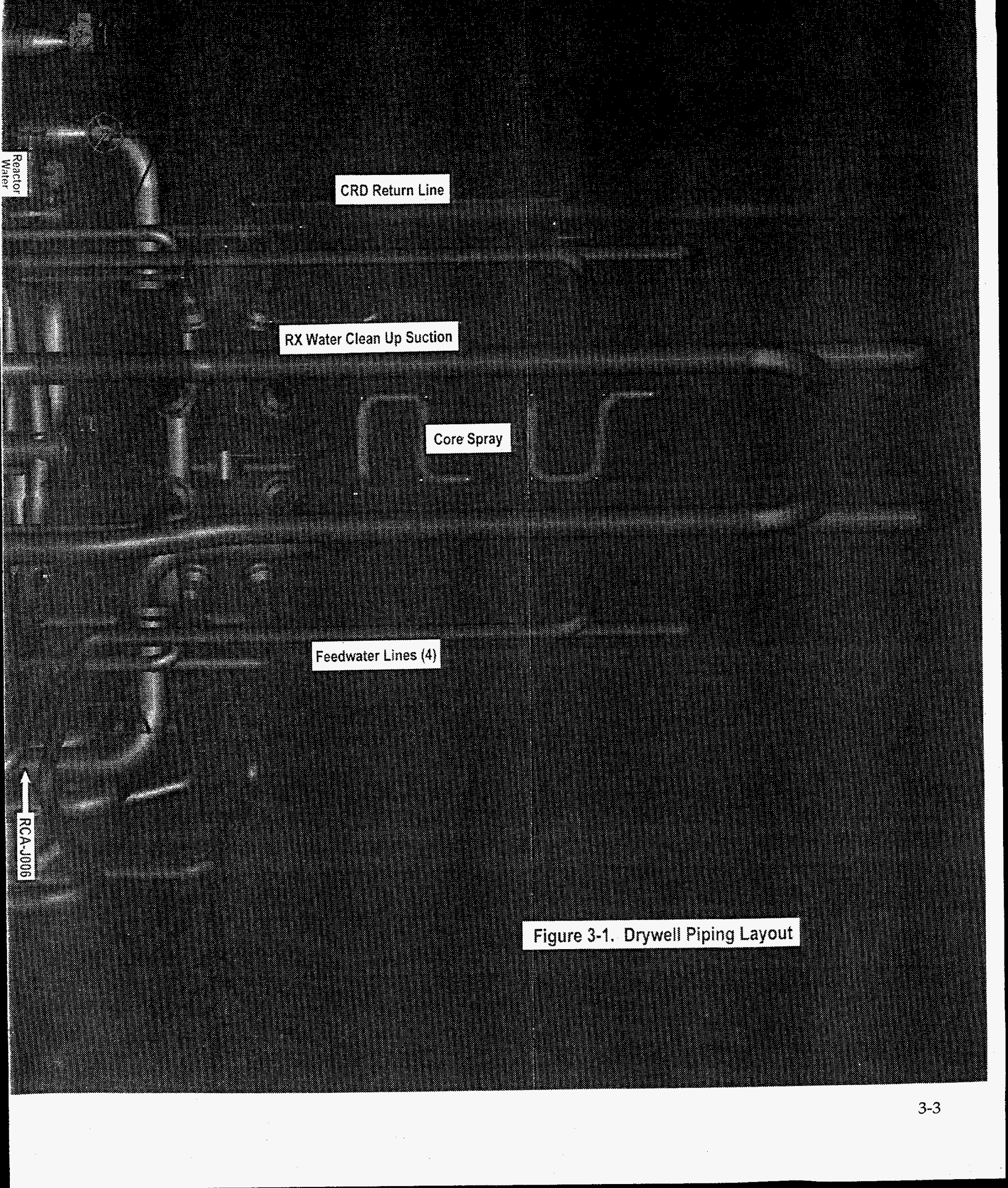


Debris Generation
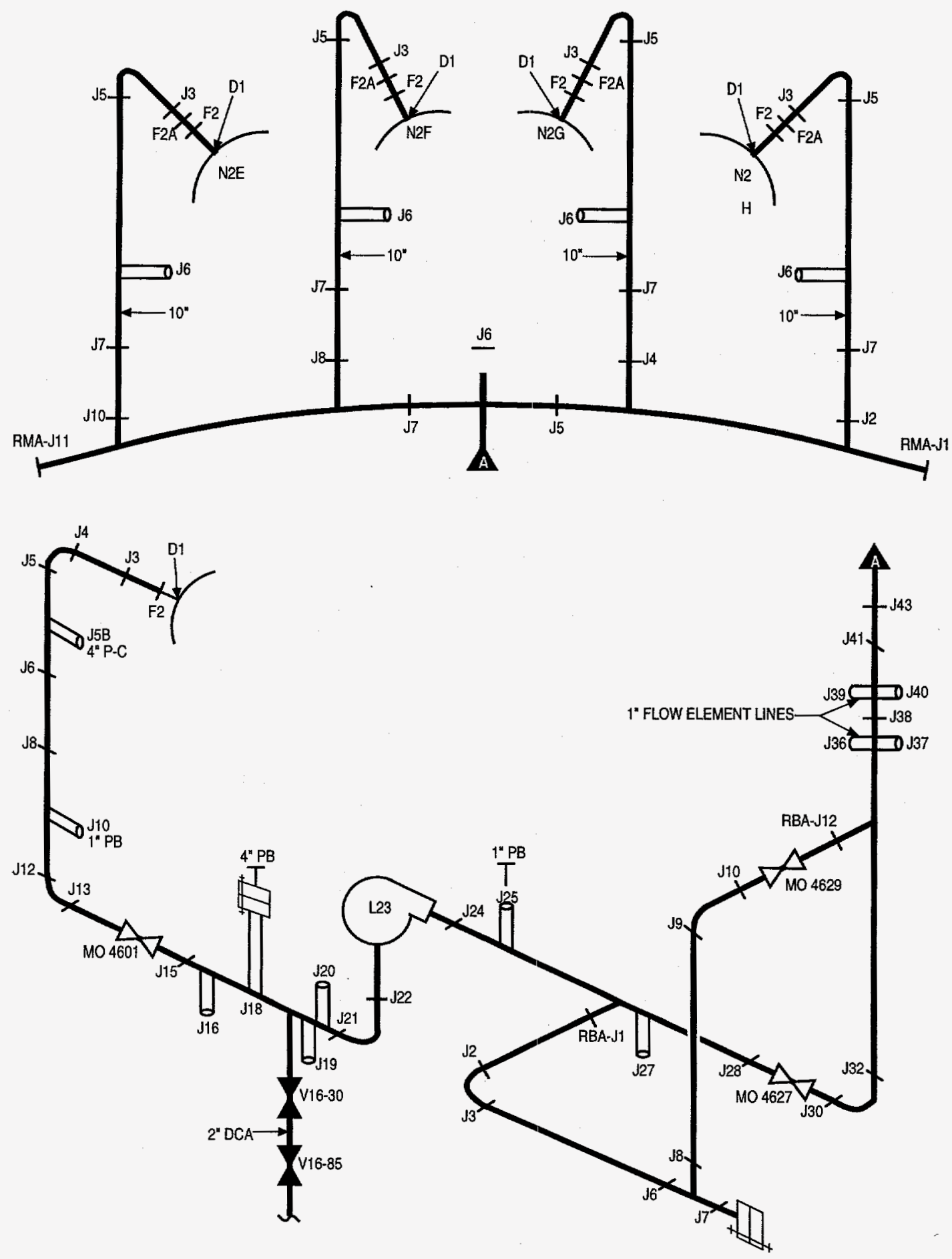

Figure 3-2 Isometric Drawing of Recirculation Loop A, Including Manifold \& Risers E, F, G, H 


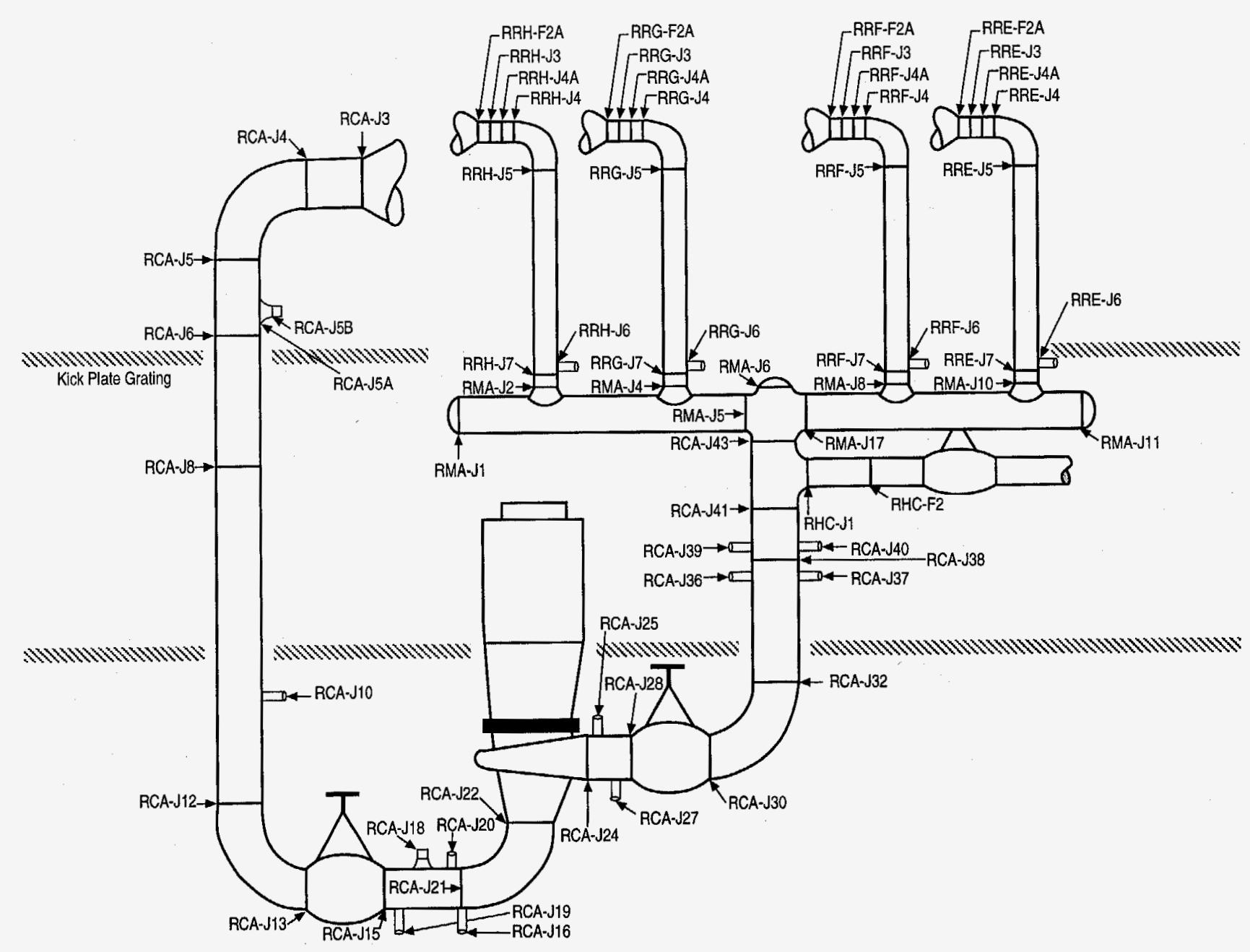

Figure 3-3 Weld Locations in Recirculation Loop A 
Figure 3-4 is the isometric drawing for feedwater loops A and B. Figure 3-5 maps these welds on to the P\&IDs for these loops. Similarly, Figure 3-6 is an isometric drawing of feedwater loops $C$ and $D$. The only welds on these loops screened out from this analysis were vessel welds FWA-D001, FWB-D001, FWC-D001, and FWD-D001, for the same reasons described above for welds RCA-D001 and RCA-F002. The remainder of the welds, together with their locations and types, are listed in Table D-1 in Appendix D.

\subsubsection{Main Steam Lines A, B, C and D}

The reference plant has four MSLs, each slightly different from the other due to drywell arrangement. Figures 3-7 and 3-8 present the MSL arrangement in the drywell. Figures 3-9 through 3-12 are the isometric drawings of the steam lines. Figure 3-13 depicts all welds mapped onto the P\&ID of MSL A. Welds screened out in those lines were vessel and nozzle welds (D001 \& J002, respectively). A complete listing of the welds in MSL A, B, C and $D$ is presented in Table D-1 in Appendix D.

\subsubsection{Additional Primary Piping Welds}

Additional welds were identified in the pressurized portions (upstream of isolation valves during normal operation) of the HPCI, RHR, and LPCS systems. A description of the weld locations in these piping systems is provided below, and a listing of the welds in these systems is provided in Table D-1 in Appendix D.

1. HPCI Lines: The HPCI system is designed to flood the core using one of the feedwater lines. The system is actuated on low reactor water level signal. Commencing operation in 30 seconds, the system takes suction from the CST and injects into Feedwater Loop A. During operation, steam is drawn from the MSL Loop B through a 10" $(25.4 \mathrm{~cm})$ line $\left(10^{\prime \prime}\right.$ or $25.4 \mathrm{~cm}$ $-D B A-B)$ for the turbine driven pump. Initially, it was believed that MO-2238 was closed during normal operation, limiting the segment of HPCI exposed to a high pressure condition to that segment located upstream of MO-2238. It was determined that this segment is $3 \mathrm{ft}(0.91 \mathrm{~m})$ in length and has three circumferential welds (J1, $\mathrm{J} 4$, and J6) and three T-welds (J2, J3, and J5). These welds were modeled and potential targets in the vicinity of them were included. In fact, MO-2238 is open during normal operation and the entire length of HPCI line in the drywell is pressurized. The additional six welds were not included as the limited quantity of debris from such a small number of welds will not significantly alter the results.

2. RHR Injection Lines: The RHR system is designed to provide adequate coolant injection to the core for a LLOCA. This system receives an actuation signal on low reactor water level or high drywell pressure and injects into the core through the recirculation lines; this would occur approximately 30-50 seconds into an accident. During normal operation, the RHR piping is not pressurized and is isolated from the recirculation piping by check valves V19-0148, V20-0082, and MO-1908. The total length of RHR injection lines subjected to high pressure during normal operation would be approximately $15 \mathrm{ft}(4.57 \mathrm{~m}$ ) (i.e., loops B, C, and $\mathrm{D}$ together); the total number of welds subjected to high pressure would be 16 . These 16 welds were modeled.

3. Core Spray Lines: LPCS system piping (Loops A and B) enters the drywell at elevation $800^{\circ}$ $(243.8 \mathrm{~m})$ and injects directly into the core at approximately $811^{\prime}-6$ " (247.3 m). During normal operation, the LPCS is isolated from the core by two check valves. The total length of high pressure piping per loop downstream of the motor-operated valves is less than $2 \mathrm{ft}(0.61 \mathrm{~m})$, and it has one circumferential weld and one $1 "$ $(2.5 \mathrm{~cm})$ T-weld. These two welds were not modeled because they are located at a high elevation for which the required P\&ID drawings were not available. Also, no additional targets were found to be in the vicinity of these welds.

\subsection{Primary Pipe Break Frequencies}

Primary pipe break frequency estimates were needed in the present study to estimate the overall frequency for loss of ECCS due to loss of NPSH margin. Appendix A presents discussion on the analyses performed, the underlying assumptions, their limitations and their applicability to the reference plant. Based on these analyses, Appendix A provided the per-weld break frequency data for 
Debris Generation

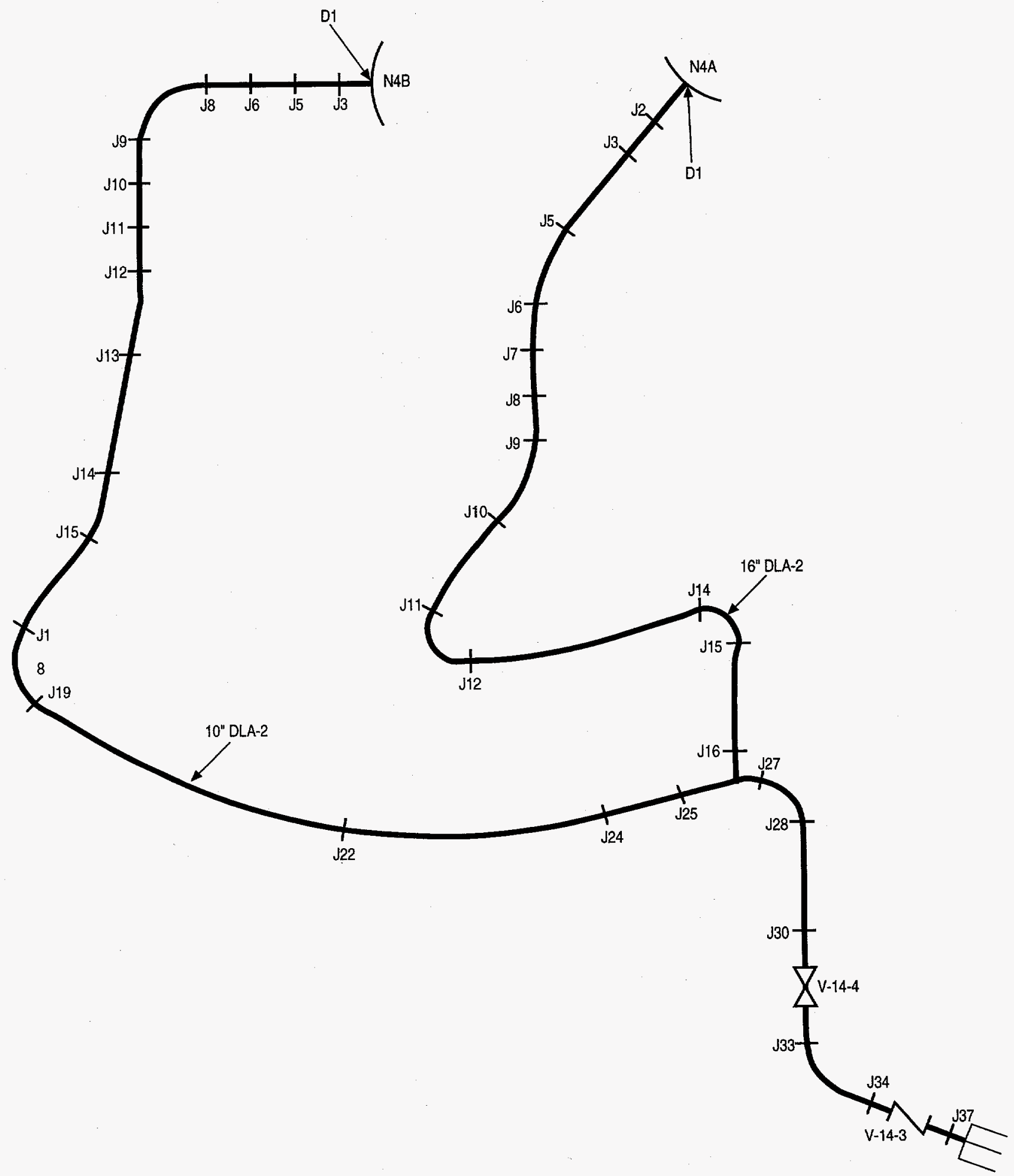

Figure 3-4 Isometric Drawing of Welds in Feedwater Loops A \& B 
Debris Generation

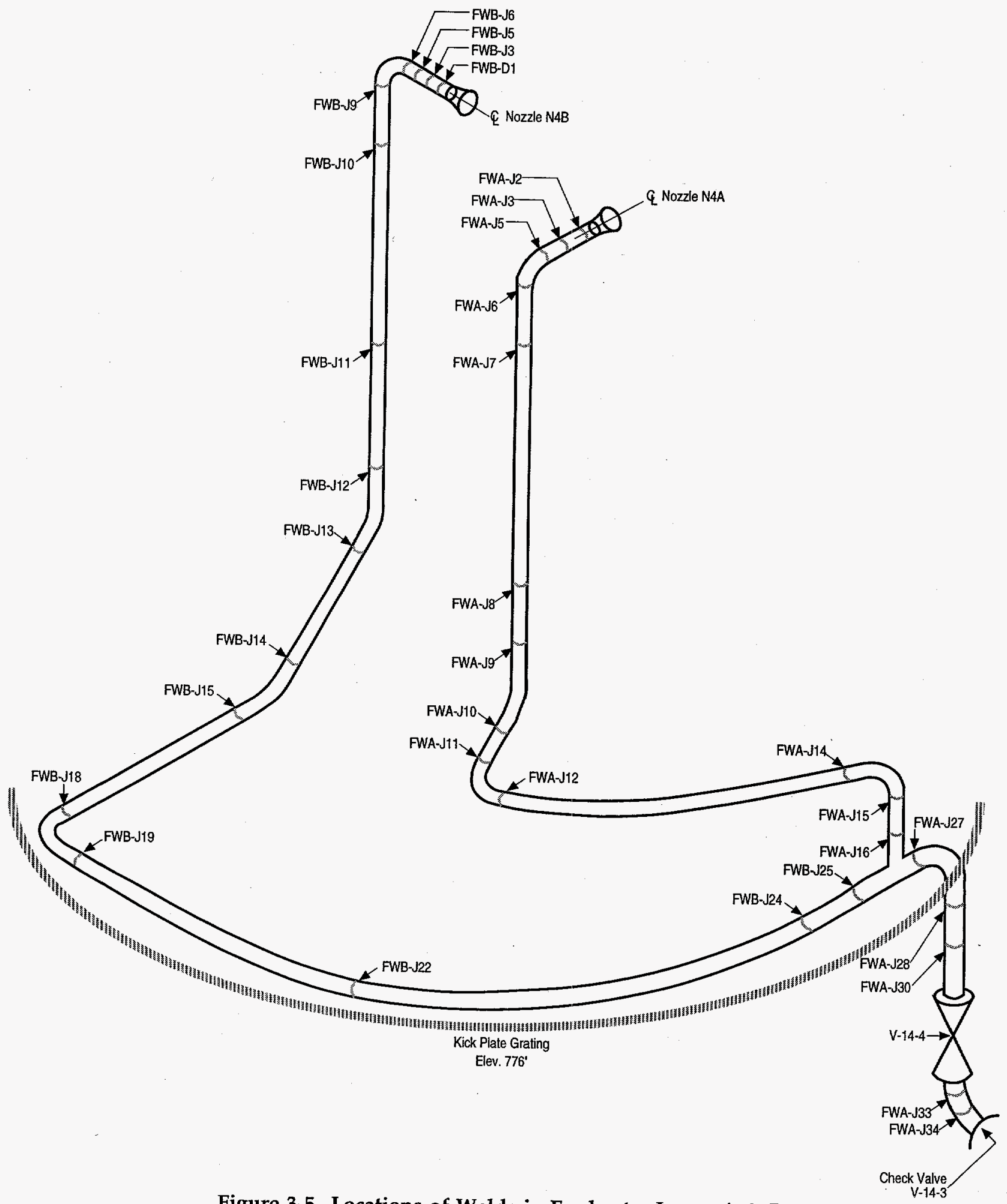

Figure 3-5 Locations of Welds in Feedwater Loops A \& B 
Debris Generation

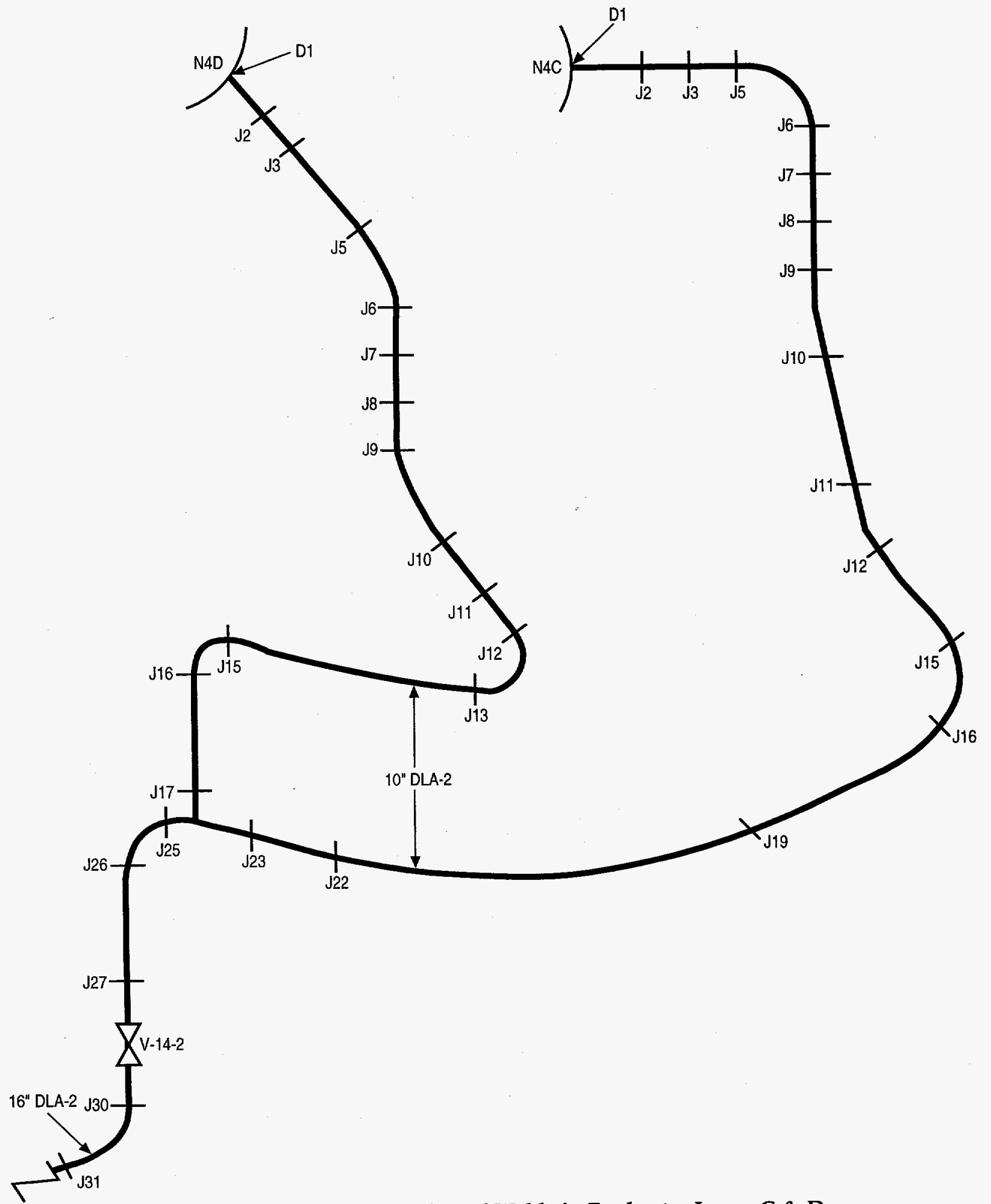

Figure 3-6 Isometric Drawing of Welds in Feedwater Loops C \& D 
Debris Generation

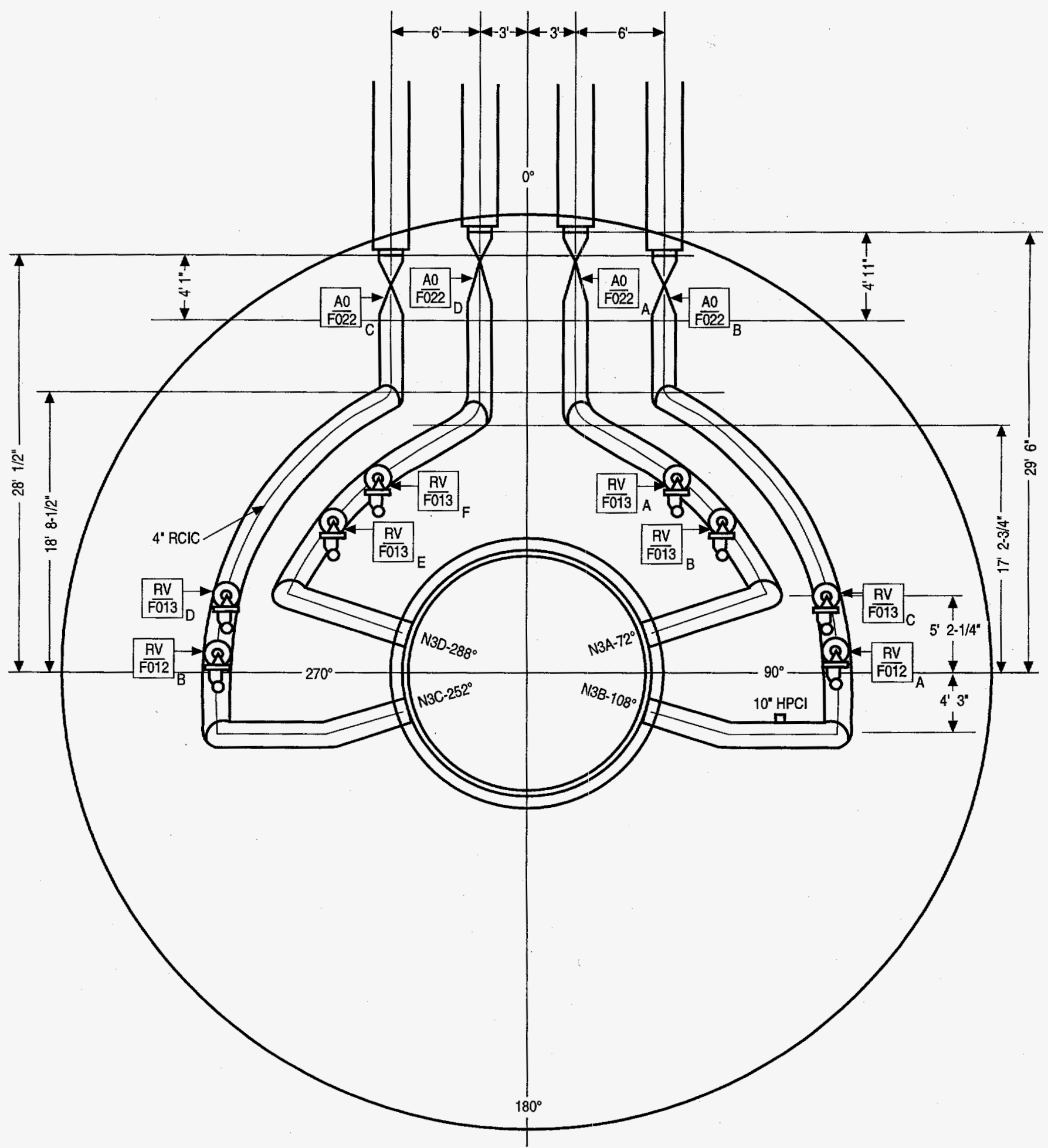

Figure 3-7 Planview of Main Steam Line Arrangement in Drywell 
Debris Generation

\section{Debris Generation}

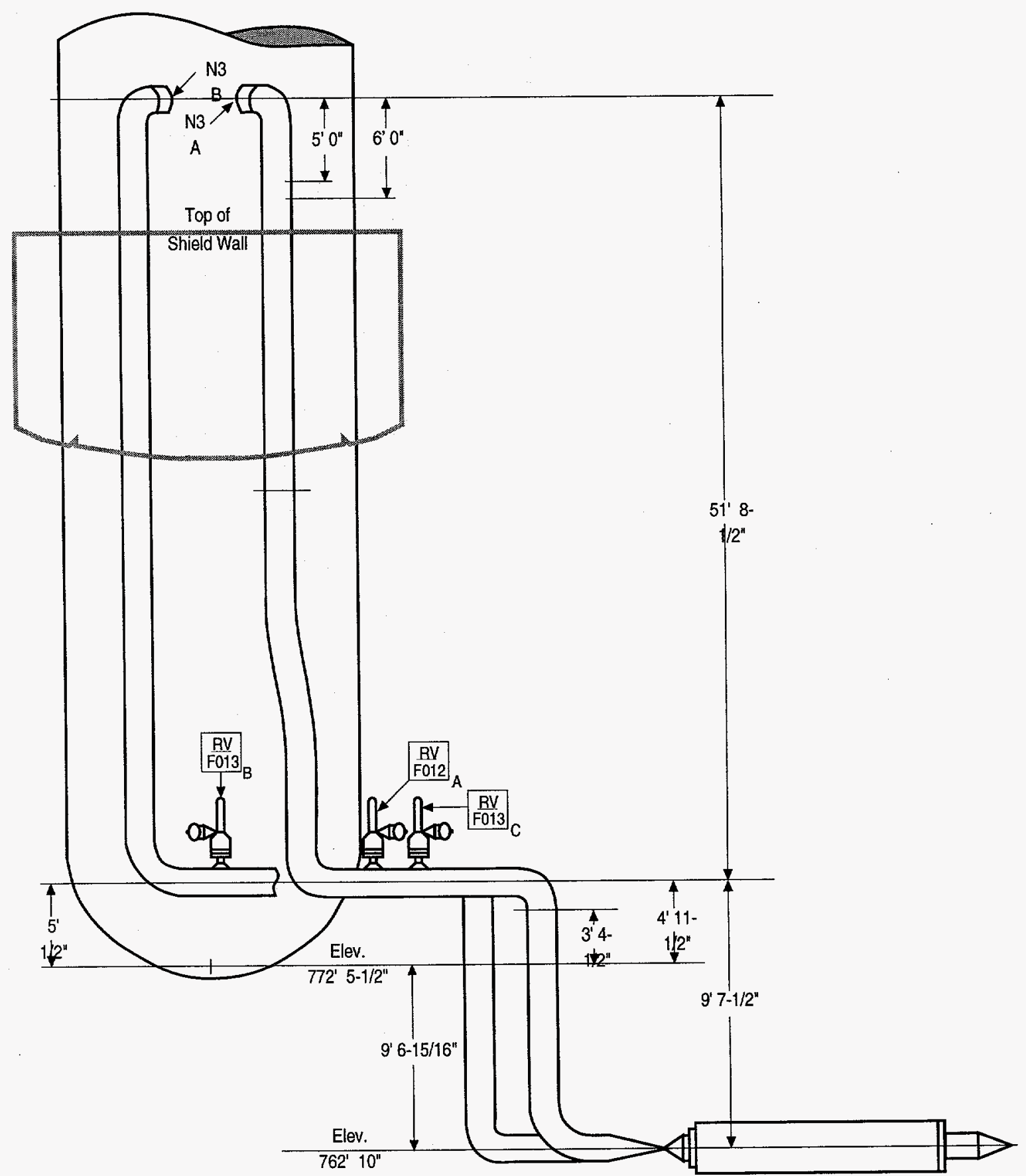

Figure 3-8 Vertical Cross-Section of Main Steam Line Arrangement in Drywell 


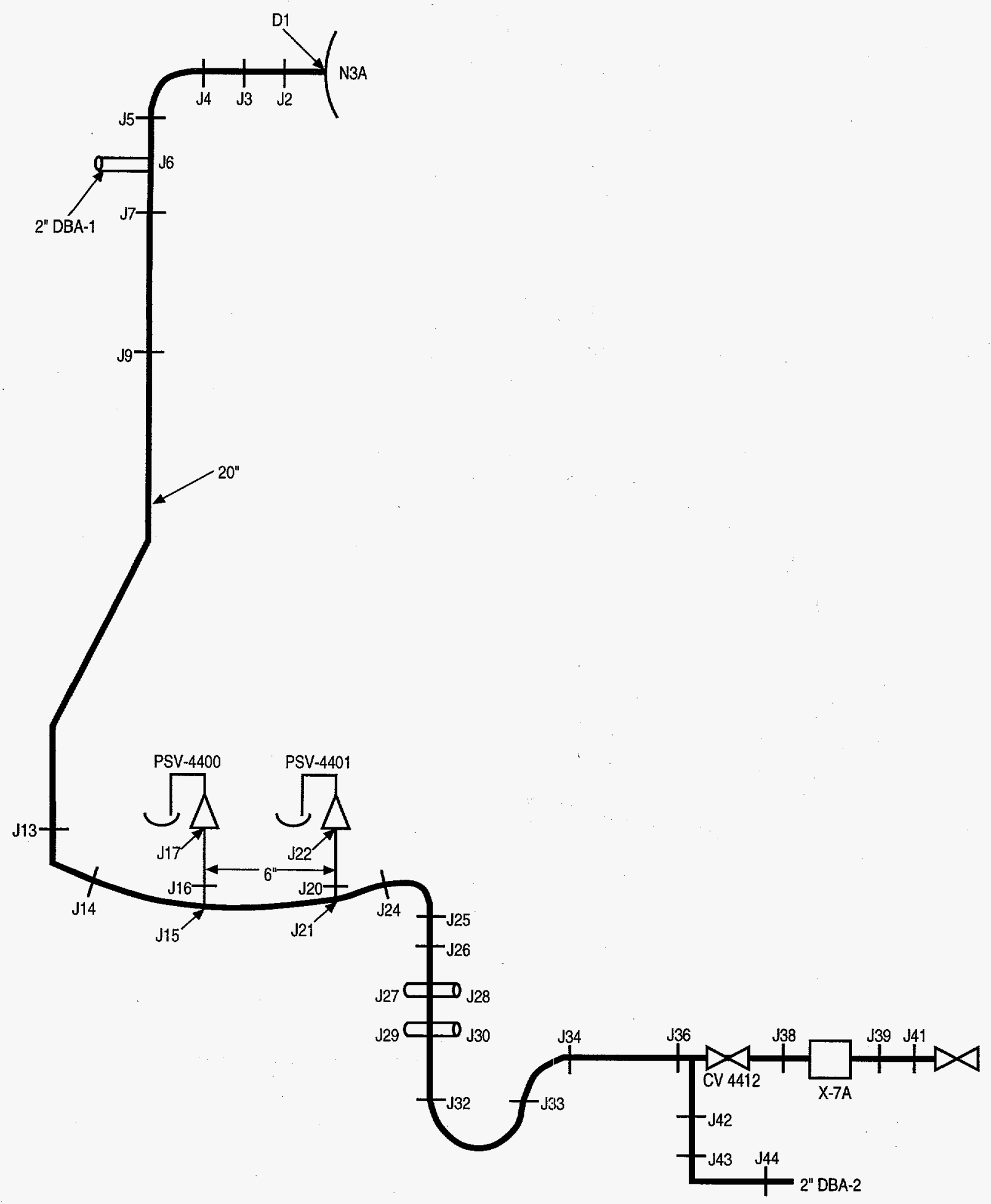

Figure 3-9 Isometric Drawing of Main Steam Line A 
Debris Generation

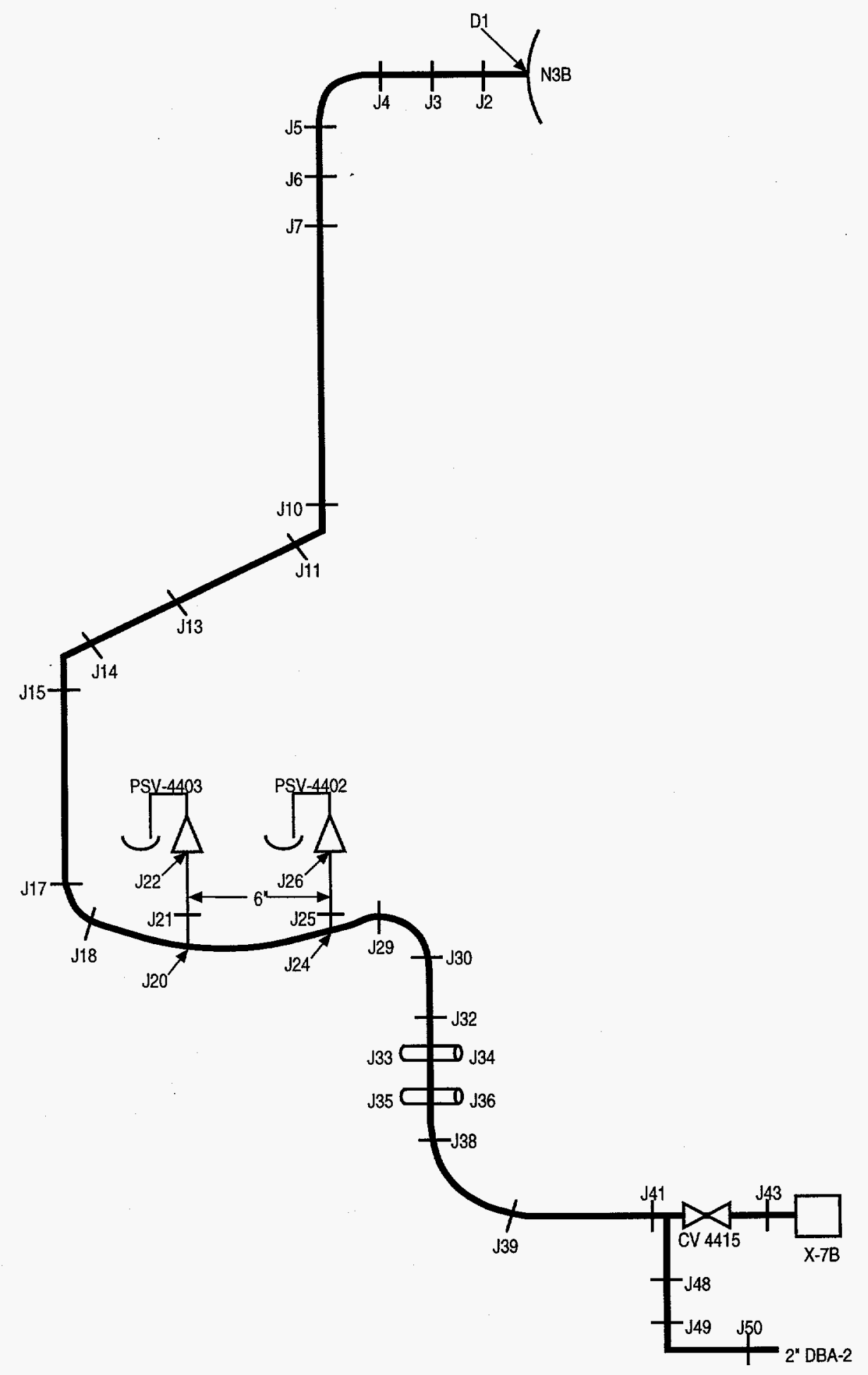

Figure 3-10 Isometric Drawing of Main Steam Line B 


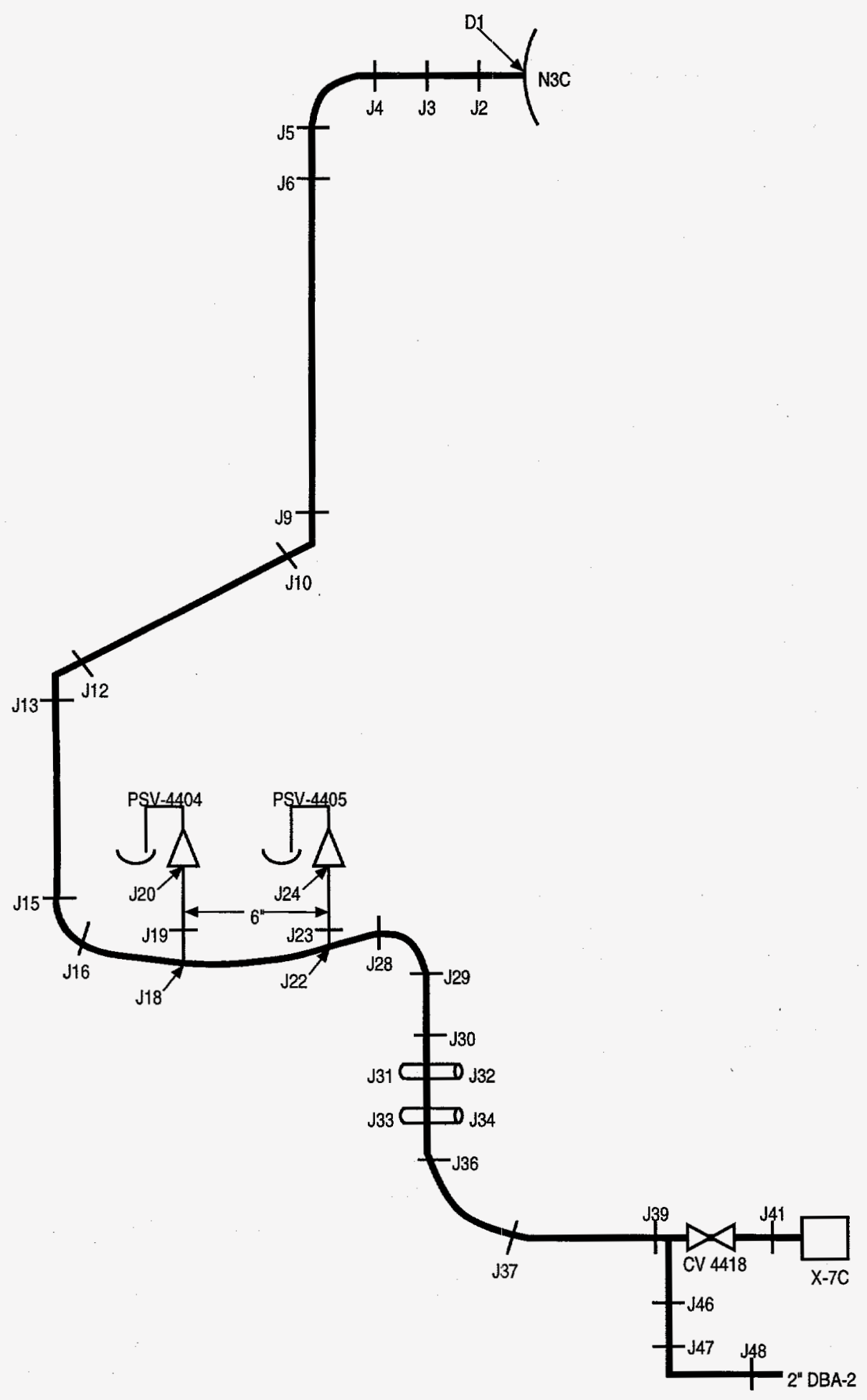

Figure 3-11. Isometric Drawing of Main Steam Line C 


\section{Debris Generation}

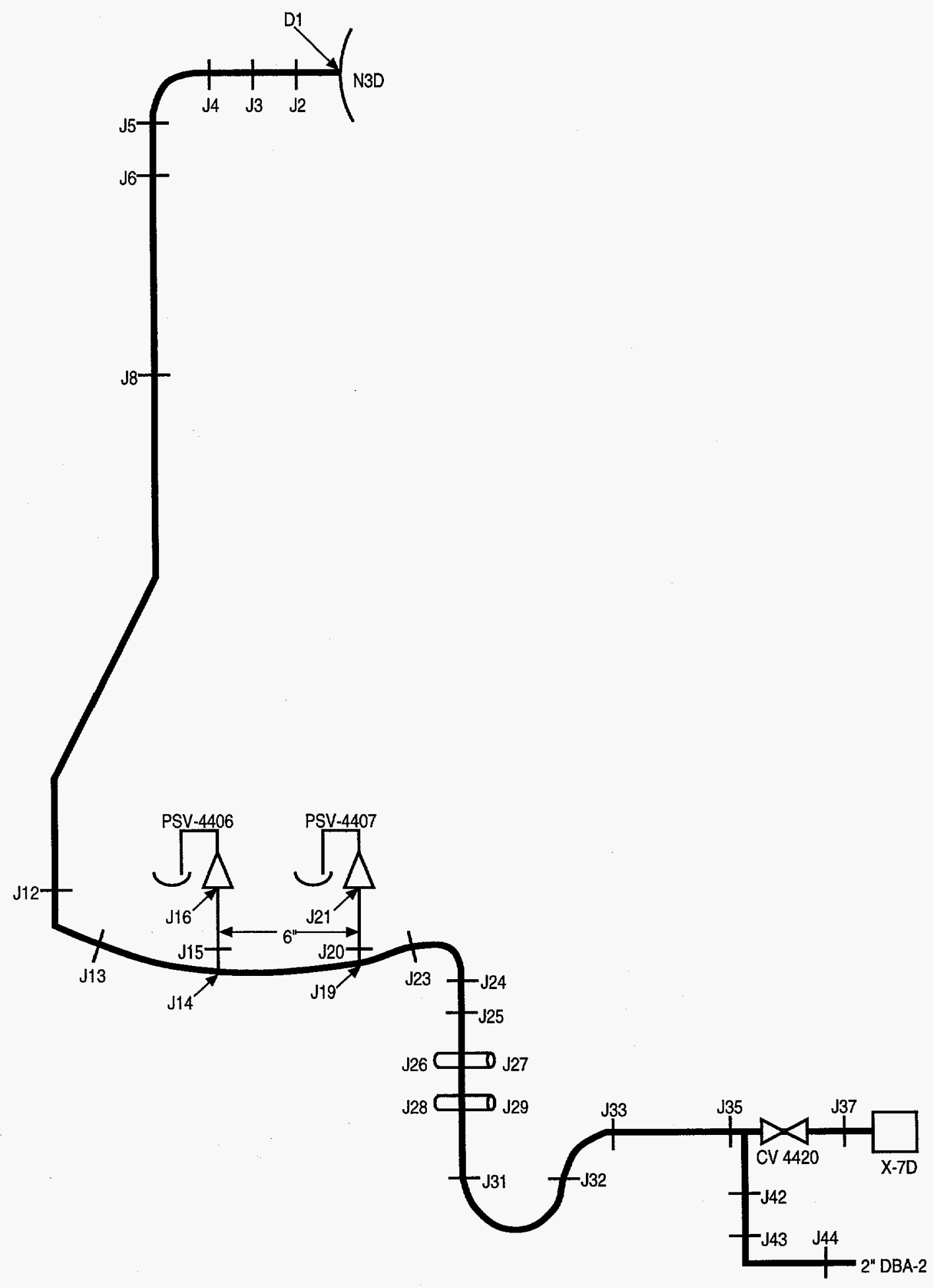

Figure 3-12 Isometric Drawing of Main Steam Line D 
Debris Generation

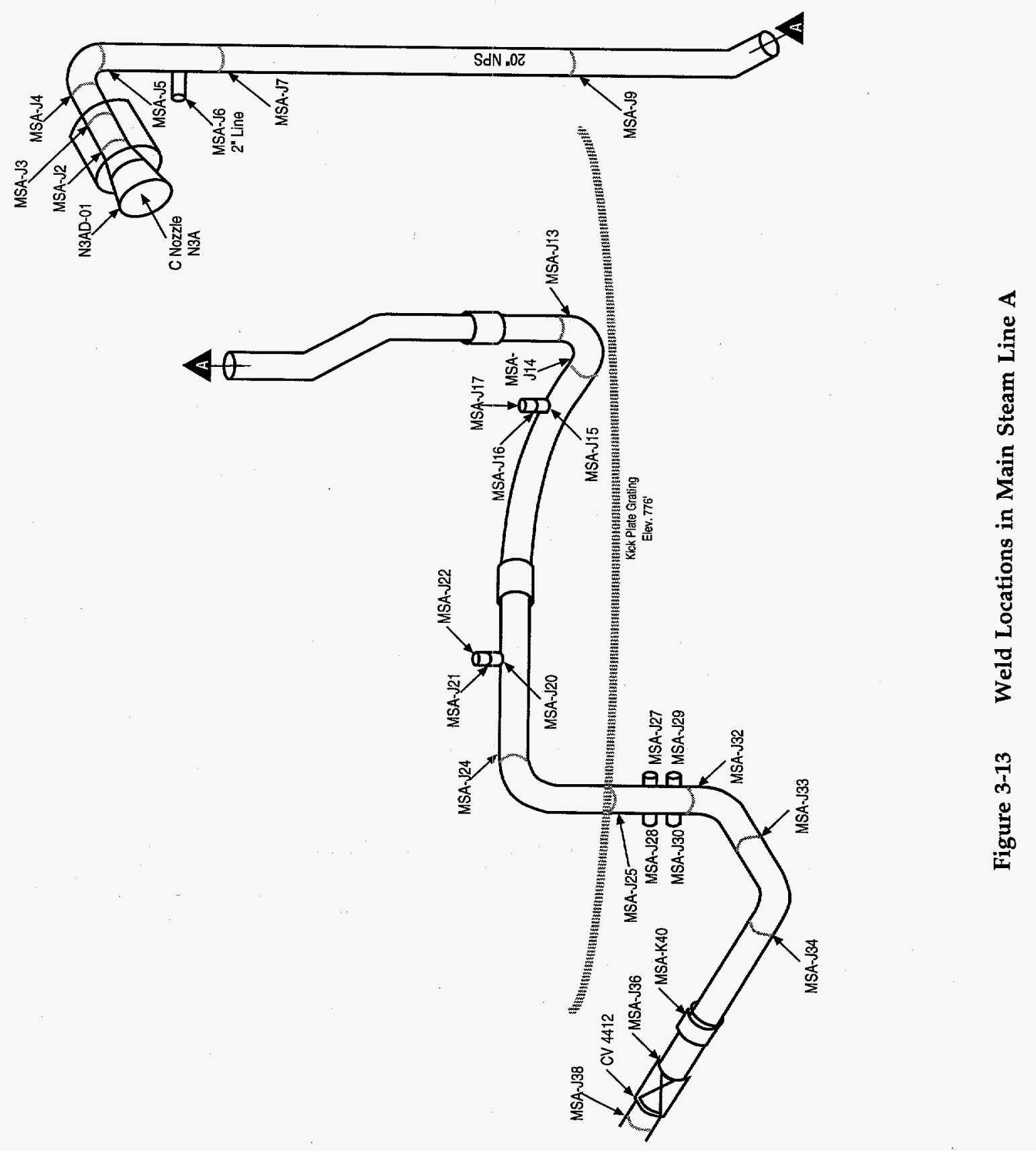


the reference plant. This section describes how these data were used to obtain the pipe break frequency estimates for the reference plant.

\subsubsection{Recommended Weld Break Frequency Data for the Reference Plant}

By using LLNL IGSCC data for the DEGB category and the assumptions discussed above [Ref. 3.1], estimates for weld break frequencies were generated. Table 3-1 presents recommended weld break point-estimate frequencies. The data in Table 3-1 were generated by applying the in-service inspection reduction factor of 10 to the LLNL IGSCC DEGB data, based on Reference 3.2 and as discussed in Appendix A. The data in Table 3-1 were applied to specific categories of reference plant piping as shown in Table 3-2.

It is important to recognize that there are large uncertainties associated with recommended point-value frequency estimates. Because an uncertainty analysis has not been performed, it is not possible to further interpret the statistical significance of the point-value estimates given in Tables 3-1 or 3-2.

\subsubsection{Pipe Break Frequency Estimates for the Reference Plant Piping}

The per-weld break frequencies given in Table 3-2 were used to calculate pipe break frequencies. The overall pipe break frequency was subsequently obtained by simply summing the break frequencies of all welds included in the analysis. Also, summations were made of all individual weld break frequencies in three separate categories, specifically:

$$
\begin{aligned}
& \text { - } \quad \text { Pipe system } \\
& \text { - } \quad \text { Pipe diameter } \\
& \text { - } \quad \text { Pipe location. }
\end{aligned}
$$

For example, the break frequency $F_{s}$ of a given pipe system was calculated to be:

$$
\boldsymbol{F}_{s}=\sum_{i=1}^{n} f_{i}^{s}
$$

where,

$$
\begin{aligned}
& f_{i}^{s} \text { represents the frequency of the } i^{\text {th }} \text { weld in } \\
& \text { the selected system category } s \text {, and } n \text { is } \\
& \text { the total number of welds in that system. }
\end{aligned}
$$

The break frequency $\boldsymbol{F}_{d}$ of a given diameter piping was calculated to be:

$$
\boldsymbol{F}_{\boldsymbol{d}}=\sum_{i=1}^{n} f_{i}^{d},
$$

where,

$f_{i}^{d} \quad$ represents the frequency of the $\mathrm{i}^{\text {th }}$ weld in the selected pipe diameter category $\mathrm{d}$, and $\mathrm{n}$ is the total number of welds.

Table 3-1 Recommended Weld DEGB Frequency Estimates

\begin{tabular}{lc}
\hline Pipe Category & Per-weld DEGB Frequency (1/Rx-yr) \\
\hline $4 "(10.2 \mathrm{~cm})$ Recirculation (304SS) & $1 \mathrm{E}-06^{1}$ \\
$12 "(30.5 \mathrm{~cm})$ Recirculation (304SS) & $2 \mathrm{E}-06^{1}$ \\
$22-28^{\prime \prime}(55.9-71.1 \mathrm{~cm})$ Recirculation (304SS) & $2 \mathrm{E}-07^{1}$ \\
Main Steam ${ }^{2}$ & $2 \mathrm{E}-07$ \\
Feedwater & $2 \mathrm{E}-07$ \\
$\mathrm{HPCI}^{2}$ & $2 \mathrm{E}-07$ \\
$\mathrm{RHR}^{2}$ & $2 \mathrm{E}-07$ \\
\hline Notes: & \\
${ }^{1}$ Derived by reducing LLNL data by a factor of 10 to account for in-service inspection. \\
${ }^{2}$ Main steam, feedwater, HPCI, and RHR welds assumed to have same failure frequency as 22-28" recirculation system welds.
\end{tabular}


Table 3-2 Weld DEGB Frequency Data for Reference BWR

\begin{tabular}{lc}
\hline Pipe Category & Per-weld DEGB Frequency (1/Rx-yr) \\
\hline $1 "-10^{\prime \prime}(2.5-25.4 \mathrm{~cm})$ Recirculation & $1 \mathrm{E}-06$ \\
$16^{\prime \prime}(40.6 \mathrm{~cm})$ Recirculation & $2 \mathrm{E}-06$ \\
$22 "(55.9 \mathrm{~cm})$ Recirculation & $2 \mathrm{E}-07$ \\
All Main Steam & $2 \mathrm{E}-07$ \\
All Feedwater & $2 \mathrm{E}-07$ \\
All HPCI & $2 \mathrm{E}-07$ \\
All RHR & $2 \mathrm{E}-07$ \\
\hline
\end{tabular}

Finally, the break frequency $F_{L}$ of co-located piping was calculated to be:

$$
\boldsymbol{F}_{L}=\sum_{i=1}^{n} f_{i}^{L},
$$

where,

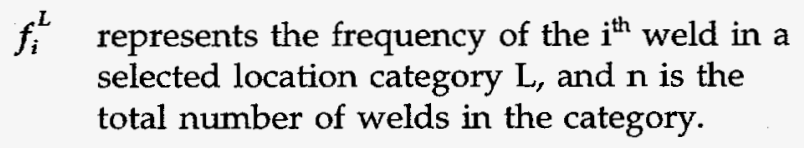

Tables 3-3, 3-4, and 3-5 summarize the calculations of pipe break frequencies for the reference BWR Mark I plant analyzed based on piping system, pipe diameter, and pipe location, respectively. These calculations are automatically performed by BLOCKAGE using data presented in Table 3-2 and in Table D-1.

Table 3-6 explicitly shows how the LLOCA frequency was calculated. A LLOCA $(\geq 6$ " or $15.2 \mathrm{~cm}$ diameter pipe break) of this type was selected as the initiating event for $\mathrm{CDF}$ calculations because DEGB events involving smaller pipes are less likely to cause loss of ECCS NPSH. In addition, some portion of smaller break sizes could be mitigated by the HPCI or RCIC systems, both of which take their initial supplies of water from the CST. During the time one of these systems is being used, the potential for strainer blockage would be reduced by pump suction from the CST. Once CST levels have dropped sufficiently to require switch over to the suppression pool, reactor decay heat levels would be substantially reduced. If loss of
NPSH occurs following switch over, the reduced decay heat levels would allow operators additional time for implementing corrective actions.

\subsubsection{Comparisons of Recommended Data With Other Data Sources}

The recommended reference plant LLOCA data were compared with LLOCA data given in several BWR 4/Mark I risk assessment studies. This comparison is displayed in Table 3-7. The point-estimate value for the reference plant LLOCA frequency, 1.0E-04/yr, was extracted from Table 3-6 and represents a summation of DEGB frequency estimates over all welds $\geq 6$ " $(15.2 \mathrm{~cm})$ located in the drywell of the reference plant in this study. The pipe break frequencies for the other plants were for the entire primary piping segment that includes piping located inside and outside the drywell.

\subsection{Insulation Types, Amount and Location}

The NUKON ${ }^{\mathrm{TM}}$ Blanket Insulation Installation Drawings were used to determine type and thickness of insulation on each primary pipe located in the drywell. The P\&ID drawings of the reference plant were used to identify locations of each of the insulated pipes and equipment, especially those insulated by NUKON ${ }^{\mathrm{TM}}$ blankets. In the reference plant, the primary lines in the containment are insulated by steel-jacketed NUKONTM. The RCIC, RWCU, and recirculation drain lines are insulated with calcium silicate material. In addition, 
Debris Generation

Table 3-3 Pipe Break Frequency Estimates Categorized by System for the Reference BWR Plant

\begin{tabular}{|c|c|c|c|c|}
\hline \multirow{2}{*}{$\begin{array}{l}\text { Pipe Diameter } \\
\text { inches }(\mathrm{cm})\end{array}$} & \multirow{2}{*}{$\begin{array}{l}\text { Total No. of } \\
\text { Welds }\end{array}$} & \multirow{2}{*}{$\begin{array}{c}\text { Per-Weld DEGB } \\
\text { Frequency } \\
(1 / \mathbf{R} x-y \mathbf{r})^{1}\end{array}$} & \multicolumn{2}{|c|}{$\begin{array}{l}\text { Pipe Break Frequency Estimate } \\
\qquad(1 / R x-y r)^{2}\end{array}$} \\
\hline & & & $\begin{array}{l}\text { Individual Pipe } \\
\text { Size Category }\end{array}$ & Total $^{3}$ \\
\hline \multicolumn{5}{|c|}{ a) Recirculation System } \\
\hline $1(2.5)$ & 25 & $1 \mathrm{E}-06$ & $2.5 \mathrm{E}-05$ & \\
\hline $1.25(3.2)$ & 2 & $1 \mathrm{E}-06$ & $2 \mathrm{E}-06$ & \\
\hline $2(5.1)$ & 2 & $1 \mathrm{E}-06$ & $2 \mathrm{E}-06$ & \\
\hline $4(12.7)$ & 26 & $1 \mathrm{E}-06$ & $2.6 \mathrm{E}-05$ & \\
\hline $10(25.4)$ & 40 & 1E-06 & $4 \mathrm{E}-05$ & \\
\hline $16(40.6)$ & 8 & $2 \mathrm{E}-06$ & $1.6 \mathrm{E}-05$ & \\
\hline $22(55.9)$ & $\underline{37}$ & 2E-07 & $7.4 \mathrm{E}-06$ & \\
\hline Subtotal & $\overline{140}$ & & & $1.2 \mathrm{E}-04$ \\
\hline \multicolumn{5}{|c|}{ b) Main Steam System } \\
\hline $1(2.5)$ & 16 & $2 \mathrm{E}-07$ & $3.2 \mathrm{E}-06$ & \\
\hline $2(5.1)$ & 12 & $2 \mathrm{E}-07$ & $2.4 \mathrm{E}-06$ & \\
\hline $6(15.2)$ & 24 & $2 \mathrm{E}-07$ & $4.8 \mathrm{E}-06$ & \\
\hline $20(50.8)$ & $\underline{63}$ & $2 \mathrm{E}-07$ & 1.3E-05 & \\
\hline Subtotal & $\overline{115}$ & & & 2.3E-05 \\
\hline \multicolumn{5}{|c|}{ c) Feedwater System } \\
\hline $10(25.4)$ & 58 & 2E-07 & $1.2 \mathrm{E}-05$ & \\
\hline $16(40.6)$ & $\underline{10}$ & 2E-07 & $2 E-06$ & \\
\hline Subtotal & $\overline{68}$ & & & 1.4E-05 \\
\hline \multicolumn{5}{|c|}{ d) HPCI System } \\
\hline $10(25.4)$ & $\underline{6}$ & $2 \mathrm{E}-07$ & $1.2 \mathrm{E}-06$ & \\
\hline Subtotal & $\overline{6}$ & & & $1.2 \mathrm{E}-06$ \\
\hline \multicolumn{5}{|c|}{ e) RHR System } \\
\hline $18(45.7)$ & 6 & $2 \mathrm{E}-07$ & $1.2 \mathrm{E}-06$ & \\
\hline $20(50.8)$ & $\underline{10}$ & $2 \mathrm{E}-07$ & $2 \mathrm{E}-06$ & \\
\hline Subtotal & $\overline{16}$ & & & 3.2E-06 \\
\hline Total Welds & 345 & \multicolumn{2}{|c|}{ Total for All Five Systems } & $1.6 \mathrm{E}-04$ \\
\hline
\end{tabular}

\footnotetext{
${ }^{1}$ Data extracted from Table 3-2.

${ }^{2}$ Pipe break frequency estimates generated by multiplying total no. of welds and corresponding per-weld DEGB frequency.

${ }^{3}$ Total pipe break frequency for a given system.
}

the reactor vessel is insulated using mirror type insulators. The insulation of primary concern for this study is NUKONTM, a fibrous, low-density fiberglass wool blanket. Detailed P\&ID drawings were available for each primary pipe detailing the type and thickness of the insulating material used.

The NUKON ${ }^{\mathrm{TM}}$ blanket material used for insulating primary piping consists of fibrous glass wool reinforced with a woven fiberglass scrim, then covered with a heavy woven fiberglass fabric (burlap-like), sewn with fiberglass thread, and attached with a velcro-type material. The base wool has a low density ( 2 to $3 \mathrm{lb} / \mathrm{ft}^{3}$ or 32.5 to 48.7 $\left.\mathrm{kg} / \mathrm{m}^{3}\right)$ and is jacketed by 22 gauge $(0.0293$ " or 0.7 $\mathrm{mm}$ ) $304 \mathrm{SS}$ covers. Photographs of installed 
Table 3-4 Pipe Break Estimates Categorized by Pipe Diameter for the Reference BWR Plant

\begin{tabular}{|c|c|c|c|c|}
\hline \multirow{2}{*}{ System } & \multirow{2}{*}{$\begin{array}{l}\text { Total No. of } \\
\text { Welds }\end{array}$} & \multirow{2}{*}{$\begin{array}{c}\text { Per-Weld DEGB } \\
\text { Frequency } \\
(1 / R x-y r)^{1}\end{array}$} & \multicolumn{2}{|c|}{$\begin{array}{l}\text { Pipe Break Frequency Estimate } \\
\qquad(1 / R x-y r)^{2}\end{array}$} \\
\hline & & & Individual System & Total $^{3}$ \\
\hline \multicolumn{5}{|c|}{ a) 1" Pipe Diameter } \\
\hline Recirculation & 25 & $1 \mathrm{E}-06$ & $2.5 \mathrm{E}-05$ & \multirow[t]{2}{*}{$2.8 \mathrm{E}-05$} \\
\hline Main Steam & 16 & 2E-07 & $3.2 \mathrm{E}-06$ & \\
\hline \multicolumn{5}{|c|}{ b) $1.25 "$ Pipe Diameter } \\
\hline Recirculation & 2 & $1 \mathrm{E}-06$ & $2 \mathrm{E}-06$ & $2 \mathrm{E}-06$ \\
\hline \multicolumn{5}{|c|}{ c) 2" Pipe Diameter } \\
\hline Recirculation & 2 & $1 E-06$ & $2 \mathrm{E}-06$ & $4.4 \mathrm{E}-06$ \\
\hline Main Steam & 12 & $2 \mathrm{E}-07$ & $2.4 \mathrm{E}-06$ & \\
\hline \multicolumn{5}{|c|}{ d) 4" Pipe diameter } \\
\hline Recirculation & 26 & $1 \mathrm{E}-06$ & $2.6 \mathrm{E}-05$ & $2.6 \mathrm{E}-05$ \\
\hline \multicolumn{5}{|c|}{ e) 6" Pipe Diameter } \\
\hline Main Steam & 24 & $2 \mathrm{E}-07$ & $4.8 \mathrm{E}-06$ & $4.8 \mathrm{E}-06$ \\
\hline \multicolumn{5}{|c|}{ f) $10^{\prime \prime}$ Pipe Diameter } \\
\hline Recirculation & 40 & $1 E-06$ & $4 \mathrm{E}-05$ & 5.3E-05 \\
\hline Feedwater & 58 & 2E-07 & $1.2 \mathrm{E}-05$ & \\
\hline $\mathrm{HPCI}$ & 6 & $2 \mathrm{E}-07$ & $1.2 \mathrm{E}-06$ & \\
\hline \multicolumn{5}{|c|}{ g) 16" Pipe Diameter } \\
\hline Recirculation & 8 & $2 \mathrm{E}-06$ & $1.6 \mathrm{E}-05$ & $1.8 \mathrm{E}-05$ \\
\hline Feedwater & 10 & $2 \mathrm{E}-07$ & $2 \mathrm{E}-06$ & \\
\hline \multicolumn{5}{|c|}{ h) 18" Pipe Diameter } \\
\hline RHR & 6 & 2E-07 & $1.2 \mathrm{E}-06$ & $1.2 \mathrm{E}-06$ \\
\hline \multicolumn{5}{|c|}{ i) $20^{\prime \prime}$ Pipe Diameter } \\
\hline Main Steam & 63 & $2 \mathrm{E}-07$ & $1.3 \mathrm{E}-05$ & $1.5 \mathrm{E}-05$ \\
\hline RHR & 10 & $2 \mathrm{E}-07$ & $2.0 \mathrm{E}-06$ & \\
\hline \multicolumn{5}{|c|}{ j) 22" Pipe Diameter } \\
\hline Recirculation & 37 & 2E-07 & $7.4 \mathrm{E}-06$ & $7.4 \mathrm{E}-06$ \\
\hline & & & Overall Total & $1.6 \mathrm{E}-04$ \\
\hline
\end{tabular}

${ }^{1}$ Data extracted from Table 3-2.

${ }^{2}$ Pipe break frequency estimates generated by multiplying total no. of welds and corresponding per-weld DEGB frequency.

${ }^{3}$ Total pipe break frequency for a given pipe diameter class.

NUKON ${ }^{\mathrm{TM}}$ insulation with and without the steel jacketing are shown in Figure 3-14.

\subsection{Break Jet Destruction Model for the Reference Plant}

A spherical zone of destruction model was used to define the zone of influence in the vicinity of postulated break where the pressure loadings are sufficient to inflict damage on the insulation blankets. This destruction model was specifically developed for the Mark I BWR plants whose drywell piping is insulated with steel jacketed NUKON ${ }^{\mathrm{TM}}$ and is based on limited experimental data. Applicability of this model should be evaluated before analyzing BWRs whose drywell piping is covered with other insulations. Appendix $B$ summarizes insights gained from previous studies, the rationale behind the present model, and provides further considerations for estimating insulation debris generated by LOCAs. 
Debris Generation

Table 3-5 Pipe Break Frequency Estimates Categorized by Pipe Location for the Reference BWR Plant

\begin{tabular}{|c|c|c|c|c|c|}
\hline \multirow{2}{*}{ System } & \multirow{2}{*}{$\begin{array}{c}\text { Pipe } \\
\text { Diameter } \\
\text { inches }(\mathrm{cm})\end{array}$} & \multirow{2}{*}{$\begin{array}{l}\text { Total No. of } \\
\text { Welds }\end{array}$} & \multirow{2}{*}{$\begin{array}{c}\text { Per-Weld DEGB } \\
\text { Frequency } \\
(1 / \mathrm{Rx}-\mathrm{yr})^{1}\end{array}$} & \multicolumn{2}{|c|}{$\begin{array}{c}\text { Pipe Break } \\
\text { Frequency Estimate } \\
(1 / \mathrm{Rx}-\mathrm{yr})^{2}\end{array}$} \\
\hline & & & & $\begin{array}{c}\text { Individual System } \\
\text { Category }\end{array}$ & Total $^{3}$ \\
\hline \multicolumn{6}{|c|}{ a) Above $776^{\prime}$ Grating (H) } \\
\hline Recirculation & $1(2.5)$ & 8 & $1 \mathrm{E}-06$ & $8 \mathrm{E}-06$ & \\
\hline Recirculation & $4(12.7)$ & 2 & 1E-06 & $2 \mathrm{E}-06$ & \\
\hline Recirculation & $10(25.4)$ & 24 & $1 \mathrm{E}-06$ & $2.4 \mathrm{E}-05$ & \\
\hline Recirculation & $22(55.9)$ & 7 & $2 \mathrm{E}-07$ & $1.4 \mathrm{E}-06$ & \\
\hline Feedwater & $10(25.4)$ & 58 & $2 \mathrm{E}-07$ & $1.2 \mathrm{E}-05$ & \\
\hline Feedwater & $16(40.6)$ & 2 & $2 \mathrm{E}-07$ & $4 \mathrm{E}-07$ & \\
\hline Main Steam & $6(15.2)$ & 24 & 2E-07 & $4.8 \mathrm{E}-06$ & \\
\hline Main Steam & $20(50.8)$ & 40 & $2 \mathrm{E}-07$ & $8 \mathrm{E}-06$ & \\
\hline \multirow[t]{2}{*}{$\mathrm{HPCI}$} & $10(25.4)$ & 6 & $2 \mathrm{E}-07$ & $1.2 \mathrm{E}-06$ & \\
\hline & \multicolumn{4}{|c|}{ b) Between Gratings (M) } & \\
\hline Recirculation & $1(2.5)$ & 9 & $1 \mathrm{E}-06$ & $9 \mathrm{E}-06$ & \\
\hline Recirculation & $4(12.7)$ & 4 & $1 \mathrm{E}-06$ & $4 \mathrm{E}-06$ & \\
\hline Recirculation & $10(25.4)$ & 16 & $1 \mathrm{E}-06$ & $1.6 \mathrm{E}-05$ & \\
\hline Recirculation & $16(40.6)$ & 8 & $2 \mathrm{E}-06$ & $1.6 \mathrm{E}-05$ & \\
\hline Recirculation & $22(55.9)$ & 11 & $2 \mathrm{E}-07$ & $2.2 \mathrm{E}-06$ & \\
\hline Feedwater & $16(40.6)$ & 8 & $2 \mathrm{E}-07$ & $1.6 \mathrm{E}-06$ & \\
\hline Main Steam & $1(2.5)$ & 16 & $2 \mathrm{E}-07$ & $3.2 \mathrm{E}-06$ & \\
\hline Main Steam & $20(50.8)$ & 23 & $2 \mathrm{E}-07$ & $4.6 \mathrm{E}-06$ & \\
\hline RHR & $18(45.7)$ & 6 & $2 \mathrm{E}-07$ & $1.2 \mathrm{E}-06$ & \\
\hline \multirow[t]{2}{*}{ RHR } & $20(50.8)$ & 10 & $2 \mathrm{E}-07$ & $2 \mathrm{E}-06$ & \\
\hline & \multicolumn{5}{|c|}{ c) Below 757' Grating (L) } \\
\hline Recirculation & $1(2.5)$ & 8 & $1 \mathrm{E}-06$ & $8 \mathrm{E}-06$ & \\
\hline Recirculation & $1.25(3.2)$ & 2 & $1 \mathrm{E}-06$ & $2 \mathrm{E}-06$ & \\
\hline Recirculation & $2(5.1)$ & 2 & $1 \mathrm{E}-06$ & $2 \mathrm{E}-06$ & \\
\hline Recirculation & $4(12.7)$ & 20 & $1 \mathrm{E}-06$ & 2E-05 & \\
\hline Recirculation & $22(55.9)$ & 19 & $2 \mathrm{E}-07$ & $3.8 \mathrm{E}-06$ & \\
\hline \multirow[t]{3}{*}{ Main Steam } & $2(5.1)$ & 12 & 2E-07 & 2.4E-06 & \\
\hline & & & & & 3.8E-05 \\
\hline & & & & $\begin{array}{l}\text { Total for All Three } \\
\text { Locations }\end{array}$ & $1.6 \mathrm{E}-04$ \\
\hline
\end{tabular}

${ }^{1}$ Data extracted from Table 3-2.

${ }^{2}$ Pipe break frequency estimates generated by multiplying total no. of welds and corresponding per-weld DEGB frequency.

${ }^{3}$ Total pipe break frequency for a given pipe location. 
Debris Generation

Table 3-6 Method Used to Calculate LLOCA Pipe Break Frequencies

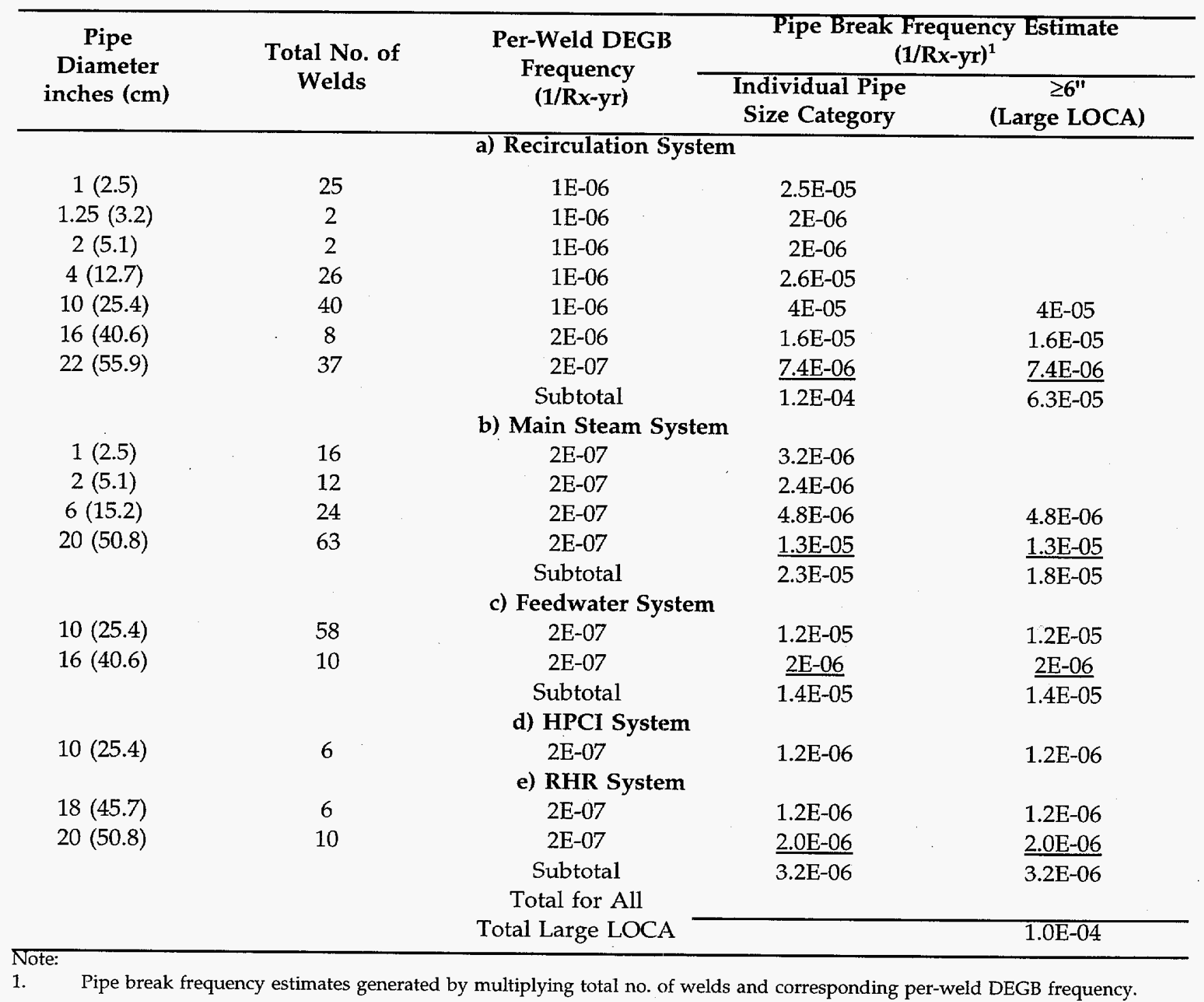


Table 3-7 Comparison of Recommended LLOCA Data with Other BWR 4/Mark I Risk Assessment Data

\begin{tabular}{|c|c|c|c|c|}
\hline Data Source & LOCA Type & $\begin{array}{c}\text { Estimated } \\
\text { Frequency } \\
(1 / y r)\end{array}$ & $\begin{array}{l}\text { Statistical } \\
\text { Category }\end{array}$ & Notes \\
\hline 1. Reference Plant & DEGB $\left(\geq 6^{\prime \prime}\right.$ or $\left.15.2 \mathrm{~cm}\right)$ & $1 \mathrm{E}-04$ & Point Estimate & \\
\hline 2. Plant 1 & Large LOCA & $3 E-04$ & Unknown & \\
\hline 3. Plant 2 & Large LOCA & 1E-04 & Mean & Based on WASH-1400 \\
\hline 4. Plant 3 & Large LOCA & 1E-04 & Mean & Based on WASH-1400 \\
\hline 5. Plant 4 & Large LOCA & $1 \mathrm{E}-04$ & Mean & Based on WASH-1400 \\
\hline 6. Plant 5 & $\begin{array}{l}\text { Large LOCA: } \\
\text { a. Recirc. suction line } \\
\text { b. Recirc. disch. line } \\
\text { c. Core spray line } \\
\text { d. Other }\end{array}$ & $\begin{array}{l}9.2 \mathrm{E}-05 \\
3.1 \mathrm{E}-04 \\
8.3 \mathrm{E}-05 \\
1.1 \mathrm{E}-04\end{array}$ & $\begin{array}{l}\text { Mean } \\
\text { Mean } \\
\text { Mean } \\
\text { Mean }\end{array}$ & $\begin{array}{l}\text { Based on Proprietary } \\
\text { Data Base }\end{array}$ \\
\hline
\end{tabular}

The following regions, relative to the weld break locations, were used to define the reference plant DGM, schematically shown in Figure 3-15:

Region I: Region I extends up to a length of 3L/D for the steel jacketed NUKON ${ }^{\mathrm{TM}}$. This region is characterized by high pressures and survivability of insulation contained in this region is highly unlikely regardless of the type of insulation or mode of encapsulation. Some protection may be provided for insulation blankets located behind large structures. Otherwise, near total destruction of insulation into transportable form is extremely likely.

Region II: Region II, enveloped by $3<\mathrm{L} / \mathrm{D}<5$, is characterized by moderate pressures. As a result, moderate damage is expected for targets located in this region. The damage in this region is influenced by such factors as break stagnation conditions and jet deflection as demonstrated by the HDR tests and the PCI tests [Ref. 3.3 and 3.4]. Other considerations such as duration of the blowdown and the break size may also play an important role.
Region III: Region III extends between 5L/D and $7 \mathrm{~L} / \mathrm{D}$ and limited damage is expected in this zone by the virtue of the fact that pressure loadings are expected to be low. The likely products would be larger shreds.

In addition to defining the zones of destruction, the DGM used in this study assumed that only a fraction of the insulation contained in each region is actually destructed into transportable form and dislodged from the targets. According to various experiments, this fraction, referred to as the destruction factor, varies for each region and depends on the type of insulation and its mode of encapsulation. For example, HDR tests suggest that steel jacketed insulation is less susceptible to destruction than non-jacketed insulation. Insights derived from the HDR experiments, review of the analyses and experiments related to the Barsebäck-2 incident, and engineering judgement suggest usage of destruction factors of $0.75,0.60$, and 0.40 for Regions I, II and III, respectively, for steel jacketed NUKON ${ }^{\mathrm{TM}}$ insulation used in the reference plant. It is assumed that the remaining fraction would consist of larger pieces such as torn blankets and 
Debris Generation

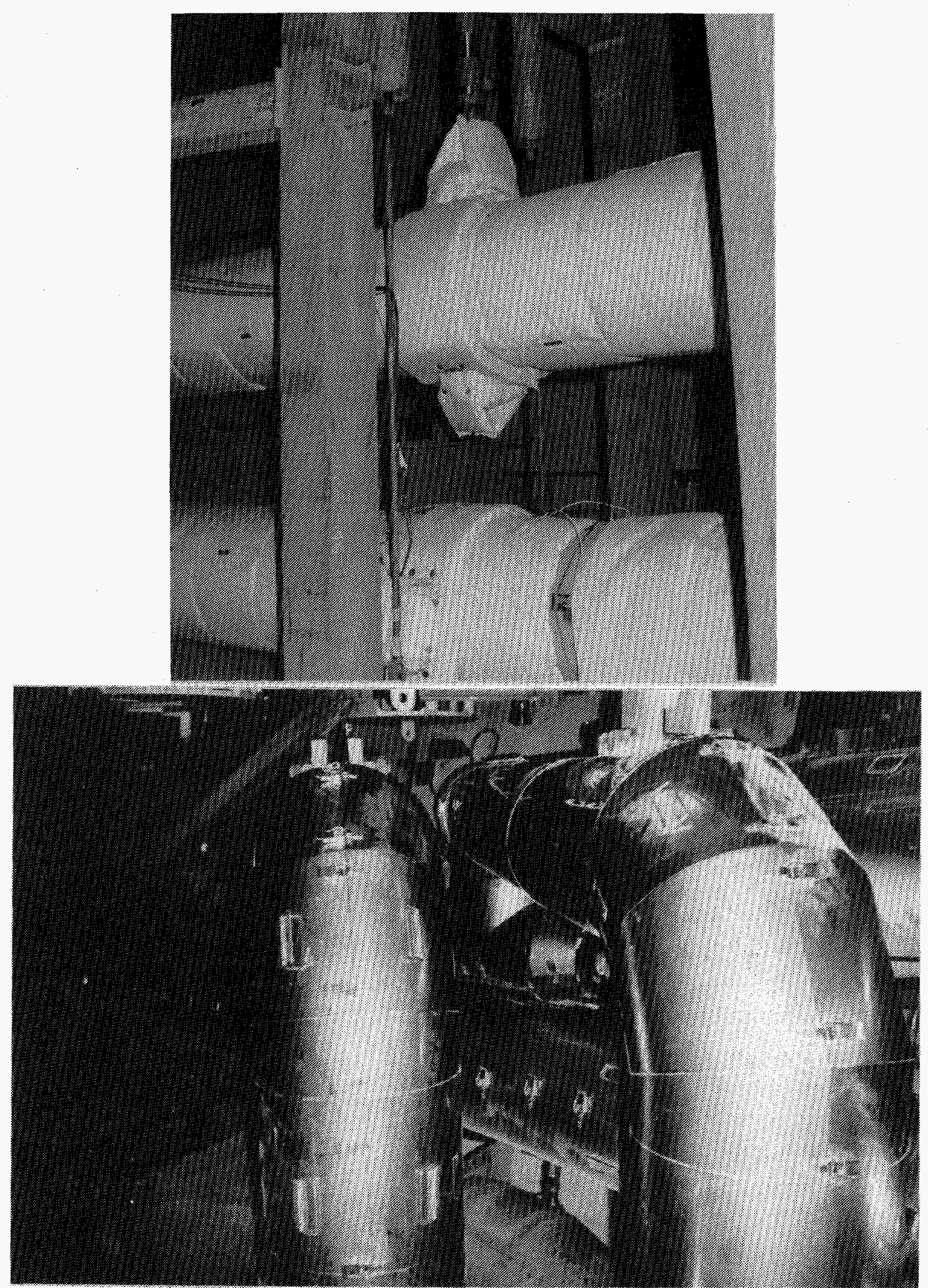

Figure 3-14 Installed NUKONTM Insulation Without Steel Jacketing (Top) and With Steel Jacketing (Bottom) 
Debris Generation

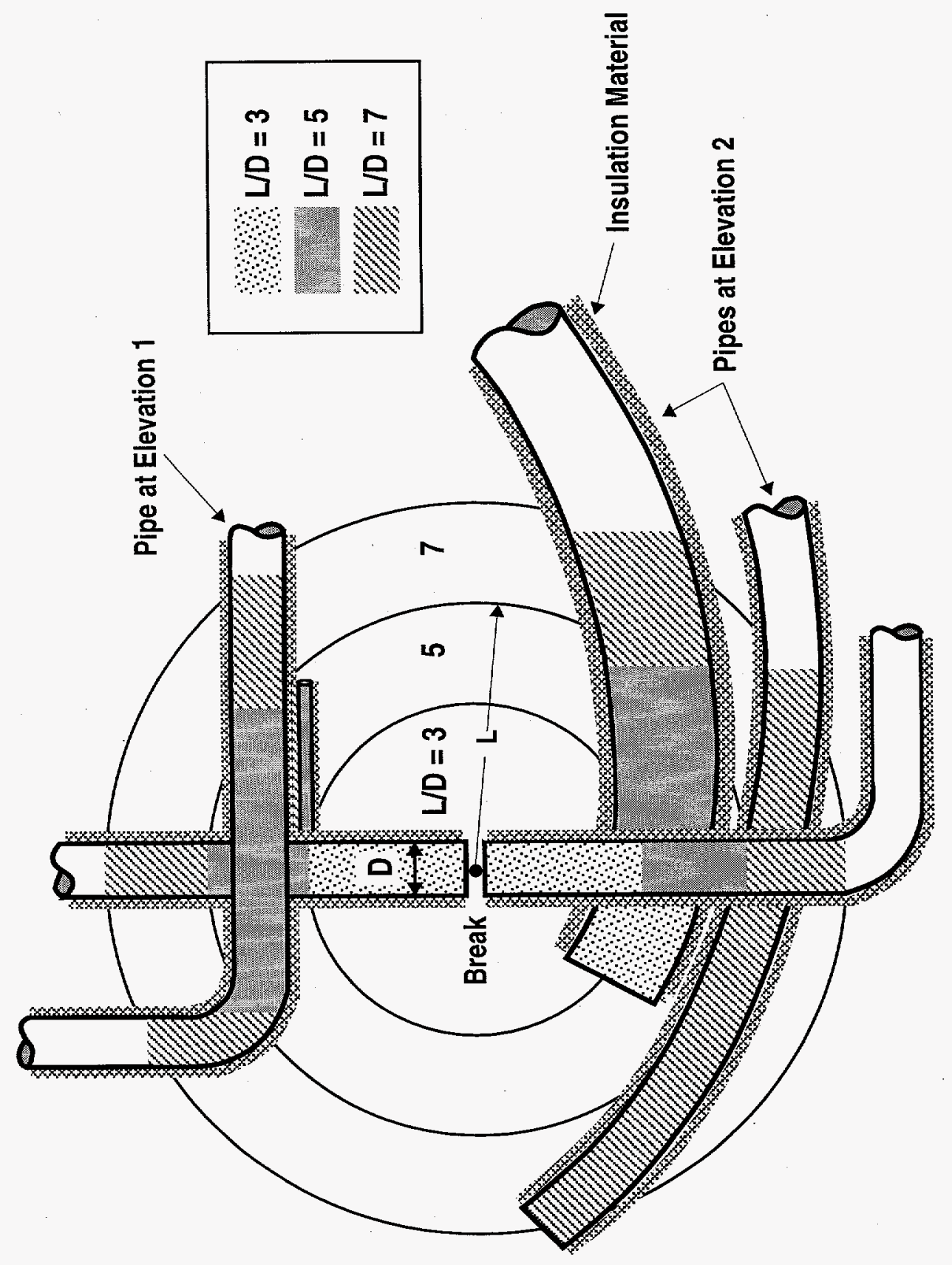

跑 
large chunks that are not transportable easily during either the blowdown or the washdown phases.

\subsection{Targeted and Destructed Insulation}

The reference plant P\&IDs were used to estimate the number of targets in each region $\left(\mathrm{N}_{\text {Target }}\right)$ and their respective lengths in each region $\left(\mathrm{L}_{\mathrm{iR}}\right)$. Target information, derived from the piping insulation drawings was used to estimate the total targeted insulation volume in each region for each weld analyzed using the following equation:

$$
V_{R}=\sum_{i=1}^{N_{\text {Tagel }}} P \pi / 4\left[(D+2 I)^{2}-D^{2}\right]_{i} L_{i R}
$$

where,

$$
\begin{aligned}
& R \quad \text { is the Region of Figure 3-15 (I, II, and } \\
& \text { III) } \\
& V_{R} \quad \text { is the volume of insulation contained in } \\
& \text { Region } \mathrm{R} \\
& N_{\text {Target }} \text { is total No. of targets in Region } \mathrm{R} \\
& i \text { is the target number; } i-1, N_{\text {Target }} \\
& D_{i} \quad \text { is the target pipe diameter (in) } \\
& I_{i} \quad \text { is the theoretical thickness of insulation } \\
& \text { blanket (in) } \\
& L_{i R} \quad \text { is the } i^{\text {th }} \text { target length belonging to } \mathrm{R}^{\text {th }} \\
& \text { Region ( } \mathrm{ft} \text { ) } \\
& P \quad \text { is unit conversion factor. }
\end{aligned}
$$

The total volume of insulation destroyed into tranportable form for each postulated break is calculated as:

$$
V_{g}=\sum_{R=I, I I, I I I} V_{R} \cdot F_{R} \cdot G
$$

where,

$$
\begin{array}{ll}
V_{g} & \begin{array}{l}
\text { is the volume of transportable debris } \\
\text { generated by a break }\left(\mathrm{ft}^{3}\right),
\end{array} \\
V_{R} & \begin{array}{l}
\text { is volume of debris targeted in } \mathrm{R}^{\text {th }} \\
\text { Region, }
\end{array} \\
F_{R} & \begin{array}{l}
\text { is the destruction factor for } \mathrm{R}^{\text {th }} \text { Region. } \\
\mathrm{G}
\end{array}
\end{array}
$$

Equations 3-4 and 3-5 were incorporated into
BLOCKAGE and require that the diameter of each target, insulation thickness on each target, and the length of each target belonging to each debris generation region be part of the input file. The following section summarizes the methodology used to calculate these input variables for each weld location.

In addition to the insulation, other sources of debris generated by a LOCA include paint chips generated in the drywell, fibrous material present in the drywell from air filters, HVAC piping and cable tray fire barriers, concrete dust, and other types of insulation. In the case of the reference plant, it was concluded that fibrous debris generated by additional sources is negligible in comparison to the quantities of fibrous debris generated by jet effects on the insulation blankets. This conclusion may not be valid for plants whose insulation is predominantly non-fibrous. Drywell particulates generated by the impact of LOCA jets on various drywell structures were accounted for in this analysis as described in Section 3.6.2.

\subsection{Types and Quantities of Debris Generated}

\subsubsection{Insulation Debris Volumes}

The BWR DGM developed for the reference plant was applied to the reference plant to estimate the volume and type of debris generated by each weld. For each weld, the plant drawings (P\&IDs and isometric drawings) were used (1) to identify the number of pipes that fell within the zone of influence (i.e., number of target pipes), and (2) to determine the diameter, length, and orientation of each target pipe with respect to each weld. Figure 3-15 schematically illustrates the three spherical regions of the BWR DGM when applied to a hypothetical weld. Major assumptions and limitations in the application of the BWR DGM to the reference plant are as follows:

1. Only welds subjected to high pressure during normal operation were considered to contribute to debris generation. Welds included in this analysis were located in the following systems: Recirculation Loops $A$ and B; MSL A, B, C and D; Feedwater Loops A, B, $C$ and D; Steam Line for HPCI turbine-driven 
pump; and RHR Loops B, C and D. The available reference plant drywell drawings did not provide sufficient information to accurately calculate target lengths for the LPCS system. As a result, pressurized portions of the LPCS system were not included in this analysis.

2. The jet is assumed to be discharged from both ends of the DEGB, since blowdown is expected from both directions. All primary piping sections insulated with steel-jacketed NUKONTM falling in a spherical region of diameter $7 \mathrm{~L} / \mathrm{D}$ were included as targets. During the plant analysis, it was recognized that 21 out of 345 welds will result in blowdown from only one side of the break. A hemispherical zone of influence was considered for these welds; however, a hemisphere may not bound the zone of influence, considering that most of the breaks are located in areas that are congested with primary pipes and valves. As a result a conservative assumption was made to use a spherical zone of influence to simplify the analysis. This assumption affects only 21 of the 345 welds, and does not significantly impact the overall results of this study.

3. The shadowing effect of containment structures (such as gratings and pipe restraints) was neglected in both selecting the targeted insulation and in estimating target lengths. It is assumed that usage of destruction factors would account for these effects.

4. For break sizes larger than 2" in diameter, plan and elevation drawings were used to determine potential targets within a spherical region having the weld at the center and radii of 3D, 5D and 7D, respectively (see Figure 315). Geometric projection was used to estimate the target length within each region. Insulation drawings for each system were then used to estimate the thickness of the blanket used for each target.

5. For breaks smaller than 2" in diameter, the nearest adjacent NUKON ${ }^{\mathrm{TM}}$ pillow was assumed to be dislodged from the pipe, even though the entire length of the pillow could extend beyond $7 \mathrm{~L} / \mathrm{D}$. Similarly, for breaks postulated at the T-welds (such as instrument pipe welds), both pillows adjacent to the weld were assumed to be destroyed and dislodged.

The detail to which the targets were analyzed can be illustrated by considering Weld RCA-J006. This weld is located in the 22" recirculation loop A at elevation $780 \mathrm{ft}$ in a congested part of the drywell. Figure 3-1 illustrates the location of this weld in the drywell relative to the rest of the piping. Various engineering drawings were used to identify each of the targets affected by the postulated DEGB at RCAJ006. Each target and its length located within a sphere of radii of 3,5 , and 7 pipe diameters, respectively, are listed in Table 3-8. As shown in Table 3-8 (see also Figure 3-1), only three targets are located within a $\mathrm{L} / \mathrm{D} \leq 3$ of this weld, which extends up to a length of $66 "(1.67 \mathrm{~m})$. Within a $\mathrm{L} / \mathrm{D} \leq 5$, an additional two targets are affected. A total of 15 targets were identified $L / D \leq 7$, which extends to a diameter of 154 " $(3.9 \mathrm{~m})$ from the break location.

In a similar fashion, targets for each of the 345 welds identified in the primary system piping, the main steam, and the feedwater lines are presented in Appendix D. The complexity of accounting for the potential break locations and targeted insulation in a three-dimensional field (i.e., the drywell, see also Figure 3-1) is illustrated by the extensiveness of Table D-1.

Target data similar to that presented in Table 3-8 was used in conjunction with Equation 3-4 for each weld to estimate the volume of fibrous insulation contained in each region. Equation 3-5, with the destruction factors and the size distribution factors developed for the reference plant, was used to calculate the volume and size distribution of fibrous debris generated by a postulated pipe break at each weld. ${ }^{2}$ These calculations demonstrated that the total volume of debris generated is an increasing function of weld diameter and that factors such as piping layout and drywell arrangement around the break had an equal or greater influence on the volume of debris generated by each weld. For the reference plant, the volume of fibrous debris generated by particular weld breaks varied from 2 to $112 \mathrm{ft}^{3}\left(0.06\right.$ to $\left.3.1 \mathrm{~m}^{3}\right)$.

\footnotetext{
${ }^{2}$ Note that these functions are automatically performed by BLOCKAGE which uses Table D-1 as input.
} 
Table 3-8 Estimation of Target Lengths for a Key Break Weld ID \#RCA-J006

\begin{tabular}{|c|c|c|c|c|c|c|c|}
\hline \multirow[b]{2}{*}{ i } & \multicolumn{2}{|c|}{ TARGET } & \multicolumn{2}{|c|}{ INSULATION } & \multicolumn{3}{|c|}{ TARGET LENGTH, ft $(\mathrm{m})\left(\mathrm{L}_{\mathrm{iR}}\right)$} \\
\hline & $\begin{array}{l}\text { Diameter }\left(D_{i}\right) \\
\text { in }(\mathrm{cm})\end{array}$ & Sys. & ID & $\begin{array}{l}\text { Thick }\left(\mathrm{I}_{\mathrm{i}}\right) \\
\text { in }(\mathrm{cm})\end{array}$ & $\mathrm{L} / \mathrm{D}=3$ & $\mathrm{~L} / \mathrm{D}=5$ & $\mathrm{~L} / \mathrm{D}=7$ \\
\hline 1 & $22.0(55.9)$ & $\mathrm{RCA}$ & NUKON $^{\mathrm{TM}}$ & $3(7.6)$ & $11(3.35)$ & $7.33(2.3)$ & $7.33(2.3)$ \\
\hline 2 & $10.0(25.4)$ & RRA & NUKON ${ }^{\mathrm{TM}}$ & $2.5(6.35)$ & 0 & 0 & $13(4.0)$ \\
\hline 3 & $10.0(25.4)$ & RRH & NUKON'TM & $2.5(6.35)$ & 0 & 0 & $13(4.0)$ \\
\hline 4 & $16.0(40.6)$ & RMA & NUKON'M & $3(7.6)$ & 0 & 0 & $5.5(1.7)$ \\
\hline 5 & $16.0(40.6)$ & RMB & NUKON'T & $3(7.6)$ & 0 & 0 & $5.5(1.7)$ \\
\hline 6 & $20.0(50.8)$ & MSA & $\mathrm{NUKON}^{\mathrm{TM}}$ & $3(7.6)$ & $5.5(1.7)$ & $6.2(1.9)$ & $8.6(2.6)$ \\
\hline 7 & $20.0(50.8)$ & MSD & NUKON ${ }^{\mathrm{TM}}$ & $3(7.6)$ & $5.5(1.7)$ & $6.2(1.9)$ & $8.6(2.6)$ \\
\hline 8 & $20.0(50.8)$ & MSB & $\mathrm{NUKON}^{\mathrm{TM}}$ & $3(7.6)$ & 0 & $4.71(1.4)$ & $12.42(3.8)$ \\
\hline 9 & $20.0(50.8)$ & MSC & NUKON ${ }^{\mathrm{TM}}$ & $3(7.6)$ & 0 & $4.71(1.4)$ & $12.42(3.8)$ \\
\hline 10 & $10.0(25.4)$ & FWA & NUKON ${ }^{T M}$ & $2.5(6.35)$ & 0 & 0 & $5.5(1.7)$ \\
\hline 11 & $10.0(25.4)$ & FWD & $\mathrm{NUKON}^{\mathrm{TM}}$ & $2.5(6.35)$ & 0 & 0 & $5.5(1.7)$ \\
\hline 12 & $10.0(25.4)$ & FWB & $\mathrm{NUKON}^{\mathrm{TM}}$ & $2.5(6.35)$ & 0 & 0 & $3.7(1.1)$ \\
\hline 13 & $10.0(25.4)$ & FWC & $\mathrm{NUKON}^{\mathrm{TM}}$ & $2.5(6.35)$ & 0 & 0 & $3.7(1.1)$ \\
\hline 14 & $16.0(40.6)$ & FWA & $\mathrm{NUKON}^{\mathrm{TM}}$ & $2.5(6.35)$ & 0 & 0 & $13.63(4.2)$ \\
\hline 15 & $16.0(40.6)$ & FWB & NUKONTM & $2.5(6.35)$ & 0 & 0 & $13.63(4.2)$ \\
\hline
\end{tabular}

Representative Welds

Four welds were selected from the total of 345 welds as representative welds to illustrate the analysis results. These weld locations are labeled in Figure 3-1 and are listed in Table 3-9. Breaks at two of these welds (RCA-J006 and MSB-J021) can be categorized as LLOCAs. The two others can be categorized as a MLOCA (RCA-J027) and as a Small LOCA (RCB-J028). Weld RCA-J006 is located in the most congested part of the drywell and was estimated to generate the largest volume of insulation debris. On the other hand, RCB-J028 is located at the bottom of the drywell in recirculation loop $B$ and generated the least amount of debris. Weld MSB-J021 is located in the safety valve stems on the MSL, and generated the least amount of insulation debris among the LLOCAs, whereas Weld RCA-J027 generated the largest volume of debris among the MLOCAs.

\subsubsection{Other Types of Debris Generated by LOCA Jets}

The potential for generation of other types of debris by LOCA jets is evident from the HDR experiments
[Ref. 3.3] where the jets were noted to have spalled concrete and blown off paint coverings. In view of this, the drywell drawings were carefully examined for other materials that may also be destructed by the LOCA jets. Based on this review, the primary contributors for drywell particle debris are calcium silicate insulation material on the RCIC, RWCU and recirculation drain lines; the Mirror( insulation on the reactor vessel; the concrete structures inside the drywell; and the paint coatings on drywell structures.

Although no specific information is available on destruction of calcium silicate by LOCA jets, applicable information can be obtained by reviewing European studies on Caposil and Newtherm 1000 insulation [Ref. 3.5, 3.6 and 3.7]. These studies suggest that steam jets created by blowdown from 80 bar and $0^{\circ} \mathrm{F}$ subcooling, may cause severe erosion up to lengths of $10 \mathrm{~L} / \mathrm{D}$. The majority of the destructed debris were greater than $0.85 \mathrm{~mm}$ in size with less than $1 \%$ of the debris less than $20 \mu \mathrm{m}$ in size. Based on a review of plant drawings, it was determined that the quantity of calcium silicate debris generated in the drywell would be very 
Debris Generation

Table 3-9 Volume of Fibrous Debris Generated by Key Breaks

\begin{tabular}{lcccccc}
\hline \multicolumn{1}{c}{ SYSTEM ID } & WELD ID & $\begin{array}{c}\text { WELD } \\
\text { Diameter } \\
\text { in }(\mathrm{cm})\end{array}$ & L/D=3 & L/D=5 & L/D=7 & $\mathrm{ft}^{3}\left(\mathrm{~m}^{3}\right)$ \\
\hline Recirculation Loop A & RCA-J006 & $22(55.9)$ & $34.6(0.97)$ & $44.8(1.25)$ & $147(4.12)$ & $112(3.14)$ \\
Main Steam B & MSB-J021 & $6(15.2)$ & $8.75(0.25)$ & $7.1(0.20)$ & $8(0.22)$ & $14(0.39)$ \\
Recirculation Loop A & RCA-J027 & $4(10.2)$ & $4.19(0.12)$ & $3.08(0.09)$ & $2.64(0.07)$ & $6(0.17)$ \\
Recirculation Loop B & RCB-J028 & $1(2.5)$ & $2.49(0.07)$ & 0 & 0 & $2(0.06)$ \\
\hline
\end{tabular}

small, and was not considered further in this study.

The Mirror ${ }^{\circledR}$ insulation is located on the reactor pressure vessel behind the concrete biological shield. The metallic insulation is well protected from most of the breaks by the biological shield. The potential for metallic debris generation was determined to be small, and was not considered further in this study.

Several concrete and painted structures are located in the drywell. Estimation of the quantity of concrete and paint chip debris generated by interaction of LOCA jets on these structures is complicated by plant specific considerations and paucity of data applicable to a DGM. This analysis relied on a BWROG study [Ref. 3.8] to estimate the quantity of paint chips generated by a LOCA jet; the BWROG estimate that $85 \mathrm{lbm}(38.6 \mathrm{~kg})$ as the quantity of paint chips generated by a LOCA blowdown jet. In addition to the paint chips, another $156 \mathrm{lbm}(70.8 \mathrm{~kg})$ of particulate debris in the form of concrete dust was assumed to have been generated in the drywell due to blowdown interactions with concrete structures. Theoretical densities of $124 \mathrm{lbm} / \mathrm{ft}^{3}$ and $156 \mathrm{lbm} / \mathrm{ft}^{3}$ were used for paint chips and concrete dust, respectively, to estimate respective volumes of the debris.

Furthermore, these volumes of particulate debris and paint chips were assumed to be generated by all breaks regardless of their size.

\subsection{Assumptions and Limitations in the Debris Generation Models}

The model proposed in this study to estimate the type and quantity of LOCA generated debris considers the following aspects: potential piping break locations; estimation of dominant pipe break frequencies; zone of influence of the break jet; destruction factors associated with each zone, and types and quantities of debris generated by the LOCA. Major assumptions and limitations in each of these phenomena are described below.

\subsubsection{Pipe Break Initiator Assumptions and Limitations}

The LOCA initiator type was assumed to be a DEGB event with full pipe separation; other breaks or leaks that represent a less severe type of pipe failure were not considered. The potential break locations considered in this study include welds in the recirculation, main steam, feedwater and ECCS piping. The welds in the main steam and feedwater piping, however, were assumed to have the same break frequencies as the welds in the 22 "-28" recirculation loop welds.

Based on the combination of probabilistic and deterministic techniques described in the NUREG/CR-4792 [Ref. 3.1], the pipe break frequency analysis focused on effects related to IGSCC, as this process appears to be the dominant mechanism for weld breaks in 304SS. There are, however, the following limitations in the IGSCC analysis in the NUREG/CR-4792 that may affect the results of the present study:

1. Local phenomena, like the effect of coolant flow on possible flushing of impurities that otherwise could aggravate the susceptibility to IGSCC, were not considered.

2. The model used "harsh" laboratory conditions to predict growth rates and times-to-initiation; it is conservative to extrapolate this "harsh" 
laboratory conditions to those existing in BWRs.

3. Pipe weld break probabilities are very sensitive to the type of residual stress; in this analysis, worst case stress assumptions were used.

4. The NUREG/CR-4792 did not give credit for actions to mitigate IGSCC; in estimating the frequency of DEGB in the reference plant, however, it was assumed that only one IGSCC mitigating action would be in place, namely an in-service inspection program. Consideration of other mitigation programs was not included.

5. Pipe breaks caused by water hammer or projectiles were not considered. The analysis did not consider scenarios involving IGSCCweakened piping coupled with other pipe challenges, for example seismic events or water hammer.

\subsubsection{LOCA Debris Types Assumptions and Limitations}

The LOCA debris source of primary concern in this study was steel-jacketed NUKON ${ }^{\text {Ty }}$ fibrous insulation. The potential for debris generation from other insulation materials, like calcium silicate or RMI, was determined to be small for the reference plant and was not considered further in this study. Consequently, application of the debris generation model to other types of insulation should be carefully evaluated.

In addition to fibrous insulation, the models developed as part of this study consider paint-chips and concrete dust as particulate debris generated in the drywell during a LOCA. Other types of drywell debris with potential to be transported to the suppression pool as a result of a LOCA, like air filters, equipment labels and miscellaneous materials which might be present in the drywell, were not included in this analysis as it was judged that, for the reference plant, the amount of such materials were negligible in comparison with the debris produced from fibrous insulation blankets. Such an assumption may not be accurate for other plants, particularly those with large quantities of RMI or other types of insulations.

\subsubsection{Break Jet Zone of Influence Model Assumptions and Limitations}

The model used in this study assumes that the jet from the DEGB will be discharged from both ends of the break, a situation which is recognized to be conservative for some welds. Due to the congested layout in Mark I containments, this model also considers that the break jet will be reflected by surrounding structures. As a result, a spherical zone of influence model was used to characterize the region in the vicinity of the break where the pressure loadings are sufficient to inflict damage on the insulation blankets.

The zone of influence used in this study was divided into three regions defined by radii of 3D, $5 \mathrm{D}$ and $7 \mathrm{D}$, with corresponding destruction factors of $0.75,0.60$ and 0.40 , specific for steel-jacketed NUKON ${ }^{\mathrm{TM}}$. Both the regions and destruction factors considered for the reference plant relied on considerable engineering judgement based on very limited data and, therefore, considerable caution must be exercised in assigning the boundaries and destruction factors for other insulation types and drywell layouts.

The same quantities of particulate debris were assumed to be generated by all breaks, regardless of their size and location. Estimation of the quantity of paint-chips and concrete dust particulate debris is complicated by plant specific considerations and scarcity of experimental or analytical data. This study relied on BWROG estimations for the production of paint chips and engineering judgement for the estimates of concrete dust generation. 
Debris Generation

\section{References for Section 3.0}

3.1 G. S. Holman and C. K. Chou, "Probability of Failure in BWR Reactor Coolant Piping," published as Lawrence Livermore National Laboratory report UCID-20914, NUREG/CR-4792, March 1989.

3.2 The American Society of Mechanical Engineers, "Risk-Based Inspection -Development of Guidelines, Volume 2 - Part 1, Light Water Reactor (LWR) Nuclear Power Plant Components," CRTD-Vol. 20-2, 1992.

3.3 A.W. Serkiz, "Containment Emergency Sump Performance," U.S. Nuclear Regulator Commission. NUREG-0897, Rev. 1, October 1985.

3.4 T. Kegel, "Air Blast Destructive Testing of NUKONTM Insulation Simulation of a Pipe Break," Colorado Engineering Experiment Station, Inc., October 1993.
3.5 M. Bloomquist, M. Delby, "Barsebäck-2 182, Oskarshamn 182, Ringhals 1: Report from tests concerning the effect of steam jet or Caposil insulation at Karlshamn, carried out between April 22-23, 1993 and May 6, 1993," ABB-Karlshamn, SDC 93-1174, June 1993.

3.6 P. Terkpa and B. Anersson. "Steam Jet Dislodgement Tests of Thermal Insulating Material of Type Newtherm 1000 and Caposil HTS," Studsvik, M.93/41, April 1993.

3.7 P. Terkpa and B. Anersson, "Steam Jet Dislodgement Tests for Two Thermal Insulating Materials," Studsvik, M-93/60, May 1993.

3.8 BWROG, "Interim Report of the BWR Owners Group ECCS Suction Strainer Committee," BWROG-94157, Dec., 1994. 


\subsection{Drywell Transport in the Reference Plant}

A fraction of the debris generated will be transported to the suppression pool by (1) the vapor flows resulting from reactor vessel blowdown, and (2) the water flows induced by the break flow and the containment sprays. A parametric drywell debris transport model was proposed in Appendix B to estimate the rate of transport of $I^{\text {th }}$ debris species to the suppression pool using the following equation:

$$
V_{s}^{I}=T(t) \cdot V_{g}^{I}
$$

where,
$V_{s}^{I}$ is the volume of $I^{\text {th }}$ debris species transported to the suppression pool $\left(\mathrm{ft}^{3}\right)$
$V_{g}^{I} \quad$ is the volume of $I^{\text {th }}$ debris species generated in the drywell $\left(\mathrm{ft}^{3}\right)$ (calculated from Eq. 3-5), and
$\mathrm{T}(\mathrm{t})$ is the drywell transport factor.

The drywell transport factor is further expressed as a sum of (1) the blowdown transport factor defined as the fraction of the debris transported by the vapor flows, and (2) the washdown transport factor defined as the fraction of the debris transported by the water flows induced by the break flow and the containment sprays, i.e.,

$$
T(t)=T_{b d}(t)+T_{w d}(t),
$$

where $T_{b d}$ and $T_{w d}$ are the blowdown and washdown transport factors, respectively.

Both $T_{b d}$ and $T_{w d}$ are strong functions of the break locations in the drywell and the structural impediments in the transport pathways. As a result, these transport factors are highly plant specific. In addition, very limited experimental data is available that is directly applicable to the reference plant. As a result, the estimates for transport factors were obtained based on engineering judgement. The following sections describe the important considerations addressed as part of this analysis.

\subsection{Drywell Debris Transport Factors for the Reference Plant}

The reference plant layout drawings and a video of the reference plant were examined closely to identify the available pathways for the debris transport and major intervening structures present in the pathway. A schematic of the reference plant drywell layout is presented as Figure 4-1. The drywell contains three coarse gratings at elevations $805^{\prime}, 776^{\prime}$, and $757^{\prime}$. These gratings and their related structures were designed to provide structural support to the pipes and also act as work platforms. Examination of the plant layout drawings and the drywell walk-down video tape revealed that:

1. The postulated breaks are located starting at elevations higher than the $+805^{\prime}$ grating down to elevations below the $+757^{\prime}$ grating.

2. Although the gratings themselves are coarse, the pipe whip restraints, cable trays and other equipment located on the gratings provide for congested pathways for debris transport. As a result, the gratings act as major impediments for the debris transport to lower elevations.

The effects of the gratings on debris transport was not explicitly modeled. However, it is recognized that the congested layout would result in retention of some of the debris and would transport the remaining debris to the drywell floor.

The vent pipes connecting the drywell to the torus are located at elevation mark $+744^{\prime}$, elevated from the drywell floor by about $4 \mathrm{ft}(1.2 \mathrm{~m})$. This leads to formation of a water pool on the drywell floor during the washdown phase. Formation of the water pool affects the debris transport in two ways: (1) it allows for heavier debris (e.g., concrete chips and undamaged blanket(s)) to settle to the bottom of the floor, and (2) it facilitates further disintegrations of fibrous shreds under hydrodynamic forces induced by gravitation fall of break flow into the pool. In addition, the vent pipe openings are equipped with jet deflectors to prevent possible damage to the vent pipes from jet forces that might accompany a pipe break in the drywell. These jet plates provide for narrow clearance for the flow and contribute to retention of some of the fibrous debris, 
Drywell Transport

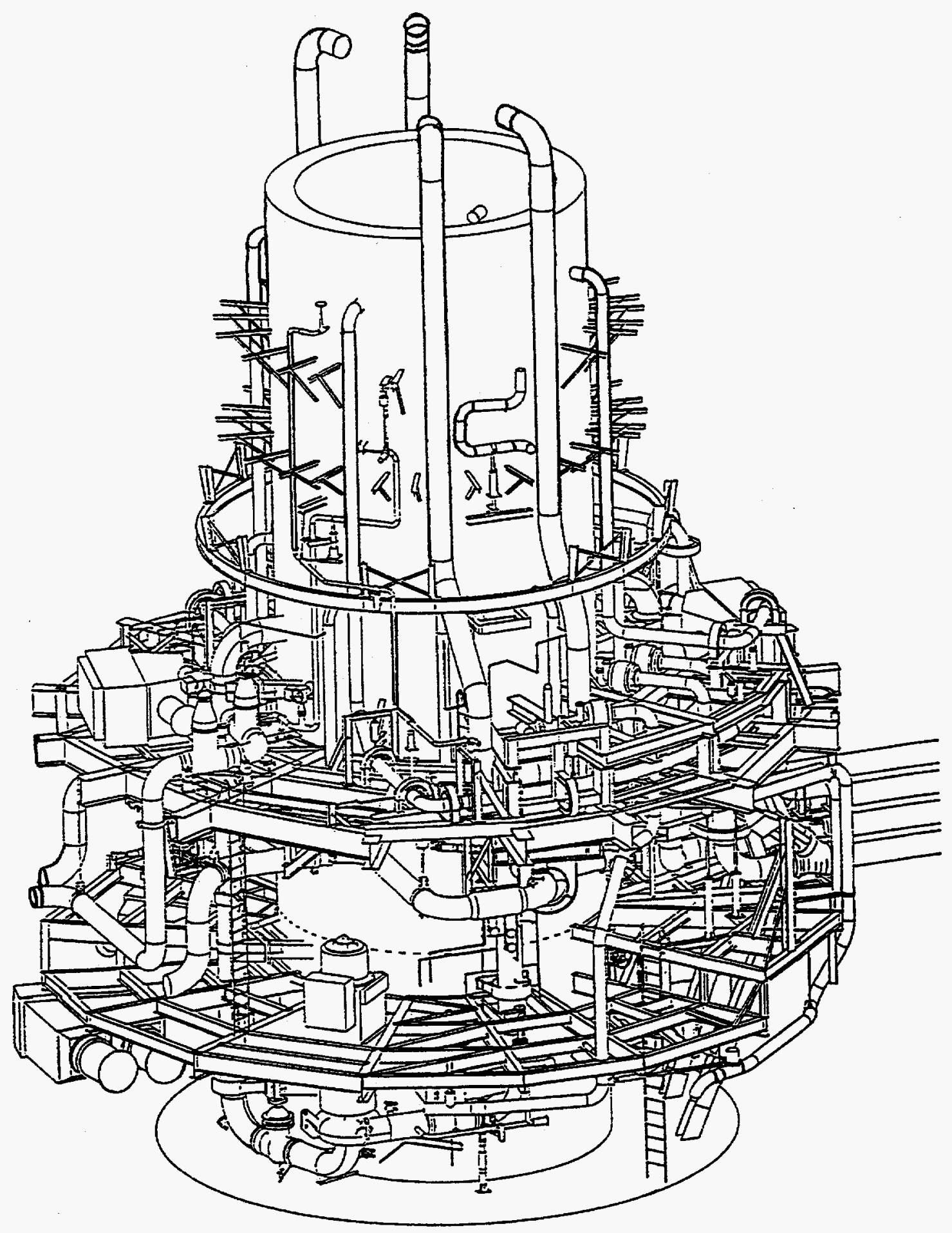

Figure 4-1 Drywell Layout 
at least during the blowdown. Additionally, there is the potential for jet plate clearances being blocked by fibrous debris. ${ }^{1}$

The congested layout of the drywell, the presence of the gratings, and the raised vent pipes will contribute to retention of a fraction of the debris generated in the drywell. These factors were the principle contributors in estimating the transport factors of Equation 4-2.

\subsubsection{Transport Factor Analysis}

Barsebäck-2 data was used to estimate the drywell transport factors. In Barsebäck-2, the LOCA was initiated when a rupture disk at the outlet of a safety relief valve inadvertently opened before the reactor reached full power and steady state pressure. The reactor pressure at the time of LOCA was $435 \mathrm{psi}$ ( $3 \mathrm{MPa}$ ). The containment sprays were turned on for drywell pressure and temperature control. As a result of blowdown from the safety valves and washdown from containment sprays, about $50 \%$ of the debris generated in the drywell was ultimately transported to the suppression pool [Ref. 4.1]; considerable fraction of this transport occurred within the first half-hour. According to the plant estimates, the majority of this transport $(>90 \%)$ was due to washdown of debris by the containment sprays and only a small fraction was transported during blowdown; thus, for Barsebäck-2, it can be concluded that total, blowdown, and washdown transport factors integrated over time are $0.5,<0.05$ and $>0.45$, respectively. These fractions are expected to be considerably different in the case of postulated breaks in the reference plant.

The postulated accident progression in the reference plant is also different from that which occurred in the Barsebäck-2 incident. In the reference plant, the containment spray initiation is not automatic. If sufficient venting is not maintained, the containment temperature and pressure could increase to the point where containment spray has to be actuated. This study assumes that such a need does not arise and that operator does not initiate containment sprays. This assumption plays a major role in determination of washdown transport fractions and

\footnotetext{
${ }^{1}$ These concerns were raised at the CSNI/PWG-1 International Task Group on ECCS Recirculation Reliability meeting held in Cologne, Germany, April 4-6, 1995.
}

reduces the washdown transport fraction from the $45 \%$ value derived from the Barsebäck- 2 incident.

In the reference plant, more than $70 \%$ of the postulated breaks are larger than $10^{\prime \prime}$ in diameter and only $15 \%$ are smaller than $4 "$ compared to the safety valve rupture that occurred in the Barsebäck-2 plant. A large break typically results in larger vapor flows in the drywell over a short period of time. This reduces the potential for condensation of steam in the drywell and as a result, it is likely that a larger fraction of the steam would be transported to the suppression in case of a LLOCA. If it is assumed that the fibrous debris can be treated as light particles thoroughly intermixed with steam, then the fraction of fibrous debris reaching the suppression pool would be proportional to the fraction of the total steam that is transported to the torus. Thus, it is very likely that larger breaks would transport larger fractions of fibrous debris to the suppression pool. On the other hand, the smaller breaks, especially in the presence of containment sprays, allow for higher condensate ratio. In such cases, as in Barsebäck-2, only a small fraction of the debris is likely to be transported by the steam. This trend is qualitatively consistent with the Karlshamn tests [Ref. 4.2] which also suggest that the blowdown transport factors are directly proportional to the steam mass flow rate and the super heat. However, the Karlshamn tests cannot be directly applied to the reference plant since the test scaled layouts are considerably different when compared to the reference plant drywell layout.

This study assumed that transport factors are primarily influenced by the surface area of the impediments and only weakly dependent on the break size, recognizing that this may overestimate transport factors for small breaks. These assumptions allowed for a simplification that resulted in eliminating the break size and system type from further consideration.

Thereafter, considerable attention was given to account for the location effects on the transport factors. The drywell layout was studied to identify locations of maximum congestion. Based on this analysis, the gratings located at elevation 757' and $776^{\prime}$ (see Figure 4-1), were identified as two major structural impediments for debris transport. These gratings support pipe whip restraints and a variety of structural supports for equipment, such as recirculation pumps and cable trays. Based on 
schematics and video images of the drywell, it was judged that the congested structural layout around these gratings allowed for limited clearance for flow and would lead to retention of debris due to steam condensation of the structural surfaces. As a result, the debris generated by the breaks located in higher elevations would have a greater opportunity to be deposited on a structural surface than those generated at lower elevations.

Based on these insights, the gratings were used as reference points and the drywell was divided into three regions: high, middle and low. Break locations below an elevation of 757' were classified as low or "L." Debris generated by a LOCA in this low elevation would encounter very few structural impediments. It was assumed that about $45 \%$ of the debris generated in this region would be transported to the suppression pool by the steam flows. The remaining $55 \%$ would be deposited on various structures in the drywell as well as on the ventpipes and the downcomers where the majority of condensation would occur. $\mathrm{A} \mathrm{T}_{\mathrm{bd}}$ of 0.45 was used for these breaks. Breaks at elevations between $757^{\prime}$ and $776^{\prime}$ were classified as middle or "M." Debris generated in this region must be transported through the tortuous space between various pipe structures and then through the grating at elevation 757'. A $\mathrm{T}_{\text {bd }}$ of 0.35 was used for these breaks based on engineering judgement. Break locations higher than 776 ' were classified as high or " $\mathrm{H}$ " and were assigned a $T_{b d}$ of 0.15 to account for the fact that debris generated at these higher elevations are impeded by the bulb-shaped drywell design which offers larger surface area, piping networks, and the highly congested $776^{\prime}$ grating.

The blowdown transport factor, $\mathrm{T}_{\mathrm{bd}}$, was used to calculate the quantity of debris transported to the suppression by the steam flows. The remaining fraction of the debris $\left(1-\mathrm{T}_{\mathrm{bd}}\right)$ was assumed to have been deposited on various drywell structures. As evident from the HDR tests [Ref. 4.3], a fraction of this debris could be firmly attached to the structures while the other fraction would be available for transport by the washdown water flows. The actual fraction transported will depend on plant specific features such as containment sprays and drywell arrangement. Once again, engineering judgement was used to estimate these fractions.

\subsubsection{Time Scales for Drywell Transport}

The foregoing discussions qualitatively divided the time dependence of debris transport into the blowdown phase and the washdown phase. The duration of each of these phases is a strong function of the break size, reactor power level, and reactor type. For the reference plant, blowdown was estimated to occur over a period of 120 seconds following a LLOCA and over a period of 1500 seconds for a MLOCA. However, the initial part of the blowdown involves purging the containment atmosphere, during which time debris transport to the suppression pool would probably be minimal. As a result, this study assumed that actual debris transport during blowdown occurs over a period of 100 seconds following a LLOCA, and over a period of 1,200 seconds following a MLOCA. The washdown of the debris is enabled immediately after the blowdown by the break flow. This continues indefinitely until the break is isolated or the ECCS flow is throttled. This study estimated that most of the loosely attached debris would probably be transported during the initial 30 minutes following the termination of a LOCA blowdown phase.

\subsection{Quantity and Types of Debris Transported to the Suppression Pool}

\subsubsection{Insulation Debris}

BLOCKAGE uses the elevation information for each weld (Table D-1), the blowdown and washdown transport factors discussed in Section 4.1 and Equation 4-1 and 4-2 to calculate the volume of the debris transported to the suppression pool for each break. Table 4-1 provides BLOCKAGE results for the quantity of debris transported to the suppression pool for the four representative weld breaks discussed in Chapter 3. As shown in this table, the volume of fibrous debris reaching the suppression pool for the example breaks varies from 1.5 to $28 \mathrm{ft}^{3}$ $\left(0.04\right.$ to $\left.0.78 \mathrm{~m}^{3}\right)$, depending on the break size location and diaméter. 
Table 4-1 Volume of Fibrous Debris Transported to Suppression Pool

\begin{tabular}{|c|c|c|c|c|c|c|c|c|}
\hline \multirow[b]{2}{*}{$\begin{array}{l}\text { Weld } \\
\text { ID }\end{array}$} & \multirow[b]{2}{*}{$\begin{array}{c}\text { Vgen } \\
\mathrm{ft}^{3}\left(\mathrm{~m}^{3}\right)\end{array}$} & \multirow[b]{2}{*}{$\begin{array}{l}\text { Loc. } \\
\text { ID }\end{array}$} & \multicolumn{2}{|c|}{ Blowdown Transport $^{1}$} & \multicolumn{2}{|c|}{ Washdown Transport ${ }^{2}$} & \multicolumn{2}{|c|}{ Total Transport } \\
\hline & & & $\begin{array}{l}\text { Transport } \\
\text { Factor }\end{array}$ & $\begin{array}{l}\text { Volume } \\
\mathrm{ft}^{3}\left(\mathrm{~m}^{3}\right)\end{array}$ & $\begin{array}{l}\text { Transport } \\
\text { Factor }\end{array}$ & $\begin{array}{l}\text { Volume } \\
\mathrm{ft}^{3}\left(\mathrm{~m}^{3}\right)\end{array}$ & Fraction & $\begin{array}{l}\text { Volume } \\
\mathrm{ft}^{3}\left(\mathrm{~m}^{3}\right)\end{array}$ \\
\hline RCA-J006 & $112(3.17)$ & $\mathrm{H}$ & 0.15 & $17(0.48)$ & 0.10 & $11(0.31)$ & 0.25 & $28(0.79)$ \\
\hline MSB-J021 & $14(0.40)$ & M & 0.35 & $5(0.14)$ & 0.15 & $2(0.06)$ & 0.50 & $7(0.20)$ \\
\hline RCA-J027 & $6(0.17)$ & $\mathrm{L}$ & 0.45 & $2.7(0.08)$ & 0.30 & $1.8(0.05)$ & 0.75 & $4.5(0.13)$ \\
\hline RCB-J028 & $2(0.06)$ & $\mathrm{L}$ & 0.45 & $0.9(0.03)$ & 0.30 & $0.6(0.02)$ & 0.75 & $1.5(0.04)$ \\
\hline
\end{tabular}

${ }^{1}$ Duration of blowdown transport is 100 seconds for RCA-J006 and MSB-J021; 1200 seconds for RCA-J027 and RCB-J028.

${ }^{2}$ Duration of washdown transport is 1800 seconds for all welds.

\subsubsection{Drywell Particulates}

As discussed in Chapter 3, the LOCA jets also generate about $85 \mathrm{lbm}(38.6 \mathrm{~kg})$ of paint chips in the drywell. This study assumed that $100 \%$ of the paint chips (i.e., $85 \mathrm{lbm}$ or $38.6 \mathrm{~kg}$ ) of paint chips would be transported to the suppression pool during the blowdown phase. Similarly, a transport factor of 1.0 was also used for the $156 \mathrm{lbm}(70.8 \mathrm{~kg})$ concrete dust debris generated in the drywell. Parametric analyses (see Appendix $C$ ) suggest that these assumptions do not significantly influence the overall BLOCKAGE results given the assumed suppression pool sludge mass of $850 \mathrm{lbm}$.

\subsection{Drywell Transport Assumptions and Limitations}

The simplified transport model used in this study to estimate the transport of LOCA generated debris from the drywell to the suppression pool assumes that transport can occur during blowdown, due to recirculating steam flow, and during washdown, due to water cascading from the break and/or actuation of the containment sprays. The transport factors in each of these phases were assumed to depend on the break elevation in the drywell, but were considered to be independent on the break size and jet subcooling. The effects of gratings and structures on debris transport was not explicitly modeled. In addition, formation of water pools on the drywell floor, that could play a significant role in the transport of debris, was not considered in the model.

In the case of the reference plant, this study assumed that containment sprays were not actuated and, regarding the break elevations, considers three possible regions derived from the particular drywell layout: high, middle and low, with transport factors of $0.25,0.50$ and 0.75 respectively. In assigning these values, however, it has to be recognized that there are very limited experimental or analytical data to verify the adequacy of the proposed transport factors; hence, considerable caution must be used to estimate the regions and corresponding transport factors for other plants or accident scenarios (for example, containment spray operation). 
Drywell Transport

\section{References for Section 4.0}

4.1 Sydkraft, "Report Concerning the Quantity of Insulation Which Was Not Washed Down in Connection with the 316 Event," PBM-9211-23, November 1992.

4.2 "Karlshamn Tests 1992. Test Report, Steam Blast on Insulated Objects," ABB Atom, Report RVE 92-205, November 1992.
4.3 A. W. Serkiz, "Containment Emergency Sump Performance," U.S. Nuclear Regulatory Commission, NUREG-0897, Rev. 1, October 1985. 


\subsection{Suppression Pool Transport}

The reference plant is equipped with a large torusshaped suppression pool containing a large volume of water. The suppression pool is designed to prevent overpressurization of the drywell by condensing steam released during blowdown events. The suppression pool is also a source of water for ECCS and long-term cooling. The torus is about $25.67^{\prime}$. $(7.82 \mathrm{~m})$ in diameter, with the center line at elevation mark of $732^{\prime}-3^{\prime \prime}$. The maximum free air volume of the torus is $94,300 \mathrm{ft}^{3}\left(2670 \mathrm{~m}^{3}\right)$, with water volume of $58,900 \mathrm{ft}^{3}\left(1668 \mathrm{~m}^{3}\right.$ ) (or $61,500 \mathrm{ft}^{3}$ [1741 $\mathrm{m}^{3}$ ] during an accident). The torus is connected to the drywell through vent pipes located at an elevation mark of $744^{\prime}$.

\subsection{Volume of Insulation Debris Introduced to the Suppression Pool}

Initially steam and debris mixtures will enter the suppression pool through the vent pipes. Table 4-1 presented the volume of the insulation debris introduced during the blowdown phase for four representative welds. In addition a total of $241 \mathrm{lbm}$ $(109.4 \mathrm{~kg})$ of drywell particulates, consisting of paint chips and concrete dust, are assumed to be added to the suppression pool during blowdown. The blowdown would be followed by washdown, which transports the water and debris mixtures to the pool. During this phase, most of the insulation added to the suppression pool consists of insulation fragments. Table 4-1 also listed the volumes of insulation debris added to the pool during this longterm washdown phase.

\subsection{Quantity and Type of Debris Contained in the Reference Plant Suppression Pool}

Large quantities of particulate matter were found to be present in BWR suppression pools during normal operation [Ref. 5.1]. This material is termed 'suppression pool sludge' and consists primarily of rust particles. Sources of rust include the suppression pool walls, downcomer inner surfaces, ECCS piping and other piping that may discharge either directly or indirectly into the suppression pool either during normal operation or during shutdown activities. Various utilities have described the sludge as consisting of various forms of iron oxides $\left(\mathrm{Fe}_{2} \mathrm{O}_{3}\right.$ and $\left.\mathrm{Fe}_{3} \mathrm{O}_{4}\right)$ red or black in color. The estimates on size distribution appear to vary from sub-micron particles to particles of several hundred microns. Both the quantity of sludge contained in the suppression pool at the time of an accident and its size distribution appear to be strongly dependent on the pool water $\mathrm{pH}$ (not specifically controlled) and desludging activities. As a result, the estimates vary from $70 \mathrm{lbm}$ to $5000 \mathrm{lbm}$ of sludge for the mass of sludge contained in the suppression pool. Some plants have also observed quantities of organic matter that apparently grow in the pools as a result of the sludge. Finally, some plants have reported presence of items such as coveralls and large quantities of plastic tapes.

No plant-specific measurements are available on the quantity or constituents of the sludge contained in the reference plant suppression pool. Similarly, accurately determined estimates for the sludge particle size distribution for the reference plant were not available. However, the plant has undertaken chemical analysis of the sludge samples which suggest that the majority of the sludge consists of iron oxides with trace amounts of $\mathrm{Ni}$ and $\mathrm{Cr}$. Discussions with plant engineers suggest that a value of $850 \mathrm{lbm}(385 \mathrm{~kg})$ may be a reasonable estimate of the amount of sludge contained in the pool. Particle size distribution data measured from the NRC suppression pool tests [Ref. 5.2] was assumed to be applicable to the reference plant (see Table B-6). This distribution data is different from the BWROG specified size distribution (see Table B-4) by the fact that it accounts for agglomeration of particles. Appendices $B$ and $E$ provide further discussions on the size distributions and their applicability. It should be noted in the range of particle sizes considered (i.e., Table B-4 vs. Table B-6), the BLOCKAGE predictions are weakly dependent on the particle size.

\subsection{Debris Transport Within the Reference Plant Suppression Pool}

This section provides an overview of the conditions and mechanisms by which the debris discussed above are transported within the suppression pool of the reference plant to the ECCS strainers. The 
following paragraphs discuss the LOCA-induced hydrodynamic conditions in Mark I containments, the suppression pool transport model, and the quantity and type of debris transported to the strainers.

\subsubsection{LOCA Induced Hydrodynamic Conditions in the Mark I Containments}

As noted in NUREG-0661 [Ref. 5.3] and Appendix B, the suppression pool is characterized by large scale turbulence during the blowdown phase of a LOCA. Initially, sudden pressurization of the drywell causes vent clearing which is followed by continuous transfer of drywell steam to the suppression pool via vertical downcomers. The steam condenses upon contact with suppression pool water. During the initial stages, especially after a LLOCA, the steam flow is sufficiently large to completely displace water from the downcomer and allow continuous flow of steam which then condenses at the downcomer exit. The hydrodynamic phenomena associated with this phase is commonly referred to as condensation oscillations. With decreases in steam flow, water enters the downcomers and causes steam condensation in the downcomers. During this process the non-condensibles form a thin layer that prevents heat transfer between steam and water. This results in build-up of pressure behind the condensation front causing the front to move closer to the vent pipe exit where the non-condensibles could be vented from the pipe. This mechanism of steam condensation results in a situation where the condensation front (or the water front) moves upwards and downwards in the downcomer. The resultant hydrodynamics are commonly referred to as chugging and continue until the drywell and wetwell pressures equalize. For a LLOCA, the condensation oscillations occur over a period of about 30 seconds followed by chugging for the remainder of the blowdown phase or the highenergy phase (a total of 100 to 120 seconds in duration). For a MLOCA, condensation oscillations are very unlikely and intense to moderate chugging is more common as evidenced in the Mark I suppression pool tests [Ref. 5.3]. Appendix B provides further details on the hydrodynamic instabilities in Mark I suppression pools.

Obviously, suppression pool transport is a complex phenomenon that cannot be easily modeled. Owing to its importance, the NRC has sponsored a series of experiments to study the effects of suppression pool hydrodynamics on debris transport [Ref. 5.4]. These experiments provided valuable insights into debris behavior during the high-energy phase characterized by high turbulence due to condensation oscillations and chugging. Coupled with the $\mathrm{ABB}$ Atom experiments [Ref. 5.5] and the Barsebäck-2 incident [Ref. 5.6], the findings of the NRC experiments can be used to draw the following conclusions related to debris transport in a Mark I suppression pool:

1. Debris in the form of fines and shredded pieces are introduced to the suppression pool through the network of vent pipes and downcomers. Since the vent pipe downcomers are equally spaced, it was assumed in this study that debris introduction into the suppression is likely to be homogeneous during the blowdown phase. Debris introduction during the washdown phase, in contrast, could be non-uniform, depending upon the location of the break, the volume of debris generated and its distribution within the water pool formed on the drywell floor.

2. Turbulence created by condensation oscillations and chugging during the blowdown will impede the settling of debris. This conclusion is valid for both the fibrous and non-fibrous debris. Turbulence in some cases may possess sufficient energy to cause further destruction of debris, which indirectly reduces the quantity of settled debris. Also, the turbulence will most likely resuspend the sludge mass contained initially on the suppression pool floor. For example, in the NRC experiments large chunks of fibrous debris introduced at the bottom of the suppression pool were immediately suspended during the chugging phenomenon and were shredded into smaller pieces within a few minutes after the start of the experiment. Similar debris behavior was also reported by

\footnotetext{
${ }^{1}$ At the Barsebäck-2 incident, the majority of the debris transport occurred during the spray washdown phase. The debris, however, were noted to have been uniformly distributed throughout the suppression pool as demonstrated by the fact that both ECCS strainers located diametrically opposite from each other were blocked at just about the same time.
} 
the $A B B$ Atom tests which involved aged mineral wool fragments and calcium silicate particles [Ref. 5.7].

3. After termination of the high-energy phase, the suppression pool rapidly reaches relative calm characterized by steady state flow patterns created by the downcomer flow, which is introduced normal to the horizontal flow established in the suppression pool by the ECCS suction. The resultant turbulence during this phase, referred to as the ECCS Recirculation Phase, may not possess sufficient energy to keep all the debris in suspension. Gravitational settling of both fibrous debris and sludge are possible during this phase, which could continue indefinitely in the reference plant. Visual observation of debris movement in the NRC experiments suggests that calm suppression pool conditions are reached within a matter of few minutes, and thereafter the settling is dictated mostly by gravity effects. In the actual plant, it may be possible that the gravity effects would be offset by the horizontal flow created by ECCS recirculation flow patterns minimizing the potential for settling.

4. From the reference plant FSAR, the suppression pool temperature is expected to be about $125^{\circ} \mathrm{F}\left(52^{\circ} \mathrm{C}\right)$ following a LLOCA provided that at least two ECCS heatexchangers perform per design. In such a case the ECCS would be operated indefinitely with no attention paid to the suppression pool cooling. However, if the suppression pool temperature were to increase beyond that allowed in the EOPs, the plant operator is expected to actuate the suppression pool cooling systems. Initiation of these systems induces large suppression pool flows in the torus coupled with suppression pool sprays. This action most likely will introduce large scale turbulence that once again may impede settling, and in some extreme cases, may resuspend some of the debris settled during the ECCS Recirculation Phase described above.

5. Debris that remains suspended in the suppression pool water would be entrained by the flow fields established by the ECCS pumps and would ultimately reach the strainer(s).
However, this assumption may not accurately reflect the actual suppression pool debris behavior and in some cases may overestimate the quantity of debris reaching the strainers. For example, in some suppression pools preferential flow paths may exist for the downcomer flow to reach the strainer. In such cases, the debris introduced into the rest of the suppression pool will have longer times available for settling. Similarly, such factors as the strainer elevation from the pool floor could also impact the quantity of debris reaching the strainer.

Based on these insights, the following debris transport model was developed for the reference plant.

\subsubsection{Reference Plant Suppression Pool Debris Transport Model}

The model employed assumes that:

1. The debris introduced to the suppression pool is distributed uniformly both during

blowdown and washdown phases.

2. The debris remains suspended in entirety during the high-energy phase that coincides with the pressure vessel blowdown.

3. All the debris contained at the bottom of the suppression pool will be resuspended and uniformly mixed with the pool water during the high energy phase.

4. After termination of the high-energy phase, the debris will settle under the influence of gravity. The settling velocities listed in Tables B-5 and B-6 in Appendix B can be used to estimate the settling rates of the fibrous debris and suppression pool sludge. These settling velocities were judged to be applicable to the reference plant as discussed in Appendix B. In addition, based on experimental results [Ref. 5.8], a settling velocity of $0.2 \mathrm{ft} / \mathrm{s}$ was assigned for paint chips, which are assumed to be $0.125 "(0.32 \mathrm{~cm})$ in width with an average weight of $0.10 \mathrm{~g}$. Finally, a settling velocity of $0.4 \mathrm{ft} / \mathrm{s}$ was assigned to concrete dust and other drywell particulates. 
5. Suppression pool cooling is not activated.

6. The volume of debris approaching the strainer can be estimated assuming homogeneous mixing of the debris with the pool bulk volume.

7. The ECCS flow rate varies with time. For all breaks the ECCS flow rate is assumed to reach the design flow of 25,000 gpm after the termination of reactor vessel blowdown. It is recognized that maximum ECCS flow for breaks $\leq 2$ " could be lower than 25,000 gpm.

\subsubsection{Quantity and Type of Debris Transported to the Strainer}

BLOCKAGE was run under the assumptions listed in 5.3.2 to estimate the quantity and type of debris reaching the strainer as a function of time for each postulated break. The governing equations used in BLOCKAGE are discussed in detail in Appendix B.

Table 5-1 presents the volumes of various debris species reaching the strainer for the representative welds. As shown in Table 5-1, only about $10 \%$ of the fibrous debris actually settle, and the remaining $90 \%$ will ultimately reach and deposit on the strainer. On the other hand, about $35 \%$ of the sludge, and about $80 \%$ of the concrete dust and the paint-chips ultimately settle on the pool floor. The remaining debris reach the strainer. These quantities could be higher if suppression pool cooling is actuated on in the later phases of LOCA progression.

\subsection{Suppression Pool Transport Assumptions and Limitations}

The suppression pool model used in this study to estimate the amount of debris reaching the strainers at the suction of the ECCS pumps considers both the transport of LOCA generated debris from the drywell as well as the suppression pool sludge. Major assumptions in this model can be summarized as follows:

1. All the fibrous and particulate debris remains suspended and uniformly distributed within the pool water during the blowdown phase. This assumption was based on experimental results specific for $\mathrm{NUKON}^{\mathrm{TM}}$ fibers and iron oxide particles simulating suppression pool sludge, and may not be applicable to other debris types.

2. During the washdown phase, all the debris in the suppression pool will begin to settle under the influence of gravity. The debris settling velocities used in this study were estimated from experiments specifically

Table 5-1 Quantity and Type of Debris Transported to the Strainer for Representative Welds

\begin{tabular}{lcccccccc}
\hline & \multicolumn{4}{c}{\begin{tabular}{c}
\multicolumn{2}{c}{ Volumes ${ }^{1}$ Present in the Suppression } \\
Pool $\left(\mathrm{ft}^{3}\right)$
\end{tabular}} & \multicolumn{3}{c}{ Total Volume ${ }^{1}$ Deposited on Strainers $\left(\mathrm{ft}^{3}\right)$} \\
Weld ID & Fiber & Sludge & $\begin{array}{c}\text { Concrete } \\
\text { Dust }\end{array}$ & $\begin{array}{c}\text { Paint } \\
\text { Chips }\end{array}$ & Fiber & Sludge & $\begin{array}{c}\text { Concrete } \\
\text { Dust }\end{array}$ & $\begin{array}{c}\text { Paint } \\
\text { Chips }\end{array}$ \\
\hline RCA-J006 & 28 & 2.6 & 1.0 & 0.70 & 24.2 & 1.10 & 0.11 & 0.10 \\
MSB-J021 & 7 & 2.6 & 1.0 & 0.70 & 6.1 & 1.04 & 0.09 & 0.08 \\
RCA-J027 & 4.5 & 2.6 & 1.0 & 0.70 & 3.9 & 0.95 & 0.06 & 0.06 \\
RCB-J028 & 1.4 & 2.6 & 1.0 & 0.70 & 1.23 & 0.67 & 0.02 & 0.02 \\
\hline
\end{tabular}

${ }^{1}$ The masses of fiber, sludge, paint chips and drywell particulates are calculated from volumes using theoretical densities $24,324,124$ and $156 \mathrm{lbm} / \mathrm{ft}^{3}$, respectively. 
conducted for NUKON ${ }^{T M}$ fragments and iron oxides particles simulating fibrous and particulate debris respectively. Specific analysis/experiments are required to estimate settling velocities for other types of debris materials and size distributions.

3. The debris is homogeneously mixed with the pool bulk volume both vertically and horizontally. It is recognized, however, that this may not be an accurate representation of debris behavior in a quiescent suppression pool, especially during the washdown phase when debris introduction could be nonuniform depending on the break location and drywell layout. Potential for these nonuniformities should be addressed on a plantspecific basis.

4. The effects of the operation of the suppression pool cooling systems in the transport of debris to the strainers were not considered for the reference plant. For those plants that rely on active suppression pool cooling systems, neglecting their effect most likely would overpredict settling and underpredict the volume of debris reaching the strainers. These concerns should be addressed on a plant-specific basis. 
Suppression Pool Transport

\section{References for Section $\mathbf{5 . 0}$}

5.1 BWR Owners' Group, "Interim Report of the BWR Owners' Group ECCS Suction Strainer Committee," BWROG-94157, December 1994.

5.2 F. Souto, E. Cramer, D. Rao, and T. Kodas, "Simulated BWR Sludge Characterization," SEA Report No. 95-554-06-A:7, March 1995.

5.3 NUREG-0661, Safety Evaluation Report, "Mark-I Containment Long-Term Program," Resolution of Generic Technical Activity A-7, USNRC, 1980.

$5.4 \quad$ F. Souto and D.V. Rao, "Experimental Investigation of Sedimentation of LOCA Generated Fibrous Debris and Sludge in BWR Suppression Pools," SEA Report No. 95-55406-A:9, June 1995.

5.5 R. Faxen, "Barsebäck 1 and 2, Okarshamn 1 and 2 - Strainers in Systems 322 and 323; Results from Blowdown Experiments in a Test Rig," ABB Atom, RVA 92-340, November 1992.
5.6 Sydkraft, "Report Concerning the Quantity of Insulation Which Was Not Washed Down in Connection with the 316 Event," PBM-9211-23, November 1992.

5.7 Faxen, R., "Barsebäck 1 and 2, Oskarshamn 1 and 2 - Strainers in Systems 322 and 323; Results from Blowdown Experiments in a Test Rig," ABB Atom, RVA 92-340, November 1992.

5.8 P. Murthy, M. Padmanabhan, and G. Hecker, "Tests of Particle Settling Velocity in Still Water," Report No. ARL/SEA/787/94/1, Alden Research Laboratories, Inc., June 1994. 


\subsection{ECCS Suction Strainer Blockage Analyses}

The analysis of ECCS suction strainer blockage for the reference plant involved understanding the RHR and LPCS systems of the reference plant, determination of the NPSH margin for the reference plant ECCS pumps, and development of the model for loss of the ECCS pumps due to the loss of adequate NPSH. Estimation of the head loss across the strainer involved two major components of the study: transient buildup of debris on the strainer and the pressure drop due to debris accumulation. The following sections provide the details of the analyses performed for the reference plant, including the head loss correlation developed from recent experimental data.

\subsection{RHR and LPCS Systems Description for the Reference Plant}

Immediately following a LOCA, water is drawn from a combination of the suppression pool and CST into the reactor core by the RHR, LPCS, RCIC and HPCI systems pumps. For a majority of the postulated breaks, the RHR and LPCS are the only adequate mitigating systems. ${ }^{1}$

The RHR and LPCS systems are designed to provide low pressure core flooding following a LOCA. These systems take suction from the suppression pool and inject water into the reactor core; the water then flows out of the break. In this mode of operation, the RHR system is commonly referred to as LPCI. Both LPCI and LPCS systems are actuated on either a low core water level or high drywell pressure signal. In the reference plant, the LPCI and LPCS systems each have two penetrations into the torus: N225A\&B for RHR, and N227A\&B for LPCS. Each of these penetrations is equipped with a pump suction strainer, semi-conical in shape. The purpose of the strainer is to filter out the debris that may damage the ECCS pump internal parts or plug the containment spray nozzles and/or core spray nozzles. Figure 6-1 is an engineering drawing of one of the reference plant strainers. The strainers are made of 14 gauge perforated steel sheets, with $301 / 8^{\prime \prime}$ holes per in ${ }^{2}\left(4.653 .2 \mathrm{~mm}\right.$ holes per $\left.\mathrm{cm}^{2}\right)$,

\footnotetext{
${ }^{1}$ For breaks $\leq 2$ " (a total of 57 breaks) the RCIC and HPCI systems can mitigate the accident. This issue is further addressed in Section 8 .
}

with an open flow area of approximately $40 \%$ of the total strainer surface area. Figure 6-1 summarizes the strainer geometrical data, along with the calculated surface and flow areas for each strainer. Figure 6-2 depicts the location and elevation of the reference plant strainers.

The LPCI injects into the recirculation discharge lines and the LPCS injects into the core through dedicated nozzles in the reactor vessel. Only one low pressure ECCS pump (LPCI or LPCS) is required for adequate core cooling; however, the emergency operating procedures (EOPs) indicate that all ECCS pumps are switched on for such events.

The LPCI system has four Byron Jackson centrifugal pumps (RHR-A, B, C, and D), each with a rated flow of 4800 gallons per minute (gpm) (18.2 $\left.\mathrm{m}^{3} / \mathrm{min}\right)$ at a discharge head of $400 \mathrm{ft}(122 \mathrm{~m})$ of water. Figure 6-3 delineates pump curves for these purnps. As shown in this figure, NPSH required for these pumps at the rated flow is about $10 \mathrm{ft}(3.05 \mathrm{~m})$ of water. The pumps are located at an elevation mark of $718^{\prime}$, or about $14 \mathrm{ft}(4.3 \mathrm{~m})$ below the suppression pool center-line. Pumps RHR-A and C take suction from strainer N225A; pumps RHR-B and $\mathrm{D}$ take suction from strainer N225B. The NPSH available at the LPCI suction is approximately $24 \mathrm{ft}$ $(7.3 \mathrm{~m})$ of water, resulting in a NPSH-margin of about $14 \mathrm{ft}(4.3 \mathrm{~m})$ of water. The estimated flow through each strainer (N225A and N225B) is 9600 $\mathrm{gpm}\left(36.4 \mathrm{~m}^{3} / \mathrm{min}\right)$, and the corresponding strainer flow velocity is $1.46 \mathrm{ft} / \mathrm{s}(0.45 \mathrm{~m} / \mathrm{s})$.

The LPCS system has two Byron Jackson centrifugal pumps (CS-A and B), each rated to provide $3100 \mathrm{gpm}\left(11.7 \mathrm{~m}^{3} / \mathrm{min}\right)$, at a discharge head of $700 \mathrm{ft}(213.4 \mathrm{~m})$ of water. Figure 6-4 delineates pump curves for these pumps. As shown in this figure, the NPSH required for these pumps at rated. flow is about $15 \mathrm{ft}(4.6 \mathrm{~m})$ of water. The NPSH available at the LPCS suction is approximately $32 \mathrm{ft}$ $(9.75 \mathrm{~m})$ of water; consequently, the NPSH margin available for LPCS is about $17 \mathrm{ft}(5.2 \mathrm{~m})$ of water. Each pump has a dedicated suction strainer. The estimated flow through the LPCS suction strainers during expected operating conditions is $3100 \mathrm{gpm}$ $\left(11.7 \mathrm{~m}^{3} / \mathrm{min}\right)$, and the corresponding strainer flow velocity is $1.60 \mathrm{ft} / \mathrm{s}(0.49 \mathrm{~m} / \mathrm{s})$.

The LPCI and LPCS pumps would be initiated by 
Strainer Blockage
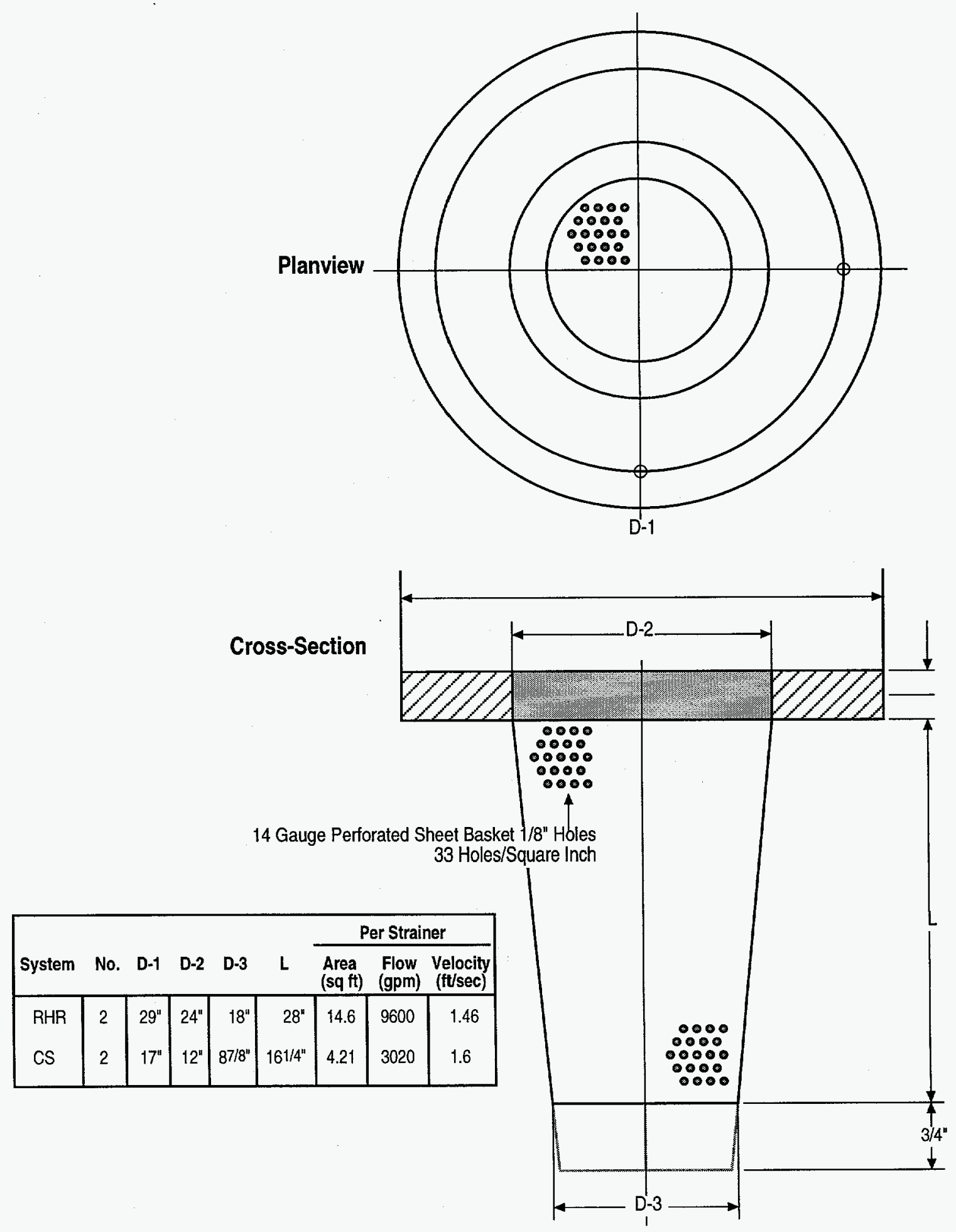

Figure 6-1 Planview \& Cross-Section of Strainer 


\section{Radial Position of Strainers}

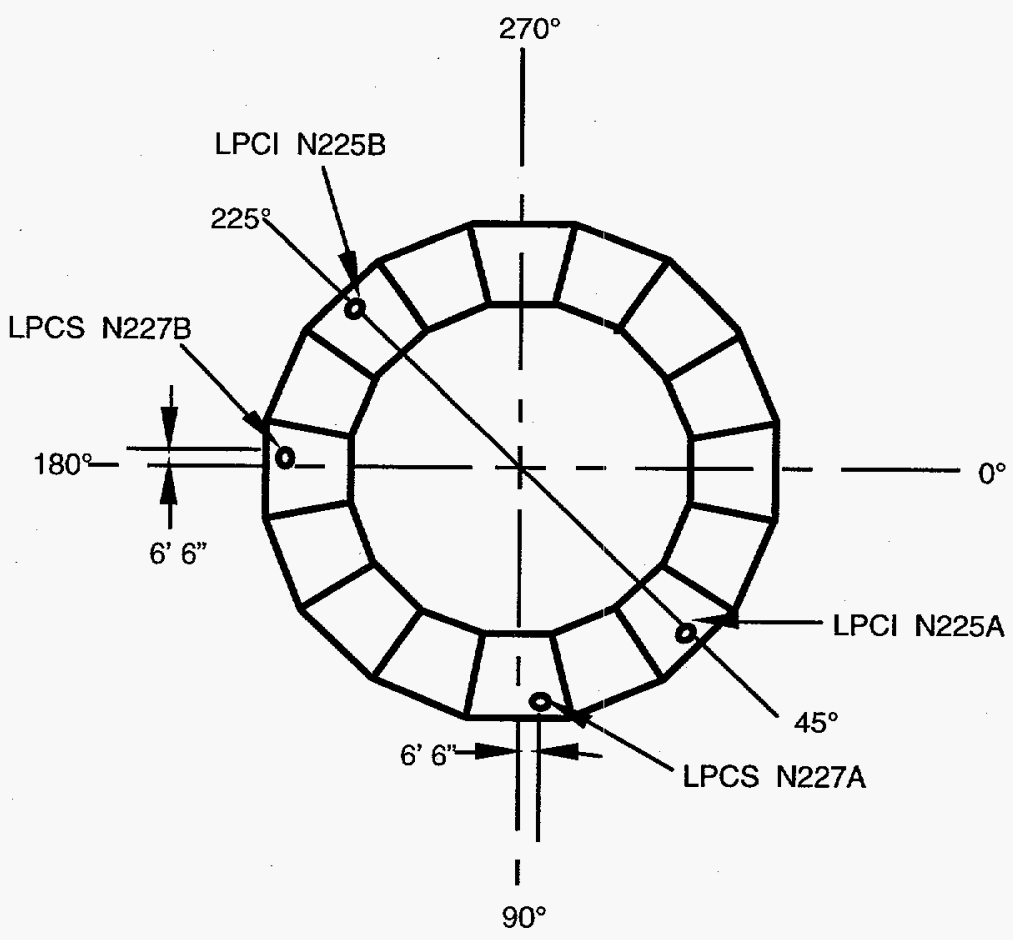

\section{Axial Position of a Representative Strainer}

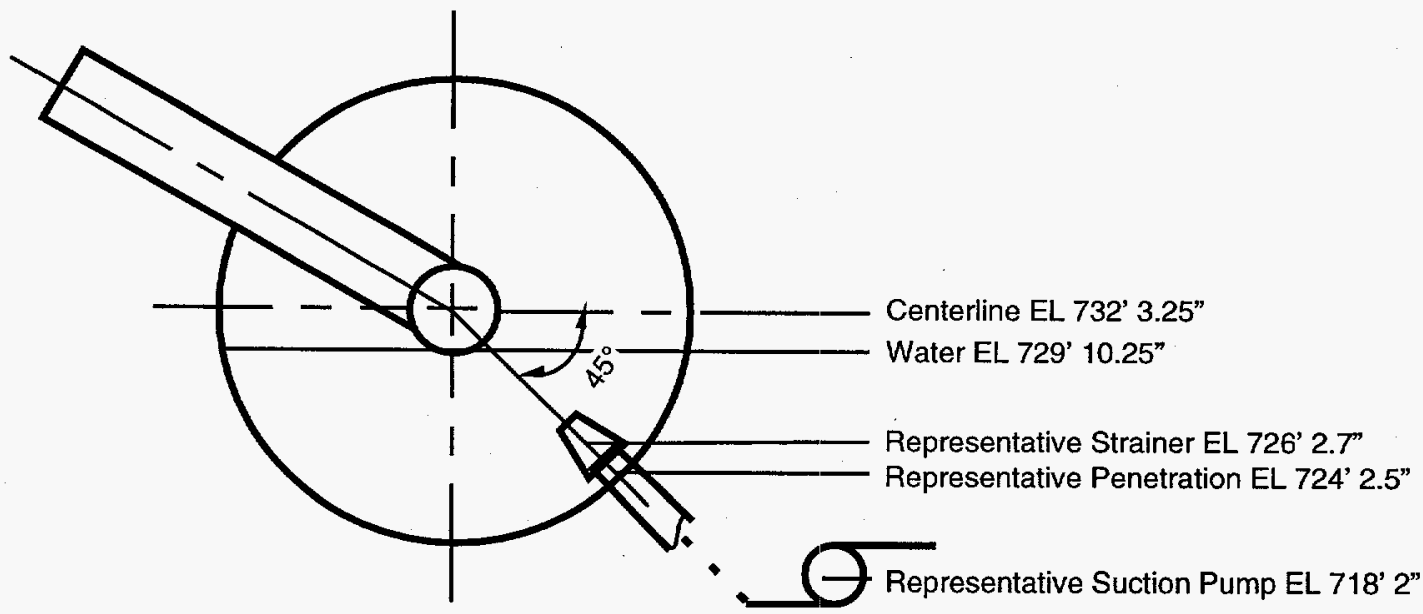

Figure 6-2 Location and Elevation of Strainers 
Strainer Blockage
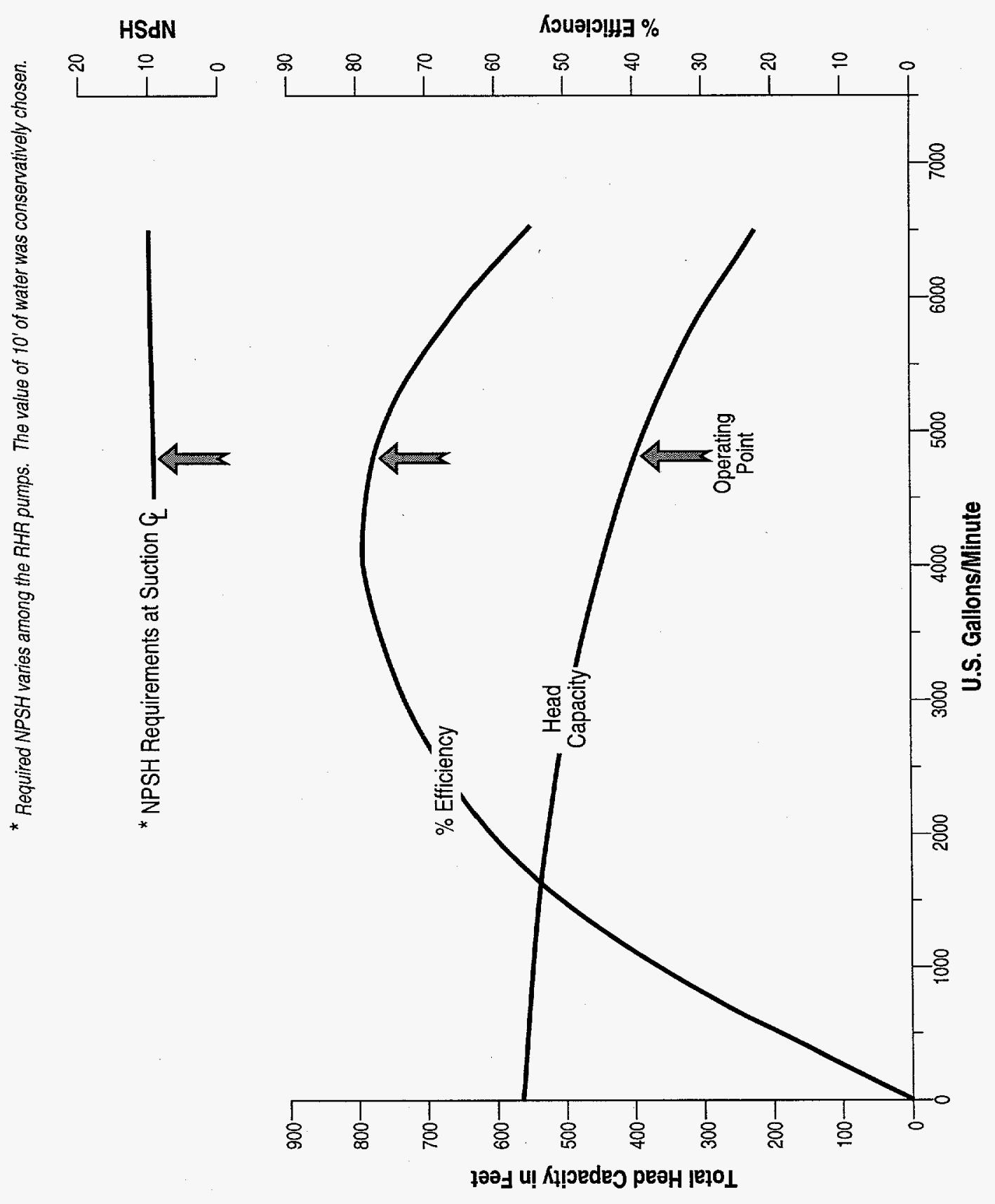

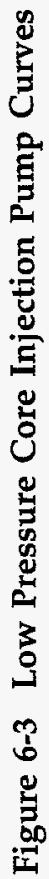




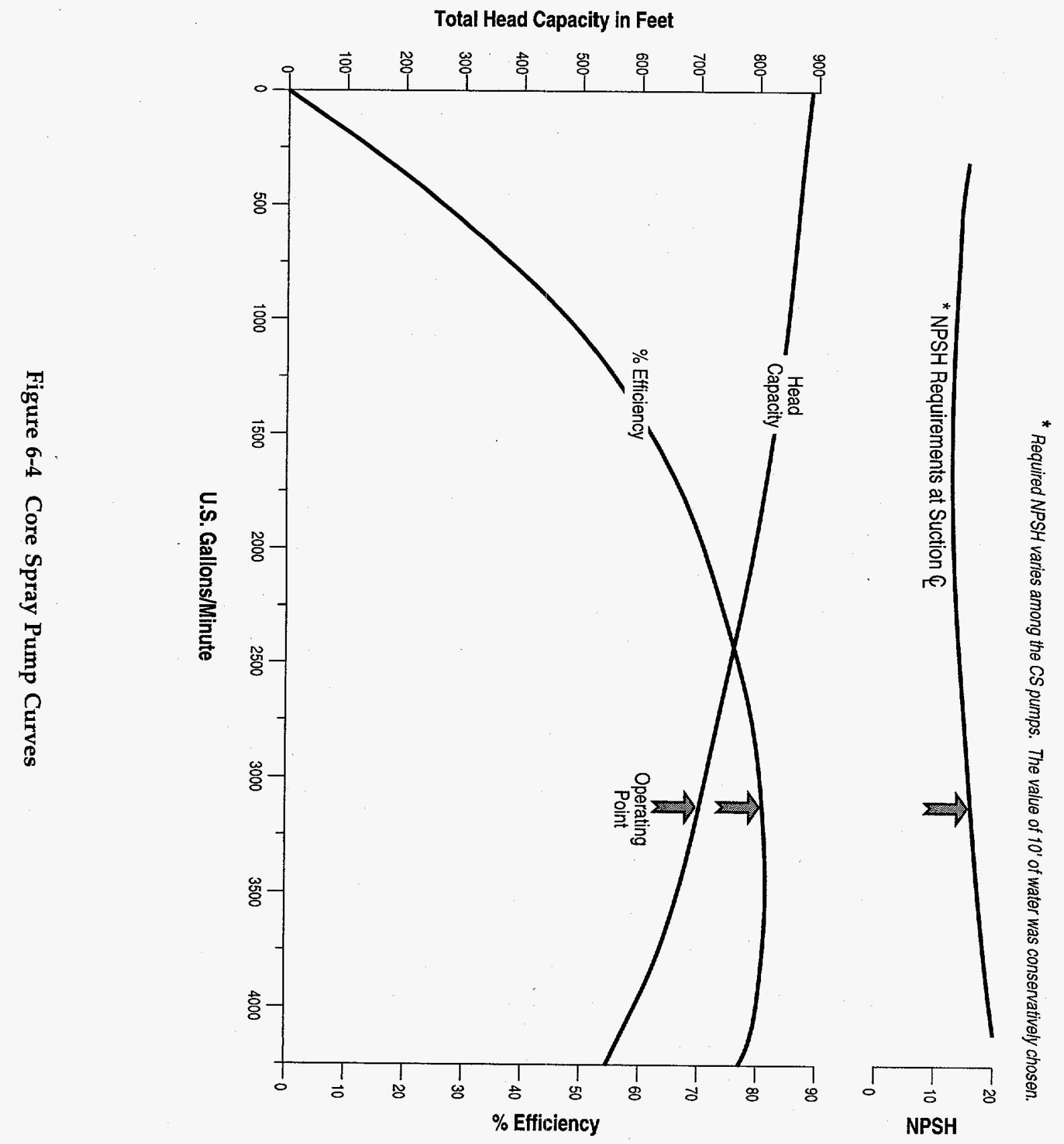


the high containment pressure signal within seconds after a LOCA. Initially, however, the reactor vessel pressure exceeds the shut-off head of both LPCI and LPCS pumps. During this period of high vessel pressure, the ECCS operates in minimum flow mode wherein each of the pumps pump about $10 \%$ of the rated pump flow taken from the suction strainers and recirculates it back into the suppression pool. This flow is required to maintain operability of the ECCS pumps. As the blowdown continues, the vessel pressure falls below the shut-off head, at which point the ECCS pumps start pumping higher quantities of suppression pool water into the reactor core. Addition of cold suppression pool water to the reactor core results in rapid reduction in vessel pressure allowing the design flow of $25,000 \mathrm{gpm}$ $\left(94.6 \mathrm{~m}^{3} / \mathrm{min}\right)$ into the core. Thus the ECCS flow rate is a function of time and break size. Flow rate information for a BWR/4 with a Mark I containment was obtained for two break sizes from the BWROG best-estimate analyses [Ref. 6.1]. Figure 6-5 plots these flow rates as functions of time for LLOCAs and MLOCAs for the reference plant. As shown in this figure, the ECCS flow is less than $2500 \mathrm{gpm}(9.5$ $\mathrm{m}^{3} / \mathrm{min}$ ) over the initial 50 seconds after a LLOCA and 500 seconds after a MLOCA. ${ }^{2}$ However, the flow quickly reaches the design flow value of 25,000 gpm $\left(94.6 \mathrm{~m}^{3} / \mathrm{min}\right)$ immediately after blowdown. As a result of this early low ECCS flow, the strainer pressure losses during the blowdown phase are expected to be relatively low.

\subsection{Model for Loss of ECCS Pumps for the Reference Plant}

As suggested in NUREG-0897, Rev. 1 [Ref 6.2], loss of ECCS pumps is assumed to occur when the $\mathrm{NPSH}_{\text {margin }}$ (i.e., $\mathrm{NPSH}_{\text {available }}-\mathrm{NPSH}_{\text {required }}$ ) is less than the predicted head loss due to strainer blockage by insulation debris. Available and required NPSH values are plant-specific and can be estimated for a given plant using the methodology described in Section 3.2.3 of NUREG-0897, Rev. 1

[Ref. 6.2]. Evaluation of $\mathrm{NPSH}_{\text {available }}$ requires estimation of containment pressure and suppression pool temperature in accordance with Reg. Guide 1.1 which states that NPSH should be calculated using atmospheric pressure and the most severe

\footnotetext{
${ }^{2}$ For breaks $\leq 2$ " the LPCI and LPCS are not needed for core heat removal unless both RCIC and HPCI fail to inject.
}

suppression pool temperature [Ref. 6.3].

Based on discussions with the reference plant engineers, the most severe suppression pool temperature following a LOCA was estimated to be approximately $180^{\circ} \mathrm{F}$ for the reference plant. ${ }^{3}$ Using this value of $180^{\circ} \mathrm{F}$, coupled with frictional loss data used in the reference plant calculations, the $\mathrm{NPSH}_{\text {available }}$ was estimated to be $24 \mathrm{ft}$ of water for LPCI pumps and $18 \mathrm{ft}$ of water for LPCS pumps. The $\mathrm{NPSH}_{\text {required }}$ for these pumps is illustrated in Figures 6-3 and 6-4, respectively. This provides an $\mathrm{NPSH}_{\text {margin }}$ of about $14 \mathrm{ft}(4.3 \mathrm{~m})$ of water for the LPCI pumps and about $17 \mathrm{ft}(5.2 \mathrm{~m})$ of water for the LPCS pumps. In this study, both the LPCI and LPCS strainers and flow rates were combined together to form a single strainer of area equal to the total areas of the individual strainers. The blockage of the strainer was assumed to produce pump loss when the predicted head loss was larger than $14 \mathrm{ft}(4.3 \mathrm{~m})$ of water, i.e., pump loss occurred when:

$$
\Delta H \geq \mathrm{NPSH}_{\text {margin }}=14 \mathrm{ft}(4.3 \mathrm{~m}) \text { of water }
$$

This present analysis assumed that all of the ECCS flow $\left(25,000 \mathrm{gpm}\right.$ or $\left.94.6 \mathrm{~m}^{3} / \mathrm{min}\right)$ was lost when the increase in head loss due to debris buildup on the strainers was greater than the available $\mathrm{NPSH}_{\text {margin }}$. As demonstrated by flat NPSH curves in Figures 6-3 and 6-4, this assumption is fairly accurate for the reference plant.

Estimation of the increase in head loss involved two major components of this study: 1) transient buildup of debris bed on the strainer and, 2) resultant head loss across the strainer due to buildup of the debris cake. The following section describes the respective models developed.

\subsection{Transient Buildup of Debris on the Strainer Model for the Reference Plant}

Transient buildup of the debris bed on the strainer surface and the makeup of the bed are strong

\footnotetext{
${ }^{3}$ Section 6.2.2.2.1 of the reference plant FSAR states that the suppression pool cooling subsystem would be turned on when the pool temperature exceeds $170^{\circ} \mathrm{F}$. An additional temperature rise of $10^{\circ} \mathrm{F}$ was assumed for conservatism.
} 


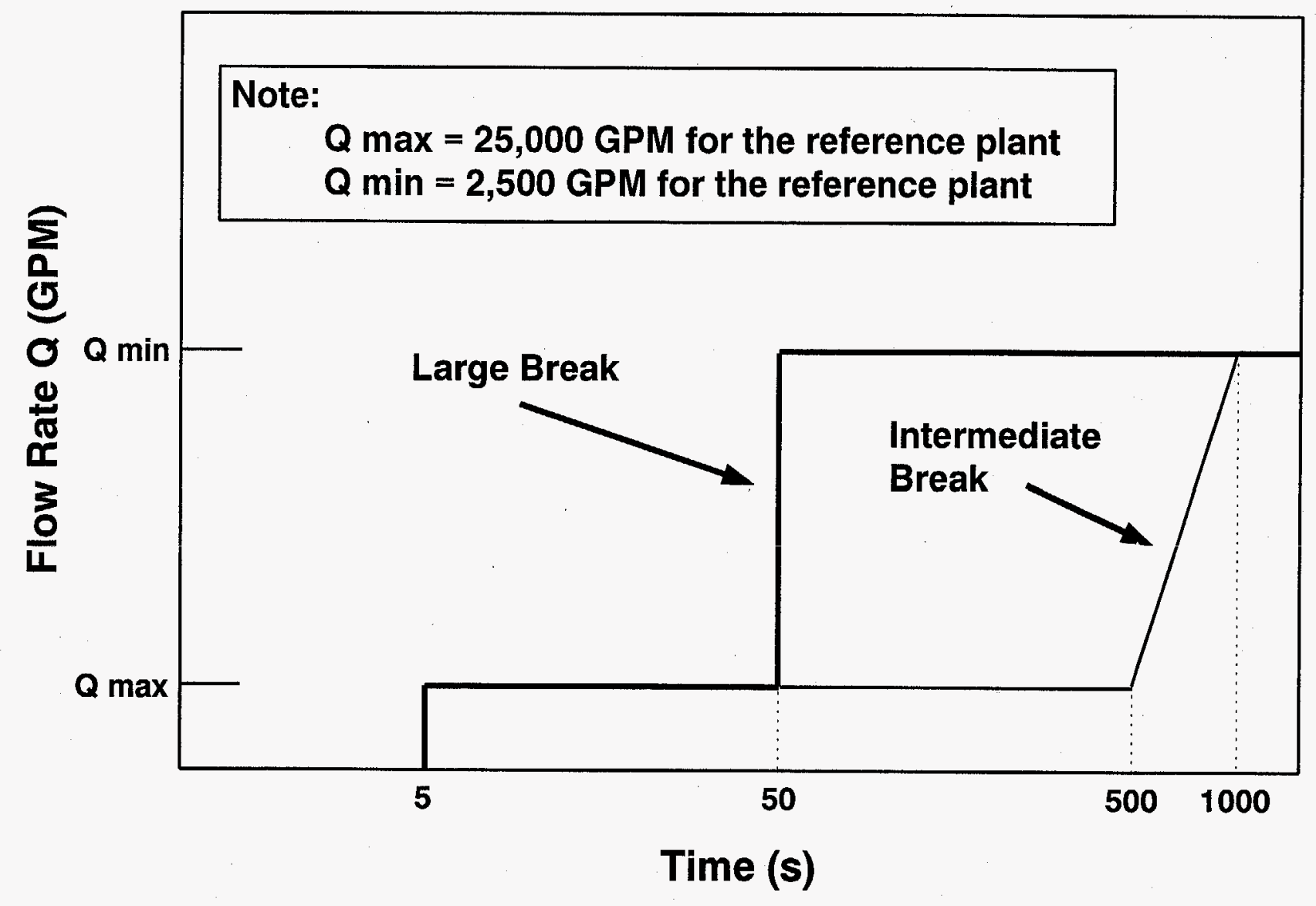


functions of the quantity of debris approaching the strainer and the trapping efficiency of the strainer.

\subsubsection{Quantity and Type of Debris Approaching the Strainer}

Section 5 summarized the calculational models used to estimate the quantity and types of debris reaching the strainer as a function of time. Table 5-1 presented the volume balances of various debris at the end of the 6 hour run time (i.e., after the pool is cleared of debris). BLOCKAGE was used to perform similar calculations for all the welds and the results are presented in Section 7.

\subsubsection{Once-Through Filtering Efficiency Model}

Experiments have suggested that only a fraction of the debris, especially the particulate debris, are trapped on the strainer surface to form the debris cake [Ref. 6.4 and 6.5]. Qualitatively, this fraction was noted to have been a complex function of the debris size, debris type, debris cake thickness and the approach velocity. A series of experiments were sponsored by NRC [Ref. 6.6] as part of this study to obtain an upper bound estimate of once-through filtration efficiency, defined as the fractional mass of the debris filtered by the debris cake during a single pass through the cake. A simplified filtering efficiency model was used to estimate the fraction of debris filtered by the cake. This model is based on the following experimental observations:

1. All the fibrous debris reaching the strainer would be trapped and retained by the strainer, except for a small quantity of finely destructed debris (i.e, size classes 1 and 2) that may escape initially when the debris bed does not bridge all of the strainer holes. However, this situation quickly changes, resulting in $100 \%$ filtering efficiency for the fibrous debris.

2. Only a fraction of the particulate debris reaching the strainer would be filtered by the debris cake formed on the strainer surface. For the simulated sludge used in the study, this fraction is found to be a strong function of the debris bed thickness and a weak function of the approach velocity. As discussed in Appendices $\mathrm{B}$ and $\mathrm{E}$, the maximum oncethrough filtration efficiency achieved in the experiments is less than $50 \%$ for debris bed theoretical thicknesses in the range of $1 / 4$ " to 2 " and for approach velocities in the range of $0.15 \mathrm{ft} / \mathrm{s}$ and $0.5 \mathrm{ft} / \mathrm{s}$. For beds thinner than $1 / 4 "$, the filtration efficiencies would be lower than $50 \%$, approaching $0 \%$ as the theoretical thickness approaches 0 inches.

Figure 6-6 illustrates the filtration model used in this study as a function of bed theoretical thickness.

\subsubsection{Quantity and Type of Debris Trapped on the Strainer}

The model developed to estimate the quantities and types of the material forming the debris cake on the strainer at time $t$ is based on the following equations:

$$
\begin{gathered}
\Delta L_{o}=\frac{1}{A_{s} c_{o}} \int_{o}^{t} e^{f i b e r} C^{f i b e r}(t) Q(t) d t \\
M_{\text {part }}=\int_{o}^{t} e^{\text {part }} \cdot C^{p a r t}(t) Q(t) d t
\end{gathered}
$$

where,

$\mathrm{t}$ is time after LOCA (s),

$\Delta \mathrm{L}_{\mathrm{o}} \quad$ is theoretical thickness of the fiber bed (ft)

$A_{s} \quad$ is strainer surface area $\left(37.62 \mathrm{ft}^{2}\right)$,

$c_{0}$ is NUKONTM as fabricated density $\left(2.4 \mathrm{lbm} / \mathrm{ft}^{3}\right)$,

$\mathrm{e}^{\text {fiber }} \quad$ is fiber filtration efficiency (1.0),

$e^{\text {part }}$ is once-through filtration efficiency at time $\mathrm{t}$ (expressed vs $\Delta \mathrm{L}_{\mathrm{o}}(\mathrm{t})$ in Fig. 6-6)

$C^{\text {fiber }}(t)$ is fiber concentration in the pool at time $\mathrm{t}\left(\mathrm{lbm} / \mathrm{ft}^{3}\right.$ of water)

$C^{\text {part }}(t)$ is particulate concentration in the pool at time $\mathrm{t}\left(\mathrm{lbm} / \mathrm{ft}^{3}\right.$ of water)

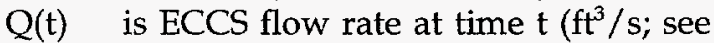
Fig. 6-5)

$\mathrm{M}_{\text {part }}$ is total mass of particulates (sludge + paint chips + drywell particulates) filtered at the strainer surface (lbm),

These equations are further discussed in Appendix $B$ and are incorporated into BLOCKAGE. Details of the BLOCKAGE runs are presented in Section 7. 

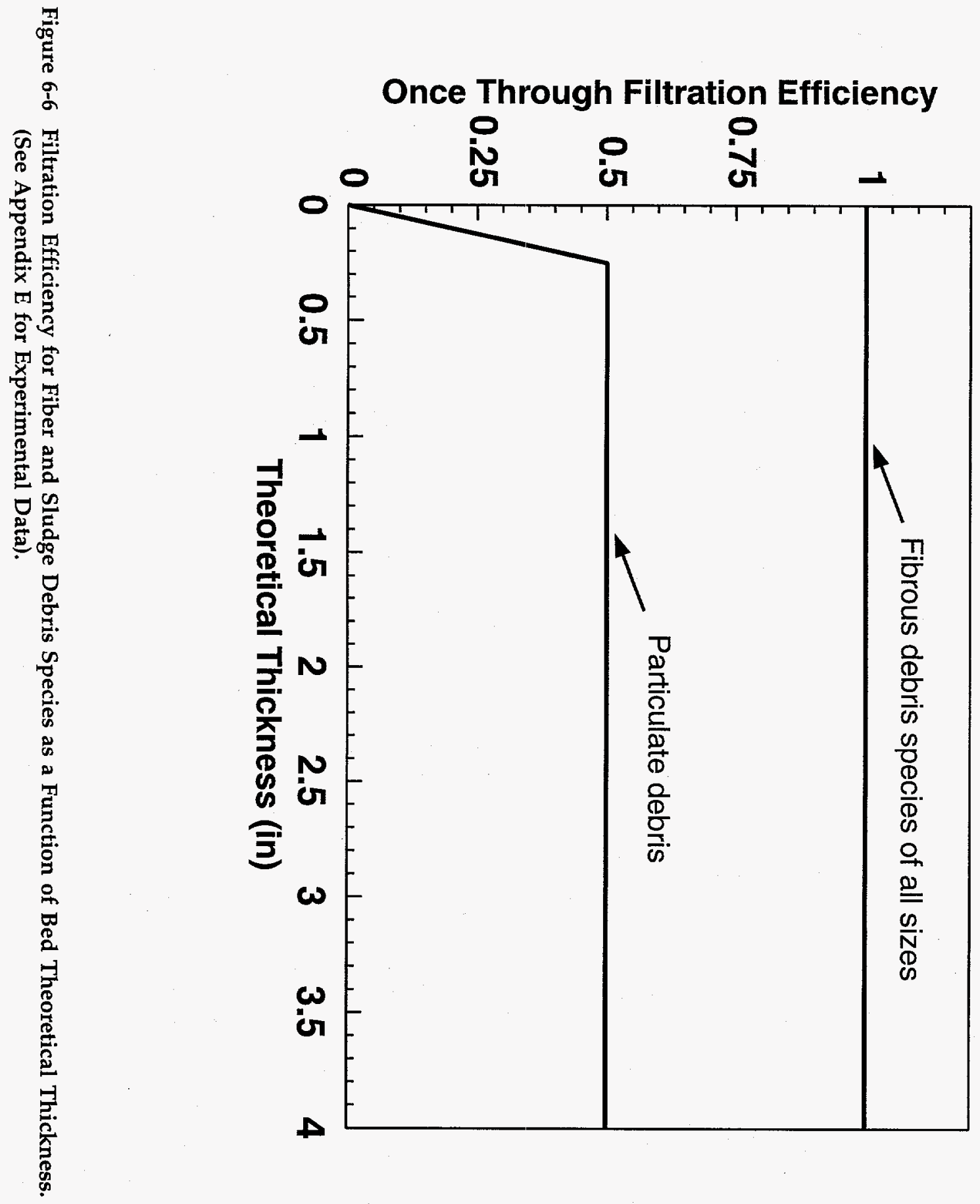
These results were obtained assuming that:

1. The once-through efficiency for particulates and fibers are given by Figure 6-6 throughout the accident progression. For particulate debris, irrespective of their size, a maximum efficiency of $50 \%$ would be achieved depending on the theoretical fiber bed thickness.

2. $50 \%$ of the particulate debris penetrating the strainer would be retained in the low flow regions of the reactor and containment systems. The remaining $50 \%$ of the debris will be brought back to the pool by the ECCS flow.

\subsection{Pressure Drop due to Debris Accumulation}

The head loss model is another component of the ECCS strainer blockage study. Due to its importance, considerable effort was expended to obtain head loss data for a variety of fibrous insulation materials used in PWRs [Ref. 6.7] for USI A-43. Since issuance of NUREG-0897, which listed the relevant correlations, additional experiments were carried out both in the U.S. and in Europe to measure head loss across the fibrous debris bed formed on the strainer surface [Ref. 6.6, 6.8, 6.9, 6.10, $6.11,6.12]$.

The NRC experiments studied head loss across the beds formed of NUKONTM fibers and iron oxide particles ranging from $<1 \mu \mathrm{m}$ to $>300 \mu \mathrm{m}$ in size. Scanning Electron Microscope images of the mixed beds formed in these experiments and the visual observation of the bed formation and compression were used in this study to develop a semitheoretical head loss model.

Appendix B provides details on the model development and theoretical basis. These model predictions were compared with the experimental data from the following sources:

1. NRC-sponsored head loss experiments at ARL as part of USI A-43 study for debris beds formed of NUKONTM fragments generated by manual shredding of insulation blankets [Ref. 6.7].

2. NRC experiments for debris beds formed of NUKONTM fragments and simulated BWR sludge [Ref. 6.6 and Appendix E].

3. Head Loss data obtained by Performance Contracting, Inc. (PCI) for debris beds formed of NUKONTM fragments of various sizes [Refs. 6.9 and 6.10].

4. Head Loss data obtained by Pennsylvania Power and Light Company (PP\&L) for mixed (NUKON ${ }^{\mathrm{TM}}$ and iron oxide) beds [Ref. 6.4].

The data from these experiments were obtained at different temperatures ranging from $60^{\circ} \mathrm{F}-125^{\circ} \mathrm{F}$; different debris bed thicknesses ranging from $0.125^{\prime \prime}$ to $4^{\prime \prime}$; and different velocities ranging from $0.15 \mathrm{ft} / \mathrm{s}$ $(0.05 \mathrm{~m} / \mathrm{s})$ to $1.5 \mathrm{ft} / \mathrm{s}(0.45 \mathrm{~m} / \mathrm{s})$. The majority of this data can be correlated using the following equation:

$$
\begin{aligned}
\frac{\Delta H}{\Delta L_{o}}= & {\left[a_{\hat{0}} S_{v}^{2}\left(1-\varepsilon_{m}\right)^{1.5}\left[1+57\left(1-\varepsilon_{m}\right)^{3}\right] \mu U\right.} \\
& \left.+b_{\hat{v}} \frac{S_{v}\left(1-\varepsilon_{m}\right)}{\varepsilon_{m}} \rho U^{2}\right] \frac{\Delta L_{m}}{\Delta L_{o}}
\end{aligned}
$$

where,

$$
\begin{array}{ll}
\mathrm{a}_{\vartheta} & 1.453 \times 10-4\left(\frac{\mathrm{ft} \text {-water/in }}{\mathrm{lbm} / \mathrm{ft}^{2} \mathrm{~s}^{2}}\right) \\
\mathrm{b}_{\vartheta} & 2.741 \times 10^{-5}\left(\frac{\mathrm{ft} \text {-water/in }}{\mathrm{lbm} / \mathrm{ft}^{2} \mathrm{~s}^{2}}\right) \\
\mathrm{S}_{\mathrm{v}} & \text { is specific surface area }\left(\mathrm{ft}^{2} / \mathrm{ft}^{3}\right) \\
\mu & \text { is dynamic viscosity }(\mathrm{lbm} / \mathrm{s}-\mathrm{ft}) \\
\mathrm{U} & \text { is velocity (ft/s) } \\
\Delta \mathrm{H} & \text { is head loss (ft-water) } \\
\rho & \text { is water density (lbm } \left./ \mathrm{ft}^{3}\right) \\
\Delta \mathrm{L}_{\mathrm{o}} & \text { is the fiber bed theoretical thickness (in) } \\
\Delta \mathrm{L}_{\mathrm{m}} & \text { (obtained from Equation B-2) } \\
\varepsilon_{\mathrm{m}} & \text { is mixed bed porosity }
\end{array}
$$

\subsubsection{Head Loss Estimate}

The head loss model was incorporated in BLOCKAGE to estimate the resultant head loss for the debris beds comprised of NUKON ${ }^{\mathrm{TM}}$ fibers and particulate debris. All the estimates were calculated for the reference plant velocity of $1.5 \mathrm{ft} / \mathrm{s}$ at an assumed suppression pool temperature of $125^{\circ} \mathrm{F}$. According to reference plant FSAR, the suppression pool temperature reaches $125^{\circ} \mathrm{F}$ immediately after blowdown. The results are presented in Section 7. 


\subsection{ECCS Strainer Blockage Analysis Assumptions and Limitations}

The model developed in this study to estimate the potential of losing NPSH margin due to ECCS pump strainer blockage following a LOCA, assumes that:

1. All the ECCS strainers (2 LPCI + 2 LPCS strainers) can be lumped together to form a single strainer with the surface area and flow rate equal to the sum of the individual strainers. This assumption is reasonable for the reference plant where the approach velocities do not vary from strainer to strainer and the available NPSH margin do not vary considerably from pump to pump. Applicability of this assumption to other plants should be carefully assessed on a plantspecific basis.

2. The model assumes that the ECCS is lost when the NPSH margin is lost.

Estimation of the head loss is based on the transient buildup and makeup of the debris bed on the strainer which, in turn, are functions of the type, quantity and the trapping and filtering efficiency. Given the types and quantities of debris reaching the strainer, the following simplified model was used in this study to estimate the fraction of debris retained by the strainer:

1. All fibrous debris reaching the strainer would be trapped and retained by the strainer.

2. Only a fraction of the particulate debris reaching the strainer would be filtered by the debris bed formed on the strainer surface; based on scoping experiments described in Appendix E, the filtration efficiency for particles is assumed to be only a function of the debris bed theoretical thickness. An important limitation of this model is that its predictions are insensitive to the particle size and incoming concentration; this is a serious limitation considering that filtration efficiencies are known to be strong functions of the particle equivalent diameter.
3. Based on engineering judgement, it was assumed that $50 \%$ of the particulate debris penetrating the strainer would be retained in the reactor and containment systems and structures; the remaining $50 \%$ of the debris would be brought back to the pool by the cascading water from the break.

The head loss correlation developed as part of this study was assumed to be suitable to both fibrous as well as mixed (fibers and particles) debris beds, and its predictions have been favorably compared with experimental data from several sources. The model, however, has the following limitations:

1. The head loss correlation was developed and validated for debris that are uniformly distributed on the strainer surface. However, experiments described in Appendix $E$ have shown that very thin beds $\left(\Delta \mathrm{L}_{\mathrm{o}} \leq 0.125\right.$ " or $0.318 \mathrm{~cm}$ ) are characterized by large scale nonuniformities that resemble partially occupied strainers. Usage of present correlation to predict head loss for such thin beds may overpredict the head loss.

Similarly the model is known to overpredict head loss across thin beds coupled with high sludge-to-fiber mass ratios where beds once again are non-uniform due to damage caused by large pressure drops associated with such beds.

2. For mixed beds, the head loss correlation uses volume averaged particulate-to-fiber mass ratio to estimate head loss without considering the spatial distributions (both vertical and horizontal) within the bed. This raises questions related to applicability of the correlation to beds that are expected to be extremely non-homogeneous (i.e., the localized fiber-to-particulate composition varies considerably with bed thickness). At the present time no experimental data is available to validate the correlation for such extremely non-homogeneous beds. 


\section{References for Section 6.0}

6.1 Memorandum from M. Marshall to A. Serkiz, Subject: Presentation Slides Used During the May 4, 1994 Meeting, Dated July 20, 1994.

6.2 A. W. Serkiz, "Containment Emergency Sump Performance," U.S. Nuclear Regulatory Commission, NUREG-0897, Rev. 1, October 1985.

6.3 U.S. NRC, "Net Positive Suction Head for Emergency Core Cooling and Containment Heat Removal System Pumps," Regulatory Guide 1.1, November 1970.

6.4 K.W. Brinkman and P.W. Brady, "Results of Hydraulic Tests on ECCS Strainer Blockage and Material Transport in a BWR Suppression Pool," Pennsylvania Power \& Light Company, EC-059-1006, Rev. 0, May 1994.

6.5 BWR Owners' Group, "Interim Report of the BWR Owners' Group ECCS Suction Strainer Committee," BWROG-94157, December 1994.

6.6 D.V. Rao and F. Souto, "Experimental Study of Head Loss and Filtration for LOCA Debris," SEA Report No. 554-06-A:8, June 1995.
6.7 D. N. Brocard, "Buoyancy, Transport, and Head Loss of Fibrous Reactor Insulation," Alden Research Laboratory, published as Sandia National Laboratories Report No. SAND82-7205, Rev, NUREG/CR-2982, Rev. 1, July 1983.

6.8 Proceedings of OECD/NEA Workshop on the Barsebäck-2 Strainer Incident, Stockholm, Sweden, January 26-27, 1994.

6.9 J. B. Nystrom, "NUKON Insulation Head Loss Tests," ARL/124-89/M670F, Alden Research Laboratories, Inc., 1989.

6.10 B. J. Pennino and G. Hecker, "Head Loss Tests with Blast-generated NUKON Insulation Debris," ARL/140-93/M670F, 1993.

6.11 Transco Products Inc., "Experimental Measurements on the Characteristics of Flow Transport, Pressure Drop, and Jet Impact on Thermal Insulation," NRC Guide 1.82, Test Report No. ITR-92-03N, 1994.

6.12 "KKL Specific ECCS Strainer Plugging Analysis According to Regulatory Guide 1.82, Rev. 1, for a Loss-of-Coolant Accident," Technical Report, Bet/93/031, Kernkraftwerk, Leibstadt, AG. 


\subsection{BWR ECCS Strainer Blockage Analysis Results}

This section presents the results of calculations performed to estimate the likelihood of loss of ECCS as a result of LOCA-generated debris. The calculations utilized the transient strainer blockage computer code, BLOCKAGE 2.3, developed as part of this study (see Appendix B). All analysis results presented are for the base case, the set of conditions judged to most realistically represent actual accident conditions for the reference plant. For this set of conditions, each of the 345 welds located in the drywell piping belonging to the normallypressurized systems (recirculation system, MSLs, feed water lines, HPCI steam supply line, and RHR lines) was evaluated in terms of:

- Estimated break frequency,

- Amount of insulation targeted by the break jet; i.e., the amount of insulation located in the weld break zone of destruction,

- Amount of insulation dislodged from the targets and destructed into transportable form,

- Amount of insulation transported to the suppression pool and the timing of its transport, i.e., short-term and long-term transport,

- Debris transport within the suppression pool during and after turbulent pool conditions,

- Time-dependent debris bed formation on the ECCS strainers, and

- Calculation of the resultant strainer head loss to evaluate whether or not loss of NPSH margin would occur for that weld break.

The break frequency of those welds that resulted in strainer head loss exceeding the available NPSH margin were summed to obtain the overall frequency for loss of ECCS. The frequency estimates were then sorted to obtain the contribution to loss of ECCS NPSH margin frequency by system and by pipe size. Additional results presented in this section include head losses, fibrous debris bed thicknesses, and associated particulate mass estimates for selected weld breaks as a function of time.
It should be recognized that the models used herein were recently developed and a verification and validation effort was undertaken to ensure that (1) each of the models described in Appendix B were implemented into BLOCKAGE accurately, and (2) individual model predictions were in agreement with applicable experimental data (e.g., suppression pool data and head loss data). In addition the model has undergone limited peer review. However, it should also be recognized that considerable engineering judgement, supported by very limited experimental data, was used to obtain point-estimates of various key parameters used in some analyses models (e.g., drywell transport model). Furthermore, the models and key parameter estimates do not reflect new information developed after April 1995. It should be noted that the results presented in this report are specific to the reference plant, hence caution should be used in generalizing the analysis results and conclusions since they may be significantly different for other BWRs. Finally, results are expressed solely as point estimates. A detailed uncertainty analysis is beyond the scope of the present study. However, a limited parametric study was performed to examine the impact of varying key parameters over a wide range on the model predictions. The results of this parametric study are summarized in Appendix C, and major conclusions are presented in Section 7.3.

\subsection{Estimated Frequency of Loss of ECCS NPSH Margin by System and Pipe Size}

Tables 7-1 and D-1 summarize the reference plant data input for BLOCKAGE for the base case. Both the LLOCA and the MLOCA time scales for accident progression are based on LOCA transient data provided by the BWROG (see Tables B-1 and B-2). Tables 7-2 and 7-3 present frequencies for loss of NPSH margin due to debris blockage by system and by pipe size, respectively. As evident from these tables, frequencies for pipe break as well as frequencies for loss of ECCS NPSH margin are dominated by weld breaks in the recirculation piping. This is a direct result of the fact that the reference plant recirculation piping is constructed of Type 304 stainless steel which has been found to be susceptible to IGSCC (see Section 3.2 and AppendixA). Also as shown in Table 7-2, almost all breaks resulted in strainer blockage leading to loss of 
Results

Table 7-1 Reference Plant Data Input to BLOCKAGE for the Base Case (Case A-6)

\section{Physical Data [Ref. Plant FSAR]}

Volume of water in the suppression pool

$58,900 \mathrm{ft}^{3}$

Planar area of the pool available for sedimentation

$5,000 \mathrm{ft}^{2}$

Strainer Surface Area

$37.62 \mathrm{ft}^{2}$

Available NPSH Margin @ 185 $\mathrm{F}$

$14 \mathrm{ft}$ water

Pool depth

$10 \mathrm{ft}$

Pool temperature

$125^{\circ} \mathrm{F}$

\section{Time Scales}

\begin{tabular}{|c|c|c|}
\hline & LLOCA & MLOCA \\
\hline Blowdown Time, $t_{\text {blowdn }}$ & $0-120 \mathrm{Sec}$ & $0-600 \mathrm{Sec}$ \\
\hline $\begin{array}{l}\text { Short-term Transport } \\
\text { (or Blowdown Transport) }\end{array}$ & $0-120 \mathrm{Sec}$ & $0-600 \mathrm{Sec}$ \\
\hline $\begin{array}{l}\text { Long-term Transport } \\
\text { (or Washdown Transport) }\end{array}$ & $120-1920 \mathrm{Sec}$ & $600-2400 \mathrm{Sec}$ \\
\hline ECCS Recirculation Run-time, $t_{\text {recirc }}$ & 6 hrs. $^{1}$ & 6 hrs. $^{1}$ \\
\hline
\end{tabular}

Note:

${ }_{1} 6 \mathrm{hrs}$. was selected in the present study as the end time for BLOCKAGE runs. Increased run-time did not significantly alter the results of BLOCKAGE runs.

\section{Fibrous Debris Data}

Debris Generation Model: Spherical

\begin{tabular}{ccc} 
Region & Description & Destruction Factor \\
I & $\mathrm{L} / \mathrm{D} \leq 3$ & 0.75 \\
II & $3<\mathrm{L} / \mathrm{D} \leq 5$ & 0.60 \\
III & $5<\mathrm{L} / \mathrm{D} \leq 7$ & 0.40 \\
\hline
\end{tabular}


Table 7-1 (cont.) Reference Plant Data Input to BLOCKAGE for the Base Case (Case A-6)

\section{Particulate Debris}

$\begin{array}{lccc} & \text { Mass } & \text { Density } & \text { Size Distribution } \\ \text { Sludge } & 850 \mathrm{lbm} & 324 \mathrm{lbm} / \mathrm{ft}^{32,3} & \text { See Table B-6 } \\ \text { Paint Chips } & 85 \mathrm{lbm} & 124 \mathrm{lbm} / \mathrm{ft}^{3} & \text { one size class } \\ \text { Concrete Particles } & 156 \mathrm{lbm} & 156 \mathrm{lbm} / \mathrm{ft}^{3} & \text { one size class }\end{array}$

${ }^{2}$ BLOCKAGE tracks the solid volume of the particulates, hence the use of the theoretical density of iron-oxide instead of the sludge bed density of $65 \mathrm{Ibm} / \mathrm{ft}^{3}$

${ }^{3} \mathrm{BLOCKAGE}$ uses the sludge bed density of $65 \mathrm{lbm} / \mathrm{ft}^{3}$ to determine the limiting compaction of the mixed debris bed cake on the strainer

\section{Drywell Transport}

\section{LLOCA}

Blowdown Transport

$\mathrm{T}_{\mathrm{bd}} / 100$ for $20 \leq \mathrm{t} \leq 100^{4}$

$\mathrm{T}_{\mathrm{bd}} / 1200$ for $0 \leq \mathrm{t} \leq 1200$

Washdown Transport

$\mathrm{T}_{\mathrm{wd}} / 1800$ for $120 \leq \mathrm{t} \leq 1920$

$\mathrm{T}_{\mathrm{wd}} / 1800$ for $1500 \leq \mathrm{t} \leq 3300$

${ }^{4} \mathrm{~T}_{\mathrm{bd}}$ and $\mathrm{T}_{w d}$ are drywell blowdown and washdown transport factors (see Table 4-1)

\section{Suppression Pool Transport}

Settling Velocity

$\begin{array}{ll}\underline{\mathbf{t}}_{\text {blowdn }} & \underline{\underline{t}}_{\text {recirc }} \\ 0.0 & 0.5 \mathrm{~V}_{\mathrm{s}}\end{array}$

If Sup. Cool. on

0.0

$\mathrm{V}_{\mathrm{s}}$ are settling velocities in Tables B-5 and B-6.

\section{ECCS Flow (BWROG Biest Estimates)}

\begin{tabular}{|c|c|c|c|c|c|}
\hline & $\leqq 5 \mathrm{~s}$ & $\underline{5-50 s}$ & $\underline{50-320} \underline{\mathrm{s}}$ & $\underline{320-500 \mathrm{~s}}$ & $\sum 500 \mathrm{~s}$ \\
\hline LLOCA & $0.0 \mathrm{gpm}$ & $2500 \mathrm{gpm}$ & $25000 \mathrm{gpm}$ & $25000 \mathrm{gpm}$ & $25000 \mathrm{gpm}$ \\
\hline $\mathrm{MLOCA}^{5}$ & $0.0 \mathrm{gpm}$ & $0.0 \mathrm{gpm}$ & $2500^{6} \mathrm{gpm}$ & Ramp 2500-25000 gpm & $25000 \mathrm{gpm}$ \\
\hline
\end{tabular}

${ }^{5}$ These flow characteristics were used for all breaks smaller than 4" including 1" and 1.25". For these smaller breaks ECCS flows are expected to be much smaller.

${ }^{6}$ For MLOCA a linear ramp was used between $320 \mathrm{sec}$ and $500 \mathrm{sec}$.

\section{Filtration Efficiency Model}

\section{Debris}

Fibers

Sludge

\section{Efficiency}

1.0

0.5 for bed thicknesses $>1 / 4^{\prime \prime}$

Linear from 0 to 0.5 for bed thicknesses $<1 / 4$ "

Reactor Systems Debris Retention Factor: 0.50 
Table 7-2 ECCS Strainer Blockage Estimates by System (Base Case)

\begin{tabular}{lccc}
\hline \multicolumn{1}{c}{ System } & No. of Breaks & $\begin{array}{c}\text { Pipe Break } \\
\text { Frequency } \\
\mathbf{( 1 / R x - Y e a r )}\end{array}$ & $\begin{array}{c}\text { Frequency for Loss of } \\
\text { NPSH Margin } \\
\mathbf{( 1 / R x - Y e a r )}\end{array}$ \\
\hline Recirculation & 140 & $1.18 \mathrm{E}-04$ & $1.18 \mathrm{E}-04$ \\
Main Steam & 115 & $2.30 \mathrm{E}-05$ & $2.12 \mathrm{E}-05$ \\
Feedwater & 68 & $1.36 \mathrm{E}-05$ & $1.36 \mathrm{E}-05$ \\
HPCI Steam Line & 6 & $1.20 \mathrm{E}-06$ & $1.20 \mathrm{E}-06$ \\
RHR Lines & 16 & $3.20 \mathrm{E}-06$ & $3.20 \mathrm{E}-06$ \\
& & & \\
Overall & 345 & $1.59 \mathrm{E}-04$ & $1.58 \mathrm{E}-04$ \\
\hline
\end{tabular}

NPSH margin; i.e., the frequency for loss of NPSH margin is about the same as the overall pipe break frequency. Considerable caution must be used in interpreting the results for 1" and $1.25^{\prime \prime}$ breaks. For these breaks the ECCS is not needed immediately for core cooling since this function is accomplished by $\mathrm{HPCI}$ and $\mathrm{RCIC}$ which take suction from the condensate storage tank.

However, RHR may be needed to run containment sprays which are usually used for containment pressure control. Thus, loss of RHR pumps due to strainer blockage in the case of breaks smaller than $2 "$ is expected to impact containment spray (e.g., Barsebäck-2 incident) but not directly impact the core cooling, at least in the short-term. This issue is further addressed in Section 8.0.

\subsection{Head-Loss and Debris Bed Transient Behavior for the Representative Welds}

\subsubsection{Time Dependent Debris Transport}

The four representative welds previously discussed can be used to illustrate the transient nature of debris transport to the suppression pool and within the suppression pool of the reference plant. RCAJ006 and MSB-J021 are classified as LLOCA and RCA-J027 and RCB-J028 are classified as MLOCA and SLOCA, respectively, based on the systems success criteria for the reference plant. Figures 7-1 and 7-2 present transport volumes of fibrous and particulate debris as functions of time for representative weld RCA-J006. A postulated break at RCA-J006, classified as a LLOCA, generates and transports the largest quantity of fibrous debris of all the welds in the reference plant. Figures 7-3 and 7-4 present the same information for representative weld RCA-J027. This break generates and transports largest volumes of fibrous debris to the suppression pool for a MLOCA. For both welds fiber transport to the suppression pool occurred over the blowdown and the initial half-hour of the washdown phase of the accident. During the blowdown phase, almost all the debris (both fibrous and particulate) are suspended in the pool water; a small fraction of the debris was transported to the strainer by the ECCS minimum flow. However, the pool concentration of debris rapidly decreased with time after blowdown due to combined effects of low pool turbulence (i.e., sedimentation) and increased transport to the strainer triggered by ECCS flow ramping. The model estimates that the suppression pool will be cleared of suspended fibrous debris within 2 to 3 flushing cycles ${ }^{1}$ after the ECCS flow reached its rated value of $25,000 \mathrm{gpm}$. During this initial phase, debris trapped on the strainer as well as that sedimenting on the suppression pool floor rapidly increased and reached asymptotic values.

Examination of Figures 7-1 and 7-3 would indicate that only a small fraction of the fibrous debris

\footnotetext{
${ }^{1}$ Note that pool flushing time or turn-over time for the reference plant is 1050 seconds (or 17.5 minutes).
} 


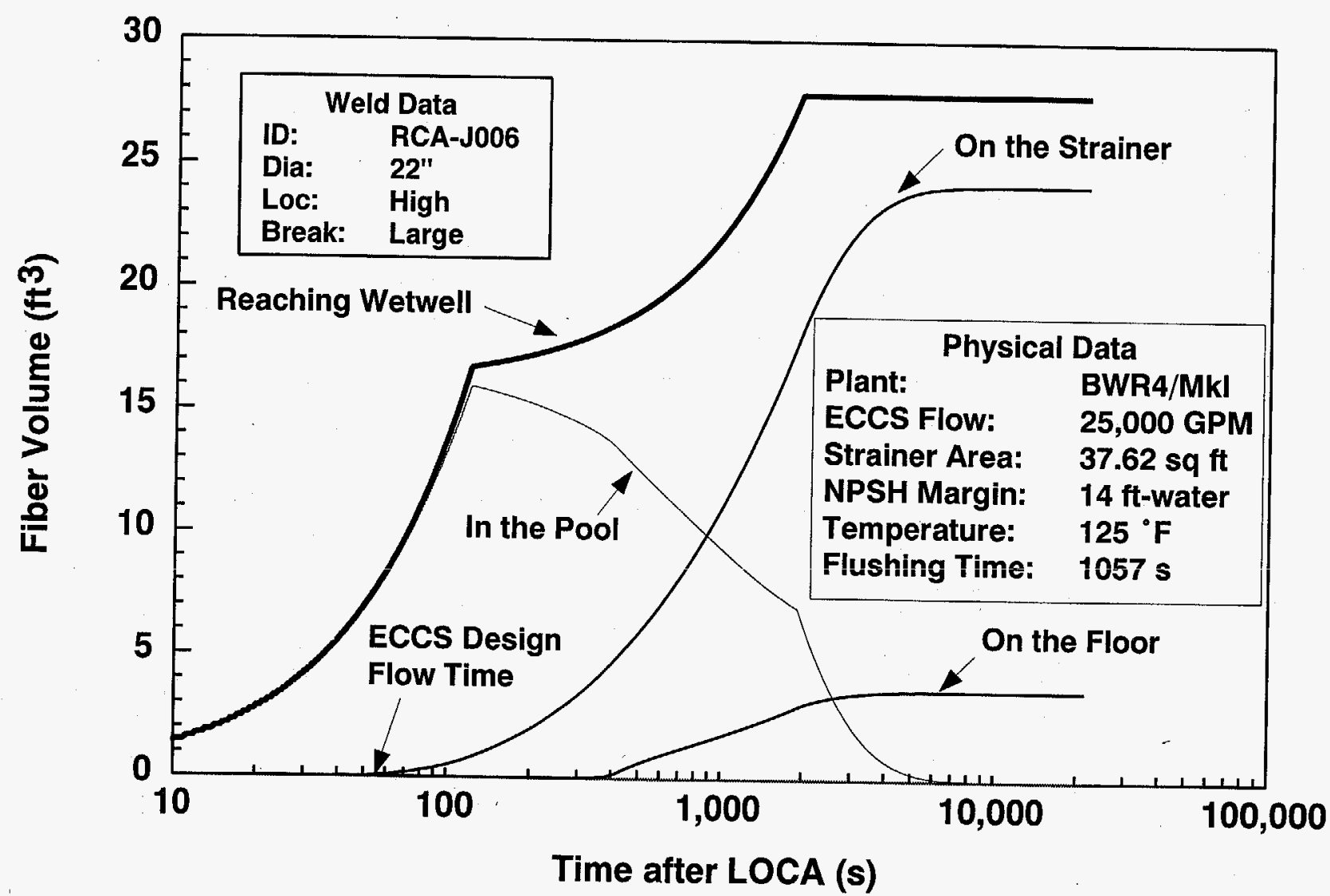

Note: The trapping efficiency for fibers is 1.0 . No fiber penetrates the strainer. 


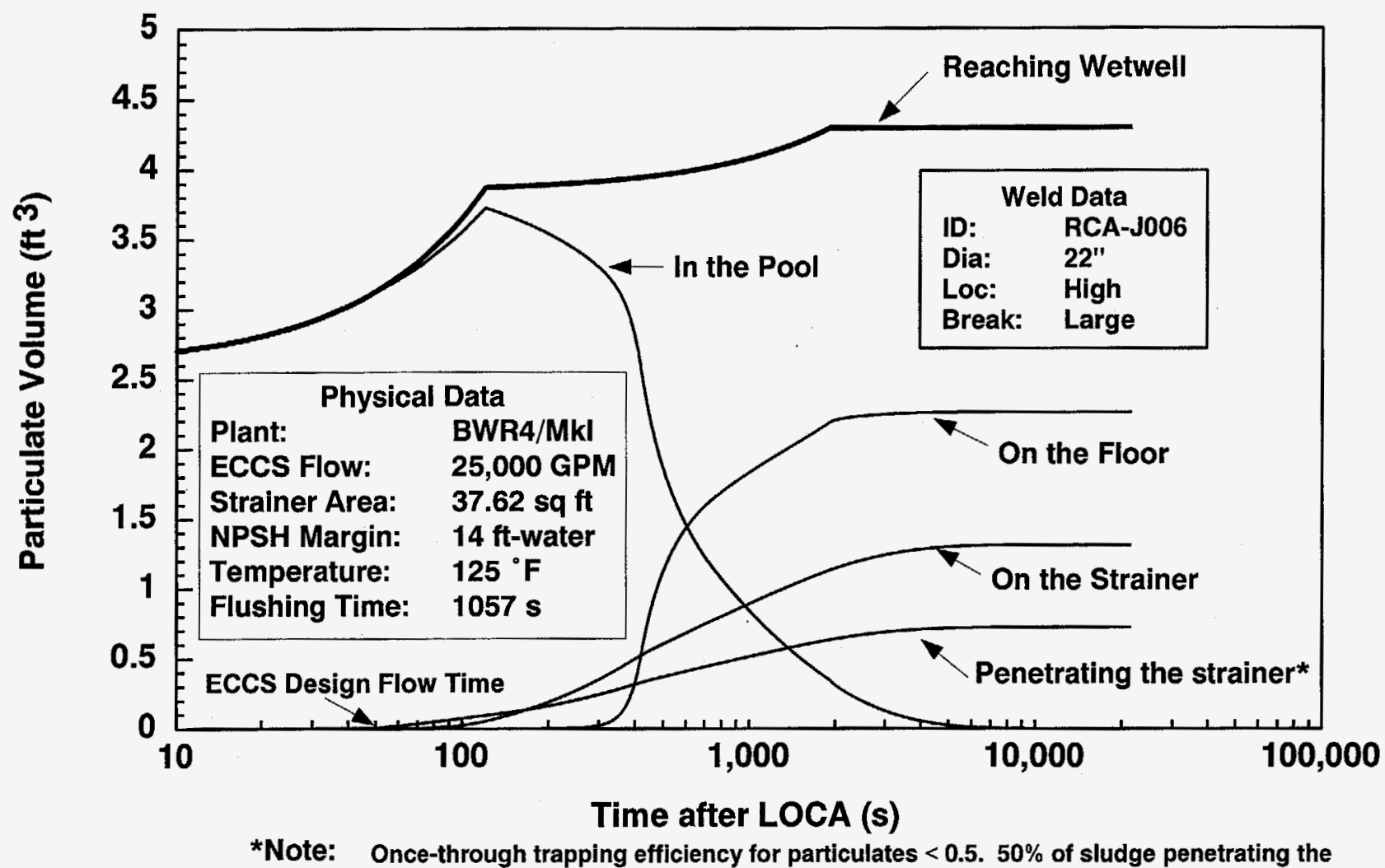
strainer is assumed to be returned to the suppression pool. 


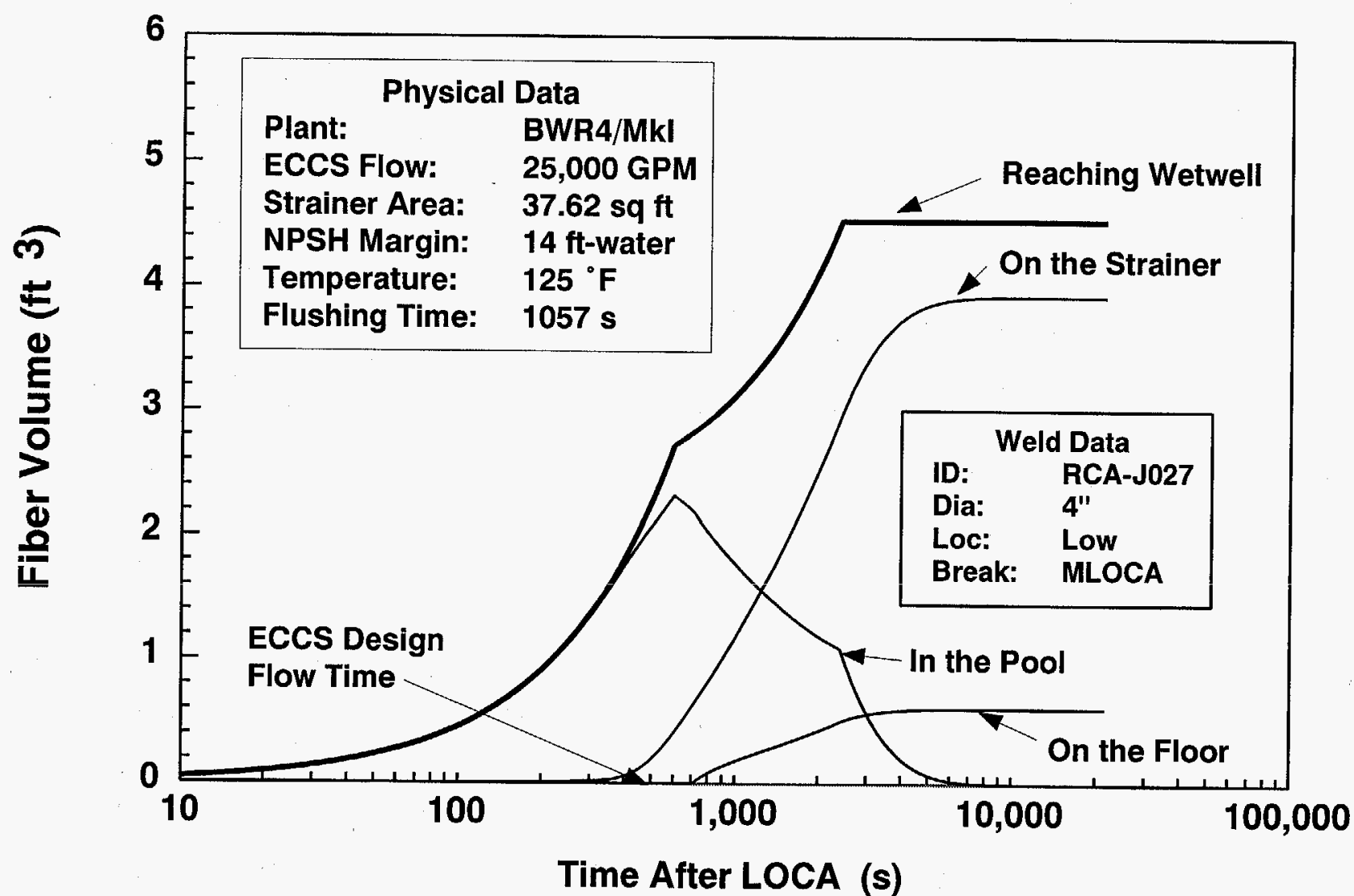

Note: The trapping efficiency for fibers is 1.0. No fiber penetrates the strainer. 


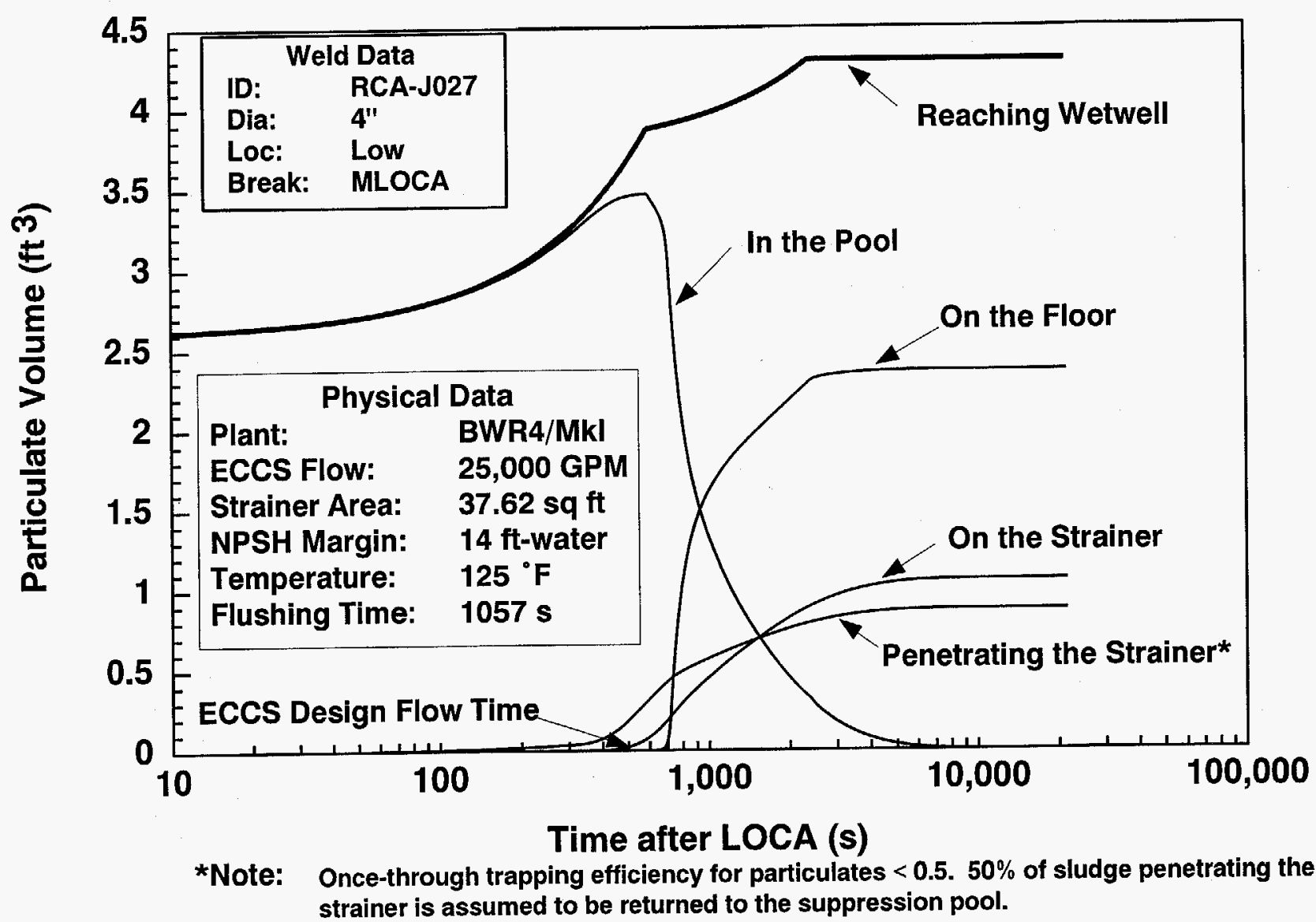

Figure 7-4 Transient Particulate Debris Transport in the Suppression Pool for RCA-J027 
Table 7-3 ECCS Strainer Blockage Estimates by Pipe Diameter (Base Case)

\begin{tabular}{cccc}
\hline $\begin{array}{c}\text { Diameter } \\
\text { (in) }\end{array}$ & No. of Breaks & $\begin{array}{c}\text { Pipe Break Frequency } \\
\text { (1/Rx-Year) }\end{array}$ & $\begin{array}{c}\text { Frequency of Loss of } \\
\text { NPSH Margin } \\
\text { (1/Rx-Year) }\end{array}$ \\
\hline 1 & 41 & $2.82 \mathrm{E}-05$ & $2.82 \mathrm{E}-05^{1}$ \\
1.25 & 2 & $2.00 \mathrm{E}-06$ & $2.00 \mathrm{E}-06^{1}$ \\
2 & 14 & $4.60 \mathrm{E}-06$ & $2.60 \mathrm{E}-06^{1}$ \\
4 & 26 & $2.60 \mathrm{E}-05$ & $2.60 \mathrm{E}-05$ \\
6 & 24 & $4.80 \mathrm{E}-06$ & $4.80 \mathrm{E}-06$ \\
10 & 104 & $5.28 \mathrm{E}-05$ & $5.28 \mathrm{E}-05$ \\
16 & 18 & $1.80 \mathrm{E}-05$ & $1.80 \mathrm{E}-05$ \\
18 & 6 & $1.20 \mathrm{E}-05$ & $1.20 \mathrm{E}-06$ \\
20 & 73 & $1.46 \mathrm{E}-06$ & $1.46 \mathrm{E}-06$ \\
22 & 37 & $7.4 \mathrm{E}-06$ & $7.40 \mathrm{E}-05$ \\
& & & \\
Overall & 345 & $1.59 \mathrm{E}-04$ & $1.58 \mathrm{E}-04$ \\
\hline
\end{tabular}

${ }^{1}$ Loss of ECCS in these cases may not directly impact core cooling function. In the short-term it leads to loss of containment spray. In the long-term it may impact RHR function if the strainers are not equipped with backflush.

$(<10 \%)$ settle on the suppression pool floor, and the remaining $90 \%$ is trapped on the ECCS strainer. This result is a direct reflection of the low settling velocities associated with the fibrous debris classes (see Table B-5). On the other hand, about $50 \%$ of the particulate debris settles to the suppression pool floor due to the relatively high settling velocities for these materials. About $33 \%$ of the particulates are trapped on the strainer, forming the debris cake.

The remaining $17 \%$ penetrates the debris bed to be deposited in the low flow regions of the reactor coolant system or in the drywell.

\subsubsection{Debris Bed Buildup on the Strainer and Resultant Head Loss}

Figures 7-5 and 7-6 present debris bed buildup history for the four representative welds (RCA-j006; MSB-J021; RCA-J027 and RCB-J028). For all welds the fiber bed buildup is very slow until the ECCS flow reaches its maximum. Thereafter, the fiber bed thickness increases rapidly with time reaching the respective asymptotes within 2 to 3 flushing cycles. Similar behavior was also observed for sludge-to- fiber make up of the debris cake. Initially, although the sludge concentration in the pool water approaching the strainer is at its maximum (see Figures 7-2 and 7-4), only a small fraction of it is actually filtered by fiber bed which is very thin (see Figure 7-5). However, as the bed thickness increases, more sludge would be filtered by the debris cake. This results in rapid increase in sludgeto-fiber mass ratio attaining its maximum value within the first cycle. Due to a combination of several factors, the sludge-to-fiber mass ratio decreases slightly from the maximum and approaches the asymptotic value. As evident from this figure, these asymptotic values are strong functions of the break size, i.e., the smallest breaks are associated with largest sludge-to-fiber ratios.

The resultant head loss across the strainer for the representative welds are plotted in Figures 7-7a and 7-7b. As evident from Figure 7-7a, the NPSH margin for the reference plant is lost within few seconds after the ECCS pumps achieve maximum flow at 50 seconds and 500 seconds, respectively, for LLOCA (RCA-J006 and MSB-J021), MLOCA (RCAJ027) and SLOCA (RCB-J028). This sharp rise in head loss at the ECCS design flow time can be 


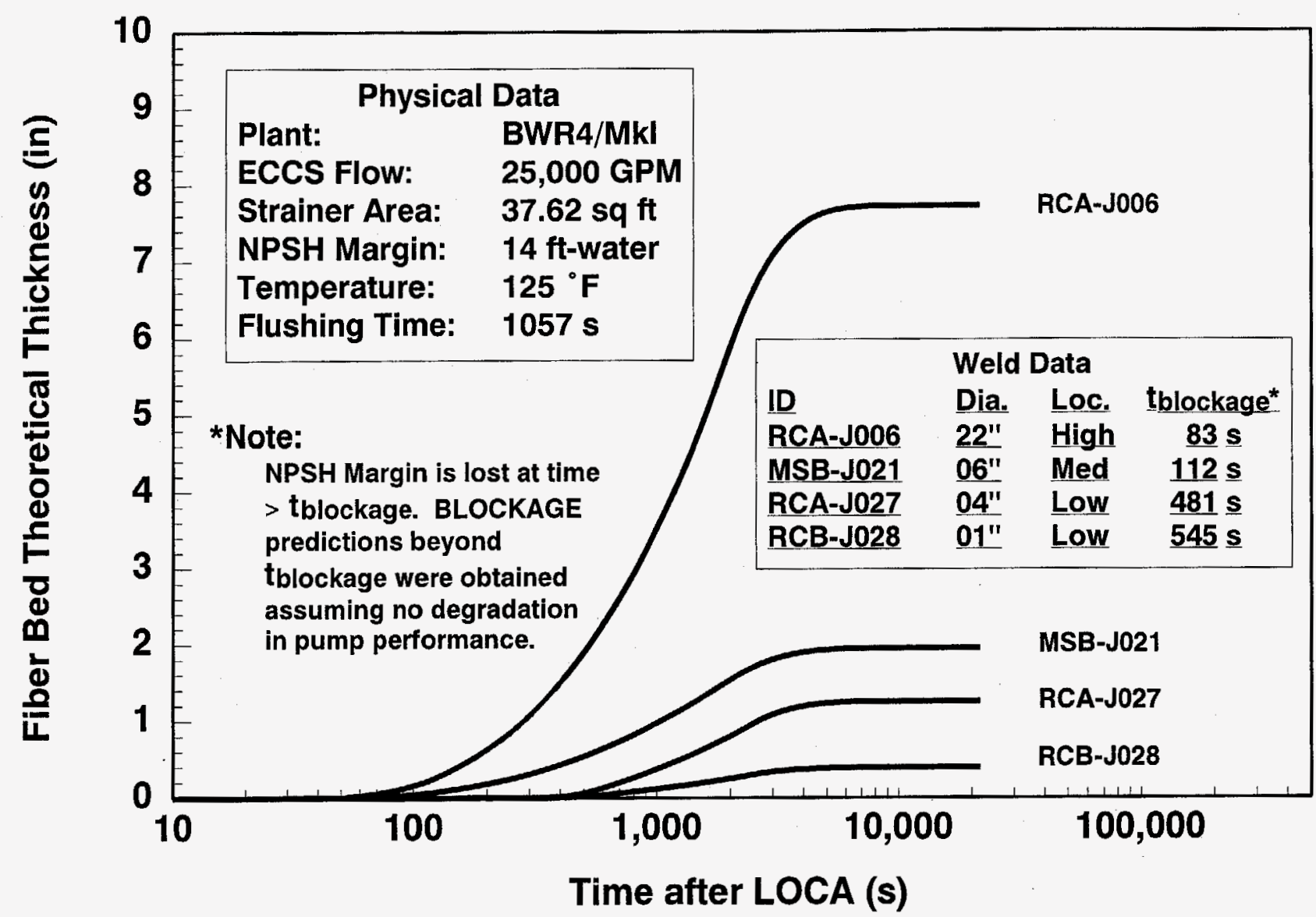

Figure 7-5 Time-Dependent Buildup of Fibrous Debris Bed on the Strainer Surface for the Representative Welds 


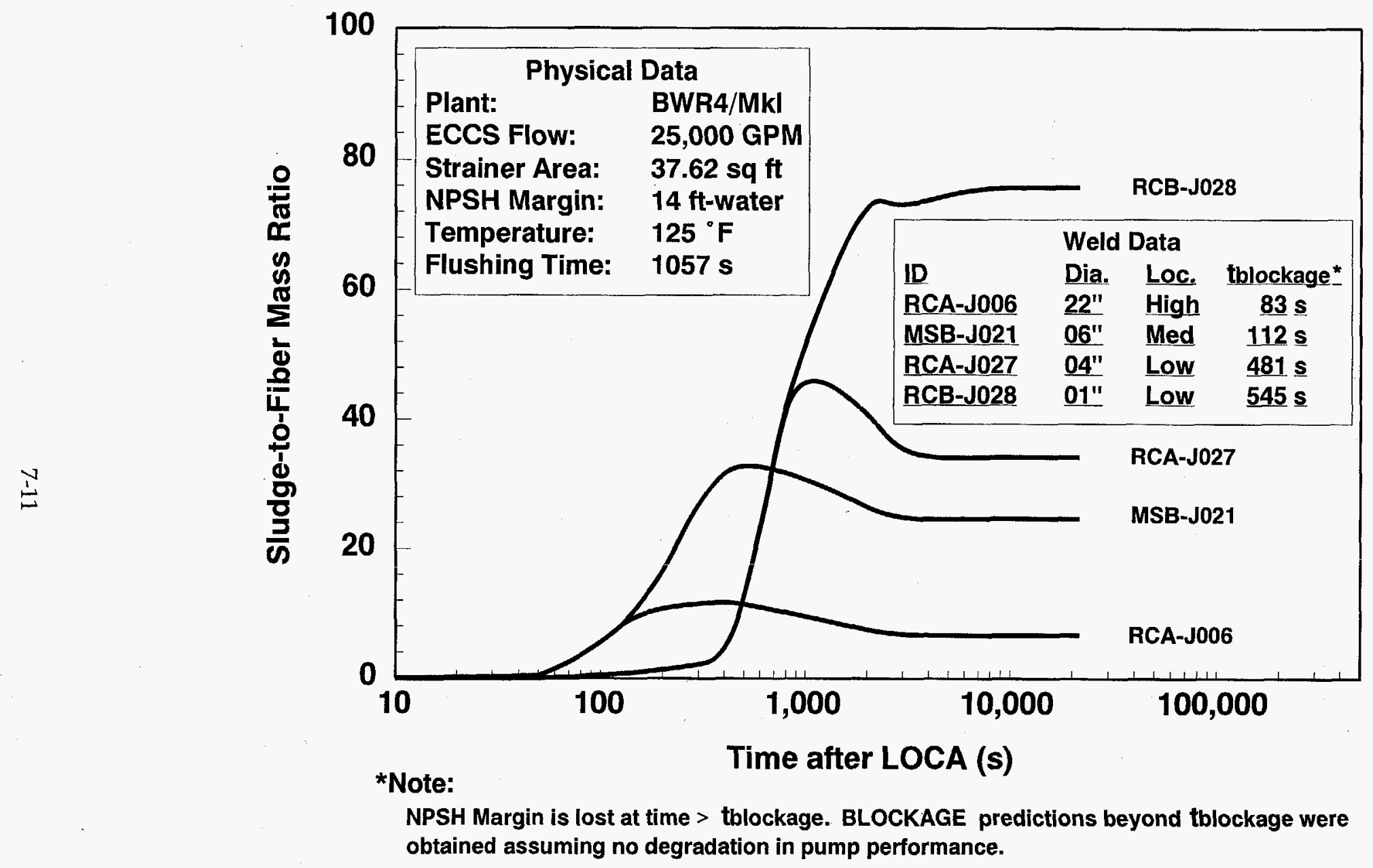

Figure 7-6 Temporal Variations of Sludge-to-Fiber Mass Ratios on the Debris Bed for the Representative Welds (Long-Term) 


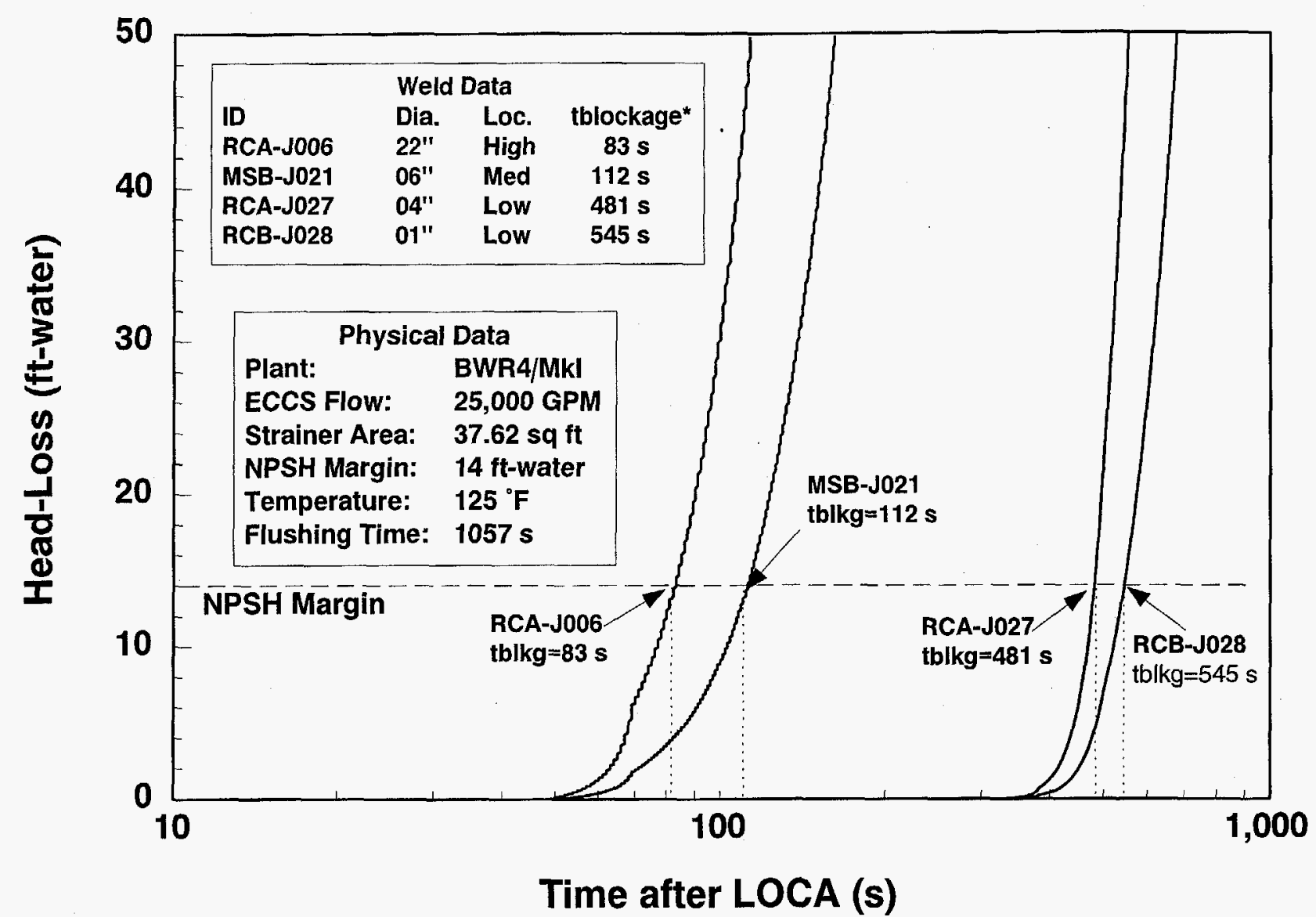

*Note:

NPSH Margin is lost at time > tblockage. BLOCKAGE predictions beyond tblockage were obtained assuming no degradation in pump performance. 


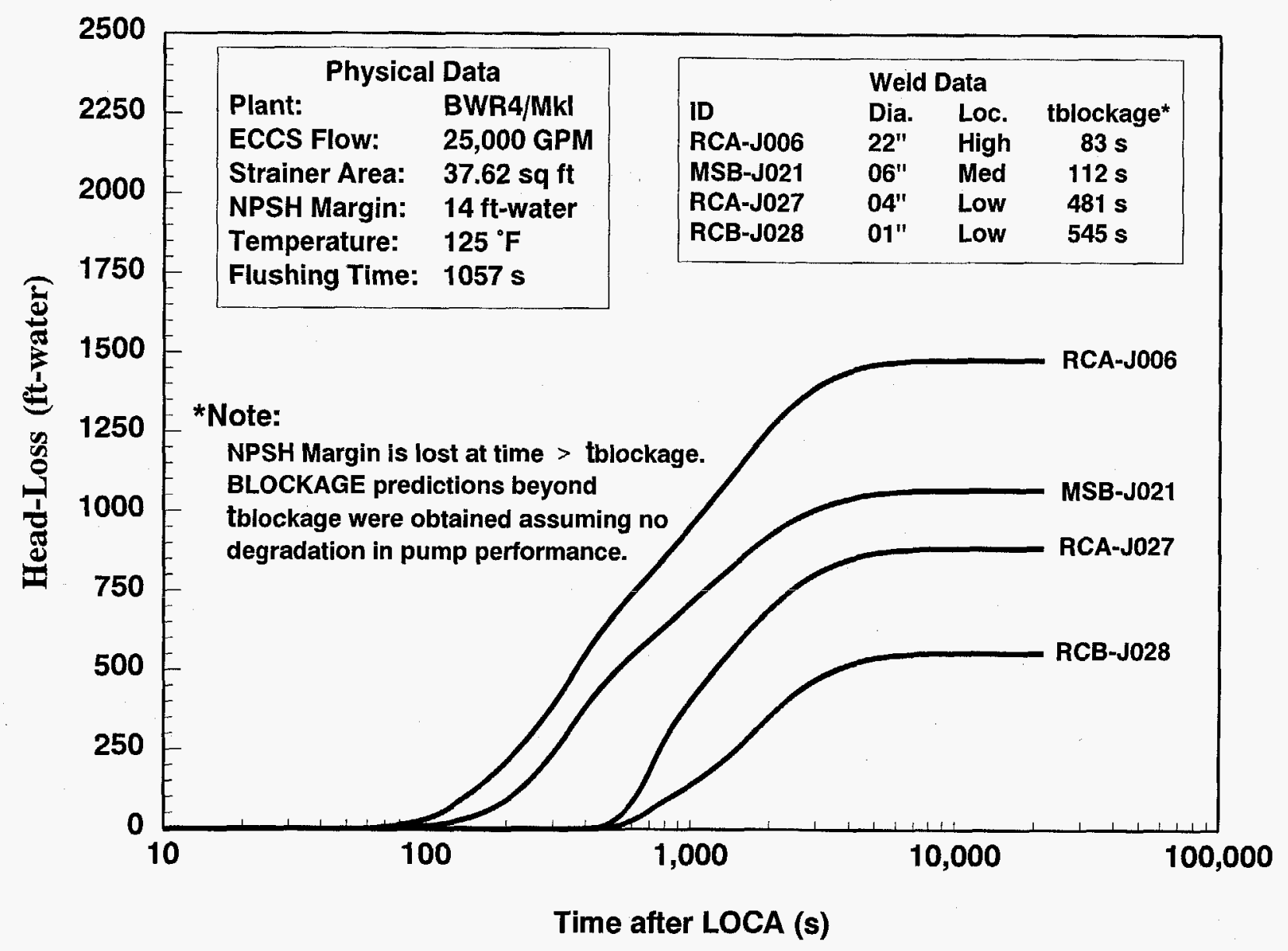

Figure 7-7b Variation of Head Loss Across the Debris Bed as a Function of Time for the Representative Welds (Long-Term) 
attributed to (1) the increased flow velocity introduces large pressure drops, and (2) increased flow also brings larger quantities of debris to the strainer. Although the NPSH is lost during this initial stage, BLOCKAGE calculations were continued for a duration of 6 hours assuming no degradation in the pump behavior to illustrate the transient nature of debris buildup. These long-term head loss characteristics are displayed in Figure $7-7 \mathrm{~b}$. Comparison of Figures 7-5 and 7-7 reveals that the head loss transient nature closely resembles the fibrous debris buildup in that it increases rapidly with time and reaches an asymptote within a few flushing cycles. The comparison also reveals that although RCA-J006 transports much larger quantities of fibrous debris to the strainer than RCBJ028 ( 8 vs. $0.4 \mathrm{in}$ ), the resultant head loss corresponding to RCA-J006 is only twice as large (1500 vs. $650 \mathrm{ft}$-water). This result is mainly attributable to larger sludge-to-fiber mass ratios associated with the latter; 7.4 for RCA-J006 vs. 76 for RCB-J028.

\subsection{Parametric Analyses}

A series of parametric analyses were performed to investigate the sensitivity of BLOCKAGE predictions to variation from the base case values of the following key model parameters:
1. Destruction factors for all three regions of Figure B-4,

2. Transport factors for all three elevations,

3. Turbulence factors used to model settling during post high-energy phase,

4. Pool geometrical parameters (volume and depth),

5. ECCS strainer surface area,

6. ECCS flow rate,

7. Variation in $\Delta \mathrm{P}$ correlations,

8. Pool temperature,

9. Debris bed filtration efficiency,

10. System retention fraction.

Table 7-4 presents the base case values for each of the factors listed above and the range over which they were varied. In most cases, the parameter range was selected to bound the estimates for that variable. Appendix $C$ presents detailed plots of variations in selected BLOCKAGE output

parameters (totaling 14) as a function of \% change in each of the parameters listed above. Figures 7-8, 7-9 and $7-10$ summarize the results of the parametric analysis. In these figures, the two most important output parameters, namely the maximum head loss (the head loss across the strainer at the end of the run) and the blockage time (defined as the time at which head loss exceeds the reference plant NPSH margin), are plotted as functions of \% change in the input variable from its base case value for two representative welds: RCA-J006 (LLOCA) and RCA-

Table 7-4 Input Parameters

\begin{tabular}{|l|c|c|l|}
\hline \multicolumn{1}{|c|}{ Input Parameter } & \multicolumn{1}{c|}{ Range } & Intervals & \multicolumn{1}{c|}{ Base Case Value } \\
\hline Suppression Pool Volume & $-50 \%$ to $+50 \%$ & $5 \%$ & $58,900 \mathrm{ft}^{3}$ \\
\hline Suppression Pool Depth & $-50 \%$ to $+50 \%$ & $5 \%$ & $10 \mathrm{ft}$ \\
\hline Insulation Destruction Factors & $-50 \%$ to $+50 \%$ & $5 \%$ & $0.75,0.6,0.4$ for L/D $=3,5, \& 7$ \\
\hline Drywell Transport Factors & $-20 \%$ to $+60 \%$ & $5 \%$ & $0.75,0.5,0.25$ for H, M, \&L \\
\hline Turbulence Factors & $-100 \%$ to $+100 \%$ & $10 \%$ & 0.5 shortly after blowdown \\
\hline Particulate Debris Volume & $-50 \%$ to $+250 \%$ & $10 \%$ & $1.76 \mathrm{ft}^{3}(\mathrm{DW}), 2.6 \mathrm{ft}^{3}(\mathrm{WW})$ \\
\hline Strainer Surface Area & $-50 \%$ to $+900 \%$ & $10 \%(<250 \%)$ & $37.62 \mathrm{ft}^{2}$ \\
\hline Available NPSH Margin & $-50 \%$ to $+100 \%$ & $5 \%$ & $14 \mathrm{ft}^{2}$ water \\
\hline ECCS Flow Rate & $-50 \%$ to $+50 \%$ & $5 \%$ & $25,000 \mathrm{gpm}$ \\
\hline$\Delta$ P Correlation Multiplier & $-50 \%$ to $+200 \%$ & $10 \%$ & 1 \\
\hline Suppression Pool Temperature & $75{ }^{\circ} \mathrm{F}$ to $175 \%$ & $5 \%$ & $125^{\circ} \mathrm{F}$ \\
\hline Strainer Filtration Efficiency & $-100 \%$ to $+100 \%$ & $10 \%$ & 0.5 after $1 / 4$ inch cake \\
\hline System Retention Fraction & $-100 \%$ to $+100 \%$ & $10 \%$ & 0.5 \\
\hline
\end{tabular}


J027 (MLOCA). As evident from these figures, in the range over which the parameters are varied, the potential for loss of NPSH margin for the reference plant is most sensitive to: (1) the ECCS flow rate, (2) the strainer surface area, (3) the filtration efficiency, and (4) the particulate volume. For example, reducing the ECCS flow rate to $50 \%$ of the base case value reduced the maximum head loss to $25 \%$ of the base predictions for both RCA-J006 and RCA-J027. However, this reduced value is still much larger than the available NPSH margin for the reference plant and further reduction in ECCS flow rate is unlikely. Similarly, although substantial reduction in maximum head loss can be obtained by decreasing the particulate volume of the filtration efficiency, the resulting head losses are still much larger than the available NPSH margin. The strainer surface area is the only independent variable which can reduce the head loss below the available NPSH margin for the reference plant.

Based on this sensitivity analysis, it was determined that model results are most sensitive to the strainer surface area. Figures 7-11 and 7-12 plot sensitivity of model results to the strainer surface area varied from the base case value of $37 \mathrm{ft}^{2}$ to $370 \mathrm{ft}^{2}$. As evident from these figures, for strainer areas larger than $300 \mathrm{ft}^{2}$ none of the postulated breaks resulted in loss of NPSH margin. 



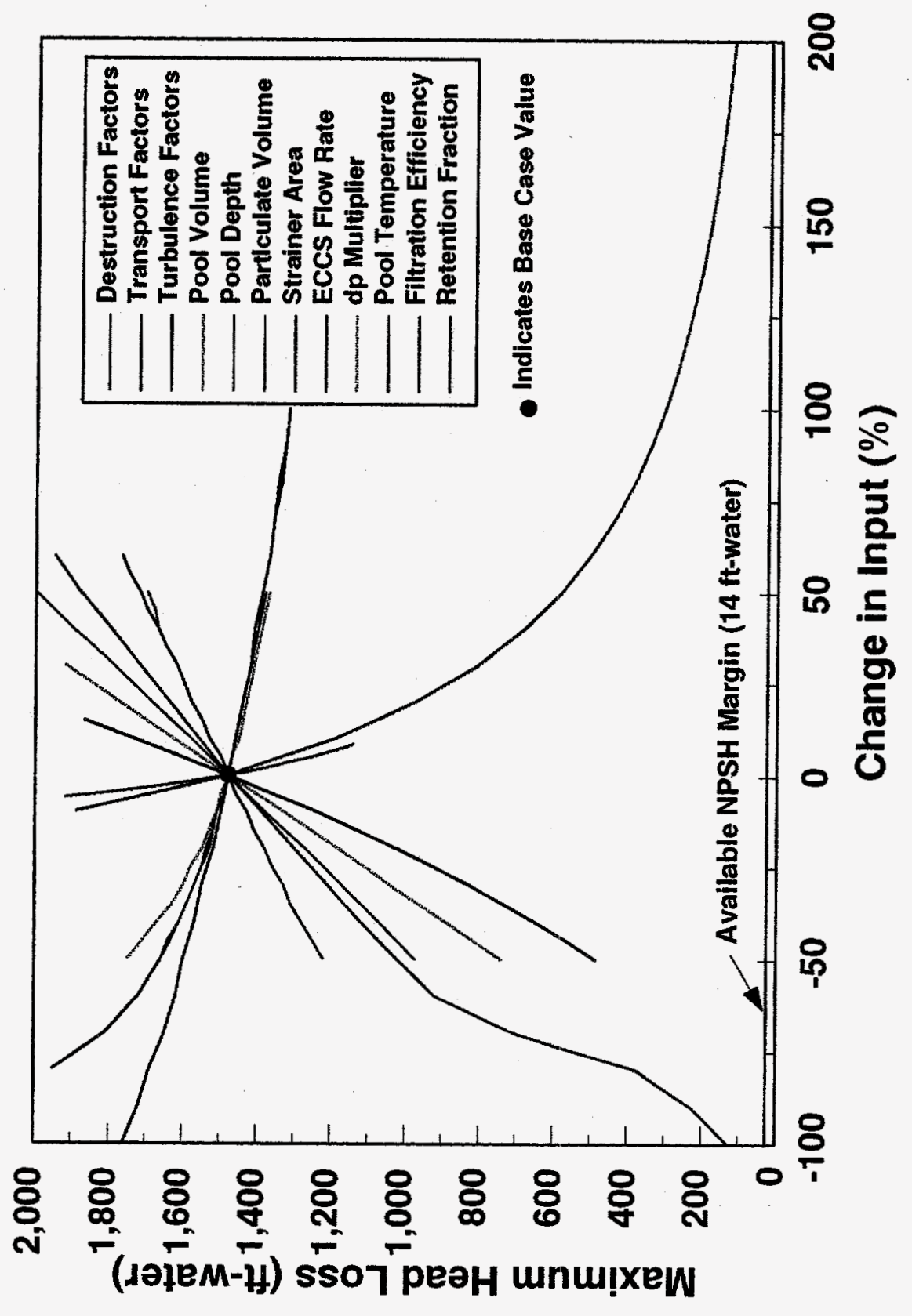

总 



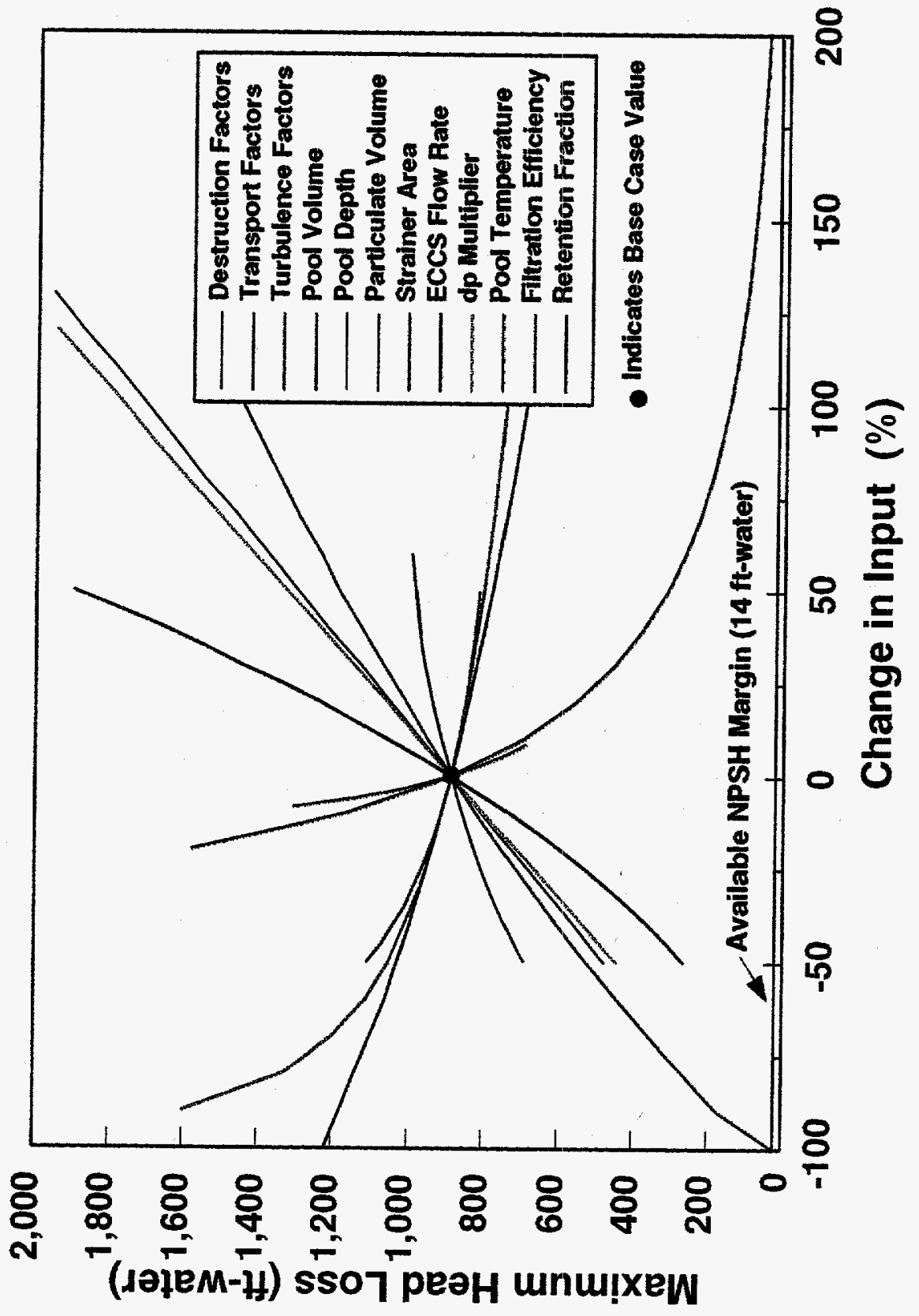

告 



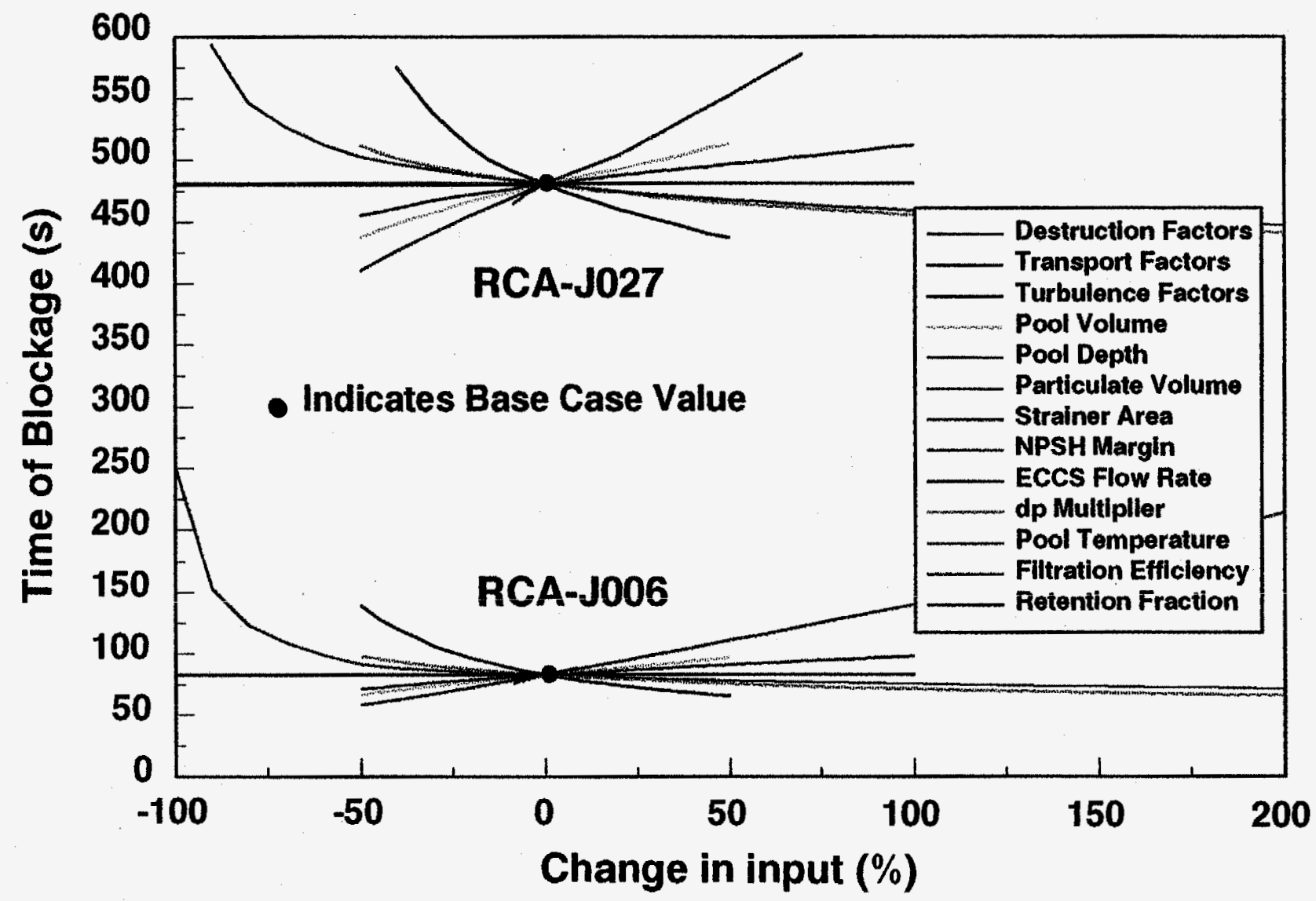

Figure 7-10 Time of Blockage 



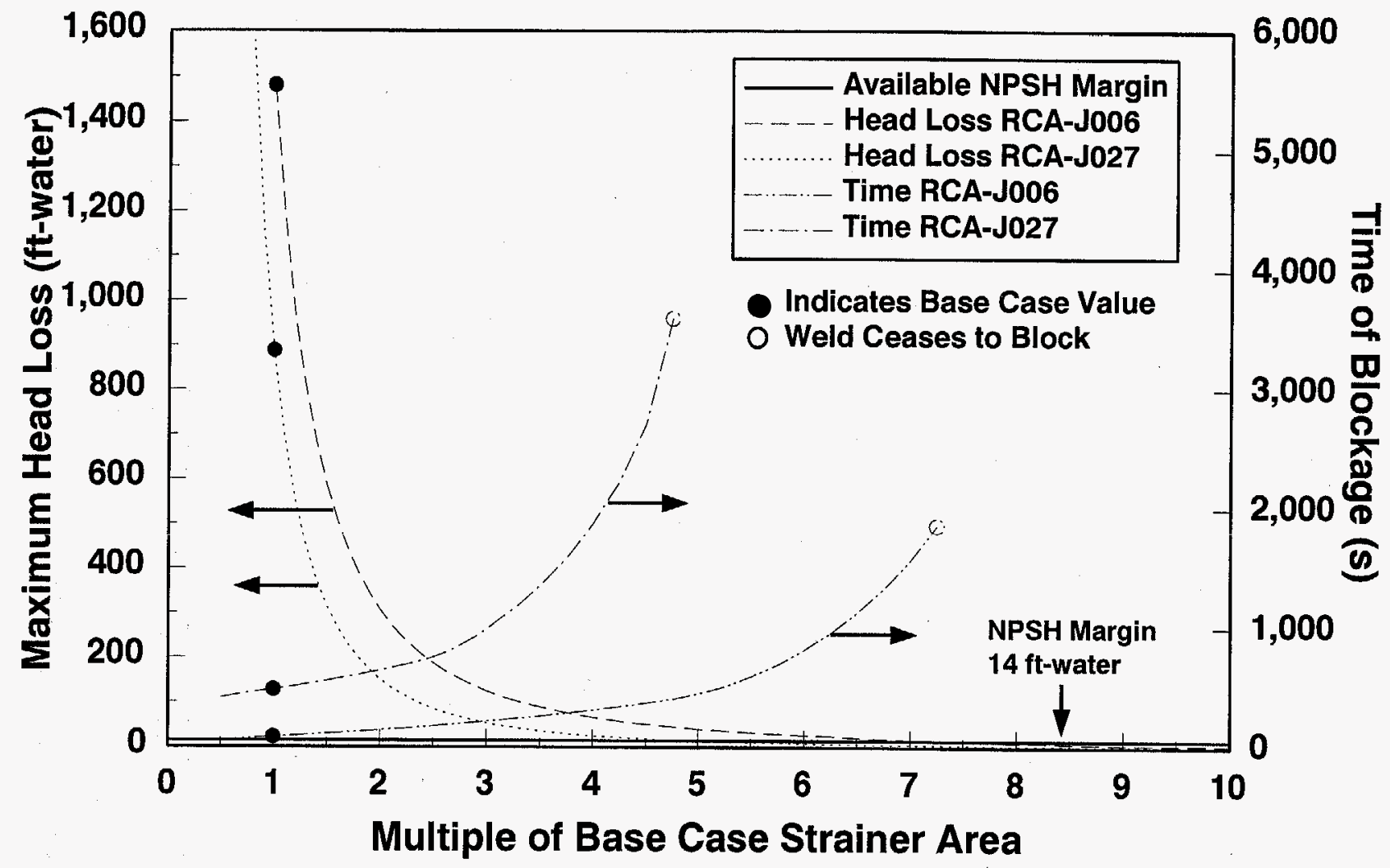

Figure 7-11 Blockage Sensitivity to Strainer Area 


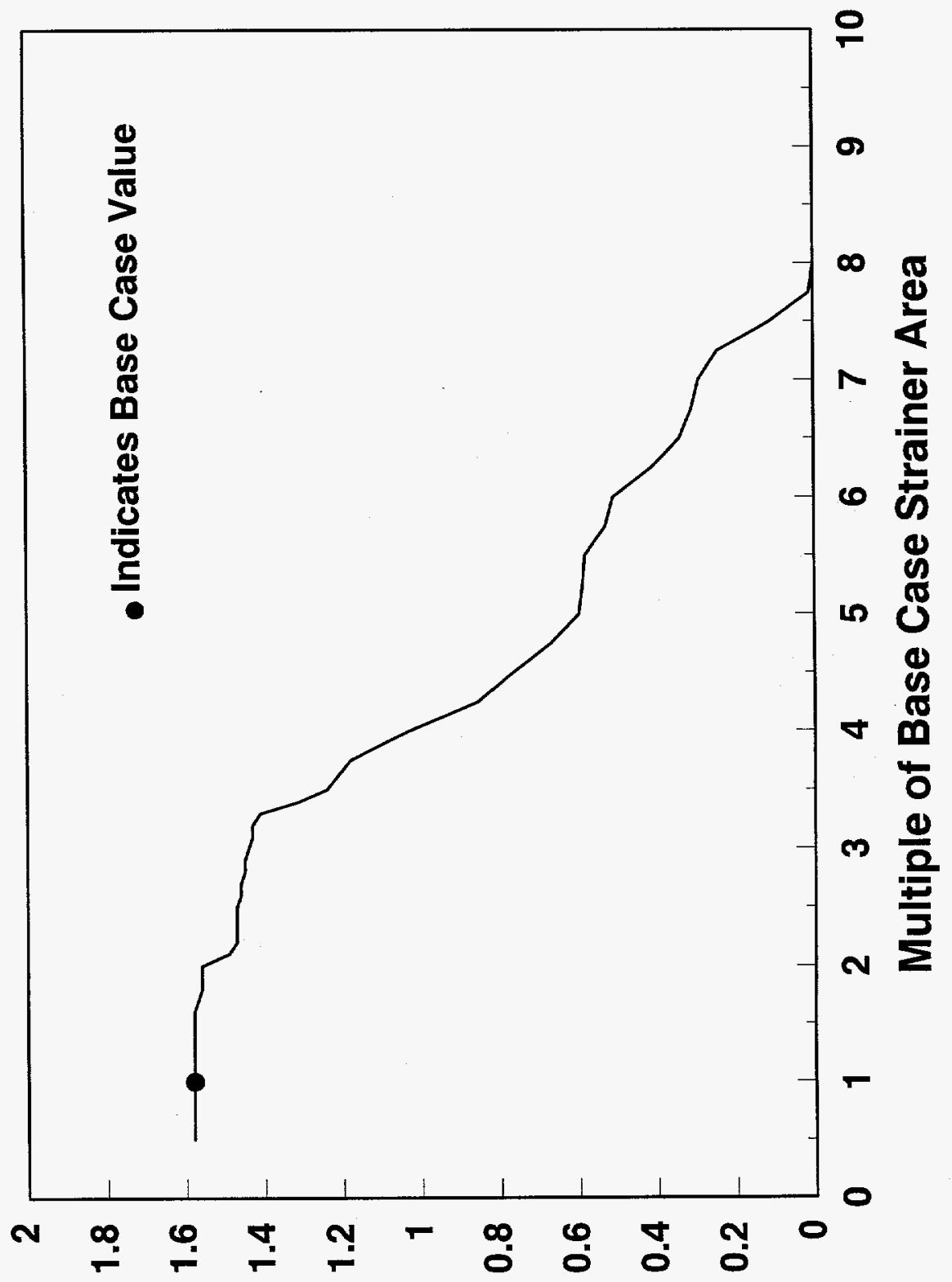

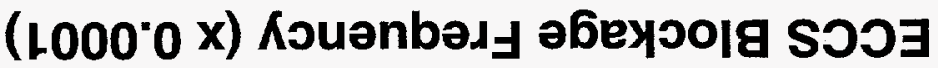




\subsection{Core Damage Frequency Estimates}

To gain additional insights into the potential safety significance of ECCS NPSH loss, CDF estimates were generated for blockage-related BWR accident sequences. This effort was focused on the development of CDF estimates for the reference BWR 4/Mark I plant. However, a limited effort was made to expand the CDF analysis to additional types of BWRs. As will be described in more detail later, the CDF estimates were limited to LLOCA initiators that correspond to the DEGB of a primary system pipe having a diameter $\geq 6$ " $(15.2 \mathrm{~cm})$.

A simplified event tree model, representing the progression and expected outcomes of various possible LOCA sequences, was used to generate the CDF estimates. The LOCA initiator frequency was quantified with data developed in Section 3.2. The quantification of the various event tree headings was based on applicable data from Section 7.0, data from BWR IPEs and other sources. Once the branches of the event tree were quantified, blockage-related CDF estimates were generated by summing the frequencies of the various blockage-related core damage accident sequences.

\subsection{Important Considerations Related to the Development of Blockage-Related CDF Estimates}

Blockage-related core damage accidents involve the failure of ECCS pumps due to: (a) the loss of NPSH, and (b) the subsequent failure to establish alternative means for core cooling and containment protection. There are a number of considerations involved in estimating the contribution of ECCS NPSH loss to CDF. Some of the more important considerations are briefly discussed below.

\section{Loss of Coolant Accident Frequency}

The frequency of a specific core damage accident sequence is directly proportional to the corresponding initiating event frequency. Consequently, the LOCA frequency is a very important consideration in estimating the frequencies of loss of ECCS NPSH due to strainer blockage scenarios.

\section{ECCS NPSH Loss Probability}

The probability of loss of ECCS NPSH represents the likelihood that, given a LOCA initiator, loss of pump NPSH would occur. The loss of NPSH probability is a function of a number of parameters, including LOCA size, type, and location. The loss of NPSH probability may be different for various items of ECCS equipment, e.g., RHR pumps versus LPCS pumps.

\section{Operator Recognition of NPSH Loss}

Early operator recognition of NPSH loss is essential to prevent affected ECCS pumps from becoming disabled. Early recognition of strainer blockage would allow operators to begin recovery actions, such as back flushing or preparation for the alignment of alternate core cooling sources.

\section{Availability of Back Flushing}

If available, strainer back flushing could allow operators to restore the operability of ECCS pumps following loss of NPSH. However, it is imperative that this action be successfully accomplished prior to loss of the pumps. At present, there are no means available at the majority of U.S. plants to perform strainer flushing operations.

\section{Alternate Means of Providing Core Cooling Depending on the specific circumstances under which the ECCS becomes disabled, alternative means of core cooling may be available. In some instances, it may be possible to manually realign the suction of certain ECCS pumps to a source of water outside of containment, such as the CST; in other instances, it may be possible to use emergency service water to provide once-through cooling to the reactor core via a cross connection to the RHR system. It may also be possible to provide core cooling via the condensate/feedwater system, depending on the LOCA size and location.}

\section{Containment Protection}

The protection of containment integrity may be an important consideration in loss of ECCS NPSH accidents, depending upon the accident sequence and the circumstances involved. The failure of containment from overpressure could create harsh environmental conditions that would have the

${ }^{1}$ For the reference plant, the difference in blockage probability between the RHR and core spray pumps is very small. 
potential to disable equipment needed to support core cooling. In addition, the long-term use of an external (ex-containment) water source for core cooling would eventually lead to containment overfill. However, because of the robust construction of the containment structure, containment failure would not be expected to occur until the overfill condition significantly exceeded the containment design basis.

\section{Timing}

Timing of various events associated with ECCS strainer blockage may be an important consideration in determining whether or not core cooling can be successfully accomplished. If, for example, loss of ECCS NPSH would occur very quickly following a LOCA, there would be very little time for the operators to establish an alternate cooling mode.

\section{Additional Considerations Related to Operator}

\section{Actions}

As previously noted, plant operators will be faced with attempting various types of recovery actions during a loss of ECCS NPSH condition. Some recovery actions may require that ECCS safety signals or containment isolation signals be bypassed.

\subsection{Event Tree Model and CDF Results}

\subsubsection{Event Tree Overview}

The simplified event tree shown in Figure 8-1 was developed for estimating CDF contributions from loss of ECCS NPSH. This event tree was based on success criteria presented in the IPE for the reference plant.

The event tree shown in Figure 8-1 represents potential loss of ECCS NPSH accidents at the reference plant caused by a LLOCA, specifically the DEGB of drywell piping with a diameter $\geq 6$ " (15.2 $\mathrm{cm})$. A LLOCA of this type was selected as the initiating event because the results developed in Section 7.0 of this report predict that DEGB events involving smaller pipes are less likely to cause loss of ECCS NPSH. In addition, some portion of smaller break sizes could be mitigated by the HPCI or RCIC systems, both of which take their initial supplies of water from the condensate storage system. During the time one of these systems is being used, the potential for strainer blockage would be eliminated by pump suction from the CST. Once CST levels have dropped sufficiently to require switchover to the suppression pool, reactor decay heat levels would be substantially reduced. If loss of NPSH occurs following switchover, the reduced decay heat levels would allow operators additional time for implementing corrective actions.

The following assumptions were made in the development of the event tree model:

1. Successful mitigation of an accident involving NPSH loss requires that core cooling be maintained for a 24-hour period following the LOCA initiating event. A 24-hour mitigating system mission time is consistent with IPE analyses and other commercial reactor PRA studies.

2. Containment failure will directly cause the disruption of core cooling, which could create harsh environmental conditions in the reactor building and subsequently disable equipment needed to sustain core cooling. This conservative assumption was made to simplify the analysis. Two potential containment failure modes were considered: (a) overpressure caused by steam; and (b) overfill with water. In the first case, containment venting was assumed to be a viable alternative to torus cooling in preventing steam-induced overpressure. In the latter case, containment overfill could occur if external water sources were used for long-term core cooling. It was determined that an overfill condition sufficient to threaten containment integrity was very unlikely to occur within the assumed 24-hour mission time; however, for completeness, the possibility of containment overfill was included in the event tree. Containment overfill was essentially excluded as a potential contributor to core damage by assigning a low screening value to the corresponding failure branch of the event tree, as will be described shortly.

3. ECCS equipment required for mitigation of the postulated LLOCA event is aligned to the suppression pool at the time the accident is initiated.

4. A loss of NPSH condition sufficient to fail one 


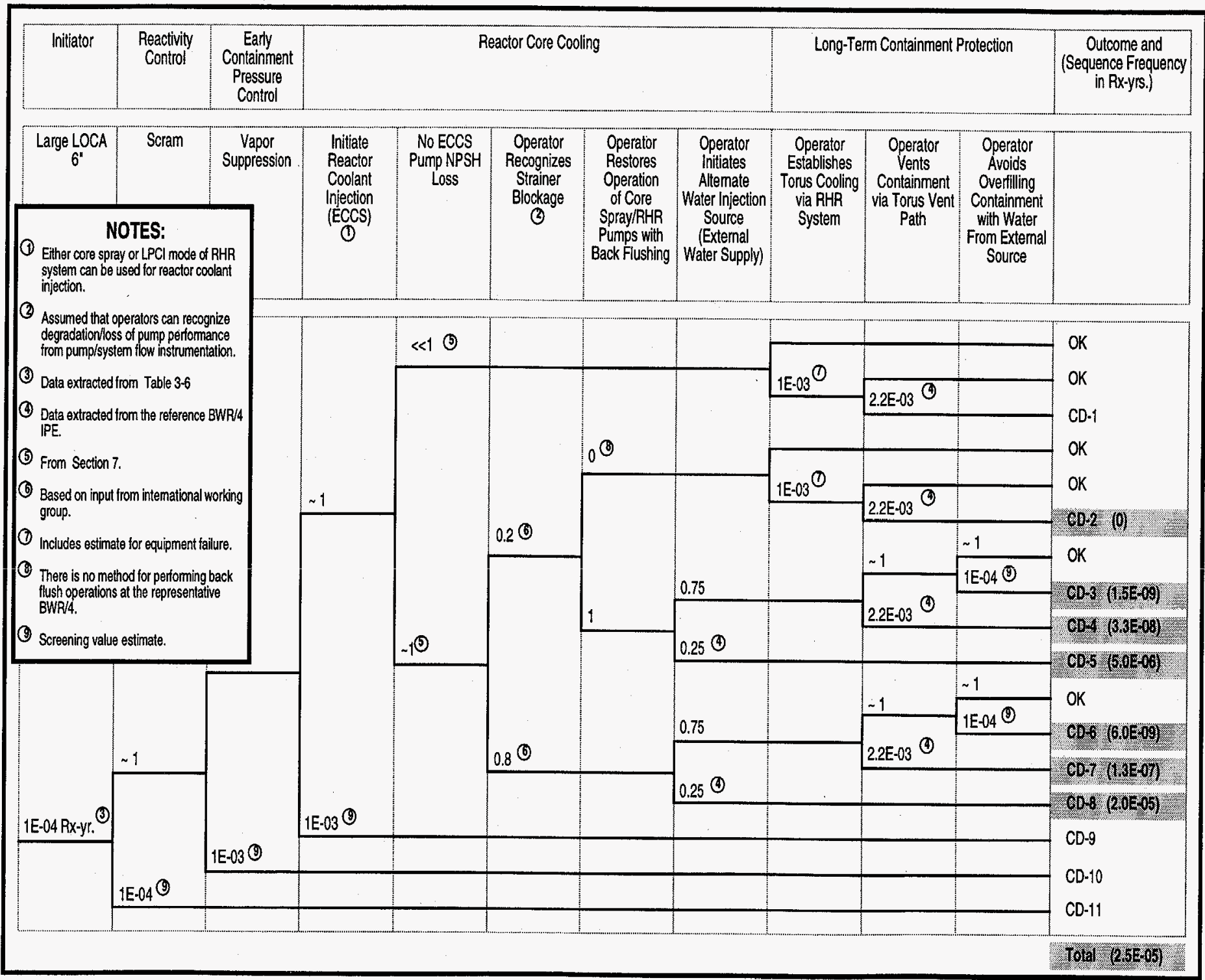

Figure 8-1 Simplified Event Tree for LLOCA at the Reference BWR/4 
ECCS pump will fail all ECCS pumps. This type of modeling simplification is reasonable, given that previous PRA studies have demonstrated that common cause failures are often much more important contributors to CDF than are various combinations of independent and/or random failures.

5. The ECCS pumps fail at 10 minutes following the LOCA initiator. At this point in the accident, core reflood will have taken place. This pump failure time was chosen so that available IPE data could be used to assess operator recovery actions. Also note that debris transport phenomena make it unlikely that pump failure would occur much before 10 minutes following the initiating event.

6. After the ECCS has been lost, no core damage will occur until the collapsed water level drops from $2 / 3$ of the core height to a point 2 $\mathrm{ft}(0.61 \mathrm{~m})$ from the bottom of the active fuel.

7. Regular testing and maintenance is performed on valves and other equipment whose operation is required to establish alternative core cooling paths after the ECCS pumps are lost.

8. The condensate/feedwater system cannot be successfully used for alternate core injection. It was assumed in the reference plant IPE that limitations on water supply inventories would preclude use of the condensate/feedwater system for mitigation of a LLOCA. In addition, injection from the condensate/feedwater system would be ineffective for some pipe break locations, and the use of the condensate/feedwater system would require the availability of offsite electrical power.

9. While no instrumentation specifically for the purpose of detecting strainer blockage is available to operators at the reference plant, readily available control room pump or system flow instrumentation may provide some indication of ECCS pump performance. Early detection of pump problems may increase the likelihood that operators could successfully establish alternate core cooling and other mitigating actions. It was not known how much advance warning these instruments could provide regarding pump strainer blockage conditions; consequently, it was assumed that operator recognition of strainer blockage would not appreciably affect the accomplishment of required mitigating actions.

10. Because of timing considerations and the possibility of permanent pump damage following strainer blockage, no credit was given to plant operations personnel for the realignment of ECCS pumps to the CST.

As is shown in Figure 8-1, the event tree includes functional representations of the LOCA initiating event, reactivity control, early containment pressure control, reactor core cooling, and the long-term protection of containment. Individual event tree headings represent specific events or actions related to the corresponding functional requirements. For example, reactivity control is accomplished with a successful reactor scram, and early containment pressure control is accomplished with venting from the drywell into the suppression pool. Upper branch lines on the event tree represent success, while bottom branch lines represent failure.

The functional requirements for reactor core cooling include: (a) initial establishment of ECCS injection; (b) status of ECCS NPSH loss; (c) operator recognition of strainer blockage; (d) restoration of ECCS pump function by strainer back flushing (if equipment is available); and (e) initiation of an alternate water source if back flushing is not available or is not successful. Events associated with the long-term protection of containment include the use of torus cooling, or the venting of containment if torus cooling is unsuccessful. Again, it was assumed that core cooling would be lost if containment integrity were compromised.

At the reference plant, adequate core cooling can be provided through either the LPCS system or the LPCI mode of the RHR system. According to the reference plant IPE, successful use of the LPCS system requires the availability of 1 of 2 redundant pumps, while successful use of the LPCI mode for core cooling requires the use of 1 of 4 RHR pumps. Note that while the normal source of LPCS water is the suppression pool, suction for this system can also be taken from CSTs via a normally-closed manual isolation valve. According to the reference plant IPE, alternate core cooling for a LLOCA event 
can be accomplished by injection from the RHR Service Water, Emergency Service Water, or General Service Water systems. To use any of these service water systems for core cooling, flow would have to be established through the RHR-RHRSW crossconnection.

The RHR system is also used to provide the preferred means of achieving post-LOCA containment heat removal. The heat removal function would be initiated by the operators and would involve the use of at least one RHR pump to establish water flow through an RHR heat exchanger. The RHR heat exchangers would, in turn, be cooled by the RHR service water system.

As can be seen in the event tree, a single event heading was used to represent loss of NPSH even though there are 6 individual ECCS pumps (2 LPCI pumps and 4 RHR pumps). This single event heading represents the possibility that common cause failure of all 6 of these ECCS pumps could occur. As previously noted, it was assumed that a loss of NPSH condition sufficient to fail one ECCS pump would fail all ECCS pumps.

The event tree also includes the possibility that operators would recognize pump degradations or failures that result from strainer blockage. While no instrumentation specifically for the purpose of detecting strainer blockage is available to operators at the reference plant, readily available control room pump or system flow instrumentation may provide some indication of ECCS pump performance. It was not known how much advance warning these instruments could provide regarding pump strainer blockage conditions; consequently, it was assumed that operator recognition of strainer blockage would not appreciably affect the accomplishment of required mitigating actions.

Nevertheless, for completeness, the event tree includes the possibility of using back flushing to restore the operation of pumps degraded or disabled because of strainer blockage. While it is recognized that there are currently no back flushing capabilities at the reference plant, the lack of back flush capability was accounted for in the event tree quantification.

If loss of NPSH causes failure of ECCS pumps, operators have the option of using an alternative means of re-establishing core cooling with service water systems via the RHR-RHRSW crossconnection. Information from the BWROG [Ref. 8.1] indicates that if ECCS injection is lost at 10 minutes after the LOCA initiator (as has been assumed), 25 minutes would be available for operator action to restore a source of core cooling before core damage would occur.

The event tree displayed in Figure 8- 1 contains a total of 11 accident sequences postulated to lead to core damage. Seven of these 11 sequences (specifically, sequences CD-2 through CD-8) involve loss of NPSH. The remaining four core damage sequences (CD-1 and CD-7 through CD-9) are independent of NPSH considerations and were neglected in the subsequent analysis to estimate strainer blockage CDF contributions.

\subsubsection{Event Tree Quantification}

In order to quantify the seven accident sequences of interest, it was first necessary to quantify the individual event tree branches. The quantification of these individual branches for the base case is displayed in Figure 8-1 and described in more detail in the following paragraphs.

The LOCA initiating event frequency, which is the first event tree heading, was quantified by using the pipe break estimates generated via the methodology described in Section 3.2. The LOCA initiator value of $1 \mathrm{E}-04 / \mathrm{Rx}-\mathrm{yr}$ was calculated from data in Table 3-6 by summing break frequencies for pipes having a diameter $\geq 6$ " $(15.2 \mathrm{~cm})$. The second, third, and fourth event headings represent, in order, reactor scram, vapor suppression of containment, and initiation of ECCS. Failure to achieve success in any of these three categories would result in an accident sequence unrelated to loss of NPSH (CD-9, CD-10, or CD-11). Screening value estimates were used to show that corresponding success paths could be approximated with probabilities of 1.0.

The fifth event tree heading, avoidance of ECCS NPSH loss, was quantified from data presented in Section 7.0. For the DEGB pipe breaks considered ( $\geq 6$ " or $15.2 \mathrm{~cm}$ ), the probability of ECCS NPSH loss is predicted to be essentially equal to 1.0 . Conversely, avoidance of NPSH loss has a probability $<<1$. This estimate of NPSH loss probability is reflected on the event tree. 
The sixth event tree heading represents operator recognition of strainer blockage via the use of existing pump/system flow instrumentation. For the purpose of this preliminary analysis, screening values of 0.2 and 0.8 were used for success and failure, respectively. However, the quantification of this particular event does not impact the overall CDF estimate for NPSH loss. This situation exists because (1) the reference plant does not have a back flushing capability, and (2) it was assumed that operator recognition of strainer blockage would not appreciably affect the subsequent accomplishment of required mitigating actions. For completeness, the seventh event tree heading represents the possibility that ECCS NPSH loss could be removed by a back flushing procedure. Failure to perform back flushing was assigned a probability of 1.0 as there is currently no means of accomplishing this mitigating action.

The eighth event tree heading represents the unavailability of alternate core cooling due to operator error ${ }^{2}$. In quantifying the probability for operator error, assumptions were made regarding the time available for such actions. If ECCS injection is lost at 10 minutes after a LOCA initiator, 25 minutes are available for operator action to restore a source of core cooling [Ref. 8.1]. Also, the reference plant IPE contains a human factors analysis relevant to the use of service water injection via the RHR-RHRSW cross tie following a LLOCA. The IPE assumes that operator diagnosis and required actions for establishing an alternate injection source must be performed within 10 minutes. This human factors analysis predicts a probability of 0.25 that an operator failure would occur. This failure probability was subsequently used in the event tree as shown in Figure 8-1. This probability is somewhat conservative given that 25 minutes rather than 10 minutes are available for operator action, but it was the only documented reference plant-specific human factors data for this action. Note that the quantification of the alternative injection flow event was assumed to be independent of operator recognition of strainer blockage conditions.

The last three event tree headings represent actions

\footnotetext{
${ }^{2}$ Equipment failures were not explicitly included in this event because operator error was assumed to dominate the alternate core cooling unavailability.
}

that pertain to the long-term protection of containment. The first of these three containment-related events involves the establishment of torus cooling via the RHR system. As indicated in the event tree, the use of torus cooling is not possible if pump NPSH loss has occurred and has not been reversed with back flushing. The quantification of this event represents a screening value estimate for RHR equipment reliability, as human factors data in the reference plant IPE predict the probability of operator failure to be very small (1E-06). If torus cooling cannot be established, the operators can take remote-manual actions to vent containment via torus vent paths. Failure to perform this action was assigned a probability of $2.2 \mathrm{E}-03$ based on data provided in the reference plant IPE. The last event tree heading represents operator action to avoid overfilling the containment with water. Operator action is a concern if water sources external to containment are being used to sustain core cooling (alternate water injection via the RHR-RHRSW cross-connection). However, as previously stated, it was determined that an overfill condition sufficient to threaten containment integrity was very unlikely to occur within the assumed 24-hour mission time. Consequently, containment overfill was essentially excluded as a potential contributor to core damage by assigning a low screening value of $1 \mathrm{E}-04$ to the corresponding failure branch of the event tree.

\subsubsection{Accident Sequence Results}

As previously noted, there are 7 core damage sequences related to NPSH loss that can potentially contribute to core damage. These sequences, CD-2 through CD-8, together with corresponding point-estimate frequency estimates, are shaded in the right-hand portion of Figure 8-1. Note that all 7 of these core damage sequences involve successful reactor scram, early containment vapor suppression, and ECCS initiation. In addition, all of these sequences involve a subsequent common cause NPSH loss that affects the ECCS (LPCS and RHR) pumps.

As can be seen in Figure 8-1, sequence CD-2 includes successful operator recognition of strainer blockage, combined with successful back flushing of strainers to restore operation of the ECCS pumps. However, following back flush operation, torus cooling is not established and operators 
subsequently fail to protect the integrity of the containment structure by venting. As a result, the ECCS is postulated to fail and core damage results. Because there is currently no means for operators to perform the required back flushing operation, this sequence frequency is zero.

Sequences CD-3, CD-4, and CD-5 involve successful operator recognition of strainer blockage coupled with failure to use a back flushing operation to restore the operability of the ECCS pumps. In sequence CD-3, operators successfully establish an alternate injection source for core cooling. Though torus cooling cannot be established because the RHR pump NPSH remains lost, operators are successful in maintaining containment structure integrity by manually venting. Even though subsequent containment overfill is postulated to lead to core damage, this situation was considered to be very unlikely during the 24-hour mitigating system mission time. Consequently, the frequency estimate for sequence CD-3 is negligible.

In sequence CD-4, an alternate injection source for core cooling is successfully established, but torus cooling cannot be established because the RHR pump NPSH remains lost. The integrity of containment is lost because the operators are unsuccessful in manually venting containment. Consequently, core cooling is postulated to be lost. This sequence was estimated to have a point-value frequency of $3.3 \mathrm{E}-08 / \mathrm{Rx}-\mathrm{yr}$. Sequence CD-5 involves the failure to establish an alternate injection source following loss of the ECCS pumps to strainer blockage. The point-value of this sequence was estimated to be $5.0 \mathrm{E}-06 / \mathrm{Rx}-\mathrm{yr}$.

Sequences CD-6, CD-7, and CD-8 involve the failure of the operator to recognize strainer blockage, while loss of the ECCS pump NPSH eventually causes core cooling to fail. In sequence $C D-6$, operators successfully establish an alternate injection source for core cooling. Though torus cooling cannot be established because the RHR pump NPSH remains lost, operators are successful in maintaining the containment structure integrity by manually venting. Again, even though subsequent containment overfill is postulated to lead to core damage, this situation was considered to be very unlikely during the 24-hour mitigating system mission time. Consequently, the frequency estimate for this sequence is also negligible.
In sequence $C D-7$, an alternate injection source for core cooling is successfully established, but torus cooling cannot be established because the RHR pump NPSH remains lost. The integrity of containment is lost because the operators are unsuccessful in manually venting containment. Consequently, core cooling is postulated to be lost. This sequence was estimated to have a point-value frequency of $1.3 \mathrm{E}-07 / \mathrm{Rx}-\mathrm{yr}$. Sequence CD-8 involves the failure of the operators to establish an alternate injection source following loss of the ECCS pumps to NPSH loss. The point-value of this sequence was estimated to be $2.0 \mathrm{E}-05 / \mathrm{Rx}-\mathrm{yr}$.

As is shown in Figure 8-1, the sum of the point-value frequency estimates for the 7 core damage sequences involving NPSH loss is $2.5 \mathrm{E}-05 / \mathrm{Rx}-\mathrm{yr}$. The two dominant sequences, CD-5. and $\mathrm{CD}-8$, involve the failure of operators to establish alternative core cooling following the loss of ECCS. Together, these two sequences represent approximately $99 \%$ of the total NPSH loss CDF estimate. The point-value CDF estimate related to ECCS NPSH loss for the reference plant, $2.5 \mathrm{E}-05 / \mathrm{Rx}-\mathrm{yr}$, is over 3 times the overall plant CDF of $7.8 \mathrm{E}-06 / \mathrm{Rx}-\mathrm{yr}$ estimated in the reference plant IPE.

The conditional probability of core damage following a LLOCA was calculated to be 0.25 by dividing the CDF estimate $(2.5 \mathrm{E}-05 / \mathrm{Rx}-\mathrm{yr})$ by the LLOCA initiator frequency (1E-04/Rx-yr). In other words, given a LLOCA initiator, core damage from ECCS NPSH loss is estimated to occur $25 \%$ of the time at the reference plant.

\subsection{CDF Parametric Analysis}

This section describes the results of a CDF parametric analysis. In the first portion of this parametric analysis, quantification changes were made to the reference plant event tree to evaluate the impact on the base case CDF. In the second portion of the parametric study, extrapolations of the reference plant analysis were made to generate CDF estimates for other BWRs, including BWR 4/Mark I designs and other BWR types. In the third and final portion of the parametric analysis, a scoping study was performed to estimate the potential benefits of possible "back-fits" for mitigation of NPSH loss conditions. 


\subsubsection{Parametric Analysis for Reference Plant CDF}

Reference plant base case results previously described demonstrated that the dominant contributor to blockage-related CDF is the failure to establish an alternate core cooling source. In particular, the two accident sequences with this failure accounted for approximately $99 \%$ of the base case CDF. Because of the significance of alternate core cooling, it was decided to focus the reference plant CDF parametric analysis on the quantification of the alternate core cooling unavailability.

The BWROG has provided estimates of the unavailability of alternate core cooling following an ECCS NPSH loss condition. In an analysis described in Reference 8.1, the estimated alternate core cooling unavailability was 0.04 for a reference BWR 4/Mark I BWR. This unavailability number was derived from an operator response evaluation that assumed failure of all ECCS pumps at 10 minutes after LOCA initiation. Using deterministic calculations, it was concluded that operators would subsequently have 25 minutes to establish alternate core cooling in order to prevent core damage. In another study related to ECCS NPSH loss [Ref. 8.2], a higher screening value of 0.10 was assumed for the unavailability of alternate core cooling. To most effectively generate bounding estimates from the parametric analysis, the value of 0.04 was used for alternate core cooling unavailability. As is shown in Figure 8-2, the point-value CDF generated with this modified unavailability number is $4.2 \mathrm{E}-06 / \mathrm{Rx}$-yr. In comparison, the point-estimate for $\mathrm{CDF}$ in the base case was $2.5 \mathrm{E}-05 / \mathrm{Rx}-\mathrm{yr}$. The CDF estimate of $4.2 \mathrm{E}-06 / \mathrm{Rx}-\mathrm{yr}$ is over half of the overall CDF of $7.8 \mathrm{E}-06 / \mathrm{Rx}-\mathrm{yr}$ estimated in the reference plant IPE.

The CDF estimate obtained with the Reference 8.1 unavailability data was used to re-calculate the conditional probability of core damage related to NPSH loss. By dividing the modified CDF estimate of $4.2 \mathrm{E}-06 / \mathrm{Rx}-\mathrm{yr}$ with the LLOCA initiator frequency (1E-04/Rx-yr), the corresponding conditional probability was determined to be 0.04 . By contrast, the base case model predicted that core damage related to NPSH loss would occur approximately $25 \%$ of the time following a LLOCA.

\subsubsection{Extrapolation of the Reference Plant Results to Other BWRs}

The contribution of NPSH loss to BWR CDF may vary significantly among plants because of differences in design and accident mitigation features. However, to facilitate a preliminary assessment of potential CDF contributions of NPSH loss at other BWRs, results from the reference plant event tree model were extrapolated to other plants. These extrapolations are described below.

The major portion of the extrapolation process was focused on other BWR 4/Mark I plants. In extrapolating the results to other BWR 4/Mark I plants, previously calculated conditional probability estimates for post-LOCA core damage related to NPSH loss at the reference plant were used. These conditional probability estimates were subsequently multiplied by LLOCA frequency estimates extracted from IPE studies of several other BWR 4/Mark I plants to estimate corresponding CDFs related to NPSH loss. These CDFs were in turn compared to overall CDF estimates included in the respective IPEs. The results of the extrapolations are presented in Table 8-1, together with results from the present analysis. Note that two different CDF conditional probability values were used, specifically the 0.25 value associated with the base case and the lower value of 0.04 derived from the parametric analysis using Reference 8.1 core cooling unavailability data.

CDF estimates related to ECCS NPSH loss given in Table 8-1 reveal that in several cases, point estimates for blockage-related $\mathrm{CDF}$ exceed overall $\mathrm{CDF}$ values predicted by IPE studies. Even with the use of unavailability data for alternate core cooling, the blockage-related CDF for plant no. 3 exceeds the corresponding IPE overall CDF. It can also be seen from Table 8-1 that IPE predictions of LLOCA CDF contributions are two or more orders of magnitude smaller than the corresponding IPE estimates of overall plant CDF. Caution should be used in drawing conclusions based on the data in Table 8-1. It was assumed that all of the BWR 4/Mark I plants in this table are similar in design to the reference plant, including the characteristics and transport rates of insulation. However, the reference plant has the smallest strainer areas of any BWR, resulting in the largest strainer pressure drops for a given amount of blockage material. 


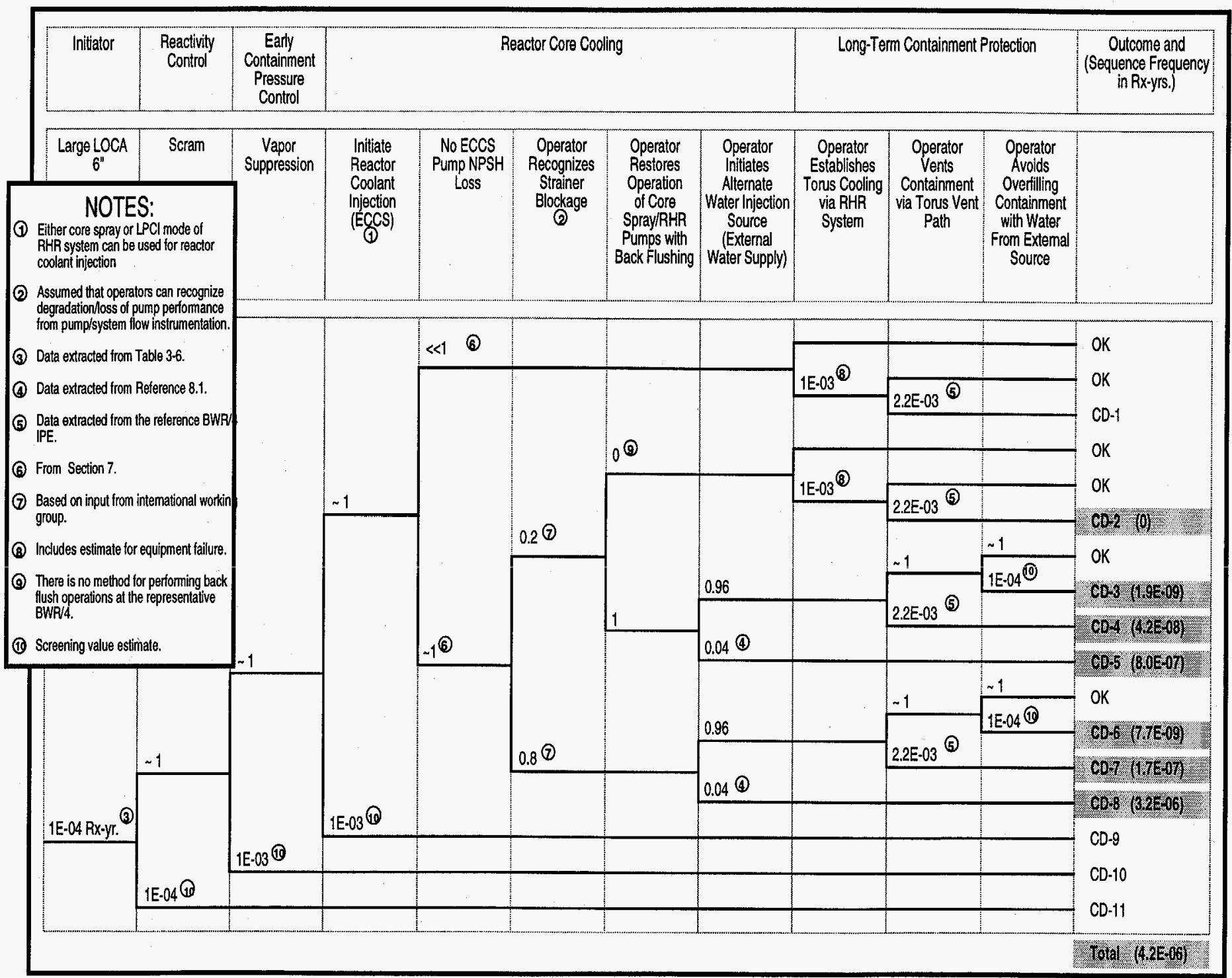

Figure 8-2 Simplified Event Tree for LLOCA at the Reference BWR/4 [Ref. 8.1 Data for Alternate Core Cooling] 
Table 8-1 Estimates of CDF Contributions from ECCS NPSH Loss at BWR 4/Mark I Plants

\begin{tabular}{|c|c|c|c|c|c|c|}
\hline \multirow{3}{*}{ Plant } & \multirow{3}{*}{$\begin{array}{c}\text { Large } \\
\text { LOCA Freq. } \\
\text { (per Rx-yr) }\end{array}$} & \multirow{3}{*}{$\begin{array}{c}\text { CDF } \\
\text { Calculated } \\
\text { in IPE } \\
\text { (per } R x-y r)\end{array}$} & \multicolumn{3}{|c|}{ Estimated CDF Contrib. from } & \multirow{3}{*}{ Notes } \\
\hline & & & \multicolumn{2}{|c|}{$\begin{array}{l}\text { NPSH Loss } \\
\text { (per Rx-yr) }\end{array}$} & \multirow{2}{*}{$\begin{array}{l}\text { Contrib. of } \\
\text { Large LOCA } \\
\text { to IPE CDF } \\
\text { (per Rx-yr) }\end{array}$} & \\
\hline & & & $\begin{array}{c}\text { Base Case } \\
\text { Results } \\
\left(0.25 \mathrm{ACCU}^{2}\right)\end{array}$ & $\begin{array}{c}\text { Parametric } \\
\text { Analysis } \\
\left(0.04 \mathrm{ACCU}^{2}\right)\end{array}$ & & \\
\hline Ref. Plant & $\begin{array}{c}1 \mathrm{E}-04 \\
\text { (this study) }\end{array}$ & $7.8 \mathrm{E}-06$ & $2.5 \mathrm{E}-05$ & $4.2 \mathrm{E}-06$ & $<8 \mathrm{E}-08$ & $\begin{array}{l}\text { CDF from } \\
\text { NPSH loss } \\
\text { based on }\end{array}$ \\
\hline & $\begin{array}{c}1.3 \mathrm{E}-04 \\
\text { (IPE) }\end{array}$ & & & & & $\begin{array}{l}\text { LOCA freq. of } \\
1 \mathrm{E}-04 / \mathrm{Rx}-\mathrm{yr}\end{array}$ \\
\hline Plant No. $1^{1}$ & $\begin{array}{c}5.9 \mathrm{E}-04 \\
\text { (IPE) }\end{array}$ & $4.8 \mathrm{E}-05$ & $1.5 \mathrm{E}-04$ & 2.4E-05 & $<7 \mathrm{E}-07$ & $\begin{array}{l}\text { IPE CDF } \\
\text { represents a } \\
\text { mean value }\end{array}$ \\
\hline Plant No. $2^{1}$ & $\begin{array}{l}1 \mathrm{E}-04 \\
(\mathrm{IPE})\end{array}$ & $8.0 \mathrm{E}-05$ & 2.5E-05 & $4 \mathrm{E}-06$ & 4.7E-08 & $\begin{array}{l}\text { IPE CDF } \\
\text { represents a } \\
\text { mean value }\end{array}$ \\
\hline Plant No. $3^{1}$ & $\begin{array}{l}\text { 1E-04 } \\
\text { (IPE) }\end{array}$ & $1.9 \mathrm{E}-06$ & 2.5E-05 & $4 \mathrm{E}-06$ & $<1.9 \mathrm{E}-08$ & $\begin{array}{l}\text { IPE CDF } \\
\text { represents a } \\
\text { mean value }\end{array}$ \\
\hline Plant No. $4^{1}$ & $\begin{array}{c}2.6 \mathrm{E}-04 \\
\text { (IPE) }\end{array}$ & 2.2E-05 & $6.5 \mathrm{E}-05$ & $1.0 \mathrm{E}-05$ & $2.5 \mathrm{E}-08$ & $\begin{array}{l}\text { IPE CDF is for } \\
\text { unit } 2 \text {; unit } 1 \\
\text { CDF is } \\
2.1 \mathrm{E}-05 / \mathrm{Rx}-\mathrm{yr}\end{array}$ \\
\hline
\end{tabular}

${ }^{1}$ Extrapolations from base case results and from parametric analysis results

${ }^{2} \mathrm{ACCU}=$ Alternate Core Cooling Unavailability

Consideration was also given to extrapolating the CDF analysis to other types of BWRs. Like BWR 4 plants, LLOCA-mitigating systems at BWR 2 and 3 plants are normally aligned to the suppression pool. Also like BWR 4 plants, the LPCS used at BWR 2 and 3 plants can be manually realigned to the CST. However, the time required to perform this manual realignment and the possibility of damage occurring to the LPCS pumps by a strainer blockage condition may make manual realignment of the LPCS ineffective for mitigating the effects of a blockage condition. For some of the BWR 2 and 3 plants, alternate sources of makeup water, such as service water via the RHR-RHRSW crosstie or condensate/feedwater, may be available. These alternate systems would be evaluated on a plant-specific basis, based on the following considerations: (1) the condensate/feedwater system would be ineffective for some pipe break locations; (2) the supply of water might be inadequate for a 24-hour mitigation interval; and (3) the use of condensate/feedwater systems requires the availability of offsite electrical power. Thus, it was determined that $\mathrm{CDF}$ contributions at BWR 2 and 3 plants involving ECCS NPSH loss have the potential to be in the same range as CDF estimates for the reference plant.

At BWR 5 and 6 plants, an automatically-actuated HPCS system is available for the mitigation of any 
size LOCA. This system is available in addition to other LLOCA-mitigating systems, specifically the LPCS and the LPCI, initially taking its suction from the CST. The availability of an automaticallyactuated HPCS at BWR 5 and 6 plants would delay potential ECCS strainer blockage until switchover could be made to the suppression pool. Even if ECCS NPSH loss takes place after the switchover, the reduced decay heat levels would provide operators with additional time for implementing alternate sources of core cooling. Based on the above considerations, it was determined that CDFs for BWR 5 and 6 plants involving ECCS NPSH loss have the potential to be lower than corresponding CDF estimates for the reference plant. However, further analysis is necessary to more completely assess the impact of BWR 5 and 6 design features on blockage-related CDF.

\subsection{European Approach for Addressing Potential Accidents Involving ECCS NPSH Loss}

In addressing the issue of ECCS NPSH loss, some members of the European ${ }^{3}$ nuclear community have taken an approach that includes three major mitigating actions:

1. Use of larger strainer areas

2. Installation of pressure differential sensors on the ECCS strainers

3. Installation of strainer back flushing equipment.

The use of larger strainer areas would reduce the likelihood that ECCS NPSH loss would occur following a LOCA. Installation of pressure differential sensors on the ECCS strainers would provide a means for operators to accurately diagnose a blockage condition; installation of strainer back flushing equipment would provide operators with a means to restore operation to pumps following loss of NPSH.

The potential benefit of these three activities on

\footnotetext{
${ }^{3}$ Sweden and Finland
}

reducing the blockage-related $\mathrm{CDF}$ at the reference plant is shown in the event tree in Figure 8-3. As can be seen in this event tree, these three mitigating actions would increase the probability that accidents would progress via the shaded paths in the event tree; these modifications would also reduce that chance that alternate water injection sources would be needed. As previously shown, failure to establish alternate water injection sources is the dominant contributor to CDF related to NPSH loss at the reference plant.

Elements used in the European approach were quantified as shown in Figure 8-3. The values used in this event tree are believed to represent reasonable screening data for estimating the benefit of the three mitigating actions. Note that the unavailability of alternative core cooling was quantified with data used in the reference plant base case analysis. Table 8-2 summarizes the updated event tree branch point probabilities along with corresponding probabilities used in the base case. The overall blockage-related CDF estimated with the European backfit elements is $1.4 \mathrm{E}-06 / \mathrm{Rx}-\mathrm{yr}$. This point estimate is a factor of 18 less than the base case blockage-related CDF point estimate of 2.5E-05/Rx-yr.

Figure 8-4 combines the European elements with Reference 8.1 data for the unavailability of alternate core cooling. In this situation, the $\mathrm{CDF}$ is 2.3E-07/Rx-yr. Without benefit of the European elements, the corresponding CDF was formerly estimated to be $4.2 \mathrm{E}-06 / \mathrm{Rx}-\mathrm{yr}$ (as shown in Figure 8-2); when combined with Reference 8.1 unavailability for alternate core cooling, the European modifications lower the point estimate blockage-related CDF by a factor of approximately 18.

\subsection{Summary and Conclusions}

Results from a preliminary event tree model have shown that ECCS NPSH loss has the potential to be a very significant contributor to BWR CDFs. In particular, the CDF contribution from this ECCS failure mode was estimated to be comparable or greater than overall plant CDF data given in several BWR IPE studies.

It is important to note that this evaluation of $\mathrm{CDF}$ related to NPSH loss has a number of limitations 


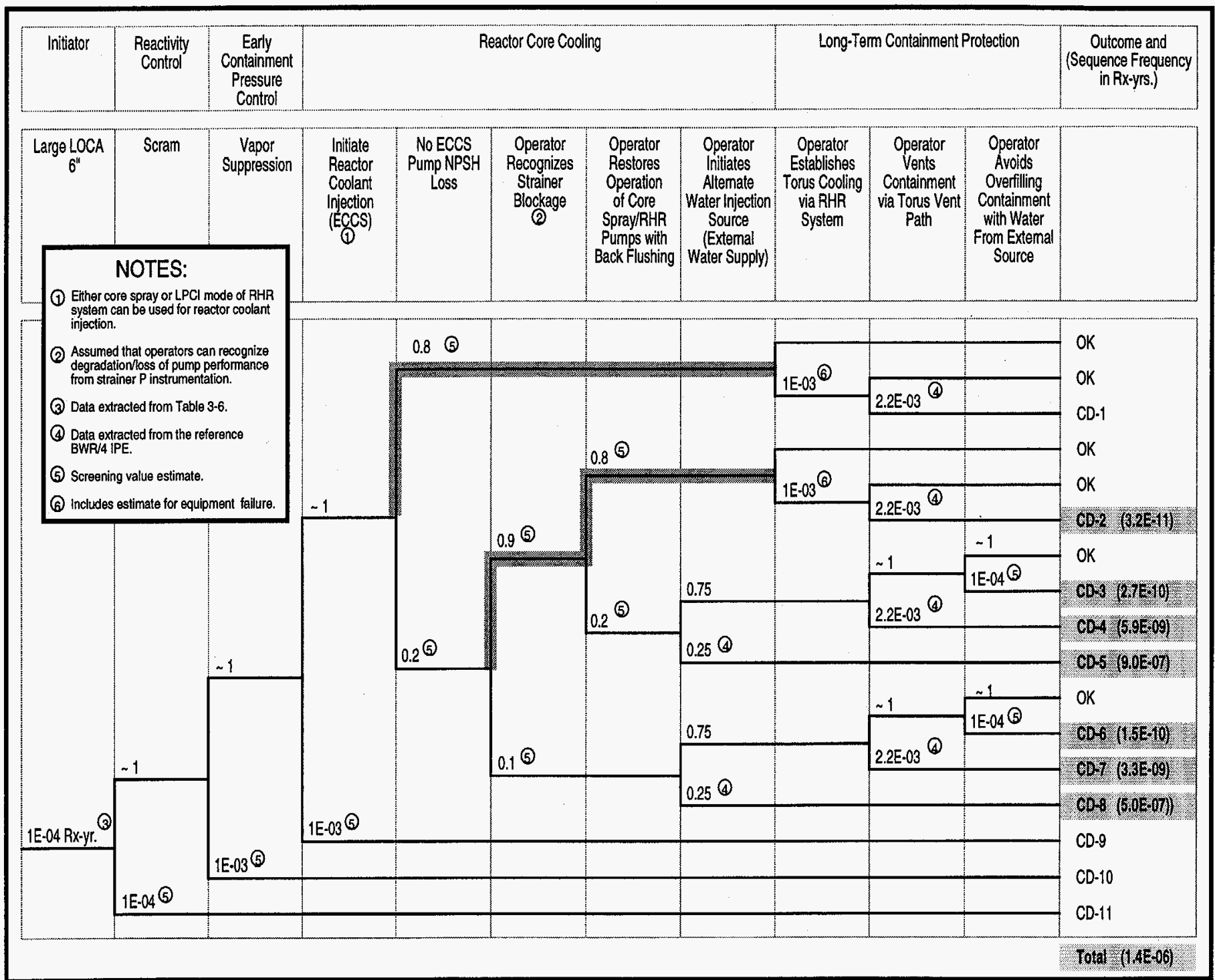

Figure 8-3 European Approach for Addressing ECCS NPSH Loss (Base Case Data for Alternate Core Cooling Unavailability) 


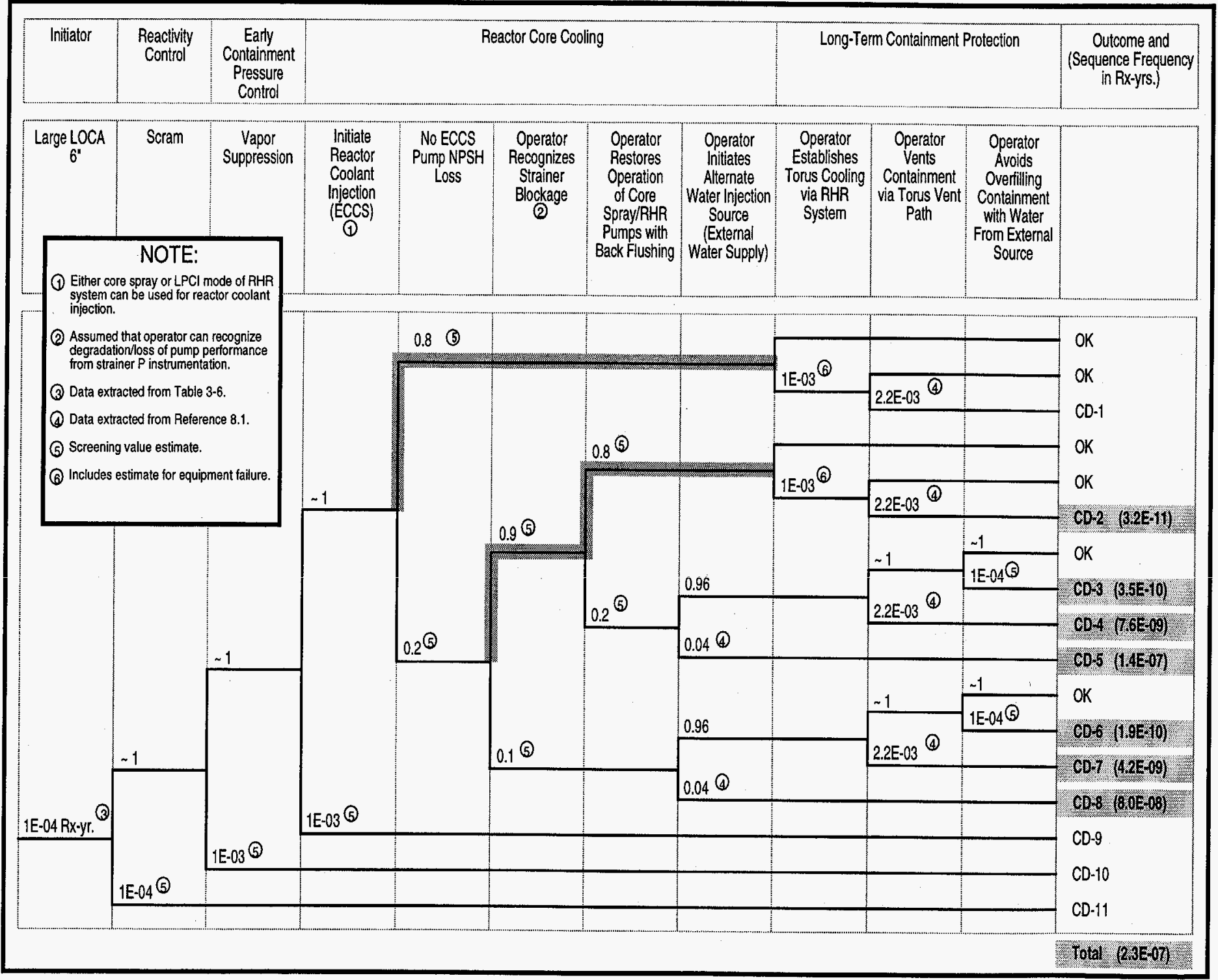

Figure 8-4 European Approach for Addressing ECCS NPSH Loss [Ref. 8.1 Data for Alternate Core Cooling Unavailability] 
Table 8-2 Comparison of Event Tree Break Point Probabilities Used in European and Base Case Event Trees

\begin{tabular}{lcc}
\hline & \multicolumn{2}{c}{ Probability of Success } \\
\cline { 2 - 3 } & Base Case & European Approach \\
\hline Avoid Core Spray/RHR Pump NPSH Loss & $<<1$ & 0.8 \\
Operator Recognizes Strainer Blockage & 0.2 & 0.9 \\
$\begin{array}{l}\text { Operator Restores Operation of Core } \\
\text { Spray/RHR Pumps with Backflushing }\end{array}$ & 0 & 0.8 \\
\hline
\end{tabular}

and uncertainties. While this study was limited to LLOCA initiating events related to pipe ruptures, there may be significant contributors to CDF from other types of LOCAs, such as smaller size pipe breaks. There are also uncertainties in the quantification of various events, including the initiating event frequency, the probability of losing pump NPSH, and the probability of establishing timely alternative core cooling following an ECCS pump failure. In extrapolating the reference plant results to other BWRs, it was assumed that such pertinent plant features as insulation characteristics and transport rates were similar to those of the reference plant. This assumption may have limited validity, however, because no uncertainty analysis has been performed, and it is not possible to interpret the statistical significance of the point value CDF estimates.

As noted in Reference 8.3, the analysis did not address possible dependencies between consecutive operator actions. While such an analysis was not done, it is believed that this analysis has correctly identified the unavailability of alternate core cooling as the major contributor to CDF related to NPSH loss for the reference plant. 


\section{References for Section $\mathbf{8 . 0}$}

8.1 Memorandum from M. Marshall to C. Serpan, Subject: Summary of the November 9, 1993 Meeting Between NRC Staff and

Representatives of the BWROG Committee on Suction Strainer, Dated: November 19, 1993.

8.2 "Submittal of BWROG Interim Safety Assessment and Operator Guidance in Response to NRC Bulletin 93-02 Supplement 1 ("Debris Plugging of Emergency Core Cooling Suction Strainers"), BWR Owners' Group, BWROG-94034, March 24, 1994.
8.3 "BWR Owners' Group Comments Regarding NRC Assumptions/Methodology for the Evaluation of ECCS Suction Strainer Performance," letter to A. W. Serkiz, NRC from L. A. England, BWR Owner's Group, BWROG-94048, April 13, 1994. 



\section{Appendix A}

BWR Coolant Pipe Weld Break Frequencies 

Table of Contents

$\underline{\text { Section }}$

Page

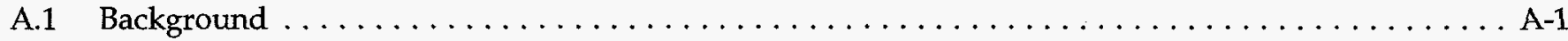

A.2 Review of General Approaches to Quantification of Weld Breaks $\ldots \ldots \ldots \ldots \ldots \ldots \ldots \ldots \ldots$ A-1

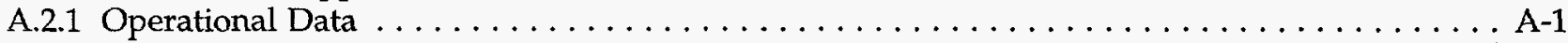

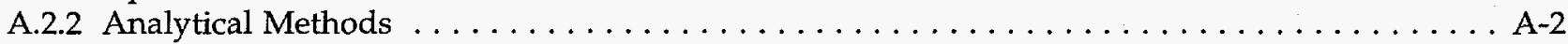

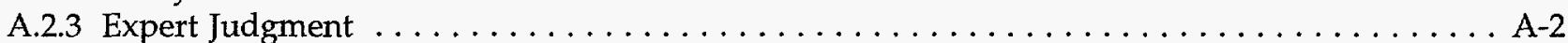

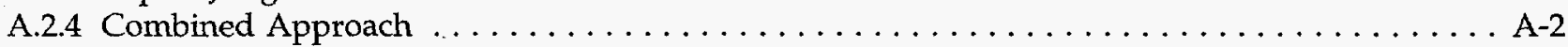

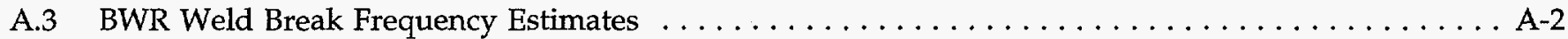

A.3.1 Approach Used to Estimate Weld Break Frequencies $\ldots \ldots \ldots \ldots \ldots \ldots \ldots \ldots \ldots \ldots \ldots$ A-2

A.3.1.1 Brief Description of LLNL Analysis Method $\ldots \ldots \ldots \ldots \ldots \ldots \ldots \ldots \ldots$ A 3

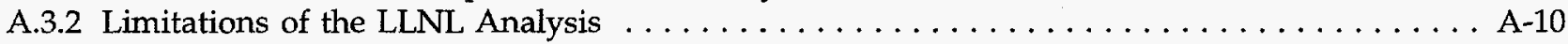

A.3.3 Recommended Weld Break Frequency Data . . . . . . . . . . . . . . . A-11

A.3.3.1 Assumptions Made in the Use and Refinement of LLNL Data . . . . . . . . . A-11

A.3.3.2 Recommended Frequency Estimates for Weld Breaks . . . . . . . . . . A-12

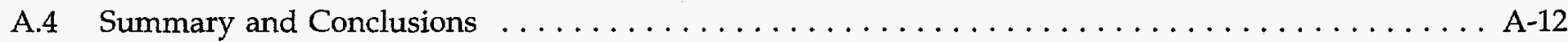

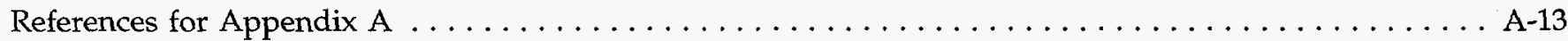

List of Figures

A-1 Weld Locations in a Recirculation Loop $\ldots \ldots \ldots \ldots \ldots \ldots \ldots \ldots \ldots \ldots \ldots \ldots \ldots \ldots$

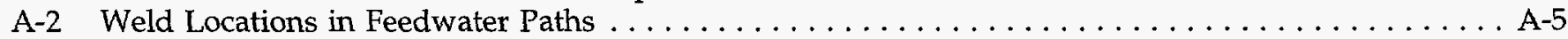

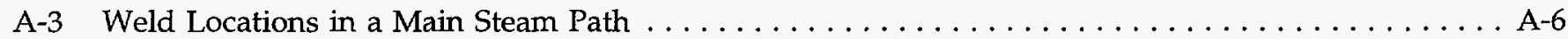

A-4 Cumulative System Probabilities of DEGB in One Recirculation Loop . . . . . . . . . . . . . A A-7

A-5 Relative Contribution of Various Welds to DEGB in Recirculation Loop . . . . . . . . . . . . . A-9

\section{List of Tables}

A-1 Frequencies for Directly-Caused DEGBs, Exclusive of IGSCC Effects $\ldots \ldots \ldots \ldots \ldots \ldots \ldots \ldots \ldots$ A-3

A-3 Frequencies for Indirectly-Caused DEGBs to Reactor Coolant Piping $\ldots \ldots \ldots \ldots \ldots \ldots \ldots \ldots$ A-8

A-2 Frequencies for IGSCC-Caused DEGBs to Recirculation Piping $\ldots \ldots \ldots \ldots \ldots \ldots \ldots \ldots \ldots$ A-8

A-4 Frequencies for IGSCC-Caused DEGBs to Recirculation Welds in Susceptible Material (304SS) . . . A-10

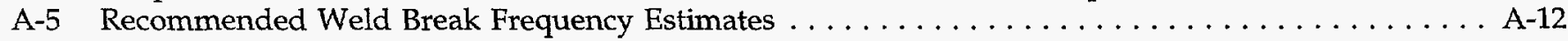



This appendix provides break frequency estimates of pipe welds in the reactor coolant piping of the reference BWR 4/Mark I plant. The break frequencies were generated for the purpose of estimating ECCS unavailability caused by blockage of BWR suppression pool suction strainers following a LOCA.

\section{A.1 Background}

As noted in NUREG/CR-4792 [Ref. A.1], older BWR plants, particularly those with a Mark I containment design, have recirculation piping that has been found to be susceptible to IGSCC. The susceptible (sensitized) Type 304 stainless steel piping used in the reference plant and some other Mark I BWRs can experience IGSCC as the result of significant tensile stress caused by the normal welding practice and a corrosive environment. If susceptible piping has not been replaced with resistant materials, stress improvement can be accomplished on weldments already installed by the induction heating stress improvement process, or by the mechanical stress improvement process. For piping with more than 2 years of operation, stress improvement is considered to be lesseffective, because cracking may already be present. If the oxygen levels in the primary coolant are reduced by implementing hydrogen water chemistry, stress corrosion cracking of even sensitized material will be reduced. Another potential mitigation scheme is an augmented inspection schedule.

NUREG-0313, Rev. 2 [Ref. A.2] lists the following austenitic materials considered to be adequately resistant to sensitization by welding:

1. Low carbon wrought austenitic steel. These include 304L, 304NG, 316NG, 347NG, and similar types.

2. Low carbon weld metal of type 308L and similar grades with a minimum of $7.5 \%$ ferrite as deposited. This may also be used as a cladding on the inside of the pipe.

3. Cast austenitic stainless steel with less than $0.035 \%$ carbon and a minimum of $7.5 \%$ ferrite.

4. Inconel 82 nickel base weld metal.

\section{A.2 Review of General Approaches to Quantification of Weld Breaks}

A number of various types of reactor equipment items are normally considered in a reactor probabilistic safety assessment, for example pumps, valves, motors, diesels, switchgear, instrumentation, and piping. Of the reactor equipment items considered in these types of analyses, piping and associated welds are generally among the most difficult to treat in regard to failure quantification. This situation exists because of the scarcity of incidents involving actual pipe failures and the difficulties associated with developing detailed analytical predictive models. The following subsections briefly discuss general methods that could be used to address pipe/weld break frequencies, and their respective advantages and disadvantages.

\section{A.2.1 Operational Data}

As was noted above, there is a scarcity of actual pipe failure events that can be applied to the quantification of reactor pipe breaks. For example, there have been no BWR recirculation system pipe breaks that have occurred to date. Actual pipe breaks of significant size have been limited to nonLOCA sensitive systems.

It is important to recognize that the limited available data are not sufficiently detailed to provide insight into specific expected break locations and timedependent variability in equipment failure frequency. On the other hand, limited data can in some cases be used as general benchmarks of "reasonableness".

Bayesian statistical techniques, such as those discussed in NUREG/CR-4407 [Ref. A.3], have been used to address the issue of very limited operational experience. For a situation involving no failures, these techniques can be used estimate a failure rate by dividing an assigned numerator ("assumed number of failures") by the population in which no breaks have actually occurred. This numerator is typically in the range of approximately 0.2 to 1 . These techniques are not ideal, in that they may not 
be able to adequately account for phenomena that are strongly dependent on aging (such as corrosion effects).

\section{A.2.2 Analytical Methods}

Probabilistic structural methods can be used to estimate pipe break frequencies. These types of analytical methods can address possible material flaws, material properties, and loadings. An example of this type of analysis is the LLNL analysis presented in NUREG/CR-4792 [Ref. A.1].

In using an analytical approach, it is imperative that the dominant failure causes are adequately addressed. Because of the complexities and assumptions used in the required models, the analytical approach can be expected to have rather large uncertainties. On the other hand, insights obtained from these calculations can be used to predict specific phenomena of interest, for example pipe locations having the highest probability of break and the progression of aging-related phenomena. In addition, analytical methods can be effective in evaluating the relative behavior of different types of materials.

\section{A.2.3 Expert Judgment}

Systematic procedures have been developed as described in NUREG-1150, Vol. 1 [Ref. A.4] and NUREG/CR-4550, Vol. 2 [Ref. A.5] to conduct expert elicitations that can be used to predict equipment failure rates. In general, the use of expert judgment is recommended only in situations where a) an issue has a significant impact on risk and/or uncertainty, and b) other sources or means of generating data are not available.

\section{A.2.4 Combined Approach}

Under some circumstances, it may to useful to combine operational and analytically-derived data to estimate pipe failure rates. In a combined approach, it may be possible to account for detailed phenomena in a deterministic model, while at the same time using operational data to judge the reasonableness of the predicted failure rates.

\section{A.3 BWR Weld Break Frequency Estimates}

In making a decision on an approach to quantify BWR weld break frequencies for later use in estimating ECCS unavailability due to debris blockage, particular attention was given to recently published cautionary information in CRTD-Vol. 20-2 [Ref. A.6] that contains ASME-sponsored work related to risk-based inspection guidelines for light water reactor components. In particular, page 15 of Reference A. 6 notes that conservative design practices have made it very unlikely that pipe failures would occur for a number of anticipated modes of failure, including excessive elastic or plastic deformation, brittle fracture, stress rupture/creep deformation (inelastic), and plastic instability. This document goes on to state that "it is generally believed within the nuclear industry that other causes not addressed in design, by ASME $\mathrm{BPVC}^{1}$ calculations or otherwise, are most likely to cause structural failures. Two common examples are intergranular stress corrosion cracking of stainless steel piping and erosion-corrosion wall thinning of carbon steel piping."

\section{A.3.1 Approach Used to Estimate Weld Break Frequencies}

Given the ASME cautionary note above about potential IGSCC degradation and the relative lack of suitable historical data for pipe failures, an analytical approach was selected as the foundation for generating pipe weld break frequency estimates. The analytical model chosen for this study was developed by the LLNL and is described in detail in NUREG/CR-4792 [Ref. A.1]. The LLNL model was chosen because it is comprehensive in nature. As will be discussed in more detail below, the LLNL model addressed both indirect and direct causes of weld breaks, including IGSCC. While the LLNL analysis was generally conservative, areas of conservatism were identified so that future refinements to the break frequency data can be made.

${ }^{1}$ Boiler and Pressure Vessel Code 
A.3.1.1

Brief Description of LLNL Analysis Method

The LLNL analysis combined probabilistic and deterministic techniques to estimate the chances that weld breaks will occur in reactor coolant piping at a BWR 4/Mark I plant. The following categories of weld breaks were considered by LLNL:

1. Breaks due to direct causes, specifically:

a) Crack growth at welded joints related to the combined effects of thermal, pressure, seismic, and other loads, and

b) Crack growth at welded joints related to IGSCC.

2. Breaks due to indirect causes, specifically the seismically-induced failure of equipment, including piping and component supports, that could lead to the break of a reactor coolant pipe.

The LLNL analysis considered three major piping systems: the recirculation, main steam and feedwater systems. However, the evaluation of IGSCC effects was limited to the recirculation system. Also, note that the main objective of the IGSCC analysis was to compare relative behavior of different types of recirculation piping materials. Typical layouts of a BWR 4/Mark I plant recirculation, main steam, and feedwater systems are shown in Figures A-1, A-2, and A-3.

The LLNL analysis provides results both in terms of "leaks" and DEGBs. As will be explained later in Section A.3.2, it was assumed that of these two break categories, only the DEGBs would be of concern for later use in the debris blockage analysis. Table A-1 summarizes probability data extracted from Tables 3.2 and 3.6 in the LLNL analysis for DEGBs related to direct causes, exclusive of IGSCC effects. Note that the LLNL results have been converted to frequencies, assuming a $40 \mathrm{yr}$ plant lifetime.

To address potential IGSCC effects, it is useful to consider the data contained in Figure A-4. This figure presents the cumulative system probability that a BWR 4/Mark I recirculation loop made from 304SS and a (fictitious) 316NG replacement loop with the same configuration will experience a DEGB given IGSCC effects. This figure is reproduced from Figure $4.9(\mathrm{a})$ in the LLNL analysis. Note that LLNL has not provided a corresponding uncertainty analysis for these results. Over a 40 year plant lifetime, these probability data predict that a recirculation loop made from $304 S S$ will experience a DEGB event with a frequency of approximately $5 \mathrm{E}-04 / \mathrm{yr}$. In contrast, the fictitious $316 \mathrm{NG}$ replacement loop was predicted to fail with a

Table A-1 Frequencies for Directly-Caused DEGBs, Exclusive of IGSCC Effects ${ }^{1}$

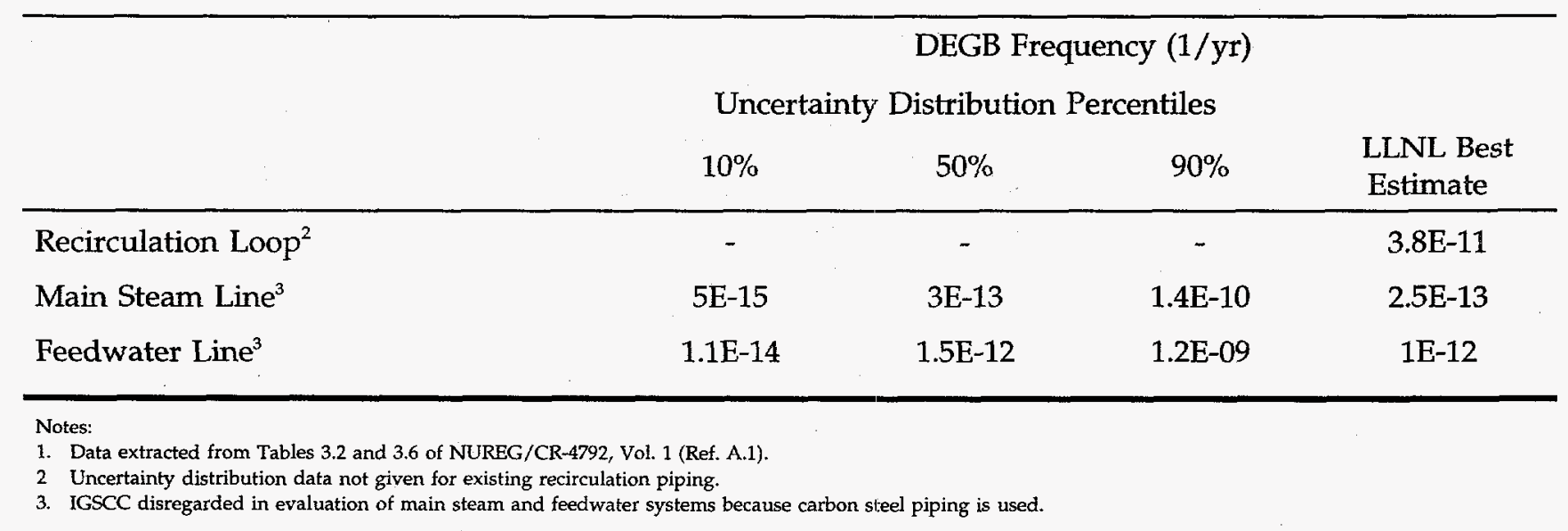


Appendix A

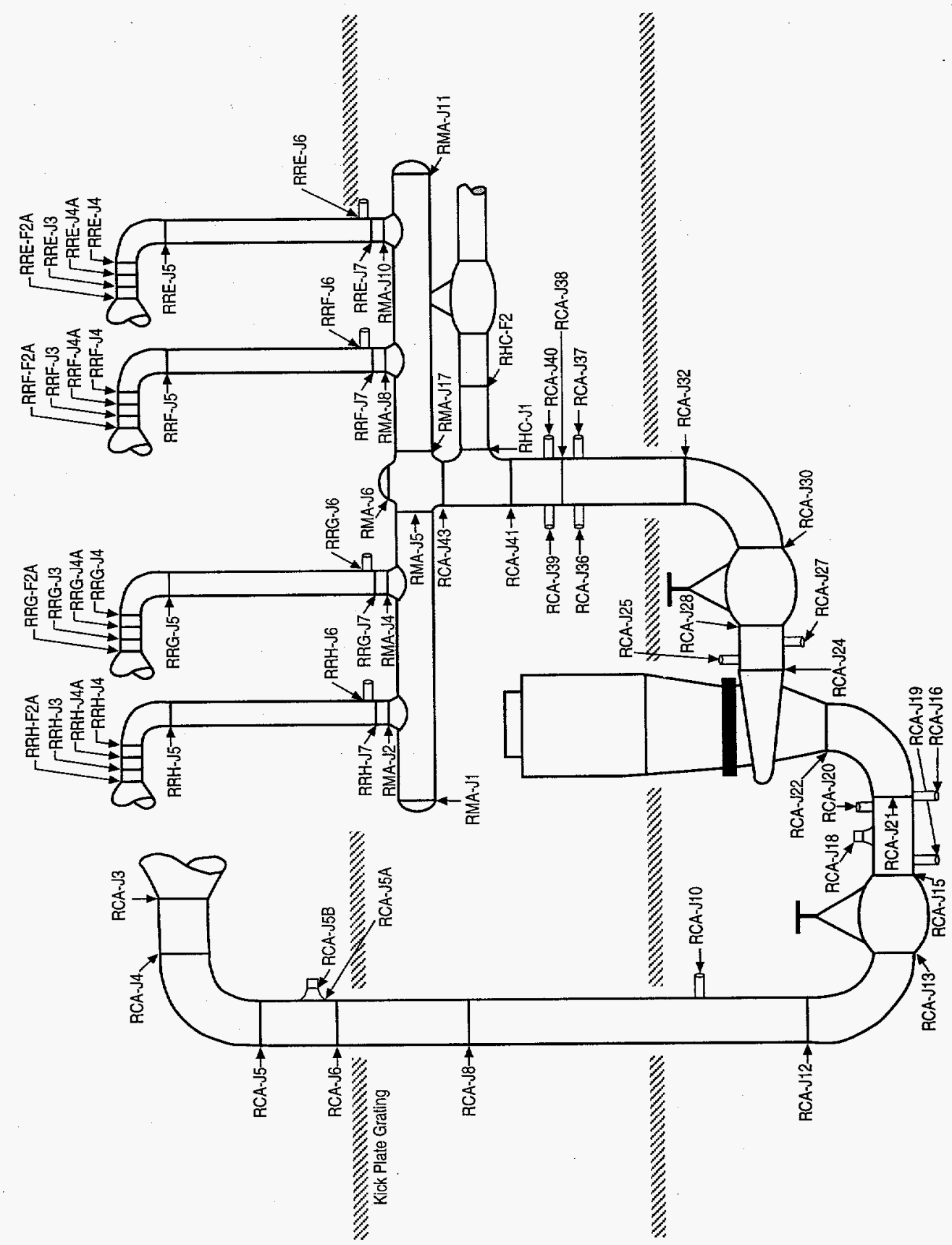

O⿱艹 
Appendix A

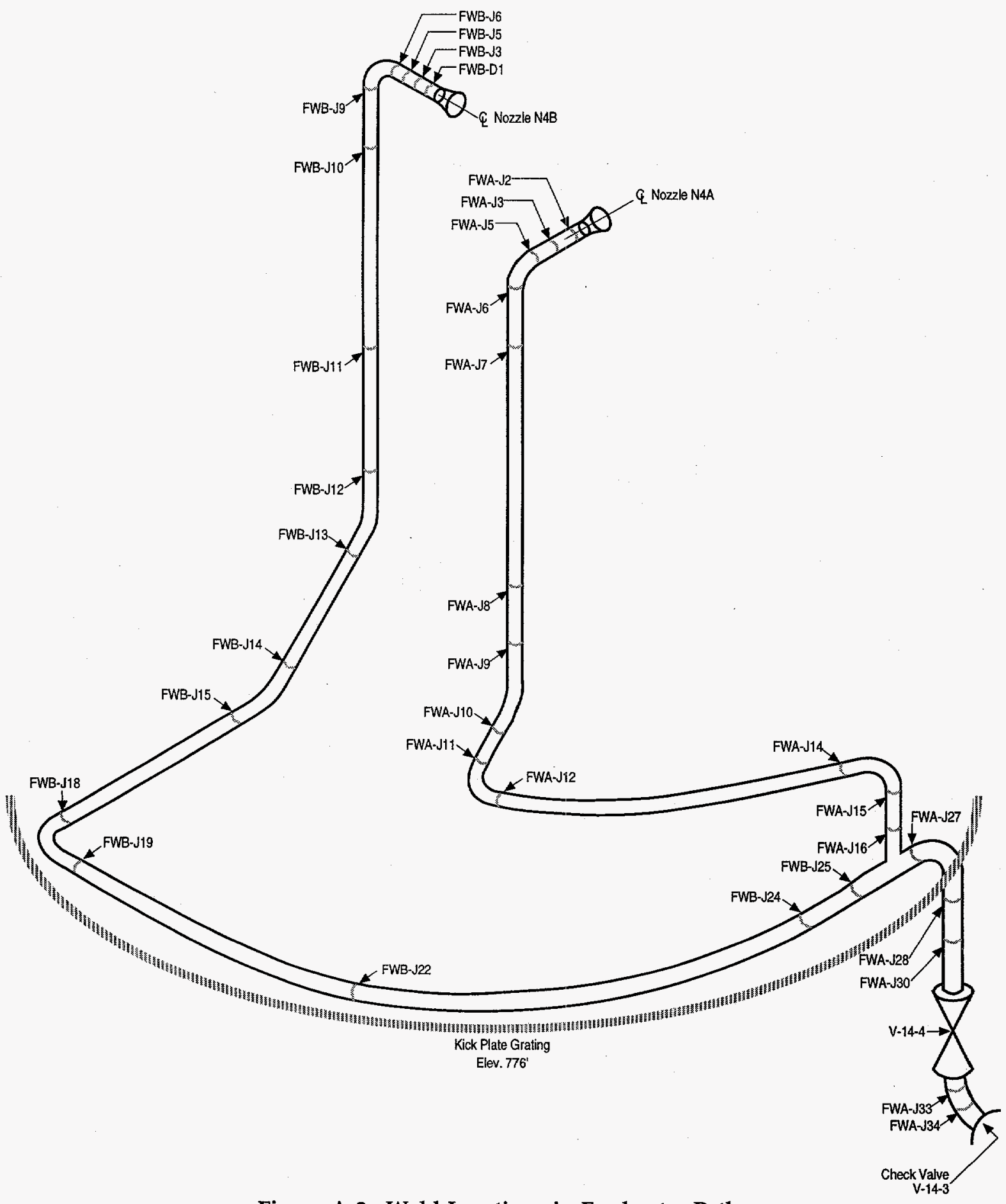

Figure A-2 Weld Locations in Feedwater Paths 
Appendix A

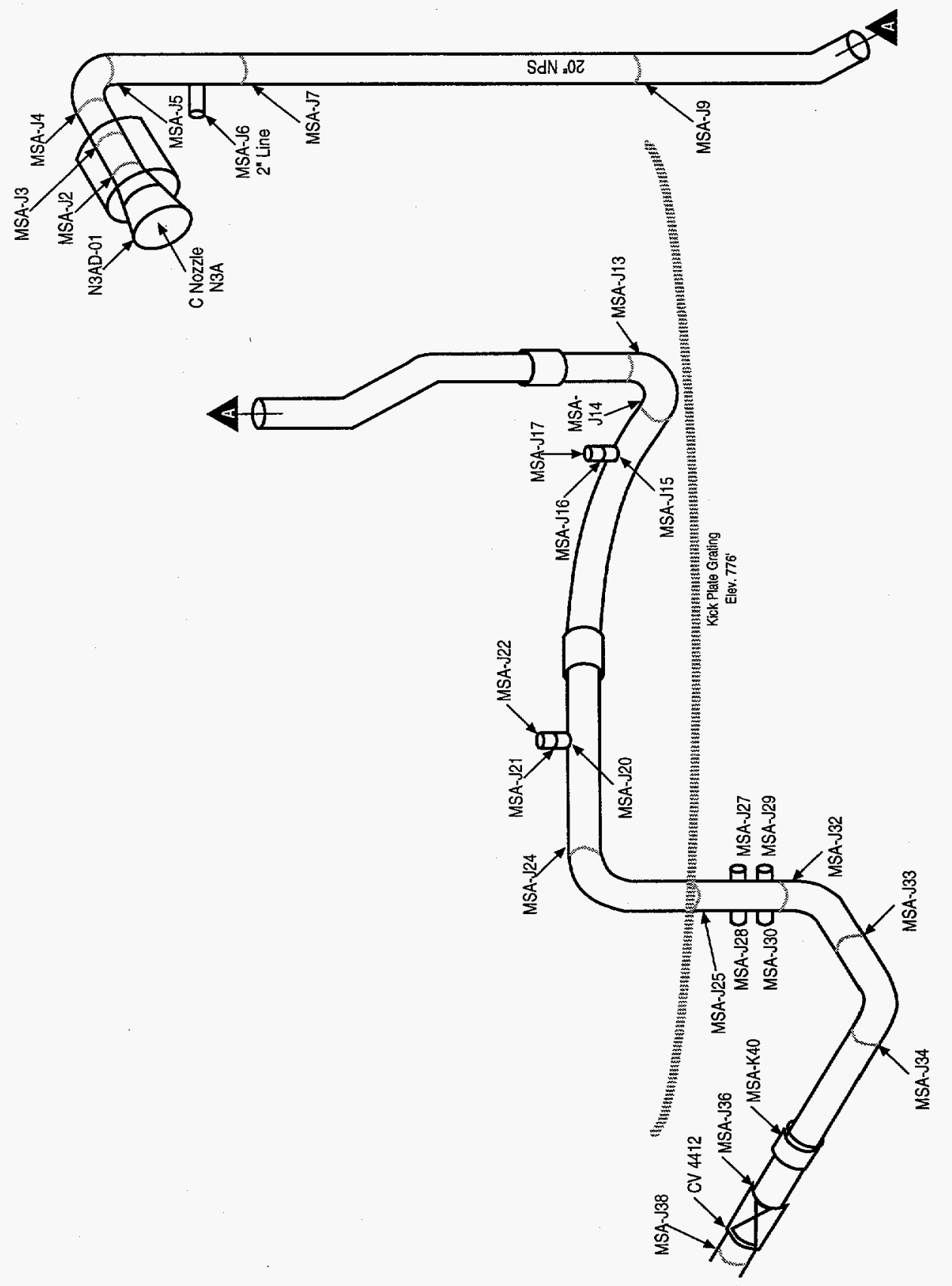

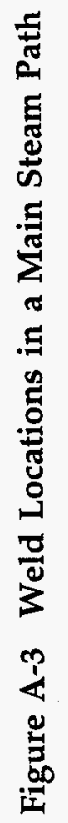




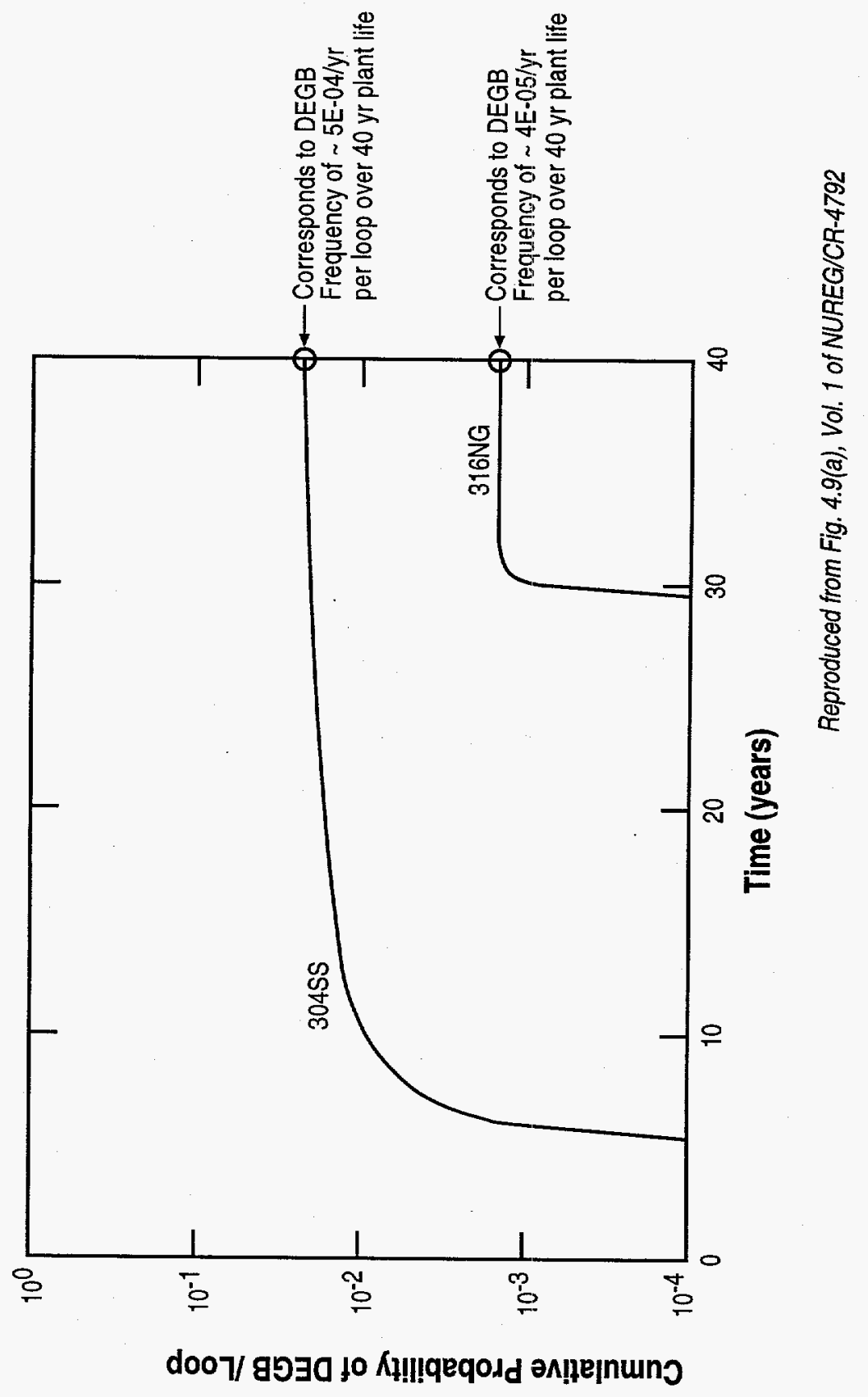

告 
Appendix A

frequency of approximately $4 \mathrm{E}-05 / \mathrm{yr}$. These data indicate that the susceptible (304SS) material is over 10 times more likely to experience a DEGB over a 40 yr plant life than the resistant (316NG) material. Table A-2 expresses the data in terms of total DEGB frequency of the recirculation system based on a total of two recirculation loops. the next most significant category, namely breaks caused by indirect means.

The LLNL study also presented the IGSCC DEGB frequency data in terms of specific weld categories. As is shown in Figure A-5, about $80 \%$ of the postulated 304SS recirculation piping DEGBs were

Table A-2 Frequencies for IGSCC-Caused DEGBs to Recirculation Piping ${ }^{1}$

\begin{tabular}{lc}
\hline Material & DEGB Frequency (1/yr.) Point Estimate \\
\hline Susceptible (304SS) & $\sim 1 \mathrm{E}-03^{2}$ \\
Resistant (316NG) & $\sim 8 \mathrm{E}-05^{3}$ \\
\hline
\end{tabular}

Notes:

1. Data extracted from Figure A-4 of this report which has been reproduced from Fig. 4.9(a), Vol. 1 of NUREG/CR-4792 (Ref. A.1)

2. DEGB frequency $=-5 \mathrm{E}-04 / \mathrm{yr}$. per loop over 40 -year plant life. Given a total of 2 loops, net DEGB frequency $=\sim 1 \mathrm{E}-03 / \mathrm{yr}$.

3. DEGB frequency $=\sim 4 \mathrm{E}-05 / \mathrm{yr}$. per loop over 40 -year plant life. Given a total of 2 loops, net DEGB frequency $=\sim 8 \mathrm{~B}-05 / \mathrm{yr}$.

Data pertaining to breaks caused by indirect means are summarized in Table A-3. Again, these data were extracted from the LLNL analysis. Based on a review of the information presented in Tables A-1, $\mathrm{A}-2$, and A-3, it was noted that the overwhelming contribution to the overall frequency of DEGB LOCA events at the reference BWR4/Mark I plant is predicted to be due to IGSCC effects on recirculation piping. Even in the case of resistant material (316NG), the IGSCC-induced DEGB frequencies are approximately an order of magnitude higher than associated with $12 "(30.5 \mathrm{~cm})$ riser welds, while about $20 \%$ of the 304 SS DEGBs were associated with 4 " $(10.2 \mathrm{~cm})$ bypass line welds. The header, 22 " $(55.9 \mathrm{~cm})$, discharge, $28 "(71.1 \mathrm{~cm})$, and suction, $28^{\prime \prime}$ $(71.1 \mathrm{~cm})$ welds were each judged to contribute less than $10 \%$ to the recirculation loop DEGB frequency, based on the statistical accuracy of the LLNL calculations. Failure data for a proposed 316NG replacement recirculation loop having no bypass piping are also displayed in Figure A-5.

Table A-3 Frequencies for Indirectly-Caused DEGBs to Reactor Coolant Piping ${ }^{1}$

\begin{tabular}{|c|c|c|c|}
\hline \multirow[b]{2}{*}{ Cause } & \multicolumn{3}{|c|}{$\begin{array}{l}\text { DEGB Frequency (1/yr.) } \\
\text { Uncertainty Distribution Percentiles }\end{array}$} \\
\hline & $10 \%$ & $50 \%$ & $90 \%$ \\
\hline Major Containment or Reactor Pressure Vessel Support Fails & $5.1 \mathrm{E}-10$ & $1.9 \mathrm{E}-07$ & $2.8 \mathrm{E}-06$ \\
\hline Failure of "Intermediate" Pipe Supports ${ }^{2}$ & - & - & $5.0 \mathrm{E}-06$ \\
\hline
\end{tabular}


Appendix A

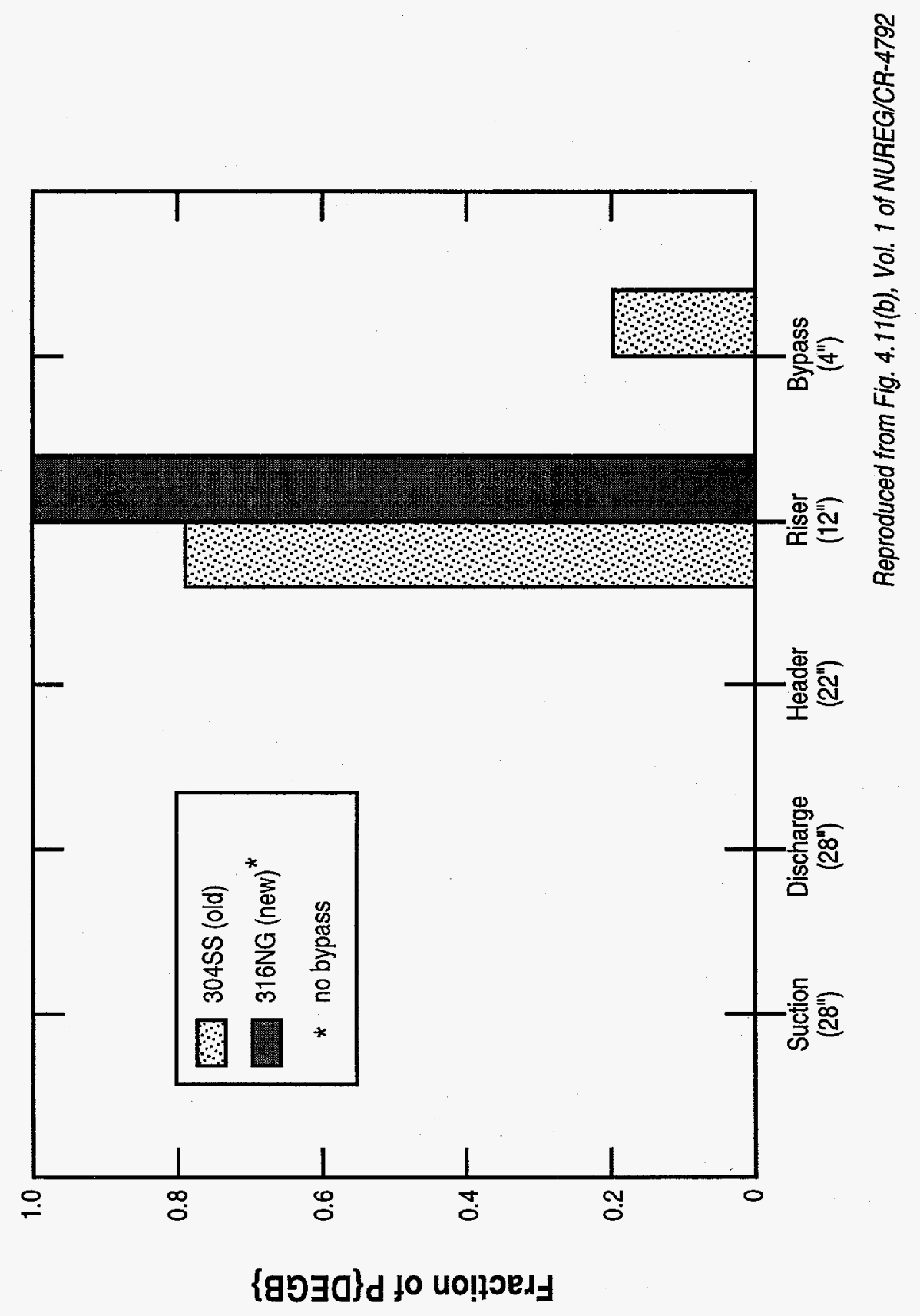

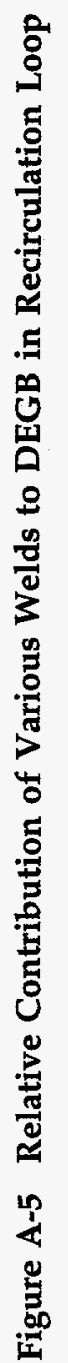


Failure data extracted from Table A-2 and Figure A-5 were used to generate IGSCC DEGB frequencies on a per-weld basis for the categories of susceptible (304SS) recirculation loop material. As shown in Table A-4, these calculations were made by multiplying the overall recirculation DEGB frequency estimate from Table A-2 by the fractional contributions given in Figure A-5, and subsequently dividing by the number of welds in a given category. The number of welds in a given category were obtained from the LLNL report.

\section{A.3.2 Limitations of the LLNL Analysis}

There were a number of limitations associated with the LLNL analysis. Because of the overwhelming. contribution of IGSCC to the predicted weld break frequencies, efforts were focused on identifying the most significant limitations associated with the IGSCC portion of the analysis. Some of the limitations of the LLNL IGSCC analysis that were identified in this study include:

1. Certain local phenomena were not considered in the LLNL analysis, for example the effect of coolant flow velocity on possible flushing of impurities that otherwise could aggravate the susceptibility to IGSCC.

2. The model used "harsh" laboratory conditions to predict growth rates and times-to-initiation. It is conservative to extrapolate the "harsh" laboratory data to the relatively benign conditions that exist in reactor facilities.

3. The failure probability is very sensitive to the type of residual stress assumed in the analysis. Consequently, plant-to-plant experiences could vary significantly depending on residual stresses that remain following pipe assembly welding and "fit up". Worst case stress assumptions were used in the analysis.

4. The analysis did not give credit for actions to mitigate the effects of IGSCC, specifically in-service inspections, weld overlay, or IHSI. In addition, the analysis did not address the mitigating effects of corrosion control programs.

5. The main objective of the analysis was to compare the behavior of different types of materials to IGSCC. This emphasis may introduce additional uncertainties in the absolute value of the break frequencies.

6. There were discrepancies between the LLNL predictions and a field test done at a BWR site. As noted in NUREG/CR-5486 [Ref. A.7],

Table A-4 Frequencies for IGSCC-Caused DEGBs to Recirculation Welds in Susceptible Material (304SS)

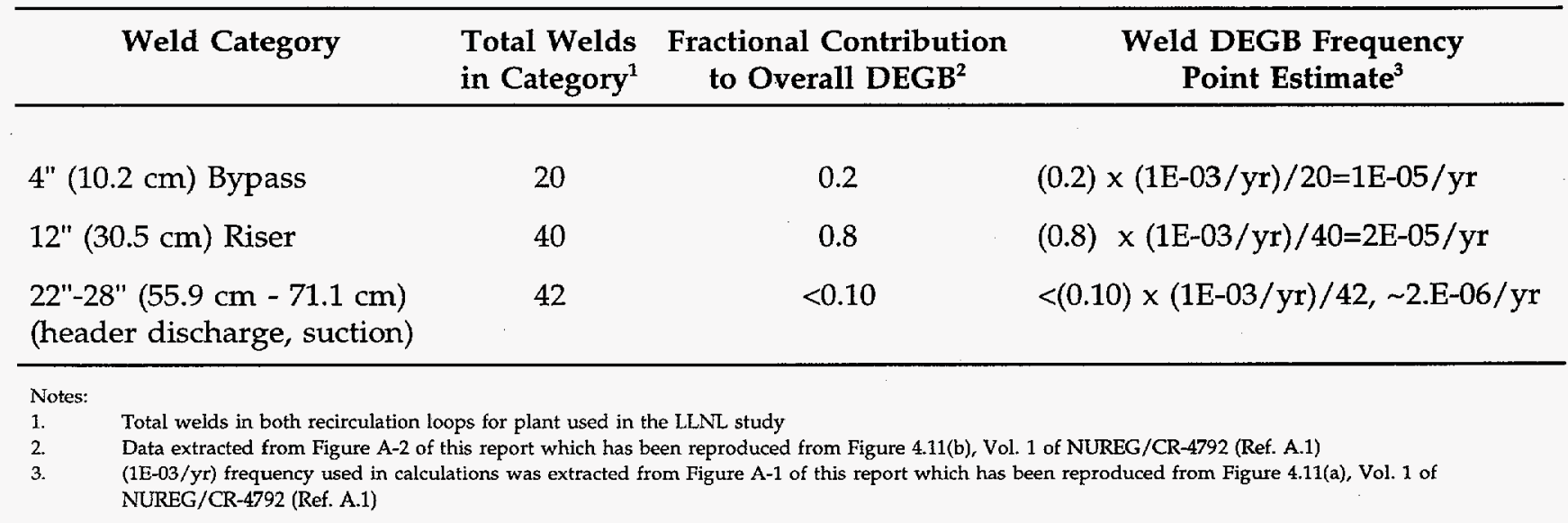


these discrepancies most likely are the result of field variations in various pertinent phenomena and analytical assumptions needed to model these phenomena. However, it is important to note that both the LLNL analysis and field results give highest priority to riser and bypass welds.

7. Pipe breaks caused by water hammer or a projectile from pump failures were not considered.

8. The analysis did not consider scenarios that involved IGSCC-weakened piping coupled with other pipe challenges (i.e., water hammer, seismic events).

\section{A.3.3 Recommended Weld Break Frequency Data}

The IGSCC-induced DEGB data were used as a starting point in deriving estimates of weld break frequencies for use in the debris blockage analysis. In using the LLNL predictions of IGSCC-induced DEGB frequency for this analysis, adjustments were made to give credit for in-service inspection activities. Subsection A.3.3.1 discusses the assumptions made in the use and refinement of the LLNL IGSCC data. Subsection A.3.3.2 presents point estimates of the weld frequencies.

\section{A.3.3.1 Assumptions Made in the Use and Refinement of LLNL Data}

In applying the LLNL data to this study, several assumptions were made. The first set of assumptions listed below applies to the recirculation system piping, while the second set of assumptions applies to the carbon steel piping used in other primary systems, for example the main steam and feedwater systems.

\section{Assumptions Pertinent to Recirculation System}

1. Of the two categories of breaks evaluated in the LLNL analysis (leaks and DEGBs), only breaks in the DEGB category were considered. It was assumed that the predicted breaks in the "leak" category would either represent mathematically- predicted flaws that do not actually pass coolant, or would only allow the passage of coolant at a rate less than needed for ECCS actuation. If either of these two conditions were to exist, sump blockage would not be of concern.

2. The recirculation system piping material for the reference plant is $304 S S$.

3. Only one IGSCC mitigating action would be in place, namely an in-service inspection program. In adjusting the data for an in-service inspection program, use was made of a discussion of risk-based inspection activities contained in CRTD-Vol. 20-2 [Ref. A.6]. In particular, it was noted on p. 81 of CRTD-Vol. 20-2 [Ref. A.6] that "a high level of inspection can significantly reduce the failure probabilities of BWR piping systems (by a factor of 10 or more)." Supporting data and analyses are contained in Table 2-12 of this reference. For the purpose of this analysis, it was decided that the LLNL frequency estimates would be reduced by a factor of $\mathbf{1 0}$ to account for an aggressive in-service inspection. The effect of this in-service inspection adjustment is to lower the 304SS DEGB frequency within about $25 \%$ of weld break frequencies predicted for the non-susceptible material ( $316 \mathrm{NG}$ ). This situation is illustrated in Figure A-4. Because the adjustments for in-service inspection bring the predicted weld break frequencies of the 304SS material close to break frequencies predicted by LLNL for IGSCC-resistant material, it was judged that additional credit for other mitigating actions, such as IHSI or HWC, was not warranted.

\section{Assumptions Pertinent to Other Major Primary Systtems}

1. As was the case for recirculation system piping, only breaks in the DEGB category were considered.

2. Carbon steel was assumed to be the material of interest.

3. It was assumed that weld break frequencies 
Appendix A

for other major primary systems, such as main steam and feedwater, would be in the same range as weld break frequencies generated for the recirculation system. It is recognized that the carbon steel used in these other systems is not susceptible to IGSCC effects. However, this assumption was judged to be reasonable because of information contained in the ASME cautionary note previously summarized in Section A.3. Specifically, this note states that erosion-corrosion wall thinning of carbon steel also represents a potential cause of pipe failure that has not been included in design or calculations. Because erosion-corrosion of carbon steel has not been explicitly addressed through design, is was judged that corresponding weld break frequencies could be in the same range as the weld break frequencies of IGSCC-susceptible material. The frequency estimate used for non-recirculation weld breaks corresponds to weld break frequencies used for the 22" $(55.9 \mathrm{~cm}) 304 \mathrm{SS}$ recirculation system welds. As will be seen shortly, the weld break frequency for this category of recirculation system welds is an order of magnitude less than weld break frequencies used for other portions of the recirculation system.

\section{A.3.3.2 Recommended Frequency Estimates for Weld Breaks}

By using the LLNL IGSCC data for the DEGB category and the assumptions discussed above in Subsection A.3.3.1, estimates for weld break frequencies were generated. The recommended frequency estimates are given in Table A-5. The data in Table A- 5 were generated by applying the in-service inspection reduction factor of 10 discussed above to the LLNL IGSCC DEGB data presented earlier in Table A-4. As noted in Table A-5, the welds associated with piping in other primary systems were assumed to have the same break frequencies as the $22 "-28$ " $(55.9 \mathrm{~cm}-71.1 \mathrm{~cm})$ recirculation welds.

It is important to recognize that there are large uncertainties associated with the recommended point-value frequency estimates. Because an uncertainty analysis has not been performed, it is not possible to further interpret the statistical significance of the point-value estimates given in Table A-5.

\section{A.4 Summary and Conclusions}

This study has used results from an analytical approach to estimate the failure frequency of DEGB weld breaks at the NUREG/CR-6224 reference plant. The analysis focused on effects related to IGSCC, as this phenomena appeared to be the dominant mechanism involved in weld breaks for the susceptible material of interest (304SS). An adjustment was made to the data to account for inservice inspection activities. Consideration of other mitigating mechanisms, for example aggressive corrosion control, was not evaluated. It is important to recognize that an uncertainty analysis was not performed. Consequently, it is not possible to interpret the statistical significance of the pointvalue estimates. It is also important to note that future studies may identify other important weld break phenomena that have not been included in this analysis.

Table A-5 Recommended Weld Break Frequency Estimates

\begin{tabular}{lc}
\hline Pipe Category Per Weld & DEGB Frequency (1/yr) - Point Estimate \\
\hline $12^{\prime \prime}(30.5 \mathrm{~cm})$ Recirculation (304SS) & $2 \mathrm{E}-06^{\mathbf{1}}$ \\
$22-28^{\prime \prime}(55.9-71.1 \mathrm{~cm})$ Recirculation (304SS) & $2 \mathrm{E}-07^{1}$ \\
Other Primary Systems ${ }^{2}$ & $2 \mathrm{E}-07$ \\
\hline
\end{tabular}

1. Derived by reducing Table A-4 data by a failure of 10 to account for in-service inspection.

2. Welds assumed to have same failure frequency as $22-28^{\prime \prime}(55.9-71.1 \mathrm{~cm})$ recirculation system welds. 


\section{References for Appendix A}

A.1 G. S. Holman and C. K. Chou, "Probability of Failure in BWR Reactor Coolant Piping," published as Lawrence Livermore National Laboratory report UCID-20914, NUREG/CR4792, March 1989.

A.2 W.S. Hazelton and W. H. Koo, "Technical Report on Material Selection and Processing Guidelines for BWR Coolant Pressure Boundary Piping," U. S. Nuclear Regulatory Commission, NUREG-0313, Rev. 2, January 1988.

A.3 R. E. Wright et. al, "Pipe Break Frequency Estimation for Nuclear Power Plants," EG\&G Idaho, Inc, EGG-2421, NUREG/CR-4407, May 1987.

A.4 U. S. Nuclear Regulatory Commission, "Severe Accident Risks: An Assessment for Five U. S. Nuclear Power Plants," NUREG-1150, Vol. 1, December 1990.
A.5 T. A. Wheeler, et. al, "Analysis of Core Damage Frequency from Internal Events: Expert Judgment Elicitation," published as Sandia National Laboratories report, SAND862084, NUREG/CR-4550, Vol. 2, April 1989.

A.6 "Risk-Based Inspection -- Development of Guidelines, Volume 2, Part 1, Light Water Reactor (LWR) Nuclear Power Plant Components," The American Society of Mechanical Engineers, CRTD-Vol. 20-2, 1992.

A.7 G.S. Holman, "Application of Reliability Techniques to Prioritize BWR Recirculation Loop Welds for In-Service Inspection," published as Lawrence Livermore National Laboratory report UCID-21838, NUREG/CR5486, December 1989. 



\section{Appendix B}

Transient ECCS Strainer Blockage Model 



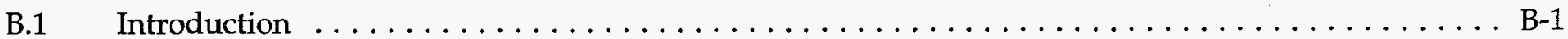

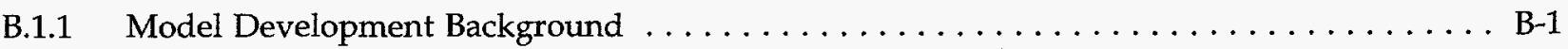

B.1.2 Loss of Coolant Accident Scenario $\ldots \ldots \ldots \ldots \ldots \ldots \ldots \ldots \ldots \ldots \ldots \ldots \ldots \ldots \ldots \ldots$

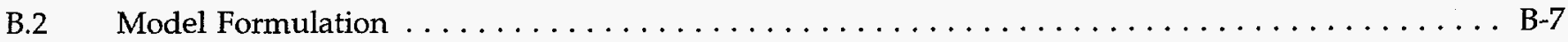

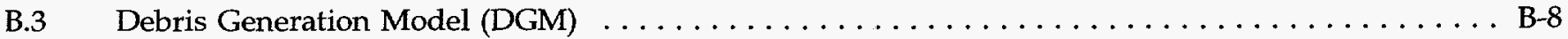

B.3.1 Relevant Findings of the Previous Studies $\ldots \ldots \ldots \ldots \ldots \ldots \ldots \ldots \ldots \ldots \ldots \ldots \ldots$

B.3.2 BWR Debris Generation Model . . . . . . . . . . . . . . . . . . . B-11

B.3.3 Methodology for Application of the Debris Generation Model . . . . . . . . . . . B-14

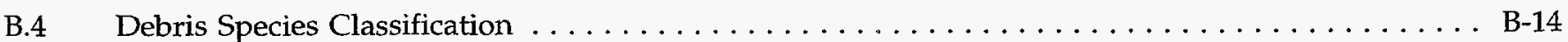

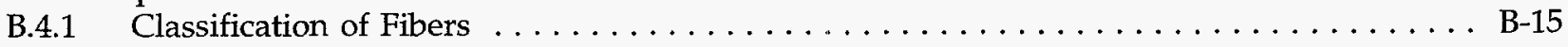

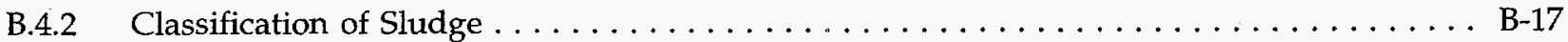

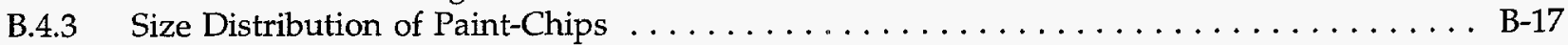

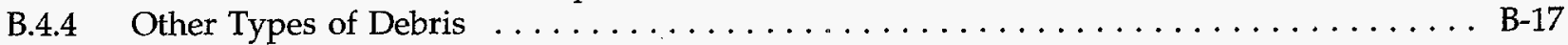

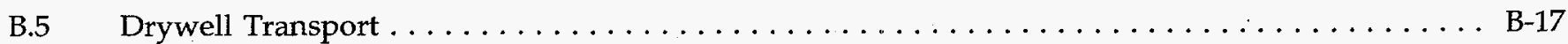

B.5.1 Relevant Findings of the Previous Studies $\ldots \ldots \ldots \ldots \ldots \ldots \ldots \ldots \ldots \ldots \ldots \ldots \ldots \ldots$

B.5.2 Drywell Debris Transport Model . . . . . . . . . . . . . . . . . . . B-19

B.5.3 Important Considerations in Estimating Transport Factors $\ldots \ldots \ldots \ldots \ldots \ldots \ldots \ldots$ B-20

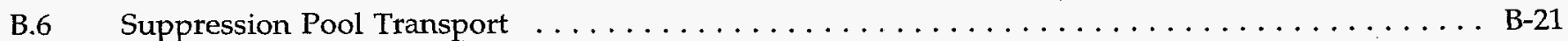

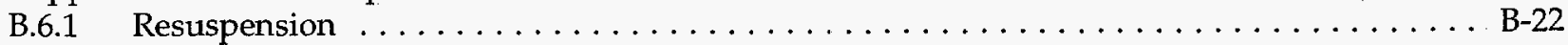

B.6.2 Sedimentation . . . . . . . . . . . .

B.6.2.1 Settling Rates for the High Energy Phase $\ldots \ldots \ldots \ldots \ldots \ldots \ldots \ldots \ldots \ldots \ldots$ B-25

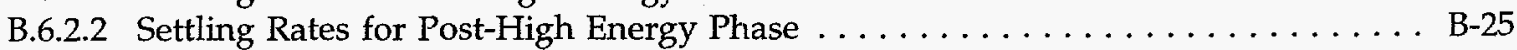

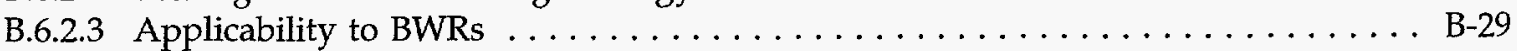

B.6.2.4 Incorporation into BLOCKAGE $\ldots \ldots \ldots \ldots \ldots \ldots \ldots \ldots \ldots \ldots \ldots \ldots \ldots \ldots$

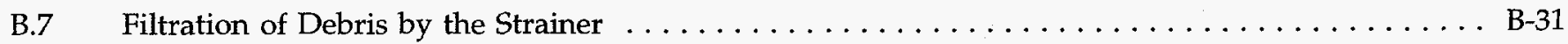

B.7.1 Phenomenological Basis for the Filtration Model $\ldots \ldots \ldots \ldots \ldots \ldots \ldots \ldots \ldots \ldots \ldots$ B-34

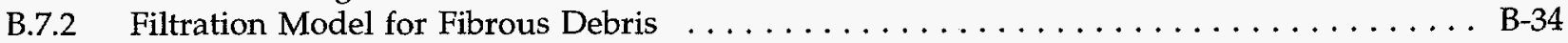

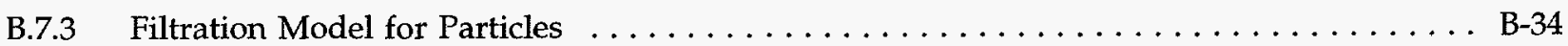

B.7.4 Filtration Model Limitations $\ldots \ldots \ldots \ldots \ldots \ldots \ldots \ldots \ldots \ldots \ldots \ldots \ldots \ldots \ldots \ldots$

B.7.5 Filtration Model Implementation in BLOCKAGE $\ldots \ldots \ldots \ldots \ldots \ldots \ldots \ldots \ldots \ldots$ B-38

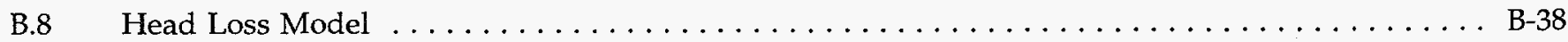

B.8.1 Phenomenological Basis for the Head Loss Model $\ldots \ldots \ldots \ldots \ldots \ldots \ldots \ldots \ldots \ldots \ldots$ B-41

B.8.2 Semi-Theoretical Head Loss Model . . . . . . . . . . . . . . . . . . . . B-41

B.8.3 Special Cases . . . . . . . . . . . . . . . . . . . . . . . . . B-46

B.8.4 Comparison of Head Loss Model Prediction with the Experimental Data for Pure NUKON ${ }^{\mathrm{TM}}$

Insulation Beds . . . . . . . . . . . . .

B.8.4.1 Comparison with NRC Experiments Head Loss Data . . . . . . . . . . . B B-48

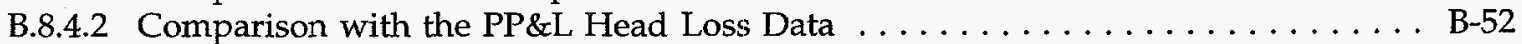

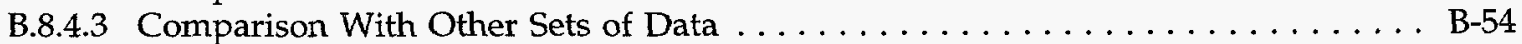

B.8.4.4 Conclusions $\ldots \ldots \ldots \ldots \ldots \ldots \ldots \ldots \ldots \ldots \ldots \ldots \ldots \ldots \ldots \ldots \ldots \ldots$ 
Appendix B

B.8.5 Comparison of Head Loss Model Predictions with the Experimental Data for Mixed Beds B-54 B.8.5.1 Comparison with NRC Experiments Head Loss Data Base . . . . . . . . . . . . B-54

B.8.5.2 Comparison with PP\&L Head Loss Data . . . . . . . . . . . . . . B -57

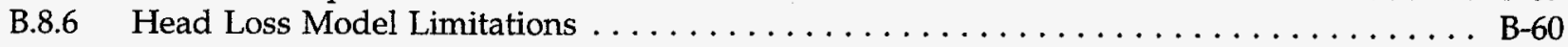

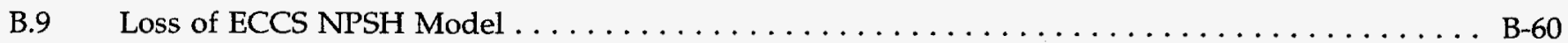

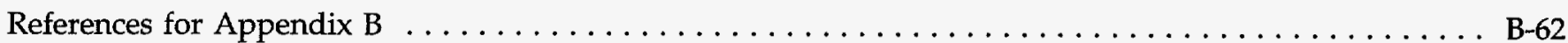


Appendix B

List of Tables

Page

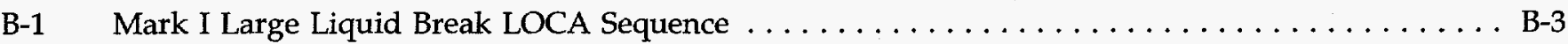

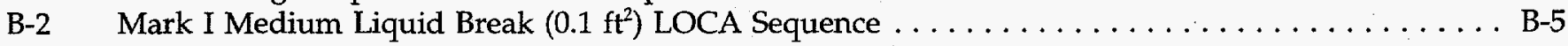

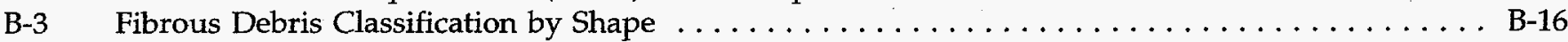

B-4 BWROG-Provided Size Distribution of the Suppression Pool Sludge $\ldots \ldots \ldots \ldots \ldots \ldots \ldots \ldots$ B-17

B-5 Settling Groups for the Fibrous Debris Used in BLOCKAGE $\ldots \ldots \ldots \ldots \ldots \ldots \ldots \ldots \ldots \ldots$ B-31

B-6 Settling Groups for the Suppression Pool Particulates Used in BLOCKAGE . . . . . . . . . B B-33

B-7 Comparison of PP\&L Experimental Data with Head Loss Model . . . . . . . . . . . . . . B-60 
B-1 LLOCA Event Progression and Its Effects On Debris Generation and Transport . . . . . . . . . . B-2

B-2 Transient Pressure Transducer Trace for Battelle-Frankfurt RS-50-C12 Test. Stagnation Conditions were 100 Bar and Saturated Fluid [Ref. NUREG/CR-2913] . . . . . . . . . . . . . . B-4

B-3 Multiple Region Insulation Debris Generation Model for PWRs . . . . . . . . . . . . . B-10

B-4 Three Region BWR Debris Generation Model Used in the Present Study . . . . . . . . . . . B-13

B-5 Settling Velocities of the Paint Chips in Calm Pools $\ldots \ldots \ldots \ldots \ldots \ldots \ldots \ldots \ldots \ldots \ldots$ B-18

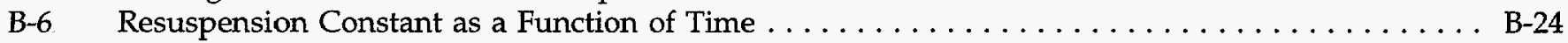

B-7 Settling Velocity Distribution for Shreds of Fibers Produced After Being Subjected to Suppression Pool Hydrodynamics During High Energy Phase . . . . . . . . . . . . . . . . B-26

B-8 Particle Size Distribution Curve for Sludge-A (BWR Sludge Simulant). Large Particle Diameter are a Result of Particle Agglomeration During Dry State (Appendix E). . . . . . . . . . . . B-27

B-9 Settling Velocities for Various Sludge and Fiber Mixtures Predicted Using the Principle of

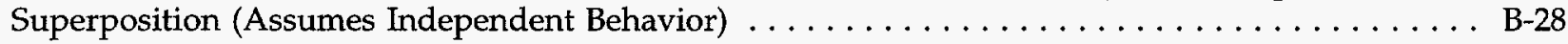

B-10 Typical Variation of ECCS Flow as a Function of Time for Mark I $\ldots \ldots \ldots \ldots \ldots \ldots \ldots$ B-32

B-11 Filtration Efficiency vs. Approach Velocity $\ldots \ldots \ldots \ldots \ldots \ldots \ldots \ldots \ldots \ldots \ldots \ldots \ldots \ldots \ldots \ldots$

B-12 Filtration Efficiency For Fiber and Sludge Debris Species as a Function of Bed Theoretical

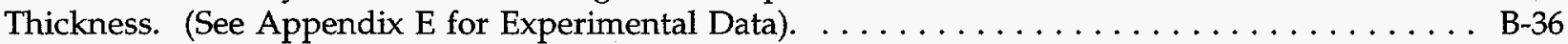

B-13 Filtration Efficiency vs. Insulation Thickness $\ldots \ldots \ldots \ldots \ldots \ldots \ldots \ldots \ldots \ldots \ldots \ldots \ldots \ldots$

B-14 Comparison of Existing Head Loss Correlations for Pure NUKON ${ }^{\mathrm{TM}}$ Fiber Beds. Shred Sizes

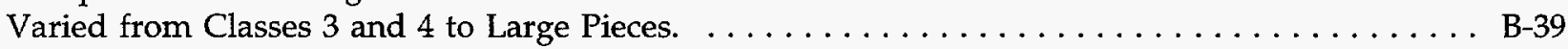

B-15 Comparison of Existing Head Correlations for Mixed Beds Formed of NUKON ${ }^{\mathrm{TM}}$ and Sludge

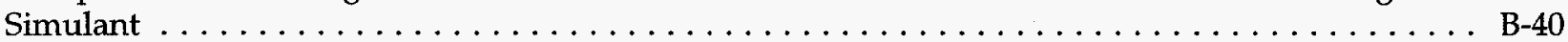

B-16 Scanning Electron Micrograph of a Clean Fiber Bed $\ldots \ldots \ldots \ldots \ldots \ldots \ldots \ldots \ldots \ldots \ldots \ldots$ B-42

B-17 Scanning Electron Micrograph of a Mixed Bed $\ldots \ldots \ldots \ldots \ldots \ldots \ldots \ldots \ldots \ldots \ldots \ldots \ldots$

B-18 Comparison of Head Loss Predictions by the Proposed Model (Eq. B-21) with Approximate

Forms (Eq. B-32a and B-34a) and with the BWROG Correlation [Ref. B.18] . . . . . . . . . . . B-49

B-19 Comparison of NRC Head Loss Experiments Data for Shape Class 3 \& 4 Fiber Beds with the

Proposed Head Loss Model . . . . . . . . . . . . . . . . . . . . . . . . . . . . B-50

B-20 Comparison of NRC Head Loss Experiments Data Shape Classes 3\&4 Fiber Beds with the

Proposed Head Loss Model and with BWROG Correlation . . . . . . . . . . . . . . . . B-51

B-21 Point-by-Point Comparison of PPL Open Loop Head Loss Data for NUKON" "Fibers" with

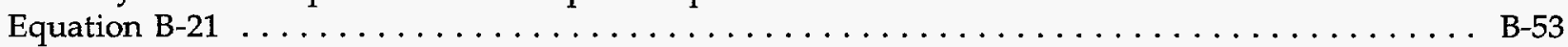

B-22 Point-by-Point Comparison of PPL Open Loop Head Loss Data for NUKON'M Shreds with

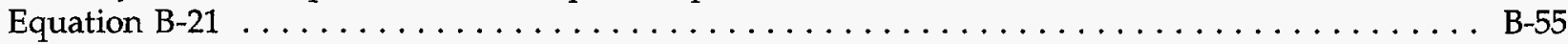

B-23 Comparison of NUREG/CR-6224 Correlation with Head Loss Data for NUKON ${ }^{\mathrm{TM}}$ from

International Data Base . . . . . . . . . . . . . . . . . . . . .

B-24 Comparison of NRC Head Loss Experiments Data with the NUREG/CR-6224 Correlations . . . . B-58

B-25 Comparison of NRC Head Loss Experiments Data with the NUREG/CR-6224 Correlations. . . B-59

B-26 Comparison of NUREG/CR-6224 Correlation with the PP\&L Experimental Data . . . . . . . . . B-61 


\section{B.1 Introduction}

\section{B.1.1 Model Development Background}

A preliminary draft of this report [Ref. B.1] assessed the potential for BWR ECCS strainer blockage due to LOCA-generated debris using the following assumptions:

1. The zone of insulation destruction for the reference plant extends from the break location to a distance of $7 \mathrm{~L} / \mathrm{D}$. This zone was divided into three regions, and destruction factors were assigned to each region.

2. The drywell transport of LOCA-generated debris is restricted by the congested drywell layout. Transport factors for the reference plant were defined based on the relative location of the postulated weld break with respect to two main gratings located in the drywell.

3. Debris transported to the suppression pool remains suspended until uniformly deposited on the ECCS strainers.

4. The pressure drop due to accumulation of debris on the strainer was estimated using an experimental correlation obtained for a clean ${ }^{1}$ NUKON ${ }^{\mathrm{TM}}$ fibrous debris bed.

Following the public meeting held to discuss ECCS blockage concerns [Ref. B.2], several inadequacies in the analyses presented in the preliminary report were identified. Two of the most significant inadequacies were:

1. The model did not consider the effect of particulates. BWR suppression pools may contain a large quantity of particulate matter, commonly known as sludge. Additional quantities of particulate matter can be generated in the drywell due to jet impingement on various structures and the destruction of non-fibrous insulations (e.g.,

${ }^{1}$ Clean in this context means no particulates loaded on the fibrous bed. calcium silicate). According to available data, some amount of these particulates will ultimately reach the strainer and result in a substantial increase in pressure drop across the strainer.

2. The model did not give credit for sedimentation of the debris while in the suppression pool. The initial large scale suppression pool turbulence lasts for a short time after a LOCA. Following this period, a substantial fraction of the debris may settle to the bottom of the suppression pool. Thus, sedimentation may significantly reduce the amount of debris transported to the ECCS strainer.

After further analysis, the decision was made to address these two issues using a two pronged approach: 1) conduct small scale experiments that provide insights into the underlying phenomena, and 2) develop a transient model that incorporates the experimental findings. The primary objective of this Appendix is to document the transient model developed for this study and to validate the results. Appendix $\mathrm{E}$ provides a detailed description of the experiments conducted at the ARL under subcontract to SEA on behalf of the NRC. These experiments are hereafter referred to as the NRC experiments.

\section{B.1.2 Loss of Coolant Accident Scenario}

This section provides a qualitative description of the various phenomena that significantly influence insulation debris generation and their transport to the suppression pool following a postulated LOCA in a BWR/4 with a Mark I containment. Figure B-1 illustrates the sequence of events after a postulated LOCA and their effect on the debris generation and debris transport in the drywell and suppression pool. Tables B-1 and B-2 present time scales associated with each phenomenon for a LLOCA and MLOCA in this plant. Descriptions related to the jet flow geometry and energy associated with blowdown from a DEGB were obtained from NUREG/CR-2913 [Ref B.3] and the Moody Model [Ref. B.4 and B.5]. Insights related to suppression pool hydrodynamics were gained mainly by reviewing NUREG-0661 [Ref B.6], which 


\begin{tabular}{|c|c|c|c|c|c|c|}
\hline $\begin{array}{c}\text { TIME > LOCA } \\
\text { (seconds) }\end{array}$ & $\begin{array}{l}\text { LOCA EVENT } \\
\text { PROGRESSION }\end{array}$ & $\begin{array}{c}\text { DEBRIS } \\
\text { GENERATION }\end{array}$ & $\begin{array}{l}\text { DRYWELL } \\
\text { TRANSPORT }\end{array}$ & $\begin{array}{c}\text { SUPPRESSION POOL } \\
\text { PHENOMENA }\end{array}$ & $\begin{array}{c}\text { SUPPRESSION } \\
\text { POOL TRANSPORT }\end{array}$ & $\begin{array}{c}\text { ECCS } \\
\text { RESPONSE }\end{array}$ \\
\hline
\end{tabular}

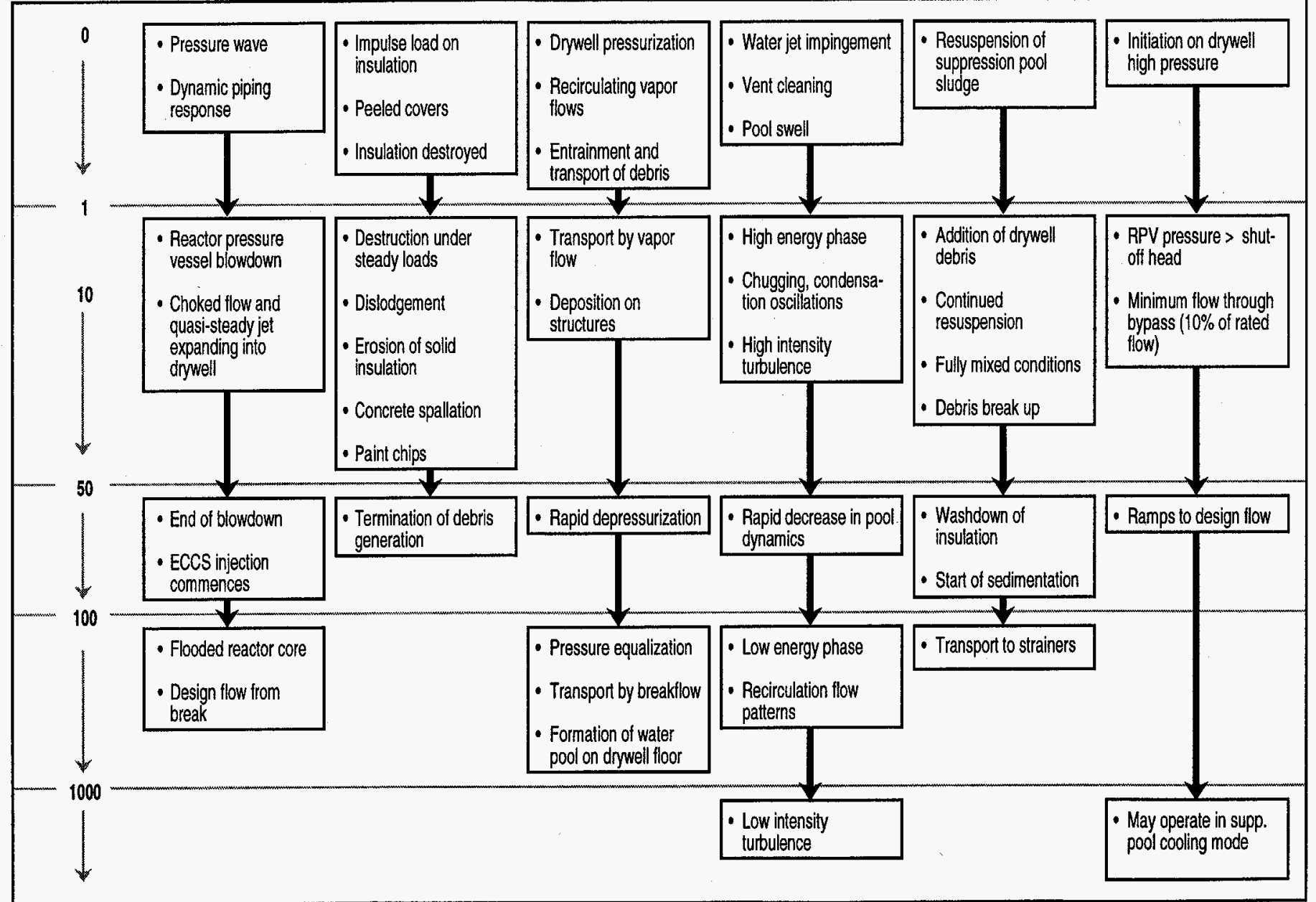

Figure B-1 LLOCA Event Progression and Its Effects On Debris Generation and Transport 
Table B-1 Mark I Large Liquid Break LOCA Sequence ${ }^{(1)}$

\begin{tabular}{|c|c|c|c|c|c|}
\hline Time (sec) & HPCI $^{(2)}$ & LPCS & LPCI & $\mathrm{RCIC}^{(2)}$ & Comments \\
\hline 0 & Initiation & Initiation & Initiation & & $\begin{array}{l}\text { High Drywell } \\
\text { LOCA Signal } \\
\text { (2 psi) }\end{array}$ \\
\hline $5-7$ & & & & Initiation & $\begin{array}{c}\text { Low Water } \\
\text { Level } 2\end{array}$ \\
\hline $5-10$ & & $\begin{array}{c}\text { Pump Start } \\
\text { (312 gpm } \\
\text { Min Flow BP) }\end{array}$ & $\begin{array}{l}\text { Pump Start } \\
(1000 \text { gpm } \\
\text { Min Flow BP) }\end{array}$ & & $\begin{array}{c}\text { Offsite Power } \\
\text { Available }\end{array}$ \\
\hline $15-25$ & $\begin{array}{l}\text { Vessel Inj } \\
2700 \text { gpm }\end{array}$ & & & & $\begin{array}{l}\text { Constant } \\
\text { Flowrate }\end{array}$ \\
\hline $20-30$ & & & & $\begin{array}{c}\text { Vessel Inj. } \\
400 \text { gpm }\end{array}$ & $\begin{array}{l}\text { Constant } \\
\text { Flowrate }\end{array}$ \\
\hline$\sim 40^{(3)}$ & & $\begin{array}{l}\text { Vessel Inj. } \\
2350 \text { gpm }\end{array}$ & & & $\begin{array}{l}\text { Flowrate is a } \\
\text { Function of } \\
\text { Vessel Pressure }\end{array}$ \\
\hline$\sim 45$ & Inj. Stops & & & Inj. Stops & $\begin{array}{c}\text { Low Vessel } \\
\text { Press }\end{array}$ \\
\hline$\sim 50^{(3)}$ & & & $\begin{array}{l}\text { Vessel Inj. } \\
13500 \mathrm{gpm}\end{array}$ & & $\begin{array}{l}\text { Flowrate is a } \\
\text { Function of } \\
\text { Vessel Pressure }\end{array}$ \\
\hline-80 & & $3000 \mathrm{gpm}$ & $15500 \mathrm{gpm}$ & & $\begin{array}{l}\text { Design } \\
\text { Flowrate }\end{array}$ \\
\hline
\end{tabular}

Notes:

(1) All the flows are for a generic plant.

(2) Initially take suction from condensate storage tank.

(3) For main steam line break LP ECCS injection 60-70 seconds.

summarized results of various experiments [Ref. B.7 and B.8] and analytical models [Ref. B.9 and B.10].

The description of the systems response and accident management was based on reviews of the EOP and the FSAR of the reference plant.

The transient model was developed to examine the potential for blockage of ECCS suction strainer leading to loss of ECCS due to debris generated and transported by a postulated LOCA in a BWR. Based on historical evidence and failure analyses, the breaks are postulated to occur at the weld locations in the high pressure piping. The HDR [Ref. B.11] tests suggest that a rupture in a high pressure piping system closely resembles a blast or an explosion generating a pressure wave. Evidence of such highly energetic pressure waves can be seen from the transient pressure traces recorded during Battelle-Frankfurt tests that simulated rupture of a $145 \mathrm{~mm}$ pipe after being subjected to $100 \mathrm{bar}$ and saturated fluid conditions (see Figure B-2). As this pressure wave propagates spherically from the rupture location into the containment, it imparts impulse loads on the structures located in its path. The extent of damage suffered by each intervening structure depends on its dynamic response to the impulse loading and on the peak pressure of the blast. Evidence of the destructive nature of the blast can be seen from videos of high pressure steam pipe break experiments conducted at Battelle-Columbus [Ref. B.12]. Immediately following the pressure wave, the flow at the pipe exit is expected to be choked for a period of time ranging from several seconds to several hundreds of seconds, depending on the break size. This process by which the BWR 
BATTELLE-FRANKFURT C12 TARGET PRESSURE

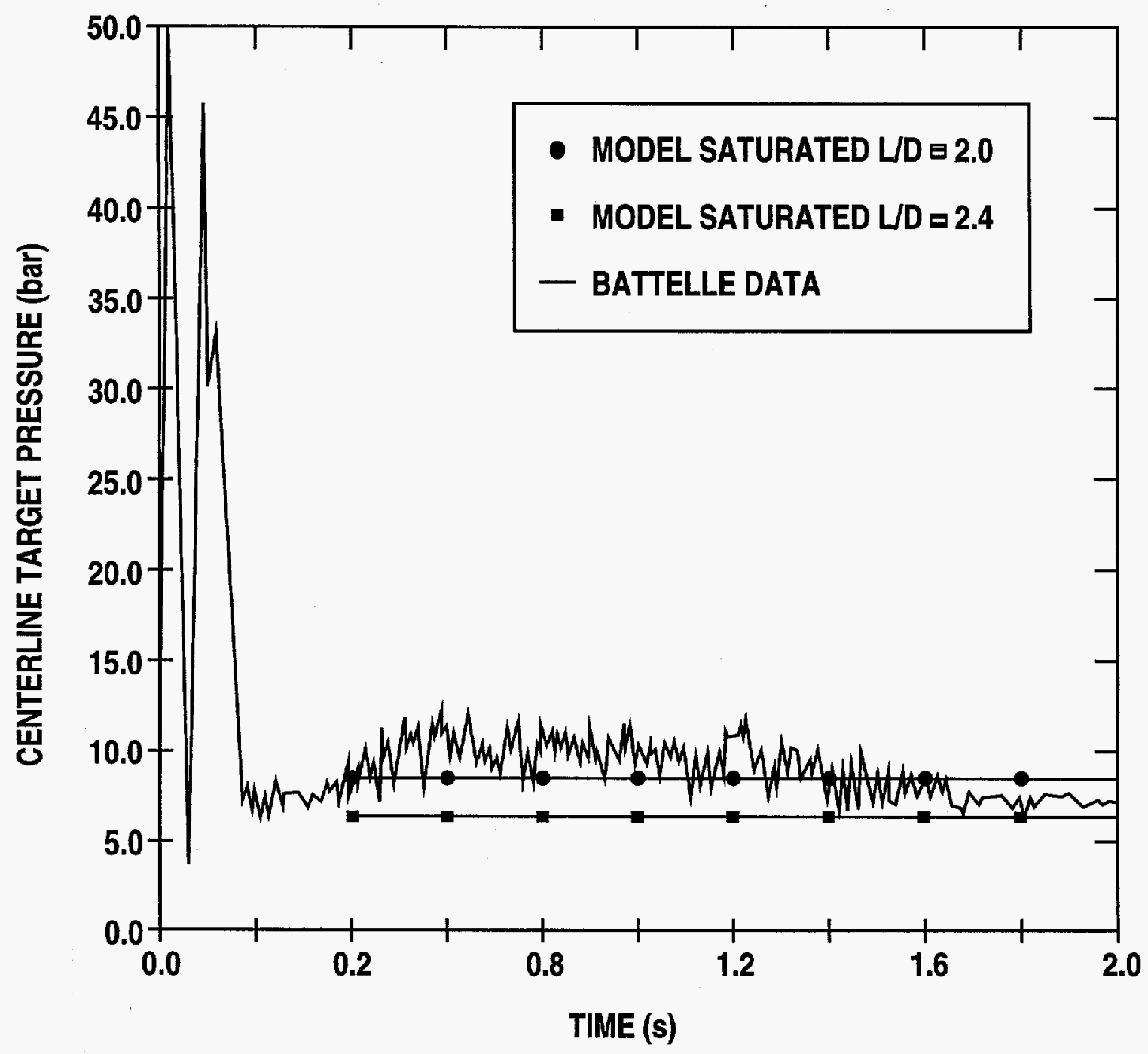

Figure B-2 Transient Pressure Transducer Trace for Battelle-Frankfurt RS-50-C12 Test. Stagnation Conditions were 100 Bar and Saturated Fluid [Ref. NUREG/CR-2913]. 
Table B-2 Mark I Medium Liquid Break (0.1 $\left.\mathrm{ft}^{2}\right)$ LOCA Sequence ${ }^{(1)}$

\begin{tabular}{|c|c|c|c|c|c|}
\hline Time (sec) & $\mathrm{HPCI}^{(2)}$ & $\overline{\text { LPCS }}$ & LPCI & $\mathbf{R C I C}^{(2)}$ & Comments \\
\hline $3-5$ & Initiation & Initiation & Initiation & & $\begin{array}{l}\text { High Drywell } \\
\text { LOCA Signal } \\
\text { (2 psi) }\end{array}$ \\
\hline $10-15$ & & $\begin{array}{l}\text { Pump Start } \\
\text { (312 gpm } \\
\text { Min Flow BP) }\end{array}$ & $\begin{array}{l}\text { Pump Start } \\
(1000 \text { gpm } \\
\text { Min Flow BP) }\end{array}$ & & $\begin{array}{c}\text { Offsite Power } \\
\text { Available }\end{array}$ \\
\hline $20-30$ & $\begin{array}{l}\text { Vessel Inj } \\
2700 \text { gpm }\end{array}$ & & & & $\begin{array}{l}\text { Constant } \\
\text { Flowrate }\end{array}$ \\
\hline $30-40$ & & & & Initiation & $\begin{array}{l}\text { Low Water } \\
\text { Level } 2\end{array}$ \\
\hline $50-60$ & & & & $\begin{array}{l}\text { Vessel Inj. } \\
400 \mathrm{gpm}\end{array}$ & $\begin{array}{l}\text { Constant } \\
\text { Flowrate }\end{array}$ \\
\hline-100 & & & & & ADS Actuation \\
\hline $320-330$ & & $\begin{array}{l}\text { Vessel Inj. } \\
\text { Begins }\end{array}$ & $\begin{array}{l}\text { Vessel Inj. } \\
\text { Begins }\end{array}$ & & $\begin{array}{c}\text { Flowrate is a } \\
\text { Function of } \\
\text { Vessel Pressure }\end{array}$ \\
\hline-420 & Inj. Stops & & & & $\begin{array}{c}\text { Low Vessel } \\
\text { Press }\end{array}$ \\
\hline-600 & & $3000 \mathrm{gpm}$ & $15500 \mathrm{gpm}$ & & $\begin{array}{c}\text { Design } \\
\text { Flowrate }\end{array}$ \\
\hline
\end{tabular}

Notes:

(1) All the flows are for a generic plant.

(2) Initially take suction from condensate storage tank.

pressure vessel continues to be vented of steam is commonly referred to as "blowdown". These choked exit flow conditions result in quasi-steady state two-phase jets emanating from both ends of the severed pipe. As these jets expand into the drywell, they gain additional kinetic energy from steam flashing and result in quasi-steady loads on the targets located in their expansion zone. The extent of damage caused by these jets is a strong function of the break size, fluid pressure and temperature at the break, and relative direction of the jets with respect to the target. Typically, these jets generate flow velocities in the drywell that are capable of peeling off the insulation blankets from the targets, destructing them into small pieces and entraining and carrying them far away from break locations. In addition, as demonstrated by the HDR tests, these jets are capable of spalling of concrete and peeling off protective coatings (such as paints). Analytical models such as those described in References B. 3 and B.5 can be used to predict pressure loadings on the targets located in the path of a freely expanding jet, which can be bounded by a right-angle cone. In congested BWR drywells, free expansion is very unlikely and the shape of the expanding jet would be closer to a sphere. In either case, these jets can generate large volumes of insulation debris and drywell particulates.

As a result of vessel blowdown, the pressure and temperature of the drywell atmosphere increases rapidly, which causes initiation of the HPCI, LPCS and LPCI pumps. In a LLOCA, however, no credit is given to the HPCI; in addition, during these initial stages of blowdown, the vessel pressure is sufficiently high to prevent low pressure injection into the core. As a result, these pumps operate in minimum flow mode, pumping no more than $10 \%$ of the rated capacity through the bypass minimum flow lines. As the drywell pressure increases, the vent pipes and the downcomers connecting the drywell to the suppression pool are cleared of water 
which is followed by purging of non-condensible gases from the drywell atmosphere during what is commonly referred to as pool swelling phase. With time, the drywell pressure reaches a sufficiently large value to maintain steady venting of steam into the suppression pool where it is condensed. This process of drywell venting creates large vapor flows within the containment which are capable of transporting a fraction of the fibrous insulation debris, especially smaller shreds, to the suppression pool where they become intermixed with the pool water and may undergo further disintegration. Both the HDR tests and ASEA/Brown Boveri, LTD., (ABB) - Karlshamm tests [Ref. B.13] clearly demonstrated that large quantities of debris can be transported by the steam flow to the suppression pool. This phase of debris transport is referred to in this report as "short-term transport" or "blowdown transport."

With time the vessel pressure decreases steadily, allowing for low pressure injection of water into the core. For a LLOCA postulated in a liquid line, low pressure injection occurs at about 40 to 50 seconds after accident initiation (see Table B-1). Flooding of the reactor core leads to rapid depressurization of the vessel and ultimate cascading of water into the drywell from the broken pipe. Because the drywell will be full of steam at the time of vessel flood, introduction of water into the drywell causes large scale condensation and a rapid decrease in the drywell pressure. At this stage, the vacuum breaker valves would open to enable non-condensible gases in the suppression pool to flow back into the drywell, leading ultimately to equalization of drywell and wetwell pressures. Thereafter, the steam flow to the suppression pool would be reduced to very low levels, ending the blowdown transport phase.

During LPCI and LPCS operation, suppression pool water is used for decay heat removal in a oncethrough mode, referred to as the ECCS recirculation phase. This phase of debris transport is referred to as 'long-term transport' or 'washdown transport', and continues until the ECCS is throttled to maintain very small flows. In this phase, the break flow and the containment sprays (if turned on for containment heat removal), will continue to washdown some of the insulation remaining in the drywell at the end of blowdown. This debris will enter the wetwell through the vent pipes and downcomers. However in most of US BWRs, the vent pipes connecting the drywell to the suppression pool are not flush with the drywell floor, allowing for formation of a water pool about 1-2 ft in depth. Gravitational sedimentation in these pools can play an important role in determining how much debris might reach the suppression pool. The majority of debris introduced at this stage are likely to be comprised of insulation pieces and drywell particulates, such as paint chips and concrete dust.

In the final stages of accident progression, the BWRs rely on long-term ECCS flow to the vessel for heat removal, and containment sprays to control drywell pressure and temperature. The operation of the drywell sprays will likely transport additional debris into the suppression pool. Two heat exchangers located downstream of the RHR pumps are used for heat rejection from the suppression pool. Operation of these heat exchangers will maintain the suppression pool temperatures below the design limits. Usually, the suppression pool cooling mode of operation of the RHR is not needed until about half an hour after the LOCA. In some cases, the suppression pool cooling system may not be needed for prolonged periods of time. If the suppression pool temperature increases beyond the limits specified in the EOP, the operator may choose to initiate the pool cooling system. Initiation of the suppression pool cooling system would have little effect on the drywell transport. However, their initiation can induce high levels of turbulence in the suppression pool. This may result in resuspension of debris that may have settled in the suppression pool during the earlier stages.

The purpose of the transient model is to predict the quantity and type of debris transported to the ECCS strainers and the resulting increase in head loss following a LOCA. Detailed modeling of all the phenomena described above that may influence debris generation and transport is extremely complex and beyond the scope of this study. As a result, the modeling efforts reported herein relied on insights gained from various experiments to develop individual parametric models to estimate:

1. Quantity and types of debris generated in the drywell as a result of a LOCA, 
2. Quantity and types of debris transported to the suppression pool and the time scales associated with the drywell transport,

3. Quantity and type of debris that ultimately approach the strainer,

4. Quantity and type of debris trapped on the strainer surface to form the debris cake, and

5. Resulting head loss across the strainer as a function of time.

The following sections present a description of each of the models and their corresponding phenomenological basis.

\section{B.2 Model Formulation}

The objective of the model is to predict the pressure drop across the strainer due to debris accumulation as a function of time. Since the pressure drop across the strainer is a function of debris composition and debris layer thickness, the type and quantity of debris reaching the strainer has to be estimated. The quantity of each type of debris reaching the strainer can be calculated if its concentration near the strainer is known. Thus, the primary variable of consequence is the concentration of various debris near the strainer as a function of time. If it is assumed that suppression pool water undergoes thorough mixing such that near-field concentration (i.e., concentration near the strainer) is essentially the same as the volume-average pool concentration, then the concentration can be calculated from a basic mass conservation principle. This principle can be expressed as:

$$
\begin{gathered}
\frac{d C^{I}}{d t}=\frac{\dot{M}_{\text {Drywell }}^{I}+\frac{\kappa_{R}^{I} M_{\text {Pool }}^{I}}{V}-\frac{C^{I} Q}{V}}{V} \\
-\frac{C^{I} A_{\text {Pool }} V_{S}^{I}}{V}
\end{gathered}
$$

I is a debris species of a distinct type (e.g., fibers, drywell particulates, sludge, etc.)

$C^{I} \quad$ is the concentration of that species at time $t$; the unknown to be determined by solving Equation B-1 $\left(\mathrm{lbm} / \mathrm{ft}^{3}\right)$

$\mathrm{V}$ is the volume of the liquid in the suppression pool $\left(\mathrm{ft}^{3}\right)$

$\dot{M}_{\text {Drywell }}^{I}$ is the mass of $\mathrm{I}^{\text {th }}$ debris species transported from the drywell per second $(\mathrm{lbm} / \mathrm{s})$ at time $\mathrm{t}$

$M_{\text {Pool }}^{I} \quad$ is the mass of $\mathrm{I}^{\text {th }}$ debris species in the sediment located at the bottom of the suppression pool $(\mathrm{lbm})$ at time $t$

$\kappa_{R}^{I} \quad$ is the resuspension coefficient (fraction/s) for $\mathrm{I}^{\text {th }}$ debris class at time $\mathrm{t}$

Q is the volumetric flow of water through the strainer $\left(\mathrm{ft}^{3} / \mathrm{s}\right)$

$V_{S}^{I} \quad$ is the effective settling velocity of the debris class $I$ at time $\mathbf{t}(\mathrm{ft} / \mathrm{s})$

$A_{\text {Pool }} \quad$ is the suppression-pool cross-sectional area available for settling $\left(\mathrm{ft}^{2}\right)^{2}$

Solution of B-1 for $\mathrm{C}^{\mathrm{I}}(\mathrm{t})$ requires knowledge of four parameters: $\dot{M}_{\text {Dywell }}^{I}, \mathrm{\kappa}_{R}^{I}, \mathrm{Q}$ and $V_{S}^{I}$. The DGM and the debris transport model described in Sections B.3 and B.5 were coupled to obtain $\dot{M}_{\text {Drywell }}^{I}$ as a function of time. Estimates for the resuspension coefficient, $\kappa_{R}^{I}$, and settling velocity, $V_{S}^{I}$, were obtained based on experimental data summarized in Section B.6.

Equations similar to B-1 can be formulated for each of the debris species, resulting in a total of $\mathrm{N}$ equations, where $\mathrm{N}$ is the total number of distinct species for which a mass-balance is desired, i.e., $\mathrm{N}$ is the sum of the number of fibrous species $\left(\mathrm{N}_{\mathrm{F}}\right)$ and the number of particulate species $\left(\mathrm{N}_{\mathrm{P}}\right)$. The solution of these equations will result in the estimation of the volume averaged concentration of each species in the suppression pool at time $t$. These concentrations can be used to estimate the theoretical thickness of the debris layer formed on the strainer using the following equation:

${ }^{2}$ For Mark I containments, the cross-sectional area varies with depth. An average cross-section should be used. 
Appendix B

$$
\Delta L_{o}=\int_{o}^{t} \sum_{I=1}^{N_{F}} \frac{e^{I} C^{I} Q}{A_{s} c_{f}} d t
$$

where,

$$
\begin{aligned}
& \Delta \mathrm{L}_{o} \quad \begin{array}{l}
\text { is the theoretical thickness of the debris } \\
\text { layer ( } \mathrm{ft} \text { ) at time } \mathrm{t},
\end{array} \\
& \mathrm{A}_{\mathrm{s}} \quad \text { is the strainer cross-sectional area }\left(\mathrm{ft}^{2}\right) \\
& \mathrm{c}_{\mathrm{f}} \quad \begin{array}{l}
\text { is the theoretical packing density (or } \\
\text { the as-fabricated packing density) of the } \\
\text { fiber species }\left(\mathrm{lbm} / \mathrm{ft}^{3}\right) \text {, }
\end{array} \\
& \mathrm{e}^{\mathrm{I}} \quad \begin{array}{l}
\text { is the filtration efficiency for } \mathrm{I}^{\text {th }} \text { debris } \\
\text { species. }
\end{array}
\end{aligned}
$$

Similarly the total mass of particulate debris trapped in the cake as a function of time can be estimated as:

$$
M_{\text {particulate }}(t)=\int_{o}^{t} \sum_{I=N_{F^{+}}}^{N} e^{I} C^{I} Q d t
$$

The filtration efficiency, $\mathrm{e}^{\mathrm{I}}$, in Equations B-2 and B-3 is assumed to be a function of debris bed thickness and debris species.

Knowing the theoretical thickness of the bed and the mass of particulates filtered by the bed, the pressure drop across the strainer can be calculated using a functional relationship of the kind:

$$
\Delta H=f\left(\Delta L_{o}, \eta, U\right)
$$

where,
$\Delta \mathrm{H} \quad$ is the strainer pressure drop (ft-water)
$U$ is the approach velocity $(\mathrm{ft} / \mathrm{s})$ calculated as $\mathrm{Q} / \mathrm{A}_{\mathrm{s}}$
$\eta \quad$ is the ratio of particulate mass to the fibrous debris mass, defined as:

$$
\eta=\frac{\int_{0}^{t} \sum_{I=N_{F}^{* 1}}^{N} e^{I} C^{I} Q d t}{\int_{0}^{t} \sum_{I=1}^{N_{F}} e^{I} C^{I} Q d t} .
$$

A functional relationship of this kind was developed based on experimental data obtained as part of this study.

All models developed for this study were incorporated into the BLOCKAGE computer code. BLOCKAGE consists of a group of modules that evaluate (1) quantity and type of debris generated in the drywell, and (2) quantity and type of debris transported to the suppression pool as a function of time. Once all the parameters in Equation B-1 are established, then the solution scheme is rather straight forward: (1) obtain the volume-averaged species concentration at time $t$ by solving $N$ equations similar to Equation B-1; (2) calculate the thickness of the debris layer on the strainer using Equation B-2; (3) calculate the fraction of the debris that is in particulate form using Equation B-5; (4) estimate the resultant pressure drop across the strainer using the appropriate functional relationship; and (5) determine if the pressure drop exceeds the available ECCS NPSH margin.

\section{B.3 Debris Generation Model (DGM)}

This section discusses the debris generation model developed as part of this study to estimate volumes of debris generated by each postulated weld break in a BWR. All breaks were assumed to be double ended guillotine breaks as defined in ANSI/ANS58.2-1988 [Ref. B.5]. The DGM was developed based on insights gained from previous studies and incorporates BWR-specific features such as congested layout and different stagnation conditions (e.g., lower operating pressure and near saturation flow). Insights gained from previous experiments are summarized below, and are followed by a description of the BWR DGM adopted for this study. 


\section{B.3.1 Relevant Findings of the Previous Studies}

Previous studies related to the resolution of USI A43 employed experimental and analytical means to gain insights into the impact of a DEGB LOCA on insulation debris generation. The findings and insights from these studies provided a starting point for developing a DGM for BWRs. Details of these studies are summarized in NUREG-0897, Rev. 1 [Ref. B.11], and NUREG/CR-2913 [B.3]. Relevant important findings can be summarized as follows:

1. The HDR tests suggest that a rupture in a high pressure piping system closely resembles a blast or pressure wave. The experimenters qualitatively noted that the pressure wave is mainly responsible for destroying the covers around the fiber-glass insulation blankets, for pulverizing the insulation blankets, for blowing open and damaging the hatchways ("doors were torn from their hatchways"), and for bending metal railings. Evidence of such highly energetic pressure waves can be seen from the transient pressure traces recorded during Battelle-Frankfurt tests that simulated rupture of a $145 \mathrm{~mm}$ pipe after being subjected to 100 bar and saturated fluid conditions. At a distance of about $2 \mathrm{D}$ from the location of the break, the pressure wave is about 60 bar in height with a FWHM of about hundred milli-seconds (see Figure B-2). As evident from the videos of the pipe break experiments conducted at Battelle-Columbus, the ruptured pipe may undergo further damage as a result of pipe whip which is a strong function of the relative location of the pipe whip restraint with respect to the rupture location.

2. The initial blast is followed by an expanding two-phase jet that causes additional damage to the insulation blankets left undestroyed by the blast wave. The pressure loadings generated by these quasi-steady jets can be predicted using methods described in References B.3 and B.5. In general, jet forces act in the diameter of $6.6 \mathrm{ft}-16.4 \mathrm{ft}(2-5 \mathrm{~m})$ from the break, depending on the break size and geometry. An expanding jet can destroy unprotected blankets located as far away as $10 \mathrm{~L} / \mathrm{D}$. Steel jacket encapsulation used in the reference plant reduces jet effects considerably.

3. The zone of influence or zone of destruction, which is characterized by pressures higher than the ambient and sufficient to inflict damage on the insulation blankets, closely resembles a right-angle cone if the two-phase jet is assumed to expand unobstructed into infinite space. Figure B-3 illustrates the shape of the predicted zone of influence and the pressure isobars within that zone, applicable to PWR conditions.

4. Insulation blankets located in the zone of influence, but relatively farther from the break, could be protected by steel encapsulation as long as the pressure loading is from outside to inside. However, in the expanding jet flow field, a shock wave arises near the target because the target structure propagates pressure waves upstream. Depending on upstream flow conditions, target size and shape, and L/D of the target, there may be substantial pressure loss across the shock-wave, which can lead to negative pressure loadings at the surface of the target. These negative pressure drops can be sufficiently large to lift protective covers off nearby targets and dislodge the blankets that subsequently will be entrained and shredded by the expanding jet. This finding is consistent with the HDR experiments, and leads to the conclusion that steel encapsulation may not protect the blankets because conventional encapsulations are not designed with that intent [Ref. B.11].

5. The orientation of the targets with respect to the primary jet direction strongly influences the damage suffered by the insulation blanket. When a target is not perpendicular to the break jet, the jet penetrates the blanket from the sides and lifts the protective covers and the blanket off the target pipe.

6. Various structures located around and behind the affected targets can reflect the jet. In some cases, the reflected jet may inflict more severe 
Appendix B

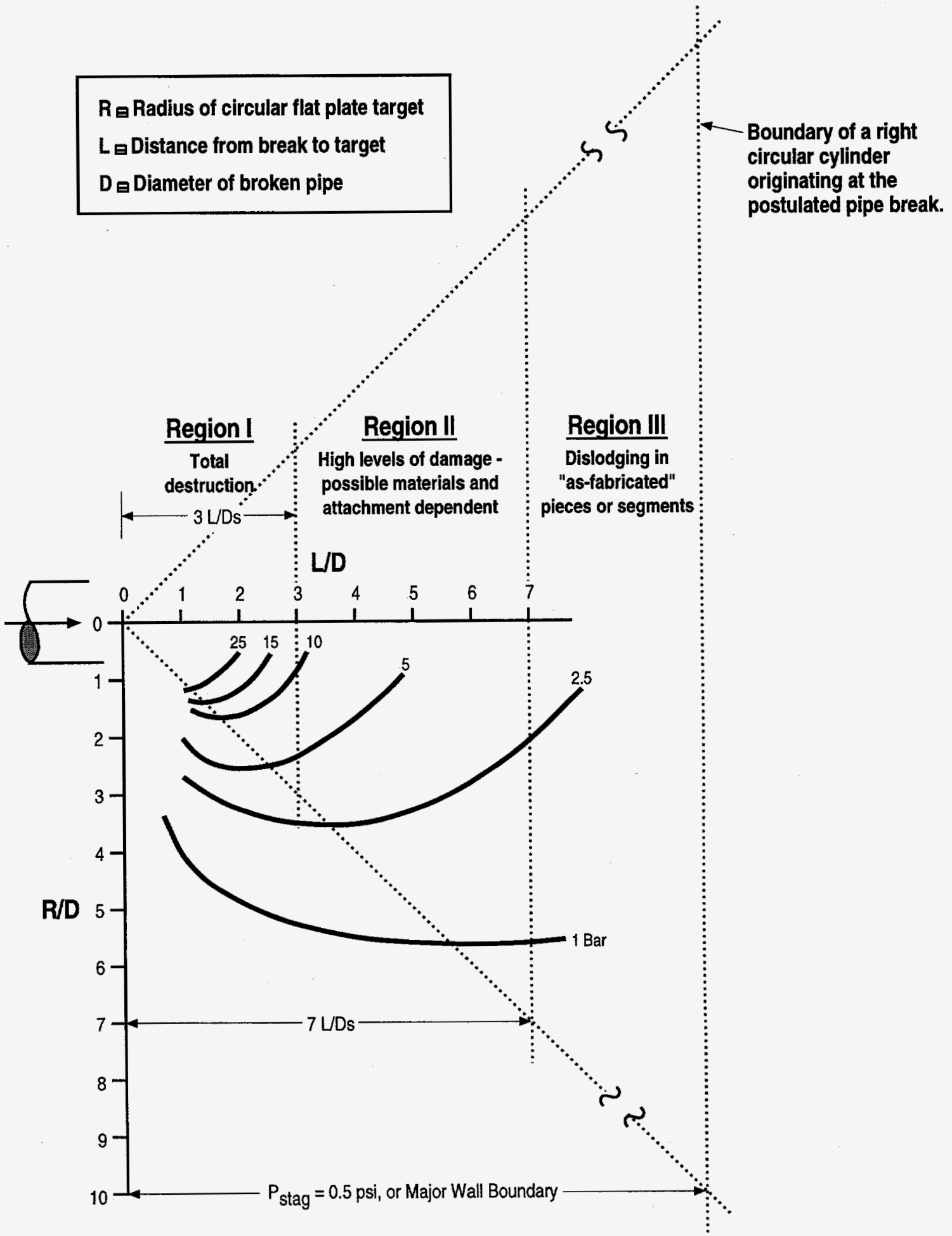

Figure B-3 Multiple Region Insulation Debris Generation Model for PWRs 
damage than the incident jet. Evidence for this can be found in HDR tests [Ref. B.11] and PCI tests [Ref. B.14], where the blankets located far away from the break jet centerline suffered more damage than those located on the centerline.

7. The generated debris vary in size depending on the distance from the break and on the type of insulation [Ref. B.14]. Also, the fraction of fines in the debris depends strongly on the insulation material. For example, a larger fraction of the debris contain fines in the case of aged mineral wool compared to NUKON ${ }^{\mathrm{TM}}$. Additionally, the mode of insulation encapsulation also affects the size distribution of the debris [Ref. B.14].

Based on these experimental findings, NUREG-0897 concluded that debris generation by LOCA jets is a complex function significantly influenced by a variety of factors, including break diameter; break location; break stagnation pressure and temperature; type of insulation and mode of encapsulation; and orientation of the targets with respect to the break jet. That study recognized that the determination of the extent of potential damage requires estimation of pressure and flow fields in the vicinity of the target during two important phases: initial transient blast loading and later quasi-steady jet loading. Even if the flow fields are known, calculating the dynamic loads on the targets and relating them to the extent of damage inflicted on the insulation blanket was found to be highly complex. As a result, NUREG-0897 did not attempt to develop a detailed DGM. Instead, they relied on the SNL two-phase jet model [Ref. B.3] to interpret the experimental results and to draw insights that could be used to develop an empirical DGM. The resultant DGM is illustrated in Figure B-3. Also shown in Figure B-3 are the pressure isobars predicted by the SNL twophase model assuming free expansion of the break jet with a stagnation pressure of $150 \mathrm{bar}$ and subcooling of $35 \mathrm{~K}$.

As shown in Figure B-3, load pressures closer to the break vary asymptotically, from a value of 150 bar near the break to 10 bar at an L/D of 3 . In this zone, survivability of insulation is unlikely regardless of the type of insulation or mode of encapsulation. At $L / D$ from 3 to 7, the pressure loadings on the postulated targets are expected to be in excess of $2 \pm 1$ bar. In this region, moderate damage to fibrous insulation blankets is likely. However, important factors appear to be the mode of encapsulation and the orientation of the blankets with respect to the break jet. For regions outside $\mathrm{L} / \mathrm{D}$ of 7 , centerline stagnation pressures remain essentially constant at about $2 \pm 1$ bar up to about $10 \mathrm{~L} / \mathrm{D}$. In this region damage suffered by the blanket appears to be dislodgement of the insulation blankets and limited shredding of the blankets. Note, however, that damage in this region can still be substantial if the blanket is not encapsulated and if it is constructed of materials such as non-reinforce ${ }^{3}$ aged mineral wool fibers, which are fragile. Beyond $10 \mathrm{~L} / \mathrm{D}$, the pressure falls to near atmospheric conditions and damage to blankets in this region is likely minimal.

\section{B.3.2 BWR Debris Generation Model}

Implicitly, the NUREG-0897 DGM is based on two assumptions: the break jet stagnation pressure is $\mathbf{1 5 0}$ bar and the break jet expands unobstructed into infinite space. These assumptions raise questions on the direct applicability of the NUREG-0897 DGM to BWRs because:

1. BWRs operate at low pressures but near saturation conditions. The stagnation conditions for a break in the MSLs are about 70 bar (1000 psi) and no subcooling $\left(\Delta \mathrm{T}_{\text {sub }}=\right.$ $\left.0^{\circ} \mathrm{F}\right)$.

2. BWR drywells are congested with various piping and containment structures, much more so than is typical of PWRs, which do not permit free expansion of a break jet into the drywell. Reflection of the break jet by the surrounding structures may redirect the jet and/or create large recirculation velocities. The HDR tests demonstrated that, in some cases, the reflected jet may inflict more damage than the incident jet [Ref. B.11]. Ensuing recirculating flow can inflict damage on the targets located outside the conical zone

\footnotetext{
${ }^{3}$ Some manufacturers employ a thin steel or iron wire to reinforce the blankets in order to improve their structural integrity.
} 
of influence that is expected for freely expanding jets.

3. The weld breaks are postulated in this study as DEGB, which result in simultaneous expansion in opposite directions of break jets originating from each of the severed ends of a DEGB. Interaction of these two expanding jets would result in a redistribution of fluid flow and pressure fields that are widely different from those estimated based on the conical zone of influence model.

This study assumed that as the initial blast wave exits the break and expands into the drywell, it would likely destroy steel-jackets around fibrous insulation blankets and cause damage to the blankets and the encased insulation materials. This initial wave (lasting less than a second), would be followed by the expanding two-phase break jet which causes destruction and dislodgement of the fibrous and/or non-fibrous insulation materials. This study takes into consideration that the break jet may be reflected (or redirected) by surrounding structures or components surrounding the break extending the zone of influence beyond the conical zone of influence proposed in NUREG-0897. Finally, interaction of the two jets expanding simultaneously from both ends of a DEGB would enhance redistribution of flow fields and would significantly alter the pressure profiles from those estimated from a conical zone of influence model. Based on these considerations, a spherical zone of destruction was judged to be more suitable for the BWRs than two back-to-back $90^{\circ}$ cones.

Having selected the shape of the zone of destruction, it is required to determine the spatial extent until which the damage can occur. In theory, the damage is possible in all the regions where the loads exceed the atmospheric pressure loading depending on the insulation type and its mode of encapsulation. However, based on experimental evidence it is known that damage is more severe closer to the break than farther from the break when the pressure loadings are expected to be lower. To account for these spatial effects, the multi-region approach suggested in NUREG-0897 was adopted for BWRs, in that the spherical zone of influence was divided into three regions. As illustrated in
Figure B-4, the following regions were used to define the BWR DGM:

Region I: Extends up to a length of 3L/D. This region is characterized by high pressures and survivability of insulation is unlikely regardless of the type of insulation or mode of encapsulation. Near total destruction of insulation into transportable form is extremely likely.

Region II: Enveloped by $3<\mathrm{L} / \mathrm{D}<5$, Region II is characterized by moderate pressures and associated moderate damage to the targeted insulation. In this region the damage is strongly dependent on the type of insulation and the mode of encapsulation.

Region III: Limited damage is expected in Region III whose outer bound is strongly dependent on the type of insulation and the system in which the break was postulated. For the steel jacketed NUKON ${ }^{\mathrm{TM}}$ used in the reference plant, the outer bound is assumed to be $7 \mathrm{~L} / \mathrm{D}$. This assumption is based on two sets of experimental data: the original HDR tests simulating PWR operating conditions (Appendix F of Ref. B.11) and more recent PCI air blast tests conducted at the CEESI [Ref. B.14].

The regions of destruction defined above are based on engineering judgement, not upon calculations of pressures for the spherically expanding jets as functions of distance. Such calculations are very complex and will have to address both the impulse loading on the insulation blankets by the initial shock wave lasting less than a second, and quasisteady pressure loading under the influence of expanding jet. Such calculations would also require information related to failure pressures of the blankets and encapsulations. In view of this, considerable caution must be exercised in defining the boundaries of each region for a specific insulation, e.g., unjacketed mineral wool, reflective metallic, etc.

Examination of the existing data base indicates that only a fraction of the insulation targeted in each region would actually be destructed into the transportable form, i.e. fines and small to medium shreds. The remaining fraction consists of large pieces such as partially destroyed blankets. It is assumed that they are not available for transport. 
Appendix B

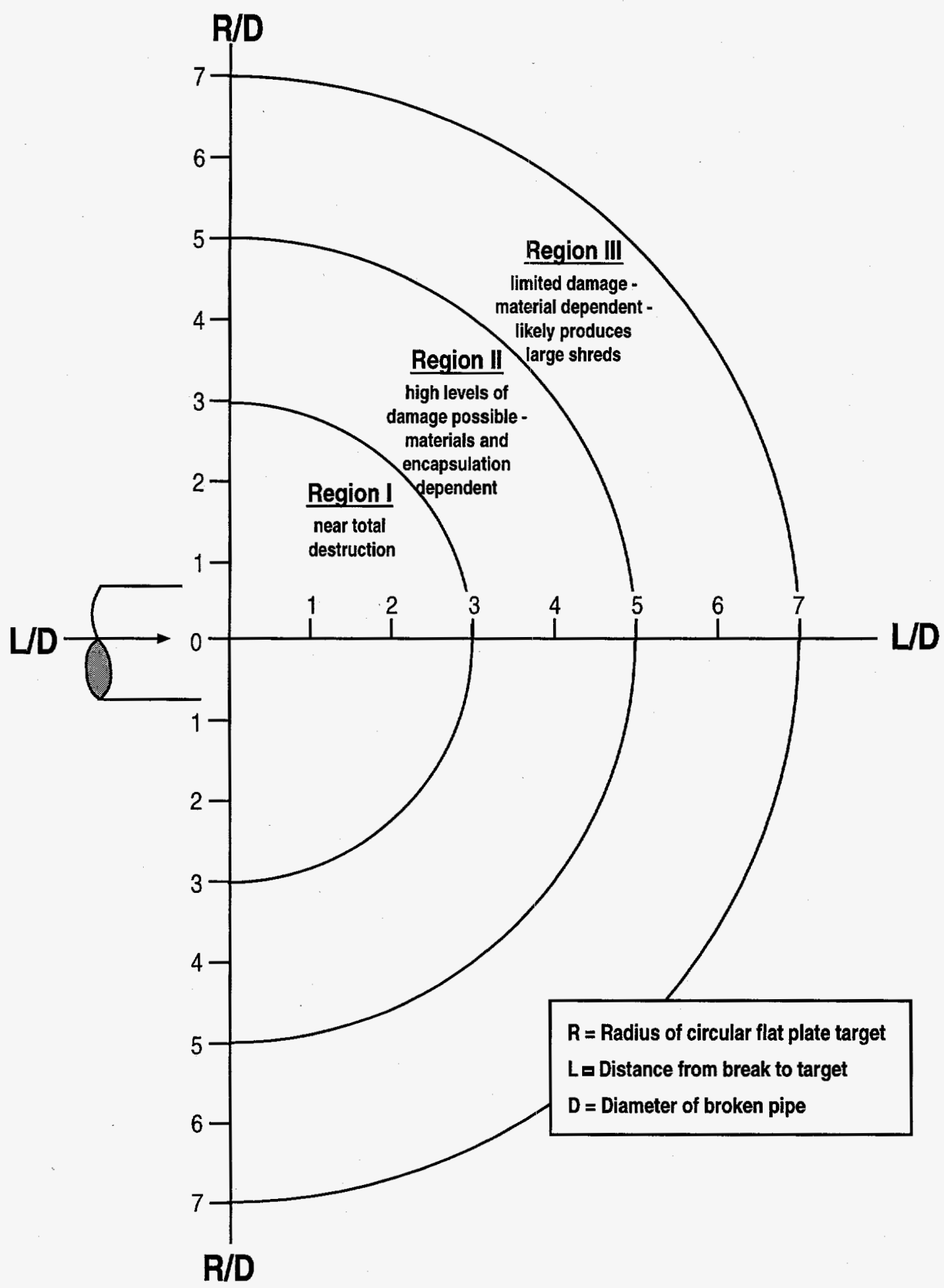

Figure B-4 Three Region BWR Debris Generation Model Used in the Present Study 
This fraction of transportable debris, referred to as the destruction factor, varies considerably depending on the insulation type and mode of encapsulation. For example, the HDR tests as well as the PCI tests reveal that the fraction of insulation reduced to transportable form is much less for steel jacketed NUKON ${ }^{\mathrm{TM}}$ compared to that for unjacketed NUKON $^{\mathrm{TM}}$. Such considerations can be effectively handled through the use of destruction factors. However, experimental data concerning the destruction factors is very limited. A review of this data suggests usage of destruction factors of 0.75 , 0.60 and 0.40 for Regions I, II, and III for steel jacketed NUKON ${ }^{\mathrm{TM}}$. Once again, considerable caution must be exercised in using these destruction factors for other insulation types or for other modes of encapsulation.

\section{B.3.3 Methodology for Application of the Debris Generation Model}

Each specific plant performing an independent analyses needs to assess the applicability of the DGM proposed here for the insulation being used in the plant. ${ }^{4}$ Once the applicability is established then, for each postulated break, the lengths of each target segment belonging to each of the destruction regions described above should be estimated using the plant piping layout drawings. The total volume of the insulation targeted by the break jet in each region, $\mathrm{V}_{\mathrm{R}}\left(\mathrm{ft}^{3}\right)$, can be estimated for each break as:

$$
V_{R}=\sum_{i=1}^{N_{\text {urger }}}\left[B \pi / 4\left((D+2 I)^{2}-D^{2}\right)_{i} L_{i R}\right]
$$

where,

$$
\begin{aligned}
& \mathrm{R} \text { is the Region (I, II or III) } \\
& \mathrm{i} \text { is the target number (1 to } \mathrm{N}_{\text {Target }} \text { ) } \\
& \mathrm{D} \text { is the target pipe diameter (in.) } \\
& \mathrm{I} \text { is the thickness of the insulation blanket } \\
& \mathrm{L}_{\mathrm{iR}} \quad \text { in the length of } \mathrm{i}^{\text {th }} \text { target in } \mathrm{R}^{\text {th }} \text { Region }
\end{aligned}
$$$$
\text { (ft) }
$$

\footnotetext{
${ }^{4}$ Note that the debris generation model included in BLOCKAGE has the required flexibility to handle a variety of modeling alternatives to the DGM discussed above.
}

B $\quad=1 / 144$; is a unit-conversion factor $\left(\mathrm{ft}^{2} / \mathrm{in}^{2}\right)$

$\mathrm{N}_{\text {Target }}$ is total no. of targets in $\mathrm{R}^{\text {th }}$ Region

The volume of debris generated by a postulated break into transportable form can be calculated as:

$$
V_{g}^{I}=\sum_{R=I, I I, I I I} V_{R} \cdot F_{R} \cdot G^{I}
$$

where,

$$
\begin{array}{ll}
\mathrm{V}_{\mathrm{g}}^{\mathrm{l}} \quad \begin{array}{l}
\text { is the volume of } \mathrm{I}^{\text {th }} \text { size-class debris } \\
\text { generated by a break }
\end{array} \\
\mathrm{V}_{\mathrm{R}} \quad \begin{array}{l}
\text { is the volume of insulation contained in } \\
\mathrm{R}^{\text {th }} \text { Region (Eq. B-6) }
\end{array} \\
\mathrm{F}_{\mathrm{R}} \quad \begin{array}{l}
\text { is the destruction factor for the } \\
\text { insulation in the } \mathrm{R}^{\text {th }} \text { region }
\end{array} \\
\mathrm{G}^{\mathrm{l}} \quad \begin{array}{l}
\text { is the mass distribution factor }
\end{array}
\end{array}
$$

Equations B-6 and B-7 were incorporated into BLOCKAGE to estimate the quantity of insulation debris generated by each break. The specific input required for performing the debris generation calculations include: boundaries of each of the regions; destruction factors for each region; and lengths of targets located in each region. This information is provided to BLOCKAGE as part of the input files.

In addition to the insulation debris, the LOCA jets may generate considerable quantities other debris in the drywell. Examples of such debris may include paint chips, fibers from air filters and HVAC piping, concrete dust and other particulate debris.

BLOCKAGE allows the user to specify up to 12 species of drywell debris in addition to fibrous insulation debris.

\section{B.4 Debris Species Classification}

To effectively handle the differences in generation and transport, the LOCA-introduced debris are classified into three species: fibrous insulation debris, non-fibrous drywell debris or drywell particulates (paint chips and concrete dust), and suppression pool sludge. Furthermore, it is recognized that each species has a characteristic size 
distribution associated with it due to randomness associated with its formation/generation. The size distributions of these debris play an important role in determination of ECCS strainer blockage potential. This impact for fibrous debris can be highlighted by contrasting between the two extremes, fine debris (or fines) and large shreds. Fine debris in this document refers to insulation debris that is reduced to small fibers by the LOCA forces; fines are easily transported to the suppression pool and tend to remain suspended for prolonged periods of time, increasing the potential for being drawn to the strainer. Large shreds are not easily transported and tend to settle on the drywell floor and/or the suppression pool floor, which decreases the potential for them to be drawn to the strainer. Additionally, the fines form more compact beds, resulting in larger pressure drops than beds of the same thickness formed by large shreds.

For sludge particles, the impact of size distribution is more complex. Being small in size, the sludge particles remain suspended for longer periods of time and most likely larger fractions of them reach the strainer. However, the smallest of the sludge particles, especially those equal to or less than a micron in size, tend to penetrate the debris layer formed on the strainer. On the other hand, the larger particles will most likely be deposited in the debris bed. As a result, the quantity of sludge trapped in the debris bed and the resultant head loss appear to increase with particle size. As evident from the discussions above, the debris size and shape influence their transport characteristics (e.g., settling velocity) and their pressure drop characteristics (e.g., compressibility and filtering efficiency). In view of its importance, considerable attention was paid as part of this study to determine expected shape and size distributions of various debris species and the filtration efficiency associated with each size class. The following sections summarize the important factors that were considered in defining the size classes.

\section{B.4.1 Classification of Fibers}

Both the HDR and PCI debris generation tests demonstrate that the fibrous debris generated by a LOCA would vary in size from fines to large shreds
[Ref. B.11 and B.14]. In general the fines can be easily carried by the vapor flow to the suppression flow. Shreds up to a few inches can be carried to the suppression pool during washdown. These shreds may undergo further disintegration during their transport, depending on the transport velocities and their original size. Based on qualitative assessment, it is judged that the debris reaching the suppression pool may resemble the six classes listed in Table B-3. The debris classes of Table B-3 can be best described as shape classes since their classification is based solely on their shape. Implicitly, however, each shape class is associated with a narrow range of sizes and thus a narrow range of settling velocities. Table $\mathrm{B}-3$ also provides a convenient means by which debris used in various suppression pool tests and head loss tests can be classified and have been widely referred to by several experimenters to identify the size/shape of the fibrous debris used in their respective experiments.

The turbulence created in the suppression pool causes further destruction of these fiber debris [Ref. B.15 and B.16]. Typically, shreds of classes 3, 4 , and 5 were reduced to classes 1,2 and 3 in the presence of turbulence. Visual inspections and settling velocity measurements [Ref. 16] indicated that the residual debris settling velocities varied between $0.1 \mathrm{~mm} / \mathrm{s}$ to $10 \mathrm{~mm} / \mathrm{s}(0.0032 \mathrm{ft} / \mathrm{s}-0.023$ $\mathrm{ft} / \mathrm{s}$ ) which falls in the range of size classes 1,2 and 3 (see Table B-3). However, owing to their illdefined shapes, it is difficult to further classify these debris by their shape classes and to develop appropriate size distribution curves (i.e., it is difficult to determine what fraction of the residual debris belongs to each shape class). A better means of characterizing fiber debris is by their settling velocities since this property influences their transport in the suppression pool. This concept was used in developing the 'settling groups', which are identified by settling velocities. Usage of settling groups instead of the shape classes described above provides for finer classification of debris. Section B.5 presents further discussion on the settling groups used for classifying the NUKONTM material and their relationship to shape classes in Table B-3. 


\begin{tabular}{|c|c|c|c|c|c|}
\hline (рәңеш!nse) $0^{\circ}$ เ & 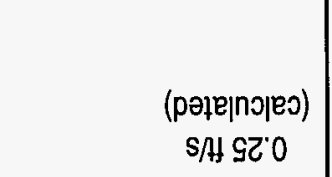 & 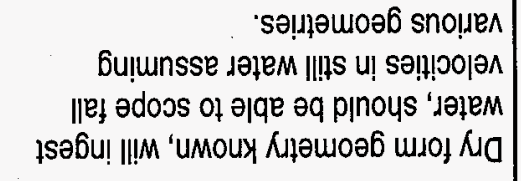 & 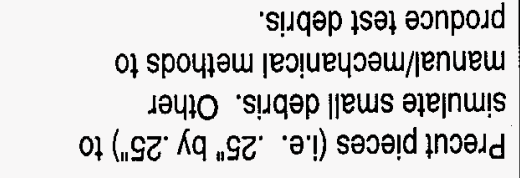 & & $L$ \\
\hline (pannseaul) $0^{\circ} /$ & $\begin{array}{r}\text { (pannseam) } \\
\text { s/H } 61^{\circ} 0 \cdot 91^{\circ} 0\end{array}$ & 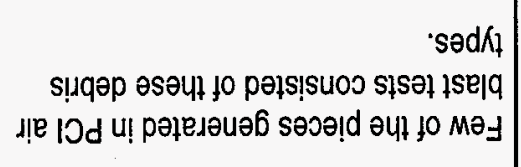 & 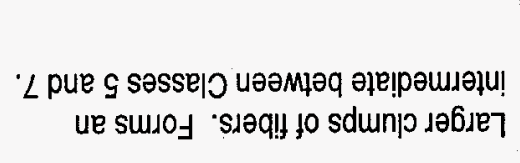 & 6 & 9 \\
\hline (pəנnseam) $0^{\circ}$ & 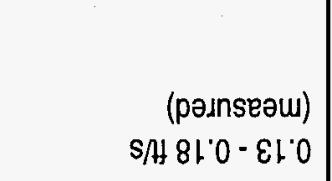 & 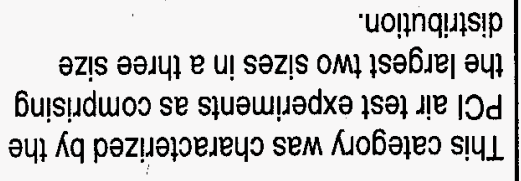 & 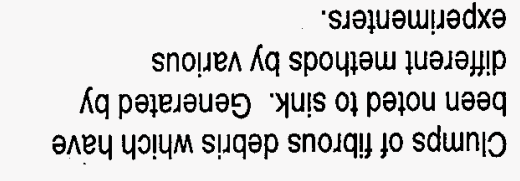 & & G \\
\hline (pesnseau) 0.1 & $\begin{array}{r}\text { (pəunseəul) } \\
\text { SA } A 1^{\circ} 0-80^{\circ} 0\end{array}$ & 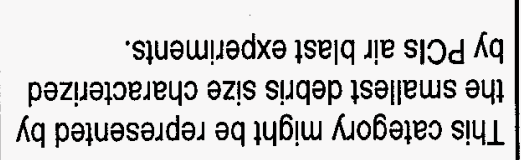 & 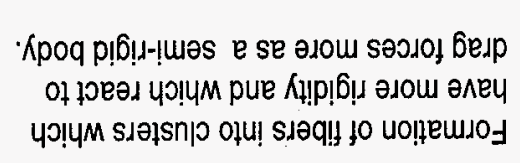 & & $t$ \\
\hline (pannseaw) 0.1 & $\begin{array}{r}\text { (pəגnseəw) } \\
S / H 90^{\circ} 0-\mathrm{s} / H+0^{\circ} 0\end{array}$ & 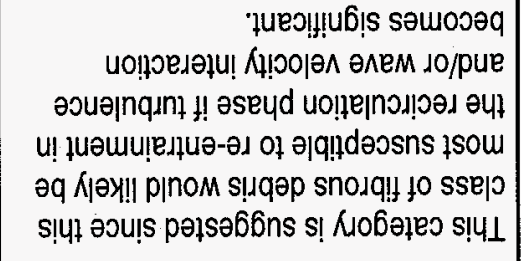 & 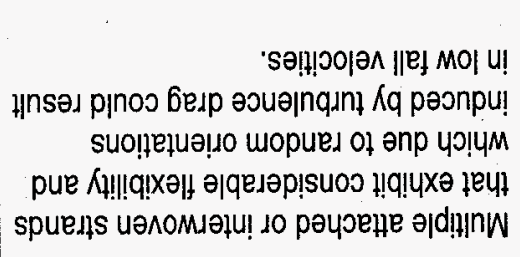 & & $\varepsilon$ \\
\hline 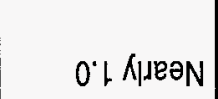 & anoqe se aures & 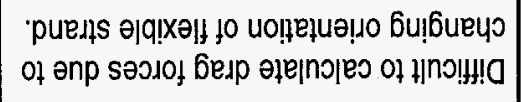 & 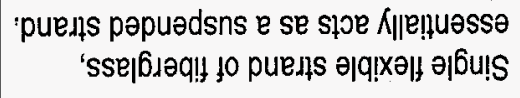 & & $\tau$ \\
\hline umouxun & 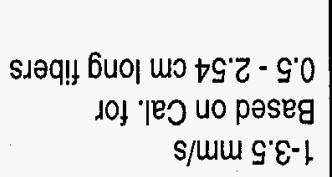 & 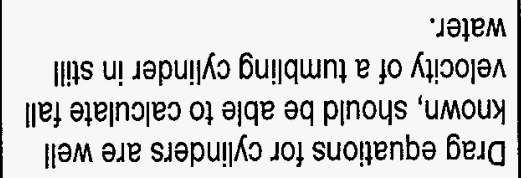 & 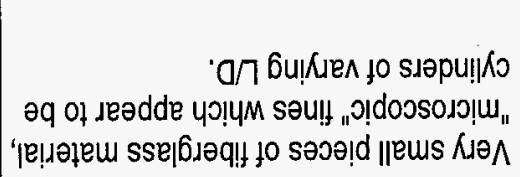 & & $\downarrow$ \\
\hline 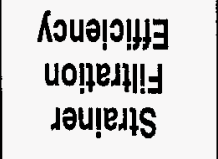 & 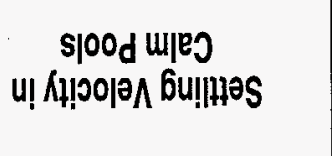 & 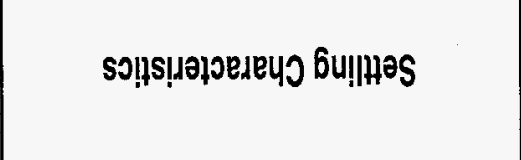 & 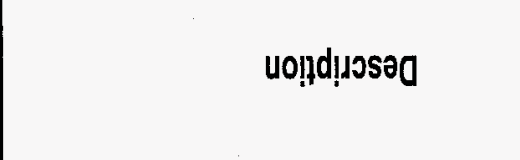 & & $\begin{array}{l}0 \\
\frac{2}{9} \\
g_{0} \\
z \\
0\end{array}$ \\
\hline
\end{tabular}




\section{B.4.2 Classification of Sludge}

A survey conducted by the BWROG revealed that majority of the sludge contained in the suppression pool consists primarily of iron oxides (i.e., $\mathrm{Fe}_{2} \mathrm{O}_{3}$ and $\mathrm{Fe}_{3} \mathrm{O}_{4}$ ). Sources of rust included pool inside lining, downcomers, vent-pipes, ECCS discharge lines and other piping that discharges into suppression during tests and start-up. For a few plants, additional quantities of sludge included such materials as concrete dust and micro-biological growth. Based on a survey of five nuclear plants, which included Mark I, II and III containments, the size distribution data tabulated in Table B-4 was provided by the BWROG as being representative of BWRs [Ref. B-17].

\begin{tabular}{|ccc|}
\hline Table B-4 & $\begin{array}{c}\text { BWROG-Provided Size Distribution } \\
\text { of the Suppression Pool Sludge }\end{array}$ \\
\hline $\begin{array}{c}\text { Size Range } \\
\mu \mathrm{m}\end{array}$ & $\begin{array}{c}\text { Average Size } \\
\boldsymbol{\mu m}\end{array}$ & $\begin{array}{c}\% \text { by } \\
\text { weight }\end{array}$ \\
\hline $0-5$ & 2.5 & $81 \%$ \\
$5-10$ & 7.5 & $14 \%$ \\
$10-75$ & 42.5 & $5 \%$ \\
\hline
\end{tabular}

However, these size distributions are associated with large uncertainties introduced by such factors as sampling techniques and potential for agglomeration. These factors should be considered while characterizing the sludge.

\section{B.4.3 Size Distribution of Paint-Chips}

A study undertaken by the BWROG examined various failure modes for epoxy coated zinc based paints found in the BWR containments [Ref. B.18]. The generated debris were characterized as large sheets, small sheets, chips and particles. The chips, about $0.125 "(0.318 \mathrm{~cm})$ to $1.0^{\prime \prime}(2.54 \mathrm{~cm})$ in width, were judged to be most common for BWR conditions. The weight range for the chips would be between $0.02 \mathrm{~g}$ to $0.16 \mathrm{~g}$, with an average of about $0.10 \mathrm{~g}$. Figure B-5 presents the measured settling velocity for the chips of this size range. For the purpose of the present evaluations, a single equivalent size class with an average weight of $0.1 \mathrm{~g}$ was used to represent the paint-chips. For such a size class, the measured settling velocity is about 0.3 $\mathrm{ft} / \mathrm{s}(9.1 \mathrm{~cm} / \mathrm{s})$ in a calm pool [Ref. B.19].

\section{B.4.4 Other Types of Debris}

Inspections have revealed that some suppression pools have contained such items as coveralls and other miscellaneous materials. No estimates for such quantities are possible. In addition, their transport characteristics are not well understood. This analysis assumes that pools will be cleared of such materials.

Limited size distribution data is available for debris generated by erosion of calcium silicate and Newtherm 1000 [Ref. B.20, B.21 and B.22]. This information can be used to characterize such debris. No size-related information is presently available on the other types of debris generated in the drywell, including metallic insulation and concrete chips. Hence, no size characterization was possible for these debris species. However, BLOCKAGE provides flexibility to include these species in future analyses.

\section{B.5 Drywell Transport}

This section describes the model used in this study for the transport of debris in the drywell. Due to limited experimental data, a simplified parametric drywell transport model was developed.

\section{B.5.1 Relevant Findings of the Previous Studies}

A limited amount of experimental and theoretical data pertinent to understanding the transport characteristics of fibrous debris during both the blowdown and recirculation phases was available. The insights drawn from this review can be summarized as follows:

1. The fibrous and particulate debris generated at the break location will be transported to the drywell floor and ultimately to the suppression pool by combined effects of recirculating vapor flows, cascading water 
Appendix B

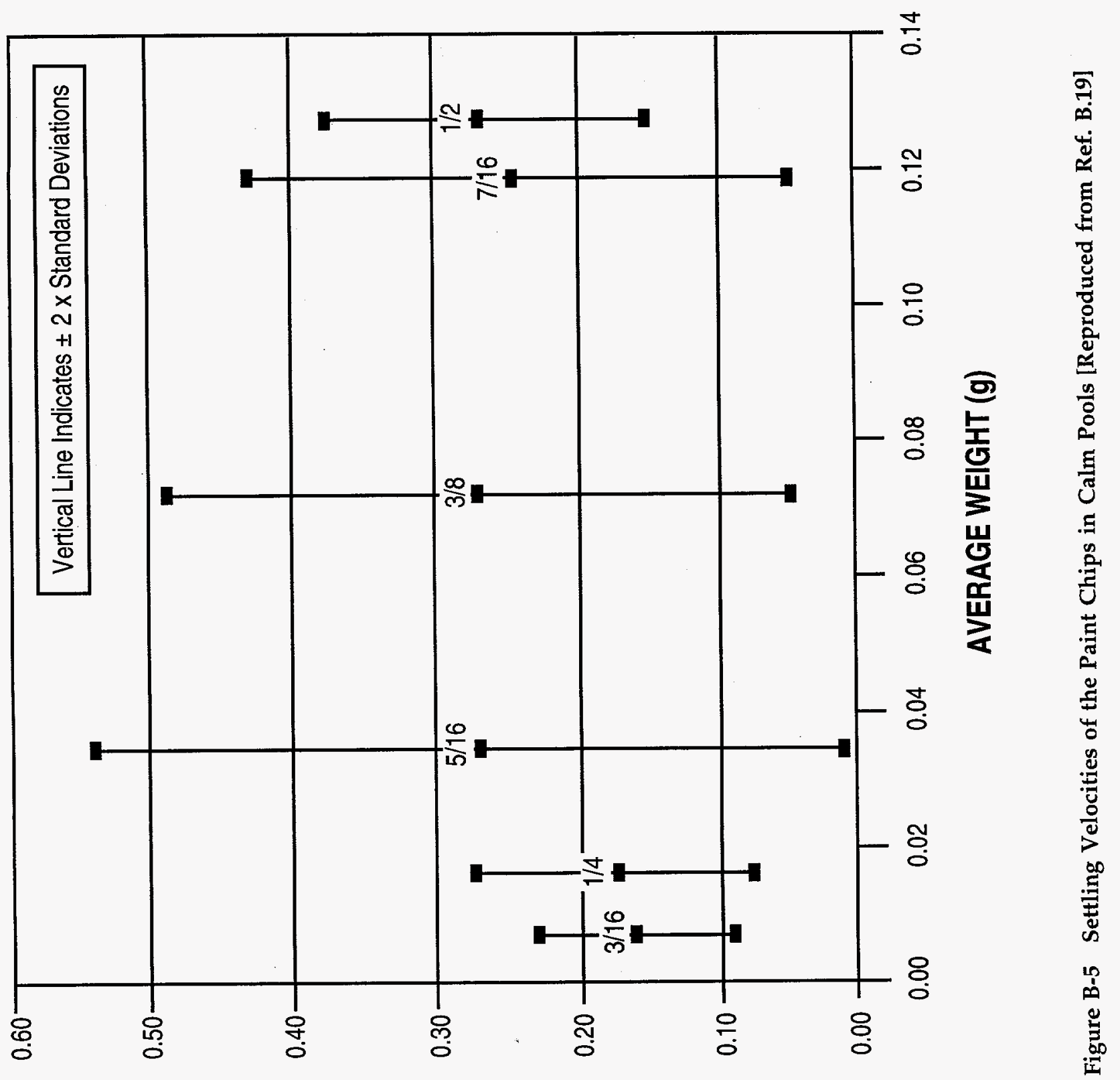

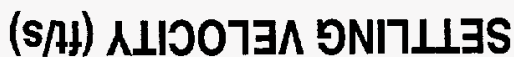


flows originating from the break and from the containment sprays, and gravitational forces. The percentage of total debris transported to the suppression pool depends on the tortuousness of the channels available for transport, flow rates, degree of superheat and debris size.

2. HDR test results show that shreds of fibrous debris are carried far from the break by the blowdown jets and are deposited in various compartments [Ref. B.11]. Considerable quantities of debris were found to have been firmly attached to containment structures, including walls, grids, and components. It is highly likely that such attached debris would remain on the structures and may never reach the suppression pool. Although the HDR containment is similar to a PWR containment, this finding is equally applicable to BWRs since initial debris transport in both cases is by blowdown; as a matter of fact, this phenomenon was also observed at the Barsebäck-2 incident [Ref. B.23].

3. Typically smaller shreds are carried by the vapor flows. The fraction transported is a strong function of the flow rates and degree of superheat. The ABB Karlshamn tests [Ref. B.13] suggest that about $10-25 \%$ of the debris can be transported to the suppression pool by the blowdown vapor flows. According to these experiments, this fraction is an increasing function of the steam flow rate and steam superheat. However, the experiment did not parametrically study the effect of the degree of congestion on the transport fraction. Also, the results are not easily scalable to actual BWR drywell configurations.

4. Several of the European tests suggest that a fraction of debris initially entrained by the vapor flow will be deposited on various drywell structures under the influence of steam condensation [Ref. B.13 and B.15]. This fraction would be readily available for transport by washdown. On the other hand, a fraction of the insulation debris would be strongly attached to the drywell structures and may not be dislodged or transported by the washdown [Ref. B.11 and B.23]. No experimental data is available on the relative magnitudes of either of these quantities.

5. Both the containment sprays and the break flow contribute to washdown of debris loosely attached to various structures. The Barsebäck-2 incident demonstrates the effectiveness of the containment sprays in transporting the debris [Ref. B.23]. This effectiveness is primarily attributable to the fact that the containment sprays cover most of the drywell. On the other hand, the break flow is expected to cover relatively smaller surface area of the drywell. Therefore, it is likely that considerably larger fractions of debris would be carried to the suppression pool in the presence of containment sprays.

6. Formation of a water pool on the drywell floor could play a significant role in the debris transport. On the one hand, existence of such a pool could allow for settling of heavier debris on the floor, impeding their transport to the suppression pool [Ref. B.24]. On the other hand, such pools can also provide a mechanism by which the larger pieces of debris can be destructed by the turbulence introduced by the water stream falling freely under the influence of gravity from the break location. The latter effect could be very important for the fibrous debris.

\section{B.5.2 Drywell Debris Transport Model}

Three important conclusions relative to drywell debris transport can be drawn from the preceding information: (1) a fraction of insulation debris will be reduced to fines and shreds that is capable of being transported to the suppression pool during the blowdown phase; (2) an additional fraction will be washed down by the break flow during the recirculation phase; and (3) a fraction of the fines and shreds will be retained within the drywell. The fraction of material retained in the containment is expected to be greatest for breaks postulated in high elevations of the drywell, moderate for breaks in the middle regions of the drywell, and smallest for breaks occurring in the lower region of the drywell. Due to the complex transport phenomena involved, 
analytical models are not capable of estimating these fractions with a high degree of certainty.

The drywell debris transport model developed for this study calculates the mass of $I^{\text {th }}$ debris species transported to the suppression pool, $\dot{M}_{d r y w l l}^{I}$, using the following equation:

$$
\dot{M}_{\text {drywell }}^{I}=T(t) \cdot V_{g}^{I} \cdot c_{o}^{I}
$$

where,

$$
\begin{aligned}
& \mathrm{V}_{\mathrm{g}} \mathrm{I} \quad \text { is the volume of } \mathrm{I}^{\text {th }} \text { debris species } \\
& \text { generated by a break (see Eq. B-7) } \\
& T(t) \text { is the time dependent drywell transport } \\
& c_{o}^{I} \quad \text { is the theoretical packing density of the } \\
& \mathrm{I}^{\text {th }} \text { debris species. }
\end{aligned}
$$

The absolute value of the transport factor integrated over time and its time dependence are difficult to determine analytically. Also, very limited experimental data is available. Available experimental data may not be directly applicable to the insulation type and drywell layout of the reference plant. Therefore, this study used a simplified parametric model to incorporate the drywell transport factor into BLOCKAGE. The basic assumptions of the model pertinent to drywell transport of debris can be summarized as follows:

1. The debris transport to the suppression pool consists of two components: (a) transport during blowdown by recirculating steam flow to the suppression pool, and (b) transport due to washdown of the debris remaining in the drywell by the break flow cascading downwards from the break location.

2. The fraction transported to the suppression pool is strongly influenced by the break location and drywell layout.

Accordingly, the transport factor in Equation B.8 is expressed as a sum of the blowdown transport factor and the washdown transport factor, i.e.,

$$
T(t)=T_{b d}(t)+T_{w d}(t)
$$

where,

$$
\begin{aligned}
& \mathrm{T}_{\text {bd }} \quad \text { is blowdown transport factor, } \\
& \mathrm{T}_{\mathrm{wd}} \text { is washdown transport factor. }
\end{aligned}
$$

Both $T_{b d}(t)$ and $T_{w d}(t)$ are strong functions of the break location in the drywell and the structural impediments in the transport pathways. As a result, these transport factors are highly plant specific. At the present time, because of the lack of supporting experimental data, considerable engineering judgement must be used to estimate the transport factors.

These equations are used in BLOCKAGE to estimate the volume/mass of debris transported to the suppression pool. The drywell transport model in BLOCKAGE can simulate a variety of scenarios that can be postulated, including short-term and long-term transport.

\section{B.5.3 Important Considerations in Estimating Transport Factors}

The potential for drywell transport of debris can be illustrated by considering the Barsebäck-2 incident in which about half of the debris dislodged from the target pipes was transported to the suppression pool [Ref. B.23]. The debris was transported by the combined effects of vapor flows initially and containment spray water thereafter. The plant estimates attribute the majority of the transport to the washdown of debris by the sprays [Ref. B.23]. While this may be true in case of the Barsebäck-2 incident, this result can not be generalized for other breaks and/or other plants. For example, a MSL break in a BWR operating at full power will induce higher vapor flows in the drywell. Such higher vapor flows can entrain and transport much larger fractions of the insulation debris generated in the drywell to the suppression pool. Additional factors, such as the drywell layout, may also significantly impact the drywell transport. For example, Barsebäck-2, which is similar in arrangement to a Mark II containment, is much less congested in layout compared to a typical Mark I plant. Also, in 
Barsebäck-2 the entrances to the downcomers are flush with the drywell floor, compared to a Mark I plant where the vent pipe entrances are elevated from the drywell floor. Factors such as these should be taken into consideration in estimating transport factors. Due to lack of experimental data, engineering judgement must be employed to determine the transport factors.

\section{B.6 Suppression Pool Transport}

This section provides a qualitative description of the various phenomena that could occur in the suppression pool during the course of a postulated LOCA in a BWR with a Mark I containment system. Figure B-1 shows the sequence of events after a postulated LOCA and the effect on debris transport in the suppression pool. Insights related to the first three phases of accident progression were gained mainly by reviewing NUREG-0661, which summarized results of various experiments and analytical models. The description of the last phase of accident progression, characterized by the longterm operation of the ECCS and containment sprays, was based on reviews of relevant EOPs and the FSAR for the reference plant.

Immediately following a postulated LOCA, the pressure and temperature of the drywell atmosphere increase rapidly. With the increase in drywell pressure, water initially standing in the downcomers accelerates into the pool, clearing the downcomers of water. This vent-clearing process generates a water jet capable of causing turbulent mixing of the suppression pool water. Immediately following vent-clearing, non-condensible gasses from the inert drywell atmosphere are discharged at the exit of the downcomers for about 10 to 15 seconds for a LLOCA, resulting in swelling of the suppression pool. During this initial stage of accident progression, the suppression pool flow fields are dominated by large scale turbulence, leading to resuspension of a large fraction of the suppression pool sludge.

With time, the vent pipe flow will consist increasingly of steam. As the flow of steam through the downcomers continues, pressure oscillations occur in the suppression pool. Based on experimental data, these oscillations can be divided into two categories: (1) "condensation oscillations," which occur at relatively high vent flow rates and are characterized by continuous periodic oscillations, with the neighboring downcomers oscillating in phase, and (2) "chugging," which occurs at lower steam flow rates and is characterized by a series of pulses typically a second or more apart.

Experimental data suggest that amplitude, frequency, and duration of the condensation oscillations are primarily functions of the mass flow rate, concentration of the non-condensibles in the mass flow, downcomer submergence, suppression pool temperature, and break size.

Chugging phenomena seem to occur over a short period of time towards the end of the drywell blowdown when the drywell pressure is not sufficient to keep the downcomer throat completely cleared of water. Existing experimental data suggests that both condensation oscillations and chugging phases are associated with turbulent flow fields. However, it appears that turbulence in the case of condensation oscillations is non-isotropic when integrated over the entire height of the pool, as demonstrated by thermal stratification observed in some extreme cases. The chugging phase, on the other hand, appears to generate large scale eddies that can propagate to the bottom of the pool. Turbulence generated by both of these phases is probably non-isotropic and exists in high levels at the exit of the downcomers where the debris is introduced into the pool. Sedimentation of debris introduced during the blowdown phase would be strongly influenced by the suppression pool turbulence introduced by condensation oscillations and chugging. Another likely effect of condensation oscillations and chugging is resuspension of suppression pool sludge.

The reference plant ECCS is designed such that shortly after a postulated LOCA, the ECCS will automatically start to pump water into the reactor vessel from either the CST or the suppression pool. This water floods the reactor core and ultimately cascades into the drywell through the postulated break. The time at which this occurs will depend on the break size and location. Because the drywell will be full of steam at the time of vessel flooding, introduction of water into the drywell causes large scale condensation and a rapid decrease in drywell pressure. At this stage, the vacuum breaker valves 
open to enable non-condensible gases in the suppression pool to flow back into the drywell, leading to equalization of drywell and wetwell pressures. Thereafter, vapor flow to the suppression pool would be reduced to very low levels. Suppression pool turbulence levels start to decay because energy cannot be introduced into the bulk of the pool to maintain high levels of turbulence. This phase of the accident will have two significant effects on debris transport: (1) water cascading from the break will result in continued washdown of debris contained in the drywell, especially near the break region, and (2) decaying turbulence levels will no longer impede debris from settling in the suppression pool.

In the final stage of accident, the BWRs rely on long-term ECCS flow to the vessel for heat removal, containment sprays to control drywell pressure and temperature, and suppression pool cooling for ultimate heat removal from the containment. Break flow, aided by the containment sprays, will continue to washdown remaining insulation, originally damaged by the LOCA, to the suppression pool. This debris will enter the wetwell through the vent pipes and the downcomers. The majority of the debris introduced into the pool during this stage is likely to be comprised of large or partially damaged insulation pieces and drywell particulates.

Actuating the suppression pool cooling features will result in establishment of large scale recirculation flow patterns within the suppression pool. During this stage, the residual turbulence is due to (1) the horizontal momentum component introduced by the recirculation flow, and (2) the vertical momentum component introduced by the jets of water exiting the downcomers. The resulting turbulence may not be sufficient to completely prevent sedimentation. Also, if pool recirculation velocities are sufficiently large, the drag in the boundary layer may reach the critical value required to cause resuspension of a small portion of the sediment at the bottom of the suppression pool. This may lead to the formation of a more uniform sediment layer and may result in transport of a small fraction of the resuspended debris to the strainer. In general, this phase will be characterized by continued washdown of debris from the drywell and sedimentation of debris present in the suppression pool.
Drywell and wetwell designs vary widely among the Mark I, II and III containment designs. These design variations substantially impact the suppression pool hydrodynamics. Separate experimental studies were carried out by the General Electric Company for each containment type in support of the resolution of suppression pool loads program. These studies indicate that hydrodynamic phenomenon are strongly dependent on containment type. For example, the Mark III drywell blowdown into the suppression pool is through horizontal pipes, as opposed to the vertical introduction of the Mark I and II designs. As a consequence, condensation oscillations in a Mark III are expected to be different in nature. Similar distinctions exist in the long-term ECCS phase; typically, in a Mark III design, the recirculation flow velocities are much larger than corresponding velocities in Mark I and Mark II designs.

\section{B.6.1 Resuspension}

Resuspension is the phenomenon by which sediment located at the bottom of the suppression pool is swirled upwards. The purpose of the resuspension model is to facilitate simulation of resuspension of suppression pool sludge during the high energy phase of the blowdown, and of possible resuspension of sludge and debris sediment during the long-term recirculation phase, when sufficient pool velocities may occur.

Resuspension is possible when turbulence levels and/or recirculation velocities in the boundary layer are capable of providing net upward drag on the debris to overcome gravitational forces. This phenomenon can be seen as opposite to sedimentation and has been widely studied in relation to settling tanks. The resuspension massflux is usually expressed as a product of the sediment mass and a coefficient, $\kappa_{R}^{I}$, referred to as the resuspension coefficient:

$$
\dot{M}_{R e-\text { Suspension }}^{I}=\kappa_{R}^{I}(t) M_{\text {Pool }}^{I}
$$

where,

$$
\dot{M}_{R e-s u s p e n s i o n}^{I}=\text { Resuspension Mass flux }(\mathrm{lbm} / \mathrm{s})
$$




$$
\begin{aligned}
& \kappa_{R}^{I}(t) \quad=\text { resuspension coefficient }(1 / \mathrm{s}) \\
& M_{\text {pool }}^{I} \quad=\text { total mass of Ith debris species } \\
& \text { contained in the suppression pool } \\
& \text { floor }(\mathrm{lbm}) \text {. }
\end{aligned}
$$

This parametric resuspension model allows for a variety of scenarios to be simulated through the usage of resuspension coefficients. For example, one scenario of interest is instantaneous resuspension of all suppression pool sludge at the start of the blowdown and no resuspension thereafter. This situation can be modeled by assigning the following time dependence function for the resuspension coefficient:

$$
\begin{aligned}
& \kappa_{R}^{I}(t)=1.0 \text { for } 0<t<1 s \\
& \kappa_{R}^{I}(t)=0.0 \text { for } t>1 s
\end{aligned}
$$

In general, $\kappa_{R}^{I}$ is a complex function of sediment particle size and shape, pool velocity profiles, and pool turbulence levels. The model developed does not attempt to model resuspension mechanistically, i.e., it does not attempt to relate the resuspension coefficient to all the individual variables listed above. Instead, it assumes that the resuspension coefficient is directly proportional to turbulence intensity.

Accordingly, $\kappa_{R}^{I}$ can be visualized to have the temporal dependence as shown in Figure B-6. As evident from this figure, the resuspension coefficient is close to 1.0 during the high energy phase as demonstrated by the NRC experiments (see Appendix E). This conclusion is equally valid for both LLOCA and MLOCA. The coefficient falls to essentially zero once the turbulence associated with the high energy phase decays. It may possess a non-zero value in the recirculation phase, depending on recirculation flow velocity profiles and containment design. Appropriate values for $\kappa_{R}^{I}$ should be obtained from the experimental studies, either full-scale experiments or experiments that are appropriately scaled. At present, appropriate data is lacking for post high-energy phase of the accident. For this phase, engineering judgment formed the basis of the values used in this study.
Equation B-10 and the resuspension coefficient time dependence (Eq. B-11) are used in BLOCKAGE to estimate the mass of debris resuspended in the suppression pool. The resuspension model in BLOCKAGE can simulate a variety of scenarios including long-term recirculation.

\section{B.6.2 Sedimentation}

Sedimentation, also referred to as gravitational settling, is a primary mechanism for removal of debris that is suspended in the suppression pool. The rate at which the debris settle is a complex function of debris characteristics (e.g., density, shape and size) and pool dynamics (e.g., turbulence levels and the flow velocity profiles). The sedimentation rates, also referred to as the settling velocities, can be calculated for debris with well-defined shapes under still pool conditions using existing analytical models [Ref. B.25, B.26, B.27 and B.28]. For undefined shapes under turbulent pool conditions, a few approximate models can be used to estimate the settling rates [Ref. B.29]. However, such models are usually based on several assumptions regarding debris shape as well as suppression pool dynamics during and after the high energy phase. Also, such models tend to be parametric in nature and their usage introduces large uncertainties into the overall calculational results.

Given the importance of sedimentation, it is desirable to minimize uncertainties in estimating the settling rates. As a result, the NRC sponsored a series of experiments to gain insights into debris behavior during and after the high energy phase (see Appendix E). The NRC experiments focused on studying the debris behavior during in-phase chugging which is typical of a MLOCA because scoping analyses have indicated that settling during the condensation oscillation phase of a LLOCA is extremely unlikely [Ref. B.30].

These NRC experiments allowed for visual observation of the debris behavior in addition to providing concentration data. Appendix E summarizes the experimental procedure as well as the data obtained from these experiments. The following sections summarize the insights gained from the experiments. 
Appendix B

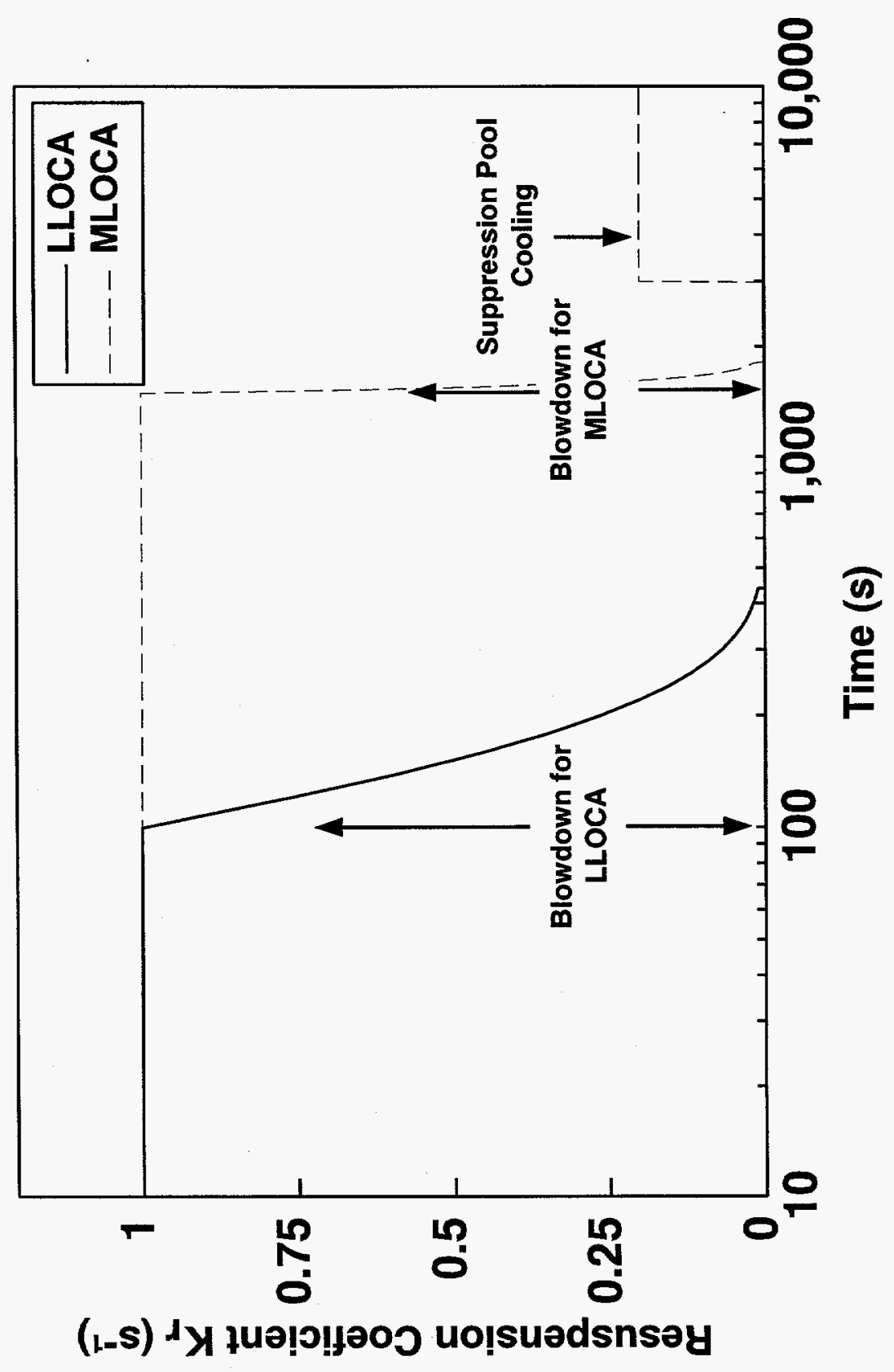




\section{B.6.2.1}

\section{Settling Rates for the High Energy} Phase

During the high energy phase the suppression pool is characterized by large-scale turbulence introduced by steam injection and subsequent condensation into the suppression pool. The high energy phase following a LLOCA lasts for about $\mathbf{5 0}$ seconds and is characterized by condensation oscillations initially followed by a few chugs. On the other hand, the high energy phase for a MLOCA lasts for about 10 minutes, and is characterized by in-phase chugs of varying intensity and frequency. Analysis of Mark I FSTF test data [Ref. B.7 and B.31] reveals that these chugs typically have a period of about 1.5 to 2.5 seconds with a corresponding water level (condensation front) motion of about $3.8 \mathrm{ft}$ to $8 \mathrm{ft}$ $(1.2$ to $2.4 \mathrm{~m}$ ) [see Appendix E]. The NRC experiments were used to draw the following insights regarding debris behavior during the high energy phase:

- The turbulence created during the high energy phase will resuspend all of the sludge initially contained at the bottom of the suppression pool.

- The turbulence is strong enough to keep the sludge as well as the fibrous debris in suspension throughout the high energy phase.

- The turbulence also results in further disintegration of fibrous debris. ${ }^{5}$

Although these insights were gained from experiments simulating moderate energy chugs typical of a MLOCA, they are judged to be valid for condensation oscillations that characterize a LLOCA. Furthermore, the results would be applicable to both Mark I and Mark II containments. Applicability of these results to Mark III containments where the vent pipes are arranged in the horizontal direction should be carefully assessed prior to using the results in a Mark III study.

${ }^{5}$ The NRC experiments demonstrated that shreds of several inches in size could be reduced to small shreds within minutes after being subjected to chugs of moderate energy ( $1.6 \mathrm{~s}$ period and 3.8 $\mathrm{ft}(1.2 \mathrm{~m})$ water displacement).

\section{B.6.2.2 Settling Rates for Post-High Energy Phase}

After cessation of the high-energy phase, the suppression pool returns to quiescent pool conditions. ${ }^{6}$ During the post-high energy phase, the residual turbulence in the pool is expected to decay, allowing for sedimentation of the suspended debris. As a result, it has been postulated that sedimentation would play an important role in delbris removal from the pool during this stage of accident progression. In the NRC experiments, the suppression pool was initially brought to a fully mixed condition by simulated chugging. After 9.6 minutes, the chugging was terminated and the turbulence in the suppression pool was allowed to decay naturally. Visual observations revealed that soon after termination of chugging, the debris began to settle to the pool floor. Water samples were drawn from five locations in the suppression pool at pre-determined intervals to measure debris concentrations. The debris concentrations were then used to estimate settling rates for each species, i.e. fibrous debris and particulate sludge. Figure B-7 presents settling velocities measured from tests ${ }^{7} \mathrm{~A}-1$, A-1R, A-2, and A-2R for fibrous debris of shape classes 3 and 4 , and shape classes 5 and 6 . Figure B-8 presents settling velocities for Sludge A particles measured from tests A-3 and B-8. Figure B-9 presents settling velocities for sludge and fiber mixtures of different mass ratios measured from the remaining tests. Based on these measurements the following conclusions can be drawn:

1. The fibrous debris undergo further destruction under the influence of shear forces induced by eddies created by the chugging. The fibrous debris usually resembled shape classes 1,2 and 3 at the end of the chugging tests. This visual observation was further confirmed by settling velocity measurements; the measured settling velocities of $0.1-10 \mathrm{~mm} / \mathrm{s}$

\footnotetext{
${ }^{6}$ This assumption may not be accurate for BWRs that are equipped with pool mixers or other systems that are intended to mix the pool water by turbulent means to prevent thermal stratification. Such pool mixers can be found in some European BWIRs and some of the Mark III US BWRs.
}

${ }^{7}$ See Appendix E for description of each test case and the characterization of the simulated BWR Sludge A. 
Appendix B
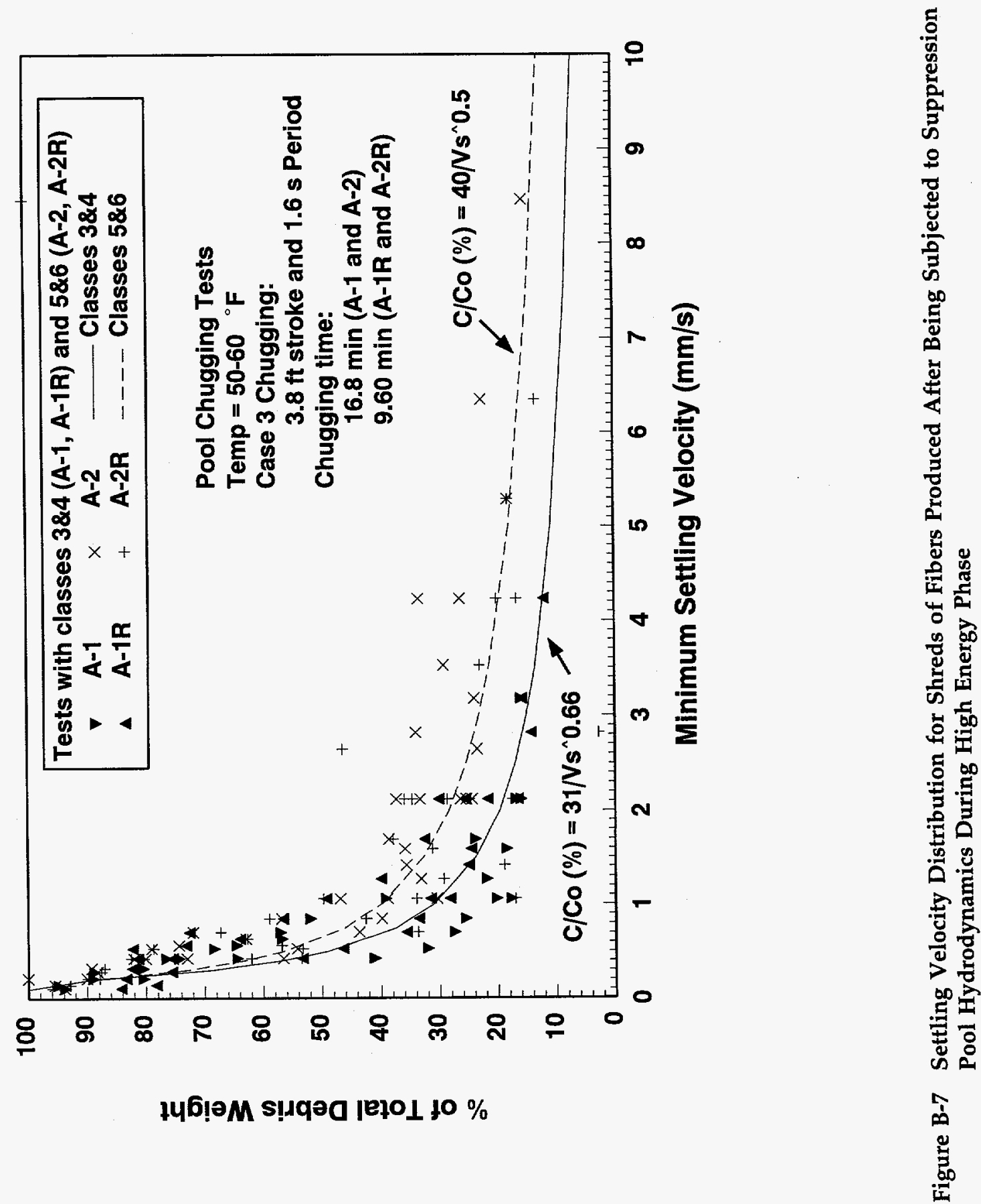


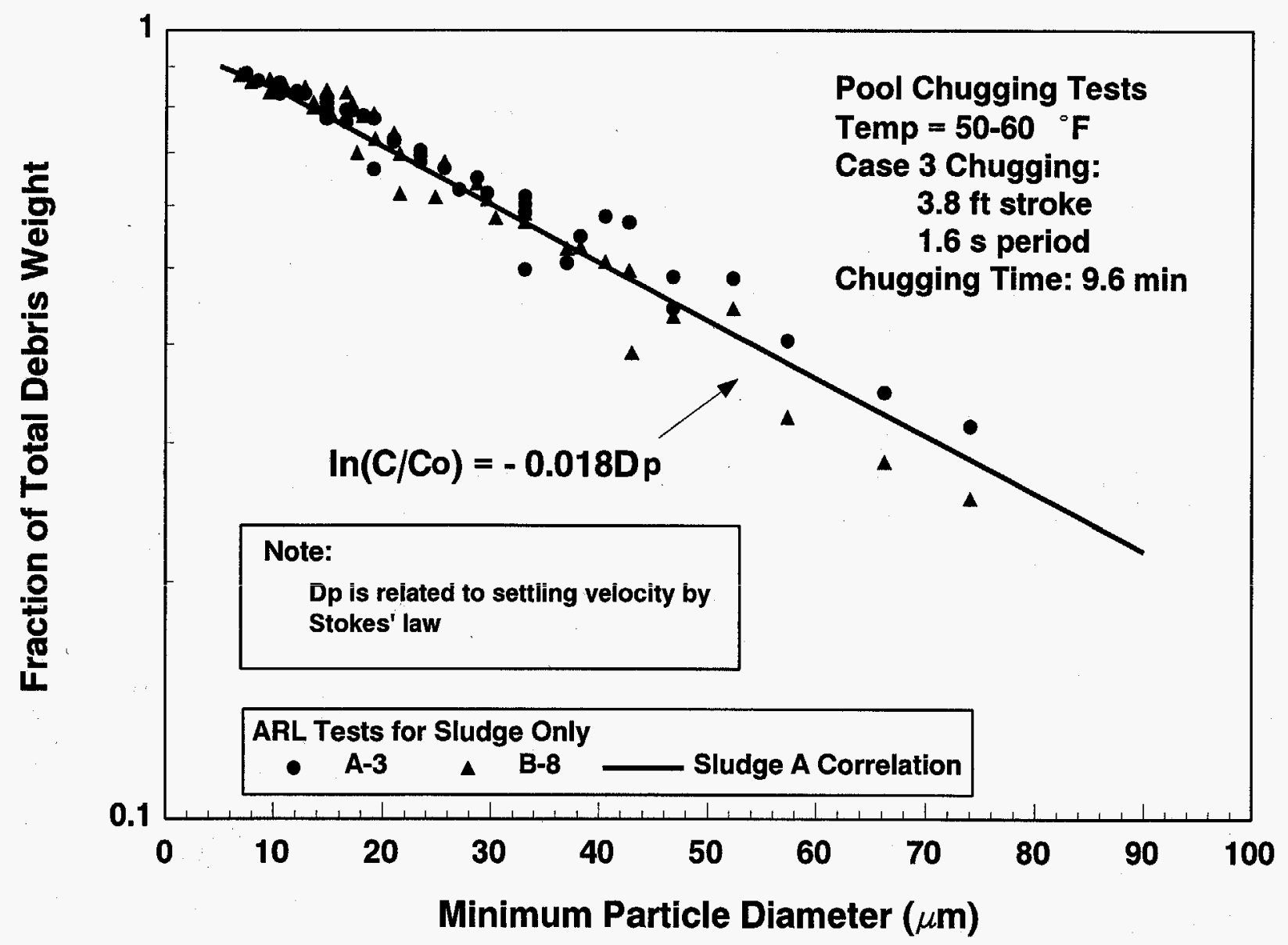


Appendix B
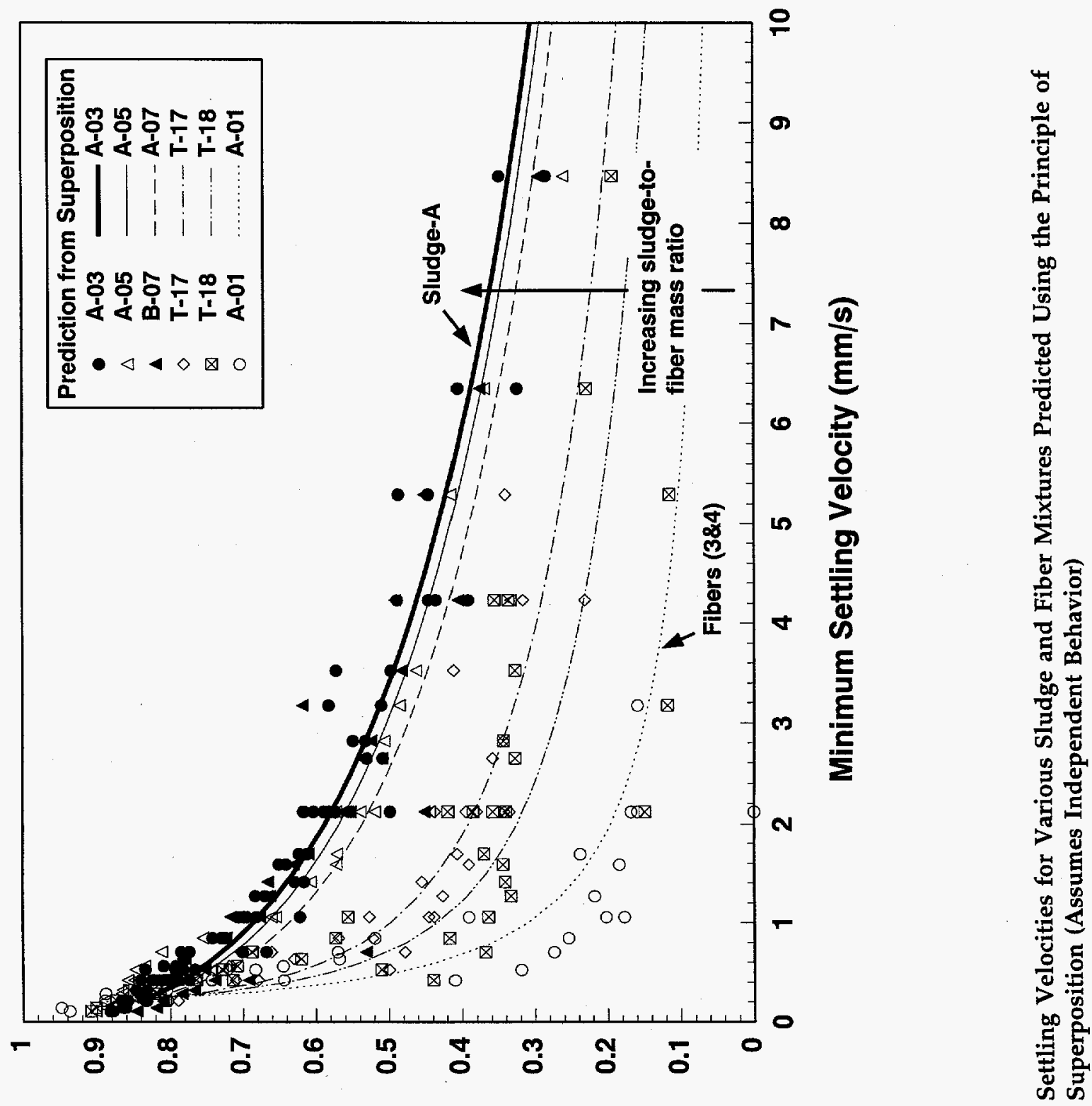

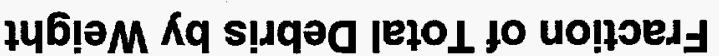

离 
fall in the range of previously established settling velocities for shape classes 1,2 and 3. Figure B-7 also shows that the settling velocities are weakly dependent on the shape class of the debris initially added to the pool.

2. Two different equations were developed each for Classes 3 \& 4 and Classes 5 \& 6:

$$
\begin{aligned}
& C / C_{o}(\%)=31 /\left(V_{s-t \text { test }}^{3 \& 4}\right)^{2 / 3} \\
& C / C_{o}(\%)=40 /\left(V_{s-t e s t}^{5 \& 6}\right)^{1 / 2}
\end{aligned}
$$

where,

$$
\begin{array}{ll}
\mathrm{V}_{\mathrm{s} \text {-test }} & \begin{array}{l}
\text { is the settling velocity } \\
\text { measured in the tests in } \\
\text { mm/s }
\end{array} \\
\mathrm{C} / \mathrm{C}_{\mathrm{o}}(\%) & \begin{array}{l}
\text { is the mass percentage of } \\
\text { debris with settling velocity } \\
\text { greater than } \mathrm{V}_{\mathrm{s} \text {-test }}
\end{array}
\end{array}
$$

In both cases more than $60 \%$ of the total debris by mass exhibit settling velocities less than $1 \mathrm{~mm} / \mathrm{s}$. Such low settling velocities suggest that fibrous debris require considerable time to settle in the suppression pool.

3. The NRC experiments demonstrated that on average the sludge particles settle faster than the fibrous shreds. About $30 \%$ of the sludge particles by mass exhibit settling velocities in excess of $10 \mathrm{~mm} / \mathrm{s}$, and about $60 \%$ of sludge particles, also by mass, have settling velocities in excess of $2 \mathrm{~mm} / \mathrm{s}$. However, about $10 \%$ of the sludge particles have settling velocities below $0.1 \mathrm{~mm} / \mathrm{s}$. The median particle settling velocity is about 3 $\mathrm{mm} / \mathrm{s}$.

The relationship for sludge concentration versus particle diameter is given by:

$$
\ln \left(C / C_{o}\right)=-0.018 D_{p}
$$

where,
$D_{p}$ is the minimum particle diameter related to the settling velocity via Stokes' law as:

$$
V_{s-t e s t}^{\text {sludge }}=g D_{p}^{2} \frac{\left(\rho_{p}-\rho_{w}\right)}{18 \mu}
$$

where,

$$
\begin{array}{ll}
V_{s-\text { sest }}^{\text {sludge }} & \begin{array}{l}
\text { is terminal velocity for sludge } \\
\text { particles measured in the } \\
\text { experiments }
\end{array} \\
\mathrm{g} & \begin{array}{l}
\text { is the acceleration due to } \\
\text { gravity }\left(\mathrm{m} / \mathrm{s}^{2}\right)
\end{array} \\
\rho_{\mathrm{p}} & \begin{array}{l}
\text { is the sludge particle density } \\
\left(\mathrm{kg} / \mathrm{m}^{3}\right)
\end{array} \\
\rho_{\mathrm{w}} & \begin{array}{l}
\text { is the water density }\left(\mathrm{kg} / \mathrm{m}^{3}\right) \\
\text { is the water viscosity (Pa.s) }
\end{array}
\end{array}
$$

The minimum diameter of the sludge particles present at the NRC experiments appear to vary from $6 \mu \mathrm{m}$ to greater than $100 \mu \mathrm{m}$. As discussed in Appendix E, the shift toward this higher particle size distribution, in comparison with the particle size distribution provided by the BWROG in Table B-4 [Ref. B.17], is likely due to agglomeration.

4. The settling velocities of sludge and fiber mixtures increase as the sludge-to-fiber mass ratio increases (see Figure B-9). The settling velocities for such mixtures can be estimated via superposition by assuming that fibers and sludge settle independently of each other.

In theory, the regression fits to the data, shown in Figures B-7 and B-8, can be used to estimate volume-averaged concentrations of fibrous and particulate debris in the suppression pool. The following section summarizes the plant-specific considerations that should be included in application of the test data to the reference plant.

\section{B.6.2.3 Applicability to BWRs}

Although considerable attention was given to accurately scale the NRC experiments to 
appropriately simulate various plant phenomena [Ref. B.16], significant differences exist between the test facility and the reference plant suppression pool. These differences include the following:

1. The test facility does not simulate the condensation oscillations that characterize a LLOCA $^{8}$.

2. In the tests, no additional turbulent energy was added to the pool during the post-high energy phase; however, in most BWRs additional turbulence is introduced to the pool via the break flow that is continually added to the pool. Additional turbulent energy can be added to the pool if the suppression pool cooling system, including the suppression pool sprays, were initiated.

3. The sludge particle size distribution used in the experiments appears to be much larger than the sludge size distribution recommended by the BWROG (Table B-4).

The effect of the differences between the test set-up and the reference plant was judged to be insignificant during the high energy phase. For example, the test results suggest that little, if any, potential exists for settling during the in-phase chugging simulated in the test facility. It is then logical to assume that debris settling is very unlikely during condensation oscillations in the reference plant, since the condensation oscillations input more turbulent energy per unit volume over a shorter period of time, resulting in even higher levels of turbulence. As a result, debris settling is highly unlikely in the reference plant suppression pool during the high energy phase, regardless of the break size, i.e.,

$$
\begin{aligned}
& V_{s}^{I}(t)=0 \quad \text { for } I=1, N_{F} \text { and } 0<t<t_{\text {blowdown }}, \\
& V_{s}^{I}(t)=0 \quad \text { for } I=N_{F}+1, N \text { and } 0<t<t_{\text {blowdown }}
\end{aligned}
$$

During the post-high energy phase, the differences between the test facility and the reference plant

\footnotetext{
${ }^{8}$ Note that the majority of the postulated breaks in the reference plant are Large Break LOCAs.
}

suppression pool were judged to be significant. It is possible that settling rates measured in the test facility are larger than those expected in the reference plant because the tests do not simulate ECCS flow through the downcomers.

Based on existing knowledge, the magnitude of this difference between the tests and the BWR pools is not easy to estimate, requiring some engineering judgment. Based on scoping analyses, it was judged that settling rates in BWRs will be no lower than $50 \%$ of those corresponding to the test facility provided suppression pool cooling systems are not turned on. Settling velocities for BWR suppression pool debris and sludge, $V_{s}$, can then be estimated using the following equations:

$$
\begin{aligned}
& V_{s}^{I}=0.5 V_{s \text {-test }}^{3 \& 4} \text { for } I=1, N_{F} \text { and } t_{\text {blowdown }}<t<t_{\text {recirc }} \\
& V_{s}^{I}=0.5 V_{s-t e s t}^{\text {sludge }} \text { for } I=N_{F}+1, N \text { and } t_{\text {blowdown }}<t<t_{\text {recin }}
\end{aligned}
$$

Settling velocities used in this study for the fibrous debris were based on settling velocities measured for shape classes 3 and 4 (Eq. B-12a). These settling velocities may not necessarily be the same for all types of fibers.

Also, equations B-16a and B-16b may not be applicable if the suppression pool cooling systems are turned on. For this case, the settling velocity would probably be closer to zero.

\section{B.6.2.4 Incorporation into BLOCKAGE}

Several alternatives were considered to input Equations B-12 and B-13 into BLOCKAGE. Of all the alternatives considered, the usage of settling groups was judged to provide the most versatile and accurate means of inputing settling characteristic data to BLOCKAGE. A total of twenty-four settling groups (or twelve for fibrous debris and twelve for particulates) were used to closely reproduce Equations B-12 and B-13. Each settling group is associated with an average settling velocity and a narrow bin width over which the settling velocity varies. Once these groups were selected, the fraction of the debris belonging to each of these groups can be directly calculated using Equations B-12 and B-13 for fibrous and particulate 
debris, respectively. Tables B-5 and B-6 present the distribution factors and settling velocities for each class of fibrous and particulate debris. As shown in these tables, each size class is characterized by two parameters, $G^{I}$ and $V_{s}^{I}$, defined as the mass distribution factor and average settling velocity. These tables were directly input to BLOCKAGE as part of the input files. It should be clearly understood that Tables B-5 and B- 6 are not generic, in that they may not be interpreted as being applicable to all plants. In particular, Table B-5 is valid for debris generated for steel jacketed NUKON ${ }^{\mathrm{TM}}$ insulation. The table may be quite different if the same information is sought for other insulations, such as Thermal Wrap ${ }^{\circledR}$, Mineral wool, or RMI. Similarly, the size distribution data presented in Table B-6 may not be applicable to all the plants. In some plants the debris may be finer as indicated by the BWROG data (see Table B-4). In other plants the sludge particles may be larger in size as suggested by PP\&L survey [Ref. B.24]. Tables B-5 and B-6 are not presented to substitute for plant specific analyses. Instead, they are presented to describe the mans by which such information can be derived into usable form for BLOCKAGE.

\section{B.7 Filtration of Debris by the Strainer}

Assuming homogeneous mixing of debris in the suppression pool, the quantity and composition of debris reaching the strainer can be estimated using Equations B-2 and B-3. The ECCS flow rate as a function of time after a LOCA is an important parameter that should be provided as input to the model. This information was obtained from Reference B.30 for the reference plant. Figure B-10 plots ECCS flow rate after a LLOCA and MLOCA as

Table B-5 Settling Groups for the Fibrous Debris Used in BLOCKAGE

\begin{tabular}{|c|c|c|}
\hline Fiber Settling Group Identifier & Settling Velocity (ft/s) & Distribution Factor \\
\hline Fiber 1 & $6.5306 \mathrm{E}-04$ & 0.43067 \\
\hline Fiber 2 & $1.6443 \mathrm{E}-03$ & 0.14922 \\
\hline Fiber 3 & $2.6061 \mathrm{E}-03$ & 0.11011 \\
\hline Fiber 4 & $4.1303 \mathrm{E}-03$ & 0.08125 \\
\hline Fiber 5 & $6.5461 \mathrm{E}-03$ & 0.05995 \\
\hline Fiber 6 & $1.0375 \mathrm{E}-02$ & 0.04424 \\
\hline Fiber 7 & $1.6443 \mathrm{E}-02$ & 0.03265 \\
\hline Fiber 8 & $2.6061 \mathrm{E}-02$ & 0.02409 \\
\hline Fiber 9 & $4.1303 \mathrm{E}-02$ & 0.01778 \\
\hline Fiber 10 & $6.5461 \mathrm{E}-02$ & 0.01312 \\
\hline Fiber 11 & $1.0375 \mathrm{E}-01$ & 0.00968 \\
\hline Fiber 12 & $2.4606 \mathrm{E}-01$ & 0.02725 \\
\hline Total & & 1.0000 \\
\hline
\end{tabular}




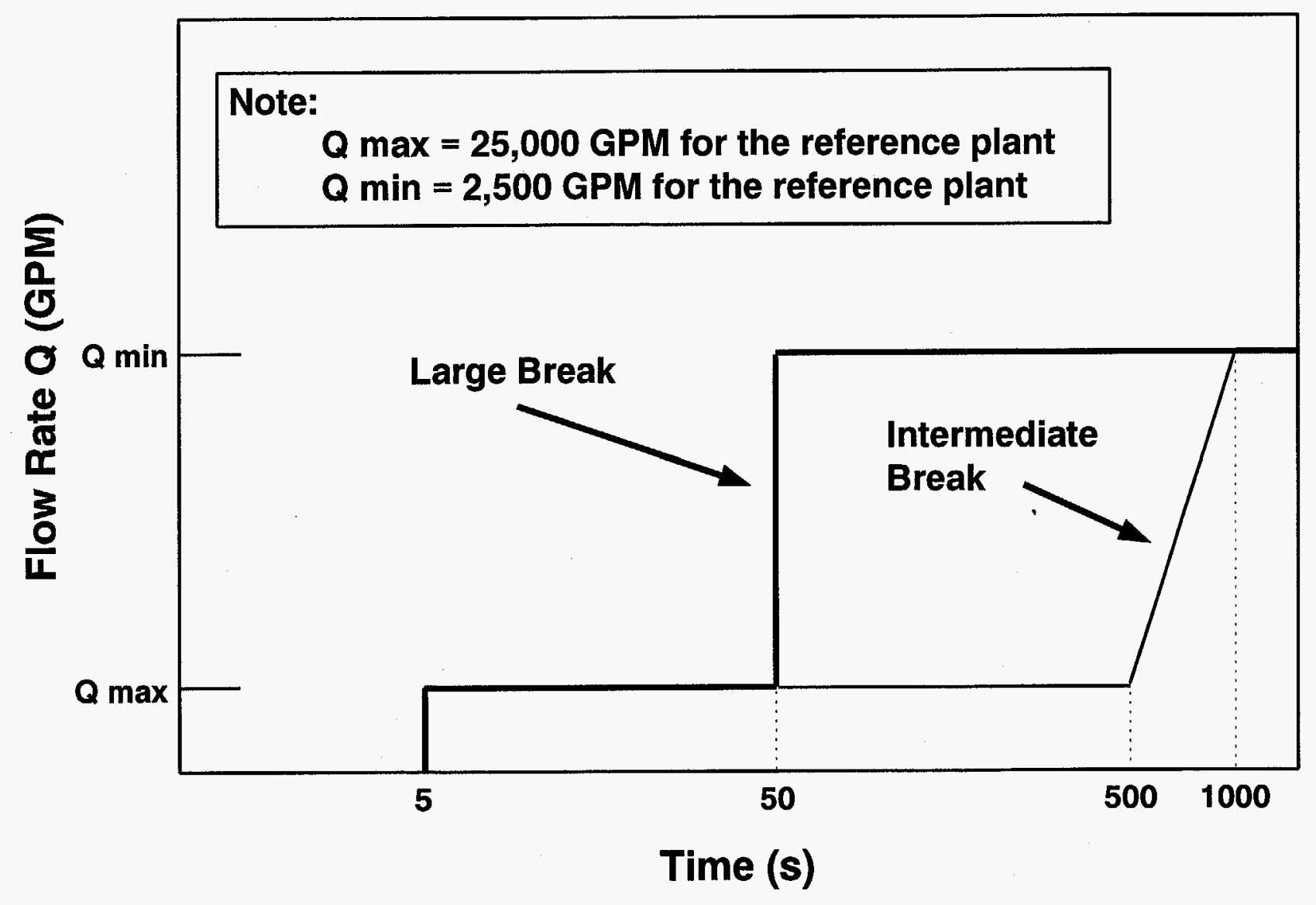


Table B-6 Settling Groups for the Suppression Pool Particulates Used in BLOCKAGE ${ }^{(1)}$

\begin{tabular}{|c|c|c|c|}
\hline $\begin{array}{c}\text { Particle Settling Group } \\
\text { Identifier }\end{array}$ & $\begin{array}{c}\text { Diameter }^{(2)} \\
(\mu \mathrm{m})\end{array}$ & $\begin{array}{c}\text { Settling } \\
\text { Velocity }(\mathrm{ft} / \mathbf{s})\end{array}$ & Distribution Factor \\
\hline Sludge 1 & 9 & $6.5306 \mathrm{E}-04$ & 0.2090 \\
\hline Sludge 2 & 14 & $1.6443 \mathrm{E}-03$ & 0.0466 \\
\hline Sludge 3 & 18 & $2.6061 \mathrm{E}-03$ & 0.0548 \\
\hline Sludge 4 & 23 & $4.1303 \mathrm{E}-03$ & 0.0633 \\
\hline Sludge 5 & 29 & $6.5461 \mathrm{E}-03$ & 0.0715 \\
\hline Sludge 6 & 37 & $1.0375 \mathrm{E}-02$ & 0.0785 \\
\hline Sludge 7 & 47 & $1.6443 \mathrm{E}-02$ & 0.0832 \\
\hline Sludge 8 & 59 & $2.6061 \mathrm{E}-02$ & 0.0844 \\
\hline Sludge 9 & 74 & $4.1303 \mathrm{E}-02$ & 0.0810 \\
\hline Sludge 10 & 93 & $6.5461 \mathrm{E}-02$ & 0.0725 \\
\hline Sludge 11 & $\geq 100$ & $1.9162 \mathrm{E}-01$ & 0.1554 \\
\hline
\end{tabular}

Notes:

(1) The finer size/settling groups were used to reproduce Equation B-13.

(2) Particle diameters were estimated using Stokes' law (Eq. B-14) assuming calm pool conditions.

a function of time for the reference plant. ${ }^{9}$ This flow rate is based on ECCS pump delivery capabilities as they are effected by the pressure in the reactor system. The plots in Figure B-10 do not reflect degradation of pump performance which would result from the loss of NPSH due to suction strainer blockage with accumulated debris. They assume that pumping rates remain constant until the NPSH limit is reached. Although this assumption is not expected to alter the results significantly for most plants, it is nevertheless important to validate the assumption for the particular plant of interest. In particular, attention should be paid to ensure that the ECCS pump required NPSH versus flow curve is fairly flat in the flow range of interest.

${ }^{9}$ Figure B-10 closely resembles similar curves for Mark II and Mark III plants (Ref. B.30).
Only a fraction of the debris reaching the strainer would be trapped or filtered by the strainer to form the debris cake on the strainer surface. Accurate estimation of this fraction, referred to as the filtration efficiency, for each debris species is vital since the head loss across the bed is a strong function of the quantity and type of debris contained in the debris cake. In this report, filtration efficiency is defined as the fraction of the debris approaching the strainer that is filtered by and contained in the debris cake. Several tests, with limited scope, were performed as part of the NRC experiments to provide bounding estimates for the filtration efficiency for two major debris species: fibers and sludge. Visual observation of the debris bed formation, aided by time-dependent concentration measurements, formed the basis for the filtration model. 
Appendix B

\section{B.7.1 Phenomenological Basis for the Filtration Model}

As observed in the NRC experiments, all the fibrous material reaching the strainer would be trapped by the strainer, except for a small quantity of very finely disintegrated fibrous debris (i.e., shape classes $1 \& 2$ ) that may escape during the initial stages of debris bed formation. During these initial stages, the debris beds would be very thin and non-uniform or lumpy. The presence of these lumps on the strainer surface causes redistribution of flow resulting in more flow through the open areas where the flow resistance is small. As a result of this redistribution, the newly arriving flocks of insulation would be carried to the open parts of the strainer where they are deposited. In addition, the non-uniformity also induces cross-flow that seems to cause radial movement of the debris from the thicker regions to the thinner regions. These effects ultimately promote the formation of a fairly uniform fibrous debris bed, especially for large bed thicknesses. In the majority of the experiments, it appeared that uniform beds are a reasonable approximation for bed theoretical thicknesses greater than $1 / 8$ inch $(3.2 \mathrm{~mm})$.

The bed formation is slightly different in the presence of sludge. In this case, initially a thin fibrous layer was formed on the strainer, but the sludge particles easily penetrated this layer, apparently because the fibrous debris layer did not have the required structure and/or strength to filter these particles. During these initial stages, visual observations as well as concentration measurements, suggested that the majority of the particles

penetrated the bed. With time, however, continuous addition of fibrous debris, if available, will provide the required structure and the bed will start to filter out the sludge particles. Based on concentration traces (see Appendix E), it can be concluded that the filtration efficiency was initially very small but increased rapidly with increasing bed thickness. Although no data is shown here explicitly, the filtration efficiency was found to be a function of the particle size distribution. ${ }^{10}$ The PP\&L experiments

\footnotetext{
${ }^{10}$ This result is also consistent with observations reported in Reference B.18.
}

[Ref. B.24] suggest that filtration efficiency in some cases (with particle sizes $>75 \mu \mathrm{m}$ ) can approach one, however, in the conduct of the NRC experiments, a filtration efficiency of one was rarely achieved.

\section{B.7.2 Filtration Model for Fibrous Debris}

The NRC experiments demonstrated that almost all the fibrous debris approaching the strainer are expected to be trapped by the strainer, except for a small quantity of class 1 and 2 fibers that escape when the debris layer does not bridge all of the strainer holes. However, the fraction of debris falling into these classes is very small and the strainer holes are expected to be quickly bridged. As a result, it is fairly accurate to assume a filtration efficiency of one for the fibrous insulation debris.

\section{B.7.3 Filtration Model for Particles}

Figures B-11 and B-12 present measured values for filtration efficiencies as a function of approach velocity and debris bed theoretical thickness, respectively. These filtration efficiencies were estimated using concentration measurements obtained during the first cycle after the cake was formed. Further details on the experimental procedure and measurement technique are summarized in Appendix E. As evident from Figures B-11 and B-12, the filtration efficiency appears to be a weak function of approach velocity and debris bed thickness; any variations can be interpreted to be within the uncertainty bounds. This conclusion appears to be valid over a velocity range of 0.15 to $0.5 \mathrm{ft} / \mathrm{s}(0.05$ to $0.15 \mathrm{~m} / \mathrm{s})$ and a theoretical thickness of 0.25 to 1.0 inch (6.3 to 25 $\mathrm{mm})$. Over this velocity and thickness range, the filtration efficiency was estimated to be $25-30 \%$ with the exception of one test for which a filtration efficiency of $50 \%$ was measured. To conservatively bound the experimental values, a value of $50 \%$ was used for all thicknesses higher than 1/4" $(6.4 \mathrm{~mm})$. Usage of $50 \%$ efficiency for bed thicknesses lower than $1 / 4$ " was deemed overly conservative. As a result, a linear variation for the filtration efficiency from 0 to $50 \%$ was used for bed theoretical thicknesses lower than 1/4". Figure B-13 illustrates the filtration efficiency curve used in the model as a function of bed theoretical thickness. 
Appendix B

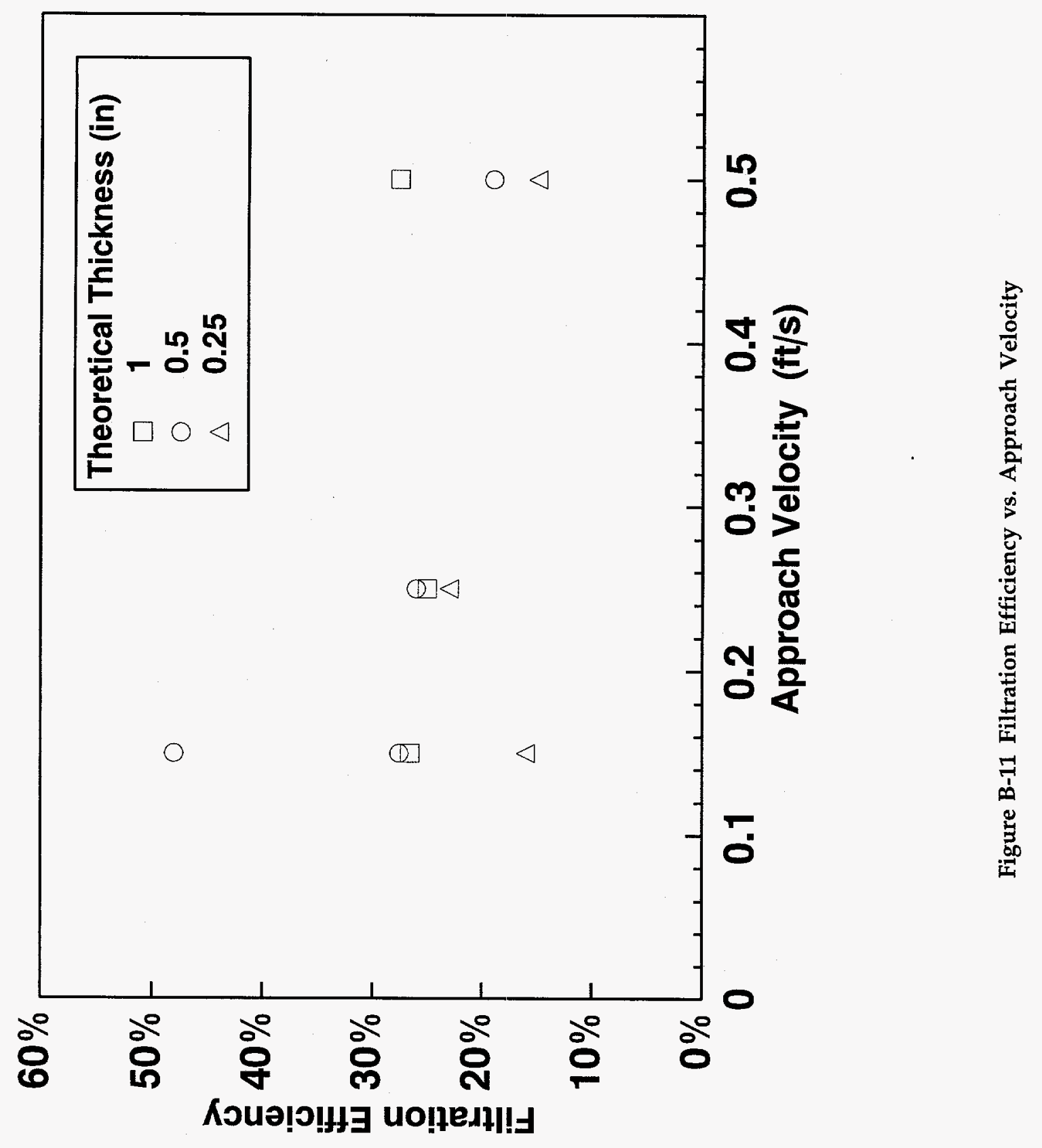




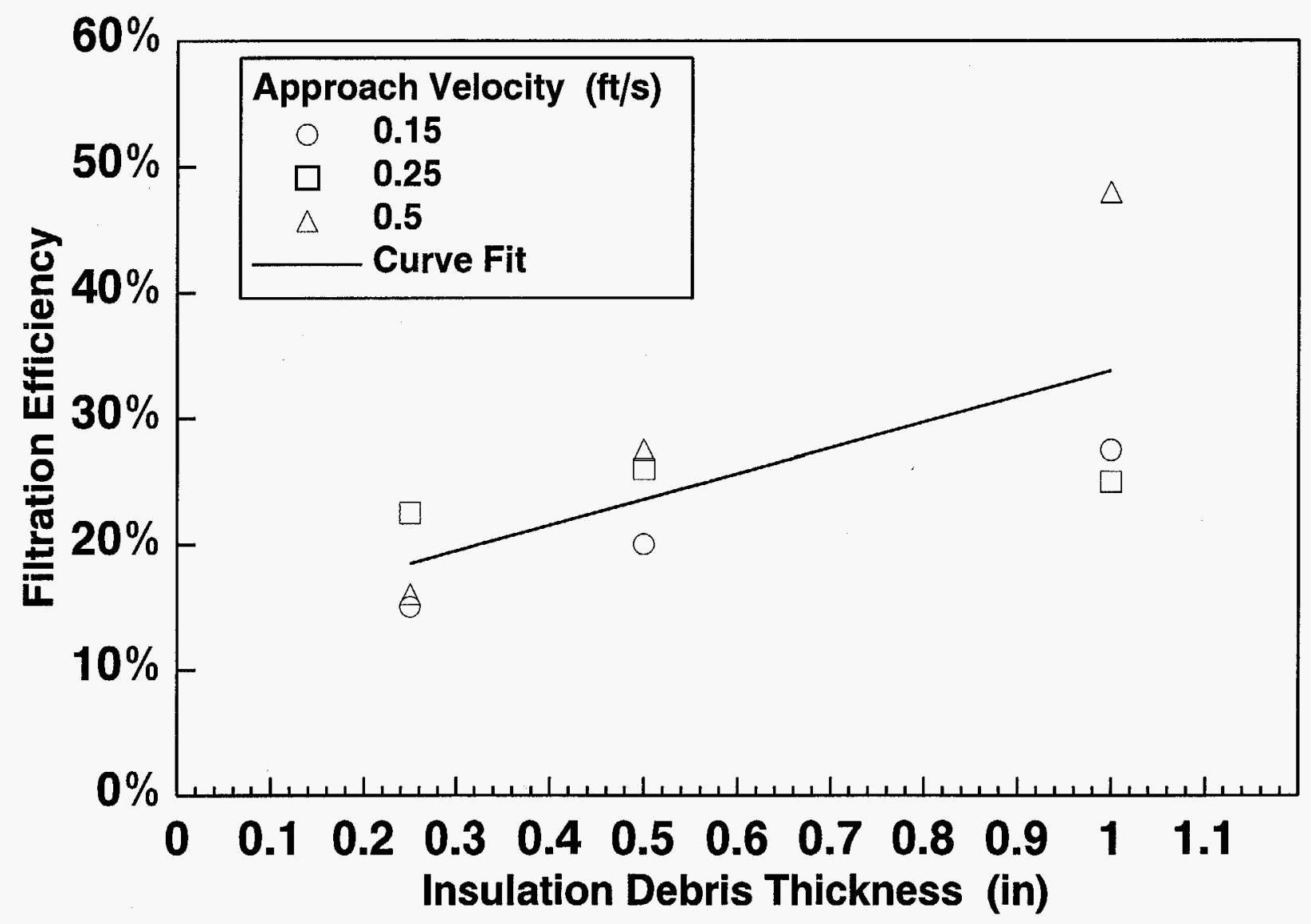

Figure B-12 Filtration Efficiency For Fiber and Sludge Debris Species as a Function of Bed Theoretical Thickness. (See Appendix E for Experimental Data). 


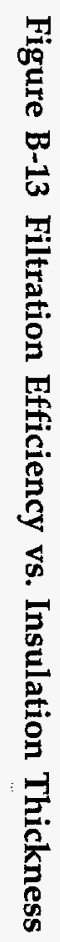

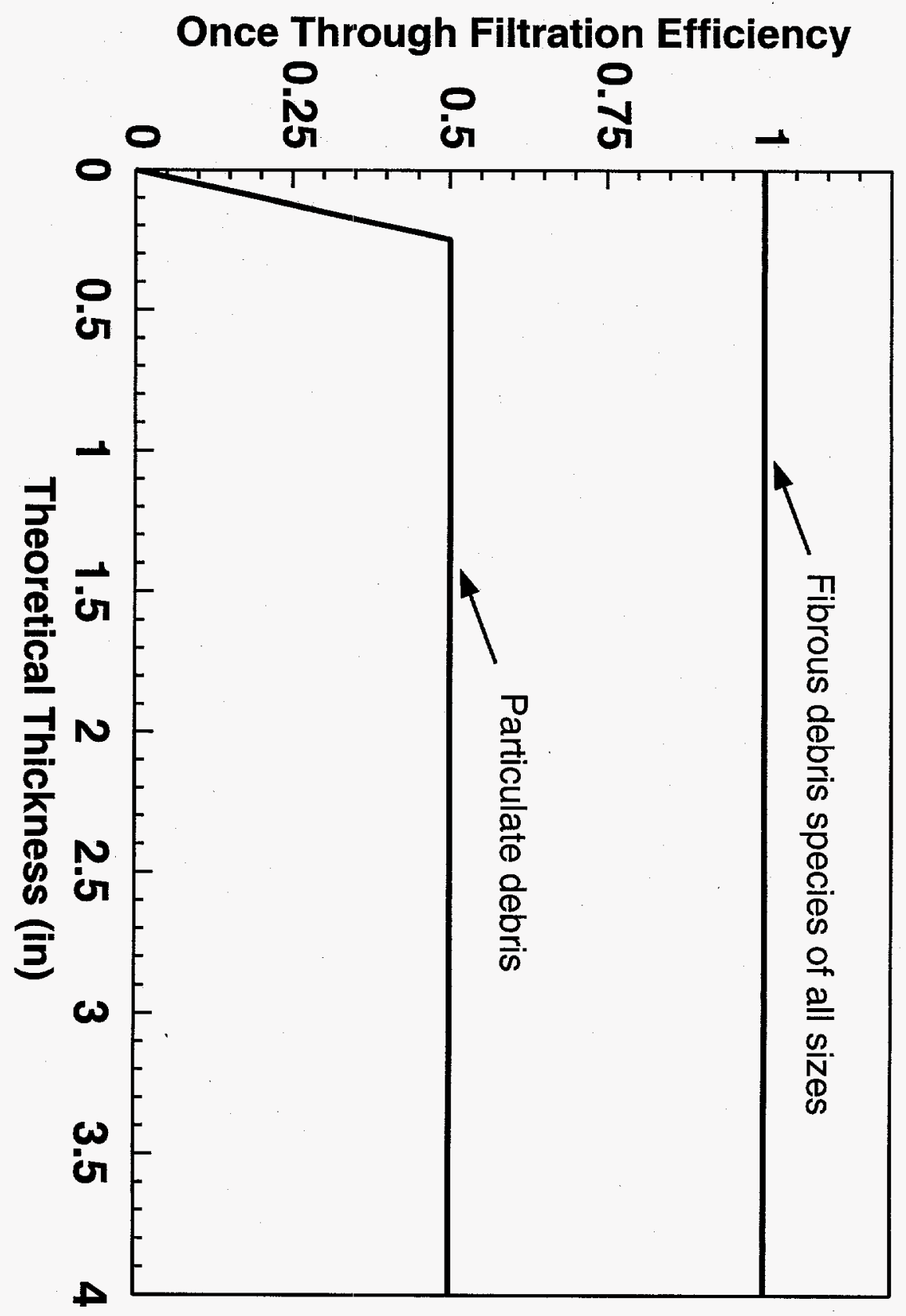


The particulate debris passing through the strainer will be carried by the ECCS flow as it cycles through the ECCS piping, the reactor vessel and associated piping, out through the break, into the drywell and back to the suppression pool. Some of the debris will settle out in regions of low flow velocities and turbulence. Likely locations for localized debris settling inside the reactor coolant system include: the bottom of the lower reactor vessel head, inside the control guide tubes and fuel channels, upper plenum steam separators and dryers, and the downcomer region outside the jet pumps. A system retention factor was adopted for this study to account for returning particulate debris back to the suppression pool. Returning all the debris to the suppression pool (i.e., retention factor of 0 ) is conservative since debris will certainly be retained either in the RCS or in the drywell. Retaining all debris within the systems (retention factor of 1.0) is not realistic since scoping calculations of the free ECCS stream velocity through the entire system does not support significant settling. A mid-range system retention factor of 0.5 was selected for this study and the sensitivity of this parameter is evaluated in the parametric analysis (Appendix C).

\section{B.7.4 Filtration Model Limitations}

The filtration model developed is based on a limited number of experiments conducted as part of this study. The model is expected to provide a reasonable upper bound estimate for the oncethrough filtration efficiency for sludge. An important limitation of the model is that its predictions are insensitive to the particle diameter and incoming effluent concentration. This is a serious limitation considering that filtration efficiencies are known to be strong functions of particle size. For example, the PP\&L experimental data [Ref. B.24] based on particle sizes $\geq 75 \mu \mathrm{m}^{11}$ suggests that close to $100 \%$ of the particles would be filtered by the debris cake. That result differs markedly from the $50 \%$ efficiency obtained for the present particle size distribution between 1-30 $\mu \mathrm{m}$.

\footnotetext{
${ }^{11}$ The PP\&L sludge particle size survey suggests that in some BWRs the sludge particle size may be different than the sludge size distribution suggested by the BWROG survey of suppression pool sludge.
}

The filtration model can, however, be refined in the future to reflect these trends if additional supporting data becomes available. Further discussions are presented in Appendix E.

\section{B.7.5 Filtration Model Implementation in BLOCKAGE}

The filtration model implemented in BLOCKAGE to estimate fibrous debris layer theoretical thickness and sludge-to-fiber ratio in the debris cake as a function of time is based on Equations B-2 and B-5.

Figure B-13 displays the simplified filtration efficiency curve presently implemented in BLOCKAGE. This curve can be modified in the future to handle such issues as variation of filtration efficiency with sludge particle size and bed thickness. In this context, it should be noted that the filtration model in BLOCKAGE was developed to be versatile to handle such issues as variation of filtration efficiency with debris type and size, and with the bed thickness. Due to lack of experimental data, Figure B-13 was used as the filtration model for all size classes, i.e., the input was prepared such that the same filtration efficiency curve is used for all size classes. However, if data becomes available, the future users may input a separate filtration efficiency curve for each of the size classes.

\section{B.8 Head Loss Model}

Estimation of head loss across the debris bed formed on the strainer surface is a critical component of the present study. Due to its importance, considerable effort was devoted as part of USI A-43 to obtain the head loss data for a variety of fibrous insulation materials used in PWRs [Ref. B.11 and B.32]. A set of empirical correlations, based on this data, were summarized in NUREG-0897. Since issuance of NUREG-0897, additional experiments were carried out both in the U.S. and in Europe to measure head loss across the debris beds consisting of pure fibers and sludge-fiber mixtures. Once again, another set of correlations were developed which were also entirely empirical in nature [Ref. B18, B.24, B.33, B.34]. Figures B-14 and B-15 compare predictions of various correlations for pure fiber beds and mixed beds, respectively. As evident from these figures, 


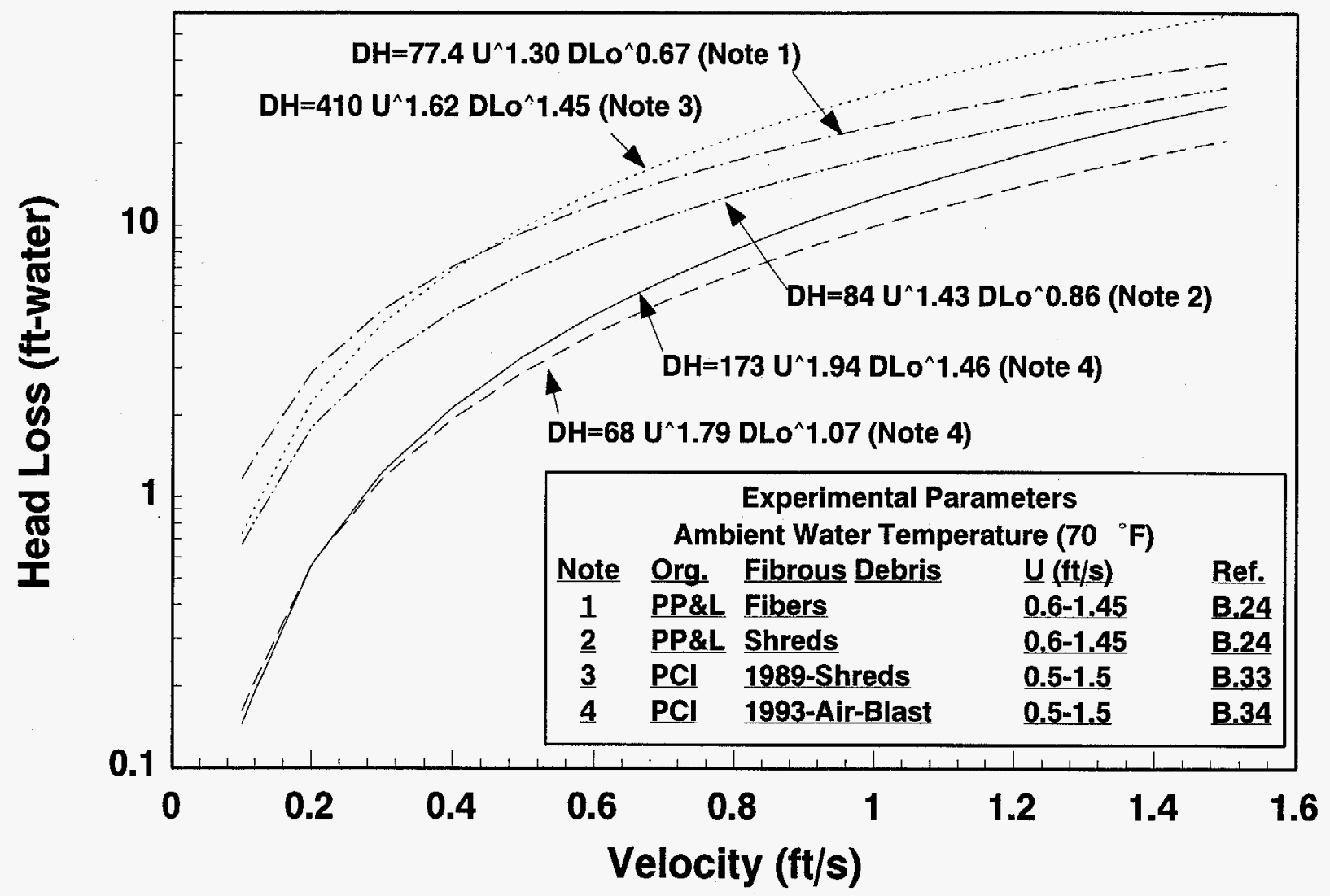




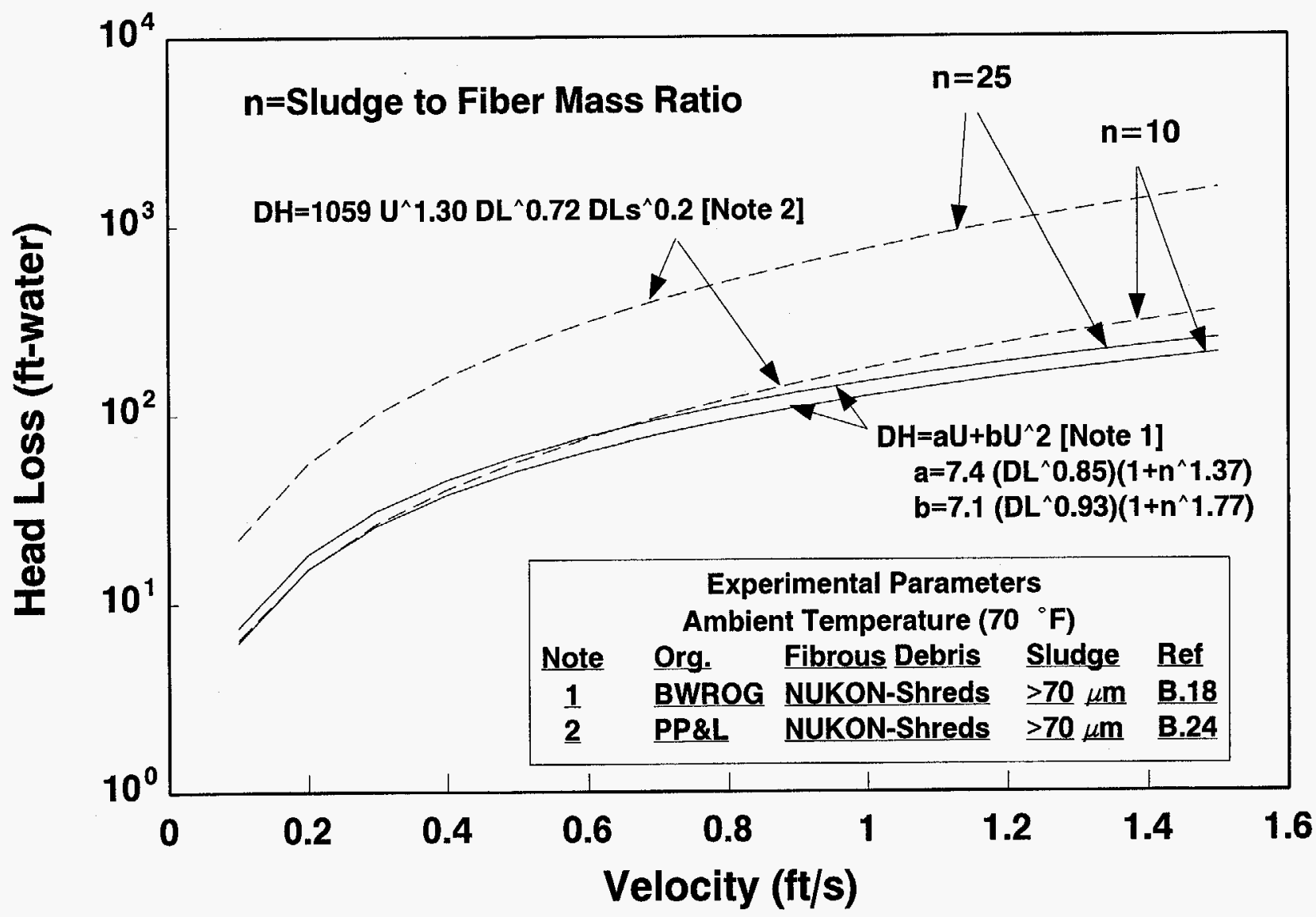


considerable scatter exists in the head loss predictions by different correlations, which raises questions related to accuracy/ applicability of each of these equations. Careful examination of the experimental data would reveal that this scattering can be attributed to:

1. Differences in the shape class of debris used. Some of the experiments used large pieces of insulations while the others used "loosely attached fibers." In terms of shape classes presented in Table B-3, some investigators used pieces larger than class 6 , while others used classes $3 \& 4$. A variety of other uncharacterized intermediate classes were also used for both pure fiber beds and mixed beds.

2. Purely empirical forms were used to correlate the experimental data which seriously limited applicability beyond the original range of parameters for which the equation was developed.

To avoid these drawbacks, a set of head loss tests were conducted as part of the NRC experiments using fibrous and sludge debris that was judged to be representative of the type of debris reaching the strainer. Furthermore, a semi-theoretical approach was used to develop the correlation. The following sections summarize the important findings of the NRC experiments and presents the formulation of the semi-theoretical head loss model developed by this study.

\section{B.8.1 Phenomenological Basis for the Head Loss Model}

Visual observation of debris bed formation on the strainer surface in the NRC experiments [Ref. B.16], formed the basis for the head loss model developed in this study. As observed in these experiments, both the pure fibrous beds and the mixed beds are compressible. For example, the actual bed thickness in almost all cases is lower than the theoretical thickness calculated based on 'as-fabricated' material packing density. Furthermore, the bed thickness decreases with increasing flow velocity, indicating an inverse relationship between the bed thickness and the pressure drop across the bed. The magnitude of compression appears to be a function of the structure of the debris shreds. The beds formed of shreds (classes $3 \& 4$ ) are more compressible compared to the beds constructed of fibers in classes $5 \& 6$. In the former case, the debris beds were seen to be compressed to about onequarter of the theoretical thicknesses at high flow velocities. On the other hand beds formed of classes $5 \& 6$ were rarely compressed to half the theoretical thickness. ${ }^{12}$

Finally, microscopic examination of pure fiber beds revealed that, in general, the fiber relative direction with respect to the flow is perpendicular (see Figure B-16). The beds are fairly uniform in structure both vertically and horizontally. Mixed beds, however, appear slightly different (see Figure B-17). All larger particles appear to be intermixed with the fibers, resembling beds formed by straining. On the other hand, the smaller particles appear to adhere to the outer surface of the bed rather than being deposited in between the fibers. This later form of deposition resembles that observed usually in aerosol filters. In either case, it can be concluded that the mixed beds are also fairly uniform and can be assumed to be formed of fibers intermixed with the sludge particles, except for a thin region close to the strainer where the bed is mostly formed of fibers only.

\section{B.8.2 Semi-Theoretical Head Loss Model}

The formation of a debris layer on the strainer surface results in a situation similar to flow through porous media, characterized by large pressure drops. As suggested initially by Muskat [Ref. B.35] and confirmed later by Ward [Ref. B.36], the pressure drop across a fibrous bed can be expressed as:

$$
\frac{\Delta P}{\Delta L}=\alpha(\varepsilon) \mu U+b(\varepsilon) \rho U^{2}
$$

where,

\footnotetext{
${ }^{12}$ For some extreme cases, especially at low velocities, the measured thicknesses are slightly larger than the theoretical thickness.
} 
Appendix B

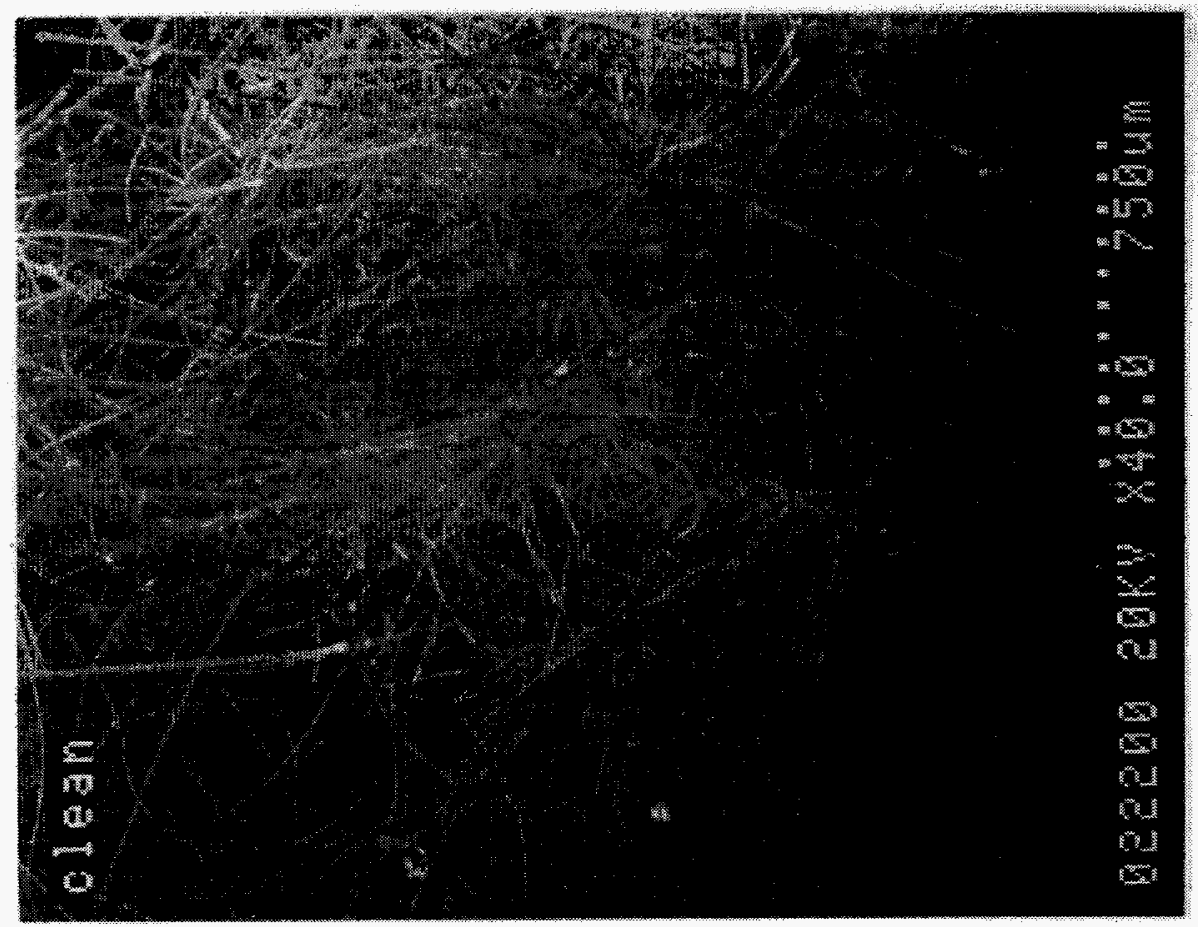

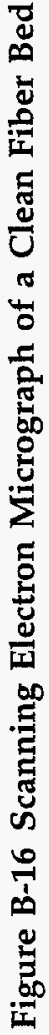

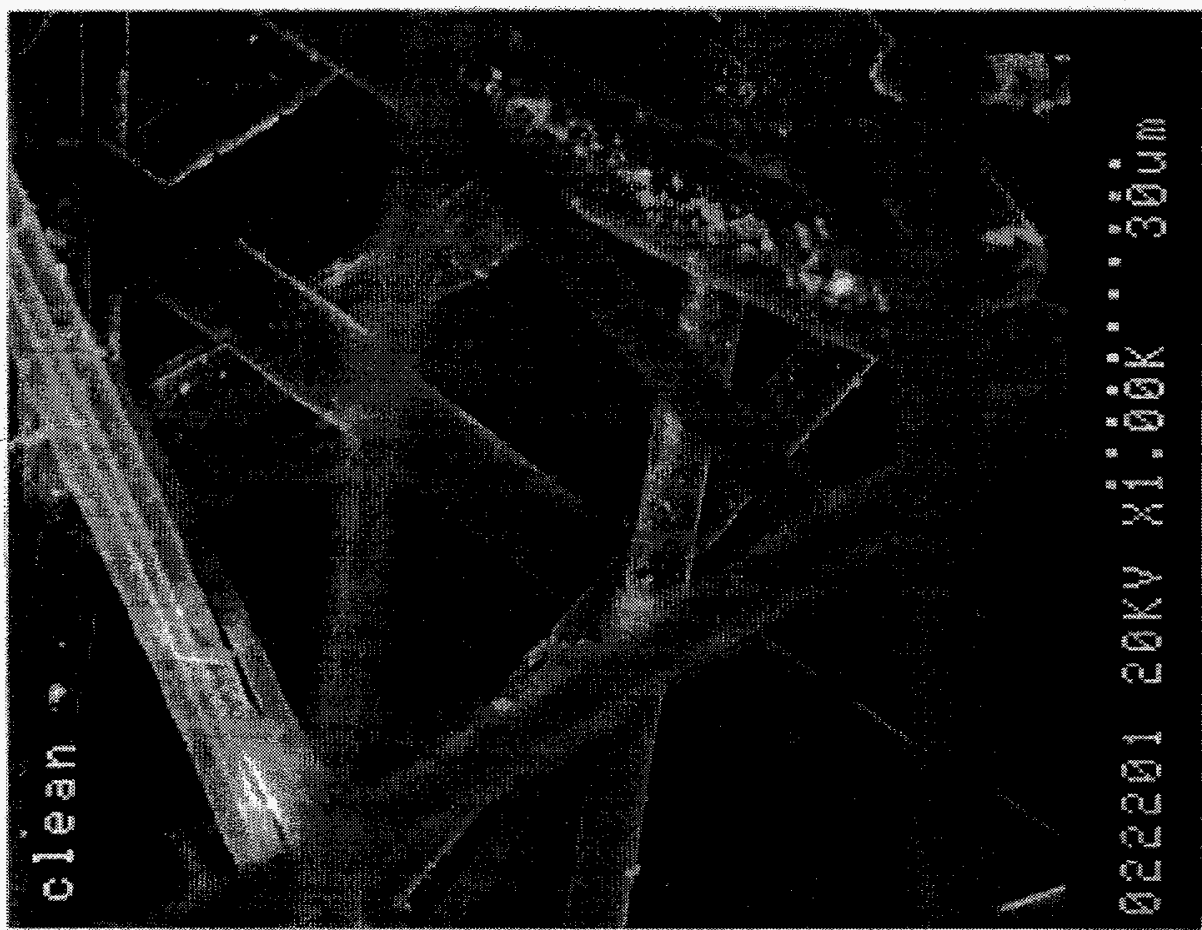


Appendix B

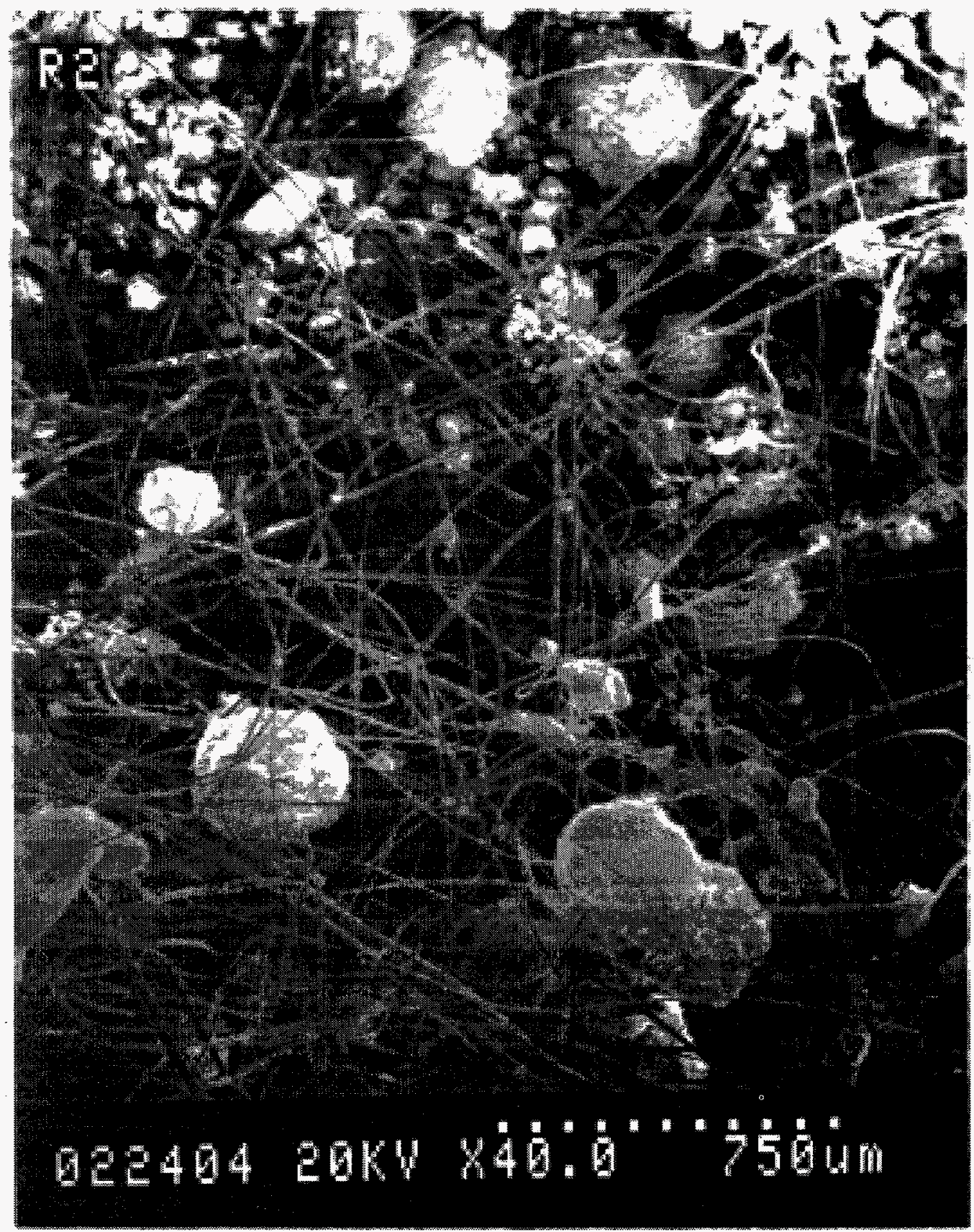

Figure B-17 Scanning Electron Micrograph of a Mixed Bed 
Appendix B

\begin{tabular}{|c|c|}
\hline$\Delta \mathrm{P}$ & $\begin{array}{l}\text { is the pressure drop due to flow } \\
\text { across the bed }\left(\text { dynes } / \mathrm{cm}^{2}\right)\end{array}$ \\
\hline$\Delta \mathrm{L}$ & $\begin{array}{l}\text { is the height or thickness of the } \\
\text { fibrous bed }(\mathrm{cm})\end{array}$ \\
\hline$\mu$ & is fluid dynamic viscosity (poise) \\
\hline & is fluid density $\left(\mathrm{g} / \mathrm{cm}^{3}\right)$ \\
\hline & is fluid velocity $(\mathrm{cm} / \mathrm{s})$ \\
\hline$\alpha(\varepsilon), \mathrm{b}(\varepsilon)$ & $\begin{array}{l}\text { are unknown functions of the bed } \\
\text { porosity. }\end{array}$ \\
\hline
\end{tabular}

Since the 1940s, experimental and theoretical efforts have been underway to determine $\alpha(\varepsilon)$ and $b(\varepsilon)$ for beds formed of different porous media. Initial efforts focused on channel flow models for porous media, which resulted in the well-known KozenyCarman Equation [Ref. B.26] for laminar flows:

$$
\frac{\Delta P}{\Delta L}=\frac{a S_{v}^{2}(1-\varepsilon)^{2}}{\varepsilon^{3}} \mu U
$$

where,

$$
\begin{aligned}
& S_{v} \quad \begin{array}{l}
\text { is the specific surface area of the } \\
\text { porous bed }\left(\mathrm{cm}^{2} / \mathrm{cm}^{3}\right)
\end{array} \\
& \varepsilon \quad \text { is the bed porosity. }
\end{aligned}
$$

In the turbulent region, Equation 18a becomes equal to:

$$
\frac{\Delta P}{\Delta L}=\frac{b S_{\nu}(1-\varepsilon)}{\varepsilon} \rho U^{2}
$$

Based on a comprehensive set of experimental data for flow through granular porous media with porosities between 0.4 and 0.85 , Ergun proposed values of 4.2 and 0.3 for the constants $a$ and $b$ [Ref. B.37].

A series of later investigators studied flow through fibrous porous media, both theoretically and experimentally. For laminar flow through fibrous porous media, characterized by high porosities, the functional relationship between pressure and porosity expressed above (i.e., $\left.\Delta \mathrm{P} \propto(1-\varepsilon)^{2}\right)$ was found not to be valid. The analytical reasoning for this conclusion can be found from the works of Kyan, et al. [Ref. B.38]. Based on a large data base for flow through fibrous media, Davies [Ref. B.39] proposed that for laminar flow through fibrous porous media, the functional equation should be:

$$
\frac{\Delta P}{\Delta L}=a S_{v}^{2}(1-\varepsilon)^{1.5}\left[1+a_{0}(1-\varepsilon)^{3}\right] \mu U
$$

Based on experimental data for flow through compressible mats made of nylon, fiberglass, Darcon, and wood pulp, Ingmanson, et al, [Ref. B.40] confirmed this relationship and suggested 3.5 and 57 for the empirical constants $a$ and $a_{0}$. To date, these constants have been in wide use for laminar flow through fibrous porous media. Using these constants, Equation B-19 can be rewritten as:

$$
\frac{\Delta P}{\Delta L}=3.5 S_{v}^{2}(1-\varepsilon)^{1.5}\left[1+57(1-\varepsilon)^{3}\right] \mu U
$$

Equation B-20a is proposed for laminar flows in fibrous porous media. These flows are traditionally referred to as low-velocity flows. For turbulent, or high velocity flows, experimental studies of Kyan, et al, and numerous other investigators [Ref. B.41] indicate that the functional relationship expressed in Equation $B-18 b$ (i.e., $\Delta P \propto(1-\varepsilon)$ ) is valid for fibrous media as well. The empirical constant is close to 0.66 , instead of 0.3 as suggested by Ergun. The equation thus becomes:

$$
\frac{\Delta P}{\Delta L}=\frac{0.66 S_{v}(1-\varepsilon)}{\varepsilon} \rho U^{2} .
$$

The overall equation, valid for laminar, transient, and turbulent flow regimes through mixed beds, can be now expressed as a sum of $20 \mathrm{a}$ and $20 \mathrm{~b}$ :

$$
\begin{aligned}
\frac{\Delta H}{\Delta L_{o}} & =\text { Units }\left[3.5 S_{v}^{2}\left(1-\varepsilon_{m}\right)^{1.5}\left[1+57\left(1-\varepsilon_{m}\right)^{3}\right] \mu U\right. \\
& \left.+0.66 S_{v} \frac{\left(1-\varepsilon_{m}\right)}{\varepsilon_{m}} \rho_{w} U^{2}\right]\left(\frac{\Delta L_{m}}{\Delta L_{o}}\right)
\end{aligned}
$$


where,

$$
\text { Units = } 1 \text { for SI units. }
$$

However, if Eq. B-21 is used in conjunction with the following English units,

$$
\begin{array}{ll}
\mathrm{S}_{\mathrm{v}} & \text { is specific surface area }\left(\mathrm{ft}^{2} / \mathrm{ft}^{3}\right) \\
\mu & \text { is dynamic viscosity }(\mathrm{lbm} / \mathrm{s}-\mathrm{ft}) \\
\mathrm{U} & \text { is velocity }(\mathrm{ft} / \mathrm{s}) \\
\Delta \mathrm{H} & \text { is head loss (ft-water) } \\
\rho_{\mathrm{w}} & \text { is water density (lbm/ } \left.\mathrm{ft}^{3}\right) \\
\Delta \mathrm{L}_{\mathrm{o}} & \begin{array}{l}
\text { is the fiber bed theoretical thickness } \\
\text { (in.) (obtained from. Equation B-2) }
\end{array} \\
\Delta \mathrm{L}_{\mathrm{m}} & \begin{array}{l}
\text { is the actual bed thickness (in.) }
\end{array}
\end{array}
$$

the unit conversion factor becomes,

$$
\begin{aligned}
\text { Units } & =\frac{1(\mathrm{ft}-\text { water })}{\left(62.37 \mathrm{lbm} / \mathrm{ft}^{3}\right)\left(32.174 \mathrm{ft} / \mathrm{s}^{2}\right)(12 \mathrm{in} / \mathrm{ft})(1 \mathrm{ft})} \\
& =4.1528 \times 10^{-5} \frac{\mathrm{ft}-\text { water } / \mathrm{in}}{\mathrm{lbm} / \mathrm{ft}^{2} \mathrm{~s}^{2}}
\end{aligned}
$$

The mixture porosity, $\varepsilon_{\mathrm{m}}$, can be given as:

$$
\varepsilon_{m}=1-\left(1+\frac{\rho_{f}}{\rho_{\mathrm{p}}} \eta\right)\left(1-\varepsilon_{o}\right) \frac{\Delta L_{o}}{\Delta L_{m}}
$$

where,

$$
\begin{array}{ll}
\rho_{\mathrm{f}} & \begin{array}{l}
\text { is fiber density }\left(175 \mathrm{lbm} / \mathrm{ft}^{3} \text { or } 2803\right. \\
\left.\mathrm{kg} / \mathrm{m}^{3}\right)
\end{array} \\
\rho_{\mathrm{p}} & \begin{array}{l}
\text { is sludge particle density }\left(324 \mathrm{lbm} / \mathrm{ft}^{3}\right. \\
\text { or } \left.5190 \mathrm{~kg} / \mathrm{m}^{3}\right)
\end{array} \\
\eta & \begin{array}{l}
\text { is sludge-to-fiber mass ratio (obtained } \\
\text { from Equation B-5) }
\end{array} \\
\varepsilon_{\mathrm{o}} & \text { is the theoretical fiber bed porosity }
\end{array}
$$

$\varepsilon_{\mathrm{o}}$ and $\Delta \mathrm{L}_{\mathrm{m}}$ (in $\mathrm{ft}$ ) can be calculated as:

$$
\begin{gathered}
\varepsilon_{o}=1-c_{o} / \rho_{f} \\
\Delta L_{m}=c_{o} / c \Delta L_{o}
\end{gathered}
$$

where,

$$
\begin{aligned}
& c_{o} \text { is the 'as-fabricated' packing density } \\
& \left(\mathrm{lbm} / \mathrm{ft}^{3}\right) \\
& \text { c is the actual packing density }\left(\mathrm{lbm} / \mathrm{ft}^{3}\right)
\end{aligned}
$$

For a given fiber mass, i.e. known theoretical thickness $\Delta \mathrm{L}_{\mathrm{o}}$, Equation B-21 has two unknowns: a) the head loss across the bed, and $b$ ) the actual bed thickness (or the actual packing density, c). For an incompressible bed, the actual bed thickness is the same as the theoretical bed thickness and porosity can be easily estimated using Equation B-23a. The remaining variable, $\Delta \mathrm{H}$, can be calculated directly using Equation B-21. However, as demonstrated by visual observations, the fibrous beds are highly compressible under the effect of differential pressure across the bed which acts as the compacting pressure.

The work by Igmanson et al suggests that the fiber bed packing density dependence on the head loss can be correlated using a regression fit of the form:

$$
c=a c_{o}\left(\Delta H / \Delta L_{o}\right)^{\gamma}
$$

where,

c is the actual packing bed density corresponding to a pressure gradient of $\Delta \mathrm{H} / \Delta \mathrm{L}$

$c_{0} \quad$ is the reference packing density (or) theoretical packing density

$a$ and $\gamma$ are empirical constants.

Experience suggests that $a$ and $\gamma$ are functions of fibrous material type and bed construction. For example, a bed constructed of larger shreds would be less susceptible to compression compared to a bed comprised of loosely attached individual fibers (e.g., classes 3 and 4). Values for $a$ and $\gamma$ are reported in the literature for Nylon, Dacron and wood fibers. No data, however, was reported for low density fiber glass, such as NUKONTM. As a result, visual inspection of the fiber bed dynamic behavior coupled with analysis of head-loss data were used to obtain the following regression fit for NUKON ${ }^{\mathrm{TM}}$ fibers: 
Appendix B

$$
c=1.3 c_{o}\left(\Delta H / \Delta L_{o}\right)^{0.38}
$$

where,

$$
\begin{array}{ll}
\mathrm{c}_{\mathrm{o}} & \text { is } 2.4 \mathrm{lbm} / \mathrm{ft}^{3}\left(38.4 \mathrm{~kg} / \mathrm{m}^{3}\right) \\
\Delta \mathrm{H} & \text { is head loss (ft-water) } \\
\Delta \mathrm{L}_{\mathrm{o}} & \text { is bed theoretical thickness (in.). }
\end{array}
$$

Equation B-25 appeared to perform well for fibers over a compacting pressure gradient of $0.5-25 \mathrm{ft}-$ water/in $(0.06$ to $2.9 \mathrm{MPa} / \mathrm{m})$.

Equation B-25 is not applicable to larger shreds that retained some of the original structural rigidity. Such beds are usually seen to be "spongy" and rarely reduce to half their original (or theoretical) thickness. In fact, there have been several cases, especially at low flow velocities, where the measured thicknesses are slightly larger than theoretical thicknesses. For such beds it is preferable to assume that the bed density is about:

$\mathrm{c}=2.4 \mathrm{lbm} / \mathrm{ft}^{3}$ for $\Delta \mathrm{H} / \Delta \mathrm{L}_{\mathrm{o}} \leq 10 \mathrm{ft}$-water $/$ inch

$c=4.8 \mathrm{lbm} / \mathrm{ft}^{3}$ for $\Delta \mathrm{H} / \Delta \mathrm{L}_{\mathrm{o}} \geq 10 \mathrm{ft}$-water $/$ inch

For mixed beds visual observations in the test apparatus were impaired by the continuous presence of sludge particles in the water. As a result, sludge data provided by the manufacturer was used to draw some insights:

1. Although sludge is compressible at very large differential pressures, it can be treated as incompressible at the pressure of present interest [Ref. B.16]. The sludge density in this range is about $65 \mathrm{lbm} / \mathrm{ft}^{3} .{ }^{13}$

2. The presence of fibrous materials reduces mixture compressibility. It is likely that

\footnotetext{
${ }^{13}$ The maximum density ever attained was no more than 100 $\mathrm{lbm} / \mathrm{ft}^{3}\left(1602 \mathrm{~kg} / \mathrm{m}^{3}\right)$ when the material was compressed in an industrial grade compactor.
}

actual mixture density would be lower than $65 \mathrm{lbm} / \mathrm{ft}^{3}\left(1041 \mathrm{~kg} / \mathrm{m}^{3}\right)$.

Based on these insights a simple compression model was developed for mixed bed density, $c$,

$c=1.3 \rho_{\mathrm{o}}\left(\Delta \mathrm{H} / \Delta \mathrm{L}_{\mathrm{o}}\right)^{0.38}$ for $\mathrm{c} \leq 65 /(1+\eta) \mathrm{lbm} / \mathrm{ft}^{3}$

$\mathrm{c}=65 \mathrm{lbm} / \mathrm{ft}^{3}$

Otherwise

Equations B-21, B-22, B-23, B-25, B-26 and B-27 formed the basic constituents of the head loss model developed as part of this study. An iterative solution scheme was adopted for solving the head loss equation (Eq. B-21). In this scheme, an initial guess for bed packing density was used to estimate the head loss which, in turn, was used to calculate the packing density using Equations B-25, B-26 and $\mathrm{B}-27$. The iterations were continued until convergence was achieved.

The model predictions were compared with experimental data reported from a variety of experiments. Before presenting this comparison, the following discussions provide simple forms of the above equation to suit special cases.

\section{B.8.3 Special Cases}

The intent of this section is to provide simple equations that can be used by the analyst to obtain a quick estimate for the head loss.

The following NUKON ${ }^{\mathrm{TM}}$ specific information was used to evaluate several variables in the equation:

- Specific Surface Area, $\mathrm{S}_{\mathrm{v}}=1.7142 \times 10^{5} \mathrm{ft}^{2} / \mathrm{ft}^{3}$ $\left(5.6243 \times 10^{5} \mathrm{~m}^{-1}\right)$

- Fiber Diameter, $\mathrm{D}=2.333 \times 10^{-5} \mathrm{ft}$ (or $\left.7.112 \mu \mathrm{m}\right)^{14}$

- Theoretical Packing Density, $c_{o}=2.4 \mathrm{lbm} / \mathrm{ft}^{3}(38.4$ $\mathrm{kg} / \mathrm{m}^{3}$ )

- Specific Volume, $\vartheta=5.5582 \times 10^{-3} \mathrm{ft}^{3} / \mathrm{lbm}$ or $3.47 \times 10^{-4} \mathrm{~m}^{3} / \mathrm{kg}$ (generic fiberglass)

- Pure Fiber Bed Porosity, $\varepsilon_{\mathrm{f}}=0.986$

\footnotetext{
${ }^{14}$ Gordon Hart of PCI; also SEM pictures.
} 
In addition, water properties were obtained from available physical tables as functions of temperature. Caution must be used by the analyst to apply these equations appropriately.

\section{Incompressible Pure Fiber Beds}

From the visual observation, it appears that pure NUKON ${ }^{\mathrm{TM}}$ beds are compressed to about half their original thickness when subjected to head losses in the range of the reference plant NPSH (14 ft water or $4.18 \times 10^{4} \mathrm{~Pa}$ ). For such a case, assume the bed to be incompressible with a packing density twice that of the theoretical one. Under such an assumption, head loss can be estimated using Equation B-21 and the following assumptions:

$$
\begin{aligned}
& \Delta L_{m}=0.5 \Delta L_{o}, \text { and } \\
& \varepsilon_{m}=1-2 c_{o} / \rho_{f}
\end{aligned}
$$

For NUKON ${ }^{\mathrm{TM}}$ Equation B-21 can be reduced to:

$$
\frac{\Delta H}{\Delta L_{o}}=9712 \mu U+0.06 \rho U^{2}
$$

Using water thermo-physical properties, this equation can be re-written as:

$$
\begin{array}{ll}
\frac{\Delta H}{\Delta L_{o}}=7.4 U+4.1 U^{2} & @ 60^{\circ} \mathrm{F} \\
\frac{\Delta H}{\Delta L_{o}}=3.7 U+4.1 U^{2} & @ 120^{\circ} \mathrm{F}
\end{array}
$$

It can be easily seen that the majority of the head loss data obtained for NUKONTM can be predicted by these equations within $\pm 20 \%$.

\section{Incompressible Mixed Beds at Low Sludge Ratios}

For a mixed bed the porosity, $\varepsilon_{\mathrm{m}}$ can be expressed as:

$$
\varepsilon_{m}=1-\left(1+\frac{\rho_{f}}{\rho_{p}} \cdot \eta\right)\left(1-\varepsilon_{f}\right) \frac{\Delta L_{f}}{\Delta L_{m}}
$$

where,

$$
\begin{array}{ll}
\rho_{\mathrm{f}} & \text { is fiber-glass density }\left(\mathrm{lbm} / \mathrm{ft}^{3}\right) \\
\rho_{\mathrm{p}} & \begin{array}{l}
\text { is sludge particle density }\left(323 \mathrm{lbm} / \mathrm{ft}^{3}\right. \\
\text { or } \left.5180 \mathrm{~kg} / \mathrm{m}^{3}\right)
\end{array} \\
\eta & \begin{array}{l}
\text { is sludge-to-fiber mass ratio on the } \\
\text { bed }
\end{array} \\
\Delta \mathrm{L}_{\mathrm{f}} & \begin{array}{l}
\text { is actual bed thickness for the pure } \\
\text { fiber bed (in.) }
\end{array} \\
\Delta \mathrm{L}_{\mathrm{m}} & \begin{array}{l}
\text { is actual bed thickness for the mixed } \\
\text { bed (in.) } \\
\text { is pure fiber bed porosity (see case } \\
\text { above). }
\end{array}
\end{array}
$$

Assuming that:

$$
\begin{aligned}
\Delta \mathrm{L}_{\mathrm{f}}= & 0.5 \Delta \mathrm{L}_{\mathrm{o}} \text { (see case above) } \\
\Delta \mathrm{L}_{\mathrm{m}}= & 0.25 \Delta \mathrm{L}_{\mathrm{o}} \text { (mostly true for low } \Delta \mathrm{H} \\
& \text { across the bed) } \\
\rho_{\mathrm{f}} / \rho_{\mathrm{p}}= & 0.54 \text { (for NUKON }{ }^{\mathrm{TM}} \text { with iron-oxide } \\
& \text { sludge) } \\
\varepsilon_{\mathrm{m}}= & 1-(1+0.54 \eta) 2\left(1-\varepsilon_{\mathrm{f}}\right) \\
\varepsilon_{\mathrm{f}}= & 1-2 \mathrm{c}_{\mathrm{o}} / \rho_{\mathrm{f}} .
\end{aligned}
$$

Equation B-21, can be re-written as:

$$
\begin{aligned}
& \frac{\Delta H}{\Delta L_{o}}=10(1+0.54 \eta)^{1.5} U+4(1+0.54 \eta) U^{2} @ 60^{\circ} \mathrm{F} \\
& \frac{\Delta H}{\Delta L_{o}}=5(1+0.54 \eta)^{1.5} U+4(1+0.54 \eta) U^{2} @ 120^{\circ} \mathrm{F}
\end{aligned}
$$

In general these equations are valid up to a sludgeto-mass ratio, $\eta$, of 10 . Beyond that ratio, usage of the complete equation is strongly recommended.

\section{Sludge Bed at High Sludge-to-Fiber Mass Ratio}

At very high sludge-to-fiber mass ratios, especially at low fiber bed thicknesses, the mixed bed would closely resemble a particle or granular bed. For such beds, the porosity can be calculated as:

$$
\varepsilon_{m}=1-c_{\text {sludge }} / \rho_{p}
$$

where,

$$
\begin{array}{ll}
\rho_{\mathrm{p}} & =324 \mathrm{lbm} / \mathrm{ft}^{3} \text { or } 519 \mathrm{~kg} / \mathrm{m}^{3} \\
\mathrm{c}_{\text {sludge }} & =65 \mathrm{lbm} / \mathrm{ft}^{3} \text { or } 1041 \mathrm{~kg} / \mathrm{m}^{3} \\
\mathrm{~S}_{v} & =1.83 \times 10^{5} \mathrm{ft}^{2} / \mathrm{ft}^{3} \text { or } 6 \times 10^{5} \mathrm{~m}^{2} / \mathrm{m}^{3}
\end{array}
$$


According to the manufacturer (Hansen

Engineering, Inc.), the sludge beds are usually not compressible much below this value. The head loss equation can be written as:

$$
\begin{aligned}
& \frac{\Delta H}{\Delta L_{\text {sludge }}}=501 U+82 U^{2} @ 60^{\circ} \mathrm{F} \\
& \frac{\Delta H}{\Delta L_{\text {sludge }}}=248 U+81 U^{2} @ 120^{\circ} \mathrm{F}
\end{aligned}
$$

The approximate and exact model predictions for head loss are presented in Figures B-18a and B-18b as head loss vs approach velocity for three different sludge-to-fiber mass ratios and a water temperature of $60^{\circ} \mathrm{F}$. For these calculations the particle diameter was assumed to be $10 \mu \mathrm{m}$ and sludge density was assumed to be $65 \mathrm{lbm} / \mathrm{ft}^{3}$. The debris cake compressibility effects were handled using Equations B-27a and B-27b which limit maximum packing density to the sludge density of $65 \mathrm{Ibm} / \mathrm{ft}^{3}$. The fibers were assumed to be NUKON ${ }^{\mathrm{TM}}$ fibers with a diameter of $7.1 \mu \mathrm{m}$. As shown in Figure B-18a, the head loss increases non-linearly with both the velocity and the sludge-to-fiber mass ratio. As evident from this figure, large approach velocities together with the large sludge-to-fiber mass ratio induce very high pressure drops. To illustrate the effect of sludge-to-fiber mass ratio, head loss is plotted as a function of $\eta$ in Figure B-18b, calculated for the same conditions described above at an approach velocity of $0.15 \mathrm{ft} / \mathrm{s}$. As shown here, the head loss increases by a factor of 200 while the sludge-to-fiber ratio is increased from 0 to 100 . Also shown in this figure are Equations B-32a and B-34a, which is an approximate form of the head loss model and the BWROG correlation [Ref. B.18] which was proposed for mixed beds. From the comparison it is clear that the approximate equation predictions are comparable to the actual equation in the respective ranges of applicability, while the BWROG correlation appears to consistently underpredict the head loss.

\section{B.8.4 Comparison of Head Loss Model Prediction with the Experimental Data for Pure NUKON ${ }^{\mathrm{TM}}$ Insulation Beds}

The following sources of experimental data are available for validating the proposed head loss equation:

1. NRC Experiments Head Loss Data Base [Ref. B.16]

2. PP\&L Head Loss Data Base [B.24]

3. PCI Head Loss Data Base [Ref. B.33 and B.34]

4. NUREG/CR-2982 Head Loss Data Base [Ref. B.32]

The following sections present the comparison between the proposed model with these experimental data.

\section{B.8.4.1 Comparison with NRC Experiments Head Loss Data}

As part of the NRC experiments, a series' of controlled tests were conducted to obtain head loss data for NUKON ${ }^{\mathrm{TM}}$ insulation debris (see Appendix E). A total of six test runs, conducted as part of this effort, focused on head loss measurements for randomly formed fibrous debris beds formed of shape classes $3 \& 4$ and $5 \& 6$ with no particulate loading (i.e., pure fibrous beds). The test procedure and the raw experimental data are presented in Appendix E. The head loss data were obtained for flow velocities in the range of $0.15-1.5 \mathrm{ft} / \mathrm{s}(0.05-$ $0.46 \mathrm{~m} / \mathrm{s})$ for two different temperatures $\left(50^{\circ} \mathrm{F}\right.$ and $125^{\circ} \mathrm{F}$ or $20^{\circ} \mathrm{C}$ and $52^{\circ} \mathrm{C}$ ) and three different theoretical bed thicknesses (1", 2" and 4"), and are plotted in Figures B-19 and B-20. As evident from these figures, the measured data is within $\pm 20 \%$ of the correlation (Eq. B-21). Note that the predictions were obtained assuming that the bed is compressible and that packing density is predictable by correlation B-25. It should be noted that the good agreement observed in this case is primarily due to the fact that the experiments were conducted in a controlled environment. Such agreement may not 


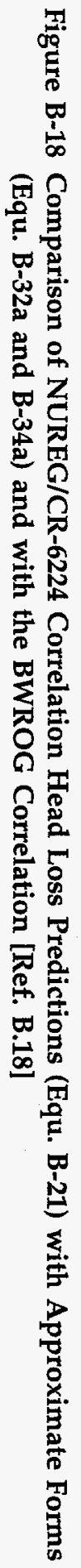
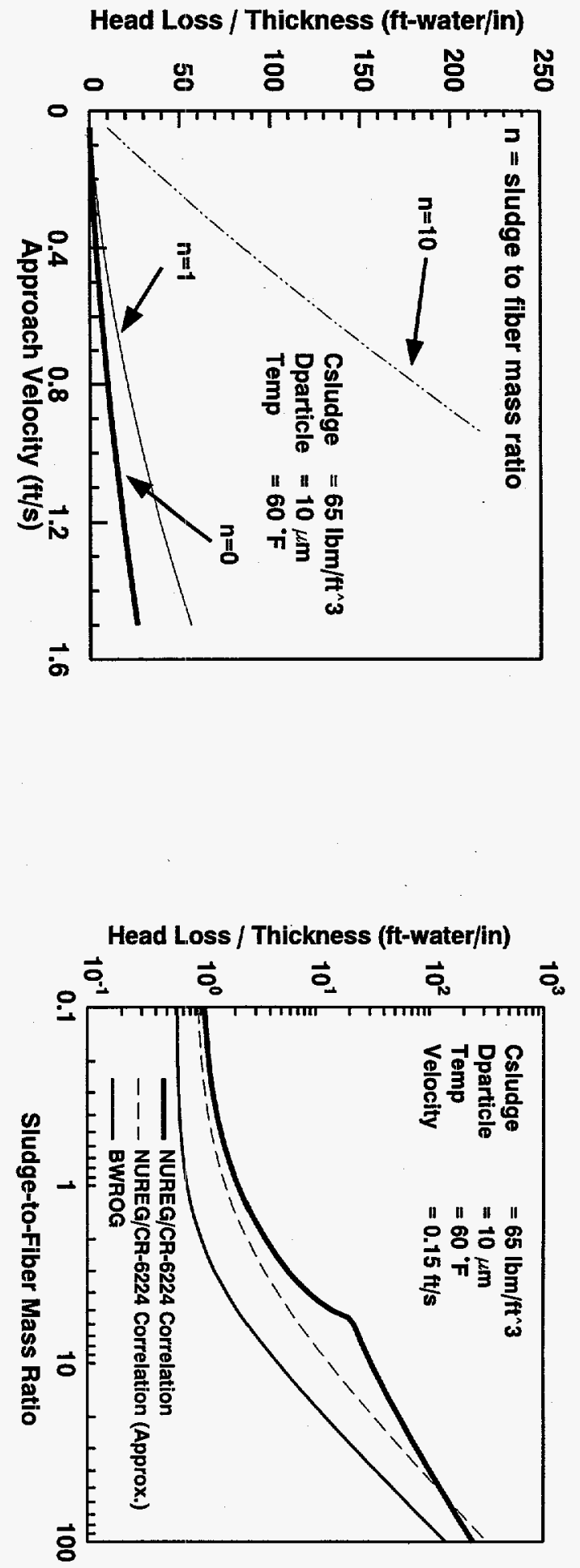


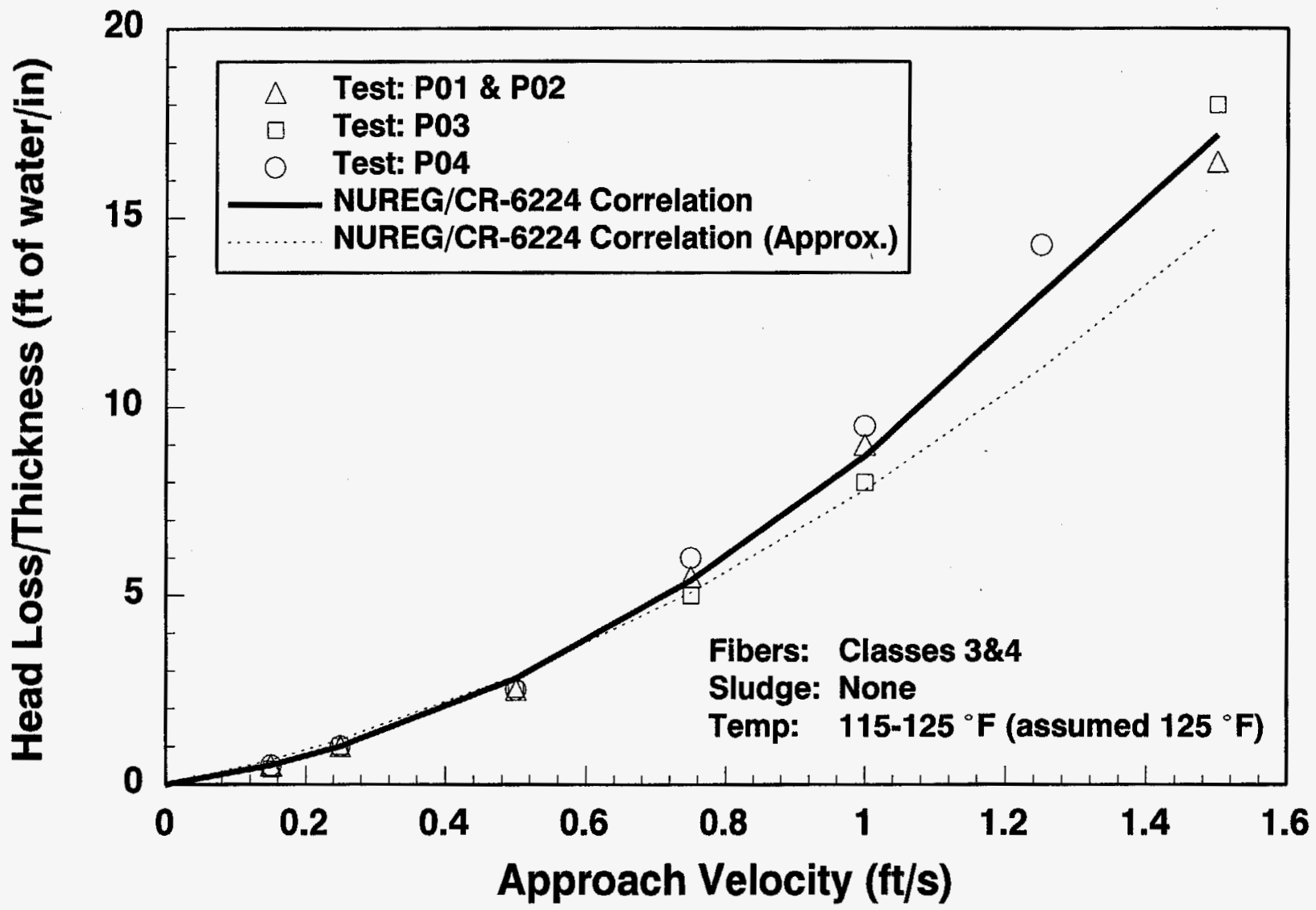

Figure B-19 Comparison of NRC Head Loss Experiments Data for Shape Class 3 \& 4 Fiber Beds with the NUREG/CR-6224 Correlation 


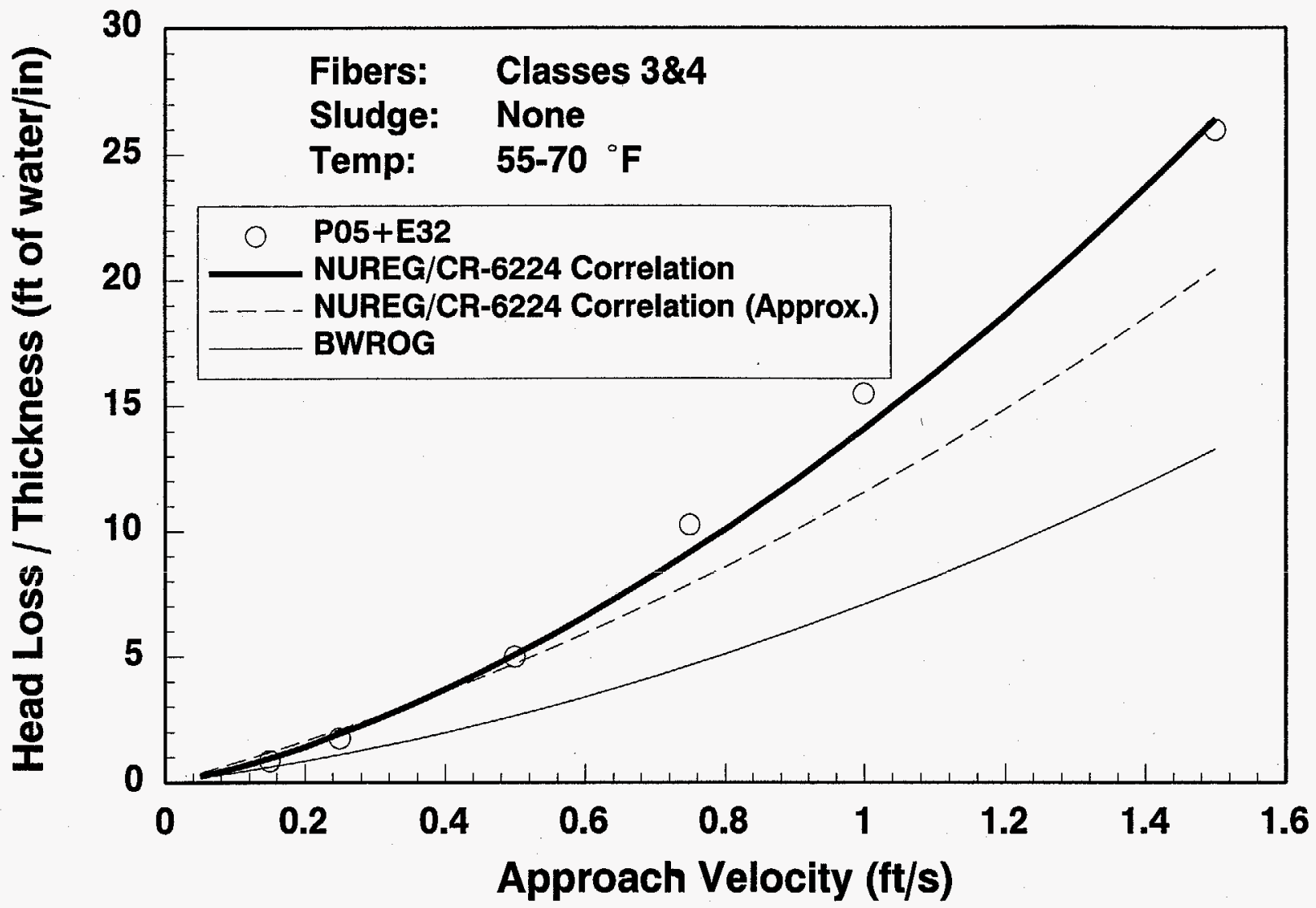


be possible for tests where the debris sizes and water temperatures vary from test to test.

Figures B-19 and B-20 also compare the experimental data with Equation B-30 which is obtained using the approximation that the bed is compressed to half its theoretical thickness. As evident from these figures, reasonable agreement was obtained at low velocities which also correspond to low head loss gradients. At higher velocities, however, Equation B-30 clearly underpredicts the head loss primarily due to the fact that it does not account for bed compressibility due to associated larger head loss gradients.

Also plotted in Figure B-20 is the head loss correlation reported by BWROG developed based on the one-pass test setup head loss data for NUKON ${ }^{\mathrm{TM}}$. As noted in Reference B.18 the data was obtained at ambient temperature using small NUKON ${ }^{\mathrm{TM}}$ shreds. This comparison suggests that this later equation considerably underpredicts the data.

\section{B.8.4.2 Comparison with the PP\&L Head Loss Data}

The PP\&L experiments employed a once through loop, equipped with a small scale strainer (surface area of $2.7 \mathrm{ft}^{2}$ or $0.25 \mathrm{~m}^{2}$ ) and a mixing tank (volume of $240 \mathrm{ft}^{3}$ or $6.8 \mathrm{~m}^{3}$ ), to obtain the head loss data. Reference B.24 provides a detailed description of the test facility and test procedure. A total of 14 runs were conducted using pure insulation debris (i.e., debris without any particulate loading). Of these, eight tests (F01-F08) used debris described as "fibers"15 and the remaining tests (FC09-FC14) used debris described as "shreds". ${ }^{16}$ The concentrations of the insulation debris in the tank varied from 0.00005 wt $\%$ to 0.003 wt $\%$. Half of the tests were conducted at a flow velocity of $0.67 \mathrm{ft} / \mathrm{s}(0.2 \mathrm{~m} / \mathrm{s})$ and the other half were conducted at $0.96 \mathrm{ft} / \mathrm{s}(0.29$ $\mathrm{m} / \mathrm{s}$ ). Insulation debris was added discretely at preselected intervals to maintain the tank concentration steady throughout each of the tests. Each test was

\footnotetext{
${ }^{15}$ Fibers were described as the loose clusters of individual fibers about $0.13 \mathrm{lbm} / \mathrm{ft}^{3}\left(2.08 \mathrm{~kg} / \mathrm{m}^{3}\right)$ in packed density

${ }^{16}$ Shreds were described as consolidated fibers that retain some of the original strength of the fiber bed.
}

run until the flow could no longer be maintained at a constant value. The concentration and the flow velocity data were used by the experimenter to obtain debris bed thickness as a function of time for each test (see Tables 1 and 2 of Ref. 24, Appendix C). This derived ${ }^{17}$ data was used as described below for comparison with the correlation presented in this study.

\section{Head Loss Data for Fibers}

As previously stated, tests F01 through F08 were obtained using "fibers" which closely resemble the debris used in the NRC experiments. Equation B-21 was used to estimate the head loss for a given velocity and theoretical debris bed thickness. Equation B-24 was used to estimate the packing density due to bed compaction and a reference temperature of $70^{\circ} \mathrm{F}\left(21^{\circ} \mathrm{C}\right)$ was used to estimate water viscosity. Figure B-21 provides point-by-point comparison of the head loss data with the correlation predictions. As evident from this figure, the correlation predictions were within $\pm 25 \%$ of the experimental data. The deviations are mainly attributable to the following uncertainties:

1. Water temperature varied from test to test since no effort was taken to control it, and

2. Debris concentration in the tank varied from the mean concentration throughout each test since debris was added manually at discrete time intervals.

Nevertheless, agreement between the correlation and the experimental data is reasonable. Better agreement may be possible if data on water temperature and actual procedures for each test are available.

\section{Head Loss Data for Shreds}

Head loss data in tests FC08-FC14 were obtained using shreds that are judged to be relatively larger than the debris used in NRC experiments. Most importantly these shreds are known to retain some of the rigidity offered by the original NUKON ${ }^{\mathrm{TM}}$ blankets. Beds formed of such debris are known to

\footnotetext{
${ }^{17}$ Derived because actual raw data consists only of concentration, and head loss as a function of time, not bed thickness and head loss as required for validating the equation.
} 

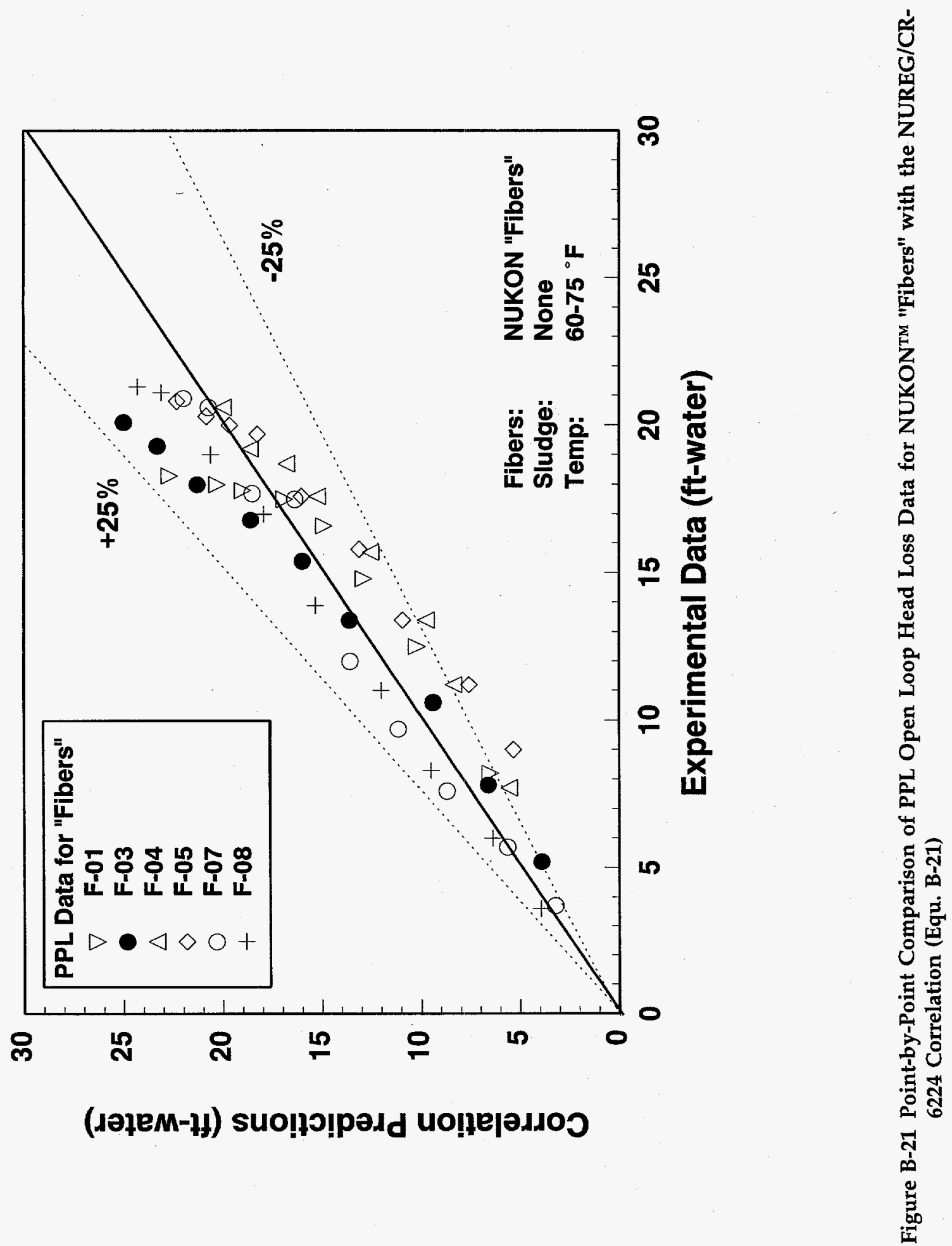
be less susceptible to compression as compared to the fibers, especially considering that head loss gradients encountered in these experiments are no larger than 7-10 ft-water/inch of debris. At such low pressure gradients it is reasonable to assume that the actual bed density is not much different from the theoretical density of $2.4 \mathrm{lbm} / \mathrm{ft}^{3}$ (38.4 $\mathrm{kg} / \mathrm{m}^{3}$ ) (see Equation B-26a). As a result, Equation B-21 predictions based on theoretical density are compared here with the experimental data; Figure B-22 illustrates this comparison. As shown in this figure, correlation predictions are once again within $\pm 25 \%$ of the experimental data.

\section{B.8.4.3 Comparison With Other Sets of Data}

Three additional sets of data are available for NUKONTM shreds of different sizes. These tests were performed between 1983 and 1993. The earlier tests, i.e., 1983 NRC/ARL [Ref. B.32] tests and 1989 PCI tests [Ref. B.33], used mechanical means to obtain the shreds used in the tests. The 1993 PCI tests subjected aged NUKONTM blankets to an air blast to generate the debris used in the experiments [B.33]. Figure B-23 plots this head loss data from all these tests as a function of water velocity. Also plotted in Figure B-23 are Equation B-21 predictions for three different packing densities $(2.4,4.8$ and 9.6 $\left.\mathrm{lbm} / \mathrm{ft}^{3}\right)$. All three curves were obtained at a reference temperature of $300 \mathrm{~K}$. The comparison shows that a packing density of $4.8 \mathrm{lbm} / \mathrm{ft}^{3}(76.9$ $\mathrm{kg} / \mathrm{m}^{3}$ ) is most suitable for the 1989 PCI tests, which is consistent with the trend that finer shreds result in more compact beds. Note that the 1989 PCI shreds are the smallest of this group of tests. ${ }^{18}$

\section{B.8.4.4 Conclusions}

Based on comparisons with the experimental data obtained by present and past experiments, it can be stated that Equation B-21 provides a reasonably accurate estimation of the head loss. The key inputs required for Equation B-21 include water temperature and bed compressibility, both of which appear to significantly influence the head loss. Equation B-25 was found to estimate the packing density of the beds formed of "fibers", i.e., clusters

\footnotetext{
${ }^{18}$ Descriptions of the debris and the photographic evidence was used to draw this conclusion.
}

of loose fibers. For shreds of small and medium sizes usage of Equation B-21 together with B-26 performs reasonably well.

\section{B.8.5 Comparison of Head Loss Model Predictions with the Experimental Data for Mixed Beds}

The following sources of experimental data are available for comparison with the head loss model developed in this study:

\section{NRC Experiments Head Loss Data Base [Ref. B.16]}

2. PP\&L Head Loss Data Base [Ref. B.24].

\section{B.8.5.1 Comparison with NRC Experiments Head Loss Data Base}

This set of experiments employed a closed loop test facility, described in Appendix E, to obtain head loss data for debris beds formed of NUKON ${ }^{\mathrm{TM}}$ insulation debris and simulated sludge. The insulation debris are small in size and can be characterized as classes 3 and 4 , whereas the simulated sludge has a median diameter of about $5 \mu \mathrm{m}$. In these tests, a known quantity of sludge was initially added to the loop and was allowed to circulate through the loop at high velocities to enable uniform mixing. After uniform mixing was reached the flow velocity was reduced to $0.15 \mathrm{ft} / \mathrm{s}(0.05 \mathrm{~m} / \mathrm{s})$ and a predetermined mass of aged NUKON ${ }^{\mathrm{TM}}$ insulation debris, previously destructed using a leaf shredder and pre-soaked in water, was added to the loop. After steady state was achieved, the head loss across the bed was measured and four samples of loop water were drawn for the purpose of concentration measurements. These concentration estimates were then used to calculate the mass of sludge filtered and retained on the debris bed at the time when head loss measurements were made. The flow velocity was then increased in steps until a velocity of $1.5 \mathrm{ft} / \mathrm{s}(0.5 \mathrm{~m} / \mathrm{s})$ was reached or the head loss exceeded about 50-60 ft-water (0.15-0.18 MPa). The tabulated data is presented in Appendix E. Almost all of the data was obtained at a water temperature of $120^{\circ} \mathrm{F}\left(49^{\circ} \mathrm{C}\right)$; bed theoretical thicknesses ranging from 0.25 " to $2 "$ ( 0.6 to $5 \mathrm{~cm})$; and sludge-to-fiber mass ratios in the range of 0.23 to 30 . Further 


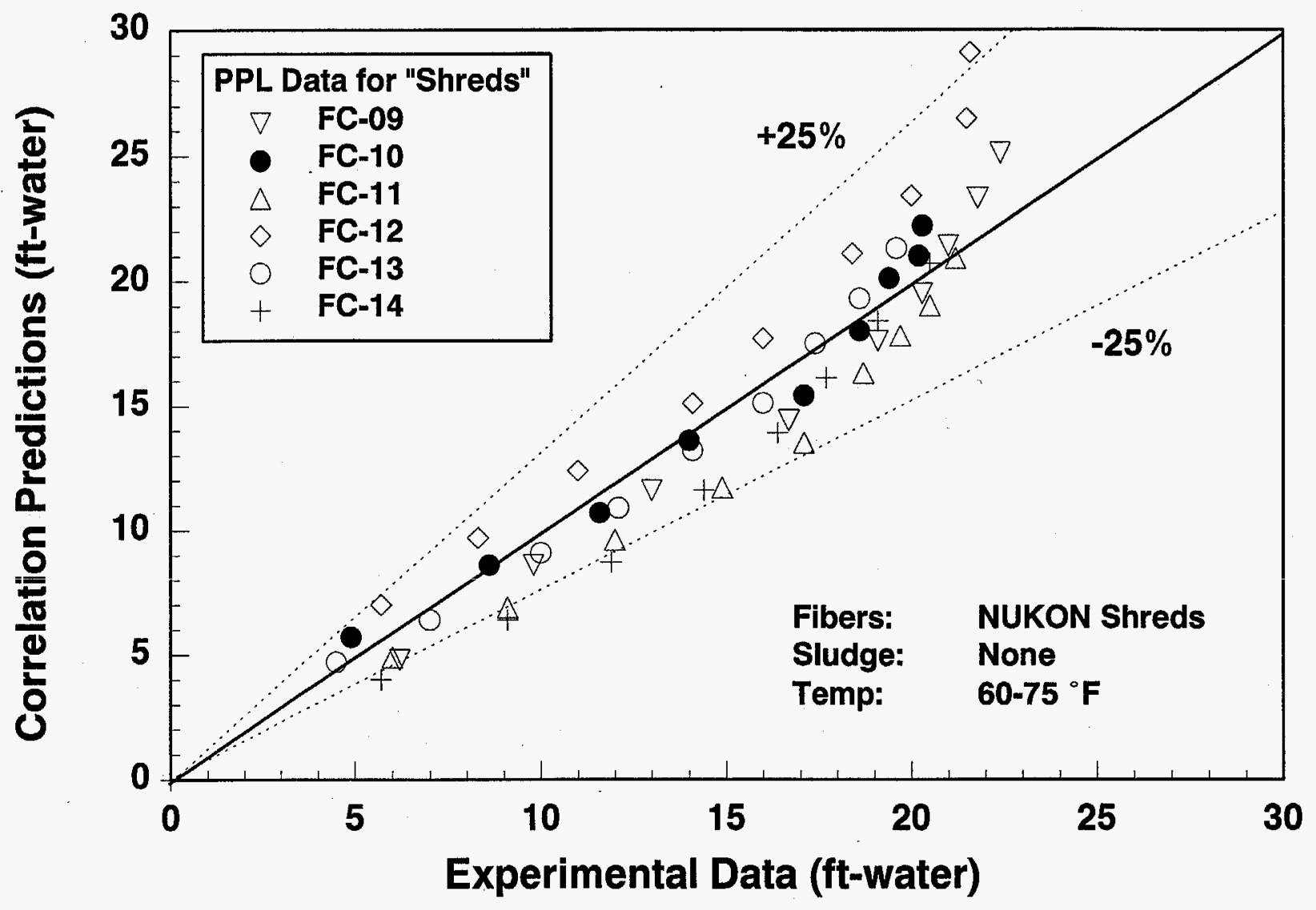




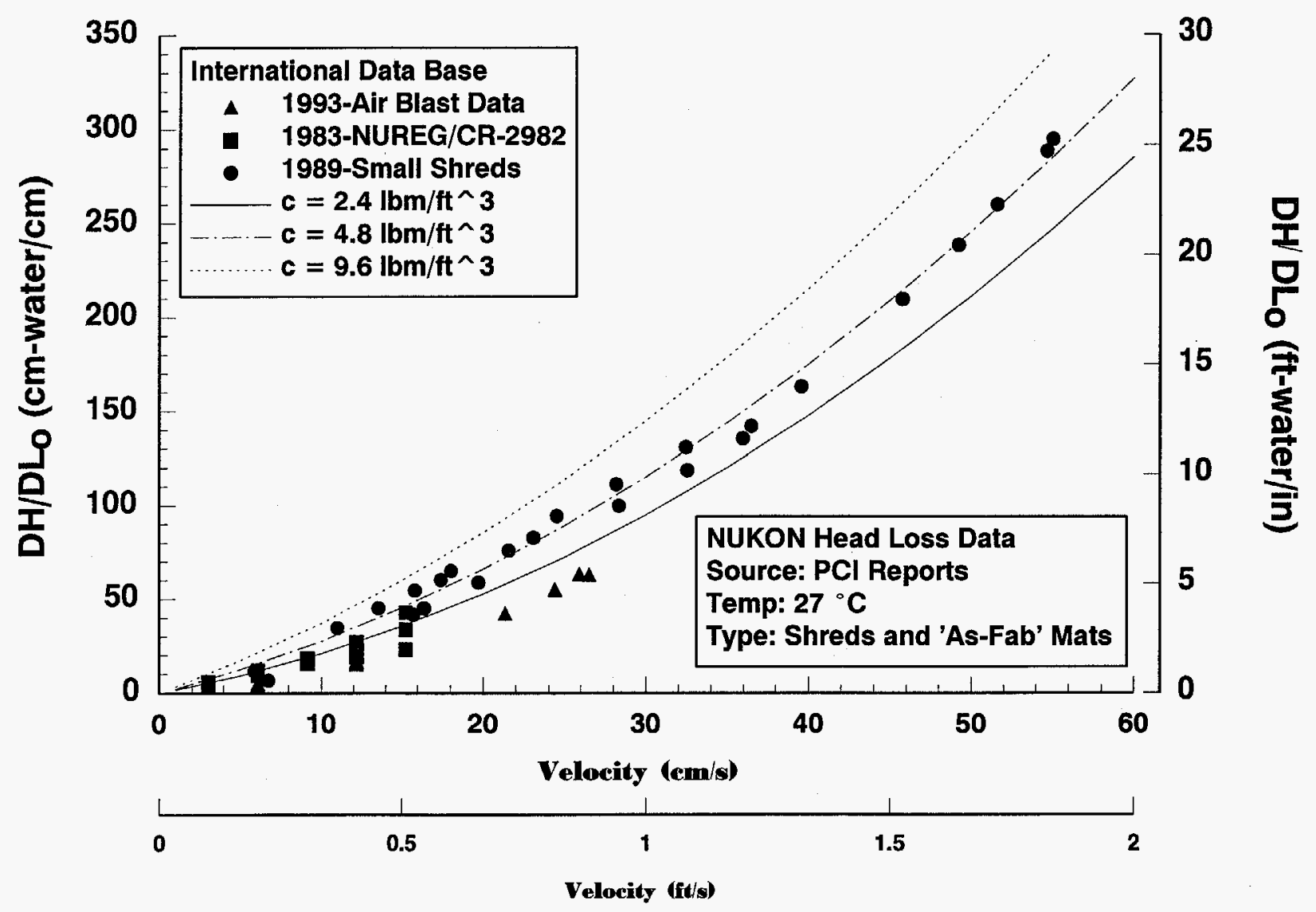

Figure B-23 Comparison of NUREG/CR-6224 Correlation with Head Loss Data for NUKON ${ }^{\mathrm{TM}}$ from International Data Base 
details on the test matrix can be found in Appendix E.

Since the amount of sludge on the fiber bed is known at the time the head loss measurement was made, application of the head loss model became direct. The following physical parameters were used:

$$
\begin{array}{ll}
\mathrm{D}_{\mathrm{f}}= & 7.112 \mu \mathrm{m} \\
\mathrm{S}_{\mathrm{vf}}= & 1.7142 \times 10^{5} \mathrm{ft}^{2} / \mathrm{ft}^{3}=5.6243 \times 10^{5} \\
\rho_{\mathrm{f}}= & 174.8 \mathrm{lbm} / \mathrm{ft}^{3}\left(2800 \mathrm{~kg} / \mathrm{m}^{3}\right) \text { and } \\
\rho_{\mathrm{p}}= & 324 \mathrm{lbm} / \mathrm{ft}^{3}\left(5190 \mathrm{~kg} / \mathrm{m}^{3}\right) \\
\mathrm{c}_{\text {sludge }}= & 65 \mathrm{lbm} / \mathrm{ft}^{3}\left(1041 \mathrm{~kg} / \mathrm{m}^{3}\right) ; \mathrm{c}_{\mathrm{o}}=2.4 \\
& \mathrm{lbm} / \mathrm{ft}^{3}\left(38.4 \mathrm{~kg} / \mathrm{m}^{3}\right)
\end{array}
$$

In addition, the following closure relationship was used for estimation of compressed bed actual thickness:

$$
\begin{array}{ll}
\mathrm{c}=1.3 \mathrm{c}_{\mathrm{o}}\left(\Delta \mathrm{H} / \Delta \mathrm{L}_{\mathrm{o}}\right)^{0.38} & \mathrm{c} \leq 65 \mathrm{lbm} / \mathrm{ft}^{3} \\
\mathrm{c}=65 \mathrm{lbm} / \mathrm{ft}^{3} & \text { Otherwise. }
\end{array}
$$

Appendix E provides point-by-point comparison of the experimental data with the correlation in a tabular form. Also, Figure B-24 compares experimental data, plotted as $\left(\Delta \mathrm{P}_{\text {mixed }}\right) /\left(\Delta \mathrm{P}_{\text {fiber }}\right)$ vs the sludge-to-fiber ratio, with the correlation predictions for bed thicknesses ranging from $1 / 4^{\prime \prime}$ to 1 ", an approach velocity of $0.15 \mathrm{ft} / \mathrm{s}$ and a water temperature of $125^{\circ} \mathrm{F}$. Good agreement was obtained over the entire range of comparison, particularly at higher fiber bed thicknesses where uniform beds are expected. The apparent large differences at low sludge-to-fiber mass ratios is attributable to associated experimental uncertainties which ranged up to $\pm 45 \%$ under these conditions. Also plotted in Figure B-24 are predictions of B-32b. Once again it appears that approximate head loss equations described in Section B.8.4 appear to perform reasonably well. Similar comparison could not be carried out with the BWROG [Ref. B.18] correlation since it was developed for ambient temperature and does not provide a means by which it can be extrapolated to $125^{\circ} \mathrm{F}$.

Similarly good comparison was obtained for other bed thicknesses and approach velocities whenever the head loss gradient is less than about $50 \mathrm{ft}$ water/inch. For higher head loss gradients, which typically occurred at higher approach velocities $(\mathrm{U}>1 \mathrm{ft} / \mathrm{s})$ coupled with large sludge-to-fiber ratios $(\eta>10)$, the correlation was found to overpredict the head loss. Figure B-25 plots this data for an approach velocity of $1.5 \mathrm{ft} / \mathrm{s}, \Delta \mathrm{L}_{\mathrm{o}}$ of $0.25 ", 0.5^{\prime \prime}$ and $1 "$, and a temperature of $125^{\circ} \mathrm{F}$. As evident from this figure, the correlation reasonably bounds the data for all thicknesses at low sludge-to-fiber mass ratios. But at high sludge-to-fiber mass ratios the correlation severely overestimates the head loss. This apparent over-prediction can be attributed to the fact that the model does not account for these beds being damaged by the high differential pressure. ${ }^{19}$ This does not pose a serious concern since in the BWR suppression pools the differential pressures are in the range of 5-25 ft-water. In this range the model predictions are in good agreement with the experimental data.

\section{B.8.5.2 Comparison with PP\&L Head Loss Data}

The PP\&L head loss data was obtained using a once-through facility described in Reference B.24. In these tests, a predetermined quantity of sludge was added to the mixing tank along with a known quantity of fibers. No additional sludge was added during the experiment, but additional quantities of fibrous material were added to maintain a certain fiber concentration level in the tank. The fibrous materials were characterized as fibers and the sludge was characterized as coarse with size distributions from $75 \mu \mathrm{m}$ to $3 \mathrm{~mm}$. Head loss across the strainer was measured as a function of time. The tests were terminated once the head loss approached about $22 \mathrm{ft}$-water $(0.07 \mathrm{MPa})$. The head loss measurements were tabulated as a function of time in Table 4 of Appendix C of Reference 24. Also presented in the table are fiber and sludge loadings on the strainer surface at respective times, calculated assuming a filtration efficiency of 1 for both fibers and particulate sludge. Considering that these filtration efficiencies were achieved for thicker beds, it is reasonable to assume that better agreement would be obtained closer to the end of the experiment. Table B-7 lists the experimental

\footnotetext{
${ }^{19}$ In the NRC experiments it was observed that holes were punched through what appeared to be initially uniform fiber bed by the shear forces resulting from high head loss (see Appendix E). Such effects were not incorporated into the present model.
} 


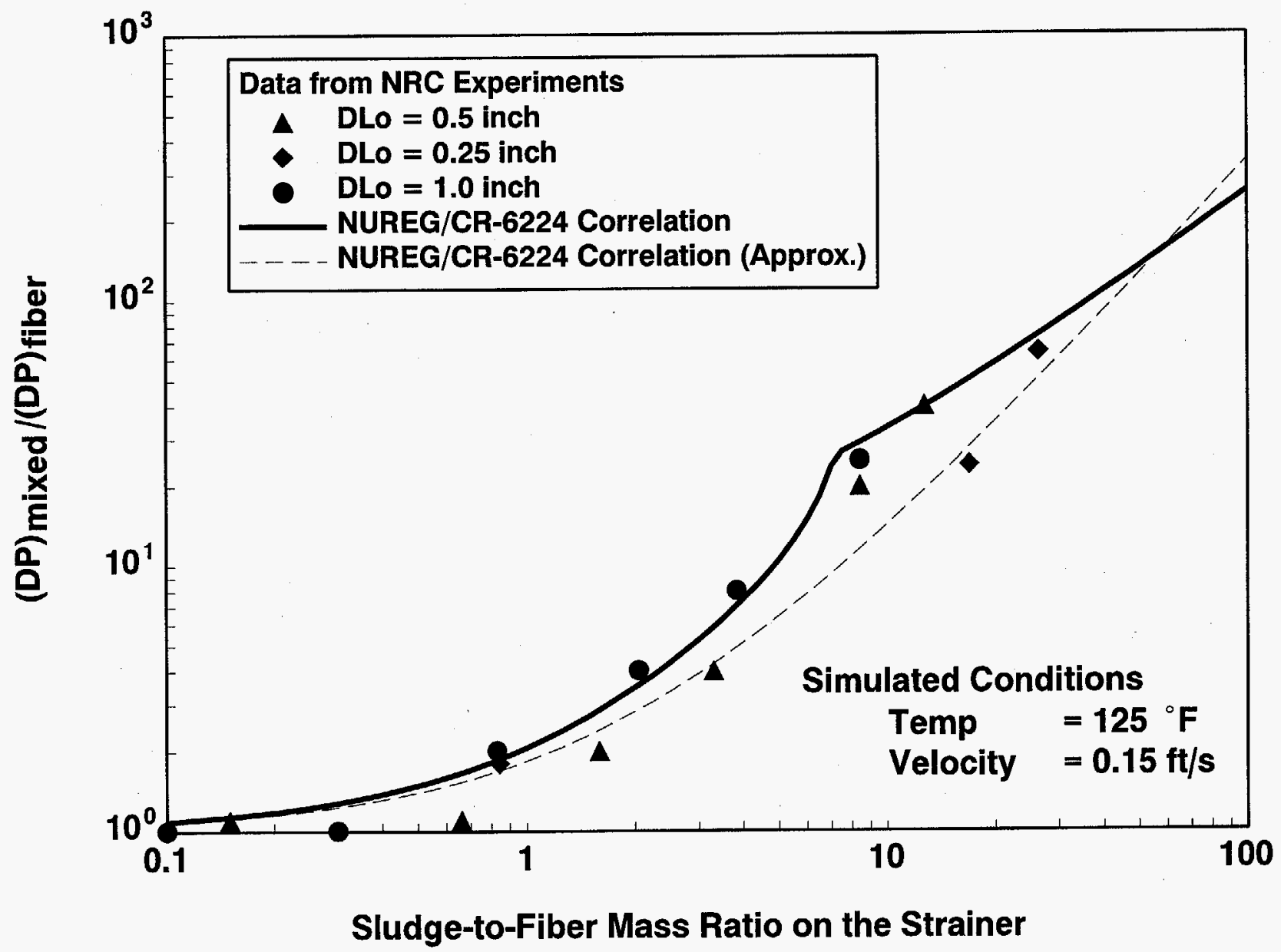

Figure B-24 Comparison of NRC Head Loss Experiments Data with the NUREG/CR-6224 Correlation 
Appendix B

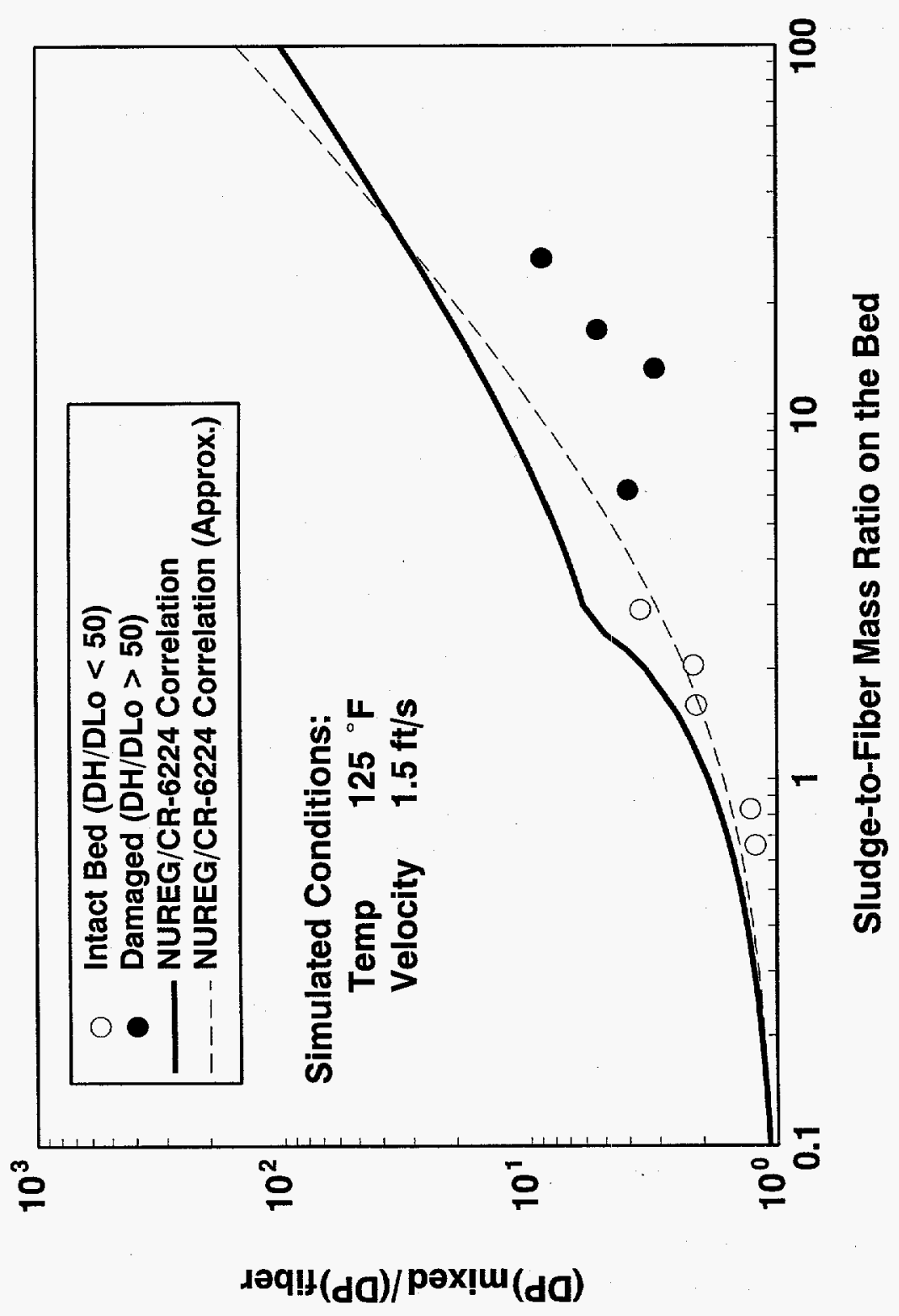

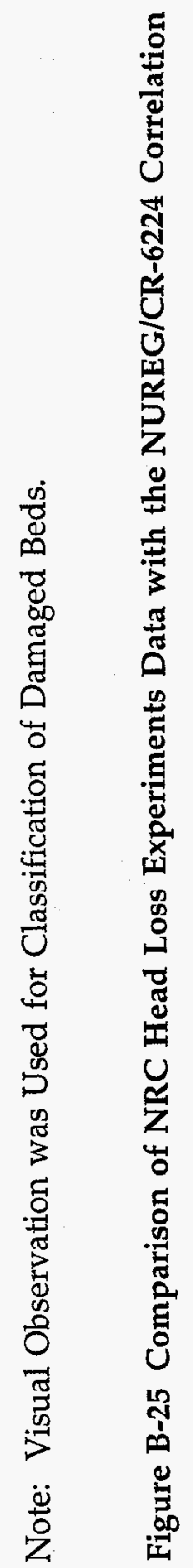


Table B-7 Comparison of PP\&L Experimental Data with Head Loss Model

\begin{tabular}{ccccccc}
\hline Test & $\begin{array}{c}\text { Time } \\
\text { min }\end{array}$ & $\begin{array}{c}\text { Approach } \\
\text { Velocity } \\
\mathbf{f t} / \text { sec }\end{array}$ & $\begin{array}{c}\text { Insulation } \\
\text { Thickness } \\
\mathbf{f t}\end{array}$ & $\begin{array}{c}\text { Sludge-to- } \\
\text { Fiber Mass } \\
\text { Ratio }\end{array}$ & $\begin{array}{c}\text { Head Loss } \\
\text { Expt. } \\
\text { ft-water }\end{array}$ & $\begin{array}{c}\text { Model } \\
\text { ft-water }\end{array}$ \\
\hline 26 & 6.5 & 0.65 & 0.033 & 3.37 & 28.1 & 28.31 \\
27 & 22.7 & 0.65 & 0.098 & 0.07 & 21.7 & 11.5 \\
29 & 40.5 & 0.67 & 0.021 & 7.62 & 22.9 & 26.03 \\
31 & 4.8 & 0.629 & 0.041 & 9.9 & 27.9 & 61 \\
32 & 4.0 & 0.593 & 0.037 & 3.04 & 27.8 & 27.7 \\
33 & 24.3 & 0.67 & 0.25 & 0.23 & 26.3 & 23.7 \\
34 & 5.4 & 0.84 & 0.028 & 4.06 & 19.9 & 23.75 \\
\hline
\end{tabular}

data which was compared with the model. Figure B-26 compares experimental data with the correlation predictions. Good agreement between the experiment and the model is observed, except for two cases: Test 27 and Test 31 . In addition, tests 28 and 30 were excluded from the comparison since both tests yielded head loss data that is inconsistent with the expected trends.

\section{B.8.6 Head Loss Model Limitations}

The head loss model is applicable only to fiber bed thicknesses where uniform bed formation is expected. Typically, this is valid for fiber bed thicknesses larger than $0.125 "(0.318 \mathrm{~cm})$. Below this value, it appears the bed does not have the required structure to bridge the strainer holes and filter the sludge particles. It appears that such thin beds may be visualized as resulting in partial blockage of the strainer. Application of the model in this range inevitably over-predicts the actual head loss. Hence, the model predictions over this range can be interpreted as upper bound estimates. Similarly the model does not take into consideration the damage inflicted on the fiber bed by high pressure drops (see Appendix $\mathrm{E}$ for further details). In general when the pressure drops exceeded $50 \mathrm{ft}$-water/in of debris bed, the bed underwent damage leading to a transition that closely resembles partially covered strainer. In this case also the model predictions were higher than the measured values. But in all cases the model predictions can be seen as bounding. Further improvements to the model may be possible. Nevertheless, it should be noted that model predictions in the parameter range of present interest are fairly close to the experimental data.

\section{B.9 Loss of ECCS NPSH Model}

As suggested in NUREG-0897, Rev. 1, loss of ECCS pumps is assumed to occur when the $\mathrm{NPSH}_{\text {margin }}$ is less than the predicted head loss due to strainer blockage, obtained using Equation B-21. The $\mathrm{NPSH}_{\text {margin }}$ is plant specific and can be estimated for a given plant using the methodology described in Section 3.2.3 of NUREG-0897, Rev. 1. This methodology can also be used to predict the effects of suppression pool temperature and containment pressure. 
Head Loss (ft-water/in of debris)

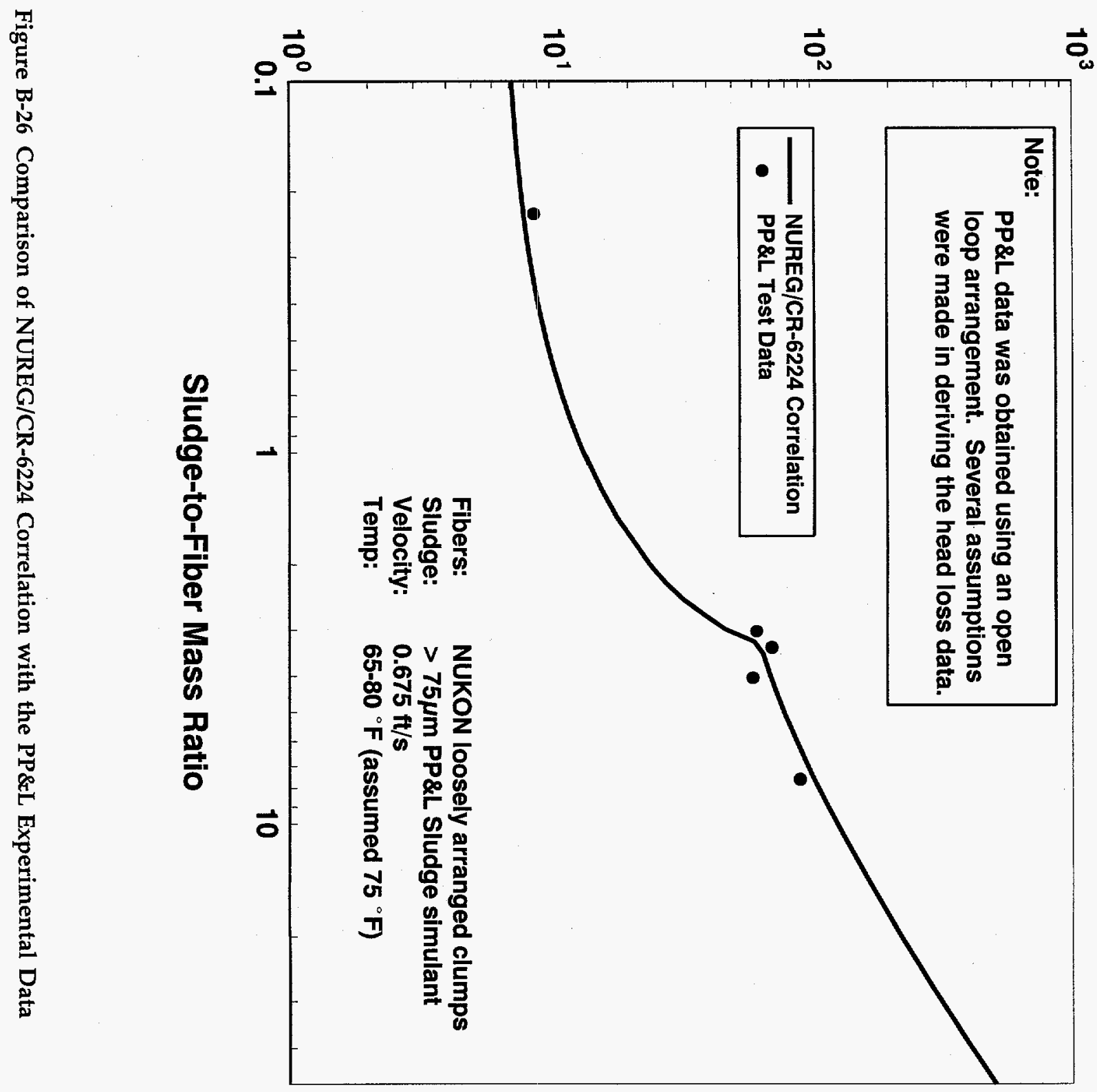


Appendix B

\section{References for Appendix B}

B.1. G. Zigler, et al., "Parametric Study of the Potential for BWR ECCS Strainer Blockage Due to LOCA-Generated Debris," Preliminary Draft Report, Science and Engineering Associates, Inc., SEA No. 93-55406-A:1, January 1994.

B.2. Memorandum from M. Marshall to C. Serpan, Subject: Summary of March 30, 1994 Public Meeting Concerning the SEA Study Results Related to the Potential for Loss of LPCI Capability in BWRs Due to LOCA Generated Debris, Dated: April 11, 1994.

B.3. G. G. Weigand et al., "Two-Phase Test Loads," published as Sandia National Laboratories Report SAND82-1935, NUREG/CR-2913, 1983.

B.4. F. J. Moody, "Prediction of Blowdown Thrust and Jet Forces," ASME Paper 69-HT-31, ASME, 1969.

B.5. American Nuclear Society, "Design Basis for Protection of Light Water Nuclear Power Plants Against the Effects of Postulated Pipe Rupture," ANSI/ANS-58.2-1988, October 1988.

B.6. NUREG-0661, "Safety Evaluation Report, Mark-I Containment Long-Term Program," Resolution of Generic Technical Activity A-7, NRC, 1980.

B.7. General Electric Company, "The General Electric Pressure Suppression Containment Analytical Model," General Electric Topical Report NEDO-10320, April 1971; Supplement 1, May 1971; Supplement 2, January 1973.

B.8. D. L. Galyardt, C. G. Hayes, and S. L. Kushman, "Mark I Containment Program Quarter-Scale Pressure Suppression Pool Swell Test Program: Scaling Evaluation, Task Number 5.5.1," General Electric Report NEDE-21627-P, January 1978.
B.9. C. K. Chan, et al, University of California, Los Angeles, "Suppression Pool Dynamics," NRC Report NUREG/CR-0264-3, February 1978.

B.10. R. L. Kiang and B. J. Grossi, "ThreeDimensional Pool Swell Modeling of a Mark I Suppression System," Electric Power Research Institute Report EPRI NP-906, October 1978.

B.11. A.W. Serkiz, "Containment Emergency Sump Performance," US Nuclear Regulatory Commission, NUREG-0897, Rev. 1, October 1985.

B.12. R.J. Olson, B.J. Darlaston, M.E. Mayfield and R.A. Schmidt, "The IPIRG Test Facility," 17th MPA Seminar, October 10-11, 1991.

B.13. "Karlshamn Tests 1992.Test Report, Steam Blast on Insulated Objects," ABB Atom, Report RVE 92-205, November 1992.

B.14. T. Kegel, "Air Blast Destructive Testing of NUKON ${ }^{\mathrm{TM}}$ Insulation Simulation of a Pipe Break LOCA," Colorado Engineering Experiment Station, Inc., October 1993.

B.15. Richard Faxen, "Barsebäck 1 and 2, Oskarshamn 1 and 2 - Strainers in Systems 322 and 323. Results from Blowdown Experiments in a Test Rig," RVA 92-340, ABB Atom, November 27, 1992.

B.16. D.V. Rao and F. Souto, "Experimental Study of Head Loss and Filtration for LOCA Debris," SEA No. 95-554-06-A:8, 1995.

B.17. Letter from T. Green to A. Serkiz, "BWR Owners' Group ECCS Suction Strainer Committee - Suppression Pool Sludge Particle Distribution," General Electric Company, OG94-661-161, September 1994.

B.18. BWR Owners' Group, "Interim Report of the BWR Owners' Group ECCS Suction Strainer Committee," BWROG-94157, December 1994. 
B.19. P. Murthy, M. Padmanabhan, and G. Hecker, "Tests of Particle Settling Velocities in Still Pools," Report No. ARL/SEA/787/94/1, Alden Research Laboratory, Inc., Holden, MA, June 1994.

B.20. M. Bloomquist, M. Delby, "Barsebäck 1 and 2, Oskarshamn 1 and 2, Ringhals 1: Report from tests concerning the effect of steam jet on Caposil insulation at Karlshamn, carried out between April 22-23, 1993, and May 6, 1993," ABB-Karlshamn, SDC 93-1174, June 1993.

B.21. P. Tarkpa and B. Anersson, "Steam Jet Dislodgement of Thermal Insulating Material of type Newtherm 1000 and Caposil HTS," Studsvik, M-93/41, April 1993.

B.22. P. Tarkpa and B. Anersson, "Steam Jet Dislodgement of Two Thermal Insulating Materials," Studsvik, M-93/60, May 1993.

B.23. Sydkraft, "Report Concerning the Quantity of Insulation Which was not Washed Down in Connection with the 314 Event," PBM-921123, November 26, 1992.

B.24. K.W. Brinkman and P.W. Brady, "Results of Hydraulic Tests on ECCS Strainer Blockage and Material Transport in a BWR Suppression Pool," Pennsylvania Power \& Light Company, EC-059-1006, Rev. 0, May 1994.

B.25. E. S. Pettyjohn and E. G. Christiansen, "Effects of Particle Shape on Free Settling Rates of Isometric Particles," Chemical Engineering Progress, Vol. 44, No. 2, pp. 157, 1948.

B.26. Perry's Chemical Engineering Handbook, Particle Dynamics, McGraw-Hill Book Co., 1977, pp. 5-61.

B.27. H. A. Becker, "The Effects of Shape and Reynolds Number on Drag in the Motion of Freely Oriented Body in an Infinite Fluid," The Canadian Journal of Chemical Engineering, 1959.
B.28. J. W. Daily and D. Harleman, "Fluid Dynamics," Addison-Wesley Publishing Company, Inc., 1966.

B.29. G. T. Orlob, "Eddy Diffusion in Homogeneous Turbulence," Trans. of ASCE, Vol., 126, Part I, 1961.

B.30. Memorandum from M. Marshall to A. Serkiz, Subject: Presentation Slides Used During the May 4, 1994 Meeting, Dated July 20, 1994 .

B.31. M.E. Teske, "Mark I Vacuum Breaker Dynamic Load Specification, Rev. 3," Report Prepared for General Electric Co., Continuum Dynamics Report 80-4, February 1980.

B.32. D. N. Brocard, "Buoyancy, Transport, and Head Loss of Fibrous Reactor Insulation," Alden Research Laboratory, published as Sandia National Laboratories Report No. SAND82-7205, Rev, NUREG/CR-2982, Rev. 1, July 1983.

B.33. J. B. Nystrom, "NUKON" Insulation Head Loss Tests," ARL/124-89/M670F, Alden Research Laboratories, Inc., 1989.

B.34. B. J. Pennino and G. Hecker, "Head Loss Tests with Blast-generated NUKON" Insulation Debris," ARL/140-93/M670F, 1993.

B.35. M. Muskat, Physical Principles of Oil Production, McGraw-Hill Book Co., Inc., New York, NY, 1949, p. 128.

B.36. J. C. Ward, "Turbulent Flow in Porous Media," Journal of the Hydraulics Division, Proceedings of ASEC, HY5, 1964.

B.37. S. Ergun, "Fluid Flow Through Packed Columns," Chemical Engineering Progress, Vol. 48, No. 2, P. 89, 1952.

B.38. C. Kyan, D. T. Wasan and R. C. Kitner, "Flow of Single-Phase Fluids Through Fibrous Beds," Ind. Eng. Chem. Fundam., Vol. 9, No. 4, 1970. 
Appendix B

B.39. C. N. Davies, "Proceedings of Institute of Mechanical Engineers," (London), B1, p. 185, 1962.

B.40. W. L. Ingmanson, B. D. Andrews, and R. C. Johnson, "Internal Pressure Distribution In Compressible Mats Under Fluid Stress," TAPI Journal, Vol. 42, No. 10, 1959. 
Appendix C

Parametric Analysis 



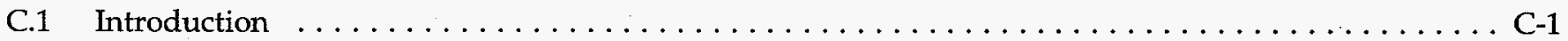

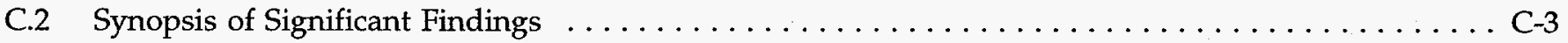

C.3 Sensitivity of Suppression Pool Volume $\ldots \ldots \ldots \ldots \ldots \ldots \ldots \ldots \ldots \ldots \ldots \ldots \ldots \ldots \ldots \ldots$

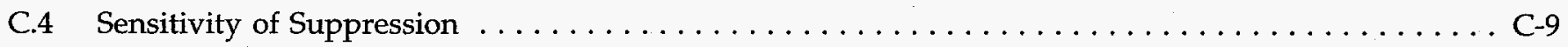

C.5 Sensitivity of Insulation Destruction Factor $\ldots \ldots \ldots \ldots \ldots \ldots \ldots \ldots \ldots \ldots \ldots \ldots \ldots \ldots \ldots \ldots$

C.6 Sensitivity of Drywell Transport Factor $\ldots \ldots \ldots \ldots \ldots \ldots \ldots \ldots \ldots \ldots \ldots \ldots \ldots \ldots \ldots$ C-17

C.7 Sensitivity of Turbulence Factor $\ldots \ldots \ldots \ldots \ldots \ldots \ldots \ldots \ldots \ldots \ldots \ldots \ldots \ldots \ldots \ldots \ldots \ldots \ldots \ldots \ldots$

C.8 Sensitivity of Particulate Debris Volume $\ldots \ldots \ldots \ldots \ldots \ldots \ldots \ldots \ldots \ldots \ldots \ldots \ldots \ldots \ldots \ldots$

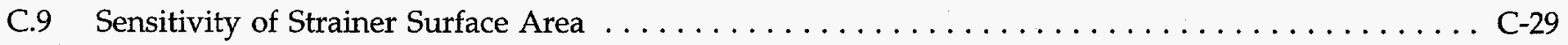

C.10 Sensitivity of Available NPSH Margin $\ldots \ldots \ldots \ldots \ldots \ldots \ldots \ldots \ldots \ldots \ldots \ldots \ldots \ldots \ldots \ldots \ldots \ldots \ldots$

C.11 Sensitivity of ECCS Flow Rate $\ldots \ldots \ldots \ldots \ldots \ldots \ldots \ldots \ldots \ldots \ldots \ldots \ldots \ldots \ldots \ldots \ldots \ldots \ldots \ldots \ldots \ldots$

C.12 Sensitivity of $\triangle \mathrm{P}$ Correlation Multiplier $\ldots \ldots \ldots \ldots \ldots \ldots \ldots \ldots \ldots \ldots \ldots \ldots \ldots \ldots \ldots \ldots$

C.13 Sensitivity of Suppression Pool Temperature $\ldots \ldots \ldots \ldots \ldots \ldots \ldots \ldots \ldots \ldots \ldots \ldots \ldots \ldots$

C.14 Sensitivity of Strainer Filtration Efficiency $\ldots \ldots \ldots \ldots \ldots \ldots \ldots \ldots \ldots \ldots \ldots \ldots \ldots \ldots \ldots$

C.15 Sensitivity of System Retention Fraction $\ldots \ldots \ldots \ldots \ldots \ldots \ldots \ldots \ldots \ldots \ldots \ldots \ldots \ldots \ldots$

List of Tables

Table

Page No.

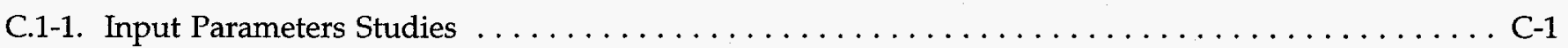

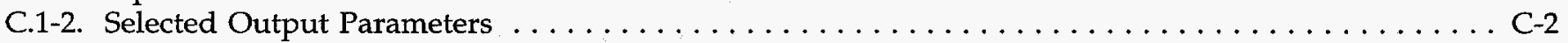

C.3-1. Calculational Cases for Suppression Pool Volume Sensitivity Study $\ldots \ldots \ldots \ldots \ldots \ldots \ldots \ldots \ldots$ C-5

C.4-1. Calculational Cases for Suppression Pool Depth Sensitivity Study $\ldots \ldots \ldots \ldots \ldots \ldots \ldots \ldots \ldots$ C-9

C.5-1. Calculational Cases for Insulation Destruction Factor Sensitivity Study $\ldots \ldots \ldots \ldots \ldots \ldots \ldots$ C-13

C.6-1. Calculational Cases for Drywell Transport Factor Sensitivity Study . . . . . . . . . . . . . . C-17

C.7-1. Calculational Cases for Turbulence Factor Sensitivity Study $\ldots \ldots \ldots \ldots \ldots \ldots \ldots \ldots \ldots \ldots$ C-21

C.8-1. Calculational Cases for the Particulate Debris Volume Sensitivity Study . . . . . . . . . . . C-25

C.9-1. Calculational Cases for the Strainer Surface Area Sensitivity Study . . . . . . . . . . . . C-29

C.10-1. Calculational Cases for the Available NPSH Margin Sensitivity Study . . . . . . . . . . C-33

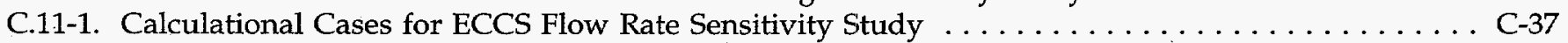

C.12-1. Calculational Cases for $\triangle \mathrm{P}$ Correlation Multiplier Sensitivity Study . . . . . . . . . . . . C-41

C.13-1. Calculational Cases for Suppression Pool Temperature Sensitivity Study . . . . . . . . . . . C-45

C.14-1. Calculational Cases for Strainer Filtration Efficiency Sensitivity Study . . . . . . . . . . . . . . C C-49

C.15-1. Calculational Cases for System Retention Fraction Sensitivity Study . . . . . . . . . . . . C-53 
Appendix C

\section{List of Figures}

C.3-1 Maximum and 30-Minute Head Loss vs. Suppression Pool Volume . . . . . . . . . . . . C-6

C.3-2 Maximum Theoretical/Actual Cake Thicknesses vs. Suppression Pool Volume . . . . . . . . . C-6

C.3-3 Time of Blockage vs Suppression Pool Volume $\ldots \ldots \ldots \ldots \ldots \ldots \ldots \ldots \ldots \ldots \ldots \ldots \ldots$ C-6

C.3-4 Frequency for Loss of NPSH vs Suppression Pool Volume $\ldots \ldots \ldots \ldots \ldots \ldots \ldots \ldots \ldots \ldots$ C-6

C.3-5 Fiber Mass Balance at the Time of Blockage for Weld RCA-J006 $\ldots \ldots \ldots \ldots \ldots \ldots \ldots \ldots$ C-7

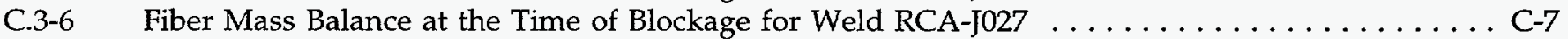

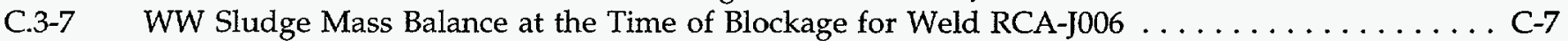

C.3-8 WW Sludge Mass Balance at the Time of Blockage for Weld RCA-J027 . . . . . . . . . . . C-7

C.3-9 DW Particulate Mass Balance at the Time of Blockage for Weld RCA-J006 . . . . . . . . . . C-8

C.3-10 DW Particulate Mass Balance at the Time of Blockage for Weld RCA-J027 . . . . . . . . . C-8

C.3-11 Sludge to Fiber Mass Ratio of the Cake at the Time of Blockage $\ldots \ldots \ldots \ldots \ldots \ldots \ldots \ldots$ C-8

C.4-1 Maximum and 30-Minute Head Loss vs. Suppression Pool Depth . . . . . . . . . . . . . . C-10

C.4-2 Maximum Theoretical/Actual Cake Thicknesses vs. Suppression Pool Depth . . . . . . . . . C-10

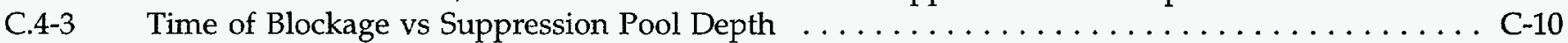

C.4-4 Frequency for Loss of NPSH vs Suppression Pool Depth . . . . . . . . . . . . . . . . . . . C C-10

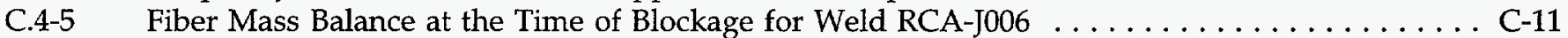

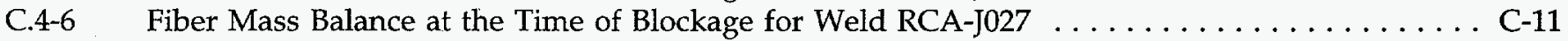

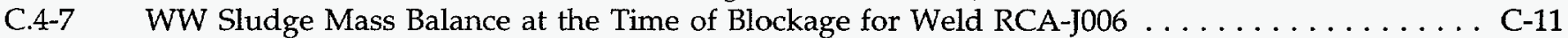

C.4-8 WW Sludge Mass Balance at the Time of Blockage for Weld RCA-J027 . . . . . . . . . . C-11

C.4-9 DW Particulate Mass Balance at the Time of Blockage for Weld RCA-J006 . . . . . . . . . . C-12

C.4-10 DW Particulate Mass Balance at the Time of Blockage for Weld RCA-J027 . . . . . . . . . . C-12

C.4-11 Sludge to Fiber Mass Ratio of the Cake at the Time of Blockage $\ldots \ldots \ldots \ldots \ldots \ldots \ldots \ldots$ C-12

C.5-1 Maximum and 30-Minute Head Loss vs. Insulation Destruction Factors . . . . . . . . . . . . C-14

C.5-2 Maximum Theoretical/Actual Cake Thicknesses vs. Insulation Destruction Factors . . . . . . . . C-14

C.5-3 Time of Blockage vs Insulation Destruction Factors $\ldots \ldots \ldots \ldots \ldots \ldots \ldots \ldots \ldots \ldots \ldots$ C-14

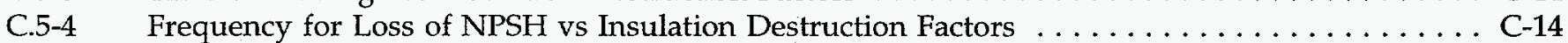

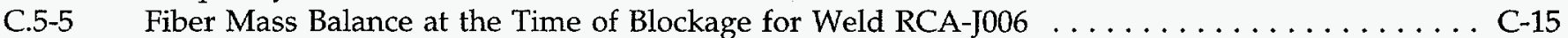

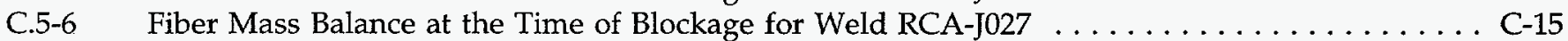

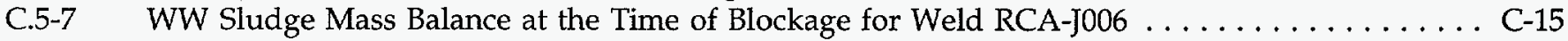

C.5-8 WW Sludge Mass Balance at the Time of Blockage for Weld RCA-J027 . . . . . . . . . . C-15

C.5-9 DW Particulate Mass Balance at the Time of Blockage for Weld RCA-J006 . . . . . . . . . C-16

C.5-10 DW Particulate Mass Balance at the Time of Blockage for Weld RCA-J027 . . . . . . . . C-16

C.5-11 Sludge to Fiber Mass Ratio of the Cake at the Time of Blockage $\ldots \ldots \ldots \ldots \ldots \ldots \ldots$ C-16

C.6-1 Maximum and 30-Minute Head Loss vs. Drywell Transport Factors . . . . . . . . . . . . C-18

C.6-2 Maximum Theoretical/Actual Cake Thicknesses vs. Drywell Transport Factors . . . . . . . . . C-18

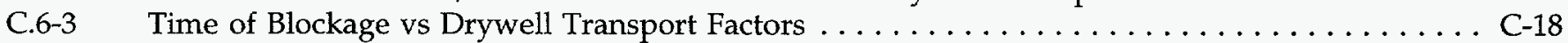

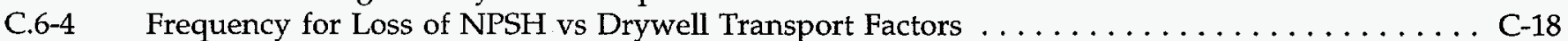

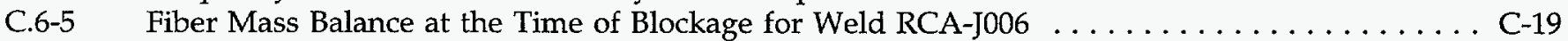

C.6-6 Fiber Mass Balance at the Time of Blockage for Weld RCA-J027 . . . . . . . . . . . . . . . C-19

C.6-7 WW Sludge Mass Balance at the Time of Blockage for Weld RCA-j006 . . . . . . . . . . . . . C-19

C.6-8 WW Sludge Mass Balance at the Time of Blockage for Weld RCA-J027 . . . . . . . . . . . . C C-19

C.6-9 DW Particulate Mass Balance at the Time of Blockage for Weld RCA-J006 . . . . . . . . . C-20

C.6-10 DW Particulate Mass Balance at the Time of Blockage for Weld RCA-J027 . . . . . . . . . C-20

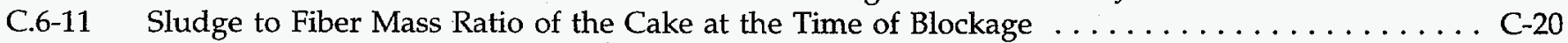

C.7-1 Maximum and 30-Minute Head Loss vs. Turbulence Factors . . . . . . . . . . . . . . . . . C-22

C.7-2 Maximum Theoretical/Actual Cake Thicknesses vs. Turbulence Factors $\ldots \ldots \ldots \ldots \ldots \ldots$ C-22

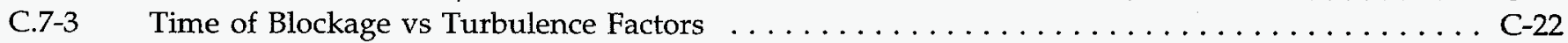

C.7-4 Frequency for Loss of NPSH vs Turbulence Factors $\ldots \ldots \ldots \ldots \ldots \ldots \ldots \ldots \ldots \ldots \ldots \ldots$ C-22 
C.7-5 Fiber Mass Balance at the Time of Blockage for Weld RCA-J006 $\ldots \ldots \ldots \ldots \ldots \ldots \ldots \ldots$ C-23

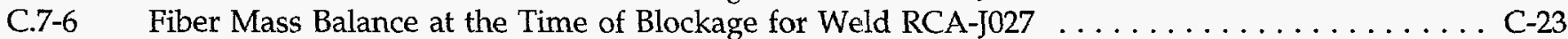

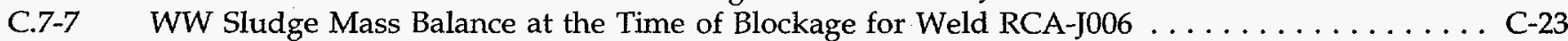

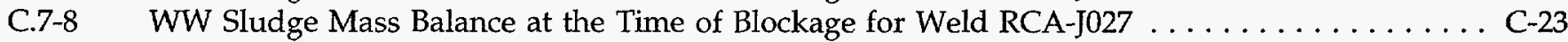

C.7-9 DW Particulate Mass Balance at the Time of Blockage for Weld RCA-J006 . . . . . . . . . C-24

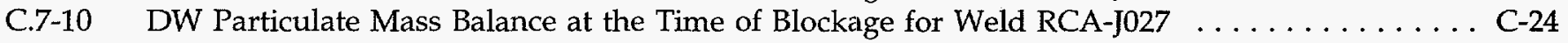

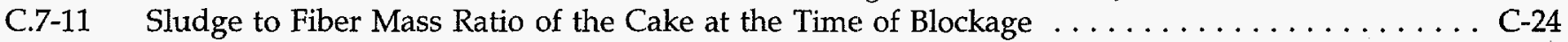

C.8-1 Maximum and 30-Minute Head Loss vs. Particulate Debris Volume . . . . . . . . . . . . C-26

C.8-2 Maximum Theoretical/Actual Cake Thicknesses vs. Particulate Debris Volume . . . . . . . . . . C-26

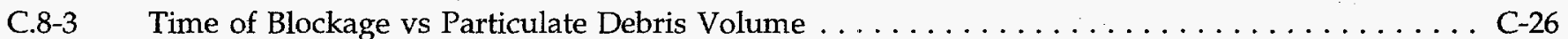

C.8-4 Frequency for Loss of NPSH vs Particulate Debris Volume $\ldots \ldots \ldots \ldots \ldots \ldots \ldots \ldots \ldots \ldots$ C-26

C.8-5 Fiber Mass Balance at the Time of Blockage for Weld RCA-J006 $\ldots \ldots \ldots \ldots \ldots \ldots \ldots \ldots$ C-27

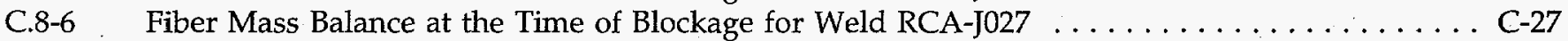

C.8-7 WW Sludge Mass Balance at the Time of Blockage for Weld RCA-J006 . . . . . . . . . . C C-27

C.8-8 WW Sludge Mass Balance at the Time of Blockage for Weld RCA-J027 . . . . . . . . . . . C-27

C.8-9 DW Particulate Mass Balance at the Time of Blockage for Weld RCA-J006 $\ldots \ldots \ldots \ldots \ldots$ C-28

C.8-10 DW Particulate Mass Balance at the Time of Blockage for Weld RCA-j027 . . . . . . . . C-28

C.8-11 Sludge to Fiber Mass Ratio of the Cake at the Time of Blockage $\ldots \ldots \ldots \ldots \ldots \ldots \ldots \ldots$ C-28

C.9-1 Maximum and 30-Minute Head Loss vs. Strainer Surface Area . . . . . . . . . . . . . C-30

C.9-2 Maximum Theoretical/Actual Cake Thicknesses vs. Strainer Surface Area . . . . . . . . . . C-30

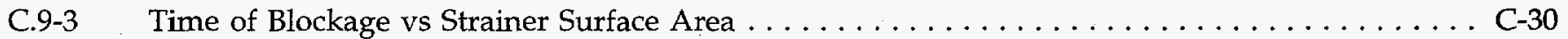

C.9-4 Frequency for Loss of NPSH vs Strainer Surface Area . . . . . . . . . . . . . . C-30

C.9-5 Fiber Mass Balance at the Time of Blockage for Weld RCA-J006 $\ldots \ldots \ldots \ldots \ldots \ldots \ldots \ldots$ C-31

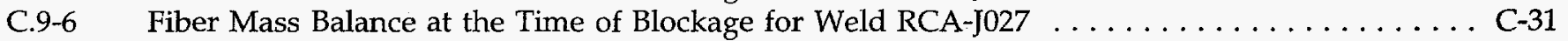

C.9-7 WW Sludge Mass Balance at the Time of Blockage for Weld RCA-J006 . . . . . . . . . . C-31

C.9-8 WW Sludge Mass Balance at the Time of Blockage for Weld RCA-J027 . . . . . . . . . . . . . C-31

C.9-9 DW Particulate Mass Balance at the Time of Blockage for Weld RCA-J006 . . . . . . . . . C C-32

C.9-10 DW Particulate Mass Balance at the Time of Blockage for Weld RCA-J027 . . . . . . . . . C-32

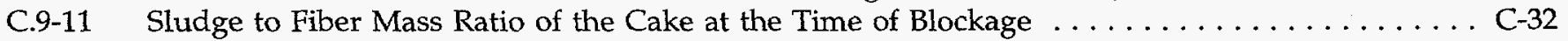

C.10-1 Maximum and 30-Minute Head Loss vs. Available NPSH Margin . . . . . . . . . . . . C-34

C.10-2 Maximum Theoretical/Actual Cake Thicknesses vs. Available NPSH Margin . . . . . . . . C C-34

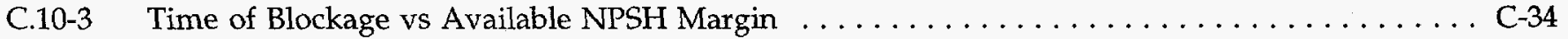

C.10-4 Frequency for Loss of NPSH vs Suppression Pool Volume $\ldots \ldots \ldots \ldots \ldots \ldots \ldots \ldots \ldots$ C-34

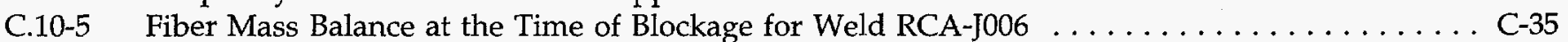

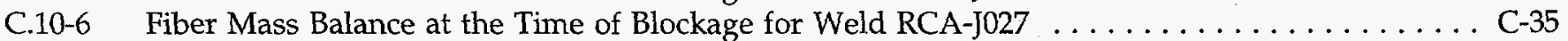

C.10-7 WW Sludge Mass Balance at the Time of Blockage for Weld RCA-J006 . . . . . . . . . . C-35

C.10-8 WW Sludge Mass Balance at the Time of Blockage for Weld RCA-J027 . . . . . . . . . . . C-35

C.10-9 DW Particulate Mass Balance at the Time of Blockage for Weld RCA-J006 . . . . . . . . . C-36

C.10-10 DW Particulate Mass Balance at the Time of Blockage for Weld RCA-J027 . . . . . . . . . . C-36

C.10-11 Sludge to Fiber Mass Ratio of the Cake at the Time of Blockage . . . . . . . . . . . C-36

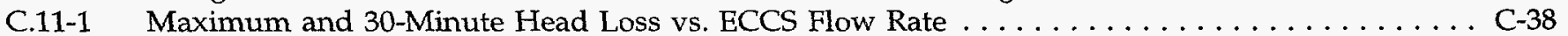

C.11-2 Maximum Theoretical/Actual Cake Thicknesses vs. ECCS Flow Rate . . . . . . . . . . . C-38

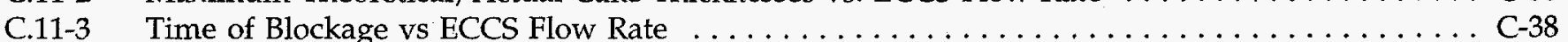

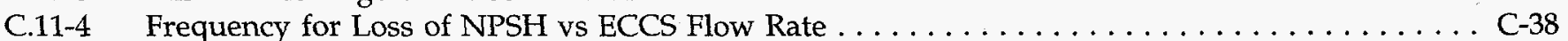

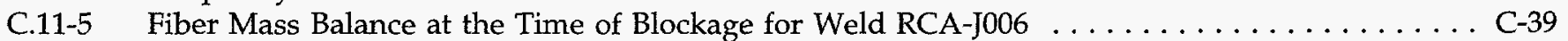

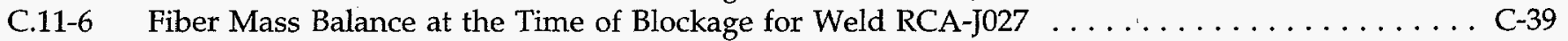

C.11-7 WW Sludge Mass Balance at the Time of Blockage for Weld RCA-j006 . . . . . . . . . . . C-39

C.11-8 WW Sludge Mass Balance at the Time of Blockage for Weld RCA-J027 . . . . . . . . . . C-39

C.11-9 DW Particulate Mass Balance at the Time of Blockage for Weld RCA-J006 . . . . . . . . . . C-40

C.11-10 DW Particulate Mass Balance at the Time of Blockage for Weld RCA-J027 . . . . . . . . . C-40

C.11-11 Sludge to Fiber Mass Ratio of the Cake at the Time of Blockage $\ldots \ldots \ldots \ldots \ldots \ldots \ldots$. C-40 
Appendix C

C.12-1 Maximum and 30-Minute Head Loss vs. $\mathrm{dP}$ Correlation Multiplier . . . . . . . . . . . C C-42

C.12-2 Maximum Theoretical/Actual Cake Thicknesses vs. dP Correlation Multiplier . . . . . . . . . C-42

C.12-3 Time of Blockage vs dP Correlation Multiplier $\ldots \ldots \ldots \ldots \ldots \ldots \ldots \ldots \ldots \ldots \ldots \ldots$ C-42

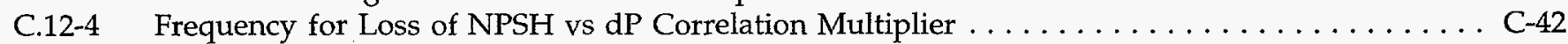

C.12-5 Fiber Mass Balance at the Time of Blockage for Weld RCA-J006 $\ldots \ldots \ldots \ldots \ldots \ldots \ldots \ldots$ C-43

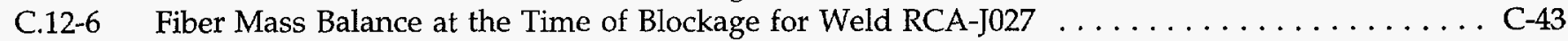

C.12-7 WW Sludge Mass Balance at the Time of Blockage for Weld RCA-J006 . . . . . . . . . C C-43

C.12-8 WW Sludge Mass Balance at the Time of Blockage for Weld RCA-J027 . . . . . . . . . . C-43

C.12-9 DW Particulate Mass Balance at the Time of Blockage for Weld RCA-J006 . . . . . . . . . . C-44

C.12-10 DW Particulate Mass Balance at the Time of Blockage for Weld RCA-J027 . . . . . . . . . C-44

C.12-11 Sludge to Fiber Mass Ratio of the Cake at the Time of Blockage . . . . . . . . . . . . C-44

C.13-1 Maximum and 30-Minute Head Loss vs. Suppression Pool Temperature . . . . . . . . . . . C-46

C.13-2 Maximum Theoretical/Actual Cake Thicknesses vs. Suppression Pool Temperature . . . . . . . C-46

C.13-3 Time of Blockage vs Suppression Pool Temperature $\ldots \ldots \ldots \ldots \ldots \ldots \ldots \ldots \ldots \ldots \ldots$ C-46

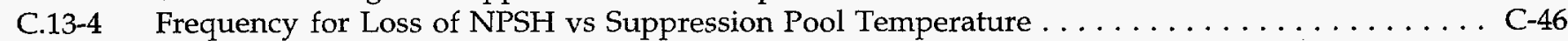

C.13-5 Fiber Mass Balance at the Time of Blockage for Weld RCA-J006 $\ldots \ldots \ldots \ldots \ldots \ldots \ldots \ldots$ C-47

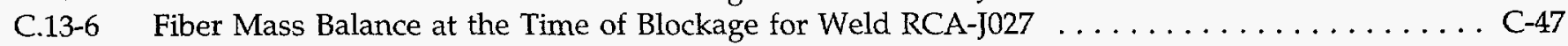

C.13-7 WW Sludge Mass Balance at the Time of Blockage for Weld RCA-J006 . . . . . . . . . . C-47

C.13-8 WW Sludge Mass Balance at the Time of Blockage for Weld RCA-J027 . . . . . . . . . C-47

C.13-9 DW Particulate Mass Balance at the Time of Blockage for Weld RCA-J006 . . . . . . . . . . C-48

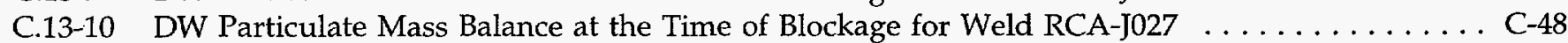

C.13-11 Sludge to Fiber Mass Ratio of the Cake at the Time of Blockage $\ldots \ldots \ldots \ldots \ldots \ldots \ldots$ C-48

C.14-1 Maximum and 30-Minute Head Loss vs. Strainer Filtration Efficiency . . . . . . . . . . . C-50

C.14-2 Maximum Theoretical/Actual Cake Thicknesses vs. Strainer Filtration Efficiency . . . . . . . . C-50

C.14-3 Time of Blockage vs Strainer Filtration Efficiency $\ldots \ldots \ldots \ldots \ldots \ldots \ldots \ldots \ldots \ldots \ldots$ C-50

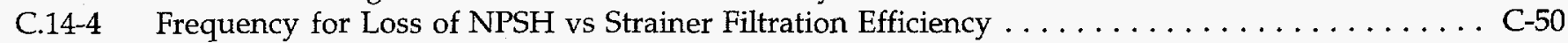

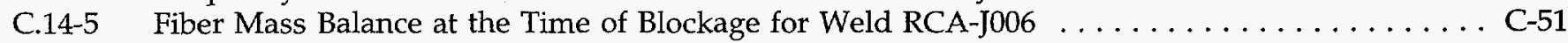

C.14-6 Fiber Mass Balance at the Time of Blockage for Weld RCA-J027 . . . . . . . . . . . . C-51

C.14-7 WW Sludge Mass Balance at the Time of Blockage for Weld RCA-j006 . . . . . . . . . C-51

C.14-8 WW Sludge Mass Balance at the Time of Blockage for Weld RCA-J027 . . . . . . . . . . . C-51

C.14-9 DW Particulate Mass Balance at the Time of Blockage for Weld RCA-J006 . . . . . . . . . . C-52

C.14-10 DW Particulate Mass Balance at the Time of Blockage for Weld RCA-J027 . . . . . . . . C-52

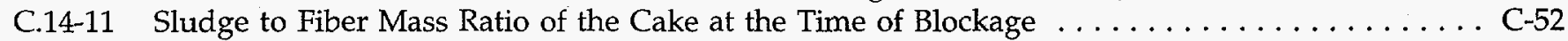

C.15-1 Maximum and 30-Minute Head Loss vs. System Retention Fraction . . . . . . . . . . . . . . C-54

C.15-2 Maximum Theoretical/Actual Cake Thicknesses vs. System Retention Fraction . . . . . . . . . . C-54

C.15-3 Time of Blockage vs System Retention Fraction . . . . . . . . . . . . . . . . . . C-54

C.15-4 Frequency for Loss of NPSH vs System Retention Fraction $\ldots \ldots \ldots \ldots \ldots \ldots \ldots \ldots \ldots$ C-54

C.15-5 Fiber Mass Balance at the Time of Blockage for Weld RCA-J006 $\ldots \ldots \ldots \ldots \ldots \ldots \ldots \ldots$ C-55

C.15-6 Fiber Mass Balance at the Time of Blockage for Weld RCA-J027 . . . . . . . . . . . . . . C C-55

C.15-7 WW Sludge Mass Balance at the Time of Blockage for Weld RCA-J006 . . . . . . . . . . . C-55

C.15-8 WW Sludge Mass Balance at the Time of Blockage for Weld RCA-J027 . . . . . . . . . . C-55

C.15-9 DW Particulate Mass Balance at the Time of Blockage for Weld RCA-J006 . . . . . . . . C C-56

C.15-10 DW Particulate Mass Balance at the Time of Blockage for Weld RCA-J027 . . . . . . . . . C-56

C.15-11 Sludge to Fiber Mass Ratio of the Cake at the Time of Blockage . . . . . . . . . . . . C 56

NUREG/CR-6224 C-vi 


\section{C.1 Introduction}

BLOCKAGE v2.3 was developed to analyze ECCS strainer performance in the reference plant following a Loss of Coolant Accident (LOCA). A parameter sensitivity analysis was performed that examined the impact of various input parameters on the model predictions. The parameters varied included debris generation model parameters, the ECCS flow rate and available NPSH margin, the suppression pool model resuspension and settling parameters, strainer surface area and filtration efficiency, and the head loss correlation. It should be noted that "Blockage" is used in this Appendix as an abbreviation for "loss of ECCS NPSH margin."

This study can be categorized as a separate effects study in that each selected input parameter was varied separately from the base case value while the remaining parameters were kept fixed. The impact on the selected output parameters was determined and is presented as plots. The plotted results are generally presented as percent changes in output versus percent change in input.

The input parameters analyzed are listed in Table C.1-1 along with the range of variation, the variation intervals, and their base case values.

The output parameters selected for analysis are presented in Table C.1-2 along with their base case values and time of selection. The ECCS blockage frequency (loss of NPSH) reflects the sensitivity of the input parameter upon overall plant risk. The parameters studied are dependent upon each specific weld in the plant; therefore, two particular welds were selected for analysis. The large and medium LOCA welds, RCA-J006 and RCA-J027, respectively, were selected as representative welds. These welds are described in Chapter 3 . All calculations were ended at 21,600 seconds.

Table C.1-1. Input Parameters Studies

\begin{tabular}{|c|c|c|c|}
\hline Input Parameter & Range & Intervals & Base Case Value \\
\hline Suppression Pool Volume & $-50 \%$ to $+50 \%$ & $5 \%$ & $58,900 \mathrm{ft}^{3}$ \\
\hline Suppression Pool Depth & $-50 \%$ to $+50 \%$ & $5 \%$ & $10 \mathrm{ft}$ \\
\hline Insulation Destruction Factors & $-50 \%$ to $+50 \%$ & $5 \%$ & $0.75,0.6,0.4$ for $\mathrm{L} / \mathrm{D}=3,5, \& 7$ \\
\hline Drywell Transport Factors & $-20 \%$ to $+60 \%$ & $5 \%$ & $0.75,0.5,0.25$ for $H, M, \& L$ \\
\hline Turbulence Factors & $-100 \%$ to $+100 \%$ & $10 \%$ & 0.5 shortly after blowdown \\
\hline Particulate Debris Volume & $-50 \%$ to $+250 \%$ & $10 \%$ & $1.76 \mathrm{ft}^{3}(\mathrm{DW}), 2.6 \mathrm{ft}^{3}(\mathrm{WW})$ \\
\hline Strainer Surface Area & $-50 \%$ to $+900 \%$ & $\begin{array}{l}10 \%(<250 \%) \\
25 \%(>250 \%)\end{array}$ & $37.62 \mathrm{ft}^{2}$ \\
\hline Available NPSH Margin & $-50 \%$ to $+100 \%$ & $5 \%$ & $14 \mathrm{ft}$-water \\
\hline ECCS Flow Rate & $-50 \%$ to $+50 \%$ & $5 \%$ & $25,000 \mathrm{gpm}$ \\
\hline$\Delta \mathrm{P}$ Correlation Multiplier & $-50 \%$ to $+200 \%$ & $10 \%$ & 1.0 \\
\hline Suppression Pool Temperature & $75^{\circ} \mathrm{F}$ to $175^{\circ} \mathrm{F}$ & $5^{\circ} \mathrm{F}$ & $125^{\circ} \mathrm{F}$ \\
\hline Strainer Filtration Efficiency & $-100 \%$ to $+100 \%$ & $10 \%$ & 0.5 after $1 / 4$ inch cake \\
\hline System Retention Fraction & $-100 \%$ to $+100 \%$ & $10 \%$ & 0.5 \\
\hline
\end{tabular}


Appendix C

A synopsis of the blockage frequency, the maximum head loss, and the time of blockage is presented in Section C.2. The detailed results of each input parameter sensitivity is presented in a separate section, i.e., Sections C.3 through C.15.

Table C.1-2. Selected Output Parameters

\begin{tabular}{|c|c|c|c|c|}
\hline Output Parameter & Units & $\begin{array}{l}\text { Base Case } \\
\text { Value for } \\
\text { RCA-J006 }\end{array}$ & $\begin{array}{l}\text { Base Case } \\
\text { Value for } \\
\text { RCA-J027 }\end{array}$ & Conditions \\
\hline ECCS Blockage Frequency & $1 / \mathrm{Rx}-\mathrm{yr}$ & 0.000158 & 0.000158 & End of Run \\
\hline Intermediate Head Loss & $\mathrm{ft}$-water & 1216 & 654.6 & At $30 \mathrm{Min}$. \\
\hline Maximum Head Loss & $\mathrm{ft}$-water & 1480 & 887.4 & End of Run \\
\hline Maximum Fiber Cake Thickness & inch & 7.729 & 1.252 & End of Run \\
\hline Time of Blockage & seconds & 82.8 & 480.5 & \\
\hline $\begin{array}{l}\text { Fiber Volume } \\
\text { On Strainer } \\
\text { On Pool Floor } \\
\text { In Pool Water }\end{array}$ & $\mathrm{ft}^{3}$ & $\begin{array}{l}0.302 \\
1 \mathrm{E}-6 \\
11.2\end{array}$ & $\begin{array}{l}0.160 \\
2 E-7 \\
2.02\end{array}$ & $\begin{array}{l}\text { At the Time } \\
\text { of Blockage }\end{array}$ \\
\hline $\begin{array}{l}\text { Wetwell Sludge Volume } \\
\text { On Strainer } \\
\text { On Pool Floor } \\
\text { In Pool Water }\end{array}$ & $\mathrm{ft}^{3}$ & $\begin{array}{c}0.00763 \\
9 \mathrm{E}-7 \\
2.55\end{array}$ & $\begin{array}{l}0.011 \\
9 \mathrm{E}-7 \\
2.47\end{array}$ & $\begin{array}{l}\text { At the Time } \\
\text { of Blockage }\end{array}$ \\
\hline $\begin{array}{l}\text { Drywell Particulate Volume } \\
\text { On Strainer } \\
\text { On Pool Floor } \\
\text { In Pool Water }\end{array}$ & $\mathrm{ft}^{3}$ & $\begin{array}{c}0.00223 \\
2 \mathrm{E}-6 \\
0.867\end{array}$ & $\begin{array}{c}0.00393 \\
3 \mathrm{E}-6 \\
0.981\end{array}$ & $\begin{array}{l}\text { At the Time } \\
\text { of Blockage }\end{array}$ \\
\hline Sludge to Fiber Mass Ratio & - & 3.85 & 10.71 & $\begin{array}{l}\text { At the Time } \\
\text { of Blockage }\end{array}$ \\
\hline
\end{tabular}




\section{C.2 Synopsis of Significant Findings}

A comparison of the sensitivity study ECCS blockage frequencies, maximum head losses, and blockage times provides an overall synopsis of the sensitivity study. The figures illustrating these comparisons were included in the study results summarized in Chapter 7.

Of the parameters varied through the ranges specified in Table C.1-1, only two parameters significantly affected the overall plant blockage frequency. These were the strainer surface area and the strainer filtration efficiency. The effect of area on the blockage frequency is shown in Figure 7-12. In this figure, the blockage frequency is shown as a function of multiples of the base case area, i.e., the multiple of one is the base case area. Figure 7-12 shows that the predicted blockage frequency was zero when the strainer surface area was increased to a value greater or equal to 7.75 times the base case area, i.e., ECCS strainer blockage was no longer predicted to occur.

The predicted ECCS blockage frequency decreased to $48 \%$ of the base case value of $0.000158 / R x-y r$ when the strainer filtration efficiency was reduced to zero, however the blockage frequency did not decrease from the base case value when the filtration efficiency was 0.05 or greater. Realistically the strainer efficiency will certainly be significantly larger the zero. This result still illustrates an important point since a strainer filtration efficiency of zero is equivalent to a calculation with no drywell particulate and no wetwell sludge, i.e., a calculation where only fibrous debris is available to block the strainer still predicts blockage to occur. Further, a calculation with the wetwell sludge removed but the drywell particulate still contributing to strainer blockage predicted the same base case blockage frequency.

The sensitivity of ECCS strainer blockage to the strainer surface area is further illustrated in Figure 7-11 which shows the maximum head losses and strainer blockage times for the large LLOCA weld break, RCA-J006, and the MLOCA weld break, RCA-J027, as a function of the area. The maximum head losses decrease rapidly as the strainer area was increase from the base case value of $37.62 \mathrm{ft}^{2}$ (total). The time elapsed until blockage occurred correspondingly increased. Strainer blockage was no longer predicted for these two welds when the strainer areas were increased to values larger than 7.25 and 4.75 times the base case area for the LLOCA and MLOCA welds, respectively. The corresponding blockage times, where blockage ceased, were 1863 and 3600 seconds.

The maximum head losses for each parameter studied were compared in Figures 7-8 and 7-9 for weld RCA-J006 and RCA-J027, respectively. These figures show the maximum head losses as a function of percentage change in the base case input parameter. The maximum head losses for both welds remained well above the available NPSH margin (14 ft-water) for all parameters studied except for the strainer area and the strainer filtration efficiency (as discussed above). The maximum head losses also dropped sharply with decreases in ECCS flow rate, particulate debris volumes, and the head loss correlation multiplier (sensitivity coefficient which multiplies the predicted head loss), however these maximum head losses do not approach the available NPSH margin within the ranges of values studied.

The time of loss of NPSH margin is plotted in Figure 7-10 for both of these welds. This figure illustrates that the time elapsed until loss of NPSH margin occurred did not change significantly for the parameters and ranges studied (except for the strainer area). The time to loss of NPSH margin for LLOCA welds tended to be in the 50 to 100 second time range and in the 450 to 550 second time range for the MLOCA welds. This implies that loss of NPSH margin occurred relatively shortly after the ECCS pumps reached their full ECCS flow rates.

This study clearly shows that the strainer surface area is the parameter which most impacts the estimates of loss of NPSH. The prediction of loss of ECCS NPSH margin could be further impacted by altering more than one parameter at a time, for example, decreasing the particulate debris while increasing the strainer area will increase the time to loss of NPSH margin faster than increasing the strainer area alone. 



\section{C.3 Sensitivity of Suppression Pool Volume}

This sensitivity study was performed by varying only the suppression pool volume in the base case input. The values used are listed in Table C.3-1.

The calculational results are presented graphically in Figures C.3-1 through C.3-11.

Table C.3-1. Calculational Cases for Suppression Pool Volume Sensitivity Study

\begin{tabular}{|c|c|c|}
\hline Case & Change, $\%$ & Pool Volume, $\mathrm{ft}^{3}$ \\
\hline $\mathrm{m} 10$ & -50 & 29450 \\
\hline $\mathrm{m} 9$ & -45 & 32395 \\
\hline $\mathrm{m} 8$ & -40 & 35340 \\
\hline $\mathrm{m} 7$ & -35 & 38285 \\
\hline $\mathrm{m} 6$ & -30 & 41230 \\
\hline $\mathrm{m} 5$ & -25 & 44175 \\
\hline $\mathrm{m} 4$ & -20 & 47120 \\
\hline $\mathrm{m} 3$ & -15 & 50065 \\
\hline $\mathrm{m} 2$ & -10 & 53010 \\
\hline $\mathrm{m} 1$ & -5 & 55955 \\
\hline Base & $\mathbf{0}$ & 58900 \\
\hline 1 & +5 & 61845 \\
\hline 2 & +10 & 64790 \\
\hline 3 & +15 & 67735 \\
\hline 4 & +20 & 70680 \\
\hline 5 & +25 & 73625 \\
\hline 6 & +30 & 76570 \\
\hline 7. & +35 & 79515 \\
\hline 8 & +40 & 82460 \\
\hline 9 & +45 & 85405 \\
\hline 10 & +50 & 88350 \\
\hline
\end{tabular}




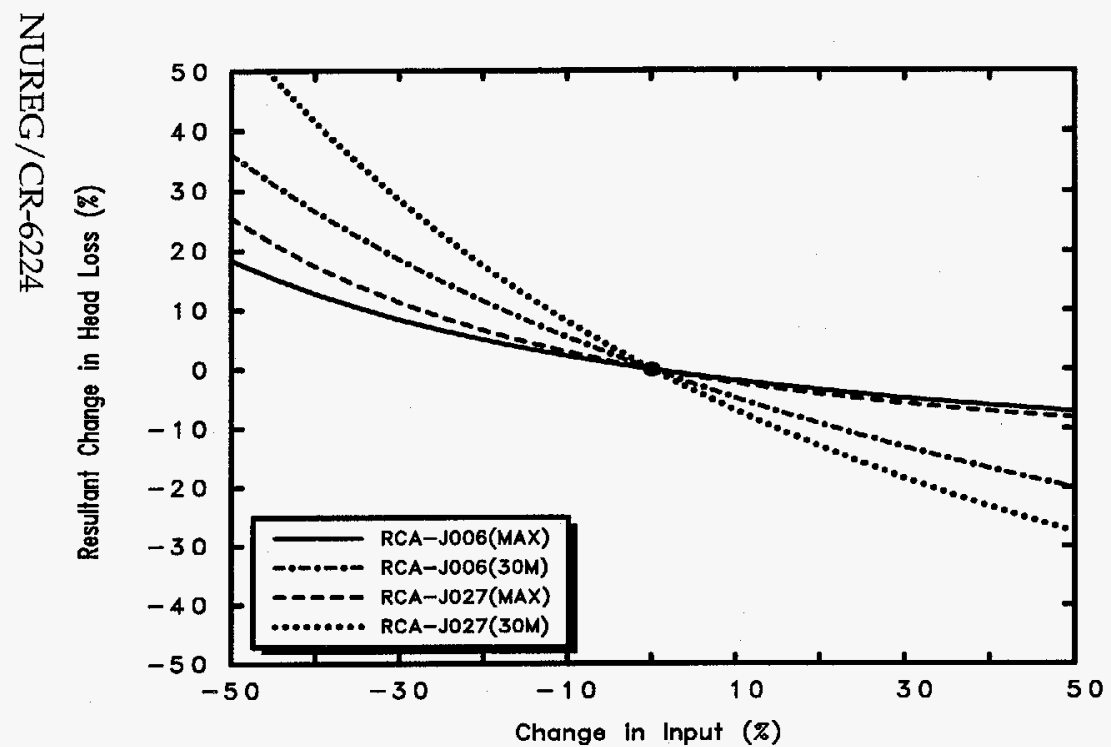

Figure C.3-1. Maximum and 30-Minute Head Loss .vs. Suppression Pool Volume

a

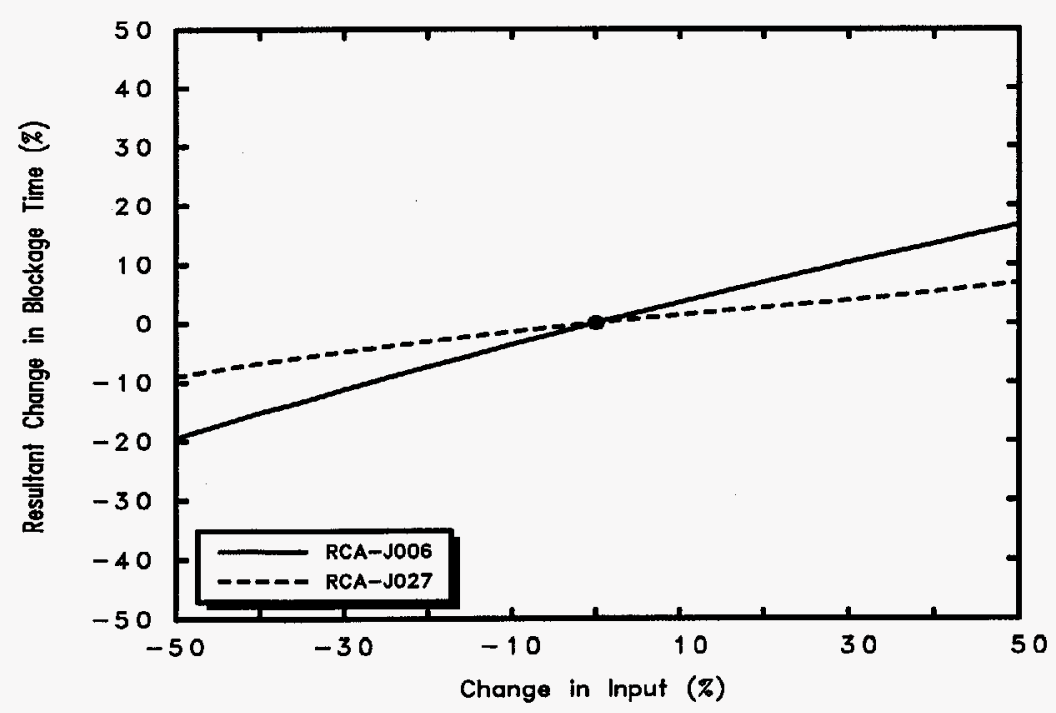

Figure C.3-3. Time of Blockage vs.

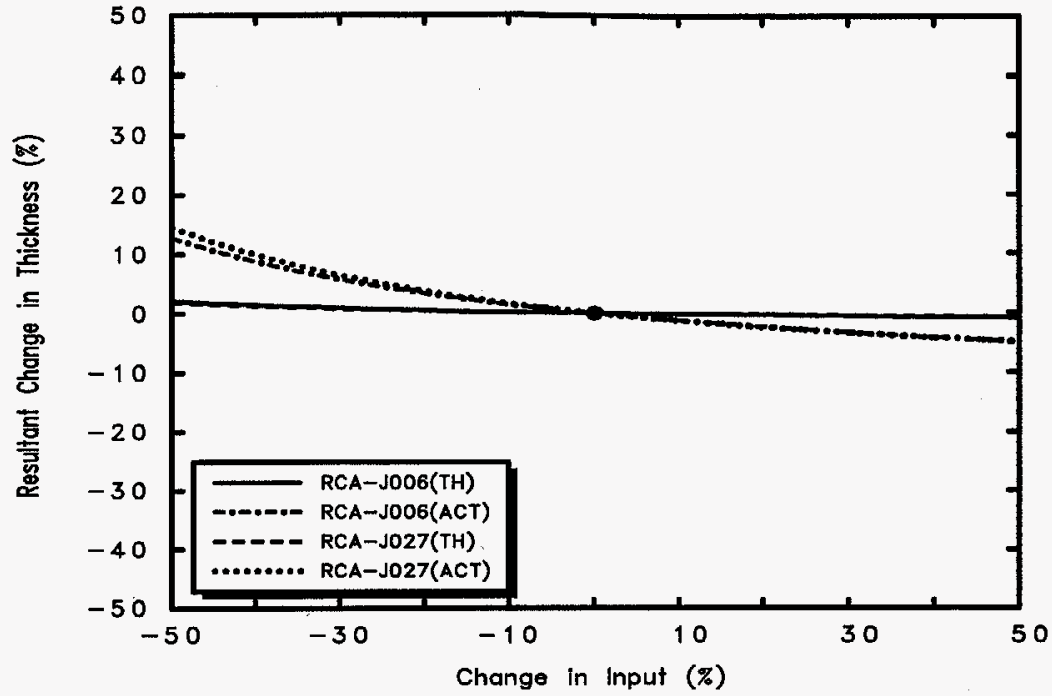

Figure C.3-2. Maximum Theoretical/Actual Cake Thicknesses .vs. Suppression Pool Volume

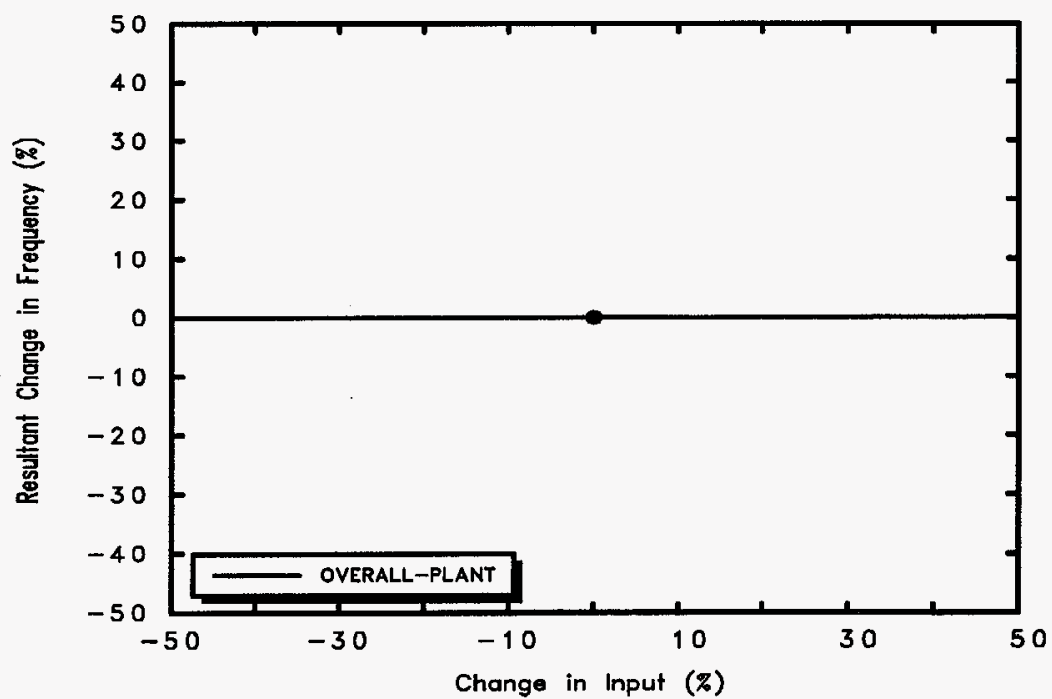

Figure C.3-4. Frequency for Loss of NPSH .vs. Suppression Pool Volume 


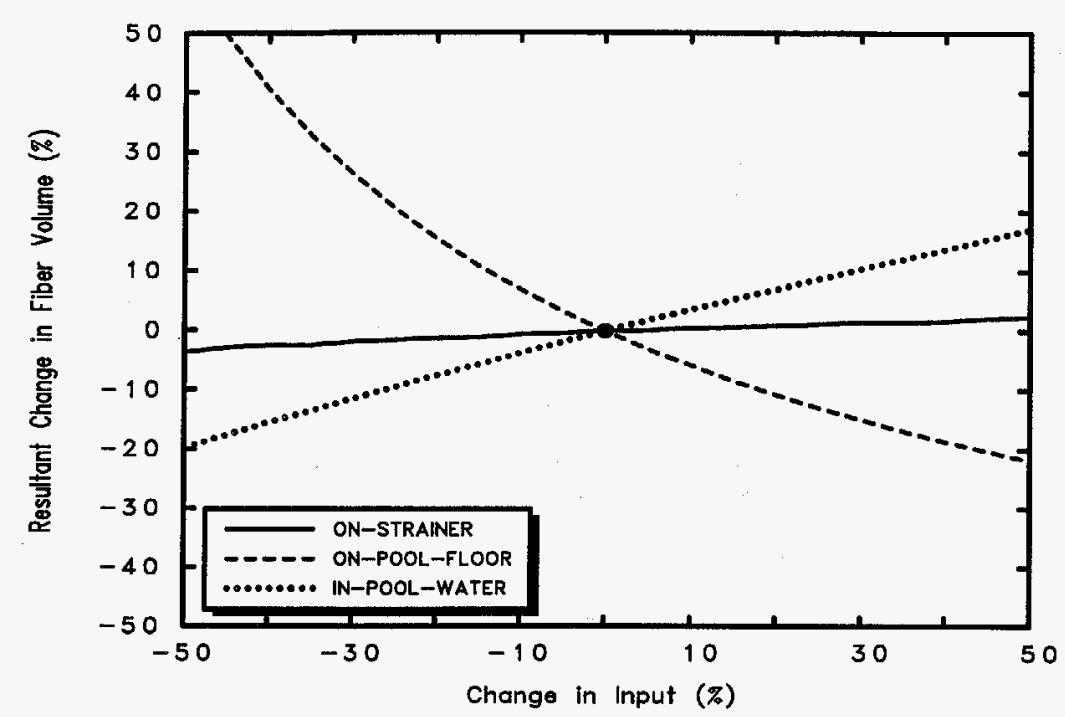

Figure C.3-5. Fiber Mass Balance at the Time of Blockage for Weld RCA-J006

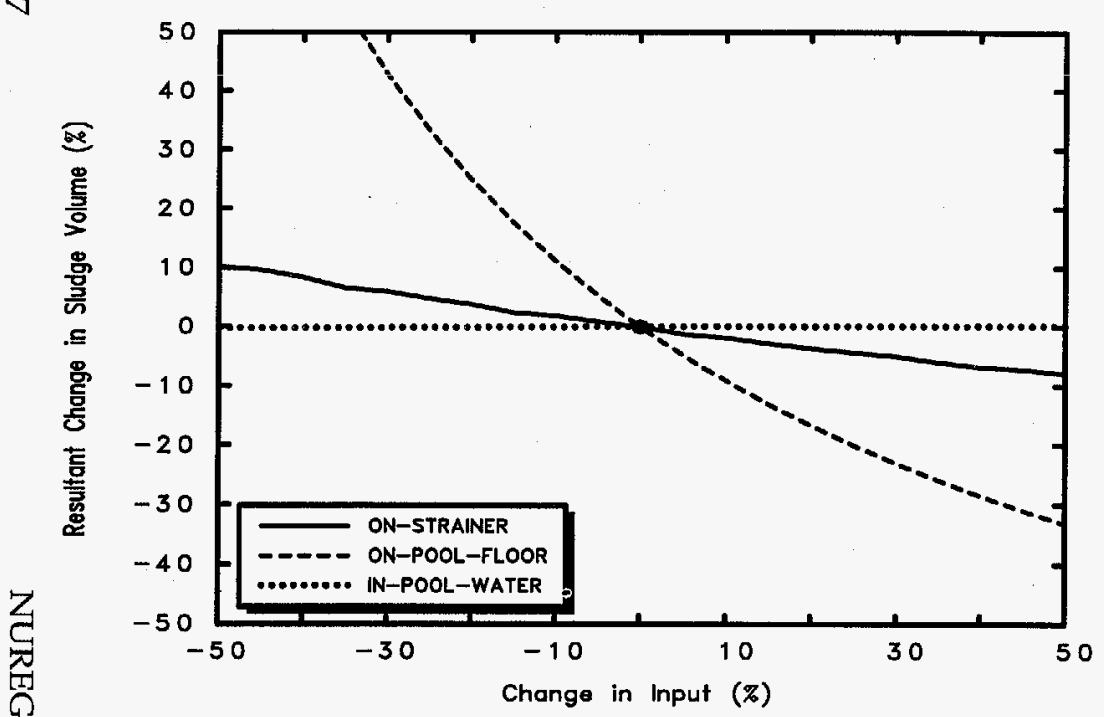

Figure C.3-7. WW Sludge Mass Balance at the Time of Blockage for Weld RCA-J006

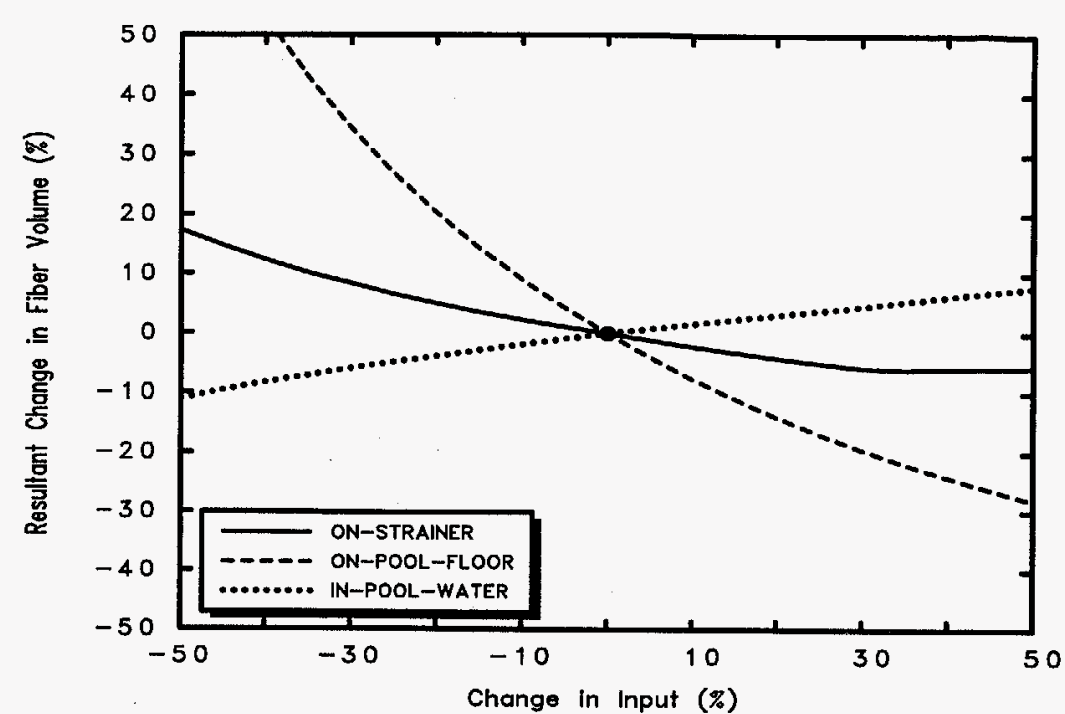

Figure C.3-6. Fiber Mass Balance at the Time
of Blockage for Weld RCA-J027

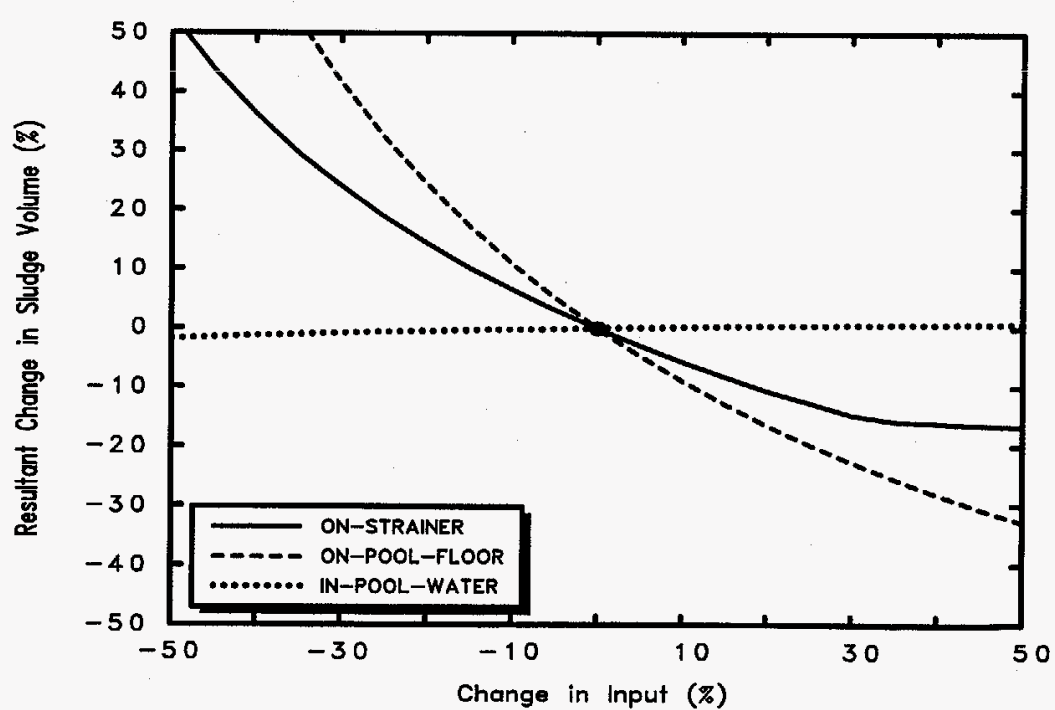

Figure C.3-8. WW Sludge Mass Balance at the Time 


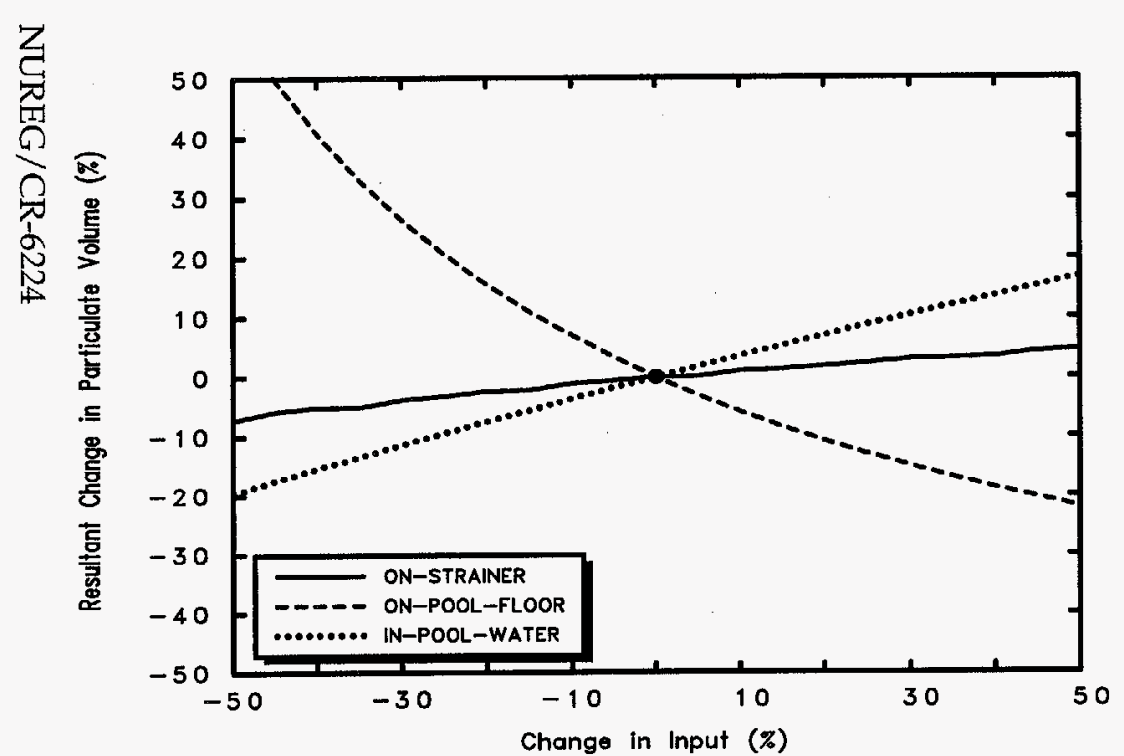
Figure C.3-9. DW Particulate Mass Balance at the Time
of Blockage for Weld RCA-J006

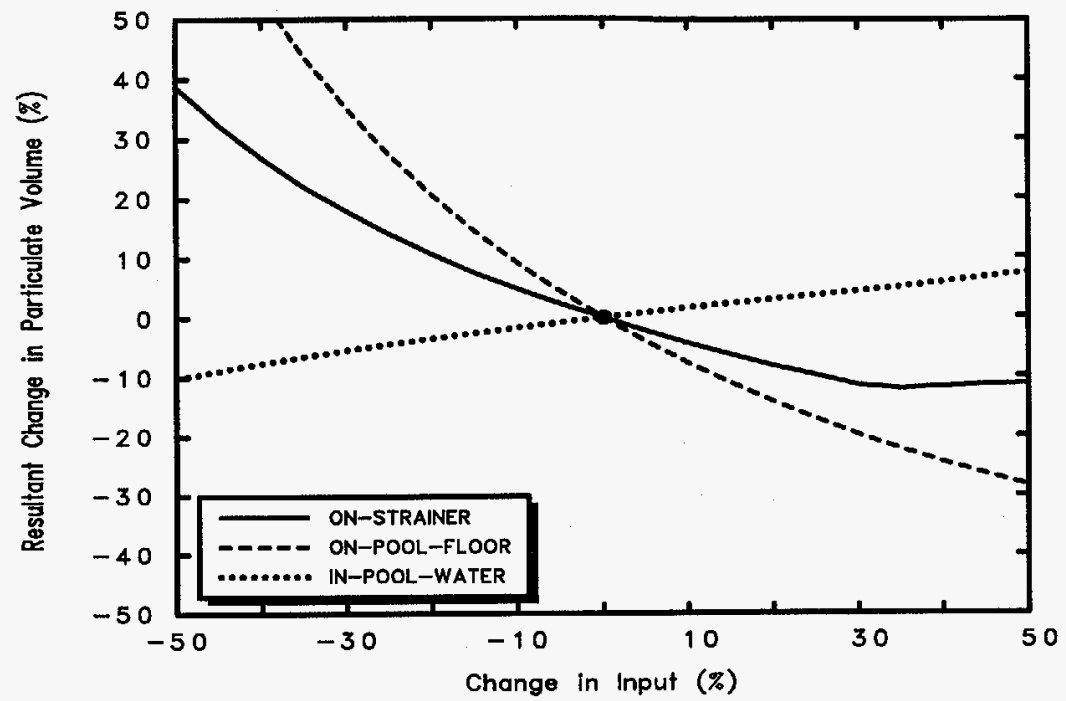

Figure C.3-10. DW Particulate Mass Balance at the Time

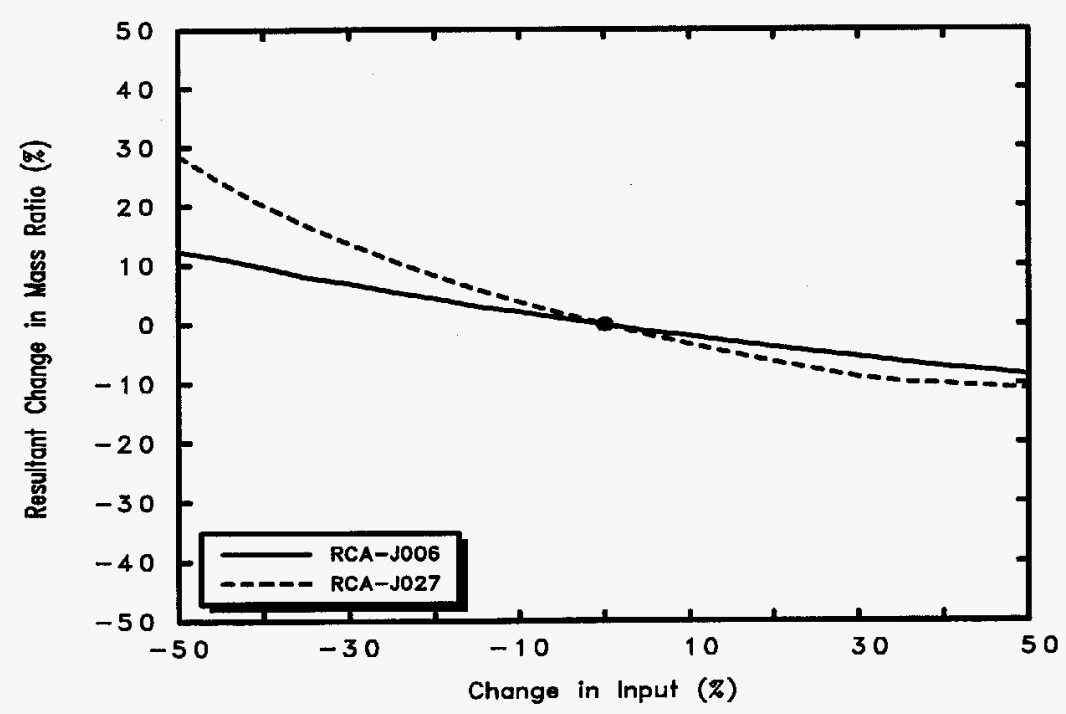

Figure C.3-11. Sludge to Fiber Mass Ratio of the Cake at the Time of Blockage 


\section{C.4 Sensitivity of Suppression Pool Depth}

This sensitivity study was performed by varying only the suppression pool surface area in the base case input. BLOCKAGE 2.3 calculates the suppression pool depth by dividing the pool volume by its surface area. The values used are listed in Table C.4-1. The calculational results are presented graphically in Figures C.4-1 through C.4-11.

Table C.4-1. Calculational Cases for Suppression Pool Depth Sensitivity Study

\begin{tabular}{|c|c|c|c|}
\hline Case & Change, $\%$ & Surface Area, $\mathrm{ft}^{3}$ & Pool Depth, $f t$ \\
\hline $\mathrm{m} 10$ & -50 & 2500 & 23.56 \\
\hline $\mathrm{m} 9$ & -45 & 2750 & 21.42 \\
\hline $\mathrm{m} 8$ & -40 & 3000 & 19.63 \\
\hline $\mathrm{m} 7$ & -35 & 3250 & 18.12 \\
\hline $\mathrm{m} 6$ & -30 & 3500 & 16.83 \\
\hline $\mathrm{m} 5$ & -25 & 3750 & 15.71 \\
\hline $\mathrm{m} 4$ & -20 & 4000 & 14.73 \\
\hline $\mathrm{m} 3$ & -15 & 4250 & 13.86 \\
\hline $\mathrm{m} 2$ & -10 & 4500 & 13.09 \\
\hline $\mathrm{m} 1$ & -5 & 4750 & 12.40 \\
\hline Base & 0 & 5000 & 11.78 \\
\hline 1 & +5 & 5250 & 11.22 \\
\hline 2 & +10 & 5500 & 10.71 \\
\hline 3 & +15 & 5750 & 10.24 \\
\hline 4 & +20 & 6000 & 9.82 \\
\hline 5 & +25 & 6250 & 9.42 \\
\hline 6 & +30 & 6500 & 9.06 \\
\hline 7 & +35 & 6750 & 8.73 \\
\hline 8 & +40 & 7000 & 8.41 \\
\hline 9 & +45 & 7250 & 8.12 \\
\hline 10 & +50 & 7500 & 7.85 \\
\hline
\end{tabular}




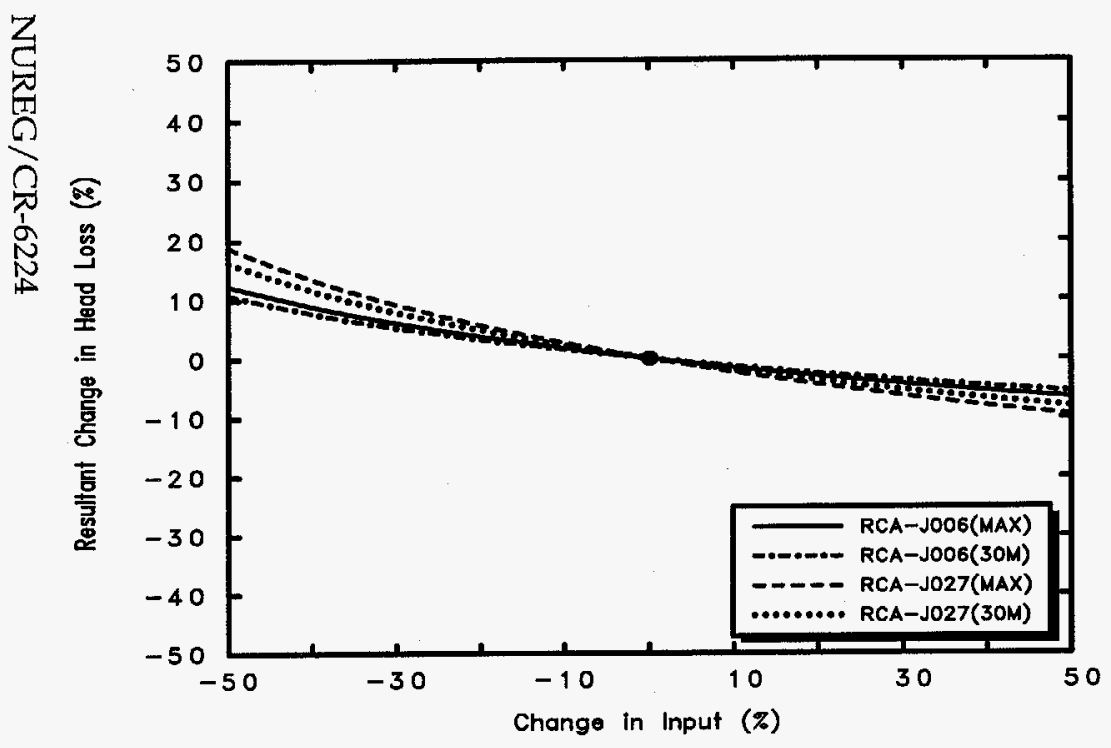

Figure C.4-1. Maximum and 30-Minute Head Loss .vs. Suppression Pool Depth

$\stackrel{?}{\circ}$

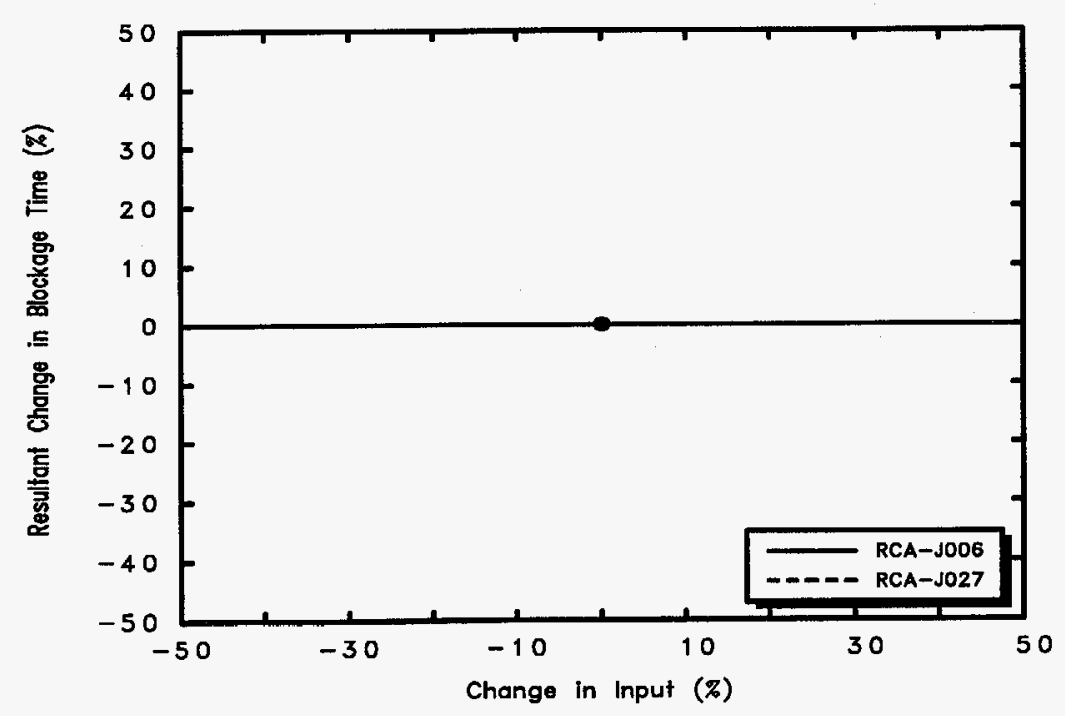

Figure C.4-3. Time of Blockage .vs.

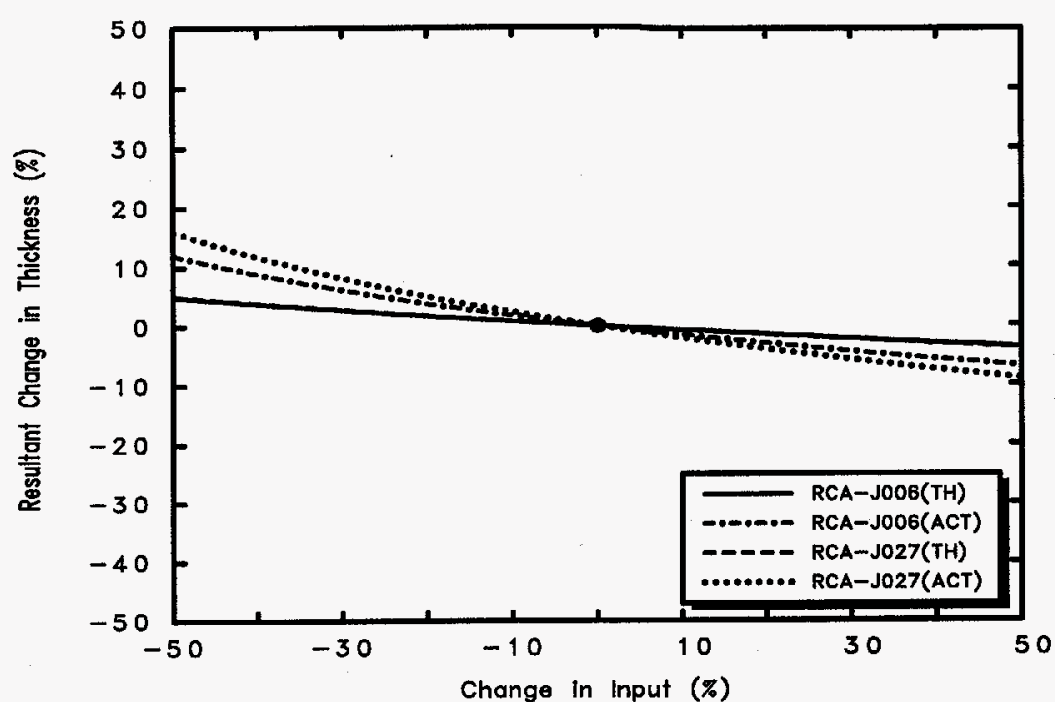

Figure C.4-2. Maximum Theoretical/Actual Cake Thicknesses .vs. Suppression Pool Depth

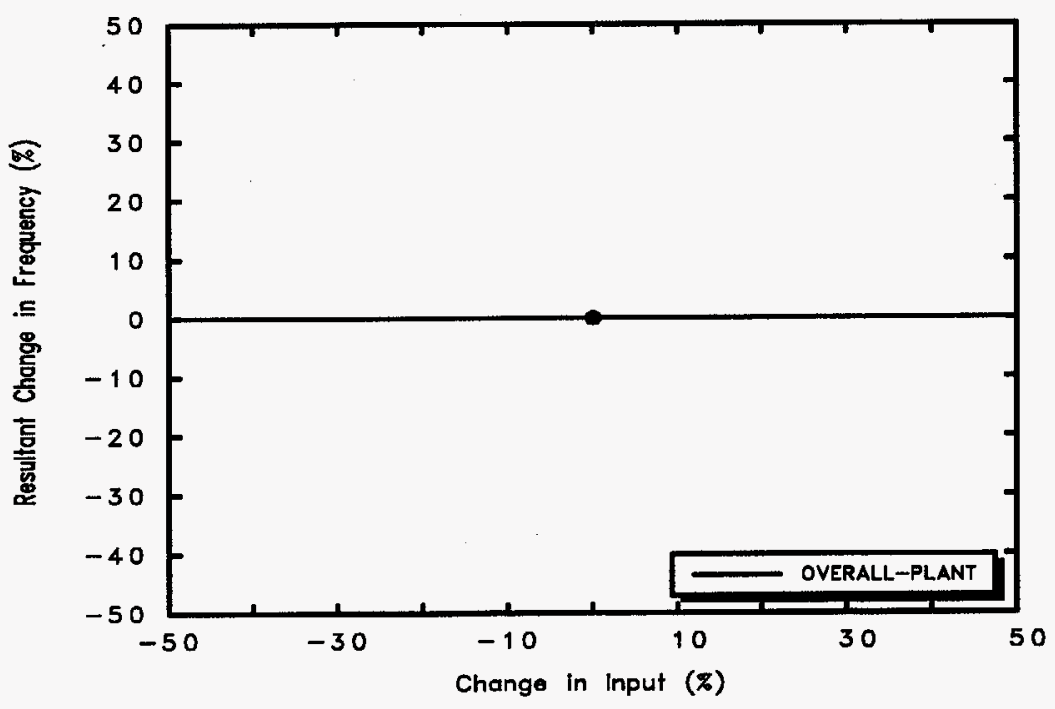

Figure C.4-4. Frequency for Loss of NPSH .vs. Suppression Pool Depth 
Appendix $C$

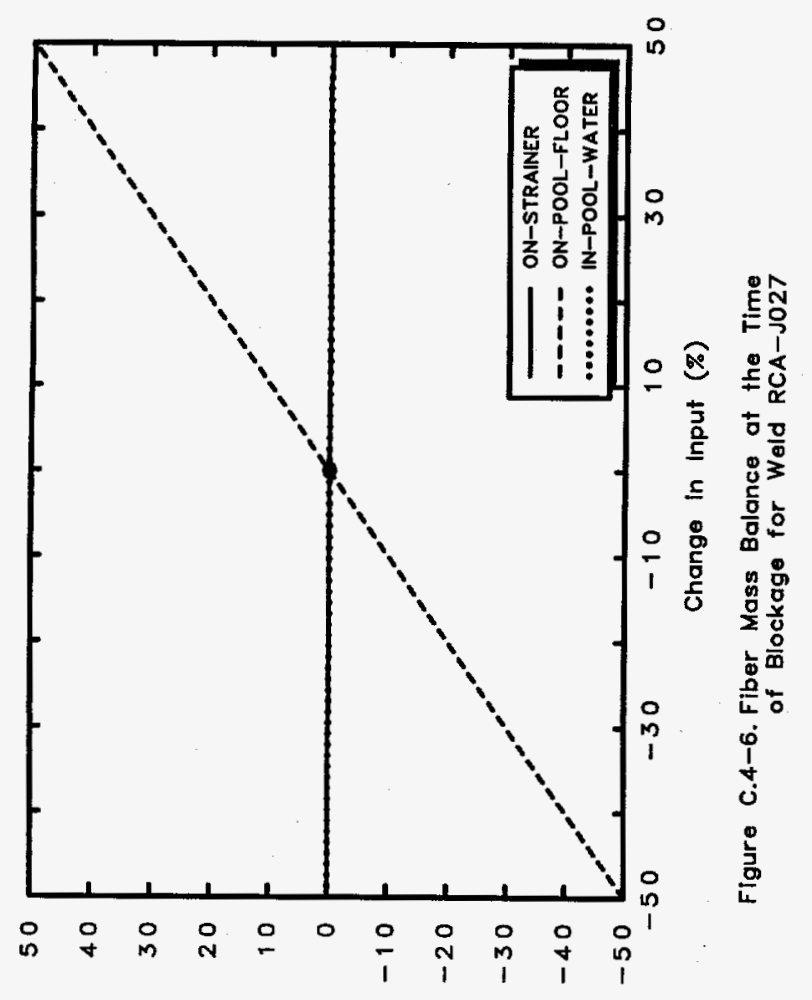

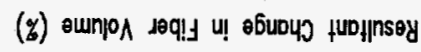

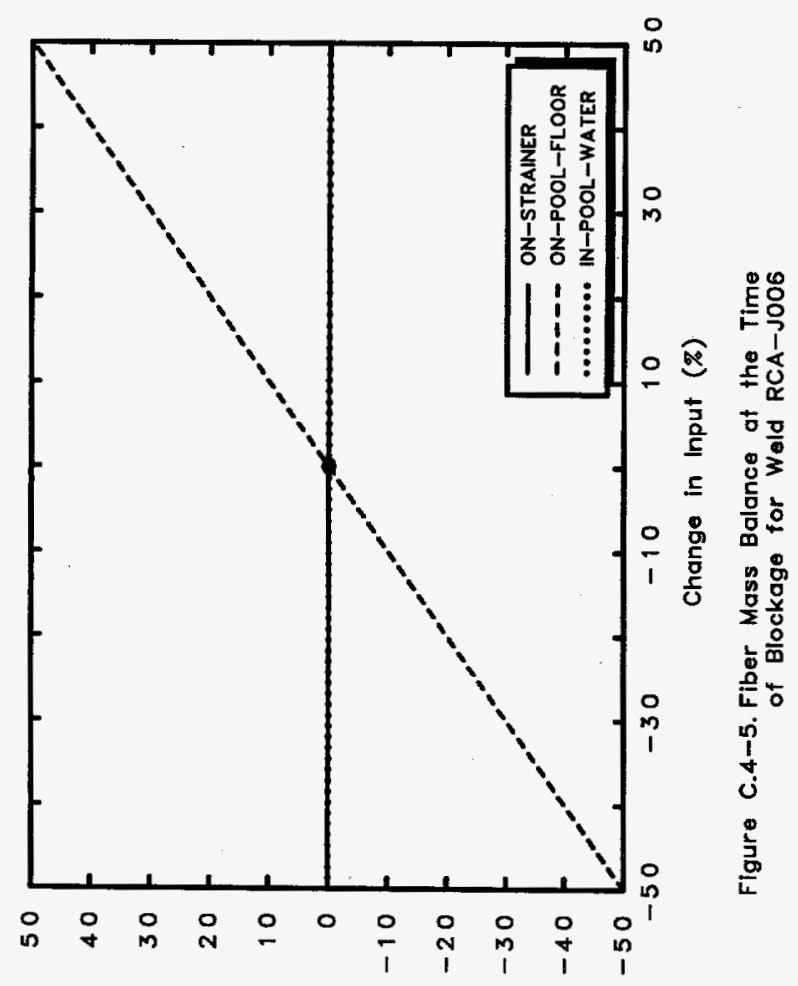

(\%) oumpo deq!J u! o6uduว „upp|nsey

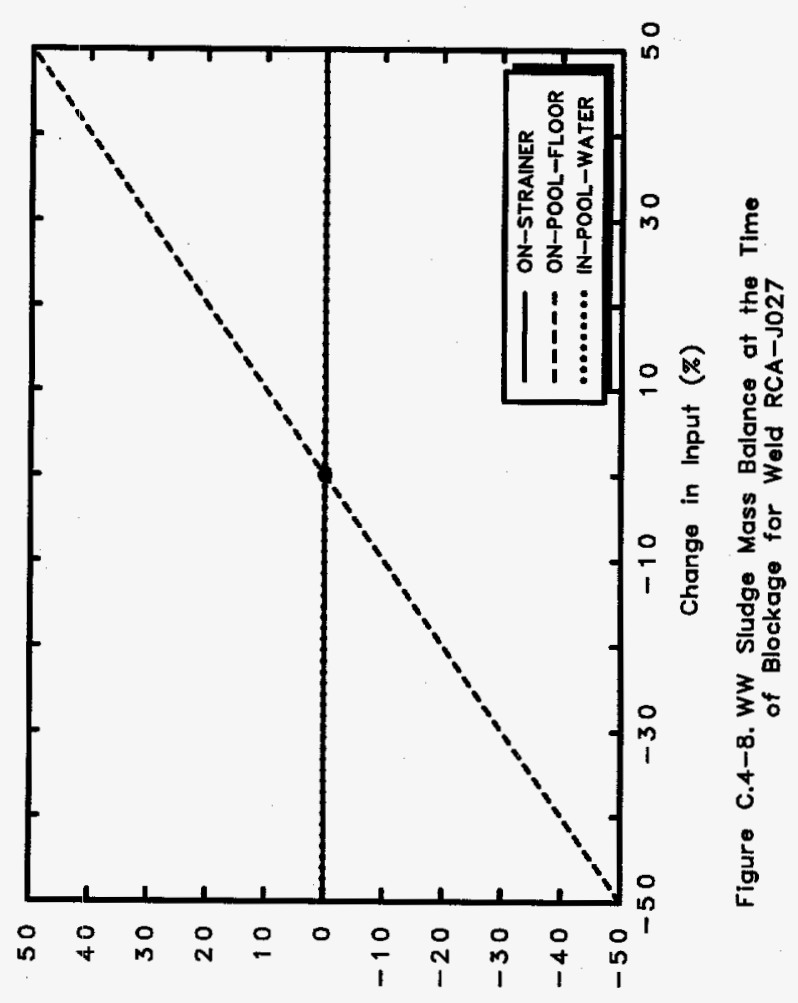

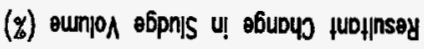

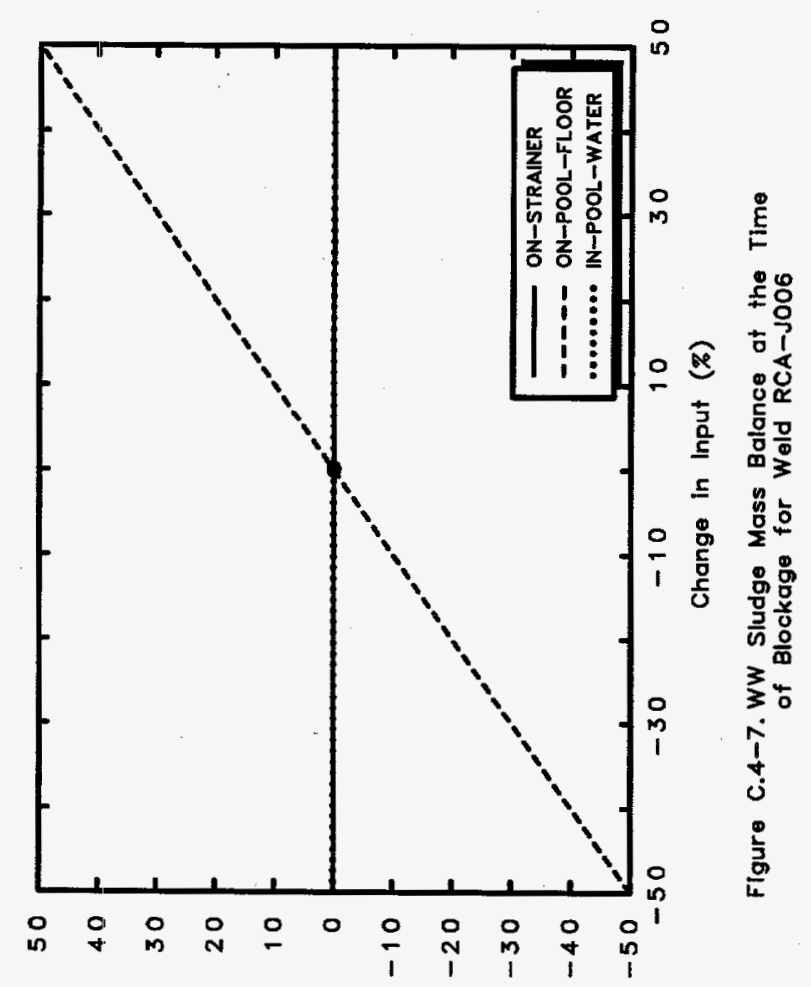

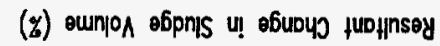


Appendix C

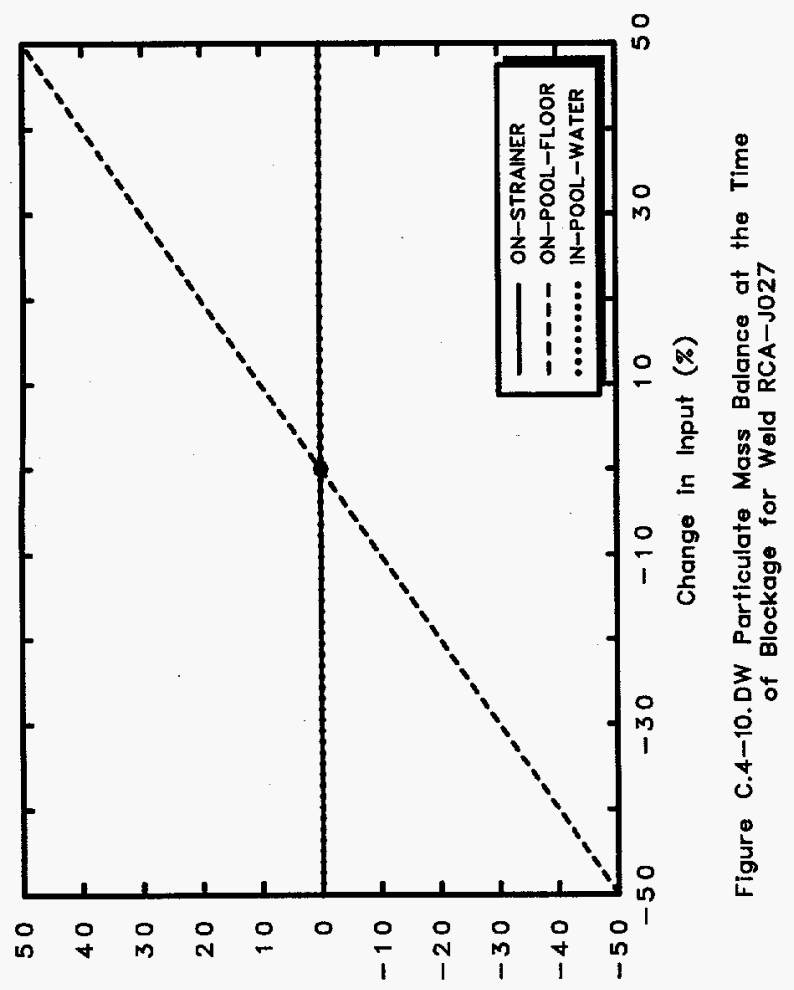

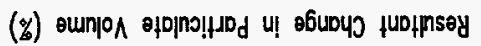
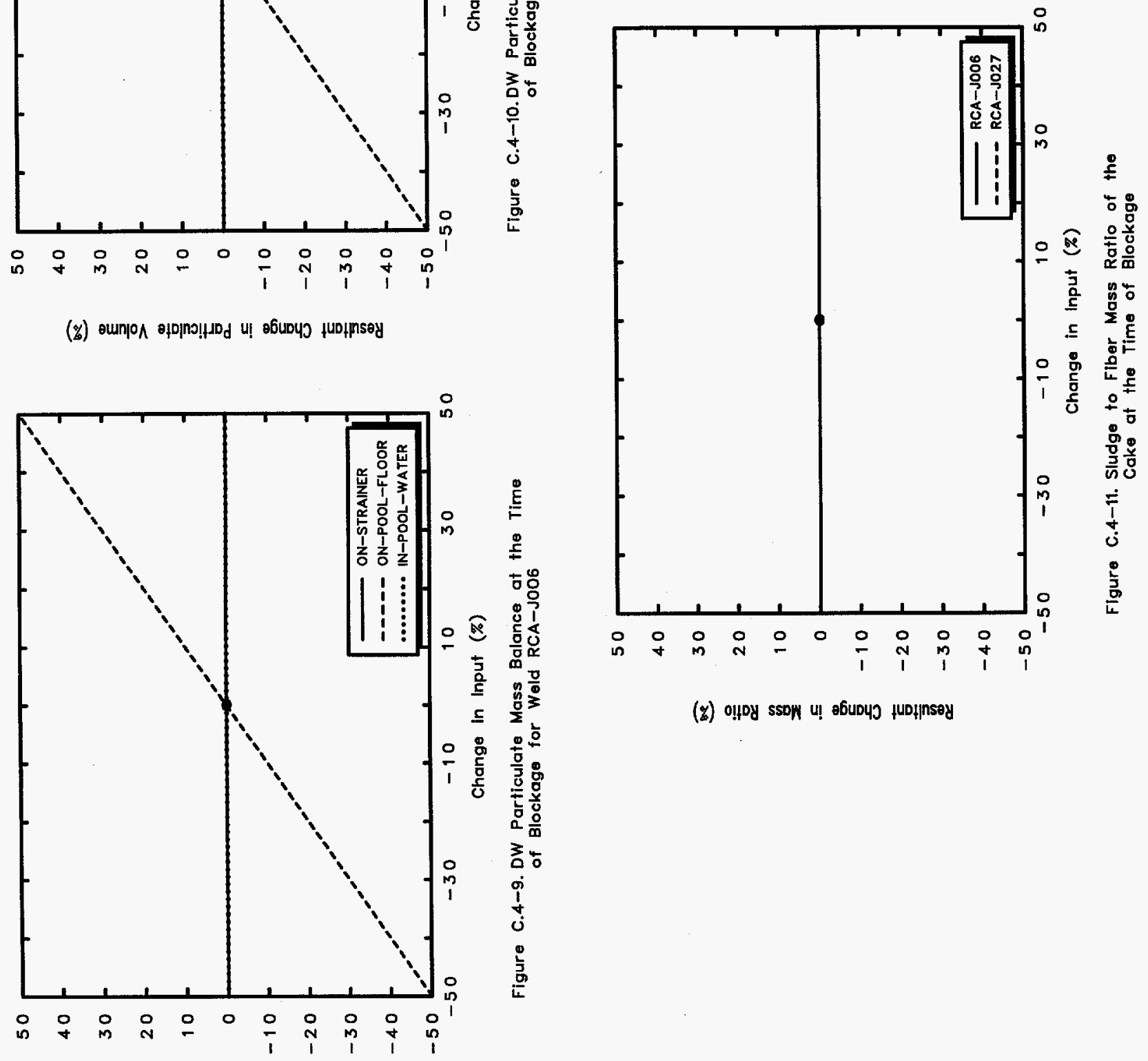

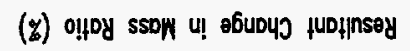

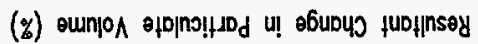




\section{C.5 Sensitivity of Insulation Destruction Factor}

This sensitivity study was performed by varying the three insulation destruction factors, i.e., one for each destruction region, in the base case input. The factors for all three regions were varied simultaneously by the same percentage rate. When the factors for the $L / D=3$ region exceeded the maximum allowable value of 1.0 , they were reset to 1.0. The values used are listed in Table C.5-1. The calculational results are presented graphically in Figures C.5-1 through C.5-11.

Table C.5-1. Calculational Cases for Insulation Destruction Factor Sensitivity Study

\begin{tabular}{|c|c|c|c|c|}
\hline Case & Change, \% & $\begin{array}{l}\text { Destruction Factor } \\
\text { for } L / D=3\end{array}$ & $\begin{array}{l}\text { Destruction Factor } \\
\text { for } L / D=5\end{array}$ & $\begin{array}{l}\text { Destruction Factor } \\
\text { for } L / D=7\end{array}$ \\
\hline $\mathrm{m} 10$ & -50 & 0.375 & 0.30 & 0.20 \\
\hline $\mathrm{m} 9$ & -45 & 0.4125 & $0 . .33$ & 0.22 \\
\hline $\mathrm{m} 8$ & -40 & 0.45 & 0.36 & 0.24 \\
\hline $\mathrm{m} 7$ & -35 & 0.4875 & 0.39 & 0.26 \\
\hline $\mathrm{m} 6$ & -30 & 0.525 & 0.42 & 0.28 \\
\hline $\mathrm{m} 5$ & -25 & 0.5625 & 0.45 & 0.30 \\
\hline $\mathrm{m} 4$ & -20 & 0.60 & 0.48 & 0.32 \\
\hline $\mathrm{m} 3$ & -15 & 0.6375 & 0.51 & 0.34 \\
\hline $\mathrm{m} 2$ & -10 & 0.675 & 0.54 & 0.36 \\
\hline $\mathrm{m} 1$ & -5 & 0.7125 & 0.57 & 0.38 \\
\hline Base & 0 & 0.75 & 0.60 & 0.40 \\
\hline 1 & +5 & 0.7875 & 0.63 & 0.42 \\
\hline 2 & +10 & 0.825 & 0.66 & 0.44 \\
\hline 3 & +15 & 0.8625 & 0.69 & 0.46 \\
\hline 4 & +20 & 0.90 & 0.72 & 0.48 \\
\hline 5 & +25 & 0.9375 & 0.75 & 0.50 \\
\hline 6 & +30 & 0.975 & 0.78 & 0.52 \\
\hline 7 & +35 & 1.0 & 0.81 & 0.54 \\
\hline 8 & +40 & 1.0 & 0.84 & 0.56 \\
\hline 9 & +45 & 1.0 & 0.87 & 0.58 \\
\hline 10 & +50 & 1.0 & 0.90 & 0.60 \\
\hline
\end{tabular}



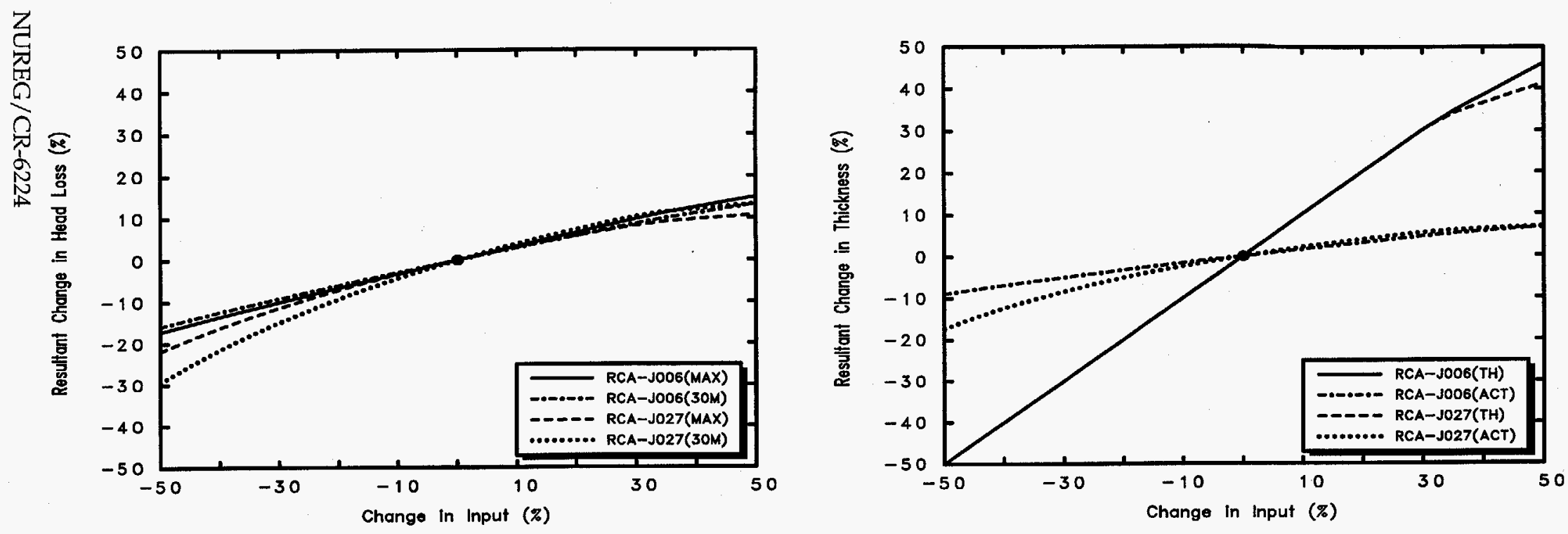

Figure C.5-1. Maximum and 30-Minute Head Loss .vs. Insulation Destruction Factors

$\stackrel{2}{\frac{1}{A}}$
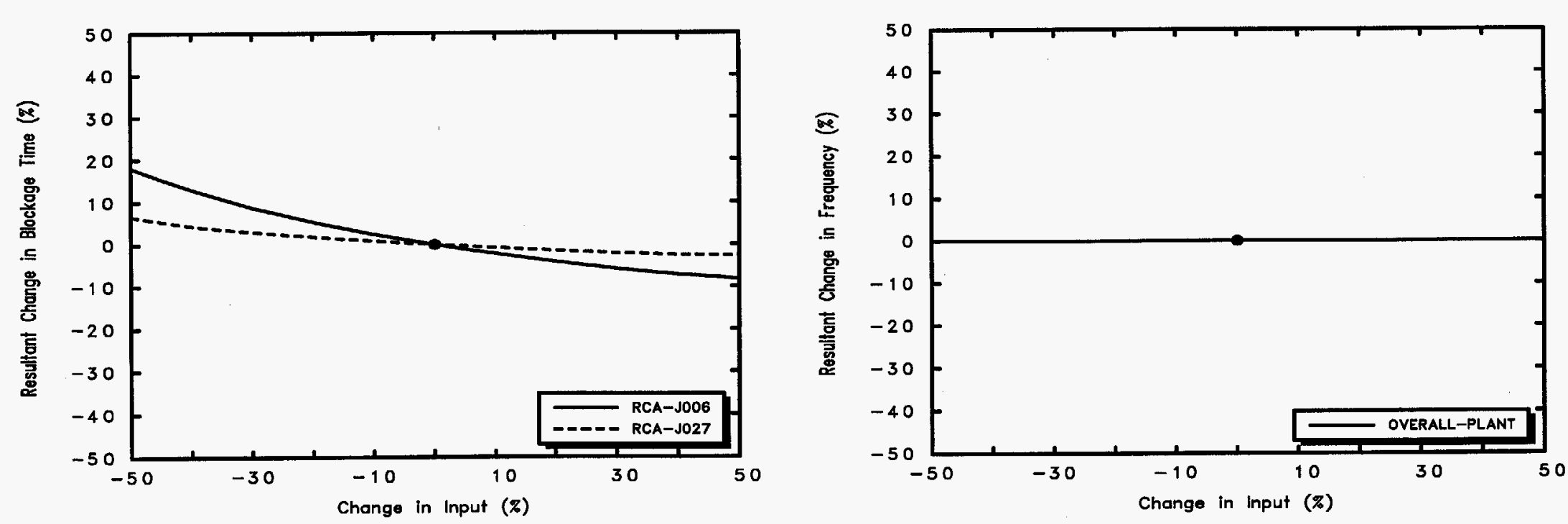

Figure C.5-3. Time of Blockage .vs.
Insulation Destruction Factors

Figure C.5-4. Frequency for Loss of NPSH .vs. Insulation Destruction Factors 


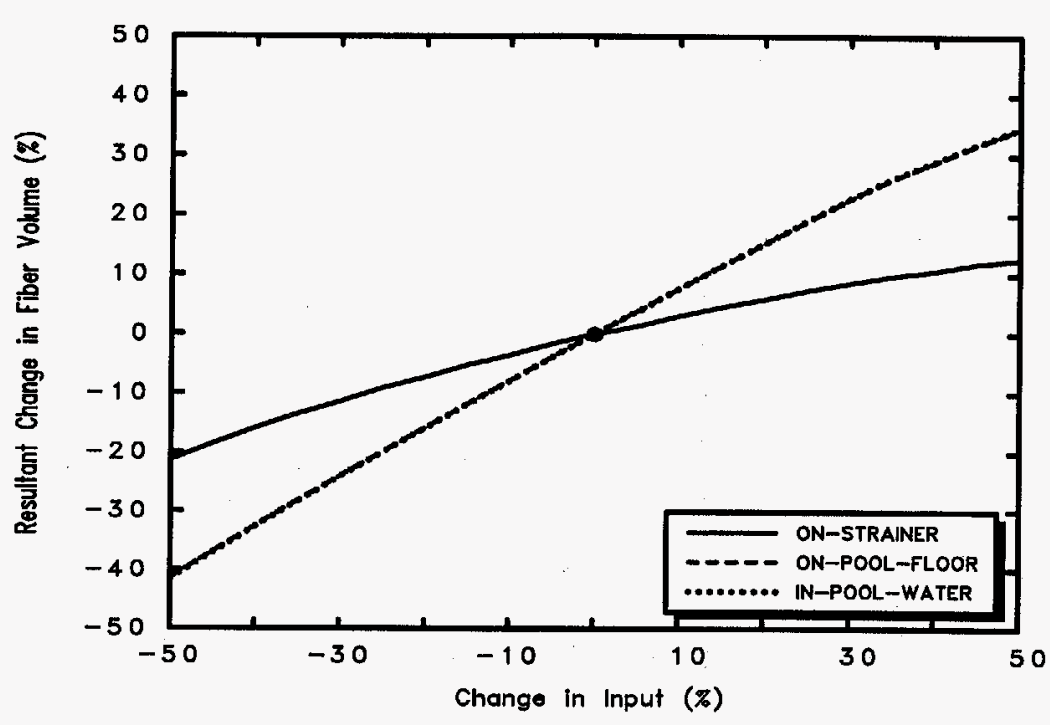

Figure C.5-5. Fiber Mass Balance of the Time
of Blockage for Weld RCA-J006

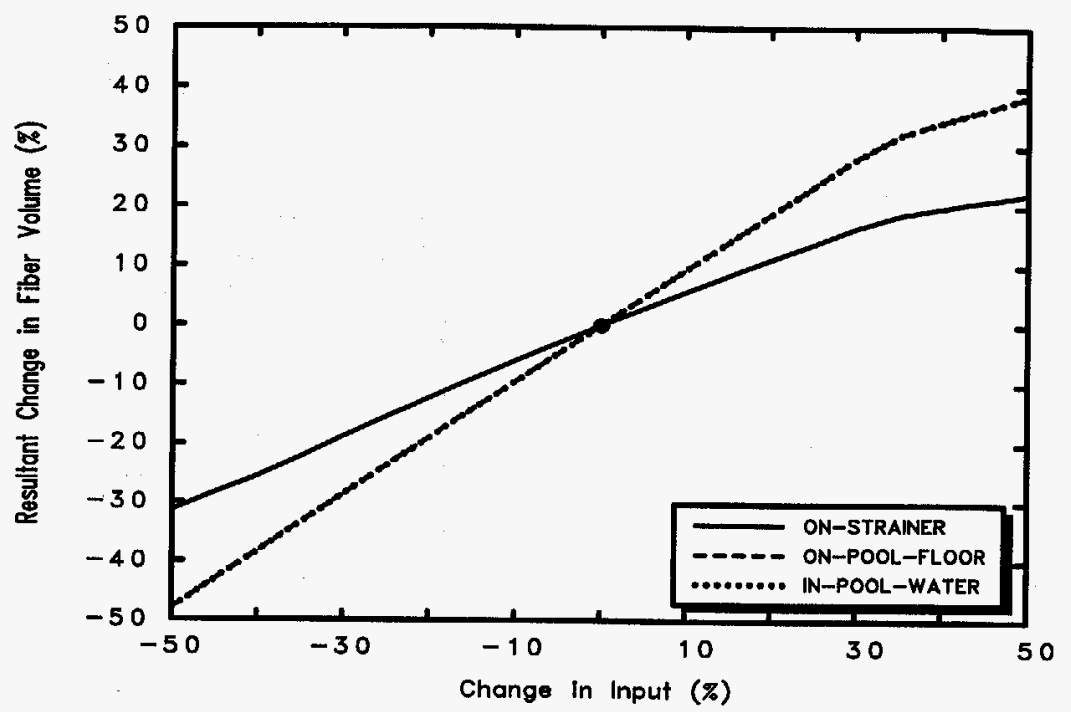

Figure C.5-6. Fiber Mass Balance at the Time
of Blockage for Weld RCA-JO27

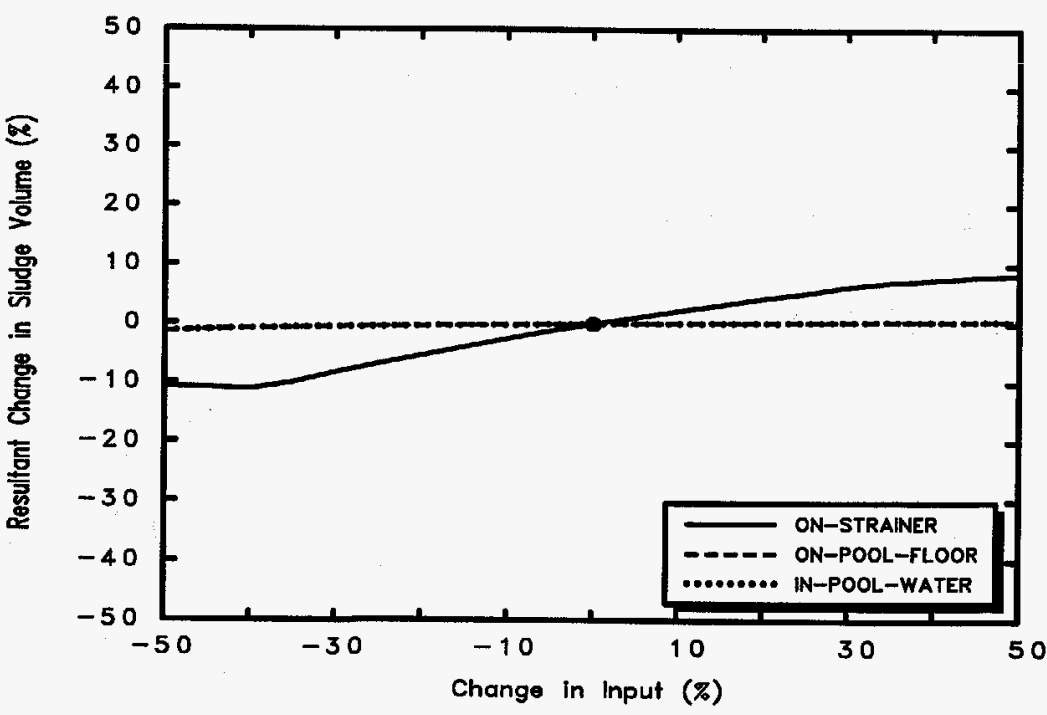

Figure C.5-8. WW Sludge Mass Balance at the Time 
Appendix C

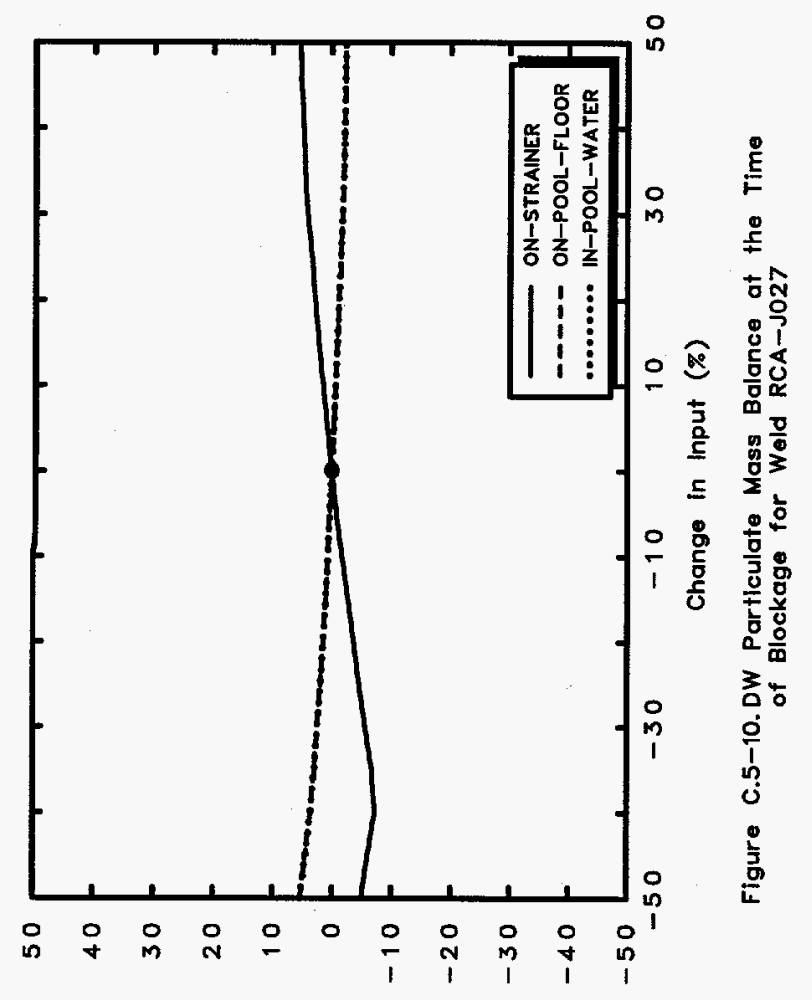

(\%) owni०
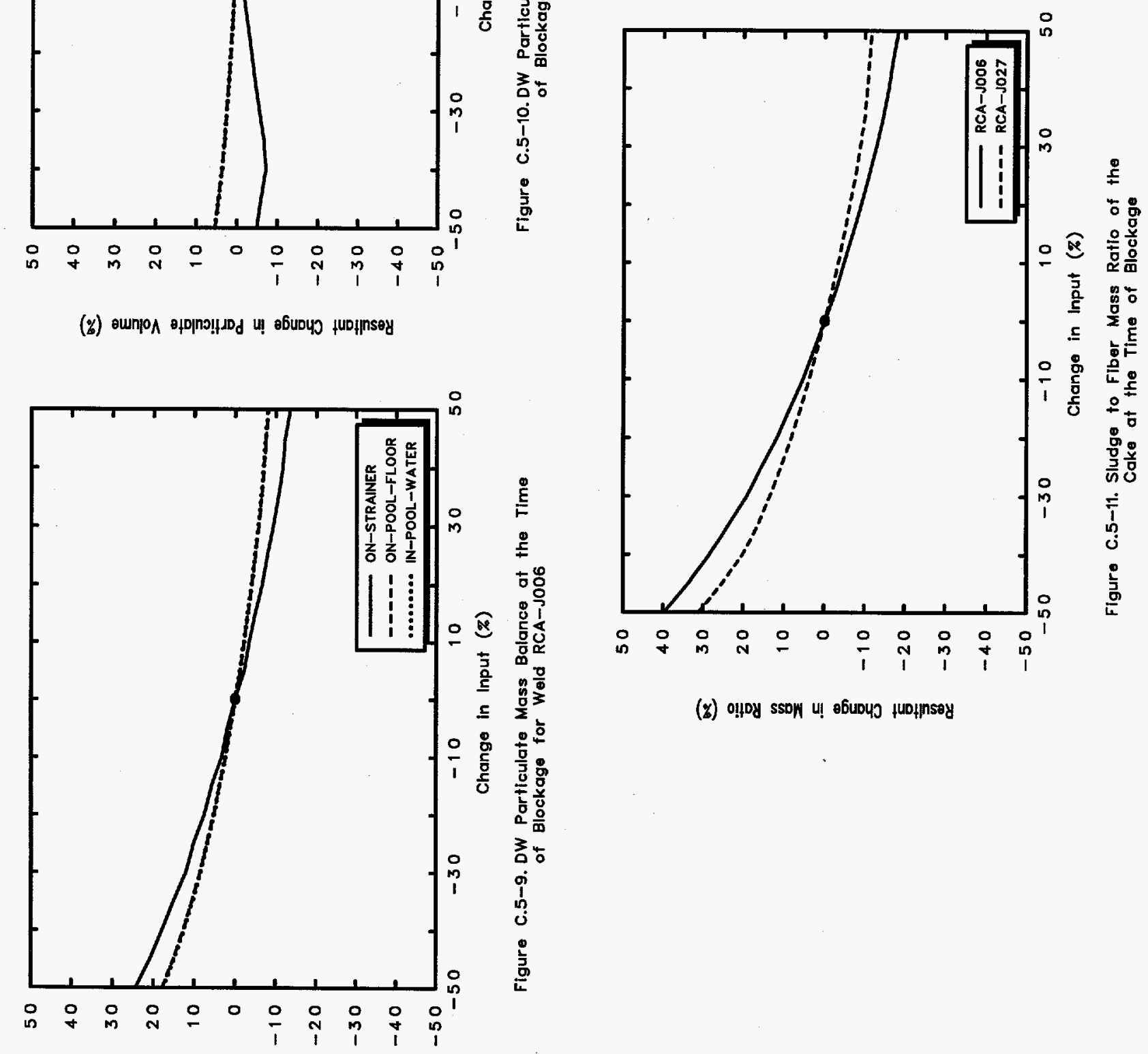

(z) olnpy ssop u! e6uduj fuppnsey

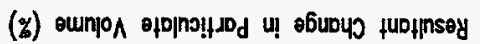




\section{C.6 Sensitivity of Drywell Transport Factor}

This sensitivity study was performed by varying the three drywell transport factors, i.e., one for each location within the drywell, in the base case input. Drywell transport is further subdivided into blowdown and washdown periods. The factors for all three locations and for both periods were varied simultaneously by the same percentage rate. When the total transport for the LOW location exceeded $100 \%$, the washdown period factors were specified to limit total transport to $100 \%$ of available drywell debris. The total transport values used (blowdown plus washidown) are listed in Table C.61. The calculational results are presented graphically in Figures C.6-1 through C.6-11.

Table C.6-1. Calculational Cases for Drywell Transport Factor Sensitivity Study

\begin{tabular}{|c|c|c|c|c|}
\hline Case & Change, \% & $\begin{array}{c}\text { High Region } \\
\text { Transport Factor }\end{array}$ & $\begin{array}{c}\text { Medium Region } \\
\text { Transport Factor }\end{array}$ & $\begin{array}{c}\text { Low Region } \\
\text { Transport Factor }\end{array}$ \\
\hline $\mathrm{m} 4$ & -20 & 0.20 & 0.40 & 0.60 \\
\hline $\mathrm{m} 3$ & -15 & 0.2125 & 0.425 & 0.6375 \\
\hline $\mathrm{m} 2$ & -10 & 0.225 & 0.45 & 0.675 \\
\hline $\mathrm{m} 1$ & -5 & 0.2375 & 0.475 & 0.7125 \\
\hline Base & 0 & 0.25 & $\mathbf{0 . 5 0}$ & $\mathbf{0 . 7 5}$ \\
\hline 1 & +5 & 0.2625 & 0.525 & 0.7875 \\
\hline 2 & +10 & 0.275 & 0.55 & 0.825 \\
\hline 3 & +15 & 0.2875 & 0.575 & 0.8625 \\
\hline 4 & +20 & 0.30 & 0.60 & 0.90 \\
\hline 5 & +25 & 0.3125 & 0.625 & 0.9375 \\
\hline 6 & +30 & 0.325 & 0.65 & 0.975 \\
\hline 7 & +35 & 0.3375 & 0.675 & 1.0 \\
\hline 8 & +40 & 0.35 & 0.70 & 1.0 \\
\hline 9 & +45 & 0.3625 & 0.725 & 1.0 \\
\hline 10 & +50 & 0.375 & 0.75 & 1.0 \\
\hline 11 & +55 & 0.3875 & 0.775 & 0.80 \\
\hline 12 & +60 & 0.40 & & \\
\hline
\end{tabular}




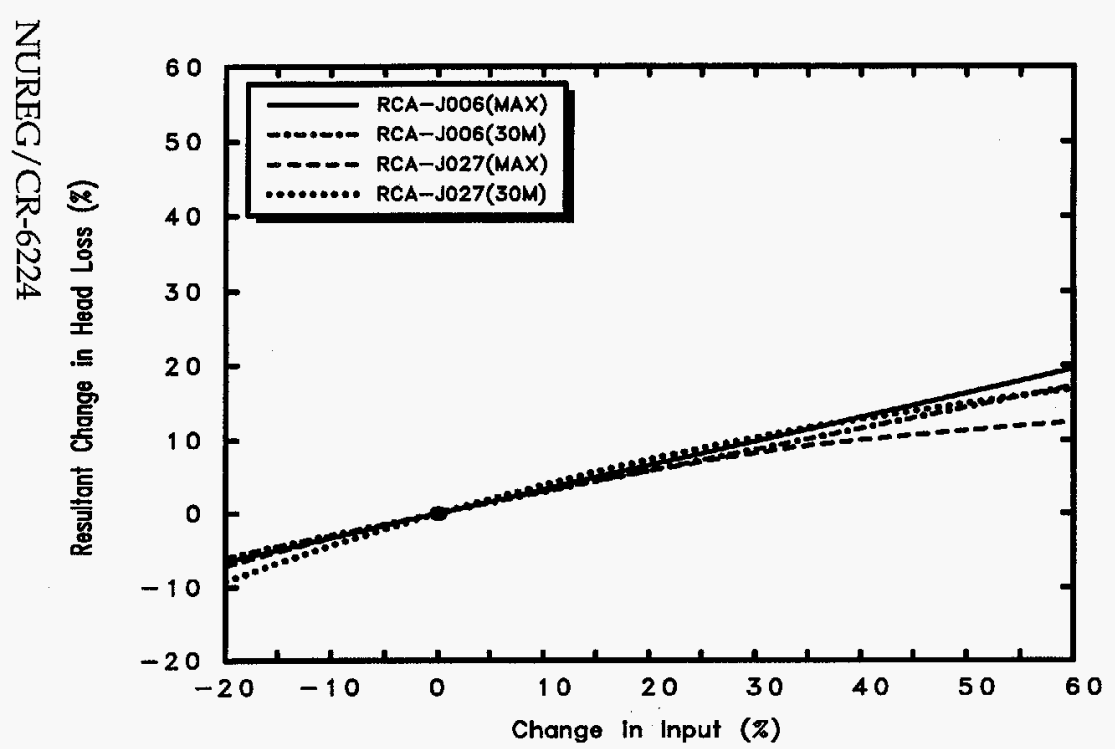

Figure C.6-1. Maximum and 30-Minute Head Loss .vs. Drywell Transport Factors

$\stackrel{?}{\infty}$

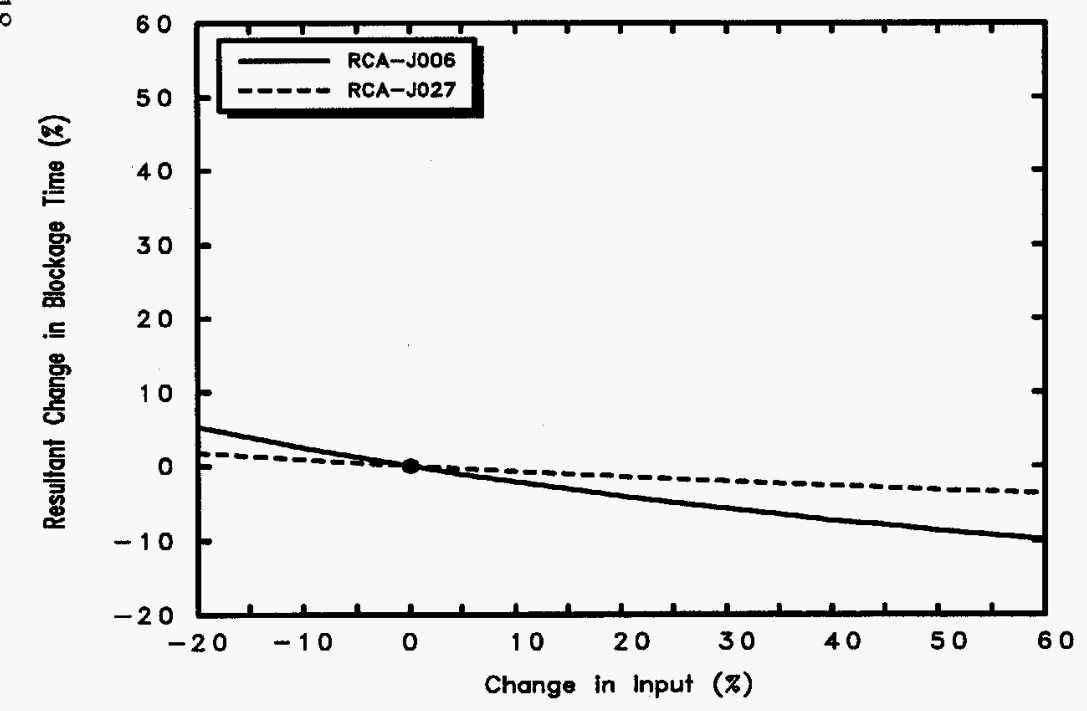

Figure C.6-3. Time of Blockage ivs.
Drywell Transport Factors

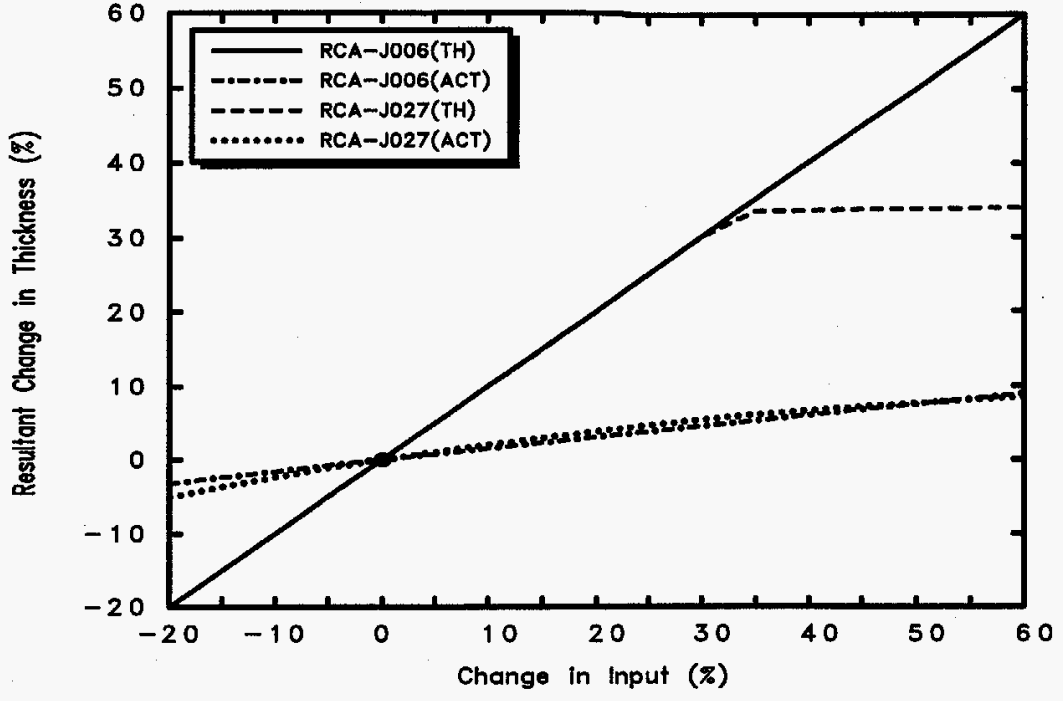

Figure C.6-2. Maximum Theoretical/Actual Cake Thicknesses .vs. Drywell Transport Factors

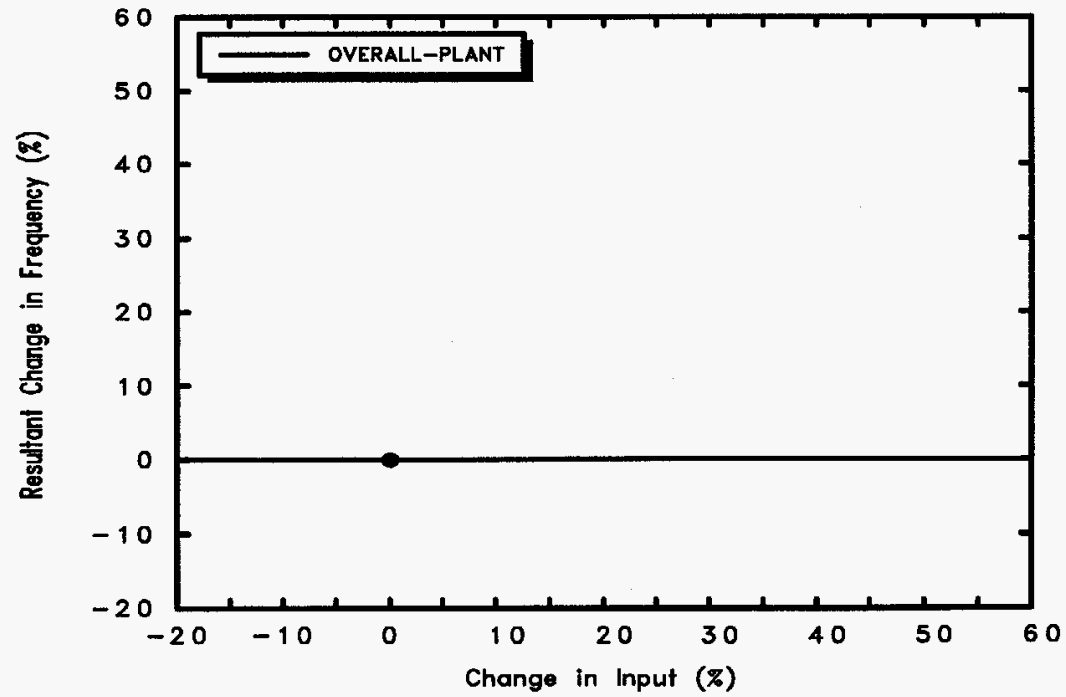

Figure C.6-4. Frequency for Loss of NPSH .vs. Drywell Transport Factors 
Appendix C

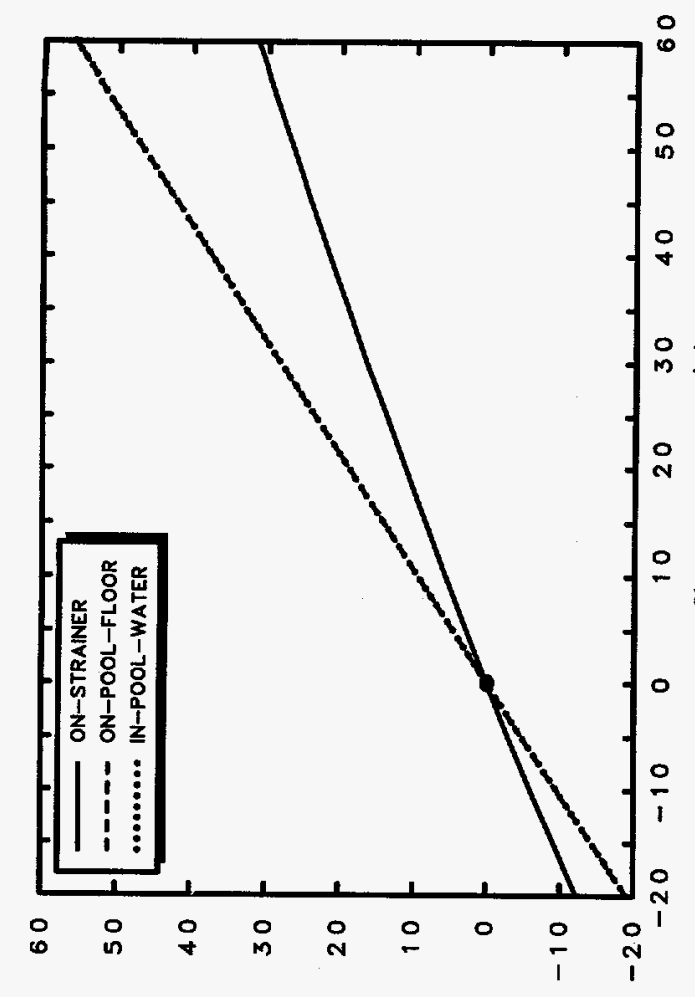

(๕) өunion deq!J u! aбudus fudfnsey

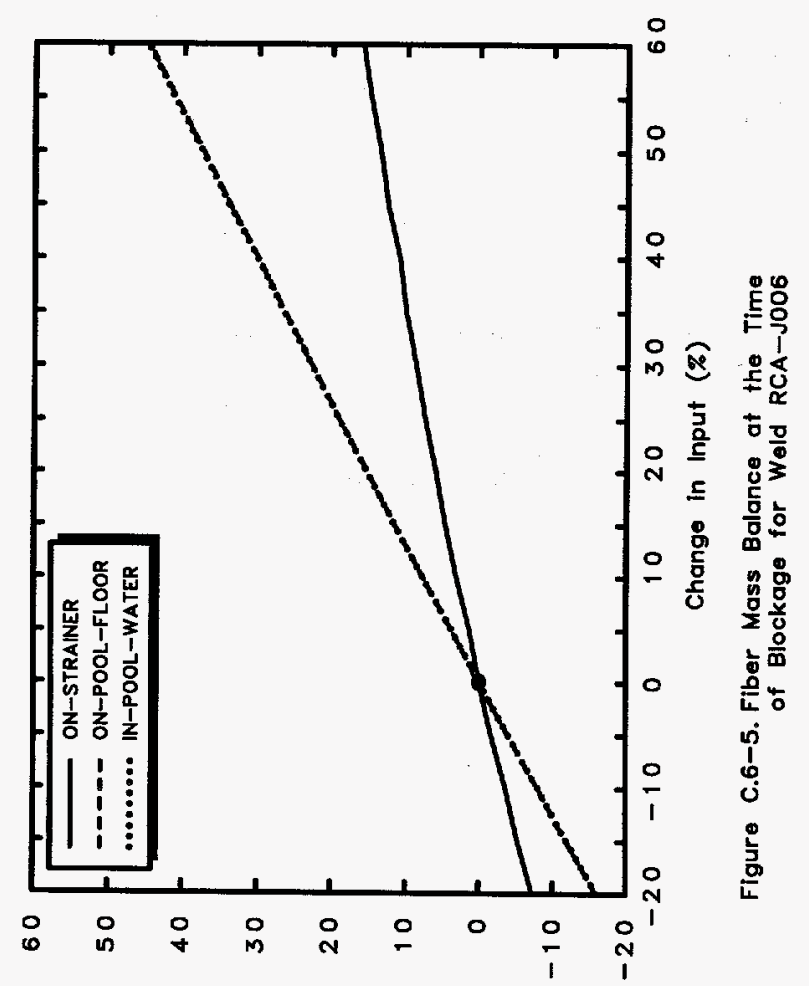

(z) ounion deq!J u! e6uouj fuop|nsey

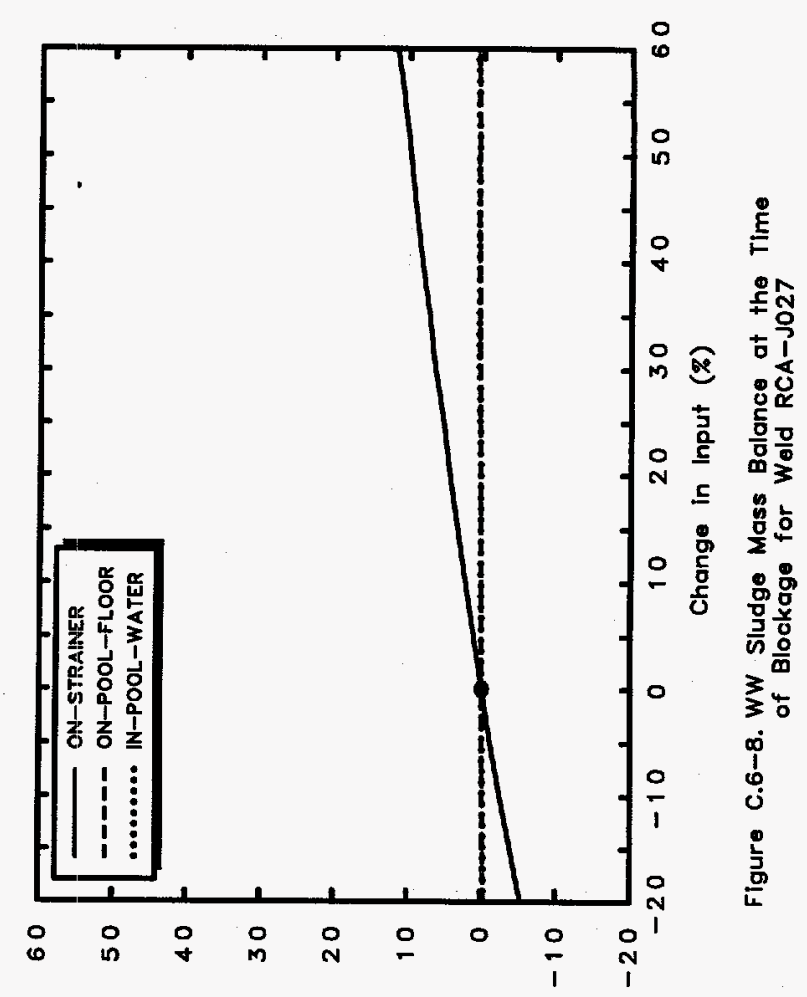

(z) ounno

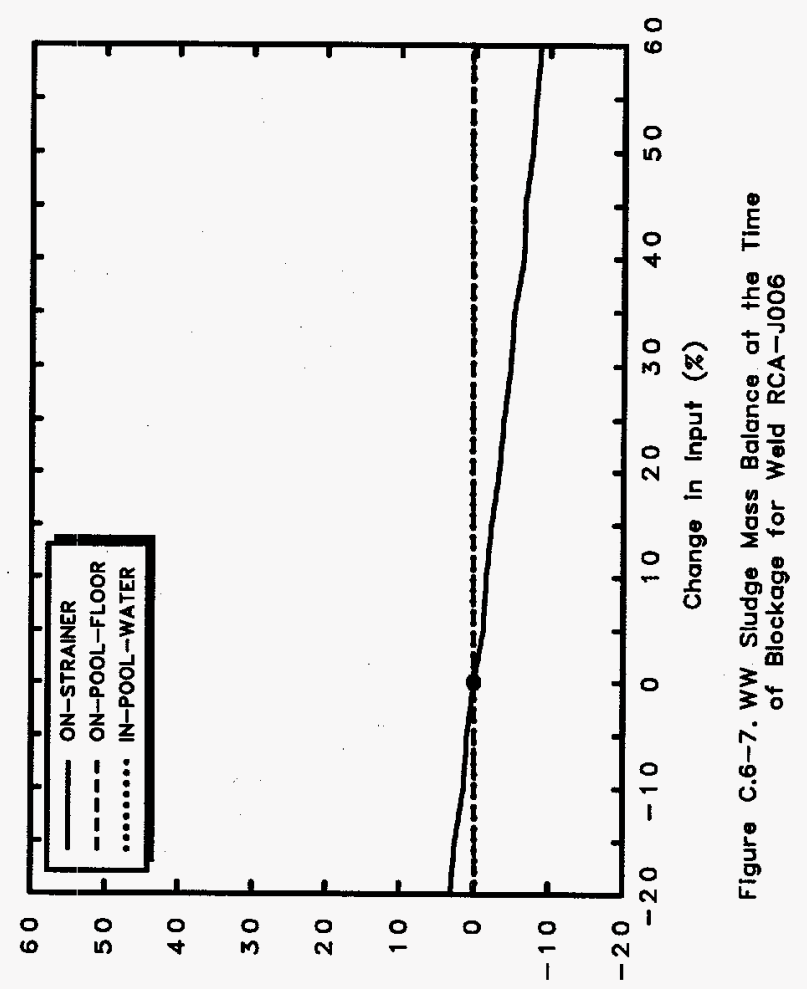

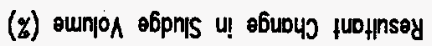

NUREG/CR-6224 
Appendix C

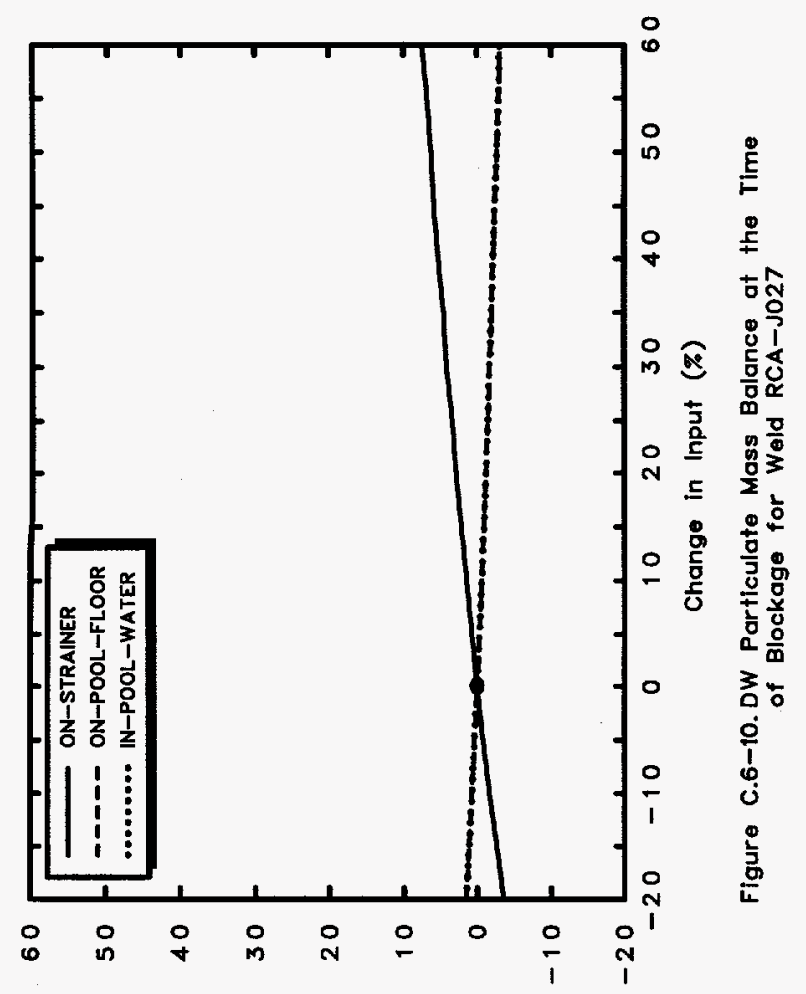

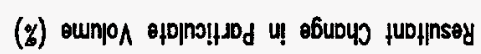
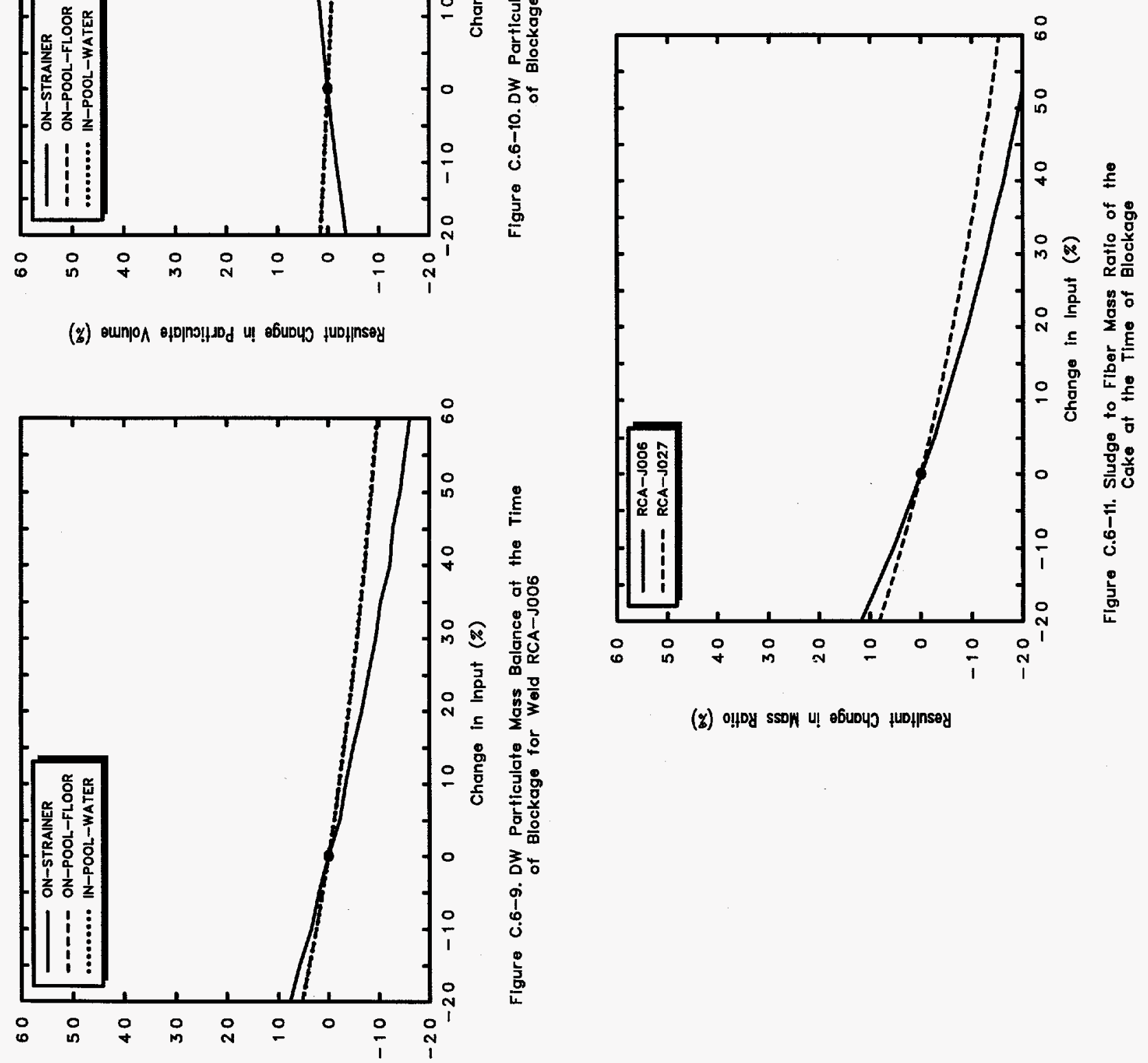

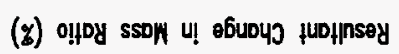

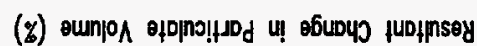




\section{C.7 Sensitivity of Turbulence Factor}

This sensitivity study was performed by varying the turbulence factors located in the base case input for both the medium and large LOCA weld breaks simultaneously by the same percentage. The same turbulence factors were used for both the LLOCAs and MLOCAs. The LLOCA and MLOCA factors increased exponentially from zero at the end of blowdown to the values listed in Table C.7-1, 300 and 120 seconds after the end of blowdown, respectively. The calculational results are presented graphically in Figures C.7-1 through C.7-11.

Table C.7-1. Calculational Cases for Turbulence Factor Sensitivity Study

\begin{tabular}{|c|c|c|}
\hline Case & Change, $\%$ & Turbulence Factor \\
\hline $\mathrm{m} 10$ & -100 & 0. \\
\hline $\mathrm{mg}$ & -90 & 0.05 \\
\hline $\mathrm{m} 8$ & -80 & 0.10 \\
\hline $\mathrm{m} 7$ & -70 & 0.15 \\
\hline m6 & -60 & 0.20 \\
\hline $\mathrm{m} 5$ & -50 & 0.25 \\
\hline $\mathrm{m} 4$ & -40 & 0.30 \\
\hline $\mathrm{m} 3$ & -30 & 0.35 \\
\hline $\mathrm{m} 2$ & -20 & 0.40 \\
\hline $\mathrm{m} 1$ & -10 & 0.45 \\
\hline Base & $\mathbf{0}$ & 0.50 \\
\hline 1 & +10 & 0.55 \\
\hline 2 & +20 & 0.60 \\
\hline 3 & +30 & 0.65 \\
\hline 4 & +40 & 0.70 \\
\hline 5 & +50 & 0.75 \\
\hline 6 & +60 & 0.80 \\
\hline 7 & +70 & 0.85 \\
\hline 8 & +80 & 0.90 \\
\hline 9 & +90 & 0.95 \\
\hline 10 & +100 & 1.00 \\
\hline
\end{tabular}


Resultant Change in Blockage Time (\%)

Resultant Change in Head Loss (\%)

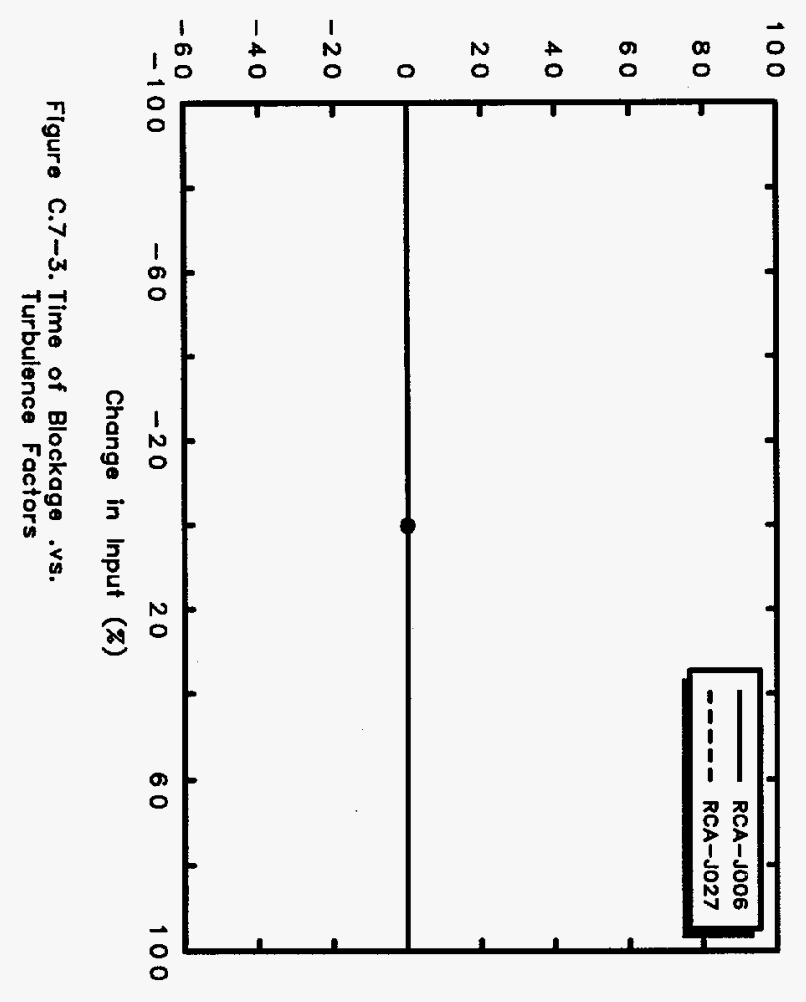

Resultant Change in Frequency (\%)

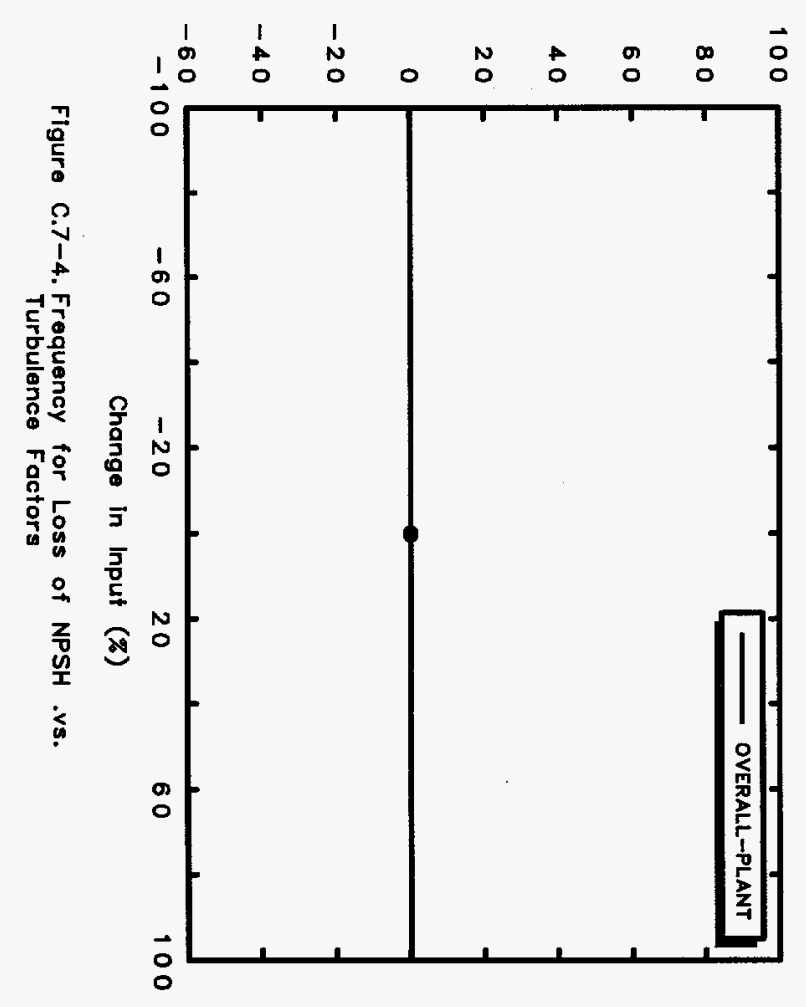

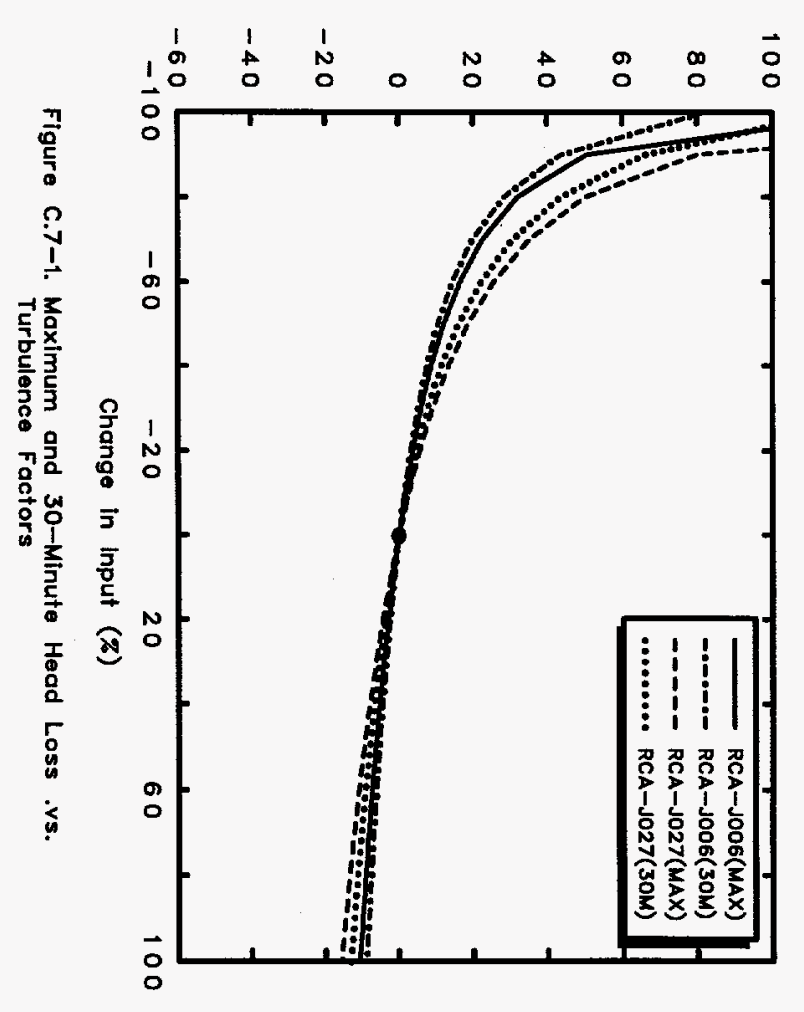

Resultant Change in Thickness (\%)

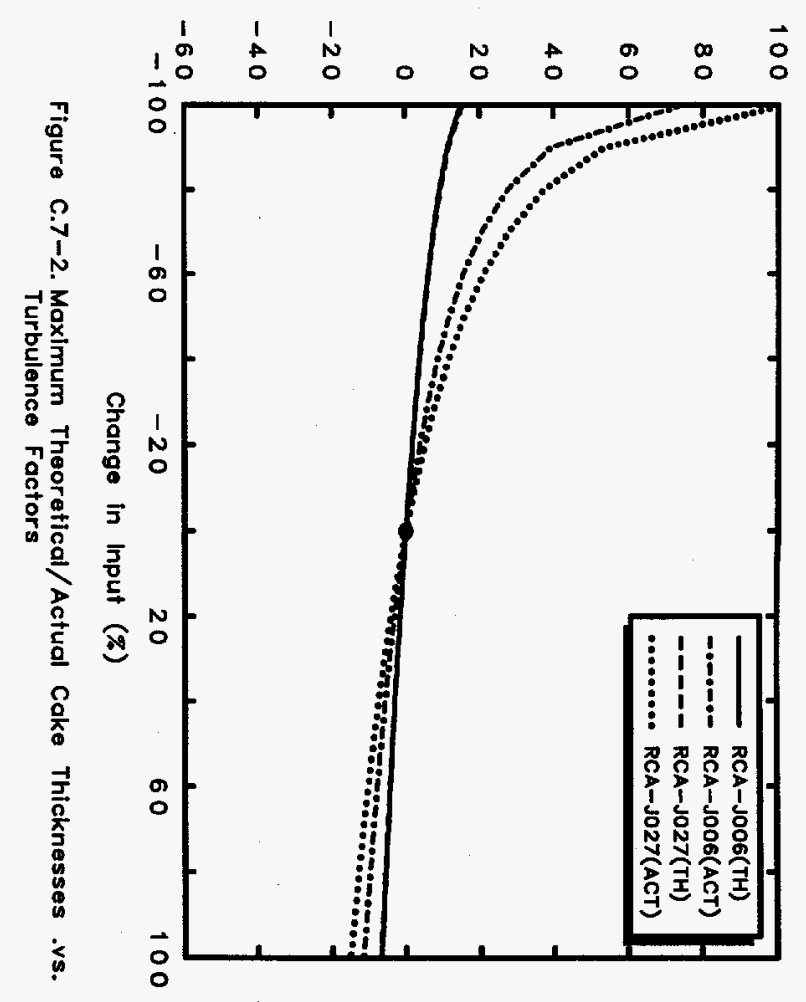

כ xịpuaddV 
Resultant Change in Sludge Volume (\%)

Resultant Change in Fiber Volume (z)

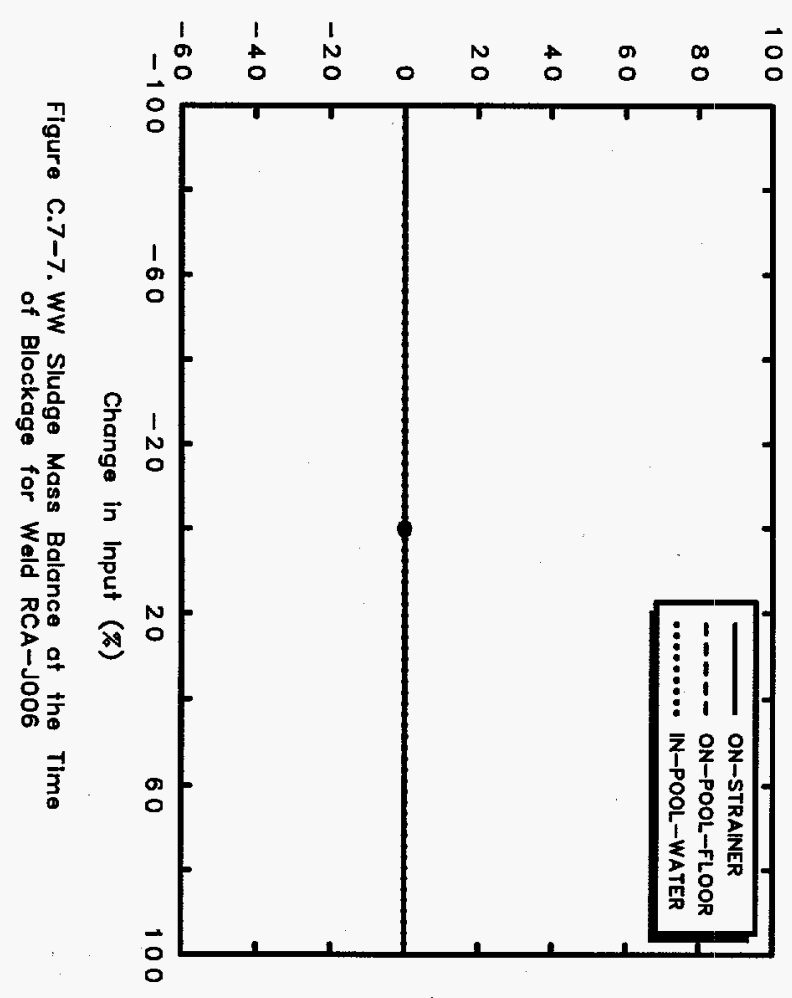

Resultant Change in Sludge Volume (\%)

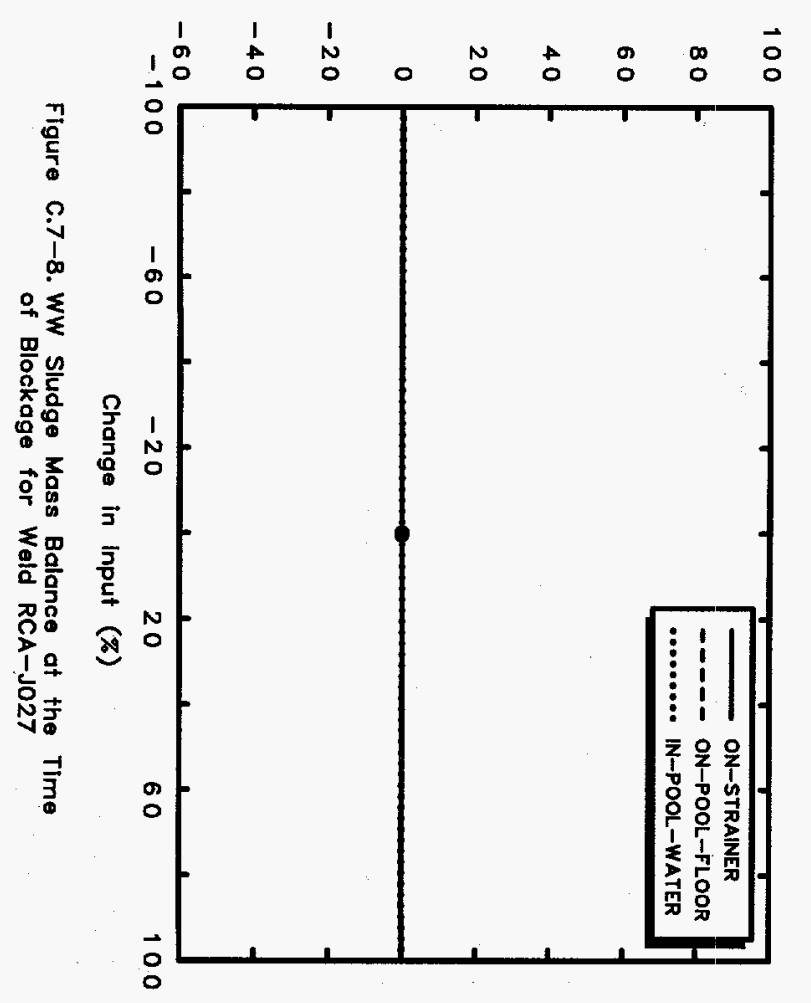

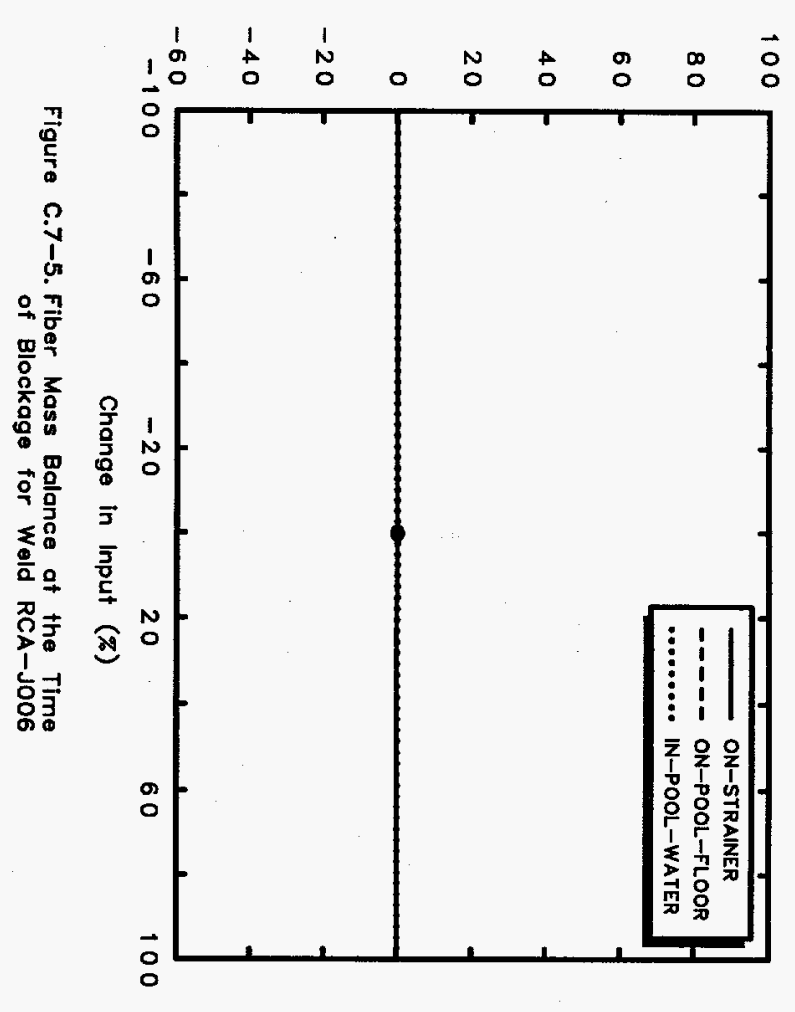

Resultant Change in Fiber Volume (\%)

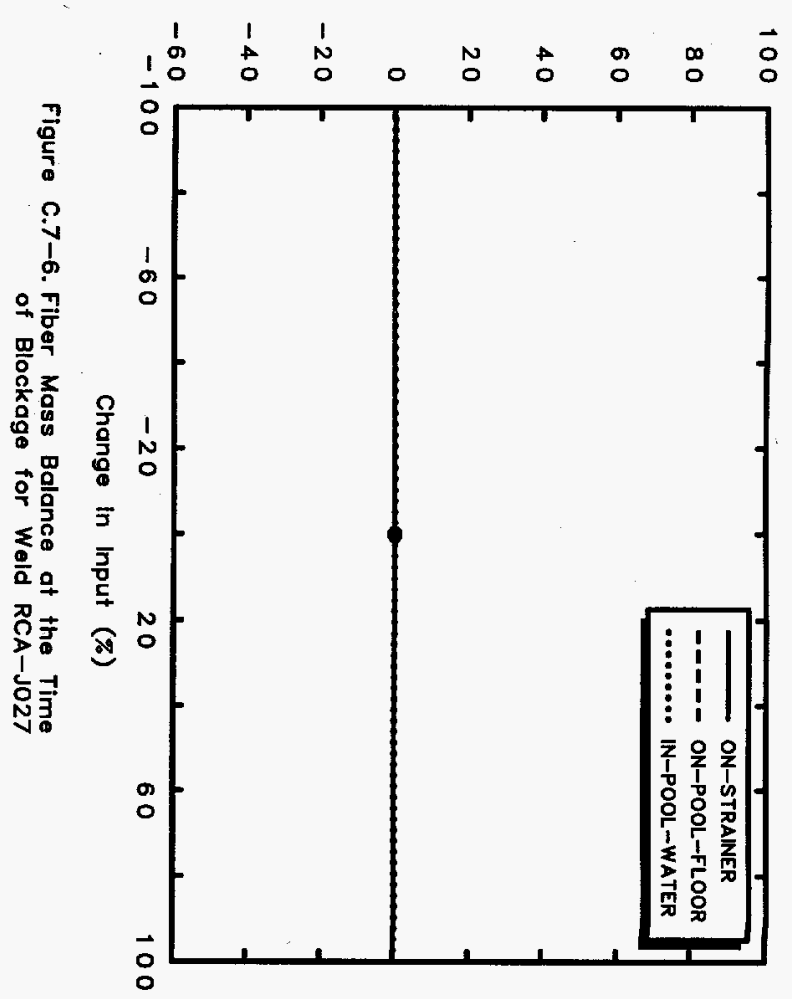




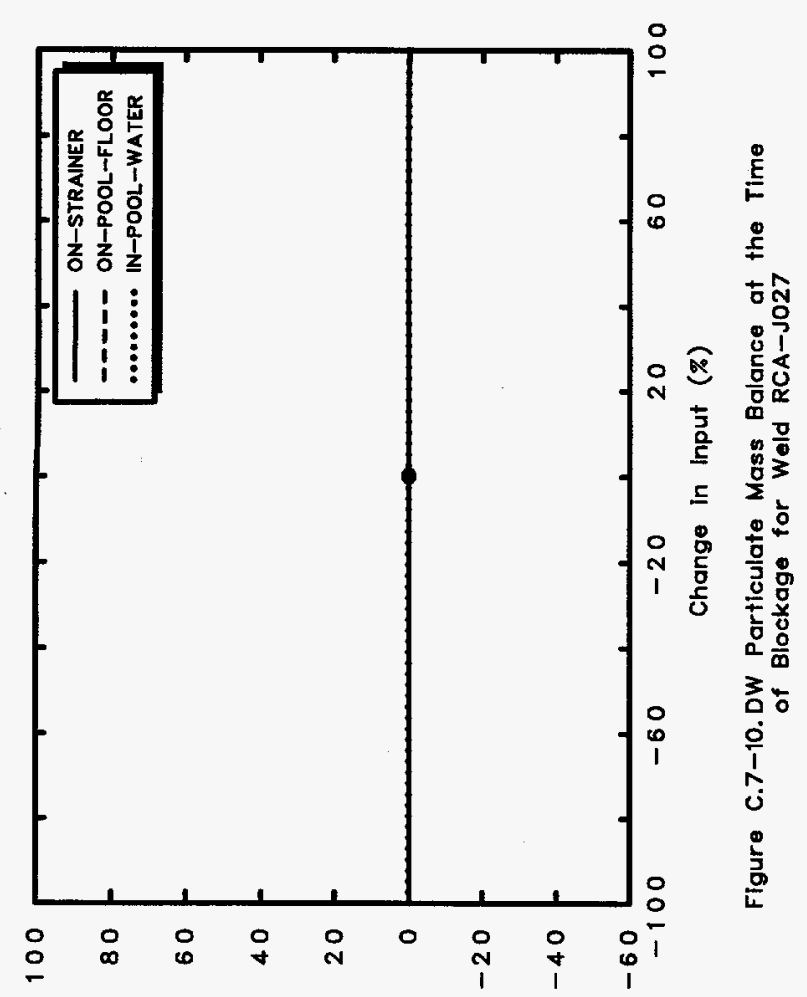

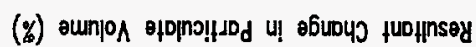

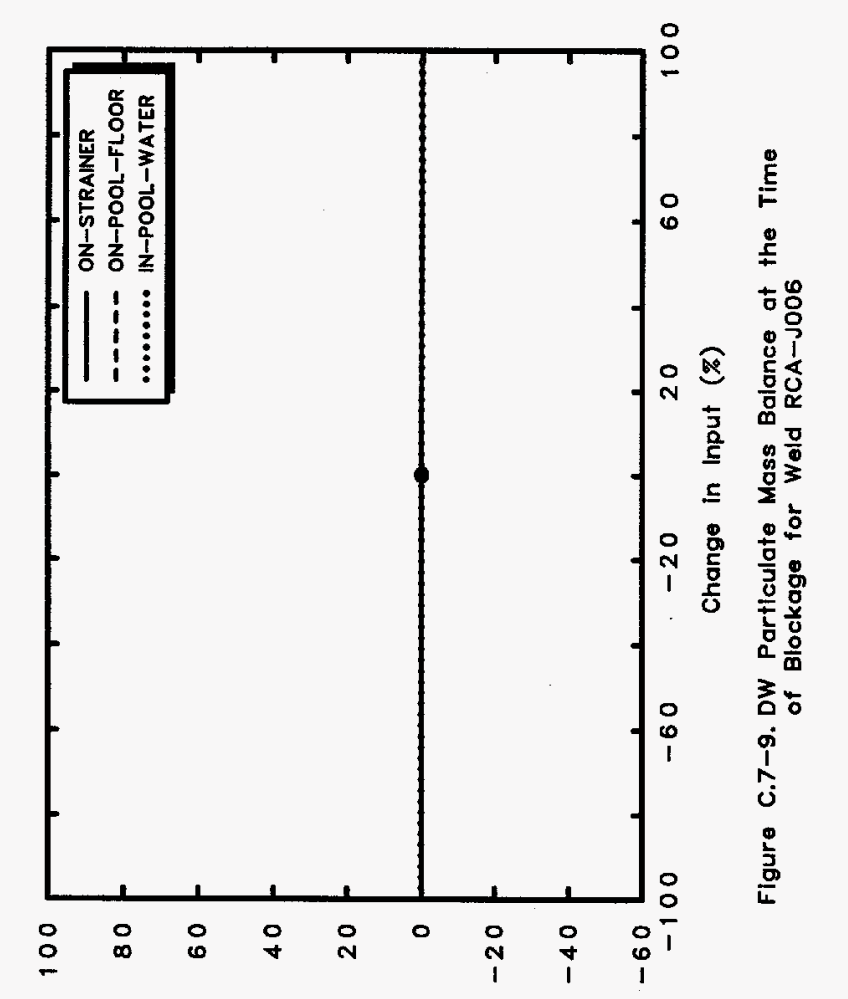

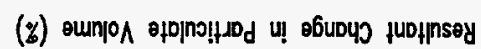

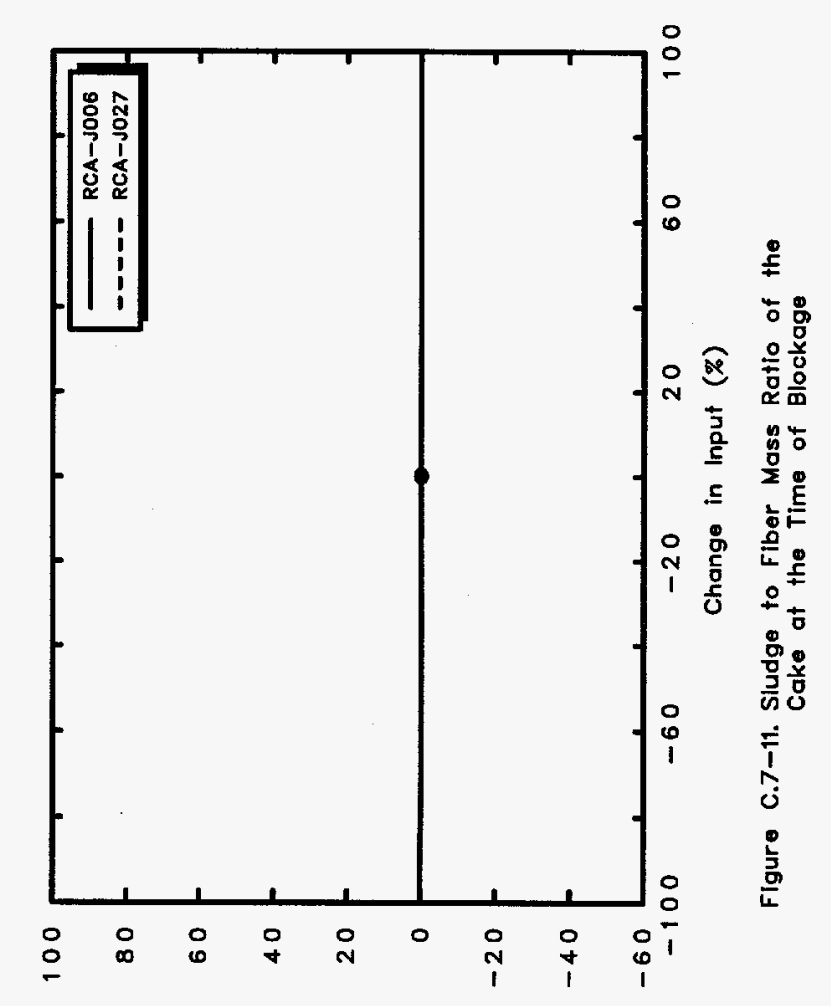

(b) o!tpy SSDY u! e6uouj fupynsoy 


\section{C.8 Sensitivity of Particulate Debris Volume}

This sensitivity study was performed by varying the base case volumes of the drywell particulate and wetwell sludge debris simultaneously by the same percentage. The values used are listed in Table $C$. 8-1. The calculational results are presented graphically in Figures C.8-1 through C.8-11.

Table C.8-1. Calculational Cases for the Particulate Debris Volume Sensitivity Study

\begin{tabular}{|c|c|c|c|}
\hline Case & $\begin{array}{c}\text { Change, } \\
\%\end{array}$ & $\begin{array}{c}\text { Drywell } \\
\text { Debris } \\
\text { Volume, } \\
\mathrm{ft}^{3}\end{array}$ & $\begin{array}{c}\text { Wetwell } \\
\text { Debris } \\
\text { Volume, } \\
\mathbf{f t}^{3}\end{array}$ \\
\hline $\mathrm{m} 5$ & -50 & 0.85 & 1.30 \\
\hline $\mathrm{m} 4$ & -40 & 1.02 & 1.56 \\
\hline $\mathrm{m} 3$ & -30 & 1.19 & 1.82 \\
\hline $\mathrm{m} 2$ & -20 & 1.36 & 2.08 \\
\hline $\mathrm{m} 1$ & -10 & 1.53 & 2.34 \\
\hline $\mathrm{Base}$ & 0 & $\mathbf{1 . 7 0}$ & 2.60 \\
\hline 1 & +10 & 1.87 & 2.86 \\
\hline 2 & +20 & 2.04 & 3.12 \\
\hline 3 & +30 & 2.21 & 3.38 \\
\hline 4 & +40 & 2.38 & 3.64 \\
\hline 5 & +50 & 2.55 & 3.90 \\
\hline 6 & +60 & 2.72 & 4.16 \\
\hline 7 & +70 & 2.89 & 4.42 \\
\hline 8 & +80 & 3.06 & 4.68 \\
\hline 9 & +90 & 3.23 & 4.94 \\
\hline
\end{tabular}

\begin{tabular}{|c|c|c|c|}
\hline 10 & +100 & 3.40 & 5.20 \\
\hline 11 & +110 & 3.57 & 5.46 \\
\hline 12 & +120 & 3.74 & 5.72 \\
\hline 13 & +130 & 3.91 & 5.98 \\
\hline 14 & +140 & 4.08 & 6.24 \\
\hline 15 & +150 & 4.25 & 6.50 \\
\hline 16 & +160 & 4.42 & 6.76 \\
\hline 17 & +170 & 4.59 & 7.02 \\
\hline 18 & +180 & 4.76 & 7.28 \\
\hline 19 & +190 & 4.93 & 7.54 \\
\hline 20 & +200 & 5.10 & 7.8 \\
\hline 21 & +210 & 5.27 & 8.06 \\
\hline 22 & +220 & 5.44 & 8.32 \\
\hline 23 & +230 & 5.61 & 8.58 \\
\hline 24 & +240 & 5.78 & 8.84 \\
\hline 25 & +250 & 5.95 & 9.10 \\
\hline & & & \\
\hline
\end{tabular}




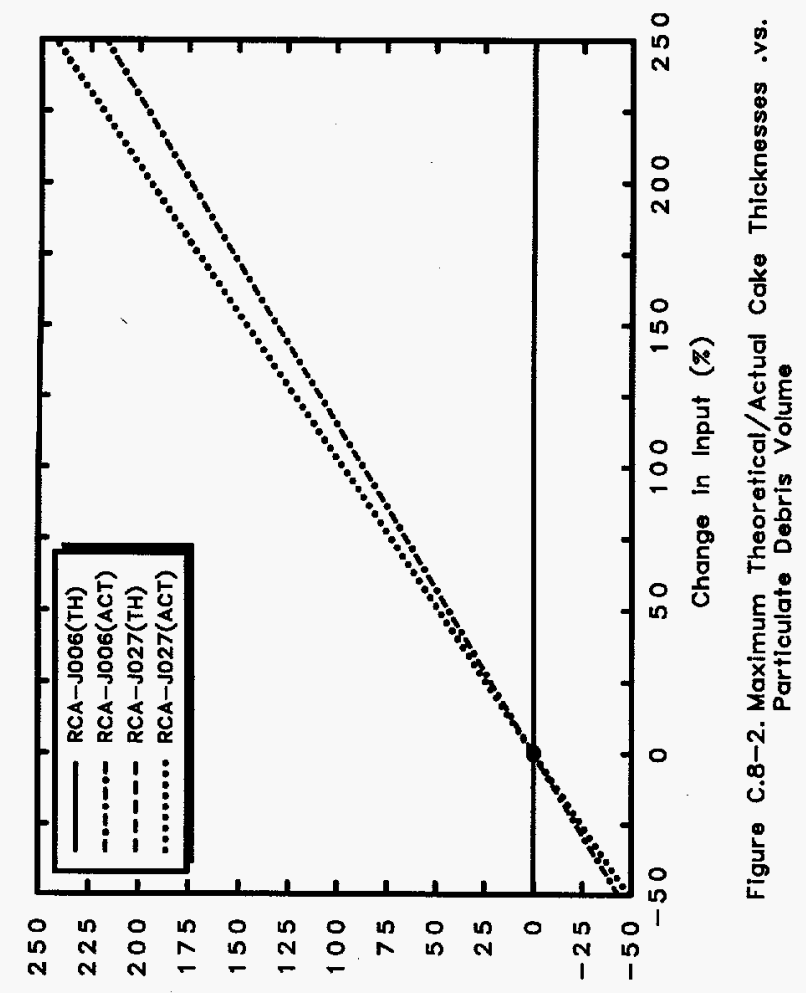

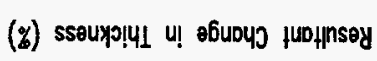

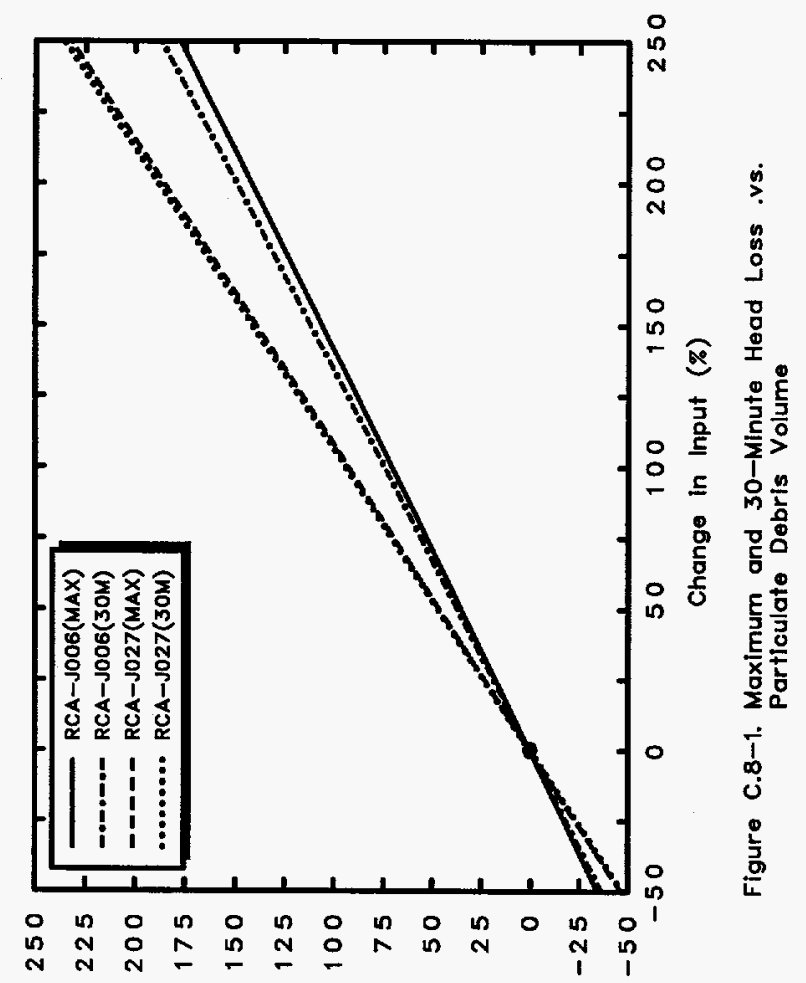

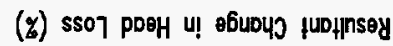

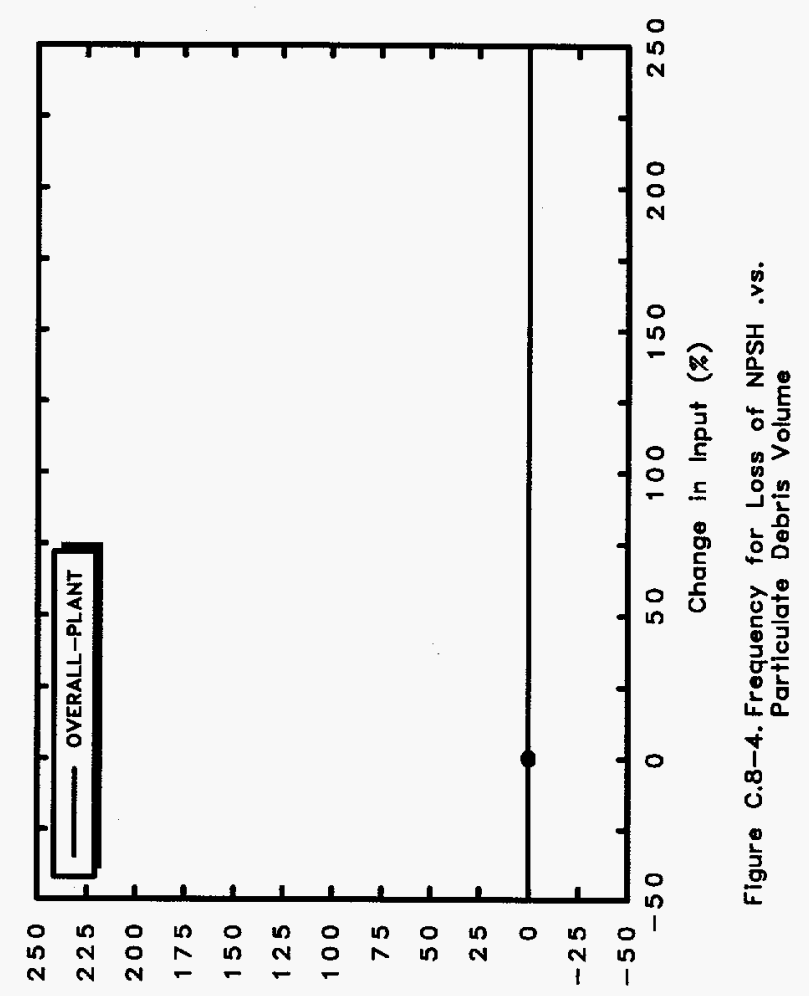

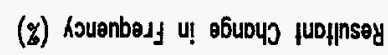

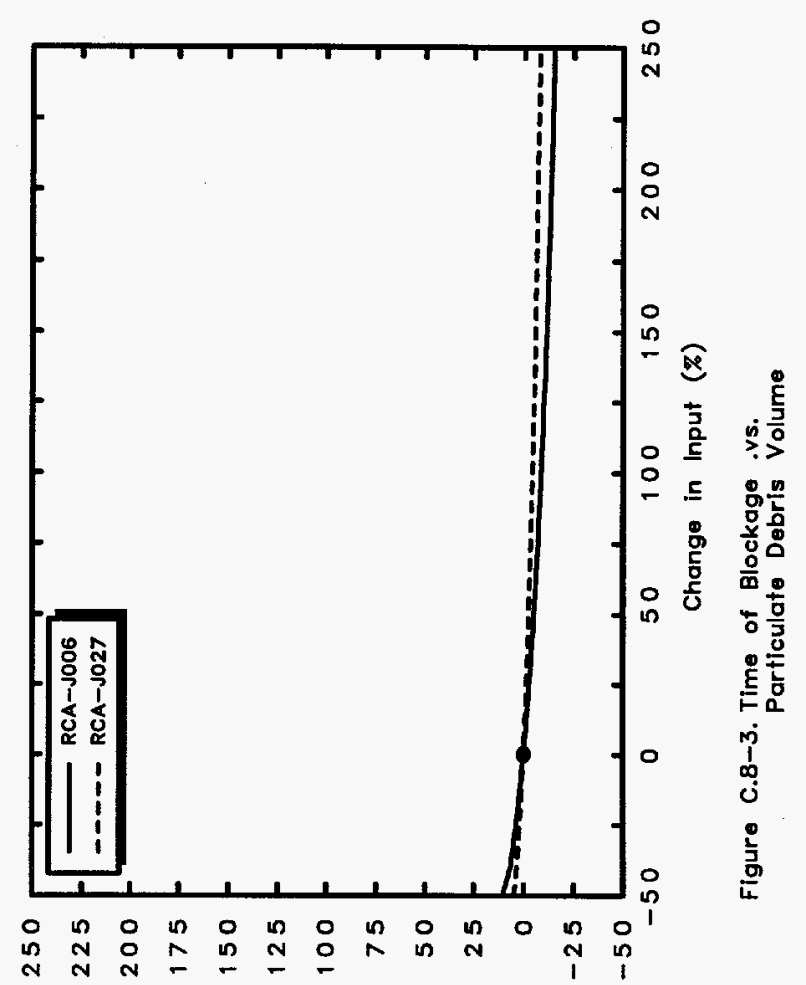

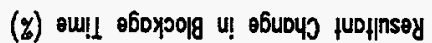


Appendix C

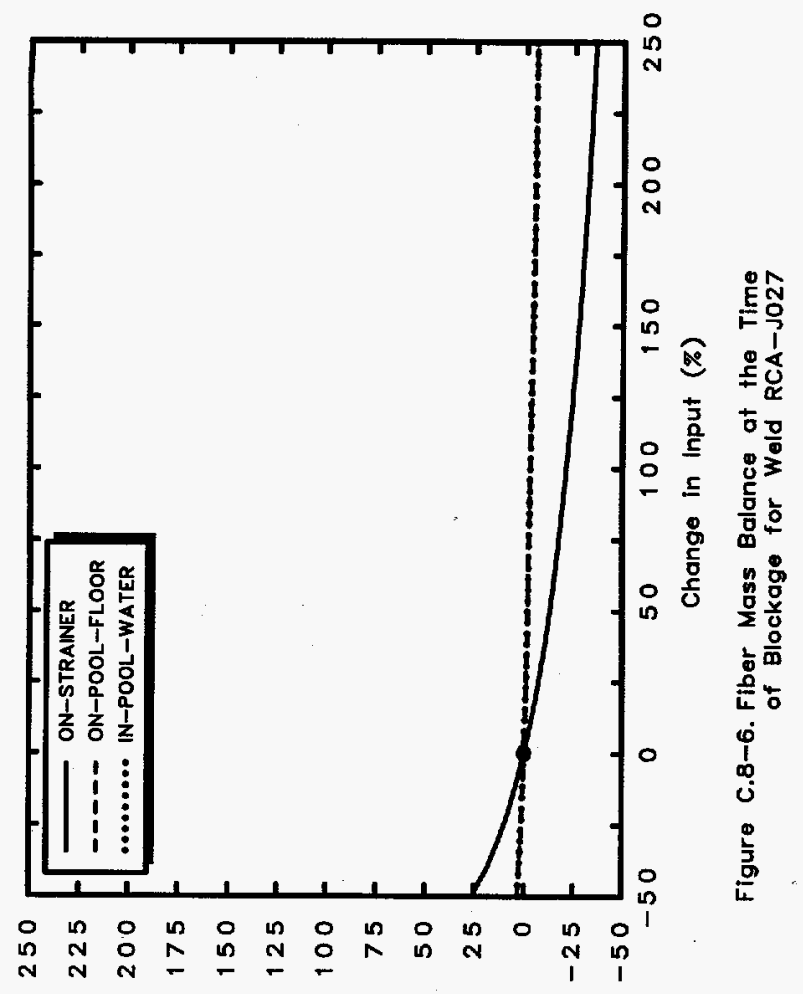

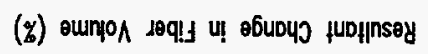

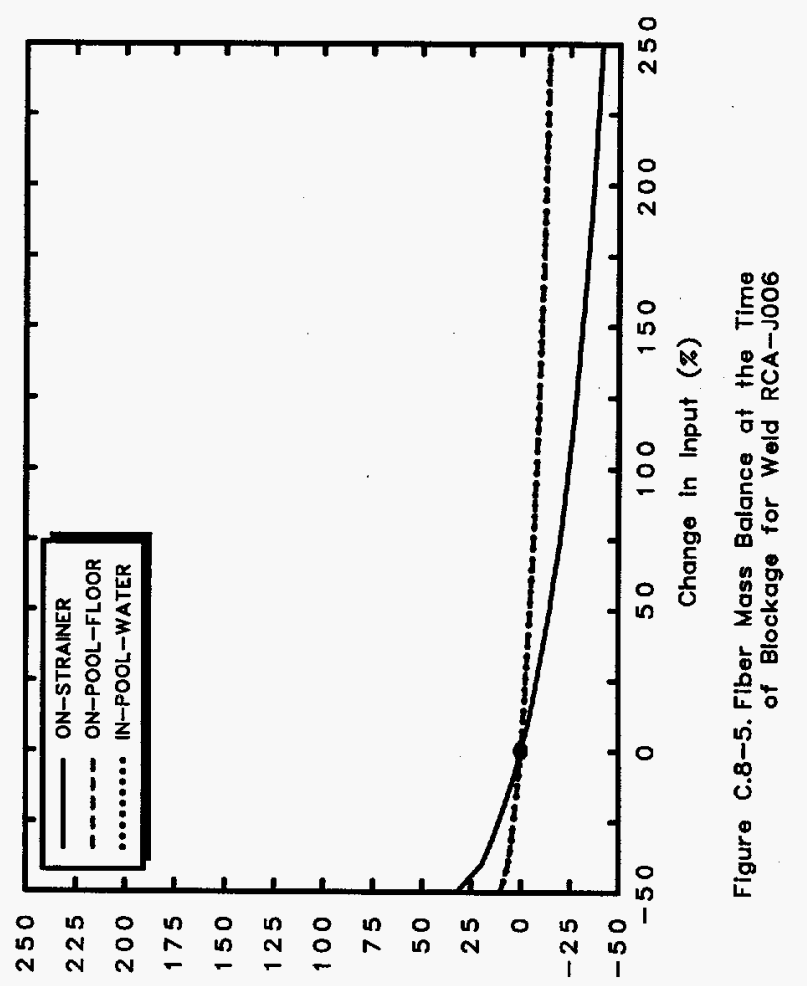

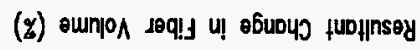

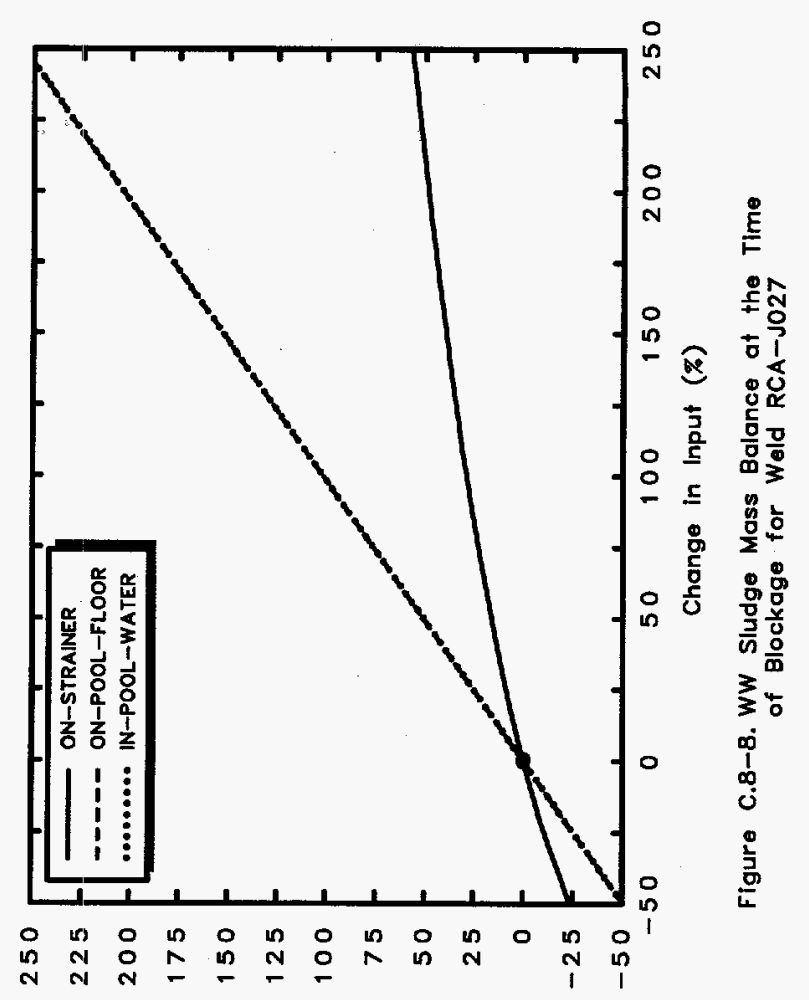

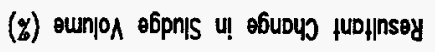

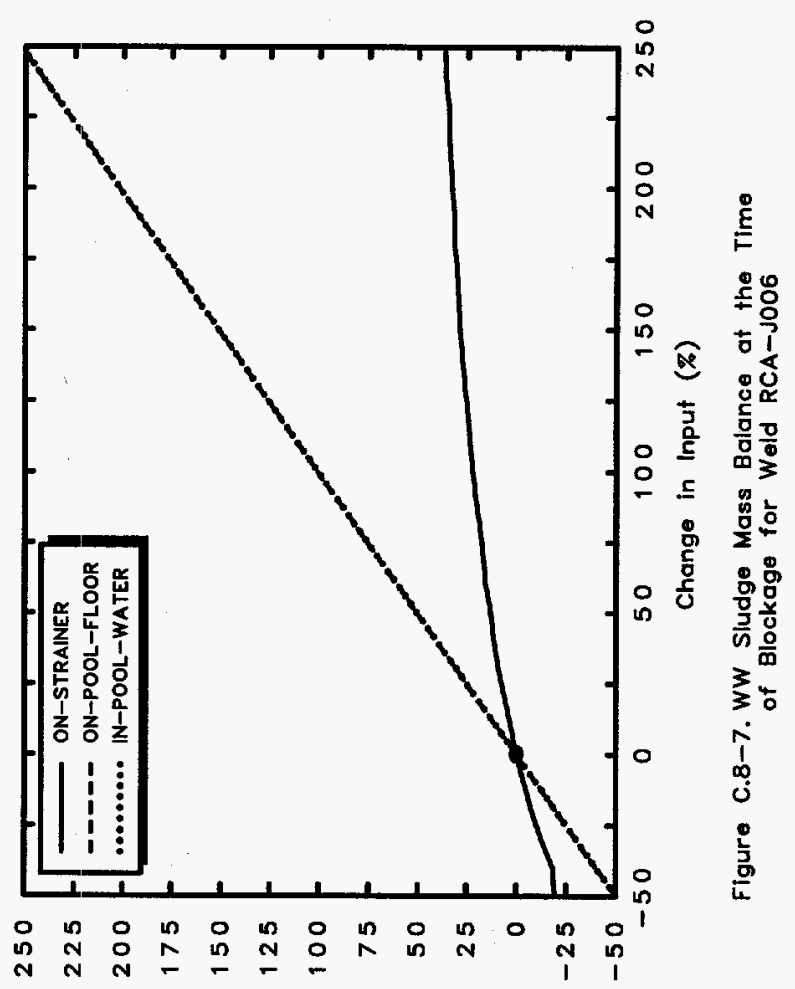

(z) ownios e6pnIS u! e6uouว fup||nsey

NUREG/CR-6224 
Appendix C

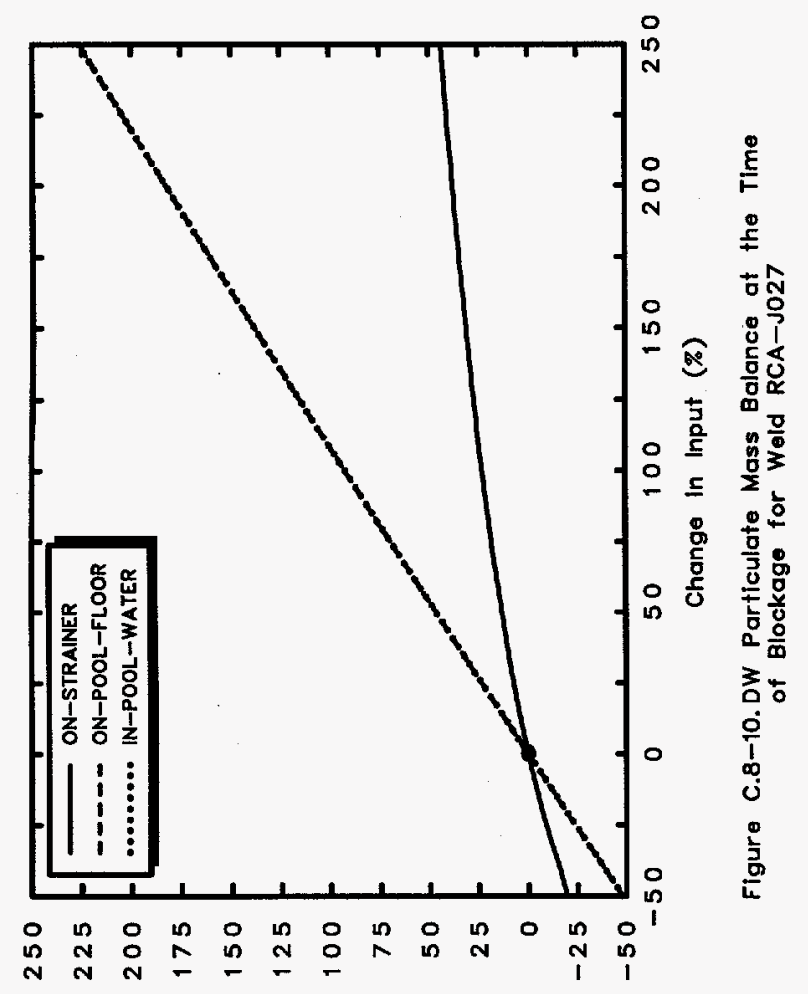

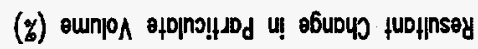
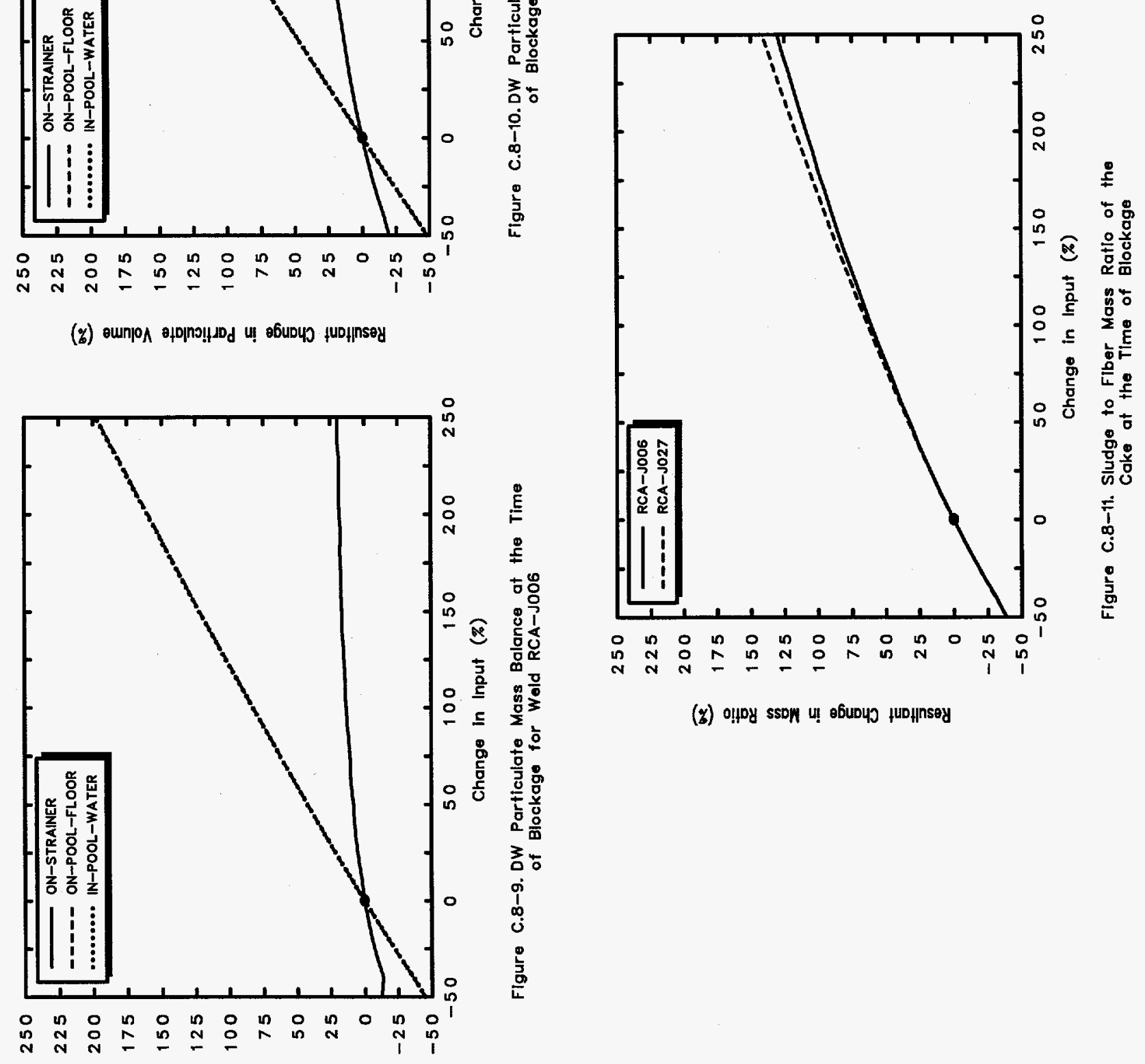

(z) o!poy sspk u! ө6upuJ fuDp|psey

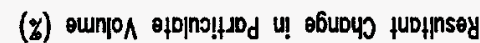




\section{C.9 Sensitivity of Strainer Surface Area}

This sensitivity study was performed by varying only the base case strainer surface area. The values used are listed in Table C.9-1. The calculational results are presented graphically in Figures C.9-1 through C.9-11. The sharp increase shown in debris deposited on the suppression pool floor as the area increased beyond about $70 \%$ is due to blockage occurring after the end of blowdown instead of before, i.e., before blowdown debris is resuspended whereas after blowdown settling rapidly increases floor deposition.

Table C.9-1. Calculational Cases for the Strainer Surface Area Sensitivity Study

\begin{tabular}{|c|c|c|}
\hline Case & Change, \% & $\begin{array}{c}\text { Surface Area, } \\
\mathrm{ft}^{2}\end{array}$ \\
\hline $\mathrm{m} 5$ & -50 & 18.81 \\
\hline $\mathrm{m} 4$ & -40 & 22.57 \\
\hline $\mathrm{m} 3$ & -30 & 26.33 \\
\hline$\overline{\mathrm{m} 2}$ & -20 & 30.10 \\
\hline $\mathrm{m} 1$ & -10 & 33.86 \\
\hline Base & 0 & 37.62 \\
\hline 1 & +10 & 41.38 \\
\hline 2 & +20 & 45.14 \\
\hline 3 & +30 & 48.91 \\
\hline 4 & +40 & 52.67 \\
\hline 5 & +50 & 56.43 \\
\hline 6 & +60 & 60.19 \\
\hline 7 & +70 & 63.95 \\
\hline 8 & +80 & 67.72 \\
\hline 9 & +90 & 71.48 \\
\hline 10 & +100 & 75.24 \\
\hline 11 & +110 & 79.00 \\
\hline 12 & +120 & 82.76 \\
\hline 13 & +130 & 86.53 \\
\hline 14 & +140 & 90.29 \\
\hline 15 & +150 & 94.05 \\
\hline 16 & +160 & 97.81 \\
\hline 17 & +170 & 101.6 \\
\hline 18 & +180 & 105.3 \\
\hline 19 & +190 & 109.1 \\
\hline 20 & +200 & 112.9 \\
\hline 21 & +210 & 116.6 \\
\hline 22 & +220 & 120.4 \\
\hline
\end{tabular}

\begin{tabular}{|c|c|c|}
\hline 23 & +230 & 124.1 \\
\hline 24 & +240 & 127.9 \\
\hline 25 & +250 & 131.7 \\
\hline 26 & +275 & 141.1 \\
\hline 27 & +300 & 150.5 \\
\hline 28 & +325 & 159.9 \\
\hline 29 & +350 & 169.3 \\
\hline 30 & +375 & 178.7 \\
\hline 31 & +400 & 188.1 \\
\hline 32 & +425 & 197.5 \\
\hline 33 & +450 & 206.9 \\
\hline 34 & +475 & 216.3 \\
\hline 35 & +500 & 225.7 \\
\hline 36 & +525 & 235.1 \\
\hline 37 & +550 & 244.5 \\
\hline 38 & +575 & 253.9 \\
\hline 39 & +600 & 263.3 \\
\hline 40 & +625 & 272.7 \\
\hline 41 & +650 & 282.2 \\
\hline 42 & +675 & 291.6 \\
\hline 43 & +700 & 301.0 \\
\hline 44 & +725 & 310.4 \\
\hline 45 & +750 & 319.8 \\
\hline 46 & +775 & 329.2 \\
\hline 47 & +800 & 338.6 \\
\hline 48 & +825 & 348.0 \\
\hline 49 & +850 & 357.4 \\
\hline 50 & +875 & 366.8 \\
\hline 51 & +900 & 376.2 \\
\hline
\end{tabular}


Appendix C

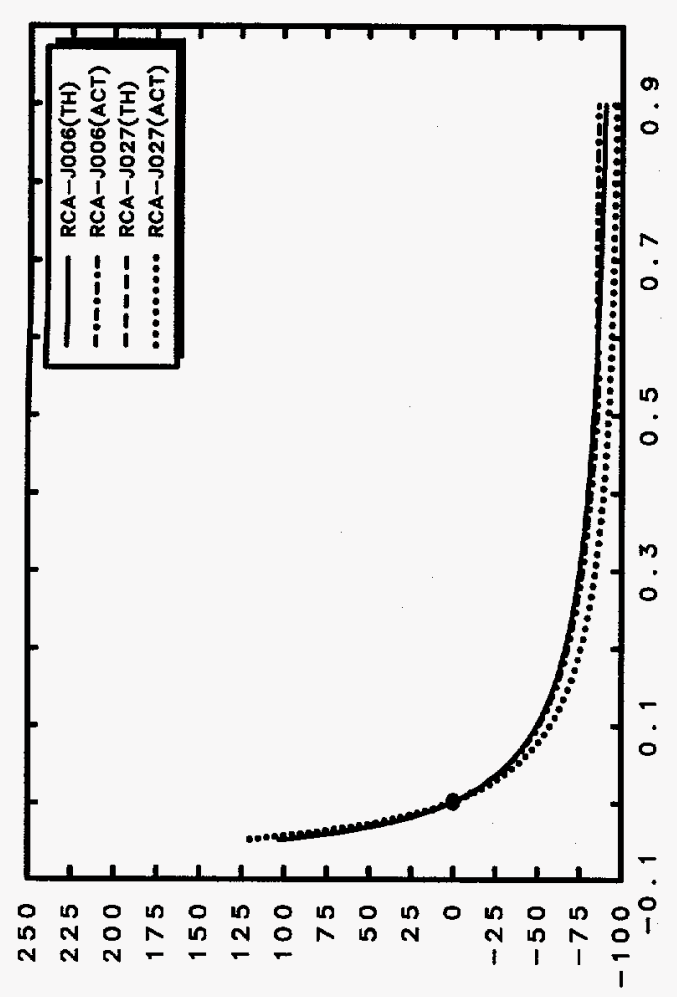

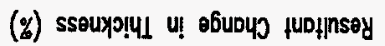

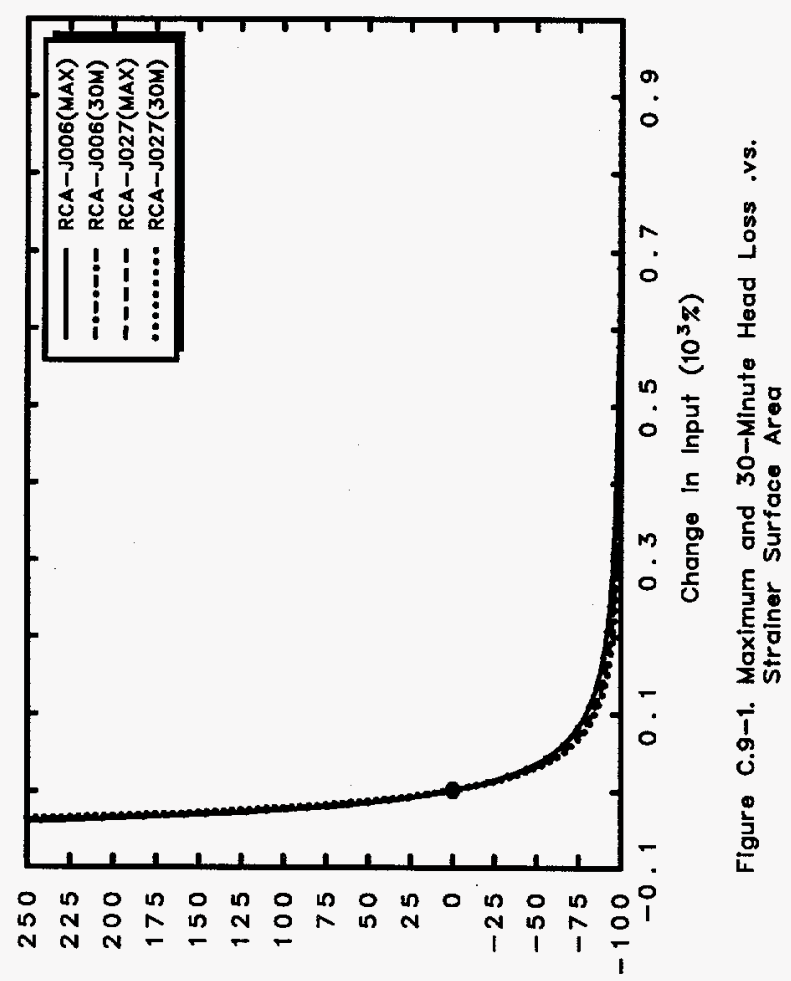

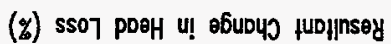

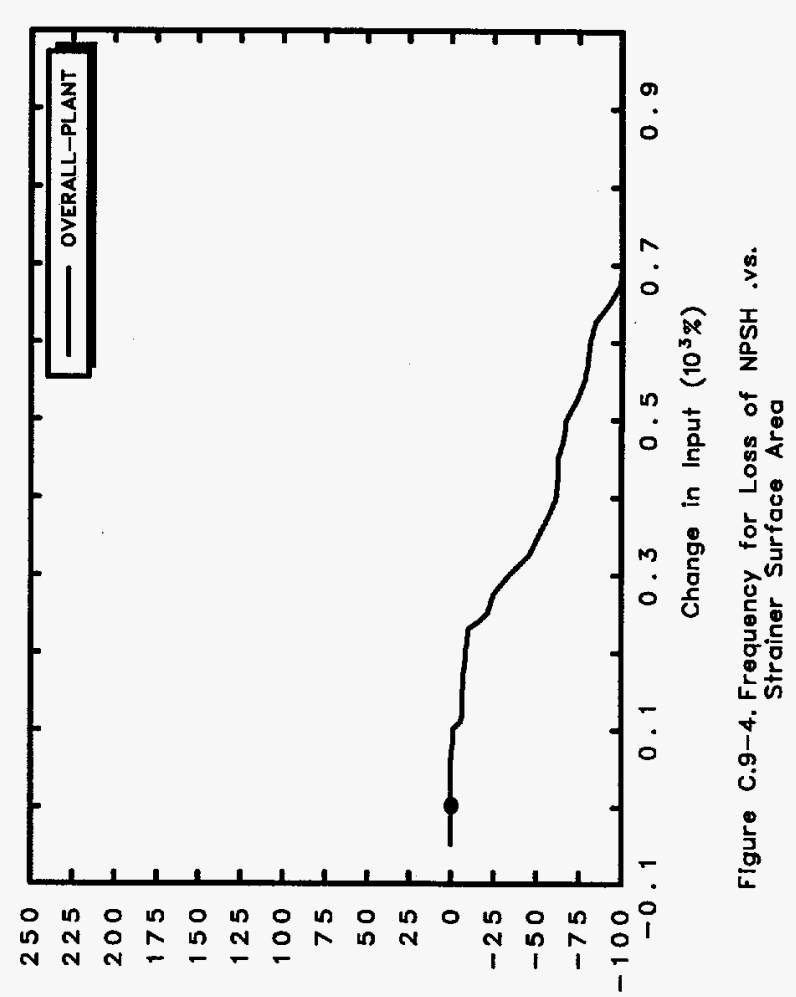

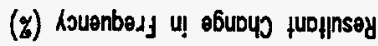

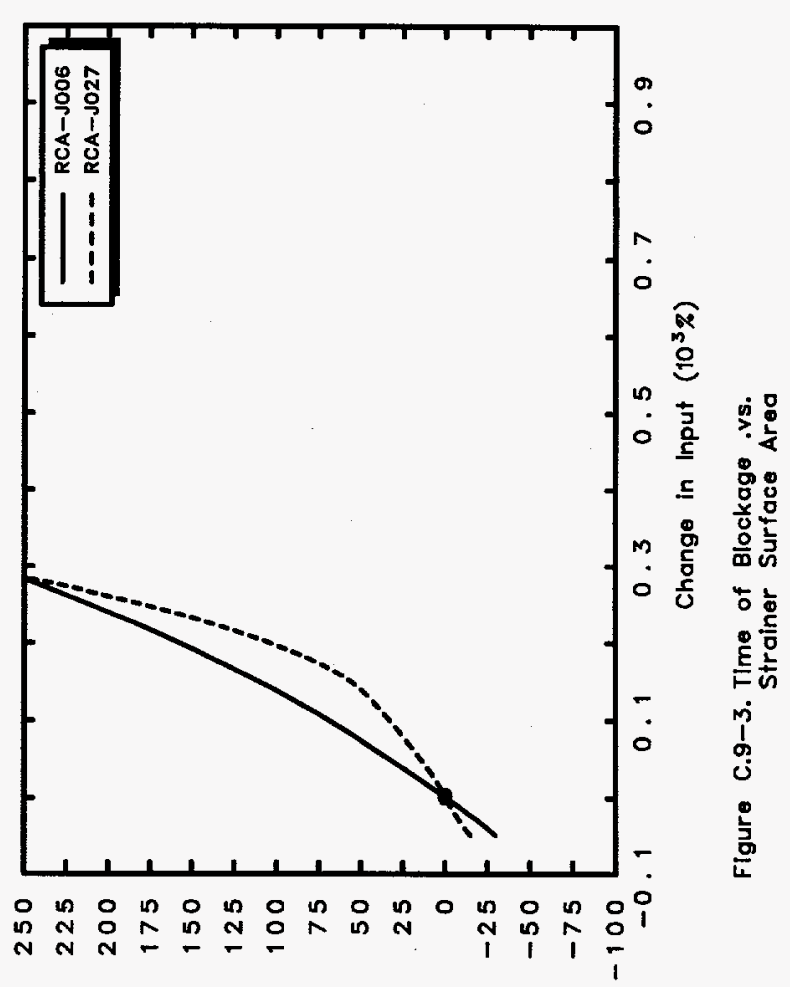

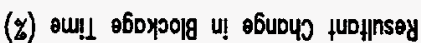


Resultant Change in Sludge Volume (z)

Resulfant Change in Fiber Volume ( $z$ )

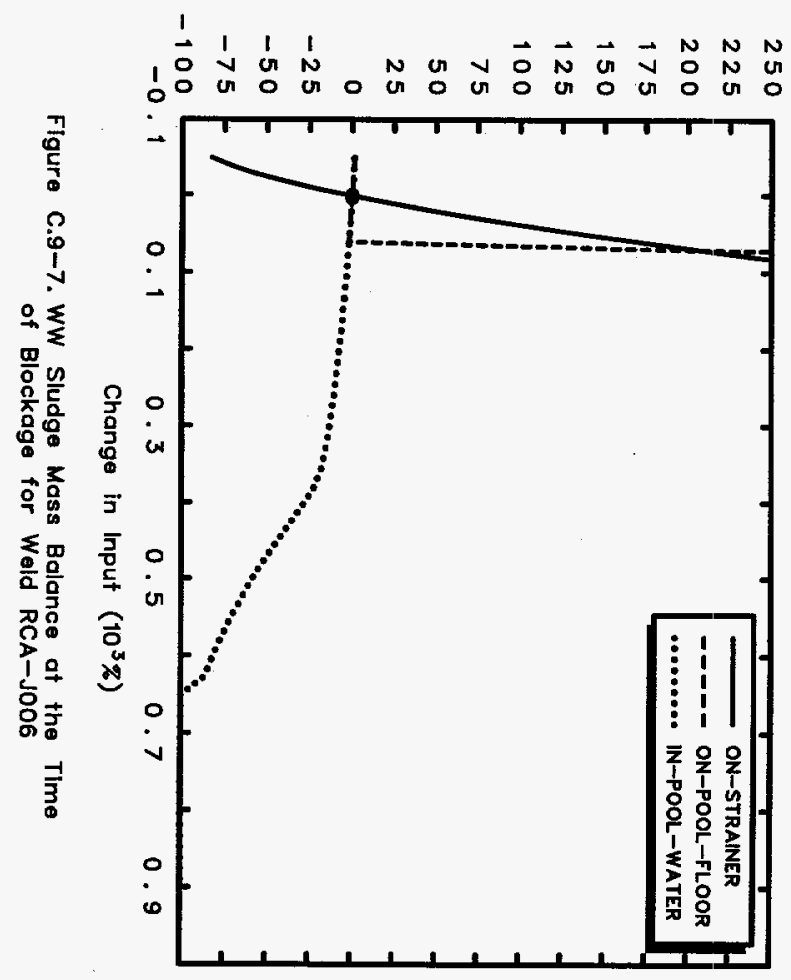

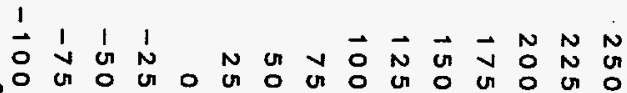

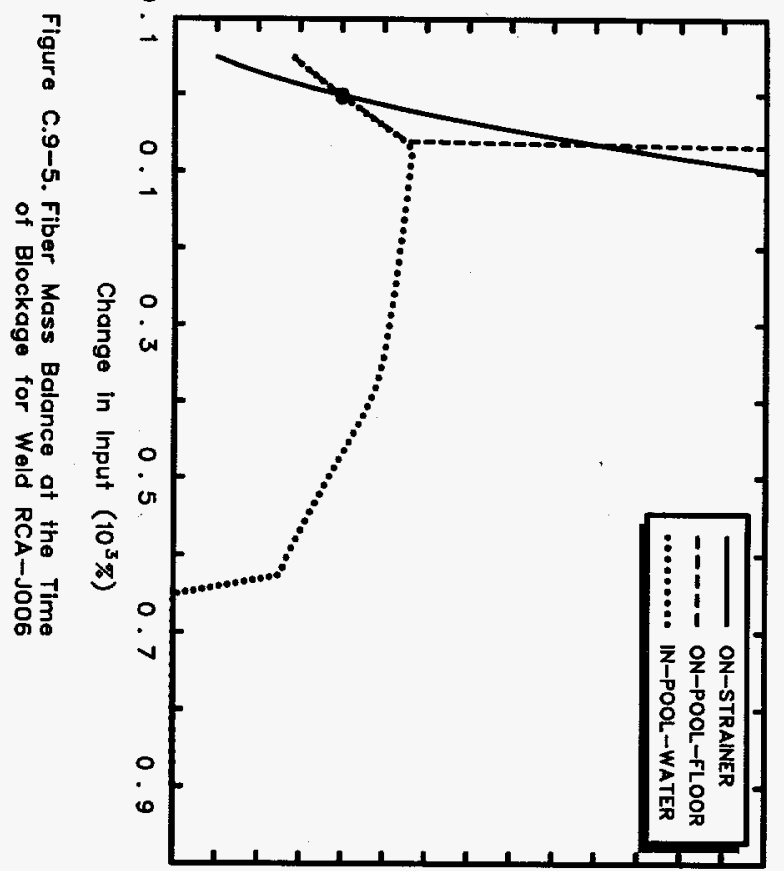

Resultant Change in Sludge Volume (z)

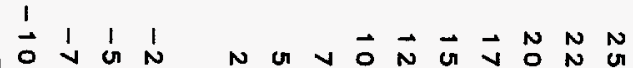

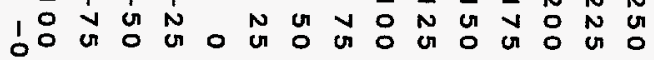

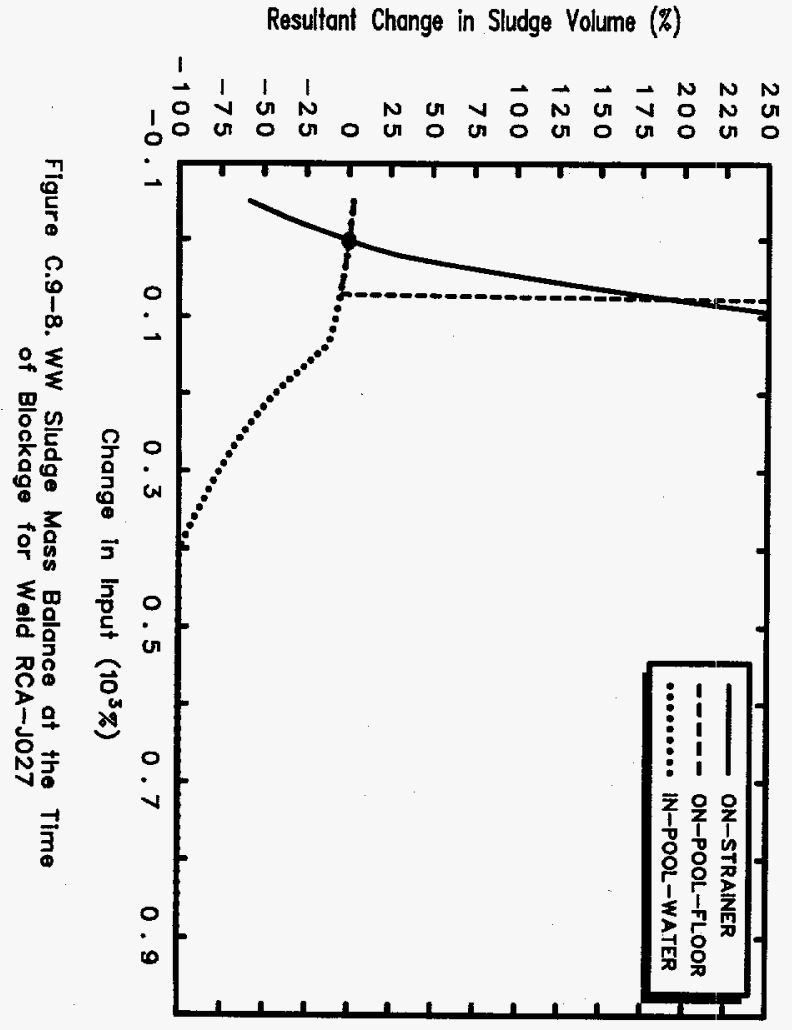

Resultant Change in Fiber Volume (F)

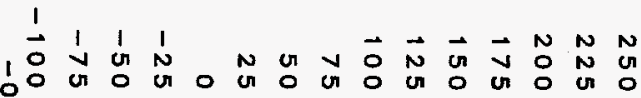

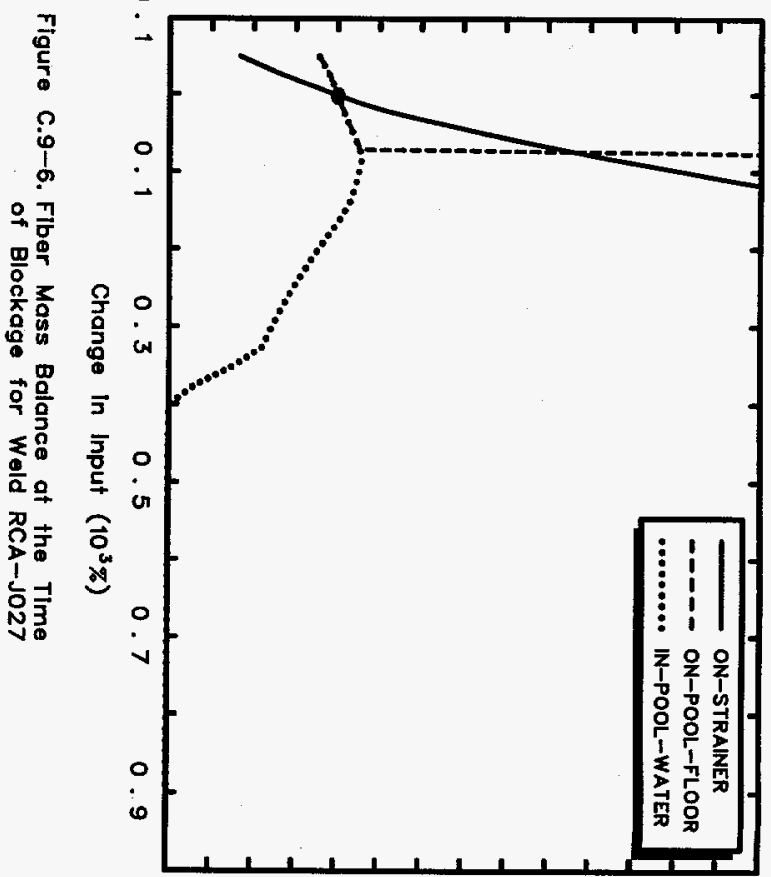


Appendix C

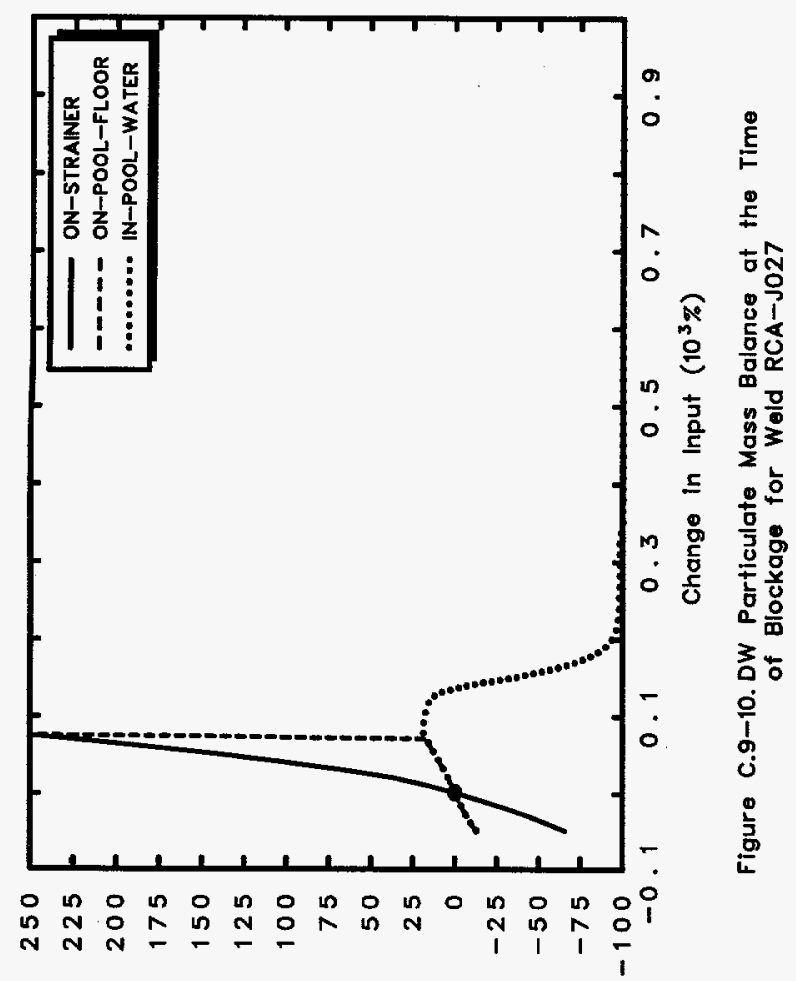

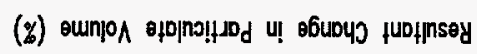
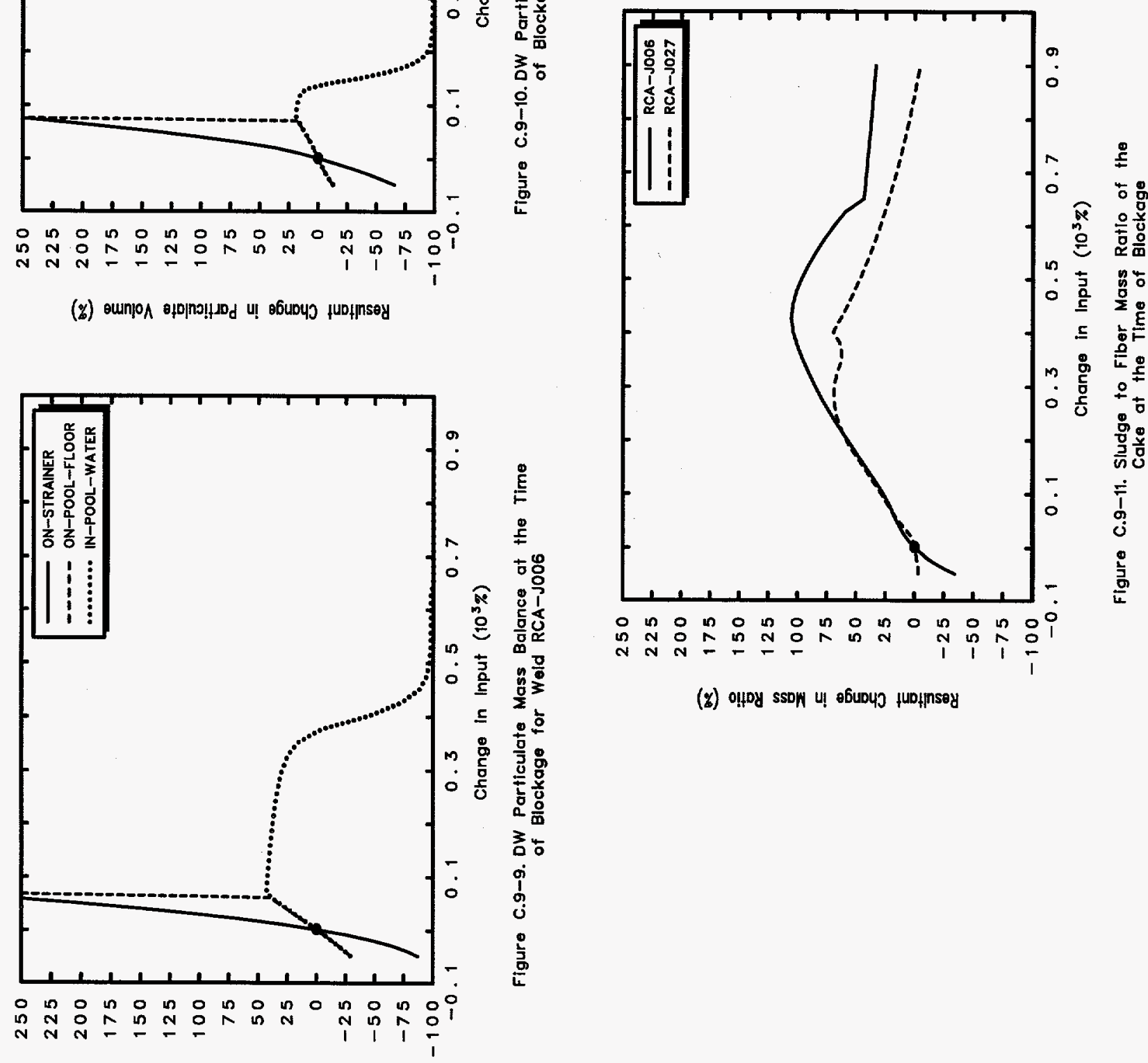

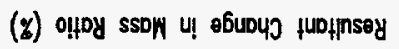

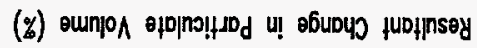




\section{C.10 Sensitivity of Available NPSH Margin}

This sensitivity study was performed by varying only the available NPSH margin in the base case input. The values used are listed in Table C.10-1. The calculational results are presented graphically in Figures C.10-1 through C.10-11.

Table C.10-1. Calculational Cases for the Available NPSH Margin Sensitivity Study

\begin{tabular}{|c|c|c|}
\hline Case & Change, $\%$ & NPSH Head, $\mathbf{f t}$ \\
\hline $\mathrm{m} 10$ & -50 & 7.0 \\
\hline $\mathrm{m} 9$ & -45 & 7.7 \\
\hline $\mathrm{m} 8$ & -40 & 8.4 \\
\hline $\mathrm{m} 7$ & -35 & 9.1 \\
\hline $\mathrm{m} 6$ & -30 & 9.8 \\
\hline $\mathrm{m} 5$ & -25 & 10.5 \\
\hline $\mathrm{m} 4$ & -20 & 11.2 \\
\hline $\mathrm{m} 3$ & -15 & 11.9 \\
\hline $\mathrm{m} 2$ & -10 & 12.6 \\
\hline $\mathrm{m} 1$ & -5 & 13.3 \\
\hline Base & $\mathbf{0}$ & $\mathbf{1 4 . 0}$ \\
\hline 1 & +5 & 14.7 \\
\hline 2 & +10 & 15.4 \\
\hline 3 & +15 & 16.1 \\
\hline
\end{tabular}

\begin{tabular}{|c|c|c|}
\hline 4 & +20 & 16.8 \\
\hline 5 & +25 & 17.5 \\
\hline 6 & +30 & 18.2 \\
\hline 7 & +35 & 18.9 \\
\hline 8 & +40 & 19.6 \\
\hline 9 & +45 & 20.3 \\
\hline 10 & +50 & 21.0 \\
\hline 11 & +55 & 21.7 \\
\hline 12 & +60 & 22.4 \\
\hline 13 & +65 & 23.1 \\
\hline 14 & +70 & 23.8 \\
\hline 15 & +75 & 24.5 \\
\hline 16 & +80 & 25.2 \\
\hline 17 & +85 & 25.9 \\
\hline 18 & +90 & 26.6 \\
\hline 19 & +95 & 27.3 \\
\hline 20 & +100 & 28.0 \\
\hline
\end{tabular}


Appendix C

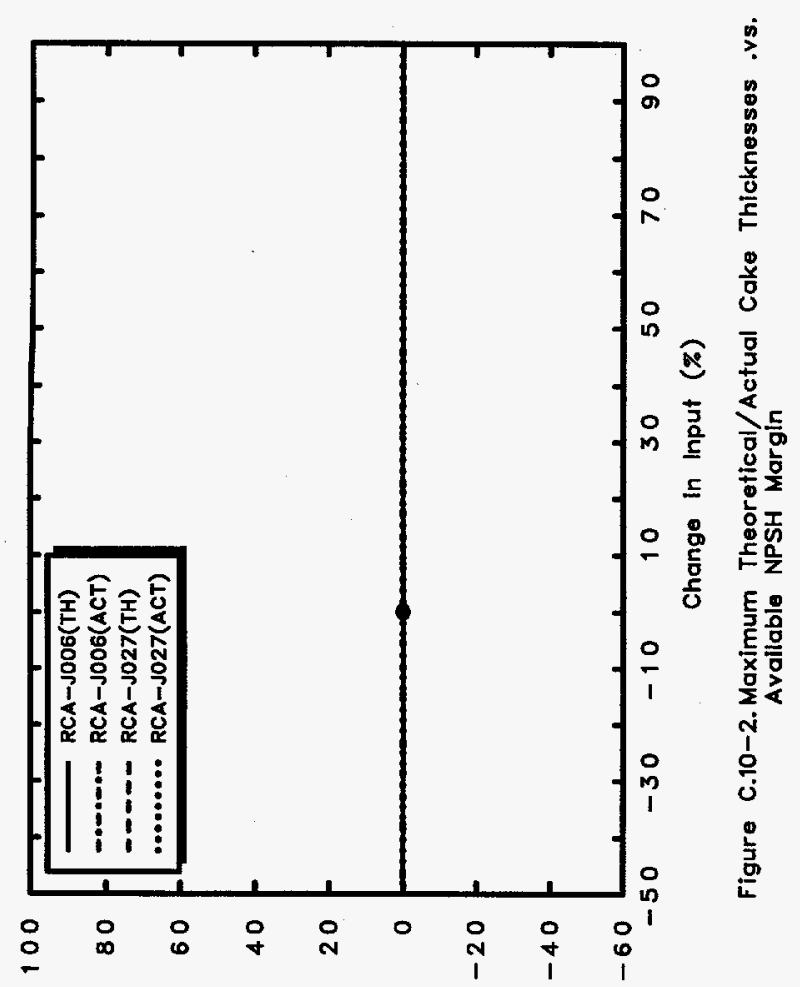

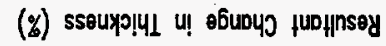

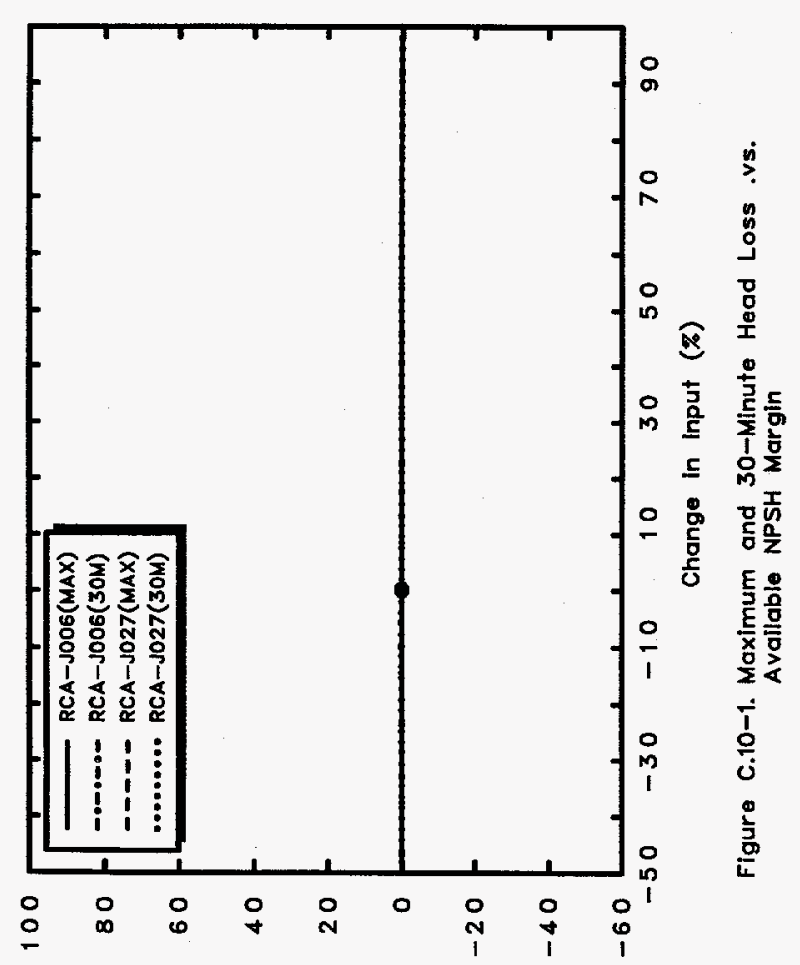

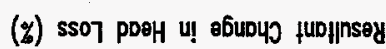

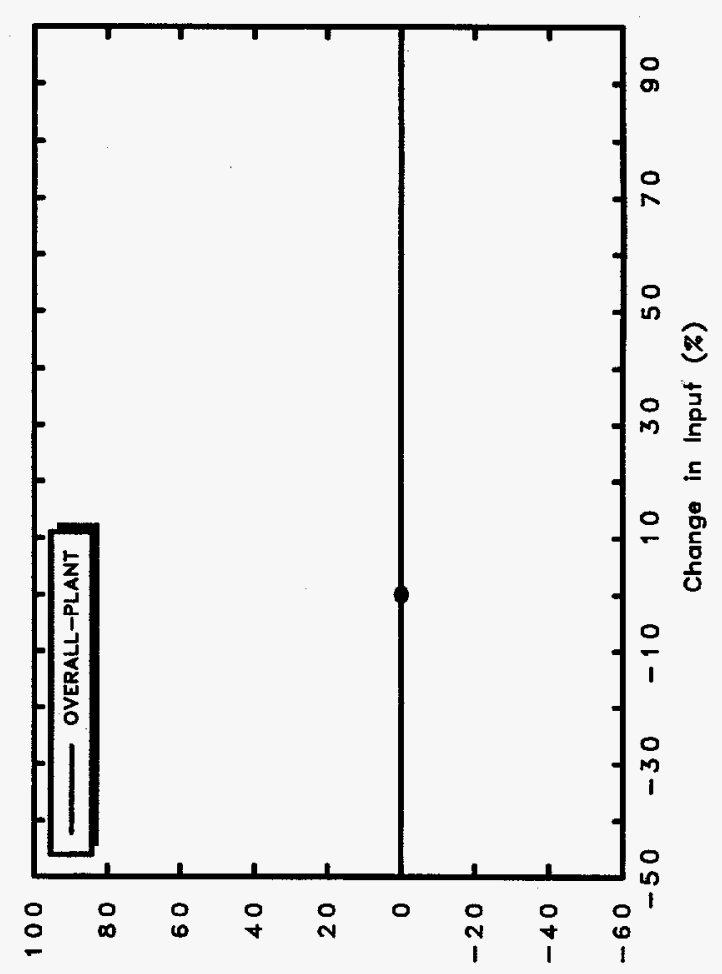

(६) Rouenbedy u! 86uduj fuopnsey

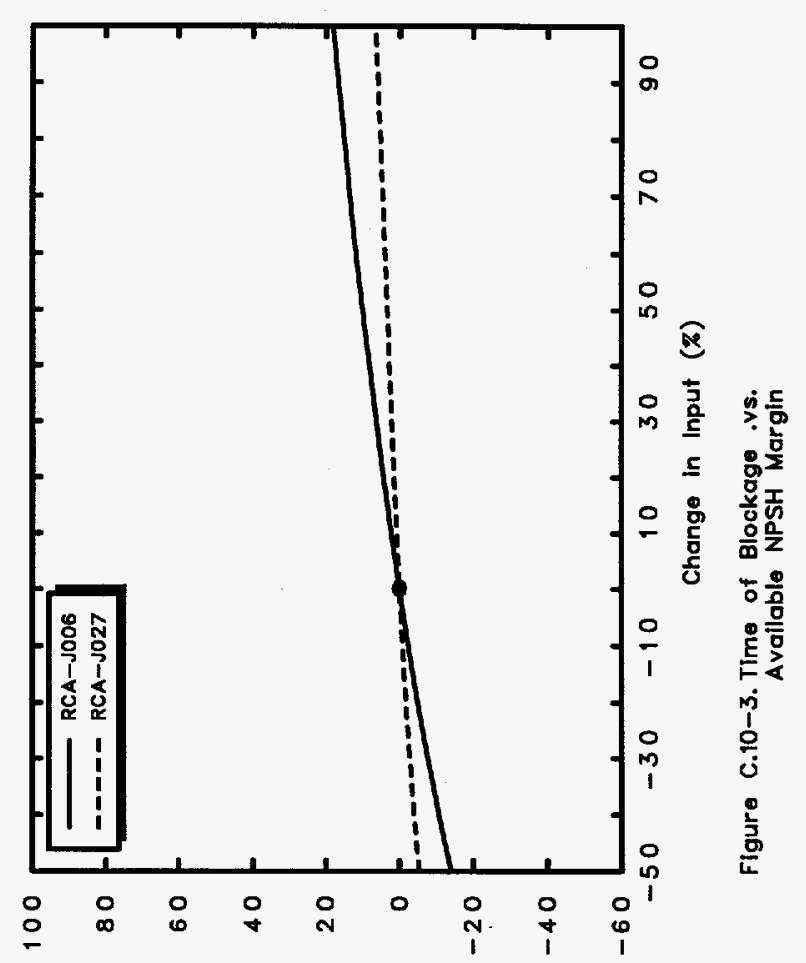

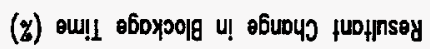




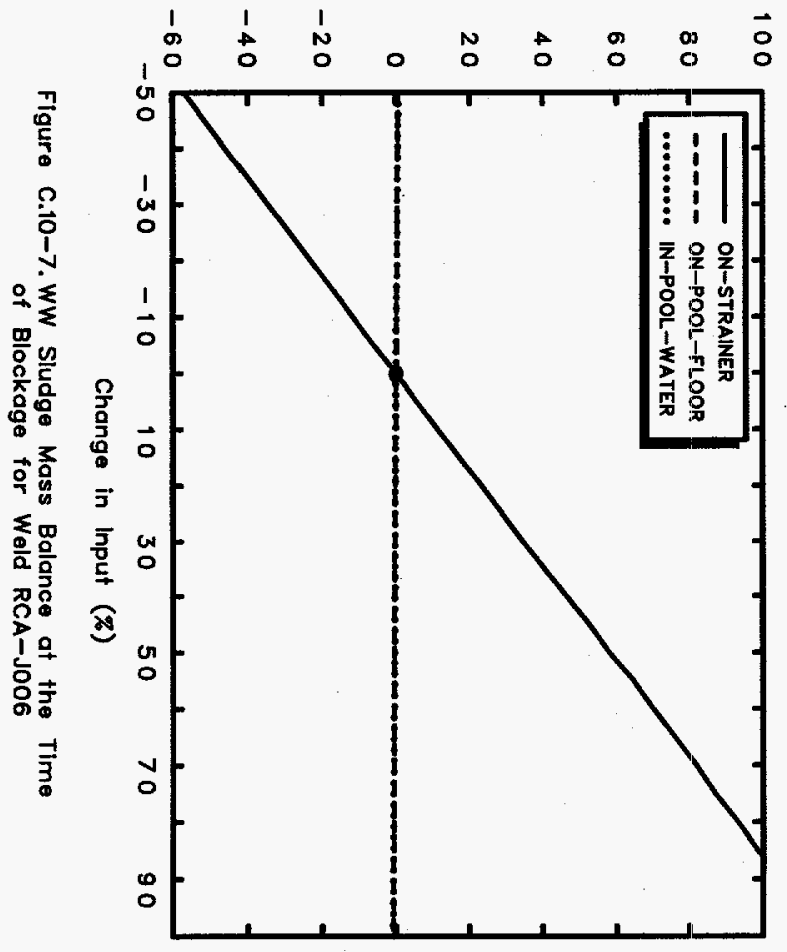

Resultant Change in Sludge Volume ( $\mathrm{x}$ )

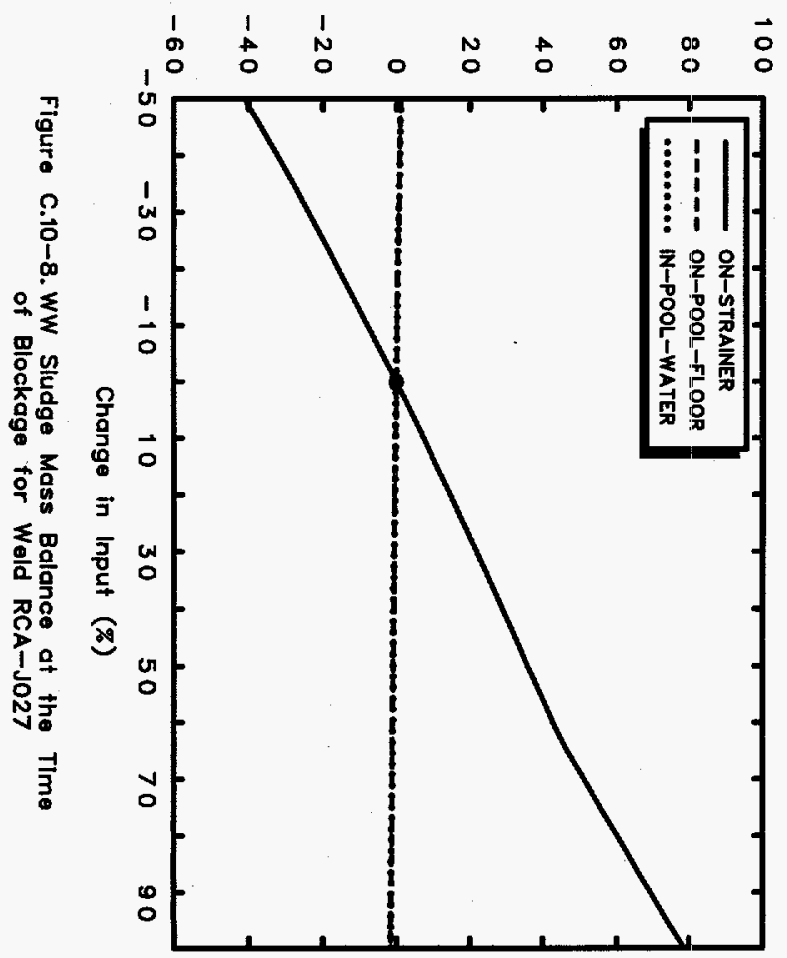

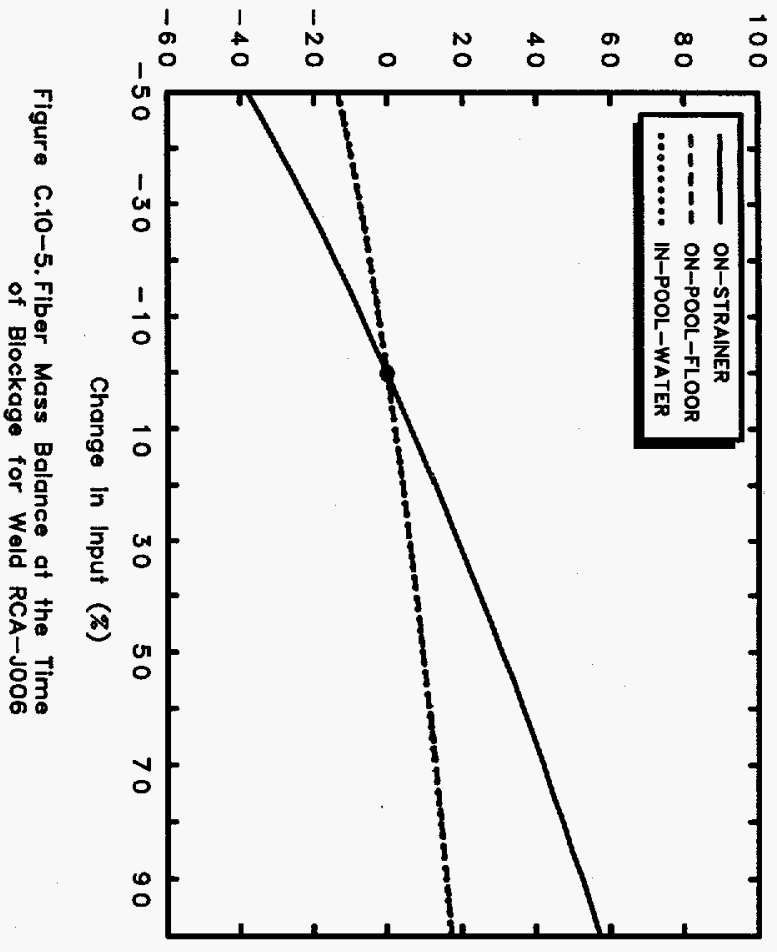

Resultant Change in Fiber Volume (F)

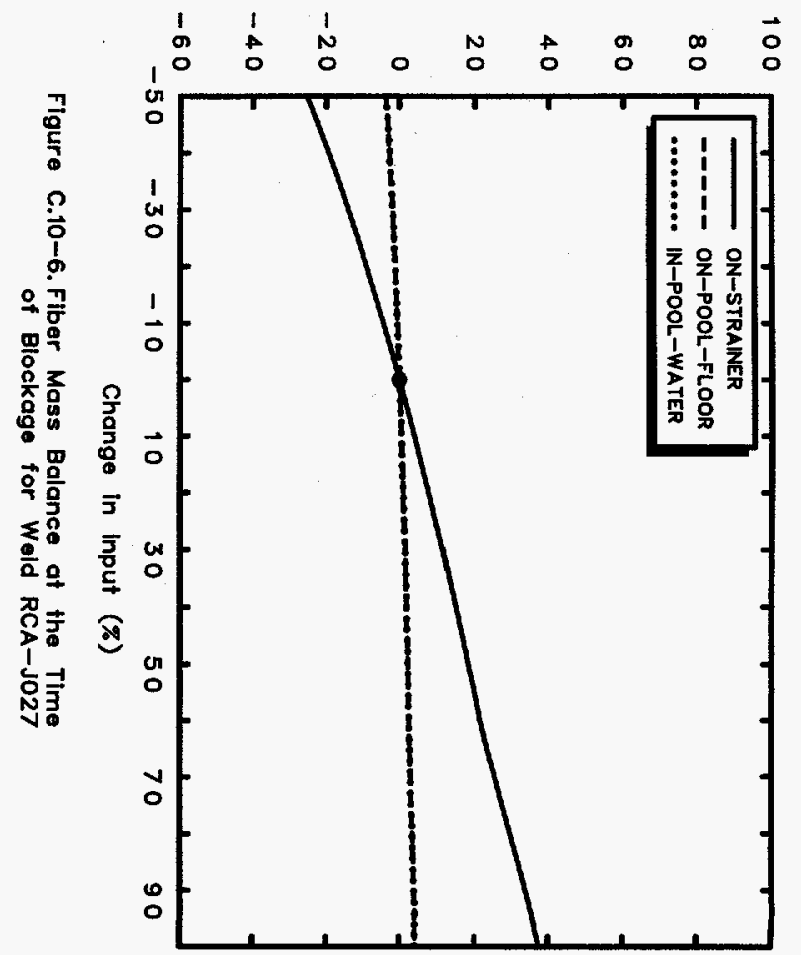




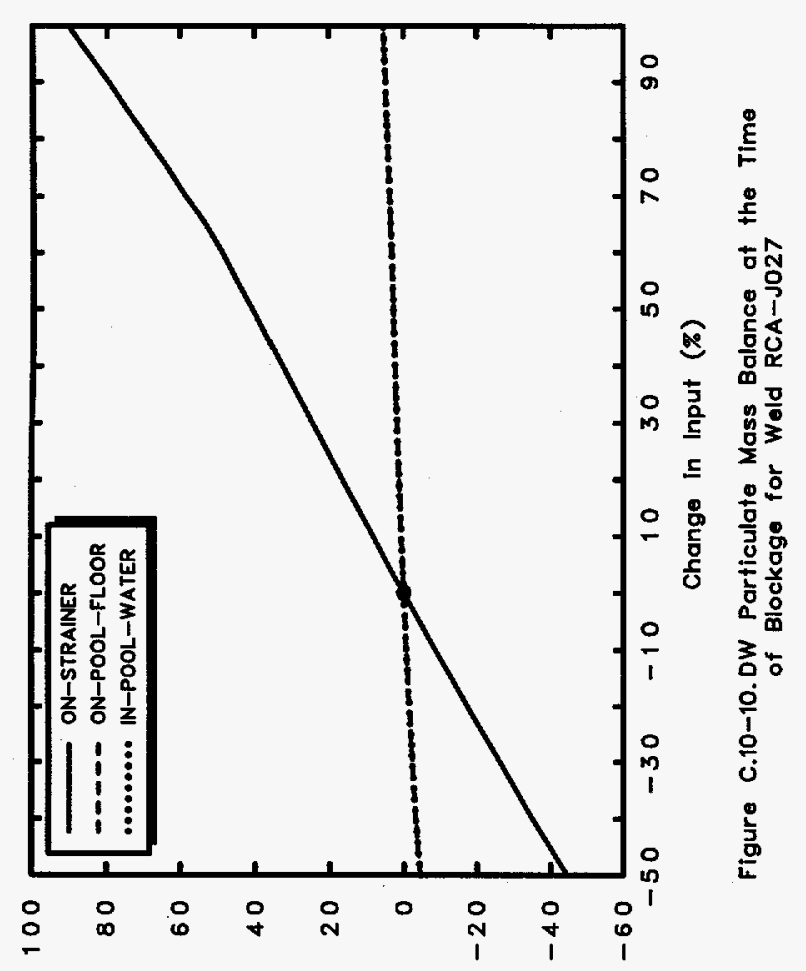

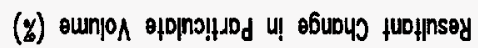

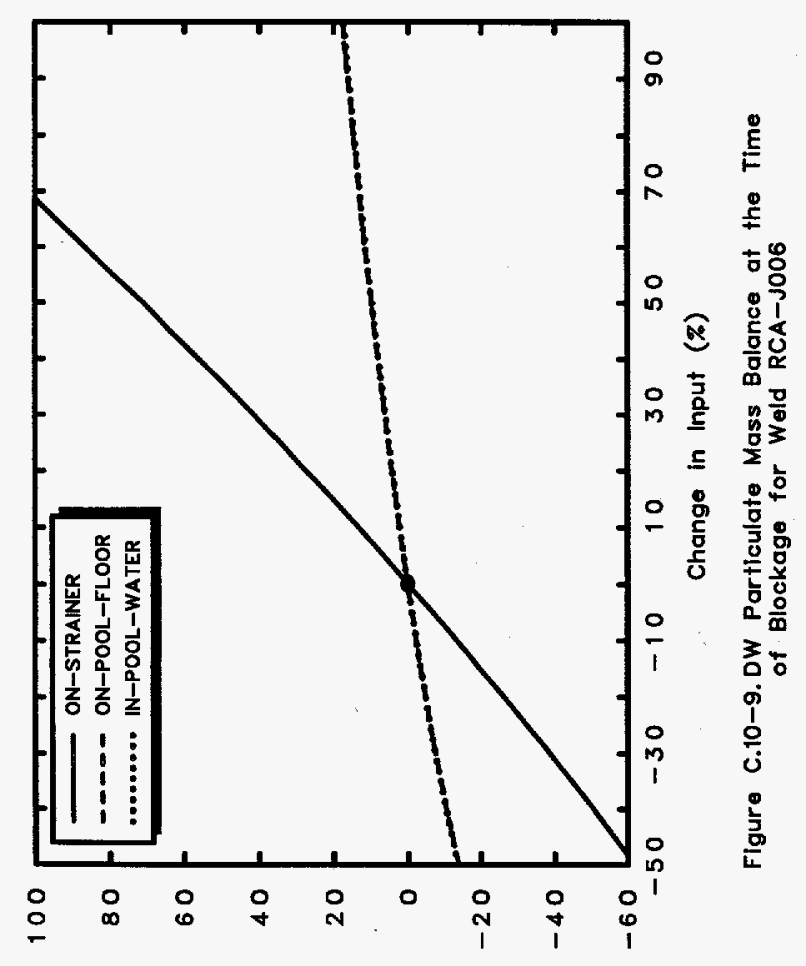

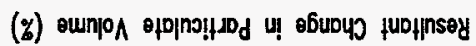

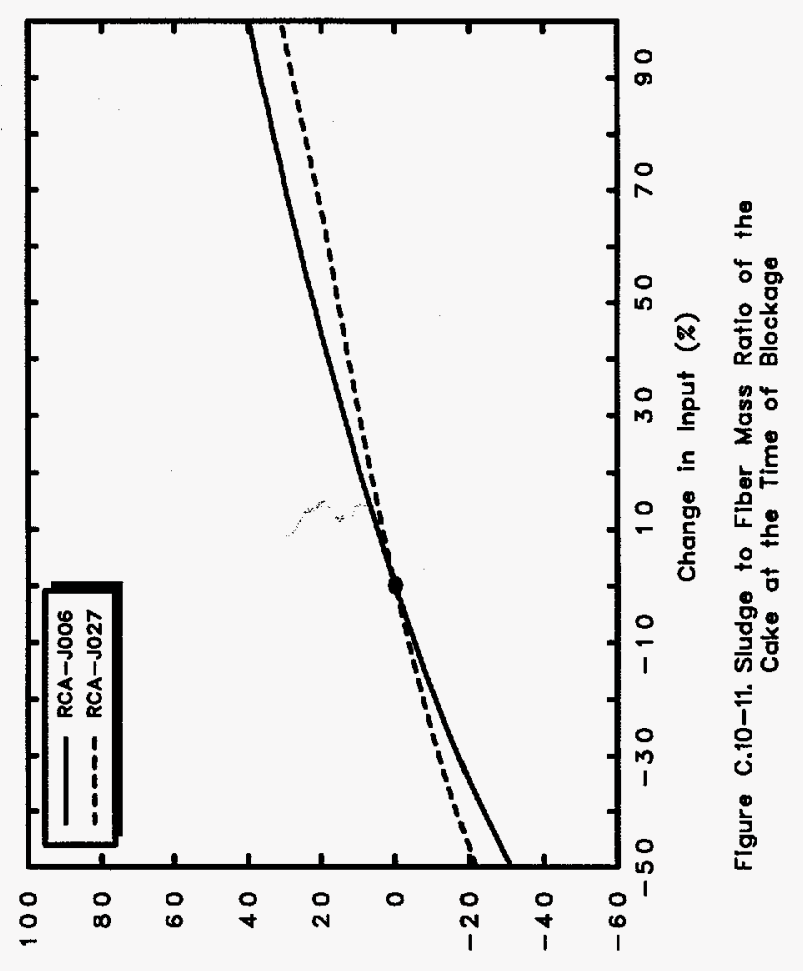

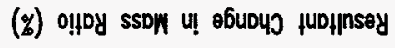




\section{C.11 Sensitivity of ECCS Flow Rate}

This sensitivity study was performed by varying only the ECCS flow rate in the base case input. The values used are listed in Table C.11-1. The calculational results are presented graphically in
Figures C.11-1 through C.11-11. The sharp increase shown in debris deposited on the suppression pool floor as the flow decreased below $-40 \%$ is due to blockage occurring after the end of blowdown instead of before, i.e., before blowdown debris is resuspended whereas after blowdown settling rapidly increases floor deposition.

Table C.11-1. Calculational Cases for ECCS Flow Rate Sensitivity Study

\begin{tabular}{|c|c|c|}
\hline Case & Change, $\%$ & $\begin{array}{c}\text { ECCS Flow Rate, } \\
\text { GPM }\end{array}$ \\
\hline $\mathrm{m} 10$ & -50 & 12500. \\
\hline $\mathrm{m} 9$ & -45 & 13750. \\
\hline $\mathrm{m} 8$ & -40 & 15000. \\
\hline $\mathrm{m} 7$ & -35 & 16250. \\
\hline $\mathrm{m} 6$ & -30 & 17500. \\
\hline $\mathrm{m} 5$ & -25 & 18750. \\
\hline $\mathrm{m} 4$ & -20 & 20000 . \\
\hline $\mathrm{m} 3$ & -15 & 21250 . \\
\hline $\mathrm{m} 2$ & -10 & 22500 . \\
\hline $\mathrm{m} 1$ & -5 & 23750 . \\
\hline Base & 0 & 25000 . \\
\hline 1 & +5 & 26250. \\
\hline 2 & +10 & 27500 . \\
\hline 3 & +15 & 28750 . \\
\hline 4 & +20 & 30000 . \\
\hline 5 & +25 & 31250. \\
\hline 6 & +30 & 32500 . \\
\hline 7 & +35 & 33750. \\
\hline 8 & +40 & 35000. \\
\hline 9 & +45 & 36250. \\
\hline 10 & +50 & 37500 . \\
\hline
\end{tabular}




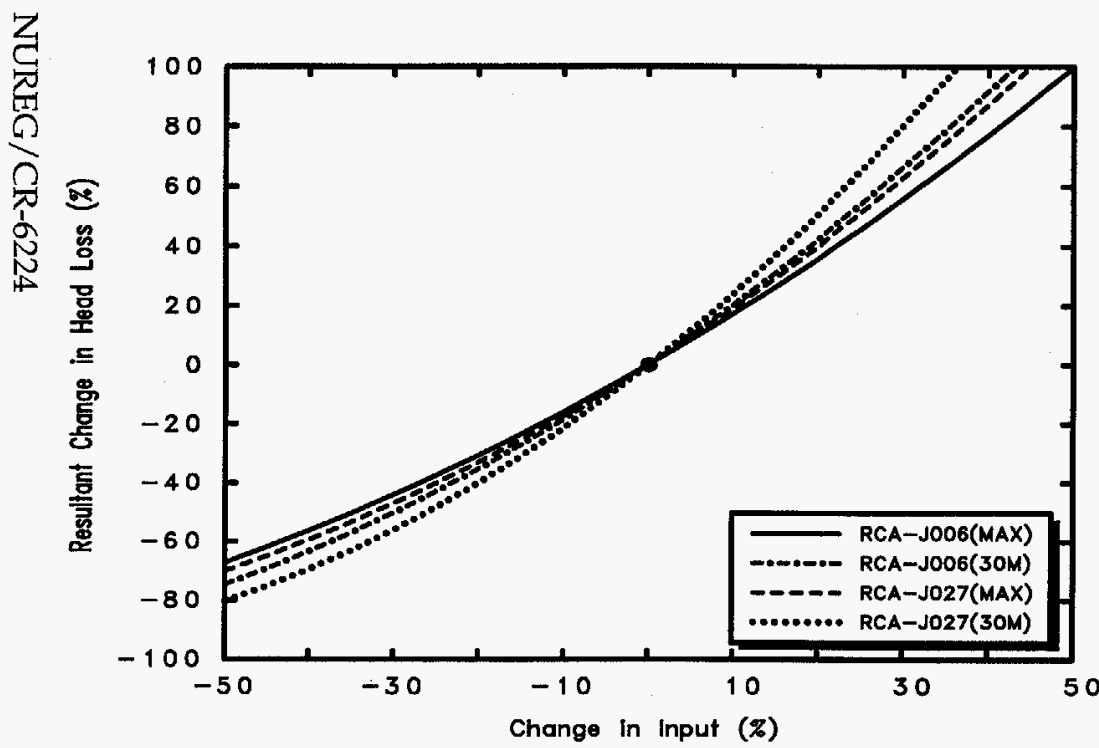

Figure C.11-1. Maximum and 30-Minute Head Loss .vs.

ఝ్ర

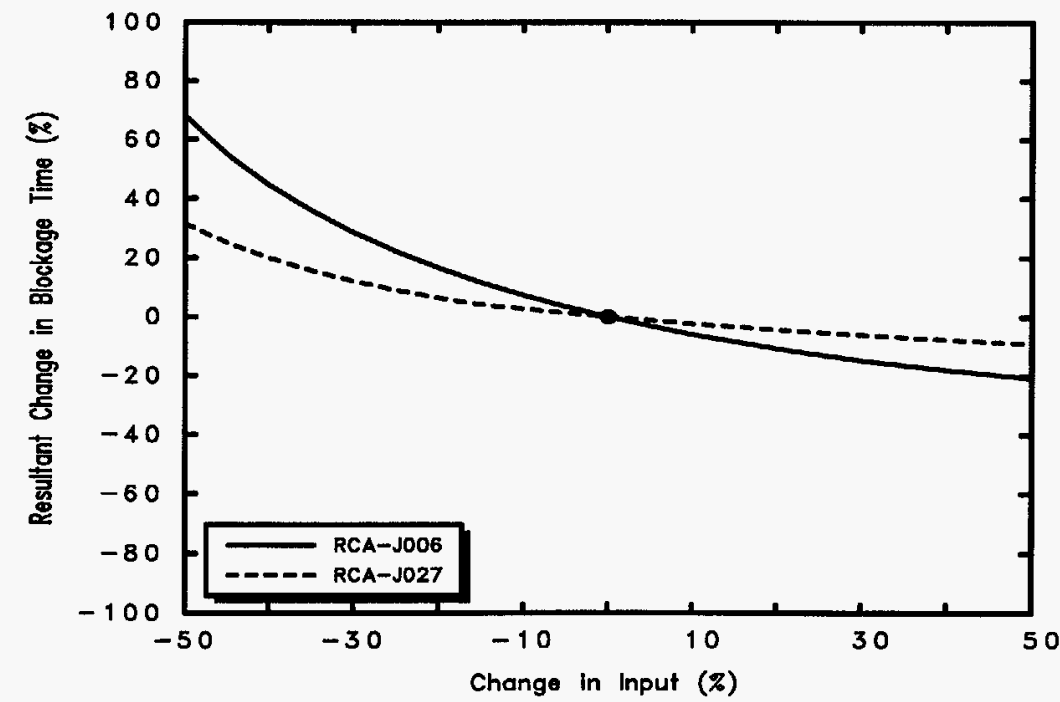

Figure C.11-3. Time of Blockage .vs.

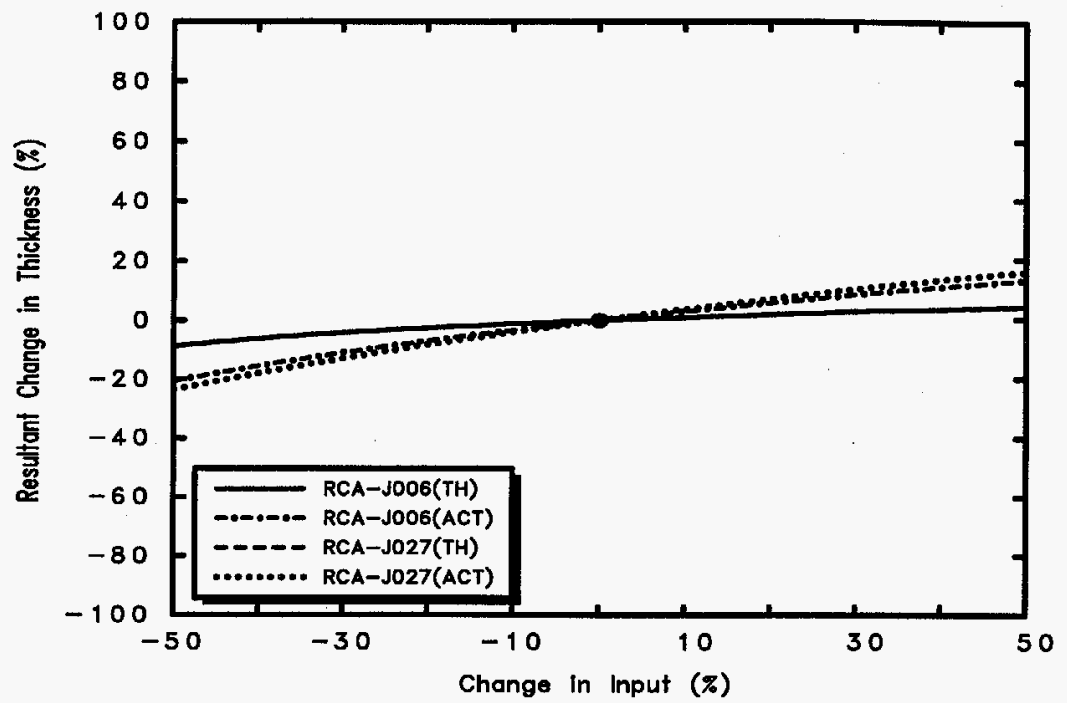

Figure C.11-2. Maximum Theoretical/Actual Cake Thicknesses .vs. ECCS Flow Rate

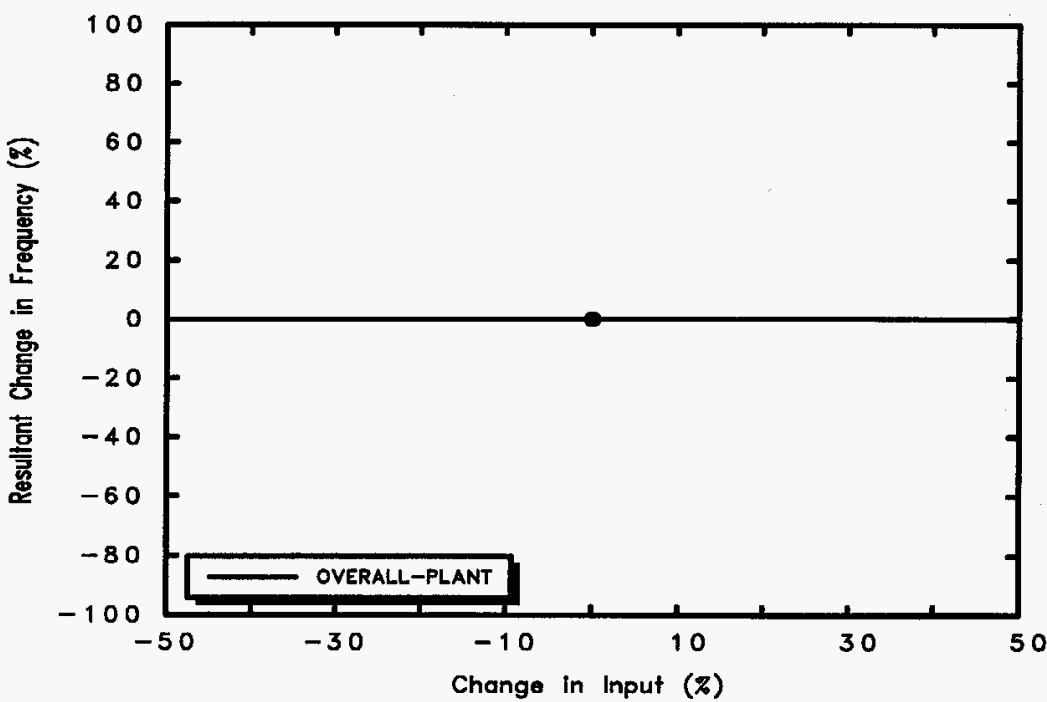

Figure C.11-4. Frequency for Loss of NPSH .vs. 
Resultant Change in Sludge Volume ( $\mathrm{z}$ )

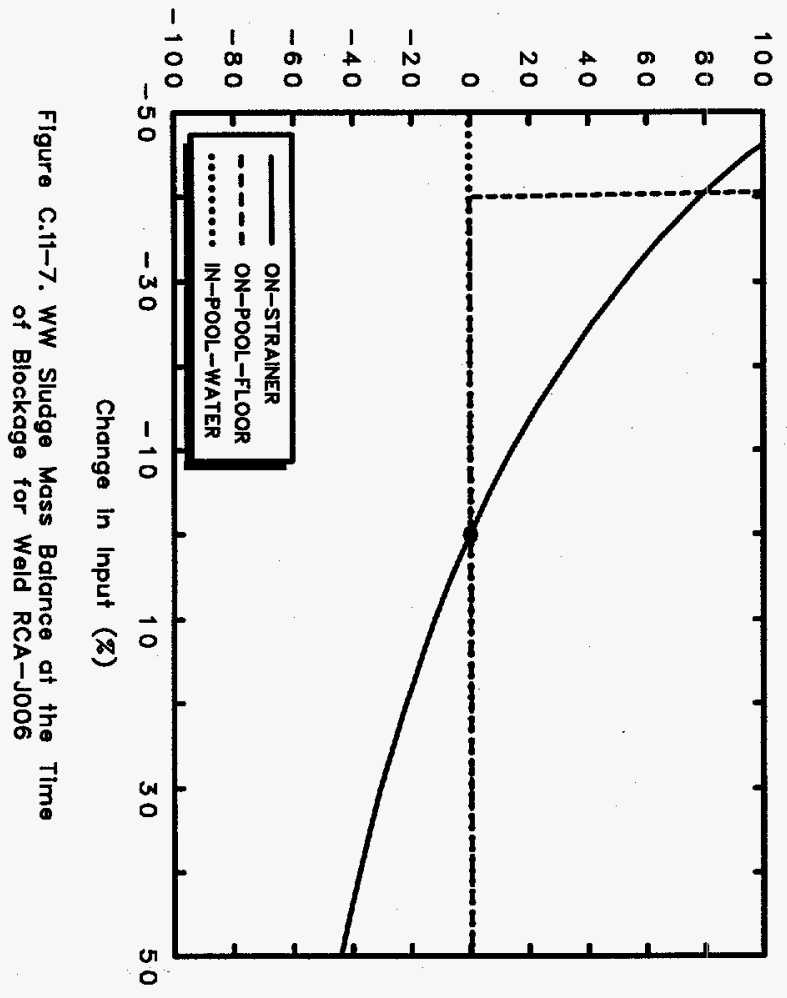

Resultant Change in Sludge Volume (m)

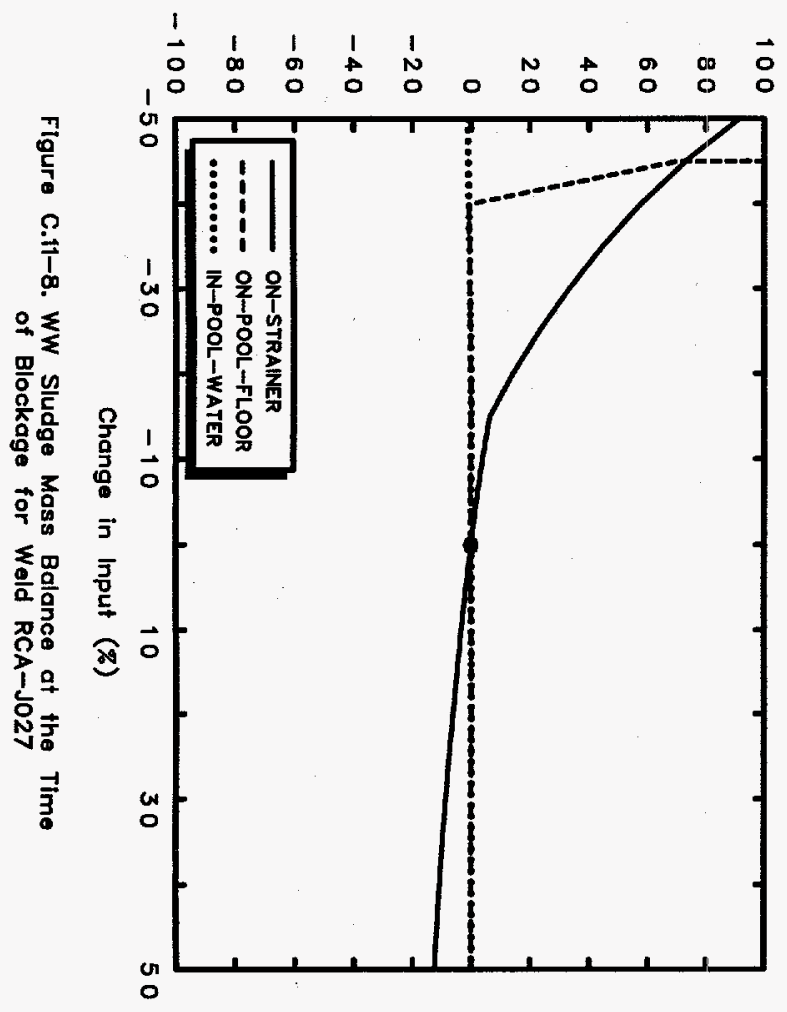

Resultant Change in Fiber Volume (z)

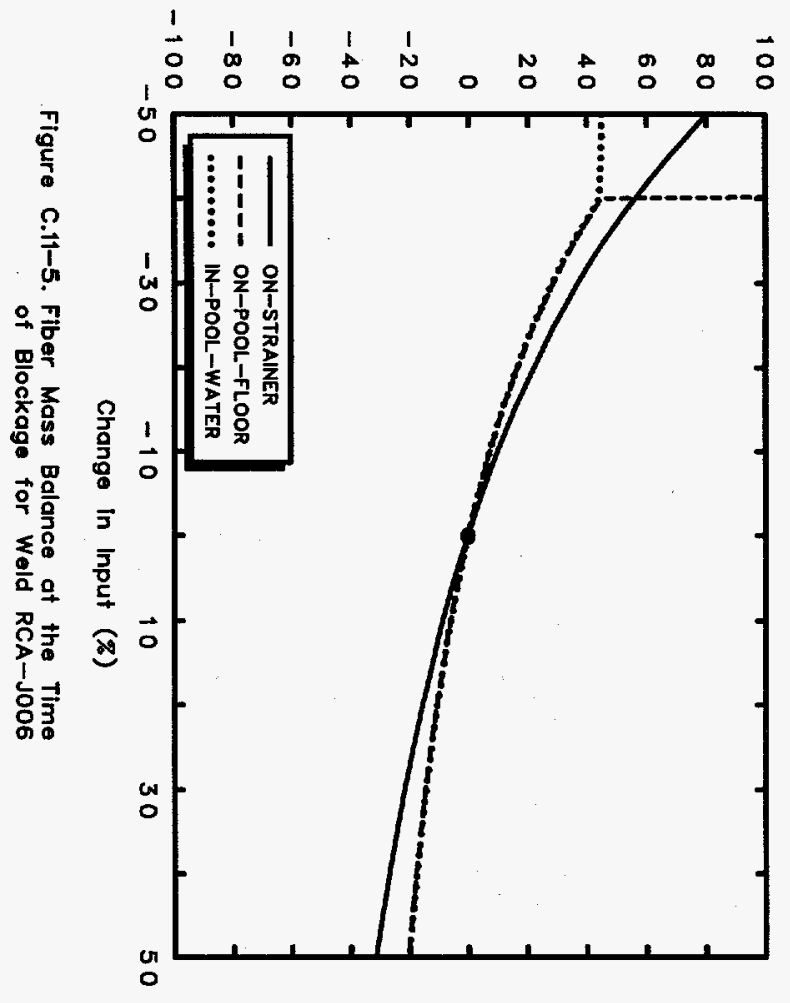

Resultant Change in Fiber Volume (\%)

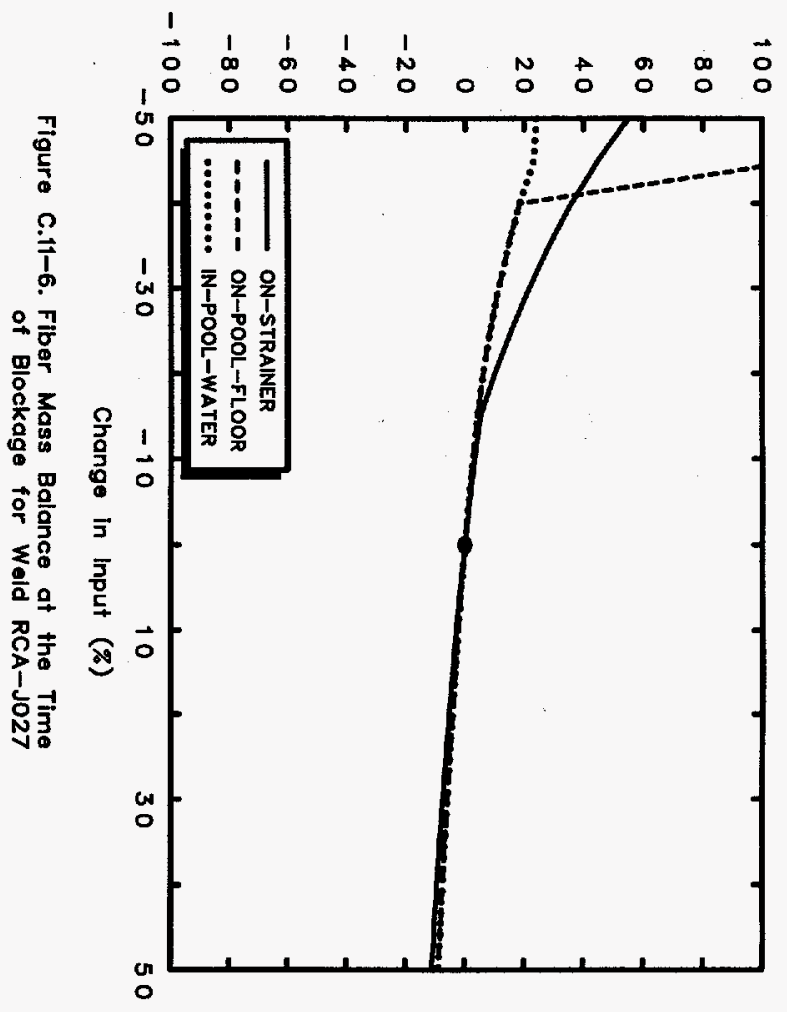




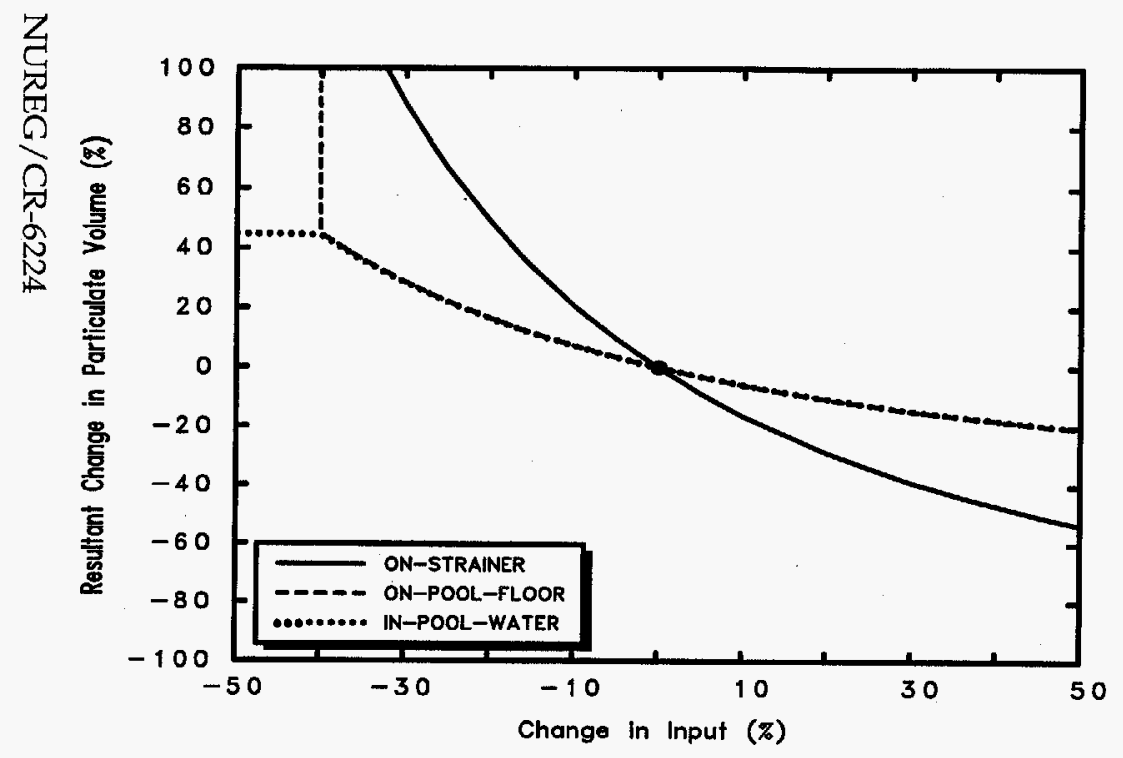

Figure C.11-9. OW Particulate Mass Balance at the Time of Blockage for Weld RCA-J006

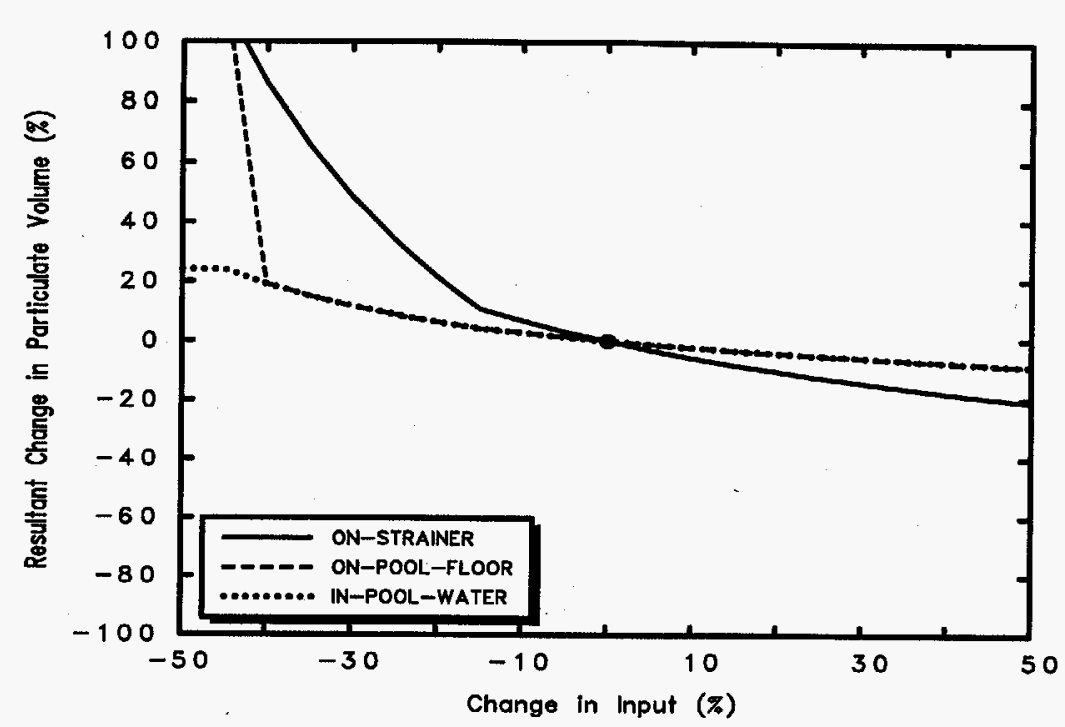
Figure C.11-10. DW Particulate Mass Balance at the Time
of Blockage for Weld RCA-JO27

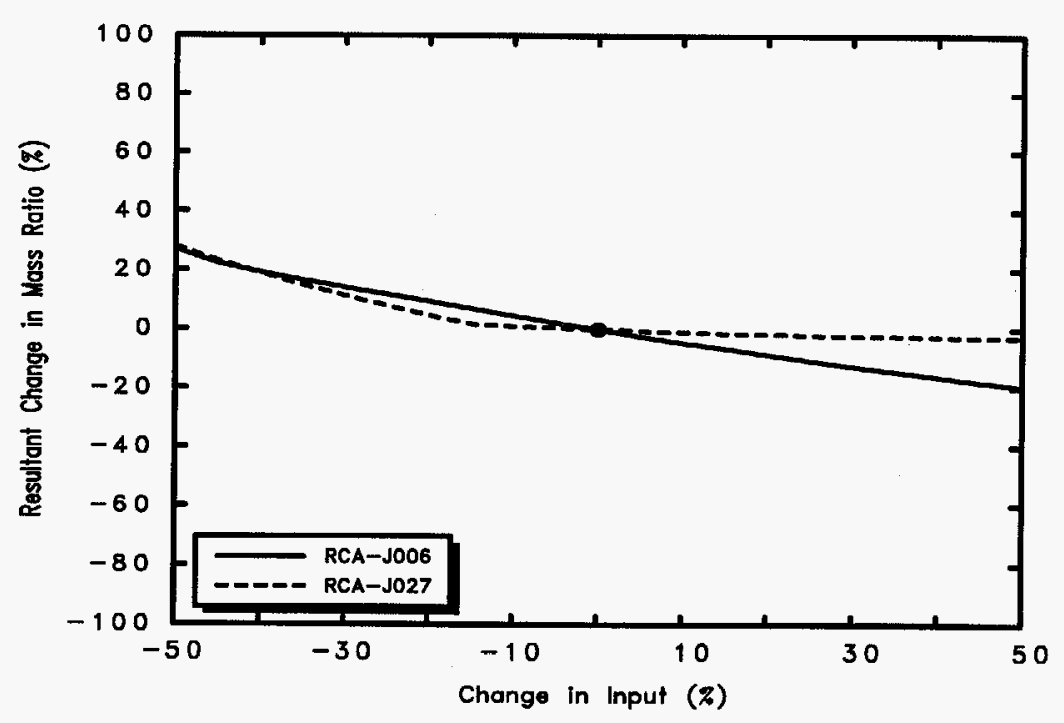
Figure C.11-11. Sludge to Fiber Mass Ratio of the
Cake at the TIme of Blockage 


\section{C.12 Sensitivity of $\Delta \mathrm{P}$ Correlation Multiplier}

This sensitivity study was performed by varying a sensitivity coefficient programmed into the head loss correlation. This coefficient simply multiplies the predicted head loss by the user specified input number. The base case used a coefficient of 1.0, thereby leaving the correlation unaffected. The values used are listed in Table C.12-1. The calculational results are presented graphically in Figures C.12-1 through C.12-11.

Table C.12-1. Calculational Cases for $\triangle P$ Correlation Multiplier Sensitivity Study

\begin{tabular}{|c|c|c|}
\hline Case & $\begin{array}{c}\text { Change } \\
\%\end{array}$ & Multiplier \\
\hline $\mathrm{m} 5$ & -50 & 0.5 \\
\hline $\mathrm{m} 4$ & -40 & 0.6 \\
\hline $\mathrm{m} 3$ & -30 & 0.7 \\
\hline $\mathrm{m} 2$ & -20 & 0.8 \\
\hline $\mathrm{m} 1$ & -10 & 0.9 \\
\hline $\mathrm{Base}$ & $\mathbf{0}$ & $\mathbf{1 . 0}$ \\
\hline 1 & +10 & 1.1 \\
\hline 2 & +20 & 1.2 \\
\hline 3 & +30 & 1.3 \\
\hline 4 & +40 & 1.4 \\
\hline 5 & +50 & 1.5 \\
\hline 6 & +60 & 1.6 \\
\hline 7 & +70 & 1.7 \\
\hline 8 & +80 & 1.8 \\
\hline 9 & +90 & 1.9 \\
\hline 10 & +100 & 2.0 \\
\hline
\end{tabular}

\begin{tabular}{|c|c|c|}
\hline Case & $\begin{array}{c}\text { Change } \\
\%\end{array}$ & Multiplier \\
\hline 11 & +110 & 2.1 \\
\hline 12 & +120 & 2.2 \\
\hline 13 & +130 & 2.3 \\
\hline 14 & +140 & 2.4 \\
\hline 15 & +150 & 2.5 \\
\hline 16 & +160 & 2.6 \\
\hline 17 & +170 & 2.7 \\
\hline 18 & +180 & 2.8 \\
\hline 19 & +190 & 2.9 \\
\hline 20 & +200 & 3.0 \\
\hline
\end{tabular}




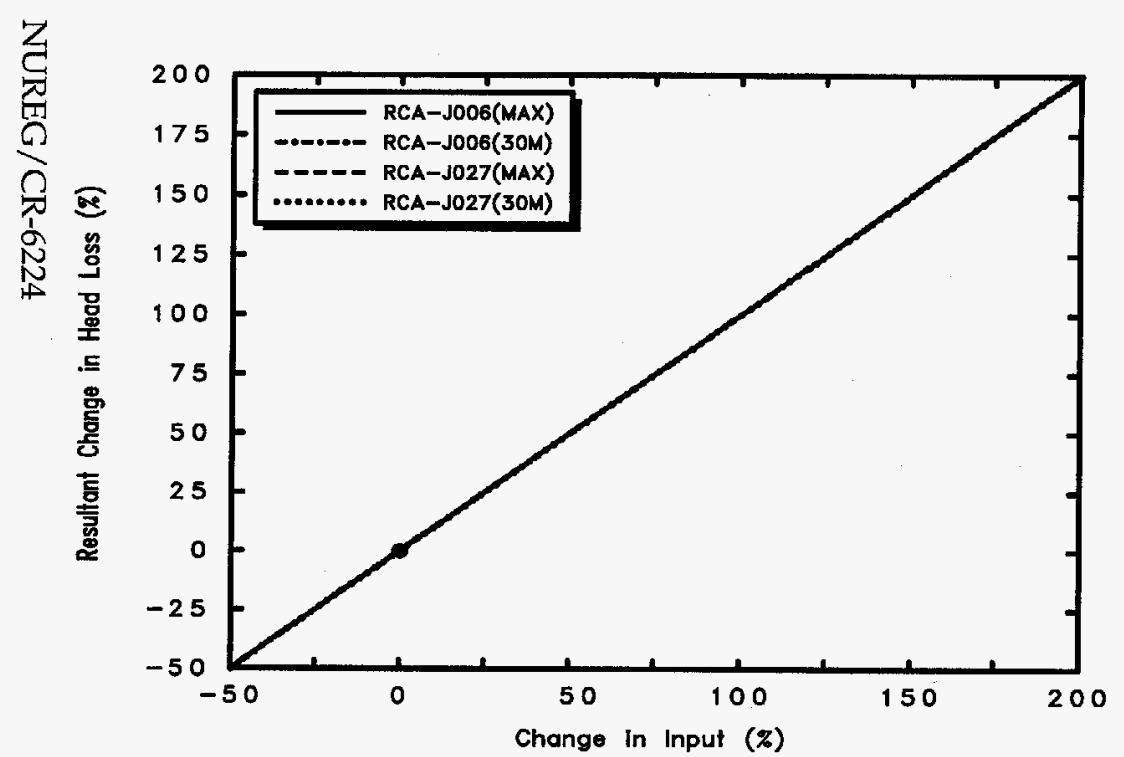

Figure C.12-1. Maximum and 30-Minute Head Loss .vs.

点

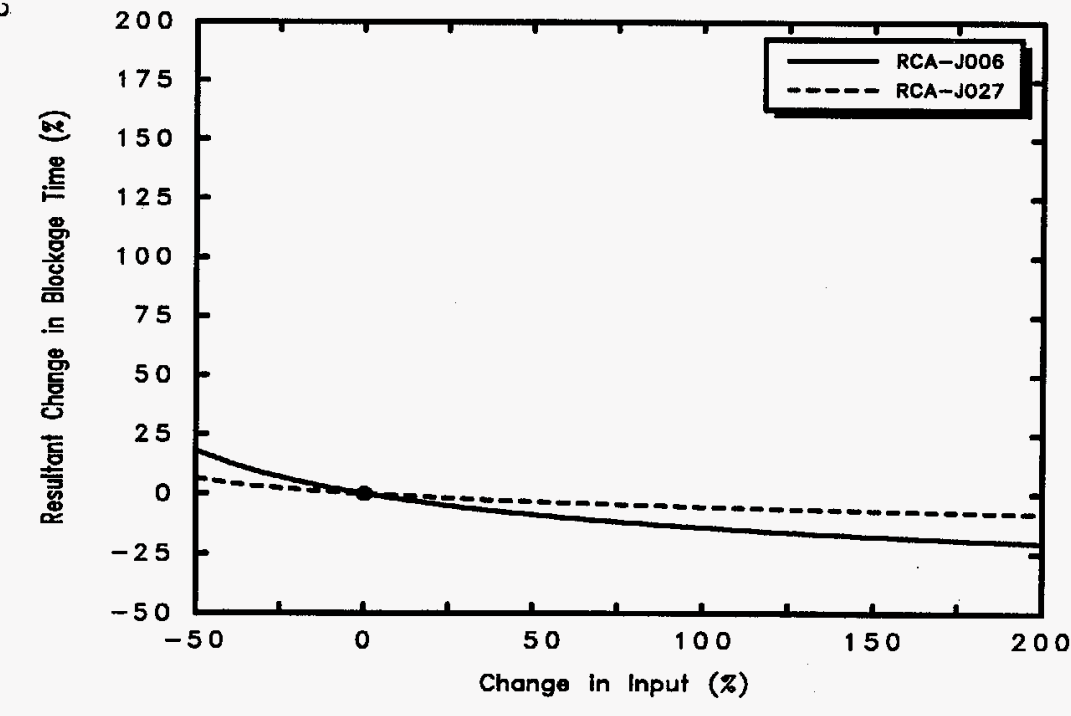

Figure C.12-3. Time of Blockage .vs.
dP Corrolation Multiplier

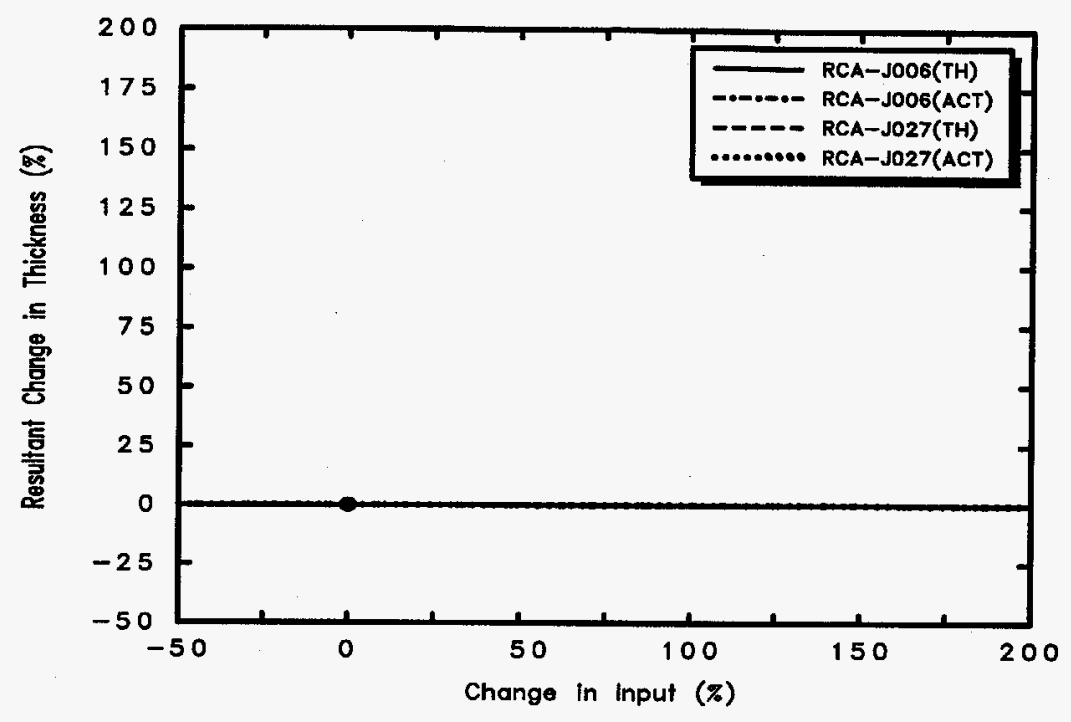

Figure C.12-2. Maximum Theoretical/Actual Cake Thicknesses .vs. dP Correlation Multiplier

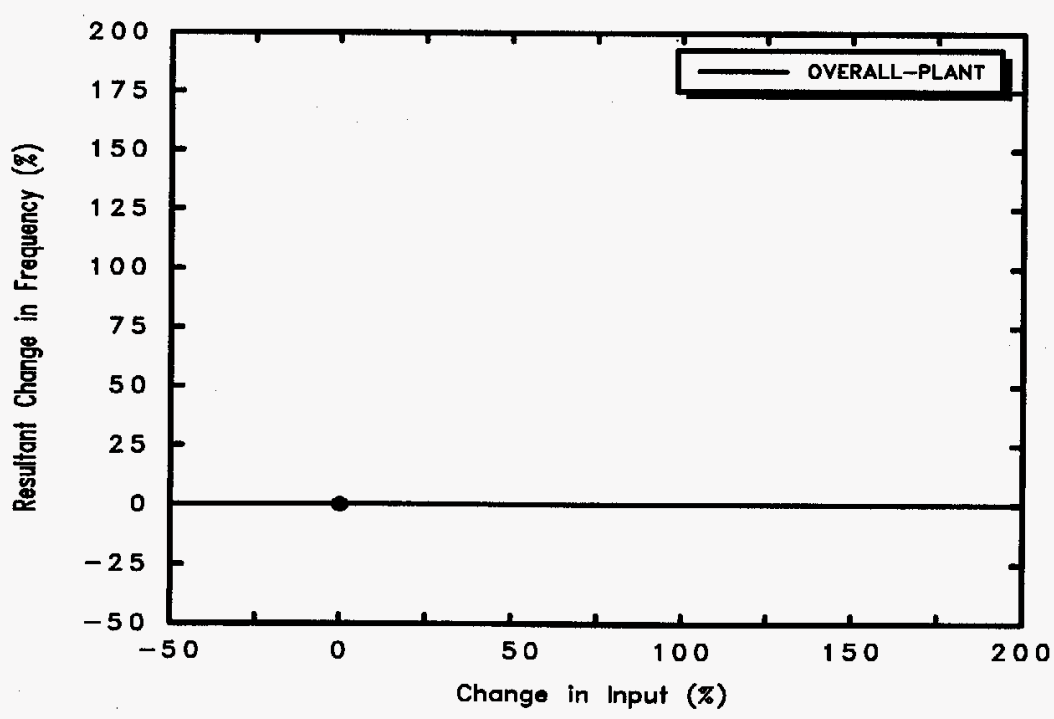

Figure C.12-4. Frequency for Loss of NPSH .vs. dP Correlation Multiplior 


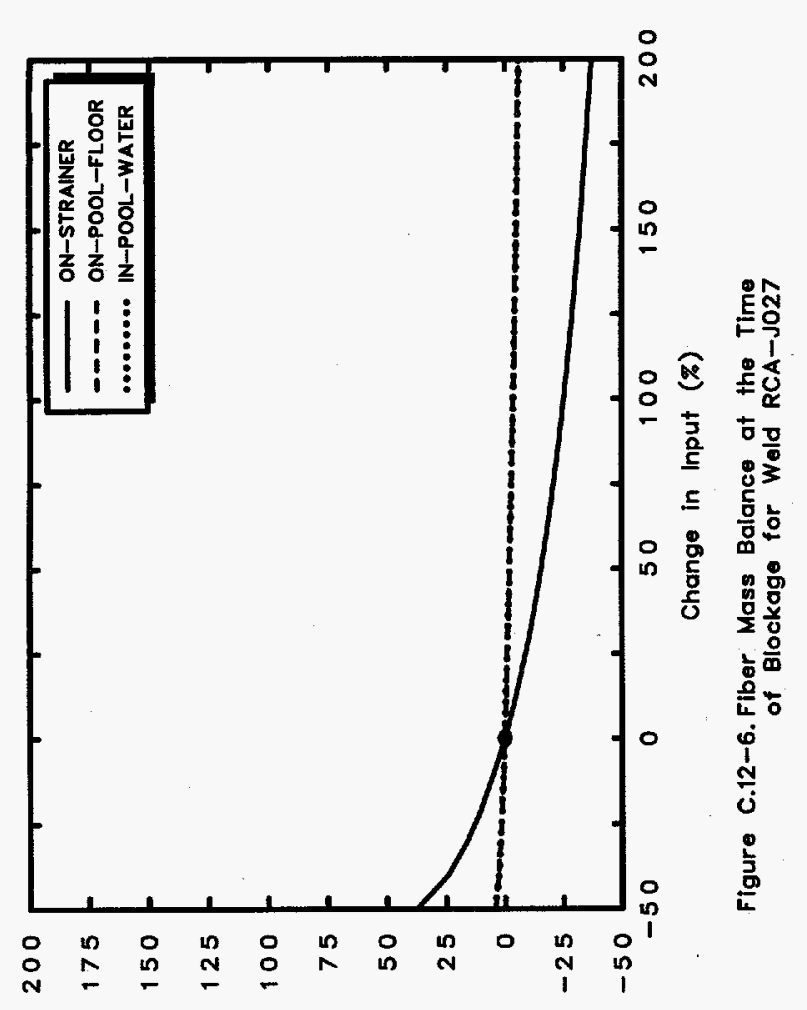

(z) oumpo seq.J u! ebudys fudp|nsey

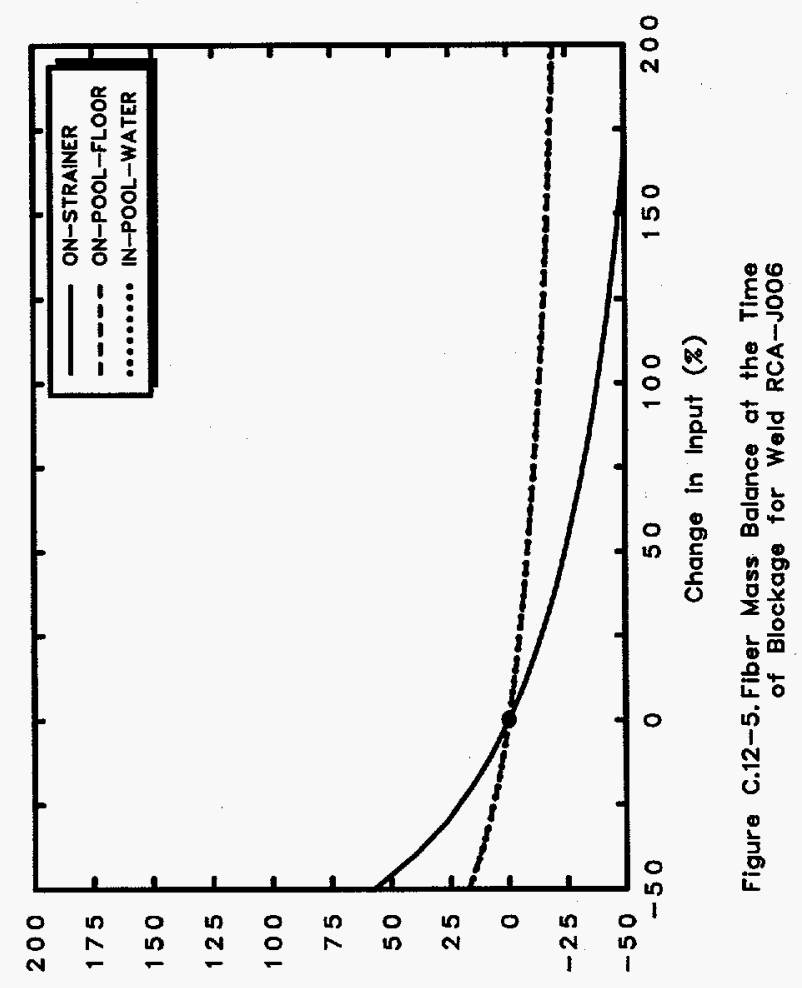

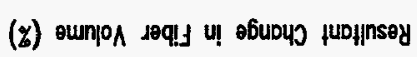

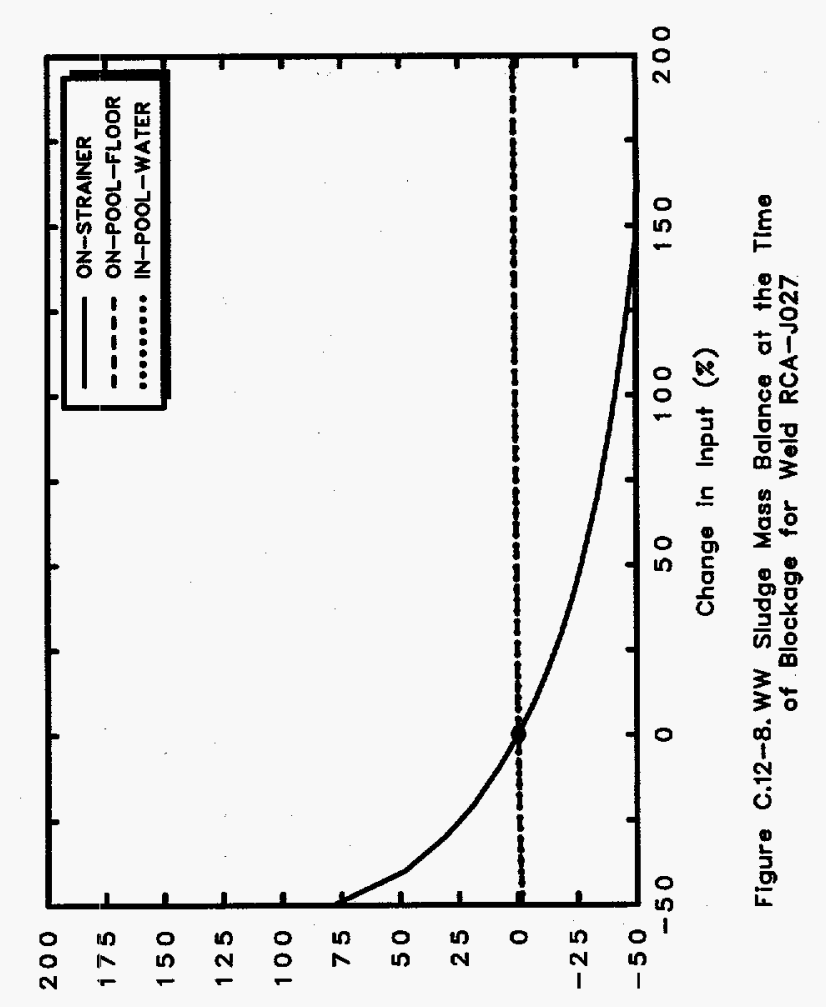

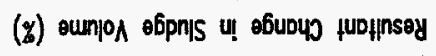

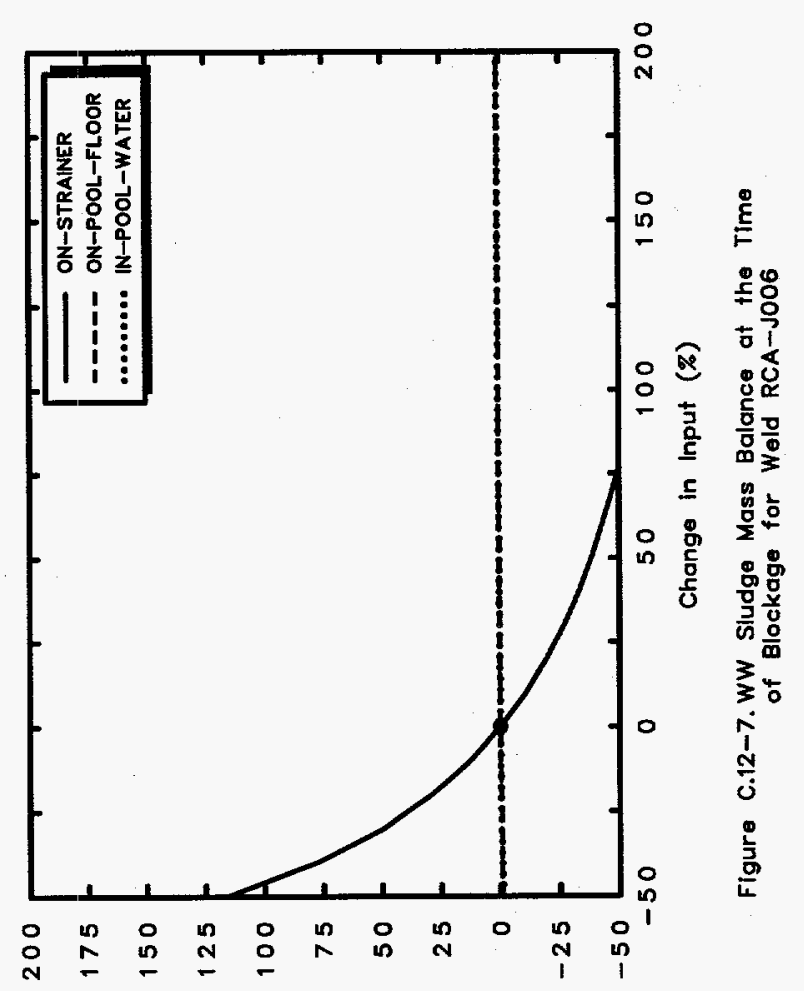

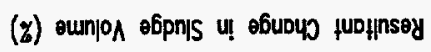


Appendix $\mathrm{C}$

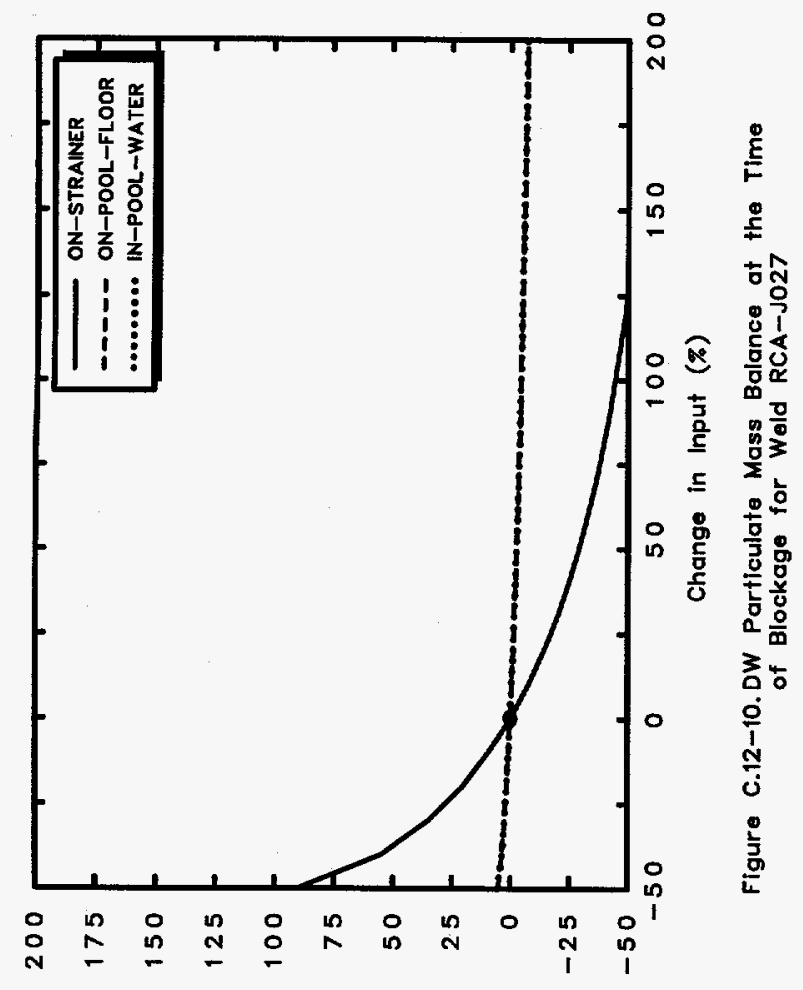

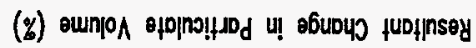
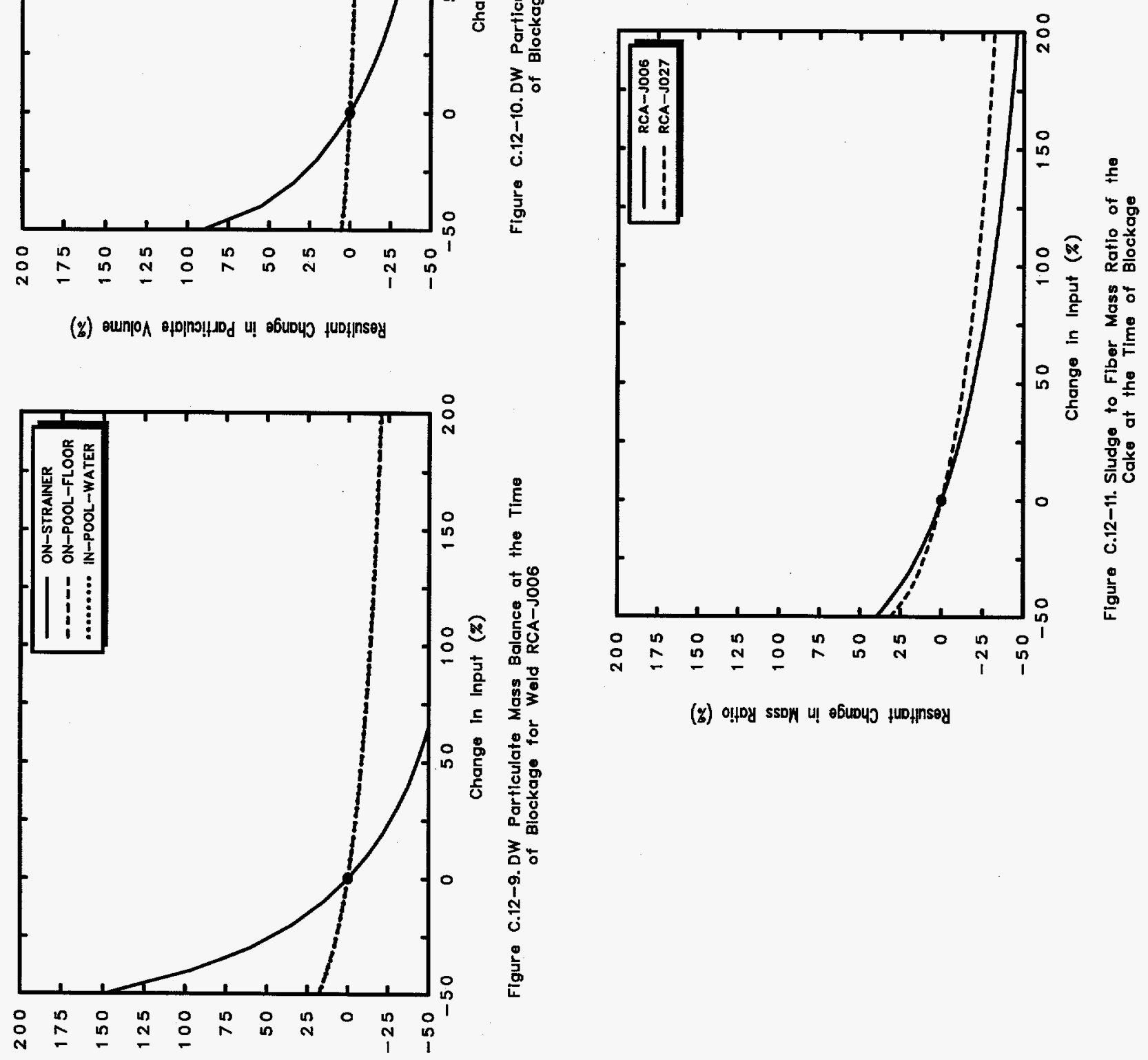

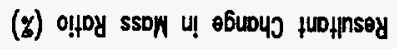

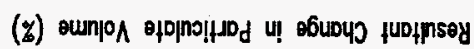




\section{C.13 Sensitivity of Suppression Pool Temperature}

This sensitivity study was performed by varying only the suppression pool temperature. The pool temperature effects water density and viscosity which were used by the head loss correlation. The base case temperature was $125^{\circ} \mathrm{F}$. The values used are listed in Table C.13-1. The calculated percentage changes in input are relatively small compared to the other sensitivity studies because the absolute temperatures were used to calculate the changes. The calculational results are presented graphically in Figures C.13-1 through C.13-11.

Table C.13-1. Calculational Cases for Suppression Pool Temperature Sensitivity Study

\begin{tabular}{|c|c|c|c|}
\hline Case & $\begin{array}{c}\text { Pool } \\
\text { Temperature } \\
{ }^{\circ} \mathbf{F}\end{array}$ & $\begin{array}{c}\text { Pool } \\
\text { Temperature } \\
{ }^{\circ} \mathbf{R}\end{array}$ & $\begin{array}{c}\text { Change } \\
\%\end{array}$ \\
\hline $\mathrm{m} 10$ & 75 & 534.7 & -8.55 \\
\hline $\mathrm{m} 9$ & 80 & 539.7 & -7.70 \\
\hline $\mathrm{m} 8$ & 85 & 544.7 & -6.84 \\
\hline $\mathrm{m} 7$ & 90 & 549.7 & -5.99 \\
\hline $\mathrm{m} 6$ & 95 & 554.7 & -5.13 \\
\hline $\mathrm{m} 5$ & 100 & 559.7 & -4.28 \\
\hline $\mathrm{m} 4$ & 105 & 564.7 & -3.42 \\
\hline $\mathrm{m} 3$ & 110 & 569.7 & -2.57 \\
\hline $\mathrm{m} 2$ & 115 & 574.7 & -1.71 \\
\hline $\mathrm{m} 1$ & 120 & 579.7 & -0.86 \\
\hline Base & 125 & 584.7 & 0 \\
\hline 1 & 130 & 589.7 & 0.86 \\
\hline 2 & 135 & 594.7 & 1.71 \\
\hline 3 & 140 & 599.7 & 2.57 \\
\hline 4 & 145 & 604.7 & 3.42 \\
\hline 5 & 150 & 609.7 & 4.28 \\
\hline 6 & 155 & 614.7 & 5.13 \\
\hline 7 & 160 & 619.7 & 5.99 \\
\hline 8 & 165 & 624.7 & 6.84 \\
\hline 9 & 170 & 629.7 & 7.70 \\
\hline 10 & 175 & 634.7 & 8.55 \\
\hline
\end{tabular}




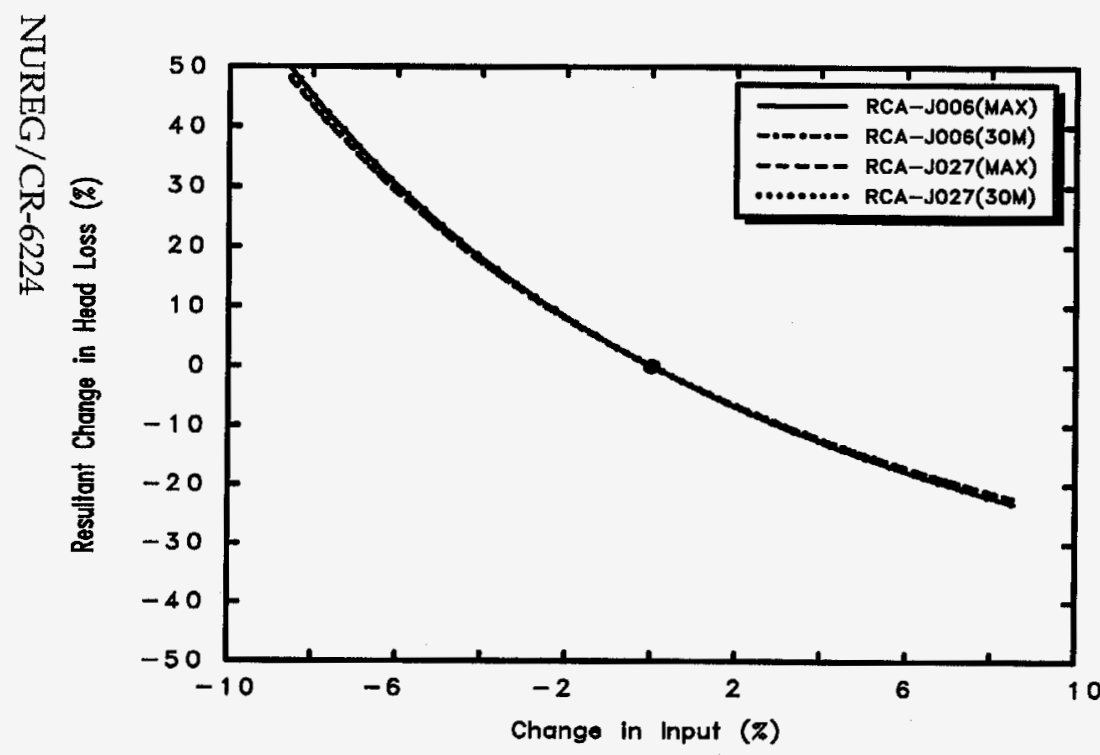

Figure C.13-1. Maximum and 30-Minute Head Loss .vs.

क

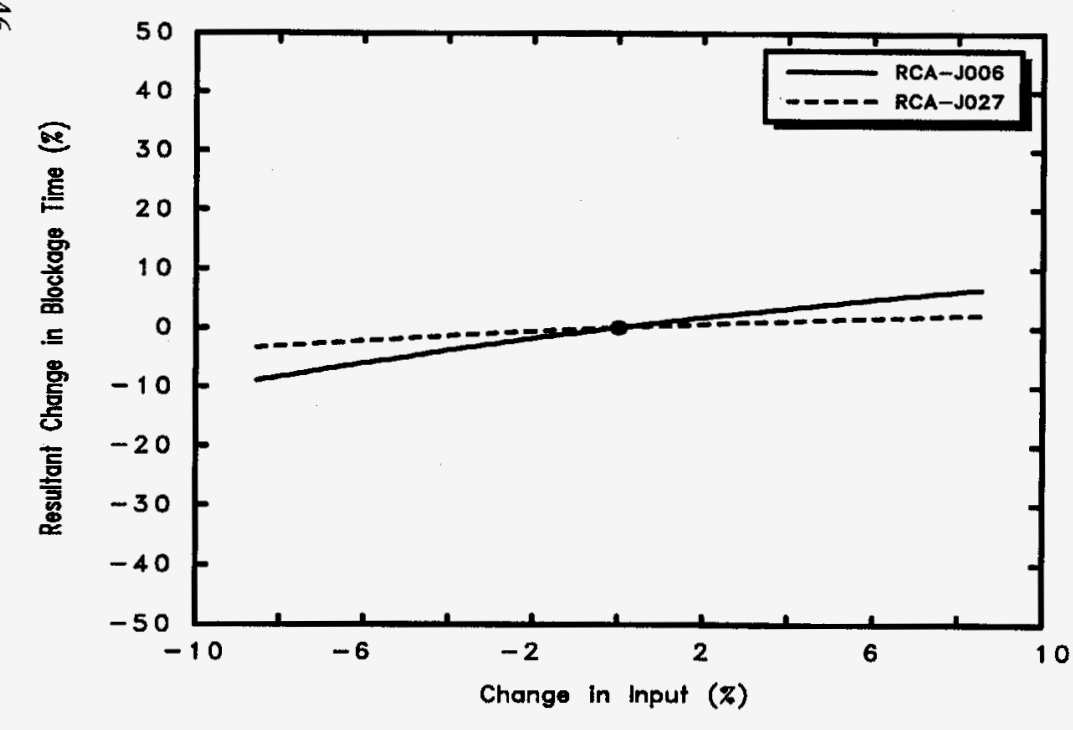

Flgure C.13-3. Time of Blockage .vs.

Suspression Pool Temperature

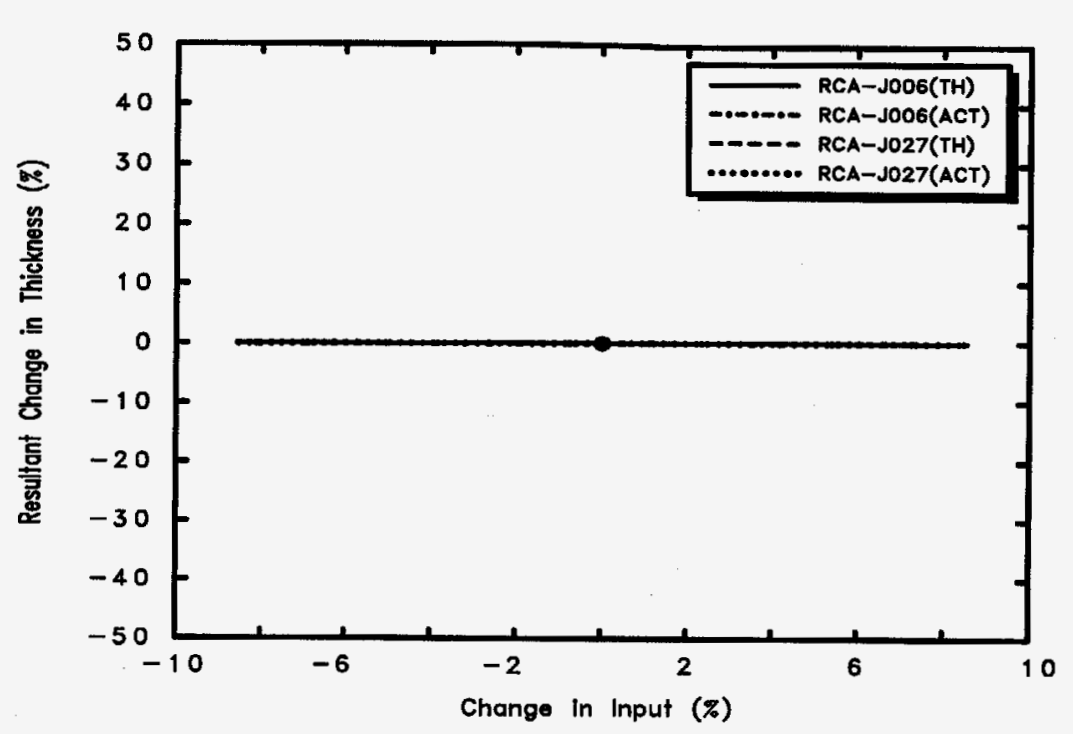

Figure C.13-2. Maximum Theoretical/Actual Cake Thicknesses .vs. Suspression Pool Temperature

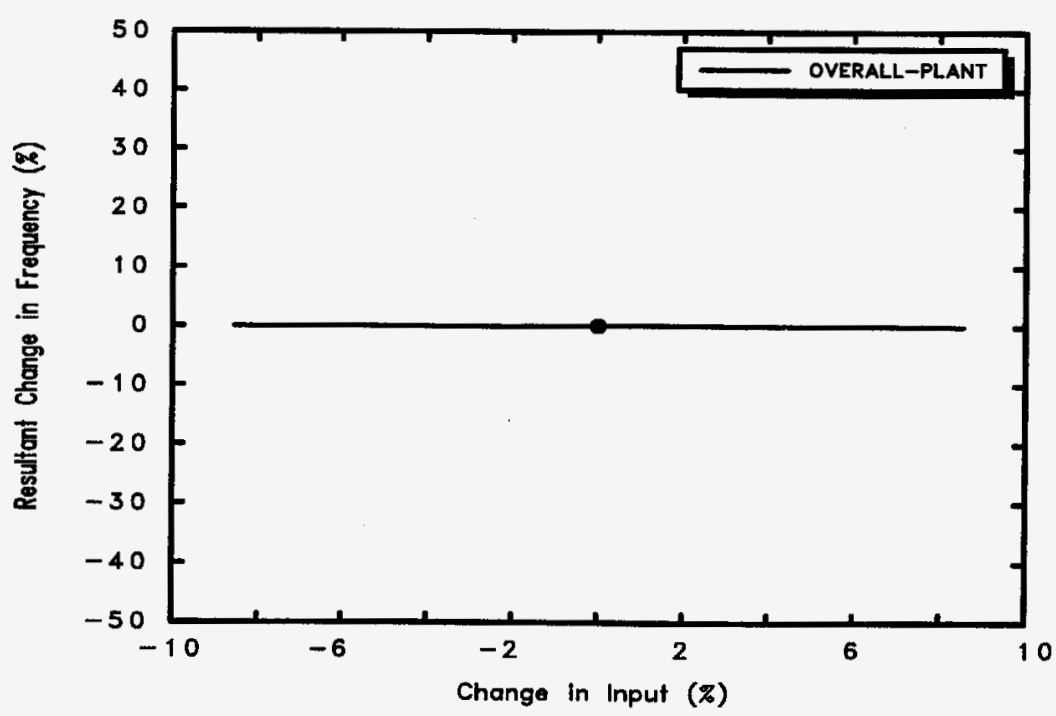

Figure C.13-4.Frequency for Loss of NPSH .vs. 

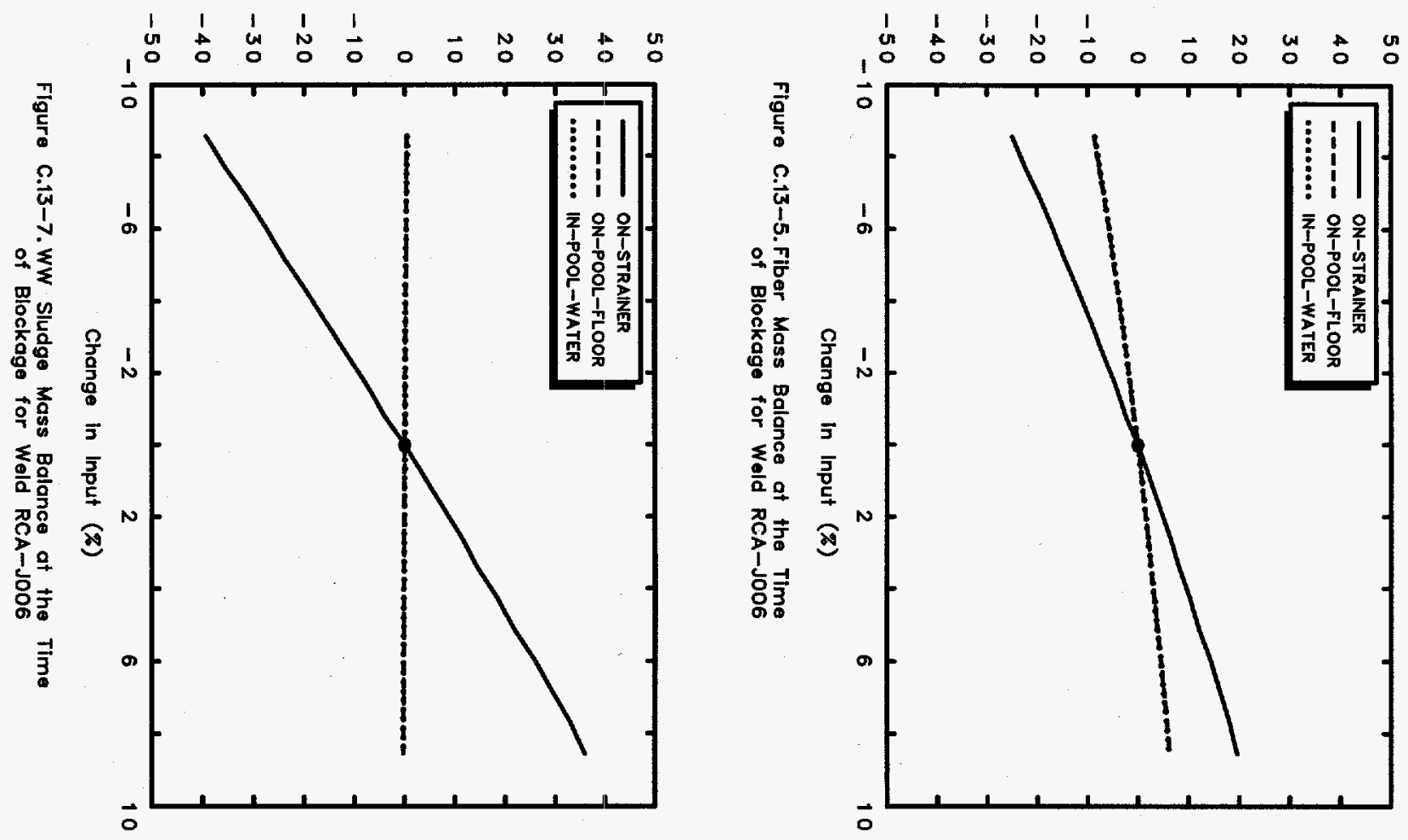

Resultant Change in Sludge Volume (\%)

Resultant Change in Fiber Volume ( $\bar{c}$ )
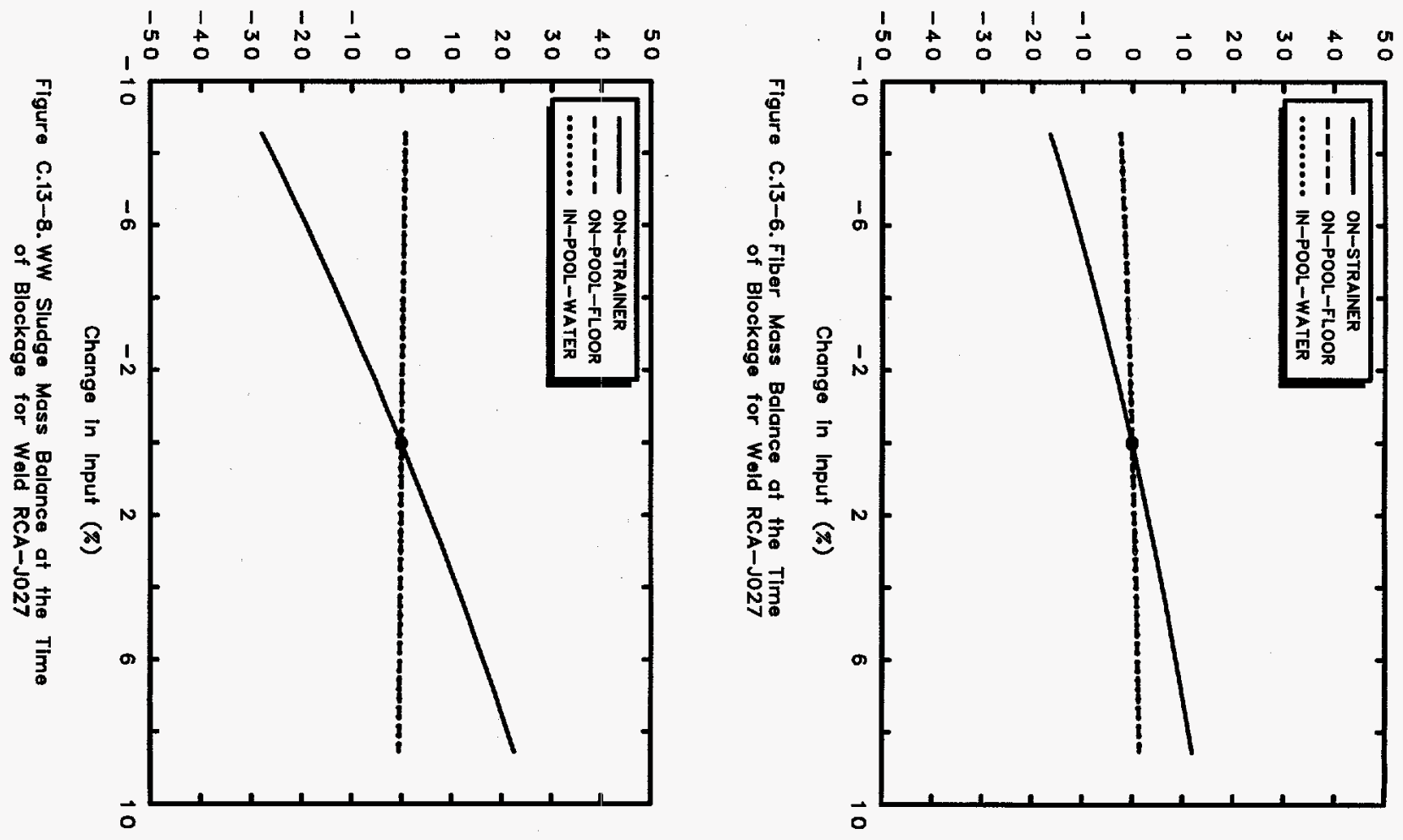


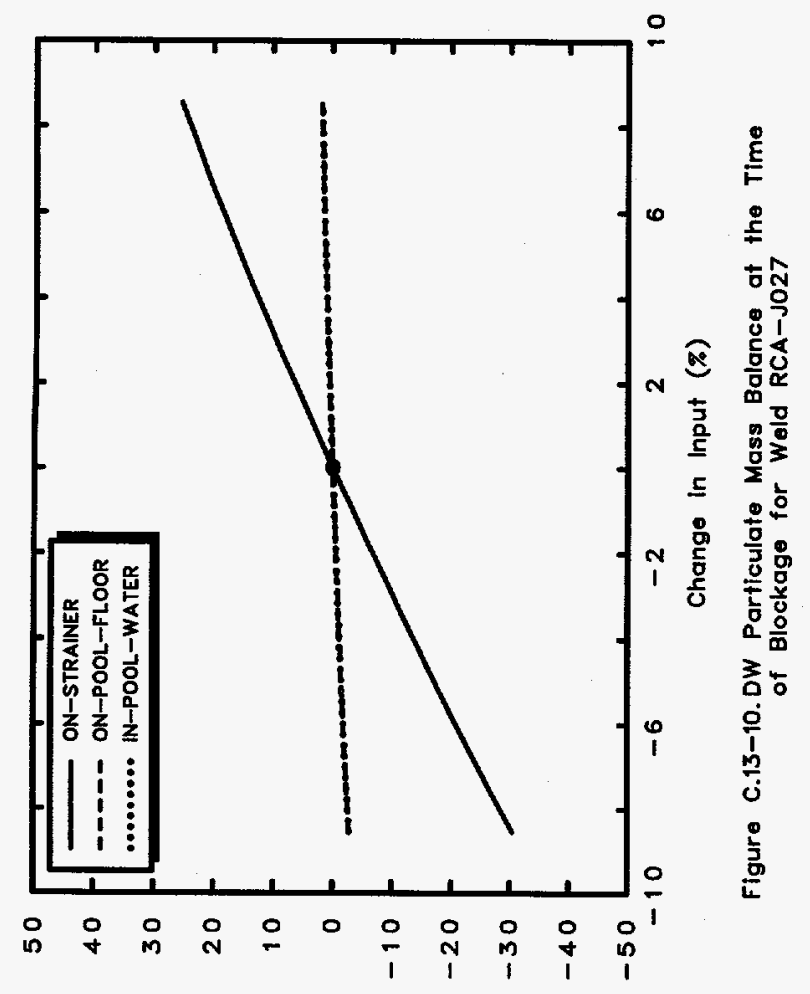

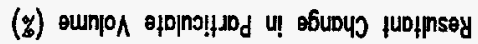

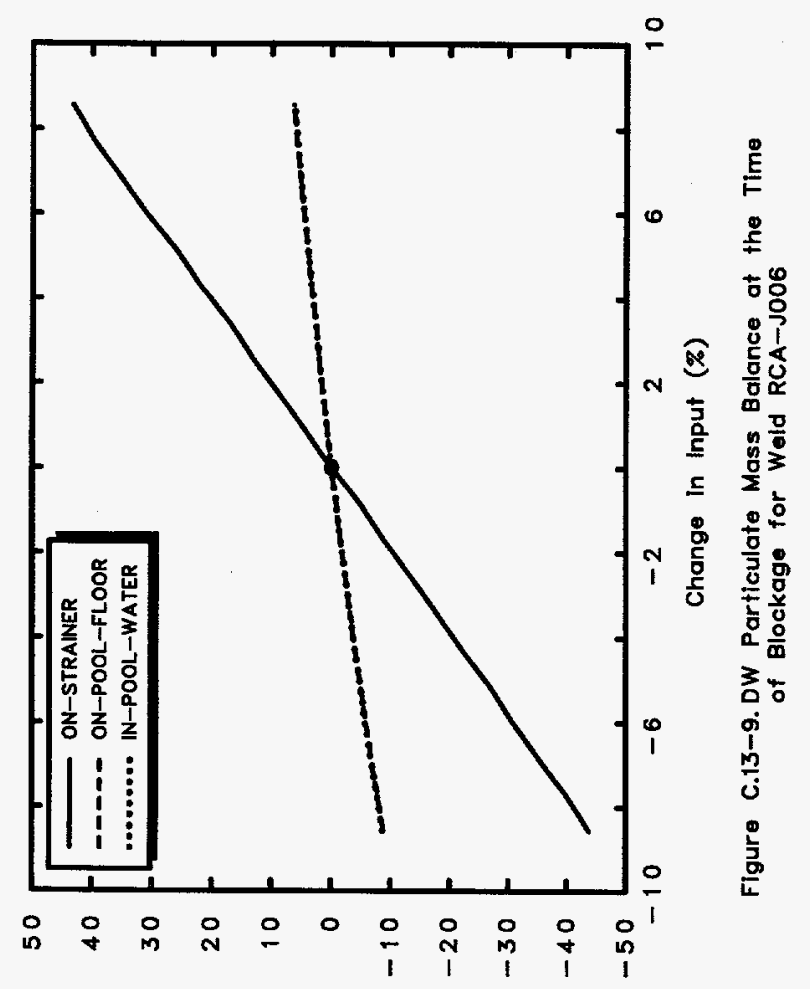

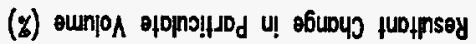

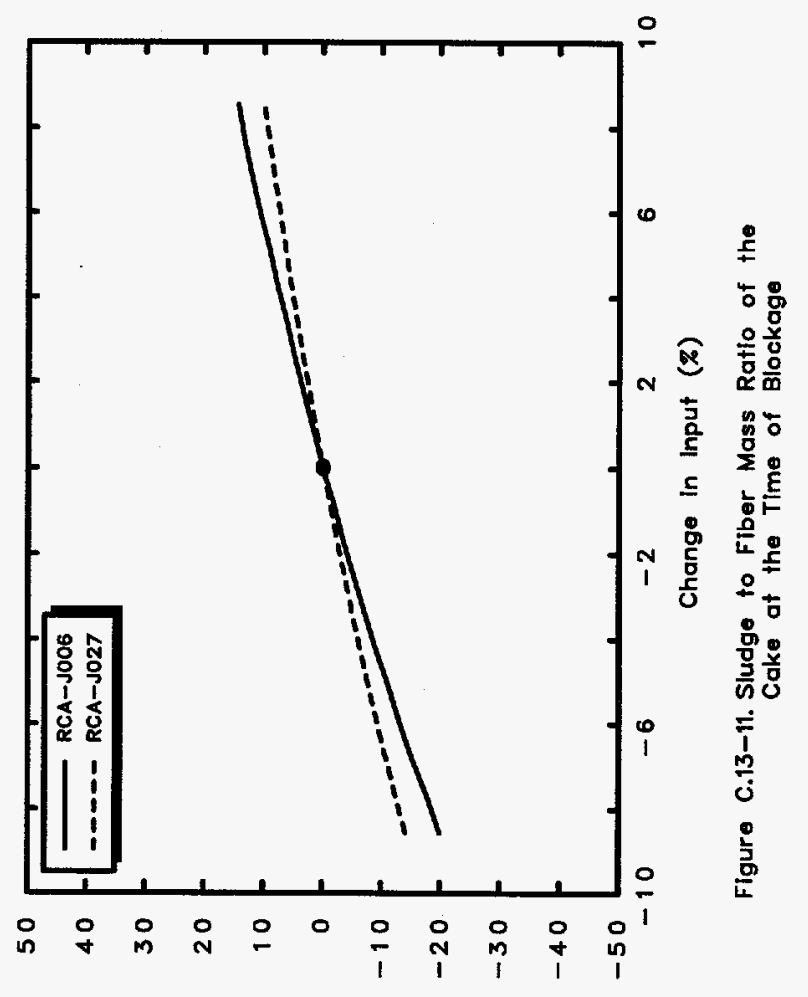

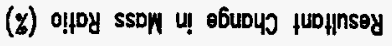




\section{C.14 Sensitivity of Strainer Filtration Efficiency}

This sensitivity study was performed by varying the strainer filtration efficiency. The efficiencies used are listed in Table C.14-1. The calculational results are presented graphically in Figures C.14-1 through C.14-11. The sharp increase shown in debris deposited on the suppression pool floor as the flow decreased below $-70 \%$ change is due to blockage occurring after the end of blowdown instead of before, i.e., before blowdown debris is resuspended whereas after blowdown settling rapidly increases floor deposition.
In general, the cake thickness decreases as the filtration efficiency decreases, however when efficiency dropped below about $-70 \%$ change, the cake thickness began to increase with further decreases in efficiency. For efficiencies greater than about 0.15 ( $-70 \%$ change), the cake thickness was limited by the density of sludge $\left(65 \mathrm{lbm} / \mathrm{ft}^{3}\right)$, i.e., the cake could not compress any further than this limit. For filtration efficiencies less than about 0.15 , the cake compressibility was governed by the empirical compressibility function for the fiber debris.

Table C.14-1. Calculational Cases for Strainer Filtration Efficiency Sensitivity Study

\begin{tabular}{|c|c|c|}
\hline Case & Change, $\%$ & Filtration Efficiency \\
\hline $\mathrm{m} 10$ & -100 & 0. \\
\hline $\mathrm{m} 9$ & -90 & 0.05 \\
\hline $\mathrm{m} 8$ & -80 & 0.10 \\
\hline $\mathrm{m} 7$ & -70 & 0.15 \\
\hline $\mathrm{m} 6$ & -60 & 0.20 \\
\hline $\mathrm{m} 5$ & -50 & 0.25 \\
\hline $\mathrm{m} 4$ & -40 & 0.30 \\
\hline $\mathrm{m} 3$ & -30 & 0.35 \\
\hline $\mathrm{m} 2$ & -20 & 0.40 \\
\hline $\mathrm{m} 1$ & -10 & 0.45 \\
\hline Base & 0 & 0.50 \\
\hline 1 & +10 & 0.55 \\
\hline 2 & +20 & 0.60 \\
\hline 3 & +30 & 0.65 \\
\hline 4 & +40 & 0.70 \\
\hline 5 & +50 & 0.75 \\
\hline 6 & +60 & 0.80 \\
\hline 7 & +70 & 0.85 \\
\hline 8 & +80 & 0.90 \\
\hline 9 & +90 & 0.95 \\
\hline 10 & +100 & 1.00 \\
\hline
\end{tabular}


Appendix C

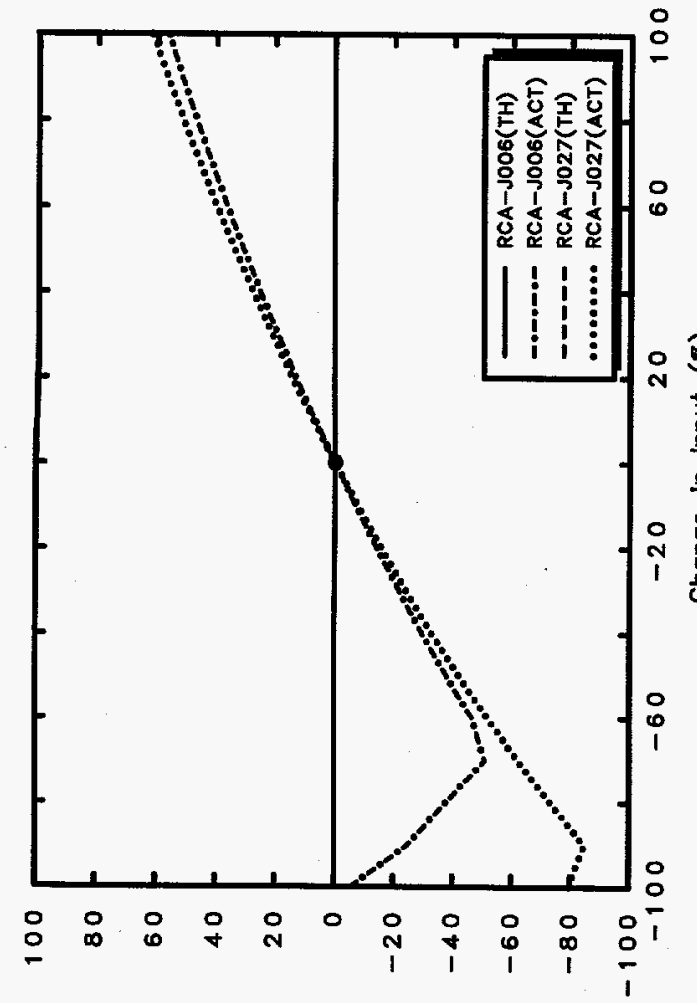

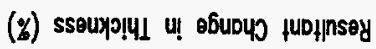

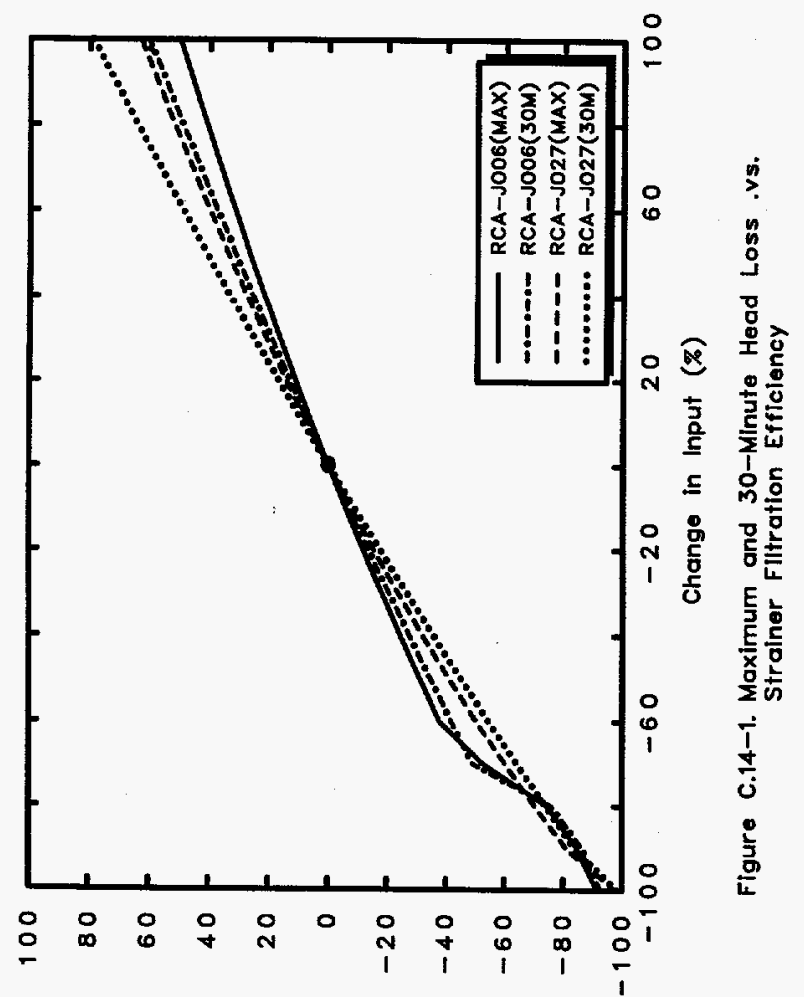

(z) ssoา pDoH u! ө6udu fuDjnsey

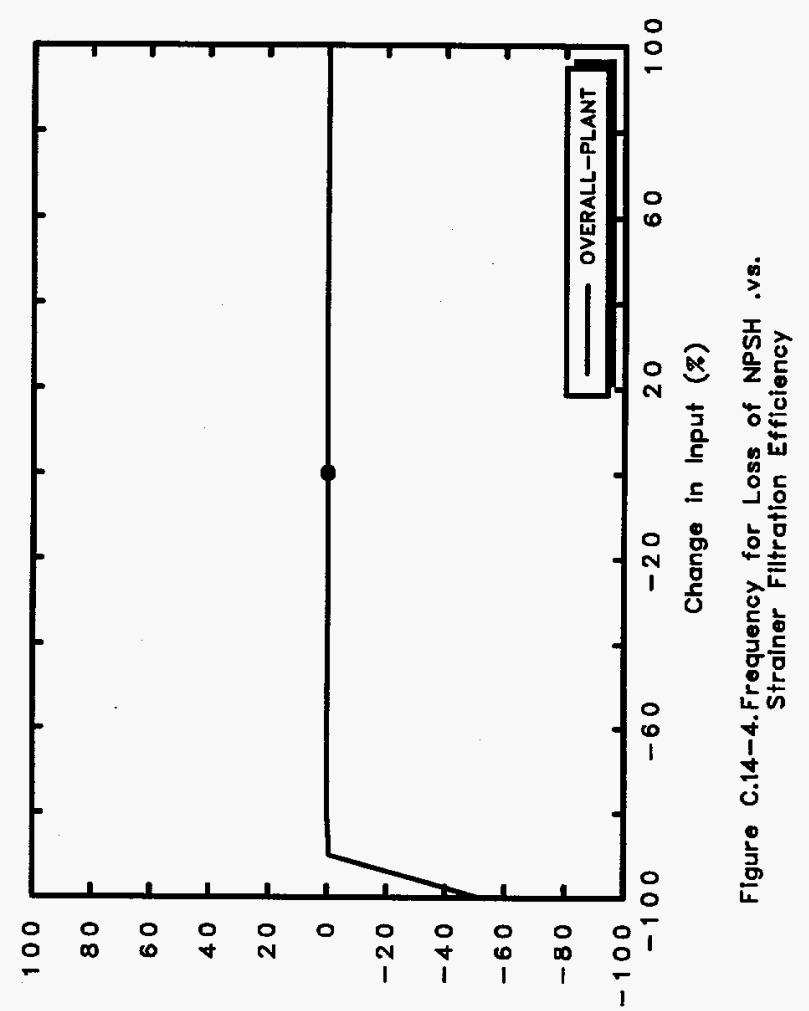

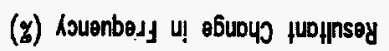

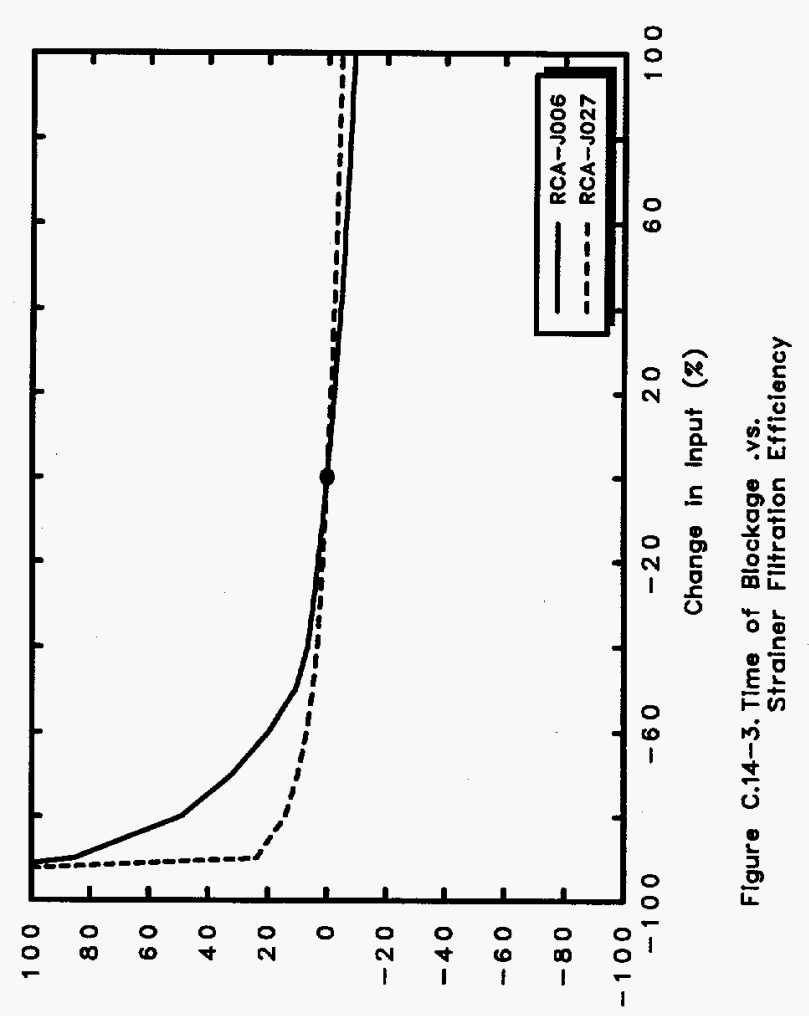

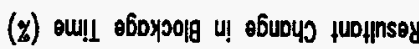



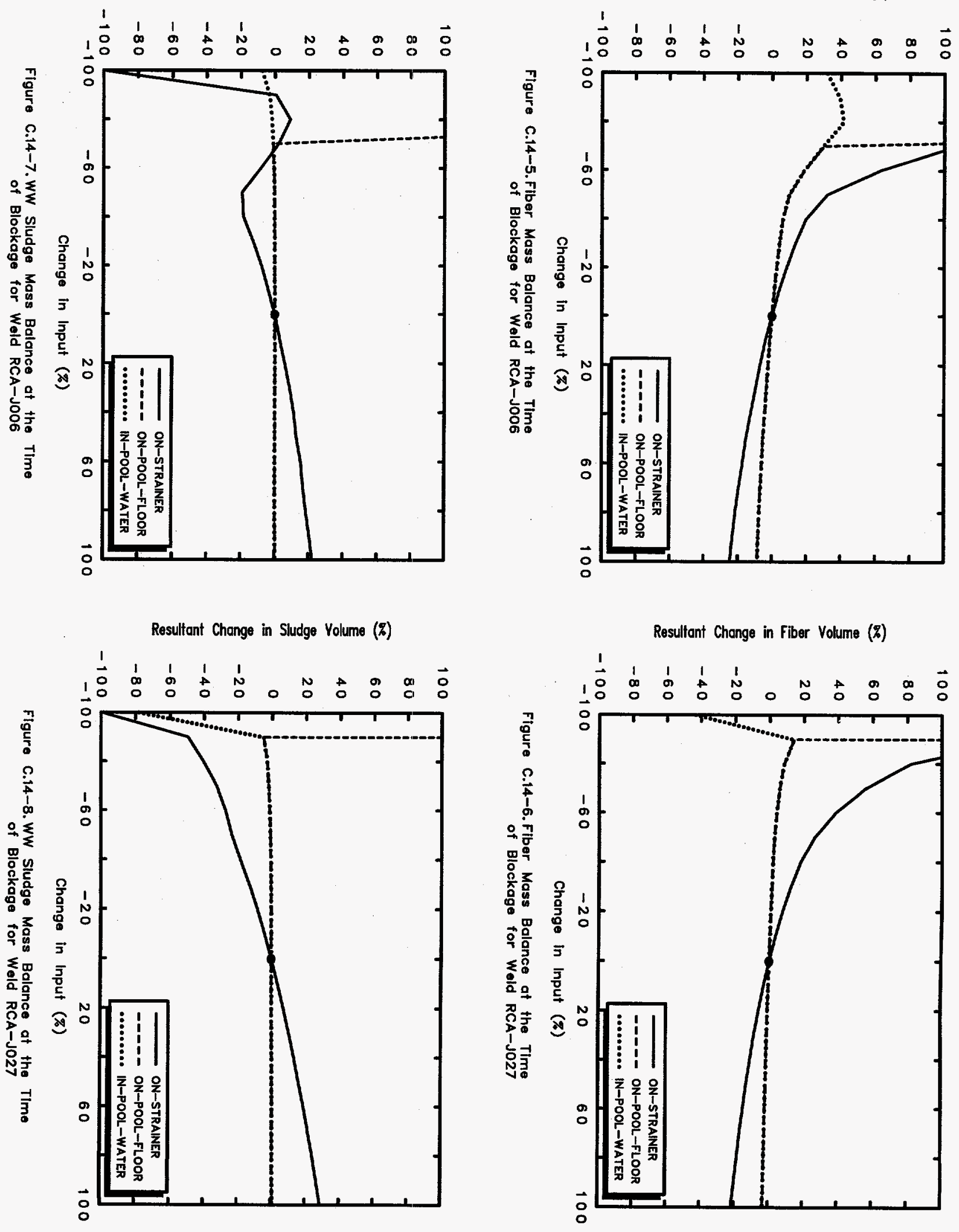

כ x!puadd $\forall$ 


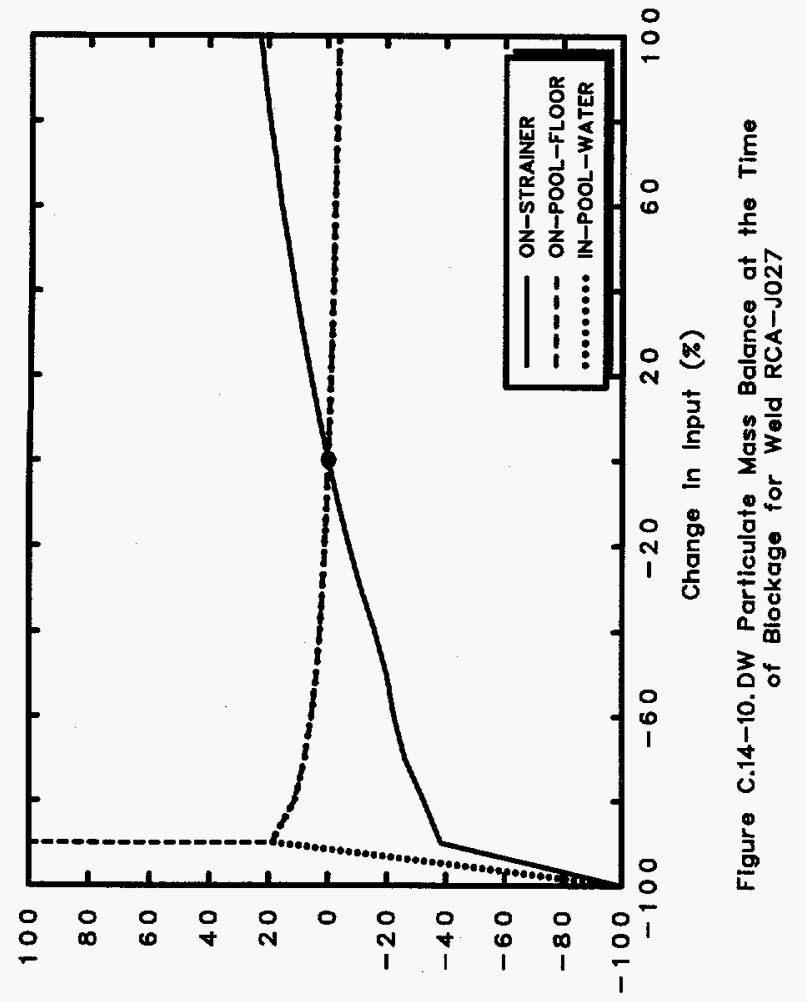

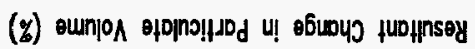

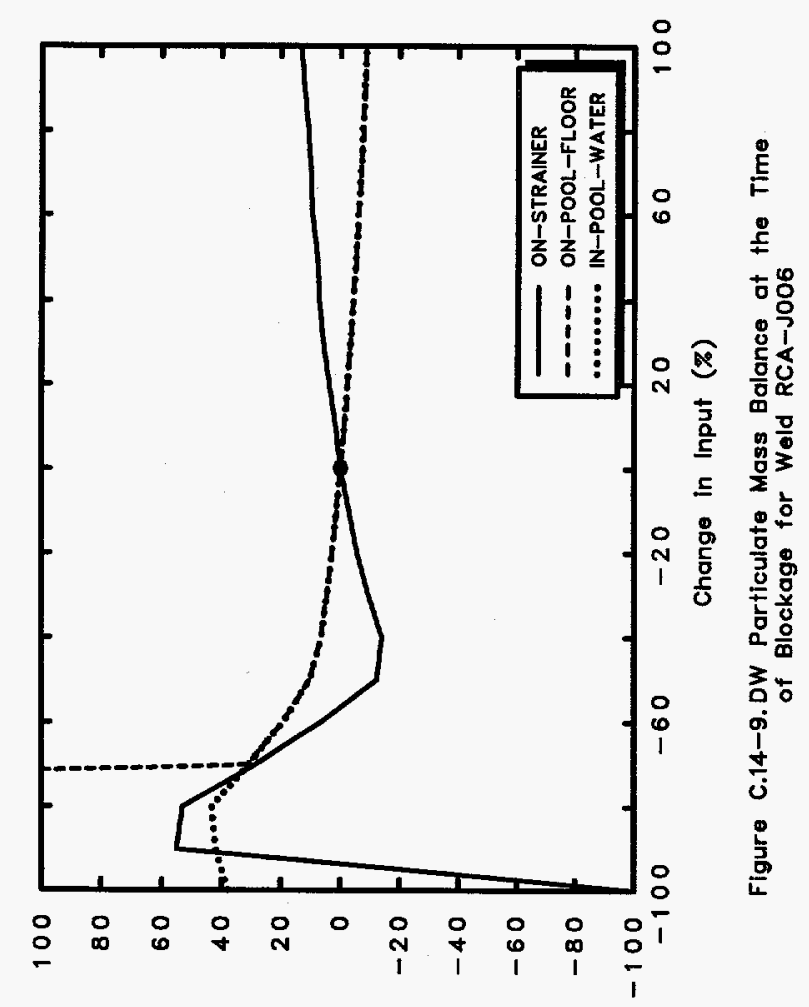

(z) ounjo

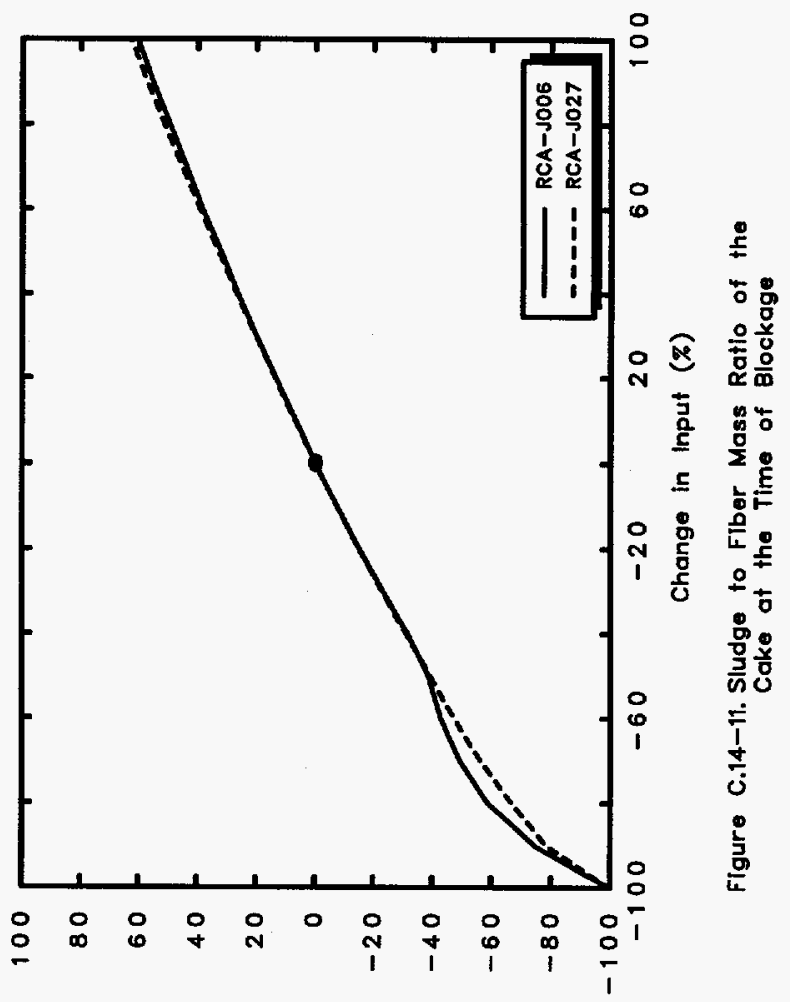

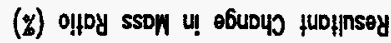


Appendix C

\section{C.15 Sensitivity of System Retention Fraction}

listed in Table C.15-1. The calculational results are presented graphically in Figures C.15-1 through C.15-11.

This sensitivity study was performed by varying the system retention fraction. The fractions used are

Table C.15-1. Calculational Cases for System Retention Fraction Sensitivity Study

\begin{tabular}{|c|c|c|}
\hline Case & Change, $\%$ & Retention Fraction \\
\hline $\mathrm{m} 10$ & -100 & 0. \\
\hline m9 & -90 & 0.05 \\
\hline $\mathrm{m} 8$ & -80 & 0.10 \\
\hline $\mathrm{m} 7$ & -70 & 0.15 \\
\hline $\mathrm{m} 6$ & -60 & 0.20 \\
\hline $\mathrm{m} 5$ & -50 & 0.25 \\
\hline $\mathrm{m} 4$ & -40 & 0.30 \\
\hline $\mathrm{m} 3$ & -30 & 0.35 \\
\hline $\mathrm{m} 2$ & -20 & 0.40 \\
\hline $\mathrm{m} 1$ & -10 & 0.45 \\
\hline Base & $\mathbf{0}$ & 0.50 \\
\hline 1 & +10 & 0.55 \\
\hline 2 & +20 & 0.60 \\
\hline 3 & +30 & 0.65 \\
\hline 4 & +40 & 0.70 \\
\hline 5 & +50 & 0.75 \\
\hline 6 & +60 & 0.80 \\
\hline 7 & +70 & 0.85 \\
\hline 8 & +80 & 0.90 \\
\hline 9 & +90 & 0.95 \\
\hline 10 & +100 & 1.00 \\
\hline
\end{tabular}




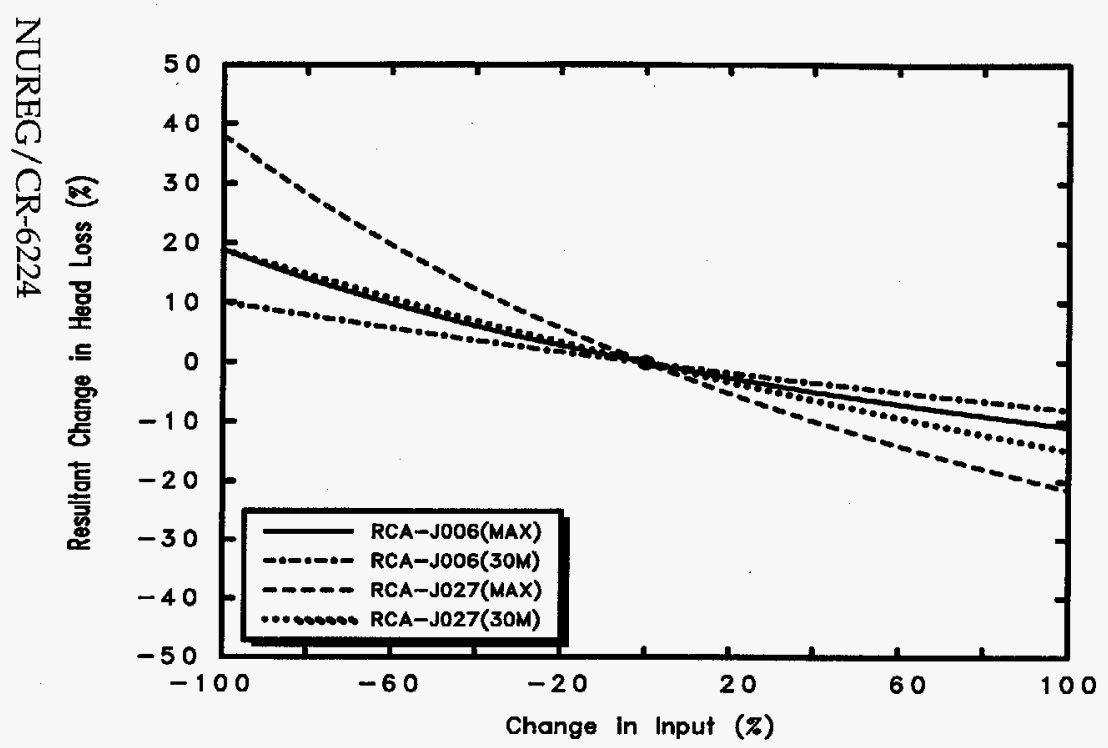

Figure C.15-1. Maximum and 30-Minute Head Loss .vs.

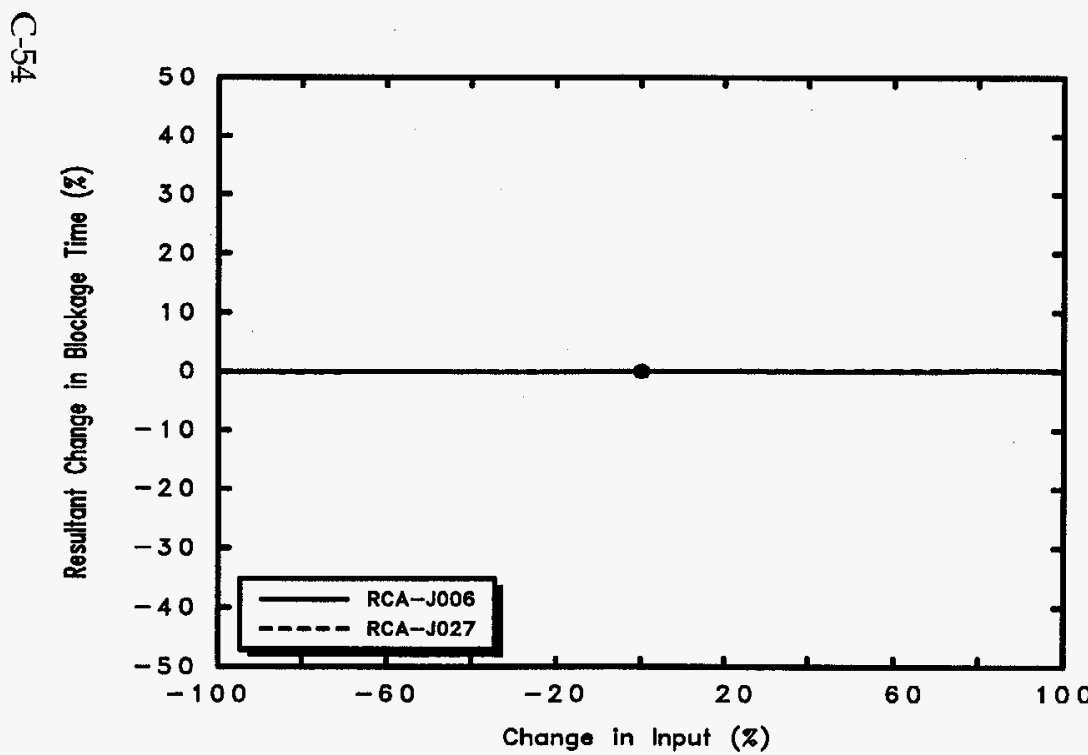

Figure C.15-3. Time of Blockage .vs.

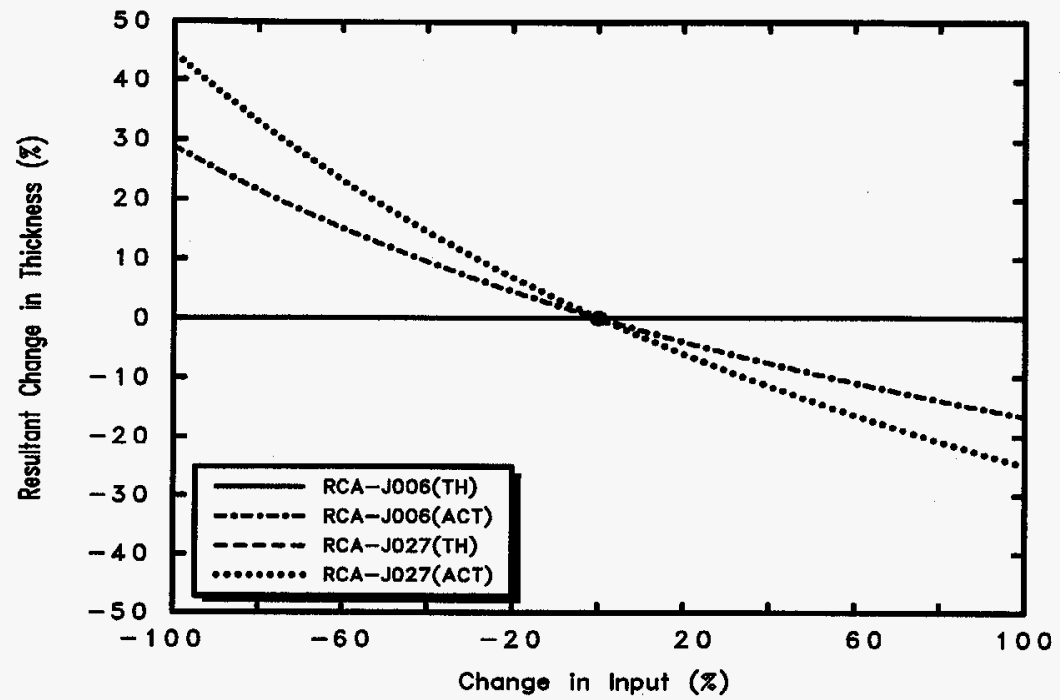

Figure C.15-2. Maximum Theoretical/Actual Cake Thicknesses .vs. System Retention Fraction

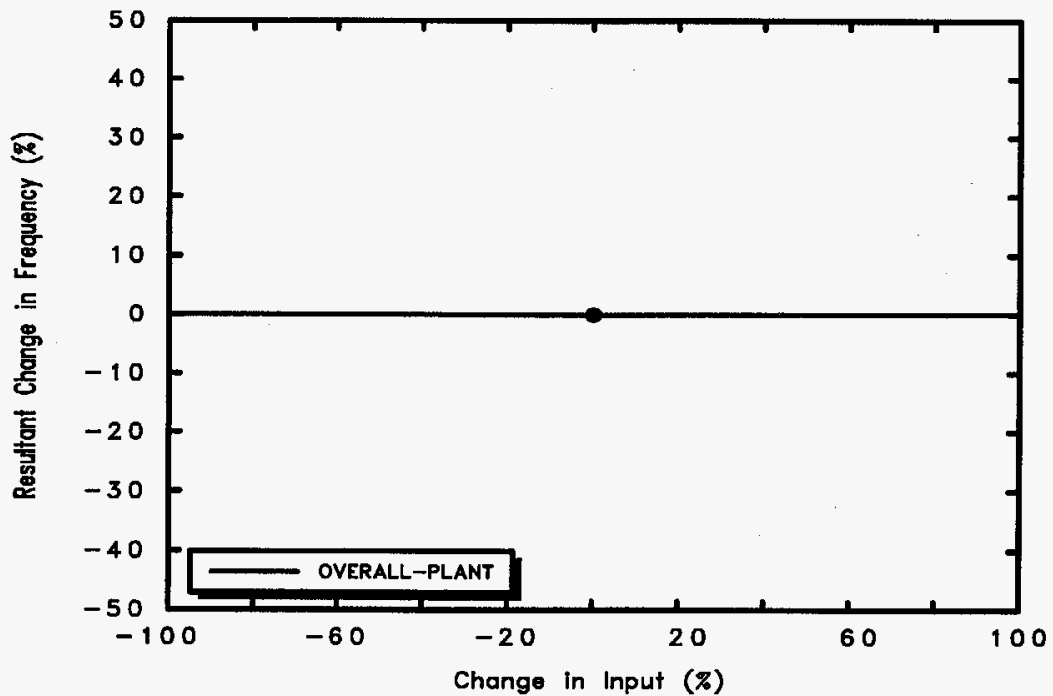

Figure C.15-4. Frequency for Loss of NPSH .vs. System Retention Fraction 


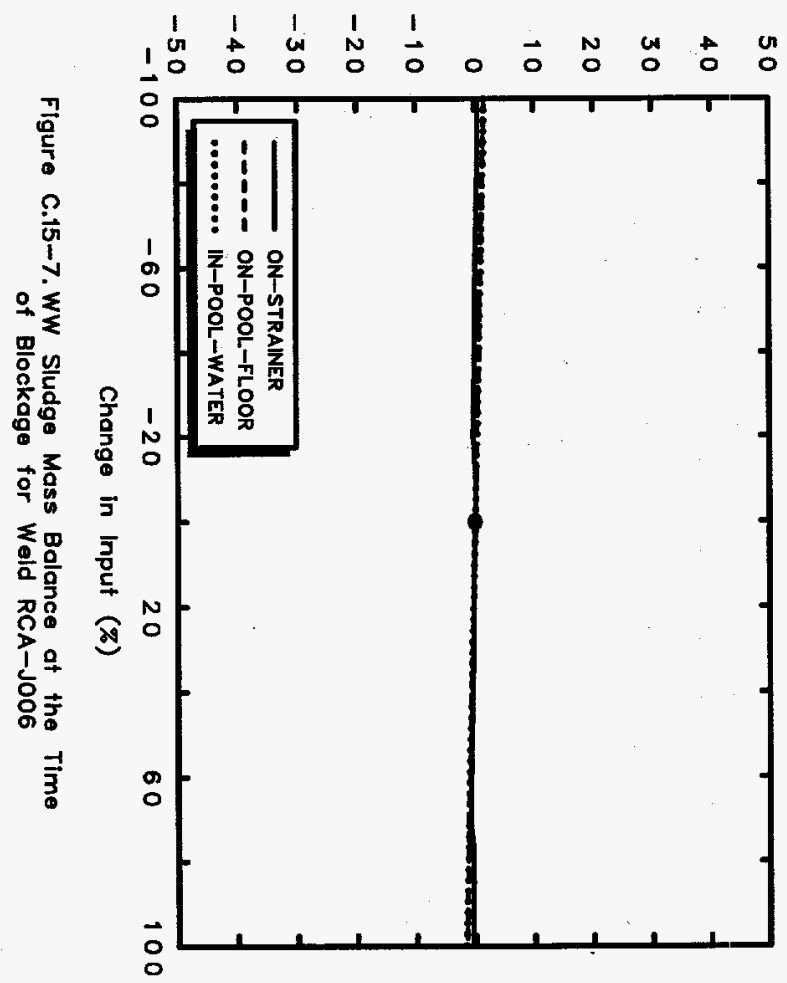

Resultant Change in Sludge Volume (z)

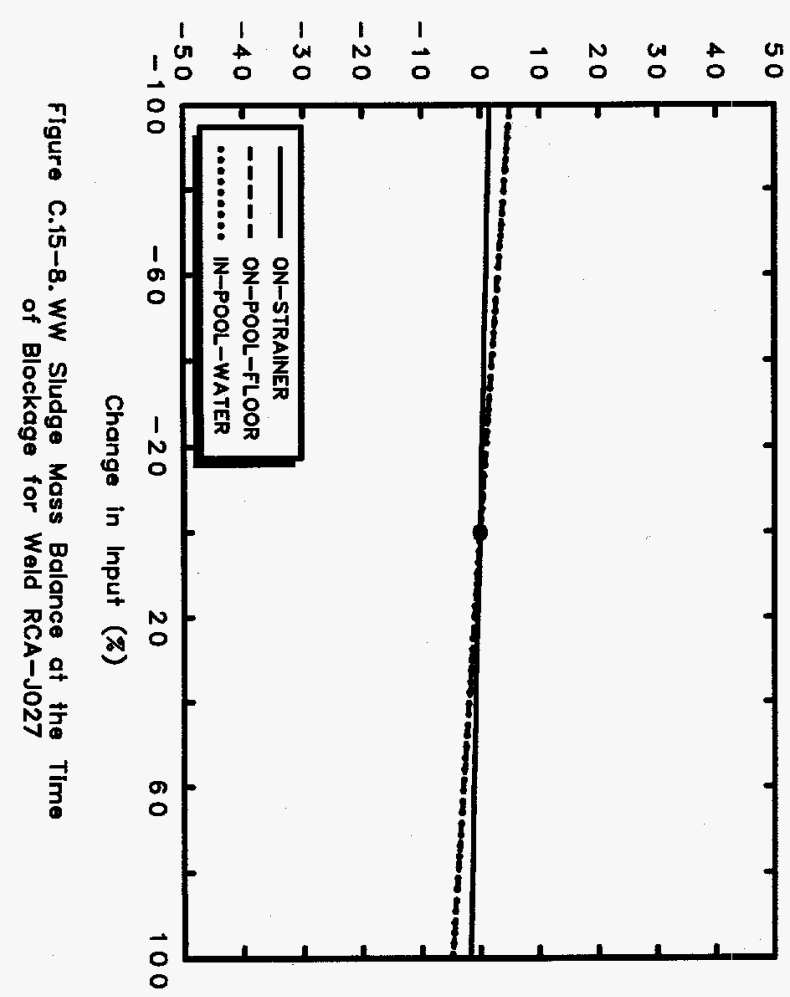

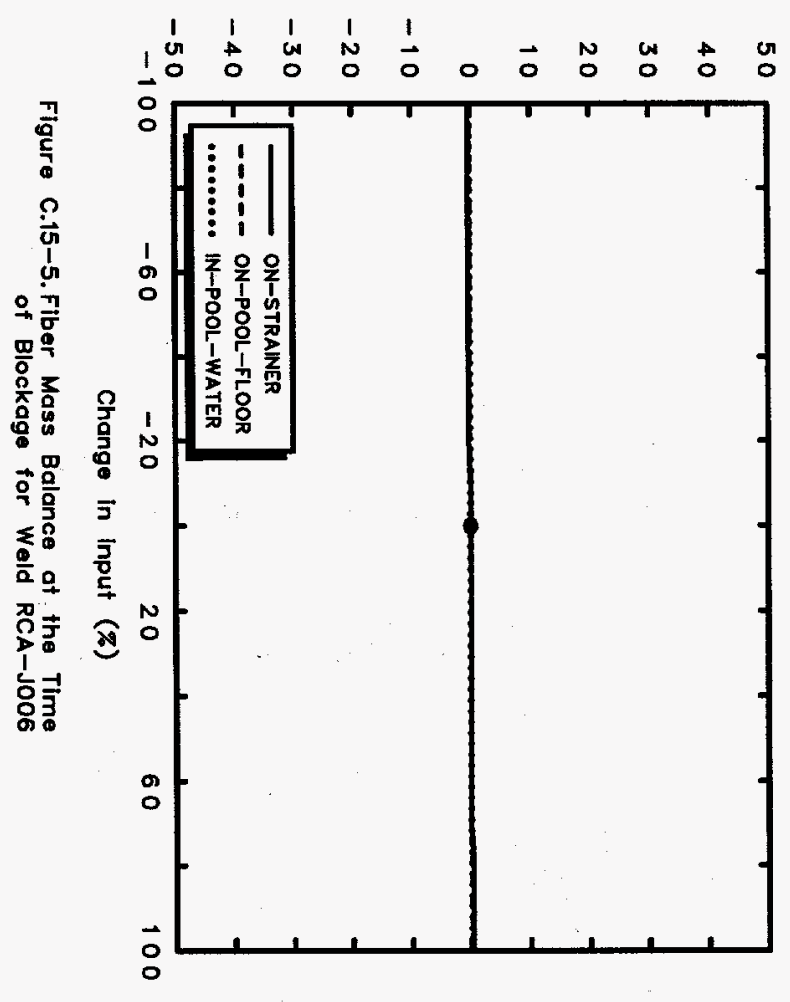

Resultant Change in Fiber Volume (z)

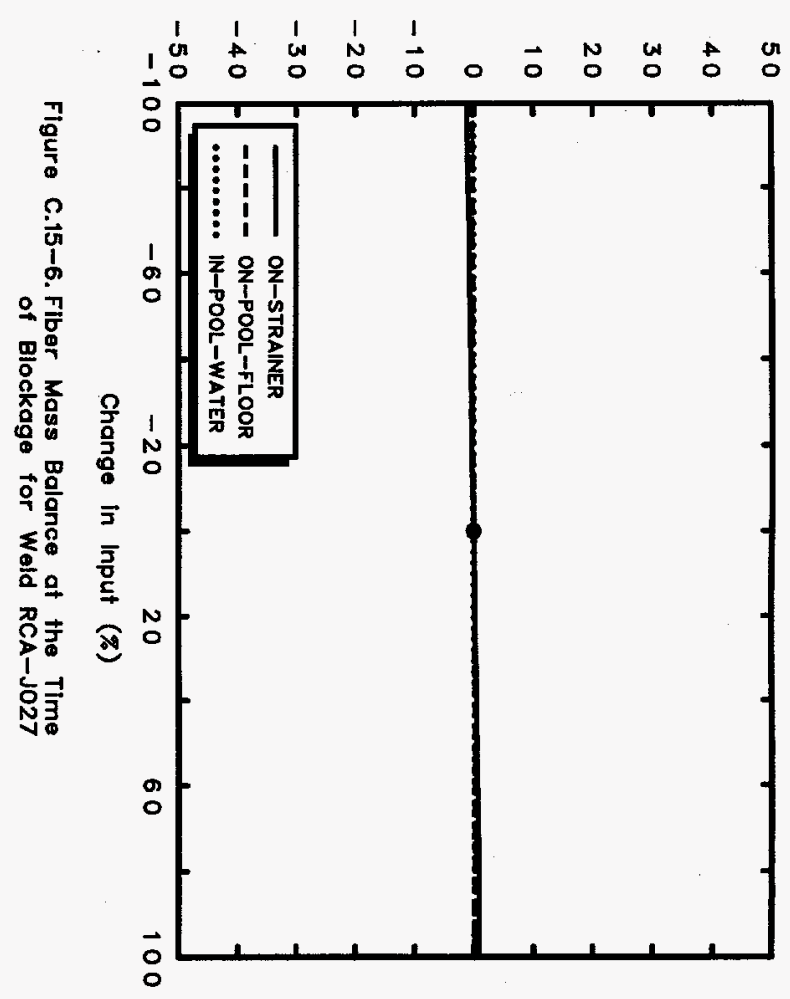


Appendix C

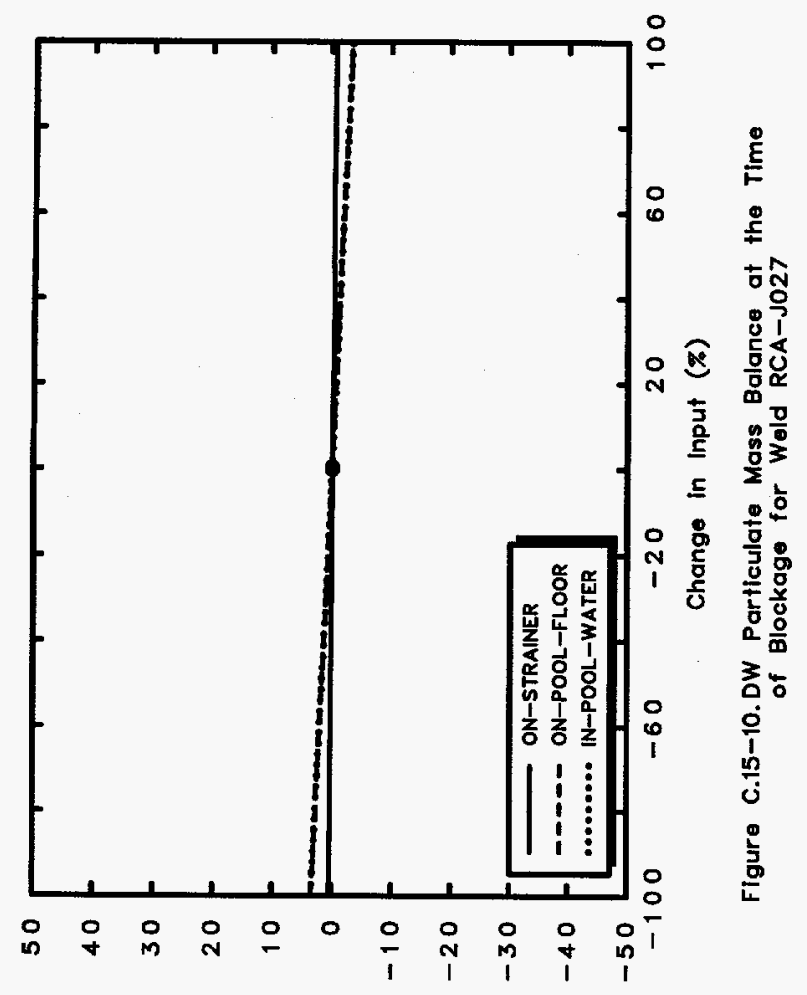

(c) ounp
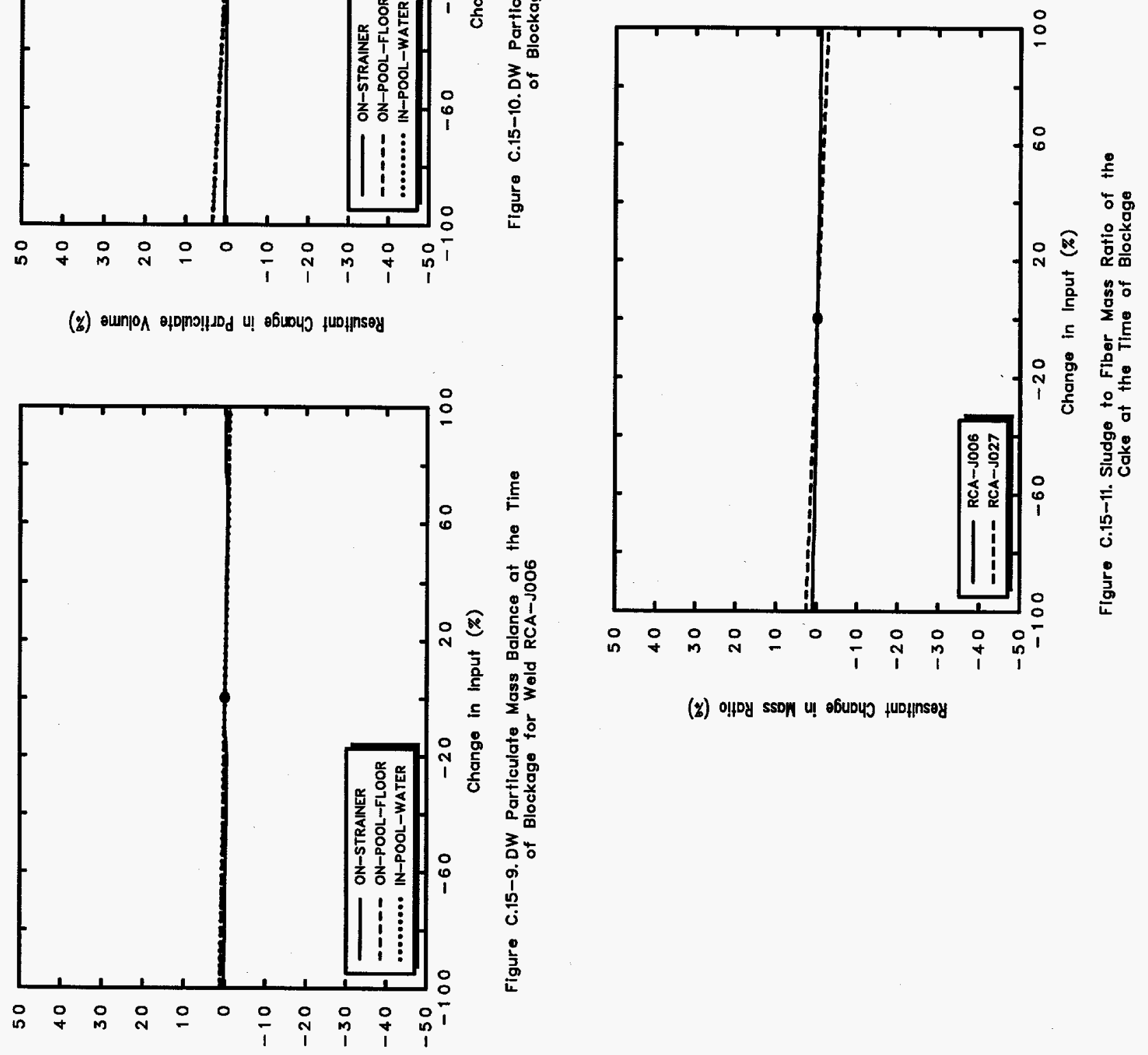

(z) o!ppy ssow u! obudu fupynsey

(6) ounjo 


\section{Appendix D}

Reference Plant Weld Data Tables 



\section{Table of Contents}

Page

Weld Location Designators D-2

Nomenclature and Notes D-3

List of Tables

Page

D-1 Listing of Targets for Welds D-5 

This appendix contains the weld information for the modeled primary system welds for the NUREG/CR-6224 reference plant. The following two pages provide a legend of weld location designators and a list of nomenclature and weld types, respectively. These two pages define the designators and nomenclature used in the weld data tables in this appendix. Weld data are included for the recirculation, main steam, feedwater, $\mathrm{HPCI}$, and RHR systems. 


\section{Recirculation System}

RCA Recirculation Loop, Suction and Discharge, "A" side

RBA Recirculation Loop, Discharge Bypass, "A" side

RMA Recirculation Loop, Manifold, "A" side

RRE Recirculation Loop, Riser (Riser "E"), "A" side

RRF

RRG

RRH

RDA

Recirculation Loop, Riser (Riser "F"), "A" side

Recirculation Loop, Riser (Riser "G"), "A" side

Recirculation Loop, Riser (Riser " $\mathrm{H}$ "), "A" side

$\mathrm{RCB}$

Recirculation Loop, Drain Line, "A" side

RBB

Recirculation Loop, Suction and Discharge, "B" side

RMB

Recirculation Loop, Discharge Bypass, "B" side

RRA

Recirculation Loop, Manifold, "B" side

RRB

Recirculation Loop, Riser (Riser "A"), "B" side

RRC

Recirculation Loop, Riser (Riser "B"), "B" side

RRD

Recirculation Loop, Riser (Riser "C"), "B" side

Recirculation Loop, Riser (Riser " $\mathrm{D}$ "), "B" side

RDB

Recirculation Loop, Drain Line, "B" side

\section{Main Steam System}

MSA

MSB

MSC

Main Steam Loop "A" and Drain

Main Steam Loop "B" and Drain

Main Steam Loop "C" and Drain

MSD

Main Steam Loop "D" and Drain

\section{Feedwater System}

FWA Feedwater Loop "A" ("A" and "B" side), "A" branch (FWA includes the 16" line that feeds both FWA and FWB.)

FWB Feedwater Loop "A" "A" and "B" side), "B" branch

FWC Feedwater Loop "B" ("C" and "D" side), "C" branch (FWC includes the 16" line that feeds both FWC and FWD.)

FWD Feedwater Loop "B" ("C" and "D" side), "D" branch

4. High Pressure Coolant Injection (HPCI) System

PSA High Pressure Coolant Injection Loop

5. Residual Heat Removal (RHR) System

RHB Reactor Heat Removal, "B" Loop

RHC Reactor Heat Removal, "C" Loop

RHD Reactor Heat Removal, "D" Loop 


\section{Nomenclature and Notes}

\section{System Identification}

1 Recirculation Loop

2 Main Steam

3 Feed Water

4 Reactor Water Cleanup

5 RCIC (Reactor Core Isolation Coolant)

6 HPCI (High Pressure Coolant Injection)

7 RHR (Residual Heat Removal)

8 Core Spray

\section{Insulation Type}

NK Nukon

MR Mirror

CS Calcium Silicate

NN None

\section{Weld Types}

D Vessel Weld

F Dissimilar Weld (stainless steel to carbon steel)

C Carbon Steel to Carbon Steel Weld

S Stainless Steel to Stainless Steel Weld

There were two types of stainless steel pipe used in the drywell piping systems at the reference plant:

Stainless steel TP 304

Stainless steel TP 316L

There are four types of carbon steel pipes in the drywell piping systems at the reference plant:

Carbon steel A-106, Gr B

Carbon steel A-333, Gr 6

Carbon steel 336 (used only on vessel nozzle safe ends)

Carbon steel 508 (used only on vessel nozzle safe ends)

The following weld designators are used to identify the types of pipe joined by the various welds evaluated in this study:

Vessel Weld

D1 CS 508 and vessel

Dissimilar Metals

F1 CS 106 and SS 316

F2 CS 106 and SS 304

F3 CS 333 and SS 316

F4 CS 333 and SS 304

F5 CS 336 and SS 304

\section{Stainless Steel}

S1 SS 304 and SS 304

S2 SS 316 and SS 304

S3 SS 316 and SS 316

\begin{tabular}{lr}
\multicolumn{2}{l}{ Carbon Steel } \\
\hline C1 & CS 106 and CS 106 \\
C2 & CS 106 and CS 333 \\
C3 & CS 333 and CS 333 \\
C4 & CS 508 and CS 333 \\
C5 & CS 508 and CS 106
\end{tabular}

Weld Location Elevation

$\mathrm{H}$-Above the $776^{\prime}$ elevation grating 

Table D-1

Listing of Targets for Welds

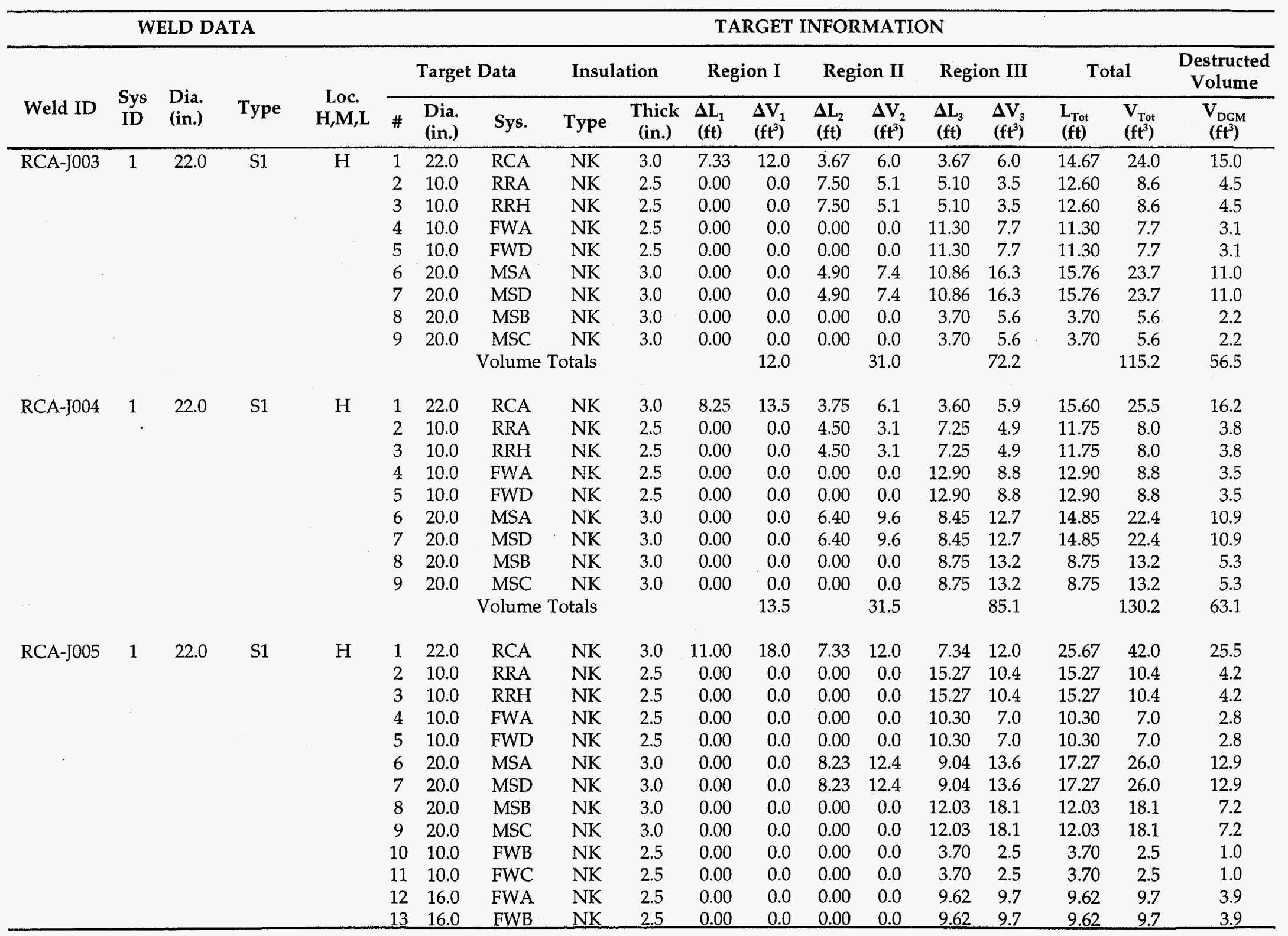




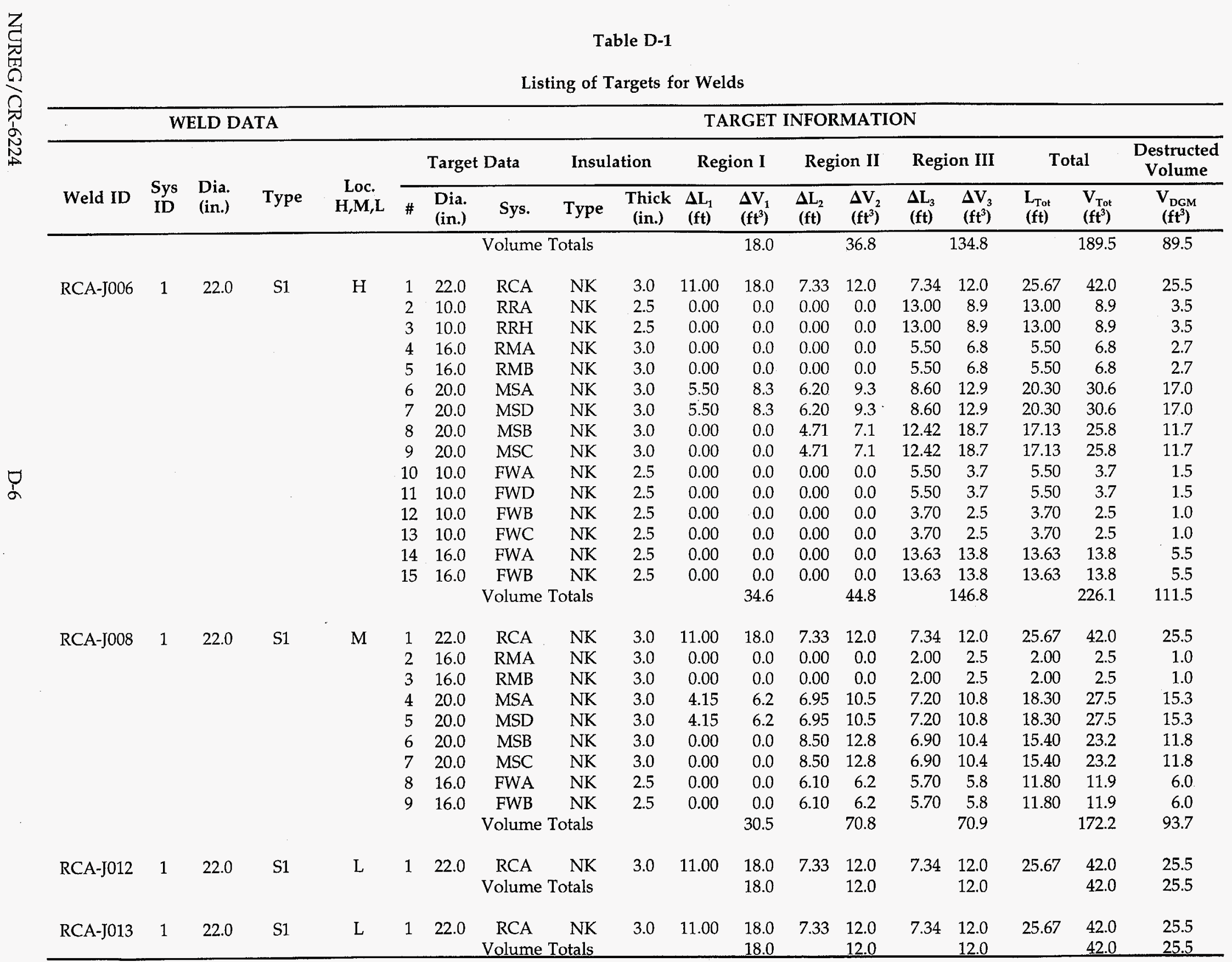


Table D-1

Listing of Targets for Welds

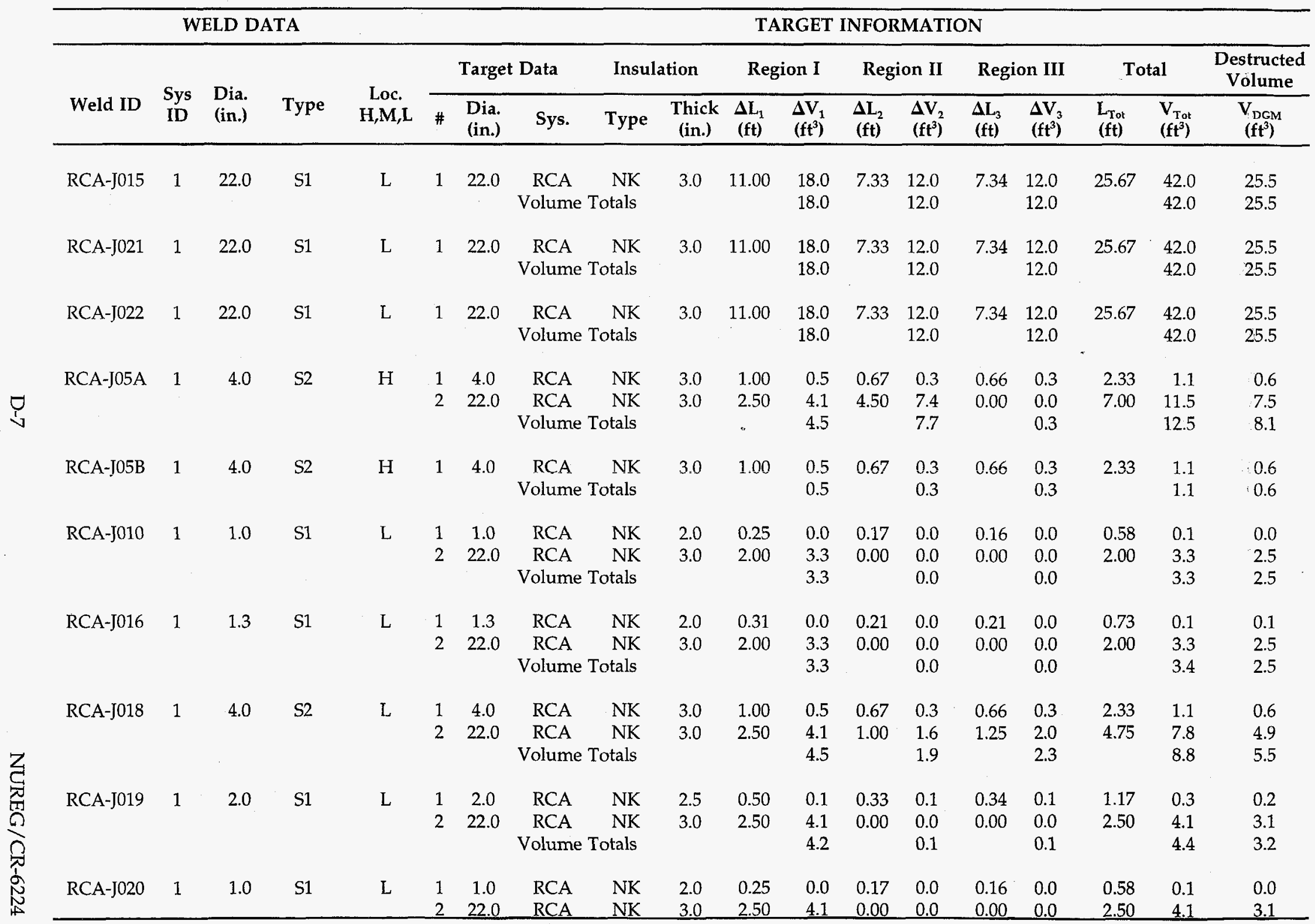




\begin{tabular}{|c|c|c|c|c|c|c|c|c|c|c|c|c|c|c|c|c|c|c|}
\hline \multicolumn{19}{|c|}{ Listing of Targets for Welds } \\
\hline \multicolumn{5}{|c|}{ WELD DATA } & \multicolumn{14}{|c|}{ TARGET INFORMATION } \\
\hline \multirow[b]{2}{*}{ Weld ID } & \multirow[b]{2}{*}{$\begin{array}{l}\text { Sys } \\
\text { ID }\end{array}$} & \multirow[b]{2}{*}{$\begin{array}{l}\text { Dia. } \\
\text { (in.) }\end{array}$} & \multirow[b]{2}{*}{ Type } & \multirow[b]{2}{*}{$\begin{array}{l}\text { Loc. } \\
\mathbf{H}, \mathbf{M}, \mathbf{L}\end{array}$} & \multicolumn{3}{|c|}{ Target Data } & \multicolumn{2}{|c|}{ Insulation } & \multicolumn{2}{|c|}{ Region I } & \multicolumn{2}{|c|}{ Region II } & \multicolumn{2}{|c|}{ Region III } & \multicolumn{2}{|c|}{ Total } & \multirow{2}{*}{$\begin{array}{c}\begin{array}{c}\text { Destructed } \\
\text { Volume }\end{array} \\
\begin{array}{c}\mathrm{V}_{\mathrm{DGM}} \\
\left(\mathrm{ft}^{3}\right)\end{array} \\
\end{array}$} \\
\hline & & & & & $\#$ & $\begin{array}{l}\text { Dia. } \\
\text { (in.) }\end{array}$ & Sys. & Type & $\begin{array}{c}\text { Thick } \\
\text { (in.) }\end{array}$ & $\begin{array}{l}\Delta \mathrm{L}_{1} \\
(\mathrm{ft})\end{array}$ & $\begin{array}{l}\Delta \mathrm{V}_{1} \\
\left(\mathrm{ft}^{3}\right)\end{array}$ & $\begin{array}{l}\Delta \mathrm{L}_{2} \\
(\mathrm{ft})\end{array}$ & $\begin{array}{l}\Delta \mathrm{V}_{2} \\
\left(\mathrm{ft}^{3}\right)\end{array}$ & $\begin{array}{l}\Delta \mathrm{L}_{3} \\
(\mathrm{ft})\end{array}$ & $\begin{array}{l}\Delta \mathbf{V}_{3} \\
\left(\mathrm{ft}^{3}\right)\end{array}$ & $\begin{array}{l}\mathbf{L}_{\text {Tot }} \\
\text { (ft) } \\
\end{array}$ & $\begin{array}{l}V_{\text {Tot }} \\
\left(\mathrm{ft}^{3}\right)\end{array}$ & \\
\hline & & & & & & & Volume & otals & & & 4.1 & & 0.0 & & 0.0 & & 4.2 & 3.1 \\
\hline RCA-J024 & 1 & 22.0 & S1 & $\mathrm{L}$ & 1 & 22.0 & RCA & NK & 3.0 & 5.50 & 9.0 & 3.66 & 6.0 & 3.69 & 6.0 & 12.85 & 21.0 & 12.8 \\
\hline RCA-J028 & 1 & 22.0 & S1 & $\mathrm{L}$ & 1 & 22.0 & $\begin{array}{c}\text { RCA } \\
\text { Volume }\end{array}$ & $\begin{array}{l}\text { NK } \\
\text { otals }\end{array}$ & 3.0 & 11.00 & 18.0 & 7.33 & $\begin{array}{l}12.0 \\
12.0\end{array}$ & 7.34 & $\begin{array}{l}12.0 \\
12.0\end{array}$ & 25.67 & $\begin{array}{l}42.0 \\
42.0\end{array}$ & $\begin{array}{l}25.5 \\
25.5\end{array}$ \\
\hline RCA-J030 & 1 & 22.0 & S1 & $\mathrm{L}$ & 1 & 22.0 & $\begin{array}{l}\text { RCA } \\
\text { Volume }\end{array}$ & $\begin{array}{l}\text { NK } \\
\text { otals }\end{array}$ & 3.0 & 11.00 & $\begin{array}{l}18.0 \\
18.0\end{array}$ & 7.33 & $\begin{array}{l}12.0 \\
12.0\end{array}$ & 7.34 & $\begin{array}{l}12.0 \\
12.0\end{array}$ & 25.67 & $\begin{array}{l}42.0 \\
42.0\end{array}$ & $\begin{array}{l}25.5 \\
25.5\end{array}$ \\
\hline RCA-J032 & 1 & 22.0 & S1 & $\mathrm{L}$ & 1 & 22.0 & $\begin{array}{c}\text { RCA } \\
\text { Volume }\end{array}$ & $\begin{array}{l}\text { NK } \\
\text { otals }\end{array}$ & 3.0 & 11.00 & $\begin{array}{l}18.0 \\
18.0\end{array}$ & 7.33 & $\begin{array}{l}12.0 \\
12.0\end{array}$ & 7.34 & $\begin{array}{l}12.0 \\
12.0\end{array}$ & 25.67 & $\begin{array}{l}42.0 \\
42.0\end{array}$ & $\begin{array}{l}25.5 \\
25.5\end{array}$ \\
\hline RCA-J038 & 1 & 22.0 & S1 & $\mathrm{L}$ & $\begin{array}{l}1 \\
2 \\
3 \\
4 \\
5\end{array}$ & $\begin{array}{l}22.0 \\
20.0 \\
16.0 \\
10.0 \\
10.0\end{array}$ & $\begin{array}{c}\text { RCA } \\
\text { RHC } \\
\text { RMA } \\
\text { RRF } \\
\text { RRG } \\
\text { Volume }\end{array}$ & $\begin{array}{l}\text { NK } \\
\text { NK } \\
\text { NK } \\
\text { NK } \\
\text { NK } \\
\text { otals }\end{array}$ & $\begin{array}{l}3.0 \\
3.0 \\
3.0 \\
2.5 \\
2.5\end{array}$ & $\begin{array}{r}11.00 \\
0.00 \\
0.00 \\
0.00 \\
0.00\end{array}$ & $\begin{array}{r}18.0 \\
0.0 \\
0.0 \\
0.0 \\
0.0 \\
18.0\end{array}$ & $\begin{array}{l}7.33 \\
4.00 \\
0.00 \\
0.00 \\
0.00\end{array}$ & $\begin{array}{r}12.0 \\
6.0 \\
0.0 \\
0.0 \\
0.0 \\
18.0\end{array}$ & $\begin{array}{r}7.34 \\
1.50 \\
18.33 \\
1.83 \\
1.83\end{array}$ & $\begin{array}{r}12.0 \\
2.3 \\
22.8 \\
1.2 \\
1.2 \\
39.6\end{array}$ & $\begin{array}{r}25.67 \\
5.50 \\
18.33 \\
1.83 \\
1.83\end{array}$ & $\begin{array}{r}42.0 \\
8.3 \\
22.8 \\
1.2 \\
1.2 \\
75.6\end{array}$ & $\begin{array}{r}25.5 \\
4.5 \\
9.1 \\
0.5 \\
0.5 \\
40.1\end{array}$ \\
\hline RCA-J041 & 1 & 22.0 & S1 & $\mathrm{M}$ & $\begin{array}{l}1 \\
2 \\
3 \\
4 \\
5\end{array}$ & $\begin{array}{l}22.0 \\
20.0 \\
16.0 \\
10.0 \\
10.0\end{array}$ & $\begin{array}{c}\text { RCA } \\
\text { RHC } \\
\text { RMA } \\
\text { RRF } \\
\text { RRG } \\
\text { Volume }\end{array}$ & $\begin{array}{l}\text { NK } \\
\text { NK } \\
\text { NK } \\
\text { NK } \\
\text { NK } \\
\text { otals }\end{array}$ & $\begin{array}{l}3.0 \\
3.0 \\
3.0 \\
2.5 \\
2.5\end{array}$ & $\begin{array}{r}11.00 \\
3.50 \\
6.00 \\
0.00 \\
0.00\end{array}$ & $\begin{array}{r}18.0 \\
5.3 \\
7.5 \\
0.0 \\
0.0 \\
30.7\end{array}$ & $\begin{array}{r}7.33 \\
2.00 \\
10.00 \\
3.00 \\
3.00\end{array}$ & $\begin{array}{r}12.0 \\
3.0 \\
12.4 \\
2.0 \\
2.0 \\
31.5\end{array}$ & $\begin{array}{r}7.34 \\
23.00 \\
8.00 \\
4.00 \\
4.00\end{array}$ & $\begin{array}{r}12.0 \\
34.6 \\
9.9 \\
2.7 \\
2.7 \\
62.0\end{array}$ & $\begin{array}{r}25.67 \\
28.50 \\
24.00 \\
7.00 \\
7.00\end{array}$ & $\begin{array}{r}42.0 \\
42.9 \\
29.8 \\
4.8 \\
4.8 \\
124.3\end{array}$ & $\begin{array}{r}25.5 \\
19.6 \\
17.0 \\
2.3 \\
2.3 \\
66.8\end{array}$ \\
\hline RCA-J043 & 1 & 22.0 & S1 & M & $\begin{array}{l}1 \\
2 \\
3 \\
4 \\
5\end{array}$ & $\begin{array}{l}22.0 \\
20.0 \\
16.0 \\
10.0 \\
10.0\end{array}$ & $\begin{array}{c}\text { RCA } \\
\text { RHC } \\
\text { RMA } \\
\text { RRF } \\
\text { RRG } \\
\text { Volume }\end{array}$ & $\begin{array}{l}\text { NK } \\
\text { NK } \\
\text { NK } \\
\text { NK } \\
\text { NK } \\
\text { otals }\end{array}$ & $\begin{array}{l}3.0 \\
3.0 \\
3.0 \\
2.5 \\
2.5\end{array}$ & $\begin{array}{r}11.00 \\
3.50 \\
6.70 \\
0.00 \\
0.00\end{array}$ & $\begin{array}{r}18.0 \\
5.3 \\
8.3 \\
0.0 \\
0.0 \\
31.6\end{array}$ & $\begin{array}{r}7.33 \\
2.00 \\
10.30 \\
3.70 \\
3.70\end{array}$ & $\begin{array}{r}12.0 \\
3.0 \\
12.8 \\
2.5 \\
2.5 \\
32.9\end{array}$ & $\begin{array}{r}7.34 \\
23.00 \\
8.00 \\
4.00 \\
4.00\end{array}$ & $\begin{array}{r}12.0 \\
34.6 \\
9.9 \\
2.7 \\
2.7 \\
62.0\end{array}$ & $\begin{array}{r}25.67 \\
28.50 \\
25.00 \\
7.70 \\
7.70\end{array}$ & $\begin{array}{r}42.0 \\
42.9 \\
31.1 \\
5.2 \\
5.2 \\
126.5\end{array}$ & $\begin{array}{r}25.5 \\
19.6 \\
17.9 \\
2.6 \\
2.6 \\
68.2\end{array}$ \\
\hline
\end{tabular}


Table D-1

Listing of Targets for Welds

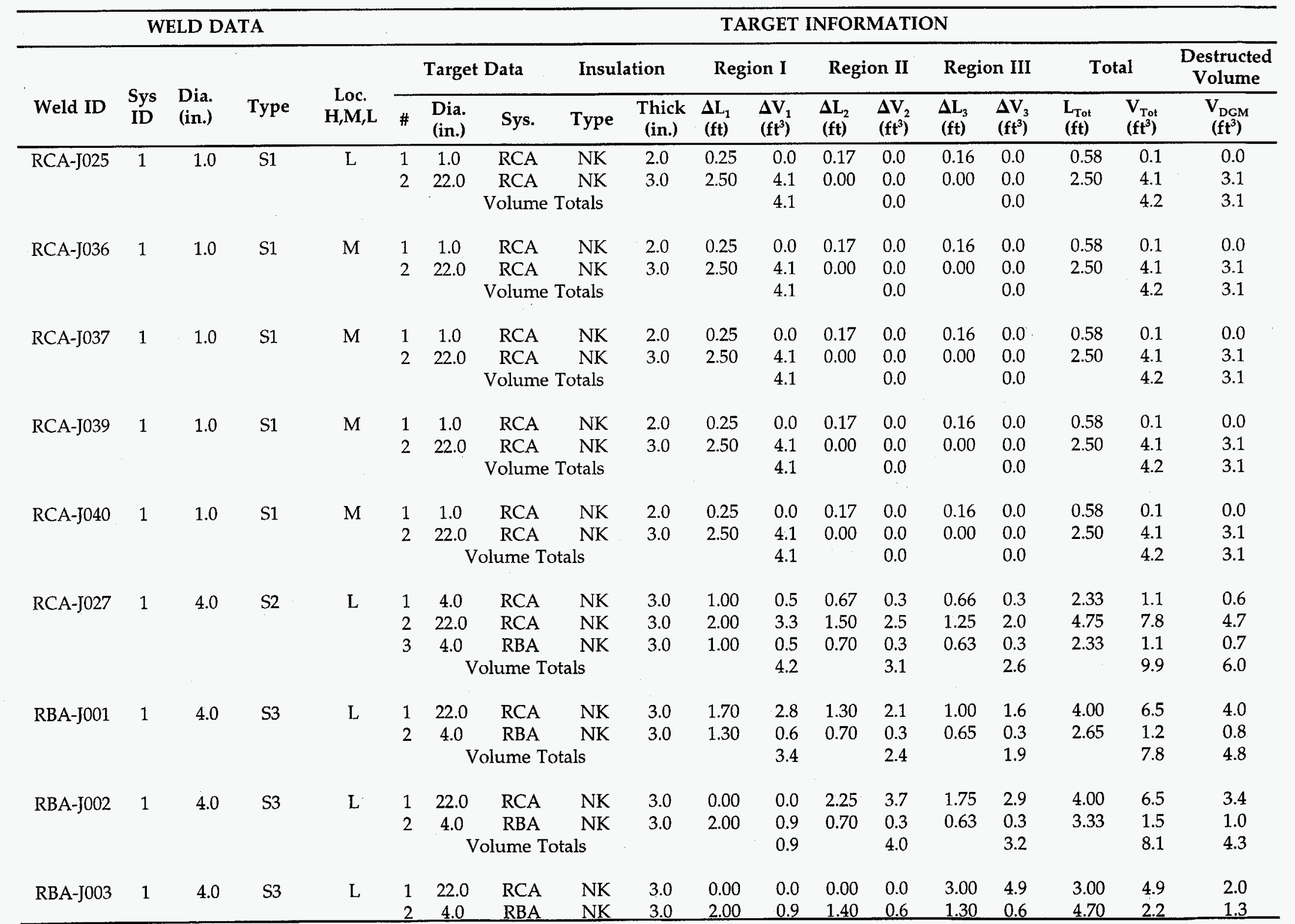




\begin{tabular}{|c|c|c|c|c|c|c|c|c|c|c|c|c|c|c|c|c|c|c|}
\hline \multicolumn{19}{|c|}{$\begin{array}{c}\text { Table D-1 } \\
\text { Listing of Targets for Welds }\end{array}$} \\
\hline \multicolumn{5}{|c|}{ WELD DATA } & \multicolumn{14}{|c|}{ TARGET INFORMATION } \\
\hline \multirow[b]{2}{*}{ Weld ID } & \multirow{2}{*}{$\begin{array}{l}\text { Sys } \\
\text { ID }\end{array}$} & \multirow{2}{*}{$\begin{array}{l}\text { Dia. } \\
\text { (in.) }\end{array}$} & \multirow[b]{2}{*}{ Type } & \multirow{2}{*}{$\begin{array}{c}\text { Loc. } \\
\text { H,M,L }\end{array}$} & \multicolumn{3}{|c|}{ Target Data } & \multicolumn{2}{|c|}{ Insulation } & \multicolumn{2}{|c|}{ Region I } & \multicolumn{2}{|c|}{ Region II } & \multicolumn{2}{|c|}{ Region III } & \multicolumn{2}{|c|}{ Total } & \multirow{2}{*}{$\begin{array}{c}\begin{array}{c}\text { Destructed } \\
\text { Volume }\end{array} \\
\begin{array}{c}V_{D G M} \\
\left(\mathrm{ft}^{3}\right)\end{array} \\
\end{array}$} \\
\hline & & & & & $\#$ & $\begin{array}{l}\text { Dia. } \\
\text { (in.) }\end{array}$ & Sys. & Type & $\begin{array}{c}\text { Thick } \\
\text { (in.) }\end{array}$ & $\begin{array}{l}\Delta \mathrm{L}_{1} \\
(\mathrm{ft})\end{array}$ & $\begin{array}{l}\Delta V_{1} \\
\left(\mathrm{ft}^{3}\right)\end{array}$ & $\begin{array}{l}\Delta \mathbf{L}_{2} \\
(\mathrm{ft})\end{array}$ & $\begin{array}{l}\Delta \mathbf{V}_{2} \\
\left(\mathrm{ft}^{3}\right)\end{array}$ & $\begin{array}{l}\Delta \mathbf{L}_{3} \\
(\mathrm{ft})\end{array}$ & $\begin{array}{l}\Delta V_{3} \\
\left(\mathrm{ft}^{3}\right)\end{array}$ & $\begin{array}{l}\mathbf{L}_{\text {Tot }} \\
(\mathrm{ft})\end{array}$ & $\begin{array}{l}V_{\text {Tot }} \\
\left(\mathrm{ft}^{3}\right)\end{array}$ & \\
\hline \multirow{4}{*}{ RBA-J006 } & \multirow{4}{*}{1} & \multirow{4}{*}{4.0} & \multirow{4}{*}{ S3 } & \multicolumn{7}{|c|}{ Volume Totals } & 0.9 & & 0.6 & & 5.5 & & 7.1 & 3.3 \\
\hline & & & & \multirow[t]{3}{*}{ L } & 1 & 22.0 & $\mathrm{RCA}$ & NK & 3.0 & 0.00 & 0.0 & 0.00 & 0.0 & 3.00 & 4.9 & 3.00 & 4.9 & 2.0 \\
\hline & & & & & 2 & 4.0 & RBA & NK & 3.0 & 2.00 & 0.9 & 1.40 & 0.6 & 1.30 & 0.6 & 4.70 & 2.2 & 1.3 \\
\hline & & & & & \multicolumn{4}{|c|}{ Volume Totals } & & & 0.9 & & 0.6 & & 5.5 & & 7.1 & 3.3 \\
\hline \multirow{3}{*}{ RBA-J007 } & \multirow[t]{3}{*}{1} & 4.0 & $\mathrm{~S} 3$ & $\mathrm{~L}$ & 1 & 22.0 & $\mathrm{RCA}$ & NK & 3.0 & 0.00 & 0.0 & 0.00 & 0.0 & 1.70 & 2.8 & 1.70 & 2.8 & 1.1 \\
\hline & & & & & 2 & 4.0 & $\mathrm{RBA}$ & NK & 3.0 & 1.00 & 0.5 & 0.70 & 0.3 & 0.63 & 0.3 & 2.33 & 1.1 & 0.7 \\
\hline & & & & & & & lume $\mathrm{T}$ & als & & & 0.5 & & 0.3 & & 3.1 & & 3.8 & 1.8 \\
\hline RBA-J008 & 1 & 4.0 & S3 & $\mathrm{L}$ & 1 & 22.0 & RCA & NK & 3.0 & 0.00 & 0.0 & 0.00 & 0.0 & 3.00 & 4.9 & 3.00 & 4.9 & 2.0 \\
\hline & & & & & 2 & 4.0 & RBA & NK & 3.0 & 2.00 & 0.9 & 1.40 & 0.6 & 1.25 & 0.6 & 4.65 & 2.1 & 1.3 \\
\hline & & & & & & & lume $\mathrm{T}$ & & & & 0.9 & & 0.6 & & 5.5 & & 7.0 & 3.3 \\
\hline RBA-J009 & 1 & 4.0 & $\mathrm{~S} 3$ & $\mathrm{~L}$ & 1 & 22.0 & RCA & NK & 3.0 & 0.00 & 0.0 & 0.00 & 0.0 & 3.00 & 4.9 & 3.00 & 4.9 & 2.0 \\
\hline & & & & & 2 & 4.0 & $\mathrm{RBA}$ & NK & 3.0 & 2.00 & 0.9 & 1.40 & 0.6 & 1.30 & 0.6 & 4.70 & 2.2 & 1.3 \\
\hline & & & & & & & ume $\mathrm{Tr}$ & & & & 0.9 & & 0.6 & & 5.5 & & 7.1 & 3.3 \\
\hline RBA-J010 & 1 & 4.0 & S3 & $\mathrm{L}$ & 1 & 22.0 & $\mathrm{RCA}$ & NK & 3.0 & 0.00 & 0.0 & 2.25 & 3.7 & 1.75 & 2.9 & 4.00 & 6.5 & 3.4 \\
\hline & & & & & 2 & 4.0 & RBA & NK & 3.0 & 2.00 & 0.9 & 0.70 & 0.3 & 0.63 & 0.3 & 3.33 & 1.5 & 1.0 \\
\hline & & & & & & & ume $\mathrm{T}$ & & & & 0.9 & & 4.0 & & 3.2 & & 8.1 & 4.3 \\
\hline RBA-J012 & 1 & 4.0 & S3 & M & 1 & 22.0 & RCA & NK & 3.0 & 1.70 & 2.8 & 1.30 & 2.1 & 1.00 & 1.6 & 4.00 & 6.5 & 4.0 \\
\hline & & & & & 2 & 4.0 & $\mathrm{RBA}$ & NK & 3.0 & 1.30 & 0.6 & 0.70 & 0.3 & 0.70 & 0.3 & 2.70 & 1.2 & 0.8 \\
\hline & & & & & & & ume $\mathrm{T}$ & & & & 3.4 & & 2.4 & & 2.0 & & 7.8 & 4.8 \\
\hline RCA-J034 & 1 & 4.0 & $\mathrm{~S} 2$ & M & 1 & 22.0 & RCA & NK & 3.0 & 2.00 & 3.3 & 1.50 & 2.5 & 1.25 & 2.0 & 4.75 & 7.8 & 4.7 \\
\hline & & & & & 2 & 4.0 & RBA & NK & 3.0 & 1.00 & 0.5 & 0.70 & 0.3 & 0.63 & 0.3 & 2.33 & 1.1 & 0.7 \\
\hline & & & & & & & lume $\mathrm{Tc}$ & & & & 3.7 & & 2.8 & & 2.3 & & 8.8 & 5.4 \\
\hline RMA-J006 & 1 & 22.0 & S1. & M & 1 & 22.0 & RMA & NK & 3.0 & 0.90 & 1.5 & 0.00 & 0.0 & 0.00 & 0.0 & 0.90 & 1.5 & 1.1 \\
\hline & & & & & 2 & 16.0 & RMA & NK & 3.0 & 5.50 & 6.8 & 3.70 & 4.6 & 3.65 & 4.5 & 12.85 & 16.0 & 9.7 \\
\hline & & & & & 3 & 10.0 & RRG & NK & 2.5 & 4.10 & 2.8 & 5.11 & 3.5 & 2.49 & 1.7 & 11.70 & 8.0 & 4.9 \\
\hline & & & & & 4 & 10.0 & RRF & NK & 2.5 & 4.10 & 2.8 & 5.11 & 3.5 & 2.49 & 1.7 & 11.70 & 8.0 & 4.9 \\
\hline & & & & & 5 & 22.0 & $\mathrm{RCA}$ & NK & 3.0 & 5.50 & 9.0 & 3.70 & 6.1 & 3.65 & 6.0 & 12.85 & 21.0 & 12.8 \\
\hline
\end{tabular}


Appendix D

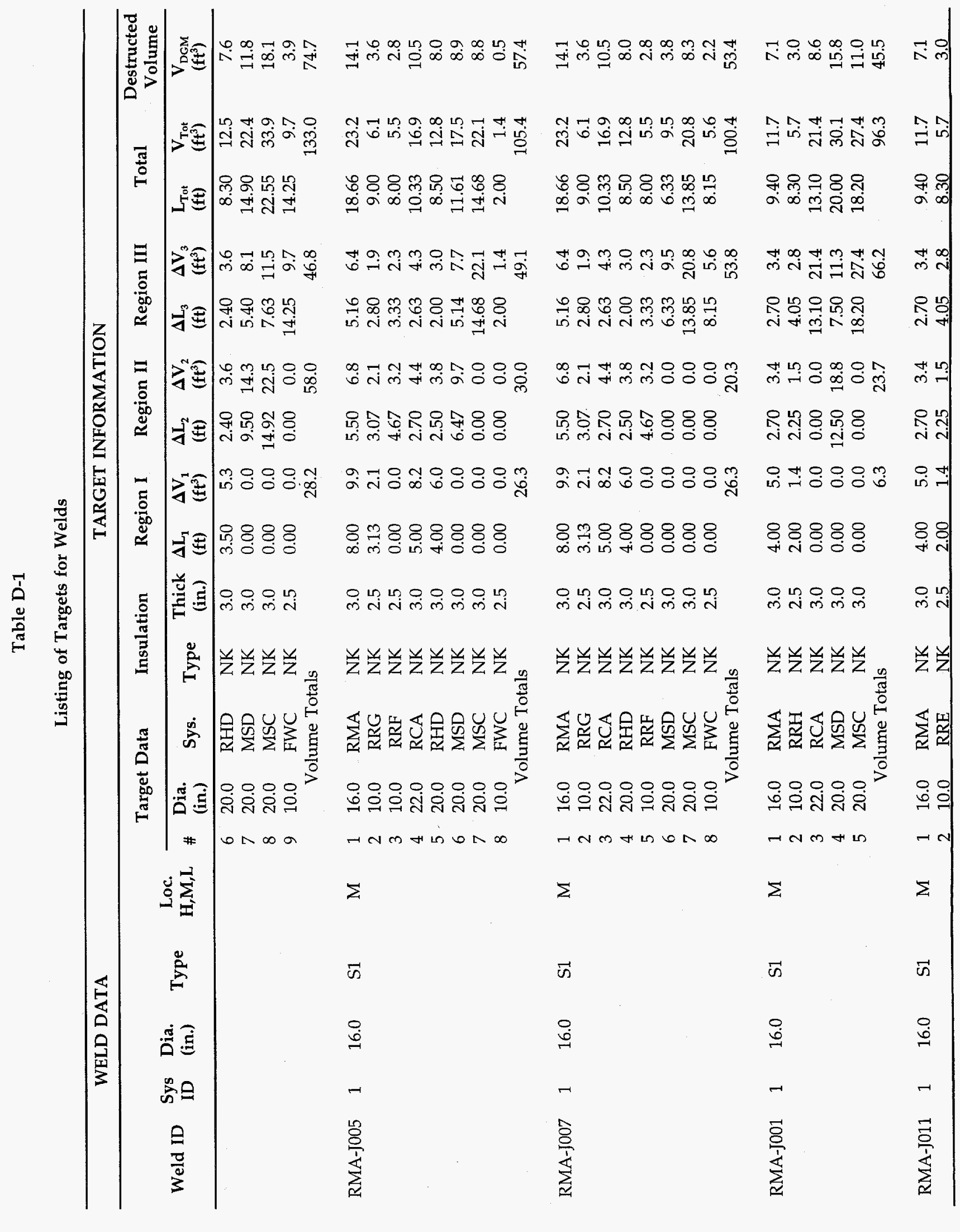




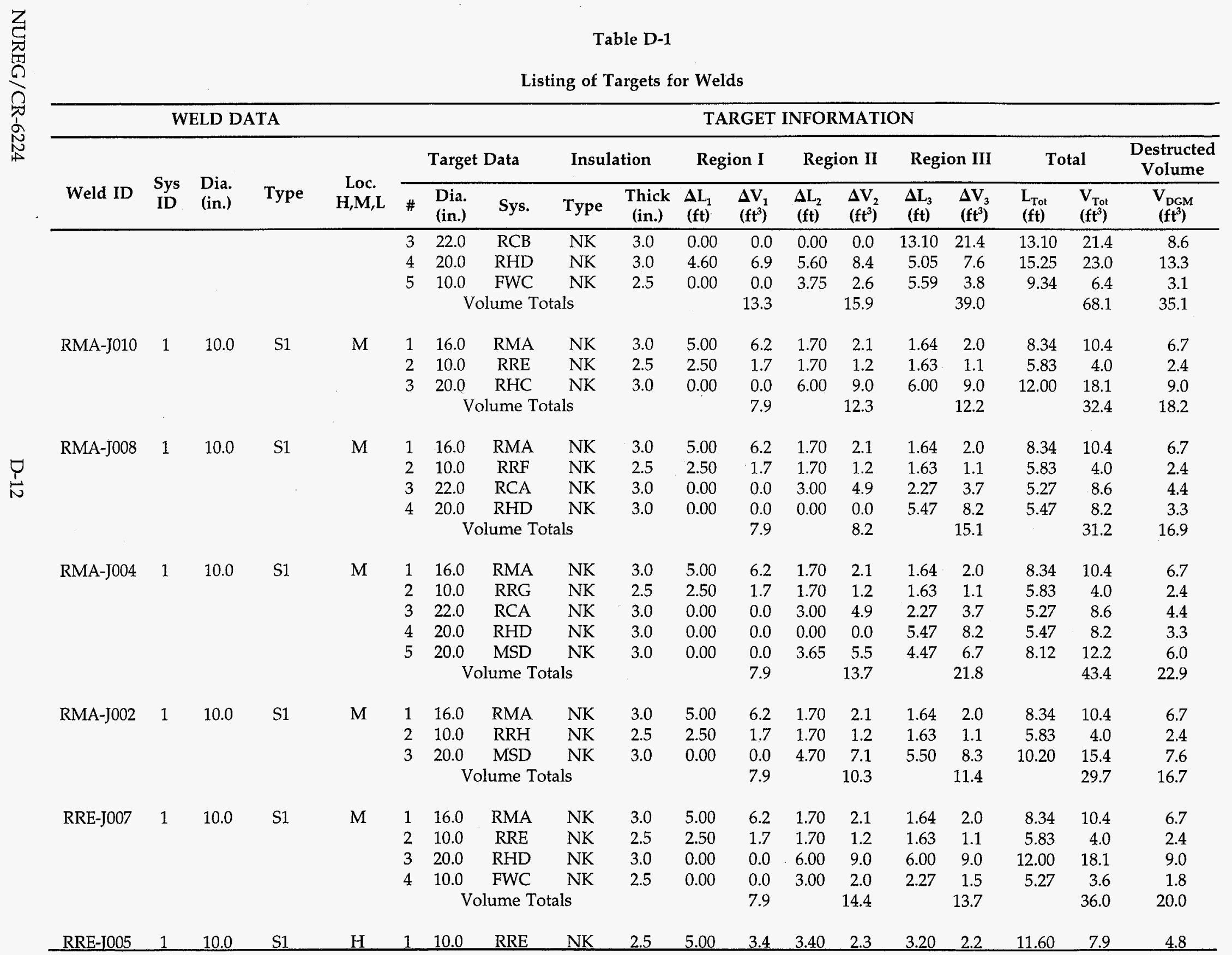


Table D-1

Listing of Targets for Welds

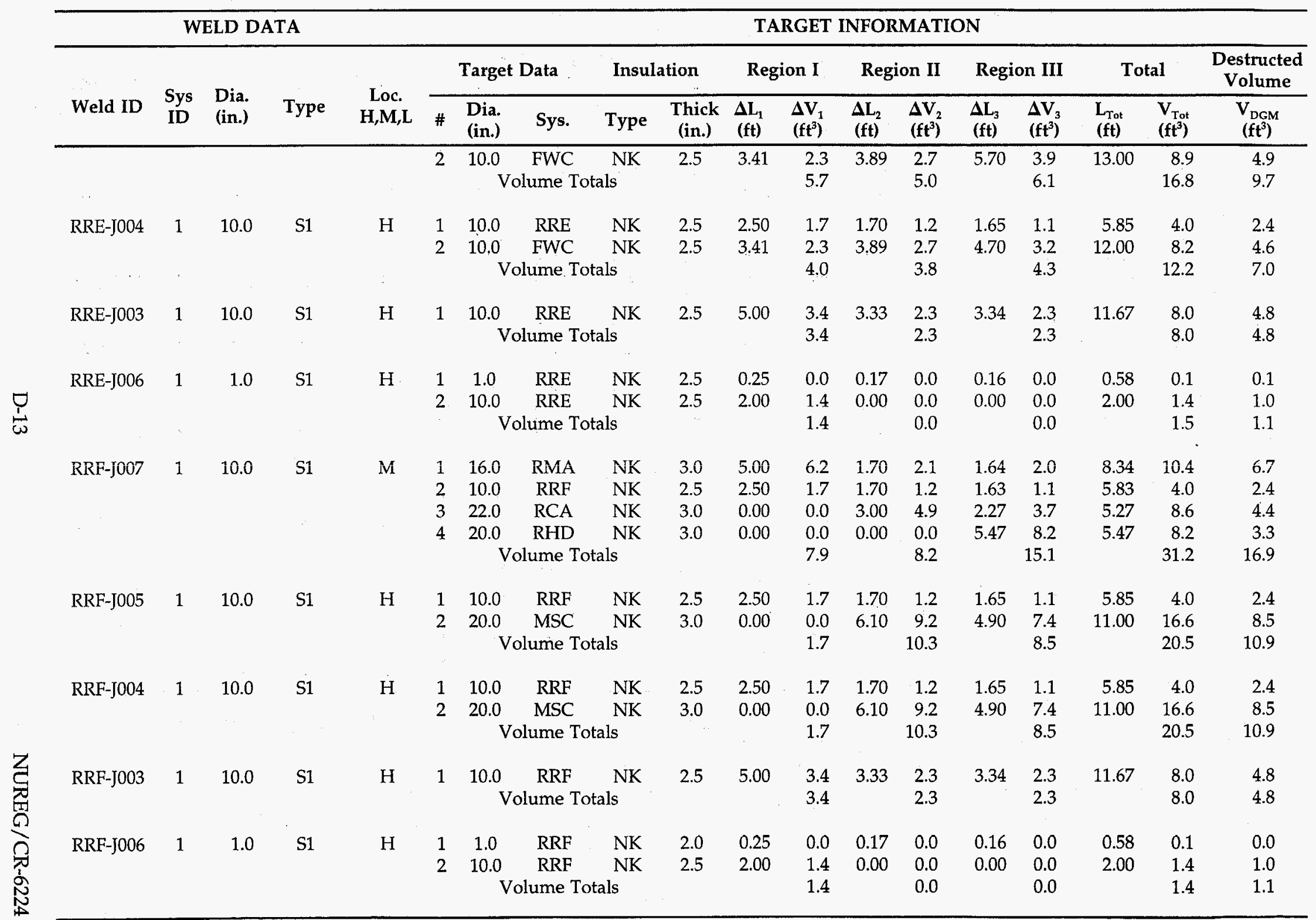


Table D-1

Listing of Targets for Welds

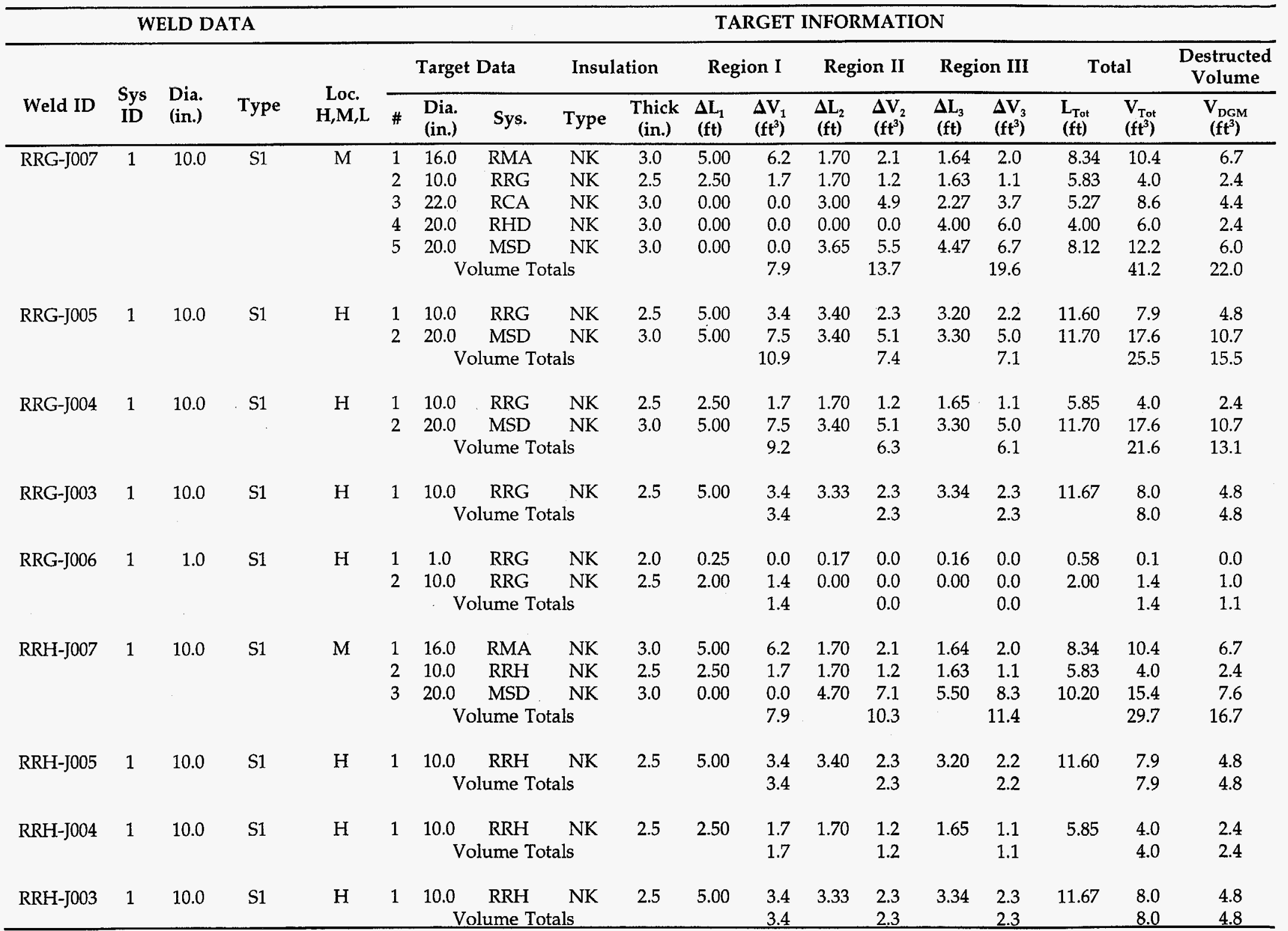


Table D-1

Listing of Targets for Welds

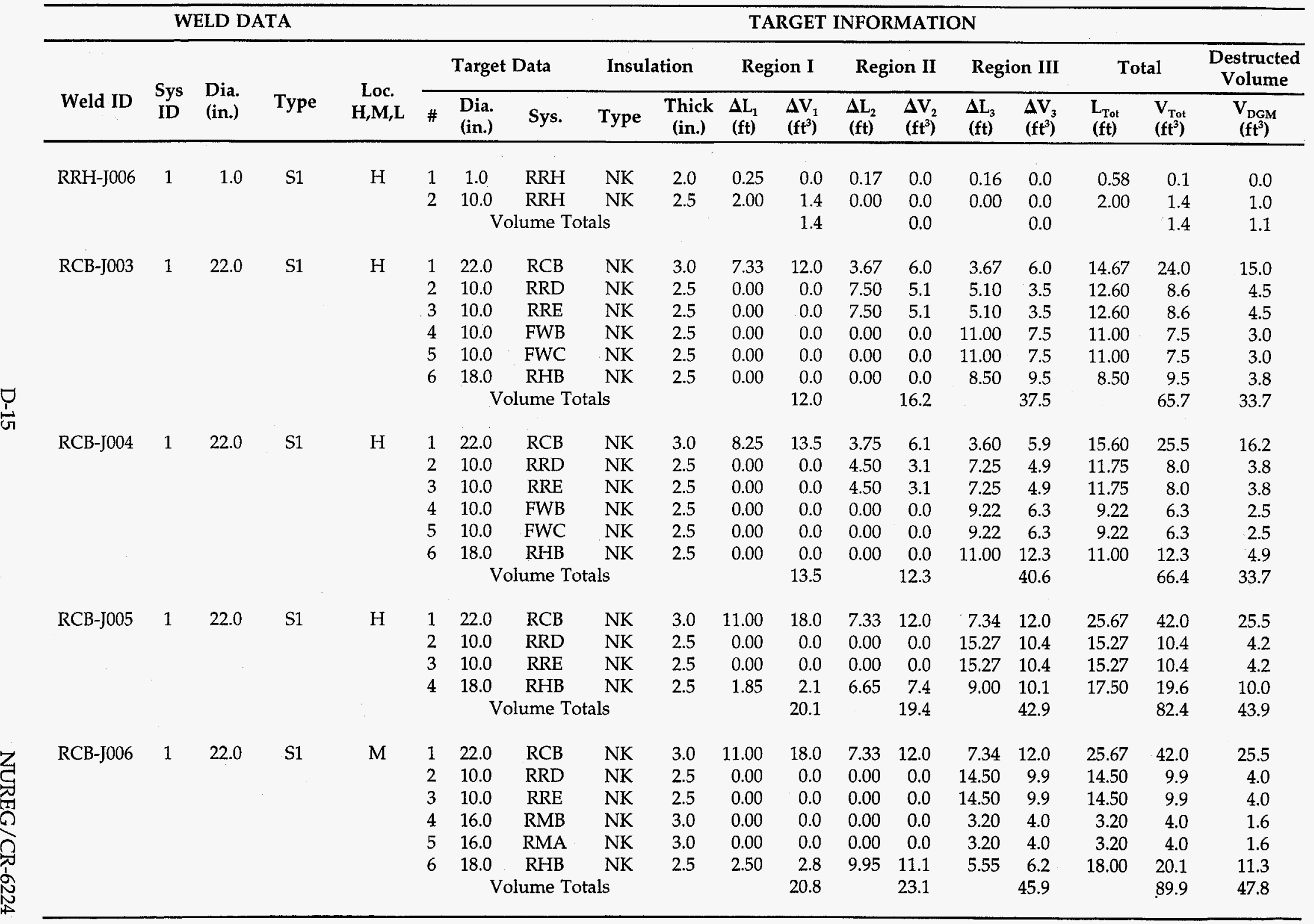




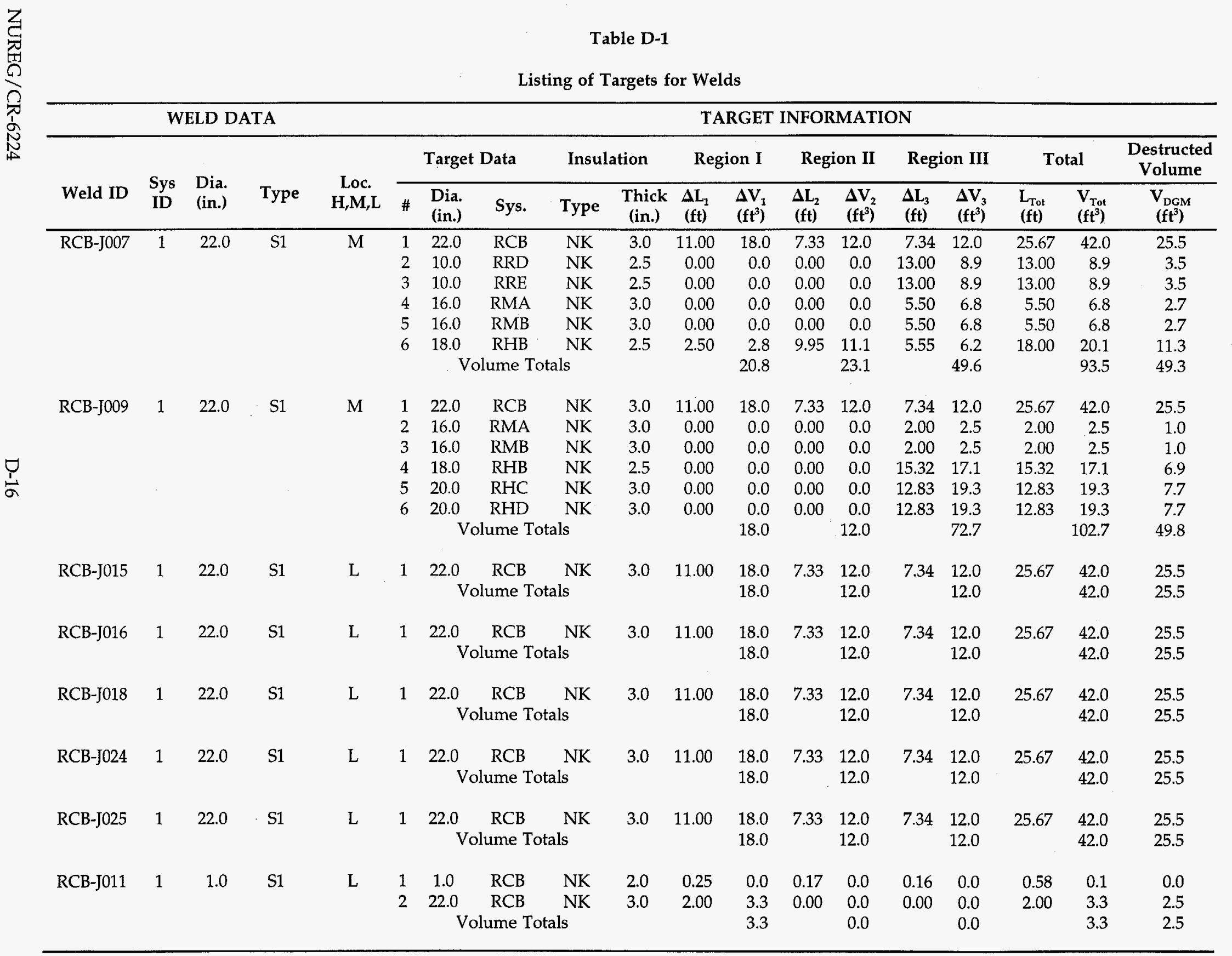


Table D-1

Listing of Targets for Welds

\begin{tabular}{|c|c|c|c|c|c|c|c|c|c|c|c|c|c|c|c|c|c|c|}
\hline \multicolumn{5}{|c|}{ WELD DATA } & \multicolumn{14}{|c|}{ TARGET INFORMATION } \\
\hline \multirow[b]{2}{*}{ Weld ID } & \multirow[b]{2}{*}{$\begin{array}{l}\text { Sys } \\
\text { ID }\end{array}$} & \multirow[b]{2}{*}{$\begin{array}{l}\text { Dia. } \\
\text { (in.) }\end{array}$} & \multirow[b]{2}{*}{ Type } & \multirow[b]{2}{*}{$\begin{array}{c}\text { Loc. } \\
\text { H,M,L }\end{array}$} & \multicolumn{3}{|c|}{ Target Data } & \multicolumn{2}{|c|}{ Insulation } & \multicolumn{2}{|c|}{ Region I } & \multicolumn{2}{|c|}{ Region II } & \multicolumn{2}{|c|}{ Region III } & \multicolumn{2}{|c|}{ Total } & \multirow{2}{*}{$\begin{array}{c}\begin{array}{c}\text { Destructed } \\
\text { Volume }\end{array} \\
\begin{array}{c}V_{\text {DGM }} \\
\left(\mathrm{ft}^{3}\right)\end{array}\end{array}$} \\
\hline & & & & & $\#$ & $\begin{array}{l}\text { Dia. } \\
\text { (in.) }\end{array}$ & Sys. & Type & $\begin{array}{c}\text { Thick } \\
\text { (in.) }\end{array}$ & $\begin{array}{l}\Delta \mathrm{L}_{1} \\
(\mathrm{ft})\end{array}$ & $\begin{array}{l}\Delta \mathbf{V}_{1} \\
\left(\mathbf{f t}^{3}\right)^{\prime}\end{array}$ & $\begin{array}{l}\Delta \mathrm{L}_{2} \\
(\mathrm{ft})\end{array}$ & $\begin{array}{l}\Delta \mathrm{V}_{2} \\
\left(\mathrm{ft}^{3}\right)\end{array}$ & $\begin{array}{l}\Delta \mathbf{L}_{3} \\
(\mathrm{ft})\end{array}$ & $\begin{array}{l}\Delta \mathbf{V}_{3} \\
\left(\mathrm{ft}^{3}\right)\end{array}$ & $\begin{array}{l}\mathrm{L}_{\text {Tot }} \\
(\mathrm{ft})\end{array}$ & $\begin{array}{l}V_{\text {Tot }} \\
\left(\mathrm{ft}^{3}\right)\end{array}$ & \\
\hline \multirow[t]{3}{*}{ RCB-J012 } & $\overline{1}$ & 1.0 & S1 & $\mathrm{L}$ & 1 & 1.0 & RCB & NK & 2.0 & 0.25 & 0.0 & 0.17 & 0.0 & 0.16 & 0.0 & 0.58 & 0.1 & 0.0 \\
\hline & & & & & 2 & 22.0 & $\mathrm{RCB}$ & NK & 3.0 & 2.00 & 3.3 & 0.00 & 0.0 & 0.00 & 0.0 & 2.00 & 3.3 & 2.5 \\
\hline & & & & \multicolumn{6}{|c|}{ Volume Totals } & & 3.3 & & 0.0 & & 0.0 & & 3.3 & 2.5 \\
\hline \multirow[t]{3}{*}{ RCB-J013 } & 1 & 1.0 & S1 & $\mathrm{L}$ & 1 & 1.0 & $\mathrm{RCB}$ & NK & 2.0 & 0.25 & 0.0 & 0.17 & 0.0 & 0.16 & 0.0 & 0.58 & 0.1 & 0.0 \\
\hline & & & & & 2 & 22.0 & $\mathrm{RCB}$ & NK & 3.0 & 2.00 & 3.3 & 0.00 & 0.0 & 0.00 & 0.0 & 2.00 & 3.3 & 2.5 \\
\hline & & & & \multicolumn{6}{|c|}{ Volume Totals } & & 3.3 & & 0.0 & & 0.0 . & & 3.3 & 2.5 \\
\hline \multirow[t]{3}{*}{ RCB-J019 } & 1 & 1.3 & S1 & $\mathrm{L}$ & 1 & 1.3 & $\mathrm{RCB}$ & NK & 3.0 & 0.31 & 0.1 & 0.21 & 0.1 & 0.21 & 0.1 & 0.73 & 0.2 & 0.1 \\
\hline & & & & & 2 & 22.0 & $\mathrm{RCB}$ & NK & 3.0 & 2.00 & 3.3 & 0.00 & 0.0 & 0.00 & 0.0 & 2.00 & 3.3 & 2.5 \\
\hline & & & & \multicolumn{6}{|c|}{ Volume Totals } & & 3.4 & & 0.1 & & 0.1 & & 3.5 & 2.6 \\
\hline \multirow[t]{3}{*}{ RCB-J021 } & 1 & 4.0 & S2 & $\mathrm{L}$ & 1 & 4.0 & $\mathrm{RCB}$ & NK & 2.5 & 1.00 & 0.4 & 0.67 & 0.2 & 0.66 & 0.2 & 2.33 & 0.8 & 0.5 \\
\hline & & & & & 2 & 22.0 & $\mathrm{RCB}$ & NK & 3.0 & 2.00 & 3.3 & 1.50 & 2.5 & 1.25 & 2.0 & 4.75 & 7.8 & 4.7 \\
\hline & & & & \multicolumn{6}{|c|}{ Volume Totals } & & 3.6 & & 2.7 & & 2.3 & & 8.6 & 5.2 \\
\hline \multirow[t]{3}{*}{ RCB-J022 } & 1 & 2.0 & S1 & $\mathrm{L}$ & 1 & 2.0 & $\mathrm{RCB}$ & NK & 2.0 & 0.50 & 0.1 & 0.33 & 0.1 & 0.34 & 0.1 & 1.17 & 0.2 & 0.1 \\
\hline & & & & & 2 & 22.0 & RCB & NK & 3.0 & 2.00 & 3.3 & 0.00 & 0.0 & 0.00 & 0.0 & 2.00 & 3.3 & 2.5 \\
\hline & & & & \multicolumn{6}{|c|}{ Volume Totals } & & 3.4 & & 0.1 & & 0.1 & & 3.5 & 2.6 \\
\hline \multirow[t]{3}{*}{ RCB-J023 } & 1 & 1.0 & S1 & $\mathrm{L}$ & 1 & 1.0 & RCB & NK & 2.0 & 0.25 & 0.0 & 0.17 & 0.0 & 0.16 & 0.0 & 0.58 & 0.1 & 0.0 \\
\hline & & & & & 2 & 22.0 & $\mathrm{RCB}$ & NK & 3.0 & 2.00 & 3.3 & 0.00 & 0.0 & 0.00 & 0.0 & 2.00 & 3.3 & 2.5 \\
\hline & & & & & & & ume $T$ & als & & & 3.3 & & 0.0 & & 0.0 & & 3.3 & 2.5 \\
\hline RCB-J027 & 1 & 22.0 & S1 & $\mathrm{L}$ & 1 & 22.0 & $\mathrm{RCB}$ & NK & 3.0 & 5.25 & 8.6 & 3.91 & 6.4 & 3.73 & 6.1 & 12.89 & 21.1 & 12.7 \\
\hline & & & & & & & ume $\mathrm{T}$ & & & & 8.6 & & 6.4 & & 6.1 & & 21.1 & 12.7 \\
\hline RCB-J031 & 1 & 22.0 & S1 & $\mathrm{L}$ & 1 & 22.0 & $\mathrm{RCB}$ & NK & 3.0 & 11.00 & 18.0 & 7.33 & 12.0 & 7.34 & 12.0 & 25.67 & 42.0 & 25.5 \\
\hline & & & & & & & ume $T$ & & & & 18.0 & & 12.0 & & 12.0 & & 42.0 & 25.5 \\
\hline${ }^{*} \mathrm{RCB}-\mathrm{J} 033$ & 1 & 22.0 & S1 & $\mathrm{L}$ & 1 & 22.0 & $\mathrm{RCB}$ & NK & 3.0 & 11.00 & 18.0 & 7.33 & 12.0 & 7.34 & 12.0 & 25.67 & 42.0 & 25.5 \\
\hline & & & & & & & ume $\mathrm{T}$ & & & & 18.0 & & 12.0 & & 12.0 & & 42.0 & 25.5 \\
\hline RCB-J035 & 1 & 22.0 & S1 & $\mathrm{L}$ & 1 & 22.0 & RCB & NK & 3.0 & 11.00 & 18.0 & 7.33 & 12.0 & 7.34 & 12.0 & 25.67 & 42.0 & 25.5 \\
\hline & & & & & & & ume $\mathrm{T}$ & & & & 18.0 & & 12.0 & & 12.0 & & 42.0 & 25.5 \\
\hline
\end{tabular}




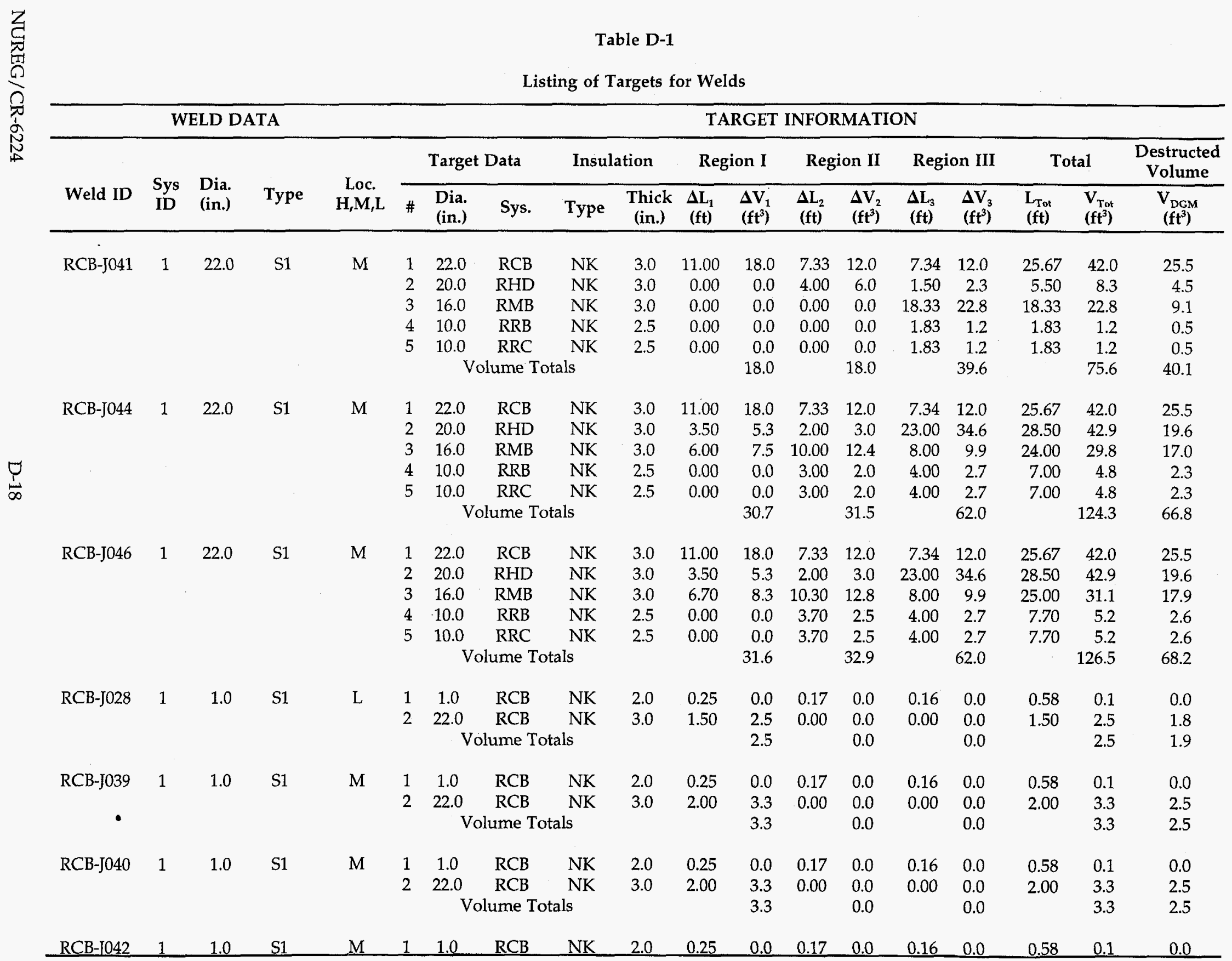


Table D-1

Listing of Targets for Welds

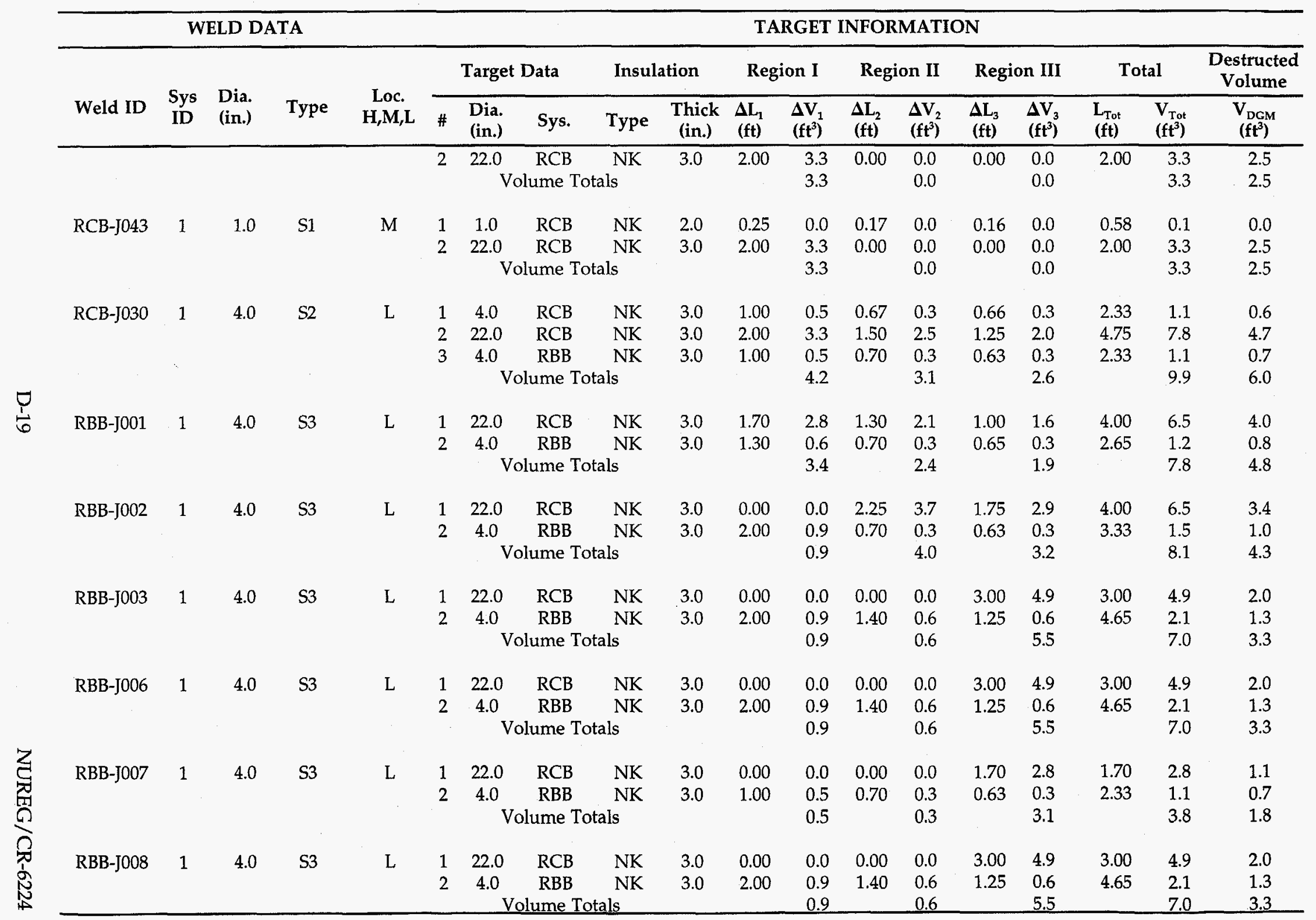


Table D-1

Listing of Targets for Welds

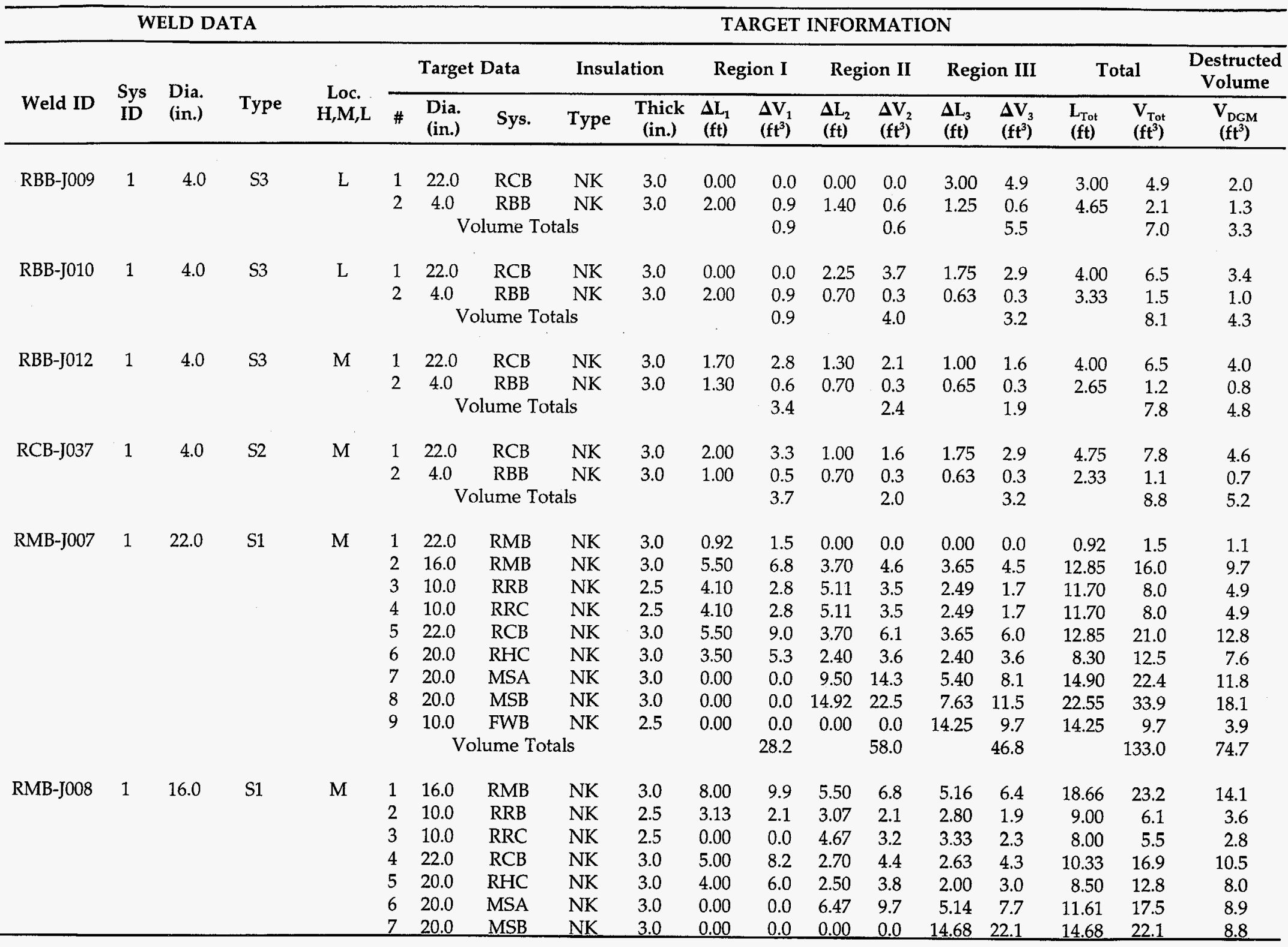


Table D-1

Listing of Targets for Welds

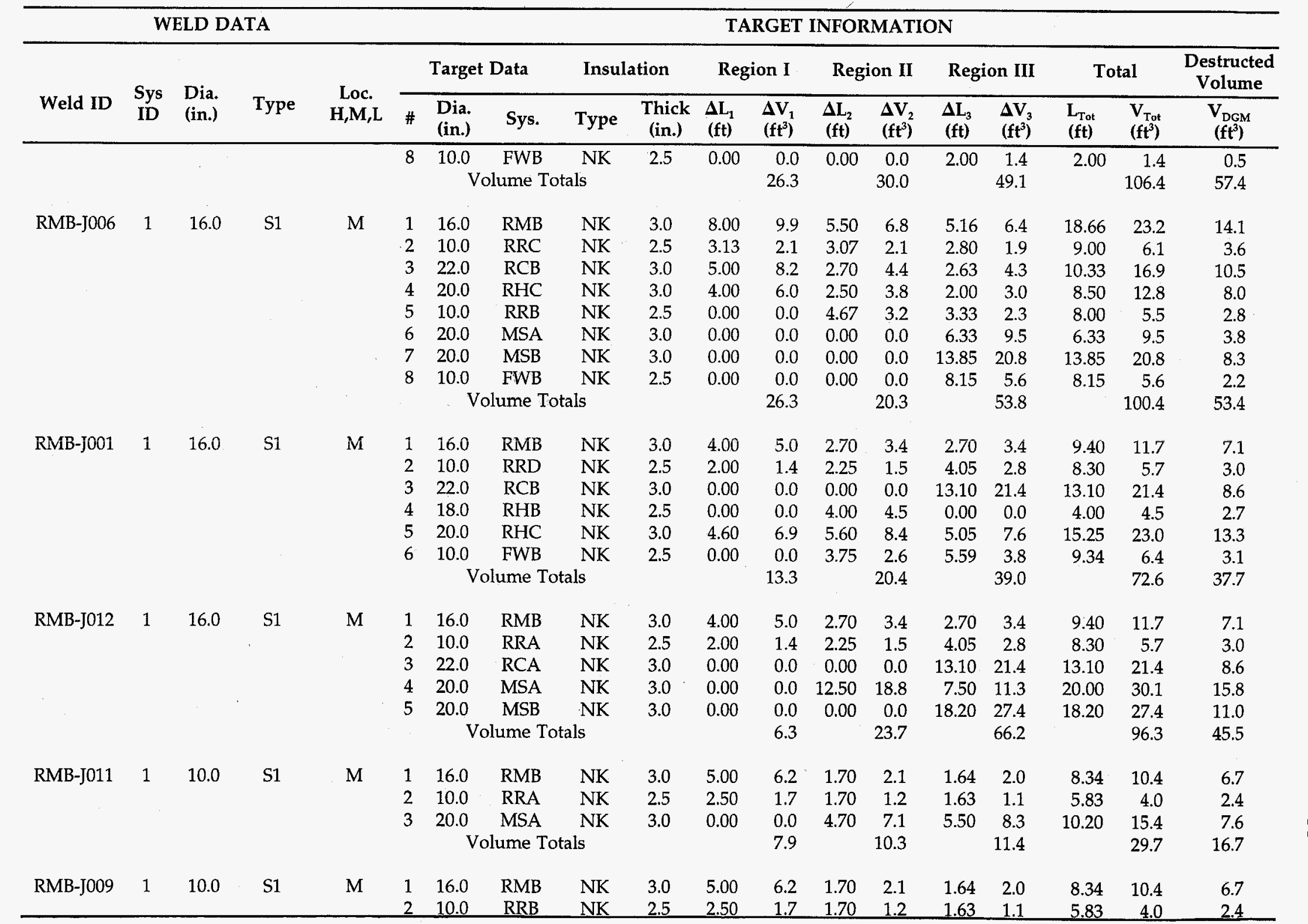




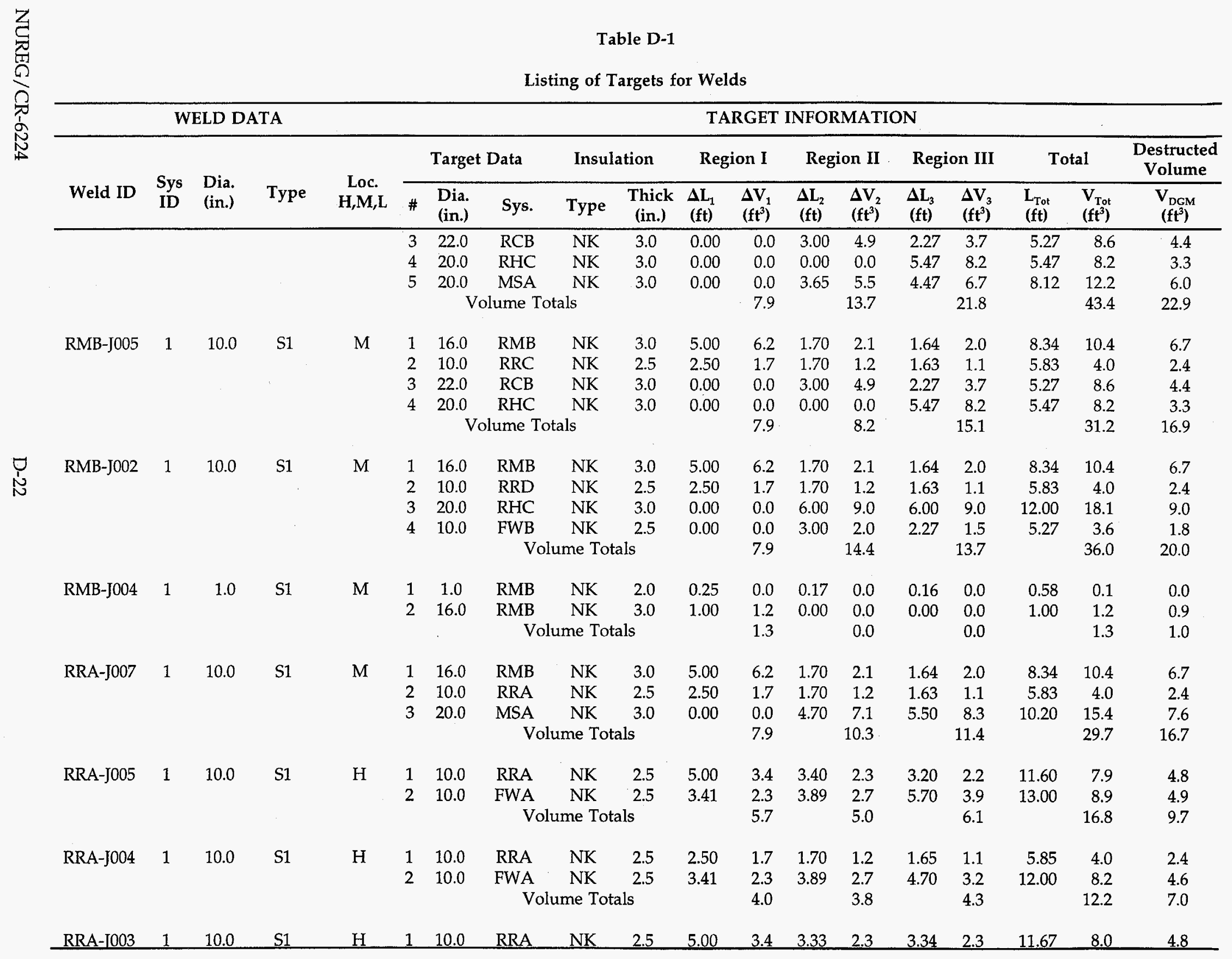


Table D-1

Listing of Targets for Welds

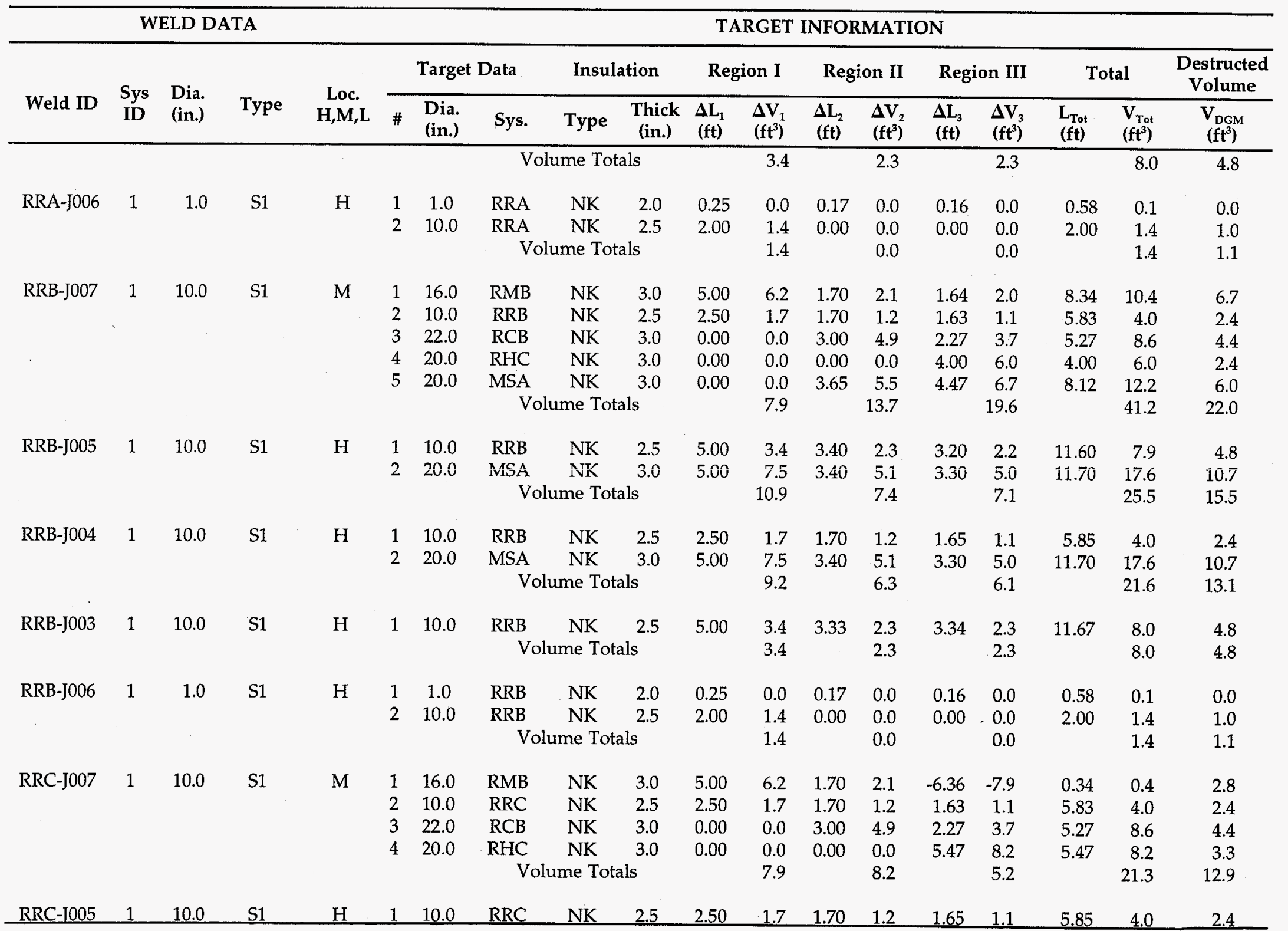


Table D-1

Listing of Targets for Welds

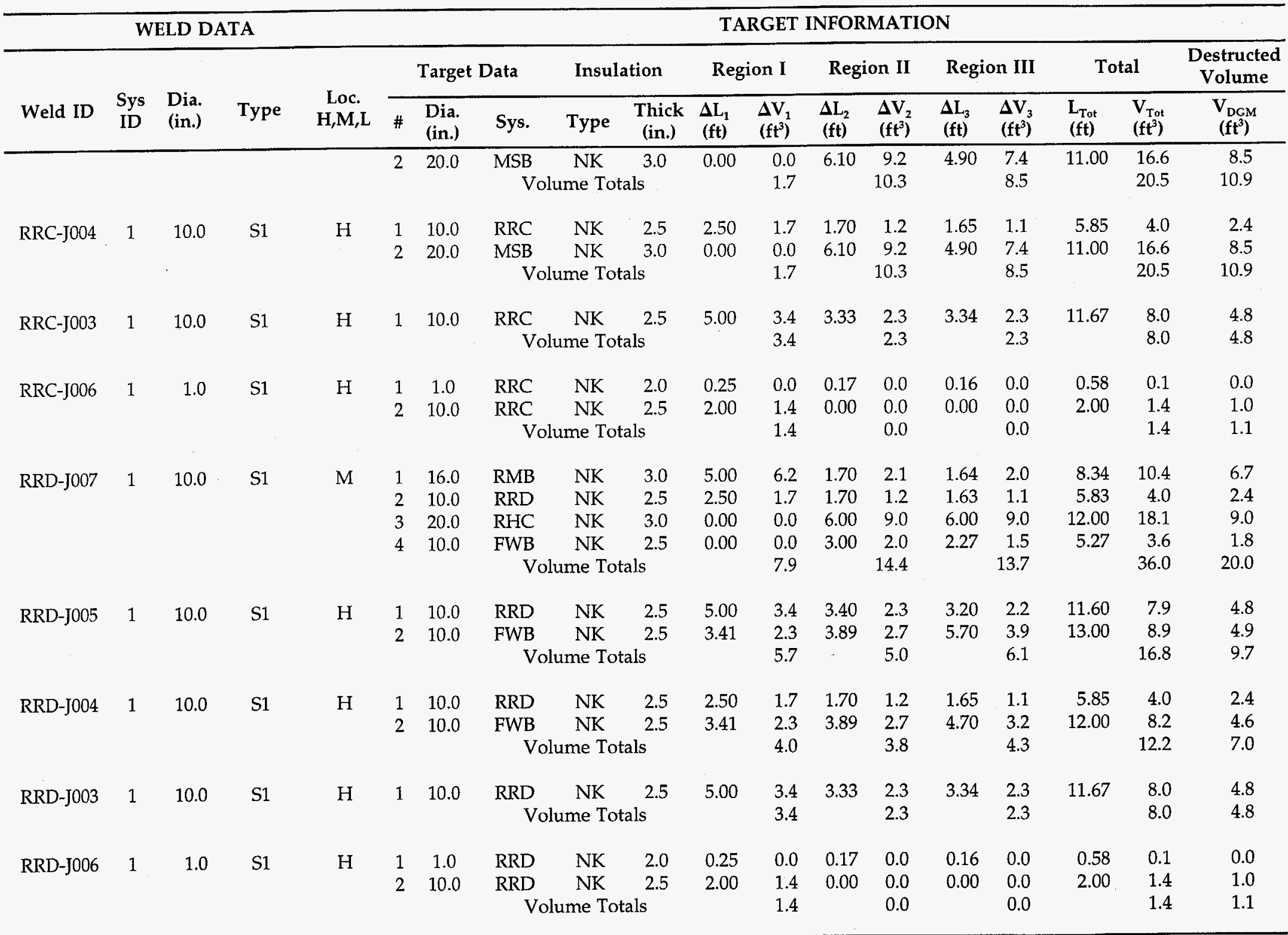


Table D-1

Listing of Targets for Welds

\begin{tabular}{|c|c|c|c|c|c|c|c|c|c|c|c|c|c|c|c|c|c|c|}
\hline \multicolumn{5}{|c|}{ WELD DATA } & \multicolumn{14}{|c|}{ TARGET INFORMATION } \\
\hline \multirow[b]{2}{*}{ Weld ID } & \multirow{2}{*}{$\begin{array}{l}\text { Sys } \\
\text { ID }\end{array}$} & \multirow{2}{*}{$\begin{array}{l}\text { Dia. } \\
\text { (in.) }\end{array}$} & \multirow[b]{2}{*}{ Type } & \multirow{2}{*}{$\begin{array}{c}\text { Loc. } \\
\text { H,M,L }\end{array}$} & \multicolumn{3}{|c|}{ Target Data } & \multicolumn{2}{|c|}{ Insulation } & \multicolumn{2}{|c|}{ Region I } & \multicolumn{2}{|c|}{ Region II } & \multicolumn{2}{|c|}{ Region III } & \multicolumn{2}{|c|}{ Total } & \multirow{2}{*}{$\begin{array}{c}\begin{array}{c}\text { Destructed } \\
\text { Volume }\end{array} \\
\begin{array}{c}\mathbf{V}_{\mathrm{DGM}} \\
\left(\mathrm{ft}^{3}\right)\end{array}\end{array}$} \\
\hline & & & & & $\#$ & $\begin{array}{l}\text { Dia. } \\
\text { (in.) }\end{array}$ & Sys. & Type & $\begin{array}{c}\text { Thick } \\
\text { (in.) }\end{array}$ & $\begin{array}{l}\Delta \mathrm{L}_{1} \\
(\mathrm{ft})\end{array}$ & $\begin{array}{l}\Delta \mathrm{V}_{1} \\
\left(\mathrm{ft}^{3}\right)\end{array}$ & $\begin{array}{l}\Delta \mathrm{L}_{2} \\
(\mathrm{ft})\end{array}$ & $\begin{array}{l}\Delta V_{2} \\
\left(\mathrm{ft}^{3}\right)\end{array}$ & $\begin{array}{l}\Delta \mathrm{L}_{3} \\
(\mathrm{ft})\end{array}$ & $\begin{array}{l}\Delta V_{3} \\
\left(f^{3}\right)^{3}\end{array}$ & $\begin{array}{l}\mathrm{L}_{\text {Tot }} \\
(\mathrm{ft})\end{array}$ & $\begin{array}{l}V_{\text {Tot }} \\
\left(\mathrm{ft}^{3}\right)\end{array}$ & \\
\hline FWA-J002 & 3 & 10.0 & $\mathrm{C4}$ & $\mathrm{H}$ & 1 & 10.0 & FWA & NK & 2.5 & 3.33 & 2.3 & 1.67 & 1.1 & 1.67 & 1.1 & 6.67 & 4.5 & 2.8 \\
\hline & & & & & & \multicolumn{4}{|c|}{ Volume Totals } & & 2.3 & & 1.1 & & 1.1 & & 4.5 & 2.8 \\
\hline FWA-J003 & 3 & 10.0 & C3 & $\mathrm{H}$ & 1 & 10.0 & FWA & NK & 2.5 & 4.17 & 2.8 & 1.66 & 1.1 & 1.67 & 1.1 & 7.50 & 5.1 & 3.3 \\
\hline & & & & & & \multicolumn{4}{|c|}{ Volume Totals } & & 2.8 & & 1.1 & & 1.1 & & 5.1 & 3.3 \\
\hline FWA-J005 & 3 & 10.0 & C3 & $\mathrm{H}$ & 1 & 10.0 & FWA & NK & 2.5 & 4.67 & 3.2 & 1.66 & 1.1 & 1.67 & 1.1 & 8.00 & 5.5 & 3.5 \\
\hline & & & & & & \multicolumn{4}{|c|}{ Volume Totals } & & 3.2 & & 1.1 & & 1.1 & & 5.5 & 3.5 \\
\hline FWA-J006 & 3 & 10.0 & $\mathrm{C} 3$ & $\mathrm{H}$ & 1 & 10.0 & FWA & NK & 2.5 & 5.00 & 3.4 & 3.33 & 2.3 & 2.50 & 1.7 & 10.83 & 7.4 & 4.6 \\
\hline & & & & & & & \multicolumn{3}{|c|}{ Volume Totals } & & 3.4 & & 2.3 & & 1.7 & & 7.4 & 4.6 \\
\hline FWA-J007 & 3 & 10.0 & $\mathrm{C} 3$ & $\mathrm{H}$ & 1 & 10.0 & FWA & NK & 2.5 & 5.00 & 3.4 & 3.33 & 2.3 & 3.34 & 2.3 & 11.67 & 8.0 & 4.8 \\
\hline & & & & & & & \multicolumn{3}{|c|}{ Volume Totals } & & 3.4 & & 2.3 & & 2.3 & & 8.0 & 4.8 \\
\hline \multirow[t]{3}{*}{ FWA-J008 } & 3 & 10.0 & $\mathrm{C} 3$ & $\mathrm{H}$ & 1 & 10.0 & FWA & NK & 2.5 & 5.00 & 3.4 & 3.33 & 2.3 & 3.34 & 2.3 & 11.67 & 8.0 & 4.8 \\
\hline & & & & & 2 & 10.0 & RRA & NK & 2.5 & 0.00 & 0.0 & 0.00 & 0.0 & 4.00 & 2.7 & 4.00 & 2.7 & 1.1 \\
\hline & & & & & & \multicolumn{4}{|c|}{ Volume Totals } & & 3.4 & & 2.3 & & 5.0 & & 10.7 & 5.9 \\
\hline \multirow[t]{3}{*}{ FWA-J009 } & 3 & 10.0 & $\mathrm{C} 3$ & $\mathrm{H}$ & 1 & 10.0 & FWA & NK & 2.5 & 5.00 & 3.4 & 3.33 & 2.3 & 3.34 & 2.3 & 11.67 & 8.0 & 4.8 \\
\hline & & & & & 2 & 10.0 & RRA & NK & 2.5 & 2.76 & 1.9 & 4.46 & 3.0 & 3.44 & 2.3 & 10.66 & 7.3 & 4.2 \\
\hline & & & & & & \multicolumn{4}{|c|}{ Volume Totals } & & 5.3 & & 5.3 & & 4.6 & & 15.2 & 9.0 \\
\hline \multirow[t]{4}{*}{ FWA-J010 } & 3 & 10.0 & $\mathrm{C} 3$ & $\mathrm{H}$ & 1 & 10.0 & FWA & NK & 2.5 & 5.00 & 3.4 & 3.33 & 2.3 & 3.34 & 2.3 & 11.67 & 8.0 & 4.8 \\
\hline & & & & & 2 & 10.0 & RRA & NK & 2.5 & 2.00 & 1.4 & 4.96 & 3.4 & 3.61 & 2.5 & 10.57 & 7.2 & 4.0 \\
\hline & & & & & 3 & 20.0 & MSA & NK & 3.0 & 0.00 & 0.0 & 0.00 & 0.0 & 7.20 & 10.8 & 7.20 & 10.8 & 4.3 \\
\hline & & & & & & \multicolumn{4}{|c|}{ Volume Totals } & & 4.8 & & 5.7 & & 15.6 & & 26.0 & 13.2 \\
\hline FWA-J011 & 3 & 10.0 & $\mathrm{C} 3$ & $\mathrm{H}$ & 1 & 10.0 & FWA & NK & 2.5 & 5.00 & 3.4 & 3.33 & 2.3 & 3.34 & 2.3 & 11.67 & 8.0 & 4.8 \\
\hline & & & & & 2 & 10.0 & FWB & NK & 2.5 & 0.00 & 0.0 & 0.00 & 0.0 & 5.88 & 4.0 & 5.88 & 4.0 & 1.6 \\
\hline & & & & & 3 & 20.0 & MSB & NK & 3.0 & 0.00 & 0.0 & 0.00 & 0.0 & 6.60 & 9.9 & 6.60 & 9.9 & 4.0 \\
\hline & & & & & & & & me Tot & & & 3.4 & & 2.3 & & 16.2 & & 21.9 & 10.4 \\
\hline FWA-J012 & 3 & 10.0 & C3 & $\mathrm{H}$ & 1 & 10.0 & FWA & NK & 2.5 & 5.00 & 3.4 & 3.33 & 2.3 & 3.34 & 2.3 & 11.67 & 8.0 & 4.8 \\
\hline & & & & & 2 & 10.0 & FWB & NK & 2.5 & 0.00 & 0.0 & 0.00 & 0.0 & 5.25 & 3.6 & 5.25 & 3.6 & 1.4 \\
\hline
\end{tabular}


Table D-1

Listing of Targets for Welds

\begin{tabular}{|c|c|c|c|c|c|c|c|c|c|c|c|c|c|c|c|c|c|c|}
\hline \multirow[b]{3}{*}{ Weld ID } & \multicolumn{4}{|c|}{ WELD DATA } & \multicolumn{14}{|c|}{ TARGET INFORMATION } \\
\hline & \multirow[b]{2}{*}{$\begin{array}{l}\text { Sys } \\
\text { ID }\end{array}$} & \multirow{2}{*}{$\begin{array}{l}\text { Dia. } \\
\text { (in.) }\end{array}$} & \multirow[b]{2}{*}{ Type } & \multirow{2}{*}{$\begin{array}{c}\text { Loc. } \\
\text { H,M,L }\end{array}$} & \multicolumn{3}{|c|}{ Target Data } & \multicolumn{2}{|c|}{ Insulation } & \multicolumn{2}{|c|}{ Region I } & \multicolumn{2}{|c|}{ Region II } & \multicolumn{2}{|c|}{ Region III } & \multicolumn{2}{|c|}{ Total } & \multirow{2}{*}{$\begin{array}{c}\begin{array}{c}\text { Destructed } \\
\text { Volume }\end{array} \\
\begin{array}{c}V_{\text {DGM }} \\
\left(\mathbf{f t}^{\mathbf{3}}\right)\end{array}\end{array}$} \\
\hline & & & & & \# & $\begin{array}{l}\text { Dia. } \\
\text { (in.) }\end{array}$ & Sys. & Type & $\begin{array}{c}\text { Thick } \\
\text { (in.) }\end{array}$ & $\begin{array}{l}\Delta \mathbf{L}_{1} \\
(\mathrm{ft})\end{array}$ & $\begin{array}{l}\Delta V_{1} \\
\left(f^{3}\right)^{\prime}\end{array}$ & $\begin{array}{l}\Delta \mathbf{L}_{2} \\
(\mathrm{ft})\end{array}$ & $\begin{array}{l}\Delta V_{2} \\
\left(f^{3}\right)^{3}\end{array}$ & $\begin{array}{l}\Delta \mathrm{L}_{3} \\
(\mathrm{ft})\end{array}$ & $\begin{array}{l}\Delta \mathbf{V}_{3} \\
\left(\mathrm{ft}^{3}\right)\end{array}$ & $\begin{array}{l}\mathbf{L}_{\text {Tot }} \\
(\mathbf{f t})\end{array}$ & $\begin{array}{l}V_{\text {Tot }} \\
\left(\mathrm{ft}^{3}\right)\end{array}$ & \\
\hline & & & & & 3 & 10.0 & PSA & NK & 2.5 & 0.00 & 0.0 & 0.00 & 0.0 & 3.86 & 2.6 & 3.86 & 2.6 & 1.1 \\
\hline & & & & & 4 & 20.0 & MSB & NK & 3.0 & 0.00 & 0.0 & 0.00 & 0.0 & 6.25 & 9.4 & 6.25 & 9.4 & 3.8 \\
\hline & & & & & & \multicolumn{4}{|c|}{ Volume Totals } & & 3.4 & & 2.3 & & 17.9 & & 23.6 & 11.1 \\
\hline FWA-J014 & 3 & 10.0 & $\mathrm{C} 3$ & $\mathrm{H}$ & 1 & 10.0 & FWA & NK & 2.5 & 5.00 & 3.4 & 3.33 & 2.3 & 3.34 & 2.3 & 11.67 & 8.0 & 4.8 \\
\hline & & & & & 2 & 10.0 & FWB & NK & 2.5 & 0.00 & 0.0 & 0.00 & 0.0 & 6.01 & 4.1 & 6.01 & 4.1 & 1.6 \\
\hline & & & & & 3 & 10.0 & PSA & NK & 2.5 & 0.00 & 0.0 & 0.00 & 0.0 & 3.86 & 2.6 & 3.86 & 2.6 & 1.1 \\
\hline & & & & & 4 & 20.0 & MSB & NK & 3.0 & 0.00 & 0.0 & 0.00 & 0.0 & 2.94 & 4.4 & 2.94 & 4.4 & 1.8 \\
\hline & & & & & & \multicolumn{4}{|c|}{ Volume Totals } & & 3.4 & & 2.3 & & 13.4 & & 19.1 & 9.3 \\
\hline \multirow[t]{6}{*}{ FWA-J015 } & 3 & 10.0 & $\mathrm{C} 3$ & $\mathrm{H}$ & 1 & 10.0 & FWA & NK & 2.5 & 5.00 & 3.4 & 3.33 & 2.3 & 3.34 & 2.3 & 11.67 & 8.0 & 4.8 \\
\hline & & & & & 2 & 10.0 & PSA & NK & 2.5 & 0.00 & 0.0 & 0.00 & 0.0 & 6.47 & 4.4 & 6.47 & 4.4 & 1.8 \\
\hline & & & & & 3 & 20.0 & MSB & NK & 3.0 & 0.00 & 0.0 & 0.00 & 0.0 & 1.13 & 1.7 & 1.13 & 1.7 & 0.7 \\
\hline & & & & & 4 & 10.0 & FWB & NK & 2.5 & 0.00 & 0.0 & 2.60 & 1.8 & 2.73 & 1.9 & 5.33 & 3.6 & 1.8 \\
\hline & & & & & 5 & 16.0 & FWA & NK & 2.5 & 0.00 & 0.0 & 0.00 & 0.0 & 0.97 & 1.0 & 0.97 & 1.0 & 0.4 \\
\hline & & & & & & \multicolumn{4}{|c|}{ Volume Totals } & & 3.4 & & 4.0 & & 11.2 & & 18.7 & 9.5 \\
\hline \multirow[t]{6}{*}{ FWA-J016 } & 3 & 10.0 & $\mathrm{C} 3$ & $\mathrm{H}$ & 1 & 10.0 & FWA & NK & 2.5 & 2.50 & 1.7 & 1.67 & 1.1 & 1.66 & 1.1 & 5.83 & 4.0 & 2.4 \\
\hline & & & & & 2 & 10.0 & PSA & NK & 2.5 & 0.00 & 0.0 & 7.33 & 5.0 & 3.67 & 2.5 & 11.00 & 7.5 & 4.0 \\
\hline & & & & & 3 & 20.0 & MSB & NK & 3.0 & 0.00 & 0.0 & 4.75 & 7.2 & 4.52 & 6.8 & 9.27 & 14.0 & 7.0 \\
\hline & & & & & 4 & 10.0 & FWB & NK & 2.5 & 3.30 & 2.2 & 1.68 & 1.1 & 1.67 & 1.1 & 6.65 & 4.5 & 2.8 \\
\hline & & & & & 5 & 16.0 & FWA & NK & 2.5 & 0.00 & 0.0 & 2.34 & 2.4 & 2.31 & 2.3 & 4.65 & 4.7 & 2.3 \\
\hline & & & & & & \multicolumn{4}{|c|}{ Volume Totals } & & 4.0 & & 16.8 & & 13.9 & & 34.7 & 18.6 \\
\hline \multirow[t]{7}{*}{ FWA-J027 } & 3 & 16.0 & $\mathrm{C} 3$ & $\mathrm{H}$ & 1 & 16.0 & FWA & NK & 2.5 & 8.00 & 8.1 & 5.33 & 5.4 & 5.34 & 5.4 & 18.67 & 18.8 & 11.4 \\
\hline & & & & & 2 & 10.0 & PSA & NK & 2.5 & 6.27 & 4.3 & 3.99 & 2.7 & 2.84 & 1.9 & 13.10 & 8.9 & 5.6 \\
\hline & & & & & 3 & 20.0 & MSB & NK & 3.0 & 0.41 & 0.6 & 9.44 & 14.2 & 6.05 & 9.1 & 15.90 & 23.9 & 12.6 \\
\hline & & & & & 4 & 10.0 & FWB & NK & 2.5 & 3.33 & 2.3 & 3.25 & 2.2 & 2.65 & 1.8 & 9.23 & 6.3 & 3.8 \\
\hline & & & & & 5 & 20.0 & MSA & NK & 3.0 & 0.00 & 0.0 & 0.00 & 0.0 & 11.92 & 17.9 & 11.92 & 17.9 & 7.2 \\
\hline & & & & & 6 & 10.0 & FWA & NK & 2.5 & 2.24 & 1.5 & 2.56 & 1.7 & 6.30 & 4.3 & 11.10 & 7.6 & 3.9 \\
\hline & & & & & & \multicolumn{4}{|c|}{ Volume Totals } & & 16.8 & & 26.3 & & 40.5 & & 83.5 & 44.5 \\
\hline FWA-J028 & 3 & 16.0 & $\mathrm{C} 3$ & M & 1 & 16.0 & FWA & NK & 2.5 & 8.00 & 8.1 & 5.33 & 5.4 & 5.34 & 5.4 & 18.67 & 18.8 & 11.4 \\
\hline & & & & & 2 & 10.0 & PSA & NK & 2.5 & 5.62 & 3.8 & 3.65 & 2.5 & -2.25 & -1.5 & 7.02 & 4.8 & 3.8 \\
\hline
\end{tabular}


Appendix D

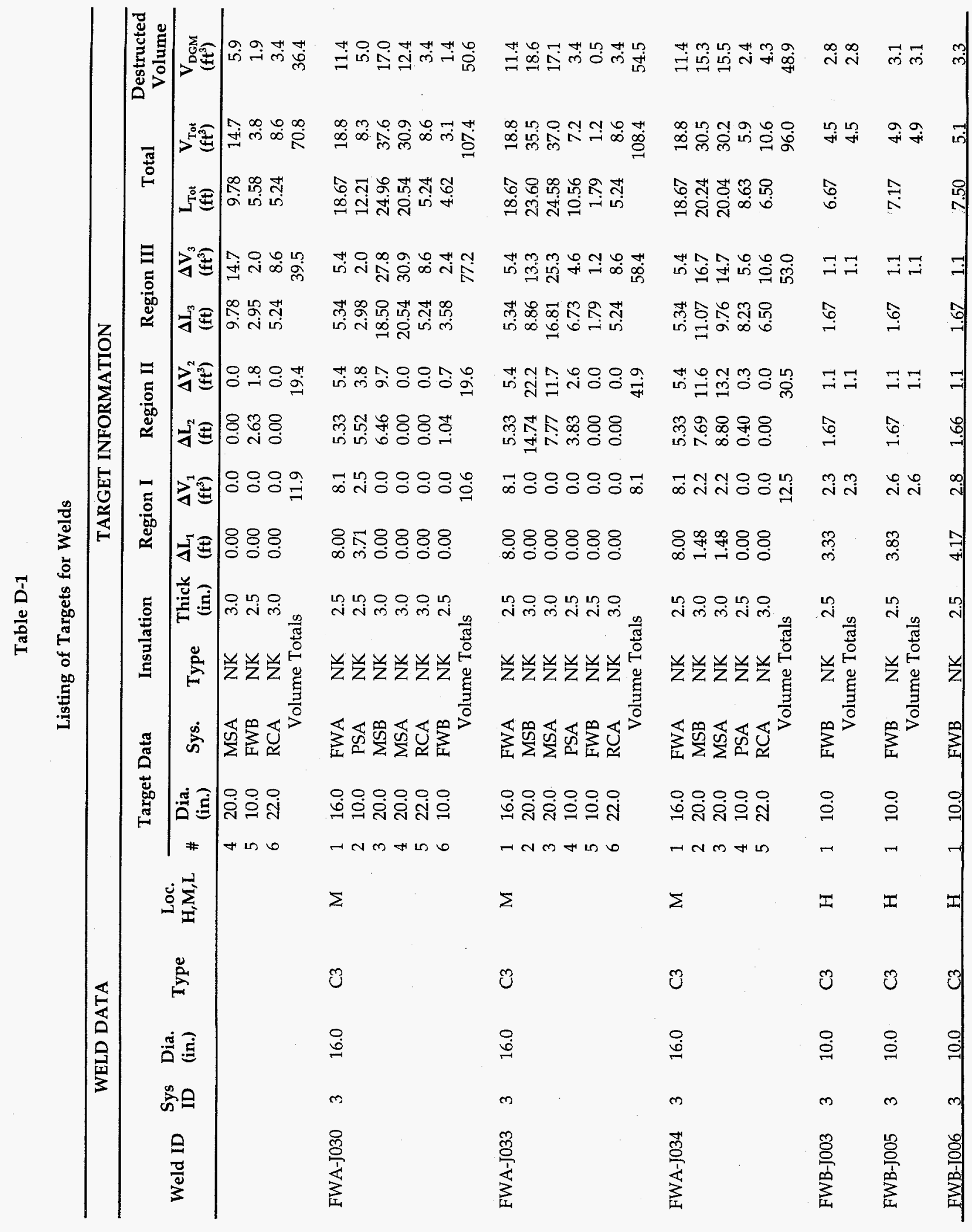


Table D-1

Listing of Targets for Welds

\begin{tabular}{|c|c|c|c|c|c|c|c|c|c|c|c|c|c|c|c|c|c|c|}
\hline \multirow[b]{3}{*}{ Weld ID } & \multicolumn{4}{|c|}{ WELD DATA } & \multicolumn{14}{|c|}{ TARGET INFORMATION } \\
\hline & \multirow[b]{2}{*}{$\begin{array}{l}\text { Sys } \\
\text { ID }\end{array}$} & \multirow[b]{2}{*}{$\begin{array}{l}\text { Dia. } \\
\text { (in.) }\end{array}$} & \multirow[b]{2}{*}{ Type } & \multirow[b]{2}{*}{$\begin{array}{l}\text { Loc. } \\
\mathbf{H}, \mathbf{M}, \mathrm{L}\end{array}$} & \multicolumn{3}{|c|}{ Target Data } & \multicolumn{2}{|c|}{ Insulation } & \multicolumn{2}{|c|}{ Region I } & \multicolumn{2}{|c|}{ Region II } & \multicolumn{2}{|c|}{ Region III } & \multicolumn{2}{|c|}{ Total } & \multirow{2}{*}{$\begin{array}{c}\begin{array}{c}\text { Destructed } \\
\text { Volume }\end{array} \\
\begin{array}{c}\mathrm{V}_{\mathrm{DGM}} \\
\left(\mathrm{ft}^{3}\right)\end{array} \\
\end{array}$} \\
\hline & & & & & $\#$ & $\begin{array}{l}\text { Dia. } \\
\text { (in.) }\end{array}$ & Sys. & Type & $\begin{array}{c}\text { Thick } \\
\text { (in.) }\end{array}$ & $\begin{array}{l}\Delta \mathrm{L}_{1} \\
(\mathrm{ft})\end{array}$ & $\begin{array}{l}\Delta V_{1} \\
\left(f^{t^{3}}\right)\end{array}$ & $\begin{array}{l}\Delta \mathrm{L}_{2} \\
(\mathrm{ft})\end{array}$ & $\begin{array}{l}\Delta V_{2} \\
\left(\mathrm{ft}^{3}\right)^{2}\end{array}$ & $\begin{array}{l}\Delta \mathrm{L}_{3} \\
(\mathrm{ft})\end{array}$ & $\begin{array}{l}\Delta \mathbf{V}_{3} \\
\left(\mathrm{ft}^{3}\right)\end{array}$ & $\begin{array}{l}\mathbf{L}_{\text {Tot }} \\
(\mathrm{ft})\end{array}$ & $\begin{array}{l}V_{\text {Tot }} \\
\left(\mathbf{f t}^{3}\right)\end{array}$ & \\
\hline & & & & & & & \multicolumn{3}{|c|}{ Volume Totals } & & 2.8 & & 1.1 & & 1.1 & & 5.1 & 3.3 \\
\hline FWB-J008 & 3 & 10.0 & $\mathrm{C} 3$ & $\mathrm{H}$ & 1 & 10.0 & \multicolumn{3}{|c|}{ Volume Totals } & 4.83 & $\begin{array}{l}3.3 \\
3.3\end{array}$ & 1.67 & $\begin{array}{l}1.1 \\
1.1\end{array}$ & 1.67 & $\begin{array}{l}1.1 \\
1.1\end{array}$ & 8.17 & $\begin{array}{l}5.6 \\
5.6\end{array}$ & $\begin{array}{l}3.6 \\
3.6\end{array}$ \\
\hline FWB-J009 & 3 & 10.0 & $\mathrm{C} 3$ & $\mathrm{H}$ & 1 & 10.0 & FWB & NK & 2.5 & 5.00 & 3.4 & 3.33 & 2.3 & 1.67 & 1.1 & 10.00 & 6.8 & 4.4 \\
\hline \multirow[t]{2}{*}{ FWB-J010 } & \multirow[t]{2}{*}{3} & \multirow[t]{2}{*}{10.0} & \multirow[t]{2}{*}{$\mathrm{C} 3$} & \multirow[t]{2}{*}{$\mathrm{H}$} & \multirow[t]{2}{*}{1} & 10.0 & FWB & NK & 2.5 & 5.00 & 3.4 & 3.33 & 2.3 & 3.00 & 2.0 & 11.33 & 7.7 & 4.7 \\
\hline & & & & & & & \multicolumn{3}{|c|}{ Volume Totals } & & 3.4 & & 2.3 & & 2.0 & & 7.7 & 4.7 \\
\hline \multirow[t]{3}{*}{ FWB-J011 } & \multirow[t]{3}{*}{3} & \multirow[t]{3}{*}{10.0} & $\mathrm{C} 3$ & $\mathrm{H}$ & 1 & 10.0 & FWB & NK & 2.5 & 5.00 & 3.4 & 3.33 & 2.3 & 3.34 & 2.3 & 11.67 & 8.0 & 4.8 \\
\hline & & & & & 2 & 10.0 & RRD & NK & 2.5 & 0.00 & 0.0 & 3.61 & 2.5 & 1.84 & 1.3 & 5.45 & 3.7 & 2.0 \\
\hline & & & & & & & & ime Tot & & & 3.4 & & 4.7 & & 3.5 & & 11.7 & 6.8 \\
\hline FWB-J012 & 3 & 10.0 & $\mathrm{C} 3$ & $\mathrm{H}$ & 1 & 10.0 & FWB & NK & 2.5 & 5.00 & 3.4 & 3.33 & 2.3 & 3.34 & 2.3 & 11.67 & 8.0 & 4.8 \\
\hline & & & & & 2 & 10.0 & RRD & NK & 2.5 & 2.76 & 1.9 & 4.46 & 3.0 & 3.68 & 2.5 & 10.90 & 7.4 & 4.2 \\
\hline & & & & & & & & ame Tot & & & 5.3 & & 5.3 & & 4.8 & & 15.4 & 9.1 \\
\hline FWB-J013 & 3 & 10.0 & $\mathrm{C} 3$ & $\mathrm{H}$ & 1 & 10.0 & FWB & NK & 2.5 & 5.00 & 3.4 & 3.33 & 2.3 & 3.34 & 2.3 & 11.67 & 8.0 & 4.8 \\
\hline & & & & & 2 & 10.0 & RRD & NK & 2.5 & 0.00 & 0.0 & 6.67 & 4.5 & 3.87 & 2.6 & 10.54 & 7.2 & 3.8 \\
\hline & & & & & 3 & 10.0 & RRC & NK & 2.5 & 0.00 & 0.0 & 0.00 & 0.0 & 1.00 & 0.7 & 1.00 & 0.7 & 0.3 \\
\hline & & & & & & & & ame Tot & & & 3.4 & & 6.8 & & 5.6 & & 15.8 & 8.9 \\
\hline FWB-J014 & 3 & 10.0 & $\mathrm{C} 3$ & $\mathrm{H}$ & 1 & 10.0 & FWB & NK & 2.5 & 5.00 & 3.4 & 3.33 & 2.3 & 3.34 & 2.3 & 11.67 & 8.0 & 4.8 \\
\hline & & & & & 2 & 10.0 & RRD & NK & 2.5 & 0.00 & 0.0 & 0.00 & 0.0 & 7.72 & 5.3 & 7.72 & 5.3 & 2.1 \\
\hline & & & & & 3 & 10.0 & RRC & NK & 2.5 & 0.00 & 0.0 & 0.00 & 0.0 & 4.33 & 3.0 & 4.33 & 3.0 & 1.2 \\
\hline & & & & & & & & ame Tot & & & 3.4 & & 2.3 & & 10.5 & & 16.2 & 8.1 \\
\hline FWB-J015 & 3 & 10.0 & $\mathrm{C} 3$ & $\mathrm{H}$ & 1 & 10.0 & FWB & NK & 2.5 & 5.00 & 3.4 & 3.33 & 2.3 & 3.34 & 2.3 & 11.67 & 8.0 & 4.8 \\
\hline & & & & & 2 & 10.0 & RRD & NK & 2.5 & 0.00 & 0.0 & 0.00 & 0.0 & 3.09 & 2.1 & 3.09 & 2.1 & 0.8 \\
\hline & & & & & & & & ime To & & & 3.4 & & 2.3 & & 4.4 & & 10.1 & 5.7 \\
\hline FWB-J018 & 3 & 10.0 & $\mathrm{C} 3$ & $\mathrm{H}$ & $\begin{array}{l}1 \\
2 \\
\end{array}$ & $\begin{array}{l}10.0 \\
20.0 \\
\end{array}$ & $\begin{array}{l}\text { FWB } \\
\text { MSB }\end{array}$ & $\begin{array}{l}\text { NK } \\
\text { NK }\end{array}$ & $\begin{array}{r}2.5 \\
3.0 \\
\end{array}$ & $\begin{array}{l}5.00 \\
0.00 \\
\end{array}$ & $\begin{array}{l}3.4 \\
0.0 \\
\end{array}$ & $\begin{array}{l}3.33 \\
0.00\end{array}$ & $\begin{array}{l}2.3 \\
0.0\end{array}$ & $\begin{array}{r}3.34 \\
4.59\end{array}$ & $\begin{array}{l}2.3 \\
6.9 \\
\end{array}$ & $\begin{array}{r}11.67 \\
4.59 \\
\end{array}$ & $\begin{array}{l}8.0 \\
6.9 \\
\end{array}$ & $\begin{array}{l}4.8 \\
2.8\end{array}$ \\
\hline
\end{tabular}


Table D-1

Listing of Targets for Welds

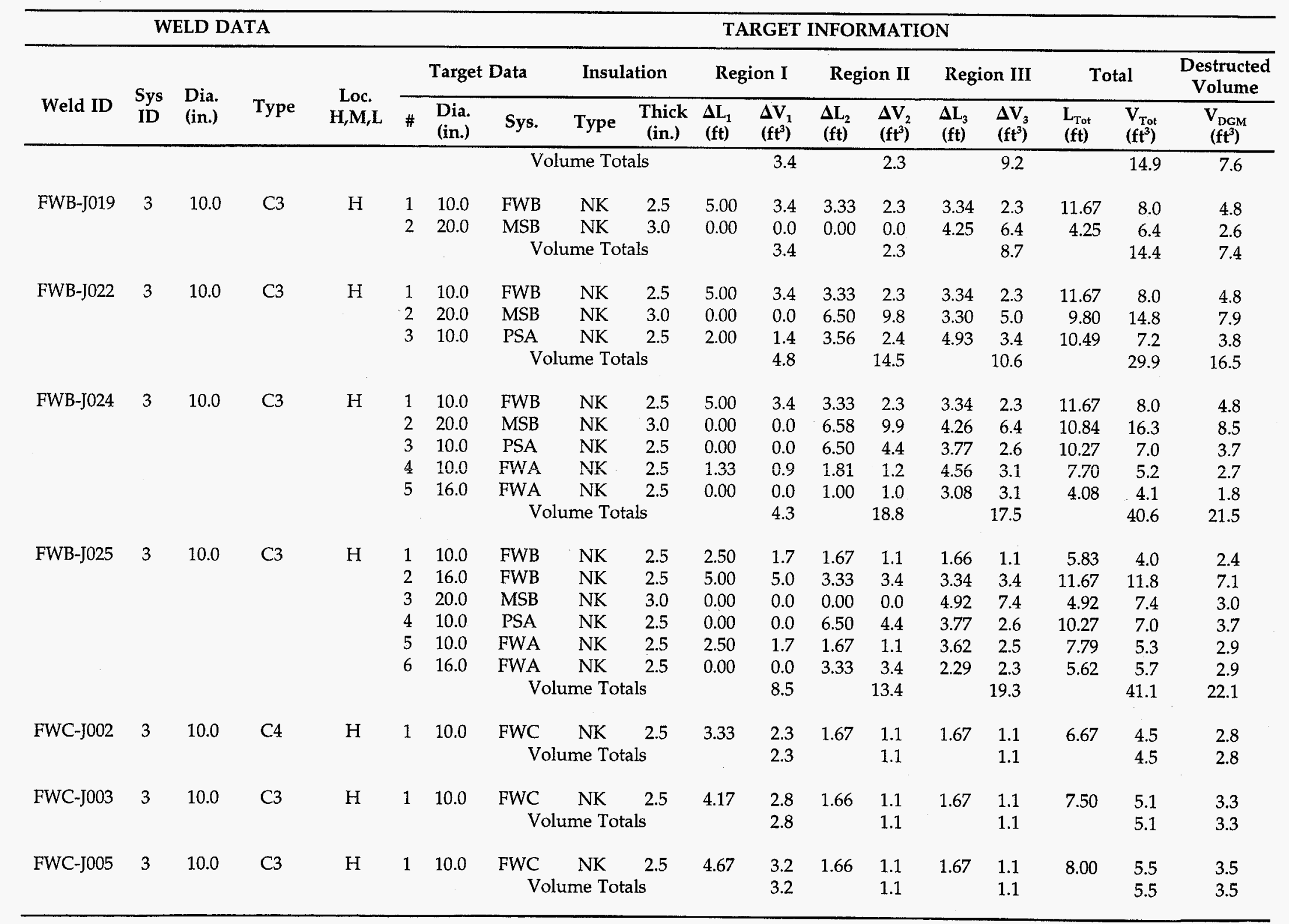


Table D-1

Listing of Targets for Welds

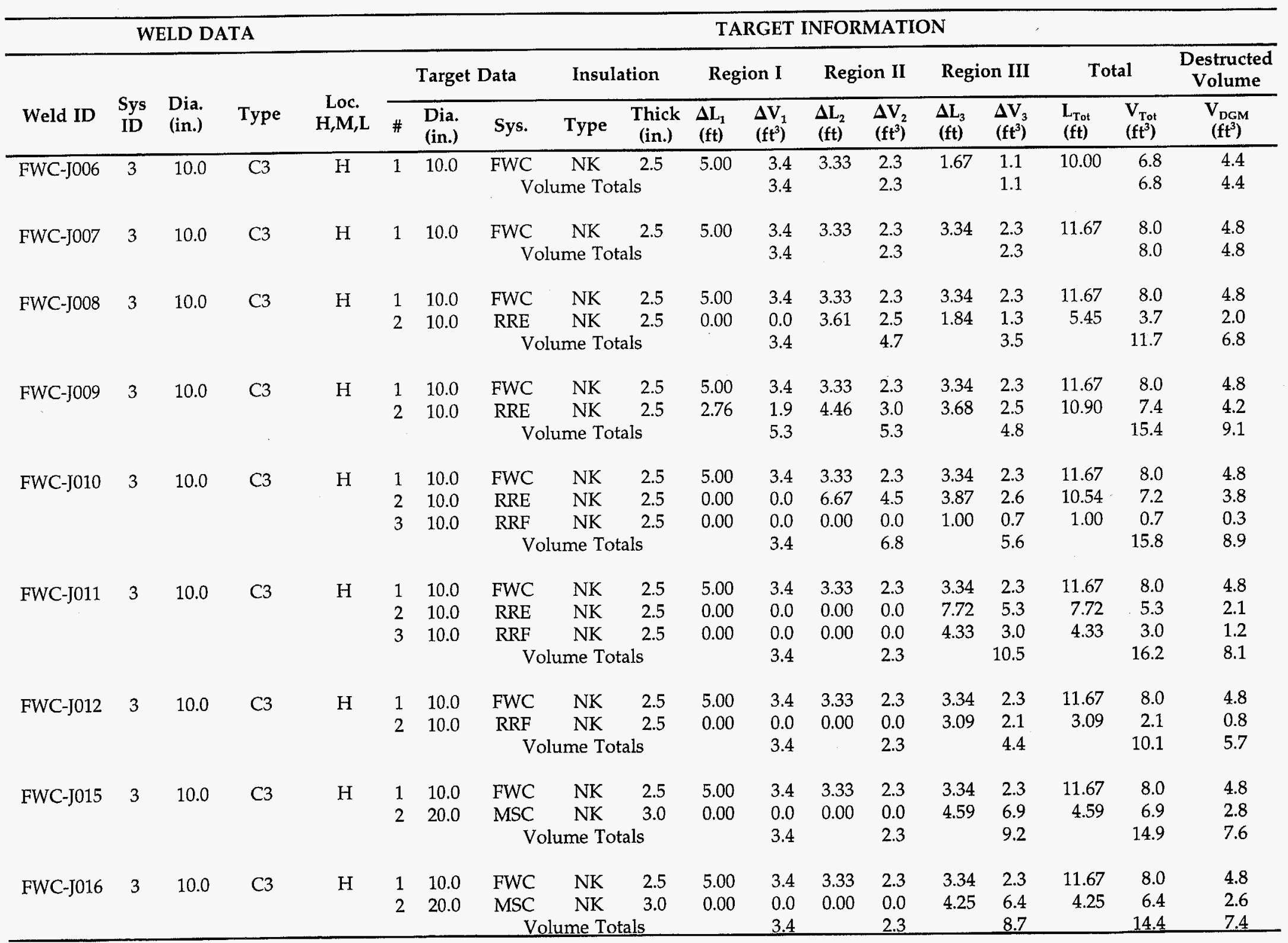


Table D-1

Listing of Targets for Welds

\begin{tabular}{|c|c|c|c|c|c|c|c|c|c|c|c|c|c|c|c|c|c|c|}
\hline \multirow[b]{3}{*}{ Weld ID } & \multicolumn{4}{|c|}{ WELD DATA } & \multicolumn{14}{|c|}{ TARGET INFORMATION } \\
\hline & \multirow{2}{*}{$\begin{array}{l}\text { Sys } \\
\text { ID }\end{array}$} & \multirow{2}{*}{$\begin{array}{l}\text { Dia. } \\
\text { (in.) }\end{array}$} & \multirow[b]{2}{*}{ Type } & \multirow{2}{*}{$\begin{array}{c}\text { Loc. } \\
\text { H,M,L }\end{array}$} & \multicolumn{3}{|c|}{ Target Data } & \multicolumn{2}{|c|}{ Insulation } & \multicolumn{2}{|c|}{ Region I } & \multicolumn{2}{|c|}{ Region II } & \multicolumn{2}{|c|}{ Region III } & \multicolumn{2}{|c|}{ Total } & \multirow{2}{*}{$\begin{array}{c}\begin{array}{c}\text { Destructed } \\
\text { Volume }\end{array} \\
\begin{array}{c}V_{\text {DGM }} \\
\left(\mathrm{ft}^{3}\right)\end{array}\end{array}$} \\
\hline & & & & & $\#$ & $\begin{array}{l}\text { Dia. } \\
\text { (in.) }\end{array}$ & Sys. & Type & $\begin{array}{c}\text { Thick } \\
\text { (in.) }\end{array}$ & $\begin{array}{l}\Delta \mathrm{L}_{1} \\
(\mathrm{ft})\end{array}$ & $\begin{array}{l}\Delta V_{1} \\
\left(\mathrm{ft}^{3}\right)\end{array}$ & $\begin{array}{l}\Delta \mathrm{L}_{2} \\
(\mathrm{ft}) \\
\end{array}$ & $\begin{array}{l}\Delta V_{2} \\
\left(\mathbf{f t}^{3}\right)\end{array}$ & $\begin{array}{c}\Delta \mathrm{L}_{3} \\
(\mathrm{ft})\end{array}$ & $\begin{array}{l}\Delta V_{3} \\
\left(f^{3}\right)^{3}\end{array}$ & $\begin{array}{l}\mathbf{L}_{\text {Tot }} \\
(\mathbf{f t})\end{array}$ & $\begin{array}{l}V_{\text {Tot }} \\
\left(\mathrm{ft}^{3}\right)\end{array}$ & \\
\hline FWC-J019 & 3 & 10.0 & $\mathrm{C} 3$ & $\mathrm{H}$ & 1 & 10.0 & FWC & NK & 2.5 & 5.00 & 3.4 & 3.33 & 2.3 & 3.34 & 2.3 & 11.67 & 8.0 & 4.8 \\
\hline & & & & & 2 & 20.0 & MSC & NK & 3.0 & 0.00 & 0.0 & 6.50 & 9.8 & 3.30 . & 5.0 & 9.80 & 14.8 & 7.9 \\
\hline & & & & & & \multicolumn{4}{|c|}{ Volume Totals } & & 3.4 & & 12.1 & & 7.2 & & 22.7 & 12.7 \\
\hline FWC-J022 & 3 & 10.0 & $\mathrm{C} 3$ & $\mathrm{H}$ & 1 & 10.0 & FWC & NK & 2.5 & 5.00 & 3.4 & 3.33 & 2.3 & 3.34 & 2.3 & 11.67 & 8.0 & 4.8 \\
\hline & & & & & 2 & 20.0 & $\mathrm{MSC}$ & NK & 3.0 & 0.00 & 0.0 & 6.58 & 9.9 & 4.26 & 6.4 & 10.84 & 16.3 & 8.5 \\
\hline & & & & & 3 & 10.0 & FWD & NK & 2.5 & 1.33 & 0.9 & 1.81 & 1.2 & 4.56 & 3.1 & 7.70 & 5.2 & 2.7 \\
\hline & & & & & 4 & 16.0 & FWC & NK & 2.5 & 0.00 & 0.0 & 1.00 & 1.0 & 3.08 & 3.1 & 4.08 & 4.1 & 1.8 \\
\hline & & & & & & \multicolumn{4}{|c|}{ Volume Totals } & & 4.3 & & 14.4 & & 14.9 & & 33.6 & 17.9 \\
\hline FWC-J023 & 3 & 10.0 & $\mathrm{C} 3$ & $\mathrm{H}$ & 1 & 10.0 & FWC & NK & 2.5 & 2.50 & 1.7 & 1.67 & 1.1 & 1.66 & 1.1 & 5.83 & 4.0 & 2.4 \\
\hline & & & & & 2 & 20.0 & MSC & NK & 3.0 & 0.00 & 0.0 & 0.00 & 0.0 & 4.92 & 7.4 & 4.92 & 7.4 & 3.0 \\
\hline & & & & & 3 & 10.0 & FWD & NK & 2.5 & 2.50 & 1.7 & 1.67 & 1.1 & 3.62 & 2.5 & 7.79 & 5.3 & 2.9 \\
\hline & & & & & 4 & 16.0 & FWC & NK & 2.5 & 0.00 & 0.0 & 3.33 & 3.4 & 2.29 & 2.3 & 5.62 & 5.7 & 2.9 \\
\hline & & & & & & & \multicolumn{3}{|c|}{ Volume Totals } & & 3.4 & & 5.6 & & 13.3 & & 22.4 & 11.3 \\
\hline FWC-J025 & 3 & 16.0 & $\mathrm{C} 3$ & $\mathrm{H}$ & 1 & 16.0 & FWC & NK & 2.5 & 8.00 & 8.1 & 5.33 & 5.4 & 5.34 & 5.4 & 18.67 & 18.8 & 11.4 \\
\hline & & & & & 2 & 20.0 & MSC & NK & 3.0 & 0.00 & 0.0 & 6.45 & 9.7 & 6.88 & 10.4 & 13.33 & 20.1 & 10.0 \\
\hline & & & & & 3 & 10.0 & FWD & NK & 2.5 & 2.24 & 1.5 & 2.56 & 1.7 & 6.30 & 4.3 & 11.10 & 7.6 & 3.9 \\
\hline & & & & & 4 & 10.0 & FWC & NK & 2.5 & 3.33 & 2.3 & 3.25 & 2.2 & 2.65 & 1.8 & 9.23 & 6.3 & 3.8 \\
\hline & & & & & 5 & 20.0 & MSD & NK & 3.0 & 0.00 & 0.0 & 0.00 & 0.0 & 11.92 & 17.9 & 11.92 & 17.9 & 7.2 \\
\hline & & & & & & & \multicolumn{3}{|c|}{ Volume Totals } & & 11.9 & & 19.0 & & 39.8 & & 70.7 & 36.2 \\
\hline \multirow[t]{6}{*}{ FWC-J026 } & 3 & 16.0 & $\mathrm{C} 3$ & M & 1 & 16.0 & FWC & NK & 2.5 & 8.00 & 8.1 & 5.33 & 5.4 & 5.34 & 5.4 & 18.67 & 18.8 & 11.4 \\
\hline & & & & & 2 & 20.0 & MSC & NK & 3.0 & 0.00 & 0.0 & 6.45 & 9.7 & 6.88 & 10.4 & 13.33 & 20.1 & 10.0 \\
\hline & & & & & 3 & 22.0 & RCB & NK & 3.0 & 0.00 & 0.0 & 0.00 & 0.0 & 5.24 & 8.6 & 5.24 & 8.6 & 3.4 \\
\hline & & & & & 4 & 10.0 & FWC & NK & 2.5 & 0.00 & 0.0 & 2.63 & 1.8 & 2.95 & 2.0 & 5.58 & 3.8 & 1.9 \\
\hline & & & & & 5 & 20.0 & MSD & NK & 3.0 & 0.00 & 0.0 & 0.00 & 0.0 & 9.78 & 14.7 & 9.78 & 14.7 & 5.9 \\
\hline & & & & & & \multicolumn{4}{|c|}{ Volume Totals } & & 8.1 & & 16.9 & & 41.1 & & 66.0 & 32.6 \\
\hline FWC-J027 & 3 & 16.0 & C3 & M & 1 & 16.0 & FWC & NK & 2.5 & 8.00 & 8.1 & 5.33 & 5.4 & 5.34 & 5.4 & 18.67 & 18.8 & 11.4 \\
\hline & & & & & 2 & 20.0 & MSC & NK & 3.0 & 0.00 & 0.0 & 6.46 & 9.7 & 18.50 & 27.8 & 24.96 & 37.6 & 17.0 \\
\hline & & & & & 3 & 10.0 & FWC & NK & 2.5 & 0.00 & 0.0 & 1.04 & 0.7 & 3.58 & 2.4 & 4.62 & 3.1 & 1.4 \\
\hline & & & & & 4 & 20.0 & MSD & NK & 3.0 & 0.00 & 0.0 & 0.00 & 0.0 & 20.50 & 30.9 & 20.50 & 30.9 & 12.3 \\
\hline
\end{tabular}




\begin{tabular}{|c|c|c|c|c|c|c|c|c|c|c|c|c|c|c|c|c|c|c|}
\hline \multicolumn{19}{|c|}{ Listing of Targets for Welds } \\
\hline \multicolumn{5}{|c|}{ WELD DATA } & \multicolumn{14}{|c|}{ TARGET INFORMATION } \\
\hline \multirow[b]{2}{*}{ Weld ID } & \multirow[b]{2}{*}{$\begin{array}{l}\text { Sys } \\
\text { ID }\end{array}$} & \multirow[b]{2}{*}{$\begin{array}{l}\text { Dia. } \\
\text { (in.) }\end{array}$} & \multirow[b]{2}{*}{ Type } & \multirow[b]{2}{*}{$\begin{array}{c}\text { Loc. } \\
\text { H,M,L }\end{array}$} & \multicolumn{3}{|c|}{ Target Data } & \multicolumn{2}{|c|}{ Insulation } & \multicolumn{2}{|c|}{ Region I } & \multicolumn{2}{|c|}{ Region II } & \multicolumn{2}{|c|}{ Region III } & \multicolumn{2}{|c|}{ Total } & \multirow{2}{*}{$\begin{array}{c}\begin{array}{c}\text { Destructed } \\
\text { Volume }\end{array} \\
\begin{array}{c}\mathbf{V}_{\text {DGM }} \\
\left(\mathbf{f t}^{3}\right)\end{array}\end{array}$} \\
\hline & & & & & $\#$ & $\begin{array}{l}\text { Dia. } \\
\text { (in.) } \\
\end{array}$ & Sys. & Type & $\begin{array}{l}\text { Thick } \\
\text { (in.) }\end{array}$ & $\begin{array}{l}\Delta \mathrm{L}_{1} \\
(\mathrm{ft})\end{array}$ & $\begin{array}{l}\Delta V_{1} \\
\left(\mathrm{ft}^{3}\right)^{\prime} \\
\end{array}$ & $\begin{array}{l}\Delta L_{2} \\
(\mathrm{ft})\end{array}$ & $\begin{array}{l}\Delta \Delta V_{2} \\
\left.\left(f^{3}\right)^{3}\right)\end{array}$ & $\begin{array}{l}\Delta \mathrm{L}_{3} \\
\text { (ft) }\end{array}$ & $\begin{array}{l}\Delta \mathbf{V}_{3} \\
\left(\mathrm{ft}^{3}\right)\end{array}$ & $\begin{array}{l}\mathbf{L}_{\text {Tot }} \\
(\mathbf{f t})\end{array}$ & $\begin{array}{l}\mathbf{V}_{\text {Tot }} \\
\left(\mathbf{f t}^{3} \mathbf{t}^{3}\right) \\
\end{array}$ & \\
\hline & & & & & 5 & 22.0 & $\begin{array}{r}\mathrm{RCB} \\
\mathrm{Vc}\end{array}$ & $\begin{array}{l}\text { NK } \\
\text { ame To }\end{array}$ & $\begin{array}{l}3.0 \\
\text { als }\end{array}$ & 0.00 & $\begin{array}{l}0.0 \\
8.1\end{array}$ & 0.00 & $\begin{array}{r}0.0 \\
15.8\end{array}$ & 3.33 & $\begin{array}{r}5.4 \\
72.0\end{array}$ & 3.33 & $\begin{array}{r}5.4 \\
95.9\end{array}$ & $\begin{array}{r}2.2 \\
44.3\end{array}$ \\
\hline FWC-J030 & 3 & 16.0 & C3 & M & $\begin{array}{l}1 \\
2 \\
3 \\
4 \\
5\end{array}$ & $\begin{array}{l}16.0 \\
20.0 \\
20.0 \\
10.0 \\
22.0\end{array}$ & $\begin{array}{c}\text { FWC } \\
\text { MSD } \\
\text { MSC } \\
\text { FWC } \\
\text { RCB } \\
\text { Vo }\end{array}$ & $\begin{array}{l}\text { NK } \\
\text { NK } \\
\text { NK } \\
\text { NK } \\
\text { NK } \\
\text { ame To }\end{array}$ & $\begin{array}{r}2.5 \\
3.0 \\
3.0 \\
2.5 \\
3.0 \\
\text { als }\end{array}$ & $\begin{array}{l}8.00 \\
0.00 \\
0.00 \\
0.00 \\
0.00\end{array}$ & $\begin{array}{l}8.1 \\
0.0 \\
0.0 \\
0.0 \\
0.0 \\
8.1\end{array}$ & $\begin{array}{r}5.33 \\
7.77 \\
14.74 \\
0.00 \\
0.00\end{array}$ & $\begin{array}{r}5.4 \\
11.7 \\
22.2 \\
0.0 \\
0.0 \\
39.3\end{array}$ & $\begin{array}{r}5.34 \\
16.81 \\
8.86 \\
1.79 \\
5.24\end{array}$ & $\begin{array}{r}5.4 \\
25.3 \\
13.3 \\
1.2 \\
8.6 \\
53.8\end{array}$ & $\begin{array}{r}18.67 \\
24.58 \\
23.60 \\
1.79 \\
5.24\end{array}$ & $\begin{array}{r}18.8 \\
37.0 \\
35.5 \\
1.2 \\
8.6 \\
101.2\end{array}$ & $\begin{array}{r}11.4 \\
17.1 \\
18.6 \\
0.5 \\
3.4 \\
51.1\end{array}$ \\
\hline FWC-J031 & 3 & 16.0 & $\mathrm{C} 3$ & M & $\begin{array}{l}1 \\
2 \\
3 \\
4\end{array}$ & $\begin{array}{l}16.0 \\
20.0 \\
20.0 \\
22.0\end{array}$ & $\begin{array}{c}\text { FWC } \\
\text { MSC } \\
\text { MSD } \\
\text { RCB } \\
\text { Vo }\end{array}$ & $\begin{array}{l}\text { NK } \\
\text { NK } \\
\text { NK } \\
\text { NK } \\
\text { ime To }\end{array}$ & $\begin{array}{r}2.5 \\
3.0 \\
3.0 \\
3.0 \\
\text { as }\end{array}$ & $\begin{array}{l}8.00 \\
1.48 \\
1.48 \\
0.00\end{array}$ & $\begin{array}{r}8.1 \\
2.2 \\
2.2 \\
0.0 \\
12.5\end{array}$ & $\begin{array}{l}5.33 \\
7.69 \\
8.80 \\
0.00\end{array}$ & $\begin{array}{r}5.4 \\
11.6 \\
13.2 \\
0.0 \\
30.2\end{array}$ & $\begin{array}{r}5.34 \\
11.07 \\
9.76 \\
6.50\end{array}$ & $\begin{array}{r}5.4 \\
16.7 \\
14.7 \\
10.6 \\
47.4\end{array}$ & $\begin{array}{r}18.67 \\
20.24 \\
20.04 \\
6.50\end{array}$ & $\begin{array}{l}18.8 \\
30.5 \\
30.2 \\
10.6 \\
90.1\end{array}$ & $\begin{array}{r}11.4 \\
15.3 \\
15.5 \\
4.3 \\
46.5\end{array}$ \\
\hline FWD-J002 & 3 & 10.0 & $\mathrm{C} 3$ & $\mathrm{H}$ & 1 & 10.0 & $\begin{array}{r}\text { FWD } \\
\text { Vo }\end{array}$ & $\begin{array}{l}\text { NK } \\
\text { ume To }\end{array}$ & $\mathrm{ls}^{2.5}$ & 3.33 & $\begin{array}{l}2.3 \\
2.3\end{array}$ & 1.67 & $\begin{array}{l}1.1 \\
1.1\end{array}$ & 1.67 & $\begin{array}{l}1.1 \\
1.1\end{array}$ & 6.67 & $\begin{array}{l}4.5 \\
4.5\end{array}$ & $\begin{array}{l}2.8 \\
2.8\end{array}$ \\
\hline FWD-J003 & 3 & 10.0 & C3 & $\mathrm{H}$ & 1 & 10.0 & $\begin{array}{r}\text { FWD } \\
\text { Vo }\end{array}$ & $\begin{array}{c}\text { NK } \\
\text { Ime To }\end{array}$ & $\mathrm{ls}^{2.5}$ & 4.17 & $\begin{array}{l}2.8 \\
2.8\end{array}$ & 1.66 & $\begin{array}{l}1.1 \\
1.1\end{array}$ & 1.67 & $\begin{array}{l}1.1 \\
1.1\end{array}$ & 7.50 & $\begin{array}{l}5.1 \\
5.1\end{array}$ & $\begin{array}{l}3.3 \\
3.3\end{array}$ \\
\hline FWD-J005 & 3 & 10.0 & $\mathrm{C} 3$ & $\mathrm{H}$ & 1 & 10.0 & $\begin{array}{r}\text { FWD } \\
\text { Vo }\end{array}$ & $\begin{array}{c}\text { NK } \\
\text { Ime To }\end{array}$ & $l^{2.5}$ & 4.50 & $\begin{array}{l}3.1 \\
3.1\end{array}$ & 1.67 & $\begin{array}{l}1.1 \\
1.1\end{array}$ & 1.66 & $\begin{array}{l}1.1 \\
1.1\end{array}$ & 7.83 & $\begin{array}{l}5.3 \\
5.3\end{array}$ & $\begin{array}{l}3.4 \\
3.4\end{array}$ \\
\hline FWD-J006 & 3 & 10.0 & $\mathrm{C} 3$ & $\mathrm{H}$ & 1 & 10.0 & $\begin{array}{l}\text { FWD } \\
\text { Vo }\end{array}$ & $\begin{array}{l}\text { NK } \\
\text { Ime To }\end{array}$ & 2.5 & 5.00 & $\begin{array}{l}3.4 \\
3.4\end{array}$ & 3.33 & $\begin{array}{l}2.3 \\
2.3\end{array}$ & 1.67 & $\begin{array}{l}1.1 \\
1.1\end{array}$ & 10.00 & $\begin{array}{l}6.8 \\
6.8\end{array}$ & $\begin{array}{l}4.4 \\
4.4\end{array}$ \\
\hline FWD-J007 & 3 & 10.0 & $\mathrm{C} 3$ & $\mathrm{H}$ & 1 & 10.0 & $\begin{array}{l}\text { FWD } \\
\text { Vo }\end{array}$ & $\begin{array}{l}\text { NK } \\
\text { Ime To }\end{array}$ & 2.5 & 5.00 & $\begin{array}{l}3.4 \\
3.4\end{array}$ & 3.33 & $\begin{array}{l}2.3 \\
2.3\end{array}$ & 3.34 & $\begin{array}{l}2.3 \\
2.3\end{array}$ & 11.67 & $\begin{array}{l}8.0 \\
8.0\end{array}$ & $\begin{array}{l}4.8 \\
4.8\end{array}$ \\
\hline FWD-J008 & 3 & 10.0 & C3 & $\mathrm{H}$ & $\begin{array}{l}1 \\
2\end{array}$ & $\begin{array}{l}10.0 \\
10.0\end{array}$ & $\begin{array}{l}\text { FWD } \\
\text { RRH } \\
\text { Vo }\end{array}$ & $\begin{array}{l}\text { NK } \\
\text { NK } \\
\text { Ime To }\end{array}$ & $\begin{array}{l}2.5 \\
2.5 \\
\text { als }\end{array}$ & $\begin{array}{l}5.00 \\
0.00\end{array}$ & $\begin{array}{l}3.4 \\
0.0 \\
3.4\end{array}$ & $\begin{array}{l}3.33 \\
0.00\end{array}$ & $\begin{array}{l}2.3 \\
0.0 \\
2.3\end{array}$ & $\begin{array}{r}3.34 \\
10.87\end{array}$ & $\begin{array}{l}2.3 \\
7.4 \\
9.7\end{array}$ & $\begin{array}{l}11.67 \\
10.87\end{array}$ & $\begin{array}{r}8.0 \\
7.4 \\
15.4\end{array}$ & $\begin{array}{l}4.8 \\
3.0 \\
7.8\end{array}$ \\
\hline
\end{tabular}


Table D-1

Listing of Targets for Welds

\begin{tabular}{|c|c|c|c|c|c|c|c|c|c|c|c|c|c|c|c|c|c|c|}
\hline \multirow[b]{3}{*}{ Weld ID } & \multicolumn{4}{|c|}{ WELD DATA } & \multicolumn{14}{|c|}{ TARGET INFORMATION } \\
\hline & \multirow{2}{*}{$\begin{array}{l}\text { Sys } \\
\text { ID }\end{array}$} & \multirow{2}{*}{$\begin{array}{l}\text { Dia. } \\
\text { (in.) }\end{array}$} & \multirow[b]{2}{*}{ Type } & \multirow{2}{*}{$\begin{array}{c}\text { Loc. } \\
\text { H,M,L }\end{array}$} & \multicolumn{3}{|c|}{ Target Data } & \multicolumn{2}{|c|}{ Insulation } & \multicolumn{2}{|c|}{ Region I } & \multicolumn{2}{|c|}{ Region II } & \multicolumn{2}{|c|}{ Region III } & \multicolumn{2}{|c|}{ Total } & \multirow{2}{*}{$\begin{array}{c}\begin{array}{c}\text { Destructed } \\
\text { Volume }\end{array} \\
\begin{array}{c}V_{\mathrm{DGM}} \\
\left(\mathrm{ft}^{3}\right)\end{array}\end{array}$} \\
\hline & & & & & $\#$ & $\begin{array}{l}\text { Dia. } \\
\text { (in.) }\end{array}$ & Sys. & Type & $\begin{array}{c}\text { Thick } \\
\text { (in.) }\end{array}$ & $\begin{array}{l}\Delta \mathrm{L}_{1} \\
(\mathrm{ft})\end{array}$ & $\begin{array}{l}\Delta \mathbf{V}_{1} \\
\left(\mathrm{ft}^{3}\right)\end{array}$ & $\begin{array}{l}\Delta L_{2} \\
(\mathrm{ft})\end{array}$ & $\begin{array}{l}\Delta V_{2} \\
\left(\mathrm{ft}^{3}\right)^{2}\end{array}$ & $\begin{array}{l}\Delta \mathrm{L}_{3} \\
(\mathrm{ft})\end{array}$ & $\underset{\left(\mathrm{ft}^{3}\right)^{3}}{\Delta V}$ & $\begin{array}{l}\mathrm{L}_{\text {Tot }} \\
(\mathrm{ft})\end{array}$ & $\begin{array}{l}V_{\text {Tot }} \\
\left(\mathrm{ft}^{3}\right)\end{array}$ & \\
\hline FWD-J009 & 3 & 10.0 & $\mathrm{C} 3$ & $\overline{\mathrm{H}}$ & 1 & 10.0 & FWD & NK & 2.5 & 5.00 & 3.4 & 3.33 & 2.3 & 3.34 & 2.3 & 11.67 & 8.0 & 4.8 \\
\hline & & & & & 2 & 10.0 & RRH & NK & 2.5 & 2.76 & 1.9 & 6.54 & 4.5 & 1.57 & 1.1 & 10.87 & 7.4 & 4.5 \\
\hline & & & & & & \multicolumn{4}{|c|}{ Volume Totals } & & 5.3 & & 6.7 & & 3.3 & & 15.4 & 9.3 \\
\hline FWD-j010 & 3 & 10.0 & C3 & $\mathrm{H}$ & 1 & 10.0 & FWD & NK & 2.5 & 5.00 & 3.4 & 3.33 & 2.3 & 3.34 & 2.3 & 11.67 & 8.0 & 4.8 \\
\hline & & & & & 2 & 10.0 & RRH & NK & 2.5 & 2.00 & 1.4 & 4.96 & 3.4 & 3.61 & 2.5 & 10.57 & 7.2 & 4.0 \\
\hline & & & & & 3 & 20.0 & MSD & NK & 3.0 & 0.00 & 0.0 & 0.00 & 0.0 & 7.20 & 10.8 & 7.20 & 10.8 & 4.3 \\
\hline & & & & & & \multicolumn{4}{|c|}{ Volume Totals } & & 4.8 & & 5.7 & & 15.6 & & 26.0 & 13.2 \\
\hline \multirow[t]{5}{*}{ FWD-J011 } & 3 & 10.0 & C3 & $\mathrm{H}$ & 1 & 10.0 & FWD & NK & 2.5 & 5.00 & 3.4 & 3.33 & 2.3 & 3.34 & 2.3 & 11.67 & 8.0 & 4.8 \\
\hline & & & & & 2 & 10.0 & RRH & NK & 2.5 & 0.00 & 0.0 & 0.00 & 0.0 & 6.65 & 4.5 & 6.65 & 4.5 & 1.8 \\
\hline & & & & & 3 & 20.0 & MSD & NK & 3.0 & 0.00 & 0.0 & 0.00 & 0.0 & 6.17 & 9.3 & 6.17 & 9.3 & 3.7 \\
\hline & & & & & 4 & 20.0 & MSC & NK & 3.0 & 0.00 & 0.0 & 0.00 & 0.0 & 6.77 & 10.2 & 6.77 & 10.2 & 4.1 \\
\hline & & & & & & \multicolumn{4}{|c|}{ Volume Totals } & & 3.4 & & 2.3 & & 26.3 & & 32.0 & 14.4 \\
\hline \multirow[t]{4}{*}{ FWD-J012 } & 3 & 10.0 & C3 & $\mathrm{H}$ & 1 & 10.0 & FWD & NK & 2.5 & 5.00 & 3.4 & 3.33 & 2.3 & 3.34 & 2.3 & 11.67 & 8.0 & 4.8 \\
\hline & & & & & 2 & 20.0 & MSC & NK & 3.0 & 0.00 & 0.0 & 0.00 & 0.0 & 5.88 & 8.9 & 5.88 & 8.9 & 3.5 \\
\hline & & & & & 3 & 10.0 & FWC & NK & 2.5 & 0.00 & 0.0 & 0.00 & 0.0 & 6.60 & 4.5 & 6.60 & 4.5 & 1.8 \\
\hline & & & & & & \multicolumn{4}{|c|}{ Volume Totals } & & 3.4 & & 2.3 & & 15.6 & & 21.3 & 10.2 \\
\hline \multirow[t]{4}{*}{ FWD-J013 } & 3 & 10.0 & $\mathrm{C} 3$ & $\mathrm{H}$ & 1 & 10.0 & FWD & NK & 2.5 & 5.00 & 3.4 & 3.33 & 2.3 & 3.34 & 2.3 & 11.67 & 8.0 & 4.8 \\
\hline & & & & & 2 & 20.0 & MSC & NK & 3.0 & 0.00 & 0.0 & 0.00 & 0.0 & 6.25 & 9.4 & 6.25 & 9.4 & 3.8 \\
\hline & & & & & 3 & 10.0 & FWC & NK & 2.5 & 0.00 & 0.0 & 0.00 & 0.0 & 5.25 & 3.6 & 5.25 & 3.6 & 1.4 \\
\hline & & & & & & \multicolumn{4}{|c|}{ Volume Totals } & & 3.4 & & 2.3 & & 15.3 & & 20.9 & 10.0 \\
\hline \multirow[t]{4}{*}{ FWD-J015 } & 3 & 10.0 & C3 & $\mathrm{H}$ & 1 & 10.0 & FWD & NK & 2.5 & 5.00 & 3.4 & 3.33 & 2.3 & 3.34 & 2.3 & 11.67 & 8.0 & 4.8 \\
\hline & & & & & 2 & 10.0 & FWC & NK & 2.5 & 0.00 & 0.0 & 0.00 & 0.0 & 6.01 & 4.1 & 6.01 & 4.1 & 1.6 \\
\hline & & & & & 3 & 20.0 & MSC. & NK & 3.0 & 0.00 & 0.0 & 0.00 & 0.0 & 2.94 & 4.4 & 2.94 & 4.4 & 1.8 \\
\hline & & & & & & \multicolumn{4}{|c|}{ Volume Totals } & & 3.4 & & 2.3 & & 10.8 & & 16.5 & 8.2 \\
\hline FWD-J016 & 3 & 10.0 & $\mathrm{C} 3$ & $\mathrm{H}$ & 1 & 10.0 & FWD & NK & 2.5 & 5.00 & 3.4 & 3.33 & 2.3 & 3.34 & 2.3 & 11.67 & 8.0 & 4.8 \\
\hline & & & & & 2 & 20.0 & MSC & NK & 3.0 & 0.00 & 0.0 & 0.00 & 0.0 & 1.13 & 1.7 & 1.13 & 1.7 & 0.7 \\
\hline & & & & & 3 & 10.0 & FWC & NK & 2.5 & 0.00 & 0.0 & 2.60 & 1.8 & 2.73 & 1.9 & 5.33 & 3.6 & 1.8 \\
\hline & & & & & 4 & 16.0 & FWC & NK & 2.5 & 0.00 & 0.0 & 0.00 & 0.0 & 0.97 & 1.0 & 0.97 & 1.0 & 0.4 \\
\hline & & & & & & & Vo & me To & & & 3.4 & & 4.0 & & 6.8 & & 14.3 & 7.7 \\
\hline
\end{tabular}




\begin{tabular}{|c|c|c|c|c|c|c|c|c|c|c|c|c|c|c|c|c|c|c|}
\hline \multicolumn{19}{|c|}{ Listing of Targets for Welds } \\
\hline \multicolumn{5}{|c|}{ WELD DATA } & \multicolumn{14}{|c|}{ TARGET INFORMATION } \\
\hline \multirow[b]{2}{*}{ Weld ID } & \multirow{2}{*}{$\begin{array}{l}\text { Sys } \\
\text { ID }\end{array}$} & \multirow{2}{*}{$\begin{array}{l}\text { Dia. } \\
\text { (in.) }\end{array}$} & \multirow[b]{2}{*}{ Type } & \multirow{2}{*}{$\begin{array}{l}\text { Loc. } \\
\mathbf{H}, \mathbf{M}, \mathrm{L}\end{array}$} & \multicolumn{3}{|c|}{ Target Data } & \multicolumn{2}{|c|}{ Insulation } & \multicolumn{2}{|c|}{ Region I } & \multicolumn{2}{|c|}{ Region II } & \multicolumn{2}{|c|}{ Region III } & \multicolumn{2}{|c|}{ Total } & \multirow{2}{*}{$\begin{array}{c}\begin{array}{c}\text { Destructed } \\
\text { Volume }\end{array} \\
\begin{array}{c}\mathrm{V}_{\mathrm{DGM}} \\
\left(\mathrm{ft}^{3}\right)\end{array} \\
\end{array}$} \\
\hline & & & & & $\#$ & $\begin{array}{l}\text { Dia. } \\
\text { (in.) }\end{array}$ & Sys. & Type & $\begin{array}{l}\text { Thick } \\
\text { (in.) }\end{array}$ & $\begin{array}{l}\Delta \mathrm{L}_{1} \\
(\mathrm{ft})\end{array}$ & $\begin{array}{l}\Delta \mathrm{V}_{1} \\
\left(\mathrm{ft}^{3}\right)\end{array}$ & $\begin{array}{l}\Delta \mathbf{L}_{2} \\
(\mathrm{ft})\end{array}$ & $\begin{array}{l}\Delta V_{2} \\
\left.\left(f^{3}\right)^{3}\right)\end{array}$ & $\begin{array}{l}\Delta \mathrm{L}_{3} \\
(\mathrm{ft})\end{array}$ & $\begin{array}{l}\Delta \mathbf{V}_{3} \\
\left(\mathrm{ftt}^{3}\right)\end{array}$ & $\begin{array}{l}\mathbf{L}_{\text {Tot }} \\
\text { (ft) }\end{array}$ & $\begin{array}{l}V_{\text {Tot }} \\
\left(\mathrm{ft}^{3}\right)\end{array}$ & \\
\hline FWD-J017 & 3 & 10.0 & $\mathrm{C} 3$ & $\mathrm{H}$ & 1 & 16.0 & FWD & NK & 2.5 & 4.00 & 4.0 & 2.67 & 2.7 & 2.66 & 2.7 & 9.33 & 9.4 & 5.7 \\
\hline & & & & & 2 & 10.0 & FWD & NK & 2.5 & 8.00 & 5.5 & 5.33 & 3.6 & 5.34 & 3.6 & 18.67 & 12.7 & 7.7 \\
\hline & & & & & 3 & 20.0 & $\mathrm{MSC}$ & NK & 3.0 & 0.00 & 0.0 & 4.75 & 7.2 & 4.52 & 6.8 & 9.27 & 14.0 & 7.0 \\
\hline & & & & & 4 & 10.0 & FWC & NK & 2.5 & 3.30 & 2.2 & 1.68 & 1.1 & 1.67 & 1.1 & 6.65 & 4.5 & 2.8 \\
\hline & & & & & 5 & 16.0 & FWC & NK & 2.5 & 0.00 & 0.0 & 2.34 & 2.4 & 2.31 & 2.3 & 4.65 & 4.7 & 2.3 \\
\hline & & & & & & & \multicolumn{3}{|c|}{ Volume Totals } & & 11.7 & & 17.0 & & 16.6 & & 45.3 & 25.6 \\
\hline MSA-J003 & 2 & 20.0 & $\mathrm{C} 1$ & $\mathrm{H}$ & 1 & 20.0 & MSA & NK & 3.0 & 5.00 & 7.5 & 3.33 & 5.0 & 3.34 & 5.0 & 11.67 & 17.6 & 10.7 \\
\hline & & & & & & & \multicolumn{3}{|c|}{ Volume Totals } & & 7.5 & & 5.0 & & 5.0 & & 17.6 & 10.7 \\
\hline MSA-J004 & 2 & 20.0 & $\mathrm{C} 1$ & $\mathrm{H}$ & 1 & 20.0 & MSA & NK & 3.0 & 5.00 & 7.5 & 3.33 & 5.0 & 3.34 & 5.0 & 11.67 & 17.6 & 10.7 \\
\hline & & & & & & & \multicolumn{3}{|c|}{ Volume Totals } & & 7.5 & & 5.0 & & 5.0 & & 17.6 & 10.7 \\
\hline MSA-J005 & 2 & 20.0 & $\mathrm{C} 1$ & $\mathrm{H}$ & 1 & 20.0 & MSA & NK & 3.0 & 5.00 & 7.5 & 3.33 & 5.0 & 3.34 & 5.0 & 11.67 & 17.6 & 10.7 \\
\hline & & & & & & & \multicolumn{3}{|c|}{ Volume Totals } & & 7.5 & & 5.0 & & 5.0 & & 17.6 & 10.7 \\
\hline \multirow{5}{*}{ MSA-J007 } & 2 & 20.0 & $\mathrm{C} 1$ & $\mathrm{H}$ & 1 & 20.0 & MSA & NK & 3.0 & 5.00 & 7.5 & 3.33 & 5.0 & 3.34 & 5.0 & 11.67 & 17.6 & 10.7 \\
\hline & & & & & 2 & 10.0 & FWA & NK & 2.5 & 0.00 & 0.0 & 4.05 & 2.8 & 4.34 & 3.0 & 8.39 & 5.7 & 2.8 \\
\hline & & & & & 3 & 20.0 & MSB & NK & 3.0 & 0.00 & 0.0 & 3.70 & 5.6 & 13.04 & 19.6 & 16.74 & 25.2 & 11.2 \\
\hline & & & & & 4 & 8.0 & CSB & NK & 3.0 & 0.00 & 0.0 & 0.00 & 0.0 & 0.00 & 0.0 & 0.00 & 0.0 & 0.0 \\
\hline & & & & & & & \multicolumn{3}{|c|}{ Volume Totals } & & 7.5 & & 13.3 & & 27.6 & & 48.5 & 24.7 \\
\hline \multirow[t]{5}{*}{ MSA-J009 } & 2 & 20.0 & $\mathrm{Cl}$ & $\mathrm{H}$ & 1 & 20.0 & MSA & NK & 3.0 & 5.00 & 7.5 & 3.33 & 5.0 & 3.34 & 5.0 & 11.67 & 17.6 & 10.7 \\
\hline & & & & & 2 & 10.0 & FWA & NK & 2.5 & 0.00 & 0.0 & 11.48 & 7.8 & 4.96 & 3.4 & 16.44 & 11.2 & 6.0 \\
\hline & & & & & 3 & 20.0 & MSB & NK & 3.0 & 0.00 & 0.0 & 3.70 & 5.6 & 11.13 & 16.8 & 14.83 & 22.3 & 10.0 \\
\hline & & & & & 4 & 8.0 & CSB & NK & 3.0 & 0.00 & 0.0 & 0.00 & 0.0 & 0.00 & 0.0 & 0.00 & 0.0 & 0.0 \\
\hline & & & & & & & \multicolumn{3}{|c|}{ Volume Totals } & & 7.5 & & 18.4 & & 25.2 & & 51.1 & 26.8 \\
\hline \multirow[t]{6}{*}{ MSA-J013 } & 2 & 20.0 & $\mathrm{C} 1$ & $\mathrm{H}$ & 1 & 20.0 & MSA & NK & 3.0 & 5.00 & 7.5 & 3.33 & 5.0 & 3.34 & 5.0 & 11.67 & 17.6 & 10.7 \\
\hline & & & & & 2 & 20.0 & MSB & NK & 3.0 & 8.61 & 13.0 & 18.76 & 28.2 & 6.90 & 10.4 & 34.27 & 51.6 & 30.8 \\
\hline & & & & & 3 & 10.0 & FWA & NK & 2.5 & 0.00 & 0.0 & 6.12 & 4.2 & 10.49 & 7.2 & 16.61 & 11.3 & 5.4 \\
\hline & & & & & 4 & 10.0 & RRB & NK & 2.5 & 7.81 & 5.3 & 9.58 & 6.5 & 0.00 & 0.0 & 17.39 & 11.9 & 7.9 \\
\hline & & & & & 5 & 10.0 & RRA & NK & 2.5 & 0.00 & 0.0 & 0.00 & 0.0 & 13.61 & 9.3 & 13.61 & 9.3 & 3.7 \\
\hline & & & & & 6 & 10.0 & RRC & NK & 2.5 & 0.00 & 0.0 & 0.00 & 0.0 & 13.61 & 9.3 & 13.61 & 9.3 & 3.7 \\
\hline
\end{tabular}


Table D-1

Listing of Targets for Welds

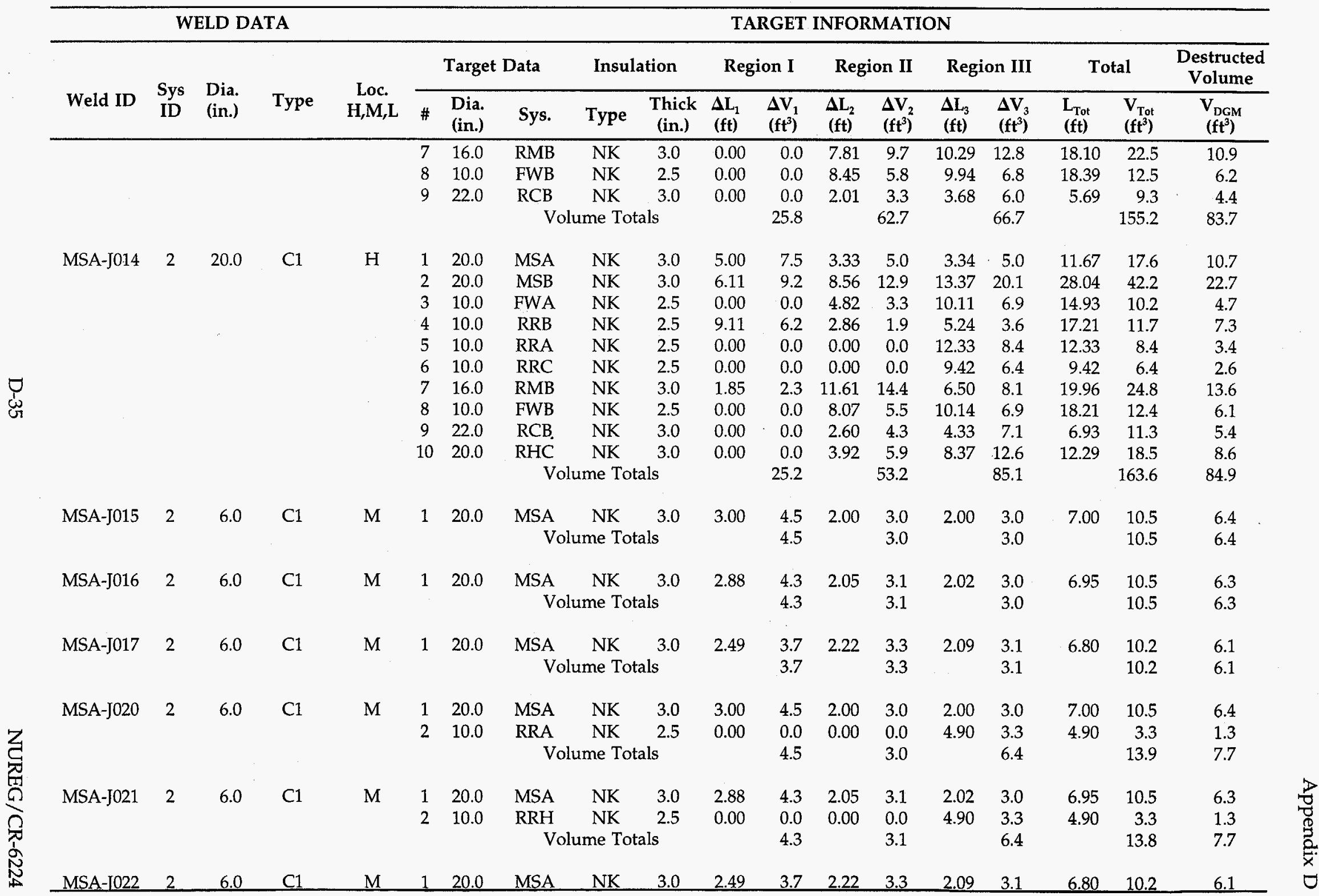




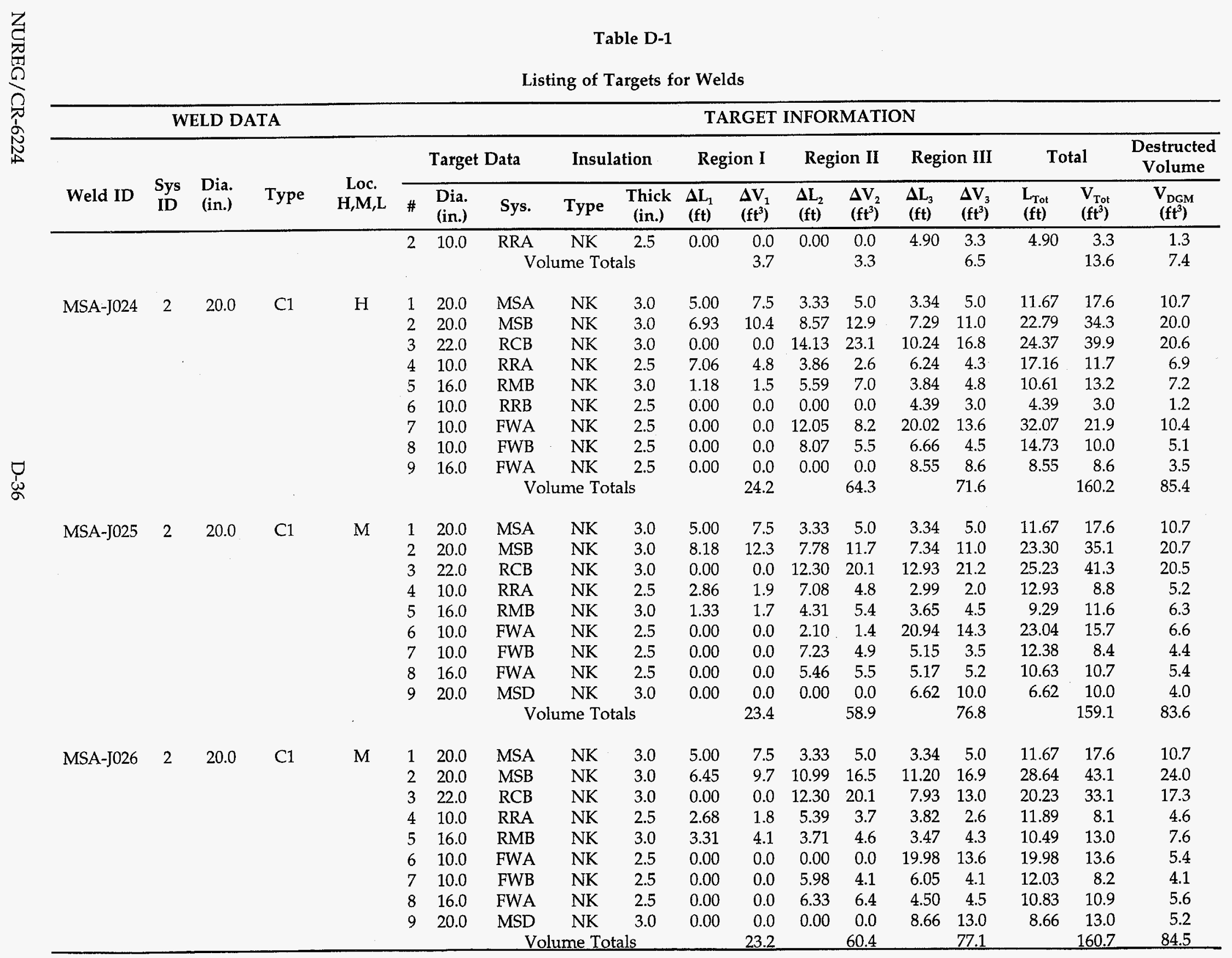


Appendix D

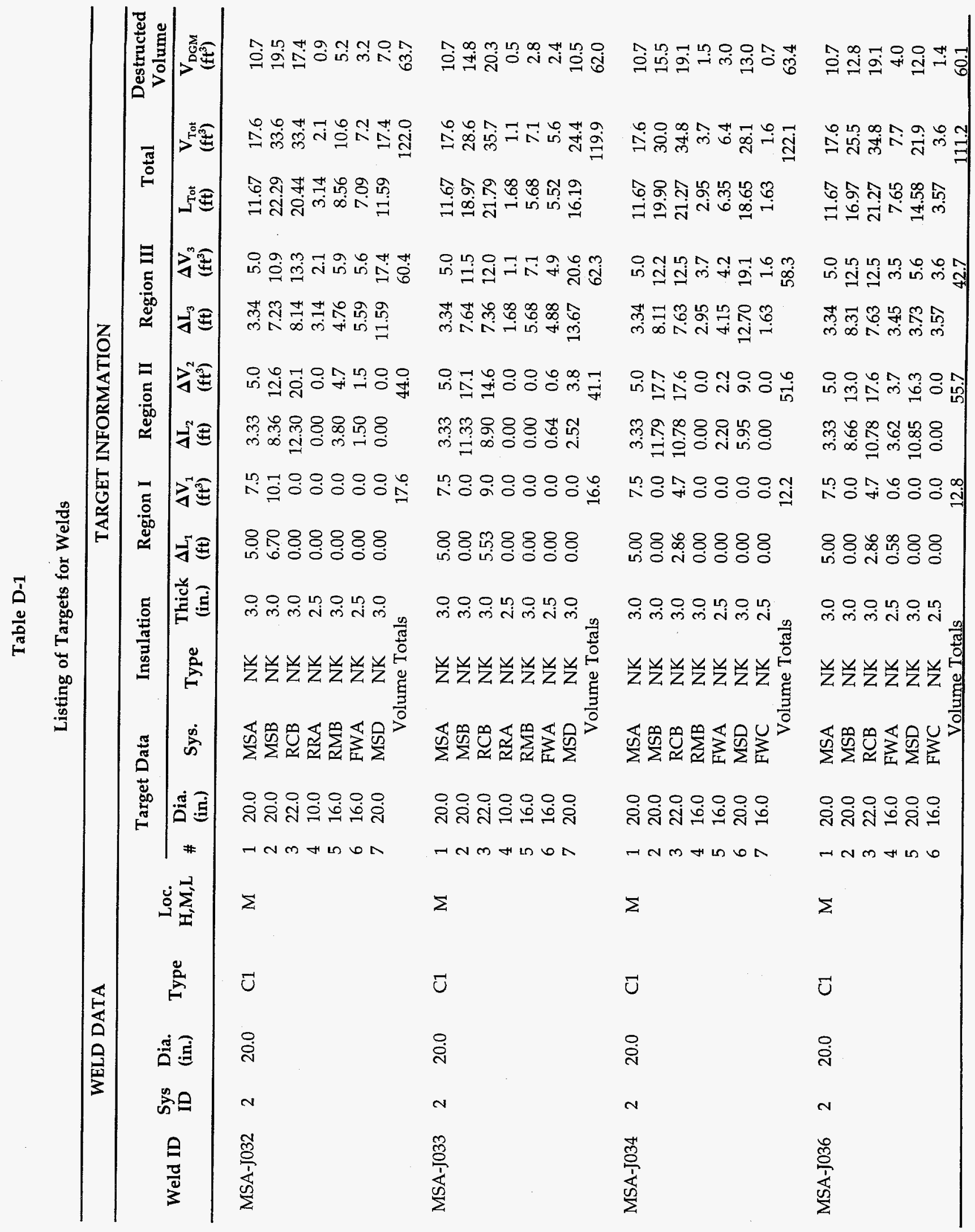




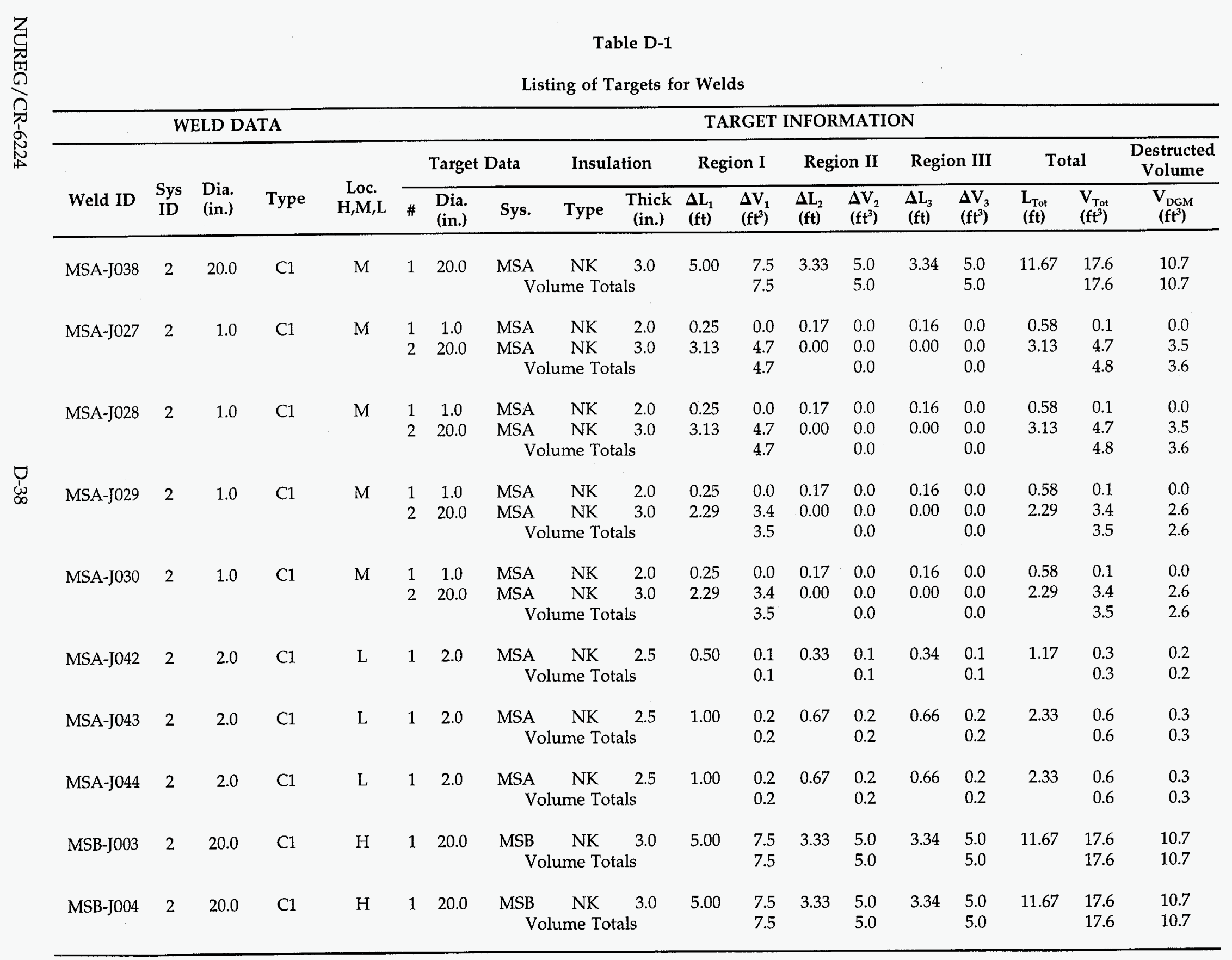


Appendix D

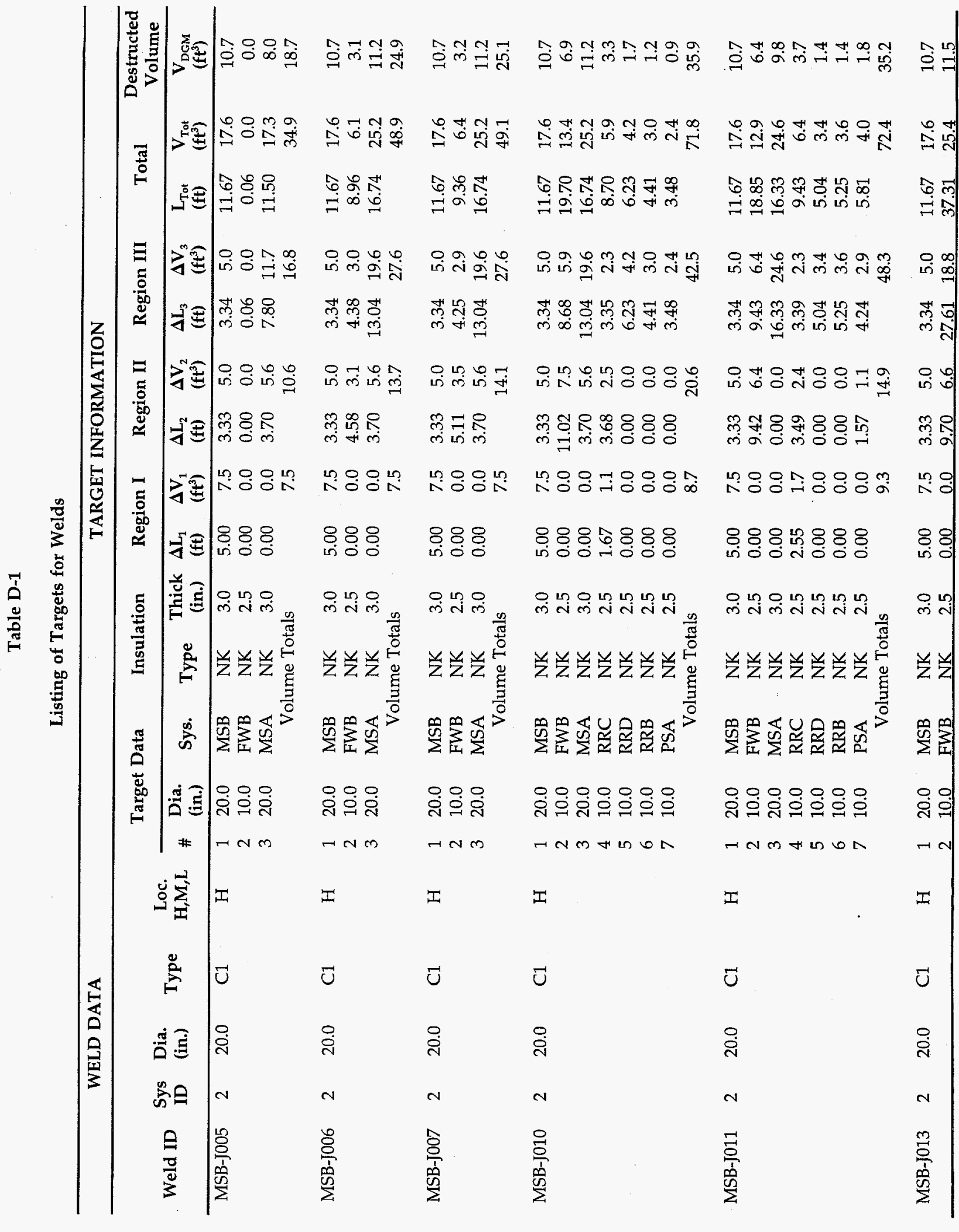




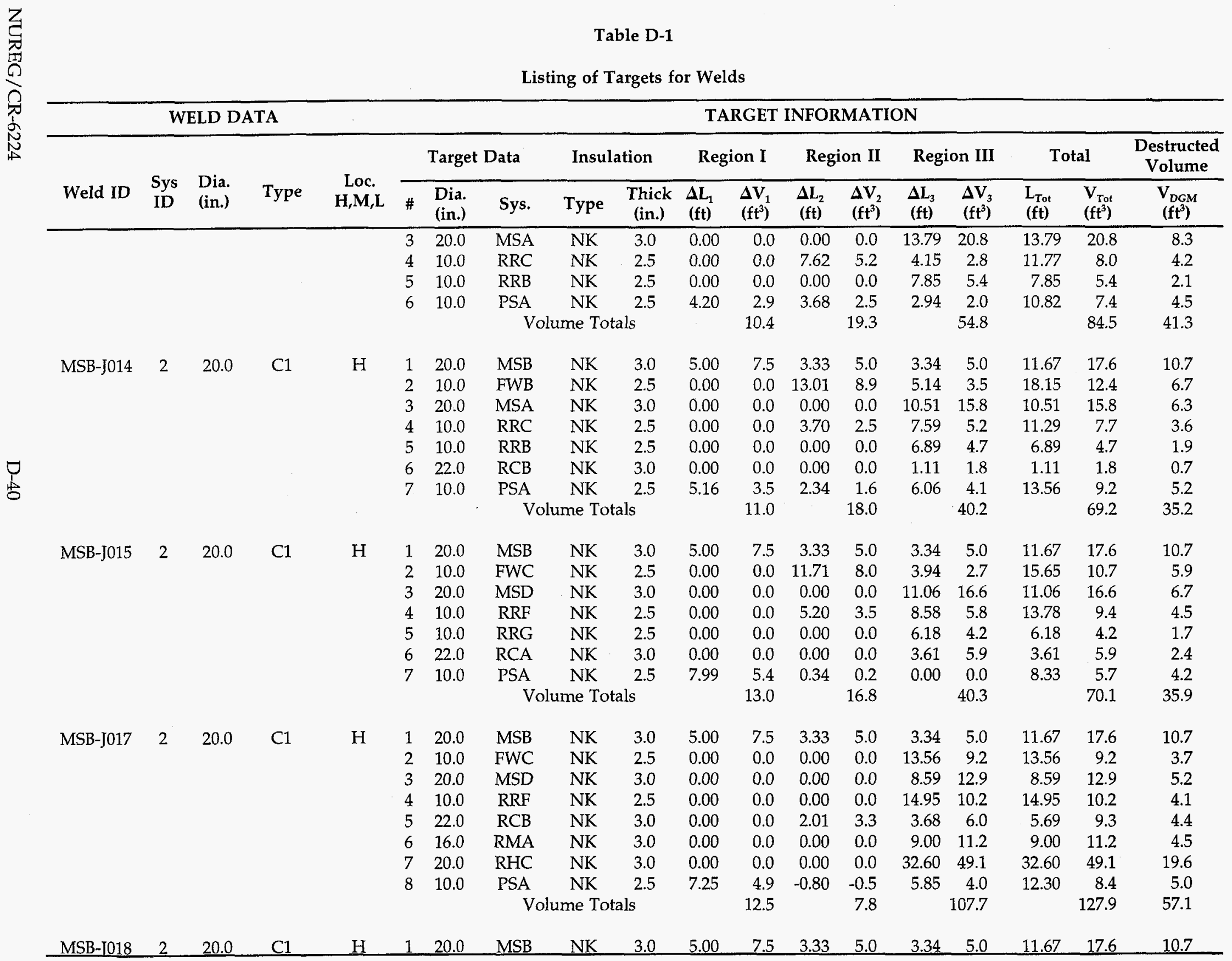


Table D-1

Listing of Targets for Welds

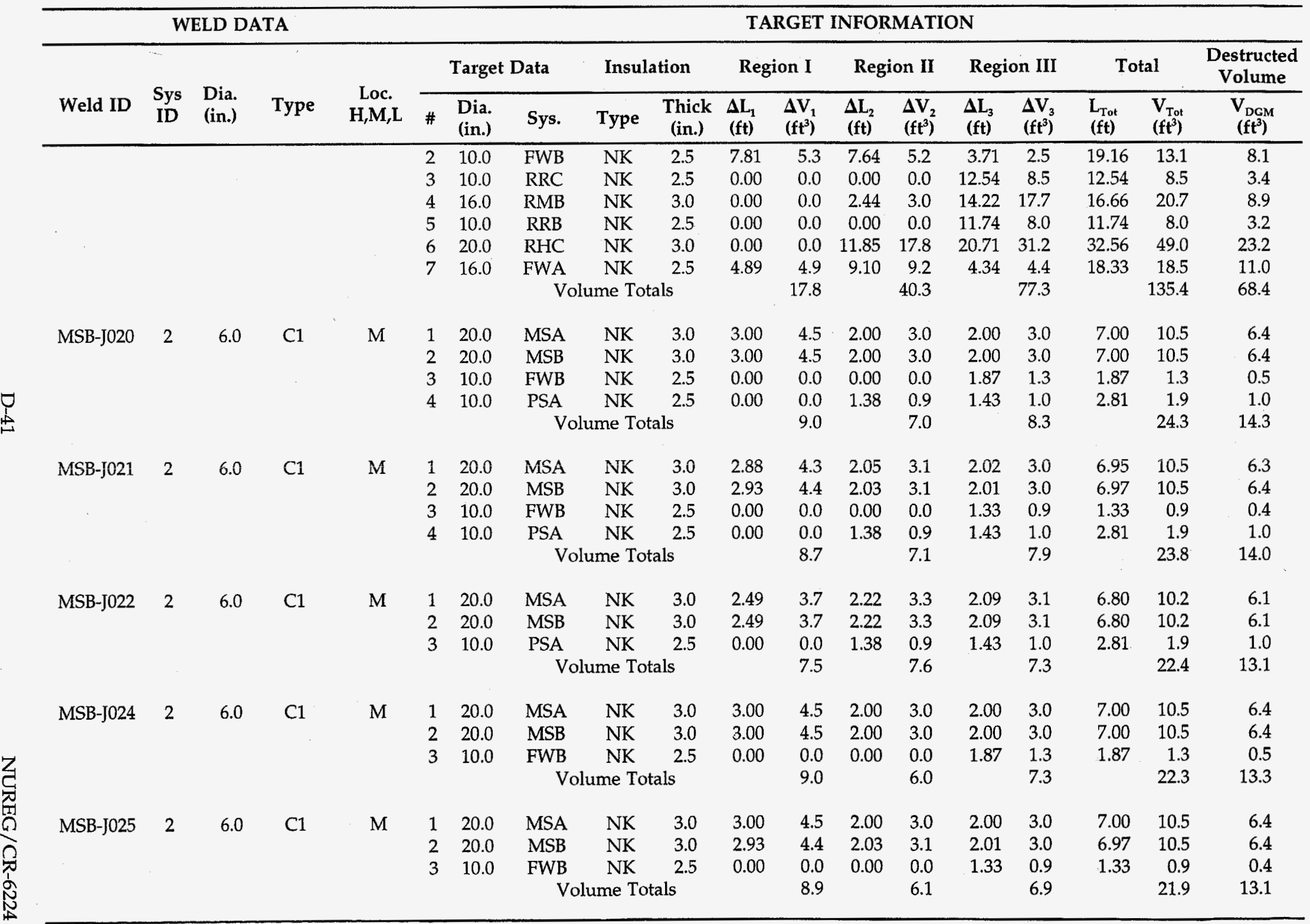


Table D-1

Listing of Targets for Welds

\begin{tabular}{|c|c|c|c|c|c|c|c|c|c|c|c|c|c|c|c|c|c|c|}
\hline \multirow[b]{3}{*}{ Weld ID } & \multicolumn{4}{|c|}{ WELD DATA } & \multicolumn{14}{|c|}{ TARGET INFORMATION } \\
\hline & \multirow[b]{2}{*}{$\begin{array}{l}\text { Sys } \\
\text { ID }\end{array}$} & \multirow[b]{2}{*}{$\begin{array}{l}\text { Dia. } \\
\text { (in.) }\end{array}$} & \multirow[b]{2}{*}{ Type } & \multirow[b]{2}{*}{$\begin{array}{c}\text { Loc. } \\
\text { H,M,L }\end{array}$} & \multicolumn{3}{|c|}{ Target Data } & \multicolumn{2}{|c|}{ Insulation } & \multicolumn{2}{|c|}{ Region I } & \multicolumn{2}{|c|}{ Region II } & \multicolumn{2}{|c|}{ Region III } & \multicolumn{2}{|c|}{ Total } & \multirow{2}{*}{$\begin{array}{c}\begin{array}{c}\text { Destructed } \\
\text { Volume }\end{array} \\
\begin{array}{c}V_{D G M} \\
\left(\mathbf{f t}^{3}\right)\end{array} \\
\end{array}$} \\
\hline & & & & & $\#$ & $\begin{array}{l}\text { Dia. } \\
\text { (in.) }\end{array}$ & Sys. & Type & $\begin{array}{c}\text { Thick } \\
\text { (in.) }\end{array}$ & $\begin{array}{l}\Delta \mathrm{L}_{1} \\
(\mathrm{ft})\end{array}$ & $\begin{array}{l}\Delta V_{1} \\
\left(\mathbf{f t}^{3}\right)^{\prime}\end{array}$ & $\begin{array}{l}\Delta \mathbf{L}_{2} \\
(\mathrm{ft})\end{array}$ & $\begin{array}{l}\Delta V_{2} \\
\left(f^{3}\right)^{3}\end{array}$ & $\begin{array}{l}\Delta \mathrm{L}_{3} \\
(\mathrm{ft})\end{array}$ & $\begin{array}{l}\Delta \mathbf{V}_{3} \\
\left(\mathrm{ft}^{3}\right)^{2}\end{array}$ & $\begin{array}{l}\mathbf{L}_{\text {Tot }} \\
(\mathrm{ft})\end{array}$ & $\begin{array}{l}V_{\mathrm{Tot}_{1}} \\
\left(\mathrm{ft}^{3}\right)\end{array}$ & \\
\hline \multirow[t]{3}{*}{ MSB-J026 } & 2 & 6.0 & $\mathrm{C} 1$ & $\bar{M}$ & 1 & 20.0 & MSA & NK & 3.0 & 3.00 & 4.5 & 2.00 & 3.0 & 2.00 & 3.0 & 7.00 & 10.5 & 6.4 \\
\hline & & & & & 2 & 20.0 & MSB & NK & 3.0 & 2.49 & 3.7 & 2.22 & 3.3 & 2.09 & 3.1 & 6.80 & 10.2 & 6.1 \\
\hline & & & & & & \multicolumn{4}{|c|}{ Volume Totals } & & 8.3 & & 6.4 & & 6.2 & & 20.8 & 12.5 \\
\hline \multirow[t]{10}{*}{ MSB-J029 } & 2 & 20.0 & $\mathrm{C} 1$ & $\mathrm{H}$ & 1 & 20.0 & MSB & NK & 3.0 & 5.00 & 7.5 & 3.33 & 5.0 & 3.34 & 5.0 & 11.67 & 17.6 & 10.7 \\
\hline & & & & & 2 & 20.0 & MSA & NK & 3.0 & 7.77 & 11.7 & 8.94 & 13.5 & 7.38 & 11.1 & 24.09 & 36.3 & 21.3 \\
\hline & & & & & 3 & 10.0 & FWB & NK & 2.5 & 7.81 & 5.3 & 5.96 & 4.1 & 3.51 & 2.4 & 17.28 & 11.8 & 7.4 \\
\hline & & & & & 4 & 16.0 & FWA & NK & 2.5 & 0.00 & 0.0 & 5.27 & 5.3 & 4.45 & 4.5 & 9.72 & 9.8 & 5.0 \\
\hline & & & & & 5 & 10.0 & FWA & NK & 2.5 & 2.14 & 1.5 & 11.42 & 7.8 & 10.38 & 7.1 & 23.94 & 16.3 & 8.6 \\
\hline & & & & & 6 & 22.0 & $\mathrm{RCB}$ & NK & 3.0 & 0.00 & 0.0 & 0.00 & 0.0 & 13.10 & 21.4 & 13.10 & 21.4 & 8.6 \\
\hline & & & & & 7 & 16.0 & RMB & NK & 3.0 & 0.00 & 0.0 & 2.01 & 2.5 & 6.56 & 8.2 & 8.57 & 10.7 & 4.8 \\
\hline & & & & & 8 & 10.0 & RRA & NK & 2.5 & 0.00 & 0.0 & 9.42 & 6.4 & 4.80 & 3.3 & 14.22 & 9.7 & 5.2 \\
\hline & & & & & 9 & 10.0 & PSA & NK & 2.5 & 0.00 & 0.0 & 15.20 & 10.4 & 5.07 & 3.5 & 20.27 & 13.8 & 7.6 \\
\hline & & & & & & \multicolumn{4}{|c|}{ Volume Totals } & & 26.0 & & 54.9 & & 66.4 & & 147.3 & 79.0 \\
\hline \multirow[t]{10}{*}{ MSB-J030 } & 2 & 20.0 & $\mathrm{C} 1$ & M & 1 & 20.0 & MSB & NK & 3.0 & 5.00 & 7.5 & 3.33 & 5.0 & 3.34 & 5.0 & 11.67 & 17.6 & 10.7 \\
\hline & & & & & 2 & 20.0 & MSA & NK & 3.0 & 9.53 & 14.3 & 9.01 & 13.6 & 7.38 & 11.1 & 25.92 & 39.0 & 23.3 \\
\hline & & & & & 3 & 10.0 & FWB & NK & 2.5 & 7.53 & 5.1 & 5.65 & 3.9 & 3.53 & 2.4 & 16.71 & 11.4 & 7.1 \\
\hline & & & & & 4 & 16.0 & FWA & NK & 2.5 & 0.00 & 0.0 & 8.23 & 8.3 & 2.19 & 2.2 & 10.42 & 10.5 & 5.9 \\
\hline & & & & & 5 & 10.0 & FWA & NK & 2.5 & 1.04 & 0.7 & 12.06 & 8.2 & 3.56 & 2.4 & 16.66 & 11.4 & 6.4 \\
\hline & & & & & 6 & 22.0 & $\mathrm{RCB}$ & NK & 3.0 & 0.00 & 0.0 & 0.00 & 0.0 & 14.95 & 24.5 & 14.95 & 24.5 & 9.8 \\
\hline & & & & & 7 & 10.0 & RRA & NK & 2.5 & 0.00 & 0.0 & 7.72 & 5.3 & 4.88 & 3.3 & 12.60 & 8.6 & 4.5 \\
\hline & & & & & 8 & 16.0 & RMB & NK & 3.0 & 0.00 & 0.0 & 3.73 & 4.6 & 5.25 & 6.5 & 8.98 & 11.2 & 5.4 \\
\hline & & & & & 9 & 10.0 & PSA & NK & 2.5 & 0.00 & 0.0 & 13.85 & 9.4 & 4.38 & 3.0 & 18.23 & 12.4 & 6.9 \\
\hline & & & & & \multicolumn{5}{|c|}{ Volume Totals } & & 27.7 & & 58.3 & & 60.5 & & 146.5 & 80.0 \\
\hline \multirow{9}{*}{ MSB-J032 } & 2 & 20.0 & $\mathrm{C} 1$ & $\mathrm{M}$ & 1 & 20.0 & MSB & NK & 3.0 & 5.00 & 7.5 & 3.33 & 5.0 & 3.34 & 5.0 & 11.67 & 17.6 & 10.7 \\
\hline & & & & & 2 & 20.0 & MSA & NK & 3.0 & 8.92 & 13.4 & 10.27 & 15.5 & 14.43 & 21.7 & 33.62 & 50.6 & 28.0 \\
\hline & & & & & 3 & 10.0 & FWB & NK & 2.5 & 6.60 & 4.5 & 6.36 & 4.3 & 3.61 & 2.5 & 16.57 & 11.3 & 7.0 \\
\hline & & & & & 4 & 16.0 & FWA & NK & 2.5 & 0.00 & 0.0 & 9.27 & 9.4 & 2.19 & 2.2 & 11.46 & 11.6 & 6.5 \\
\hline & & & & & 5 & 10.0 & FWA & NK & 2.5 & 0.09 & 0.1 & 5.09 & 3.5 & 9.19 & 6.3 & 14.37 & 9.8 & 4.6 \\
\hline & & & & & 6 & 22.0 & RCB & NK & 3.0 & 0.00 & 0.0 & 0.00 & 0.0 & 14.95 & 24.5 & 14.95 & 24.5 & 9.8 \\
\hline & & & & & 7 & 10.0 & RRA & NK & 2.5 & 0.00 & 0.0 & 6.68 & 4.6 & 4.88 & 3.3 & 11.56 & 7.9 & 4.1 \\
\hline & & & & & 8 & 16.0 & RMB & NK & 3.0 & 0.00 & 0.0 & 4.44 & 5.5 & 4.86 & 6.0 & 9.30 & 11.6 & 5.7 \\
\hline & & & & & 9 & 10.0 & PSA & NK & 2.5 & 0.00 & 0.0 & 12.98 & 8.8 & 4.80 & 3.3 & 17.78 & 12.1 & 6.6 \\
\hline
\end{tabular}


Table D-1

Listing of Targets for Welds

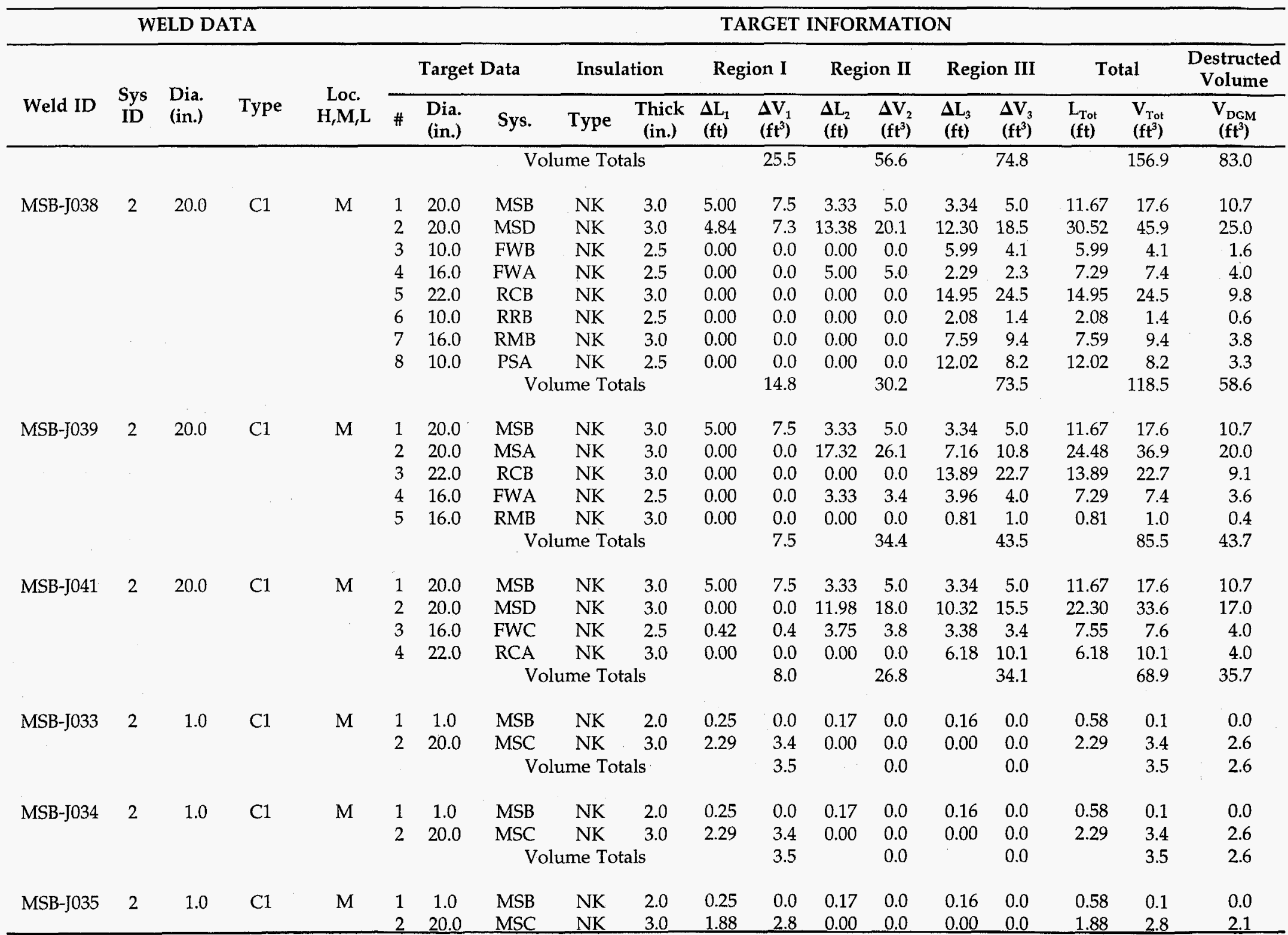


Table D-1

Listing of Targets for Welds

\begin{tabular}{|c|c|c|c|c|c|c|c|c|c|c|c|c|c|c|c|c|c|c|}
\hline \multirow[b]{3}{*}{ Weld ID } & \multicolumn{4}{|c|}{ WELD DATA } & \multicolumn{14}{|c|}{ TARGET INFORMATION } \\
\hline & \multirow[b]{2}{*}{$\begin{array}{l}\text { Sys } \\
\text { ID }\end{array}$} & \multirow[b]{2}{*}{$\begin{array}{l}\text { Dia. } \\
\text { (in.) }\end{array}$} & \multirow[b]{2}{*}{ Type } & \multirow[b]{2}{*}{$\begin{array}{c}\text { Loc. } \\
\mathbf{H}, \mathbf{M}, \mathbf{L}\end{array}$} & \multicolumn{3}{|c|}{ Target Data } & \multicolumn{2}{|c|}{ Insulation } & \multicolumn{2}{|c|}{ Region I } & \multicolumn{2}{|c|}{ Region II } & \multicolumn{2}{|c|}{ Region III } & \multicolumn{2}{|c|}{ Total } & \multirow{2}{*}{$\begin{array}{c}\begin{array}{c}\text { Destructed } \\
\text { Volume }\end{array} \\
\begin{array}{c}\mathrm{V}_{\mathrm{DGM}} \\
\left(\mathrm{ft}^{3}\right)\end{array}\end{array}$} \\
\hline & & & & & $\#$ & $\begin{array}{l}\text { Dia. } \\
\text { (in.) }\end{array}$ & Sys. & Type & $\begin{array}{c}\text { Thick } \\
\text { (in.) }\end{array}$ & $\begin{array}{l}\Delta \mathbf{L}_{1} \\
(\mathrm{ft})\end{array}$ & $\begin{array}{l}\Delta \mathrm{V}_{1} \\
\left(\mathrm{ft}^{3}\right)\end{array}$ & $\begin{array}{l}\Delta \mathrm{L}_{2} \\
(\mathrm{ft})\end{array}$ & $\underset{\left(\mathrm{ft}^{3}\right)}{\Delta \mathrm{V}_{2}}$ & $\begin{array}{l}\Delta \mathrm{L}_{3} \\
(\mathrm{ft})\end{array}$ & $\begin{array}{l}\Delta \mathbf{V}_{3} \\
\left(\mathbf{f t}^{3}\right)^{2}\end{array}$ & $\begin{array}{l}\mathrm{L}_{\mathrm{Tot}} \\
\text { (ft) }\end{array}$ & $\begin{array}{l}V_{\text {TTot }} \\
\left(\mathrm{ft}^{3}\right)\end{array}$ & \\
\hline \multirow{4}{*}{ MSB-J036 } & \multirow{4}{*}{2} & \multirow{4}{*}{1.0} & \multirow{4}{*}{$\mathrm{C} 1$} & \multirow{4}{*}{ M } & & \multicolumn{4}{|c|}{ Volume Totals } & & 2.9 & & 0.0 & & 0.0 & & 2.9 & 2.2 \\
\hline & & & & & \multirow{3}{*}{$\begin{array}{l}1 \\
2\end{array}$} & 1.0 & MSB. & NK & 2.0 & 0.25 & 0.0 & 0.17 & 0.0 & 0.16 & 0.0 & 0.58 & 0.1 & 0.0 \\
\hline & & & & & & 20.0 & MSC & NK & 3.0 & 1.88 & 2.8 & 0.00 & 0.0 & 0.00 & 0.0 & 1.88 & 2.8 & 2.1 \\
\hline & & & & & & \multicolumn{4}{|c|}{ Volume Totals } & & 2.9 & & 0.0 & & 0.0 & & 2.9 & 2.2 \\
\hline \multirow[t]{2}{*}{ MSB-J048 } & \multirow[t]{2}{*}{2} & \multirow[t]{2}{*}{2.0} & $\mathrm{C} 1$ & $\mathrm{~L}$ & 1 & 2.0 & MSB & CS & 2.5 & 0.50 & 0.0 & 0.33 & 0.0 & 0.34 & 0.0 & 1.17 & 0.0 & 0.0 \\
\hline & & & & & & & & Ime Tot & & & 0.0 & & 0.0 & & 0.0 & & 0.0 & 0.0 \\
\hline MSB-J049 & 2 & 2.0 & $\mathrm{C} 1$ & $\mathrm{~L}$ & 1 & 2.0 & MSB & CS & 2.5 & 1.00 & 0.0 & 0.67 & 0.0 & 0.66 & 0.0 & 2.33 & 0.0 & 0.0 \\
\hline & & & & & & & & Ime Tot & & & 0.0 & & 0.0 & & 0.0 & & 0.0 & 0.0 \\
\hline MSB-J050 & 2 & 2.0 & $\mathrm{C} 1$ & $\mathrm{~L}$ & 1 & 2.0 & MSB & CS & 2.5 & 1.00 & 0.0 & 0.67 & 0.0 & 0.66 & 0.0 & 2.33 & 0.0 & 0.0 \\
\hline & & & & & & & & Ime Tot & & & 0.0 & & 0.0 & & 0.0 & & 0.0 & 0.0 \\
\hline MSC-J003 & 2 & 20.0 & $\mathrm{Cl}$ & $\mathrm{H}$ & 1 & 20.0 & MSC & NK & 3.0 & 5.00 & 7.5 & 3.33 & 5.0 & 3.34 & 5.0 & 11.67 & 17.6 & 10.7 \\
\hline & & & & & & & & Ime Tot & & & 7.5 & & 5.0 & & 5.0 & & 17.6 & 10.7 \\
\hline MSC-J004 & 2 & 20.0 & $\mathrm{C} 1$ & $\mathrm{H}$ & 1 & 20.0 & MSC & NK & 3.0 & 5.00 & 7.5 & 3.33 & 5.0 & 3.34 & 5.0 & 11.67 & 17.6 & 10.7 \\
\hline & & & & & & & & Ime Tot & & & 7.5 & & 5.0 & & 5.0 & & 17.6 & 10.7 \\
\hline MSC-J005 & 2 & 20.0 & $\mathrm{C} 1$ & $\mathrm{H}$ & 1 & 20.0 & MSC & NK & 3.0 & 5.00 & 7.5 & 3.33 & 5.0 & 3.34 & 5.0 & 11.67 & 17.6 & 10.7 \\
\hline & & & & & 2 & 10.0 & FWC & NK & 2.5 & 0.00 & 0.0 & 0.00 & 0.0 & 0.06 & 0.0 & 0.06 & 0.0 & 0.0 \\
\hline & & & & & 3 & 20.0 & MSD & NK & 3.0 & 0.00 & 0.0 & 3.70 & 5.6 & 7.80 & 11.7 & 11.50 & 17.3 & 8.0 \\
\hline & & & & & & & & Ime Tot & & & 7.5 & & 10.6 & & 16.8 & & 34.9 & 18.7 \\
\hline MSC-J006 & 2 & 20.0 & $\mathrm{C} 1$ & $\mathrm{H}$ & 1 & 20.0 & MSC & NK & 3.0 & 5.00 & 7.5 & 3.33 & 5.0 & 3.34 & 5.0 & 11.67 & 17.6 & 10.7 \\
\hline & & & & & 2 & 10.0 & FWC & NK & 2.5 & 0.00 & 0.0 & 4.58 & 3.1 & 4.38 & 3.0 & 8.96 & 6.1 & 3.1 \\
\hline & & & & & 3 & 20.0 & MSD & NK & 3.0 & 0.00 & 0.0 & 3.70 & 5.6 & 13.04 & 19.6 & 16.74 & 25.2 & 11.2 \\
\hline & & & & & & & & Ime Tot & & & 7.5 & & 13.7 & & 27.6 & & 48.9 & 24.9 \\
\hline MSC-J009 & 2 & 20.0 & $\mathrm{Cl}$ & $\mathrm{H}$ & 1 & 20.0 & MSC & NK & 3.0 & 5.00 & 7.5 & 3.33 & 5.0 & 3.34 & 5.0 & 11.67 & 17.6 & .10 .7 \\
\hline & & & & & 2 & 10.0 & FWC & NK & 2.5 & 0.00 & 0.0 & 11.02 & 7.5 & 8.68 & 5.9 & 19.70 & 13.4 & 6.9 \\
\hline & & & & & 3 & 20.0 & MSD & NK & 3.0 & 0.00 & 0.0 & 3.70 & 5.6 & 13.04 & 19.6 & 16.74 & 25.2 & 11.2 \\
\hline & & & & & 4 & 10.0 & RRF & NK & 2.5 & 1.67 & 1.1 & 3.68 & 2.5 & 3.35 & 2.3 & 8.70 & 5.9 & 3.3 \\
\hline
\end{tabular}


Table D-1

Listing of Targets for Welds

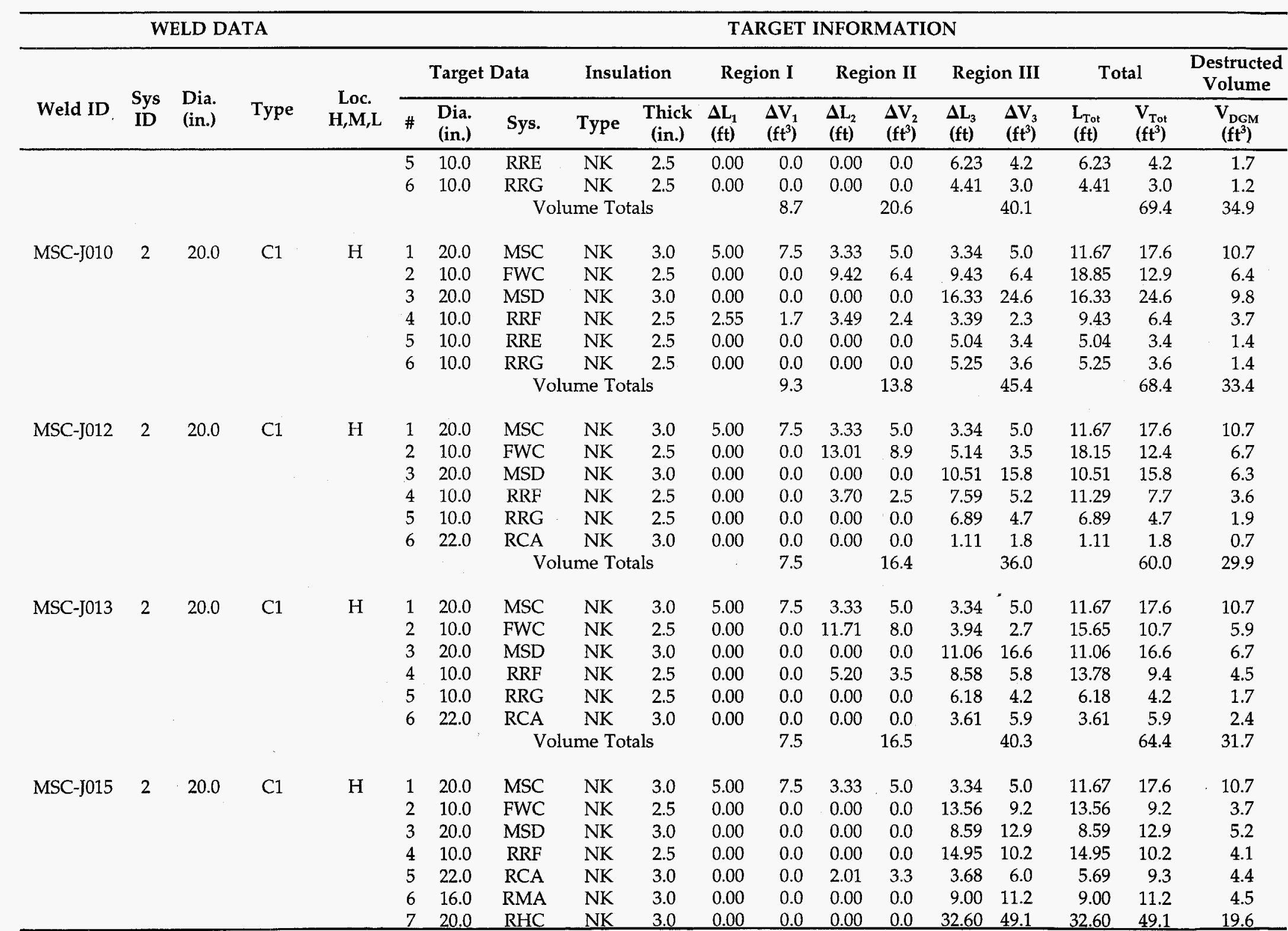




\begin{tabular}{|c|c|c|c|c|c|c|c|c|c|c|c|c|c|c|c|c|c|c|}
\hline & & & & & & & & & $\begin{array}{l}\text { ole D-1 } \\
\text { argets fo }\end{array}$ & & & & & & & & Listing of Targets for Welds & \\
\hline \multicolumn{5}{|c|}{ WELD DATA } & \multicolumn{14}{|c|}{ TARGET INFORMATION } \\
\hline \multirow[b]{2}{*}{ Weld ID } & \multirow[b]{2}{*}{$\begin{array}{l}\text { Sys } \\
\text { ID }\end{array}$} & \multirow[b]{2}{*}{$\begin{array}{l}\text { Dia. } \\
\text { (in.) }\end{array}$} & \multirow[b]{2}{*}{ Type } & \multirow{2}{*}{$\begin{array}{c}\text { Loc. } \\
\text { H,M,L }\end{array}$} & \multicolumn{3}{|c|}{ Target Data } & \multicolumn{2}{|c|}{ Insulation } & \multicolumn{2}{|c|}{ Region I } & \multicolumn{2}{|c|}{ Region II } & \multicolumn{2}{|c|}{ Region III } & \multicolumn{2}{|c|}{ Total } & \multirow{2}{*}{$\begin{array}{c}\begin{array}{c}\text { Destructed } \\
\text { Volume }\end{array} \\
\begin{array}{c}\mathbf{V}_{\mathrm{DGM}} \\
\left(\mathrm{ft}^{3}\right)\end{array}\end{array}$} \\
\hline & & & & & $\#$ & $\begin{array}{l}\text { Dia. } \\
\text { (in.) }\end{array}$ & Sys. & Type & $\begin{array}{l}\text { Thick } \\
\text { (in.) }\end{array}$ & $\begin{array}{l}\Delta \mathbf{L}_{1} \\
(\mathrm{ft})\end{array}$ & $\begin{array}{l}\Delta \mathrm{V}_{1} \\
\left(\mathrm{ft}^{3}\right)\end{array}$ & $\begin{array}{l}\Delta \mathrm{L}_{2} \\
(\mathrm{ft})\end{array}$ & $\begin{array}{l}\Delta \mathbf{V}_{2} \\
\left(\mathrm{ft}^{3}\right)\end{array}$ & $\begin{array}{l}\Delta \mathrm{L}_{3} \\
(\mathrm{ft})\end{array}$ & $\begin{array}{l}\Delta \mathbf{V}_{3} \\
\left(\mathrm{ft}^{3}\right)^{\prime}\end{array}$ & $\begin{array}{l}\mathbf{L}_{\text {Tot }} \\
\text { (ft) }\end{array}$ & $\begin{array}{l}\mathrm{V}_{\text {Tot }} \\
\left(\mathrm{ft}^{3}\right)\end{array}$ & \\
\hline & & & & & & & \multicolumn{3}{|c|}{ Volume Totals } & & 7.5 & & 8.3 & \multicolumn{2}{|r|}{103.7} & & 119.5 & 52.1 \\
\hline MSC-J016 & 2 & 20.0 & $\mathrm{C} 1$ & $\mathrm{H}$ & 1 & 20.0 & MSC & NK & 3.0 & 5.00 & 7.5 & 3.33 & 5.0 & 3.34 & 5.0 & 11.67 & 17.6 & 10.7 \\
\hline & & & & & 2 & 10.0 & FWC & NK & 2.5 & 7.81 & 5.3 & 7.64 & 5.2 & 3.71 & 2.5 & 19.16 & 13.1 & 8.1 \\
\hline & & & & & 3 & 10.0 & RRF & NK & 2.5 & 0.00 & 0.0 & 0.00 & 0.0 & 12.54 & 8.5 & 12.54 & 8.5 & 3.4 \\
\hline & & & & & 4 & 16.0 & RMA & NK & 3.0 & 0.00 & 0.0 & 2.44 & 3.0 & 14.22 & 17.7 & 16.66 & 20.7 & 8.9 \\
\hline & & & & & 5 & 10.0 & RRG & NK & 2.5 & 0.00 & 0.0 & 0.00 & 0.0 & 11.74 & 8.0 & 11.74 & 8.0 & 3.2 \\
\hline & & & & & 6 & 20.0 & RHC & NK & 3.0 & 0.00 & 0.0 & 11.85 & 17.8 & 20.71 & 31.2 & 32.56 & 49.0 & 23.2 \\
\hline & & & & & & \multicolumn{4}{|c|}{ Volume Totals } & & 12.9 & & 31.1 & & 73.0 & & 116.9 & 57.5 \\
\hline MSC-J018 & 2 & 6.0 & $\mathrm{C} 1$ & M & 1 & 20.0 & MSA & NK & 3.0 & 3.00 & 4.5 & 2.00 & 3.0 & 2.00 & 3.0 & 7.00 & 10.5 & 6.4 \\
\hline & & & & & 2 & 20.0 & MSC & NK & 3.0 & 3.00 & 4.5 & 2.00 & 3.0 & 2.00 & 3.0 & 7.00 & 10.5 & 6.4 \\
\hline & & & & & 3 & 10.0 & FWC & NK & 2.5 & 0.00 & 0.0 & 0.00 & 0.0 & 1.87 & 1.3 & 1.87 & 1.3 & 0.5 \\
\hline & & & & & & \multicolumn{4}{|c|}{ Volume Totals } & & 9.0 & & 6.0 & & 7.3 & & 22.3 & 13.3 \\
\hline \multirow[t]{4}{*}{ MSC-J019 } & 2 & 6.0 & $\mathrm{C} 1$ & M & 1 & 20.0 & MSA & NK & 3.0 & 2.88 & 4.3 & 2.05 & 3.1 & 2.02 & 3.0 & 6.95 & 10.5 & 6.3 \\
\hline & & & & & 2 & 20.0 & MSC & NK & 3.0 & 2.93 & 4.4 & 2.03 & 3.1 & 2.01 & 3.0 & 6.97 & 10.5 & 6.4 \\
\hline & & & & & 3 & 10.0 & FWC & NK & 2.5 & 0.00 & 0.0 & 0.00 & 0.0 & 1.33 & 0.9 & 1.33 & 0.9 & 0.4 \\
\hline & & & & & & \multicolumn{4}{|c|}{ Volume Totals } & & 8.7 & & 6.1 & & 7.0 & & 21.9 & 13.0 \\
\hline \multirow{3}{*}{ MSC-J020 } & 2 & 6.0 & $\mathrm{C} 1$ & M & 1 & 20.0 & MSA & NK & 3.0 & 2.49 & 3.7 & 2.22 & 3.3 & 2.09 & 3.1 & 6.80 & 10.2 & 6.1 \\
\hline & & & & & 2 & 20.0 & MSC & NK & 3.0 & 2.49 & 3.7 & 2.22 & 3.3 & 2.09 & 3.1 & 6.80 & 10.2 & 6.1 \\
\hline & & & & & & \multicolumn{4}{|c|}{ Volume Totals } & & 7.5 & & 6.7 & & 6.3 & & 20.5 & 12.1 \\
\hline \multirow[t]{4}{*}{ MSC-J022 } & 2 & 6.0 & $\mathrm{C} 1$ & $M$ & 1 & 20.0 & MSA & NK & 3.0 & 3.00 & 4.5 & 2.00 & 3.0 & 2.00 & 3.0 & 7.00 & 10.5 & 6.4 \\
\hline & & & & & 2 & 20.0 & MSC & NK & 3.0 & 3.00 & 4.5 & 2.00 & 3.0 & 2.00 & 3.0 & 7.00 & 10.5 & 6.4 \\
\hline & & & & & 3 & 10.0 & FWC & NK & 2.5 & 0.00 & 0.0 & 0.00 & 0.0 & 1.87 & 1.3 & 1.87 & 1.3 & 0.5 \\
\hline & & & & & & & & me To & & & 9.0 & & 6.0 & & 7.3 & & 22.3 & 13.3 \\
\hline MSC-J023 & 2 & 6.0 & $\mathrm{C} 1$ & $\mathbf{M}$ & 1 & 20.0 & MSA & NK & 3.0 & 3.00 & 4.5 & 2.00 & 3.0 & 2.00 & 3.0 & 7.00 & 10.5 & 6.4 \\
\hline & & & & & 2 & 20.0 & MSC & NK & 3.0 & 2.93 & 4.4 & 2.03 & 3.1 & 2.01 & 3.0 & 6.97 & 10.5 & 6.4 \\
\hline & & & & & 3 & 10.0 & FWC & NK & 2.5 & 0.00 & 0.0 & 0.00 & 0.0 & 1.33 & 0.9 & 1.33 & 0.9 & 0.4 \\
\hline & & & & & & & & me To & & & 8.9 & & 6.1 & & 6.9 & & 21.9 & 13.1 \\
\hline MSC-I024 & 2 & 6.0 & $\mathrm{C} 1$ & $\mathrm{M}$ & 1 & 20.0 & MSA & NK & 3.0 & 3.00 & 4.5 & 2.00 & 3.0 & 2.00 & 3.0 & 7.00 & 10.5 & 6.4 \\
\hline
\end{tabular}


Appendix D

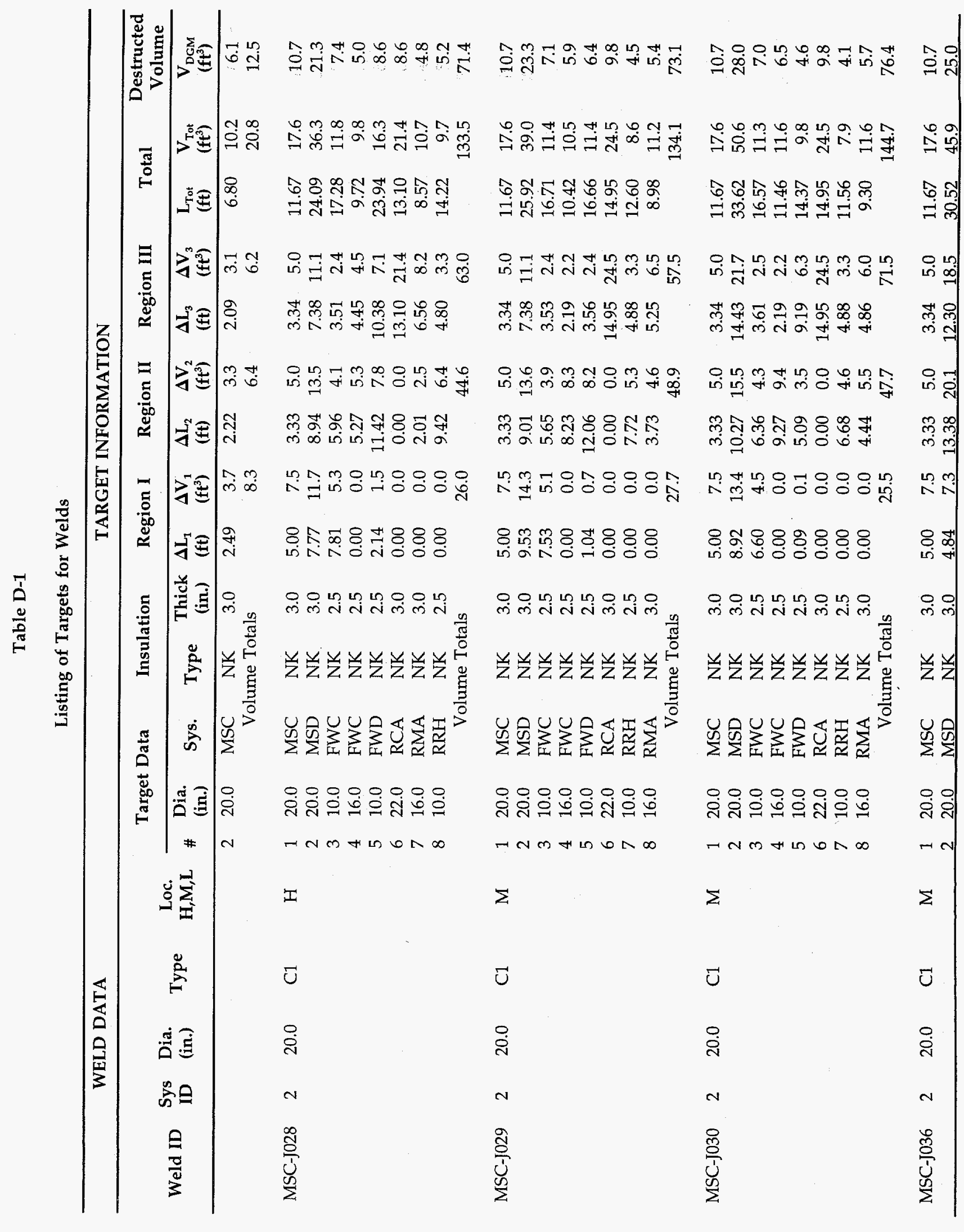


Table D-1

Listing of Targets for Welds

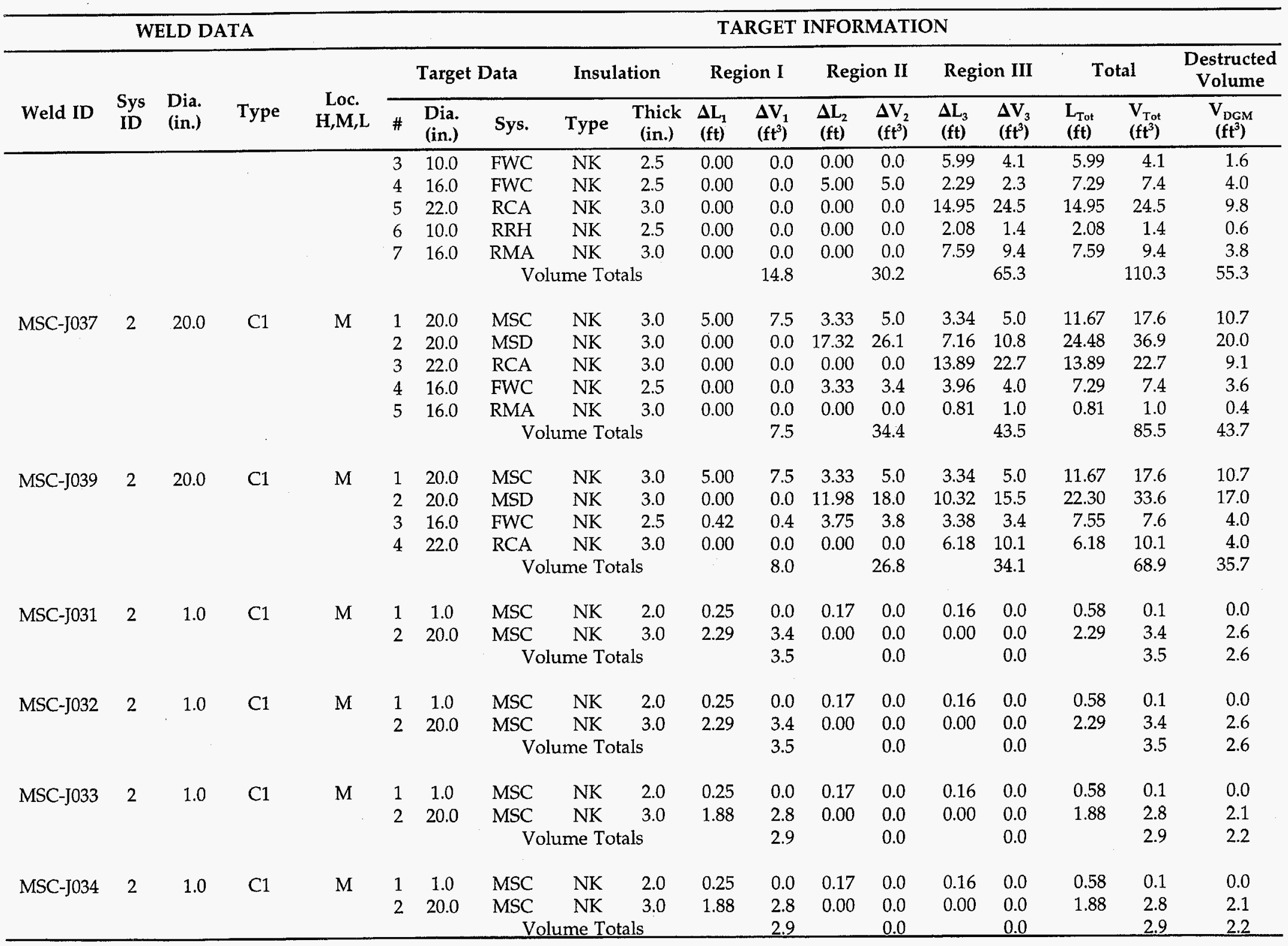


Table D-1

Listing of Targets for Welds

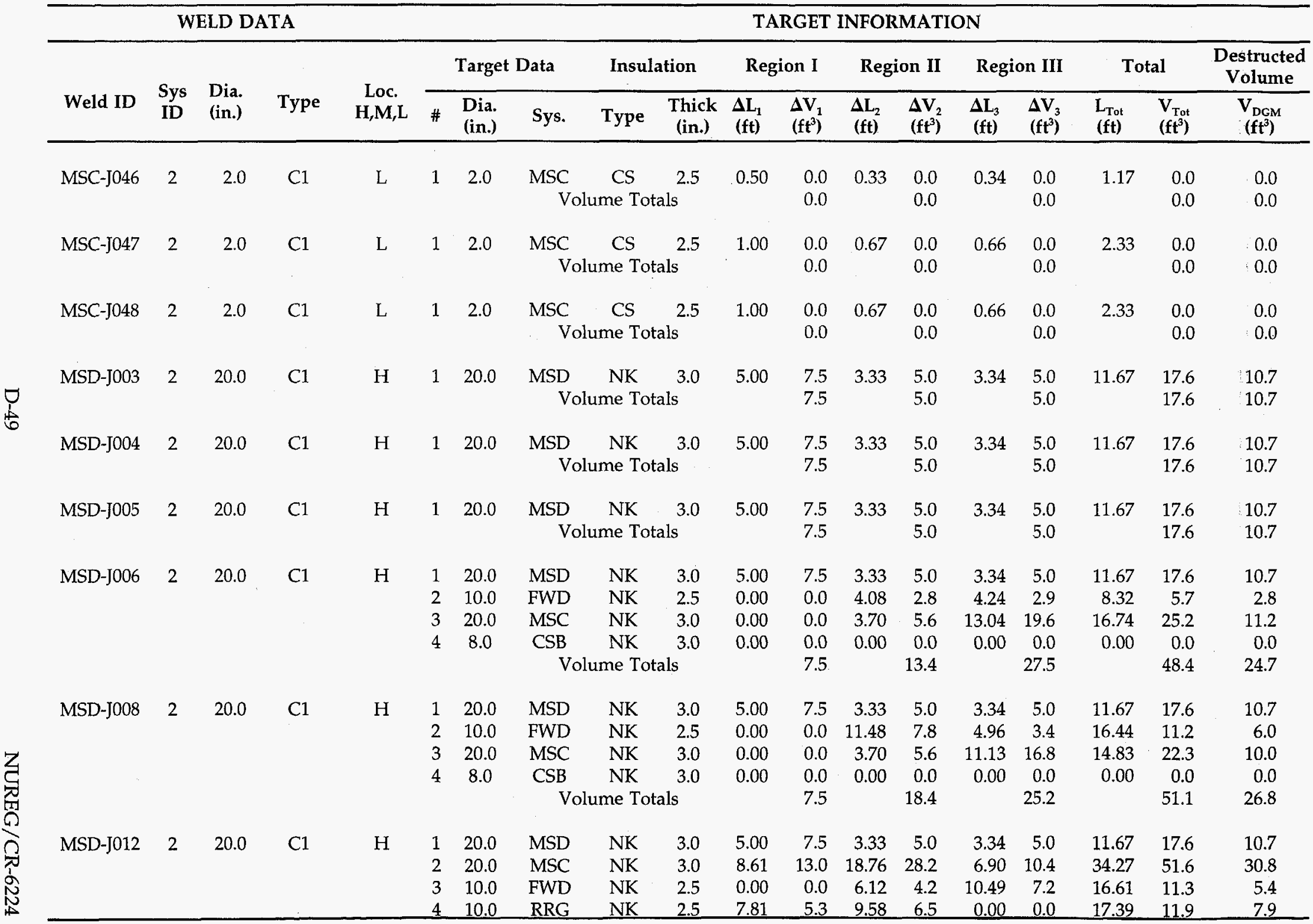


Table D-1

Listing of Targets for Welds

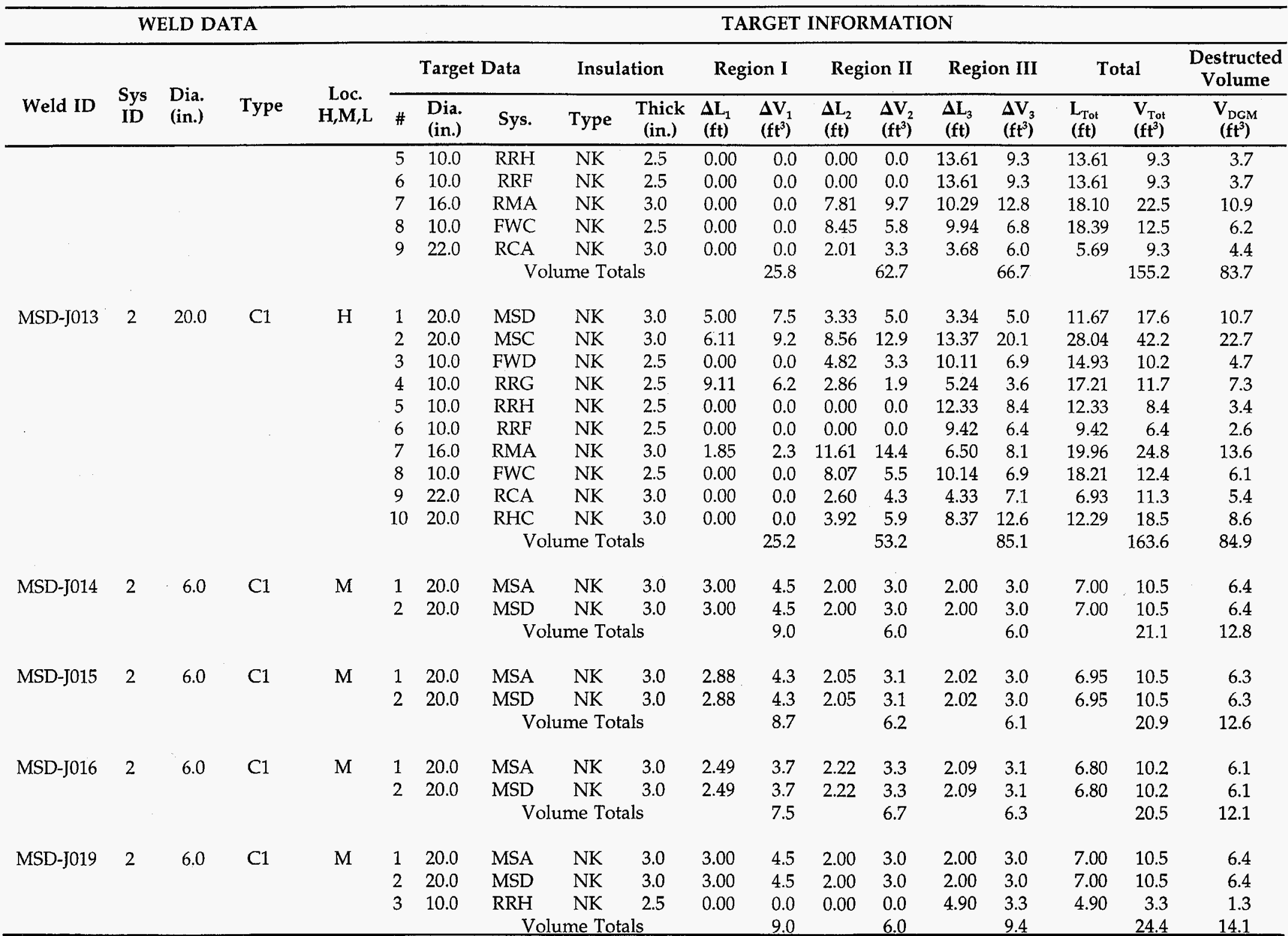


Table D-1

Listing of Targets for Welds

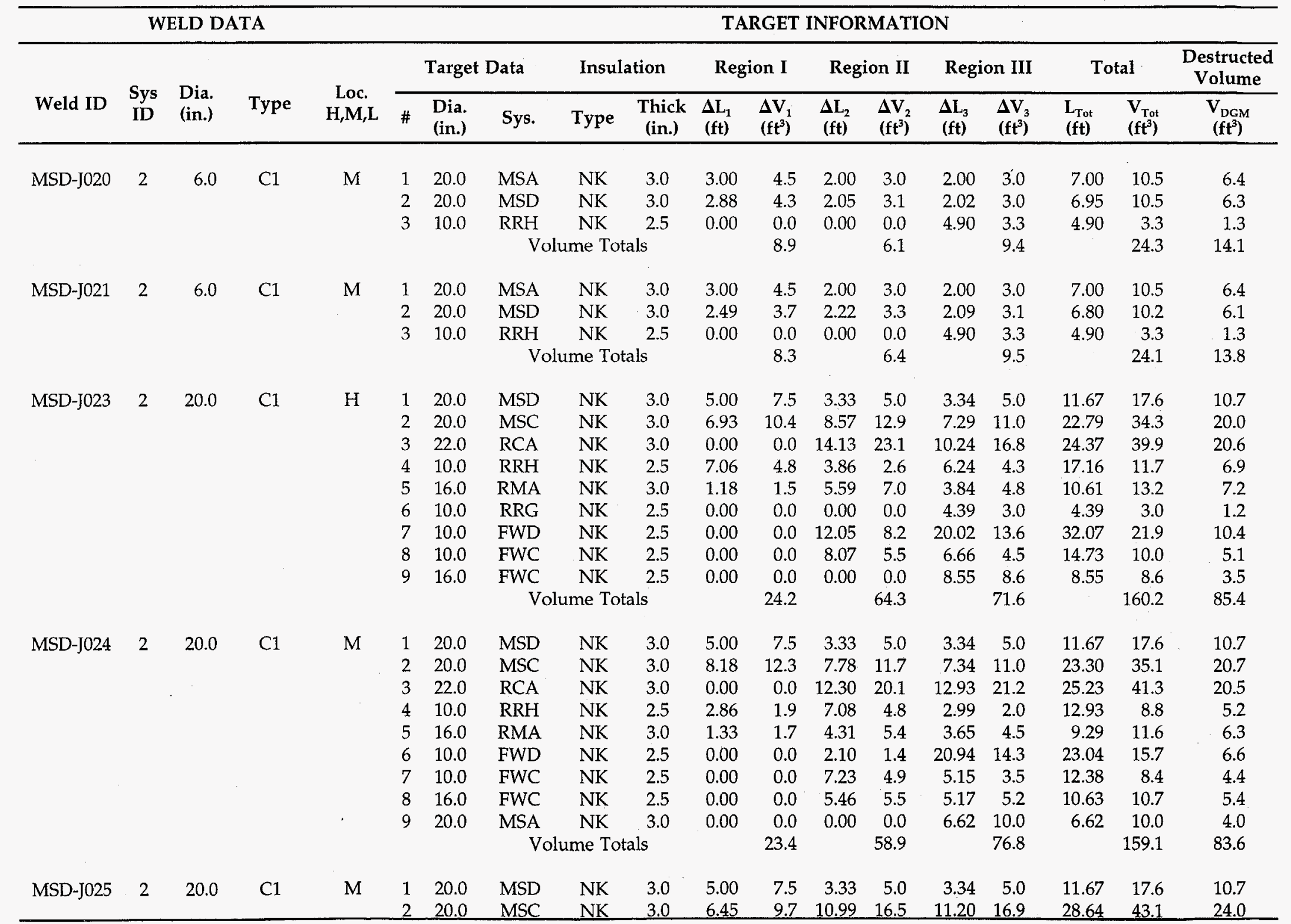


Table D-1

Listing of Targets for Welds

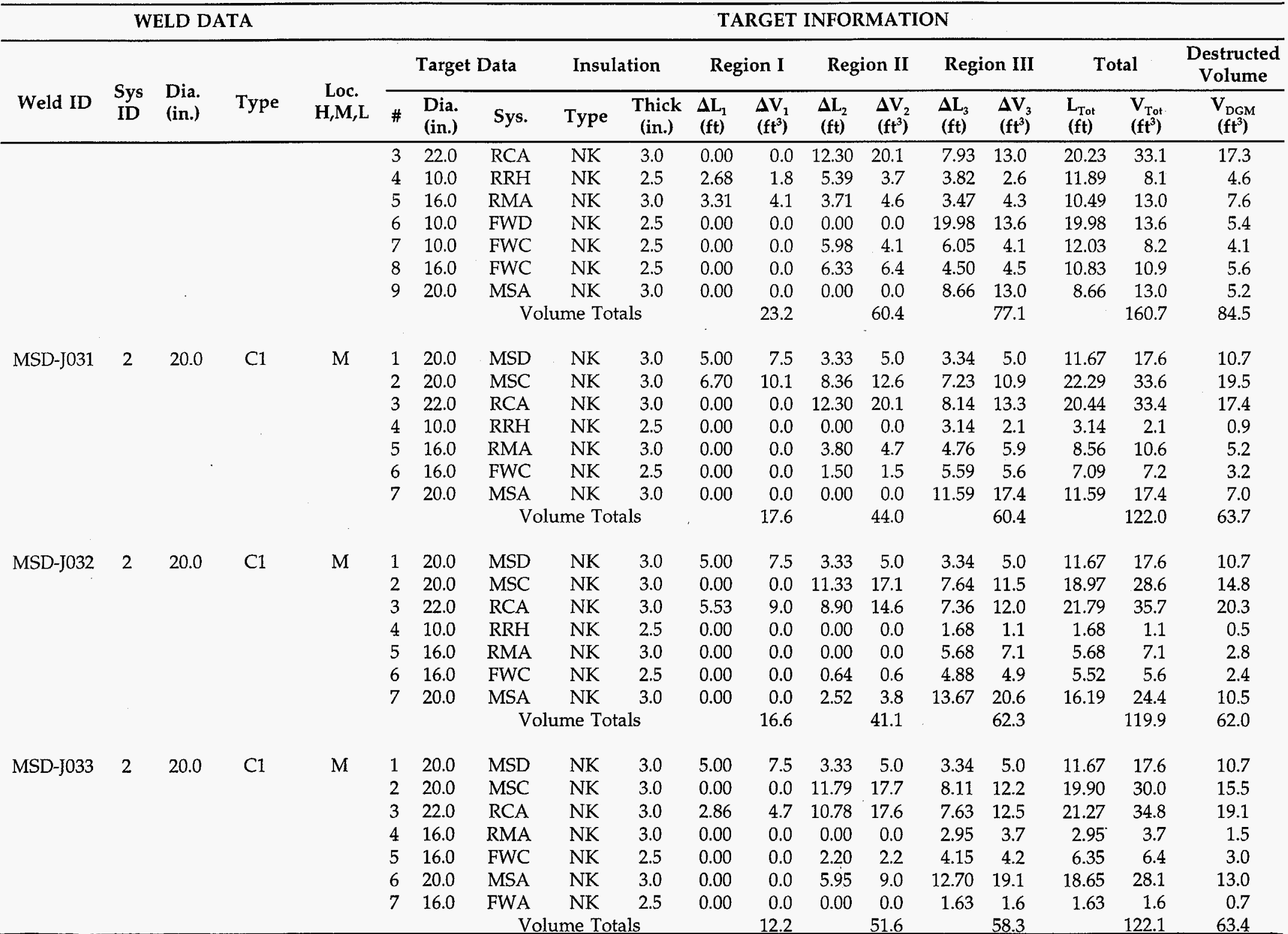


Table D-1

Listing of Targets for Welds

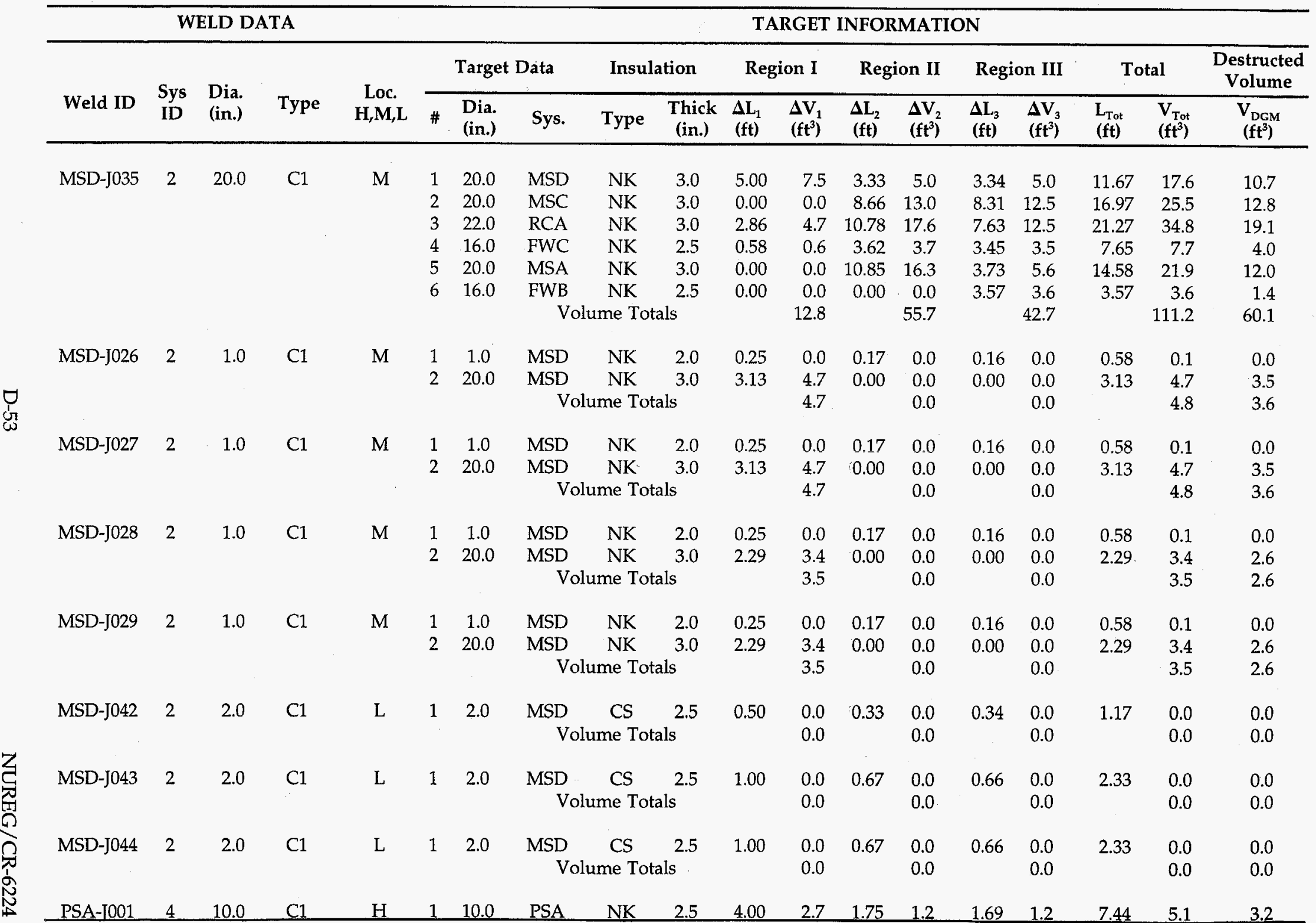




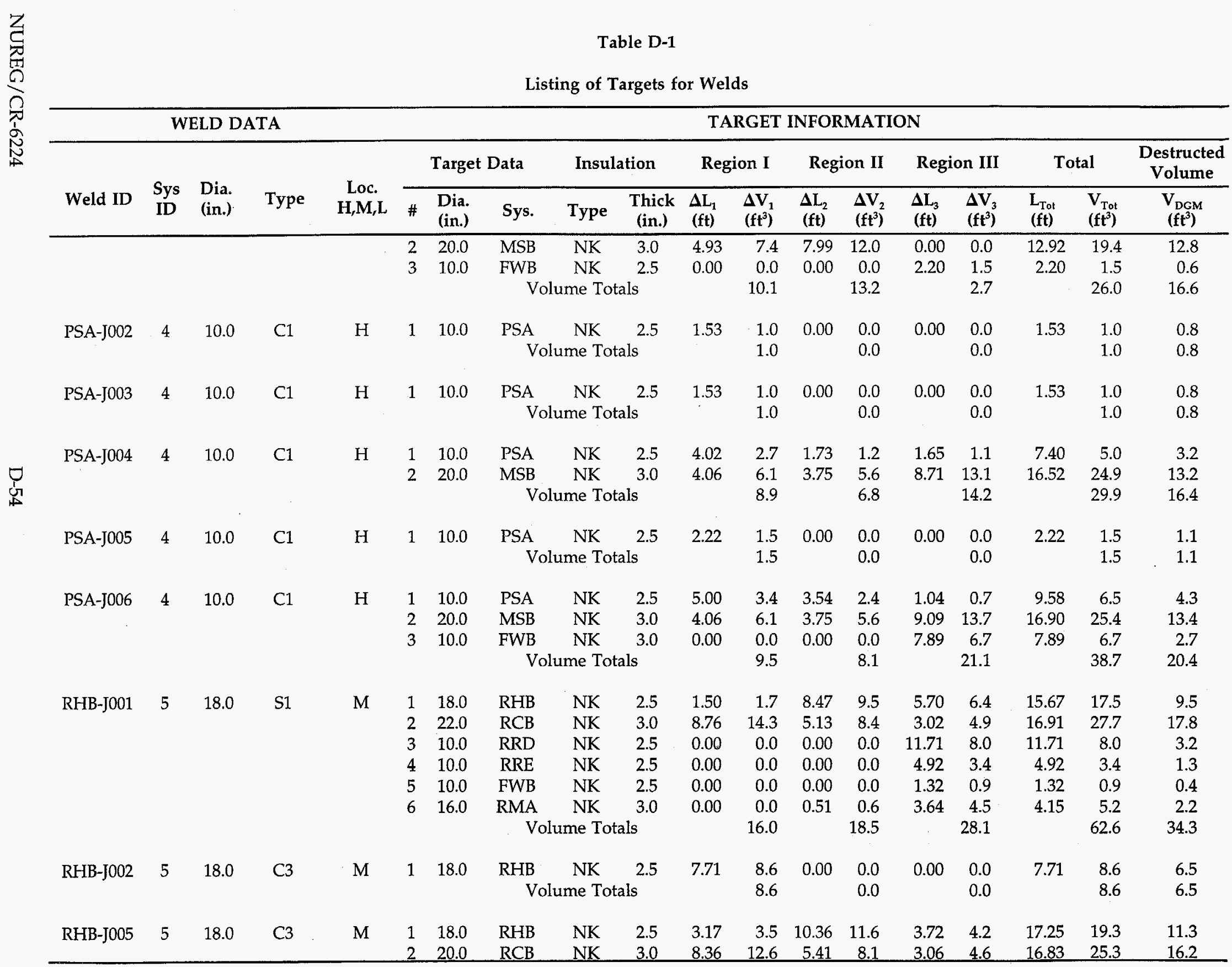


Table D-1

Listing of Targets for Welds

\begin{tabular}{|c|c|c|c|c|c|c|c|c|c|c|c|c|c|c|c|c|c|c|}
\hline \multirow[b]{3}{*}{ Weld ID } & \multicolumn{4}{|c|}{ WELD DATA } & \multicolumn{14}{|c|}{ TARGET INFORMATION } \\
\hline & \multirow{2}{*}{$\begin{array}{l}\text { Sys } \\
\text { ID }\end{array}$} & \multirow{2}{*}{$\begin{array}{l}\text { Dia. } \\
\text { (in.) }\end{array}$} & \multirow[b]{2}{*}{ Type } & \multirow{2}{*}{$\begin{array}{c}\text { Loc. } \\
\text { H,M,L }\end{array}$} & \multicolumn{3}{|c|}{ Target Data } & \multicolumn{2}{|c|}{ Insulation } & \multicolumn{2}{|c|}{ Region I } & \multicolumn{2}{|c|}{ Region II } & \multicolumn{2}{|c|}{ Region III } & \multicolumn{2}{|c|}{ Total } & \multirow{2}{*}{$\begin{array}{c}\begin{array}{c}\text { Destructed } \\
\text { Volume }\end{array} \\
\begin{array}{c}V_{\mathrm{DGM}} \\
\left(\mathrm{ft}^{3}\right)\end{array} \\
\end{array}$} \\
\hline & & & & & $\#$ & $\begin{array}{l}\text { Dia. } \\
\text { (in.) }\end{array}$ & Sys. & Type & $\begin{array}{c}\text { Thick } \\
\text { (in.) }\end{array}$ & $\begin{array}{l}\Delta \mathrm{L}_{1} \\
(\mathrm{ft})\end{array}$ & $\begin{array}{l}\Delta V_{1} \\
\left(\mathrm{ft}^{3}\right)\end{array}$ & $\begin{array}{c}\Delta \mathbf{L}_{2} \\
(\mathrm{ft})\end{array}$ & $\begin{array}{l}\Delta \mathbf{V}_{2} \\
\left(\mathrm{ft}^{3}\right)^{2}\end{array}$ & $\begin{array}{c}\Delta \mathrm{L}_{3} \\
\text { (ft) }\end{array}$ & $\begin{array}{l}\Delta \mathrm{V}_{3} \\
\left(\mathrm{ft}^{3}\right)\end{array}$ & $\begin{array}{l}\mathrm{L}_{\text {Tot }} \\
(\mathrm{ft})\end{array}$ & $\begin{array}{l}V_{\text {Tot }} \\
\left(\mathrm{ft}^{3}\right)\end{array}$ & \\
\hline & & & & & 3 & 10.0 & RRD & NK & 2.5 & 0.00 & 0.0 & 3.51 & 2.4 & 8.86 & 6.0 & 12.37 & 8.4 & 3.9 \\
\hline & & & & & 4 & 16.0 & RMA & NK & 3.0 & 0.00 & 0.0 & 1.76 & 2.2 & 3.85 & 4.8 & 5.61 & 7.0 & 3.2 \\
\hline & & & & & 5 & 10.0 & FWB & NK & 2.5 & 0.00 & 0.0 & 0.00 & 0.0 & 5.12 & 3.5 & 5.12 & 3.5 & 1.4 \\
\hline \multirow[t]{6}{*}{ RHB-J007 } & 5 & 18.0 & $\mathrm{C} 3$ & $\mathrm{M}$ & 1 & 18.0 & RHB & NK & 2.5 & 0.00 & 0.0 & 1.77 & 2.0 & 5.98 & 6.7 & 7.75 & 8.7 & 3.9 \\
\hline & & & & & 2 & 22.0 & $\mathrm{RCB}$ & NK & 3.0 & 0.00 & 0.0 & 8.29 & 13.6 & 1.13 & 1.8 & 9.42 & 15.4 & 8.9 \\
\hline & & & & & 3 & 10.0 & RRD & NK & 2.5 & 0.00 & 0.0 & 9.35 & 6.4 & 3.81 & 2.6 & 13.16 & 9.0 & 4.9 \\
\hline & & & & & 4 & 10.0 & FWB & NK & 2.5 & 0.00 & 0.0 & 1.76 & 1.2 & 5.80 & 4.0 & 7.56 & 5.2 & 2.3 \\
\hline & & & & & 5 & 10.0 & RMA & NK & 3.0 & 0.00 & 0.0 & 1.75 & 1.5 & 3.75 & 3.2 & 5.50 & 4.7 & 2.2 \\
\hline & & & & & & \multicolumn{4}{|c|}{ Volume Totals } & & 0.0 & & 24.6 & & 18.3 & & 42.9 & 22.1 \\
\hline \multirow[t]{5}{*}{ RHB-J008 } & 5 & 18.0 & C3 & M & 1 & 18.0 & RHB & NK & 2.5 & 0.00 & 0.0 & 3.44 & 3.8 & 4.67 & 5.2 & 8.11 & 9.1 & 4.4 \\
\hline & & & & & 3 & 10.0 & RRD & NK & 2.5 & 0.00 & 0.0 & 3.51 & 2.4 & 8.21 & 5.6 & 11.72 & 8.0 & 3.7 \\
\hline & & & & & 4 & 10.0 & FWB & NK & 2.5 & 0.00 & 0.0 & 0.00 & 0.0 & 6.11 & 4.2 & 6.11 & 4.2 & 1.7 \\
\hline & & & & & 5 & 10.0 & RMA & NK & 3.0 & 0.00 & 0.0 & 0.00 & 0.0 & 6.96 & 5.9 & 6.96 & 5.9 & 2.4 \\
\hline & & & & & & \multicolumn{4}{|c|}{ Volume Totals } & & 0.0 & & 6.2 & & 39.9 & & 46.1 & 19.7 \\
\hline \multirow[t]{6}{*}{ RHB-J010 } & 5 & 18.0 & $\mathrm{C} 3$ & M & 1 & 18.0 & RHB & NK & 2.5 & 0.00 & 0.0 & 2.90 & 3.2 & 5.21 & 5.8 & 8.11 & 9.1 & 4.3 \\
\hline & & & & & 2 & 22.0 & $\mathrm{RCB}$ & NK & 3.0 & 0.00 & 0.0 & 0.00 & 0.0 & 10.95 & 17.9 & 10.95 & 17.9 & 7.2 \\
\hline & & & & & 3 & 10.0 & RRD & NK & 2.5 & 0.00 & 0.0 & 3.00 & 2.0 & 8.00 & 5.5 & 11.00 & 7.5 & 3.4 \\
\hline & & & & & 4 & 10.0 & FWB & NK & 2.5 & 0.00 & 0.0 & 0.00 & 0.0 & 5.12 & 3.5 & 5.12 & 3.5 & 1.4 \\
\hline & & & & & 5 & 10.0 & RMA & NK & 3.0 & 0.00 & 0.0 & 0.00 & 0.0 & 6.96 & 5.9 & 6.96 & 5.9 & 2.4 \\
\hline & & & & & & & \multicolumn{3}{|c|}{ Volume Totals } & & 0.0 & & 5.3 & & 38.6 & & 43.9 & 18.6 \\
\hline \multirow[t]{5}{*}{ RHC-J001 } & 5 & 20.0 & S1 & M & 1 & 22.0 & RCA & NK & 3.0 & 9.68 & 15.8 & 3.56 & 5.8 & 3.36 & 5.5 & 16.60 & 27.2 & 17.6 \\
\hline & & & & & 2 & 16.0 & RMA & NK & 3.0 & 8.74 & 10.9 & 7.20 & 9.0 & 6.88 & 8.6 & 22.82 & 28.4 & 16.9 \\
\hline & & & & & 3 & 10.0 & RRF & NK & 2.5 & 0.00 & 0.0 & 3.42 & 2.3 & 3.77 & 2.6 & 7.19 & 4.9 & 2.4 \\
\hline & & & & & 4 & 10.0 & RRG & NK & 2.5 & 0.00 & 0.0 & 3.42 & 2.3 & 3.77 & 2.6 & 7.19 & 4.9 & 2.4 \\
\hline & & & & & 5 & 20.0 & RHC & NK & 2.5 & 5.00 & 6.1 & 3.33 & 4.1 & 25.76 & 31.6 & 34.09 & 41.8 & 19.7 \\
\hline
\end{tabular}




\begin{tabular}{|c|c|c|c|c|c|c|c|c|c|c|c|c|c|c|c|c|c|c|}
\hline & & & & & & & Lis & $\mathrm{ng}$ of 1 & $\begin{array}{l}\text { ole D-1 } \\
\text { argets } f\end{array}$ & or We & & & & & & & & \\
\hline \multicolumn{5}{|c|}{ WELD DATA } & \multicolumn{14}{|c|}{ TARGET INFORMATION } \\
\hline \multirow[b]{2}{*}{ Weld ID } & \multirow[b]{2}{*}{$\begin{array}{l}\text { Sys } \\
\text { ID }\end{array}$} & \multirow[b]{2}{*}{$\begin{array}{l}\text { Dia. } \\
\text { (in.) }\end{array}$} & \multirow[b]{2}{*}{ Type } & \multirow[b]{2}{*}{$\begin{array}{c}\text { Loc. } \\
\text { H,M,L }\end{array}$} & \multicolumn{3}{|c|}{ Target Data } & \multicolumn{2}{|c|}{ Insulation } & \multicolumn{2}{|c|}{ Region I } & \multicolumn{2}{|c|}{ Region II } & \multicolumn{2}{|c|}{ Region III } & \multicolumn{2}{|c|}{ Total } & \multirow{2}{*}{$\begin{array}{c}\begin{array}{c}\text { Destructed } \\
\text { Volume }\end{array} \\
\begin{array}{c}\mathrm{V}_{\mathrm{DGM}} \\
\left(\mathbf{f t}^{3}\right)\end{array} \\
\end{array}$} \\
\hline & & & & & $\#$ & $\begin{array}{l}\text { Dia. } \\
\text { (in.) }\end{array}$ & Sys. & Type & $\begin{array}{c}\text { Thick } \\
\text { (in.) }\end{array}$ & $\begin{array}{l}\Delta \mathrm{L}_{1} \\
(\mathrm{ft})\end{array}$ & $\begin{array}{l}\Delta \mathrm{V}_{1} \\
\left(\mathrm{ft}^{3}\right)\end{array}$ & $\begin{array}{l}\Delta \mathrm{L}_{2} \\
(\mathrm{ft})\end{array}$ & $\begin{array}{l}\Delta V_{2} \\
\left(\mathrm{ft}^{3}\right)\end{array}$ & $\begin{array}{l}\Delta \mathrm{L}_{3} \\
(\mathrm{ft}) \\
\end{array}$ & $\begin{array}{l}\Delta \mathbf{V}_{3} \\
\left(\mathrm{ft}^{3}\right) \\
\end{array}$ & $\begin{array}{l}\mathrm{L}_{\text {Tot }} \\
(\mathrm{ft})\end{array}$ & $\begin{array}{l}V_{\text {Tot }} \\
\left(\mathrm{ft}^{3}\right)\end{array}$ & \\
\hline RHC-J003 & 5 & 20.0 & C3 & $\mathrm{M}$ & 1 & 22.0 & RCA & NK & 3.0 & 8.41 & 13.8 & 4.47 & 7.3 & 3.47 & 5.7 & 16.35 & 26.8 & 17.0 \\
\hline & & & & & 2 & 16.0 & RMA & NK & 3.0 & 7.30 & 9.1 & 7.90 & 9.8 & 7.11 & 8.8 & 22.31 & 27.7 & 16.2 \\
\hline & & & & & 3 & 10.0 & RRF & NK & 2.5 & 0.00 & 0.0 & 2.61 & 1.8 & 4.07 & 2.8 & 6.68 & 4.6 & 2.2 \\
\hline & & & & & 4 & 10.0 & RRG & NK & 2.5 & 0.00 & 0.0 & 2.61 & 1.8 & 4.07 & 2.8 & 6.68 & 4.6 & 2.2 \\
\hline & & & & & 5 & 20.0 & RHC & NK & 3.0 & 5.00 & 7.5 & 6.50 & 9.8 & 21.43 & 32.3 & 32.93 & 49.6 & 24.4 \\
\hline & & & & & 6 & 20.0 & MSC & NK & 3.0 & 0.00 & 0.0 & 5.71 & 8.6 & 8.36 & 12.6 & 14.07 & 21.2 & 10.2 \\
\hline & & & & & 7 & 20.0 & MSD & NK & 3.0 & 0.00 & 0.0 & 2.31 & 3.5 & 4.88 & 7.3 & 7.19 & 10.8 & 5.0 \\
\hline & & & & & 8 & 10.0 & FWC & $\mathrm{NK}$ & 2.5 & 0.00 & 0.0 & 0.00 & 0.0 & 10.00 & 6.8 & 10.00 & 6.8 & 2.7 \\
\hline & & & & & & & \multicolumn{3}{|c|}{ Volume Totals } & & 30.4 & & 42.6 & & 79.1 & & 152.0 & 79.9 \\
\hline \multirow[t]{9}{*}{ RHC-J006 } & 5 & 20.0 & $\mathrm{C} 3$ & M & 1 & 22.0 & RCA & NK & 3.0 & 0.00 & 0.0 & 10.00 & 16.4 & 9.15 & 15.0 & 19.15 & 31.3 & 15.8 \\
\hline & & & & & 2 & 16.0 & RMA & NK & 3.0 & 0.00 & 0.0 & 9.09 & 11.3 & 3.31 & 4.1 & 12.40 & 15.4 & 8.4 \\
\hline & & & & & 3 & 10.0 & RRF & NK & 2.5 & 0.00 & 0.0 & 0.00 & 0.0 & 5.35 & 3.6 & 5.35 & 3.6 & 1.5 \\
\hline & & & & & 4 & 10.0 & RRG & NK & 2.5 & 0.00 & 0.0 & 0.00 & 0.0 & 5.35 & 3.6 & 5.35 & 3.6 & 1.5 \\
\hline & & & & & 5 & 20.0 & RHC & NK & 3.0 & 4.00 & 6.0 & 6.00 & 9.0 & 6.00 & 9.0 & 16.00 & 24.1 & 13.5 \\
\hline & & & & & 6 & 20.0 & MSC & NK & 3.0 & 0.00 & 0.0 & 5.00 & 7.5 & 7.00 & 10.5 & 12.00 & 18.1 & 8.7 \\
\hline & & & & & 7 & 20.0 & MSD & NK & 3.0 & 0.00 & 0.0 & 2.00 & 3.0 & 5.00 & 7.5 & 7.00 & 10.5 & 4.8 \\
\hline & & & & & 8 & 10.0 & FWC & NK & 2.5 & 0.00 & 0.0 & 6.00 & 4.1 & 3.00 & 2.0 & 9.00 & 6.1 & 3.3 \\
\hline & & & & & & \multicolumn{4}{|c|}{ Volume Totals } & & 6.0 & & 51.3 & & 55.5 & & 112.9 & 57.5 \\
\hline \multirow[t]{9}{*}{ RHC-J008 } & 5 & 20.0 & C3 & M & 1 & 22.0 & RCA & NK & 3.0 & 0.00 & 0.0 & 0.00 & 0.0 & 11.30 & 18.5 & 11.30 & 18.5 & 7.4 \\
\hline & & & & & 2 & 16.0 & RMA & NK & 3.0 & 0.00 & 0.0 & 5.95 & 7.4 & 3.05 & 3.8 & 9.00 & 11.2 & 6.0 \\
\hline & & & & & 3 & 10.0 & RRF & NK & 2.5 & 0.00 & 0.0 & 0.00 & 0.0 & 2.60 & 1.8 & 2.60 & 1.8 & 0.7 \\
\hline & & & & & 4 & 10.0 & RRG & NK & 2.5 & 0.00 & 0.0 & 0.00 & 0.0 & 2.60 & 1.8 & 2.60 & 1.8 & 0.7 \\
\hline & & & & & 5 & 20.0 & RHC & NK & 3.0 & 3.00 & 4.5 & 6.00 & 9.0 & 6.00 & 9.0 & 15.00 & 22.6 & 12.4 \\
\hline & & & & & 6 & 20.0 & MSC & NK & 3.0 & 0.00 & 0.0 & 3.00 & 4.5 & 7.00 & 10.5 & 10.00 & 15.1 & 6.9 \\
\hline & & & & & 7 & 20.0 & MSD & NK & 3.0 & 0.00 & 0.0 & 2.00 & 3.0 & 4.00 & 6.0 & 6.00 & 9.0 & 4.2 \\
\hline & & & & & 8 & 10.0 & FWC & NK & 2.5 & 0.00 & 0.0 & 7.00 & 4.8 & 3.00 & 2.0 & 10.00 & 6.8 & 3.7 \\
\hline & & & & & & & \multicolumn{3}{|c|}{ Volume Totals } & & 4.5 & & 28.7 & & 53.5 & & 86.7 & 42.0 \\
\hline \multirow[t]{5}{*}{ RHC-J009 } & 5 & 20.0 & $\mathrm{C} 3$ & M & 1 & 22.0 & RCA & NK & 3.0 & 0.00 & 0.0 & 0.00 & 0.0 & 11.30 & 18.5 & 11.30 & 18.5 & 7.4 \\
\hline & & & & & 2 & 16.0 & RMA & NK & 3.0 & 0.00 & 0.0 & 0.00 & 0.0 & 10.50 & 13.1 & 10.50 & 13.1 & 5.2 \\
\hline & & & & & 3 & 10.0 & RRG & NK & 2.5 & 0.00 & 0.0 & 0.00 & 0.0 & 0.50 & 0.3 & 0.50 & 0.3 & 0.1 \\
\hline & & & & & 4 & 20.0 & $\mathrm{RHC}$ & NK & 3.0 & 4.71 & 7.1 & 9.40 & 14.2 & 5.39 & 8.1 & 19.50 & 29.4 & 17.1 \\
\hline & & & & & 5 & 10.0 & FWC & NK & 2.5 & 0.00 & 0.0 & 6.50 & 4.4 & 3.50 & 2.4 & 10.00 & 6.8 & 3.6 \\
\hline
\end{tabular}


Table D-1

Listing of Targets for Welds

\begin{tabular}{|c|c|c|c|c|c|c|c|c|c|c|c|c|c|c|c|c|c|c|}
\hline \multirow[b]{3}{*}{ Weld ID } & \multicolumn{4}{|c|}{ WELD DATA } & \multicolumn{14}{|c|}{ TARGET INFORMATION } \\
\hline & \multirow[b]{2}{*}{$\begin{array}{l}\text { Sys } \\
\text { ID }\end{array}$} & \multirow[b]{2}{*}{$\begin{array}{l}\text { Dia. } \\
\text { (in.) }\end{array}$} & \multirow[b]{2}{*}{ Type } & \multirow[b]{2}{*}{$\begin{array}{c}\text { Loc. } \\
\text { H,M,L }\end{array}$} & \multicolumn{3}{|c|}{ Target Data } & \multicolumn{2}{|c|}{ Insulation } & \multicolumn{2}{|c|}{ Region I } & \multicolumn{2}{|c|}{ Region II } & \multicolumn{2}{|c|}{ Region III } & \multicolumn{2}{|c|}{ Total } & \multirow{2}{*}{$\begin{array}{c}\begin{array}{c}\text { Destructed } \\
\text { Volume }\end{array} \\
\begin{array}{c}V_{\text {DGM }} \\
\left(\mathbf{f t}^{3}\right)\end{array} \\
\end{array}$} \\
\hline & & & & & \# & $\begin{array}{l}\text { Dia. } \\
\text { (in.) }\end{array}$ & Sys. & Type & $\begin{array}{c}\text { Thick } \\
\text { (in.) }\end{array}$ & $\begin{array}{l}\Delta \mathbf{L}_{1} \\
(\mathrm{ft})\end{array}$ & $\begin{array}{l}\Delta \mathrm{V}_{1} \\
\left(\mathrm{ft}^{3}\right)\end{array}$ & $\begin{array}{l}\Delta \mathbf{L}_{2} \\
(\mathrm{ft})\end{array}$ & $\begin{array}{l}\Delta V_{2} \\
\left(\mathrm{ft}^{3}\right)\end{array}$ & $\begin{array}{l}\Delta \mathbf{L}_{3} \\
(\mathrm{ft})\end{array}$ & $\begin{array}{l}\Delta V_{3} \\
\left(\mathrm{ft}^{3}\right)\end{array}$ & $\begin{array}{l}\mathrm{L}_{\text {Tot }} \\
(\mathbf{f t})\end{array}$ & $\begin{array}{l}V_{\text {Tot }} \\
\left(f^{3} t^{3}\right) \\
\end{array}$ & \\
\hline & & & & & 6 & 20.0 & MSC & NK & 3.0 & 0.00 & 0.0 & 3.50 & 5.3 & 6.50 & 9.8 & 10.00 & 15.1 & 7.1 \\
\hline & & & & & 7 & 20.0 & MSD & NK & 3.0 & 0.00 & 0.0 & 0.00 & 0.0 & 1.00 & 1.5 & 1.00 & 1.5 & 0.6 \\
\hline & & & & & & & Vo & ume To & & & 7.1 & & 23.9 & & 53.7 & & 84.6 & 41.1 \\
\hline \multirow[t]{8}{*}{ RHD-J001 } & 5 & 20.0 & S1 & $\mathrm{M}$ & 1 & 22.0 & RCB & NK & 3.0 & 9.68 & 15.8 & 3.56 & 5.8 & 3.36 & 5.5 & 16.60 & 27.2 & 17.6 \\
\hline & & & & & 2 & 16.0 & $\mathrm{RMB}$ & NK & 3.0 & 8.74 & 10.9 & 7.20 & 9.0 & 6.88 & 8.6 & 22.82 & 28.4 & 16.9 \\
\hline & & & & & 3 & 10.0 & $\mathrm{RRC}$ & NK & 2.5 & 0.00 & 0.0 & 3.42 & 2.3 & 3.77 & 2.6 & 7.19 & 4.9 & 2.4 \\
\hline & & & & & 4 & 10.0 & RRB & NK & 2.5 & 0.00 & 0.0 & 3.42 & 2.3 & 3.77 & 2.6 & 7.19 & 4.9 & 2.4 \\
\hline & & & & & 5 & 20.0 & RHD & NK & 2.5 & 5.00 & 6.1 & 3.33 & 4.1 & 25.76 & 31.6 & 34.09 & 41.8 & 19.7 \\
\hline & & & & & 6 & 20.0 & MSB & NK & 3.0 & 0.00 & 0.0 & 2.76 & 4.2 & 10.94 & 16.5 & 13.70 & 20.6 & 9.1 \\
\hline & & & & & 7 & 20.0 & MSA & NK & 3.0 & 0.00 & 0.0 & 2.23 & 3.4 & 4.95 & 7.5 & 7.18 & 10.8 & 5.0 \\
\hline & & & & & & & \multicolumn{3}{|c|}{ Volume Totals } & & 32.8 & & 31.0 & & 74.7 & & 138.6 & 73.1 \\
\hline \multirow[t]{9}{*}{ RHD-J003 } & 5 & 20.0 & $\mathrm{C} 3$ & $\mathrm{M}$ & 1 & 22.0 & RCB & NK & 3.0 & 8.41 & 13.8 & 4.47 & 7.3 & 3.47 & 5.7 & 16.35 & 26.8 & 17.0 \\
\hline & & & & & 2 & 16.0 & $\mathrm{RMB}$ & NK & 3.0 & 7.30 & 9.1 & 7.90 & 9.8 & 7.11 & 8.8 & 22.31 & 27.7 & 16.2 \\
\hline & & & & & 3 & 10.0 & RRC & NK & 2.5 & 0.00 & 0.0 & 2.61 & 1.8 & 4.07 & 2.8 & 6.68 & 4.6 & 2.2 \\
\hline & & & & & 4 & 10.0 & RRB & NK & 2.5 & 0.00 & 0.0 & 2.61 & 1.8 & 4.07 & 2.8 & 6.68 & 4.6 & 2.2 \\
\hline & & & & & 5 & 20.0 & RHD & NK & 3.0 & 5.00 & 7.5 & 6.50 & 9.8 & 21.43 & 32.3 & 32.93 & 49.6 & 24.4 \\
\hline & & & & & 6 & 20.0 & MSB & NK & 3.0 & 0.00 & 0.0 & 5.71 & 8.6 & 8.36 & 12.6 & 14.07 & 21.2 & 10.2 \\
\hline & & & & & 7 & 20.0 & MSA & NK & 3.0 & 0.00 & 0.0 & 2.31 & 3.5 & 4.88 & 7.3 & 7.19 & 10.8 & 5.0 \\
\hline & & & & & 8 & 10.0 & FWD & NK & 2.5 & 0.00 & 0.0 & 0.00 & 0.0 & 10.00 & 6.8 & 10.00 & 6.8 & 2.7 \\
\hline & & & & & & & \multicolumn{3}{|c|}{ Volume Totals } & & 30.4 & & 42.6 & & 79.1 & & 152.0 & 79.9 \\
\hline \multirow[t]{9}{*}{ RHD-J006 } & 5 & 20.0 & $\mathrm{C} 3$ & M & 1 & 22.0 & $\mathrm{RCB}$ & NK & 3.0 & 0.00 & 0.0 & 10.00 & 16.4 & 9.15 & 15.0 & 19.15 & 31.3 & 15.8 \\
\hline & & & & & 2 & 16.0 & RMB & NK & 3.0 & 0.00 & 0.0 & 9.09 & 11.3 & 3.31 & 4.1 & 12.40 & 15.4 & 8.4 \\
\hline & & & & & 3 & 10.0 & RRC & NK & 2.5 & 0.00 & 0.0 & 0.00 & 0.0 & 5.35 & 3.6 & 5.35 & 3.6 & 1.5 \\
\hline & & & & & 4 & 10.0 & RRB & NK & 2.5 & 0.00 & 0.0 & 0.00 & 0.0 & 5.35 & 3.6 & 5.35 & 3.6 & 1.5 \\
\hline & & & & & 5 & 20.0 & RHD & NK & 3.0 & 4.00 & 6.0 & 6.00 & 9.0 & 6.00 & 9.0 & 16.00 & 24.1 & 13.5 \\
\hline & & & & & 6 & 20.0 & MSB & NK & 3.0 & 0.00 & 0.0 & 5.00 & 7.5 & 7.00 & 10.5 & 12.00 & 18.1 & 8.7 \\
\hline & & & & & 7 & 20.0 & MSA & NK & 3.0 & 0.00 & 0.0 & 2.00 & 3.0 & 5.00 & 7.5 & 7.00 & 10.5 & 4.8 \\
\hline & & & & & 8 & 10.0 & FWD & NK & 2.5 & 0.00 & 0.0 & 6.00 & 4.1 & 3.00 & 2.0 & 9.00 & 6.1 & 3.3 \\
\hline & & & & & & & \multicolumn{3}{|c|}{ Volume Totals } & & 6.0 & & 51.3 & & 55.5 & & 112.9 & 57.5 \\
\hline RHD-J008 & 5 & 20.0 & $\mathrm{C} 3$ & $\mathbf{M}$ & 1 & 22.0 & RCB & NK & 3.0 & 0.00 & 0.0 & 0.00 & 0.0 & 11.30 & 18.5 & 11.30 & 18.5 & 7.4 \\
\hline & & & & & 2 & 16.0 & $\mathrm{RMB}$ & NK & 3.0 & 0.00 & 0.0 & 5.95 & 7.4 & 3.05 & 3.8 & 9.00 & 11.2 & 6.0 \\
\hline
\end{tabular}




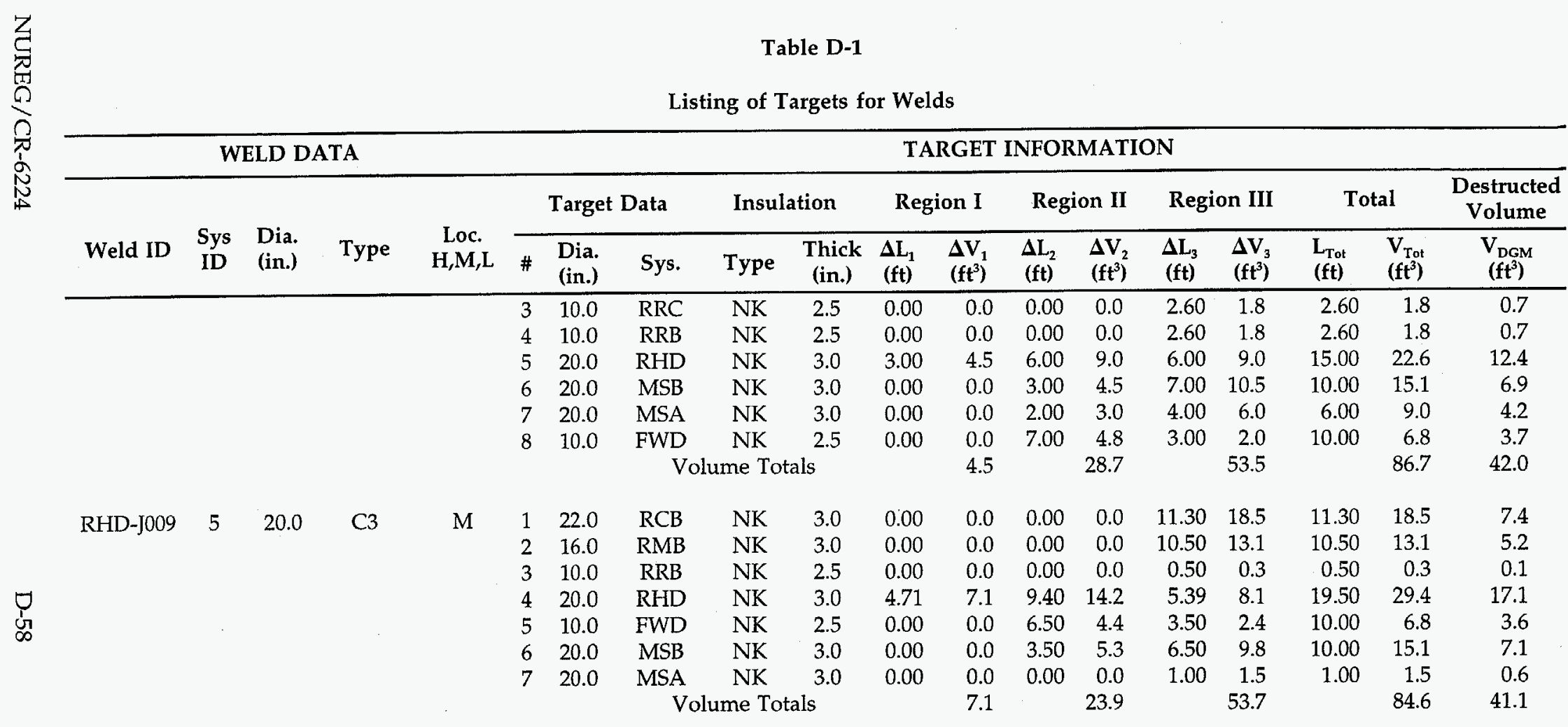




\section{Appendix E}

Experimental Investigation of Sedimentation and Head Loss Associated with LOCA Debris 



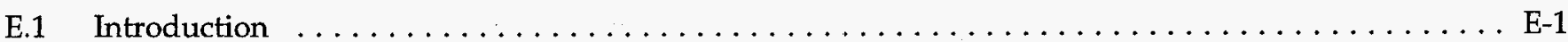

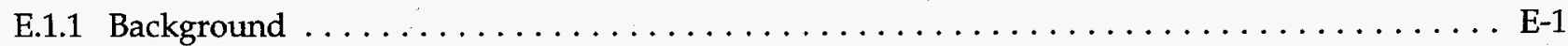

E.1.2 Experimental Program Overview $\ldots \ldots \ldots \ldots \ldots \ldots \ldots \ldots \ldots \ldots \ldots \ldots \ldots \ldots \ldots \ldots \ldots \ldots \ldots \ldots \ldots$

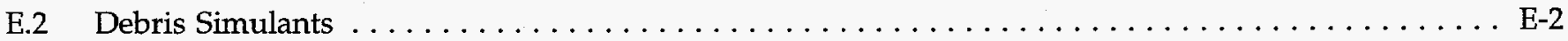

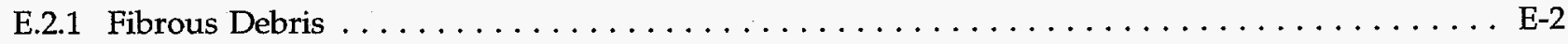

E.2.2 Suppression Pool Sludge $\ldots \ldots \ldots \ldots \ldots \ldots \ldots \ldots \ldots \ldots \ldots \ldots \ldots \ldots \ldots \ldots \ldots$ E-6

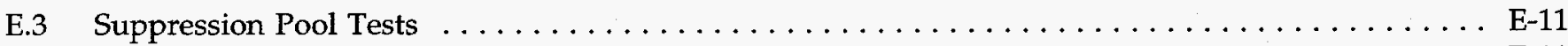

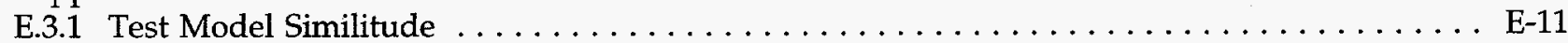

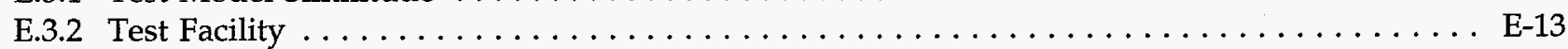

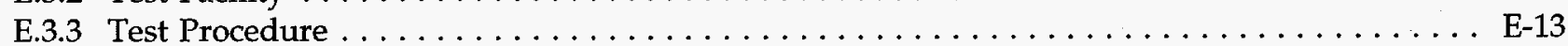

E.3.4 Results and Discussions . . . . . . . . . . . . . . . . . . . . . . . . . . . E E-19

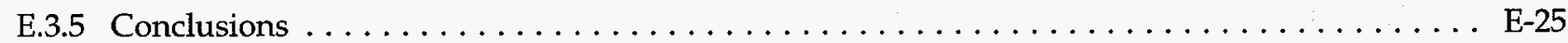

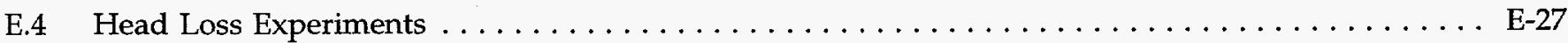

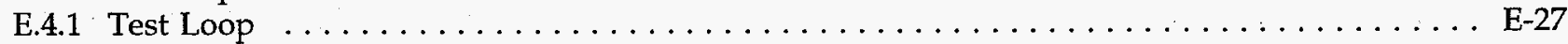

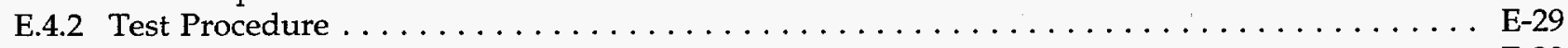

E.4.3 Results and Discussions . . . . . . . . . . . . . . . . . . . . . . E

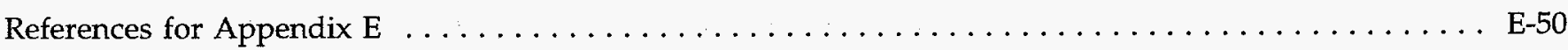

List of Tables

E-1 BWROG-Provided Size Distribution of the Suppression Pool Sludge $\ldots \ldots \ldots \ldots \ldots \ldots \ldots \ldots \ldots$ E-6

E-2 Iron Oxide Particles Supplied by Hansen Engineering, Inc. $\ldots \ldots \ldots \ldots \ldots \ldots \ldots \ldots \ldots \ldots \ldots$

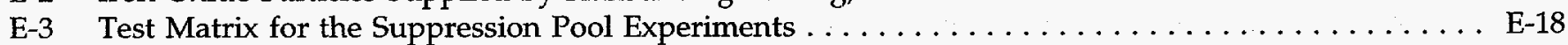

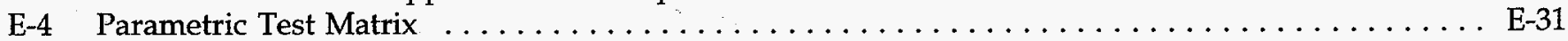

E-5 Comparison of Experimental Data with Head Loss Model Correlation . . . . . . . . . . . . E E-38

E-6 Comparison Between Model Predictions and Test Data for 2" Nominal Thickness Beds ......... E-40

E-7 Comparison Between Model Predictions and Test Data for 1" Nominal Thickness Bed . . . . . . . E-41

E-8 Comparison Between Model Predictions and Test Data 0.5" Nominal Thickness Bed . . . . . . . . . E-42

E-9 Comparison Between Model Predictions and Test Data for 0.25 "Theoretical Bed Thickness ...... E-43 


\section{List of Figures}

Page

E-1 Representative Sample of Shredded NUKONTM Fibrous Debris - Class 3 \& $4 \ldots \ldots \ldots$

E-2 Representative Sample of Shredded NUKON'T Fibrous Debris - Class 5 \& $6 \ldots \ldots$. . . . . . . . . E-4

E-3 Representative Sample of Shredded NUKONтM Fibrous Debris - Kernels . . . . . . . . . . . . . E-5

E-4 SEM of Sludge A $(750 \mu \mathrm{m}$ magnification $) \ldots \ldots \ldots \ldots \ldots \ldots$

E-5 SEM of Sludge B $(30 \mu \mathrm{m}$ magnification $) \ldots \ldots \ldots \ldots \ldots \ldots \ldots$

E-6 Sludge-A Particle Size Frequency Distribution. A Sedigraph Instrument Was Used to Measure the Size

Distribution Data. . . . . . . . . . . . . . . . . . . . . . . . . . E-10

E-7 SEM of Sludge A Collected After Circulating in Test Loop (750 $\mu$ m magnification) . . . . . . . . . . E-12

E-8 Modeled Suppression Pool Geometry . . . . . . . . . . . . . . . . . . . . . . E E-14

E-9 $\quad 1: 2.4$ Suppression Pool Segment Model $\ldots \ldots \ldots \ldots \ldots \ldots \ldots \ldots$

E-10 Mechanical Drive for Chugging Simulation . . . . . . . . . . . . . . . . . . . . E

E-11 Mechanical Drive in Suppression Pool Tests . . . . . . . . . . . . . . . . . . . . . . . . . E-17

E-12 Debris Settling in Suppression Pool; Test A-1R1: $3.8 \mathrm{ft}$ amplitude; 1.65 period (Case 3) NUKON ${ }^{\mathrm{TM}}$ :

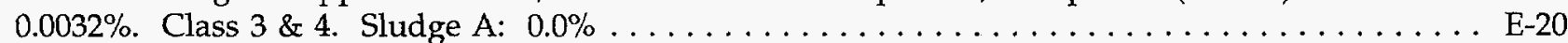

E-13 Debris Settling in Suppression Pool; Test A-3R1: $3.8 \mathrm{ft}$ amplitude; 1.65 period (Case 3). NUKONTM:

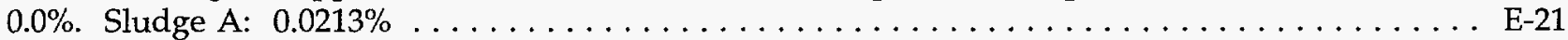

E-14 Debris Settling in Suppression Pool; Test A-5: $3.8 \mathrm{ft}$ amplitude, 1.65 period (Case 3). NUKONrM: $0.0032 \%$. Class 3 \& 4 . Sludge A: $0.0213 \% \ldots \ldots \ldots \ldots \ldots$

E-15 Settling Velocity Distribution for Classes 3\&4 and 5\&6 Shreds After Being Subjected to Simulated

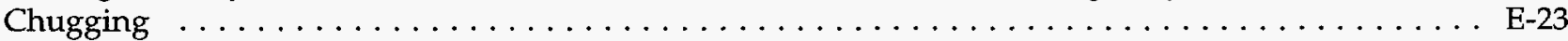

E-16 Settling Velocities for Various Sludge and Fiber Mixtures Predicting Using the Principle of Superposition (Assumes Independent Behavior) $\ldots \ldots \ldots \ldots \ldots \ldots \ldots$

E-17 Particle Size Distribution Curve for Sludge A . . . . . . . . . . . . . . . . . . . . E E $\ldots$

E-18 Head Loss Testing Facility - Flow Loop . . . . . . . . . . . . . . . . . . . . . . . . . . . . E-28

E-19 Typical Transient Head Loss for Pure Fiber Bed - Test P-01 . . . . . . . . . . . . . . . . . . E-30

E-20 Comparison of the Head Loss Data for Pure Fiber Beds with the NUREG/CR-6224 Correlation . . . E-33

E-21 Head Loss vs. Time (Type A Sludge 500\%) . . . . . . . . . . . . . . . . . . . . . . . . . . E-34

E-22 Head Loss vs. Time (Type A Sludge $5000 \%) \ldots \ldots \ldots \ldots \ldots \ldots$

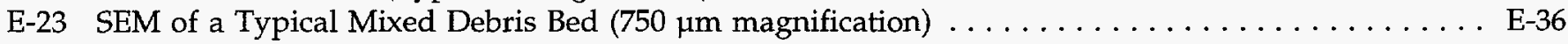

E-24 Comparison of Experimental Head Loss Data for Selected Bed Thicknesses and Approach Velocities with NUREG/CR-6224 Correlation . . . . . . . . . . . . . . . . . . . . . . E-37

E-25 Loop Water Concentration as a Function of Time. Data Collected From Two Sampling Ports Located at Top and Bottom of the Strainer Simultaneously. . . . . . . . . . . . . . . . . . . E-45

E-26 SEM of Sludge A Particles Collected in Test Loop After Circulating Through Mixed Debris Bed (750 $\mu$ m

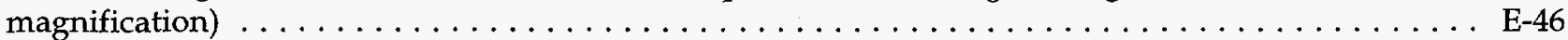

E-27 Cumulative and Once-Through Filtration Efficiency Measured From Test P27. . . . . . . . . . . . E-47

E-28 Filtration Efficiency vs. Approach Velocity . . . . . . . . . . . . . . . . . . . E-48

E-29 Cumulative Filtration Efficiencies of the Fibrous Debris Bed vs. Theoretical Thickness . . . . . . . E-49 


\section{E.1 Introduction}

\section{E.1.1 Background}

A version 2.0 of the ECCS strainer blockage computer code BLOCKAGE [Ref. E.1] was based on the following insights gained from limited experimental data:

- Debris settling in the suppression pool in the presence of turbulence can be modeled through introduction of a turbulence factor, $\tau$, defined as the ratio of turbulent settling velocity-to-the terminal velocity in a still water pool. The model related the turbulence factor to the break size through the use of Fick's second law of eddy diffusion.

- A semi-theoretical head loss model was developed to estimate head loss across the strainer due to accumulation of fibrous debris on the strainer surface. The resultant debris cake was assumed to possess a packing density of $2.4 \mathrm{lbm} / \mathrm{ft}^{3}\left(38.4 \mathrm{~kg} / \mathrm{m}^{3}\right)$, and compressibility effects were neglected.

- Increase in pressure drop due to deposition of sludge in addition to the fibrous materials was estimated based on approximate theoretical and experimental development as suggested by References E.2 and E.3.

- All particulate debris reaching the debris cake would be filtered by the cake and will contribute to the head loss [Ref. E.4].

Since these assumptions played a key role in estimating the potential for ECCS strainer blockage, it was essential that additional experimentation be carried out to verify the accuracy of the assumptions. In response to this need, a set of experiments were conducted to obtain the required experimental data in the following general areas:

- Fibrous and particulate debris behavior in the suppression pool during various phases of accident progression, and

- Filtration of various debris by the strainer and the resultant head loss across the strainer.
The experiments were conducted at the ARL under subcontract to SEA on behalf of the NRC [Ref. E-5 and E-6]. These experiments are hereinafter referred to as the NRC experiments.

The experimental data were analyzed by SEA and the BLOCKAGE code was revised. This Appendix summarizes these experimental investigations and their findings. In presenting the discussions it is assumed that the reader is familiar with the LOCA progression scenario and suppression pool phenomenology discussed in Appendix B.

\section{E.1.2 Experimental Program Overview}

In response to the need for experimental data, two sets of experiments were carried out. The first set of experiments focused on meeting the data needs related to LOCA debris transport in the suppression pool during both the high energy phase and the post-high energy phase. These experiments, referred to as the suppression pool tests, addressed the following specific areas needing experimental data:

1. Resuspension of debris contained at the bottom of the pool during the high energy phase.

2. Mixing and fragmentation of fibrous debris when subjected to high levels of turbulence during the high energy phase.

3. Settling characteristics of fibrous and particulate debris during high energy phase.

4. Settling of debris in the post-high energy phase as the pool turbulence levels decay.

A reduced scale suppression pool test facility was designed and fabricated as part of this program making use of suppression pool hydrodynamic data obtained from Mark I suppression pool loads program [Ref. E.7 and E.8]. The experimental set-up and the experimental procedure are described in Section E. 3 below. This section also addresses such concerns as scalability of the test results to BWRs and the limitations of the experimental findings.

The second set of experiments, termed the head-loss tests, addressed data needs in the following specific areas: 
1. Effect of fibrous debris class (classes $3 \& 4$ vs $5 \& 6)$ on the head loss across the debris cake.

2. The once-through efficiencies of the fibrous beds to filter/trap micron range sludge particles.

3. The deposition morphology of the debris cake.

4. Head loss across the cake as a function of types and particle size distributions of the bed constituents.

5. The effect of water temperature on the head loss.

A closed loop test facility was designed to conduct these experiments, which encompassed several approach velocities $(0.15-1.5 \mathrm{ft} / \mathrm{s}$ or $0.05-0.5 \mathrm{~m} / \mathrm{s})$, temperatures $\left(70-125^{\circ} \mathrm{F}\right.$ or $\left.21-52^{\circ} \mathrm{C}\right)$, theoretical bed thicknesses $\left(1 / 8^{\prime \prime}-4^{\prime \prime}\right.$ or $\left.0.3-10.2 \mathrm{~cm}\right)$ and sludge-tofiber mass ratios (0-60). The design of the test loop and the experimental procedures are described in Section E.4 below, which also summarizes the important findings and their applicability to actual BWRs.

\section{E.2 Debris Simulants}

A total of three debris species, namely fibrous NUKONTM, iron oxide particles and paint chips, were used in these experiments to simulate debris. Since the debris size was known to influence both the settling rates and the head loss, considerable attention was given to the following areas: (1) identification of representative size distributions of the debris likely to reach the BWR suppression pool following a LOCA; (2) generation/acquisition of test debris that closely resemble those identified debris sizes and shapes; (3) implementation of proper controls on debris production for use in the experiments; and (4) characterization of the debris that were ultimately used in each of the tests. The debris characterization of iron oxide particles was accomplished using techniques such as scanning electron microscope (SEM) and sedimentation velocity (sedigraph) analyses. The following sections summarize the relevant characteristics of the test debris used in the experiments.

\section{E.2.1 Fibrous Debris}

The NUKON ${ }^{\mathrm{TM}}$ insulation material, artificially aged in ovens in accordance with ASTM procedures, was provided by PCI. For steel-jacketed NUKON'M, the LOCA generated debris varies in size from fines to partially fragmented blankets. Table B-3 in Appendix $B$ provides illustrative examples of various debris classes that are likely to be transported to the suppression pool after a LOCA. Previous head loss and debris transport experiments have focused on obtaining relevant data using class 6 and 7 debris, i.e., small shreds that maintain considerable structural rigidity. Typically, manual or mechanical methods were used to produce such debris. However, careful analysis of debris produced in the Barsebäck-2 event, as well as that produced by PCI air-blast tests, suggests that considerable quantities of debris consist of debris finer than size class 6 of Table B-3. Also, various analyses suggested that these finer debris, typically classes 3, 4 and 5 are most likely to be transported to the suppression pool and ultimately to be transported to the ECCS suction strainer. On the other hand, the PCI air-blast tests suggested that very limited quantities of the debris of classes 1 and 2 , namely individual fibers of various lengths, would be produced in a LOCA for steel jacketed NUKON ${ }^{\mathrm{TM}}$. Based on these scoping analyses, it was judged that the most likely debris reaching the suppression pool following a LOCA in the reference plant would closely resemble a combination of classes $3,4,5$ and 6 .

Considerable attention was then paid to generating fibrous debris simulants that can be classified as classes $3,4,5$ and 6 . Based on various exploratory studies, it was decided that a leaf shredder best provided a mechanism by which the aged NUKON ${ }^{\mathrm{TM}}$ blankets could be shredded into such fine shreds. In this method, the full size aged NUKON ${ }^{\mathrm{TM}}$ blankets were first cut up manually into large pieces, typically several inches in size. These pieces were then subjected to the leaf shredder to generate the desired fragment sizes. Usually, the generated debris were graded and separated to screen out large pieces, if necessary. Figures E-1, E2 , and E-3 are photographs of the three fragments classes used in the experiments: 
Appendix E

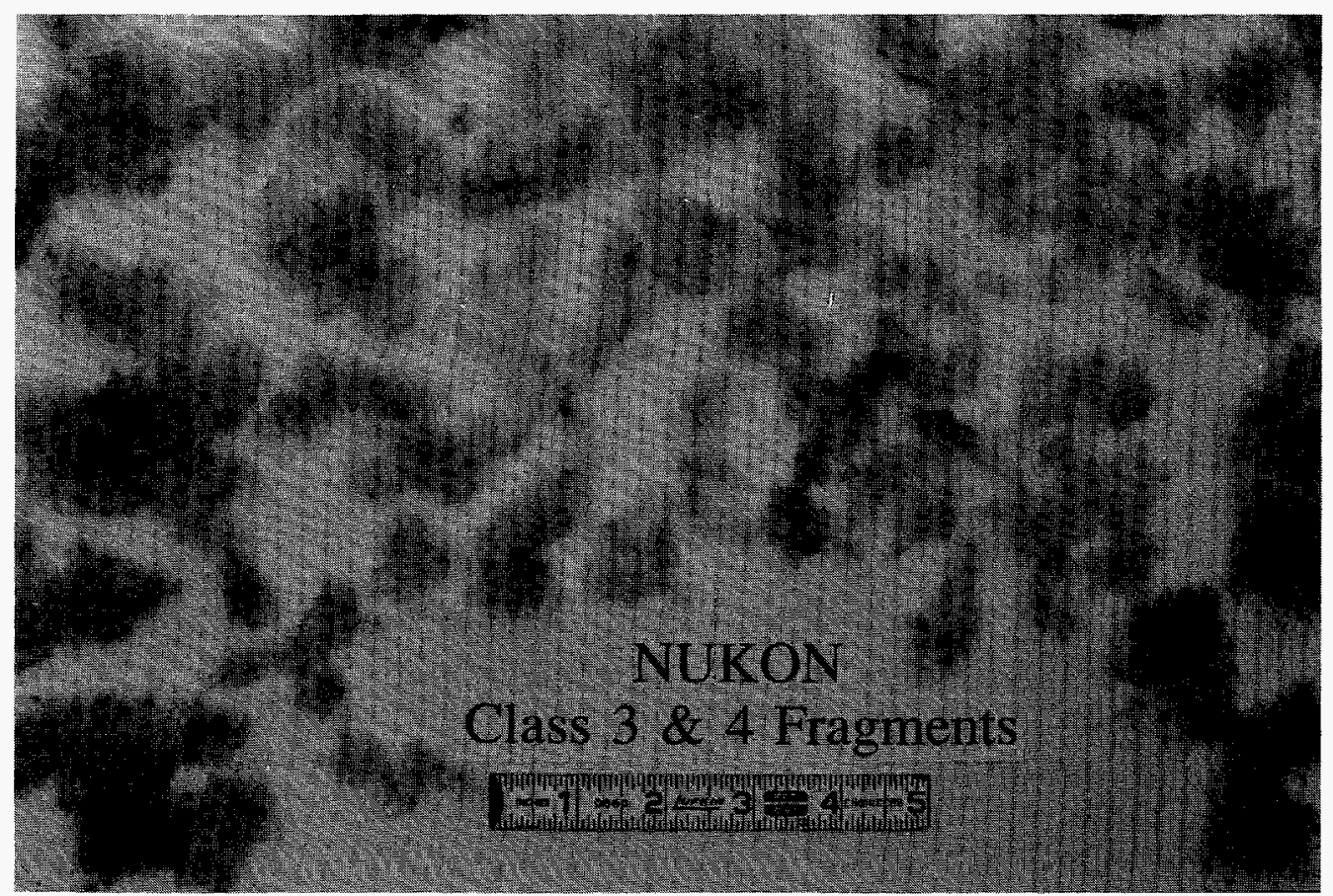

Figure E-1 Representative Sample of Shredded NUKON ${ }^{\mathrm{TM}}$ Fibrous Debris - Class 3 \& 4 
Appendix E

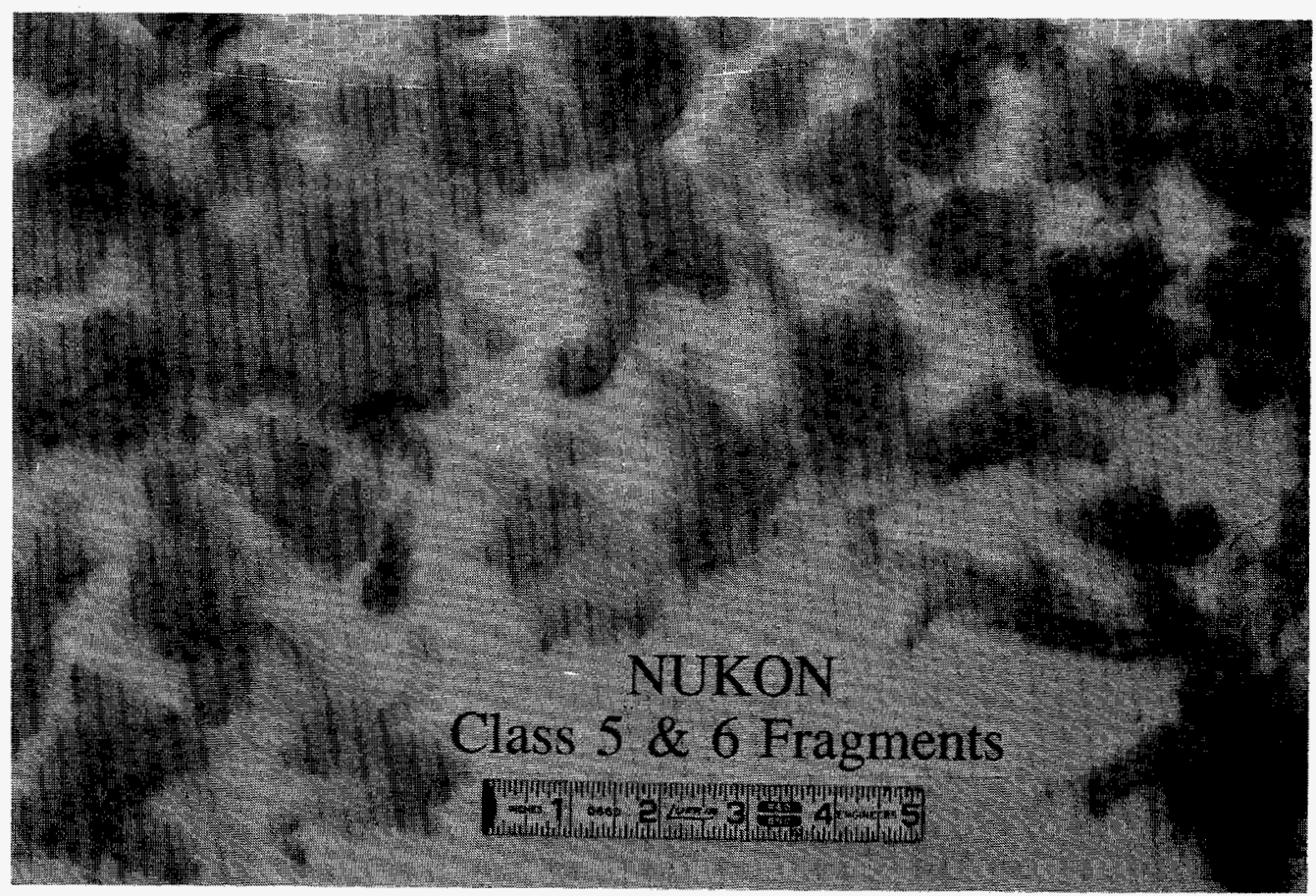

Figure E-2 Representative Sample of Shredded NUKON ${ }^{\mathrm{TM}}$ Fibrous Debris - Class 5 \& 6 


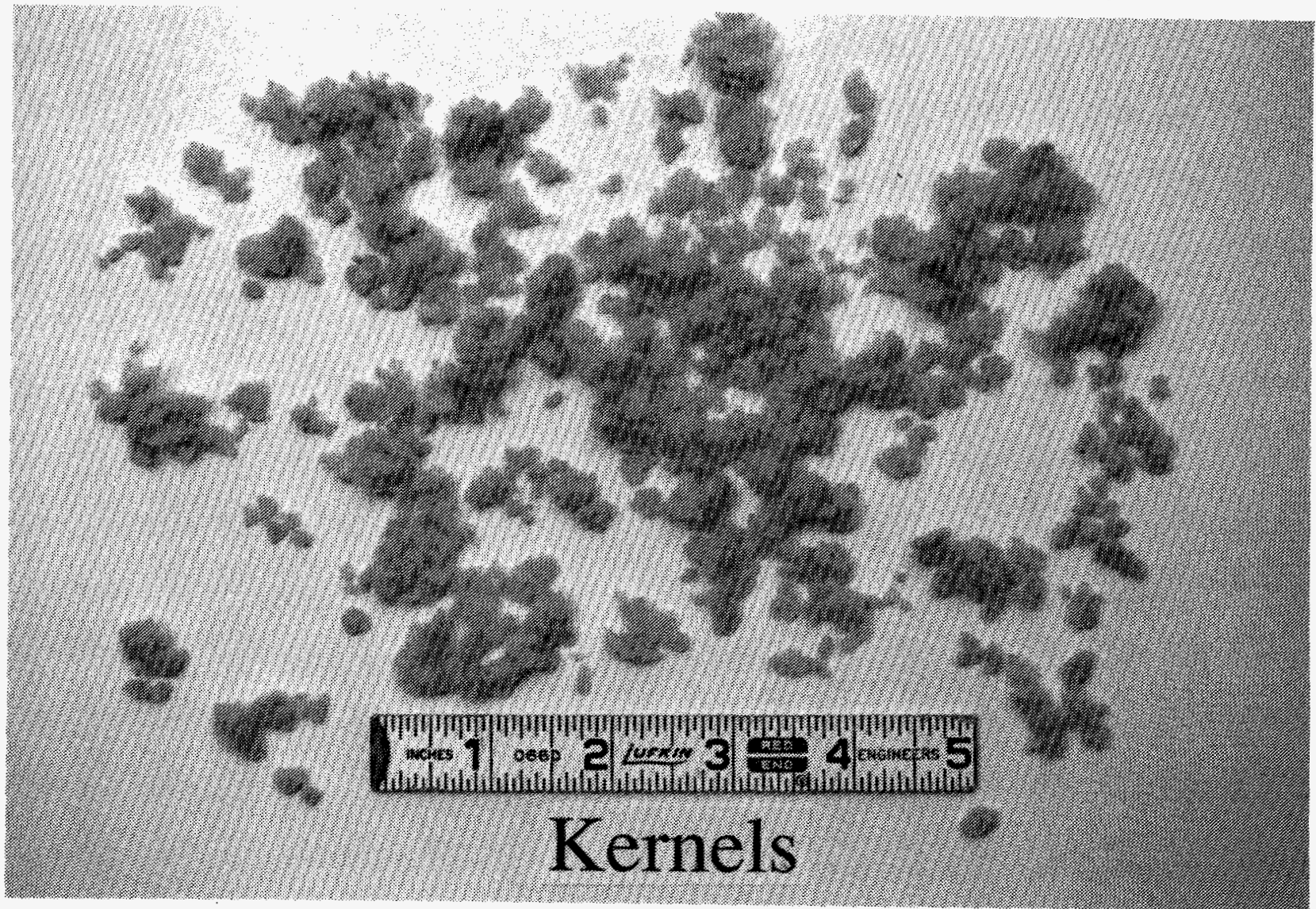

Figure E-3 Representative Sample of Shredded NUKON ${ }^{\mathrm{TM}}$ Fibrous Debris - Kernels 
1. Classes 3\&4: This class of fragments, shown in Figure E-1, varied from individual fibers to loosely attached groups of fibers. The cakes produced were compressible in nature and often did not possess structural rigidity to completely recover from a compressed state. Most of the experiments were conducted using this class of fibers.

2. Classes 5\&6: This class of fragments (see Figure E-2) were slightly larger in size compared to the previous size class. Most importantly, these fragments appeared to retain some of the structural rigidity of the original blankets. The cakes formed of these fibers appeared to be "springy" and were qualitatively less compressible. Fiber fragments of this class were only used in limited set of experiments to examine the impact of fragment size on the head loss.

3. Kernels: As shown in Figure E-3, "Kernels" were balled up small fragments of insulation obtained by prolonged exposure of the insulation to the leaf shredder. Initially, insulation kernels were thought to simulate the worst case debris fragments and were used in the exploratory testing. Later, however, these kernels were judged to be non-prototypical of LOCA debris and were rejected from further use in any of the tests.

Thus, only Classes $3 \& 4$ and Classes $5 \& 6$ were used in the parametric tests summarized in this appendix. This is applicable to both the suppression pool tests and the head loss tests.

\section{E.2.2 Suppression Pool Sludge}

Large quantities of particulate matter was found to be present in the US-BWR suppression pools during normal operation [Ref. E.9]. Commonly termed as 'suppression pool sludge' or 'sludge', this material consists mostly of rust particles (i.e., $\mathrm{Fe}_{2} \mathrm{O}_{3}$ and $\mathrm{Fe}_{3} \mathrm{O}_{4}$ ). Considerable efforts were expended by the BWROG to characterize the sludge commonly found in various BWRs [Ref. E.10]. This BWROG survey of five nuclear plants, which included Mark I, II and III containments, provided the size distribution data tabulated in Table E-1 for BWR suppression pool sludge. In addition to the suppression pool sludge, sizable quantities of other particulate debris are expected to reach the suppression pool. Size distribution data on these particles was not readily available, forcing engineering judgement.

\begin{tabular}{|c|c|c|}
\hline \multicolumn{3}{|c|}{$\begin{array}{c}\text { Table E-1 BWROG-Provided Size Distribution } \\
\text { of the Suppression Pool Sludge }\end{array}$} \\
\hline $\begin{array}{l}\text { Particle Size } \\
\mu \mathrm{m}\end{array}$ & $\begin{array}{l}\text { Average Size } \\
\mu \mathrm{m}\end{array}$ & $\%$ by weight \\
\hline $0-5$ & 2.5 & $81 \%$ \\
\hline $5-10$ & 7.5 & $14 \%$ \\
\hline $10-75$ & 42.5 & $5 \%$ \\
\hline
\end{tabular}

To create a simulant of this sludge for use in the head loss and suppression pool tests, SEA surveyed various vendors of special powders. The intent of this survey was to identify a vendor who could provide iron-oxide powders with the size distribution that closely matched the BWROG size distribution (see Table E-1). Based on a vendor's specifications, it was determined that a combination of iron oxide powders \#2008 and \#9101-N, sold commercially by Hansen Engineering, Inc., best matched the BWROG size distribution data. ${ }^{1}$ Size distribution of these powders are listed in Table E-2. By comparing Tables E-1 and E-2 it can be seen that a mixture of powders consisting of $95 \%$ of powder $\# 2008$ and $5 \%$ of powder $\# 9101-\mathrm{N}$ best simulates the BWROG suppression pool sludge. This mixture, termed Sludge A, was used in most of the head loss and the suppression pool tests. In addition to Sludge A, some of the head loss experiments used two other powder mixtures, namely Sludge B and Mix A. Sludge B consisted of $100 \% \# 9101-N$ iron oxide powder and was used primarily to address the possibility that the sludge particles

\footnotetext{
${ }^{1}$ It should be noted that no efforts were made to simulate the sludge with non-iron oxide powders (e.g., ceramic powders) since agglomeration characteristics of such powders may not be representative of BWR suppression pool sludge. Strong concerns were expressed by various desludging companies that while the particle size distribution provided by the BWROG may be representative of the primary sludge particles, it may not account for formation of larger agglomerates which are typically found in the BWR suppression pools. In view of these concerns, it was decided not to explore the possibility of simulating the sludge with non-iron oxide particles.
} 
Table E-2 Iron Oxide Particles Supplied by Hansen Engineering, Inc.

\begin{tabular}{cccccc}
\hline $\mathrm{Fe}_{3} \mathrm{O}_{\mathbf{4}}$ Specification & $<\mathbf{2 \mu \mathrm { m }}$ & $\mathbf{2 - 5} \boldsymbol{\mu m}$ & $\mathbf{5 - 1 0} \boldsymbol{\mu m}$ & $\mathbf{1 0 - 3 5} \boldsymbol{\mu m}$ & $>\mathbf{3 5} \boldsymbol{\mu m}$ \\
\hline$\# 2008$ & $5 \%$ & $80 \%$ & $15 \%$ & $0 \%$ & $0 \%$ \\
$\# 9101-\mathrm{N}$ & $\sim 0 \%$ & $\sim 0 \%$ & $\sim 0 \%$ & $82 \%$ & $\sim 18 \%$
\end{tabular}

recommended by the BWROG, and therefore Sludge $A$, may be smaller than the sludge particles found in other suppression pools. On the other hand, Mix A consisting of $90 \%$ Sludge $A$ and $10 \%$ of unqualified paint chips, was developed to address the impact of additional quantities of drywell particulates transported to the strainer.

Figures E-4 and E-5 present the SEM images of Sludge $A$ and $B$, respectively, in their dry state. As evident from Figure E-5, Sludge B consists of individual spherical iron oxide particles ranging in size from 10 to $150 \mu \mathrm{m}$. On the other hand, as evident from Figure E-4, Sludge A is made up of several large particles that range in size from 50-300 $\mu \mathrm{m}$ intermixed with a small quantity of $1-10 \mu \mathrm{m}$ primary particles. At higher magnification, these large particles were found to be agglomerates of smaller particles ranging in size from sub-micron to few microns. Further efforts to characterize the Sludge A used in the experiments led to the following conclusions [Ref. E.11]:

- It appeared that Sludge A consisted of primary particles which were spherical in shape and size distribution that closely matched the manufacturer specifications with a median diameter of $5 \mu \mathrm{m}$ (see Figure E-6). The size distribution data plotted in Figure E-6 was obtained after subjecting sludge $A$ to ultrasonic generator for 15 minutes in the presence of a surfactant. This technique disperses the agglomerates into primary particles whose size can then be measured using a sedigraph which measures settling velocity of particles and then relates it to particle diameter. In Figure E-6, the primary peak corresponding to a particle diameter of $5 \mu \mathrm{m}$, was judged to be due to powder \#2008 and the secondary peak, corresponding to a particle diameter of $30 \mu \mathrm{m}$, appears to be due to \#9101-N powder.

- The primary particles form large agglomerates that are not easily broken. These agglomerates can be approximated to be spheres, and vary in size from $50-300 \mu \mathrm{m}$. It is possible that the agglomeration phenomena may have been enhanced by the fact that the powders were supplied in dry form where the particles are in continuous contact with the adjacent particles for long periods of time.

- Evidence suggests that considerable disintegration of agglomerates occurred when they passed through the impeller of the pump used in the head loss experiments. Figure E-7 presents SEM image of the sludge after it was allowed to circulate through the loop for over several loop cycles. Clearly, very few large agglomerates survive the pump turbulence and the majority of the sludge consists of the smaller particles. However, since SEM pictures provide qualitative nature of the samples, they could not be directly used to draw conclusions regarding what fraction of the agglomerates actually disintegrated into the primary particles.

- Evidence also suggests that it is unlikely that agglomerates can be broken up by the turbulence created in the suppression pool experiments. Attempts to break up the agglomerates by simple laboratory methods such as stirring and subjecting liquid samples to mechanical vibrators resulted in no considerable changes in the debris size distribution.

Further details on the sludge characterization efforts are summarized in Reference E.11. Based on these 
Appendix E

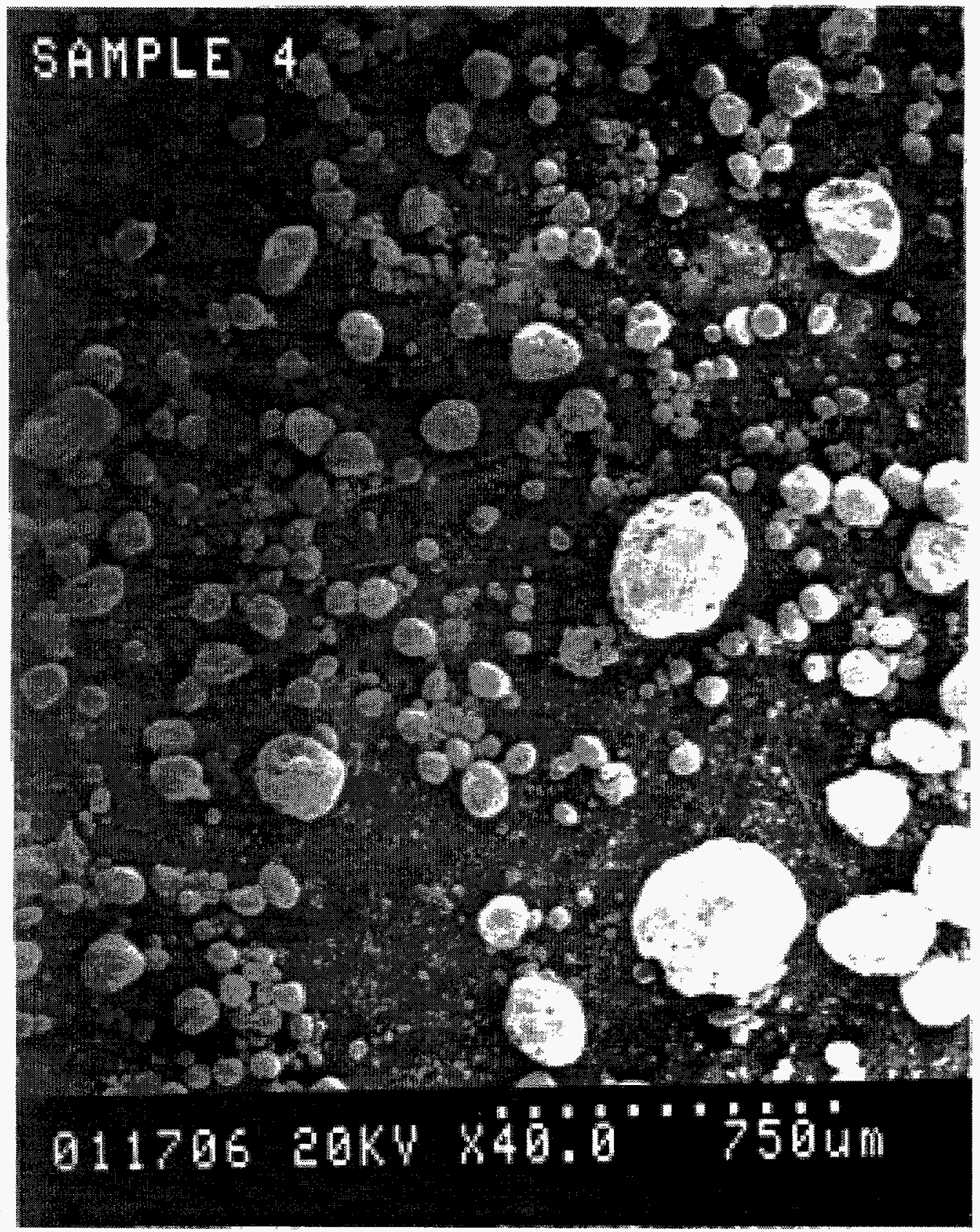

Figure E-4 SEM of Sludge A (750 $\mu \mathrm{m}$ magnification) 
Appendix E

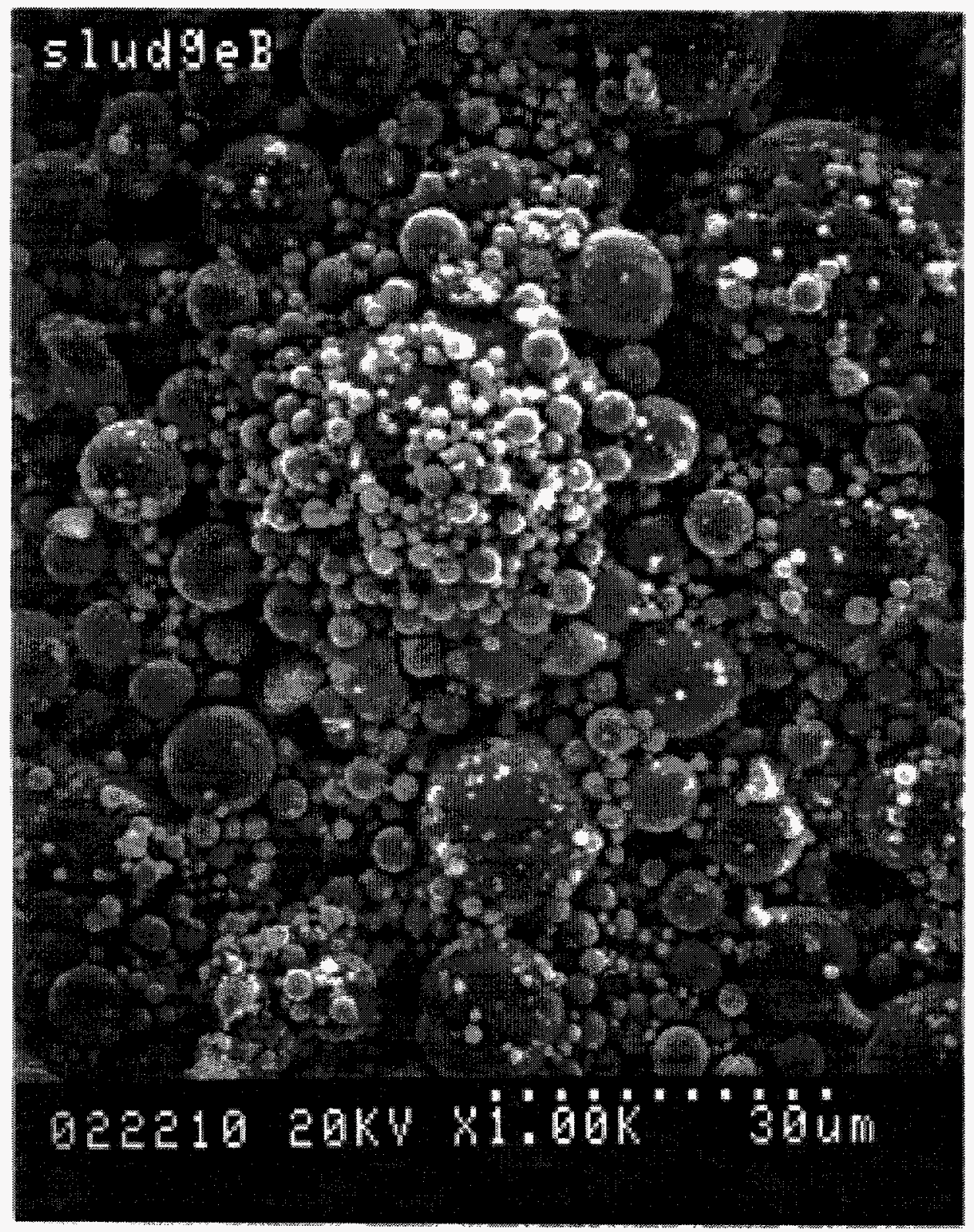

Figure E-5 SEM of Sludge B (30 $\mu \mathrm{m}$ magnification) 


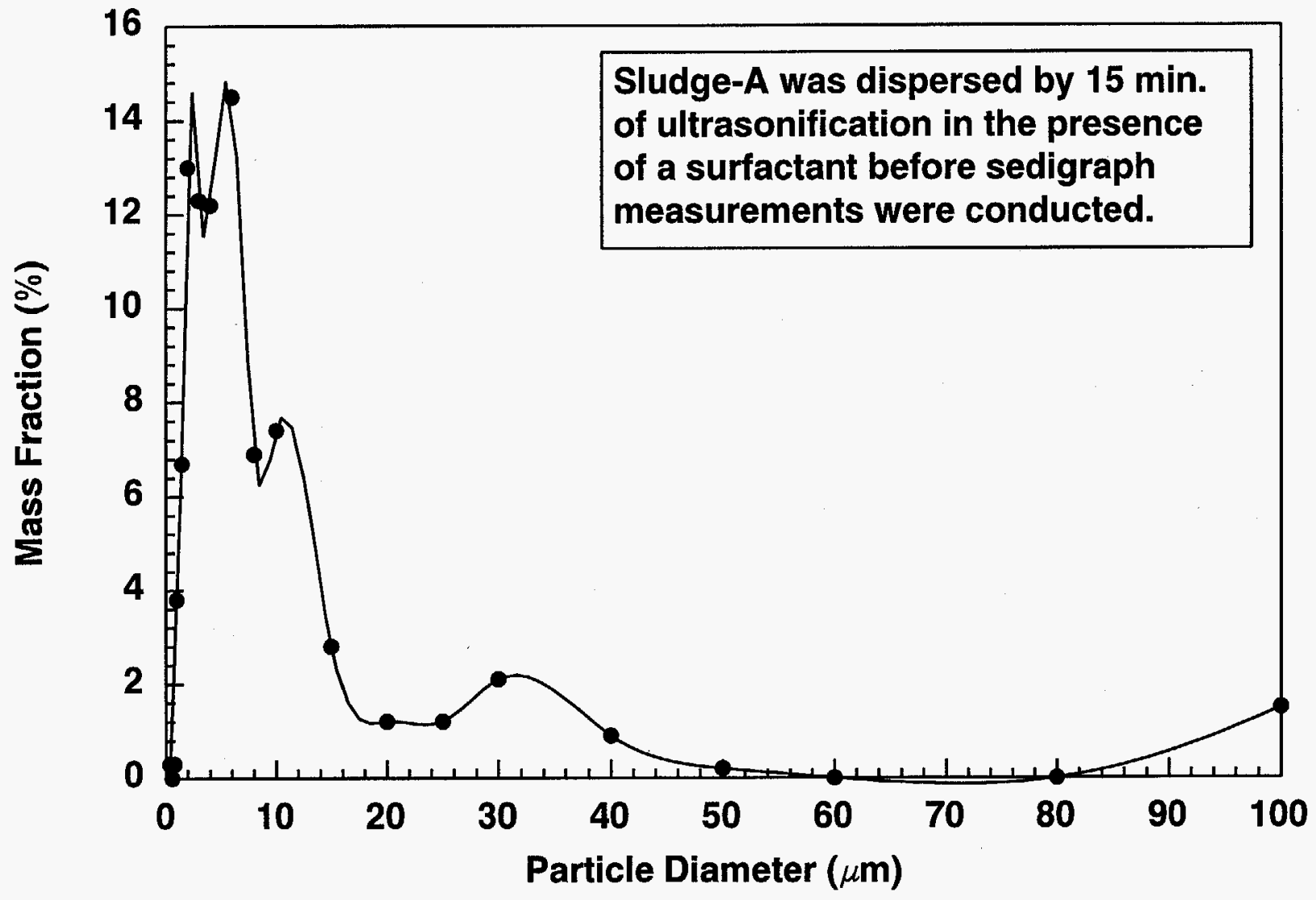


analyses, it was concluded that Figures E-4 and E-7 are representative of particle size distributions used in the suppression pool and head loss experiments, respectively.

\section{E.3 Suppression Pool Tests}

The overall purpose of the suppression pool tests was to provide insights into debris transport within the suppression pool following a LOCA. However, the underlying processes are too complex to be addressed by a single set of experiments. Several scoping analyses were conducted using a previous version of BLOCKAGE to identify the most important phenomena that influence the model predictions. Based on these scoping studies, and discussions with experts in related fields, the following phenomena were selected for further study:

1. Debris Transport/Sedimentation within the suppression pool during the high energy phase that immediately follows a MLOCA, and

2. Debris Transport/Sedimentation within the suppression pool during the post-high energy phase.

A reduced scale test facility (1:2.4 scale) of a typical Mark I containment was used to conduct experiments into these two areas. The following sections provide details related to scaling issues associated with the test facility design, test set-up instrumentation, test procedure and finally the experimental results and their applicability to actual BWRs. Reference E.5 presents further details on these issues.

\section{E.3.1 Test Model Similitude}

The pool dynamic conditions associated with the high energy phase of a MLOCA are usually referred to as chugging. The downcomer water oscillations during this chugging phase result in addition of kinetic energy to the suppression pool, thereby generating turbulence in the pool. This turbulence results in mixing of debris in the pool, the extent of which depends on the kinetic energy input per unit volume of the suppression pool. Since the experiments used the actual size debris, similitude requires that (1) the kinetic energy per unit volume in the test set-up be the same as that in the actual BWR pool following a LOCA, and (2) that the mode of turbulence generation in both cases be the same. Practical considerations limited the model geometrical scale to 1:2.4 of the actual BWR downcomer and torus geometry. This required scaling other operating parameters of the test set-up (e.g., chugging frequency and chugging amplitude) such that total kinetic energy input per unit pool volume in the present testing was the same as that in an actual BWR suppression pool.

The Mark I FSTF tests [Ref. E.7] provided limited data that could be used to estimate the specific energy input during chugging following a MLOCA in a MARK I containment. Based on these tests, two types of chugging were observed following a MLOCA: Type 1 where the neighboring downcomers oscillate in phase, i.e., the oscillations are synchronized; and Type 2 where the oscillations are relatively unsynchronized. Only Type 1 chugging was considered in this study since this is more prototypical of MLOCA. For several Type 1 chugs, the FSTF tests provided traces of wall pressures and vent line (downcomer) pressures. From these traces, three special cases of Type 1 chugging were identified from the Mark I test data. Each case represented different amounts of chugging energy that corresponded to initial, middle and later stages of chugging. However, actual kinetic energy imparted to the suppression pool during each chug was not directly available from the FSTF data. As a result, an analytical model was developed by ARL to derive the energy input values from the chugging pressure tracers recorded in the FSTF tests [Ref. E.13]. The model provided estimates of period of downcomer oscillation and amplitude of two-phase level movement for each of the three cases. The resulting period and amplitude for the steam-water interface inside the downcomers for each of these three cases are:

- $\quad$ Case 1: 2.4 seconds; 8 feet; high energy; initial stage of a LOCA

- $\quad$ Case 2: 1.9 seconds; 5 feet; medium energy; middle stage of a LOCA

- Case 3: 1.6 seconds; 3.8 feet; low energy; final stages of a LOCA 
Appendix E

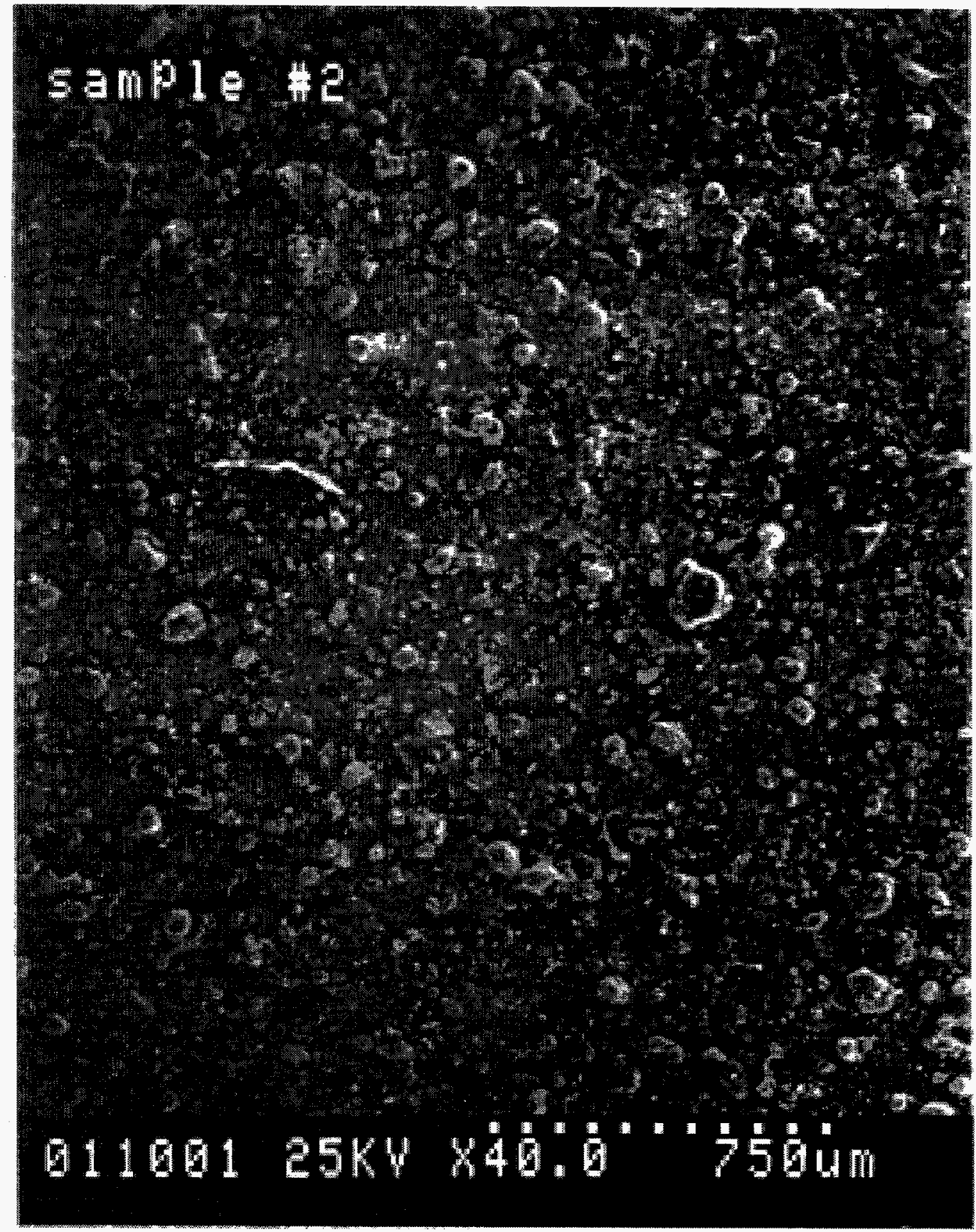

Figure E-7 SEM of Sludge A Collected After Circulating in Test Loop (750 $\mu \mathrm{m}$ magnification) 
A simple energy and turbulence generation model was developed to determine the specific energy input to a Mark I suppression pool corresponding to Cases 2 and 3 . Based on this model it was concluded that since the model set-up was scaled (1:2.4) and the debris were actual size, the similitude criterion would be met if the simulated chugging period and amplitude in the model set-up were reduced by a factor of 2.4 from the values listed above. Table E-3 presents the test parameters used in this study to simulate Cases 2 and 3 chugs described above. Since Cases 2 and 3 led to complete suspension, there was no need to conduct Case 1.

\section{E.3.2 Test Facility}

A 1:2.4 geometric scale simulation of a segment of a Mark I BWR suppression pool, based on the geometric details of GE FSTF, was constructed with a curved steel bottom and two plexi-glass side walls for viewing. Figure E-8 shows the test set-up geometry and Figure E-9 presents photographic image of the test set-up. The downcomer watersteam oscillations typical of chugging were simulated in the test set-up by plungers, mechanically moved to the scaled frequency, amplitude and position versus time. Figure E-10 illustrates the drive mechanism, while a photograph of the mechanism is presented as Figure E-11. The plungers were driven by a variable speed $50 \mathrm{HP}$ electric motor through a cam arrangement. In the present cam arrangement, all the plungers oscillated in phase, producing a Type I simulated chug. The position of the cam-follower pin determined the amplitude of the chug and the motor speed determined the chugging frequency. The cam pin position and the pump speed settings were selected to closely reproduce the chugging conditions listed in Table E-3.

The test facility was instrumented with five concentration sample ports which were used to draw preselected volumes of pool water for the purpose of determining debris concentration at that location. These sample ports were located in the center of the tank at five equi-spaced vertical locations; i.e., at $0.5,1.33,2.2,3.0$ and $3.8 \mathrm{ft}(0.15$, $0.41,0.76,0.91$ and $1.16 \mathrm{~m}$ ) off the floor. Scaled to an actual Mark I suppression pool, these distances correspond to $1.2,3.2,5.2,7.2$ and $9.2 \mathrm{ft}(0.37,0.98$,
$1.58,2.19$ and $2.80 \mathrm{~m}$ ) off the floor. Hereafter, these full-scale lengths were used to identify each of the sample ports. About 0.8 liters of pool water were drawn from each of the five ports simultaneously at preselected time intervals. The samples were filtered, dried and weighed according to the test procedures to estimate the concentrations in terms of mass of debris per unit mass of water.

\section{E.3.3 Test Procedure}

The step-by-step procedure followed in the tests can be summarized as follows:

- Fill tank to 56 inches $(1.42 \mathrm{~m}$ ) (full-scale height of $11.2 \mathrm{ft}$ or $3.41 \mathrm{~m}$ ) above the floor with clear water.

- Add a known quantity of pre-soaked NUKONTM insulation fragments to the tank and allow the debris to settle to the bottom of the tank.

- Add a pre-determined quantity of sludge to the tank and allow the sludge to settle to the bottom of the tank.

- Set the variable speed motor controller frequency to the pre-determined value and adjust the cam pin position to simulate the chugging conditions of interest. Run the simulated chugging for a total of 4 minutes (or 9.6 full-scale minutes).

- Draw water samples at every 60 seconds (or 2.4 full-scale minutes) while simulated chugging is continuing.

- Terminate simulated chugging after 4 minutes (or 9.6 full-scale minutes) and allow for the turbulence to decay.

- Draw water samples at every 1 minute (2.4 fullscale minutes) during simulated chugging and every 2 minutes ( 4.8 full-scale minutes) after the simulated chugging ceased.

The water samples were then used to estimate debris concentration using the filtration method described in Reference E.13. The concentration measurements for each of the test are presented in 
Appendix E

Top View
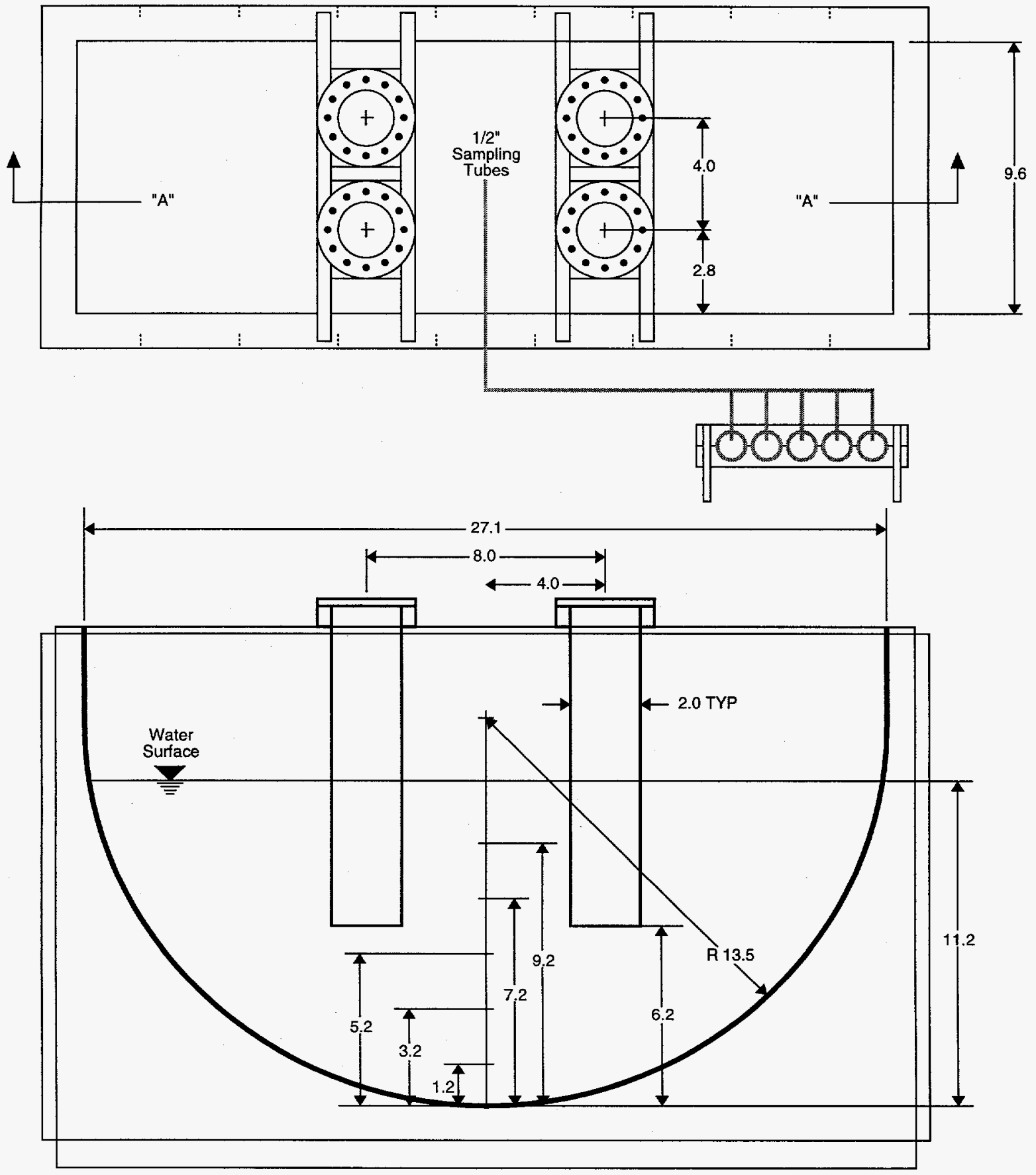

Section A-A

Note: All pool dimensions in feet (actual Mark I suppression pool)

Figure E-8 Modeled Suppression Pool Geometry 
Appendix E

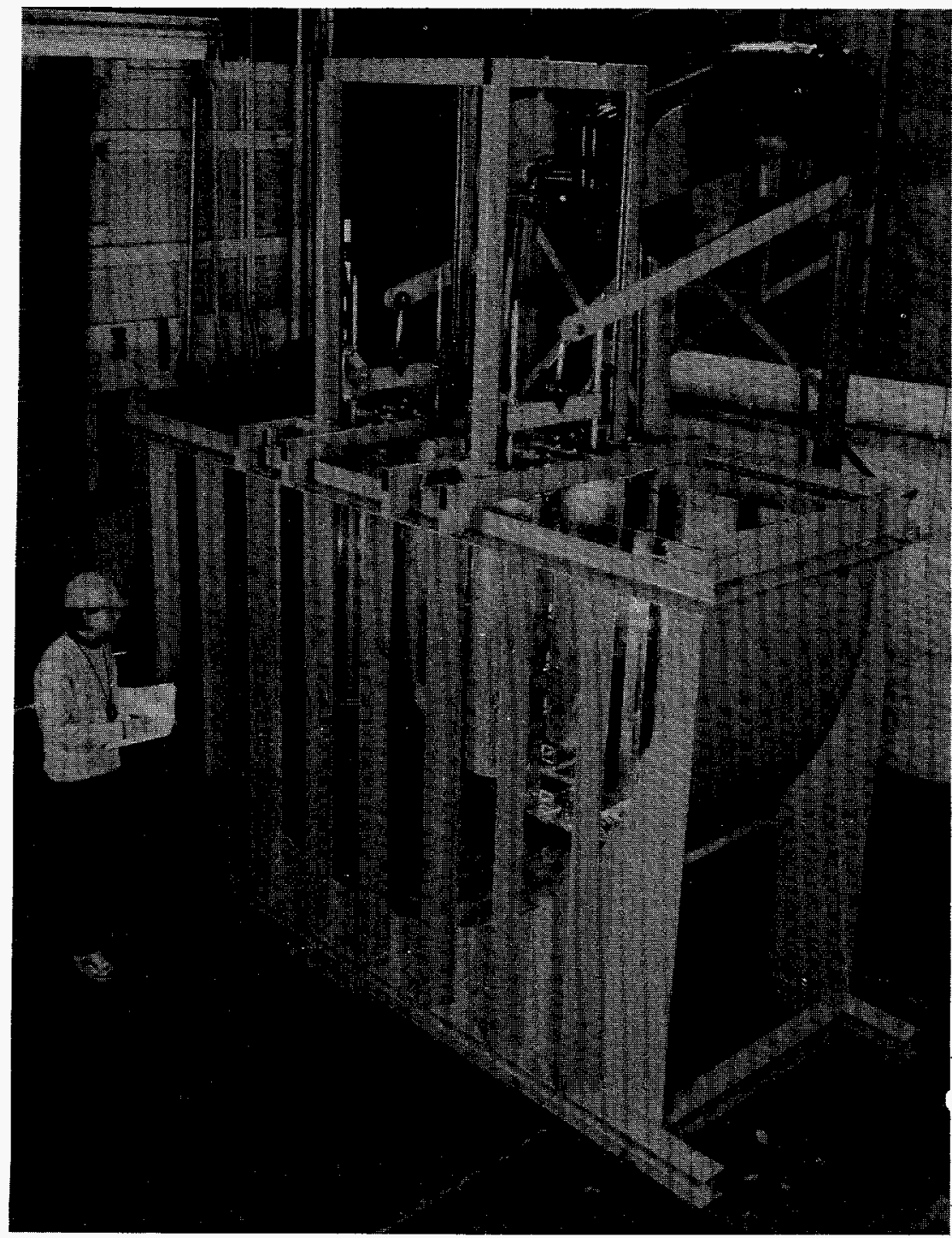

Figure E-9 1:2.4 Suppression Pool Segment Model 
Appendix E

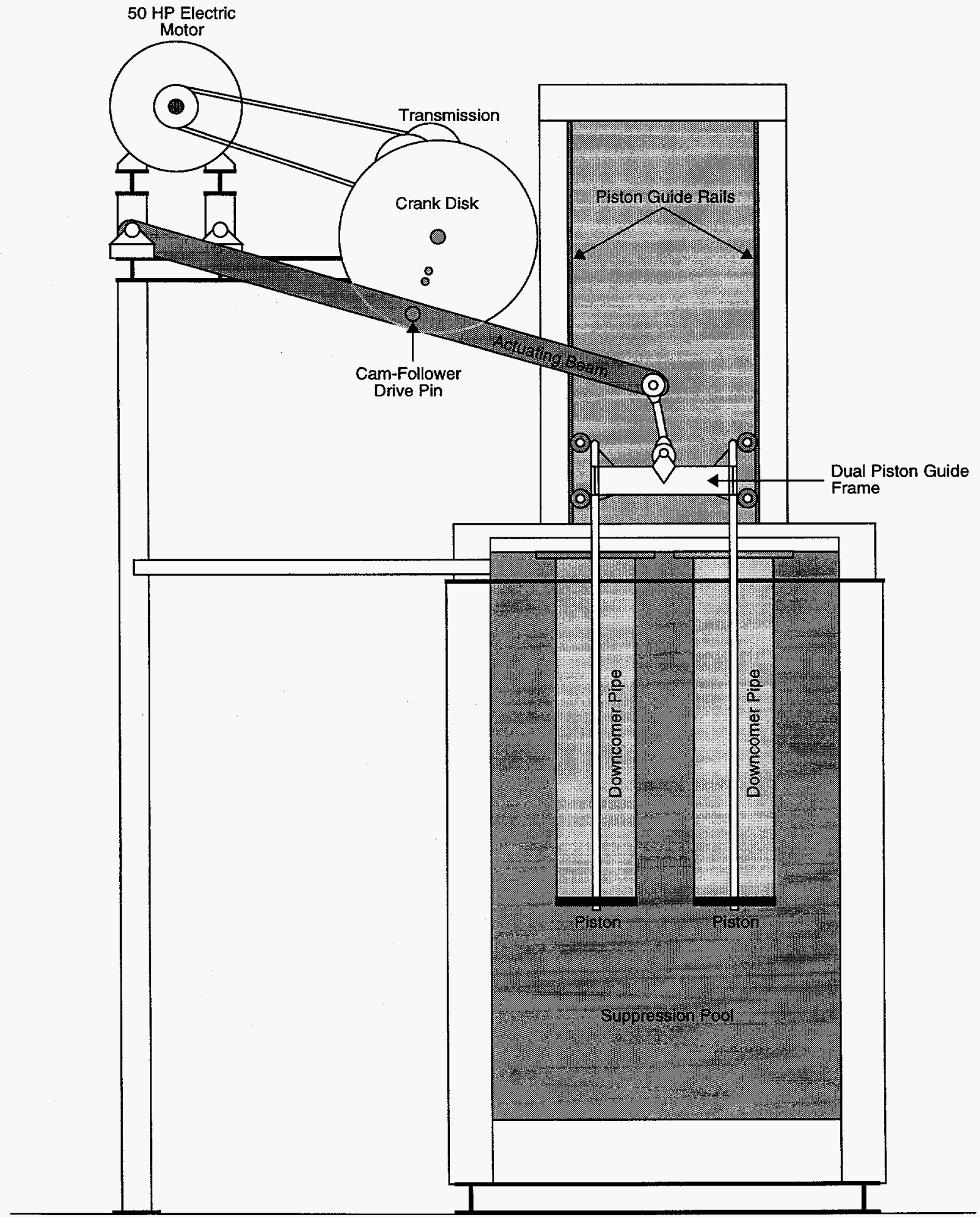

Figure E-10 Mechanical Drive for Chugging Simulation 
Appendix $\mathrm{E}$

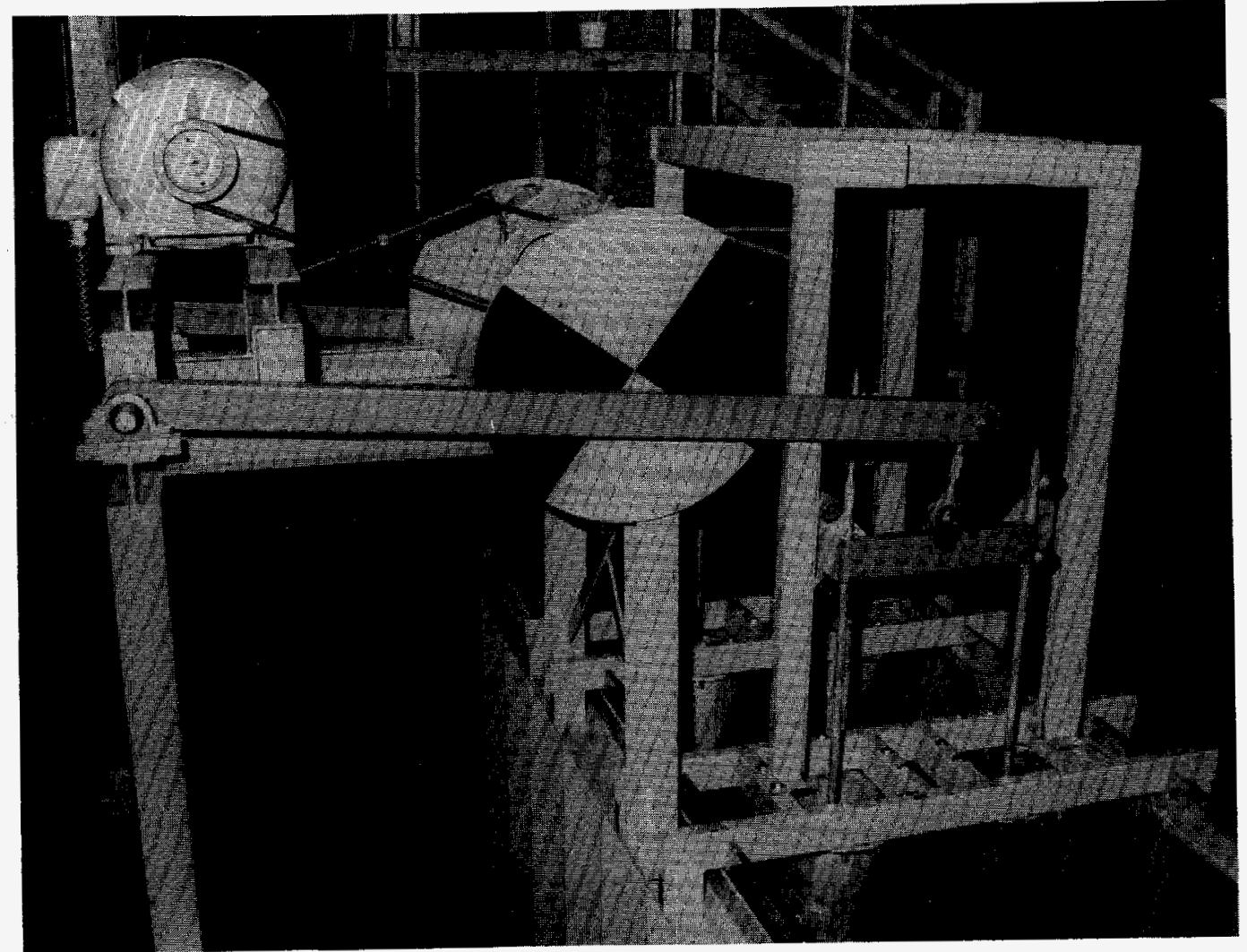

Figure E-11 Mechanical Drive in Suppression Pool Tests 
Appendix E

Table E-3 Test Matrix for the Suppression Pool Experiments

\begin{tabular}{|c|c|c|c|}
\hline Test \# & Debris Type & $\begin{array}{c}\text { Concentration in Water } \\
(\% \text { by Weight })\end{array}$ & $\begin{array}{c}\text { Full Scale Chugging Period; } \\
\text { Interface Amplitude in Downcomers }\end{array}$ \\
\hline \multicolumn{4}{|c|}{ Parametric Tests } \\
\hline \multicolumn{4}{|c|}{ Different Fiber Classes; Sludge Type A } \\
\hline A-1 R1 & $\begin{array}{l}\text { NUKON } \\
\text { Class } 3 \& 4\end{array}$ & $0.0032 \%$ & $1.6 \mathrm{sec} ; 3.8 \mathrm{ft}$ (Case 3$)$ \\
\hline A-2 R1 & $\begin{array}{l}\text { NUKON } \\
\text { Class 5\&6 }\end{array}$ & $0.0032 \%$ & $1.6 \mathrm{sec} ; 3.8 \mathrm{ft}$ (Case 3$)$ \\
\hline A-3 R1 & Sludge A & $0.0213 \%$ & $1.6 \mathrm{sec} ; 3.8 \mathrm{ft}$ (Case 3$)$ \\
\hline A-4 R1 & $\begin{array}{l}\text { NUKON } \\
\text { Class 5\&6 } \\
\text { Sludge A }\end{array}$ & $\begin{array}{l}0.0032 \% \\
0.0213 \%\end{array}$ & $1.6 \mathrm{sec} ; 3.8 \mathrm{ft}$ (Case 3 ) \\
\hline A-5 & $\begin{array}{l}\text { NUKON } \\
\text { Class 3\&4 } \\
\text { Sludge A }\end{array}$ & $\begin{array}{l}0.0032 \% \\
0.0213 \%\end{array}$ & $1.6 \mathrm{sec} ; 3.8 \mathrm{ft}$ (Case 3$)$ \\
\hline \multicolumn{4}{|c|}{ Different Concentrations } \\
\hline B-6 & $\begin{array}{l}\text { NUKON } \\
\text { Class 5\&6 } \\
\text { Sludge A }\end{array}$ & $\begin{array}{l}0.0011 \% \\
0.0213 \%\end{array}$ & $1.6 \mathrm{sec} ; 3.8 \mathrm{ft}$ (Case 3$)$ \\
\hline B-7 & $\begin{array}{l}\text { NUKON } \\
\text { Class 3\&4 } \\
\text { Sludge A }\end{array}$ & $\begin{array}{l}0.0011 \% \\
0.0213 \%\end{array}$ & $1.6 \mathrm{sec} ; 3.8 \mathrm{ft}$ (Case 3 ) \\
\hline B-8 & Sludge A & $0.0638 \%$ & $1.6 \mathrm{sec} ; 3.8 \mathrm{ft}($ Case 3$)$ \\
\hline \multicolumn{4}{|c|}{ Drywell Particulates (These tests were deleted.) } \\
\hline \multicolumn{4}{|c|}{ Different Period \& Amplitude (Tests D-12 and D-13 were deleted.) } \\
\hline D-11 R1 & $\begin{array}{l}\text { NUKON } \\
\text { Class 3\&4 }\end{array}$ & $0.0032 \%$ & $1.9 \mathrm{sec} ; 5 \mathrm{ft}$ (Case 2$)$ \\
\hline D-14 R1 & $\begin{array}{l}\text { NUKON } \\
\text { Class 5\&6 } \\
\text { Sludge A }\end{array}$ & $\begin{array}{l}0.0032 \% \\
0.0208 \%\end{array}$ & $1.9 \mathrm{sec} ; 5 \mathrm{ft}$ (Case 2) \\
\hline \multicolumn{4}{|c|}{ Re-entrainment of Debris (Included as a part of all tests by starting with debris at pool bottom.) } \\
\hline \multicolumn{4}{|c|}{ Insulation Debris Introduction Method (These tests were deleted.) } \\
\hline \multicolumn{4}{|c|}{ Repeat Tests } \\
\hline D-11 & $\begin{array}{l}\text { NUKON } \\
\text { Class } 3 \& 4\end{array}$ & $0.0032 \%$ & $2.1 \mathrm{sec} ; 5 \mathrm{ft}$ \\
\hline D-14 & $\begin{array}{l}\text { NUKON } \\
\text { Class 5\&6 } \\
\text { Sludge A }\end{array}$ & $\begin{array}{l}0.0032 \% \\
0.0213 \%\end{array}$ & $2.1 \mathrm{sec} ; 5 \mathrm{ft}$ \\
\hline \multicolumn{4}{|c|}{ Other Concentration Ratios } \\
\hline $\mathrm{T}-17$ & $\begin{array}{l}\text { NUKON } \\
\text { Class } 3 \& 4 \\
\text { Sludge A }\end{array}$ & $\begin{array}{l}0.0032 \% \\
0.0032 \%\end{array}$ & $1.6 \mathrm{sec} ; 3.8 \mathrm{ft}$ (Case 3$)$ \\
\hline $\mathrm{T}-18$ & $\begin{array}{l}\text { NUKON } \\
\text { Class } 3 \& 4 \\
\text { Sludge A }\end{array}$ & $\begin{array}{l}0.0032 \% \\
0.0016 \%\end{array}$ & $1.6 \mathrm{sec} ; 3.8 \mathrm{ft}$ (Case 3$)$ \\
\hline
\end{tabular}


Reference E.5. The following section presents the insights gained from these measurements.

\section{E.3.4 Results and Discussions}

The matrix for the final series of tests conducted using the suppression pool facility are listed in Table E-3. For each test, the initial averaged concentration was obtained by dividing the total mass of the debris added to the tank by the mass of tank water. The concentration measurements obtained at different time intervals were then normalized with respect to the initial concentration. The average concentrations during simulated chugging versus height in the tank were plotted in subplots a) of Figures E-12, E-13 and E-14 for tests A-1R1, A-3R1 and A-5, respectively. Concentration measurements at specific times are plotted as function of height in subplots b) and c) of these figures. Settling velocities calculated from the concentration measurements versus time are shown in subplots d) of the respective figures. Reference E.5 presents a set of these figures for each test case listed in Table E-3. In all these figures, the distances and test times are plotted as full-scale values obtained by multiplying the actual test values by 2.4. Such figures and computer manipulation of the data were used to draw the following insights regarding debris behavior during and after high energy phase.

\section{Debris Behavior During Chugging}

Debris initially on the floor became fully resuspended within the first few simulated chugging oscillations as observed by visual inspections, both for low and middle chugging energy levels (Cases 3 and 2). The debris tested included Class $3 \& 4$, Class $5 \& 6$ fibrous debris with and without sludge. As seen from the time averaged vertical concentration profiles (see Figures E-12a, E-13a and E-14a) for all practical purposes the debris remained fully mixed and suspended in the pool, even for the lowest energy. Any fluctuations in the vertical concentration profiles are attributable to the randomness associated with concentration sampling. Together these figures can be used to conclude that turbulence introduced by even low energy chugs, such as case 3 chugs, will result in fully mixed conditions soon after the chugging starts, irrespective of where the debris was introduced, i.e., on the floor or near the downcomer.
These tests demonstrated that the potential for debris settling is negligible during the chugging phase.

Visual observations during simulated chugging tests with NUKON ${ }^{\mathrm{TM}}$ debris, both with classes $3 \& 4$ and $5 \& 6$, showed further disintegration of fibrous debris into smaller sizes, including individual fibers. In general, the disintegration occurred close to the downcomer where the shreds were subjected to cyclic shear forces of the downward jet and ingestion into the downcomer. This visual observation is supported by concentration measurements which revealed that more than 10$15 \%$ of the debris remains suspended for time periods larger than 100 minutes after termination of simulated chugging, which is only possible if the debris underwent considerable disintegration.

In the suppression pool tests, the debris was introduced at the bottom of the tank, which is different from the actual BWR suppression pools where the fibrous debris are introduced through the downcomers. Introduction of fibrous debris through the downcomers may heighten the potential for fragmentation of debris.

\section{Settling after Chugging}

In all tests, simulated chugging was terminated after 4 test minutes or 9.6 full-scale minutes. Visual observations suggest that debris, especially the sludge particles, start to sediment immediately after termination of simulated chugging, indicating rapid decay in turbulence levels. These observations were confirmed by concentration measurements which were plotted in Figures E-12c, E-13c and E-14c, for tests A-1R1, A-3R1 and A-5, respectively. As can be seen from these figures, the measured concentration at each sampling position decreased with time due to gravitational settling. In addition, as can be seen from Figures E-12b, E-13b and E-14b, the measured concentration at the lower elevations (e.g., $1.2 \mathrm{ft}$, or $0.32 \mathrm{~m}$, off the floor) was continually larger than the corresponding at higher elevations (e.g., $9.2 \mathrm{ft}$, or $2.80 \mathrm{~m}$, off the floor), which is also consistent with gravitational settling. The concentration data with time were analyzed using a settling column approach to obtain settling velocities as described in Reference E.12. Figures E-12d, E-13d and E-14d plot these settling velocities for the three tests described above, as minimum settling velocities versus the 
Appendix E

a) AVERAGE CONCENTRATION DURING CHUGGING

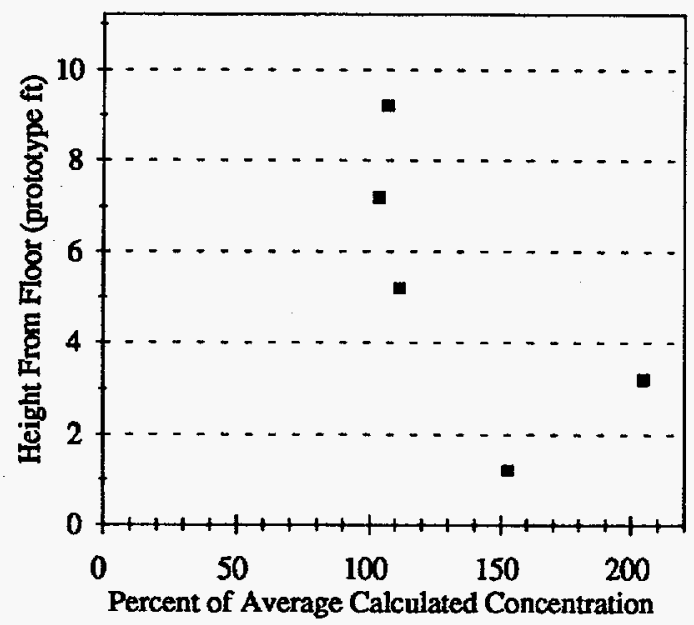

c) CONCENTRATION VS TIME

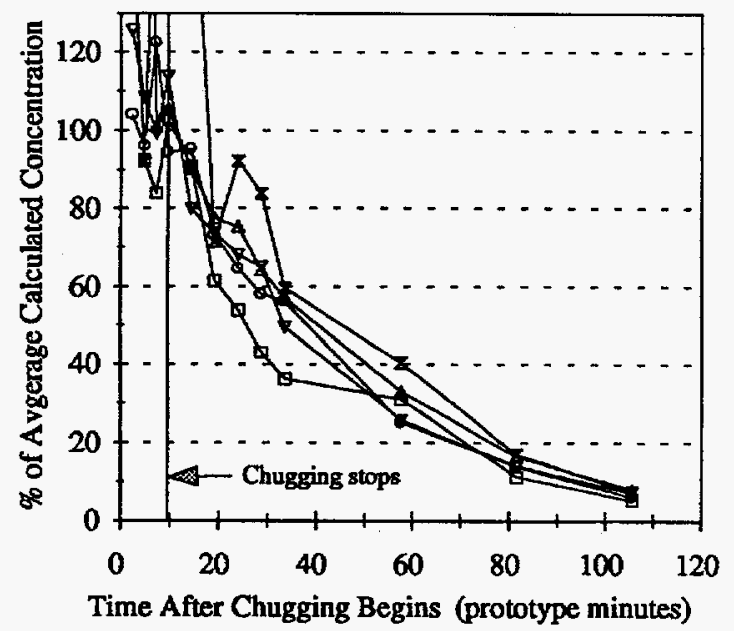

Sample Distance From Floor (prototype ft)

$\leftarrow 9.2-7.2 \rightarrow 5.2 \div 3.2 \div 1.2$ b) VERTICAL CONCENTRATTON PROFILES

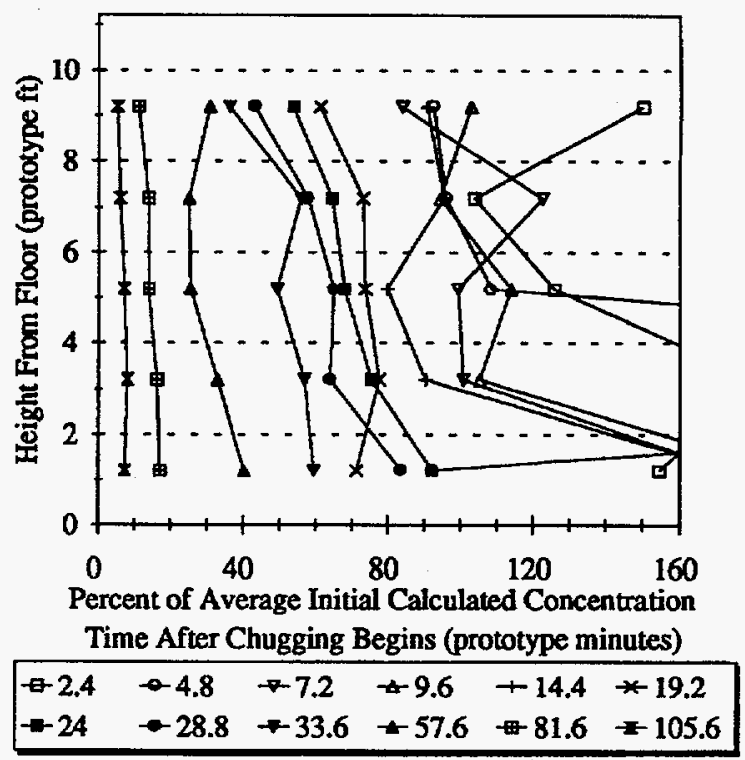

d) SETTLNG VELOCTTY AFTER CHUGGING

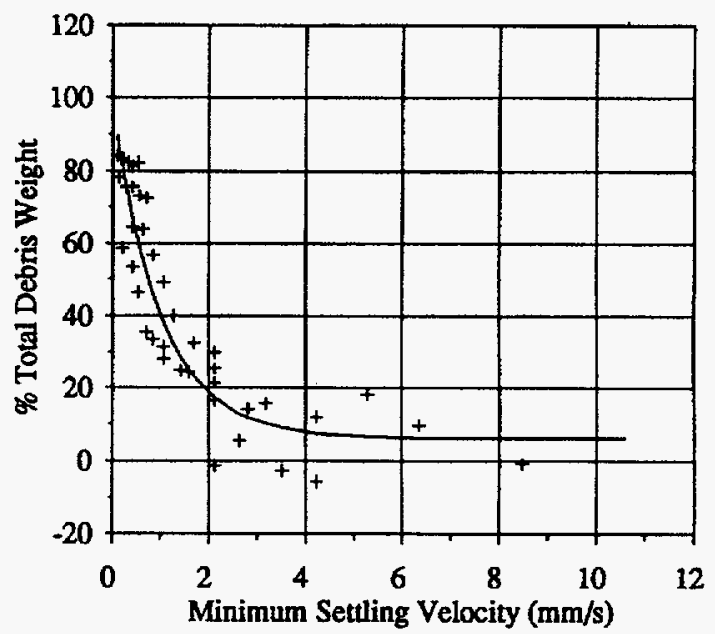

Note: 'prototype' in this figure refers to the equivalent of full-scale

Figure E-12 Debris Settling in Suppression Pool; Test A-1R1: $3.8 \mathrm{ft}$ amplitude; 1.65 period (Case 3) NUKON'M: $0.0032 \%$. Class 3 \& 4 . Sludge A: $0.0 \%$ 
a) AVERAGE CONCENTRATION DURING CHUGGING

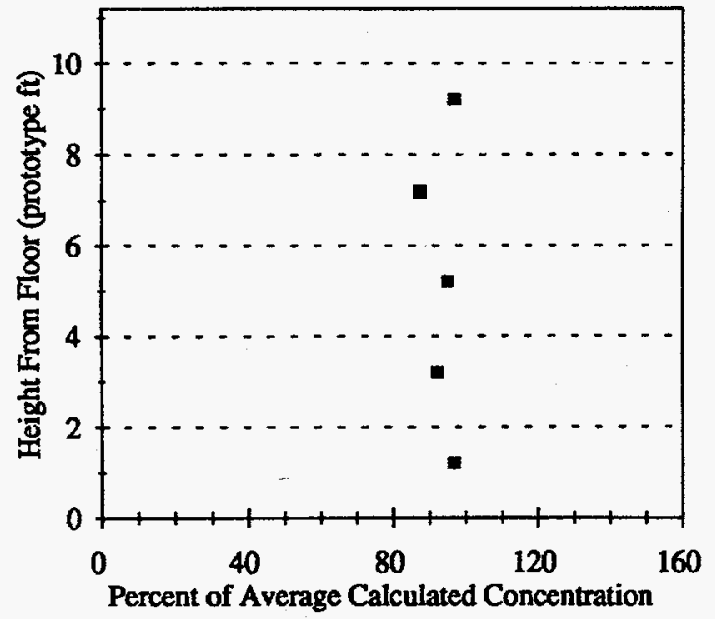

c) CONCENTRATION VS TIME

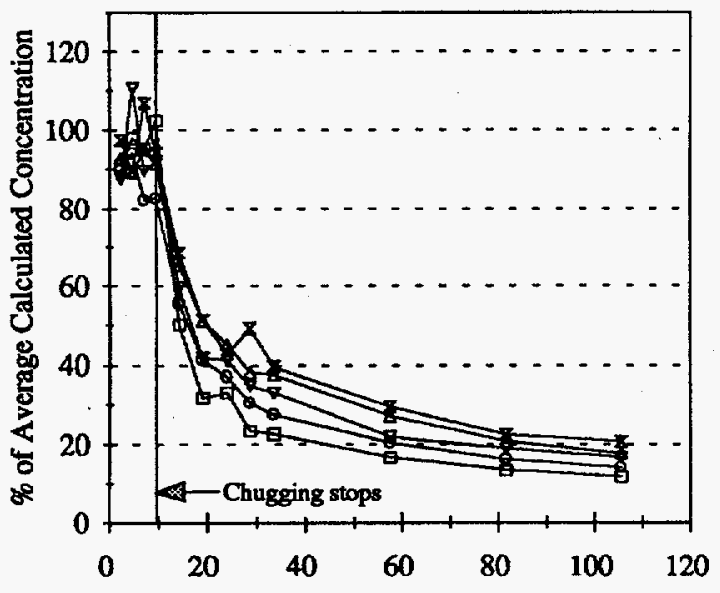

Time After Chugging Begins (prototype minutes)

Sample Distance From Floor (prototype $\mathrm{ft}$ ) $\nleftarrow 9.2-7.2-5.2+3.2 \div 1.2$ b) VERTICAL CONCEINTRATION PROFILES

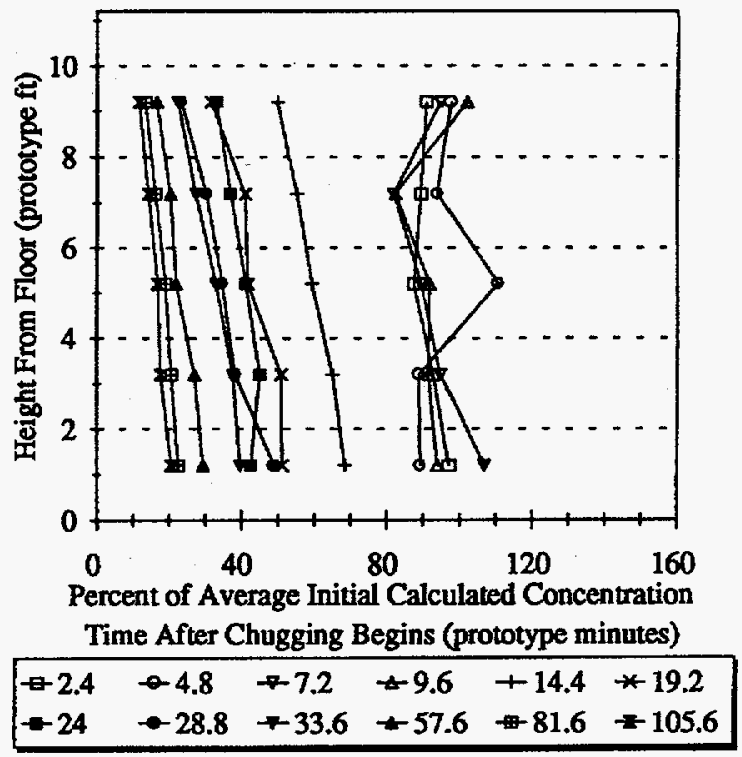

d) SETTLING VELOCITY AFTER CHUGGING

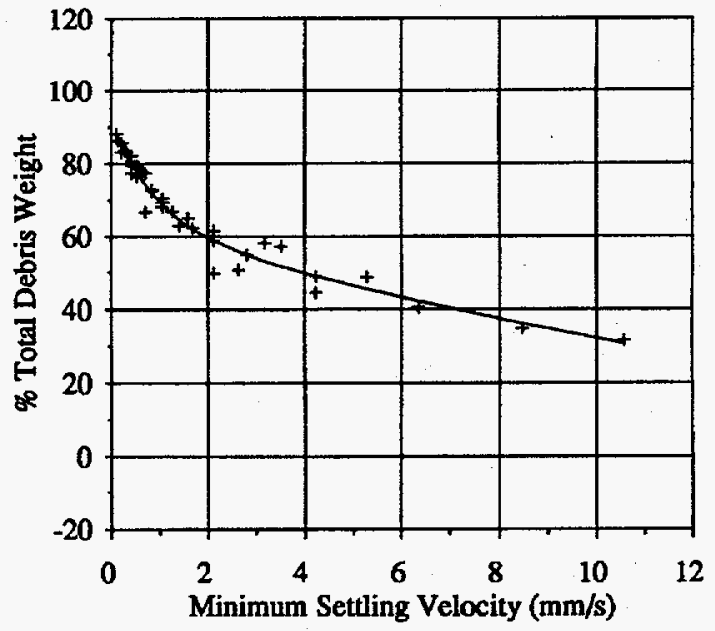

Note: 'prototype' in this figure refers to the equivalent of full-scale

Figure E-13 Debris Settling in Suppression Pool; Test A-3R1: $3.8 \mathrm{ft}$ amplitude; 1.65 period (Case 3). NUKON ${ }^{\mathrm{TM}}: 0.0 \%$. Sludge A: $0.0213 \%$ 
a) AVERAGE CONCENTRATION DURING CHUGGING

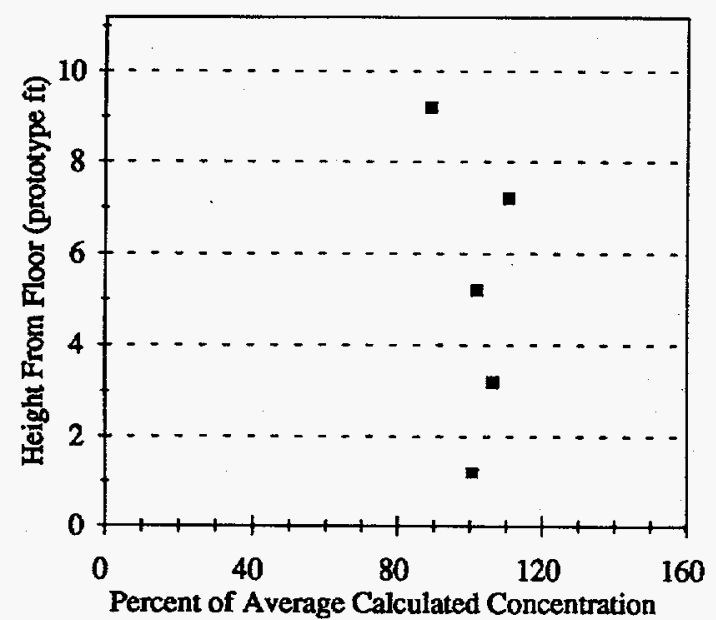

c) CONCENTRATION VS TIMB

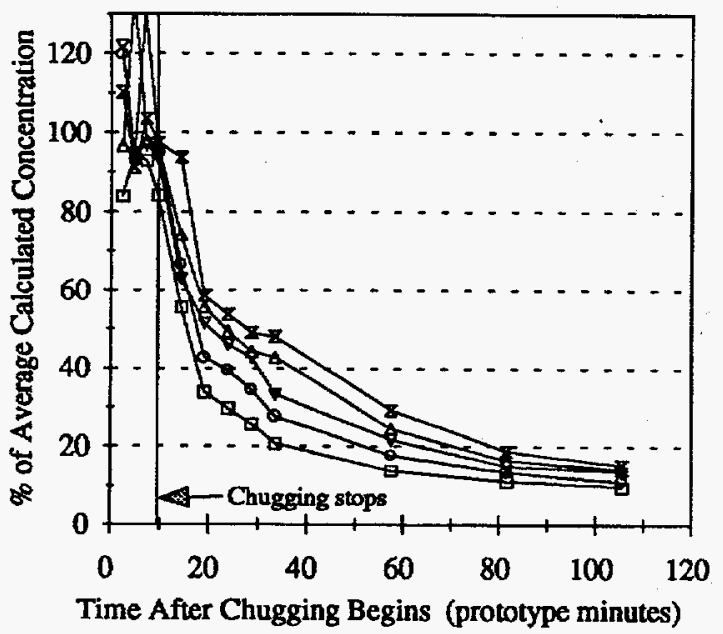

Sample Distance From Floor (prototype ft) $\because 9.2-7.2 \div 5.2 \varangle 3.2 \div 1.2$ b) VERTICAL CONCENTRATION PROFILES

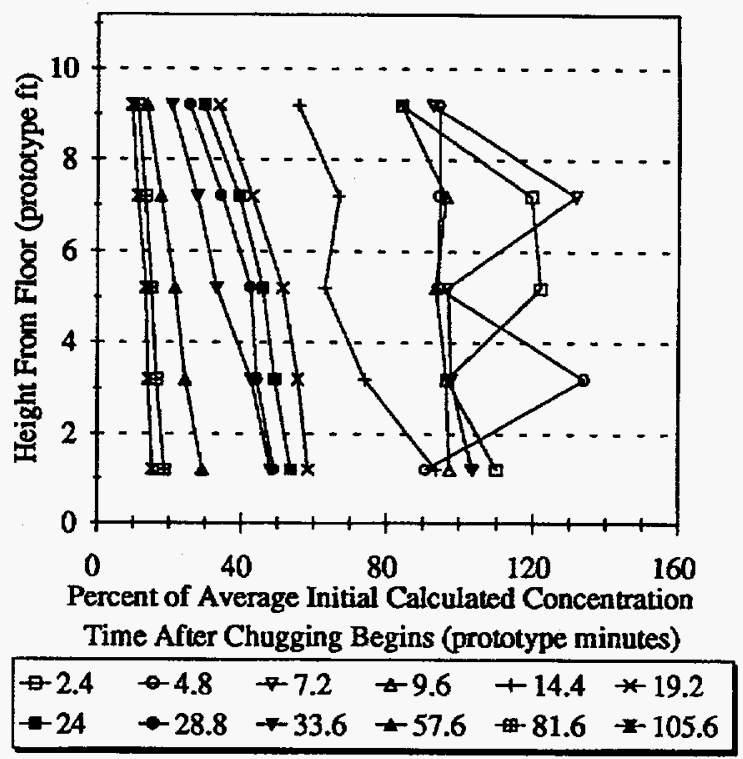

d) SETTLING VELOCITY AFTER CHUGGING

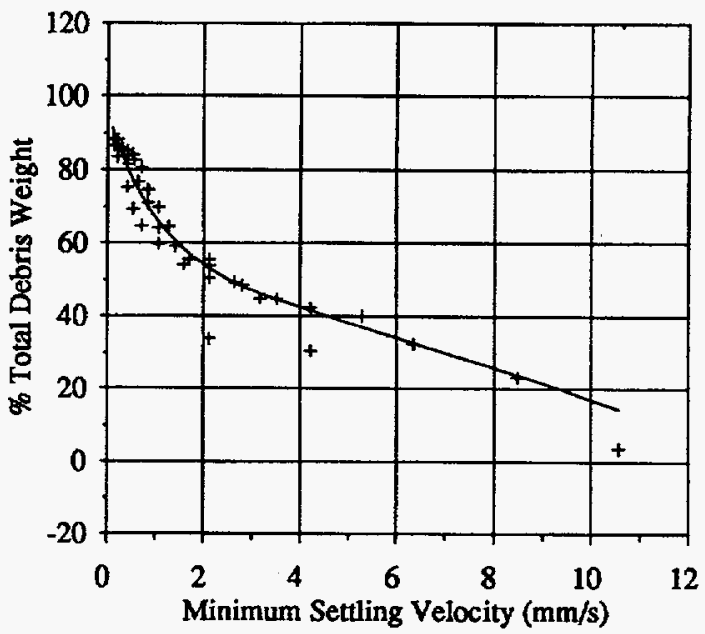

Note: 'prototype' in this figure refers to the equivalent of full-scale

Figure E-14 Debris Settling in Suppression Pool; Test A-5: $3.8 \mathrm{ft}$ amplitude, 1.65 period (Case 3). NUKON' ${ }^{\mathrm{TM}}$ : $0.0032 \%$. Class $3 \& 4$. Sludge A: $0.0213 \%$ 
Appendix E

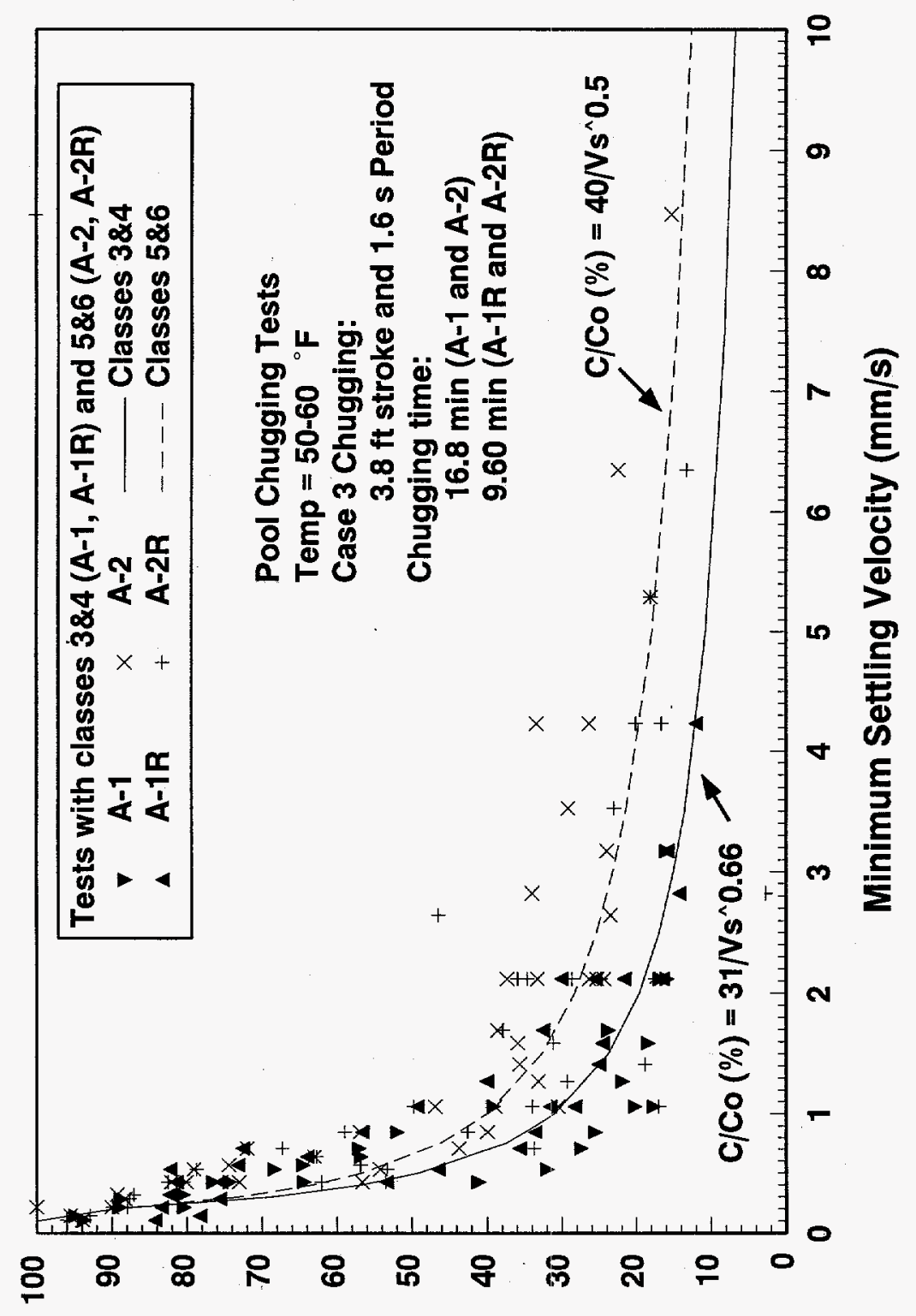

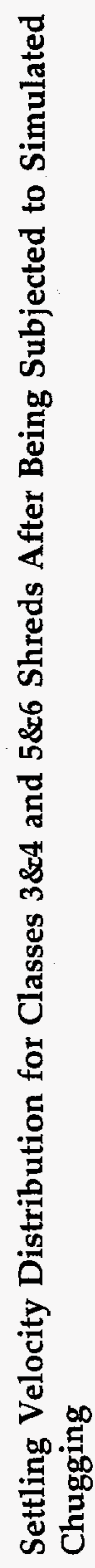

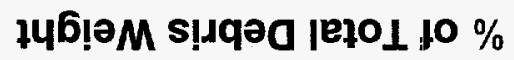

 


\section{Fraction of Total Debris by Weight}

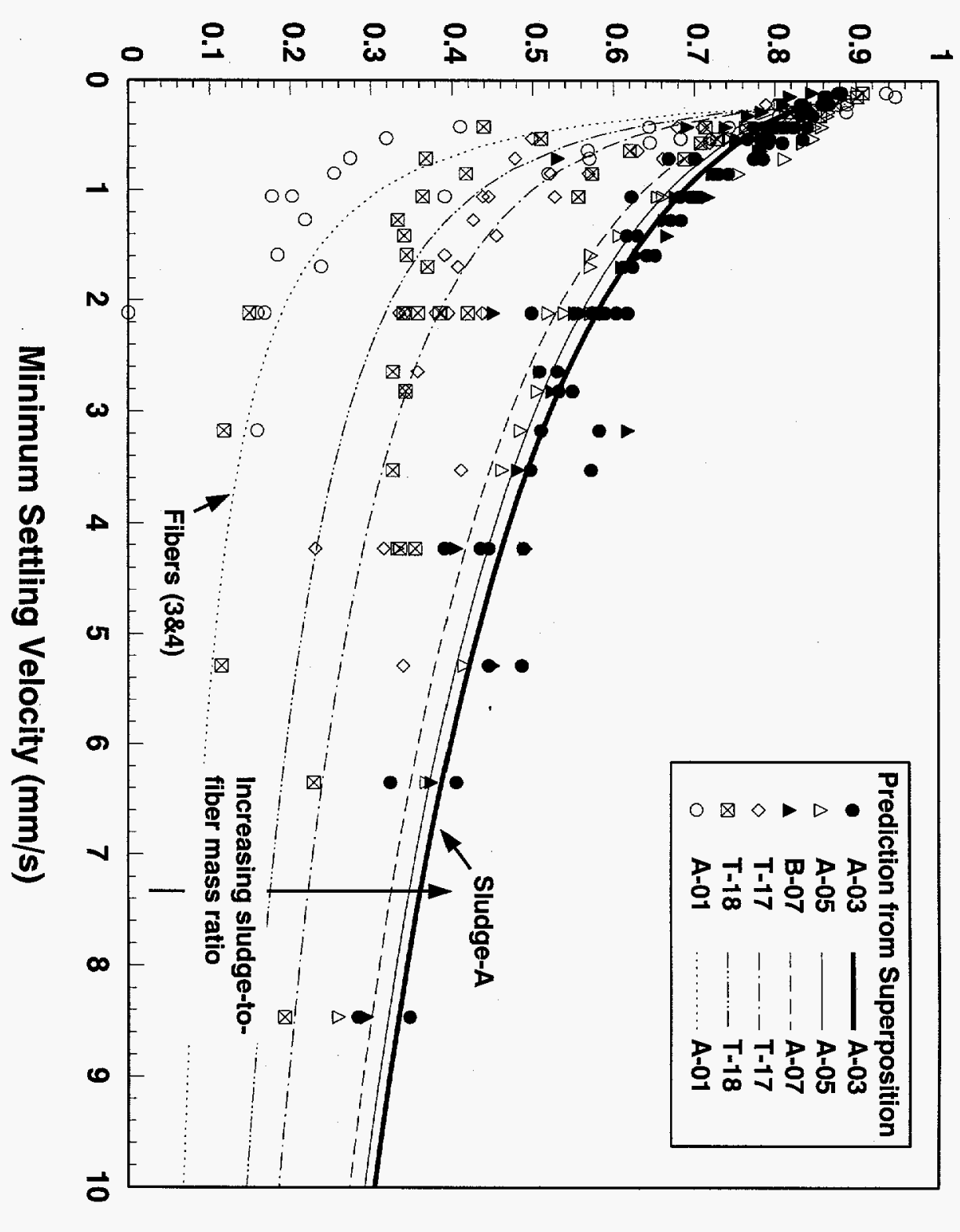


fraction of debris possessing those velocities. Figure E-15 plots settling velocity versus weight fraction for insulation debris of classes $3 \& 4$ and $5 \& 6$. Figure E-16 presents similar data for sludge and fiber mixtures of different sludge-to-fiber mass ratios. Also shown on Figure E-16 are the best-fit curves for fibers of class $3 \& 4$, for sludge- $A$ and for mixtures of various sludge-to-fiber mass ratios obtained using the superposition principle which assumes that fibers and mixtures settle separately. In each case it can be seen that the best fit curve provides a close approximation of the data. These figures can be used to draw the following insights:

- As a result of fragmentation suffered by the debris during the high energy phase, settling rates are weakly dependent on the class of the fibers ( $3 \& 4$ vs $5 \& 6$ ) initially added to the tank (see Figure E-15). Two different equations were developed for each for Classes $3 \& 4$ and Classes $5 \& 6$ and listed on Figure E-15. The slight differences in the settling velocity suggests that possibly class $5 \& 6$ possesses slightly larger pieces at the termination of chugging. However, the differences appear to be negligible.

- In general, the sludge possess larger settling velocities as demonstrated by the fact that $50 \%$ of the insulation debris possesses settling velocity less than $1 \mathrm{~mm} / \mathrm{s}$, whereas $50 \%$ of the tested Sludge A possesses settling velocity in excess of $3 \mathrm{~mm} / \mathrm{s}$.

- The settling velocities for sludge and fiber mixtures can be estimated using the principle of superposition. This suggests that fibrous and non-fibrous species settle independently of each other.

The settling velocity measurements can also be used to draw several insights into size distribution of the debris, especially the particulate debris. From Stokes' law it is known that for spherical particles the settling velocities, $V_{s}$, in calm pools can be estimated using the following equation:

$$
V_{s}=\frac{D_{p}^{2} g\left(\rho_{p}-\rho_{w}\right)}{18 \mu}
$$

where,

$D_{p} \quad$ is the equivalent diameter of the debris
particle,
$\rho_{p}$ is the density of the debris particle,
$\rho_{w}$ is the density of water,
$\mu$ is the viscosity of water,
$g$ is the acceleration of gravity.

This equation can be inversed to estimate the minimum particle diameter once the settling velocity is known as follows:

$$
D_{p}=\sqrt{\frac{18 \mu V_{s}}{g\left(\rho_{p}-\rho_{w}\right)}}
$$

The particle size distribution data obtained in this manner for sludge only is plotted in Figure E-17. This figure suggests that more than $50 \%$ of the Sludge A consists of particles a minimum diameter larger than $40 \mu \mathrm{m}$; and more than $25 \%$ are larger than $70 \mu \mathrm{m}$. Clearly, these estimates indicate that sludge particles in the tank are larger than manufacturer's specifications for powder \#2008. This observation is also consistent with the SEM pictures (e.g., Figures E-4) of dry Sludge A samples. This confirms that the iron-oxide sludge particles tend to agglomerate and form large agglomerates that are not easily disintegrated by turbulence. However, it is not clear if the agglomeration is typical of actual BWR conditions or it was a result of the fact that sludge mixtures in the present experiments were provided in dry form.

\section{E.3.5 Conclusions}

The suppression pool tests conducted with a 1:2.4 scale model of a Mark I suppression pool segment with NUKONTM fibrous debris and iron oxide sludge indicate that:

- During simulated chugging, both the fibrous and particulate debris remained fully mixed in the tank, even at lowest simulated chugging energies (i.e., Case 3 chugging). The turbulence created by these lower energy chugs was capable of resuspending the debris initially contained at the bottom of the tank 
Appendix E

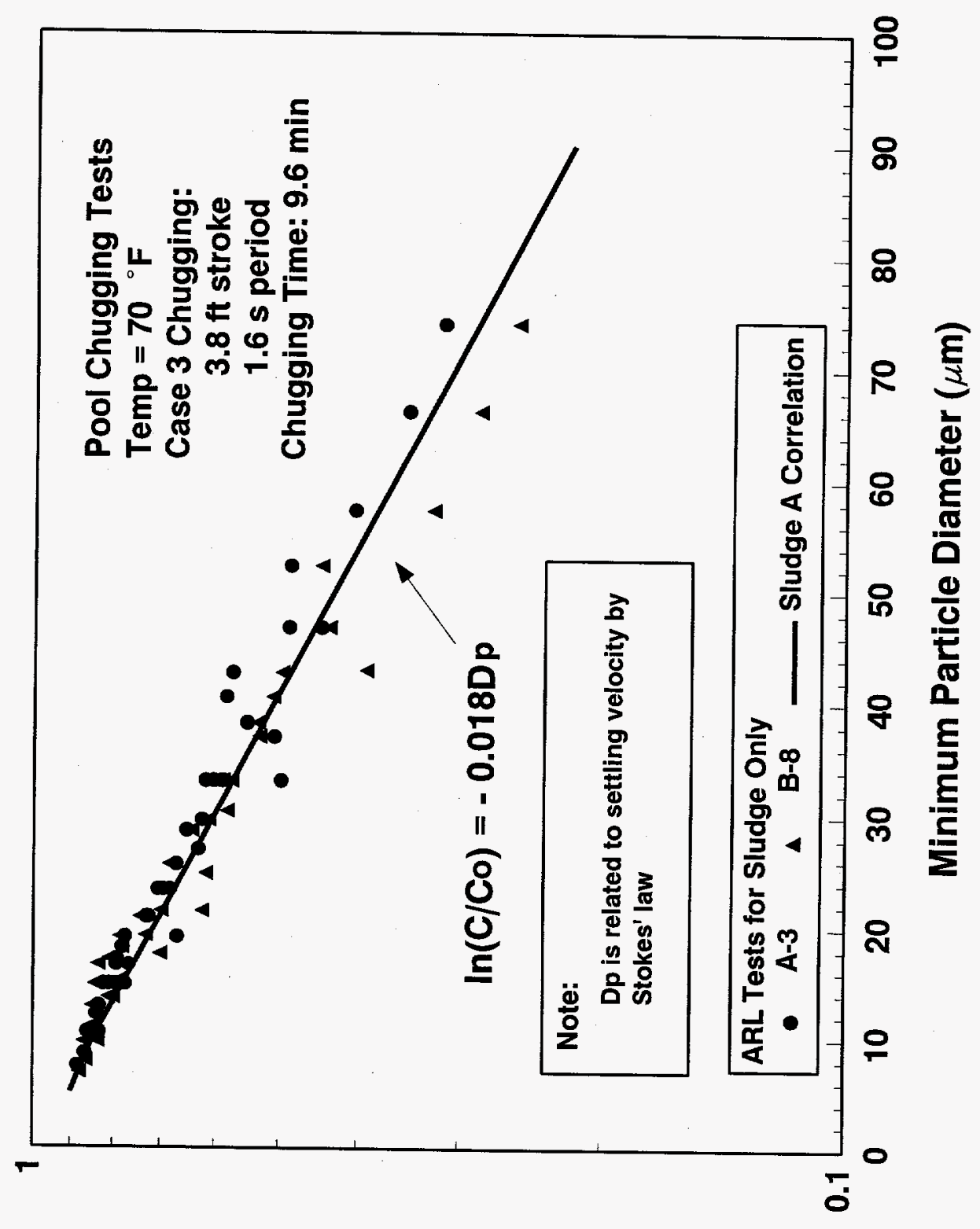

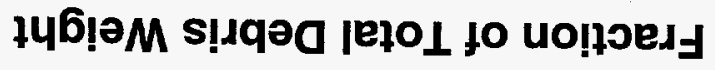


and resulted in uniform vertical concentration profiles. Although this data was obtained for the lowest energy chugs, it is believed to be equally valid for other phases of accident progression, including condensation oscillations typical of LLOCAs and Case 1 and Case 2 chugging that characterize both MLOCA and the final stages of a LLOCA.

- Even during the lowest energy chugging, the fibrous debris underwent further fragmentation into smaller sizes, including individual fibers. In general, the fragmentation occurred near the downcomers where the fibrous debris was subjected to cyclic shear forces from downward jet and ingestion into the downcomer.

- Visual observations suggest that the turbulence decays soon after termination of simulated chugging. This enables settling of the debris in the post-high energy phase. This observation may not be valid for the actual BWRs since in the later case additional turbulence is continually added to the suppression pool by the recirculating ECCS. Higher levels of turbulence may be present in a BWR suppression pool if the RHR is operated in the suppression pool cooling mode for heat removal. Since these phenomena can not be easily simulated in the test set-up, engineering judgement must be employed in estimating the correction factors that account for the effect of such phenomena on the settling velocities.

- The sludge simulant used in the present study (Sludge A) was made up of large agglomerates that settled quickly in the posthigh energy phase. There is a possibility that these agglomerates may have been formed in the present tests because the iron oxide powders were supplied in the dry form, where the individual particles are in physical contact with each other. This potential for agglomeration may be minimized in an actual BWR case, where the particles are in suspension thereby minimizing the chance for collision. Several factors may contribute towards agglomeration in the suppression pool, and all these processes are not very well understood.
- In the post-high energy phase, the vertical concentration profiles are slightly nonuniform. However, for strainer blockage analysis, it is reasonable to assume that the concentration profile is uniform near the strainer.

These conclusions related to post high-energy phase do not consider the effect of recirculation flow patterns within the suppression pool established by the ECCS flow. Simulation of such flow may provide additional insights related to horizontal variation of concentration profiles, which is essential to determine near-field concentration and possible re-entrainment of debris that may have settled during the earlier states of accident progression.

\section{E.4 Head Loss Experiments}

This study was conducted to determine the pressure drop characteristics of beds formed of NUKONTM fibrous insulation debris mixed with iron oxide particles used to simulate the suppression pool sludge. The study measured head loss across the strainer as a function of a) approach velocity; b) quantities and types of debris contained on the strainer; and c) water temperature.

An additional component of the study was to obtain estimates for the filtration efficiency of the debris cake formed on the strainer surface to remove particulate material passing through it. The sizes and types of debris used in the study are presented in Section E.2.

\section{E.4.1 Test Loop}

A closed flow loop, shown in Figure E-18, was used to conduct the tests. A stainless steel perforated plate, with $1 / 8$ inch $(0.3 \mathrm{~cm})$ holes and 30 holes per square inch was used for the ECCS strainers, as in actual BWRs. The strainer was located in a $12^{\prime \prime}$ (30.5 $\mathrm{cm}$ ) diameter vertical test section equipped with plexiglass mid-region. Two sample ports, located one each above and below the strainer, were used to draw water samples from the loop which were then used to estimate sludge concentration. The rest of the loop consisted of $4^{\prime \prime}(10.2 \mathrm{~cm})$ diameter piping to maintain higher velocities and to minimize the potential for sedimentation. A venturi flow meter located on the 4" piping section was used to 
Appendix E

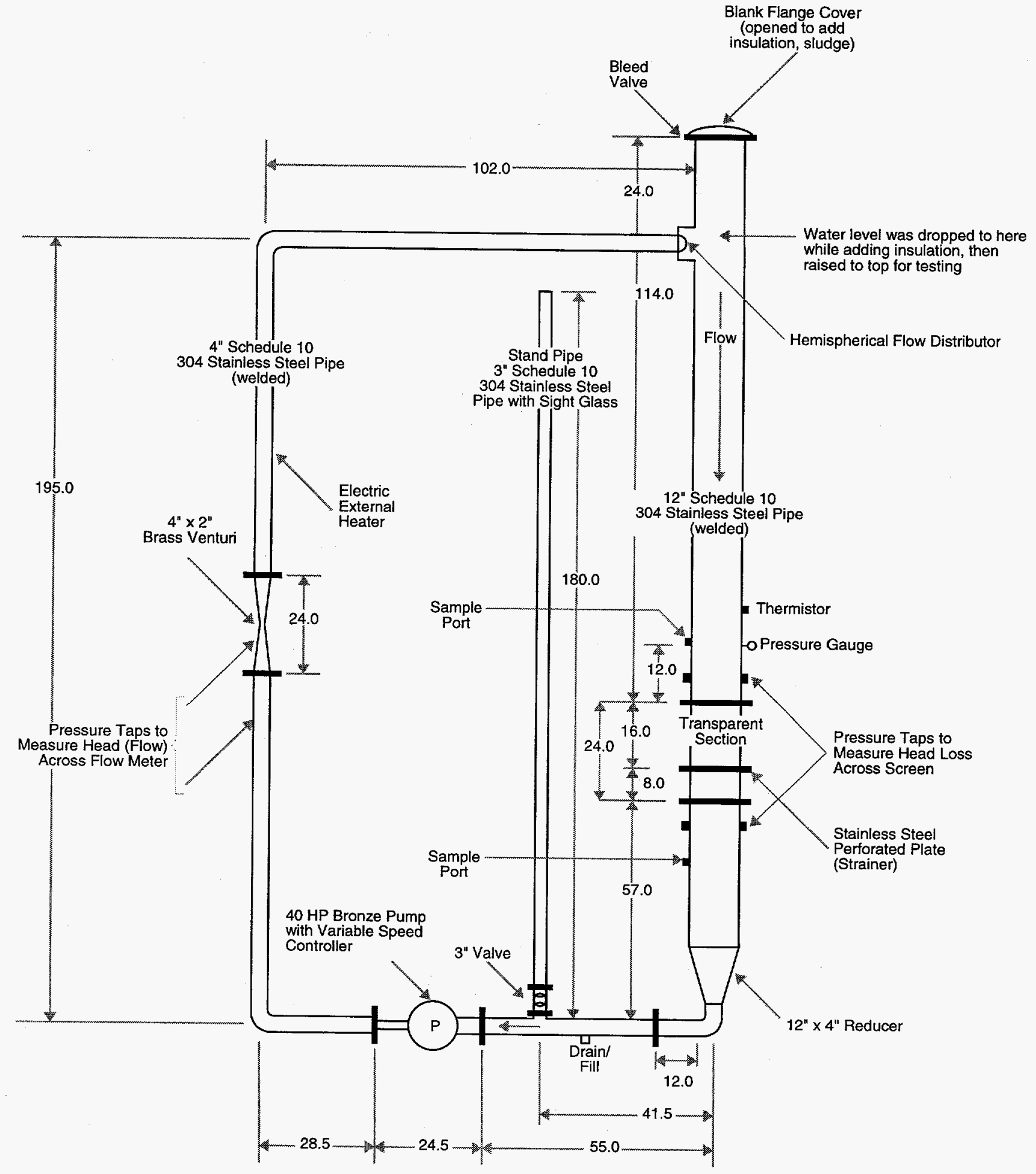

Figure E-18 Head Loss Testing Facility - Flow Loop 
measure the flow rate through the loop. A variable speed $40 \mathrm{HP}(30 \mathrm{~kW})$ centrifugal pump was used to circulate the water through the loop and to control the flow velocities in the 12 " section that varied between $0.15-1.5 \mathrm{ft} / \mathrm{s}(0.05-0.5 \mathrm{~m} / \mathrm{s})$. The heating pads attached to the piping network were used to help reach the water temperature of $125^{\circ} \mathrm{F}\left(52^{\circ} \mathrm{C}\right)$, although in some tests were conducted at ambient temperature $\left(75^{\circ} \mathrm{F}\right.$ or $\left.24^{\circ} \mathrm{C}\right)$.

\section{E.4.2 Test Procedure}

Based on exploratory testing, most of the tests were conducted at a water temperature of $125^{\circ} \mathrm{F}\left(52^{\circ} \mathrm{C}\right)$, with the insulation added all at once (after the sludge) to obtain an estimate of time of cake formation on the strainer. Prior to adding the insulation debris, a pre-determined quantity of sludge was added to the loop and was allowed to circulate with the water for over 15 minutes at the highest flow velocity (over 20 loop cycles) such that uniform sludge concentration could be attained. This process of circulating the sludge for over 20 loop cycles through the pump impeller may also resulted in break up of substantial portion of the large agglomerates. After a uniform distribution of sludge was obtained, the pump speed was set to obtain the initial approach velocity of $0.15 \mathrm{ft} / \mathrm{s}$, and a known quantity of fibrous insulation, pre-soaked in water to eliminate air pockets, was added to the loop. The bed was allowed to form on the strainer surface and the head loss across the strainer assembly was measured after steady state was reached. The water samples were then drawn and used to estimate sludge concentration in the loop. These sludge concentration measurements were in turn used to estimate the amount of sludge trapped in the debris cake at the time when the head loss measurement was made. After these measurements were carried out, the pump speed was increased to obtain a higher approach velocity. The procedure was repeated at this and all subsequent velocities until the head loss reached about 50-60 ft-water or until the approach velocity reached its maximum value of $1.5 \mathrm{ft} / \mathrm{s}$. Typically, the head loss data was obtained for six different approach velocities, namely $0.15,0.25,0.5,0.75,1.0,1.5 \mathrm{ft} / \mathrm{s}(0.05,0.08$, $0.15,0.23,0.30,0.5 \mathrm{~m} / \mathrm{s})$. In all cases, only stable head losses were finally used in the correlation development and the concentration measurements obtained corresponding to these stable head losses were used to estimate the type and quantities of debris contained in the debris cake. Also, whenever possible, visual observations were used to draw insights into debris bed buildup and its actual thickness.

In addition to the head loss experiments described above, the test loop was also used to obtain approximate estimates of filtration efficiency of the debris bed formed on the strainer surface. In these experiments, the sludge was added initially to the loop and after complete mixing was observed, the insulation debris were added all at-once. Frequent measurements of water concentration within one flow cycle after the fibrous debris cake was formed were used to estimate once-through filtration efficiencies.

\section{E.4.3 Results and Discussions}

The head loss data were obtained for theoretical insulation bed thicknesses in the range of 0.125 " to 4.0 " $(0.32$ to $10.2 \mathrm{~cm})$; approach velocities in the range of 0.15 to $1.5 \mathrm{ft} / \mathrm{s}(0.05$ to $0.5 \mathrm{~m} / \mathrm{s})$; at temperatures of $75^{\circ} \mathrm{F}\left(24^{\circ} \mathrm{C}\right)$ and $125^{\circ} \mathrm{F}\left(52^{\circ} \mathrm{C}\right)$; and for sludge-to-fiber mass ratios in the range of 0 to 60 (or $0 \%$ to $6000 \%$ ). The final test matrix is enclosed as Table E-4. Figure E-19 presents typical transient head loss traces for a pure fiber bed of theoretical thickness of $4^{\prime \prime}(10.2 \mathrm{~cm})$ at a water temperature of $125^{\circ} \mathrm{F}\left(52^{\circ} \mathrm{C}\right)$ (i.e, Test P04). As shown in this figure, at the initial approach velocity where the debris bed was formed, the head loss climbed gradually to a steady value. Based on visual observation, it could be seen that during this time the fibrous bed builds up gradually as the flocks of insulation are brought to the strainer by the flow. Once all the debris reached the strainer and the bed undergoes compression, the head loss attains a stable value. This stable value is recorded and then the flow is increased in steps until a maximum of $1.5 \mathrm{ft} / \mathrm{s}(0.5$ $\mathrm{m} / \mathrm{s}$ ) is reached or until the resultant head loss challenges the structural integrity of the test loop.

As the flow is ramped up in steps, the head loss follows it closely increasing with velocity. To avoid 
Appendix E

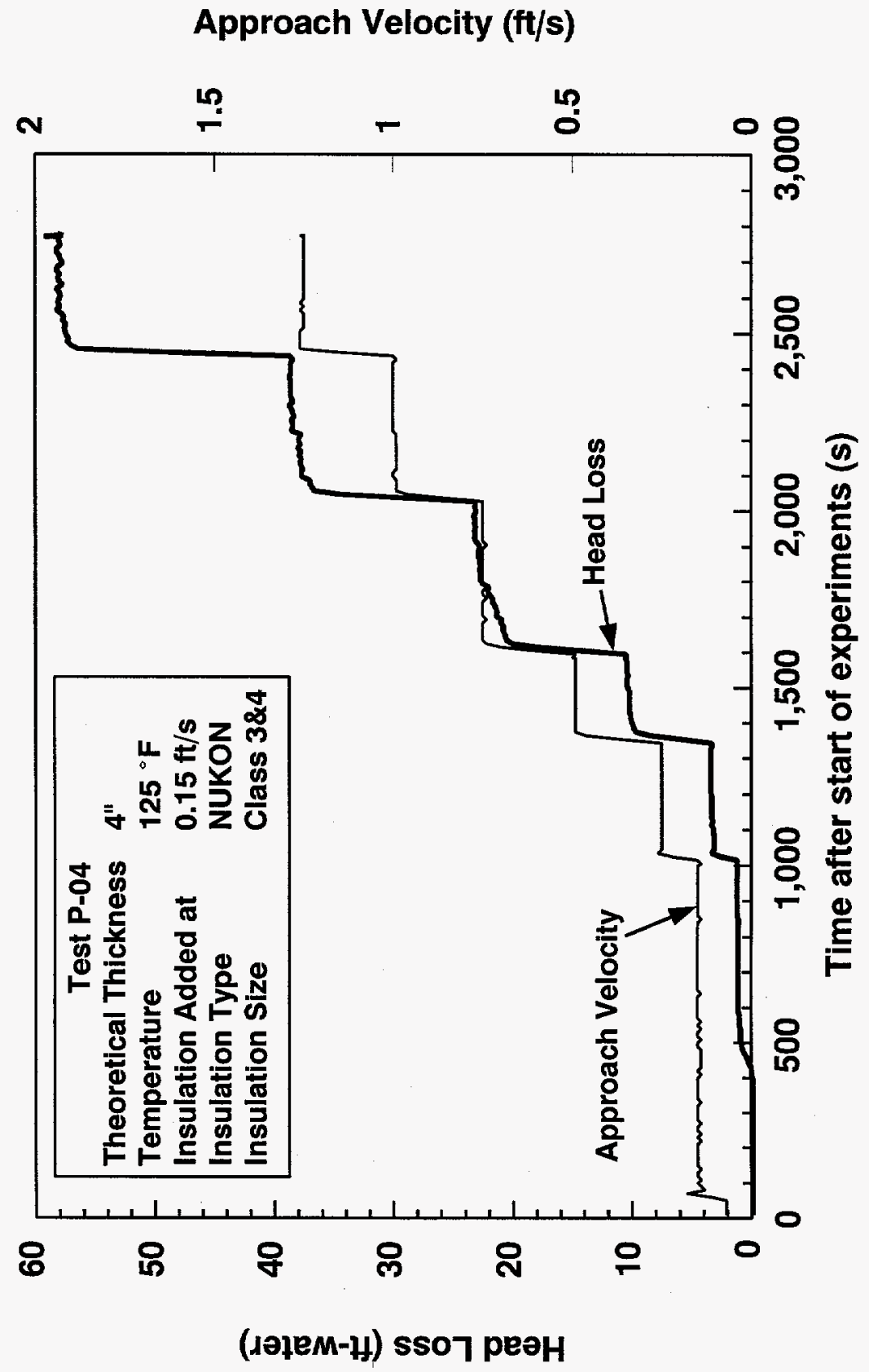

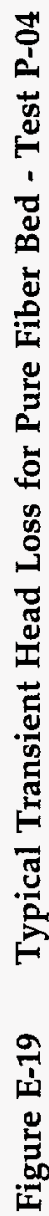


Appendix E

Table E-4 Parametric Test Matrix

\begin{tabular}{|c|c|c|c|c|c|c|c|}
\hline Test & $\begin{array}{c}\text { Nominal Fibrous } \\
\text { Thickness } \\
\text { inch }\end{array}$ & $\begin{array}{l}\text { Insulation } \\
\text { Class }\end{array}$ & $\begin{array}{l}\text { Sludge/ } \\
\text { Insulation } \\
\text { Ratio (\%) }\end{array}$ & $\begin{array}{c}\text { Insulation } \\
\text { Added @ } \\
\text { Velocity } \\
\text { ft/s }\end{array}$ & $\begin{array}{l}\text { Water } \\
\text { Temp. } \\
{ }^{\circ} \mathbf{F}\end{array}$ & $\begin{array}{c}\text { Particulate } \\
\text { Type }\end{array}$ & Remarks \\
\hline P01 & 1 & $3 \& 4$ & 0 & 0.15 & 125 & $\mathrm{~N} / \mathrm{A}$ & Head Loss Test \\
\hline $\mathrm{P} 02$ & 1 & $5 \& 6$ & 0 & 0.15 & 125 & $\mathrm{~N} / \mathrm{A}$ & Head Loss Test \\
\hline $\mathrm{P} 03$ & 2 & $5 \& 6$ & 0 & 0.15 & 125 & $\mathrm{~N} / \mathrm{A}$ & Head Loss Test \\
\hline P04 & 4 & $3 \& 4$ & 0 & 0.15 & 125 & $\mathrm{~N} / \mathrm{A}$ & Head Loss Test \\
\hline P05 & 2 & $5 \& 6$ & 0 & 0.15 & 50 & $N / A$ & Head Loss Test \\
\hline P06 & 1 & $5 \& 6$ & 100 & 0.15 & 125 & Sludge A & Head Loss Test \\
\hline P07 & 2 & $3 \& 4$ & 100 & 0.15 & 125 & Sludge A & Head Loss Test \\
\hline P08 & 2 & $5 \& 6$ & 100 & 0.15 & 125 & Sludge A & Head Loss Test \\
\hline P09 & 0.5 & $3 \& 4$ & 100 & 0.15 & 125 & Sludge A & Head Loss Test \\
\hline P10 & 0.5 & $3 \& 4$ & 250 & 0.15 & 125 & Sludge A & Head Loss Test \\
\hline P11 & 0.5 & $3 \& 4$ & 500 & 0.15 & 125 & Sludge A & Head Loss Test \\
\hline P12 & 1 & $3 \& 4$ & 50 & 0.15 & 125 & Sludge A & Head Loss Test \\
\hline P13 & 1 & $3 \& 4$ & 250 & 0.15 & 125 & Sludge A & Head Loss Test \\
\hline P14 & 1 & $3 \& 4$ & 500 & 0.15 & 125 & Sludge A & Head Loss Test \\
\hline P15 & 1 & $3 \& 4$ & 1000 & 0.15 & 125 & Sludge A & Head Loss Test \\
\hline P16 & 2 & $3 \& 4$ & 50 & 0.15 & 125 & Sludge A & Head Loss Test \\
\hline P17 & 4 & $3 \& 4$ & 50 & 0.15 & 125 & Sludge A & Head Loss Test \\
\hline P18 & 4 & $3 \& 4$ & 100 & 0.15 & 125 & Sludge A & Head Loss Test \\
\hline P19 & 2 & $3 \& 4$ & 50 & 0.15 & 50 & Sludge A & Head Loss Test \\
\hline P20 & 1 & $3 \& 4$ & 100 & 0.15 & 125 & Sludge B & Head Loss Test \\
\hline P21 & 2 & $3 \& 44$ & 100 & 0.15 & 125 & Sludge B & Head Loss Test \\
\hline P22 & 1 & $3 \& 4$ & 100 & 0.15 & 125 & Mix A & Head Loss Test \\
\hline P23 & 2 & $3 \& 4$ & 100 . & 0.15 & 125 & $\operatorname{Mix} A$ & Head Loss Test \\
\hline P24 & 1 & $3 \& 4$ & 100 & 0.15 & 125 & Sludge A & Filtration Test \\
\hline P25 & 1 & $3 \& 4$ & 100 & 0.25 & 125 & Sludge A & Filtration Test \\
\hline P26 & 1 & $3 \& 4$ & 100 & 0.5 & 125 & Sludge A & Filtration Test \\
\hline P27 & 0.5 & $3 \& 4$ & 100 & 0.15 & 125 & Sludge A & Filtration Test \\
\hline P28 & 0.5 & $3 \& 4$ & 100 & 0.25 & 125 & Sludge A & Filtration Test \\
\hline P29 & 0.5 & $3 \& 4$ & 100 & 0.5 & 125 & Sludge A & Filtration Test \\
\hline P30 & 0.25 & $3 \& 4$ & 100 & 0.15 & 125 & Sludge A & Filtration Test \\
\hline P31 & 0.25 & $3 \& 4$ & 100 & 0.25 & 125 & Sludge A & Filtration Test \\
\hline P32 & 0.25 & $3 \& 4$ & 100 & 0.5 & 125 & Sludge A & Filtration Test \\
\hline P33 & 0.5 & $3 \& 4$ & 1000 & 0.15 & 125 & Sludge A & Head Loss Test \\
\hline P38 & 1 & $3 \& 4$ & 750 & 0.15 & 125 & Sludge A & Head Loss Test \\
\hline $\mathrm{P} 40$ & 0.5 & $3 \& 4$ & 0 & 0.15 & 125 & Sludge A & Low Debris Thickness \\
\hline P41 & 0.25 & $3 \& 4$ & 0 & 0.15 & 125 & Sludge A & Low Debris Thickness \\
\hline P42 & 0.125 & $3 \& 4$ & 0 & 0.15 & 125 & Sludge A & Low Debris Thickness \\
\hline P43 & 0.5 & $3 \& 4$ & 2000 & 0.15 & 125 & Sludge A & with High Sludge Ratios \\
\hline P44 & 0.25 & $3 \& 4$ & 500 & 0.15 & 125 & Sludge A & with High Sludge Ratios \\
\hline P45 & 0.25 & $3 \& 4$ & 1000 & 0.15 & 125 & Sludge A & with High Sludge Ratios \\
\hline P46 & 0.25 & $3 \& 4$ & 2000 & 0.15 & 125 & Sludge A & with High Sludge Ratios \\
\hline P47 & 0.25 & $3 \& 4$ & 3000 & 0.15 & 125 & Sludge A & with High Sludge Ratios \\
\hline P48 & 0.25 & $3 \& 4$ & 5000 & 0.15 & 125 & Sludge A & with High Sludge Ratios \\
\hline P49 & 0.125 & $3 \& 4$ & 1000 & 0.15 & 125 & Sludge A & with High Sludge Ratios \\
\hline P50 & 0.125 & $3 \& 4$ & 2000 & 0.15 & 125 & Sludge A & with High Sludge Ratios \\
\hline P51 & 0.125 & $3 \& 4$ & 3000 & 0.15 & 125 & Sludge A & with High Sludge Ratios \\
\hline P52 & 0.125 & $3 \& 4$ & 4000 & 0.15 & 125 & Sludge A & with High Sludge Ratios \\
\hline P53 & 0.125 & $3 \& 4$ & 6000 & 0.15 & 125 & Sludge A & with High Sludge Ratios \\
\hline P34 & 1 & $3 \& 4$ & 1000 & 0.15 & 125 & Sludge A & Repeat of P15 \\
\hline P35 & 2 & $3 \& 4$ & 100 & 0.15 & 125 & Sludge A & Repeat of P07 \\
\hline P36 & 2 & $3 \& 4$ & 100 & 0.15 & 125 & Sludge B & Repeat of P21 \\
\hline P37 & 0.5 & $3 \& 4$ & 100 & 0.15 & 125 & Sludge A & Repeat of P09 \\
\hline
\end{tabular}


these hysterisis effects ${ }^{2}$, the stable head losses measured while the approach velocity was on its way up were recorded for use in the correlation development. These stable values for pure fiber beds are listed in Table E-5.

Within the range tested, for pure fiber beds, insulation debris classes ( $3 \& 4$ vs $5 \& 6$ ) had no significant effect on head loss. In all cases, head loss increased with both the bed thickness and the approach velocity. The data shows that head loss increase with bed thickness is fairly linear whereas its dependence on the velocity is non-linear. This trend is exhibited in Figure E-20 which plots 'head loss per unit thickness of the fiber bed' versus the approach velocity ${ }^{3}$. Also shown on the figure are the predictions of the NUREG/CR-6224 correlation, which is described in detail in Appendix B.

Comparison of the correlation predictions with the experimental data, shown in Table E-5, also demonstrates that the effect of temperature on the head loss can be accounted for by the viscosity term used in the correlation. This is an important finding and can be effectively used to extend the correlation to other temperatures as needed by the analyst.

Figures E-21 and E-22 are the transient head loss traces for the mixed beds of different sludge-to-fiber mass ratios. In both cases, the bed theoretical insulation thickness was $0.25^{\prime \prime}(0.6 \mathrm{~cm})$, the operating temperature was $125^{\circ} \mathrm{F}\left(52^{\circ} \mathrm{C}\right)$, and the same procedure was followed for debris introduction. In both cases, the resultant head losses were significantly larger than those corresponding to a no-sludge (pure fiber bed) condition. However, the transient head loss behavior in these two cases was distinctly different, leading to the following conclusions:

- At low head losses, the debris beds are fairly uniform and can be best described as mixed beds where the sludge particles are intermixed with the fibers. Figure E-23 presents an SEM image of mixed beds typically observed at low

\footnotetext{
${ }^{2}$ The hysterisis effect is discussed in detail in Reference E.6.

${ }^{3}$ The fact that experimental data collected for different theoretical thicknesses collapsed into a single line when plotted in this manner confirms the linearity of head loss with respect to fiber bed thickness.
}

sludge-to-fiber mass ratios and/or low approach velocities that are characterized by lower compacting pressures. Such beds behaved very similar to pure fiber beds in that head loss increased significantly for each corresponding increase in velocity. Visual observation of these beds suggests that they remain fairly uniform throughout the experiment.

- When the head losses across the beds are sufficiently large, they damage the debris bed punching holes through the bed. These damaged beds resemble a partially plugged strainer and usually result in lower head losses. In Figure E-22, such a transition occurred as the flow velocity was increased from $0.50 \mathrm{ft} / \mathrm{s}(0.05 \mathrm{~m} / \mathrm{s})$ to $0.75 \mathrm{ft} / \mathrm{s}(0.08$ $\mathrm{m} / \mathrm{s}$ ). As evident from this figure, this increase is instantaneously followed by an increase in head loss. However, apparently the bed structure was unable to support such high losses allowing for radical change in bed configuration. As a result, the head losses decreased with time ultimately reaching a steady state at a much lower value. This behavior is repeated at each increasing velocity. Further increase in velocity appears to have little effect on the head loss. For example, in Figure E-22 increasing velocity from $1 \mathrm{ft} / \mathrm{s}$ to $1.5 \mathrm{ft} / \mathrm{s}(0.3 \mathrm{~m} / \mathrm{s}$ to $0.5 \mathrm{~m} / \mathrm{s})$ resulted in no notable increase in head loss.

Further insights gained from the analysis of the head loss data are summarized in Reference E.6.

The stable head loss data obtained from the experiments (including that for damaged beds) are listed in Tables E-6, E-7, E-8 and E-9 for mixed beds of different fiber thicknesses and sludge to fiber mass ratios. Within the range of mixed beds tested, the insulation debris classes ( $3 \& 4$ vs $5 \& 6$ ) or the sludge particle size (Sludge A vs Sludge B) do not appear to have had significant effect on the head loss. In all cases, the head loss increased fairly linearly with respect to the fiber bed thickness. However, head loss variation with approach velocity and sludge-to-fiber mass ratio is non-linear. To illustrate head loss dependence on sludge-to-fiber mass ratio, Figure E-24 plots the head loss for the mixed beds as a function of sludge-to-fiber mass ratio in the fiber bed for three flow velocities $(0.15$, 


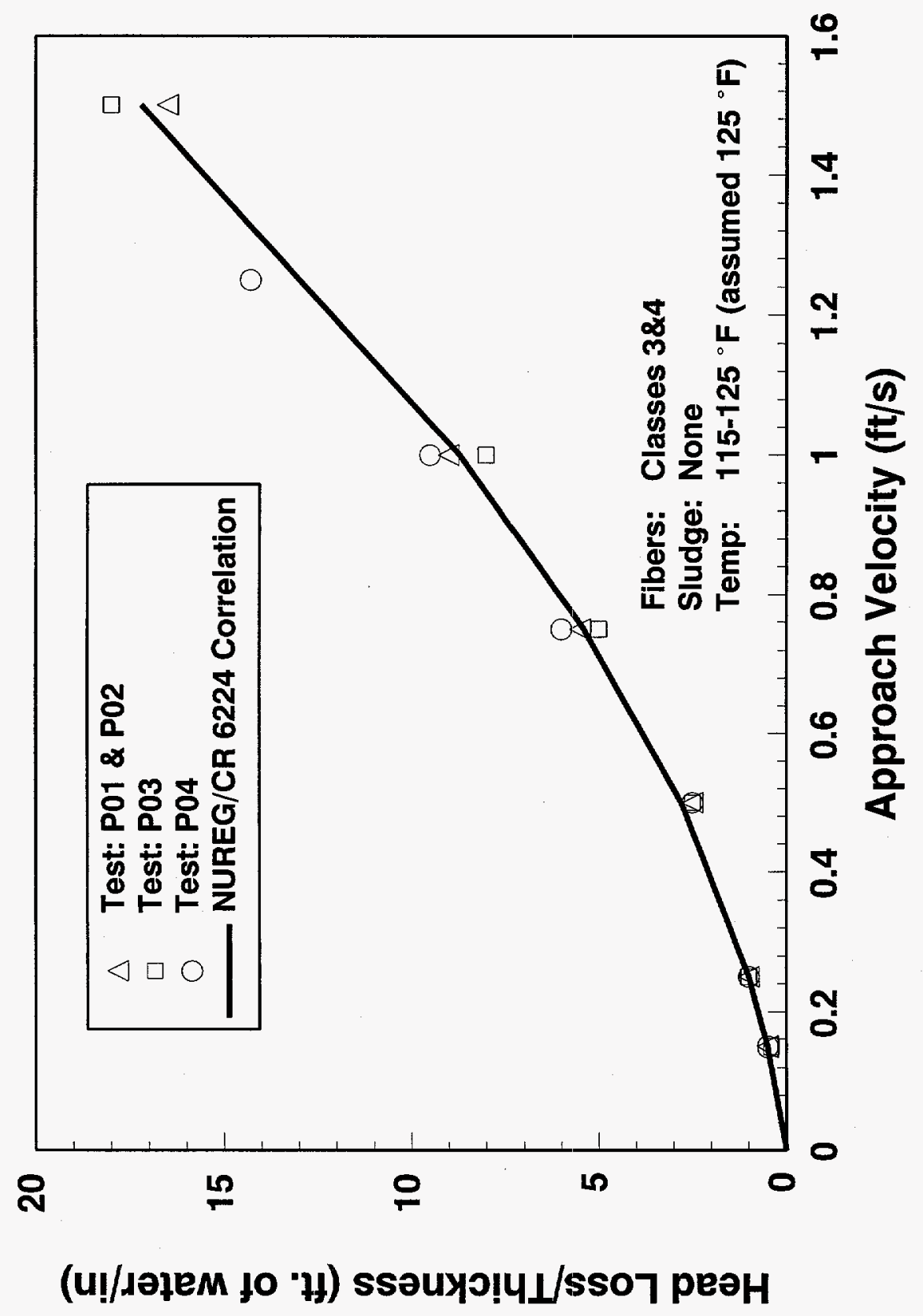

章 
Appendix E

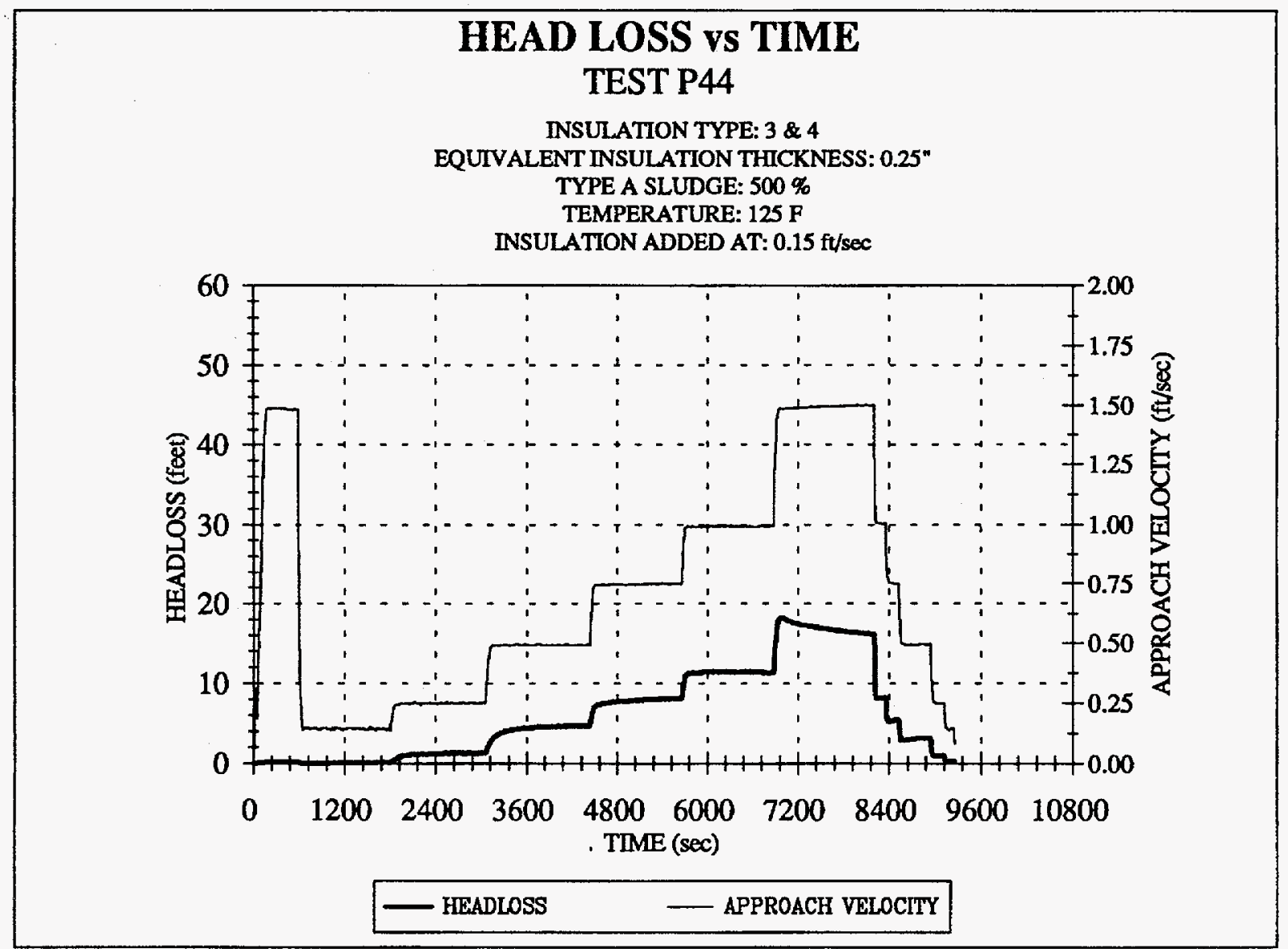

Figure E-21 Head Loss vs. Time (Type A Sludge 500\%) 


\section{HEAD LOSS vs TIME TEST P48}

INSULATION TYPE: 3 \& 4

EQUTVALENT INSULATION THCKNESS: $0.25^{\prime \prime}$

TYPE A SLUDGE: $5000 \%$

TEMPERATURE: $125 \mathrm{~F}$

INSULATION ADDED AT: $0.15 \mathrm{ft} / \mathrm{sec}$

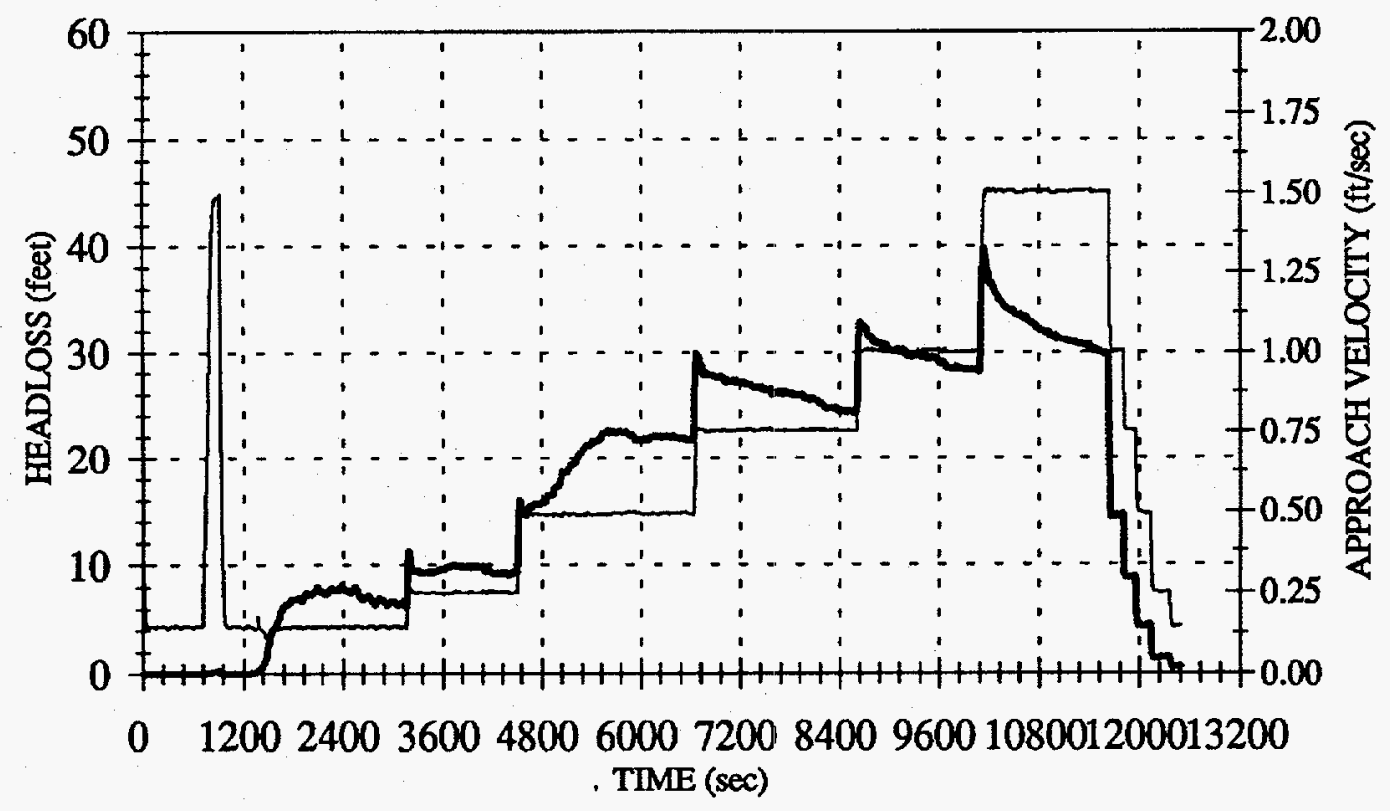

Figure E-22 Head Loss vs. Time (Type A Sludge 5000\%) 
Appendix E

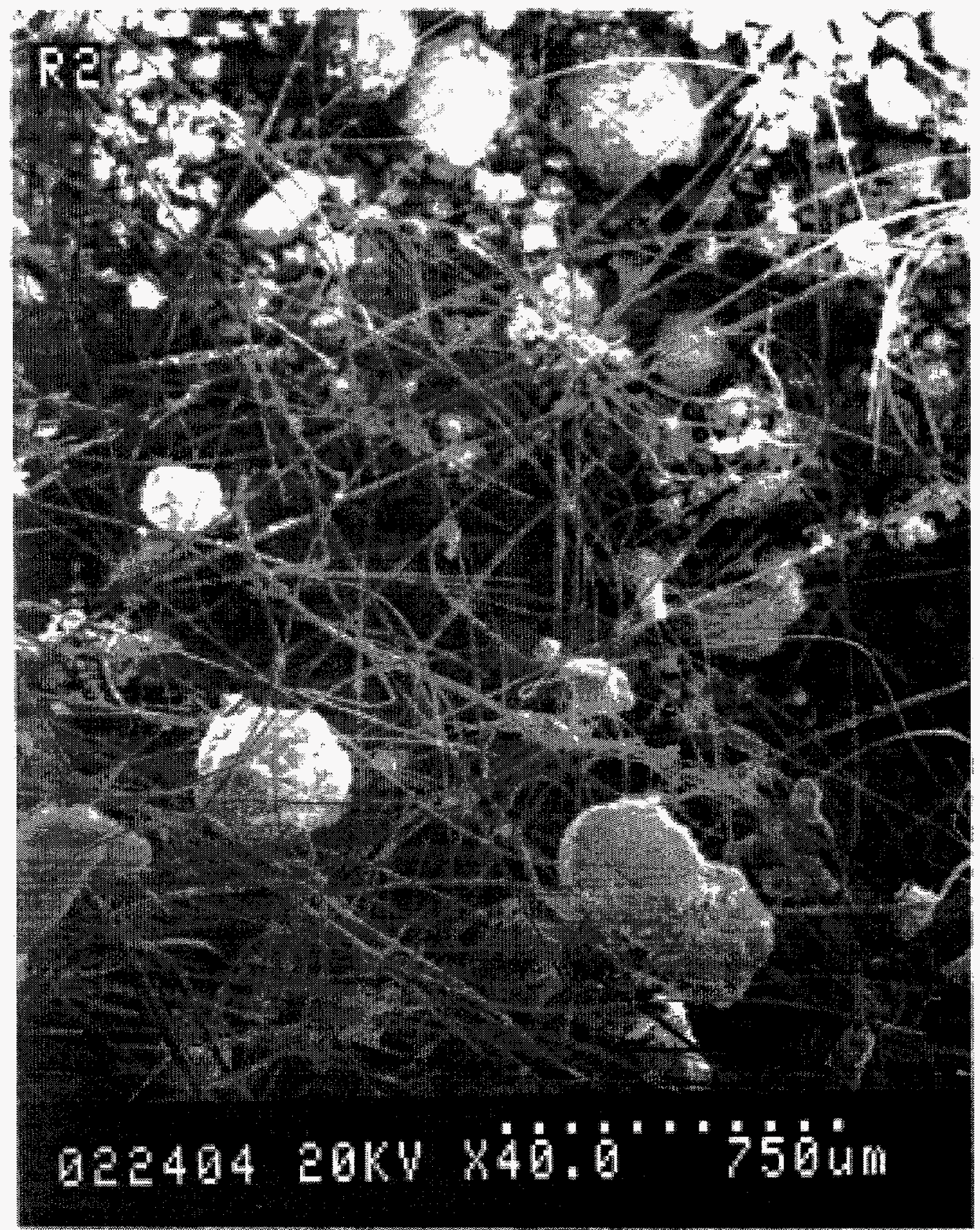

Figure E-23 SEM of a Typical Mixed Debris Bed (750 $\mu \mathrm{m}$ magnification) 


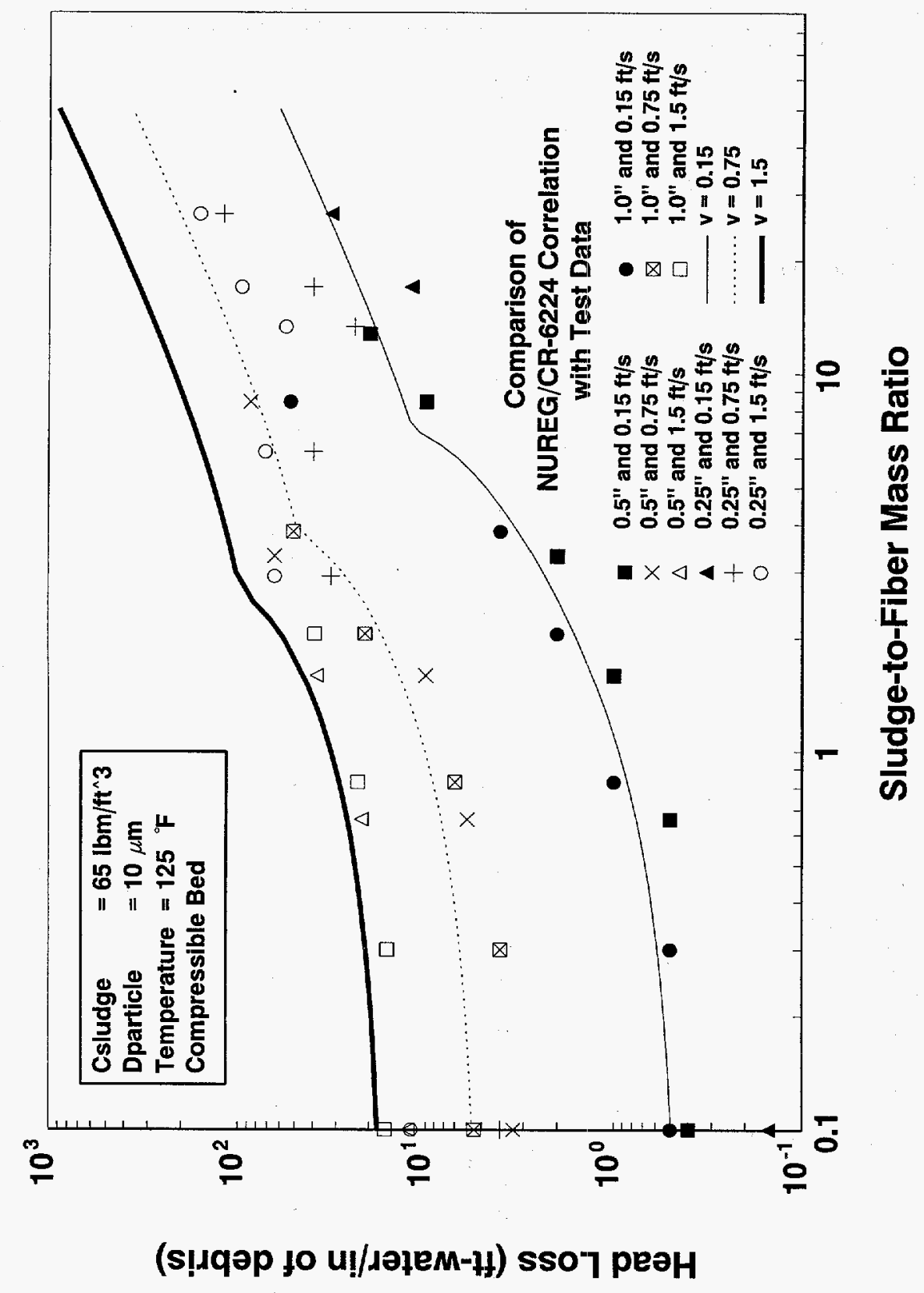


Appendix E

Table E-5 Comparison of Experimental Data with Head Loss Model Correlation

\begin{tabular}{|c|c|c|c|c|c|}
\hline $\mathbf{V}_{\text {approach }}$ & ft-water & Data for $\Delta$ & ft-water & $\begin{array}{c}\text { Correlation } \\
\qquad \mathrm{H}_{\text {loss }} \\
\text { ft-water }\end{array}$ & $\begin{array}{c}\text { Experimental Result - } \\
\text { Correlation Prediction } \\
\text { ft-water }\end{array}$ \\
\hline \multicolumn{6}{|c|}{ P01 \& P02: 1" Theo. Thick.; No Sludge; $125^{\circ} \mathrm{F}$} \\
\hline & P01 & $\mathrm{P} 02$ & Average & & \\
\hline 0.15 & 0.5 & 0.5 & $0.5^{\circ}$ & 0.5 & 0.0 \\
\hline 0.25 & 1.0 & 1.0 & 1.0 & 1.0 & 0.0 \\
\hline 0.50 & 2.0 & 3.0 & 2.5 & 2.8 & -0.3 \\
\hline 0.75 & 4.0 & 7.0 & 5.5 & 5.4 & 0.1 \\
\hline 1.00 & 8.0 & 10.0 & 9.0 & 8.7 & 0.3 \\
\hline 1.50 & 14.0 & 19.0 & 16.5 & 17.2 & -0.7 \\
\hline \multicolumn{6}{|c|}{ P05 \& E32: 2" Theo. Thick.; No Sludge; $50^{\circ} \mathrm{F}$} \\
\hline & P05 & $\mathrm{E} 32$ & Average & & \\
\hline 0.15 & 2.0 & 1.3 & 1.7 & 1.9 & -0.2 \\
\hline 0.25 & 4.0 & 3.0 & 3.5 & 3.8 & -0.3 \\
\hline 0.50 & 12.0 & 8.0 & 10.0 & 10.1 & -0.1 \\
\hline 0.75 & 25.0 & 16.0 & 20.5 & 18.6 & 1.9 \\
\hline 1.00 & 38.0 & 25.0 & 31.5 & 28.6 & 2.9 \\
\hline 1.50 & 57.0 & 47.0 & 52.0 & 52.7 & -0.7 \\
\hline \multicolumn{6}{|c|}{ P03: 2" Theo. Thick.; No Sludge; $125^{\circ} \mathrm{F}$} \\
\hline & $\mathrm{P} 03$ & & Average & & \\
\hline 0.15 & 1.0 & & 1.0 & 0.96 & 0.0 \\
\hline 0.25 & 2.0 & & 2.0 & 2.0 & 0.0 \\
\hline 0.50 & 5.0 & & 5.0 & 5.6 & -0.6 \\
\hline 0.75 & 10.0 & & 10.0 & 10.7 & -0.7 \\
\hline 1.00 & 16.0 & & 16.0 & 17.2 & -1.2 \\
\hline 1.50 & 36.0 & & 36.0 & 34.7 & 1.3 \\
\hline \multicolumn{6}{|c|}{ P04: $4^{\prime \prime}$ Theo. Thick,; No Sludge; $125^{\circ} \mathrm{F}$} \\
\hline & P04 & & Average & & \\
\hline 0.15 & 2.0 & & 2.0 & 1.9 & 0.1 \\
\hline 0.25 & 4.0 & & 4.0 & 4.0 & 0.0 \\
\hline 0.50 & 10.0 & & 10.0 & 11.2 & -1.2 \\
\hline 0.75 & 24.0 & & 24.0 & 21.9 & 2.1 \\
\hline 1.00 & 38.0 & & 38.0 & 35.1 & 2.9 \\
\hline 1.25 & 57.0 & & 57.0 & 51.2 & 5.8 \\
\hline \multicolumn{6}{|c|}{ P40: $0.50 "$ Theo. Thick.; No Sludge; $125^{\circ} \mathrm{F}$} \\
\hline & $\mathrm{P} 40$ & & Average & & \\
\hline 0.15 & 0.2 & & 0.2 & 0.16 & 0.0 \\
\hline 0.25 & 0.3 & & 0.3 & 0.35 & -0.1 \\
\hline 0.50 & 0.9 & & 0.9 & 1.06 & -0.2 \\
\hline 0.75 & 1.7 & & 1.7 & 2.10 & -0.4 \\
\hline 1.00 & 3.0 & & 3.0 & 3.46 & -0.5 \\
\hline 1.50 & 6.2 & & 6.2 & 7.06 & -0.9 \\
\hline \multicolumn{6}{|c|}{ P42: $0.125^{\prime \prime}$ Theo. Thick.; No Sludge; $125^{\circ} F$} \\
\hline & P04 & & Average & & \\
\hline 0.15 & 0.1 & & 0.1 & 0.04 & 0.1 \\
\hline 0.25 & 0.1 & & 0.1 & 0.08 & 0.0 \\
\hline 0.50 & 0.3 & & 0.3 & 0.24 & 0.0 \\
\hline 0.75 & 0.5 & & 0.5 & 0.47 & 0.0 \\
\hline 1.00 & 1.0 & & 1.0 & 0.80 & 0.2 \\
\hline 1.50 & 1.5 & & 1.5 & 1.61 & -0.1 \\
\hline
\end{tabular}


0.75 and $1.5 \mathrm{ft} / \mathrm{s}$ or $0.05,0.23$ and $0.5 \mathrm{~m} / \mathrm{s}$ ) and different thicknesses. The following conclusions can be drawn based on the analysis of the data:

- For undamaged beds, head loss increases steadily with the sludge-to-fiber mass ratio. Initially the increase is rapid and possibly due to combined effects of compressibility and decreasing porosity. Ultimately, however, the head loss increases linearly with sludge-to-fiber ratio. Such a transition can be interpreted as being due to the fact that, at higher sludge-tofiber mass ratios, the bed resembles a 'sludge bed' or a 'grain bed.' See Appendix B for further discussions which include development of a semi-theoretical calculation that can be used to predict head loss for undamaged beds. These predictions are plotted on Figure E-24, showing good agreement with the data.

- The head loss data suggests that thin beds undergo severe damage when the head loss increases to about $50 \mathrm{ft}$-water/inch of debris. ${ }^{4}$ Beyond this point the beds are characterized by large holes. For such beds, the head loss increases only marginally with the sludge-tofiber mass ratio. In this region, NUREG/CR6224 correlation overpredicts the data primarily because the model does not account for possible damage in the beds.

In addition to the head loss data, the present set of experiments provided valuable insights into oncethrough filtration efficiency of the fiber beds. As previously described, the filtration efficiencies were estimated from the concentration measurements obtained several times within the first flushing cycle. Figure E-25 illustrates the concentration measurements for Test P27. In this test, the sludge was initially added to the loop and was brought to uniform concentration. The pre-soaked insulation debris was added all at once to the loop at $0 \mathrm{~s}$. Through out the experiment, water samples were drawn from above and below the strainer at every 20 seconds. These water samples were later analyzed to estimate sludge concentration in the loop water. Figure E-25 plots the sludge

\footnotetext{
${ }^{4}$ Such a behavior was not observed for thick beds possibly because thick beds possess required structure to withstand large pressure drops.
}

concentrations obtained in this method as a function of time. Before the fibrous debris was added, concentrations of sludge both above and below the strainer are very close to the theoretical value of $0.075 \mathrm{~g} / \mathrm{L}$. $^{5}$ However, as expected, this trend changed once the debris bed formed on the strainer. Due to filtration of sludge by the fiber bed, the concentration below the bed was found to be substantially lower than that above the bed; this trend is especially evident during the first flushing cycle. This trend continued for few flushing cycles, after: which the concentrations above and below the bed nearly equaled. Thereafter the concentrations both above and below the strainer steadily decreased with time, ultimately reaching about $1 / 3$ to $1 / 4$ of the initial value. After that point, the change in concentration was minimal, indicating that filter bed has reached an equilibrium. This equilibrium can be attributed to the fact that the sludge particles left over in the flow beyond this point are micron and sub-micron range. Figure E-26 is an SEM image of the sludge particles contained in the loop after the concentrations attained steady state. These particles are typically much smaller than the average pore size and consequently would not be filtered by the bed irrespective of the number of passes.

The concentration profiles, such as those illustrated in Figure E-25, were used to estimate the bed filtration efficiency as a function of time. Two types of filtration efficiencies were measured from the concentration data: 'once-through efficiency' and 'cumulative efficiency'. The once-through efficiency is a measure of the fraction of the sludge that is filtered by the debris bed during one pass and is defined as:

$$
e_{\text {once-through }}=\frac{C_{\text {top }}-C_{\text {bottom }}}{C_{\text {top }}}
$$

where,

$$
\begin{aligned}
\mathrm{e}_{\text {once-through }}= & \text { once-through efficiency } \\
\mathrm{C}_{\text {top }}= & \text { sludge concentration above the bed } \\
& (\mathrm{g} / \mathrm{L})
\end{aligned}
$$

\footnotetext{
${ }^{5}$ Theoretical estimate is based on the fact that in Test P27, $39 \mathrm{~g}$ of sludge was added to a loop water volume of $520 \mathrm{~L}$.
} 
Appendix E

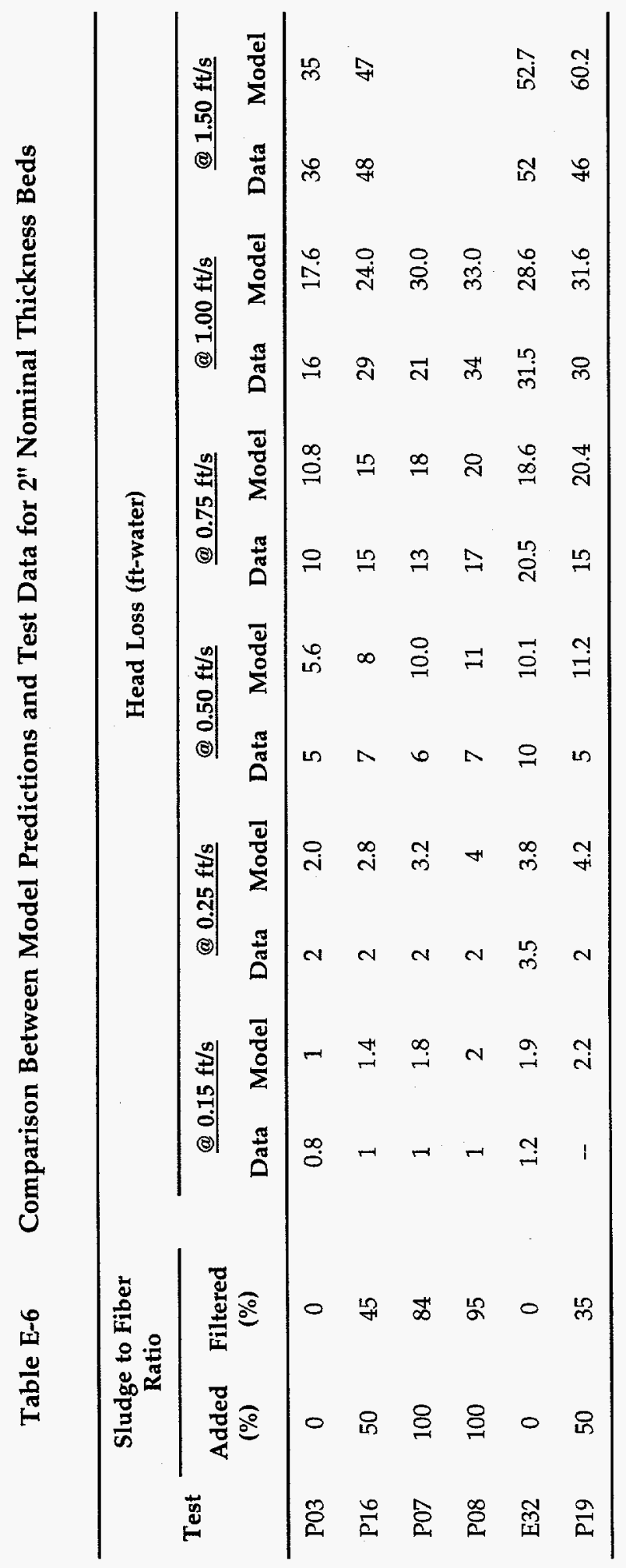




\begin{tabular}{|c|c|c|c|c|c|c|c|c|c|c|c|c|c|c|}
\hline \multirow{3}{*}{ Test } & \multicolumn{2}{|c|}{$\begin{array}{l}\text { Sludge to Fiber } \\
\text { Ratio }\end{array}$} & \multicolumn{12}{|c|}{ Head Loss (ft-water) } \\
\hline & \multirow{2}{*}{$\begin{array}{l}\text { Added } \\
(\%)\end{array}$} & \multirow{2}{*}{$\begin{array}{c}\text { Filtered } \\
(\%)\end{array}$} & \multicolumn{2}{|c|}{$@ 0.15 \mathrm{ft} / \mathrm{s}$} & \multicolumn{2}{|c|}{ @ $0.25 \mathrm{ft} / \mathrm{s}$} & \multicolumn{2}{|c|}{$0.50 \mathrm{ft} / \mathrm{s}$} & \multicolumn{2}{|c|}{$@ 0.75 \mathrm{ft} / \mathrm{s}$} & \multicolumn{2}{|c|}{$@ 1.00 \mathrm{ft} / \mathrm{s}$} & \multicolumn{2}{|c|}{$@ 1.50 \mathrm{ft} / \mathrm{s}$} \\
\hline & & & Data & Model & Data & Model & Data & Model & Data & Model & Data & Model & Data & Model \\
\hline P01 & 0 & 0 & 0.5 & 0.5 & 1 & 1 & 2 & 2.8 & 4 & 5.4 & 8 & 8.7 & 14 & 17.2 \\
\hline P02 & 0 & 0 & 0.5 & 0.5 & 1 & 1 & 3 & 2.8 & 7 & 5.4 & 10 & 8.7 & 19 & 17.2 \\
\hline Average & 0 & 0 & 0.5 & 0.5 & 1 & 1 & 2.5 & 2.8 & 5.5 & 5.4 & 9 & 8.7 & 16.5 & 17.2 \\
\hline P12 & 50 & 30 & - & 0.6 & 1 & 1.3 & 2 & 3.6 & 4 & 6.8 & 7 & 10.8 & 16 & 21 \\
\hline E34 & 100 & 83 & - & 0.9 & 1 & 1.8 & 4 & 5.1 & 8 & 9.5 & 13 & 15 & 25 & 30 \\
\hline P24 & 100 & 83 & - & 0.9 & 1 & 1.8 & 3 & 5.1 & 6 & 9.5 & 10 & 15 & 23 & 30 \\
\hline P26 & 100 & 83 & - & 0.9 & - & 1.8 & 3 & 5.1 & 6 & 9.5 & 12 & 15 & 22 & 30 \\
\hline Average & 100 & 83 & -- & 0.9 & 1 & 1.8 & 3 & 5.1 & 7 & 9.5 & 12 & 15 & 23 & 30 \\
\hline P13 & 250 & 205 & - & 1.7 & 6 & 6.8 & 12 & 9.5 & 21 & 18 & 26 & 29 & 39 & 43 \\
\hline P14 & 500 & 383 & 4 & 3.4 & 12 & 7 & 31 & 22 & 51 & 51 & -- & -- & -- & -- \\
\hline P15 & 1000 & 843 & 53 & 29 & - & -- & -- & -- & -- & -- & -- & - & -- & -- \\
\hline
\end{tabular}


Table E-8 Comparison Between Model Predictions and Test Data 0.5" Nominal Thickness Bed

\begin{tabular}{|c|c|c|c|c|c|c|c|c|c|c|c|c|c|c|}
\hline \multirow{3}{*}{ Test } & \multicolumn{2}{|c|}{$\begin{array}{l}\text { Sludge to Fiber } \\
\text { Ratio }\end{array}$} & \multicolumn{12}{|c|}{ Head Loss (ft-water) } \\
\hline & \multirow{2}{*}{$\begin{array}{l}\text { Added } \\
(\%)\end{array}$} & \multirow{2}{*}{$\begin{array}{l}\text { Filtered } \\
\quad(\%)\end{array}$} & \multicolumn{2}{|c|}{$@ 0.15 \mathrm{ft} / \mathrm{s}$} & \multicolumn{2}{|c|}{$@ 0.25 \mathrm{ft} / \mathrm{s}$} & \multicolumn{2}{|c|}{ @ $0.50 \mathrm{ft} / \mathrm{s}$} & \multicolumn{2}{|c|}{ @ $0.75 \mathrm{ft} / \mathrm{s}$} & \multicolumn{2}{|c|}{$@ 1.00 \mathrm{ft} / \mathrm{s}$} & \multicolumn{2}{|c|}{$@ 1.50 \mathrm{ft} / \mathrm{s}$} \\
\hline & & & Data & Model & Data & Model & Data & Model & Data & Model & Data & Model & Data & Model \\
\hline P09 & 100 & 66 & - & 0.4 & - & 0.8 & 2.0 & 2.2 & 3 & 4.2 & 5 & 6.7 & 10 & 13.5 \\
\hline P27 & 100 & 66 & -- & 0.4 & -- & 0.8 & 1 & 2.2 & 2.5 & 4.2 & 4.5 & 6.7 & 10.3 & 13.5 \\
\hline P28 & 100 & 66 & -- & 0.4 & -- & 0.8 & 1.3 & 2.2 & 2.6 & 4.2 & 4.4 & 6.7 & 9.1 & 13.5 \\
\hline P29 & 100 & 66 & -- & 0.4 & - & 0.8 & 1.5 & 2.2 & 3 & 4.2 & 5 & 6.7 & 11.7 & 13.5 \\
\hline Average & 100 & 66 & - & 0.4 & -- & 0.8 & 1.5 & 2.2 & 2.8 & 4.2 & 4.7 & 6.7 & 10.3 & 13.5 \\
\hline P10 & 250 & 159 & -- & 0.7 & 1 & 1.4 & 2 & 3.8 & 5 & 7.1 & 9 & 11.2 & 19 & 22 \\
\hline P11 & 500 & 330 & 1 & 1.4 & 3 & 2.8 & 14 & 8.3 & 32 & 18 & 37 & 35 & -- & -- \\
\hline P33R & 1000 & 1000 & 5 & 7 & 15 & 12 & 34 & 25 & 43 & 42 & -- & -- & -- & - \\
\hline P43 & 2000 & 1274 & 10 & 9 & 18 & 17 & 50 & 35 & -- & -- & -- & -- & -- & -- \\
\hline P40 & 0 & 0 & 0.2 & 0.2 & 0.3 & 0.4 & 1 & 1.1 & 1.7 & 2.1 & 3 & 3.5 & 7.2 & 7.1 \\
\hline
\end{tabular}


Table E-9 Comparison Between Model Predictions and Test Data for 0.25" Theoretical Bed Thickness

\begin{tabular}{|c|c|c|c|c|c|c|c|c|c|c|c|c|c|c|}
\hline \multirow{3}{*}{ Test } & \multicolumn{2}{|c|}{$\begin{array}{l}\text { Sludge to Fiber } \\
\text { Ratio }\end{array}$} & \multicolumn{12}{|c|}{ Head Loss (ft-water) } \\
\hline & \multirow{2}{*}{$\begin{array}{l}\text { Added } \\
(\%)\end{array}$} & \multirow{2}{*}{$\begin{array}{c}\text { Filtered } \\
(\%)\end{array}$} & \multicolumn{2}{|c|}{$0.15 \mathrm{ft} / \mathrm{s}$} & \multicolumn{2}{|c|}{ (3) $0.25 \mathrm{ft} / \mathrm{s}$} & \multicolumn{2}{|c|}{$@ 0.50 \mathrm{ft} / \mathrm{s}$} & \multicolumn{2}{|c|}{$@ 0.75 \mathrm{ft} / \mathrm{s}$} & \multicolumn{2}{|c|}{$@ 1.00 \mathrm{ft} / \mathrm{s}$} & \multicolumn{2}{|c|}{$@ 1.50 \mathrm{ft} / \mathrm{s}$} \\
\hline & & & Data & Model & Data & Model & Data & Model & Data & Model & Data & Model & Data & Model \\
\hline P41 & 0 & 0 & 0 & 0.08 & 0 & 0.2 & 0 & 0.5 & 1 & 1 & 2 & 1.6 & 3 & 3.2 \\
\hline $\mathrm{P} 44$ & 500 & 292 & -- & 0.6 & 2 & 1.3 & 5 & 3.5 & 8 & 7 & 12 & 12.5 & 16 & 25 \\
\hline $\mathrm{P} 45$ & 1000 & 622 & - & 2 & 4 & 5 & 6 & 10.5 & 10 & 16 & 13 & 23 & 18 & 40 \\
\hline P46 & 2000 & 1333 & -- & 5 & 2 & 8.4 & 4 & 18.1 & 6 & 29.3 & 8 & 41.5 & 14 & 70 \\
\hline P47 & 3000 & 1692 & 3 & 6 & 4 & 10.3 & 6 & 22 & 10 & 36 & 16 & 51 & 24 & 86 \\
\hline P48 & 5000 & 2651 & 8 & 9 & 10 & 15 & 22 & 32 & 30 & 52 & 34 & 75 & 40 & 127 \\
\hline
\end{tabular}


Appendix E

$$
\mathrm{C}_{\text {bottom }}=\begin{aligned}
& \text { sludge concentration below the bed } \\
& (\mathrm{g} / \mathrm{L})
\end{aligned}
$$

On the other hand, the cumulative efficiency is a measure of the fraction of the total sludge added to the loop that is filtered by the debris bed as a function of time and is defined as:

$$
e_{\text {cumulative }}=\frac{M_{\text {total }}-M_{\text {cake }}}{M_{\text {total }}}
$$

where,

$$
\begin{aligned}
& \mathrm{e}_{\text {cumulative }}=\text { cumulative filtration efficiency } \\
& \mathrm{M}_{\text {total }}=\text { total sludge added to the loop (g) } \\
& \mathrm{M}_{\text {cake }}=\text { total sludge filtered by the cake }
\end{aligned}
$$

Figure E-27 presents estimated once-through filtration efficiencies for $0.5^{\prime \prime}(1.3 \mathrm{~cm})$ thick fiber bed at $0.15 \mathrm{ft} / \mathrm{s}(0.05 \mathrm{~m} / \mathrm{s})$ (i.e, Test P27) as a function of time. As evident from this figure two alternatives exist for estimating the once-through efficiency. In the first case, instantaneous concentrations both upstream and downstream of the strainer can be used to estimate the once-through efficiency as a function of time. The efficiencies obtained using this method may reach as high as 33\% during the first cycle and level off at about $15 \%$ during the subsequent cycles. However, the trends exhibited by the data varied from test to test primarily because of large experimental uncertainties associated with concentration measurements. To minimize these variations, it was decided to obtain the filtration efficiency estimates based on time averaged concentrations for each cycle. These time averaged concentrations for first and second cycles are plotted in Figure E-25 for test P27. The oncethrough efficiencies obtained from these time averaged concentrations are plotted in Figure E-27 for both the first and second cycles. Both the instantaneous and time averaged efficiencies suggest that filtration efficiency attains a maximum during the first cycle and decreases with every subsequent cycle. Based on SEM images of the sludge particles leftover in the water below the strainer, it is concluded that this decrease in efficiency is a reflection of shift in sludge particle distribution towards the smaller sizes $(<1 \mu \mathrm{m})$; i.e., the fraction of micron size particles contained in the water after few flushing cycles was significantly lower than that in the sludge originally added to the loop. Since such a shift in particle size was not expected in the case of an open-loop arrangement, such as the BWR suppression pool, it is possible that the filtration efficiency in the open loop may not decrease with time. As a result, the peak once-through filtration efficiencies were interpreted to be the filtration efficiency corresponding to an once-through arrangement. These once-through filtration efficiency estimates are plotted in Figure E-28 for several bed thicknesses and approach velocities. Within the range tested, it appears that the oncethrough filtration efficiencies were fairly independent of both the approach velocity and fiber bed thickness. In all cases, the maximum efficiency attained is about $45 \%$. Note however that this estimate of $45 \%$ is associated with large uncertainties introduced by experimental uncertainties involved with concentration measurements. Based on a bounding analysis, it was determined that a once-through efficiency of $50 \%$ bounds the present data. Note, however, that this efficiency estimate is approximate considering the test facility used to measure the efficiency.

Figure E-27 also presents the cumulative filtration efficiencies for Test P27. As shown in this figure the cumulative filtration efficiency increased steadily with time ultimately reaching an asymptotic value of $66 \%$. These asymptotic values are plotted as functions of theoretical thickness in Figure E-29. As evident from this figure the cumulative efficiency varies from $50 \%$ to $95 \%$ as the thickness increases from $1 / 8$ " to $2 "$. Beyond $2 "$ the cumulative filtration efficiency is about $95 \%$. 


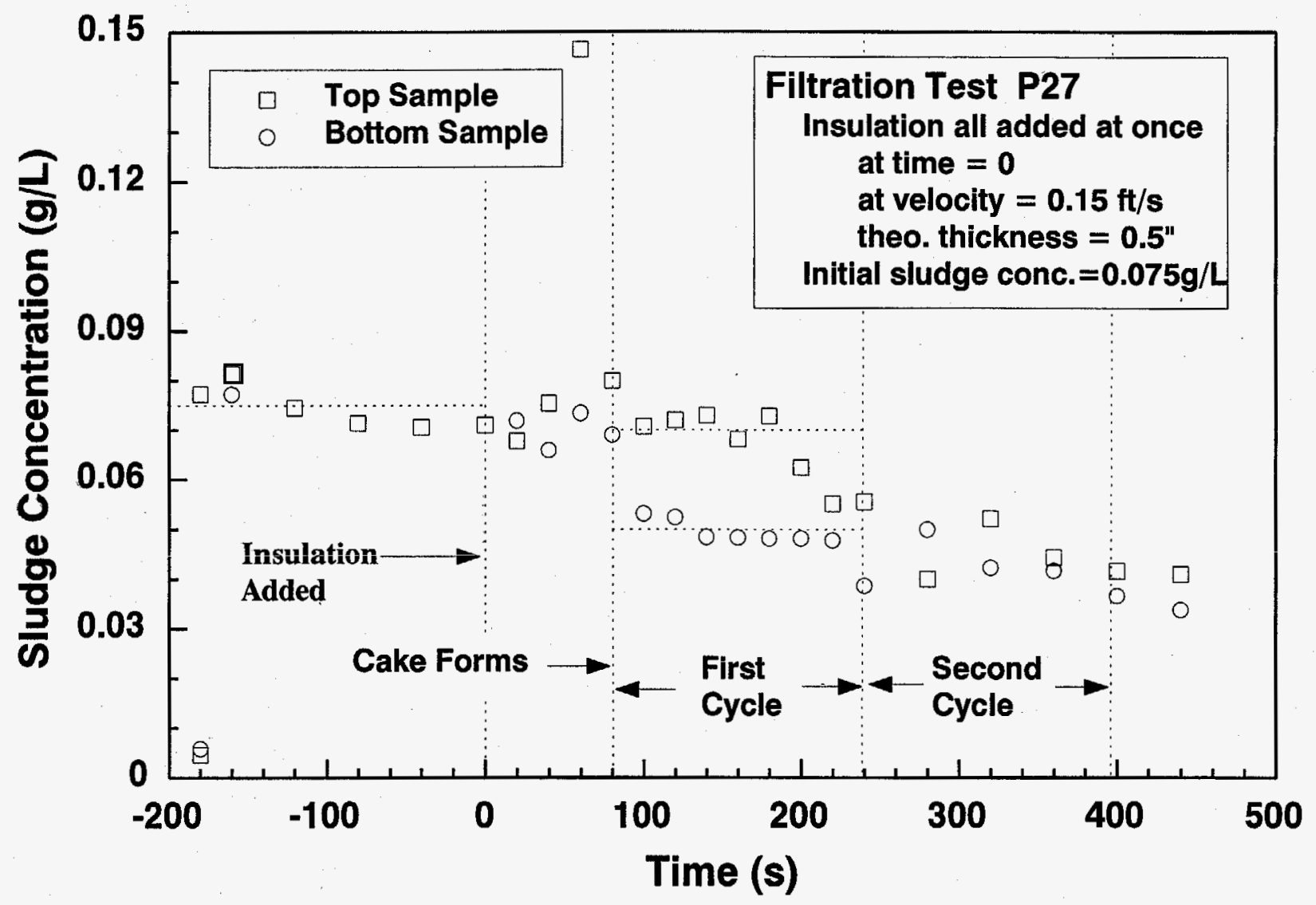

Figure E-25 Loop Water Concentration as a Function of Time. Data Collected From Two Sampling Ports Located at Top and Bottom of the Strainer Simultaneously. 
Appendix E

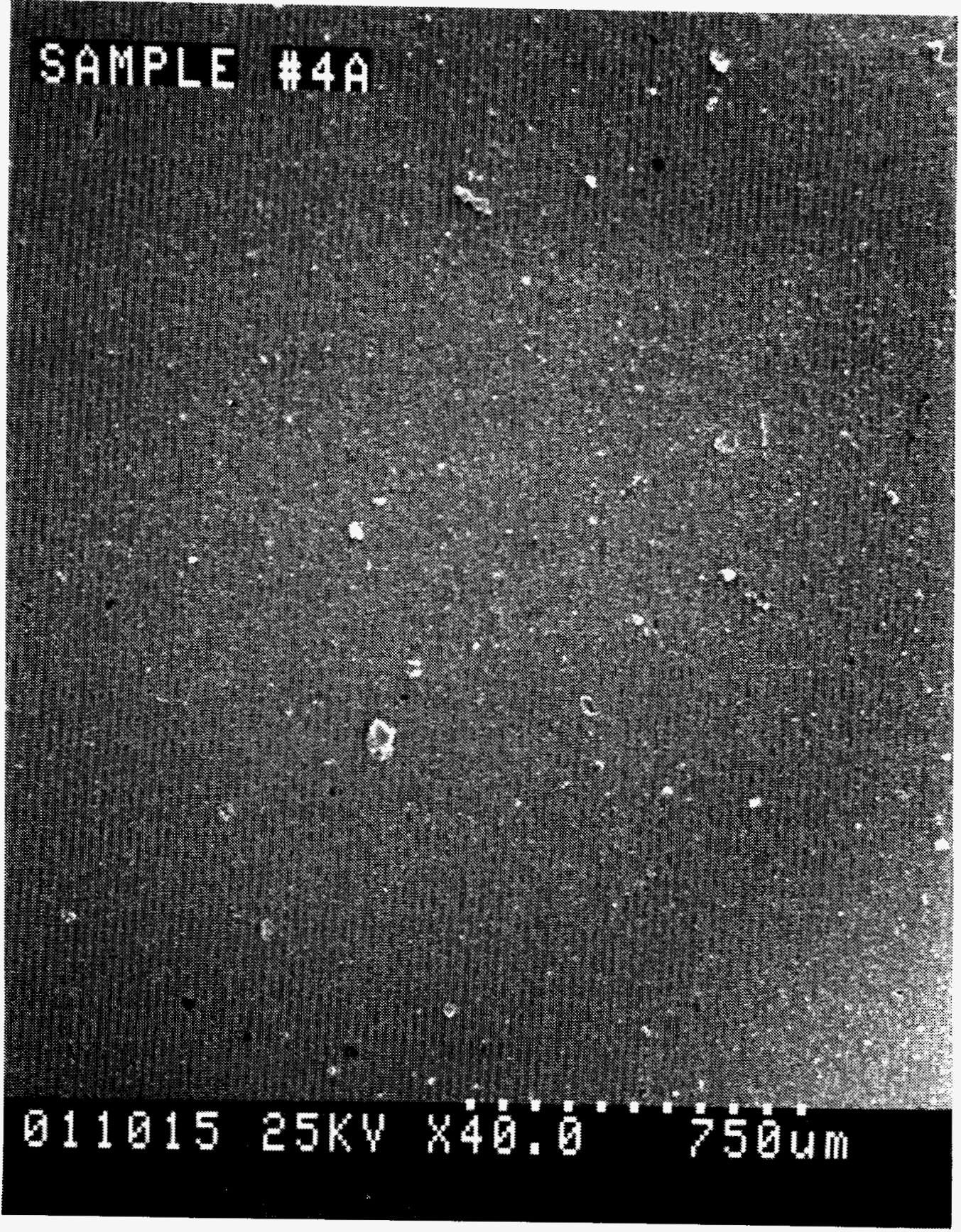

Figure E-26 SEM of Sludge A Particles Collected in Test Loop After Circulating Through Mixed Debris Bed (750 $\mu \mathrm{m}$ magnification) 


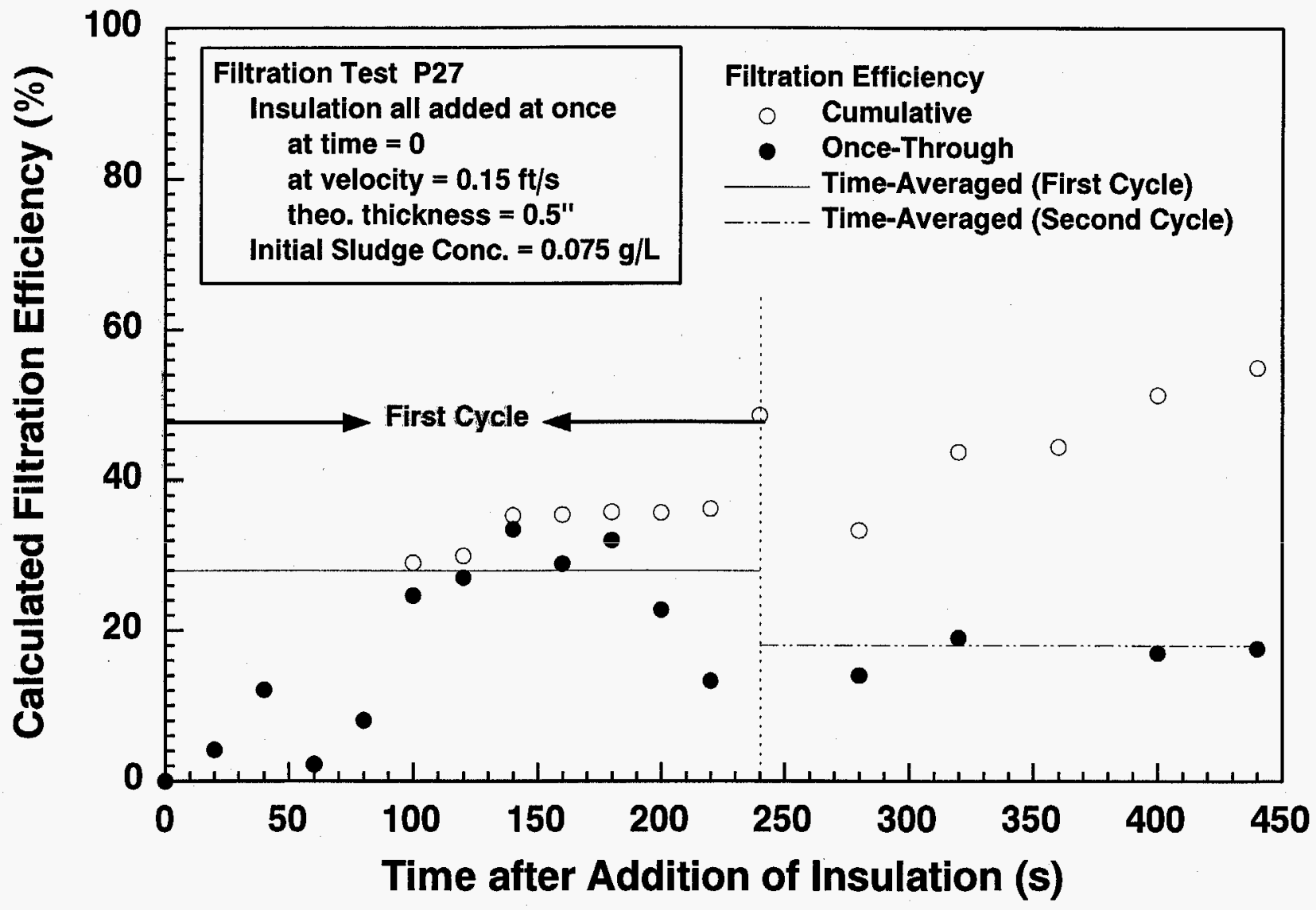

Figure E-27 Cumulative and Once-Through Filtration Efficiency Measured From Test P27. 


Filtration Efficiency

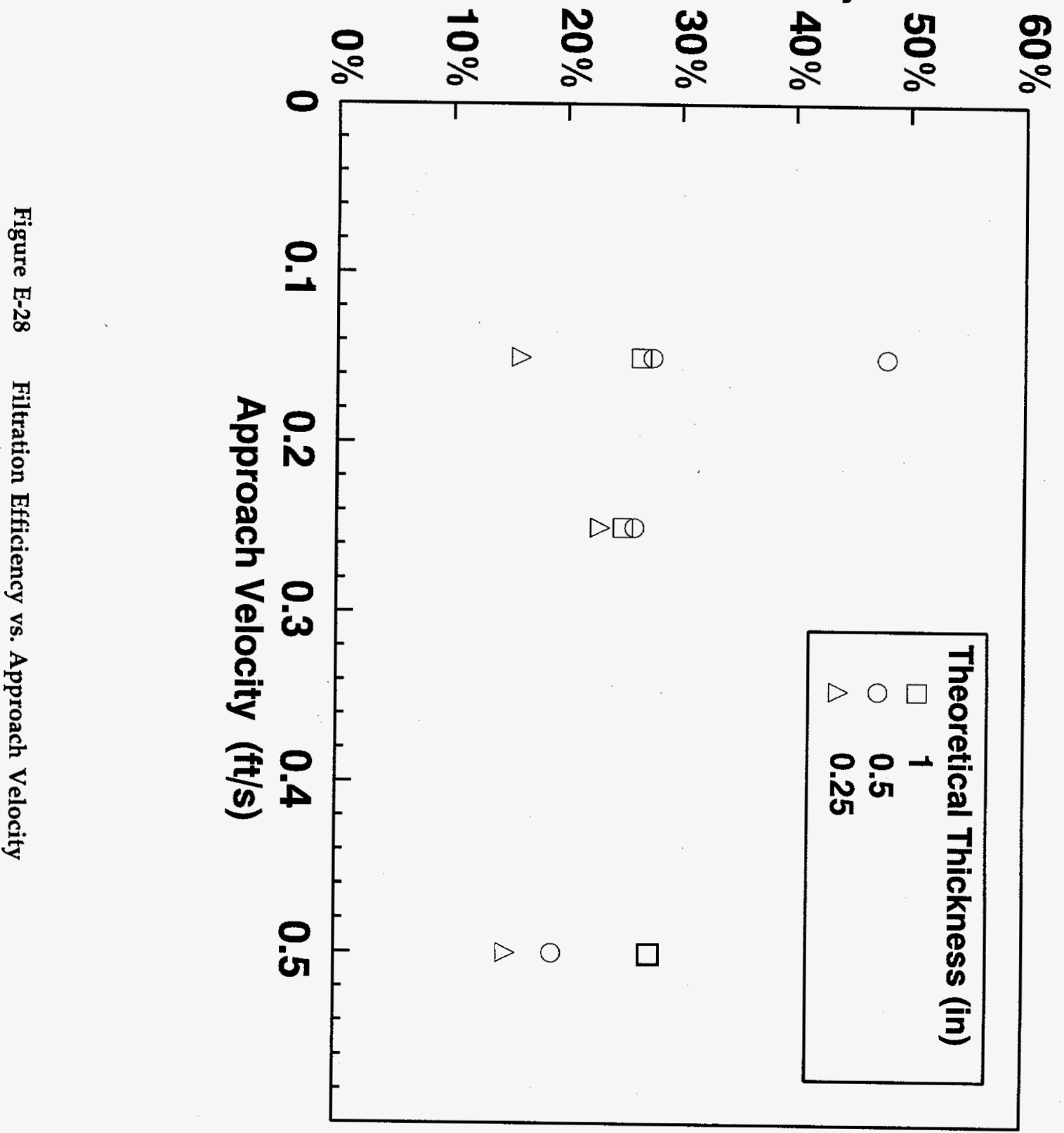


Cumulative Filtration Efficiency

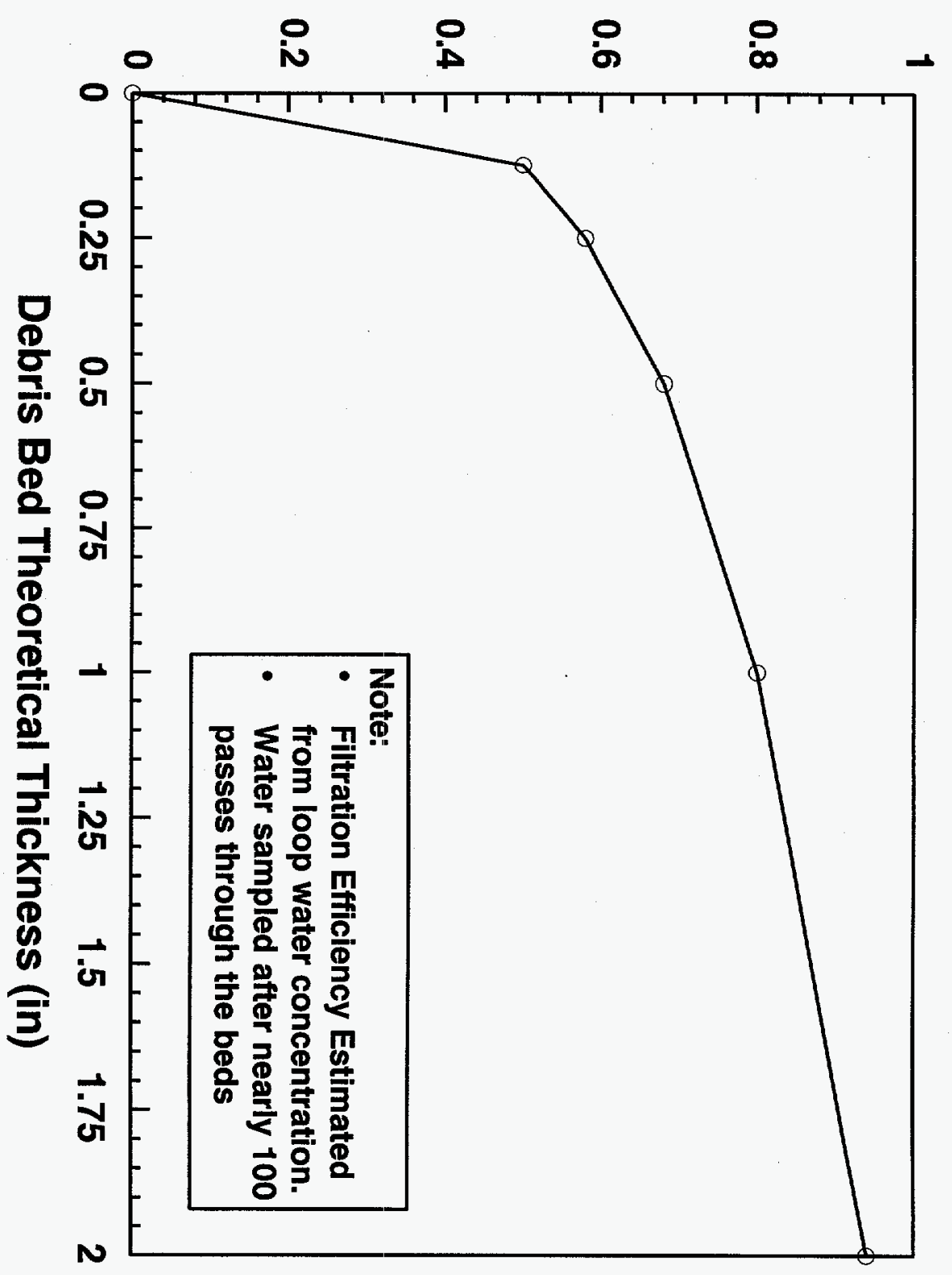


Appendix E

\section{References for Appendix E}

E.1 Zigler, G., et al, "Parametric Study of the Potential for BWR ECCS Strainer Blockage due to LOCA Generated Debris," Draft Report for Comment, NUREG/CR-6224 (SEA No. 93554-06-A:1), August 1994.

E.2 Ives, K.J. and V. Pienvichitr, "Kinetics of the Filtration of Dilute Suspensions," in Chemical Engineering Science, Vol. 20, pp. 965-973, 1965.

E.3 "Proceedings of the OECD/NEA Workshop on the Barsebäck Strainer Incident," Stockholm, Sweden, January 26-27, 1994.

E.4 Brinkman, K.W and P.W. Brady, "Results of Hydraulic Tests on ECCS Strainer Blockage and Material Transport in a BWR Suppression Pool," EC-059-1006, Revision 0, Pennsylvania Power \& Light Company, 1994.

E.5 Souto, F. J. and D. V. Rao, "Experimental Investigation of Sedimentation of LOCA Generated Debris and Sludge in BWR Suppression Pools," SEA No. 95-554-06-A:9, 1995.

E.6 Rao, D. V. and F. Souto, "Experimental Study of Head Loss and Filtration for LOCA Debris," SEA No. 95-554-06-A:8, 1995.
E.7 "Mark I Containment Full Scale Test Program," Final Report, General Electric, NEDE-24539-P, 1979.

E.8 "Mark I Containment Long-Term Program," Safety Evaluation Report, Resolution of Generic Technical Activity A-7, NUREG-0661, 1980.

E.9 "Debris in Containment and the Residual Heat Removal System," NRC Information Notice 94-57, August 12, 1994.

E.10 "BWR Owners' Group ECCS Suction Strainer Committee Suppression Pool Sludge Particle Size Distribution," letter from General Electric to A.W. Serkiz, USNRC, dated September 13, 1994.

E.11 Souto, F.J., E. Cramer, T. Kodas and D.V. Rao, "Simulated BWR Sludge Characterization," SEA No. 95-554-06-A:7, 1995.

E.12 Camp, T.R., "Sedimentation and Design of Settling Tanks," Proceedings of the ASCE, Paper No. 2285, 1945.

E.13 Johnson, A.B., M. Padmanabhan, and G.E. Hecker, "NUKON" Insulation and Sludge Settling Following a LOCA in a BWR Suppression Pool," Alden Research Laboratory, Inc., March 1995. 


\title{
Appendix F
}

\author{
Resolution of Comments on: \\ NUREG/CR-6224 Draft for Comment \\ "Parametric Study of the Potential for BWR ECCS Strainer Blockage \\ Due to LOCA Debris Generation"
}



Table of Contents

Page

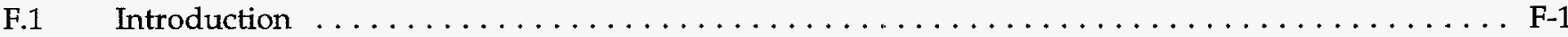

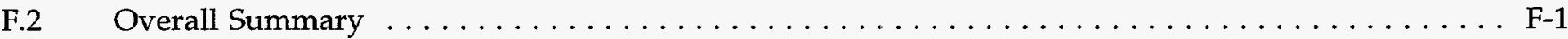

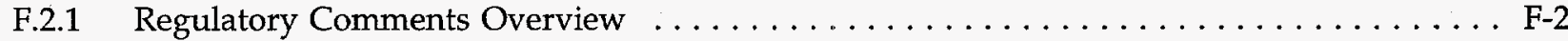

F.2.2 Technical Comments Overview $\ldots \ldots \ldots \ldots \ldots \ldots \ldots \ldots \ldots \ldots \ldots \ldots \ldots \ldots \ldots$ F-2

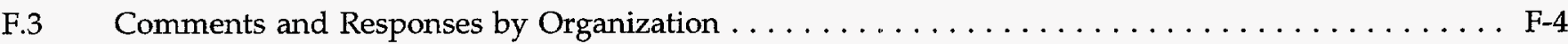

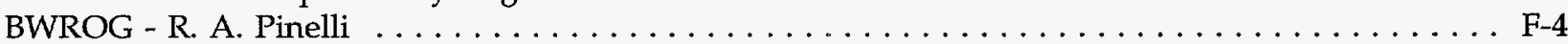

Consejo de Seguridad Nuclear - Fernando Robledo . . . . . . . . . . . . . . F-37

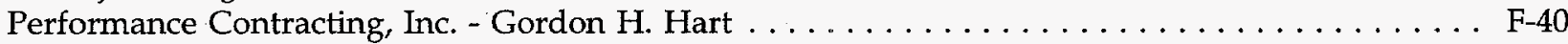

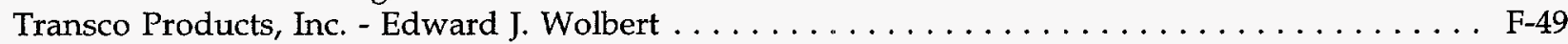

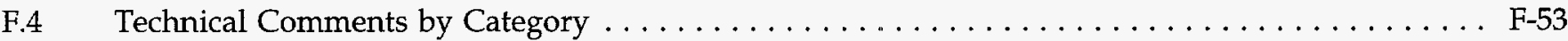

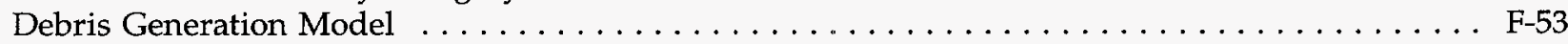

Debris Transport Model $\ldots \ldots \ldots \ldots \ldots \ldots \ldots \ldots \ldots \ldots \ldots \ldots \ldots \ldots \ldots \ldots \ldots \ldots \ldots$

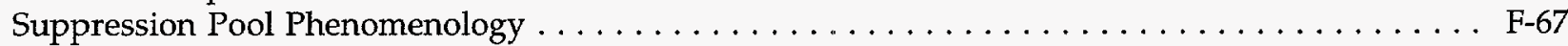

Head Loss Model . . . . . . . . . . . . . . . . . . . . . . . . . . . . . . . . . . . F-69

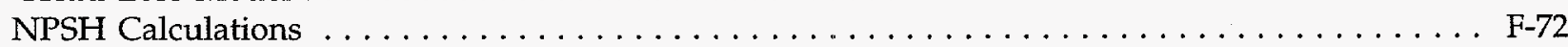

Pipe Break Frequency and Modeling $\ldots \ldots \ldots \ldots \ldots \ldots \ldots \ldots \ldots \ldots \ldots \ldots \ldots \ldots \ldots \ldots$

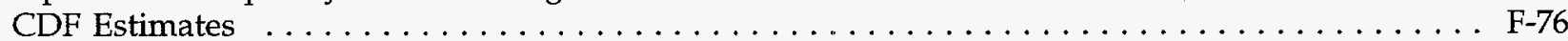

Future Applicability / Plant Specific Analyses $\ldots \ldots \ldots \ldots \ldots \ldots \ldots \ldots \ldots \ldots \ldots \ldots$ 



\section{F.1 Introduction}

This appendix presents the resolution of public comments originating from a technical peer review of Draft NUREG/CR-6224, dated August 1994. Five sets of comments were received by the NRC from two foreign nuclear regulatory organizations, two American manufacturer of insulation products, and a nuclear utility organization representing licensees of boiling water reactors.

The comments were submitted by:

Mr. Edward J. Wolbert

Transco Products, Inc.

Chicago, Illinois

Mr. Gordon H. Hart

Performance Contracting, Inc.

Kansas City, Kansas

Dr. Fernando Robledo

Consejo de Seguridad Nuclear

Madrid, Spain

Mr. R.A. Pinelli

BWR Owner's Group

Parsippany, New Jersey

Dr. Juhani Hyvärinen

Nuclear Safety Department

SÄTEILYTURVAKESKUS (STUK)

Finish Center for Radiation and Nuclear Safety

Helsinki, Finland

All comments received were reviewed in detail by both the USNRC and SEA. The comments from Dr. Juhani Hyvärinen of the Finish Center for Radiation and Nuclear Safety arrived too late for an official response; his comments, however, were very beneficial and were taken into consideration in the revision of NUREG/CR-6224. The comments of the other four organizations were classified into three categories:

- regulatory

- technical

- editorial.
The following table presents the breakdown of the comments by the four organizations and their categorization:

\begin{tabular}{|l|c|c|c|}
\hline Commentor & Technical & Regulatory & Editorial \\
\hline $\begin{array}{l}\text { Consejo de } \\
\text { Seguridad }\end{array}$ & 4 & 1 & 0 \\
\hline $\begin{array}{l}\text { Performance } \\
\text { Contracting Inc. }\end{array}$ & 6 & 3 & 7 \\
\hline Transco & 4 & 1 & 9 \\
\hline BWROG & 43 & 5 & 26 \\
\hline
\end{tabular}

The regulatory comments were addressed and responded to by the NRC. SEA took the lead in addressing and responding to the technical and editorial comments, with review and comment by the NRC. The technical comments were further categorized with respect to the technical areas addressed:

1. Debris Generation Model

2. Debris Transport

3. Suppression Pool Phenomenology

4. Head Loss Model

5. NPSH Calculations

6. Pipe Break Frequency and Modeling

7. CDF Estimates

8. Future Applicability / Plant Specific Analyses

Section F.2 presents an overall summary of the comments received. Section F.3 presents the comments and the responses grouped by the organizations in the order submitted. Section F.4 presents the technical comments grouped in accordance to which of the 8 technical areas were addressed.

\section{F.2 Overall Summary}

A total of 111 comments were received and addressed. Of these, 41 were editorial in nature and incorporated in the revised NUREG/CR-6224, as appropriate. The remaining 67 comments were classified as 10 regulatory in nature and 57 of technical substance. 


\section{F.2.1 Regulatory Comments Overview}

Most of the regulatory comments dealt with applicability of NUREG/CR-6224 models, conclusions, and insights to BWRs other than the reference plant. The NRC responded that NUREG/CR-6224 was intended to be a plant specific analysis of the reference plant and that a more comprehensive guidance on the BWR strainer blockage analysis was incorporated into DG-1038, Revision 2 to Regulatory Guide 1.82 .

Other comments related to applicability of ANSI/ANS-58.2-1988 jet models to the development of BWR debris generation model, and the regulatory basis for calculating the available NPSH margin. The NRC responded that the present spherical debris generation model is an approximation of the two idealized alternatives (i.e., full separations with no jet interaction and limited separation with zero relative motion of the pipes) offered by the ANSI/ANS-58.2-1988 jet models. In addition, the NRC noted that the spherical zone of influence better represents damage inflicted by the over pressure blast wave which was not incorporated into the ANSI/ANS-58.2-1988 jet models. In regard to NPSH margin, NRC responded that the available margin should be evaluated assuming atmospheric containment pressure and the most severe suppression pool water temperature in accordance with Regulatory Guide 1.1.

\section{F.2.2 Technical Comments Overview}

There was considerable overlap of the technical comments which were sometimes repetitive. No significant new data, experimental results and insights, calculations, or analysis methodologies were provided with the comments which had not been considered and adopted, as applicable and appropriate, into the NUREG/CR-6224 Draft for Comment. Most of the technical comments addressed four areas: debris generation model, debris transport model, pipe break frequency and modeling and CDF estimates.

\section{Debris Generation Model}

This area elicited the greatest number of technical comments. Most of the comments were in regard to the adoption of the spherical model for debris generation as opposed to back-to-back right angle cone(s), narrow angle cone(s), or other previously developed jet expansion models. SEA responded to these comments by stating that, based on engineering judgement and analysis of limited experimental data, a multi-region spherical zone of destruction model was selected to account for the effects of (1) the blast wave that proceeds the quasisteady blowdown jet, (2) the interaction of jets originating from both ends of the postulated DEGB and expanding in opposite directions, (3) relative motion of the broken ends, and (4) congested layout of the BWR drywell. Varying destruction factors for each region accounts for the experimental evidence that (1) levels of destruction vary strongly with distance from the break with the most severe destruction being closest to the break, and (2) some degree of protection is offered by shadowing of the targets by other structures and by the method used to encapsulate the insulation. Different insulations display different degrees of sensitivity to each of these factors. No specific supportive calculations or data were provided which would substantiate not adopting the spherical debris generation model. Development of an analytically based debris generation model validated by a modest series of debris generation tests would significantly improve the present understanding of this critical area.

\section{Debris Transport Model}

Most of the comments in this area expressed that NUREG/CR-6224 Draft for Comment (1) overestimated the drywell debris transport, (2) interpreted the Barsebäck-2 data erroneously, (3) did not consider insights gained from the ABB Karlshamn tests, and (4) did not handle the containment sprays in the reference plant in a consistent manner. SEA's response to these comments were to (1) lower the transport factors from the previous base case value of $62.5 \%$ for breaks located in the mid-location to $50 \%$ (with commensurate adjustments to the two other locations), (2) revise the text to clearly state that the model allows for larger fractions of generated debris to be transported during blowdown compared to those derived from Barsebäck-2 incident to account for the fact that larger postulated breaks in the reference plant would correspond to larger vapor velocities in the drywell and thus larger transport 
factors; (3) continue not adopting the transport factors derived from the ABB Karlshamn experiments. The CSNI/PWG-1 International Task Group on ECCS Recirculation Reliability also questioned the applicability of these experiments to actual BWR drywell given scaling factors not considered in the experimental set-up, and (4) lower the washdown transport factors since the containment sprays are not initiated in the reference plant.

Drywell debris transport could be analyzed using currently available computational fluid dynamic codes coupled with accident analysis aerosol transport computer codes in order to provide better understanding of this critical area.

\section{Pipe Break Frequency and Modeling}

Comments in this area were mostly associated with questioning the pipe break probabilities derived for use in NUREG/CR-6224 Draft for Comment, including questioning why NUREG/CR-6224 Draft for Comment had not adopted the pipe break probabilities derived by the BWROG. A detailed review of the BWROG March 24, 1994 submittal revealed that the BWROG estimate was based on EPRI data not available for use or review by the $\mathrm{NRC}$, that there was no data presented which demonstrated that IGSCC were accounted for in the analysis, and that the overall approach was based on pipe sections and not applicable to the DEGB caused by circumferential welds which forms the basis of NUREG/CR-6224. For these reasons NUREG/CR-6224 retained the break estimates derived from the model derived in NUREG/CR-4792 taking into account the effects of IGSCC and enhanced inspections.

\section{CDF Estimates}

The approach taken to derive CDF estimates attributable to loss of ECCS elicited the most number of comments second only to those addressing the debris generation model. The comments were mainly directed at questioning some of the assumptions used in the event tree model. The overall objective of the event tree modeling was to provide a scoping estimate of the CDF related to ECCS NPSH loss. The assumptions used in NUREG/CR-6224 were reviewed in light of the comments received and judged to be reasonable. 


\begin{tabular}{|c|c|c|c|}
\hline \multicolumn{4}{|c|}{ |Commentor: BWROG-R. A. Pinelli } \\
\hline \begin{tabular}{c|c} 
Comment \# I \\
Location \\
N
\end{tabular} & Type & Comment & Response \\
\hline $\begin{array}{l}\text { BWROG-A1/ } \\
\text { General }\end{array}$ & Regulatory & $\begin{array}{l}\text { Please provide additional discussion on the applicability } \\
\text { of the overall analytical method used in this analysis } \\
\text { with respect to future regulatory guidance and plant- } \\
\text { specific analyses. Although it is understood that the } \\
\text { NUREG analysis is specific to the reference plant, there } \\
\text { are numerous references to "plant specific" issues (e.g., } \\
\text { transport factors, strainer specifics, etc.), that generically } \\
\text { speaking, could be applied to all plants. Examples } \\
\text { include: } \\
\text { - Debris Generation: Figure } 2.1 \\
\text { Drywell Location Effects: Plant-Specific } \\
\text { - } \\
\text { Duppression Pool Transport: Containment- } \\
\text { - Strainer Failure Criteria: Figure } 2.1 \\
\text { Reference to some examples of plant/containment- } \\
\text { specific sensitivities might be appropriate. For example, } \\
\text { other plants may be able to reduce the CDF based upon } \\
\text { much larger strainer surface area already existing in the } \\
\text { plants, elevated downcomers, deflector plates above the } \\
\text { downcomers, or downcomer baffling. Additional } \\
\text { discussion of the ability to mitigate the LOCA with a } \\
\text { source other than the suppression pool, and the impact } \\
\text { of this on the lowering of CDF values might also be } \\
\text { valuable. (This is briefly mentioned but not used to } \\
\text { separate the product designs from recommended } \\
\text { actions.) } \\
\text { In general, additional information concerning the } \\
\text { parameters and assumptions used in the analysis will } \\
\text { assist members in performing plant-specific analyses. }\end{array}$ & $\begin{array}{l}\text { The primary objective of this report was to analyze a } \\
\text { reference BWR plant in essentially the same detail as } \\
\text { was performed for a reference PWR plant used in the } \\
\text { resolution of USI A-43, "Containment Emergency } \\
\text { Sump Performance." A BWR/4 with a Mark I } \\
\text { containment was selected as the reference plant by } \\
\text { NRC staff to facilitate calculations. The variability of } \\
\text { BWR containments, insulations employed, and other } \\
\text { plant-specific design or operational features prevent } \\
\text { generic extrapolation of results discussed in the report } \\
\text { without accounting for such differences. The report } \\
\text { has been revised to include a parametric analysis } \\
\text { which investigates the sensitivity of various design } \\
\text { parameters. } \\
\text { Generic extrapolations of these insights are strongly } \\
\text { discouraged due to the plant-specific nature of these } \\
\text { calculations. }\end{array}$ \\
\hline
\end{tabular}




\begin{tabular}{|c|c|c|c|}
\hline \multicolumn{4}{|c|}{ Commentor: BWROG - R. A. Pinelli } \\
\hline $\begin{array}{l}\text { Comment \# / } \\
\text { Location }\end{array}$ & Type & Comment & Response \\
\hline $\begin{array}{l}\text { BWROG-B5/ } \\
\text { Section } 4.1\end{array}$ & Technical & $\begin{array}{l}\text { Please consider the use of more realistic estimates of } \\
\text { pipe break frequency based on actual operating } \\
\text { experience [Reference BWROG Safety Assessment } \\
\text { provided to the NRC on March 24, 1994], rather than } \\
\text { on analytical estimates. }\end{array}$ & $\begin{array}{l}\text { The BWROG estimate of pipe break frequency was } \\
\text { considered. However, the BWROG estimate was not } \\
\text { used for the following reasons: } \\
\text { 1) Plant operational experience used to support the } \\
\text { BWROG frequency analysis was based on EPRI } \\
\text { documents that were not available to use for review. } \\
\text { 2) There was no evidence presented on the BWROG } \\
\text { study to show that phenomena strongly dependent } \\
\text { on aging (e.g., IGSCC) were accounted for in the } \\
\text { statistical analysis of the plant operational data. } \\
\text { 3) In Section } 4.1 .1 \text { the BWROG approach was based } \\
\text { on pipe sections, as opposed to pipe welds. The } \\
\text { number of welds was significantly more important } \\
\text { than the number of pipe sections in determining pipe } \\
\text { break frequency. (LLNL Study, NUREG/CR-4792) }\end{array}$ \\
\hline $\begin{array}{l}\text { BWROG-B6a/ } \\
\text { Appendix } \\
\text { A.3.3.1 }\end{array}$ & Technical & $\begin{array}{l}\text { Please consider crediting ISI programs and IGSCC } \\
\text { monitoring programs, such as erosion/corrosion } \\
\text { monitoring on the carbon steel piping, hydrogen water } \\
\text { chemistry, induction heating stress improvement, etc. } \\
\text { These actions can reduce pipe break frequencies to } \\
\text { values below those determined in the LLNL study. } \\
\text { Also, given the high quality of steam in the main } \\
\text { steam line, flow-accelerated corrosion is not likely. In } \\
\text { Appendix A.3.3.1, the assumptions regarding carbon } \\
\text { steel rupture frequencies are extremely conservative, } \\
\text { and do not recognize erosion-corrosion monitoring and } \\
\text { control programs in existence today. }\end{array}$ & $\begin{array}{l}\text { The pipe break frequency estimates were specific to } \\
\text { the reference plant at the time of the plant visit. The } \\
\text { licensee had an ISI program that included some, but } \\
\text { not all, of the potential actions cited in the comment. } \\
\text { The study estimated that the licensee's program } \\
\text { reduced the break frequencies to about } 10 \% \text { of what } \\
\text { they would have been without any IGSCC-mitigating } \\
\text { actions. Thus, an order of magnitude reduction in } \\
\text { estimated pipe break frequencies has already been } \\
\text { credited in the analyses. Consideration of potential } \\
\text { improvements to the reference plant ISI program was } \\
\text { beyond the scope of this study. }\end{array}$ \\
\hline
\end{tabular}




\begin{tabular}{|c|c|c|c|}
\hline \multicolumn{4}{|c|}{ Commentor: BWROG-R.A. Pinelli } \\
\hline $\begin{array}{l}\text { Comment \# I } \\
\text { Location }\end{array}$ & Type & Comment & Response \\
\hline $\begin{array}{l}\text { BWROG-B6b/ } \\
\text { Appendix A } \\
\text { Figure A-4 }\end{array}$ & Technical & $\begin{array}{l}\text { The LLNL study described in Appendix A used for } \\
\text { DEGB pipe break analysis does not consider } \\
\text { preventative plant maintenance that should identify } \\
\text { potential DEGBs. The graph used in Figure A-4 seems } \\
\text { to be developed to determine the frequency of } \\
\text { preventative maintenance activities and may not be } \\
\text { appropriate for determining an annual frequency of } \\
\text { DEGBs. Note the jumps in failure probability at } 5 \\
\text { years for susceptible material, and } 29 \text { years for resistant } \\
\text { piping material. SEA did credit a supplemental } \\
\text { correction factor to make allowance for actions to limit } \\
\text { the likelihood of a DEGB. }\end{array}$ & $\begin{array}{l}\text { The "jump" in Figure A-4 may or may not be real; the } \\
\text { curve was fit to sparse and uncertain data. If it was } \\
\text { real, an alternative interpretation of the jump for } \\
\text { 316NG piping would be that IGSCC developed } \\
\text { slowly but accelerated after reaching a critical point. } \\
\text { If that was so, preventive plant maintenance would } \\
\text { not be very effective in identifying potential DEGBs. } \\
\text { It would also imply that experience in the first } \\
\text { twenty years of plant life was not a good basis for } \\
\text { predicting DEGB frequency at an older plant. }\end{array}$ \\
\hline $\begin{array}{l}\text { BWROG-B7/ } \\
\text { Appendix A }\end{array}$ & Technical & $\begin{array}{l}\text { In Appendix A, the pipe-break-per-weld frequencies } \\
\text { are based upon the most susceptible material. This is } \\
\text { not realistic for all plants. Note the DEGB frequency of } \\
304 S S \text { is a factor of } 12.5 \text { higher than for } 316 N G \text {. This } \\
\text { makes a large difference in CDF. }\end{array}$ & $\begin{array}{l}\text { This study considered only the reference plant } \\
\text { equipped with } 304 \text { SS piping which is a susceptible } \\
\text { material. The results may not be applicable to any } \\
\text { other plant because of factors such as plant specific } \\
\text { piping materials, configurations, sizes, weld locations, } \\
\text { etc. }\end{array}$ \\
\hline $\begin{array}{l}\text { BWROG-B8a/ } \\
\text { Appendix A }\end{array}$ & Technical & $\begin{array}{l}\text { Pipe break frequency is the same as NUREG/CR- } 4550 \text {, } \\
\text { Volume } 1 \text {. Given the amount of piping in the drywell } \\
\text { compared to the overall plant piping, it is much more } \\
\text { likely that a break will occur outside the drywell, } \\
\text { rather than inside. }\end{array}$ & $\begin{array}{l}\text { NUREG/CR-6224 pipe break frequency estimates are } \\
\text { for the portions of high pressure piping contained in } \\
\text { the drywell and are plant specific. NUREG/CR- } 4550 \\
\text { pipe break frequency estimates are for all of the high } \\
\text { pressure piping in the plant and should not be } \\
\text { compared with those found in NUREG/CR-6224. }\end{array}$ \\
\hline $\begin{array}{l}\text { BWROG-B8b/ } \\
\text { Appendix A }\end{array}$ & Techinical & $\begin{array}{l}\text { Also, the Technical Specification LCO for unidentified } \\
\text { drywell leakage should limit the likelihood of a DEGB } \\
\text { in the drywell. It is very unlikely that a major line } \\
\text { break can occur without any warning signs. }\end{array}$ & $\begin{array}{l}\text { This study used an estimate that the ISI program at } \\
\text { the reference plant would avert all but } 10 \% \text { of the } \\
\text { potential DEGBs. }\end{array}$ \\
\hline
\end{tabular}




\begin{tabular}{|c|c|c|c|}
\hline \multicolumn{4}{|c|}{ Commentor: BWROG - R. A. Pinelli } \\
\hline $\begin{array}{c}\text { Comment \# I } \\
\text { Location }\end{array}$ & Type & Comment & Response \\
\hline $\begin{array}{l}\text { BWROG-A2a/ } \\
\text { General }\end{array}$ & Technical & $\begin{array}{l}\text { A sensitivity analysis should be performed, perhaps } \\
\text { with accelerated public review, prior to issuing the } \\
\text { final report. Sensitivity should at least cover the } \\
\text { spherical model versus the cone and the effect of } \\
\text { transport factors. An uncertainty analysis would } \\
\text { probably not be warranted due to the large amount of } \\
\text { engineering judgement noted throughout the text. }\end{array}$ & $\begin{array}{l}\text { A parametric sensitivity analysis has been } \\
\text { incorporated as an Appendix to NUREG/CR-6224. }\end{array}$ \\
\hline $\begin{array}{l}\text { BWROG-A2b/ } \\
\text { General }\end{array}$ & Technical & $\begin{array}{l}\text { For example, it would be very beneficial to plants that } \\
\text { already have larger strainers if the NUREG addressed } \\
\text { additional sensitivities regarding strainer size. The } \\
\text { NUREG identifies changes if the strainer size is double } \\
\text { that at the lead plant. But, if additional runs were } \\
\text { made at } 3 \text { times, } 4 \text { times, etc., a curve could be } \\
\text { developed for determining the probability of failure for } \\
\text { large breaks based on changing the strainer size. }\end{array}$ & $\begin{array}{l}\text { The extent of the parametric study in the } \\
\text { NUREG/CR- } 6224 \text { Draft for Comment was limited by } \\
\text { time and resources. Additional parametric analyses } \\
\text { have now been incorporated as Appendix } C \text { to } \\
\text { NUREG/CR- } 6224 \text {. The extended parametric study } \\
\text { varied the strainer area up to } 10 \text { times the area of the } \\
\text { reference plant strainer. }\end{array}$ \\
\hline $\begin{array}{l}\text { BWROG-B1/ } \\
\text { Executive } \\
\text { Summary } \\
\text { page xiii } \\
\text { 1st paragraph }\end{array}$ & Editorial & $\begin{array}{l}\text { Contrary to statements in the NUREG/CR (page xiii, } \\
\text { 1st paragraph), the events at the Perry Nuclear Plant } \\
\text { did not demonstrate that larger quantities of fibrous } \\
\text { debris will reach the strainers than would have been } \\
\text { predicted by the model and analysis developed for the } \\
\text { resolution of USI A-43, with the exception that } \\
\text { previously unanticipated, unanalyzed fiber sources } \\
\text { contributed to a larger fiber loading. More } \\
\text { significantly, the Perry events demonstrated the } \\
\text { importance of the combined effect of particulate and } \\
\text { fibrous debris. As currently described in the NUREG, } \\
\text { the reader could infer that the Perry event also } \\
\text { invalidated the solution to USI A-43 (Reg. Guide 1.82). }\end{array}$ & $\begin{array}{l}\text { NUREG/CR-6224 was modified to clarify this } \\
\text { statement. It was not intended to infer that the Perry } \\
\text { event invalidated the solution to USI A- } 43 \text {. }\end{array}$ \\
\hline
\end{tabular}




\begin{tabular}{|c|c|c|c|}
\hline \multicolumn{4}{|c|}{ Commentor: BWROG-R.A. Pinelli } \\
\hline $\begin{array}{l}\text { Comment \# I } \\
\text { Location }\end{array}$ & Type & Comment & Response \\
\hline $\begin{array}{l}\text { BWROG-B2/ } \\
\text { Section } 1.1 \\
\text { page } 1-1 \\
\text { 3rd paragraph } \\
\text { last sentence }\end{array}$ & Editorial & $\begin{array}{l}\text { The last sentence of the third paragraph on page } 1-1 \\
\text { indicates that the Barsebäck-2 event demonstrated that } \\
\text { "small particles, in combination with debris fibers } \\
\text { significantly increased the pressure drop...." The basis } \\
\text { for this statement is questionable. We believe it more } \\
\text { accurate to state that the Perry event, not the } \\
\text { Barsebäck-2 event, provided insights on the combined } \\
\text { debris effect. }\end{array}$ & $\begin{array}{l}\text { NUREG/CR- } 6224 \text { was modified to clarify this } \\
\text { statement. }\end{array}$ \\
\hline $\begin{array}{l}\text { BWROG-B3/ } \\
\text { Section } 2.7\end{array}$ & Regulatory & $\begin{array}{l}\text { Please provide the basis (e.g., Regulatory Guide } 1.1 \text { ) for } \\
\text { not accounting for pressurization of the pool or for } \\
\text { reduction in the available NPSH due to an increase in } \\
\text { pool water temperature for the reference plant. }\end{array}$ & $\begin{array}{l}\text { The NPSH was calculated according to Reg. Guide } \\
1.1 \text { which stated that NPSH should be calculated } \\
\text { assuming atmospheric containment pressure and } \\
\text { most severe pool temperature. NUREG/CR- } 6224 \text { was } \\
\text { modified to clarify this statement. }\end{array}$ \\
\hline $\begin{array}{l}\text { BWROG-B4/ } \\
\text { Section } 3.6\end{array}$ & Technical & $\begin{array}{l}\text { Additional information as to how the available NPSH } \\
\text { was determined would be helpful to the analyst. Of } \\
\text { interest is whether the following items were } \\
\text { considered: suction line losses, the actual pool water } \\
\text { temperature used, the minimum suppression pool } \\
\text { level, etc. In summary, please clarify the bases for the } \\
\text { stated NPSH values? }\end{array}$ & $\begin{array}{l}\text { NUREG-0897, Rev. 1, outlines a methodology that } \\
\text { can be used to estimate the NPSH margins. } \\
\text { NUREG/CR-6224 was modified to include details on } \\
\text { how NUREG-0897 methodology was applied to } \\
\text { estimate NPSH for the reference plant in accordance } \\
\text { with Reg. Guide } 1.1 \text {. }\end{array}$ \\
\hline
\end{tabular}




\begin{tabular}{|c|c|c|c|}
\hline \multicolumn{4}{|c|}{ Commentor: BWROG-R. A. Pinelli } \\
\hline $\begin{array}{l}\text { Comment \# I } \\
\text { Location }\end{array}$ & Type & Comment & Response \\
\hline $\begin{array}{l}\text { BWROG-B9/ } \\
\text { Appendix A }\end{array}$ & Technical & $\begin{array}{l}\text { The technical justification for excluding other IGSCC } \\
\text { mitigating actions in Reactor Recirculation systems is } \\
\text { unclear. Please consider a sensitivity analysis to } \\
\text { evaluate the effect of this further reduction in pipe } \\
\text { break frequency on the overall NUREG analysis. }\end{array}$ & $\begin{array}{l}\text { The pipe break frequency estimates were specific to } \\
\text { the reference plant at the time of the plant visit. The } \\
\text { licensee had an ISI program that included some, but } \\
\text { not all, of the potential actions cited in your } \\
\text { comment. The study estimated that the licensee's } \\
\text { program reduced the break frequencies to about } 10 \% \\
\text { of what they would have been without any IGSCC- } \\
\text { mitigating actions. Thus, an order of magnitude } \\
\text { reduction in estimated pipe break frequencies has } \\
\text { already been credited in our analyses. A sensitivity } \\
\text { analysis is beyond the scope of NUREG/CR-6224. }\end{array}$ \\
\hline $\begin{array}{l}\text { BWROG-B10/ } \\
\text { Section } 4.2\end{array}$ & Technical & $\begin{array}{l}\text { We disagree with the reasoning supporting the } \\
\text { spherical jet expansion model. If indeed the basis for } \\
\text { the sphere is the jet being deflected by surrounding } \\
\text { pipe, then it would seem that the deflection would } \\
\text { absorb most of the jet's energy, resulting in a much } \\
\text { smaller zone of influence. The spherical model results } \\
\text { in an overly conservative model. }\end{array}$ & $\begin{array}{l}\text { The basis for choosing the spherical model was that } \\
\text { after a break in a steam line there would be jets from } \\
\text { each side of the break. The interaction of these two } \\
\text { expanding jets would cause a redistribution of fluid } \\
\text { flow, leading to pressure fields that may be widely } \\
\text { different from those estimated based on the conical } \\
\text { zone-of-influence model. The assumption of a } \\
\text { spherical expansion is not in itself more conservative } \\
\text { than a conical model; the degree of conservatism } \\
\text { depends on how the other parameters of the model } \\
\text { (such as destruction factor or zone of destruction) are } \\
\text { chosen. }\end{array}$ \\
\hline
\end{tabular}




\begin{tabular}{||l|l|l|l||}
\hline $\begin{array}{l}\text { Commentor: BWROG-R. A. Pinelli } \\
\text { Location }\end{array}$ & Type & Comment & \multicolumn{1}{|c||}{ Response } \\
\hline $\begin{array}{l}\text { BWROG-B11/ } \\
\text { Section 4.2 }\end{array}$ & Technical & $\begin{array}{l}\text { The NUREG states that blowdown is expected in both } \\
\text { directions from the DEGB. This is not true for all } \\
\text { breaks modeled in the study. For breaks which have a } \\
\text { blowdown from only one side of the break, such as } \\
\text { RHR or HPCI, a single-sided zone of influence would } \\
\text { appear more appropriate. }\end{array}$ & $\begin{array}{l}\text { During the plant analysis, it was recognized that 21 } \\
\text { out of } 345 \text { welds will result in blowdown from only } \\
\text { one side of the break, for example, RHR piping } \\
\text { welds. A hemispherical zone of influence was } \\
\text { considered for these welds; however, a hemisphere } \\
\text { may not bound the zone of influence considering that } \\
\text { most of the breaks are located in areas that are } \\
\text { congested with primary pipes and valves. As a } \\
\text { result, a conservative assumption to use a spherical } \\
\text { zone of influence was made to simplify the analysis. } \\
\text { Usage of a spherical zone of influence did not double } \\
\text { the volume of debris generated as one might assume } \\
\text { because for the majority of these breaks, the targets } \\
\text { are located to one side of the break. The increase in } \\
\text { debris volume for several breaks is no more than } \\
\text { 25\%. Finally, this assumption affects only } 21 \text { of the } \\
\text { 345 welds and does not vary the overall results of } \\
\text { this study. }\end{array}$ \\
\hline
\end{tabular}




\begin{tabular}{|c|c|c|c|}
\hline \multicolumn{4}{|c|}{ Commentor: BWROG - R. A. Pinelli } \\
\hline $\begin{array}{l}\text { Comment \# / } \\
\text { Location }\end{array}$ & Type & Comment & Response \\
\hline $\begin{array}{l}\text { BWROG-B12/ } \\
\text { Section } 4.2\end{array}$ & Technical & $\begin{array}{l}\text { Use of the Battelle video as a basis for the debris } \\
\text { generation model questions the validity of the model. } \\
\text { The International Piping Integrity Research Group Test } \\
\text { 1.3-7 was performed at pressure and temperature } \\
\text { conditions typical of PWRs ( } 2250 \text { psig and } 550^{\circ} \mathrm{F} \text { ). } \\
\text { Based on the discussion in the NUREG, the initial blast } \\
\text { (pressure wave) is the initiating failure mechanism, } \\
\text { followed by the secondary mechanism of the "fluid } \\
\text { jet...peeling off the unprotected layer." Without the } \\
\text { first mechanism, the second should not occur. It is } \\
\text { difficult to understand how this pressure wave can be } \\
\text { characterized from the video. } \\
\text { Furthermore, it would not seem likely that the } \\
\text { spherical jet effects from a single pipe break can be } \\
\text { identified from the video, given that there were no } \\
\text { target pipes in the experimental set-up. }\end{array}$ & $\begin{array}{l}\text { The Battelle video was shown at the 3-30-94 public } \\
\text { meeting to illustrate a pipe break jet and to solicit } \\
\text { views regarding the modelling of such an expanding } \\
\text { break jet. The BWROG comments dated } 4-14-94 \\
\text { (received following this meeting) stated: } \\
\text { "The BWROG also agrees with SEA's recognition that } \\
\text { most BWRs have highly congested piping in the } \\
\text { drywell and that a guillotine-type pipe break may be } \\
\text { better represented by a spherical zone of destruction } \\
\text { than by two back-to-back } 90^{\circ} \text { cones. Based on test } \\
\text { information in the public arena concerning insulation } \\
\text { systems currently installed in U.S. nuclear plants, the } \\
\text { BWROG agrees that fibrous insulation materials } \\
\text { located within a zone of destruction with a radius of } \\
\text { three times the pipe diameter are highly likely to } \\
\text { suffer destruction, with or without metal jacketing. } \\
\text { With an expanding jet, the corresponding destruction } \\
\text { would decrease significantly with increasing distance } \\
\text { from the guillotine break, as pointed out by SEA." } \\
\text { The analyses and results presented in NUREG/CR- } \\
6224 \text { utilize BWR operating pressures with a reduced } \\
\text { jet expansion distance, but have retained the } \\
\text { spherical model. Although the Battelle videos were } \\
\text { not designed to investigate insulation destruction, } \\
\text { discussions with staff familiar with the tests revealed } \\
\text { that each test severely destroyed piping insulation } \\
\text { within }+/- \text { seven L/D's of the break location, } \\
\text { necessitating continued re-insulation of that portion } \\
\text { of the test loop. }\end{array}$ \\
\hline
\end{tabular}




\begin{tabular}{|c|c|c|c|}
\hline \multicolumn{4}{|c|}{ Commentor: BWROG - R. A. Pinelli } \\
\hline $\begin{array}{l}\text { Comment \# I } \\
\text { Location }\end{array}$ & Type & Comment & Response \\
\hline $\begin{array}{l}\text { BWROG-B12 / } \\
\text { (cont.) }\end{array}$ & Technical & & $\begin{array}{l}\text { Although break jet expansion models have been } \\
\text { developed for predicting structural loads, these codes } \\
\text { do not have the capability to predict the types and } \\
\text { amounts of LOCA generated insulation debris which } \\
\text { might occur. The video was a reminder of the } \\
\text { destructive nature of a pipe break. }\end{array}$ \\
\hline $\begin{array}{l}\text { BWROG-B13/ } \\
\text { Section } 4.2\end{array}$ & Technical & $\begin{array}{l}\text { The spherical debris generation model does not } \\
\text { conserve momentum. The } 3 / 5 / 7 \mathrm{~L} / \mathrm{D} \text { zones of } \\
\text { destruction used in the NUREG/CR- } 6224 \text { analysis are } \\
\text { based on calculations of pressures as a function of } \\
\text { distance from a break assuming a conical-shaped jet. If } \\
\text { a spherical expansion is postulated, pressures should } \\
\text { be calculated using an expanding spherical surface. } \\
\text { Destruction zones should then be based on the } \\
\text { distances at which load pressures occur which are } \\
\text { equivalent to those in a conical jet at } 3 / 5 / 7 \mathrm{~L} / \mathrm{D} \text {. Use } \\
\text { of load pressures typical of a conical jet in a postulated } \\
\text { spherical expansion effectively overstates the available } \\
\text { momentum by a factor proportional to the ratio of the } \\
\text { total surface area of the sphere to the portion of that } \\
\text { surface area which falls within the cone. For a } 90^{\circ} \\
\text { cone, the surface area of the sphere at any given L/D } \\
\text { is four times larger than the portion of that surface } \\
\text { within the cone. }\end{array}$ & $\begin{array}{l}\text { The zones of destruction are based upon engineering } \\
\text { judgement, not upon calculations of pressure as a } \\
\text { function of distance. The calculations of pressures } \\
\text { for a steady-state expanding jet were cited to provide } \\
\text { the background for previous work and to explain one } \\
\text { source of insight that contributed to engineering } \\
\text { judgement. To avoid misunderstanding, the isobars } \\
\text { were eliminated from Figure } 4-3 \text { of NUREG/CR-6224 } \\
\text { Draft for Comment (Figure B-4 in this report), along } \\
\text { with the note explaining the isobars. Also, the } \\
\text { discussion of those isobars were removed. }\end{array}$ \\
\hline
\end{tabular}




\begin{tabular}{|c|c|c|c|c|c|}
\hline & 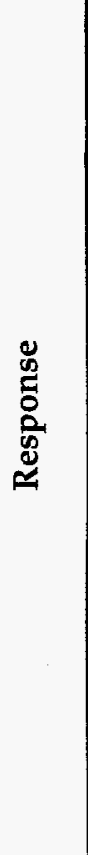 & 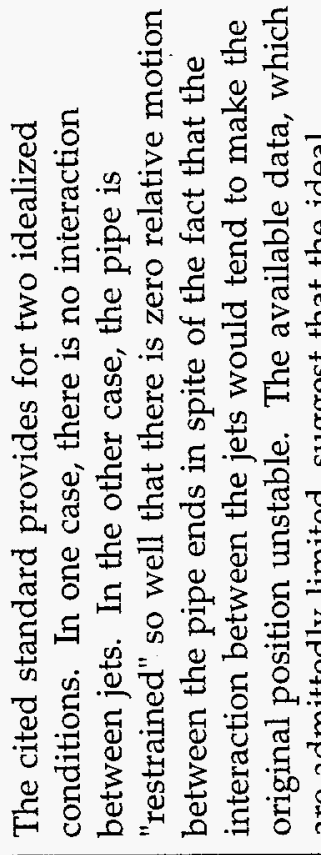 & 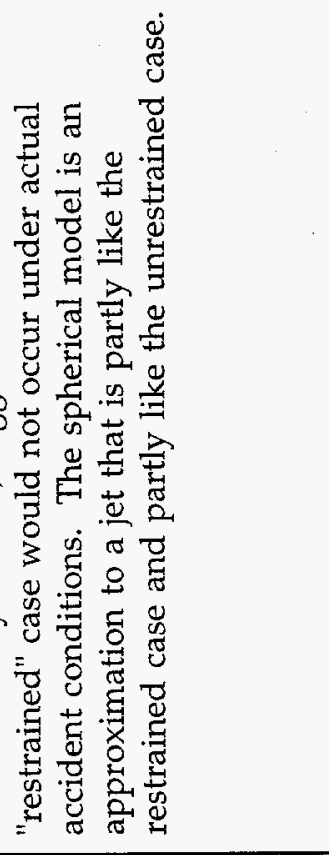 & & \\
\hline$\stackrel{\Sigma}{*}$ & $\begin{array}{l}\vec{\Xi} \\
\text { İ } \\
\text { : }\end{array}$ & 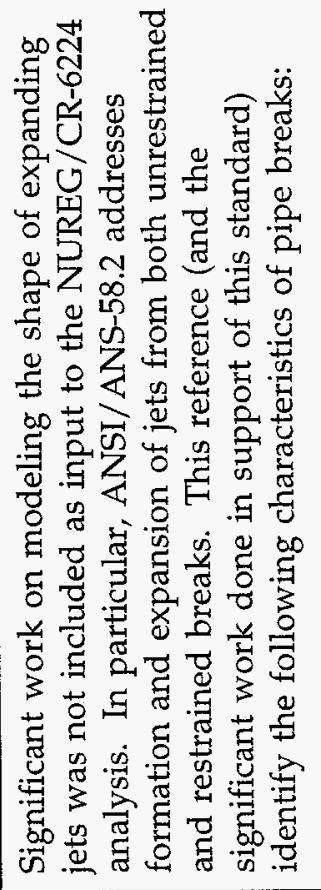 & 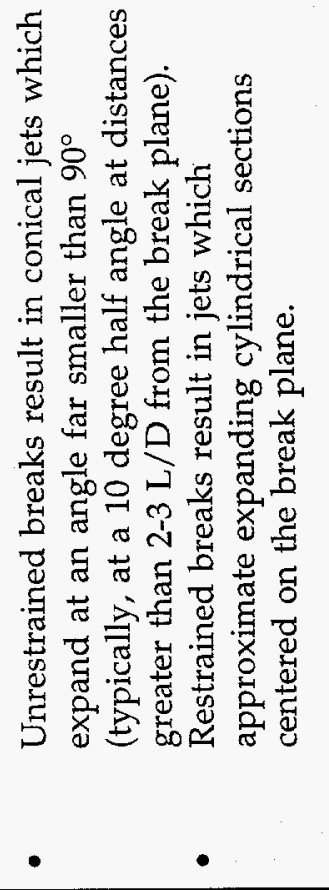 & 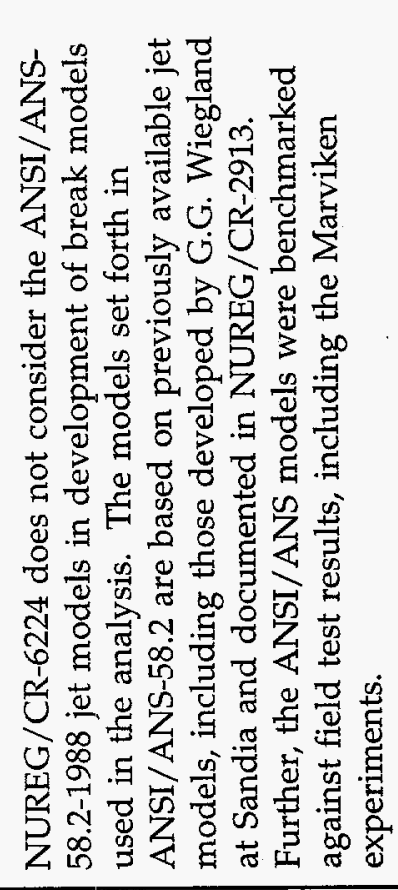 & 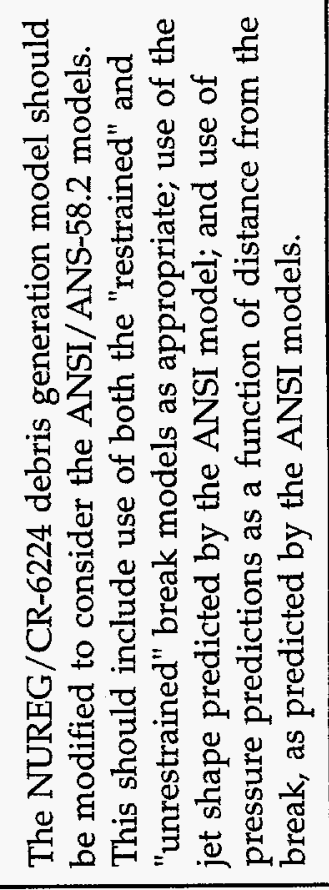 \\
\hline $\mid \begin{array}{l}3 \\
\vdots \\
\dot{3} \\
\dot{1} \\
\dot{1} \\
1 \\
0\end{array}$ & 岕 & 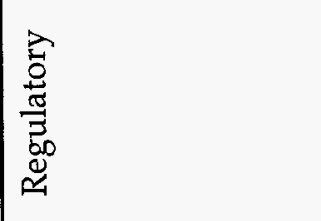 & & & \\
\hline 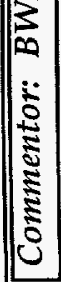 & 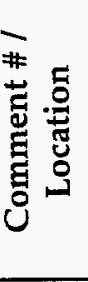 & 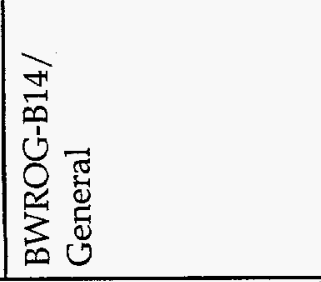 & & & \\
\hline
\end{tabular}




\begin{tabular}{|c|c|c|c|}
\hline \multicolumn{4}{|c|}{ Commentor: BWROG-R. A. Pinelli } \\
\hline $\begin{array}{c}\text { Comment \# I } \\
\text { Location }\end{array}$ & Type & Comment & Response \\
\hline \begin{tabular}{l|l}
\multirow{2}{*}{} & BWROG-B15/ \\
N & Section 4.2 .4 \\
& Item \#3
\end{tabular} & Technical & $\begin{array}{l}\text { The basis for excluding shadowing effects from } \\
\text { consideration is unclear. The insulation on the } \\
\text { backside of the target pipes (with respect to the break } \\
\text { source) would definitely not be damaged into "fines" } \\
\text { like that on the front side of the same pipe. We } \\
\text { suggest that credit be taken for this type of shadowing } \\
\text { effect in the debris generation model. With respect to } \\
\text { item \#3 of Section } 4.2 .4 \text {, it is agreed that taking credit } \\
\text { for shadowing effects of containment structures is } \\
\text { difficult, but the shadowing of target pipes themselves } \\
\text { should be relatively easy. }\end{array}$ & $\begin{array}{l}\text { The insulation on the back side of a pipe should not } \\
\text { experience the same forces as that on the front side. } \\
\text { This may lead to reduced contribution of insulation } \\
\text { debris, especially at distances farther from the break. } \\
\text { However, this level of knowledge does not exist } \\
\text { experimentally or analytically. This is one of the } \\
\text { effects considered in estimating the destruction } \\
\text { factors for each region. Individual plants should } \\
\text { account for the shadowing effect in their individual } \\
\text { analyses if resources permit. } \\
\text { Not all debris were assumed to be "fines." (See } \\
\text { Appendix B). }\end{array}$ \\
\hline $\begin{array}{l}\text { BWROG-B16/ } \\
\text { Section } 4.2 .3\end{array}$ & Technical & $\begin{array}{l}\text { In Section } 4.2 .3 \text {, "Other Types of Debris Generated by } \\
\text { LOCA Jets," the basis for the } 2.6 \mathrm{cu} \text {. ft. of particulate } \\
\text { debris that is generated in the drywell and transported } \\
\text { to the suppression pool is not apparent. }\end{array}$ & $\begin{array}{l}\text { The amount used in NUREG/CR- } 6224 \text { Draft for } \\
\text { Comment was based on engineering judgement. This } \\
\text { version of NUREG/CR-6224 was modified by use of } \\
\text { BWROG interim report (Dec. 94) (Appendix III). }\end{array}$ \\
\hline
\end{tabular}




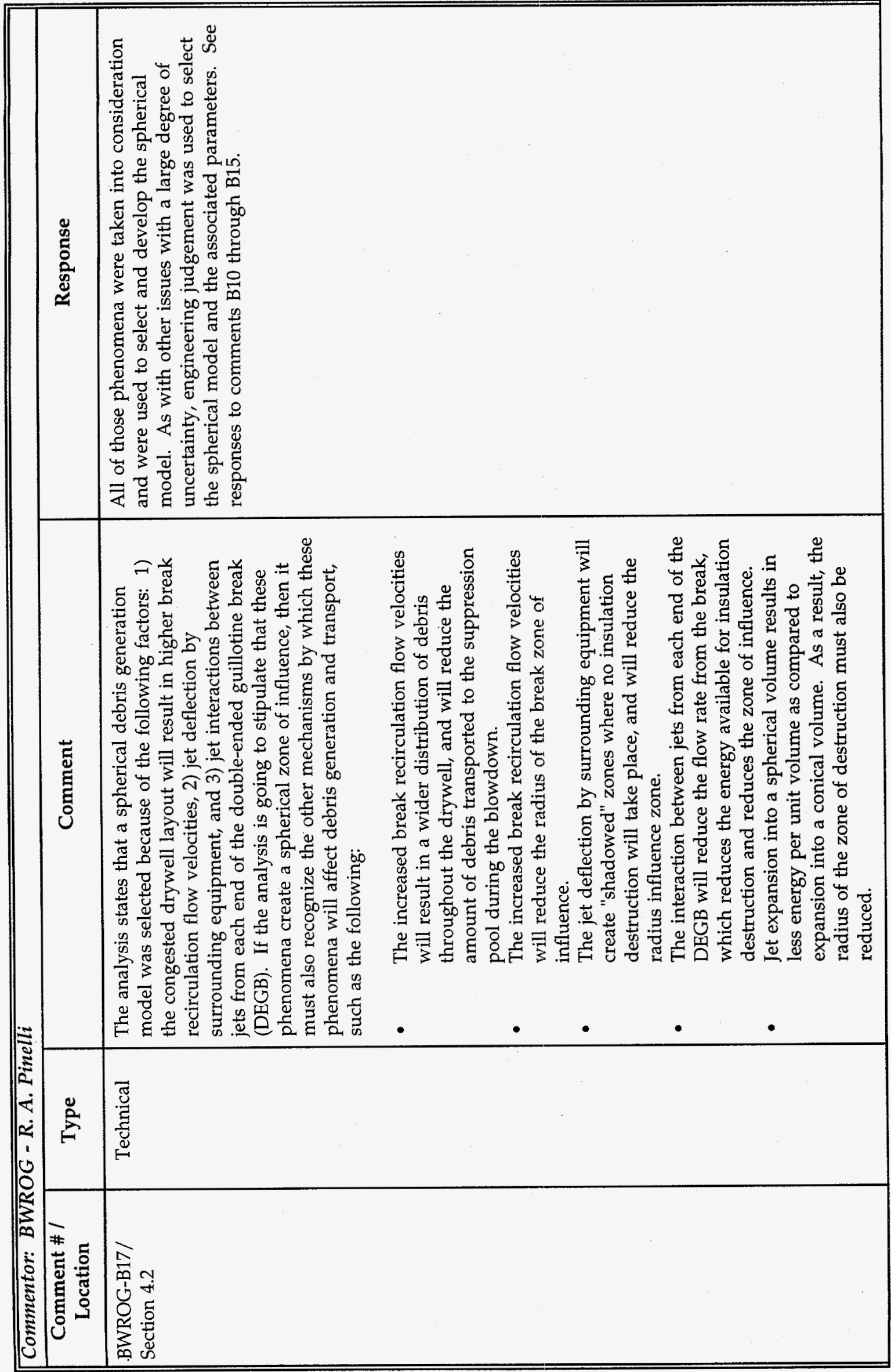




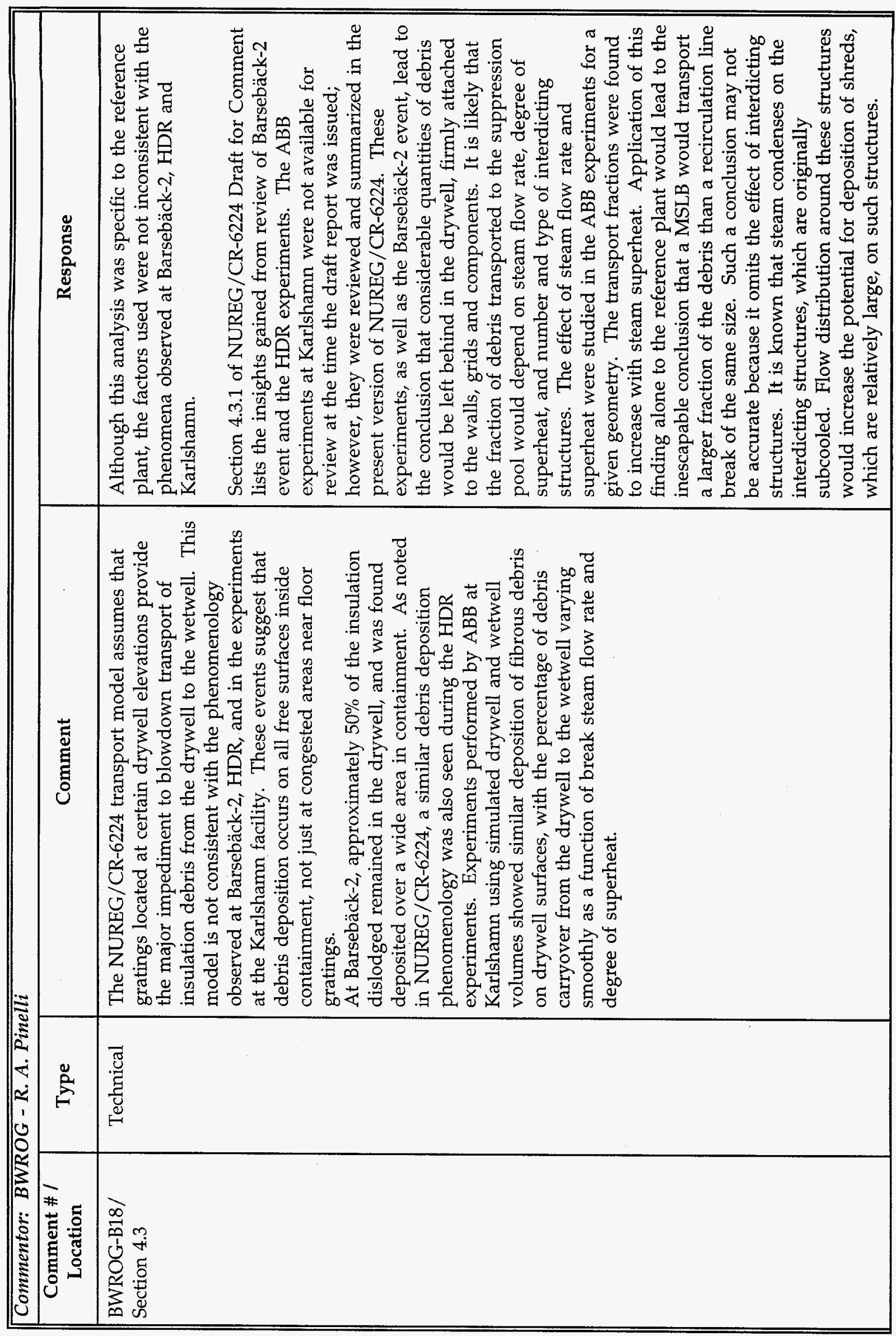




\begin{tabular}{|c|c|c|c|}
\hline \multicolumn{4}{|c|}{ Commentor: BWROG - R. A. Pinelli } \\
\hline $\begin{array}{c}\text { Comment \# I } \\
\text { Location }\end{array}$ & Type & Comment & Response \\
\hline $\begin{array}{l}\text { BWROG-B18 } \\
\text { (cont.) / }\end{array}$ & Technical & $\begin{array}{l}\text { Taken together, these events present a strong case that } \\
\text { separation and deposition of fibrous insulation debris } \\
\text { from the blowdown flow will occur on all free surfaces } \\
\text { in the drywell. A potential physical explanation for } \\
\text { this phenomenon is that: 1) separation occurs due to } \\
\text { the different density of the wet fibrous debris as the } \\
\text { blowdown flow is turned by obstructions, and 2) that } \\
\text { the fibrous debris then adheres to the surface to } \\
\text { varying extents based on the amount of condensate } \\
\text { present on the surfaces, initial "wetness" of the debris, } \\
\text { and perhaps surface roughness. The NUREG/CR-6224 } \\
\text { model should be modified to better reflect the } \\
\text { phenomenology observed at Barsebäck-2, HDR and } \\
\text { Karlshamn. }\end{array}$ & $\begin{array}{l}\text { Obviously, the larger and the rougher the area } \\
\text { offered by these structures, the larger the fraction } \\
\text { deposited in the drywell. It is then likely that a } \\
\text { MSLB located at a higher elevation may actually } \\
\text { transport a lower fraction of debris than a } \\
\text { recirculation break located at a lower elevation, } \\
\text { because steam flow from the former encounters a } \\
\text { larger interdicting area. None of the experiments } \\
\text { have attempted to quantify these separate effects. In } \\
\text { the absence of such studies, it was decided to use } \\
\text { engineering judgement to estimate individual } \\
\text { contributions of superheat and interdiction area and } \\
\text { conclude that since the drywell is very congested at } \\
\text { the gratings (offering large surface areas for } \\
\text { deposition of debris and significant alteration of flow } \\
\text { patterns) considerable condensation is expected on } \\
\text { these structures in spite of degrees of superheat } \\
\text { offered by a MSLB due to large thermal inertia of } \\
\text { these structures. Therefore, a transport fraction is } \\
\text { influenced more by the congested layout of the } \\
\text { drywell than the superheat. This judgement formed } \\
\text { the basis for the assumption that the transport } \\
\text { fraction is a function of drywell layout alone. }\end{array}$ \\
\hline
\end{tabular}




\begin{tabular}{|c|c|c|c|}
\hline \multicolumn{4}{|c|}{$\mid \begin{array}{l}\text { Commentor: BWROG - R. A. Pinelli } \\
\end{array}$} \\
\hline $\begin{array}{l}\text { Comment \# I } \\
\text { Location }\end{array}$ & Type & Comment & Response \\
\hline \multirow[t]{3}{*}{$\begin{array}{l}\text { BWROG-B19/ } \\
\text { Section } 4.3 .1 \\
\text { page } 4-21 \text { to } 4-22\end{array}$} & \multirow[t]{3}{*}{ Technical } & $\begin{array}{l}\text { The NUREG/CR- } 6224 \text { analysis of the Barsebäck-2 } \\
\text { incident does not properly reflect the impact of } \\
\text { containment spray operation. [Reference Section } 4.3 .1 \text {, } \\
\text { p.4-21 to } 4-22 \text { ] }\end{array}$ & $\begin{array}{l}\text { The impact of containment spray operation versus } \\
\text { other debris transport mechanisms is not clear in the } \\
\text { Barsebäck-2 incident, but the incident does illustrate } \\
\text { that a large fraction of debris can be transported to } \\
\text { the wetwell. NUREG/CR- } 6224 \text { was modified to } \\
\text { clarify this issue. }\end{array}$ \\
\hline & & $\begin{array}{l}\text { At Barsebäck-2, a "small break" (actually, the lifting of } \\
\text { a relief valve) occurred at a pressure below normal } \\
\text { operating system pressure. This "break" destroyed } \\
\text { mineral wool insulation in the jet flow, and distributed } \\
\text { it around the drywell volume. The NUREG/CR- } 6224 \\
\text { model assumes that the blowdown flow at Barsebäck-2 } \\
\text { was the dominant cause of the } 50 \% \text { debris carryover } \\
\text { observed from the drywell to the wetwell. This } \\
\text { interpretation of the Barsebäck-2 event is not credible. } \\
\text { Based on consideration of the small size of the "break" } \\
\text { (and the relatively small amount of energy available to } \\
\text { drive blowdown transport), it is unlikely that a } \\
\text { significant percentage of the destroyed insulation was } \\
\text { transported by the blowdown mass flow itself. This } \\
\text { expectation is corroborated by the results of tests } \\
\text { performed at Karlshamn, which showed very small } \\
\text { carryover fractions from a simulated drywell volume to } \\
\text { a simulated wetwell volume for small steam breaks. }\end{array}$ & $\begin{array}{l}\text { NUREG/CR- } 6224 \text { transport model does not assume } \\
\text { that the dominant cause for debris transport in } \\
\text { Barsebäck-2 event was blowdown. NUREG/CR- } 6224 \\
\text { Draft for Comment cited the Barsebäck-2 event to } \\
\text { simply illustrate the potential for transport of large } \\
\text { quantities of debris to the suppression pool. The } \\
\text { NUREG/CR-6224 transport model allows for } \\
\text { transport of debris in both blowdown and washdown } \\
\text { phases. Due to lack of experimental data however, } \\
\text { engineering judgement was used to estimate the } \\
\text { transport factors for each phase. This version of } \\
\text { NUREG/CR-6224 was modified to clarify this issue. }\end{array}$ \\
\hline & & $\begin{array}{l}\text { The NUREG/CR- } 6224 \text { debris transport model currently } \\
\text { does not properly consider the impact of containment } \\
\text { spray system operation during the Barsebäck-2 event. } \\
\text { The NUREG model should be altered to include a } \\
\text { more credible evaluation of the importance of } \\
\text { containment spray washdown effects. Also, the model } \\
\text { should reflect significant operating and design } \\
\text { differences between Barsebäck- } 2 \text { and the reference } \\
\text { Mark } 1 \text { plant analyzed in the NUREG. Some of the } \\
\text { differences that must be addressed include: }\end{array}$ & $\begin{array}{l}\text { NUREG/CR- } 6224 \text { addresses all the three issues listed } \\
\text { in the comment. For example, NUREG/CR- } 6224 \\
\text { recognizes that actuation of containment sprays in } \\
\text { the reference plant was not automatic and hence } \\
\text { debris transport due to sprays was not a part of the } \\
\text { base case. Similarly, credit was given for jacketed } \\
\text { NUKONTM vs mineral wool through the use of } \\
\text { destruction factors and limiting the zone of influence } \\
\text { to } 7 \mathrm{~L} / \mathrm{D} \text {. Note that zone of influence in Barsebäck-2 } \\
\text { extended far beyond } 7 \mathrm{~L} / \mathrm{D} \text { (by some plant estimates } \\
\text { up to } 20 \mathrm{~L} / \mathrm{D} \text { ). }\end{array}$ \\
\hline
\end{tabular}




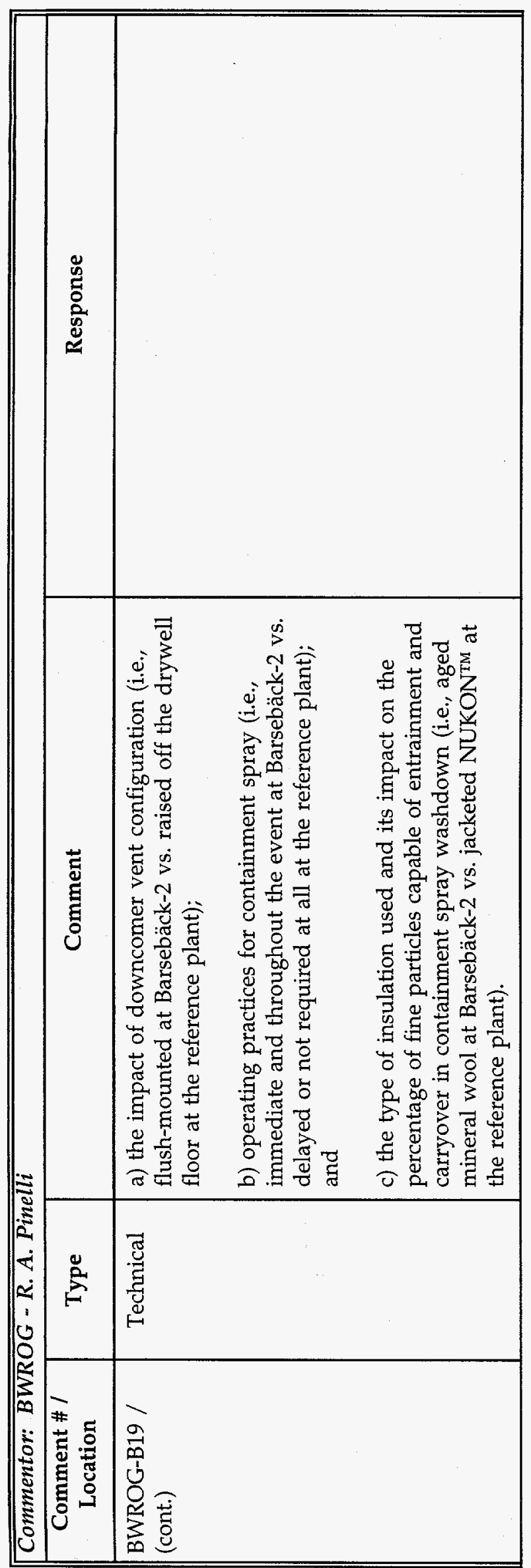




\begin{tabular}{|c|c|c|c|}
\hline \multicolumn{4}{|c|}{ Commentor: BWROG - R. A. Pinelli } \\
\hline $\begin{array}{c}\text { Comment \# / } \\
\text { Location }\end{array}$ & Type & Comment & Response \\
\hline $\begin{array}{l}\text { BWROG-B20/ } \\
\text { Section } 4.3\end{array}$ & Technical & $\begin{array}{l}\text { The NUREG/CR-6224 analysis assumes that blowdown } \\
\text { results in transport of a fixed fraction of the total } \\
\text { debris generated, independent of break size. } \\
\text { At a given location in the drywell, the NUREG model } \\
\text { predicts that the blowdown from a 2" line will result in } \\
\text { the same percentage of debris carryover to the wetwell } \\
\text { as will blowdown of a } 24 \text { " line, even though the } 24 " \\
\text { lines has hundreds of times more energy available to } \\
\text { drive the blowdown. This result cannot be correct. } \\
\text { Realistically, the percentage of debris transport by } \\
\text { blowdown from a } 2 " \text { line break will be negligible, as } \\
\text { the mass flow rate from the break is small compared to } \\
\text { the total volume of the drywell. Again, this } \\
\text { expectation is supported by the phenomenology } \\
\text { observed at Karlshamn by ABB. Extrapolation of } \\
\text { information from the events at Barsebäck-2 appears to } \\
\text { support the modeling decision in the NUREG. Since } \\
\text { the impact of containment spray operation was not } \\
\text { properly considered, the model was forced to fit an } \\
\text { approximate } 50 \% \text { blowdown fraction for a } 1.5 " \text { break, } \\
\text { rather than attributing the great majority of this } \\
\text { transport fraction to the effects of containment spray } \\
\text { washdown. } \\
\text { The NUREG/CR-6224 model assumes that break } \\
\text { leakage will result in transport of } 25 \% \text { of the debris } \\
\text { remaining in the drywell post-blowdown, independent } \\
\text { of the break size. As stated above, the fraction of } \\
\text { debris carried over by leakage out of the break must be } \\
\text { a function of the break size. Leakage flow rates from a } \\
2 " \text { line break are orders of magnitude smaller than } \\
\text { those from a } 24 " \text { line break. Since the "break" leakage } \\
\text { flow is the driving force for this component of the } \\
\text { transport, it is not credible to use one fixed transport } \\
\text { percentage, independent of break size. }\end{array}$ & $\begin{array}{l}\text { It is acknowledged that break sizes play a vital role } \\
\text { in transport of debris during both blowdown and } \\
\text { washdown phases. A conclusive set of experimental } \\
\text { data that could be used to quantify such dependence } \\
\text { was not available. Also, see response to comment } \\
\text { B-19 regarding other issues raised as part of this } \\
\text { comment. }\end{array}$ \\
\hline
\end{tabular}




\begin{tabular}{||l|l|l|l||}
\hline $\begin{array}{c}\text { Commentor: BWROG - R. A. Pinelli } \\
\text { Location }\end{array}$ & Type & \multicolumn{1}{|c|}{ Comment } & Response \\
\hline $\begin{array}{l}\text { BWROG-B21/ } \\
\text { Section 4.3.1 }\end{array}$ & Editorial & $\begin{array}{l}\text { Please provide the reference for the 1.5" diameter of the } \\
\text { Barsebäck-2 safety relief valve diaphragm rupture. }\end{array}$ & $\begin{array}{l}\text { The diameter of the rupture disk which burst at } \\
\text { Barsebäck-2 is 154 mm (6.06 inches) in accordance } \\
\text { with Appendix D of Draft 3 of the CSNI/PWG-1 } \\
\text { International Task Group Report, March 1995. }\end{array}$ \\
\hline $\begin{array}{l}\text { BWROG-B22/ } \\
\text { Section 4.3.2 }\end{array}$ & Technical & $\begin{array}{l}\text { In Section 4.3.2, please provide the reasoning behind } \\
\text { the increase in } \mathrm{T}_{\text {wd }} \text { for breaks in the higher elevations } \\
\text { of the drywell. }\end{array}$ & $\begin{array}{l}\text { The larger washdown transport factors for higher } \\
\text { elevations used in NUREG/CR-6224 Draft for } \\
\text { Comment were based on the assumption that 25\% of } \\
\text { the debris left behind after the blowdown will be } \\
\text { transported during washdown. The washdown } \\
\text { model was updated in this version of NUREG/CR- } \\
\text { 6224 and no longer uses higher washdown transport } \\
\text { factors for breaks located in higher elevations. }\end{array}$ \\
\hline
\end{tabular}




\begin{tabular}{|c|c|c|c|}
\hline \multicolumn{4}{|c|}{ Commentor: BWROG - R. A. Pinelli } \\
\hline $\begin{array}{l}\text { Comment \# I } \\
\text { Location }\end{array}$ & Type & Comment & Response \\
\hline $\begin{array}{l}\text { BWROG-B23/ } \\
\text { Section } 4.3\end{array}$ & Technical & $\begin{array}{l}\text { The analysis assumes that up to } 81 \% \text { of the insulation } \\
\text { debris generated will be transported to the suppression } \\
\text { pool. These values are overly conservative and are not } \\
\text { supported by any experimental or historical data. In } \\
\text { the event at Barsebäck-2, only } 50 \% \text { of the insulation } \\
\text { debris was transported to the suppression pool, and } \\
\text { the testing at HDR demonstrated that insulation debris } \\
\text { will be distributed throughout the containment. }\end{array}$ & $\begin{array}{l}\text { The drywell transport model for the reference plant } \\
\text { was modified since the publication of NUREG/CR- } \\
6224 \text { Draft for Comment. In this final version, the } \\
\text { total transport factors vary from } 25 \% \text { to } 75 \% \\
\text { depending on the relative location of the break in the } \\
\text { drywell. According to these analyses, breaks located } \\
\text { closest to the drywell floor transport } 75 \% \text { of the } \\
\text { generated debris to the suppression pool. These } \\
\text { estimates were judged to be bounding and are based } \\
\text { on engineering judgement necessitated by the lack of } \\
\text { experimental data. Reviewers' interpretation of the } \\
\text { Barsebäck-2 incident and conclusion that these } \\
\text { transport factors are overly conservative is not } \\
\text { necessarily accurate because: } \\
\text { 1. The break in the Barsebäck-2 event was at the } \\
\text { equivalent mid location, not the lowest location } \\
\text { for which a transport factor of } 75 \% \text { was used in } \\
\text { the present analysis. } \\
\text { 2. The majority of the transport in Barsebäck-2 } \\
\text { occurred during washdown which highlights the } \\
\text { potential that the transport fraction could have } \\
\text { been larger had it been proceeded by large } \\
\text { blowdown vapor flows. }\end{array}$ \\
\hline $\begin{array}{l}\text { BWROG-B24/ } \\
\text { Section } 4.4\end{array}$ & Technical & $\begin{array}{l}\text { The timing for introduction of debris to the } \\
\text { suppression pool should be modified to correctly } \\
\text { reflect a revised model of blowdown versus } \\
\text { containment spray washdown transport, as noted in } \\
\text { previous comments. In particular, the time when } \\
\text { operation of containment spray may occur should be } \\
\text { factored into the source term for introduction of debris } \\
\text { into the suppression pool. }\end{array}$ & $\begin{array}{l}\text { Initiation of the containment spray is not automatic at } \\
\text { the reference plant. Hence, transport by containment } \\
\text { sprays was not included in estimating the quantity of } \\
\text { debris transported during washdown. Therefore, } \\
\text { time scales of debris transport due to washdown by } \\
\text { containment sprays was not explicitly discussed. } \\
\text { NUREG/CR-6224 was modified to clarify this issue. }\end{array}$ \\
\hline
\end{tabular}




\begin{tabular}{|c|c|c|c|}
\hline \multicolumn{4}{|c|}{ Commentor: BWROG - R. A. Pinelli } \\
\hline $\begin{array}{l}\text { Comment \# I } \\
\text { Location }\end{array}$ & Type & Comment & Response \\
\hline $\begin{array}{l}\text { BWROG-B25/ } \\
\text { Appendix B }\end{array}$ & Technical & $\begin{array}{l}\text { The complexity of the pool transport model would } \\
\text { seem unwarranted in light of the numerous } \\
\text { engineering judgements and soft assumptions required. } \\
\text { Many of the semi-empirical constants introduced in the } \\
\text { model have little or no chance of experimental } \\
\text { evaluation. }\end{array}$ & $\begin{array}{l}\text { Individual plants are not prohibited from using a less } \\
\text { complex solution for this issue. The authors agree } \\
\text { that there were uncertainties associated with the pool } \\
\text { transport models. As a result, parametric studies } \\
\text { were performed and have been added to } \\
\text { NUREG/CR-6224. Also, these transport models were } \\
\text { revised to reflect important insights gained from the } \\
\text { suppression pool experiments sponsored by NRC to } \\
\text { study debris transport in a turbulent suppression } \\
\text { pool after a LOCA. }\end{array}$ \\
\hline $\begin{array}{l}\text { BWROG-B26/ } \\
\text { Appendix B } \\
\text { page B2 } \\
\text { 2nd paragraph } \\
\text { last sentence }\end{array}$ & Editorial & $\begin{array}{l}\text { At the end of the second paragraph on page B-2 of } \\
\text { Appendix B, consider replacing "...resuspension of } \\
\text { suppression pool sludge." with "the continued } \\
\text { suspension of suppression pool sludge initially } \\
\text { suspended by pool swell." }\end{array}$ & $\begin{array}{l}\text { NUREG/CR- } 6224 \text { was modified to reflect this } \\
\text { comment. }\end{array}$ \\
\hline $\begin{array}{l}\text { BWROG-B27/ } \\
\text { Appendix B } \\
\text { page B-4 } \\
\text { 1st paragraph }\end{array}$ & Editorial & $\begin{array}{l}\text { In the first paragraph on page B-4 of Appendix B, } \\
\text { consider replacing "the drag" with "the fluid velocity" } \\
\text { in the sentence beginning "Also, if pool recirculation } \\
\text { velocities..." Additionally, eliminate "small" as an } \\
\text { adjective characterizing the portion of sediment } \\
\text { resuspended and transported. }\end{array}$ & $\begin{array}{l}\text { NUREG/CR-6224 was modified to reflect this } \\
\text { comment. }\end{array}$ \\
\hline $\begin{array}{l}\text { BWROG-B28/ } \\
\text { Appendix B } \\
\text { page B-6 } \\
\text { sentence follow- } \\
\text { ing Equ. } 3\end{array}$ & Editorial & $\begin{array}{l}\text { In the sentence following equation (3) on page B- } 6 \text { of } \\
\text { Appendix B, please provide a reference(s) for the } \\
\text { experiments which revealed the strong influence of } \eta \\
\text { on pressure drop. }\end{array}$ & $\begin{array}{l}\text { NUREG/CR- } 6224 \text { was modified to reflect this } \\
\text { comment. }\end{array}$ \\
\hline $\begin{array}{l}\text { BWROG-B29/ } \\
\text { Appendix B } \\
\text { Section B.2.1 } \\
\text { 4th sentence }\end{array}$ & Editorial & $\begin{array}{l}\text { Appendix B, Section B.2.1: In the fourth sentence, } \\
\text { please characterize or provide a relative order of } \\
\text { magnitude for "prolonged periods of time." The length } \\
\text { of a prolonged period is not intuitively obvious to the } \\
\text { reader (i.e., is it on the order of } 1 \text { minutes, } 1 \text { hour, } 1 \\
\text { day?). }\end{array}$ & $\begin{array}{l}\text { Figure B-7 provides quantitative information about } \\
\text { the relative settling velocities (and therefore times) } \\
\text { for classes } 3 \& 4 \text { and } 5 \& 6 .\end{array}$ \\
\hline
\end{tabular}




\begin{tabular}{|c|c|c|c|}
\hline \multicolumn{4}{|c|}{ Commentor: BWROG - R.A. Pinelli } \\
\hline $\begin{array}{l}\text { Comment \# / } \\
\text { Location }\end{array}$ & Type & Comment & Response \\
\hline $\begin{array}{l}\text { BWROG-B30/ } \\
\text { Appendix B } \\
\text { Section B.2.2 }\end{array}$ & Technical & $\begin{array}{l}\text { Appendix B, Section B.2.2: The mathematical basis for } \\
\text { equations } 6 \text { and } 7 \text { is not obvious. Why isn't } \\
\qquad g^{1}(t)=\frac{1}{T} \\
\text { for } 0<t<T \text {, as } T \Rightarrow 0 \text { worst case. }\end{array}$ & $\begin{array}{l}\text { Numerical implementation of Equations } 6 \& 7 \\
\text { simulate the special case under discussion, i.e., } 100 \% \\
\text { of the destructed debris are Class I and } 100 \% \text { of that } \\
\text { debris reaches the suppression pool within } 1 \mathrm{sec} \text { after } \\
\text { the LOCA. Relative to the problem time scale } 1 \mathrm{sec} \\
\text { is short enough to be considered instantaneous. } \\
\mathrm{g}^{1}(\mathrm{t})=1 / \mathrm{T} \text { is inaccurate since } \int \mathrm{g}(\mathrm{t}) \mathrm{dt} \text { should not } \\
\text { exceed } 1 \text {. }\end{array}$ \\
\hline $\begin{array}{l}\text { BWROG-B31/ } \\
\text { Appendix B } \\
\text { Section B. } 2.3\end{array}$ & Editorial & $\begin{array}{l}\text { Appendix B, Section B.2.3: With respect to the phrase } \\
\text { "not intended to be mechanistic" in the first paragraph, } \\
\text { it is not clear that we should then use the model. It } \\
\text { must have some physical basis. }\end{array}$ & $\begin{array}{l}\text { NUREG/CR-6224 was modified to reflect this } \\
\text { comment. }\end{array}$ \\
\hline $\begin{array}{l}\text { BWROG-B32/ } \\
\text { Appendix B } \\
\text { Section B.2.3 }\end{array}$ & Technical & $\begin{array}{l}\text { Appendix B, Section B.2.3: With respect to the } \\
\text { instantaneous resuspension of sludge, all the mass is } \\
\text { not resuspended as claimed since: } \\
\qquad \frac{d M_{\text {pool }}^{I}}{d t}=M_{\text {Reslspension }}^{I} \\
\qquad M_{\text {pool }}^{I}=M_{\text {Resuspension }}(0) e^{-k r t} \text { for } 0<t<1 \mathrm{sec} \text {. }\end{array}$ & $\begin{array}{l}\text { Numerical implementation of Eq. } 9 \text { assumes that all } \\
\text { the sludge mass is resuspended within a second. } \\
\text { Relative to the time scales of the present problem, } 1 \\
\text { sec is short enough to be approximated as } \\
\text { instantaneous. }\end{array}$ \\
\hline
\end{tabular}


Appendix $\mathrm{F}$

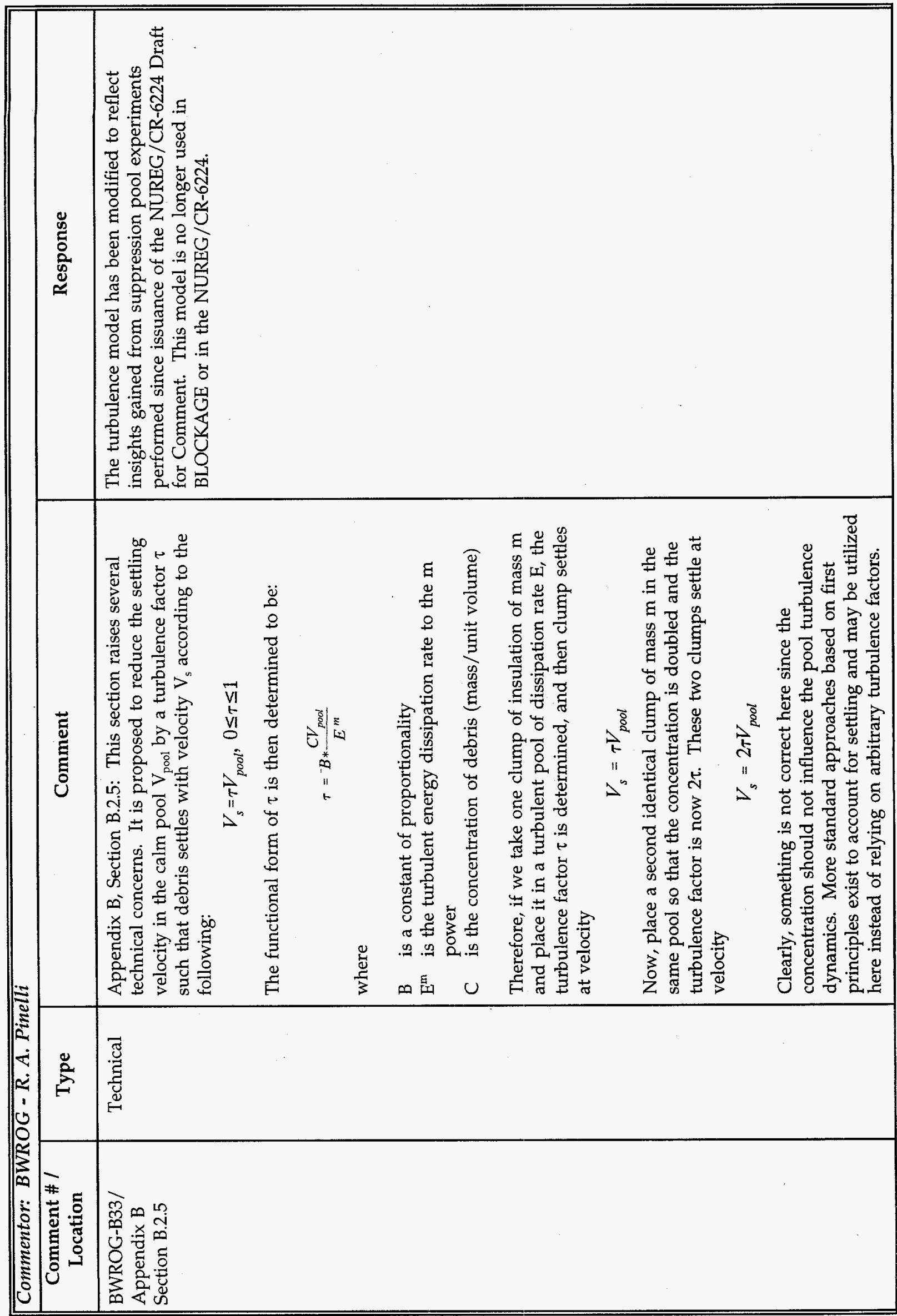




\begin{tabular}{|c|c|c|c|}
\hline \multicolumn{4}{|c|}{ Commentor: BWROG - R. A. Pinelli } \\
\hline $\begin{array}{l}\text { Comment \# I } \\
\text { Location }\end{array}$ & Type & Comment & Response \\
\hline $\begin{array}{l}\text { BWROG-B34/ } \\
\text { Appendix B } \\
\text { Section B. } 2.6\end{array}$ & Technical & $\begin{array}{l}\text { Appendix B, Section B.2.6: The possibility of } \\
\text { determining the constants } D_{I-I} \text { and } D_{I-J} \text {, which transfer } \\
\text { mass of one class to another during the high energy } \\
\text { phase is remote at best. Can insulation to the pool be } \\
\text { estimated by a factor of } 2 \text { ? }\end{array}$ & $\begin{array}{l}\text { It is difficult to estimate } D_{\mathrm{JI}} \text { and } D_{\mathrm{IJ}-} \text {. No plans exist } \\
\text { to obtain these values theoretically or experimentally } \\
\text { at the present time. As a result, these constants were } \\
\text { removed from the revised NUREG/CR-6224. }\end{array}$ \\
\hline $\begin{array}{l}\text { BWROG-B35/ } \\
\text { Appendix B } \\
\text { Section B.2.8.1 }\end{array}$ & Editorial & $\begin{array}{l}\text { Appendix B, Section B.2.8.1: This section, "Empirical } \\
\text { Equation for Head loss," is mislabeled in that the } \\
\text { discussion is a general derivation of head loss across } \\
\text { fibrous beds. }\end{array}$ & $\begin{array}{l}\text { After further review, it was determined that the } \\
\text { section labeling was appropriate since it deals only } \\
\text { with the development of the empirical equation. }\end{array}$ \\
\hline $\begin{array}{l}\text { BWROG-B36/ } \\
\text { Appendix B } \\
\text { Section B.2.8.1 }\end{array}$ & Editorial & $\begin{array}{l}\text { Appendix B, Section B.2.8.1: Regarding the definition } \\
\text { of parameters used in equation (24), the units of } \Delta \mathrm{H} \\
\text { and } \Delta \mathrm{L} \text { should be the same. }\end{array}$ & Units are correct as stated. \\
\hline $\begin{array}{l}\text { BWROG-B37/ } \\
\text { Appendix B } \\
\text { Section B.2.8.2 }\end{array}$ & Editorial & $\begin{array}{l}\text { Appendix B, Section B.2.8.2: Identify the units for V } \\
\text { for consistency with definitions of other parameters. } \\
\text { However, units would not seem to matter since } a(\varepsilon) \\
\text { and } b(\varepsilon) \text { are yet to be defined. }\end{array}$ & $\begin{array}{l}\text { NUREG/CR-6224 was modified to reflect this } \\
\text { comment. }\end{array}$ \\
\hline $\begin{array}{l}\text { BWROG-B38/ } \\
\text { Appendix B } \\
\text { Section B.2.8.2 }\end{array}$ & Editorial & $\begin{array}{l}\text { Appendix B, Section B.2.8.2: } 7.112 \mu \mathrm{m} \text { appears to be a } \\
\text { very large fiber diameter. Please provide the basis for } \\
\text { this value. }\end{array}$ & $\begin{array}{l}\text { A reference for the properties of NUKONTM was } \\
\text { added to NUREG/CR-6224. }\end{array}$ \\
\hline $\begin{array}{l}\text { BWROG-B39/ } \\
\text { Appendix B } \\
\text { Section B.2.8.2 } \\
\text { equation } 31\end{array}$ & Editorial & $\begin{array}{l}\text { Appendix B, Section B.2.8.2: Does the fact that } \\
\text { equation (31) follows the statement that all units are in } \\
\text { C.G.S. units indicate that equation (31) is not in C.G.S. } \\
\text { units? }\end{array}$ & $\begin{array}{l}\text { Yes. Equation } 31 \text { is in the same units as Equation } 24 \text {. } \\
\text { NUREG/CR-6224 was modified to reflect this } \\
\text { comment. }\end{array}$ \\
\hline $\begin{array}{l}\text { BWROG-B40/ } \\
\text { Appendix B } \\
\text { Section B.2.8.2 } \\
\text { last paragraph } \\
\text { first sentence }\end{array}$ & Editorial & $\begin{array}{l}\text { Appendix B, Section B.2.8.2: Regarding the first } \\
\text { sentence of the last paragraph, a comparison between } \\
\text { equations (31) and (24) is not intuitively obvious to the } \\
\text { reader. The } \pm 20 \% \text { would appear reasonable only if } \\
\mu=1 \text {. }\end{array}$ & $\begin{array}{l}\text { The factor } \mu \text { should not be included in Equation } 31 \text {. } \\
\text { NUREG/CR- } 6224 \text { was modified to reflect this } \\
\text { comment. }\end{array}$ \\
\hline
\end{tabular}




\begin{tabular}{|c|c|c|c|}
\hline \multicolumn{4}{|c|}{ Commentor: BWROG - R. A. Pinelli } \\
\hline $\begin{array}{c}\text { Comment \# I } \\
\text { Location }\end{array}$ & Type & Comment & Response \\
\hline $\begin{array}{l}\text { BWROG-B41/ } \\
\text { Appendix B } \\
\text { Section B.2.8.3 }\end{array}$ & Technical & $\begin{array}{l}\text { Appendix B, Section B.2.8.3: With respect to the "Bed } \\
\text { Compressibility" section, the reason for placing } \\
\text { emphasis on a parameter with an approximate } 15 \% \\
\text { effect is unclear, especially considering the uncertainty } \\
\text { in other parameters. Can head loss be estimated to } \\
15 \% \text { ? Can insulation dislodgement be estimated to a } \\
\text { factor of } 2 \text { ? }\end{array}$ & $\begin{array}{l}\text { The intent of B. } 2.8 .3 \text { was to examine if } \\
\text { compressibility is important or not. It was not to } \\
\text { emphasize the importance of compressibility. }\end{array}$ \\
\hline $\begin{array}{l}\text { BWROG-B42/ } \\
\text { Appendix B } \\
\text { Section B.2.8.3 }\end{array}$ & Technical & $\begin{array}{l}\text { Appendix B, Section B.2.8.3: The section addressing } \\
\text { "Filtration of Particulates" presents a formula for } \\
\text { deriving the effective porosity, } \varepsilon_{1} \text {, using the particulate } \\
\text { mass retained by the fiber bed, } \mathrm{M}_{\mathrm{p}} \text {. Realistically, } \mathrm{M}_{\mathrm{p}} \\
\text { cannot be determined. }\end{array}$ & $\begin{array}{l}\text { Based on head loss and filtration experiments } \\
\text { conducted as part of this study a filtration model was } \\
\text { developed to estimate } M_{p} \text { as a function of sludge } \\
\text { density. NUREG/CR- } 6224 \text { has been revised to } \\
\text { include these details. }\end{array}$ \\
\hline $\begin{array}{l}\text { BWROG-B43/ } \\
\text { Appendix B } \\
\text { Section B.2.8.3 }\end{array}$ & Technical & $\begin{array}{l}\text { Appendix B, Section B.2.8.3: Regarding the section } \\
\text { addressing "Filtration of Particulates," it is difficult to } \\
\text { envision how the analysis can be used with data for } \\
\text { validation. Specifically, to estimate the increase in } \\
\text { head loss resulting from particulates in a fibrous bed, } \\
\text { the derivation requires that the analyst know } \eta \text {, the } \\
\text { ratio of mass of particulates on the bed to the mass of } \\
\text { fiber in the bed. We have no knowledge of the mass } \\
\text { of particulates which is actually in the bed, and only } \\
\text { know from experiments the mass of particulates which } \\
\text { approach the bed. Some of the particulates } \\
\text { approaching the bed will pass through the bed and } \\
\text { some will be trapped in the bed. }\end{array}$ & $\begin{array}{l}\text { Experiments were conducted as part of this study to } \\
\text { estimate filtration efficiency of the fiber beds. These } \\
\text { efficiencies were used to estimate } \eta \text {. As with any } \\
\text { experimentally measured variables, there are } \\
\text { uncertainties associated with these efficiencies. }\end{array}$ \\
\hline $\begin{array}{l}\text { BWROG-B44/ } \\
\text { Section } 4.5 .2 \\
\text { 2nd paragraph } \\
\text { ref. } 15 \& 16\end{array}$ & Editorial & $\begin{array}{l}\text { In the second paragraph of Section } 4.5 .2 \text {, references } \\
\# 4.15 \text { and } 4.16 \text { appear to be reversed. }\end{array}$ & $\begin{array}{l}\text { NUREG/CR-6224 was modified to reflect this } \\
\text { comment. }\end{array}$ \\
\hline
\end{tabular}




\begin{tabular}{|c|c|c|c|}
\hline \multicolumn{4}{|c|}{ Commentor: BWROG - R. A. Pinelli } \\
\hline $\begin{array}{l}\text { Comment \# I } \\
\text { Location }\end{array}$ & Type & Comment & Response \\
\hline $\begin{array}{l}\text { BWROG-B45/ } \\
\text { Section } 4.5 .2 \\
\text { page } 4-28 \\
\text { equ. } 12\end{array}$ & Technical & $\begin{array}{l}\text { In Section } 4.5 .2 \text {, equation } \# 4.12 \text { on page } 4-28 \text { needs to } \\
\text { be benchmarked against experimental data such as PCI } \\
\text { testing at ARL in 1994, PP\&L testing at ARL in 1994, or } \\
\text { CDI testing for BWROG in } 1994 \text {. The assumption that } \\
100 \% \text { filtration efficiency for bed thicknesses }>1 \mathrm{~mm} \\
\text { appears to be overly conservative and would appear to } \\
\text { conflict with experimental data. }\end{array}$ & $\begin{array}{l}\text { NUREG/CR- } 6224 \text { was revised to include these } \\
\text { comparisons. Also, this version of NUREG/CR- } 6224 \\
\text { incorporated a revised filtration model based on new } \\
\text { experimental data obtained as part of the NRC } \\
\text { experiments. }\end{array}$ \\
\hline $\begin{array}{l}\text { BWROG-B46/ } \\
\text { Section } 4.5 .2 \\
\text { last paragraph }\end{array}$ & Editorial & $\begin{array}{l}\text { Please provide a reference for the Swedish data } \\
\text { mentioned in the last paragraph of Section } 4.5 .2 \text {. }\end{array}$ & $\begin{array}{l}\text { NUREG/CR- } 6224 \text { was modified to reflect this } \\
\text { comment. }\end{array}$ \\
\hline $\begin{array}{l}\text { BWROG-B47/ } \\
\text { Appendix B } \\
\text { Section B2.8.1 } \\
\text { equ. } 24\end{array}$ & Editorial & $\begin{array}{l}\text { With respect to Section B2.8.1 of Appendix B, the } \\
\text { BWROG data appears to be consistent with that } \\
\text { conservatively predicted by equation \#B-24, as opposed } \\
\text { to "validating" the correlation. }\end{array}$ & $\begin{array}{l}\text { NUREG/CR- } 6224 \text { was modified to reflect this } \\
\text { comment. }\end{array}$ \\
\hline $\begin{array}{l}\text { BWROG-B48/ } \\
\text { Appendix B } \\
\text { Section B2.8.3 }\end{array}$ & Editorial & $\begin{array}{l}\text { Comments should be added to Section B. } 2.8 .3 \text { of } \\
\text { Appendix B to reference emergent work in progress } \\
\text { which will provide more information regarding the } \\
\text { effects of particulates, including size, fiber thickness, } \\
\text { partial loading, etc. }\end{array}$ & $\begin{array}{l}\text { Appendix B has been modified to include up-to-date } \\
\text { information obtained from studies and experimental } \\
\text { data publicly available as of April } 1995 \text {. }\end{array}$ \\
\hline $\begin{array}{l}\text { BWROG-B49/ } \\
\text { Section } 4.5 .4 \\
\text { Fig. } 16,17 \& 18\end{array}$ & Editorial & $\begin{array}{l}\text { In Section } 4.5 .4 \text {, the referenced figures \#3-16 and \#3-17 } \\
\text { should be \#3-17 and \#3-18, respectively. Also, contrary } \\
\text { to the test, the available NPSH is not shown on these } \\
\text { figures. Further, Section } 4.5 .4 \text { implies a required NPSH } \\
\text { of } 15 \mathrm{ft} . \text {, whereas Figure \#3-18 indicates that } 10 \mathrm{ft} \text {. was } \\
\text { used. }\end{array}$ & $\begin{array}{l}\text { NUREG/CR- } 6224 \text { was modified to reflect this } \\
\text { comment. }\end{array}$ \\
\hline
\end{tabular}




\begin{tabular}{|c|c|c|c|}
\hline \multicolumn{4}{|c|}{ Commentor: BWROG - R. A. Pinelli } \\
\hline $\begin{array}{c}\text { Comment \# / } \\
\text { Location }\end{array}$ & Type & Comment & Response \\
\hline $\begin{array}{l}\text { BWROG-B50/ } \\
\text { Section } 4.5 .2 \\
\text { equ. } 11 \& 12\end{array}$ & Editorial & $\begin{array}{l}\text { In Section } 4.5 .2, \text { it is not clear whether the delta-H } \\
\text { determined using equations } \# 4.11 \text { and } \# 4.12 \text { utilized the } \\
\text { actual pool water temperature. Please indicate the pool } \\
\text { water temperature used and the basis for this selection. }\end{array}$ & $\begin{array}{l}\text { The value of } 120^{\circ} \mathrm{F} \text { was a typographical error. It } \\
\text { should read } 180^{\circ} \mathrm{F} \text {. According to Reg. Guide } 1-1 \text {, the } \\
\text { NPSH should be calculated using atmospheric } \\
\text { pressure and most severe suppression pool } \\
\text { temperature. For the reference plant the most severe } \\
\text { suppression pool temperature was estimated to be } \\
180^{\circ} \mathrm{F} \text { based on discussions with the plant systems } \\
\text { engineers. }\end{array}$ \\
\hline $\begin{array}{l}\text { BWROG-B51/ } \\
\text { Section } 4.5 .4\end{array}$ & Technical & $\begin{array}{l}\text { In Section } 4.5 .4 \text {, please explain the basis for using the } \\
120^{\circ} \text { pool water temperature for available NPSH. }\end{array}$ & $\begin{array}{l}\text { The value of } 120^{\circ} \mathrm{F} \text { was a typographical error. It } \\
\text { should read } 180^{\circ} \mathrm{F} \text {. According to Reg. Guide } 1-1 \text {, the } \\
\text { NPSH should be calculated using atmospheric } \\
\text { pressure and most severe suppression pool } \\
\text { temperature. For the reference plant the most severe } \\
\text { suppression pool temperature was estimated to be } \\
180^{\circ} \mathrm{F} \text { based on discussions with the plant systems } \\
\text { engineers. }\end{array}$ \\
\hline BWROG-B52/ & Technical & $\begin{array}{l}\text { The report states that the available NPSH for } \\
\text { atmospheric containment pressure and } 120^{\circ} \mathrm{F} \text { pool } \\
\text { temperature is } 24 \text { feet of water for RHR and } 32 \text { feet of } \\
\text { water for CS. These values are incorrect for } 120^{\circ} \mathrm{F} \text { pool } \\
\text { temperature at the reference plant. The actual values } \\
\text { for } 120^{\circ} \mathrm{F} \text { should be greater than } 35 \text { feet of water. }\end{array}$ & $\begin{array}{l}\text { The values } 24 \mathrm{ft} \text { and } 32 \mathrm{ft} \text { correspond to a pool } \\
\text { temperature of } 180^{\circ} \mathrm{F} \text {. Refer to the response to } \\
\text { comment BWROG-B3 for additional details on how } \\
\text { they were estimated. }\end{array}$ \\
\hline $\begin{array}{l}\text { BWROG-B53/ } \\
\text { Section 5.1.1 }\end{array}$ & Editorial & $\begin{array}{l}\text { In Section 5.1.1, please provide the basis for using } 2.6 \\
\text { cu. } \mathrm{ft} \text {. of suppression pool sludge for the reference } \\
\text { plant. }\end{array}$ & $\begin{array}{l}\text { During the May } 4,1994 \text { meeting between members of } \\
\text { the BWROG and NRC, the BWROG suggested that } \\
\text { quantity of sludge may vary from } 70-5000 \mathrm{lbm} \\
\text { depending on the plant. After discussing with the } \\
\text { reference plant personnel, a value of } 850 \mathrm{lbm} \text { was } \\
\text { judged to be appropriate for the reference plant. This } \\
\text { value translated into } 2.6 \mathrm{ft}^{3} \text { using density for iron } \\
\text { oxide of } 324 \mathrm{lbm} / \mathrm{ft}^{3} \text {. }\end{array}$ \\
\hline
\end{tabular}




\begin{tabular}{|c|c|c|c|}
\hline \multicolumn{4}{|c|}{ Commentor: BWROG - R. A. Pinelli } \\
\hline $\begin{array}{l}\text { Comment \# / } \\
\text { Location }\end{array}$ & Type & Comment & Response \\
\hline $\begin{array}{l}\text { BWROG-B54/ } \\
\text { Section 4.5.4 } \\
\text { Table 5-2 }\end{array}$ & Editorial & $\begin{array}{l}\text { Table } 5-2 \text { notes that NPSH for the reference plant was } \\
\text { calculated at } 170^{\circ} \mathrm{F} \text {. This is inconsistent with Section } \\
4.5 .4 \text { which indicates that available head is calculated at } \\
120^{\circ} \mathrm{F} \text {. }\end{array}$ & $\begin{array}{l}\text { This was a typographical error. The report has been } \\
\text { revised to reflect a pool temperature of } 180^{\circ} \mathrm{F} \text {. }\end{array}$ \\
\hline $\begin{array}{l}\text { BWROG-B55/ } \\
\text { Section } 5.1 .3 \\
\text { last sentence }\end{array}$ & Editorial & $\begin{array}{l}\text { Regarding the last sentence of Section } 5.1 .3 \text {, it is our } \\
\text { understanding that the Barsebäck- } 2 \text { incident was not a } \\
\text { "particulate" flow blockage event. Please provide the } \\
\text { basis for this position. }\end{array}$ & $\begin{array}{l}\text { Section } 5 \text { has been revised and the referenced } \\
\text { statement was deleted. }\end{array}$ \\
\hline
\end{tabular}




\begin{tabular}{|c|c|c|c|}
\hline \multicolumn{4}{|c|}{ Commentor: BWROG - R. A. Pinelli } \\
\hline $\begin{array}{l}\text { Comment \# I } \\
\text { Location }\end{array}$ & Type & Comment & Response \\
\hline $\begin{array}{l}\text { BWROG-B56/ } \\
\text { Section } 5.2 \\
\text { Item } 3\end{array}$ & Technical & $\begin{array}{l}\text { With respect to the conclusion drawn in item } 3 \text { that the } \\
\text { use of a } 3 \mathrm{~L} / \mathrm{D}, 100 \% \text { transport model assumption is } \\
\text { essentially equivalent to the more complicated } 7 \mathrm{~L} / \mathrm{D} \\
\text { model, can one conclude that the models result in the } \\
\text { same amount of debris? If so, would the } 3 \mathrm{~L} / \mathrm{D} \text { model } \\
\text { be acceptable for performing plant-specific analyses? If } \\
\text { not, the purpose of the comparison between the two } \\
\text { models is not apparent. }\end{array}$ & $\begin{array}{l}\text { The origin of case \#3, "Break Zone of Destruction } \\
\text { Reduced to } 3 \mathrm{~L} / \mathrm{D} \text { ", was at the March } 30,1994 \text { NRC } \\
\text { Public Meeting. In that meeting, it was suggested } \\
\text { that a possible simple alternate to the base case is } \\
\text { complete destruction and transport of all insulation } \\
\text { contained within } 3 \mathrm{~L} / \mathrm{D} \text { to the suppression pool } \\
\text { instantaneously after the accident. Case \#3 was } \\
\text { developed to examine the impact of such } \\
\text { assumptions for the reference plant and provide } \\
\text { limited insights. The fact that case \#3 predictions are } \\
\text { closer to the base case for the reference plant should } \\
\text { not be used as a sole justification to generalize and } \\
\text { use "3 L/D model". For example, in a different plant } \\
\text { the transport factors may be different from those } \\
\text { assumed for the base case, which would then allow } \\
\text { for smaller quantity of debris being transported in } \\
\text { the base case as compared to the "3 L/D model". } \\
\text { The debris generation model should be reviewed if } \\
\text { the insulation used in the plant is different from the } \\
\text { steel jacketed NUKONM employed in the reference } \\
\text { plant. Thus, it is strongly recommended that the } \\
\text { analyst perform independent analyses specific to each } \\
\text { plant to evaluate the applicability of debris } \\
\text { generation model to that plant. The } 3 \mathrm{~L} / \mathrm{D} \text { case was } \\
\text { examined for illustrative purposes only and is no } \\
\text { longer discussed in this final version of NUREG/CR- } \\
6224 \text {. }\end{array}$ \\
\hline
\end{tabular}




\begin{tabular}{|c|c|c|c|}
\hline \multicolumn{4}{|c|}{$\overline{\text { inelli }}$} \\
\hline $\begin{array}{l}\text { Comment \# I } \\
\text { Location }\end{array}$ & Type & Comment & Response \\
\hline $\begin{array}{l}\text { BWROG-B57/ } \\
\text { Section 6.1 } \\
\text { page 6-1 }\end{array}$ & Technical & $\begin{array}{l}\text { Section } 6.1 \text {, Page } 6-1 \text { : In addition to the frequency of a } \\
\text { LOCA, the break location is also important because it } \\
\text { affects the time available to the operator for alignment } \\
\text { of alternate means of injecting water into the reactor } \\
\text { vessel. Different break locations would be expected to } \\
\text { have different frequencies. }\end{array}$ & $\begin{array}{l}\text { It is acknowledged that break location has an } \\
\text { influence on the time available for an operator to } \\
\text { align an alternate means of injection. However, an } \\
\text { analysis of the timing associated with various break } \\
\text { locations would have required a number of detailed } \\
\text { plant-specific deterministic analyses. The overall } \\
\text { objective of the NUREG/CR-6224 event tree model } \\
\text { was to provide a scoping estimate of the CDF related } \\
\text { to ECCS NPSH loss. Therefore, consideration of } \\
\text { timing differences among different break locations } \\
\text { was beyond the scope of the study. Note that the } \\
\text { non-recovery data used in the event tree model was } \\
\text { extracted from the reference plant IPE. The IPE did } \\
\text { not distinguish among the various possible break } \\
\text { locations, but instead used a single value to represent } \\
\text { the probability of unsuccessful alternate injection for } \\
\text { all large LOCA breaks. Use of a single failure } \\
\text { probability for all large LOCA break locations is } \\
\text { consistent with the reference plant IPE. }\end{array}$ \\
\hline $\begin{array}{l}\text { BWROG-B58/ } \\
\text { Chapter } 6\end{array}$ & Technical & $\begin{array}{l}\text { It appears as if the event trees were solved by simply } \\
\text { multiplying the function probabilities across. If this is } \\
\text { so, add the assumption that the functions included in } \\
\text { the event trees are independent of each other and have } \\
\text { no basic events or human interactions in common. }\end{array}$ & $\begin{array}{l}\text { The event trees were solved by multiplying the } \\
\text { function probabilities. The simplified model used in } \\
\text { NUREG/CR- } 6224 \text { did assume independence among } \\
\text { the various functions. NUREG/CR- } 6224 \text { was revised } \\
\text { to reflect this comment. }\end{array}$ \\
\hline $\begin{array}{l}\text { BWROG-B59/ } \\
\text { Chapter } 6\end{array}$ & Technical & $\begin{array}{l}\text { Point-value estimates were developed in the CDF } \\
\text { estimates. As no uncertainty analysis was performed, } \\
\text { the significance of these estimates are subject to } \\
\text { interpretation. Moreover, it appears that conservative } \\
\text { assumptions are implicit in these estimates. The } \\
\text { analyses should be expanded so as to develop the true } \\
\text { range of CDF values, and the more significant } \\
\text { contributions. }\end{array}$ & $\begin{array}{l}\text { The development of an uncertainty analysis was } \\
\text { beyond the scope of the CDF analysis. }\end{array}$ \\
\hline
\end{tabular}




\begin{tabular}{|c|c|c|c|}
\hline $\begin{array}{l}\text { Comment \# I } \\
\text { Location }\end{array}$ & Type & Comment & Response \\
\hline $\begin{array}{l}\text { BWROG-B60/ } \\
\text { Figure } 6-1\end{array}$ & Technical & $\begin{array}{l}\text { The event tree in Figure } 6-1 \text { gives an unrealistically low } \\
\text { probability of the operators recognizing strainer } \\
\text { blockage. The operators at the reference plant have } \\
\text { been trained on recognizing strainer blockage and have } \\
\text { procedures which provide guidance on strainer } \\
\text { blockage. Simulator scenarios at the reference plant } \\
\text { have demonstrated that operators will recognize } \\
\text { strainer blockage in nearly all instances. }\end{array}$ & $\begin{array}{l}\text { At the time of the plant visit, it was understood that } \\
\text { operators at the reference plant were not formally } \\
\text { trained to recognize strainer blockage. Given the } \\
\text { time scale for strainer blockage, it is unlikely the } \\
\text { operators would recognize the situation with } \\
\text { sufficient time to effectively respond. }\end{array}$ \\
\hline $\begin{array}{l}\text { BWROG-B61/ } \\
\text { Section } 6.2 .1 \\
\text { Figure } 6-1\end{array}$ & Technical & $\begin{array}{l}\text { The event tree in Figure } 6-1 \text { incorrectly gives a } 0 \% \\
\text { probability of restoring ECCS with backflushing. The } \\
\text { reference plant has procedures to backflush ECCS } \\
\text { section strainers in the event of clogging. This should } \\
\text { also be corrected in Section } 6.2 .1 \text { of the text. }\end{array}$ & $\begin{array}{l}\text { This study was based on the reference plant's } \\
\text { configuration as of January 1994. At that time the } \\
\text { understanding was that this plant did not have a } \\
\text { formally approved method to perform backflushing } \\
\text { operations. Although backflushing procedures could } \\
\text { have been put into place since that time, it is beyond } \\
\text { the scope of this report to incorporate design or } \\
\text { procedural changes that have been implemented } \\
\text { since that time. }\end{array}$ \\
\hline $\begin{array}{l}\text { BWROG-B62/ } \\
\text { Section } 6.2 \\
\text { page } 6-4\end{array}$ & Technical & $\begin{array}{l}\text { Section } 6.2 \text {, Page } 6-4: \text { The determination of conditional } \\
\text { core damage frequency for this event is directly related } \\
\text { to the assumption that all ECCS section strainers block } \\
\text { within } 10 \text { minutes with a probability of } 1.0 \text {. If the } \\
\text { likelihood of ECCS suction strainer blockage is much } \\
\text { less than } 1.0 \text { or if only a limited number of strainers } \\
\text { are blocked, the results are much less damaging. }\end{array}$ & $\begin{array}{l}\text { This assumption was judged to be reasonable based } \\
\text { on results from deterministic analyses. }\end{array}$ \\
\hline $\begin{array}{l}\text { BWROG-B63/ } \\
\text { Section } 6.2 \\
\text { Assumption } 6\end{array}$ & Technical & $\begin{array}{l}\text { Assumption } 6 \text { in Section } 6.2 \text { notes that core damage } \\
\text { occurs when the water level drops from } 2 / 3 \text { core. A } \\
\text { LOCA not located in the recirculation pump suction } \\
\text { piping would reflood to a higher level in the reactor } \\
\text { vessel and take longer to boil down. }\end{array}$ & $\begin{array}{l}\text { It is acknowledged that the LOCA break location can } \\
\text { influence the time available for recovery actions. See } \\
\text { the response to question B57. }\end{array}$ \\
\hline
\end{tabular}




\begin{tabular}{|c|c|c|c|}
\hline \multicolumn{4}{|c|}{$\sqrt{\text { Commentor: BWROG - R. A. Pinelli }}$} \\
\hline $\begin{array}{l}\text { Comment \# I } \\
\text { Location }\end{array}$ & Type & Comment & Response \\
\hline $\begin{array}{l}\text { BWROG-B64/ } \\
\text { Section } 6.2 \\
\text { Assumption } 8\end{array}$ & Technical & $\begin{array}{l}\text { Assumption } 8 \text { in Section } 6.2 \text { states that the } \\
\text { condensate/feedwater systems cannot be successfully } \\
\text { used for alternate injection to the reactor vessel. This } \\
\text { is correct in that the condenser hotwell does not have } \\
\text { sufficient water capacity for long term injection and the } \\
\text { pipe break could be in one of these lines. However, } \\
\text { these systems can be used for short term injection. Use } \\
\text { of either of these systems will allow the operators more } \\
\text { time to diagnose the problem and align other alternate } \\
\text { injection sources. Use of the RCIC and HPCI systems } \\
\text { can also be used for other than large LOCA events to } \\
\text { extend the time available for alternate injection, even if } \\
\text { the flow rates are not sufficient to maintain reactor } \\
\text { vessel water level. }\end{array}$ & $\begin{array}{l}\text { It is recognized that the use of the condensate/ } \\
\text { feedwater system could, in some cases, provide } \\
\text { operators with additional time to establish backup } \\
\text { cooling. However, as was stated in the response to } \\
\text { question B.57, the event tree model was not intended } \\
\text { to represent an in-depth evaluation of all possible } \\
\text { break locations. The exclusion of the } \\
\text { condensate/feedwater system for large LOCA } \\
\text { mitigation was consistent with the reference plant } \\
\text { IPE. With regard to the use of HPCI or RCIC for } \\
\text { large LOCA mitigation, it is doubtful if sufficient } \\
\text { steam pressure would exist following a large LOCA } \\
\text { to operate the steam-driven pumps that are used in } \\
\text { the RCIC and HPCI systems. }\end{array}$ \\
\hline $\begin{array}{l}\text { BWROG-B65/ } \\
\text { Section } 6.2 .2 \\
\text { page 6-6 } \\
\text { 5th paragraph }\end{array}$ & Editorial & $\begin{array}{l}\text { Section 6.2.2, Page 6-6, Fifth Paragraph: After loss of } \\
\text { ECCS due to strainer blockage, there is approximately } \\
25 \text { minutes available for operator action to establish an } \\
\text { alternate injection source. However, there is an } \\
\text { assumption listed that notes operator diagnosis and } \\
\text { required actions must be completed within } 10 \text { minutes. } \\
\text { This leads to a failure probability of } 0.25 \text {. If the entire } \\
25 \text { minutes is assumed to be available, the failure } \\
\text { probability for alternate injection would decrease by } \\
\text { approximately an order of magnitude. This has a } \\
\text { significant impact on the core damage frequency (e.g., } \\
\left.\text { HPCS from CST could drop CDF from } 10^{-5} \text { to } 10^{-7}\right) \text {. }\end{array}$ & $\begin{array}{l}\text { The reference plant IPE assumes that operator } \\
\text { diagnosis and required actions to establish an } \\
\text { alternate injection source must be performed within } \\
10 \text { minutes. This human factors analysis predicts a } \\
\text { probability of } 0.25 \text { that an operator failure would } \\
\text { occur. This probability was used in the event tree in } \\
\text { Figure } 8-1 \text {. This probability is somewhat } \\
\text { conservative, but it was the only documented plant- } \\
\text { specific data available for this action. NUREG/CR- } \\
6224 \text { was modified to provide this clarification. }\end{array}$ \\
\hline
\end{tabular}




\begin{tabular}{|c|c|c|c|}
\hline \multicolumn{4}{|c|}{ Commentor: BWROG - R. A. Pinelli } \\
\hline $\begin{array}{l}\text { Comment \# I } \\
\text { Location }\end{array}$ & Type & Comment & Response \\
\hline $\begin{array}{l}\text { BWROG-B66/ } \\
\text { Section } 6.3 .2 \\
\text { page } 6-10 \& 11 \\
\text { Table } 6-1\end{array}$ & Regulatory & $\begin{array}{l}\text { Section } 6.3 .2 \text { Page } 6-10 \text { \& Table } 6-1 \text {, Page } 6-11 \text { : } \\
\text { Extrapolation of the results of the reference plant to } \\
\text { other plants cannot be meaningfully done simply by } \\
\text { taking the LOCA frequency used in the various IPEs, } \\
\text { and coupling with the conditional CDF from strainer } \\
\text { fouling. Different designs (includes BWR/4s) would } \\
\text { be expected to give different results for the conditional } \\
\text { CDF. All that can be stated based upon the } \\
\text { NUREG/CR-6224 analysis, without a more in-depth } \\
\text { analysis, is that strainer fouling can be expected to } \\
\text { have a significant effect on the CDF contribution from } \\
\text { LOCAs. }\end{array}$ & $\begin{array}{l}\text { It is recognized that the extrapolations to other plants } \\
\text { were very preliminary. The report did acknowledge } \\
\text { some of the uncertainties with the extrapolation } \\
\text { process. The intent of the extrapolations was to } \\
\text { demonstrate that strainer fouling may have the } \\
\text { potential to have a significant effect on CDF } \\
\text { contributions at other BWRs. The conditional CDF } \\
\text { from the reference plant was used in these } \\
\text { calculations only because conditional CDF } \\
\text { information for other plant types was unavailable. A } \\
\text { formal evaluation of blockage-related CDF at other } \\
\text { BWRs was beyond the scope of our study. }\end{array}$ \\
\hline $\begin{array}{l}\text { BWROG-B67/ } \\
\text { Section } 6.3 .2\end{array}$ & Editorial & $\begin{array}{l}\text { In Section 6.3.2, replace references to "torus" with } \\
\text { "suppression pool" or "wetwell" in this section since } \\
\text { BWR-5 and BWR-6 plants do not have a torus as } \\
\text { stated. }\end{array}$ & $\begin{array}{l}\text { NUREG/CR-6224 was modified to reflect this } \\
\text { comment. }\end{array}$ \\
\hline
\end{tabular}




\begin{tabular}{|c|c|c|c|}
\hline \multicolumn{4}{|c|}{ Commentor: BWROG - R. A. Pinelli } \\
\hline $\begin{array}{c}\text { Comment \# / } \\
\text { Location }\end{array}$ & Type & Comment & Response \\
\hline $\begin{array}{l}\text { BWROG-B68/ } \\
\text { Section } 6.4\end{array}$ & Regulatory & $\begin{array}{l}\text { The CDF estimate in Section } 6.4 \text { is shown to be } 1.4 \text { E- } 06 \\
\text { by the use of: } \\
\text { 1) larger strainer areas that prevent loss of NPSH } \\
80 \% \text { of the time; } \\
\text { 2) installation of pressure differential sensors on } \\
\text { ECCS strainers providing operator recognition of } \\
\text { strainer blockage } 90 \% \text { of the time; and } \\
\text { 3) installation of strainer backflushing equipment } \\
\text { which is successful in restoring operation of ECCS } \\
\text { pumps } 80 \% \text { of the time. } \\
\text { What does the } 1.4 \text { E-06 CDF value mean with respect } \\
\text { to an acceptable plant CDF? That is, is this CDF value } \\
\text { considered to be acceptable even though the ECCS can } \\
\text { be lost in } 20 \% \text { of the postulated LOCA breaks from } \\
\text { loss of pump NPSH? Please provide more insight into } \\
\text { the acceptability of having strainers which do not } \\
\text { prevent loss of pump NPSH for all breaks. Consider } \\
\text { including this information in the Summary and } \\
\text { Conclusion section. }\end{array}$ & $\begin{array}{l}\text { The value of "1.4E- } 06 / \mathrm{yr} \text { " had no particular } \\
\text { significance with respect to an "acceptable plant } \\
\text { CDF." As described in Section } 6.4 \text { of NUREG/CR- } \\
6224 \text { Draft for Comment, this result was generated } \\
\text { with data that were judged at the time of the study } \\
\text { to represent reasonable screening data to credit the } 3 \\
\text { major mitigating actions listed on p. } 6-12 \text {. It was not } \\
\text { the intent of this exercise to pass judgment on the } \\
\text { acceptability of having strainers that do not prevent } \\
\text { loss of pump NPSH for all breaks. }\end{array}$ \\
\hline
\end{tabular}




\begin{tabular}{|c|c|c|c|}
\hline \multicolumn{4}{|c|}{ Commentor: Consejo de Seguridad Nuclear - Fernando Robledo } \\
\hline $\begin{array}{c}\text { Comment \# I } \\
\text { Location }\end{array}$ & Type & Comment & Response \\
\hline \multirow[t]{3}{*}{$\begin{array}{l}\text { CSN-1 / } \\
\text { Appendix A, } \\
\text { Chapter } 6\end{array}$} & \multirow[t]{3}{*}{ Regulatory } & $\begin{array}{l}\text { NUREG/CR- } 6224 \text { shows an extensive review of the existing } \\
\text { literature to obtain the frequency of the initiating event: the } \\
\text { rupture of a high energy line inside the containment. The } \\
\text { value adopted in the study is very specific for the reference } \\
\text { plant: 1E- } 4 \text {. This value is based in the potential of IGSCC for } \\
\text { the materials of the RCS in the reference plant, lowered one } \\
\text { order of magnitude by the benefits obtained with ISI. For } \\
\text { other types of materials, the frequency of the initiating event } \\
\text { is very low, for example } 1 \mathrm{E}-10 \text {, } 1 \mathrm{E}-11 \text {, as it could be inferred } \\
\text { from NUREG/CR-6224 for some plants, the issue analyzed } \\
\text { here would become insignificant for the safety. }\end{array}$ & $\begin{array}{l}\text { While one can show the probability of a LOCA } \\
\text { may be unlikely, U.S. regulations (10CFR } 50.50 .46 \text { ) } \\
\text { require that the ECCS system be able (assuming a } \\
\text { LOCA) to provide long-term cooling. } \\
\text { NUREG/CR-6224 analyzed the reference plant for } \\
\text { the assumption that a LOCA could occur and was } \\
\text { based on insulation materials installed in the } \\
\text { reference plant. }\end{array}$ \\
\hline & & $\begin{array}{l}\text { In addition, for these plants, all the safety measures installed } \\
\text { to protect them against the consequences of a large or medium } \\
\text { LOCA would be very little useful for the plant safety. I feel } \\
\text { that the nuclear safety is not mature enough to reach this } \\
\text { conclusion. }\end{array}$ & $\begin{array}{l}\text { The NRC's approach to strainer blockage as being } \\
\text { a compliance issue implicitly incorporates this } \\
\text { approach. }\end{array}$ \\
\hline & & $\begin{array}{l}\text { Therefore, I think that the impact of the strainers blockage } \\
\text { issue in the plant safety should be based on the conditional } \\
\text { probability of strainer blockage given a LOCA, instead of the } \\
\text { probability of the initiating event. }\end{array}$ & $\begin{array}{l}\text { The NRC prefers to present an overall core } \\
\text { damage probability instead of the conditional } \\
\text { probabilities of ECCS blockage. }\end{array}$ \\
\hline $\begin{array}{l}\text { CSN-2 / } \\
\text { General }\end{array}$ & Technical & $\begin{array}{l}\text { NUREG/CR- } 6224 \text { pays very little attention to the behavior of } \\
\text { other thermal insulating materials different to NUKONTM. I } \\
\text { think that the potential for strainer blockage from other } \\
\text { thermal insulating materials, i.e., metallic reflective, etc., } \\
\text { should be analyzed in the report. }\end{array}$ & $\begin{array}{l}\text { RMI is one of a number of insulations installed in } \\
\text { U.S. plants that should be evaluated on a plant } \\
\text { specific basis. However, since RMI was not a } \\
\text { "dominant" insulation for the reference plant, } \\
\text { such an analysis was not included in NUREG/CR- } \\
6224 \text {. Other materials used in LWRs should be } \\
\text { evaluated, but the burden for the evaluation, with } \\
\text { respect to ECCS strainer blockage, will be placed } \\
\text { on the licensees. DG-1038, Revision } 2 \text { to the } \\
\text { Regulatory Guide 1.82, provides guidance on the } \\
\text { features needed to prevent or mitigate strainer } \\
\text { blockage as well as providing guidance on aspects } \\
\text { of a strainer blockage analysis. }\end{array}$ \\
\hline
\end{tabular}




\begin{tabular}{|c|c|c|c|}
\hline \multicolumn{4}{|c|}{ Commentor: Consejo de Seguridad Nuclear - Fernando Robledo } \\
\hline $\begin{array}{c}\text { Comment \# / } \\
\text { Location }\end{array}$ & Type & Comment & Response \\
\hline $\begin{array}{l}\mathrm{CSN}-3 / \\
\text { General }\end{array}$ & Technical & $\begin{array}{l}\text { NUREG/CR- } 6224 \text { establishes that the extrapolation of the } \\
\text { reference plant to BWR } 5 \text { and } 6 \text { is little reliable because of the } \\
\text { characteristics of the ECCS in these plants. I feel that the } \\
\text { influence of these differences in the ECCS design should be } \\
\text { more precisely quantified in the report. }\end{array}$ & $\begin{array}{l}\text { The NRC agrees that other plants need to be } \\
\text { analyzed, but such analysis was not in the scope } \\
\text { of NUREG/CR-6224. DG-1038, Revision } 2 \text { to the } \\
\text { Regulatory Guide 1.82, provides guidance on the } \\
\text { features needed to prevent or mitigate strainer } \\
\text { blockage as well as providing guidance on aspects } \\
\text { of a strainer blockage analysis. Additionally, the } \\
\text { derivation of more precise CDF estimates for other } \\
\text { BWRs was beyond the scope of our study. }\end{array}$ \\
\hline $\begin{array}{l}\text { CSN-4 / } \\
\text { Section } 6.2\end{array}$ & Technical & $\begin{array}{l}\text { Figs. } 6-3 \text { and } 6-4 \text { show the efficiency of the measures taken in } \\
\text { some European countries as a consequence of the Barsebäck-2 } \\
\text { Incident. These figures clearly show that these measures are } \\
\text { very little efficient to correct the problem. For example, from } \\
\text { Fig. } 6-3 \text {, the contribution to the core damage frequency of the } \\
\text { sequence LOCA + ECCS failure by strainer blockage remains } \\
\text { very high. I think, that this situation stems from the } \\
\text { inadequate quantification of several headers in the event trees } \\
\text { shown in Figs. } 6-3 \text { and } 6-4 \text {. In particular, I think that the } \\
\text { following headers are inadequately quantified: } \\
\text { a) Header: Avoid Core Spray/RHR pump NPSH loss. } \\
\text { I think, that the quantification of the probability to avoid core } \\
\text { spray/RHR pump NPSH loss is very low: } 0.2 \text {. In some } \\
\text { European countries the strainer areas were enlarged through } \\
30 \text { times the initial area; according with Figs. } 5-1 \text { and } 5-5 \text { of } \\
\text { NUREG/CR-6224, this great area enlargement should result in } \\
\text { a very high probability to avoid core spray/RHR pump NPSH } \\
\text { loss. I propose a value of } 1 \mathrm{E}-2 \text {. } \\
\text { b) Header: Operator recognizes strainer blockages. } \\
\text { Some European countries have installed specific } \\
\text { instrumentation oriented to detect the strainer blockage. } \\
\text { Therefore, the probability that the operator does not recognize } \\
\text { the strainer blockage should be very low, around 1E-2. }\end{array}$ & $\begin{array}{l}\text { The probabilistic analysis in NUREG/CR- } 6224 \text { is } \\
\text { a bounding analysis, and the worst case } \\
\text { probability was used. Plants which can establish } \\
\text { lower failure probabilities for systems and } \\
\text { components are not prohibited from taking credit } \\
\text { for such probabilities by NUREG/CR-6224. The } \\
\text { events identified were generated with data that } \\
\text { were judged to represent reasonable screening } \\
\text { data for the European approach to strainer } \\
\text { blockage. }\end{array}$ \\
\hline
\end{tabular}


Appendix $F$

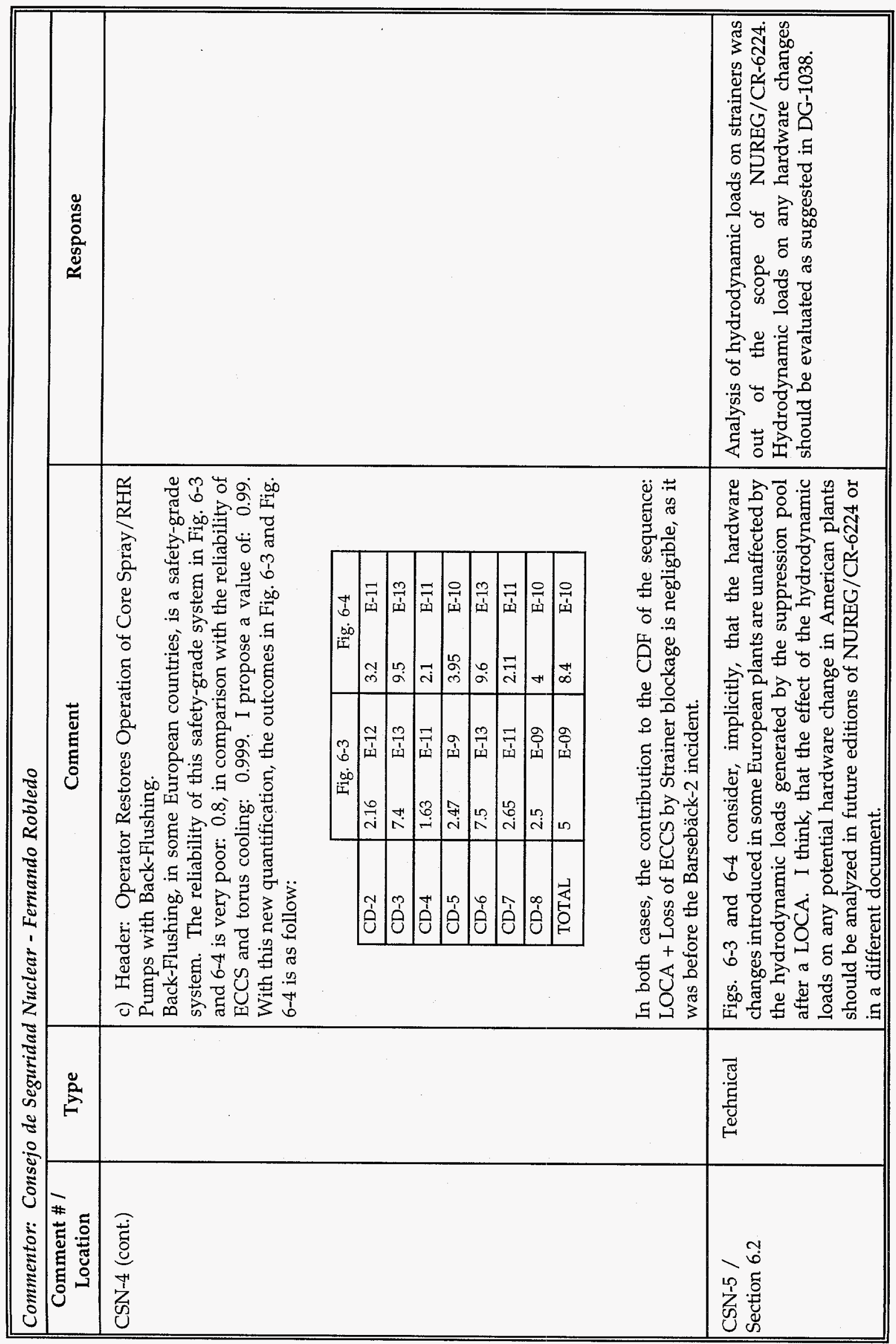




\begin{tabular}{|c|c|c|c|}
\hline \multicolumn{4}{|c|}{ Commentor: Performance Contracting, Inc. - Gordon H. Hart } \\
\hline $\begin{array}{c}\text { Comment \# I } \\
\text { Location }\end{array}$ & Type & Comment & Response \\
\hline $\begin{array}{l}\text { PCI-1 / } \\
\text { General }\end{array}$ & Regulatory & $\begin{array}{l}\text {...The approach, taken by SEA in the NUREG, of allowing for } \\
\text { some fibrous debris entrapment in the drywell and some } \\
\text { sedimentation of both fibrous and particulate debris in the } \\
\text { suppression pool, is reasonable and realistic. More } \\
\text { importantly, it may allow for practical, effective solutions that } \\
\text { would not be disruptive to plant operation: } \\
\text { - Implementation of drywell and suppression pool cleaning } \\
\text { procedures to reduce the quantity of particulate in the pool } \\
\text { following a LOCA; } \\
\text { - Design and installation of new larger surface area } \\
\text { strainers that can be installed without draining the } \\
\text { suppression pool and yet can stay within the original } \\
\text { structural bounds on the ECCS piping that penetrates the } \\
\text { wet well. } \\
\text { PCI (formerly the Contracting Division of Owens-Corning } \\
\text { Fiberglass Corporation) has followed the strainer blockage } \\
\text { nuclear safety issue since } 1973 \text { and we have found it a } \\
\text { complex subject, at best. The more recent additional concern } \\
\text { of the combined effects of fibrous insulation debris and } \\
\text { particulate has made the accurate prediction of post-LOCA } \\
\text { BWR ECCS behavior, and suction strainer blockage, } \\
\text { exceedingly difficult. We acknowledge that the simpler } \\
\text { course, from a regulatory perspective, would be to take an } \\
\text { extremely conservative position such as was taken by SKi in } \\
\text { Sweden (leading to the "robust solution"): } \\
\text { - } 100 \% \text { of the insulation within a defined zone of destruction } \\
\text { is reduced to individual fibers; } \\
100 \% \text { of the generated fibrous debris and particulate debris } \\
\text { is transported instantaneously to the suppression pool; }\end{array}$ & $\begin{array}{l}\text { DG-1038, Revision } 2 \text { to Regulatory Guide } 1.82 \text {, } \\
\text { provides guidance on the features needed to prevent } \\
\text { or mitigate strainer blockage as well as providing } \\
\text { guidance on aspects of a strainer blockage analysis. }\end{array}$ \\
\hline
\end{tabular}




\begin{tabular}{|c|c|c|c|}
\hline \multicolumn{4}{|c|}{ Commentor: Performance Contracting, Inc. - Gordon H. Hart } \\
\hline $\begin{array}{c}\text { Comment \# I } \\
\text { Location }\end{array}$ & Type & Comment & Response \\
\hline PCI-1 (cont.) & & $\begin{array}{l}\text { - } 100 \% \text { of that fibrous debris remains suspended in the } \\
\text { suppression pool indefinitely, as is any particulate debris } \\
\text { (sludge) originating in either the drywell or the } \\
\text { suppression pool; } \\
\text { - } 100 \% \text { of the fibrous debris and the particulate debris in the } \\
\text { pool is eventually collected on the strainers. } \\
\text { The problem with this extremely conservative approach is } \\
\text { that it requires a "robust (mechanical) solution" consisting of } \\
\text { huge new strainers and, possibly, backflushing. The design, } \\
\text { fabrication, and installation of a "robust solution" would be } \\
\text { a major plant modification requiring suppression pool } \\
\text { draining, structural modifications to the ECCS pipe } \\
\text { penetrations, and a large investment of labor and radiation } \\
\text { dose for installation. } \\
\text { If, instead, a less conservative approach is taken, but one } \\
\text { which can be shown to be realistic, it is likely that most } \\
\text { BWR's can find a satisfactory solution consisting of less } \\
\text { disruptive modifications. }\end{array}$ & \\
\hline
\end{tabular}




\begin{tabular}{|c|c|c|c|}
\hline \multicolumn{4}{|c|}{ Commentor: Performance Contracting, Inc. - Gordon H. Hart } \\
\hline $\begin{array}{c}\text { Comment \# I } \\
\text { Location }\end{array}$ & Type & Comment & Response \\
\hline $\begin{array}{l}\text { PCI-2 / } \\
\text { General }\end{array}$ & Regulatory & $\begin{array}{l}\text { This engineering study reported in NUREG/CR- } 6224 \text { focuses } \\
\text { entirely on the reference plant and on metal jacketed } \\
\text { NUKONTM Insulation, the predominant pipe insulation in } \\
\text { that plant's drywell. Studies in Europe have focused on } \\
\text { other types of containment insulation, some fibrous and some } \\
\text { reflective metallic. While we estimate that NUKONTM } \\
\text { represents about } 85 \% \text { of the mass-type drywell pipe } \\
\text { insulation in the US BWR's, it only represents about } 35 \% \text { of } \\
\text { the total drywell pipe insulation. Most of the remainder } \\
\text { consists of reflective metallic insulation (RMI), made in the } \\
\text { U.S., which is different from that being tested in Europe. } \\
\text { PCI would encourage the USNRC to eventually evaluate RMI } \\
\text { with respect to its post-LOCA behavior including, but not } \\
\text { limited to, its impact on strainer blockage. We would also } \\
\text { encourage that evaluation to be sufficiently comprehensive to } \\
\text { address the different designs of RMI installed currently in US } \\
\text { BWR drywells ( } 1 \text { mil aluminum foil, } 2 \text { mil stainless steel foil, } \\
\text { etc.) Unlike the mass insulation, of which NUKON }{ }^{T M} \text { is the } \\
\text { dominant, there is no dominant RMI design incorporated in } \\
\text { the US BWR drywells. PCI would also encourage the NRC } \\
\text { to apply the same conservation and engineering rigor to the } \\
\text { evaluation of RMI as it, and the international community, has } \\
\text { applied to the evaluation of NUKON }{ }^{T M} \text { Insulation and other } \\
\text { fibrous insulation materials. }\end{array}$ & $\begin{array}{l}\text { RMI is one of a number of insulations installed in } \\
\text { U.S. plants that should be evaluated on a plant } \\
\text { specific basis. However, since RMI was not a } \\
\text { "dominant" insulation for the reference plant, such an } \\
\text { analysis was not included in NUREG/CR- } 6224 \text {. The } \\
\text { NRC staff will continue to follow domestic and } \\
\text { foreign tests concerning RMI and other insulation } \\
\text { materials. }\end{array}$ \\
\hline
\end{tabular}




\begin{tabular}{|c|c|c|c|}
\hline \multicolumn{4}{|c|}{ Commentor: Performance Contracting, Inc. - Gordon H: Hart } \\
\hline $\begin{array}{c}\text { Comment \# / } \\
\text { Location }\end{array}$ & Type & Comment & Response \\
\hline $\begin{array}{l}\text { PCI-3 / } \\
\text { Section } 1.1 \\
\text { page 1-1 } \\
\text { 3rd paragraph } \\
\text { last sentence }\end{array}$ & Editorial & $\begin{array}{l}\text { It is stated that "the Barsebäck-2 event demonstrated that } \\
\text { small particles, in combination with debris fibers, } \\
\text { significantly increased the pressure drop across the strainers." } \\
\text { In talking to people at the utility SydKraft and to the } \\
\text { regulators in Sweden (SKi), our understanding is that the } \\
\text { collected debris was } 100 \% \text { shredded mineral wool insulation. } \\
\text { It was postulated by SKi that the mineral wool fibers } \\
\text { collected on the strainers filtered out mineral wool particles. } \\
\text { That may or may not have been the case. We do know, } \\
\text { however, that aged, degraded mineral wool, tested for head } \\
\text { loss, gives values for head loss that are several times higher } \\
\text { than given by new, unexposed mineral wool of the same } \\
\text { initial density (as described in the Swiss report "KKL-Specific } \\
\text { ECCS Strainers Plugging Analysis according to Reg. Guides } \\
\text { 1.82, Rev. } 1 \text { for a LOCA"). }\end{array}$ & $\begin{array}{l}\text { It is true that the Barsebäck- } 2 \text { event was primarily } \\
\text { caused by the fibrous bed. NUREG/CR- } 6224 \text { was } \\
\text { modified to clarify this issue. }\end{array}$ \\
\hline $\begin{array}{l}\text { PCI-4A / } \\
\text { Section } 2-5 \\
\text { page 2-6 } \\
\text { 3rd paragraph } \\
\text { 2nd sentence } \\
\end{array}$ & Editorial & $\begin{array}{l}\text { PCI understands that estimates of sludge mass found in } \\
\text { suppression pools has been found to vary from } 70 \mathrm{lbm} \text { to } \\
5000 \mathrm{lbm} \text { (see also p. } 4-24,4 \text { th paragraph, last sentence), } \\
\text { depending on plant and suppression pool cleaning } \\
\text { procedures during outages. }\end{array}$ & $\begin{array}{l}\text { The sludge mass range of } 70 \mathrm{lbm} \text { to } 7000 \mathrm{lbm} \text { was } \\
\text { obtained based on discussions with the BWROG } \\
\text { representatives on May } 4,1994 \text {. }\end{array}$ \\
\hline $\begin{array}{l}\text { PCI-4B / } \\
\text { Section 2-5 } \\
\text { page 2-6 } \\
\text { 3rd paragraph } \\
\text { 2nd sentence }\end{array}$ & Technical & $\begin{array}{l}\text { However, this statement is apparently not true for plants that } \\
\text { have a Torous Water Clean-Up (TWCU) system. At least one } \\
\text { of the US BWR's has a TWCU system that operates } \\
\text { periodically during plant operation and is very effective. The } \\
\text { owner utility of that plant recently tried to perform a full } \\
\text { pool cleaning during a refueling outage. However, they } \\
\text { collected such an insignificant amount of particulate debris } \\
\text { that the process was discontinued. The mass of particulate } \\
\text { debris collected was on the order of } 10 \mathrm{lbm} \text {, much less than } \\
\text { the stated lower limit of } 70 \mathrm{lbm} \text {. }\end{array}$ & $\begin{array}{l}\text { The reference plant did not have Torous Water } \\
\text { Clean-Up (TWCU). Therefore, no credit for periodic } \\
\text { cleaning of the torous was given. }\end{array}$ \\
\hline
\end{tabular}




\begin{tabular}{|c|c|c|c|}
\hline \multicolumn{4}{|c|}{ Commentor: Performance Contracting, Inc. - Gordon H. Hart } \\
\hline $\begin{array}{l}\text { Comment \# / } \\
\text { Location }\end{array}$ & Type & Comment & Response \\
\hline $\begin{array}{l}\text { PCI-5A / } \\
\text { Section 2-6 } \\
\text { page 2-7 } \\
\text { Subpoint } 2 \\
\text { 1st sentence }\end{array}$ & Editorial & $\begin{array}{l}\text { We believe this sentence would be more accurate if it was } \\
\text { rewritten to say, "...plant insulation consists mostly of low } \\
\text { and high density removable fiberglass blankets, reflective } \\
\text { metallic insulation (with metal foils), and conventional, } \\
\text { permanent mass insulation." The problem with using the } \\
\text { term "fiberglass insulation" is that it does not differentiate } \\
\text { between removable blankets and conventional, permanent } \\
\text { insulation, where both may be fiberglass materials. The } \\
\text { problem with using the term "metallic" is that many people } \\
\text { do not really know that it is constructed of multiple layers of } \\
\text { thin metal foil. Finally, the problem with listing the term } \\
\text { mineral wool is that we believe that only one US BWR has } \\
\text { any mineral wool (about } 20 \% \text { of its total drywell pipe } \\
\text { insulation) and its owner utility is currently in the process of } \\
\text { replacing that material. There is, however, some calcium } \\
\text { silicate (conventional, permanent) insulation in some BWRs. } \\
\text { Therefore, we believe that "conventional permanent": would } \\
\text { be a more accurate and comprehensive term than "mineral } \\
\text { wool". }\end{array}$ & $\begin{array}{l}\text { The referenced portions of NUREG/CR-6224 were } \\
\text { reviewed in light of this comment. }\end{array}$ \\
\hline $\begin{array}{l}\text { PCI-5B / } \\
\text { Section } 2.6 \\
\text { page } 2-7 \\
\text { Subpoint } 3\end{array}$ & Editorial & $\begin{array}{l}\text { PCI's understanding is that suppression pool sludge consists } \\
\text { of iron oxide particles flushed from the inside of the RHR } \\
\text { piping and blown from the interior of steam relief valves. } \\
\text { We believe that this information is worth stating so people } \\
\text { reading the document understand the probable source of } \\
\text { most of this sludge. }\end{array}$ & $\begin{array}{l}\text { Additional sources for sludge are downcomers, vent } \\
\text { pipes and the torus shell. It was not clear if all the } \\
\text { sources could be easily identified. However, the } \\
\text { report was modified to identify sources of sludge. }\end{array}$ \\
\hline $\begin{array}{l}\text { PCI-6A / } \\
\text { Section } 3.4 \\
\text { page } 3-16 \\
\text { 1st paragraph } \\
\text { 1st sentence }\end{array}$ & Editorial & $\begin{array}{l}22 \text { gauge stainless steel has a thickness of about } 0.030^{\prime \prime} \text {, not } \\
0.045^{\prime \prime} \text {. }\end{array}$ & $\begin{array}{l}\text { NUREG/CR- } 6224 \text { has been modified to reflect the } \\
\text { proper thickness in inches. }\end{array}$ \\
\hline
\end{tabular}




\begin{tabular}{|c|c|c|c|}
\hline \multicolumn{4}{|c|}{ Commentor: Performance Contracting, Inc. - Gordon H. Hart } \\
\hline $\begin{array}{l}\text { Comment \#I } \\
\text { Location }\end{array}$ & Type & Comment & Response \\
\hline $\begin{array}{l}\text { PCI-6B / } \\
\text { Section } 3.4 \\
\text { page 3-16 } \\
\text { 2nd paragraph } \\
\text { 1st sentence }\end{array}$ & Editorial & $\begin{array}{l}\text { The description of NUKON"M blanket material is not exactly } \\
\text { correct. We suggest this be rewritten as: "The NUKON" } \\
\text { blanket material used for insulation primary piping consists } \\
\text { of fibrous glass wool reinforced with a woven fiberglass } \\
\text { scrim, then covered with a heavy woven fiberglass fabric } \\
\text { (burlap - like), sewn with fiberglass thread, and attached with } \\
\text { a velcro-type material..." }\end{array}$ & $\begin{array}{l}\text { NUREG/CR-6224 was modified to reflect the } \\
\text { description of NUKON }{ }^{\mathrm{TM}} \text { blanket material. }\end{array}$ \\
\hline $\begin{array}{l}\mathrm{PCI}-7 / \\
\text { Section } 4.2 .2 \\
\text { pages } 4-14 \text { to } 4-16\end{array}$ & Technical & $\begin{array}{l}\text { The selection of those spherical zones of destruction, as } \\
\text { described with the three destruction factors of } 0.75,0.60 \text {, and } \\
0.40 \text { for Zones I, II, and III, respectively, is conservative but } \\
\text { understandable given the limited data available. This is a } \\
\text { very difficult subject to address. However, the publicly } \\
\text { available test evidence suggests that pipe shadowing does } \\
\text { reduce the destruction of targeted NUKONTM Insulation and } \\
\text { that NUKON }{ }^{\mathrm{TM}} \text { metal jacketing can have a highly protective } \\
\text { effect on targeted NUKONTM insulation (i.e., that no debris } \\
\text { is generated). }\end{array}$ & $\begin{array}{l}\text { It is acknowledged that the data were limited and } \\
\text { that, combined with engineering judgement, resulted } \\
\text { in the selection of the spherical model. Also, } \\
\text { shadowing can reduce the debris generated. } \\
\text { However, in order to minimize the complexity of the } \\
\text { model, shadowing was not addressed explicitly. } \\
\text { Instead, destruction factors were used in the analysis } \\
\text { to account such factors as shadowing and partially } \\
\text { damaged blankets. }\end{array}$ \\
\hline $\begin{array}{l}\text { PCI-8 / } \\
\text { Section } 4.3 \\
\text { pages } 4-21 \text { to } 4-24\end{array}$ & Technical & $\begin{array}{l}\text { In view of the reported } 50 \% \text { insulation debris transported to } \\
\text { the pool at Barsebäck-2, PCI understands the need for } \\
\text { conservatism in selecting debris transport factors for } \\
\text { transport from the drywell to the wetwell. However, } \\
\text { subsequent testing by the Swedish utilities has shown } \\
\text { transport factors of less than } 10 \% \text {. And, the accuracy of the } \\
\text { transport data from Barsebäck-2 has been questioned and is } \\
\text { currently under review by SKi. There are also significant } \\
\text { differences between US BWR's and Swedish BWR's relative } \\
\text { to downcomer design. Therefore, we believe that the } \\
\text { transport factors of } 25 \%, 50 \% \text {, and } 75 \% \text { are conservative. }\end{array}$ & $\begin{array}{l}\text { It is recognized that there are large uncertainties in } \\
\text { drywell debris transport predictions and that the } \\
\text { Barsebäck-2 data of } 50 \% \text { transport was not directly } \\
\text { applicable to the reference plant due to differences in } \\
\text { plant design. Therefore, engineering judgement was } \\
\text { used to select transport factors which were consistent } \\
\text { with the best estimate nature of this study. }\end{array}$ \\
\hline
\end{tabular}




\begin{tabular}{|c|c|c|c|}
\hline \multicolumn{4}{|c|}{ Commentor: Performance Contracting, Inc. - Gordon H. Hart } \\
\hline $\begin{array}{c}\text { Comment \# I } \\
\text { Location }\end{array}$ & Type & Comment & Response \\
\hline $\begin{array}{l}\text { PCI-9 / } \\
\text { Section 5.2 } \\
\text { pages 5-7 to 5-24 }\end{array}$ & Technical & $\begin{array}{l}\text { PCI finds that these parametric analyses are particularly } \\
\text { valuable in highlighting significant variables for, and hence } \\
\text { solutions to, strainer blockage. Of those presented, the } \\
\text { doubling of the strainer surface area may be the most feasible } \\
\text { and practical solution of those evaluated. Those analyses } \\
\text { where the zone of destruction was reduced from } \mathrm{L} / \mathrm{D} \text { to } \\
\text { 3L/D is confusing because other independent variables were } \\
\text { also changed: the destruction factor was increased from } 0.75 \\
\text { to } 1.00 \text { and the transport factor was also increased to } 1.00 \text {. } \\
\text { Could these 3L/D cases be rerun with the original } \\
\text { destruction factors and transport factors so that zone of } \\
\text { destruction is the only variable changed? }\end{array}$ & $\begin{array}{l}\text { A more detailed parametric analysis is included in } \\
\text { the revised NUREG/CR-6224. These analyses, } \\
\text { however, do not include the 3L/D case requested by } \\
\text { the reviewer. The original 3L/D case was carried out } \\
\text { for illustrative purposes, and based on some of the } \\
\text { reviewer comments (e.g., See BWROG-B56), it was } \\
\text { decided not to include it in the revised NUREG. }\end{array}$ \\
\hline $\begin{array}{l}\text { PCI-10 / } \\
\text { Section B.2.1 }\end{array}$ & Editorial & $\begin{array}{l}\text { At the beginning, the statement is made, "The insulation } \\
\text { debris may vary in size from finely disintegrated fibers to } \\
\text { large shreds." These large shreds are described in Table B-1 } \\
\text { (Size 5) as the largest two sizes in a three size distribution in } \\
\text { PCI's air blast experiments. PCI agrees it is important to } \\
\text { include this large Size } 5 \text {, which included "shreds" as large as } \\
24 \text { " } \times 30 \text { " } \times 3 \text { " (thick) in our air blast tests. The description } \\
\text { might be clearer if a statement were added in this section } \\
\text { emphasizing that "shreds" can include insulation debris of } \\
\text { this large a size. The drawing on Table B-1, for Size 5, leads } \\
\text { the reader to conclude otherwise. }\end{array}$ & $\begin{array}{l}\text { Size classes described in Table B-1 of the Draft } \\
\text { NUREG/CR-6224 included those that were judged } \\
\text { most likely to be transported to the suppression pool. } \\
\text { Debris as large as } 24 \text { "x } 30 " \times 3 " \text { were not included since } \\
\text { such debris would probably either break up into } \\
\text { smaller pieces during drywell transport or settle at } \\
\text { the bottom of the drywell. Discussions related to size } \\
\text { classes of the fibrous data were revised to reflect } \\
\text { insights gained from the most recent NRC } \\
\text { experiments. }\end{array}$ \\
\hline
\end{tabular}




\begin{tabular}{|c|c|c|c|}
\hline \multicolumn{4}{|c|}{ Commentor: Performance Contracting, Inc. - Gordon H. Hart } \\
\hline $\begin{array}{c}\text { Comment \# I } \\
\text { Location }\end{array}$ & Type & Comment & Response \\
\hline $\begin{array}{l}\text { PCI-11 / } \\
\text { Section B.2.8 } \\
\text { page B-25 }\end{array}$ & Technical & $\begin{array}{l}\text { Statements are made about the need to exclude head loss } \\
\text { data collected on low values of shredded insulation debris } \\
\text { thickness. PCI agrees that those thin beds were non-uniform, } \\
\text { at } 1 / 4 \text { " and } 1 / 2 \text { " thickness, and therefore only represented } \\
\text { partial blockage of the strainers surface. Consequently, } \\
\text { measured pressure drops for those tests were unusually small } \\
\text { and the results were understandably not used in developing } \\
\text { Equation } 24 . \\
\text { However, PCI has a problem with this approach as we look } \\
\text { to the future: if large surface area strainers are eventually } \\
\text { proposed as plant modifications (maybe with areas of } 150 \mathrm{ft}^{2} \\
\text { each, giving a total strainer area per plant of } 600 \text { to } 900 \mathrm{ft}^{2} \text {, } \\
\text { which might lead to theoretical debris thicknesses of less than } \\
1 / 2 "), \text { then Equation } 24 \text { would not be valid! In fact, with } \\
\text { portions of the strainers having no fibrous debris at all due } \\
\text { to non-uniform coverage, sludge particles may not ever get } \\
\text { trapped on those clean screen areas. Therefore, to allow for } \\
\text { accurate design of large surface area strainers, we } \\
\text { recommend the development of a second equation which } \\
\text { could be used for NUKONTM thicknesses less than } 1 " \text {. }\end{array}$ & $\begin{array}{l}\text { Based on recent NRC experiments, it appears that } \\
\text { while thinner beds (theoretical thickness }<1 / 4 " \text { ) are } \\
\text { likely to be non-uniform, the degree of non- } \\
\text { uniformity depends on a variety of factors, including } \\
\text { approach velocity, debris size class, and debris } \\
\text { concentration. The data suggest that uniform fibrous } \\
\text { beds can be formed at theoretical thicknesses as low } \\
\text { as } 1 / 8^{\prime \prime} \text {. As shown in Table B- } 7 \text { of this report, the } \\
\text { correlation was in good agreement with the } \\
\text { experimental data to thicknesses of } 1 / 8^{\prime \prime} \text {. Thus, it is } \\
\text { not accurate to conclude that the head loss equation } \\
\text { is only valid for very thick ( } 7 ") \text { beds. } \\
\text { In addition, it is clear that filtration efficiency is } \\
\text { strongly dependent on the bed thickness. The model } \\
\text { was revised to reflect this finding using measured } \\
\text { filtration efficiencies. }\end{array}$ \\
\hline
\end{tabular}




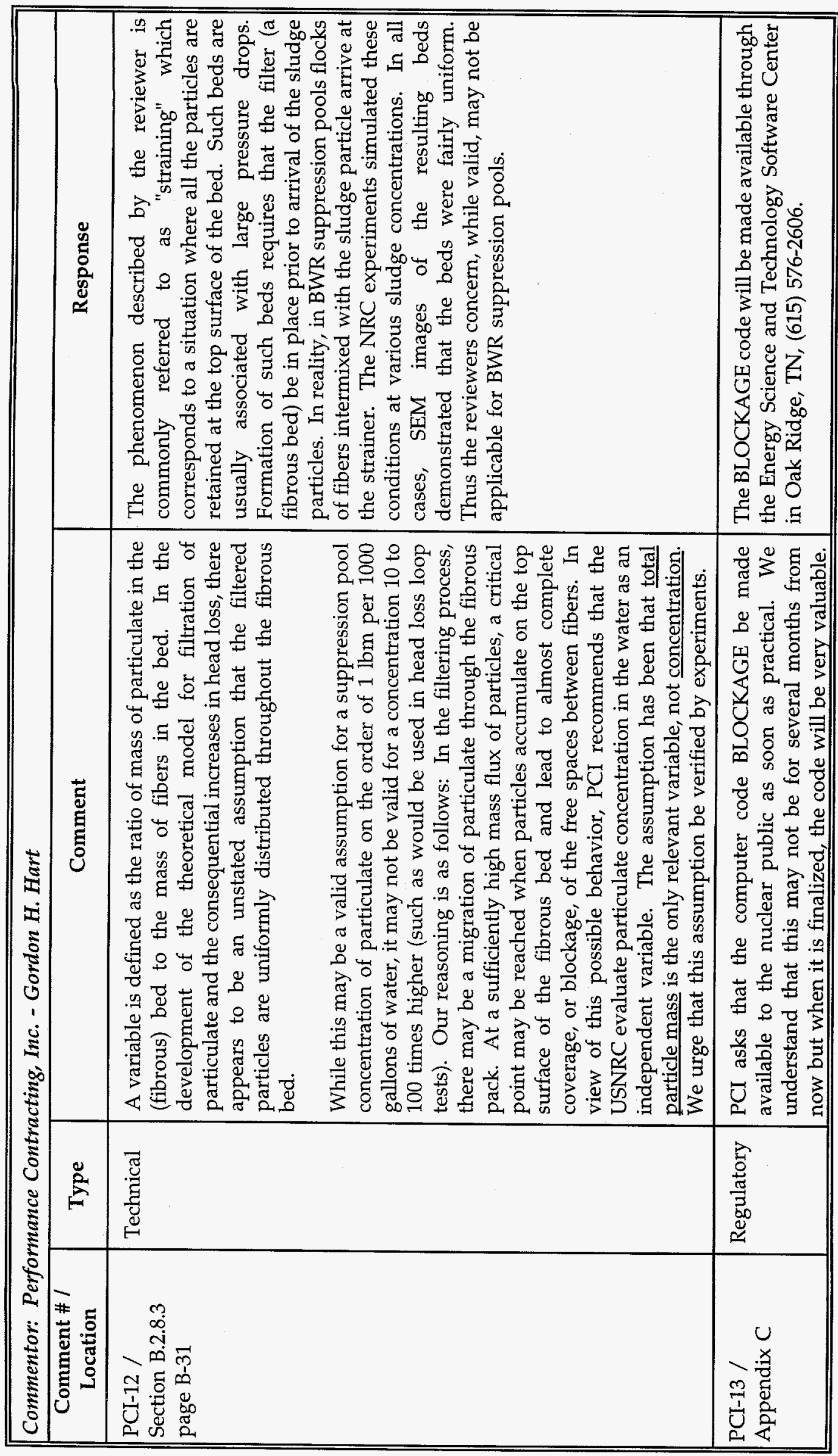




\begin{tabular}{|c|c|c|c|}
\hline \multicolumn{4}{|c|}{ Commentor: Transco Products, Inc. - Edward J. Wolbert } \\
\hline $\begin{array}{l}\text { Comment \# I } \\
\text { Location }\end{array}$ & Type & Comment & Response \\
\hline $\begin{array}{l}\text { TPI-1 / } \\
\text { Section 2.6; } \\
\text { page 2-7 } \\
\text { subpoint 2; } \\
\text { last sentence }\end{array}$ & Editorial & $\begin{array}{l}\text { The last sentence states "Conclusions derived for steel-jacketed } \\
\text { NUKON }{ }^{\mathrm{TM}} \text { may not necessarily be conservative when compared } \\
\text { with metallic (metal reflective), mineral wool, high density } \\
\text { fiberglass, or unjacketed NUKON }{ }^{\mathrm{TM}} \text { insulation." The wording } \\
\text { could lead the reader to believe that there may be a basis for } \\
\text { believing that some materials (i.e., metal reflective) cause more } \\
\text { blockage than the subject fiber material, when in fact there is no } \\
\text { data to support this. The word "conservative" should be } \\
\text { changed to "representative". }\end{array}$ & $\begin{array}{l}\text { NUREG/CR- } 6224 \text { has been changed to reflect this } \\
\text { comment. The word conservative was deleted } \\
\text { and replaced with representative in this section. }\end{array}$ \\
\hline $\begin{array}{l}\text { TPI-2 / } \\
\text { Section } 3.3 .4 \\
\text { page 3-5 } \\
\text { subpoint } 3 \\
\text { last sentence }\end{array}$ & Technical & $\begin{array}{l}\text { The last sentence of the paragraph indicates that no additional } \\
\text { targets were found to be in the vicinity of the core spray welds. } \\
\text { However, Figure } 3-1 \text { appears to show that the core spray is } \\
\text { straddled by two of the main steam risers. Were these main } \\
\text { steam lines considered in the target analysis for the core spray? }\end{array}$ & $\begin{array}{l}\text { In two-dimensional figures, the main steam lines } \\
\text { appeared to be close to the core spray. In reality, } \\
\text { they were not very close. Additionally, main } \\
\text { steam lines were considered, but it was found } \\
\text { that they were not insulated above elevation } \\
796^{\prime} 5^{\prime \prime} \text {. }\end{array}$ \\
\hline $\begin{array}{l}\text { TPI-3A / } \\
\text { Section } 3.4 \\
\text { page 3-16 } \\
\text { first paragraph } \\
\text { first sentence }\end{array}$ & Editorial & $\begin{array}{l}\text { The first sentence of the first paragraph states that "The primary } \\
\text { lines in the containment are insulated using } 22 \text { gauge }(0.045 ") \\
\text { steel-jacketed NUKON"M..." However, } 22 \text { gauge stainless steel } \\
\text { is } 0.0293 \text { " thick, not } 0.045 " \text {. }\end{array}$ & $\begin{array}{l}\text { NUREG/CR-6224 was modified to reflect the } \\
\text { proper thickness in inches. }\end{array}$ \\
\hline $\begin{array}{l}\text { TPI-3B / } \\
\text { Section } 3.4 \\
\text { page } 3-16 \\
\text { 2nd paragraph } \\
\text { 2nd sentence }\end{array}$ & Editorial & $\begin{array}{l}\text { In addition, in the second sentence of the second paragraph it } \\
\text { is stated that "The blanket has a low density }\left(2 \text { to } 3 \mathrm{lb} / \mathrm{ft}^{3}\right) \text { and } \\
\text { is completely jacketed by } 22 \text { gauge } 304 \mathrm{SS} \text { covers..." However, } \\
\text { the stated density is that of the base wool, not of the entire } \\
\text { blanket. }\end{array}$ & $\begin{array}{l}\text { NUREG/CR- } 6224 \text { has been modified to reflect this } \\
\text { comment. }\end{array}$ \\
\hline $\begin{array}{l}\text { TPI-3C / } \\
\text { Section } 3.4\end{array}$ & Editorial & $\begin{array}{l}\text { Also, the text indicates that the blanket is completely covered } \\
\text { by jacketing. However, the type of "boots" installed at hangers, } \\
\text { such as is visible in the upper picture in Figure 3-14, are rarely } \\
\text { covered with metal jacketing. Were these boots metal-jacketed } \\
\text { at the reference plant, and was the volume of insulation for } \\
\text { these boots considered in the target analysis? }\end{array}$ & $\begin{array}{l}\text { The engineering drawings provided were not } \\
\text { detailed enough to draw such information. } \\
\text { Therefore, in this analysis it was assumed that the } \\
\text { blanket was completely jacketed. However, NRC } \\
\text { believes that individual plants should pay close } \\
\text { attention to such details as part of their plant- } \\
\text { specific analysis. }\end{array}$ \\
\hline
\end{tabular}




\begin{tabular}{|c|c|c|c|}
\hline \multicolumn{4}{|c|}{ Commentor: Transco Products, Inc. - Edward J. Wolbert } \\
\hline $\begin{array}{l}\text { Comment \#/ } \\
\text { Location }\end{array}$ & Type & Comment & Response \\
\hline $\begin{array}{l}\text { TPI- } 4 \text { / } \\
\text { Sections } 4.2 \text { and } \\
4.3 \\
\text { page } 4-10 \text { to } 4-24\end{array}$ & Regulatory & $\begin{array}{l}\text { The document seems to go to great lengths at times to limit the } \\
\text { applicability of the report to the reference plant. Yet in this } \\
\text { paragraph, the applicability of the debris generation model } \\
\text { seems to be extended to envelope other Mark I BWR's with } \\
\text { steel-jacketed NUKONTM. } \\
\text { If the applicability is limited only to the reference plant, should } \\
\text { there not be a more detailed discussion of how the factors were } \\
\text { arrived at in order to establish a consistent methodology within } \\
\text { the industry? }\end{array}$ & $\begin{array}{l}\text { NUREG/CR-6224 analyzed the reference plant } \\
\text { and was not intended to be used for other plant- } \\
\text { specific analyses without addressing the } \\
\text { applicability of assumptions used for the reference } \\
\text { plant. }\end{array}$ \\
\hline $\begin{array}{l}\text { TPI-5 / } \\
\text { Section } 4.2 .1 \\
\text { page } 4-11 \\
\text { subpoint } 4 \\
\text { last sentence }\end{array}$ & Editorial & $\begin{array}{l}\text { The last sentence in the paragraph states that "...conventional } \\
\text { encapsulations are designed to withstand pressure loading from } \\
\text { outside to inside." This statement is not necessarily correct. } \\
\text { The attachment hardware is designed and located to withstand } \\
\text { seismic acceleration of the underlying mass outward from the } \\
\text { piping and/or equipment. }\end{array}$ & $\begin{array}{l}\text { NUREG/CR-6224 was modified to reflect this } \\
\text { comment. }\end{array}$ \\
\hline $\begin{array}{l}\text { TPI-6 / } \\
\text { Section } 4.2 .2 \\
\text { page } 4-14 \\
\text { second column } \\
\text { paragraph } 2 \\
\text { last sentence }\end{array}$ & Editorial & $\begin{array}{l}\text { The last sentence of the paragraph titled "Region III:" states } \\
\text { "This 7L/D limit is also consistent with } 1982 \text { and } 1983 \text { Alden } \\
\text { Research Laboratories (ARL) experiments sponsored by the } \\
\text { NRC [Ref. } 4.9 \text { and } 4.10] " . \text { Reference } 4.10 \text { however deals with } \\
\text { the buoyancy, transport and head loss of fibrous reactor } \\
\text { insulation, and did not develop data on the generation of } \\
\text { debris. }\end{array}$ & $\begin{array}{l}\text { NUREG/CR- } 6224 \text { was modified to reflect the } \\
\text { correct reference. }\end{array}$ \\
\hline $\begin{array}{l}\text { TPI-7 / } \\
\text { Section } 4.3 .1 \\
\text { page } 4-22 \\
\text { second column } \\
\text { subpoint } 1 \\
\text { first sentence }\end{array}$ & Technical & $\begin{array}{l}\text { The text indicates that "...debris transport to the pool consists of } \\
\text { two components: (a) transport during blowdown by } \\
\text { recirculating steam flow to the suppression pool, and (b) } \\
\text { transport due to washdown of the debris remaining in the } \\
\text { drywell by the break flow cascading downwards from the } \\
\text { break location." The effects of activation of containments } \\
\text { sprays should also be mentioned, either as part of (b) or as a } \\
\text { separate item. This comment is also applicable to Table 5-2 on } \\
\text { page 5-5. }\end{array}$ & $\begin{array}{l}\text { NUREG/CR- } 6224 \text { was modified to address the } \\
\text { activation of containment spray. }\end{array}$ \\
\hline
\end{tabular}




\begin{tabular}{|c|c|c|c|}
\hline $\begin{array}{l}\text { Comment \# I } \\
\text { Location }\end{array}$ & Type & Comment & Response \\
\hline $\begin{array}{l}\text { TPI-8 / } \\
\text { Section } 4.5 .1 \\
\text { page } 4-25 \\
\text { second column } \\
\text { first \& second } \\
\text { sentences }\end{array}$ & Editorial & $\begin{array}{l}\text { In the first and second full sentences at the top of the column } \\
\text { it is asserted that the head loss tests were performed on "...as } \\
\text { fabricated blankets...", and that the "...blankets were used "as-is" } \\
\text { for head loss measurements..." This however is not accurate. } \\
\text { The tests were run on the as-fabricated base wool; in other } \\
\text { words, unshredded base wool, without the cloth covering. This } \\
\text { is an important distinction since the added cloth layers could } \\
\text { be expected to significantly alter the test results and the } \\
\text { resultant best fit regression equations. The same comment is } \\
\text { applicable to paragraph } 4.5 .2 \text { where the phrase "...as fabricated } \\
\text { NUKON }{ }^{T M} \text { blankets..." is used again. }\end{array}$ & $\begin{array}{l}\text { It is correct that the head loss measurements were } \\
\text { for unshredded base wool without cloth covering. } \\
\text { NUREG/CR-6224 was modified to clarify this } \\
\text { point. }\end{array}$ \\
\hline $\begin{array}{l}\text { TPI-9 / } \\
\text { Section } 4.5 .4 \\
\text { page } 4-29 \\
\text { second column } \\
\text { last paragraph } \\
\text { first sentence }\end{array}$ & Editorial & $\begin{array}{l}\text { Near the bottom of the column "...25,000 GMP..." should be } \\
25,000 \text { GPM. }\end{array}$ & $\begin{array}{l}\text { NUREG/CR- } 6224 \text { was modified to reflect this } \\
\text { comment. }\end{array}$ \\
\hline $\begin{array}{l}\text { TPI-10 / } \\
\text { Section } 5.2 \\
\text { page } 5-15 \\
\text { subpoint } 1 \\
\text { first sentence }\end{array}$ & Technical & $\begin{array}{l}\text { In the first sentence at the top of page } 5-15 \text { it is stated that } \\
\text { "...with doubling the strainer area, few large breaks generated } \\
\text { volumes sufficient to cause loss of NPSH margin at the } \\
\text { reference plant" However, Figure } 5-5 \text { still shows that all six } \\
\text { cases evaluated exceed the } 15 \mathrm{ft} \text {-water NPSH margin. Please } \\
\text { clarify. }\end{array}$ & $\begin{array}{l}\text { This section of NUREG/CR- } 6224 \text { has been } \\
\text { modified and the revised section does provide the } \\
\text { requested clarification. }\end{array}$ \\
\hline $\begin{array}{l}\text { TPI-11 / } \\
\text { Appendix B } \\
\text { Section B.2.8.1 } \\
\text { page B-25 } \\
\text { first sentence }\end{array}$ & Editorial & $\begin{array}{l}\text { In the first sentence, the phrase "...and Transco insulation } \\
\text { marketed by Transco, Inc." should be replaced with "...and } \\
\text { THERMAL-WRAP® blanket insulation marketed by Transco } \\
\text { Products Inc.". }\end{array}$ & $\begin{array}{l}\text { NUREG/CR- } 6224 \text { was modified to reflect this } \\
\text { comment. }\end{array}$ \\
\hline
\end{tabular}




\begin{tabular}{|c|c|c|c|}
\hline \multicolumn{4}{|c|}{ Commentor: Transco Products, Inc. - Edward J. Wolbert } \\
\hline $\begin{array}{c}\text { Comment \# I } \\
\text { Location }\end{array}$ & Type & Comment & Response \\
\hline $\begin{array}{l}\mathrm{TPI}-12 / \\
\text { Appendix D }\end{array}$ & Technical & $\begin{array}{l}\text { For the postulated pipe breaks below the } 757^{\prime} \text { elevation, no } \\
\text { indication is given as to whether insulation on the recirculation } \\
\text { pumps was considered as a target. Are the recirculation pumps } \\
\text { at the reference plant insulated with fibrous material, and if so } \\
\text { was this volume of insulation considered in the target analysis? } \\
\text { The large area of insulation normally on recirculation pumps in } \\
\text { BWR's could represent a substantial volume of debris for } \\
\text { certain primary pipe breaks. }\end{array}$ & $\begin{array}{l}\text { Insulation on the recirculation pumps was not } \\
\text { included in this analysis. }\end{array}$ \\
\hline
\end{tabular}




\section{F.4 Technical Comments by Category}

\begin{tabular}{|c|c|c|c|}
\hline \multicolumn{4}{|c|}{ Category 1: Debris Generation Model } \\
\hline $\begin{array}{l}\text { Comment \# I } \\
\text { Location }\end{array}$ & Type & Comment & Response \\
\hline $\begin{array}{l}\text { BWROG-B10/ } \\
\text { Section } 4.2\end{array}$ & Technical & $\begin{array}{l}\text { We disagree with the reasoning supporting the spherical jet } \\
\text { expansion model. If indeed the basis for the sphere is the jet } \\
\text { being deflected by surrounding pipe, then it would seem } \\
\text { that the deflection would absorb most of the jet's energy, } \\
\text { resulting in a much smaller zone of influence. The spherical } \\
\text { model results in an overly conservative model. }\end{array}$ & $\begin{array}{l}\text { The basis for choosing the spherical model was } \\
\text { that after a break in a steam line there would be } \\
\text { jets from each side of the break. The interaction } \\
\text { of these two expanding jets would cause a } \\
\text { redistribution of fluid flow, leading to pressure } \\
\text { fields that may be widely different from those } \\
\text { estimated based on the conical zone-of-influence } \\
\text { model. The assumption of a spherical expansion } \\
\text { is not in itself more conservative than a conical } \\
\text { model; the degree of conservatism depends on } \\
\text { how the other parameters of the model (such as } \\
\text { destruction factor or zone of destruction) are } \\
\text { chosen. }\end{array}$ \\
\hline $\begin{array}{l}\text { BWROG-B11/ } \\
\text { Section } 4.2\end{array}$ & Technical & $\begin{array}{l}\text { The NUREG states that blowdown is expected in both } \\
\text { directions from the DEGB. This is not true for all breaks } \\
\text { modeled in the study. For breaks which have a blowdown } \\
\text { from only one side of the break, such as RHR or HPCI, a } \\
\text { single-sided zone of influence would appear more } \\
\text { appropriate. }\end{array}$ & $\begin{array}{l}\text { During the plant analysis, it was recognized that } \\
21 \text { out of } 345 \text { welds will result in blowdown } \\
\text { from only one side of the break, for example, } \\
\text { RHR piping welds. A hemispherical zone of } \\
\text { influence was considered for these welds; } \\
\text { however, a hemisphere may not bound the zone } \\
\text { of influence considering that most of the breaks } \\
\text { are located in areas that are congested with } \\
\text { primary pipes and valves. As a result, a } \\
\text { conservative assumption to use a spherical zone } \\
\text { of influence was made to simplify the analysis. } \\
\text { Usage of a spherical zone of influence did not } \\
\text { double the volume of debris generated as one } \\
\text { might assume because for the majority of these } \\
\text { breaks, the targets are located to one side of the } \\
\text { break. The increase in debris volume for several } \\
\text { breaks is no more than } 25 \% \text {. Finally, this } \\
\text { assumption affects only } 21 \text { of the } 345 \text { welds and } \\
\text { does not vary the overall results of this study. }\end{array}$ \\
\hline
\end{tabular}




\begin{tabular}{|c|c|c|c|}
\hline \multicolumn{4}{|c|}{ Category 1: Debris Generation Model } \\
\hline $\begin{array}{l}\text { Comment \# / } \\
\text { Location }\end{array}$ & Type & Comment & Response \\
\hline $\begin{array}{l}\text { BWROG-B12/ } \\
\text { Section } 4.2\end{array}$ & Technical & $\begin{array}{l}\text { Use of the Battelle video as a basis for the debris generation } \\
\text { model questions the validity of the model. The International } \\
\text { Piping Integrity Research Group Test } 1.3-7 \text { was performed at } \\
\text { pressure and temperature conditions typical of PWRs ( } 2250 \\
\text { psig and } 550^{\circ} \mathrm{F} \text { ). Based on the discussion in the NUREG, } \\
\text { the initial blast (pressure wave) is the initiating failure } \\
\text { mechanism, followed by the secondary mechanism of the } \\
\text { "fluid jet...peeling off the unprotected layer." Without the } \\
\text { first mechanism, the second should not occur. It is difficult } \\
\text { to understand how this pressure wave can be characterized } \\
\text { from the video. } \\
\text { Furthermore, it would not seem likely that the spherical jet } \\
\text { effects from a single pipe break can be identified from the } \\
\text { video, given that there were no target pipes in the } \\
\text { experimental set-up. }\end{array}$ & $\begin{array}{l}\text { The Battelle video was shown at the 3-30-94 } \\
\text { public meeting to illustrate a pipe break jet and } \\
\text { to solicit views regarding the modelling of such } \\
\text { an expanding break jet. The BWROG comments } \\
\text { dated 4-14-94 (received following this meeting) } \\
\text { stated: } \\
\text { "The BWROG also agrees with SEA's recognition } \\
\text { that most BWRs have highly congested piping in } \\
\text { the drywell and that a guillotine-type pipe break } \\
\text { may be better represented by a spherical zone of } \\
\text { destruction than by two back-to-back } 90^{\circ} \text { cones. } \\
\text { Based on test information in the public arena } \\
\text { concerning insulation systems currently installed } \\
\text { in U.S. nuclear plants, the BWROG agrees that } \\
\text { fibrous insulation materials located within a } \\
\text { zone of destruction with a radius of three times } \\
\text { the pipe diameter are highly likely to suffer } \\
\text { destruction, with or without metal jacketing. } \\
\text { With an expanding jet, the corresponding } \\
\text { destruction would decrease significantly with } \\
\text { increasing distance from the guillotine break, as } \\
\text { pointed out by SEA." } \\
\text { The analyses and results presented in } \\
\text { NUREG/CR-6224 utilize BWR operating } \\
\text { pressures with a reduced jet expansion distance, } \\
\text { but have retained the spherical model. } \\
\text { Although the Battelle videos were not designed } \\
\text { to investigate insulation destruction, discussions } \\
\text { with staff familiar with the tests revealed that } \\
\text { each test severely destroyed piping insulation } \\
\text { within +/- seven L/D's of the break location, } \\
\text { necessitating continued re-insulation of that } \\
\text { portion of the test loop. }\end{array}$ \\
\hline
\end{tabular}




\begin{tabular}{|c|c|c|c|}
\hline \multicolumn{4}{|c|}{ Category 1: Debris Generation Model } \\
\hline $\begin{array}{l}\text { Comment \# I } \\
\text { Location }\end{array}$ & Type & Comment & Response \\
\hline $\begin{array}{l}\text { BWROG-B12 / } \\
\text { (cont.) }\end{array}$ & Technical & ?. & $\begin{array}{l}\text { Although break jet expansion models have been } \\
\text { developed for predicting structural loads, these } \\
\text { codes do not have the capability to predict the } \\
\text { types and amounts of LOCA generated } \\
\text { insulation debris which might occur. The video } \\
\text { was a reminder of the destructive nature of a } \\
\text { pipe break. }\end{array}$ \\
\hline $\begin{array}{l}\text { BWROG-B13/ } \\
\text { Section } 4.2\end{array}$ & Technical & $\begin{array}{l}\text { The spherical debris generation model does not conserve } \\
\text { momentum. The } 3 / 5 / 7 \mathrm{~L} / \mathrm{D} \text { zones of destruction used in } \\
\text { the NUREG/CR-6224 analysis are based on calculations of } \\
\text { pressures as a function of distance from a break assuming a } \\
\text { conical-shaped jet. If a spherical expansion is postulated, } \\
\text { pressures should be calculated using an expanding spherical } \\
\text { surface. Destruction zones should then be based on the } \\
\text { distances at which load pressures occur which are } \\
\text { equivalent to those in a conical jet at } 3 / 5 / 7 \mathrm{~L} / \mathrm{D} \text {. Use of } \\
\text { load pressures typical of a conical jet in a postulated } \\
\text { spherical expansion effectively overstates the available } \\
\text { momentum by a factor proportional to the ratio of the total } \\
\text { surface area of the sphere to the portion of that surface area } \\
\text { which falls within the cone. For a } 90^{\circ} \text { cone, the surface area } \\
\text { of the sphere at any given L/D is four times larger than the } \\
\text { portion of that surface within the cone. }\end{array}$ & $\begin{array}{l}\text { The zones of destruction are based upon } \\
\text { engineering judgement, not upon calculations of } \\
\text { pressure as a function of distance. The } \\
\text { calculations of pressures for a steady-state } \\
\text { expanding jet were cited to provide the } \\
\text { background for previous work and to explain } \\
\text { one source of insight that contributed to } \\
\text { engineering judgement. To avoid } \\
\text { misunderstanding, the isobars were eliminated } \\
\text { from Figure } 4-3 \text { of NUREG/CR-6224 Draft for } \\
\text { Comment (Figure B- } 4 \text { in this report), along with } \\
\text { the note explaining the isobars. Also, the } \\
\text { discussion of isobars were removed. }\end{array}$ \\
\hline
\end{tabular}




\begin{tabular}{|c|c|c|c|}
\hline \multicolumn{4}{|c|}{ Category 1: Debris Generation Model } \\
\hline $\begin{array}{l}\text { Comment \# I } \\
\text { Location }\end{array}$ & Type & Comment & Response \\
\hline $\begin{array}{l}\text { BWROG-B15/ } \\
\text { Section 4.2.4 } \\
\text { Item \#3 }\end{array}$ & Technical & $\begin{array}{l}\text { The basis for excluding shadowing effects from } \\
\text { consideration is unclear. The insulation on the backside of } \\
\text { the target pipes (with respect to the break source) would } \\
\text { definitely not be damaged into "fines" like that on the front } \\
\text { side of the same pipe. We suggest that credit be taken for } \\
\text { this type of shadowing effect in the debris generation model. } \\
\text { With respect to item \#3 of Section } 4.2 .4 \text {, it is agreed that } \\
\text { taking credit for shadowing effects of containment structures } \\
\text { is difficult, but the shadowing of target pipes themselves } \\
\text { should be relatively easy. }\end{array}$ & $\begin{array}{l}\text { The insulation on the back side of a pipe should } \\
\text { not experience the same forces as that on the } \\
\text { front side. This may lead to reduced } \\
\text { contribution of insulation debris, especially at } \\
\text { distances farther from the break. However, this } \\
\text { level of knowledge does not exist experimentally } \\
\text { or analytically. This is one of the effects } \\
\text { considered in estimating the destruction factors } \\
\text { for each region. Individual plants should } \\
\text { account for the shadowing effect in their } \\
\text { individual analyses if resources permit. } \\
\text { Not all debris were assumed to be "fines." (See } \\
\text { Appendix B). }\end{array}$ \\
\hline $\begin{array}{l}\text { BWROG-B16/ } \\
\text { Section 4.2.3 }\end{array}$ & Technical & $\begin{array}{l}\text { In Section } 4.2 .3 \text {, "Other Types of Debris Generated by LOCA } \\
\text { Jets," the basis for the } 2.6 \mathrm{cu} \text {. ft. of particulate debris that is } \\
\text { generated in the drywell and transported to the suppression } \\
\text { pool is not apparent. }\end{array}$ & $\begin{array}{l}\text { The amount used in NUREG/CR- } 6224 \text { Draft for } \\
\text { Comment was based on engineering judgement. } \\
\text { This version of NUREG/CR-6224 was modified } \\
\text { by use of BWROG interim report (Dec. 94) } \\
\text { (Appendix III). }\end{array}$ \\
\hline
\end{tabular}




\begin{tabular}{|c|c|c|c|}
\hline \multicolumn{4}{|c|}{ Category 1: Debris Generation Model } \\
\hline $\begin{array}{l}\text { Comment \# I } \\
\text { Location }\end{array}$ & Type & Comment & Response \\
\hline $\begin{array}{l}\text { BWROG-B17/ } \\
\text { Section } 4.2\end{array}$ & Technical & $\begin{array}{l}\text { The analysis states that a spherical debris generation model was } \\
\text { selected because of the following factors: 1) the congested } \\
\text { drywell layout will result in higher break recirculation flow } \\
\text { velocities, 2) jet deflection by surrounding equipment, and 3) jet } \\
\text { interactions between jets from each end of the double-ended } \\
\text { guillotine break (DEGB). If the analysis is going to stipulate } \\
\text { that these phenomena create a spherical zone of influence, then } \\
\text { it must also recognize the other mechanisms by which these } \\
\text { phenomena will affect debris generation and transport, such as } \\
\text { the following: } \\
\text { - } \\
\text { The increased break recirculation flow velocities will } \\
\text { result in a wider distribution of debris throughout the } \\
\text { drywell, and will reduce the amount of debris } \\
\text { transported to the suppression pool during the } \\
\text { blowdown. } \\
\text { The increased break recirculation flow velocities will } \\
\text { reduce the radius of the break zone of influence. } \\
\text { The jet deflection by surrounding equipment will create } \\
\text { "shadowed" zones where no insulation destruction will } \\
\text { take place, and will reduce the radius influence zone. } \\
\text { The interaction between jets from each end of the } \\
\text { DEGB will reduce the flow rate from the break, which } \\
\text { reduces the energy available for insulation destruction } \\
\text { and reduces the zone of influence. } \\
\text { Jet expansion into a spherical volume results in less } \\
\text { energy per unit volume as compared to expansion into } \\
\text { a conical volume. As a result, the radius of the zone of } \\
\text { destruction must also be reduced. }\end{array}$ & $\begin{array}{l}\text { All of those phenomena were taken into } \\
\text { consideration and were used to select and develop } \\
\text { the spherical model. As with other issues with a } \\
\text { large degree of uncertainty, engineering judgement } \\
\text { was used to select the spherical model and the } \\
\text { associated parameters. See responses to comments } \\
\text { B10 through B15. }\end{array}$ \\
\hline $\begin{array}{l}\text { BWROG-B30/ } \\
\text { Appendix B } \\
\text { Section B.2.2 }\end{array}$ & Technical & $\begin{array}{l}\text { Appendix B, Section B.2.2: The mathematical basis for } \\
\text { equations } 6 \text { and } 7 \text { is not obvious. Why isn't } \\
\qquad g^{1}(t)=\frac{1}{T} \\
\text { for } 0<t<T \text {, as } T \Rightarrow 0 \text { worst case. }\end{array}$ & $\begin{array}{l}\text { Numerical implementation of Equations } 6 \& 7 \\
\text { simulate the special case under discussion, i.e., } \\
100 \% \text { of the destructed debris are Class I and } 100 \% \\
\text { of that debris reaches the suppression pool within } 1 \\
\text { sec after the LOCA. Relative to the problem time } \\
\text { scale } 1 \text { sec is short enough to be considered } \\
\text { instantaneous. } \mathrm{g}^{1}(\mathrm{t})=1 / \mathrm{T} \text { is inaccurate since } \int \mathrm{g}(\mathrm{t}) \mathrm{dt} \\
\text { should not exceed } 1 \text {. }\end{array}$ \\
\hline
\end{tabular}




\begin{tabular}{|c|c|c|c|}
\hline \multicolumn{4}{|c|}{ Category 1: Debris Generation Model } \\
\hline $\begin{array}{c}\text { Comment \# / } \\
\text { Location }\end{array}$ & Type & Comment & Response \\
\hline $\begin{array}{l}\text { BWROG-B56/ } \\
\text { Section } 5.2 \\
\text { Item } 3\end{array}$ & Technical & $\begin{array}{l}\text { With respect to the conclusion drawn in item } 3 \text { that the use of a } \\
3 \mathrm{~L} / \mathrm{D}, 100 \% \text { transport model assumption is essentially } \\
\text { equivalent to the more complicated } 7 \mathrm{~L} / \mathrm{D} \text { model, can one } \\
\text { conclude that the models result in the same amount of debris? } \\
\text { If so, would the } 3 \mathrm{~L} / \mathrm{D} \text { model be acceptable for performing } \\
\text { plant-specific analyses? If not, the purpose of the comparison } \\
\text { between the two models is not apparent. }\end{array}$ & $\begin{array}{l}\text { The origin of case \#3, "Break Zone of Destruction } \\
\text { Reduced to } 3 \mathrm{~L} / \mathrm{D} \text { ", was at the March } 30,1994 \\
\text { NRC Public Meeting. In that meeting, it was } \\
\text { suggested that a possible simple alternate to the } \\
\text { base case is complete destruction and transport of } \\
\text { all insulation contained within } 3 \mathrm{~L} / \mathrm{D} \text { to the } \\
\text { suppression pool instantaneously after the accident. } \\
\text { Case \#3 was developed to examine the impact of } \\
\text { such assumptions for the reference plant and } \\
\text { provide limited insights. The fact that case \#3 } \\
\text { predictions are closer to the base case for the } \\
\text { reference plant should not be used as a sole } \\
\text { justification to generalize and use "3 L/D model". } \\
\text { For example, in a different plant the transport } \\
\text { factors may be different from those assumed for } \\
\text { the base case, which would then allow for smaller } \\
\text { quantity of debris being transported in the base } \\
\text { case as compared to the "3 L/D model". The } \\
\text { debris generation model should be reviewed if the } \\
\text { insulation used in the plant is different from the } \\
\text { steel jacketed NUKONTM employed in the reference } \\
\text { plant. Thus, it is strongly recommended that the } \\
\text { analyst perform independent analyses specific to } \\
\text { each plant to evaluate the applicability of debris } \\
\text { generation model to that plant. The } 3 \mathrm{~L} / \mathrm{D} \text { case } \\
\text { was examined for illustrative purposes only and is } \\
\text { no longer discussed in this final version of } \\
\text { NUREG/CR-6224. }\end{array}$ \\
\hline
\end{tabular}




\begin{tabular}{|c|c|c|c|}
\hline \multicolumn{4}{|c|}{ Category 1: Debris Generation Model } \\
\hline $\begin{array}{l}\text { Comment \# I } \\
\text { Location }\end{array}$ & Type & Comment & Response \\
\hline $\begin{array}{l}\mathrm{PCI}-7 / \\
\text { Section } 4.2 .2 \\
\text { pages } 4-14 \text { to } 4-16\end{array}$ & Technical & $\begin{array}{l}\text { The selection of those spherical zones of destruction, as } \\
\text { described with the three destruction factors of } 0.75,0.60 \text {, and } \\
0.40 \text { for Zones I, II, and III, respectively, is conservative but } \\
\text { understandable given the limited data available. This is a very } \\
\text { difficult subject to address. However, the publicly available test } \\
\text { evidence suggests that pipe shadowing does reduce the } \\
\text { destruction of targeted NUKON } \\
\text { NUKON Insulation and that } \\
\text { on targeted NUKON jacketing can have a highly protective effect } \\
\text { generated). }\end{array}$ & $\begin{array}{l}\text { It is acknowledged that the data were limited and } \\
\text { that, combined with engineering judgement, } \\
\text { resulted in the selection of the spherical model. } \\
\text { Also, shadowing can reduce the debris generated. } \\
\text { However, in order to minimize the complexity of } \\
\text { the model, shadowing was not addressed explicitly. } \\
\text { Instead, destruction factors were used in the } \\
\text { analysis to account such factors as shadowing and } \\
\text { partially damaged blankets. }\end{array}$ \\
\hline $\begin{array}{l}\text { PCI-9 / } \\
\text { Section 5.2 } \\
\text { pages 5-7 to 5-24 }\end{array}$ & Technical & $\begin{array}{l}\mathrm{PCI} \text { finds that these parametric analyses are particularly } \\
\text { valuable in highlighting significant variables for, and hence } \\
\text { solutions to, strainer blockage. Of those presented, the } \\
\text { doubling of the strainer surface area may be the most feasible } \\
\text { and practical solution of those evaluated. Those analyses where } \\
\text { the zone of destruction was reduced from } 7 \mathrm{~L} / \mathrm{D} \text { to } 3 \mathrm{~L} / \mathrm{D} \text { is } \\
\text { confusing because other independent variables were also } \\
\text { changed: the destruction factor was increased from } 0.75 \text { to } 1.00 \\
\text { and the transport factor was also increased to } 1.00 \text {. Could these } \\
\text { 3L/D cases be rerun with the original destruction factors and } \\
\text { transport factors so that zone of destruction is the only variable } \\
\text { changed? }\end{array}$ & $\begin{array}{l}\text { A more detailed parametric analysis is included in } \\
\text { the revised NUREG/CR- } 6224 \text {. These analyses, } \\
\text { however, do not include the 3L/D case requested } \\
\text { by the reviewer. The original 3L/D case was } \\
\text { carried out for illustrative purposes, and based on } \\
\text { some of the reviewer comments (e.g., See BWROG- } \\
\text { B56), it was decided not to include it in the revised } \\
\text { NUREG. }\end{array}$ \\
\hline $\begin{array}{l}\text { TPI-2 / } \\
\text { Section } 3.3 .4 \\
\text { page 3-5 } \\
\text { subpoint } 3 \\
\text { last sentence }\end{array}$ & Technical & $\begin{array}{l}\text { The last sentence of the paragraph indicates that no additional } \\
\text { targets were found to be in the vicinity of the core spray welds. } \\
\text { However, Figure } 3-1 \text { appears to show that the core spray is } \\
\text { straddled by two of the main steam risers. Were these main } \\
\text { steam lines considered in the target analysis for the core spray? }\end{array}$ & $\begin{array}{l}\text { In two-dimensional figures, the main steam lines } \\
\text { appeared to be close to the core spray. In reality, } \\
\text { they were not very close. Additionally, main steam } \\
\text { lines were considered, but it was found that they } \\
\text { were not insulated above elevation } 796^{\prime} 5^{\prime \prime} \text {. }\end{array}$ \\
\hline $\begin{array}{l}\text { TPI-12 / } \\
\text { Appendix D }\end{array}$ & Technical & $\begin{array}{l}\text { For the postulated pipe breaks below the } 757^{\prime} \text { elevation, no } \\
\text { indication is given as to whether insulation on the recirculation } \\
\text { pumps was considered as a target. Are the recirculation pumps } \\
\text { at the reference plant insulated with fibrous material, and if so } \\
\text { was this volume of insulation considered in the target analysis? } \\
\text { The large area of insulation normally on recirculation pumps in } \\
\text { BWR's could represent a substantial volume of debris for } \\
\text { certain primary pipe breaks. }\end{array}$ & $\begin{array}{l}\text { Insulation on the recirculation pumps was not } \\
\text { included in this analysis. }\end{array}$ \\
\hline
\end{tabular}




\begin{tabular}{|c|c|c|c|}
\hline \multicolumn{4}{|c|}{ Category 2: Debris Transport Model } \\
\hline $\begin{array}{l}\text { Comment \# I } \\
\text { Location }\end{array}$ & Type & Comment & Response \\
\hline $\begin{array}{l}\text { BWROG-B18/ } \\
\text { Section } 4.3\end{array}$ & Technical & $\begin{array}{l}\text { The NUREG/CR- } 6224 \text { transport model assumes that gratings } \\
\text { located at certain drywell elevations provide the major } \\
\text { impediment to blowdown transport of insulation debris from } \\
\text { the drywell to the wetwell. This model is not consistent with } \\
\text { the phenomenology observed at Barsebäck-2, HDR, and in the } \\
\text { experiments at the Karlshamn facility. These events suggest } \\
\text { that debris deposition occurs on all free surfaces inside } \\
\text { containment, not just at congested areas near floor gratings. } \\
\text { At Barsebäck-2, approximately } 50 \% \text { of the insulation dislodged } \\
\text { remained in the drywell, and was found deposited over a wide } \\
\text { area in containment. As noted in NUREG/CR-6224, a similar } \\
\text { debris deposition phenomenology was also seen during the } \\
\text { HDR experiments. Experiments performed by ABB at } \\
\text { Karlshamn using simulated drywell and wetwell volumes } \\
\text { showed similar deposition of fibrous debris on drywell surfaces, } \\
\text { with the percentage of debris carryover from the drywell to the } \\
\text { wetwell varying smoothly as a function of break steam flow } \\
\text { rate and degree of superheat. }\end{array}$ & $\begin{array}{l}\text { Although this analysis was specific to the reference } \\
\text { plant, the factors used were not inconsistent with } \\
\text { the phenomena observed at Barsebäck-2, HDR and } \\
\text { Karlshamn. } \\
\text { Section } 4.3 .1 \text { of NUREG/CR-6224 Draft for } \\
\text { Comment lists the insights gained from review of } \\
\text { Barsebäck-2 event and the HDR experiments. The } \\
\text { ABB experiments at Karlshamn were not available } \\
\text { for review at the time the draft report was issued; } \\
\text { however, they were reviewed and summarized in } \\
\text { the present version of NUREG/CR-6224. These } \\
\text { experiments, as well as the Barsebäck-2 event, lead } \\
\text { to the conclusion that considerable quantities of } \\
\text { debris would be left behind in the drywell, firmly } \\
\text { attached to the walls, grids and components. It is } \\
\text { likely that the fraction of debris transported to the } \\
\text { suppression pool would depend on steam flow } \\
\text { rate, degree of superheat, and number and type of } \\
\text { interdicting structures. The effect of steam flow } \\
\text { rate and superheat were studied in the ABB } \\
\text { experiments for a given geometry. The transport } \\
\text { fractions were found to increase with steam } \\
\text { superheat. Application of this finding alone to the } \\
\text { reference plant would lead to the inescapable } \\
\text { conclusion that a MSLB would transport a larger } \\
\text { fraction of the debris than a recirculation line break } \\
\text { of the same size. Such a conclusion may not be } \\
\text { accurate because it omits the effect of interdicting } \\
\text { structures. It is known that steam condenses on } \\
\text { the interdicting structures, which are originally } \\
\text { subcooled. Flow distribution around these } \\
\text { structures would increase the potential for } \\
\text { deposition of shreds, which are relatively large, on } \\
\text { such structures. }\end{array}$ \\
\hline
\end{tabular}




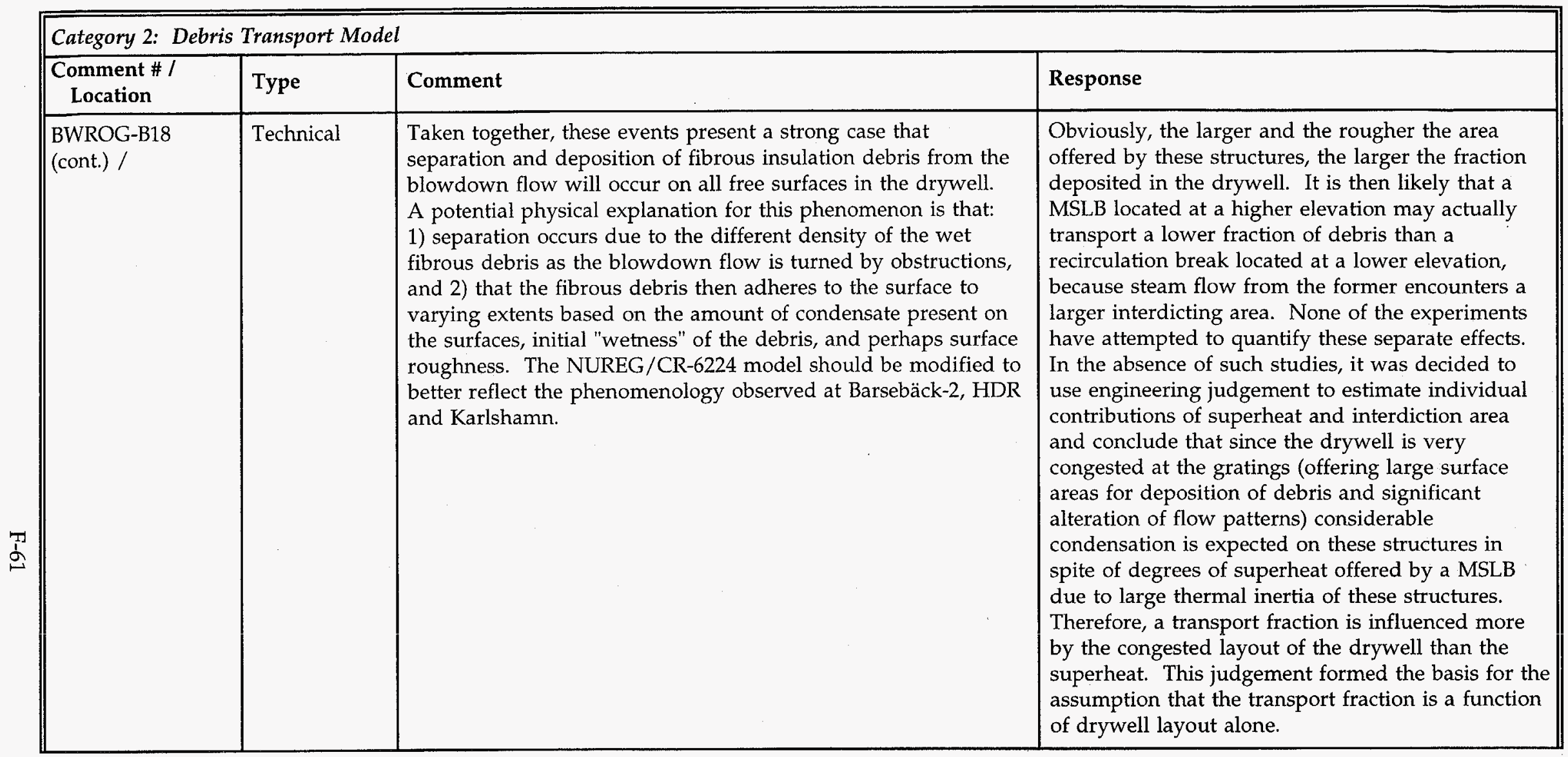




\begin{tabular}{|c|c|c|}
\hline $\begin{array}{c}\text { Comment \# / } \\
\text { Location }\end{array}$ & Type & Comment \\
\hline \multirow[t]{2}{*}{$\begin{array}{l}\text { BWROG-B19/ } \\
\text { Section } 4.3 .1 \\
\text { page } 4-21 \text { to } 4-22\end{array}$} & \multirow[t]{2}{*}{ Technical } & $\begin{array}{l}\text { The NUREG/CR- } 6224 \text { analysis of the Barsebäck- } 2 \text { incident does } \\
\text { not properly reflect the impact of containment spray operation. } \\
\text { [Reference Section } 4.3 .1, \text { p.4-21 to } 4 \text {-22] }\end{array}$ \\
\hline & & $\begin{array}{l}\text { At Barsebäck-2, a "small break" (actually, the lifting of a relief } \\
\text { valve) occurred at a pressure below normal operating system } \\
\text { pressure. This "break" destroyed mineral wool insulation in the } \\
\text { jet flow, and distributed it around the drywell volume. The } \\
\text { NUREG/CR- } 6224 \text { model assumes that the blowdown flow at } \\
\text { Barsebäck- } 2 \text { was the dominant cause of the } 50 \% \text { debris } \\
\text { carryover observed from the drywell to the wetwell. This } \\
\text { interpretation of the Barsebäck- } 2 \text { event is not credible. Based } \\
\text { on consideration of the small size of the "break" (and the } \\
\text { relatively small amount of energy available to drive blowdown } \\
\text { transport), it is unlikely that a significant percentage of the } \\
\text { destroyed insulation was transported by the blowdown mass } \\
\text { flow itself. This expectation is corroborated by the results of } \\
\text { tests performed at Karlshamn, which showed very small } \\
\text { carryover fractions from a simulated drywell volume to a } \\
\text { simulated wetwell volume for small steam breaks. }\end{array}$ \\
\hline
\end{tabular}

simulated wetwell volume for small steam breaks.

The NUREG/CR-6224 debris transport model currently does not properly consider the impact of containment spray system operation during the Barsebäck- 2 event. The NUREG model should be altered to include a more credible evaluation of the importance of containment spray washdown effects. Also, the model should reflect significant operating and design

differences between Barsebäck-2 and the reference Mark 1 plan analyzed in the NUREG. Some of the differences that must be addressed include:

Response

The impact of containment spray operation versus other debris transport mechanisms is not clear in the Barsebäck-2 incident, but the incident does illustrate that a large fraction of debris can be transported to the wetwell. NUREG/CR-6224 was modified to clarify this issue.

NUREG/CR-6224 transport model does not assume that the dominant cause for debris transport in Barsebäck-2 event was blowdown. NUREG/CR6224 Draft for Comment cited the Barsebäck-2 event to simply illustrate the potential for transport of large quantities of debris to the suppression pool. The NUREG/CR-6224 transport model allows for transport of debris in both blowdown and washdown phases. Due to lack of experimental data however, engineering judgement was used to estimate the transport factors for each phase. This version of NUREG/CR-6224 was modified to clarify this issue.

NUREG/CR-6224 addresses all the three issues listed in the comment. For example, NUREG/CR6224 recognizes that actuation of containment sprays in the reference plant was not automatic and hence debris transport due to sprays was not a part of the base case. Similarly, credit was given for jacketed NUKONTM vs mineral wool through the use of destruction factors and limiting the zone of influence to $7 \mathrm{~L} / \mathrm{D}$. Note that zone of influence in Barsebäck-2 extended far beyond $7 \mathrm{~L} / \mathrm{D}$ (by some plant estimates up to $20 \mathrm{~L} / \mathrm{D}$ ). 
Appendix $\mathrm{F}$

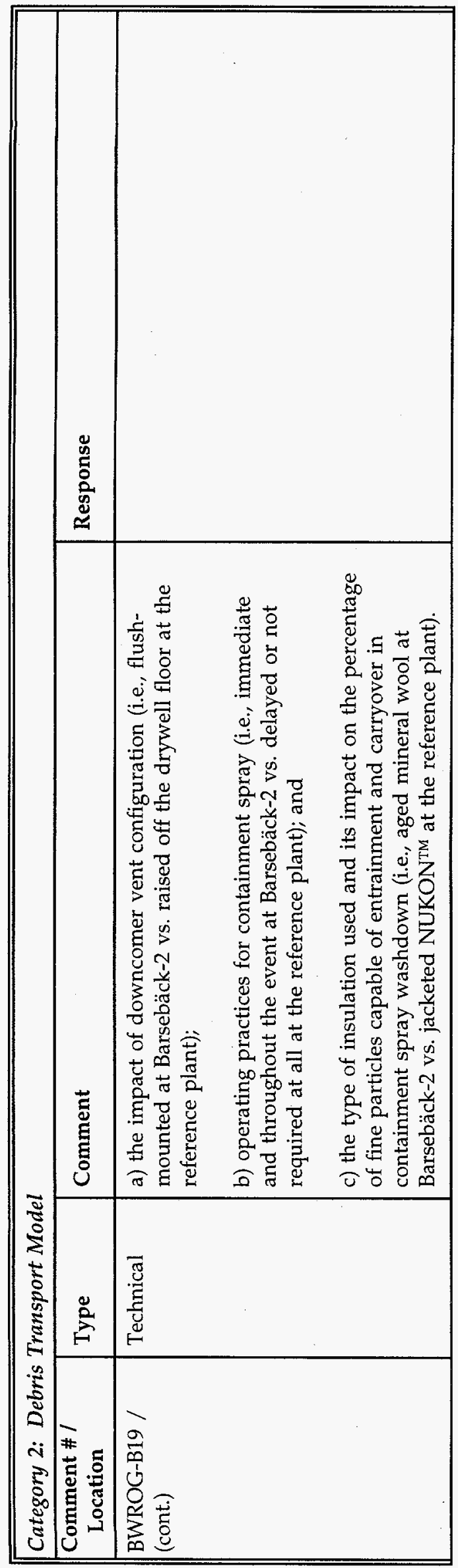




\begin{tabular}{|c|c|c|c|}
\hline \multicolumn{4}{|c|}{ Category 2: Debris Transport Model } \\
\hline $\begin{array}{l}\text { Comment \# I } \\
\text { Location }\end{array}$ & Type & Comment & Response \\
\hline \multirow[t]{2}{*}{$\begin{array}{l}\text { BWROG-B20/ } \\
\text { Section } 4.3\end{array}$} & \multirow[t]{2}{*}{ Technical } & $\begin{array}{l}\text { The NUREG/CR- } 6224 \text { analysis assumes that blowdown results } \\
\text { in transport of a fixed fraction of the total debris generated, } \\
\text { independent of break size. } \\
\text { At a given location in the drywell, the NUREG model predicts } \\
\text { that the blowdown from a } 2^{\prime \prime} \text { line will result in the same } \\
\text { percentage of debris carryover to the wetwell as will blowdown } \\
\text { of a } 24 \text { " line, even though the } 24 \text { " lines has hundreds of times } \\
\text { more energy available to drive the blowdown. This result } \\
\text { cannot be correct. Realistically, the percentage of debris } \\
\text { transport by blowdown from a 2" line break will be negligible, } \\
\text { as the mass flow rate from the break is small compared to the } \\
\text { total volume of the drywell. Again, this expectation is } \\
\text { supported by the phenomenology observed at Karlshamn by } \\
\text { ABB. Extrapolation of information from the events at } \\
\text { Barsebäck-2 appears to support the modeling decision in the } \\
\text { NUREG. Since the impact of containment spray operation was } \\
\text { not properly considered, the model was forced to fit an } \\
\text { approximate } 50 \% \text { blowdown fraction for a } 1.5 \text { " break, rather } \\
\text { than attributing the great majority of this transport fraction to } \\
\text { the effects of containment spray washdown. }\end{array}$ & $\begin{array}{l}\text { It is acknowledged that break sizes play a vital role } \\
\text { in transport of debris during both blowdown and } \\
\text { washdown phases. A conclusive set of } \\
\text { experimental data that could be used to quantify } \\
\text { such dependence was not available. Also, see } \\
\text { response to comment B-19 regarding other issues } \\
\text { raised as part of this comment. }\end{array}$ \\
\hline & & $\begin{array}{l}\text { The NUREG/CR- } 6224 \text { model assumes that break leakage will } \\
\text { result in transport of } 25 \% \text { of the debris remaining in the } \\
\text { drywell post-blowdown, independent of the break size. As } \\
\text { stated above, the fraction of debris carried over by leakage out } \\
\text { of the break must be a function of the break size. Leakage flow } \\
\text { rates from a 2" line break are orders of magnitude smaller than } \\
\text { those from a } 24 \text { " line break. Since the "break" leakage flow is } \\
\text { the driving force for this component of the transport, it is not } \\
\text { credible to use one fixed transport percentage, independent of } \\
\text { break size. }\end{array}$ & \\
\hline
\end{tabular}


Appendix F

\begin{tabular}{|c|c|c|c|c|c|}
\hline & 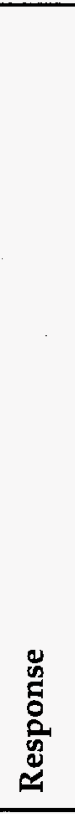 & 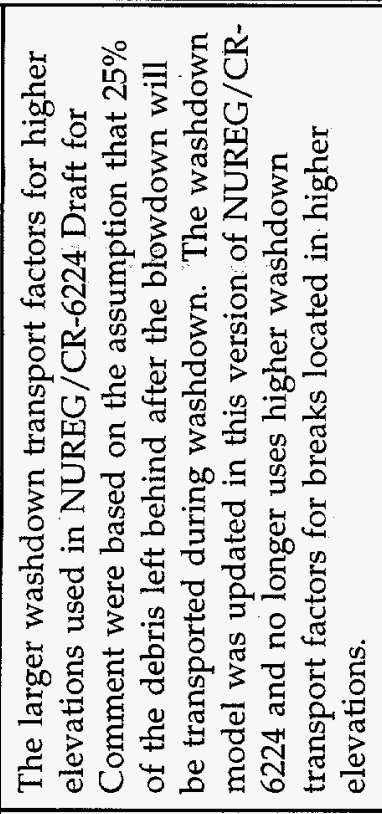 & 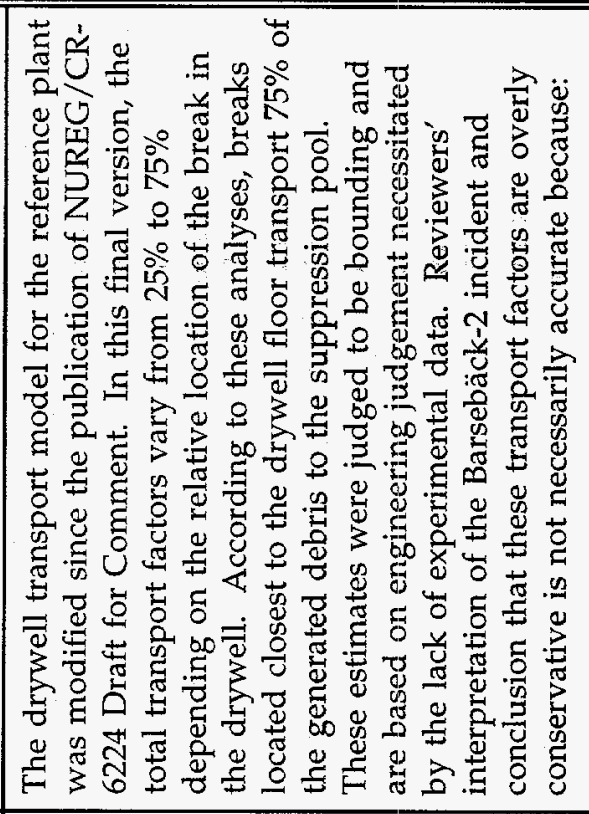 & 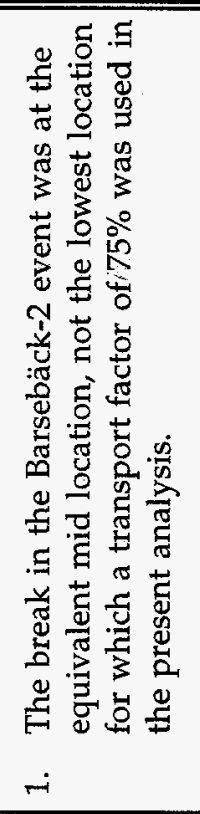 & 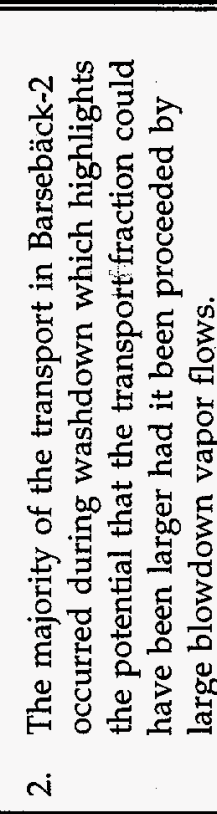 \\
\hline & 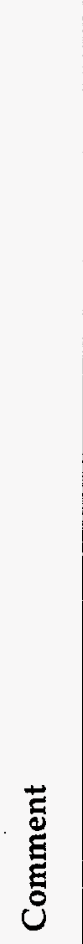 & 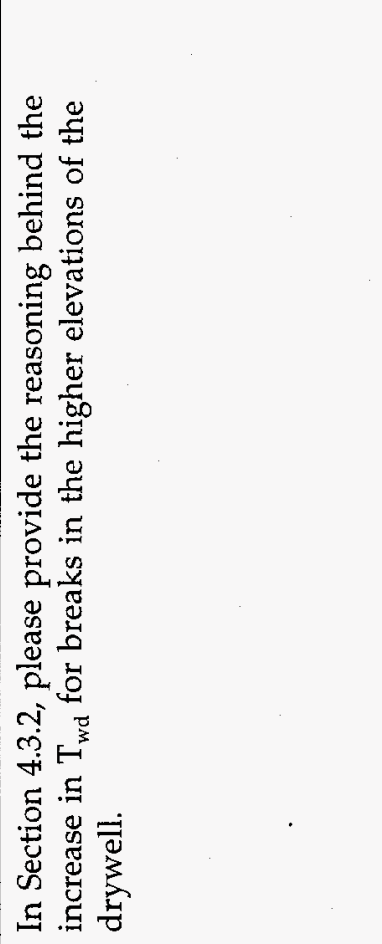 & 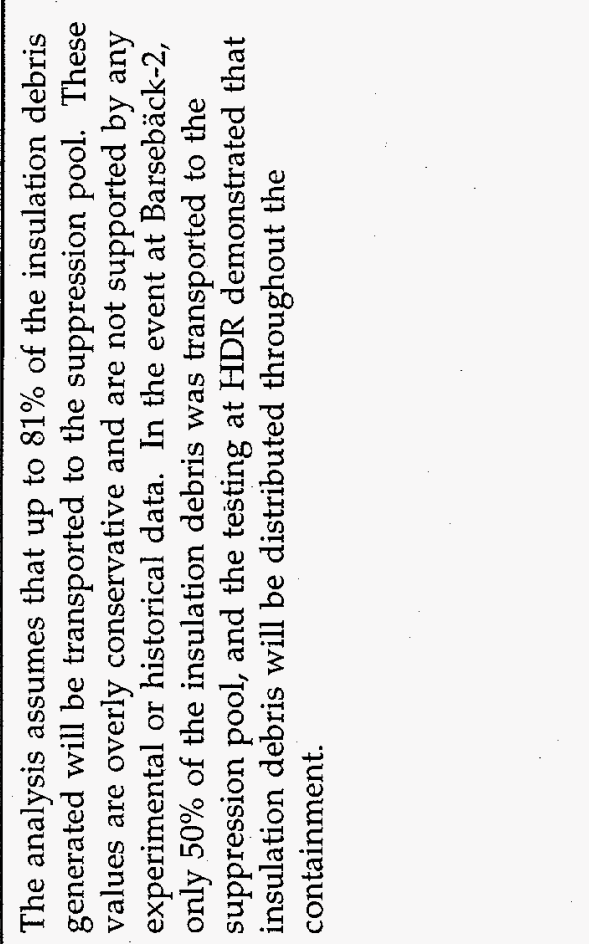 & & \\
\hline & 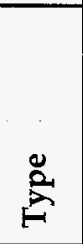 & 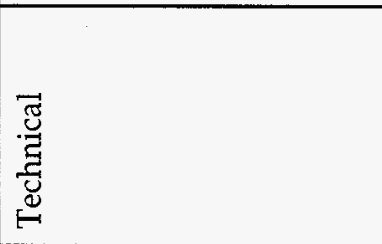 & 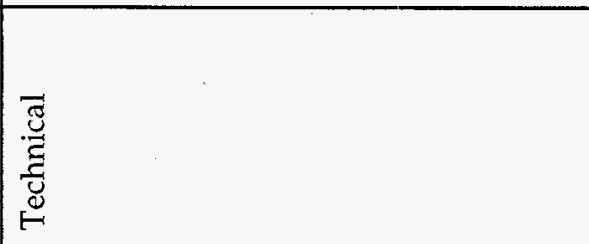 & & \\
\hline $\bar{\delta}$ & 苞 & 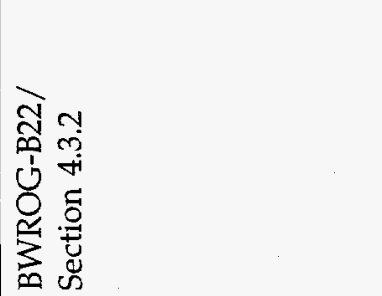 & 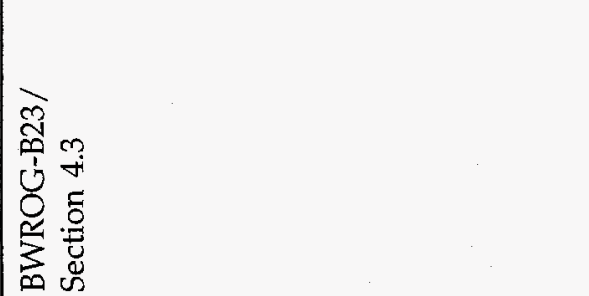 & & \\
\hline
\end{tabular}




\begin{tabular}{|c|c|c|c|}
\hline \multicolumn{4}{|c|}{ Category 2: Debris Transport Model } \\
\hline $\begin{array}{c}\text { Comment \# / } \\
\text { Location }\end{array}$ & Type & Comment & Response \\
\hline $\begin{array}{l}\text { BWROG-B24/ } \\
\text { Section } 4.4\end{array}$ & Technical & $\begin{array}{l}\text { The timing for introduction of debris to the suppression pool } \\
\text { should be modified to correctly reflect a revised model of } \\
\text { blowdown versus containment spray washdown transport, as } \\
\text { noted in previous comments. In particular, the time when } \\
\text { operation of containment spray may occur should be factored } \\
\text { into the source term for introduction of debris into the } \\
\text { suppression pool. }\end{array}$ & $\begin{array}{l}\text { Initiation of the containment spray is not automatic } \\
\text { at the reference plant. Hence, transport by } \\
\text { containment sprays was not included in estimating } \\
\text { the quantity of debris transported during } \\
\text { washdown. Therefore, time scales of debris } \\
\text { transport due to washdown by containment sprays } \\
\text { was not explicitly discussed. NUREG/CR-6224 } \\
\text { was modified to clarify this issue. }\end{array}$ \\
\hline $\begin{array}{l}\text { PCI-8 / } \\
\text { Section } 4.3 \\
\text { pages 4-21 to 4-24 }\end{array}$ & Technical & $\begin{array}{l}\text { In view of the reported } 50 \% \text { insulation debris transported to the } \\
\text { pool at Barsebäck-2, PCI understands the need for conservatism } \\
\text { in selecting debris transport factors for transport from the } \\
\text { drywell to the wetwell. However, subsequent testing by the } \\
\text { Swedish utilities has shown transport factors of less than } 10 \% \text {. } \\
\text { And, the accuracy of the transport data from Barsebäck- } 2 \text { has } \\
\text { been questioned and is currently under review by SKi. There } \\
\text { are also significant differences between US BWR's and Swedish } \\
\text { BWR's relative to downcomer design. Therefore, we believe } \\
\text { that the transport factors of } 25 \%, 50 \% \text {, and } 75 \% \text { are } \\
\text { conservative. }\end{array}$ & $\begin{array}{l}\text { It is recognized that there are large uncertainties in } \\
\text { drywell debris transport predictions and that the } \\
\text { Barsebäck-2 data of 50\% transport was not directly } \\
\text { applicable to the reference plant due to differences } \\
\text { in plant design. Therefore, engineering judgement } \\
\text { was used to select transport factors which were } \\
\text { consistent with the best estimate nature of this } \\
\text { study. }\end{array}$ \\
\hline $\begin{array}{l}\text { TPI-7 / } \\
\text { Section } 4.3 .1 \\
\text { page } 4-22 \\
\text { second column } \\
\text { subpoint } 1 \\
\text { first sentence }\end{array}$ & Technical & $\begin{array}{l}\text { The text indicates that "...debris transport to the pool consists of } \\
\text { two components: (a) transport during blowdown by } \\
\text { recirculating steam flow to the suppression pool, and (b) } \\
\text { transport due to washdown of the debris remaining in the } \\
\text { drywell by the break flow cascading downwards from the } \\
\text { break location." The effects of activation of containments sprays } \\
\text { should also be mentioned, either as part of (b) or as a separate } \\
\text { item. This comment is also applicable to Table } 5-2 \text { on page 5-5. }\end{array}$ & $\begin{array}{l}\text { NUREG/CR-6224 was modified to address the } \\
\text { activation of containment spray. }\end{array}$ \\
\hline
\end{tabular}




\begin{tabular}{|c|c|c|c|}
\hline $\begin{array}{c}\text { Comment \# I } \\
\text { Location }\end{array}$ & Type & Comment & Response \\
\hline $\begin{array}{l}\text { BWROG-B32/ } \\
\text { Appendix B } \\
\text { Section B.2.3 }\end{array}$ & Technical & $\begin{array}{l}\text { Appendix B, Section B.2.3: With respect to the instantaneous } \\
\text { resuspension of sludge, all the mass is not resuspended as } \\
\text { claimed since: } \\
\qquad \frac{d M_{\text {pool }}^{I}}{d t}={ }^{-} M_{\text {Resuspension }}^{I} \\
\qquad M_{\text {pool }}^{I}=M_{\text {Resuspension }}(0) e^{-k t} \text { for } 0<t<1 \mathrm{sec} \text {. }\end{array}$ & $\begin{array}{l}\text { Numerical implementation of Eq. } 9 \text { assumes that all } \\
\text { the sludge mass is resuspended within a second. } \\
\text { Relative to the time scales of the present problem, } 1 \\
\text { sec is short enough to be approximated as } \\
\text { instantaneous. }\end{array}$ \\
\hline
\end{tabular}




\begin{tabular}{|c|c|c|c|}
\hline \multicolumn{4}{|c|}{ Category 3: Suppression Pool Phenomenology } \\
\hline $\begin{array}{l}\text { Comment \# / } \\
\text { Location }\end{array}$ & Type & Comment & Response \\
\hline $\begin{array}{l}\text { BWROG-B33/ } \\
\text { Appendix B } \\
\text { Section B.2.5 }\end{array}$ & Technical & $\begin{array}{l}\text { Appendix B, Section B.2.5: This section raises several technical } \\
\text { concerns. It is proposed to reduce the settling velocity in the } \\
\text { calm pool } \mathrm{V}_{\text {pool }} \text { by a turbulence factor } \tau \text { such that debris settles } \\
\text { with velocity } \mathrm{V}_{\mathrm{s}} \text { according to the following: } \\
\qquad V_{s}=\tau V_{\text {pool }}, 0 \leq \tau \leq 1 \\
\text { The functional form of } \tau \text { is then determined to be: } \\
\qquad \tau=B * \frac{C V_{\text {pool }}}{E^{m}} \\
\text { where } \\
\text { B is a constant of proportionality } \\
\mathrm{E}^{\mathrm{m}} \quad \text { is the turbulent energy dissipation rate to the m power } \\
\text { C is the concentration of debris (mass/unit volume) } \\
\text { Therefore, if we take one clump of insulation of mass m and } \\
\text { place it in a turbulent pool of dissipation rate } \mathrm{E} \text {, the turbulence } \\
\text { factor } \tau \text { is determined, and then clump settles at velocity } \\
\text { Now, place a second identical clump of mass m in the same } \\
\qquad V_{s}=\tau V_{\text {pool }} \\
\text { pool so that the concentration is doubled and the turbulence } \\
\text { factor is now } 2 \tau \text {. These two clumps settle at velocity } \\
\qquad V_{s}=2 \tau V_{\text {pool }} \\
\text { Clearly, something is not correct here since the concentration } \\
\text { should not influence the pool turbulence dynamics. More } \\
\text { standard approaches based on first principles exist to account } \\
\text { for settling and may be utilized here instead of relying on } \\
\text { arbitrary turbulence factors. }\end{array}$ & $\begin{array}{l}\text { The turbulence model has been modified to reflect } \\
\text { insights gained from suppression pool experiments } \\
\text { performed since issuance of the NUREG/CR-6224 } \\
\text { Draft for Comment. This model is no longer used } \\
\text { in BLOCKAGE or in the NUREG/CR-6224. }\end{array}$ \\
\hline $\begin{array}{l}\text { BWROG-B34/ } \\
\text { Appendix B } \\
\text { Section B.2.6 }\end{array}$ & Technical & $\begin{array}{l}\text { Appendix B, Section B.2.6: The possibility of determining } \\
\text { the constants } D_{I-1} \text { and } D_{I-I} \text {, which transfer mass of one class } \\
\text { to another during the high energy phase is remote at best. } \\
\text { Can insulation to the pool be estimated by a factor of } 2 \text { ? }\end{array}$ & $\begin{array}{l}\text { It is difficult to estimate } D_{\mathrm{III}} \text { and } D_{\mathrm{IJ}} \text {. No plans } \\
\text { exist to obtain these values theoretically or } \\
\text { experimentally at the present time. As a result, } \\
\text { these constants were removed from the revised } \\
\text { NUREG/CR-6224. }\end{array}$ \\
\hline
\end{tabular}




\begin{tabular}{|c|c|c|c|}
\hline \multicolumn{4}{|c|}{ Category 4: Head Loss Model } \\
\hline $\begin{array}{l}\text { Comment \# I } \\
\text { Location }\end{array}$ & Type & Comment & Response \\
\hline $\begin{array}{l}\text { BWROG-B41/ } \\
\text { Appendix B } \\
\text { Section B.2.8.3 }\end{array}$ & Technical & $\begin{array}{l}\text { Appendix B, Section B.2.8.3: With respect to the "Bed } \\
\text { Compressibility" section, the reason for placing emphasis on } \\
\text { a parameter with an approximate } 15 \% \text { effect is unclear, } \\
\text { especially considering the uncertainty in other parameters. } \\
\text { Can head loss be estimated to } 15 \% \text { ? Can insulation } \\
\text { dislodgement be estimated to a factor of } 2 \text { ? }\end{array}$ & $\begin{array}{l}\text { The intent of B.2.8.3 was to examine if } \\
\text { compressibility is important or not. It was not } \\
\text { to emphasize the importance of compressibility. }\end{array}$ \\
\hline $\begin{array}{l}\text { BWROG-B42/ } \\
\text { Appendix B } \\
\text { Section B.2.8.3 }\end{array}$ & Technical & $\begin{array}{l}\text { Appendix B, Section B.2.8.3: The section addressing } \\
\text { "Filtration of Particulates" presents a formula for deriving } \\
\text { the effective porosity, } \varepsilon_{1} \text {, using the particulate mass retained } \\
\text { by the fiber bed, } \mathrm{M}_{\mathrm{p}} \text {. Realistically, } \mathrm{M}_{\mathrm{p}} \text { cannot be determined. }\end{array}$ & $\begin{array}{l}\text { Based on head loss and filtration experiments } \\
\text { conducted as part of this study a filtration model } \\
\text { was developed to estimate } M_{p} \text { as a function of } \\
\text { sludge density. NUREG/CR-6224 has been } \\
\text { revised to include these details. }\end{array}$ \\
\hline $\begin{array}{l}\text { BWROG-B43/ } \\
\text { Appendix B } \\
\text { Section B.2.8.3 }\end{array}$ & Technical & $\begin{array}{l}\text { Appendix B, Section B.2.8.3: Regarding the section } \\
\text { addressing "Filtration of Particulates," it is difficult to } \\
\text { envision how the analysis can be used with data for } \\
\text { validation. Specifically, to estimate the increase in head loss } \\
\text { resulting from particulates in a fibrous bed, the derivation } \\
\text { requires that the analyst know } \eta \text {, the ratio of mass of } \\
\text { particulates on the bed to the mass of fiber in the bed. We } \\
\text { have no knowledge of the mass of particulates which is } \\
\text { actually in the bed, and only know from experiments the } \\
\text { mass of particulates which approach the bed. Some of the } \\
\text { particulates approaching the bed will pass through the bed } \\
\text { and some will be trapped in the bed. }\end{array}$ & $\begin{array}{l}\text { Experiments were conducted as part of this } \\
\text { study to estimate filtration efficiency of the fiber } \\
\text { beds. These efficiencies were used to estimate } \eta \text {. } \\
\text { As with any experimentally measured variables, } \\
\text { there are uncertainties associated with these } \\
\text { efficiencies. }\end{array}$ \\
\hline $\begin{array}{l}\text { BWROG-B45/ } \\
\text { Section } 4.5 .2 \\
\text { page } 4-28 \\
\text { equ. } 12\end{array}$ & Technical & $\begin{array}{l}\text { In Section 4.5.2, equation \#4.12 on page } 4-28 \text { needs to be } \\
\text { benchmarked against experimental data such as PCI testing } \\
\text { at ARL in 1994, PP\&L testing at ARL in 1994, or CDI testing } \\
\text { for BWROG in 1994. The assumption that } 100 \% \text { filtration } \\
\text { efficiency for bed thicknesses }>1 \text { mm appears to be overly } \\
\text { conservative and would appear to conflict with experimental } \\
\text { data. }\end{array}$ & $\begin{array}{l}\text { NUREG/CR-6224 was revised to include these } \\
\text { comparisons. Also, this version of NUREG/CR- } \\
6224 \text { incorporated a revised filtration model } \\
\text { based on new experimental data obtained as part } \\
\text { of the NRC experiments. }\end{array}$ \\
\hline
\end{tabular}




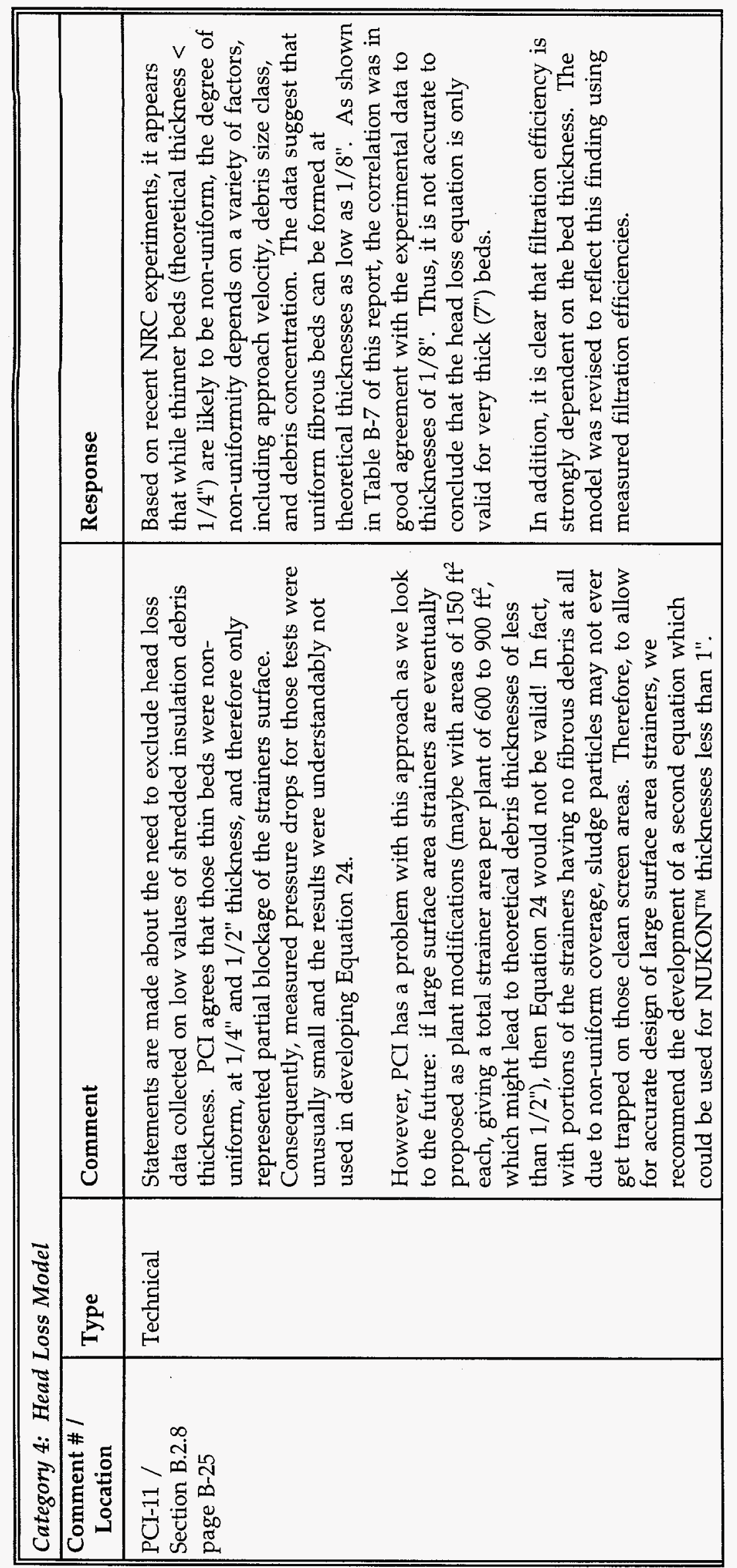




\begin{tabular}{|c|c|c|c|}
\hline \multicolumn{4}{|c|}{ Category 4: Head Loss Model } \\
\hline $\begin{array}{c}\text { Comment \#I } \\
\text { Location }\end{array}$ & Type & Comment & Response \\
\hline $\begin{array}{l}\text { PCI-12 / } \\
\text { Section B.2.8.3 } \\
\text { page B-31 }\end{array}$ & Technical & $\begin{array}{l}\text { A variable is defined as the ratio of mass of particulate in } \\
\text { the (fibrous) bed to the mass of fibers in the bed. In the } \\
\text { development of the theoretical model for filtration of } \\
\text { particulate and the consequential increases in head loss, } \\
\text { there appears to be an unstated assumption that the filtered } \\
\text { particles are uniformly distributed throughout the fibrous } \\
\text { bed. } \\
\text { While this may be a valid assumption for a suppression pool } \\
\text { concentration of particulate on the order of } 1 \mathrm{lbm} \text { per } 1000 \\
\text { gallons of water, it may not be valid for a concentration } 10 \\
\text { to } 100 \text { times higher (such as would be used in head loss } \\
\text { loop tests). Our reasoning is as follows: In the filtering } \\
\text { process, there may be a migration of particulate through the } \\
\text { fibrous pack. At a sufficiently high mass flux of particles, a } \\
\text { critical point may be reached when particles accumulate on } \\
\text { the top surface of the fibrous bed and lead to almost } \\
\text { complete coverage, or blockage, of the free spaces between } \\
\text { fibers. In view of this possible behavior, PCI recommends } \\
\text { that the USNRC evaluate particulate concentration in the } \\
\text { water as an independent variable. The assumption has been } \\
\text { that total particle mass is the only relevant variable, not } \\
\text { concentration. We urge that this assumption be verified by } \\
\text { experiments. }\end{array}$ & $\begin{array}{l}\text { The phenomenon described by the reviewer is } \\
\text { commonly referred to a "straining" which } \\
\text { corresponds to a situation where all the particles } \\
\text { are retained at the top surface of the bed. Such } \\
\text { beds are usually associated with large pressure } \\
\text { drops. Formation of such beds requires that the } \\
\text { filter (a fibrous bed) be in place prior to arrival } \\
\text { of the sludge particles. In reality, in BWR } \\
\text { suppression pools flocks of fibers intermixed } \\
\text { with the sludge particle arrive at the strainer. } \\
\text { The NRC experiments simulated these } \\
\text { conditions at various sludge concentrations. In } \\
\text { all cases, SEM images of the resulting beds } \\
\text { demonstrated that the beds were fairly uniform. } \\
\text { Thus the reviewers concern, while valid, may } \\
\text { not be applicable for BWR suppression pools. }\end{array}$ \\
\hline
\end{tabular}




\begin{tabular}{|c|c|c|c|}
\hline \multicolumn{4}{|c|}{ Category 5: NPSH Calculations } \\
\hline $\begin{array}{c}\text { Comment \# / } \\
\text { Location }\end{array}$ & Type & Comment & Response \\
\hline $\begin{array}{l}\text { BWROG-B4/ } \\
\text { Section } 3.6\end{array}$ & Technical & $\begin{array}{l}\text { Additional information as to how the available NPSH was } \\
\text { determined would be helpful to the analyst. Of interest is } \\
\text { whether the following items were considered: suction line } \\
\text { losses, the actual pool water temperature used, the } \\
\text { minimum suppression pool level, etc. In summary, please } \\
\text { clarify the bases for the stated NPSH values? }\end{array}$ & $\begin{array}{l}\text { NUREG-0897, Rev. 1, outlines a methodology } \\
\text { that can be used to estimate the NPSH margins. } \\
\text { NUREG/CR-6224 was modified to include } \\
\text { details on how NUREG-0897 methodology was } \\
\text { applied to estimate NPSH for the reference plant } \\
\text { in accordance with Reg. Guide } 1.1 \text {. }\end{array}$ \\
\hline $\begin{array}{l}\text { BWROG-B51/ } \\
\text { Section } 4.5 .4\end{array}$ & Technical & $\begin{array}{l}\text { In Section } 4.5 .4 \text {, please explain the basis for using the } 120^{\circ} \\
\text { pool water temperature for available NPSH. }\end{array}$ & $\begin{array}{l}\text { The value of } 120^{\circ} \mathrm{F} \text { was a typographical error. It } \\
\text { should read } 180^{\circ} \mathrm{F} \text {. According to Reg. Guide } 1-1 \text {, } \\
\text { the NPSH should be calculated using atmo- } \\
\text { spheric pressure and most severe suppression } \\
\text { pool temperature. For the reference plant the } \\
\text { most severe suppression pool temperature was } \\
\text { estimated to be } 180^{\circ} \mathrm{F} \text { based on discussions with } \\
\text { the plant systems engineers. }\end{array}$ \\
\hline BWROG-B52/ & Technical & $\begin{array}{l}\text { The report states that the available NPSH for atmospheric } \\
\text { containment pressure and } 120^{\circ} \mathrm{F} \text { pool temperature is } 24 \text { feet } \\
\text { of water for RHR and } 32 \text { feet of water for CS. These values } \\
\text { are incorrect for } 120^{\circ} \mathrm{F} \text { pool temperature at the reference } \\
\text { plant. The actual values for } 120^{\circ} \mathrm{F} \text { should be greater than } 35 \\
\text { feet of water. }\end{array}$ & $\begin{array}{l}\text { The values } 24 \mathrm{ft} \text { and } 32 \mathrm{ft} \text { correspond to a pool } \\
\text { temperature of } 180^{\circ} \mathrm{F} \text {. Refer to the response to } \\
\text { comment BWROG-B3 for additional details on } \\
\text { how they were estimated. }\end{array}$ \\
\hline $\begin{array}{l}\text { TPI-10 / } \\
\text { Section } 5.2 \\
\text { page } 5-15 \\
\text { subpoint } 1 \\
\text { first sentence }\end{array}$ & Technical & $\begin{array}{l}\text { In the first sentence at the top of page } 5-15 \text { it is stated that } \\
\text { "...with doubling the strainer area, few large breaks } \\
\text { generated volumes sufficient to cause loss of NPSH margin } \\
\text { at the reference plant" However, Figure } 5-5 \text { still shows that } \\
\text { all six cases evaluated exceed the } 15 \mathrm{ft} \text {-water NPSH margin. } \\
\text { Please clarify. }\end{array}$ & $\begin{array}{l}\text { This section of NUREG/CR- } 6224 \text { has been } \\
\text { modified and the revised section does provide } \\
\text { the requested clarification. }\end{array}$ \\
\hline
\end{tabular}




\begin{tabular}{|c|c|c|c|}
\hline \multicolumn{4}{|c|}{ Category 6: Pipe Break Frequency and Modeling } \\
\hline $\begin{array}{l}\text { Comment \# / } \\
\text { Location }\end{array}$ & Type & Comment & Response \\
\hline $\begin{array}{l}\text { BWROG-B5/ } \\
\text { Section } 4.1\end{array}$ & Technical & $\begin{array}{l}\text { Please consider the use of more realistic estimates of pipe } \\
\text { break frequency based on actual operating experience } \\
\text { [Reference BWROG Safety Assessment provided to the NRC } \\
\text { on March 24, 1994], rather than on analytical estimates. }\end{array}$ & $\begin{array}{l}\text { The BWROG estimate of pipe break frequency } \\
\text { was considered. However, the BWROG estimate } \\
\text { was not used for the following reasons: } \\
\text { 1) Plant operational experience used to support } \\
\text { the BWROG frequency analysis was based on } \\
\text { EPRI documents that were not available to use } \\
\text { for review. } \\
\text { 2) There was no evidence presented on the } \\
\text { BWROG study to show that phenomena strongly } \\
\text { dependent on aging (e.g., IGSCC) were } \\
\text { accounted for in the statistical analysis of the } \\
\text { plant operational data. } \\
\text { 3) In Section } 4.1 .1 \text { the BWROG approach was } \\
\text { based on pipe sections, as opposed to pipe } \\
\text { welds. The number of welds was significantly } \\
\text { more important than the number of pipe } \\
\text { sections in determining pipe break frequency. } \\
\text { (LLNL Study, NUREG/CR-4792) }\end{array}$ \\
\hline $\begin{array}{l}\text { BWROG-B6a/ } \\
\text { Appendix } \\
\text { A.3.3.1 }\end{array}$ & Technical & $\begin{array}{l}\text { Please consider crediting ISI programs and IGSCC } \\
\text { monitoring programs, such as erosion/corrosion monitoring } \\
\text { on the carbon steel piping, hydrogen water chemistry, } \\
\text { induction heating stress improvement, etc. These actions } \\
\text { can reduce pipe break frequencies to values below those } \\
\text { determined in the LLNL study. Also, given the high quality } \\
\text { of steam in the main steam line, flow-accelerated corrosion } \\
\text { is not likely. In Appendix A.3.3.1, the assumptions } \\
\text { regarding carbon steel rupture frequencies are extremely } \\
\text { conservative, and do not recognize erosion-corrosion } \\
\text { monitoring and control programs in existence today. }\end{array}$ & $\begin{array}{l}\text { The pipe break frequency estimates were specific } \\
\text { to the reference plant at the time of the plant } \\
\text { visit. The licensee had an ISI program that } \\
\text { included some, but not all, of the potential } \\
\text { actions cited in the comment. The study } \\
\text { estimated that the licensee's program reduced } \\
\text { the break frequencies to about } 10 \% \text { of what they } \\
\text { would have been without any IGSCC-mitigating } \\
\text { actions. Thus, an order of magnitude reduction } \\
\text { in estimated pipe break frequencies has already } \\
\text { been credited in the analyses. Consideration of } \\
\text { potential improvements to the reference plant ISI } \\
\text { program was beyond the scope of this study. }\end{array}$ \\
\hline
\end{tabular}




\begin{tabular}{|c|c|c|c|}
\hline \multicolumn{4}{|c|}{ Category 6: Pipe Break Frequency and Modeling } \\
\hline $\begin{array}{l}\begin{array}{c}\text { Comment \# I } \\
\text { Location }\end{array} \\
\end{array}$ & Type & Comment & Response \\
\hline $\begin{array}{l}\text { BWROG-B6b/ } \\
\text { Appendix A } \\
\text { Figure A-4 }\end{array}$ & Technical & $\begin{array}{l}\text { The LLNL study described in Appendix A used for DEGB } \\
\text { pipe break analysis does not consider preventative plant } \\
\text { maintenance that should identify potential DEGBs. The } \\
\text { graph used in Figure A- } 4 \text { seems to be developed to } \\
\text { determine the frequency of preventative maintenance } \\
\text { activities and may not be appropriate for determining an } \\
\text { annual frequency of DEGBs. Note the jumps in failure } \\
\text { probability at } 5 \text { years for susceptible material, and } 29 \text { years } \\
\text { for resistant piping material. SEA did credit a supplemental } \\
\text { correction factor to make allowance for actions to limit the } \\
\text { likelihood of a DEGB. }\end{array}$ & $\begin{array}{l}\text { The "jump" in Figure A-4 may or may not be } \\
\text { real; the curve was fit to sparse and uncertain } \\
\text { data. If it was real, an alternative interpretation } \\
\text { of the jump for 316NG piping would be that } \\
\text { IGSCC developed slowly but accelerated after } \\
\text { reaching a critical point. If that was so, } \\
\text { preventive plant maintenance would not be very } \\
\text { effective in identifying potential DEGBs. It } \\
\text { would also imply that experience in the first } \\
\text { twenty years of plant life was not a good basis } \\
\text { for predicting DEGB frequency at an older plant. }\end{array}$ \\
\hline $\begin{array}{l}\text { BWROG-B7/ } \\
\text { Appendix A }\end{array}$ & Technical & $\begin{array}{l}\text { In Appendix A, the pipe-break-per-weld frequencies are } \\
\text { based upon the most susceptible material. This is not } \\
\text { realistic for all plants. Note the DEGB frequency of } 304 S S \text { is } \\
\text { a factor of } 12.5 \text { higher than for } 316 N G \text {. This makes a large } \\
\text { difference in CDF. }\end{array}$ & $\begin{array}{l}\text { This study considered only the reference plant } \\
\text { equipped with } 304 S S \text { piping which is a } \\
\text { susceptible material. The results may not be } \\
\text { applicable to any other plant because of factors } \\
\text { such as plant specific piping materials, } \\
\text { configurations, sizes, weld locations, etc. }\end{array}$ \\
\hline $\begin{array}{l}\text { BWROG-B8a/ } \\
\text { Appendix A }\end{array}$ & Technical & $\begin{array}{l}\text { Pipe break frequency is the same as NUREG/CR- } 4550 \text {, } \\
\text { Volume } 1 \text {. Given the amount of piping in the drywell } \\
\text { compared to the overall plant piping, it is much more likely } \\
\text { that a break will occur outside the drywell, rather than } \\
\text { inside. }\end{array}$ & $\begin{array}{l}\text { NUREG/CR-6224 pipe break frequency } \\
\text { estimates are for the portions of high pressure } \\
\text { piping contained in the drywell and are plant } \\
\text { specific. NUREG/CR-4550 pipe break frequency } \\
\text { estimates are for all of the high pressure piping } \\
\text { in the plant and should not be compared with } \\
\text { those found in NUREG/CR-6224. }\end{array}$ \\
\hline $\begin{array}{l}\text { BWROG-B8b/ } \\
\text { Appendix A }\end{array}$ & Technical & $\begin{array}{l}\text { Also, the Technical Specification LCO for unidentified } \\
\text { drywell leakage should limit the likelihood of a DEGB in the } \\
\text { drywell. It is very unlikely that a major line break can occur } \\
\text { without any warning signs. }\end{array}$ & $\begin{array}{l}\text { This study used an estimate that the ISI program } \\
\text { at the reference plant would avert all but } 10 \% \text { of } \\
\text { the potential DEGBs. }\end{array}$ \\
\hline
\end{tabular}




\begin{tabular}{|c|c|c|c|}
\hline \multicolumn{4}{|c|}{ Category 6: Pipe Break Frequency and Modeling } \\
\hline $\begin{array}{l}\text { Comment \# I } \\
\text { Location }\end{array}$ & Type & Comment & Response \\
\hline $\begin{array}{l}\text { BWROG-B9/ } \\
\text { Appendix A }\end{array}$ & Technical & $\begin{array}{l}\text { The technical justification for excluding other IGSCC } \\
\text { mitigating actions in Reactor Recirculation systems is } \\
\text { unclear. Please consider a sensitivity analysis to evaluate } \\
\text { the effect of this further reduction in pipe break frequency } \\
\text { on the overall NUREG analysis. }\end{array}$ & $\begin{array}{l}\text { The pipe break frequency estimates were specific } \\
\text { to the reference plant at the time of the plant } \\
\text { visit. The licensee had an ISI program that } \\
\text { included some, but not all, of the potential } \\
\text { actions cited in your comment. The study } \\
\text { estimated that the licensee's program reduced } \\
\text { the break frequencies to about } 10 \% \text { of what they } \\
\text { would have been without any IGSCC-mitigating } \\
\text { actions. Thus, an order of magnitude reduction } \\
\text { in estimated pipe break frequencies has already } \\
\text { been credited in our analyses. A sensitivity } \\
\text { analysis is beyond the scope of NUREG/CR- } \\
6224 \text {. }\end{array}$ \\
\hline $\begin{array}{l}\text { BWROG-B57/ } \\
\text { Section } 6.1 \\
\text { page } 6-1\end{array}$ & Technical & $\begin{array}{l}\text { Section } 6.1 \text {, Page } 6-1 \text { : In addition to the frequency of a } \\
\text { LOCA, the break location is also important because it affects } \\
\text { the time available to the operator for alignment of alternate } \\
\text { means of injecting water into the reactor vessel. Different } \\
\text { break locations would be expected to have different } \\
\text { frequencies. }\end{array}$ & $\begin{array}{l}\text { It is acknowledged that break location has an } \\
\text { influence on the time available for an operator to } \\
\text { align an alternate means of injection. However, } \\
\text { an analysis of the timing associated with various } \\
\text { break locations would have required a nuimber } \\
\text { of detailed plant-specific deterministic analyses. } \\
\text { The overall objective of the NUREG/CR-6224 } \\
\text { event tree model was to provide a scoping } \\
\text { estimate of the CDF related to ECCS NPSH loss. } \\
\text { Therefore, consideration of timing differences } \\
\text { among different break locations was beyond the } \\
\text { scope of the study. Note that the non-recovery } \\
\text { data used in the event tree model was extracted } \\
\text { from the reference plant IPE. The IPE did not } \\
\text { distinguish among the various possible break } \\
\text { locations, but instead used a single value to } \\
\text { represent the probability of unsuccessful } \\
\text { alternate injection for all large LOCA breaks. } \\
\text { Use of a single failure probability for all large } \\
\text { LOCA break locations is consistent with the } \\
\text { reference plant IPE. }\end{array}$ \\
\hline
\end{tabular}




\begin{tabular}{|c|c|c|c|}
\hline \multicolumn{4}{|c|}{ Category 7: CDF Estimates } \\
\hline $\begin{array}{l}\text { Comment \# / } \\
\text { Location }\end{array}$ & Type & Comment & Response \\
\hline $\begin{array}{l}\text { BWROG-B58/ } \\
\text { Chapter } 6\end{array}$ & Technical & $\begin{array}{l}\text { It appears as if the event trees were solved by simply } \\
\text { multiplying the function probabilities across. If this is so, } \\
\text { add the assumption that the functions included in the event } \\
\text { trees are independent of each other and have no basic events } \\
\text { or human interactions in common. }\end{array}$ & $\begin{array}{l}\text { The event trees were solved by multiplying the } \\
\text { function probabilities. The simplified model } \\
\text { used in NUREG/CR- } 6224 \text { did assume } \\
\text { independence among the various functions. } \\
\text { NUREG/CR-6224 was revised to reflect this } \\
\text { comment. }\end{array}$ \\
\hline $\begin{array}{l}\text { BWROG-B59/ } \\
\text { Chapter } 6\end{array}$ & Technical & $\begin{array}{l}\text { Point-value estimates were developed in the CDF estimates. } \\
\text { As no uncertainty analysis was performed, the significance } \\
\text { of these estimates are subject to interpretation. Moreover, it } \\
\text { appears that conservative assumptions are implicit in these } \\
\text { estimates. The analyses should be expanded so as to } \\
\text { develop the true range of CDF values, and the more } \\
\text { significant contributions. }\end{array}$ & $\begin{array}{l}\text { The development of an uncertainty analysis was } \\
\text { beyond the scope of the CDF analysis. }\end{array}$ \\
\hline $\begin{array}{l}\text { BWROG-B60/ } \\
\text { Figure 6-1 }\end{array}$ & Technical & $\begin{array}{l}\text { The event tree in Figure } 6-1 \text { gives an unrealistically low } \\
\text { probability of the operators recognizing strainer blockage. } \\
\text { The operators at the reference plant have been trained on } \\
\text { recognizing strainer blockage and have procedures which } \\
\text { provide guidance on strainer blockage. Simulator scenarios } \\
\text { at the reference plant have demonstrated that operators will } \\
\text { recognize strainer blockage in nearly all instances. }\end{array}$ & $\begin{array}{l}\text { At the time of the plant visit, it was understood } \\
\text { that operators at the reference plant were not } \\
\text { formally trained to recognize strainer blockage. } \\
\text { Given the time scale for strainer blockage, it is } \\
\text { unlikely the operators would recognize the } \\
\text { situation with sufficient time to effectively } \\
\text { respond. }\end{array}$ \\
\hline $\begin{array}{l}\text { BWROG-B61/ } \\
\text { Section 6.2.1 } \\
\text { Figure 6-1 }\end{array}$ & Technical & $\begin{array}{l}\text { The event tree in Figure } 6-1 \text { incorrectly gives a } 0 \% \\
\text { probability of restoring ECCS with backflushing. The } \\
\text { reference plant has procedures to backflush ECCS section } \\
\text { strainers in the event of clogging. This should also be } \\
\text { corrected in Section } 6.2 .1 \text { of the text. }\end{array}$ & $\begin{array}{l}\text { This study was based on the reference plant's } \\
\text { configuration as of January } 1994 \text {. At that time } \\
\text { the understanding was that this plant did not } \\
\text { have a formally approved method to perform } \\
\text { backflushing operations. Although backflushing } \\
\text { procedures could have been put into place since } \\
\text { that time, it is beyond the scope of this report to } \\
\text { incorporate design or procedural changes that } \\
\text { have been implemented since that time. }\end{array}$ \\
\hline
\end{tabular}




\begin{tabular}{|c|c|c|c|}
\hline \multicolumn{4}{|c|}{ Category 7: CDF Estimates } \\
\hline $\begin{array}{l}\text { Comment \# / } \\
\text { Location }\end{array}$ & Type & Comment & Response \\
\hline $\begin{array}{l}\text { BWROG-B62/ } \\
\text { Section } 6.2 \\
\text { page } 6-4\end{array}$ & Technical & $\begin{array}{l}\text { Section 6.2, Page 6-4: The determination of conditional core } \\
\text { damage frequency for this event is directly related to the } \\
\text { assumption that all ECCS section strainers block within } 10 \\
\text { minutes with a probability of } 1.0 \text {. If the likelihood of ECCS } \\
\text { suction strainer blockage is much less than } 1.0 \text { or if only a } \\
\text { limited number of strainers are blocked, the results are } \\
\text { much less damaging. }\end{array}$ & $\begin{array}{l}\text { This assumption was judged to be reasonable } \\
\text { based on results from deterministic analyses. }\end{array}$ \\
\hline $\begin{array}{l}\text { BWROG-B63/ } \\
\text { Section } 6.2 \\
\text { Assumption } 6\end{array}$ & Technical & $\begin{array}{l}\text { Assumption } 6 \text { in Section } 6.2 \text { notes that core damage occurs } \\
\text { when the water level drops from } 2 / 3 \text { core. A LOCA not } \\
\text { located in the recirculation pump suction piping would } \\
\text { reflood to a higher level in the reactor vessel and take longer } \\
\text { to boil down. }\end{array}$ & $\begin{array}{l}\text { It is acknowledged that the LOCA break location } \\
\text { can influence the time available for recovery } \\
\text { actions. See the response to question B57. }\end{array}$ \\
\hline $\begin{array}{l}\text { BWROG-B64/ } \\
\text { Section } 6.2 \\
\text { Assumption } 8\end{array}$ & Technical & $\begin{array}{l}\text { Assumption } 8 \text { in Section } 6.2 \text { states that the } \\
\text { condensate/feedwater systems cannot be successfully used } \\
\text { for alternate injection to the reactor vessel. This is correct in } \\
\text { that the condenser hotwell does not have sufficient water } \\
\text { capacity for long term injection and the pipe break could be } \\
\text { in one of these lines. However, these systems can be used } \\
\text { for short term injection. Use of either of these systems will } \\
\text { allow the operators more time to diagnose the problem and } \\
\text { align other alternate injection sources. Use of the RCIC and } \\
\text { HPCI systems can also be used for other than large LOCA } \\
\text { events to extend the time available for alternate injection, } \\
\text { even if the flow rates are not sufficient to maintain reactor } \\
\text { vessel water level. }\end{array}$ & $\begin{array}{l}\text { It is recognized that the use of the condensate/ } \\
\text { feedwater system could, in some cases, provide } \\
\text { operators with additional time to establish } \\
\text { backup cooling. However, as was stated in the } \\
\text { response to question B.57, the event tree model } \\
\text { was not intended to represent an in-depth } \\
\text { evaluation of all possible break locations. The } \\
\text { exclusion of the condensate/feedwater system } \\
\text { for large LOCA mitigation was consistent with } \\
\text { the reference plant IPE. With regard to the use } \\
\text { of HPCI or RCIC for large LOCA mitigation, it is } \\
\text { doubtful if sufficient steam pressure would exist } \\
\text { following a large LOCA to operate the steam- } \\
\text { driven pumps that are used in the RCIC and } \\
\text { HPCI systems. }\end{array}$ \\
\hline
\end{tabular}




\begin{tabular}{|c|c|c|c|c|}
\hline & 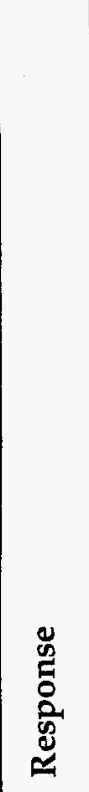 & 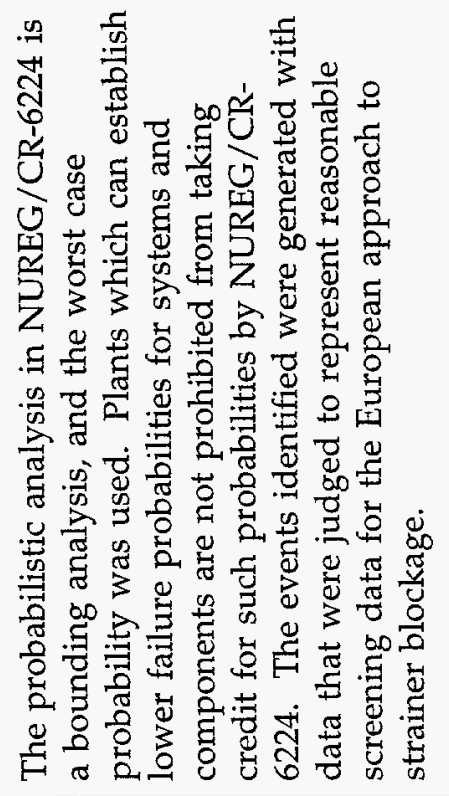 & & \\
\hline & 苞 & 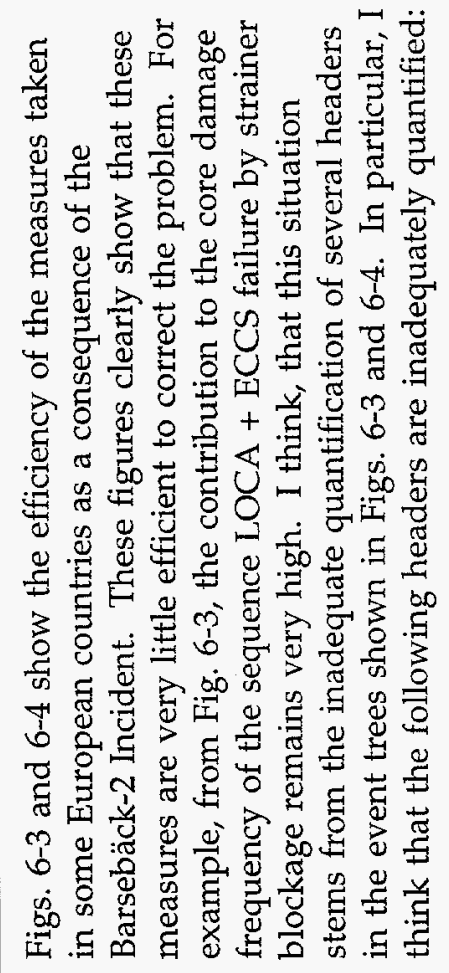 & 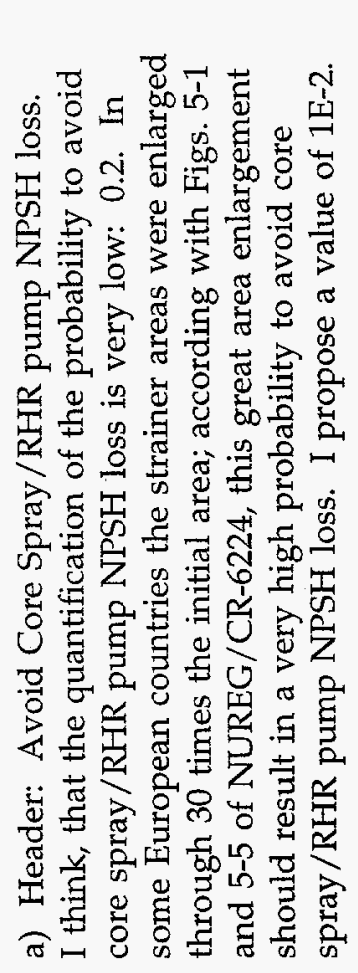 & 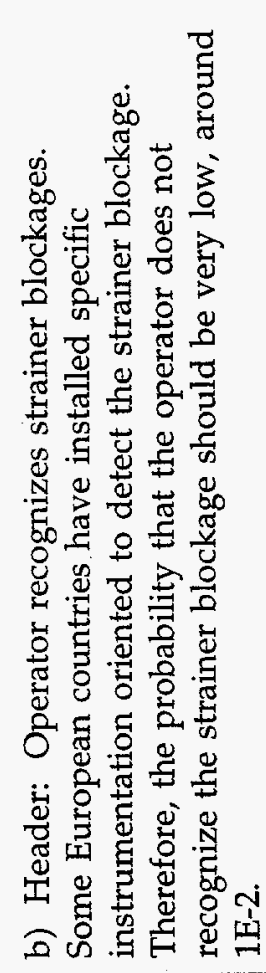 \\
\hline 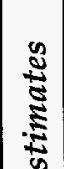 & 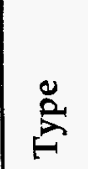 & 胥 & & \\
\hline $\begin{array}{l}\text { 岁 } \\
\stackrel{0}{0} \\
\overrightarrow{5} \\
\overrightarrow{8} \\
\stackrel{+}{0} \\
\overrightarrow{5}\end{array}$ & 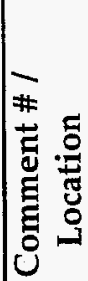 & 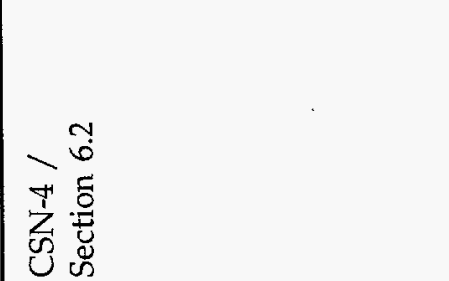 & & \\
\hline
\end{tabular}


Appendix $\mathrm{F}$

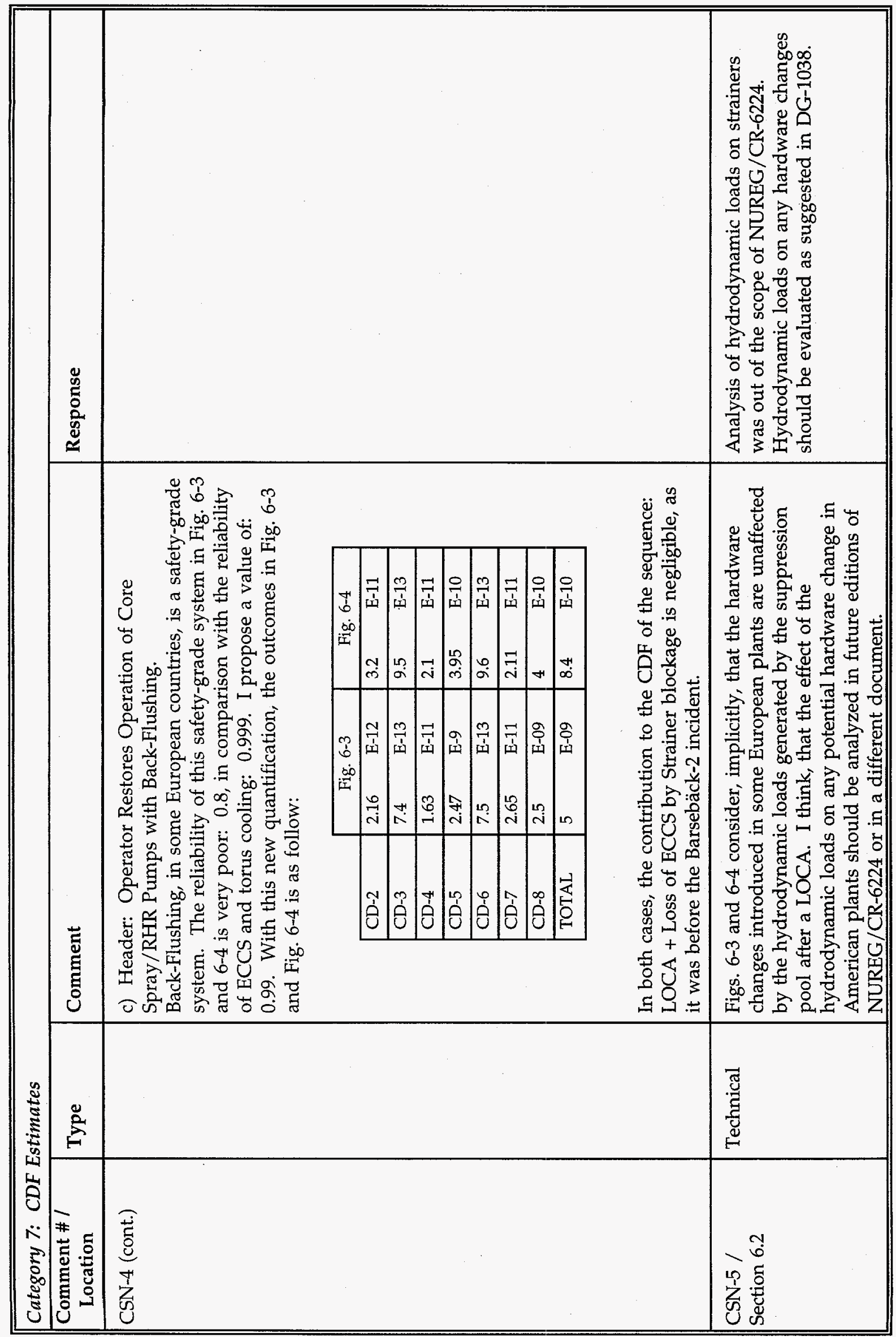




\begin{tabular}{|c|c|c|c|}
\hline \multicolumn{4}{|c|}{ Category 8: Future Applicability / Plant Specific Analyses } \\
\hline $\begin{array}{l}\text { Comment \# I } \\
\text { Location }\end{array}$ & Type & Comment & Response \\
\hline $\begin{array}{l}\text { BWROG-A2a/ } \\
\text { General }\end{array}$ & Technical & $\begin{array}{l}\text { A sensitivity analysis should be performed, perhaps with } \\
\text { accelerated public review, prior to issuing the final report. } \\
\text { Sensitivity should at least cover the spherical model versus } \\
\text { the cone and the effect of transport factors. An uncertainty } \\
\text { analysis would probably not be warranted due to the large } \\
\text { amount of engineering judgement noted throughout the text. }\end{array}$ & $\begin{array}{l}\text { A parametric sensitivity analysis has been } \\
\text { incorporated as an Appendix to NUREG/CR- } \\
6224 \text {. }\end{array}$ \\
\hline $\begin{array}{l}\text { BWROG-A2b/ } \\
\text { General }\end{array}$ & Technical & $\begin{array}{l}\text { For example, it would be very beneficial to plants that } \\
\text { already have larger strainers if the NUREG addressed } \\
\text { additional sensitivities regarding strainer size. The NUREG } \\
\text { identifies changes if the strainer size is double that at the } \\
\text { lead plant. But, if additional runs were made at } 3 \text { times, } 4 \\
\text { times, etc., a curve could be developed for determining the } \\
\text { probability of failure for large breaks based on changing the } \\
\text { strainer size. }\end{array}$ & $\begin{array}{l}\text { The extent of the parametric study in the } \\
\text { NUREG/CR- } 6224 \text { Draft for Comment was } \\
\text { limited by time and resources. Additional } \\
\text { parametric analyses have now been incorporated } \\
\text { as Appendix C to NUREG/CR- } 6224 \text {. The } \\
\text { extended parametric study varied the strainer } \\
\text { area up to } 10 \text { times the area of the reference } \\
\text { plant strainer. }\end{array}$ \\
\hline $\begin{array}{l}\text { BWROG-B25/ } \\
\text { Appendix B }\end{array}$ & Technical & $\begin{array}{l}\text { The complexity of the pool transport model would seem } \\
\text { unwarranted in light of the numerous engineering } \\
\text { judgements and soft assumptions required. Many of the } \\
\text { semi-empirical constants introduced in the model have little } \\
\text { or no chance of experimental evaluation. }\end{array}$ & $\begin{array}{l}\text { Individual plants are not prohibited from using } \\
\text { a less complex solution for this issue. The } \\
\text { authors agree that there were uncertainties } \\
\text { associated with the pool transport models. As a } \\
\text { result, parametric studies were performed and } \\
\text { have been added to NUREG/CR-6224. Also, } \\
\text { these transport models were revised to reflect } \\
\text { important insights gained from the suppression } \\
\text { pool experiments sponsored by NRC to study } \\
\text { debris transport in a turbulent suppression pool } \\
\text { after a LOCA. }\end{array}$ \\
\hline
\end{tabular}




\begin{tabular}{|c|c|c|c|}
\hline \multicolumn{4}{|c|}{ Category 8: Future Applicability / Plant Specific Analyses } \\
\hline $\begin{array}{l}\text { Comment \# I } \\
\text { Location }\end{array}$ & Type & Comment & Response \\
\hline $\begin{array}{l}\text { CSN-2 / } \\
\text { General }\end{array}$ & Technical & $\begin{array}{l}\text { NUREG/CR-6224 pays very little attention to the behavior } \\
\text { of other thermal insulating materials different to NUKON } \\
\text { I think that the potential for strainer blockage from other } \\
\text { thermal insulating materials, i.e., metallic reflective, etc., } \\
\text { should be analyzed in the report. }\end{array}$ & $\begin{array}{l}\text { RMI is one of a number of insulations installed } \\
\text { in U.S. plants that should be evaluated on a } \\
\text { plant specific basis. However, since RMI was } \\
\text { not a "dominant" insulation for the reference. } \\
\text { plant, such an analysis was not included in } \\
\text { NUREG/CR-6224. Other materials used in } \\
\text { LWRs should be evaluated, but the burden for } \\
\text { the evaluation, with respect to ECCS strainer } \\
\text { blockage, will be placed on the licensees. DG- } \\
1038 \text {, Revision } 2 \text { to the Regulatory Guide } 1.82 \text {, } \\
\text { provides guidance on the features needed to } \\
\text { prevent or mitigate strainer blockage as well as } \\
\text { providing guidance on aspects of a strainer } \\
\text { blockage analysis. }\end{array}$ \\
\hline $\begin{array}{l}\text { CSN-3 / } \\
\text { General }\end{array}$ & Technical & $\begin{array}{l}\text { NUREG/CR- } 6224 \text { establishes that the extrapolation of the } \\
\text { reference plant to BWR } 5 \text { and } 6 \text { is little reliable because of } \\
\text { the characteristics of the ECCS in these plants. I feel that the } \\
\text { influence of these differences in the ECCS design should be } \\
\text { more precisely quantified in the report. }\end{array}$ & $\begin{array}{l}\text { The NRC agrees that other plants need to be } \\
\text { analyzed, but such analysis was not in the scope } \\
\text { of NUREG/CR- } 6224 \text {. DG-1038, Revision } 2 \text { to the } \\
\text { Regulatory Guide } 1.82 \text {, provides guidance on the } \\
\text { features needed to prevent or mitigate strainer } \\
\text { blockage as well as provides guidance on } \\
\text { aspects of a strainer blockage analysis. } \\
\text { Additionally, the derivation of more precise CDF } \\
\text { estimates for other BWRs was beyond the scope } \\
\text { of our study. }\end{array}$ \\
\hline $\begin{array}{l}\text { PCI-4B / } \\
\text { Section } 2-5 \\
\text { page 2-6 } \\
\text { 3rd paragraph } \\
\text { 2nd sentence }\end{array}$ & Technical & $\begin{array}{l}\text { However, this statement is apparently not true for plants } \\
\text { that have a Torous Water Clean-Up (TWCU) system. At } \\
\text { least one of the US BWR's has a TWCU system that operates } \\
\text { periodically during plant operation and is very effective. } \\
\text { The owner utility of that plant recently tried to perform a } \\
\text { full pool cleaning during a refueling outage. However, they } \\
\text { collected such an insignificant amount of particulate debris } \\
\text { that the process was discontinued. The mass of particulate } \\
\text { debris collected was on the order of } 10 \mathrm{lbm} \text {, much less than } \\
\text { the stated lower limit of } 70 \mathrm{lbm} \text {. }\end{array}$ & $\begin{array}{l}\text { The reference plant did not have Torous Water } \\
\text { Clean-Up (TWCU). Therefore, no credit for } \\
\text { periodic cleaning of the torous was given. }\end{array}$ \\
\hline
\end{tabular}


2. TITLE AND SUBTILE

Parametric Study of the Potential for BWR ECCS Strainer Blockage Due to LOCA Generated Debris

Final Report

5. AUTHOR(S)

G. Zigler, J. Brideau, D.V.Rao, C. Shaffer, F. Souto, W. Thomas

\begin{tabular}{|c|r|}
\hline 3. DATE REPORT PUBLIS AED \\
\hline MONTH & YEAR \\
October & 1995 \\
\hline
\end{tabular}

4. FIN OR GRANT NUMBER L1854

6. TYPE OF REPORT

7. PERIOD COVERED (nctuative Dates)

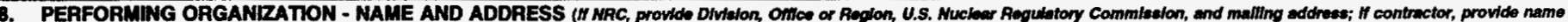
and malling eddrows.

Science and Engineering Associates, Inc.

6100 Uptown Blvd. NE

Albuquerque, NM 87110

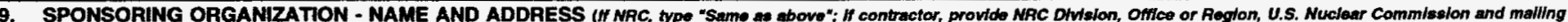
address.)

Division of Safety Issue Resolution

Office of Nuclear Regulatory Research

U.S. Nuclear Regulatory Commission

Washington, DC 20555-0001

10. SUPPLEMENTARY NOTES

11. ABSTRACT (200 words or less)

This report documents a plant-specific study for a BWR/4 with a Mark I containment that evaluated the potential for LOCA generated debris and the probability of losing long term recirculation capability due ECCS pump suction strainer blockage. The major elements of this study were: (1) acquisition of detailed piping layouts and installed insulation details for a reference BWR; (2) analysis of plant specific piping weld failure probabilities to estimate the LOCA frequency; (3) development of an insulation and other debris generation and drywell transport models for the reference BWR; (4) modeling of debris transport in the suppression pool; (5) development of strainer blockage head loss models for estimating loss of NPSH margin; (6) estimation of core damage frequency attributable to loss of ECCS recirculation capability following a LOCA. Elements 2 through 5 were combined into a computer code, BLOCKAGE 2.3.

A point estimate of overall DEGB pipe break frequency (per Rx-year) of 1.59E-04 was calculated for the reference plant, with a corresponding overall ECCS loss of NPSH frequency (per Rx-year) of 1.58E-04. The calculated point estimate of core damage frequency (per Rx-year) due to blockage related accident sequences for the reference BWR ranged from 4.2E-06 to 2.5E-05. The results of this study show that unacceptable strainer blockage and loss of NPSH margin can occur within the first few minutes after ECCS pumps achieve maximum flows when the ECCS strainers are exposed to LOCA generated fibrous debris in the presence of particulates (sludge, paint chips, concrete dust). Generic or unconditional extrapolation of these reference plant calculated results should not be undertaken.

12. KEY WOADSWESCRIPTOAS (Let word or phreses that will mesist nesauchere in locenting the report)

\begin{tabular}{|c|c|}
\hline 13. & $\begin{array}{l}\text { AVAILABILTV STATEMENT } \\
\text { Unlimited }\end{array}$ \\
\hline 14. & SECURTY CLASSIFICATION \\
\hline & $\begin{array}{l}\text { (This Page) } \\
\text { Unclassified }\end{array}$ \\
\hline
\end{tabular}

15. NUMBER OF PAGES
BWR Suction Strainers
Loss of NPSH
Debris Generation
Debris Transport
Debris Interceptors
Head Loss Correlations
16. PRICE 